$$
\text { سازمان برنامه و بودجه كشورى }
$$

\title{
زنالجح ذهصيسحى
}

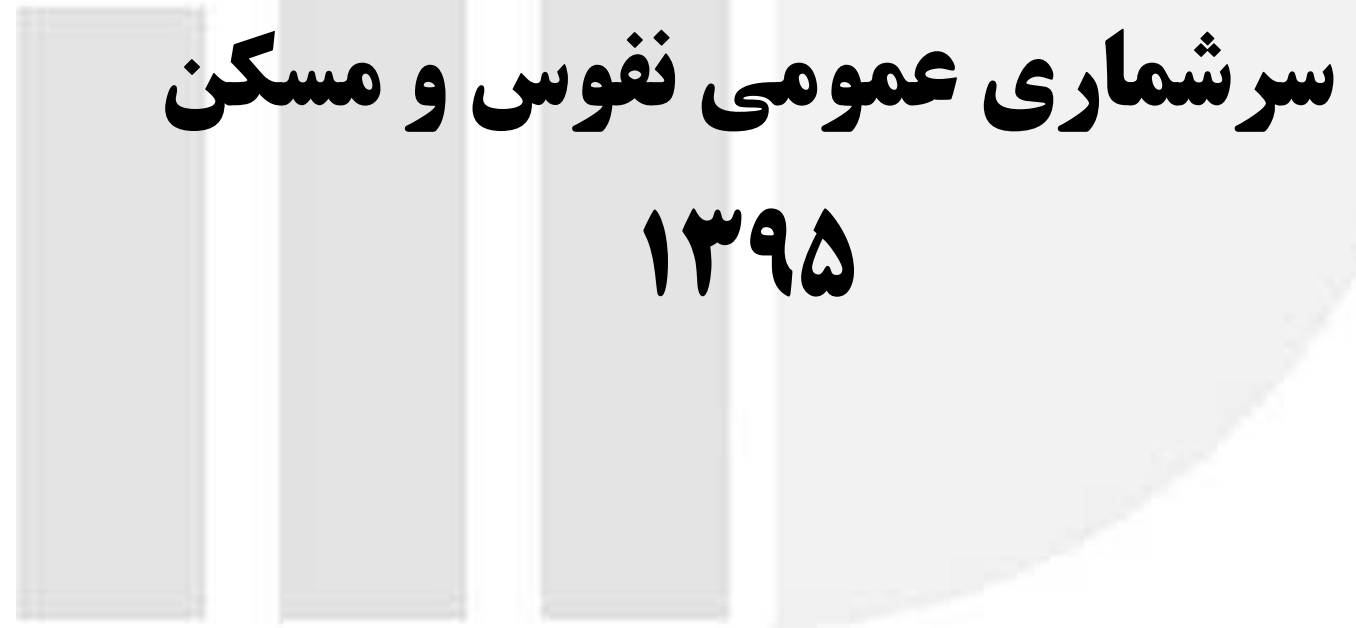

كل كشور

$$
1-1
$$




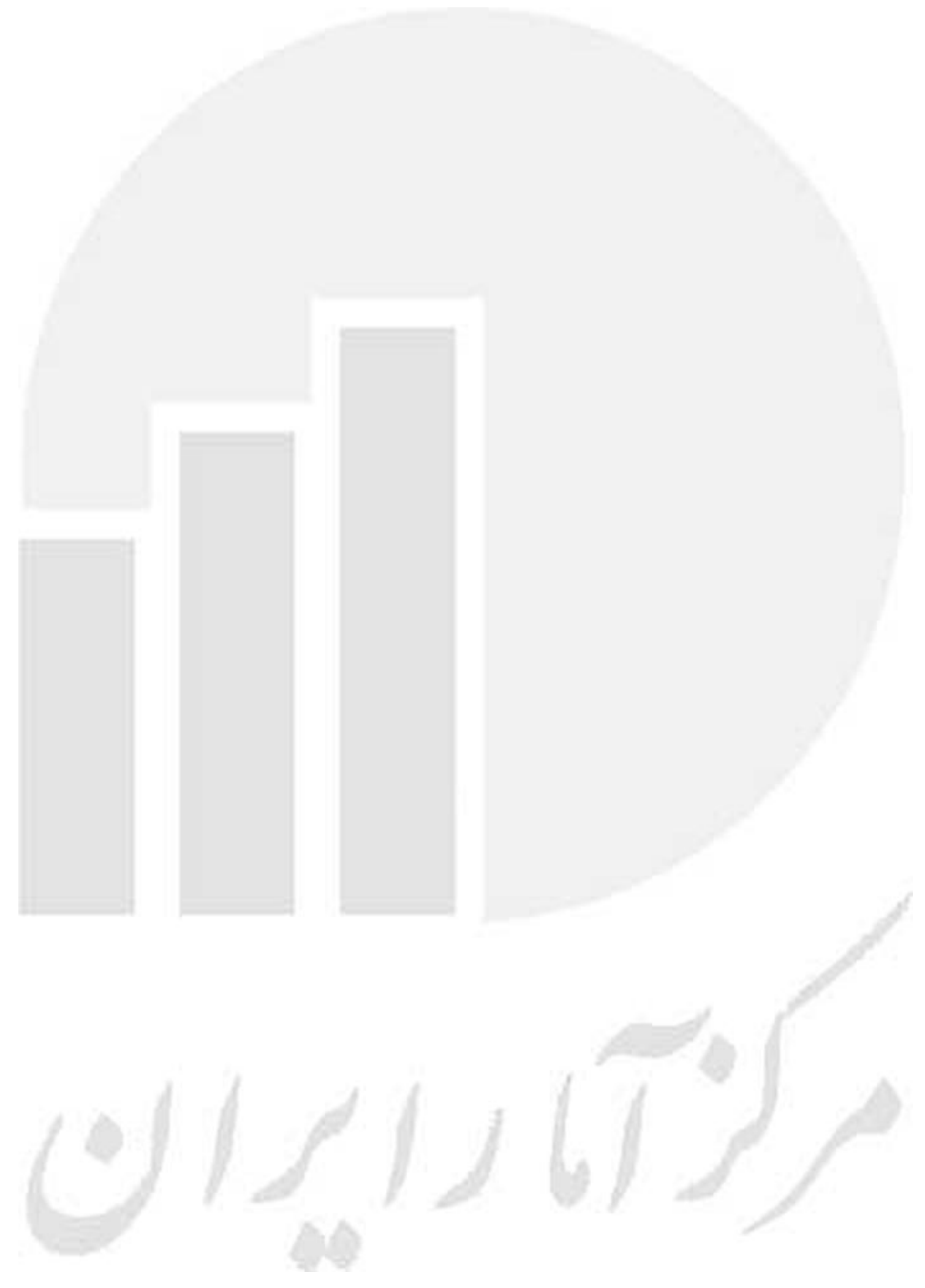




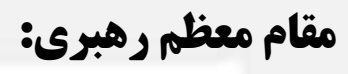

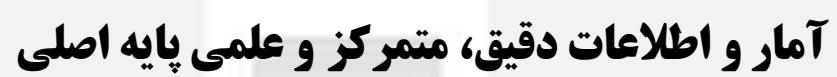

در تصميم كيرى كار آملد براى كشور است .

بيانات رهبرمعظم انقلاب اسلامى در ديدار با رئيس و مديران مركز آمار ايران

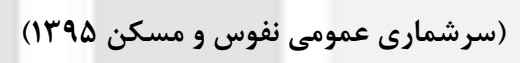

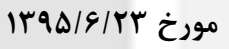




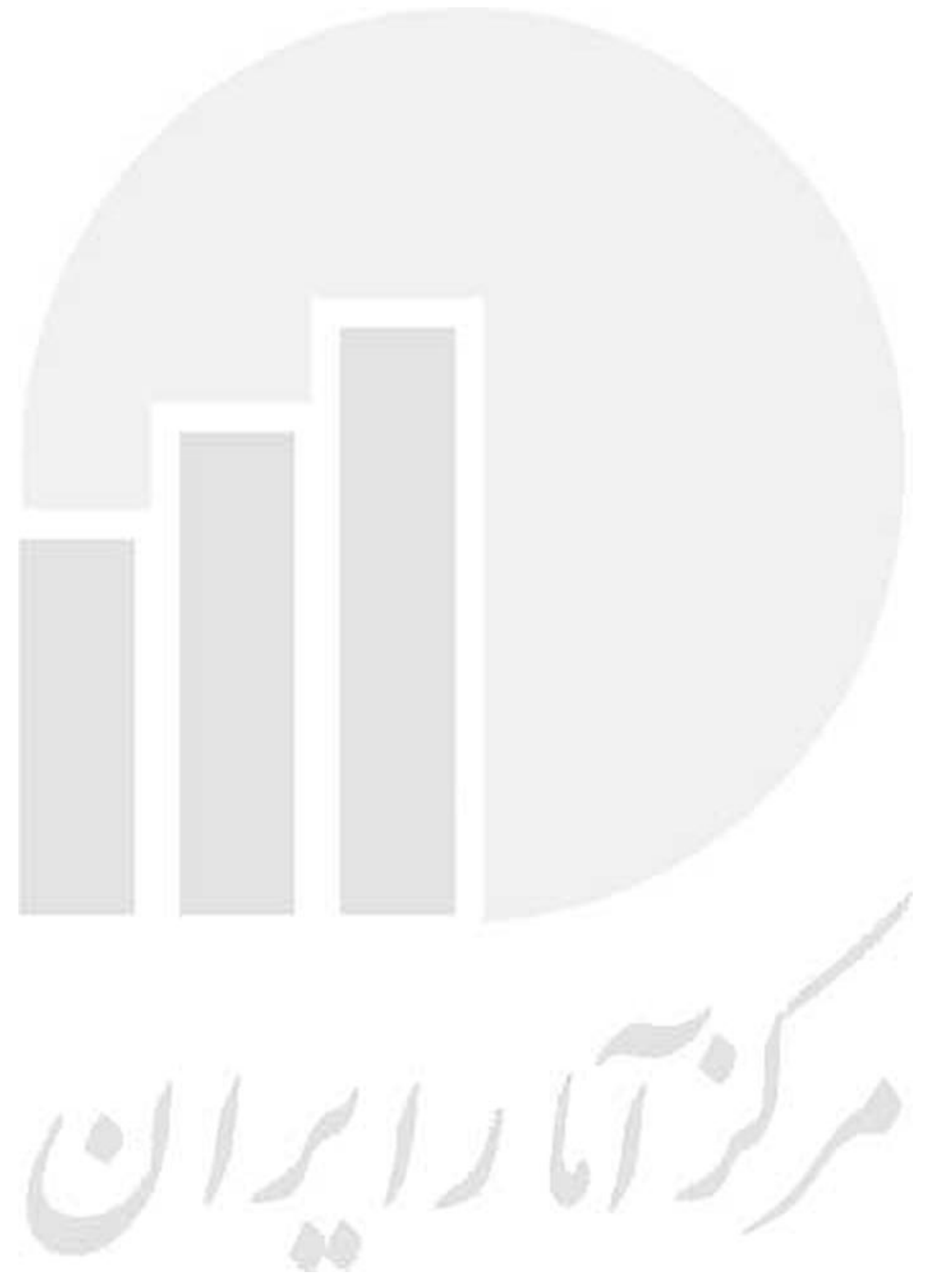




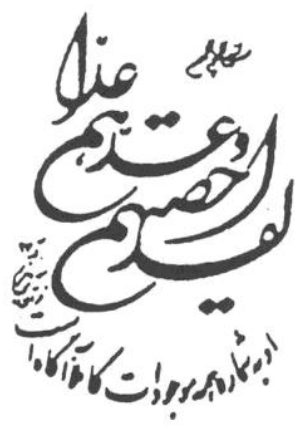

$$
\begin{aligned}
& \text { ד }
\end{aligned}
$$

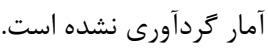

$$
\begin{aligned}
& \text { آمار در دسترس نيست. } \\
& \text { اتاً يا عملاً وجود ندارد. }
\end{aligned}
$$

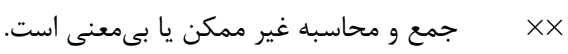

$$
\begin{aligned}
& \text { رقم كمتر از نصف واحد است. } \\
& \text { رقم (نسبت) ناجيز و قابل صرفنظركرد احن است. } \\
& \text { *رقم غير قطعى است. } \\
& \text { | * * رقم جنبه تخمينى دارد. } \\
& \text { Q به دليل حفظ محرمانكى، رقم قابل انتشار نيست. }
\end{aligned}
$$

اختلاف در سرجمعها به علت سرراست كردن ارقام است. محاسبه نسبتها و شاخصها قبل از سرراست كردن ارقام صورت كرفته است. 


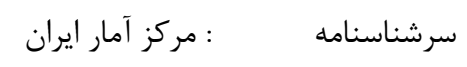

Statistical Centre of Iran

عنوان و نام بديدآور : نتايج تفصيلى سرشمارى عمومى نفوس و مسكن - هوس|// رياست جمهورى، سازمان برنامه و بودجه كشور، مركز آمار ايران

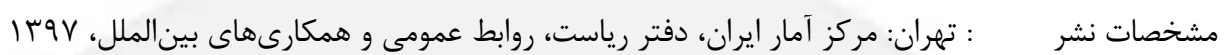

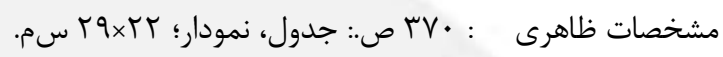

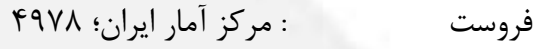

$$
\begin{aligned}
& \text { شابك } \\
& \text { وضعيت فهرستنويسى : فييا }
\end{aligned}
$$

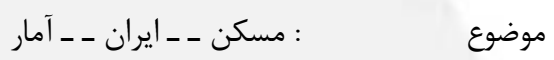

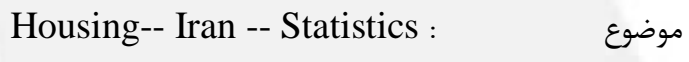

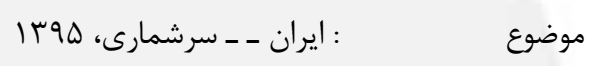

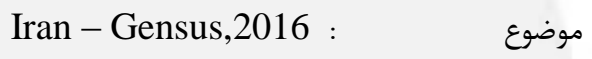

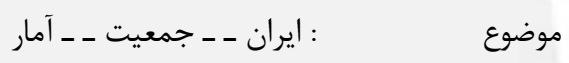

$$
\begin{aligned}
& \text { Iran-- Population -- Statistics : }
\end{aligned}
$$

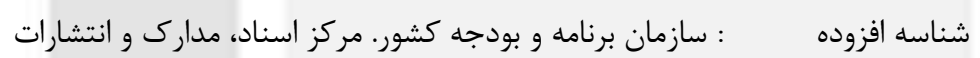

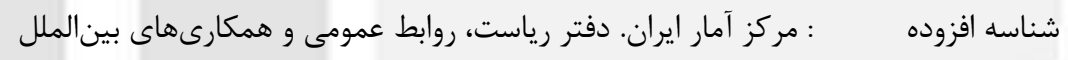

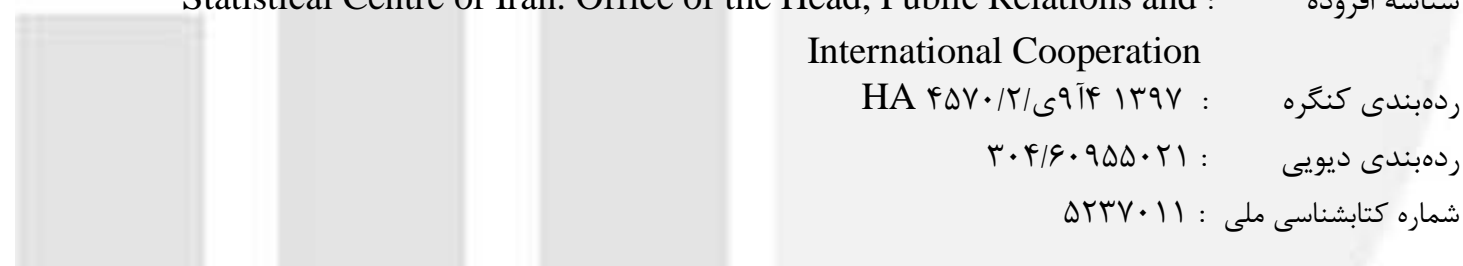

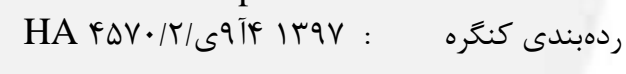

شماره كتابشناسى ملى :

口 $\quad$ مركز آمار /يران

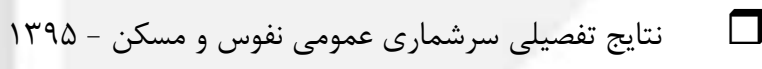

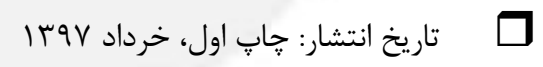

$\square$

PqVA:

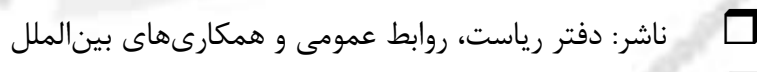

口

جابٍ در خإٍخانه مركز آمار ايران

نقل قول از مطالب اين كتاب با ذكر منبع بلامانع است.

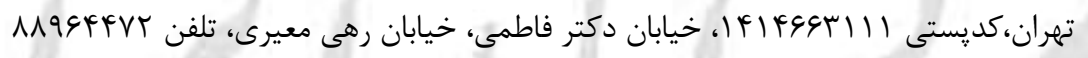

دMagkYVY دورنكارن

URL: http://www.amar.org.ir

E-mail: sci@sci.org.ir

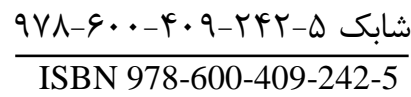




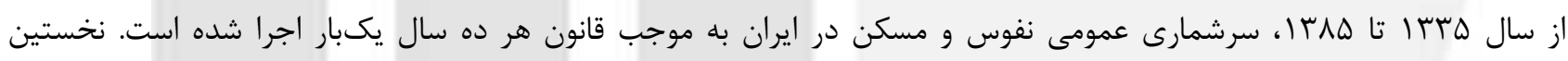

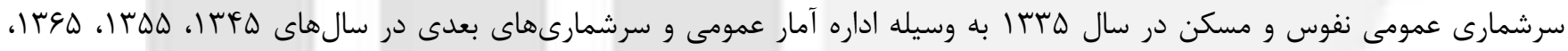
إن

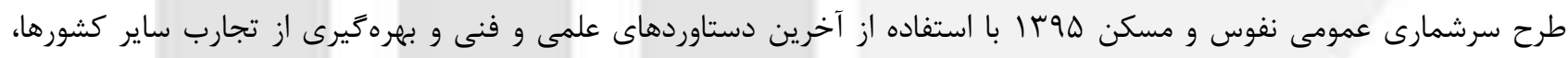

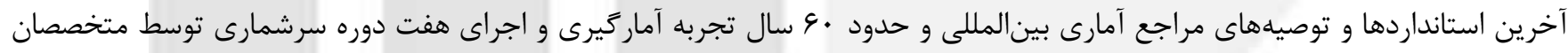

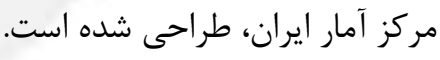

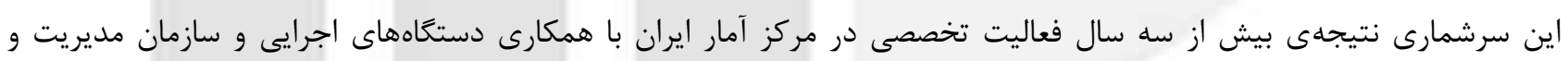

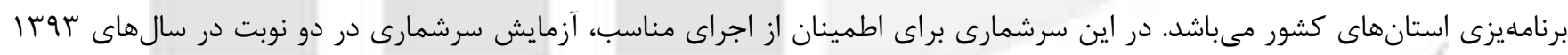

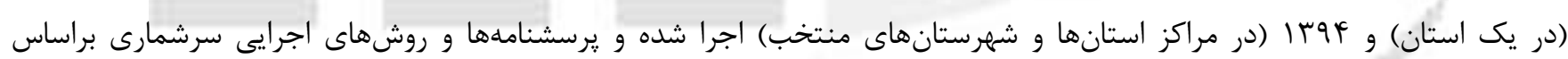

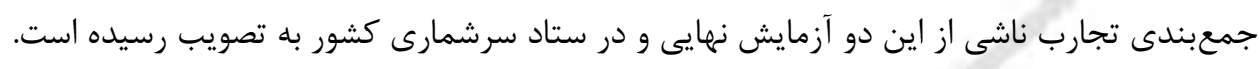

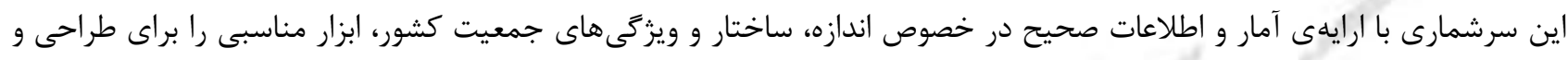

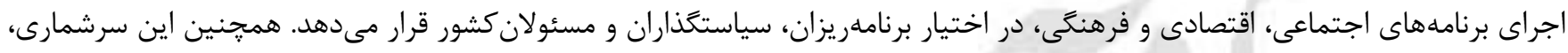

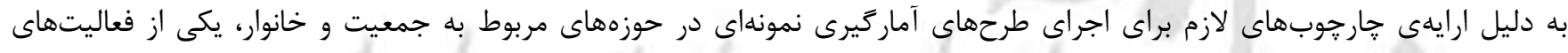

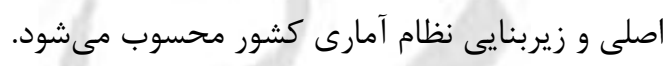

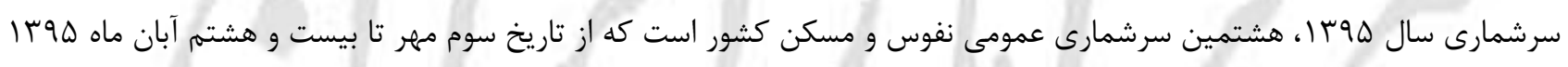

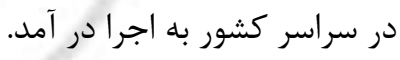




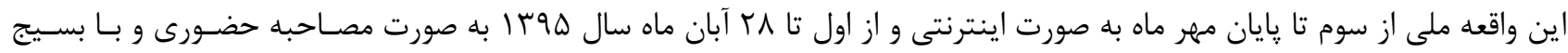

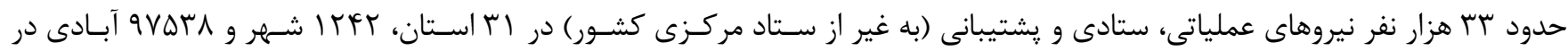
سراسر كشور به اجرا در آمد.

سرشمارى سال هوسا با ويزگى هايى اجرا شد كه آن را از تجربههاى ييشين سرشمارى در كشور متمايز مى كند. در اين سرشمارى

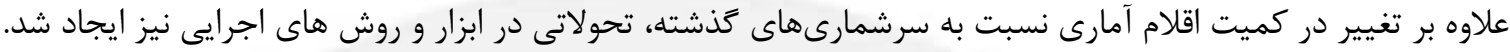

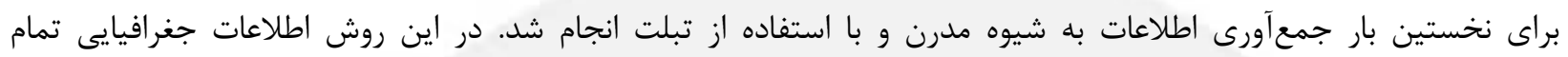

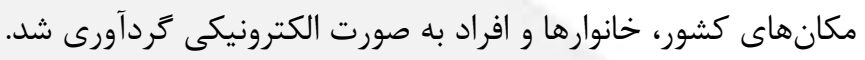

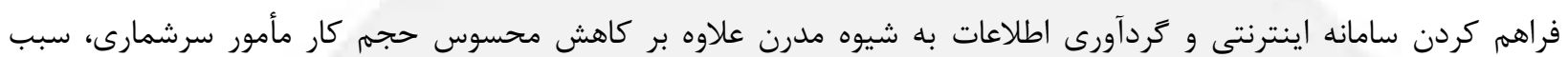
افزايش دقت و كيفيت اطلاعات شد.

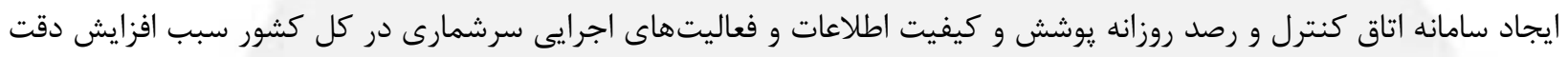
و بهبود كيفيت اطلاعات كرديد. براى اولين بار در اين سرشمارى به منظور كاهش حجم كار مـامور و بـهدنبـال آن افـزايش كيفيـت اطلاعـات سرشـمارى از فايـل

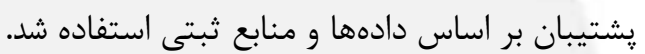

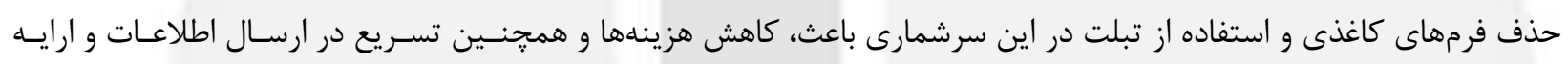
نتايج شد. اطلاعات كستردهاى كه از اين سرشمارى درخصوص مشخصات و ويزگگ هاى جمعيت و مسكن به دست آمده است، در قالب نشريات

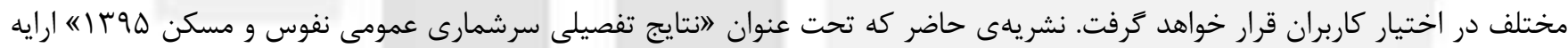

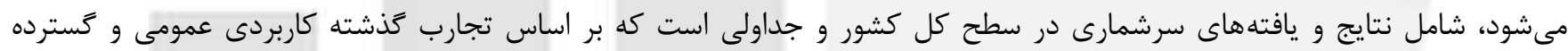

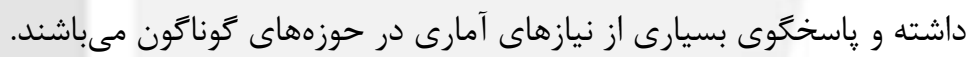

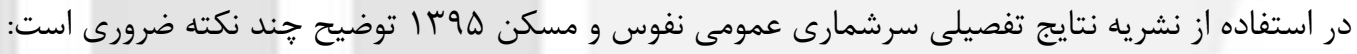

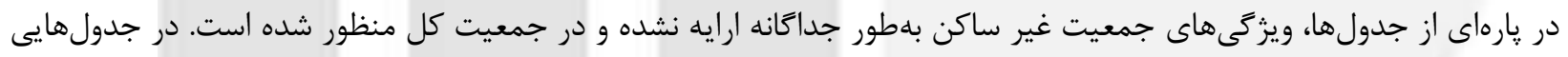

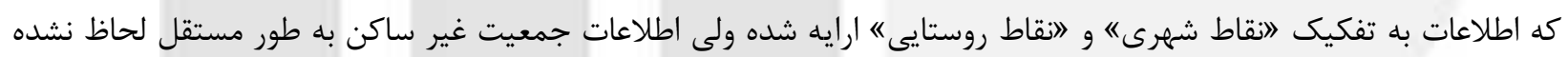

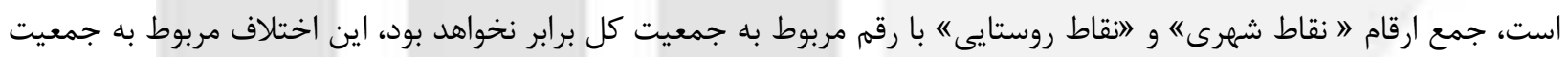

$$
\text { غيرساكن است. }
$$

واحدهاى مسكونى معمولى كه در اين سرشمارى مورد مطالعه قرار گرفتهاند فقط شامل آن دسته از واحدهاى مسكونى است كه در

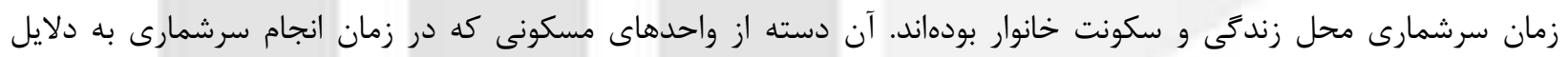

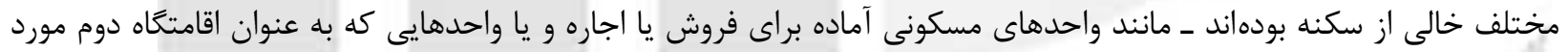

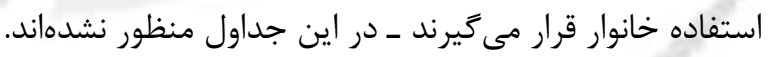

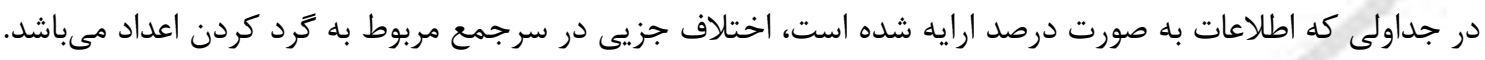

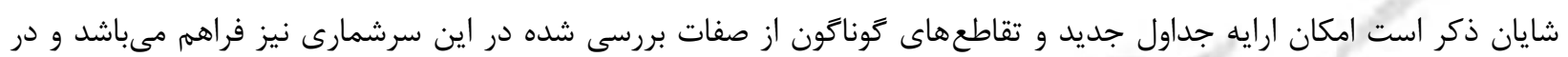

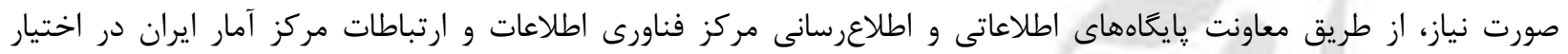
كاربران قرار خواهد كرفت.

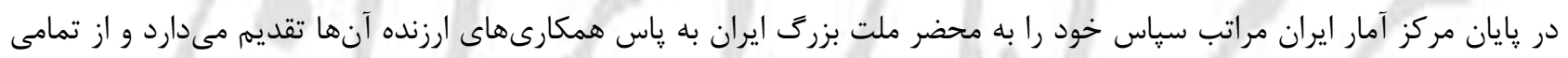

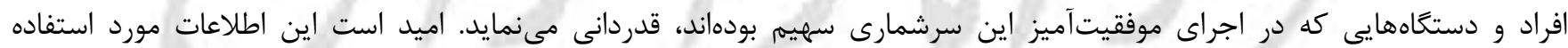
برنامه يزان، محققان و يزوهشكَران قرار كيرد.

\section{اميدعلى يارسا رييس مركز آمار ايران}

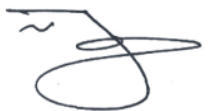




\section{فهرست مندر جات}

11 تعاريف و مفاهيم - م

11 شاخصهاى عمده

r) كزيده يافتهها

\section{فصل اول: جمعيت (ويز كىهاى عمومى جمعيت، مهاجرت، سواد و تحصيلات، فعاليت، زناشويى و بارورى)}

149

ird

ITS

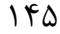

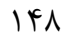

$10 \cdot$

109

IVF

TTA

rTI

TF.

rFq

TQD

TET

rVq

TAD

rMN

rq1

rqv

r..

$r \cdot r$

$r \cdot \varphi$

$r \cdot \Lambda$

riv

rT.

rTr

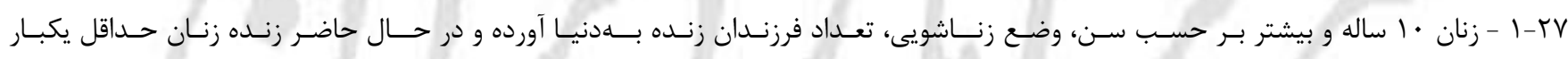
rTQ

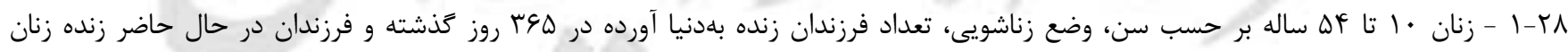
rTV

1 - 1 - جمعيت بر حسب سن، جنس و وضع سكونت.

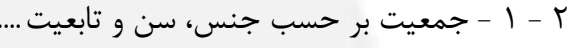

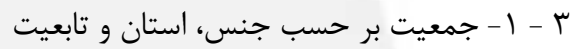

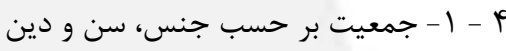

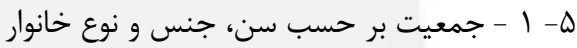

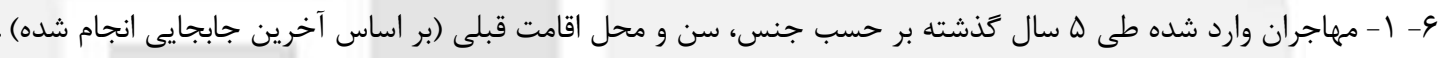

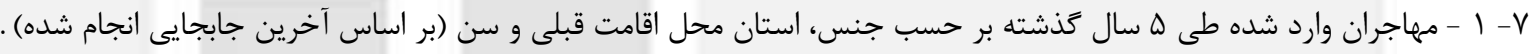

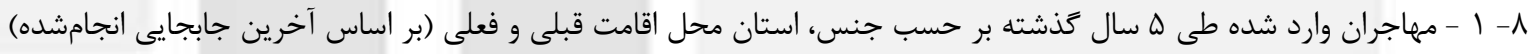

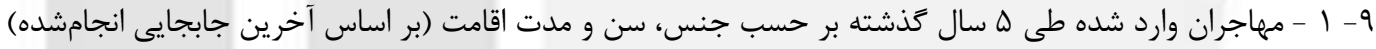

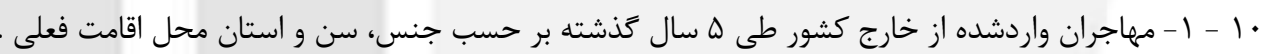

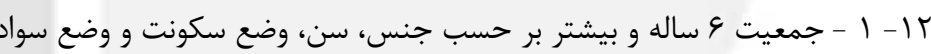

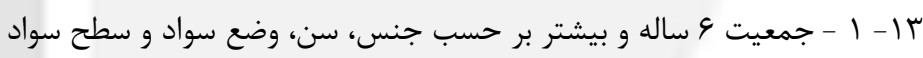

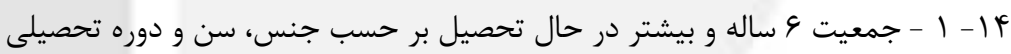

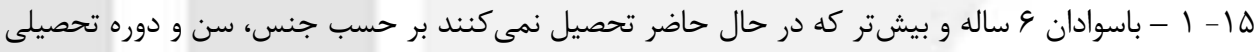

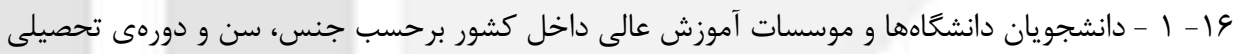

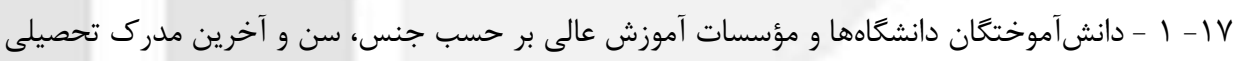

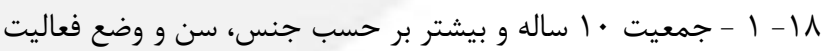

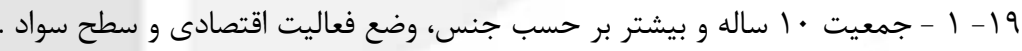

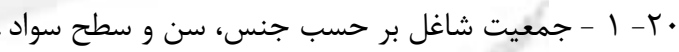

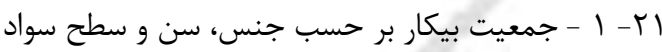

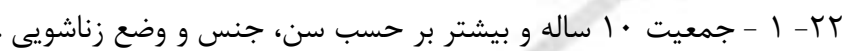

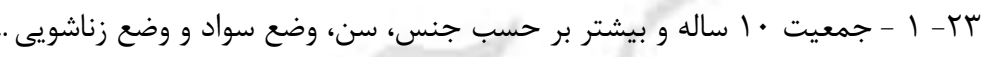
FF

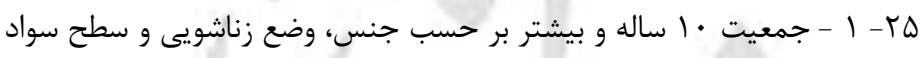

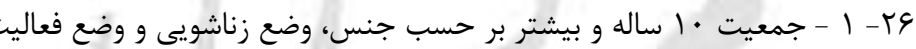

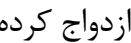

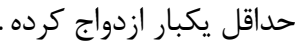




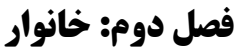

ו ו

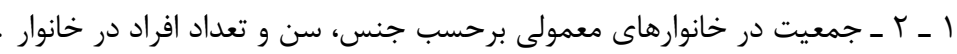

rrv

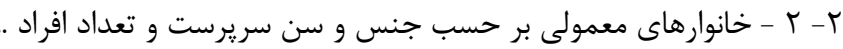

THT

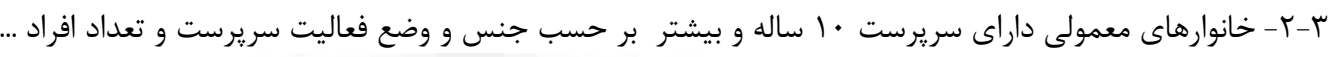

req

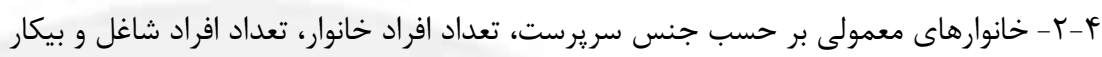
$r \Delta \omega$

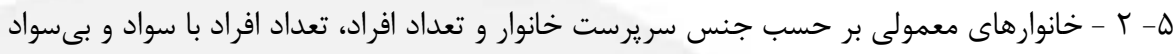
एद)

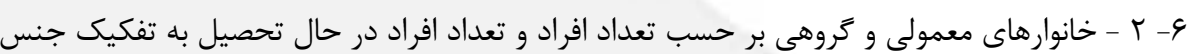
TQT

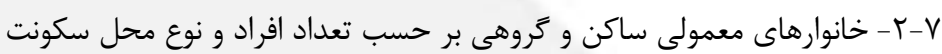
reF

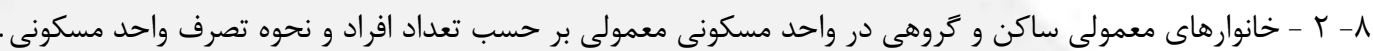

\section{فصل سوم: مسكن}

TSV

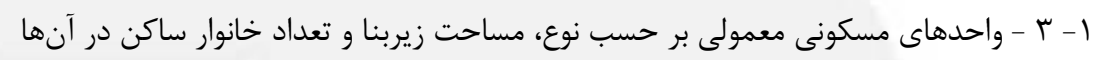

$\mu \gamma$.

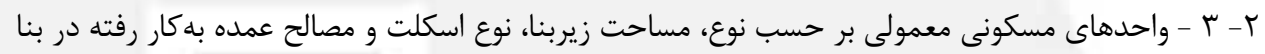




\section{فهرست نمودارها}

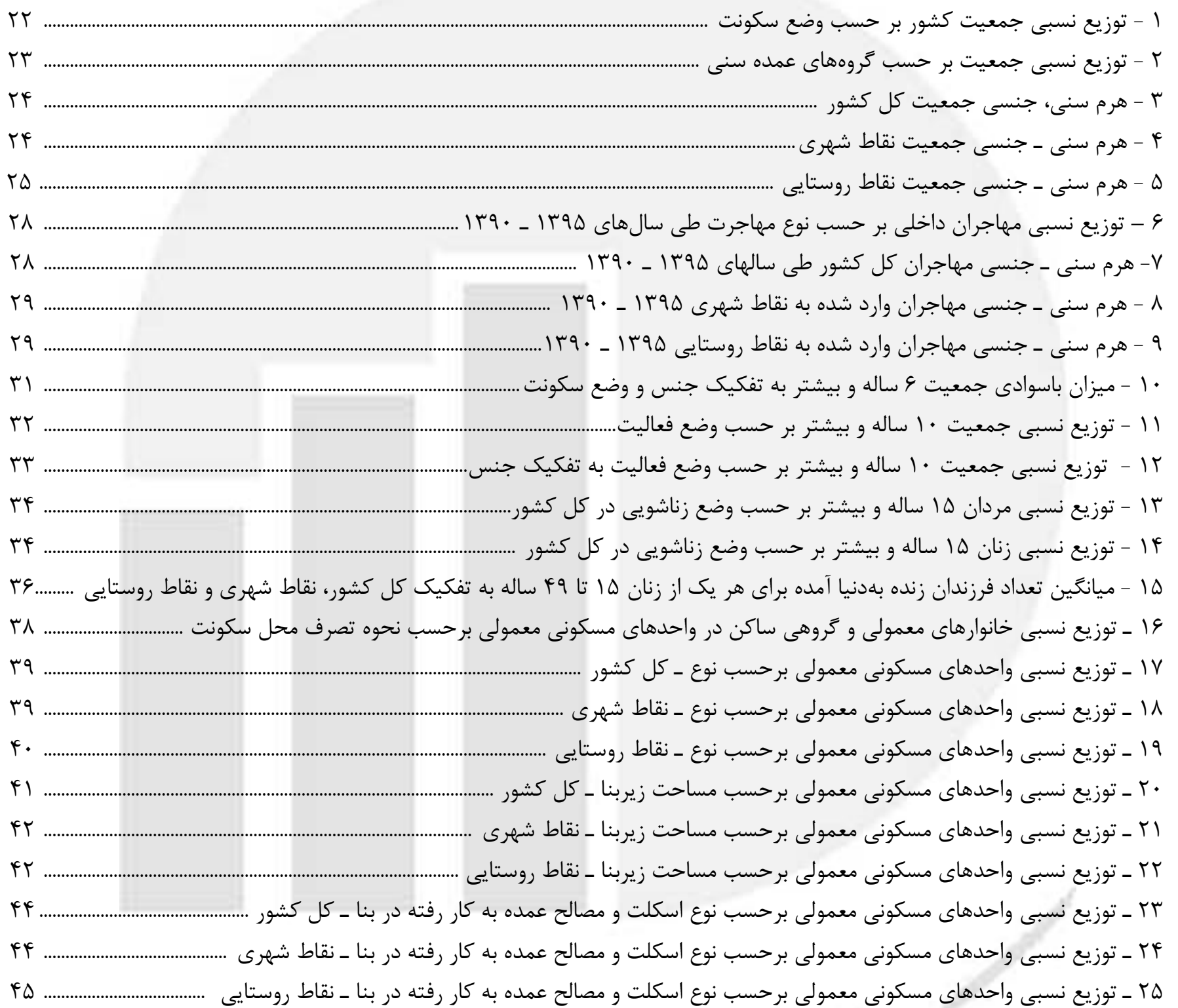


نقشه استانى جمههورى اسلامى ايران : هوسا

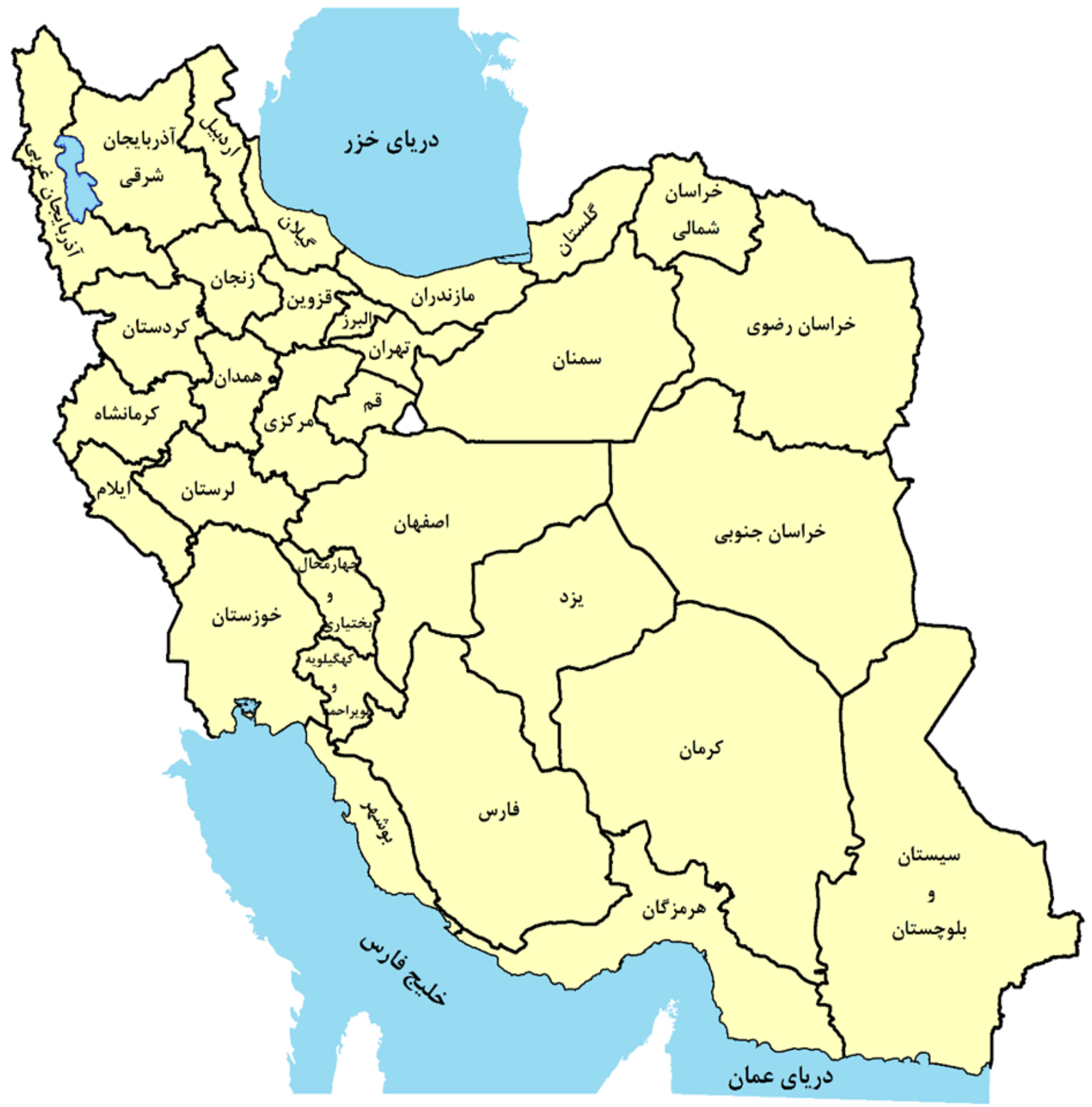


تعاريف و مفاهيم

جمعيت و خانوار

جمعيت (جامعه مورد سرشمارى)

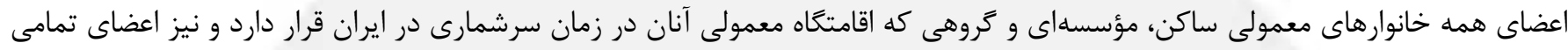

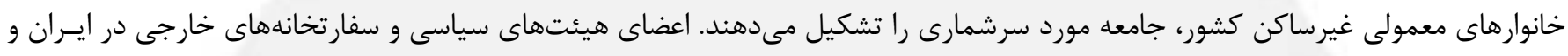

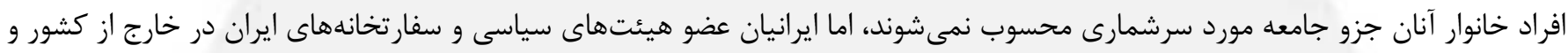
افراد خانوار آنان، جزو جامعه مورد سرشمارى به حساب مى آيند.

خانوار معمولى

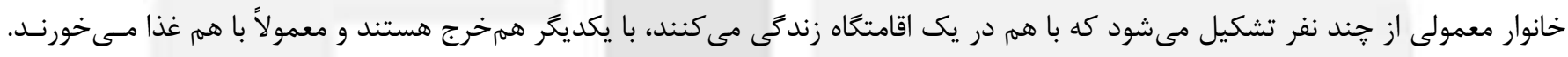
در مواردى خانوار معمولى مىتواند يك نفره باشد.

خانوار معمولى ساكن خانوارى كه در اقامتخاه ثابت (مكانهاى محل سكونت ساكن ساخته شده از مصالح سخت و نيز خادر ثابت، آلونـك، كيــر و ...) سـكونت دارد، اخـانوار معمولى ساكن هن ناميده مىشود.

خانوار معمولى غير ساكن خانوارى كه در زمان سرشمارى معولى در اقامتخاه ثابتى سكونت ندارد، "خانوار معمولى غيرساكنه ناميده مىشود. اين دسته از خانوارها سه كروه زير

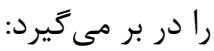

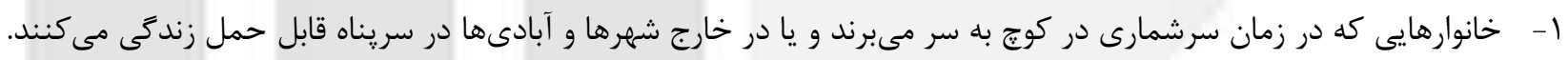

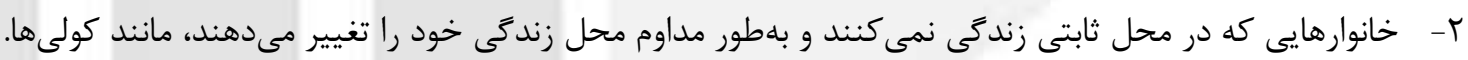

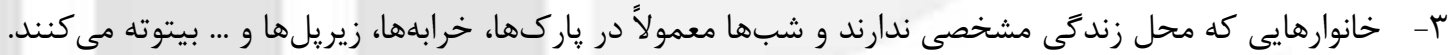

خانوار كروهى

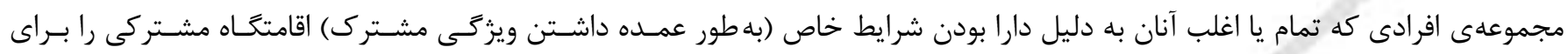

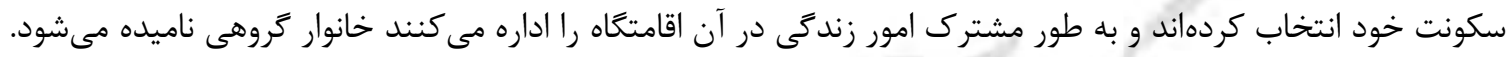

خانوار مؤسسهاى

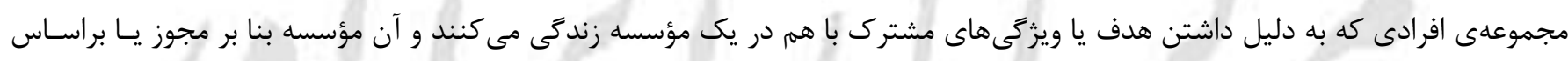

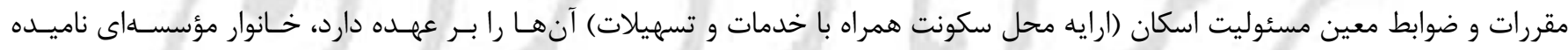

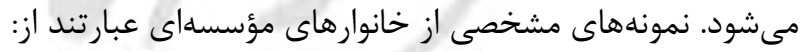

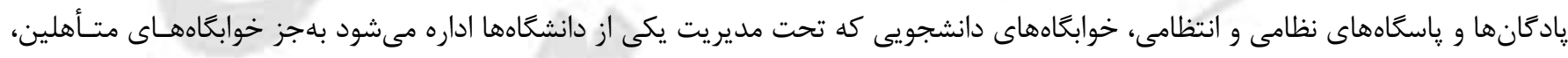
آسايشخاههاى روانى و و ب... 
اقامتخاه معمولى إقاه

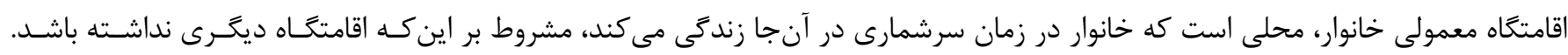

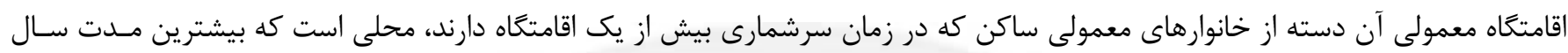
را در آنجا باهسر مىبرند.

شهر (نقطه شهرى) منظور از شهر، هر يك از نقاط جغرافيايى است كه براساس مصوبه هيات وزيران شهر شناخته شود و داراى شهردارى باشند.

آبادى (نقطه روستايى)

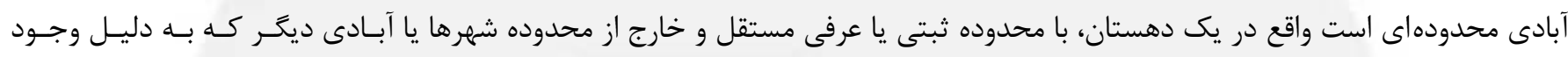

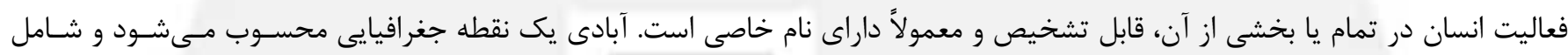

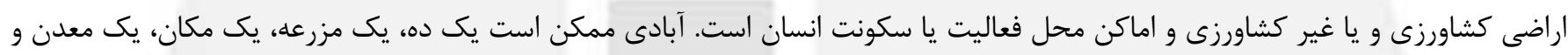
امثال آن باشد.

جمعيت ساكن در نقاط شهرى

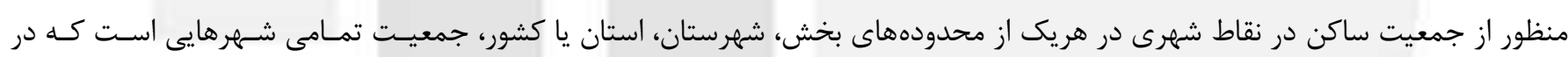

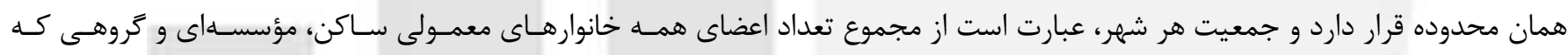
اقامتخاه معمولى آنان در زمان سرشمارى در درد آن شهر واقع است.

جمعيت ساكن در نقاط روستايى

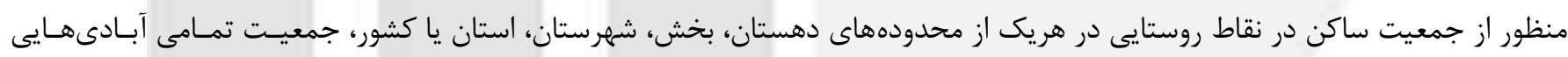

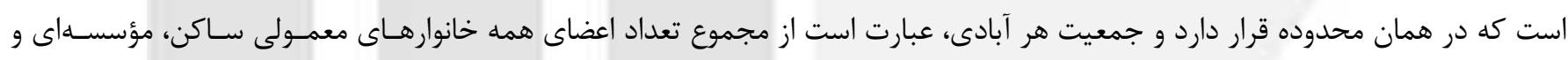

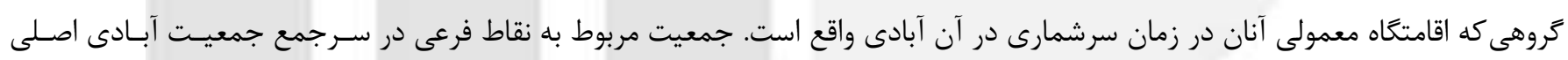
لحاظ مىشود.

\section{جمعيت غيرساكن}

منظور از جمعيت غير ساكن در هريك از محدودههاى شهرستان، استان يا كشور، جمعيت تمامى خانوارهاى معمولى غير ساكنى اسـت كـه در همان محدوده سرشمارى شدهاند.

سريرست خانوار

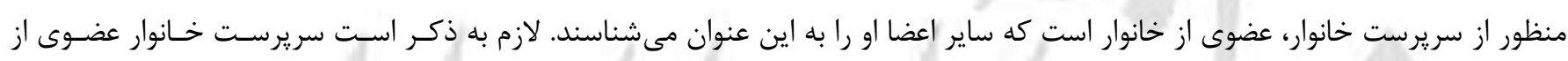

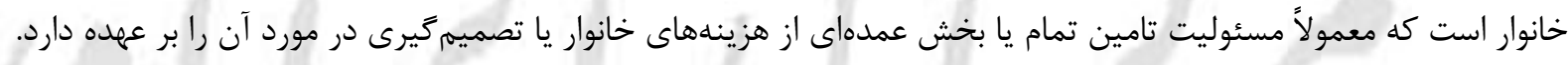

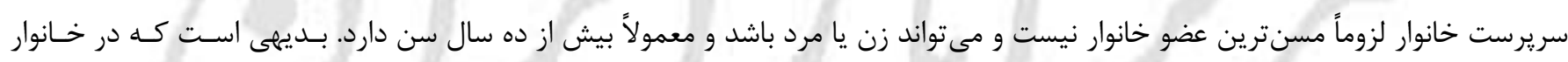
يكنفره، تنها عضو خانوار سريرست خانوار محسوب مى شئود

سن منظور از سن، تعداد سالهاى كاملى است كه از زمان تولد فرد كذشته است. 


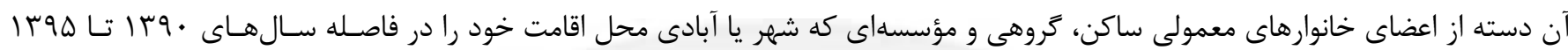
تغيير دادهاند، مهاجر شناخته مىشوند.

مدت اقامت

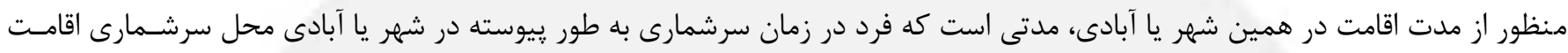
داشته است و به صورت سال تمام در نظر گرفته مىشود.

محل اقامت قبلى

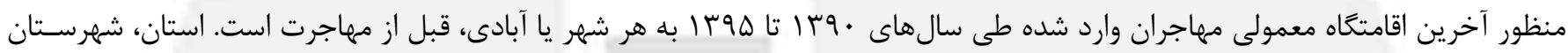
و شهر محل اقامت قبلى بر اساس محدوده فعلى تقسيمات كشورى تعيين مىشود.

سواد و تحصيلات در حال تحصيل

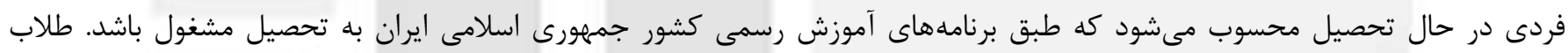

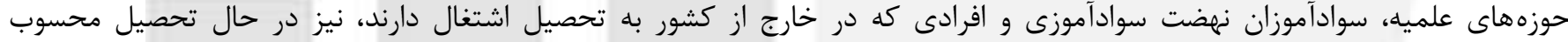
مى شوند.

باسواد

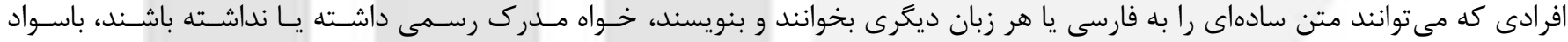

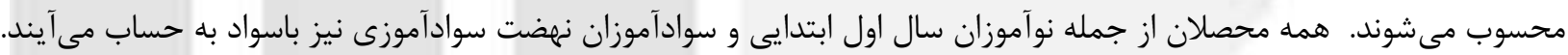

پايه، دوره يا مدرك تحصيلى

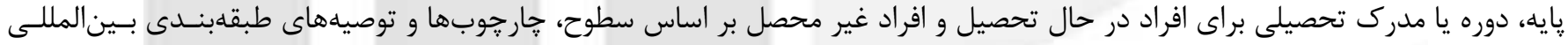

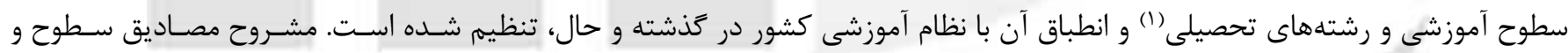

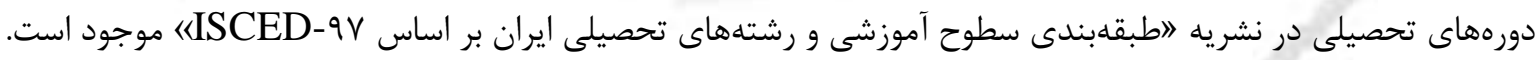

فعاليت

كار

كار، آن دسته از فعاليتهاى اقتصادى (فكرى يا بدنى) است كه بهمنظور كسب درآمد (نقدى يا غيرنقدى) انجام شود و هدف آن توليد كالا يا ارايه خدمت است. فعاليت افراد زير نيز كار محسوب مى شود: - افرادى كه بدون دريافت مزد در كسب و كار يكى از اعضاى خانوار خود كه با وى نسبت خويشاوندى دارند كـار مسىكنـــ (كاركنـان فـاميلى بدون مزد). - افرادى كه در حال انجام خدمت وظيفه هستند. - افرادى كه خدمت در بسيج شغل آنان محسوب مىشود و از اين بابت مزد وحقوق دريافت مى كنند. 
- افرادى كه به منظور كسب درامد يا سود نقدى يا غيرنقدى در محل سكونت كارهاى خدماتى يا توليدى نظير قاليبافى، خيـاطى، آرايشـخرى،

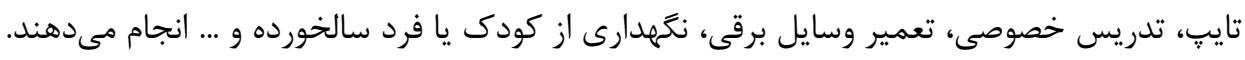

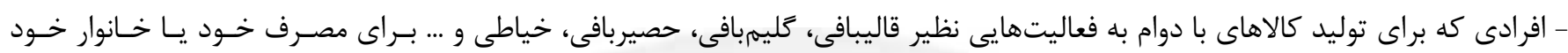

مشغول هستند.

- افرادى كه در حال ساختن، بازسازى يا تعمير اساسى منزل خود هستند.

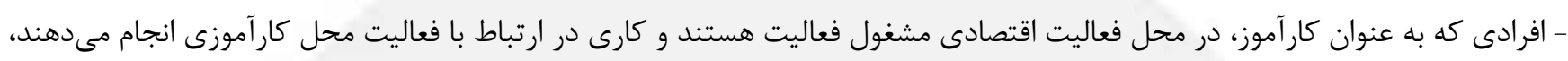

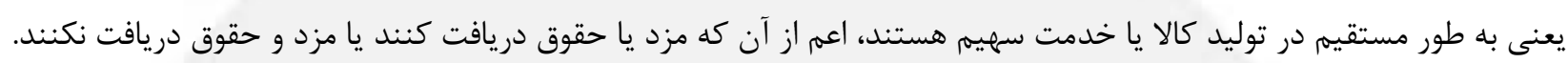

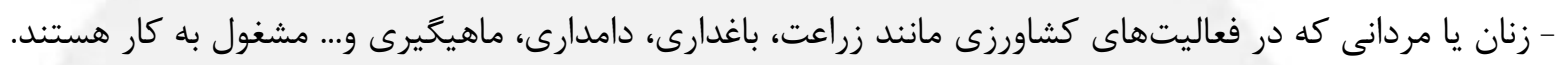

وضع فعاليت

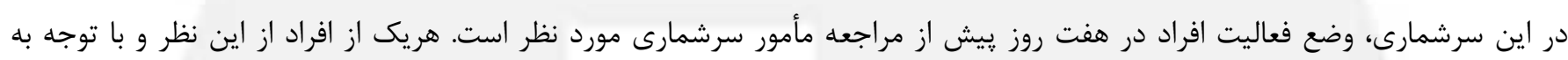

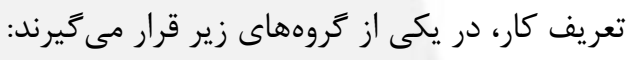

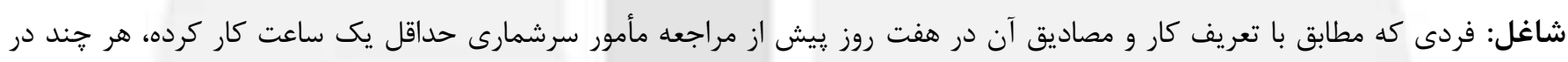

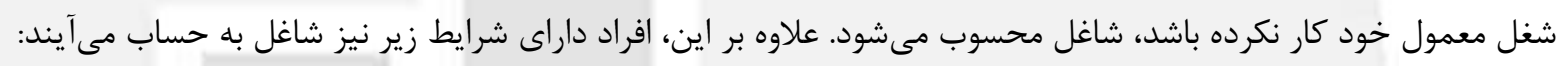

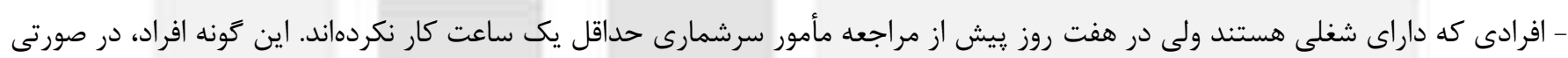

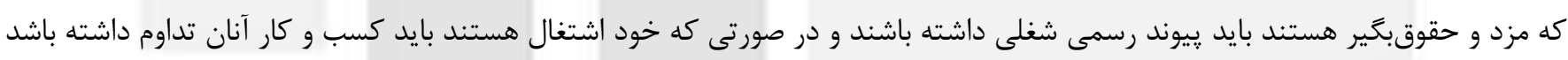

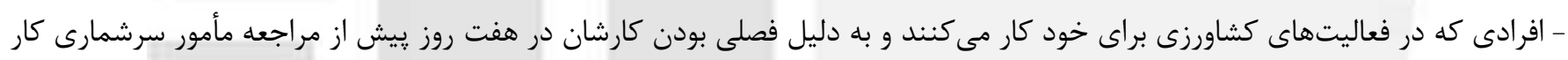

نكردهاند.

- افرادى كه به دليل نوبتى بودن كارشان در هفت روز بِ بيش از مراجعه مأمور سرشمارى سركار خود نرفتهاندان.

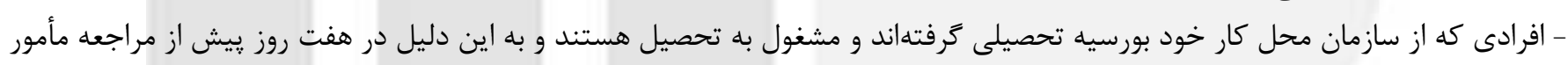
سرشمارى كار نكردهاند.

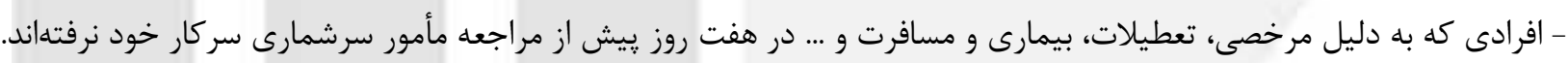

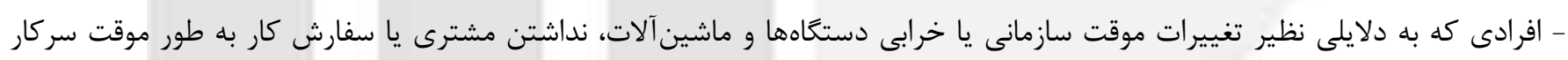
نرفتهاند.

- افرادى كه از كار خود معلق شدهاند ولى بيوند رسمى شغلى دارند.

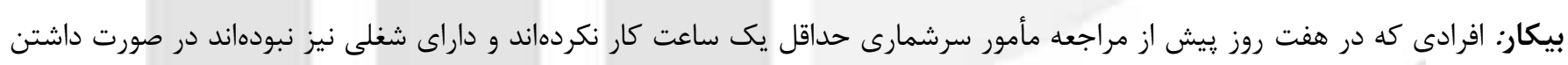
دو شرط زير بيكار محسوب مىشوند.

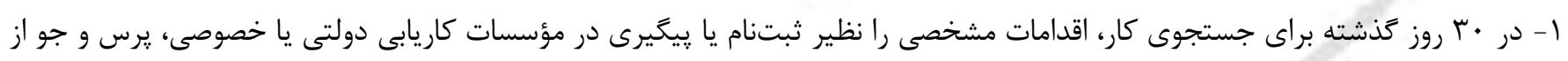

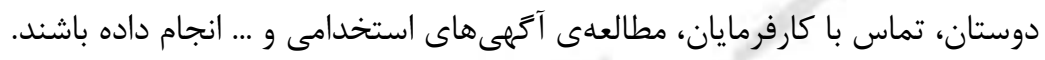

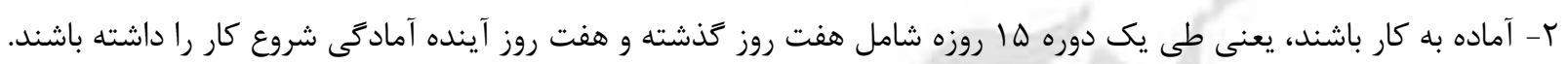

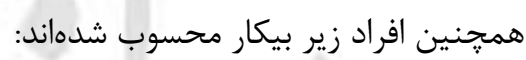
- در انتظار شروع كار جديد هستند، يعنى براى آنان كارى مهيا شده و قرار است در آينده به آن كار مشغول شوند و نيز آماده به كار (طبق تعريف) هستند.

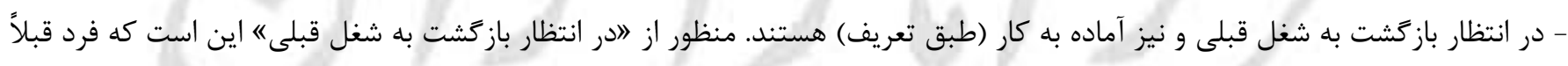

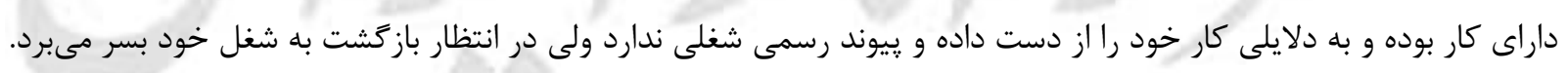

جمعيت فعال اقتصادى

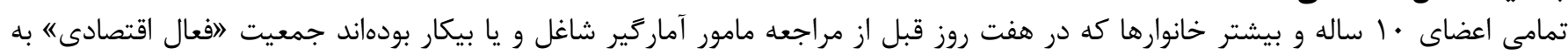
شمار مى آيند. 
محصلان، خانهداران و دارندكان درآمد بدون كار، جنانجه شاغل يا بيكار نيز بودهاند، افعال اقتصادى" محسوب مىشوند.

جمعيت غيرفعال اقتصادى تمامى اعضاى • ا ساله و بيشتر خانوارها كه در هفت روز قبل الفئ ازئ مراجعه مامور آماركيرى شاغل و يا بيكار نبودهاند جمعيت اغير فعال اقتصادى" به شمار مى آيند.

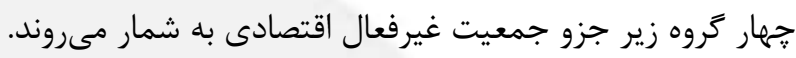

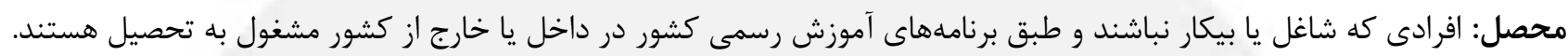

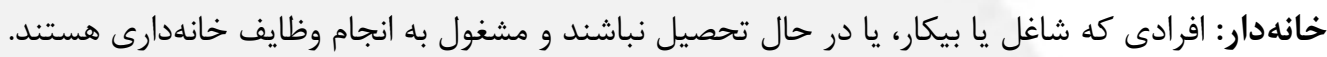

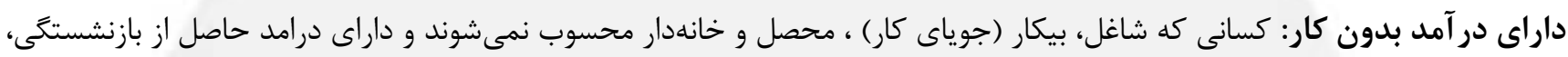

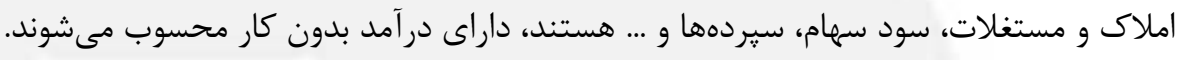

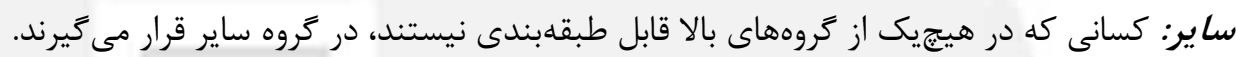

زناشويى و بارورى

داراى همسر: زنان يا مردانى كه عقد ازدواج (دايم يا موقت)، بستهاند حتى اكر زندگى مشتركى را آغاز نكـرده باشــند، داراى همسـر محسـوب مىشوند. بى همسر به دليل فوت همسر: زنان يا مردانى كه همسرشان فوت كرده است و تا زمان سرشمارى مجدداً ازدواج نكردهاند، بىهمسر به دليـل فوت همسر شناخته مىشوند. بى همسر به دليل طلاق: زنان يا مردانى كه از همسر خود طلاق كرفتهاند و تا زمان سرشمارى مجدداً ازدواج نكـردانــ، بـىهمسـر بـهـ دليـل طلاق تلقى مىشوند.

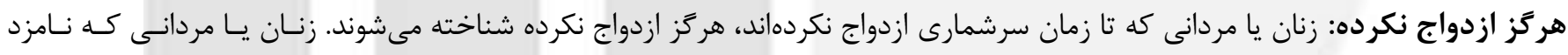

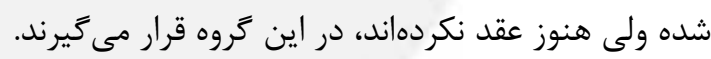

فرزند زنده به دنيا آورده

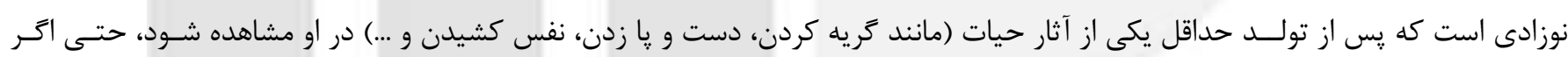
بلافاصله فوت كرده باشد.

فرزند در حال حاضر زنده

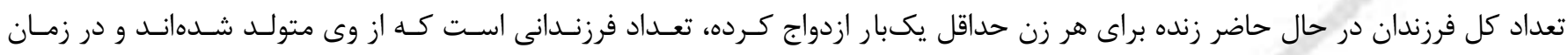

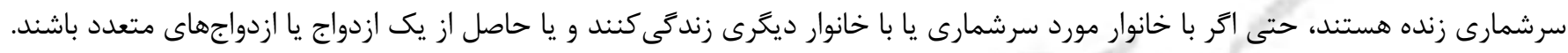

\section{مسكن واحد مسكونى منىن}

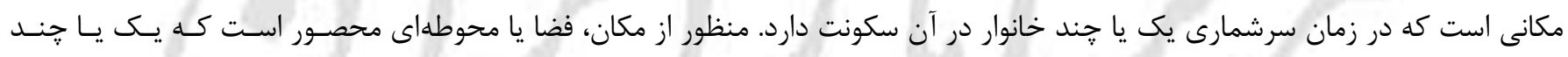

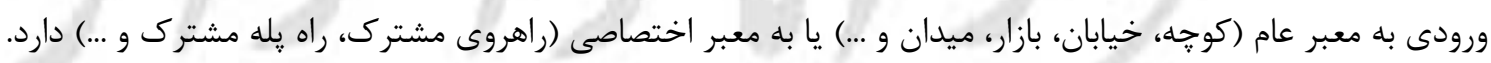

نوع محل سكونت خانوار

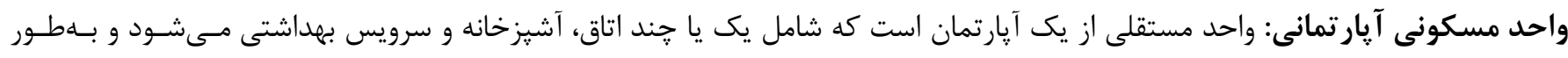

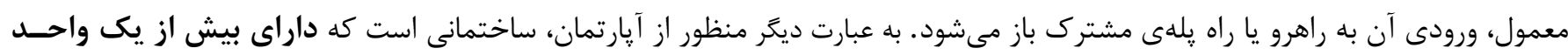


مستقل براى سكونت، فعاليت اقتصادى و ... است. در اين نوع ساختمان، حياط، پيار كينَ، راهرو، راه يله و ... غيراختصاصى است و بـهـ صـورت

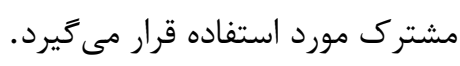

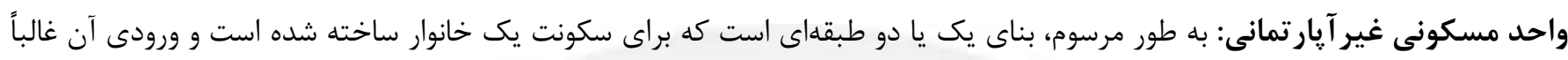

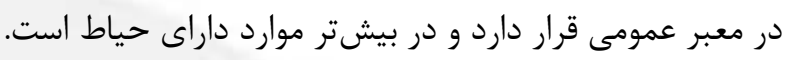

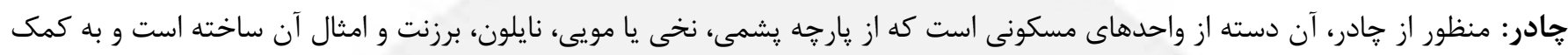
تير كهاى جوبى يا فلزى و طناب بريا مىشود.

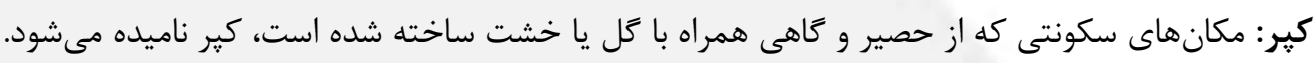

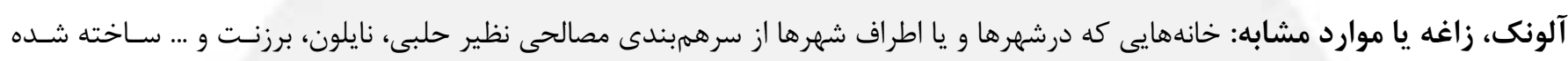
است، آلونك محسوب مىشود. زاعه يا موارد ميشابه:

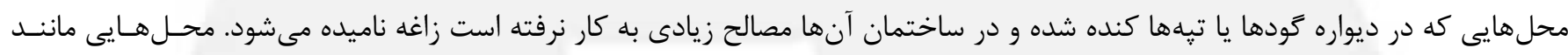

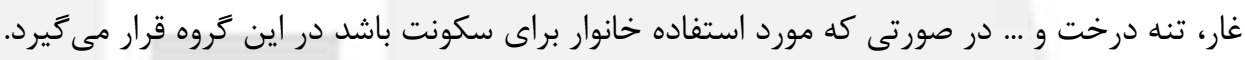

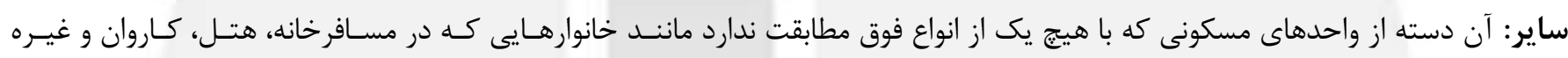

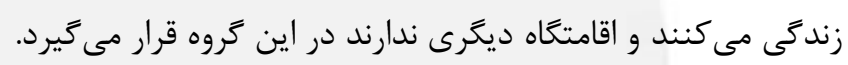

نحوه تصرف محل سكونت خانوار

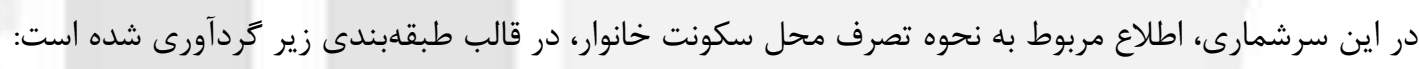

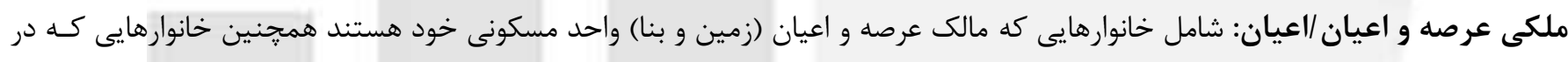

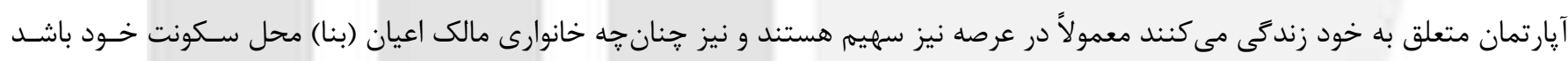

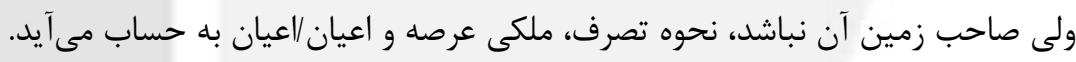

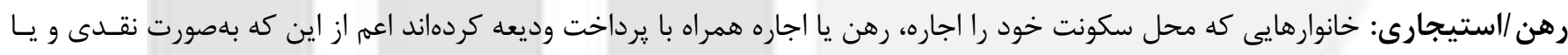

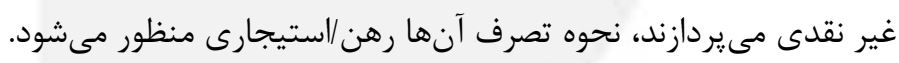

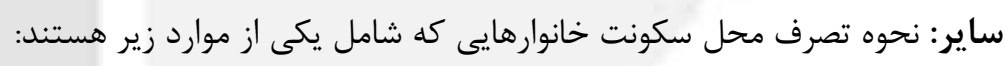

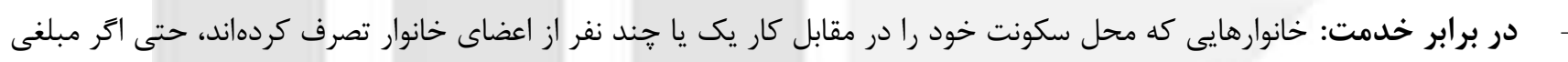

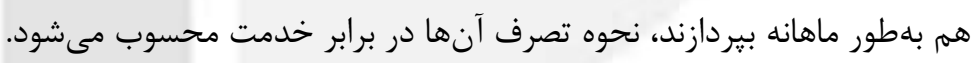

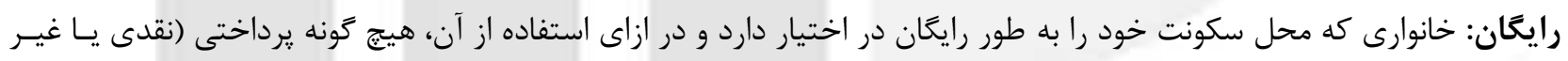

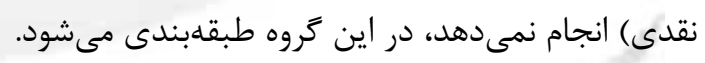

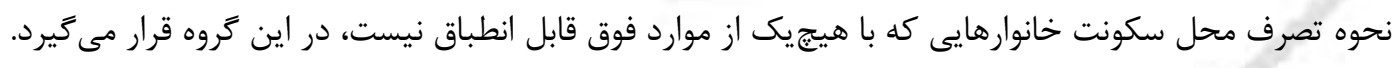

\section{مساحت زيربناى واحد مسكونى}

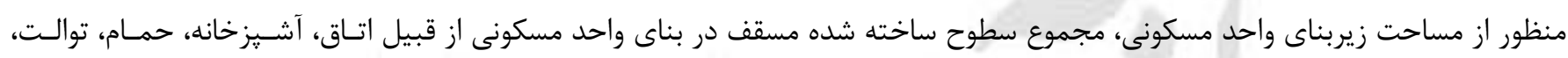

انبارى، صندوق خانه، يستو و ز... است.

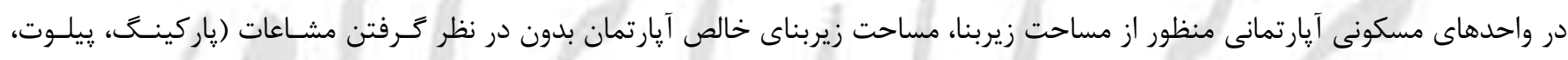

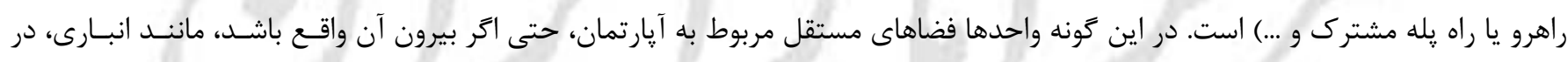
مساحت زيربنا منظور مىشود. در واحدهاى مسكونى غير آيارتمانى، مساحت تمام سطوح ساخته شده شامل راهروها، راه يله، خريشته و ... در محاسبه مساحت زيربنـا منظـور

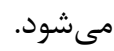
در مناطق روستايى، فضاهايى كه در محل سكونت خانوار به منظور فعاليتهاى مرتبط با كشاورزى يا نكهدارى و يرورش دام و طيور ييشبينس

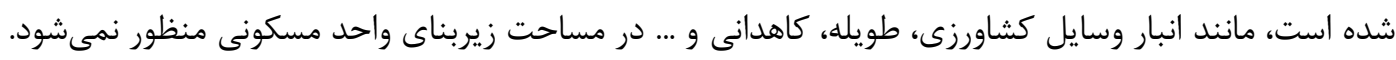




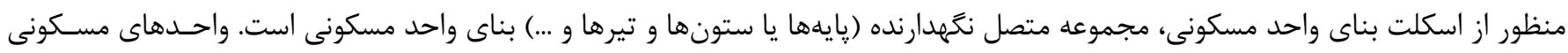
از نظر نوع اسكلت در يكى از سه گروه زير قرار مي مئيرند:

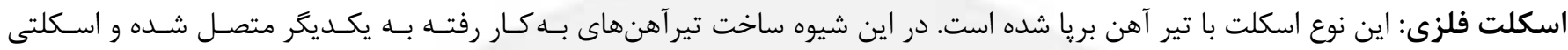
يكيار خه را تشكيل داده است كه بار بنا را تحمل مي كن كند. بتون آرمه: در اين روش ساخت اسكلت بنا از بتون آرمه (بتون همراه باد با آرماتور و ميلكَرد) ساخته شده است است.

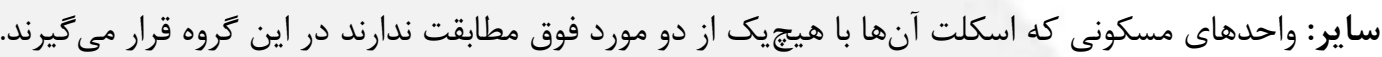

مصالح عمده به كار رفته در بناى واحد مسكونى

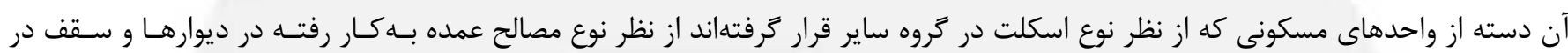
كروههاى زير طبقابندى مىشوند: آجر و آهن يا سنَ و آهن

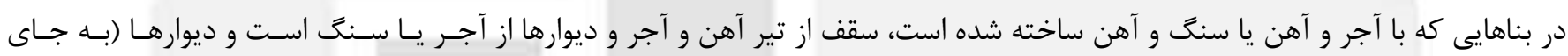

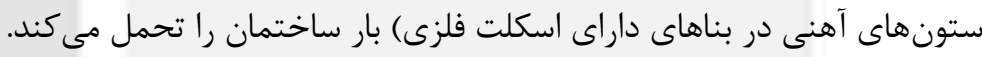

آجر و جوب يا سنى و جوب

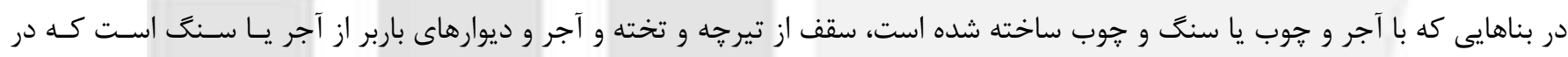
نتيجه از محل اتصال تيرها با ديوارها، سنكَينى سقف به ديوارها منتقل مى شود و ديوارها بار بار بنا را تحمل مئى كنيند.

بلوك سيمانى (با هر نوع سقف)

در اين نوع بناها در ديوارها از بلوك سيمانى استفاده شده است. در سقف اين نوع بناها از آهن، تيرجه و بلوك يا از جوب استفاده مىشود. تمام آجر يا سنغ و آجر

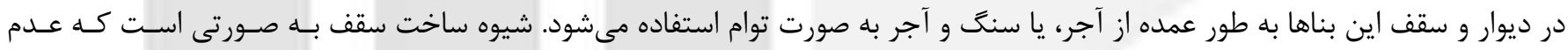

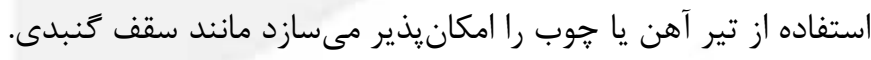

تمام جوب

در اين نوع بناها كه بيشتر در مناطق با آب و هواى مرطوب رايج است بهطور عمده جوب در اشكال مختلف، مصالح عمده بهكار رفته در ساخت بنا را تشكيل مىدهد.

خشت و جوب

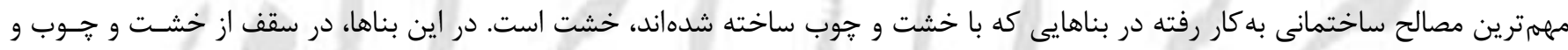

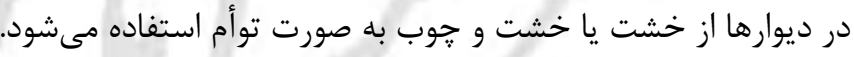

خشت و كَل

بناهاى خشت و كلى، بلهور عمده با خشت ساخته شدهاند و كل به عنوان ملات و نكاهدارنده خشتها بر روى هم در آن بهكار رفته است.

ساير اكر مصالح عمده به كار رفته در واحد مسكونى با هيج يك از مصالح مذكور مطابقت نداشته باشد ساير محسوب مىشود. 
شاخصهاى عمده

افزايش مطلق دوره

افزايش مطلق جمعيت يا واحد مسكونى معمولى در يك دوره عبارت است از تغيير تعداد جمعيت يا واحد مسكونى معمـولى در طـى آن دوره و از إبطه زير به دست مى آيد:

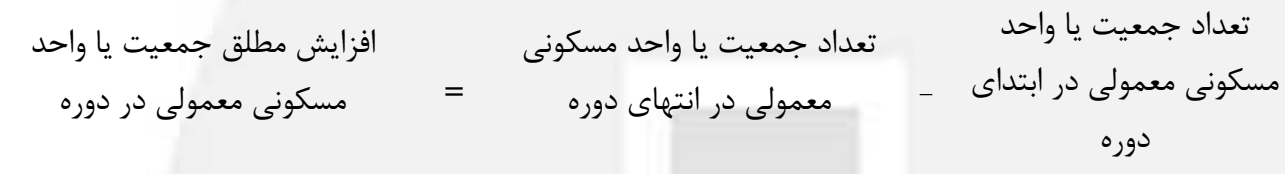

افزايش نسبى دوره
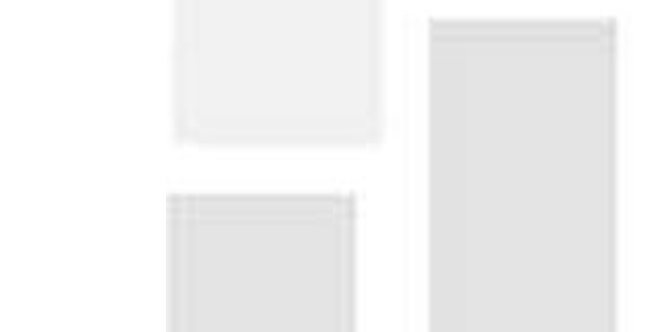

افزايش نسبى جمعيت يا واحد تعداد جمعيت يا واحد مسكونى معمولى دوري

افزايش نسبى جمعيت يا واحد مسكونى معمولى در يك دوره از رابطه زير به دست مى آيد: مسكونى معمولى در دوره در انتهاى دوره تعداد جمعيت يا واحد مسكونى معمولى در

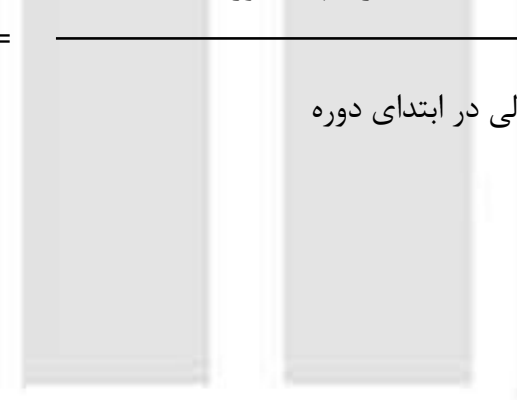
$+x)$

$$
P_{n}=p_{o}(1+r)^{n} \Rightarrow r=\sqrt[n]{\frac{P_{n}}{P_{o}}}-1
$$


متوسط بعد خانوار عبارت است از متوسط تعداد افراد در خانوار و از تقسيم تعداد جمعيت به تعداد كل خانوار حاصل مى شود.

تعداد خانوار

ميزان باسوادى

عبارت است از نسبت تعداد افراد باسواد به جمعيت 9 ساله و بيشتر كه بهصورت درصد بيان مىشود.

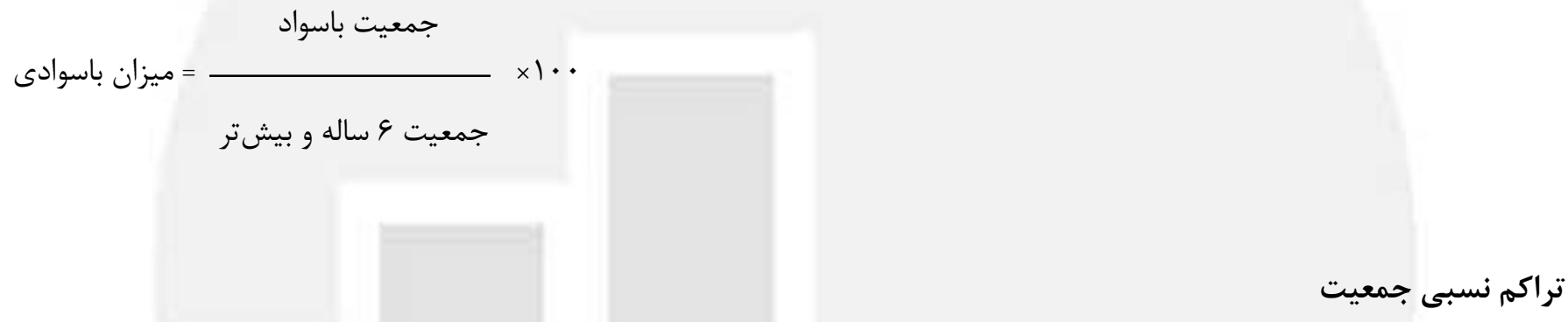

تراكم نسبى جمعيت عبارت است از متوسط تعداد افراد جمعيت يك منطقه در هر كيلومتر مربع از مساحت آن منطقه.

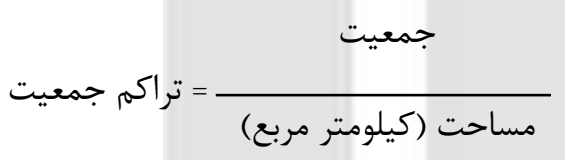

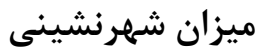

عبارت است از نسبت تعداد جمعيت ساكن در نقاط شهرى به جمعيت كل كشور.

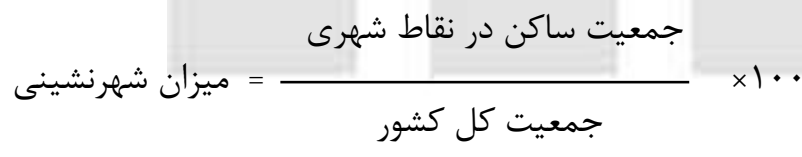

نسبت جنسى

نسبت جنسى عبارت است از نسبت تعداد مردان به زنان كه به صورت درصد بيان مىشود.

نسبت جنسى $=\frac{M}{F} \times 1 \cdots$

كه در آن، M تعداد مردان و F تعداد زنان است. 
ميانغين سنى ميانكَين سنى، متوسط سن افراد يكى جامعه است و از تقسيم كردن مجموع حاصل ضرب هاى هريك از سـنين منفـرد در فراوانى افـراد در آن سن، به كل جمعيت حاصل مىشود.

$$
\text { ميانغين سنى }=\frac{\sum_{i=.}^{\omega} i . F_{i}}{\sum_{i=.}^{\omega} F_{i}}
$$

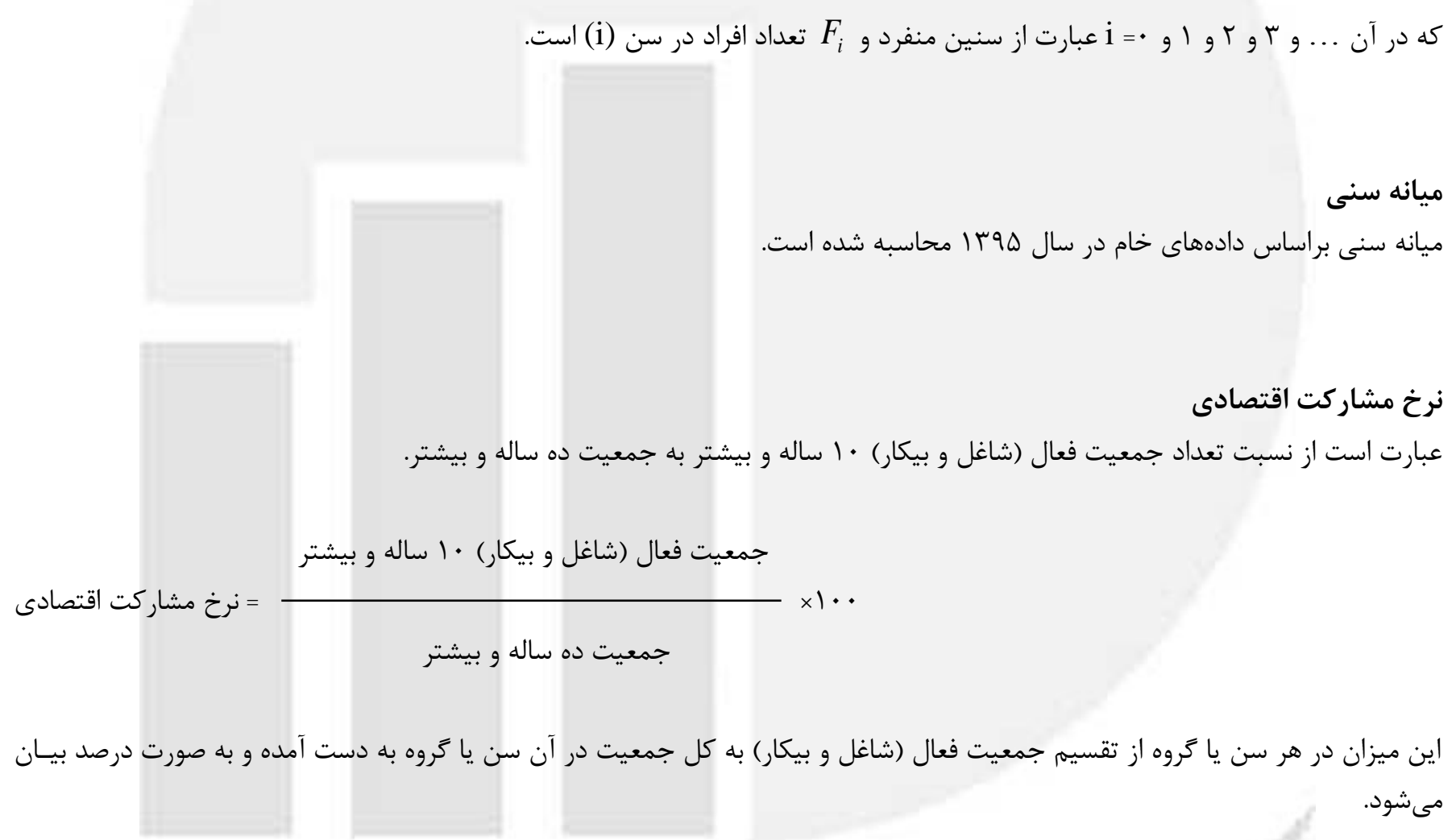




\section{كزيده يافتهها}

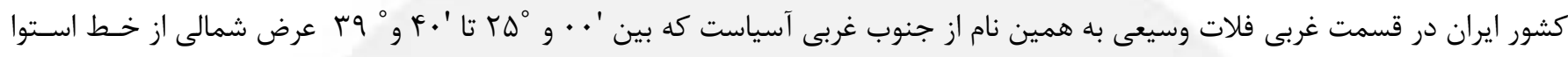

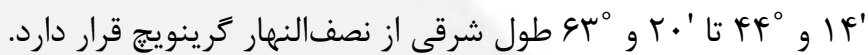

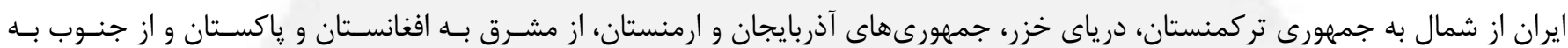

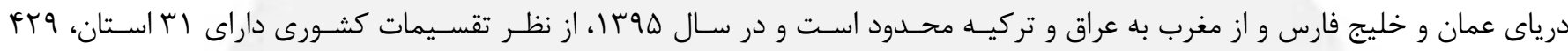
شهرستان، DV • ا بخش، TDA

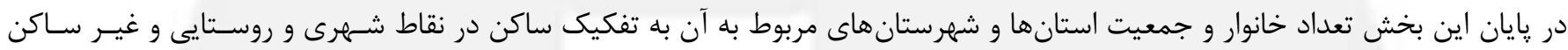

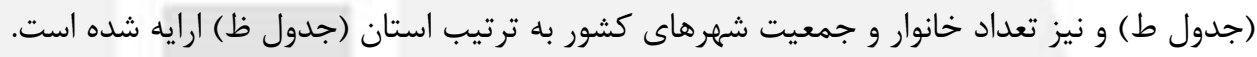

الف - تعداد شهرستانها، بخشها، دهستانها، شهرها، آبادىهاى داراى سكنه و كل آبادىهاى كشور به تفكيك استان

\begin{tabular}{|c|c|c|c|c|c|c|}
\hline كل آبادىها & آبادىهاى داراى سكنه & شهر' & دهستان & بخش & شهرستان & 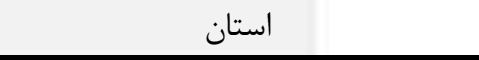 \\
\hline 9VAYA & EYTAF & IYFY & 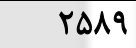 & $1 \cdot \Delta V$ & Frq & 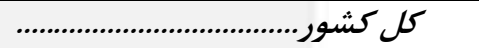 \\
\hline$r \cdot v \varepsilon$ & rVI. & Gr & Ifr & fF & $r \cdot$ & 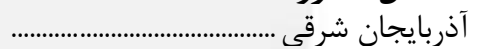 \\
\hline rद99 & $r \cdot r$. & pr & 111 - (1) & f. & IV & جان غربى ............................................ \\
\hline $1 \wedge \Delta 9$ & $I V \cdot \Lambda$ & rq & VI & rq & $1 \cdot$ & 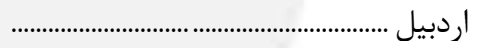 \\
\hline rFqV & 1999 & $1 \cdot v$ & ITV & $\Delta \cdot$ & TF & (1) \\
\hline prr & 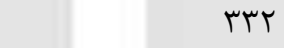 & IV & rq & Ir & 4 & …………………... \\
\hline $1 \cdot \wedge r$ & sVG & $r \Delta$ & pq & rq & $1 \cdot$ & 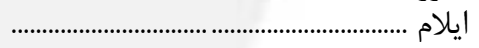 \\
\hline$\wedge \Delta \cdot$ & gr. & rv & $\uparrow \wedge$ & $r \Delta$ & $1 \cdot$ & 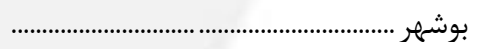 \\
\hline $1 \cdot r k$ & $V \times 1$ & fr & vi & r & 19 & تهران ........ \\
\hline 911 & $\Lambda \cdot r$ & f. & $\Delta \cdot$ & $r \omega$ & 9 & 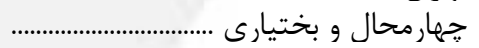 \\
\hline ras. & $|\vee \wedge|$ & r⿳ & 9) & $r \Delta$ & 11 & 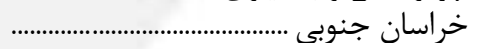 \\
\hline vrqu & rthi & Vr & 194 & $\checkmark \cdot$ & th & 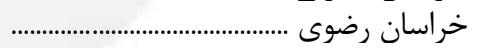 \\
\hline Ir.. & 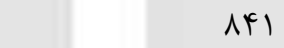 & rt & id & 19 & $\Lambda$ & 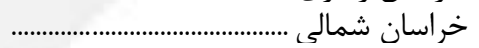 \\
\hline gref & F. Ft & Ve & lfF & $9 V$ & tr & 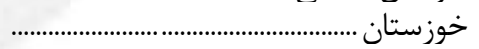 \\
\hline 1110 & $9 \mathrm{TV}$ & rI & $\uparrow \wedge$ & IV & $\wedge$ & 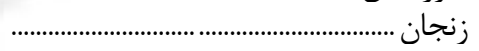 \\
\hline trti & $\Delta F q$ & $r \cdot$ & ו & 10 & $\wedge$ & 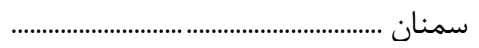 \\
\hline १९४^ & VIFA & rv & $11 \mathrm{r}$ & ¡人 & 19 & 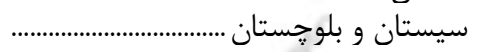 \\
\hline NTVG & fIDT & $1 \cdot r$ & $r \cdot \Delta$ & $\Lambda f$ & rq & 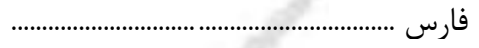 \\
\hline $114 \mathrm{~V}$ & AVG & $r \Delta$ & f4 & 19 & 4 & 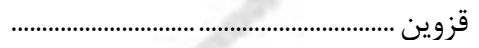 \\
\hline 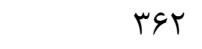 & tra & q & 9 & $\Delta$ & 1 & 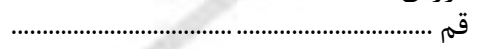 \\
\hline 119. & $19 \mathrm{VV}$ & rq & 19 & 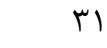 & $1 \cdot$ & 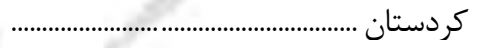 \\
\hline IIVEV & DEFT & V) & $|0|$ & $\Delta \wedge$ & r & 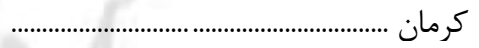 \\
\hline TIOT & rब१ی & rt & 19 & ו & If & 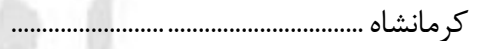 \\
\hline 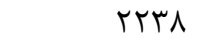 & ISFT & IV & $f \Delta$ & 19 & $\Lambda$ & كهزيلويه و بويراحمد ... \\
\hline $1 \cdot \Delta r$ & $1 \cdot 1 \cdot$ & rq & q. & rV & If & 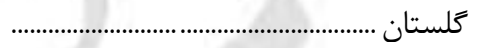 \\
\hline$r q \cdot \Delta$ & rDSV & $\Delta T$ & $1 \cdot 9$ & pr & 19 & 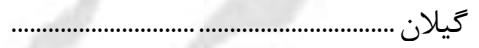 \\
\hline THID & rव^ब & $r \omega$ & Av & ו & 11 & لرستان ...... \\
\hline 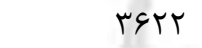 & rQIV & $\Delta \Lambda$ & וזו & $\Delta \varphi$ & tr & مازندران ............ \\
\hline $19 \cdot F^{2}$ & 1199 & س & 99 & r & it & 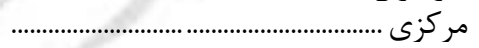 \\
\hline trVE & IVIO & rی & $\Lambda \Delta$ & r人 & Ir & هرمز \\
\hline $17 \cdot 9$ & $1 \cdot V 4$ & rq & $V^{\mu}$ & $r \omega$ & 9 & 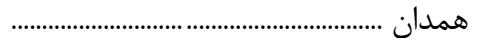 \\
\hline$r q \Delta \Delta$ & $11 T V$ & r) & is & YI & $1 \cdot$ & 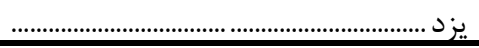 \\
\hline
\end{tabular}




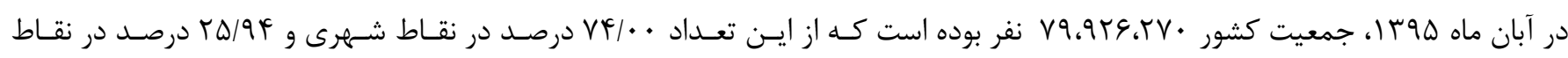
روستايى سكونت داشته و بقيه غير ساكن بودهاند.

ب - جمعيت بر حسب جنس به تفكيك وضع سكونت

\begin{tabular}{|c|c|c|c|c|}
\hline \multirow{2}{*}{ 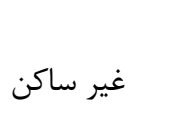 } & \multicolumn{2}{|c|}{ ساكن } & \multirow[b]{2}{*}{ جمع } & \multirow[b]{2}{*}{ جنس } \\
\hline & نقاط روستايى & نقاط شهرى & & \\
\hline 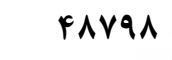 & $r \cdot V r \cdot q r \Delta$ & DQIF\&AFV & V৭৭r\&rV. & 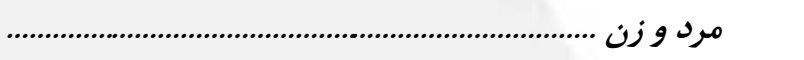 \\
\hline reYVq & $1 \cdot G r \cdot \Delta F q$ & rqAFIfIF & F. FqAFFr & مرد .......... \\
\hline 9Tוq & $1 \cdot 1 \cdots v \varepsilon$ & سrF & rqFTVATA & زن \\
\hline
\end{tabular}

نمودار ا - توزيع نسبى جمعيت كشور بر حسب وضع سكونت (درصد)
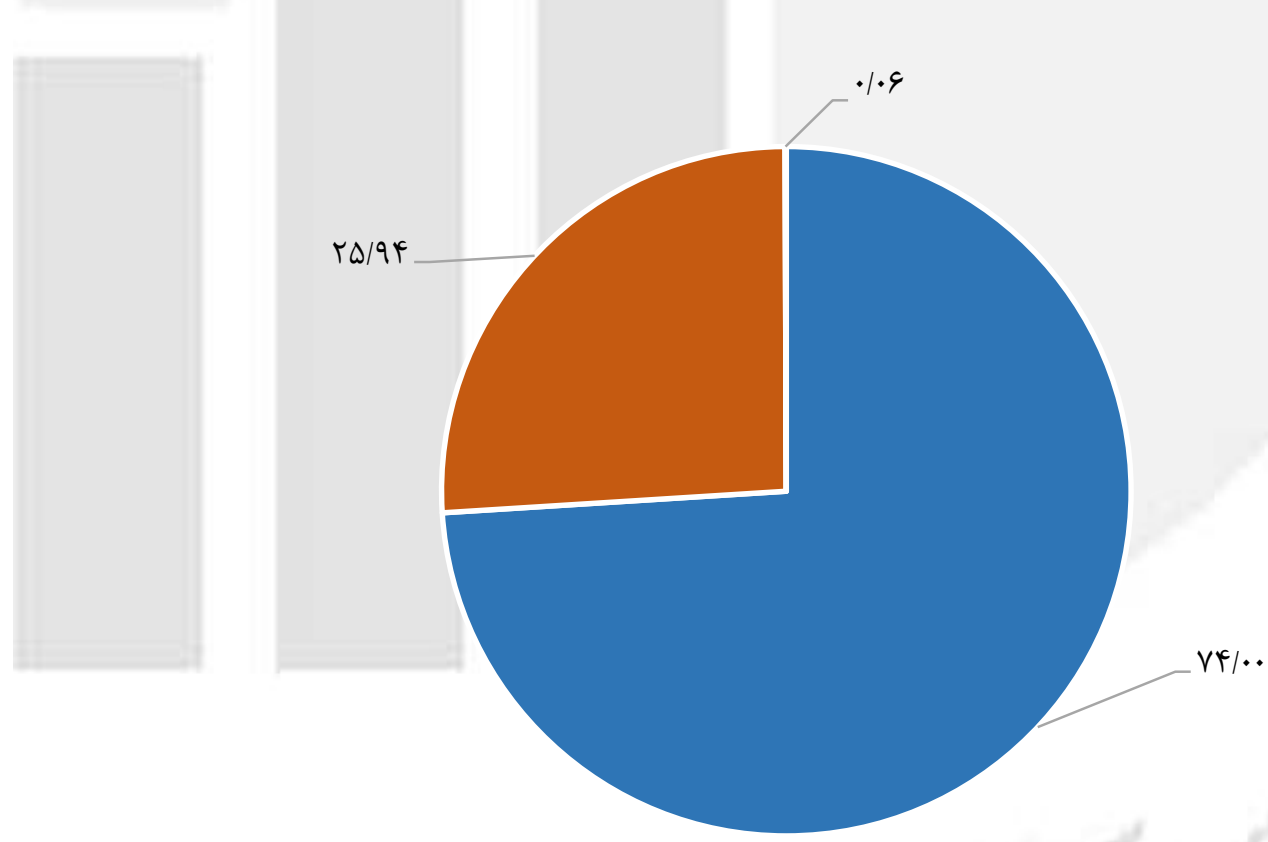

" غير ساكن [ نقاط روستايى " نقاط شهرى

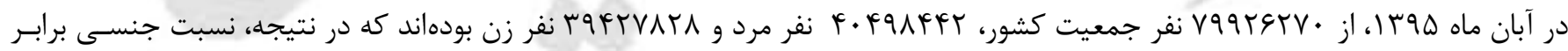

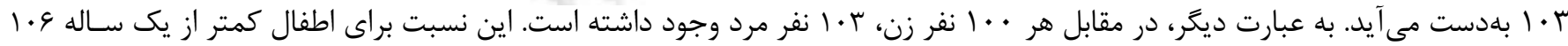

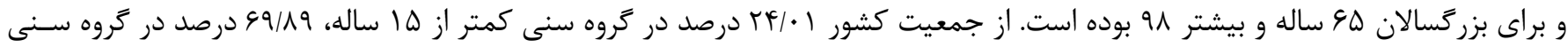
ل4 
״ - جمعيت برحسب سن به تفكيك جنس

\begin{tabular}{|c|c|c|c|c|c|}
\hline \multirow{2}{*}{ نسبت جنسى } & \multirow[b]{2}{*}{ زن } & \multirow{2}{*}{ مرد } & \multicolumn{2}{|c|}{ مرد و زن } & \multirow[b]{2}{*}{ سن } \\
\hline & & & درصد & تعداد & \\
\hline $1 \cdot r$ & rafrrara & F. Fq1FFF & $1 \cdots$, & rqqugrr. & 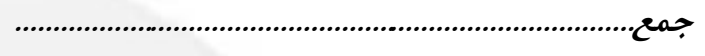 \\
\hline 1.9 & sVrqIV & VITEIf & $1, V$ & $\mid$ rAvar| & 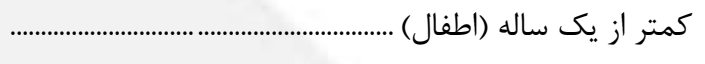 \\
\hline 1.9 & TFIDTFQ & $r q \mid V . . r$ & $\Lambda, \Lambda$ & V.rTMEV & 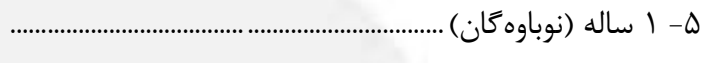 \\
\hline $1 \cdot 0$ & $r \cdot r r \cdot r l$ & rtratrt & $v / 9$ & r & ـ 1-9 ساله (كود \\
\hline $1 \cdot \Delta$ & riNFIrq & rTAVYGQ & $\Delta, \varphi$ & fFrlfap & 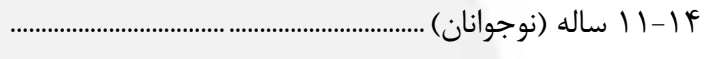 \\
\hline $1 \cdot r$ & DArqYIr & G.TYGGT & $1 f, \Lambda$ & 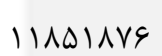 & 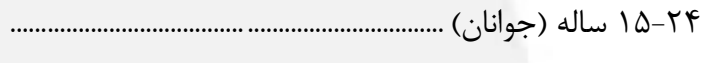 \\
\hline $1 \cdot r$ & TIVAVETV & TrTTYRAT & $\Delta \Delta, 1$ & $r q \cdot 1 \cdot r \mid 1$ & \\
\hline $9 \wedge$ & TFGOVVG & TF. DVFT & 9,1 & YAVIQIA & 9 9 ساله و بيشتر (بزرًً \\
\hline
\end{tabular}

نمودار r- توزيع نسبى جمعيت بر حسب تروههاى عمده سنى (درصد)

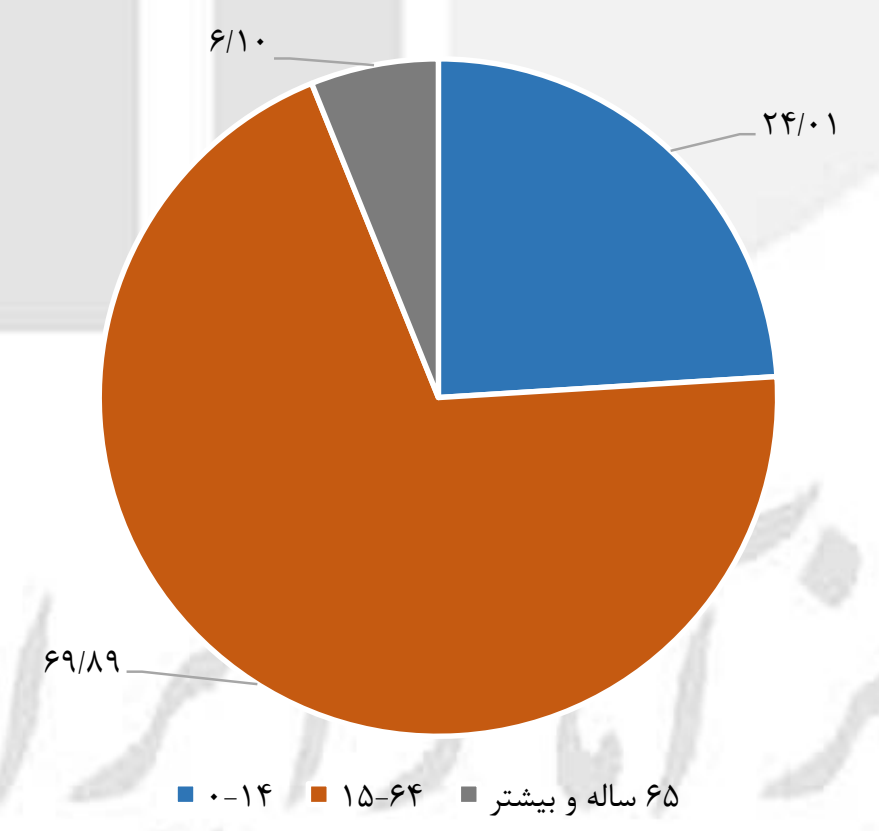


نمودار ب - هرم سنى - جنسى جمعيت كل كشور

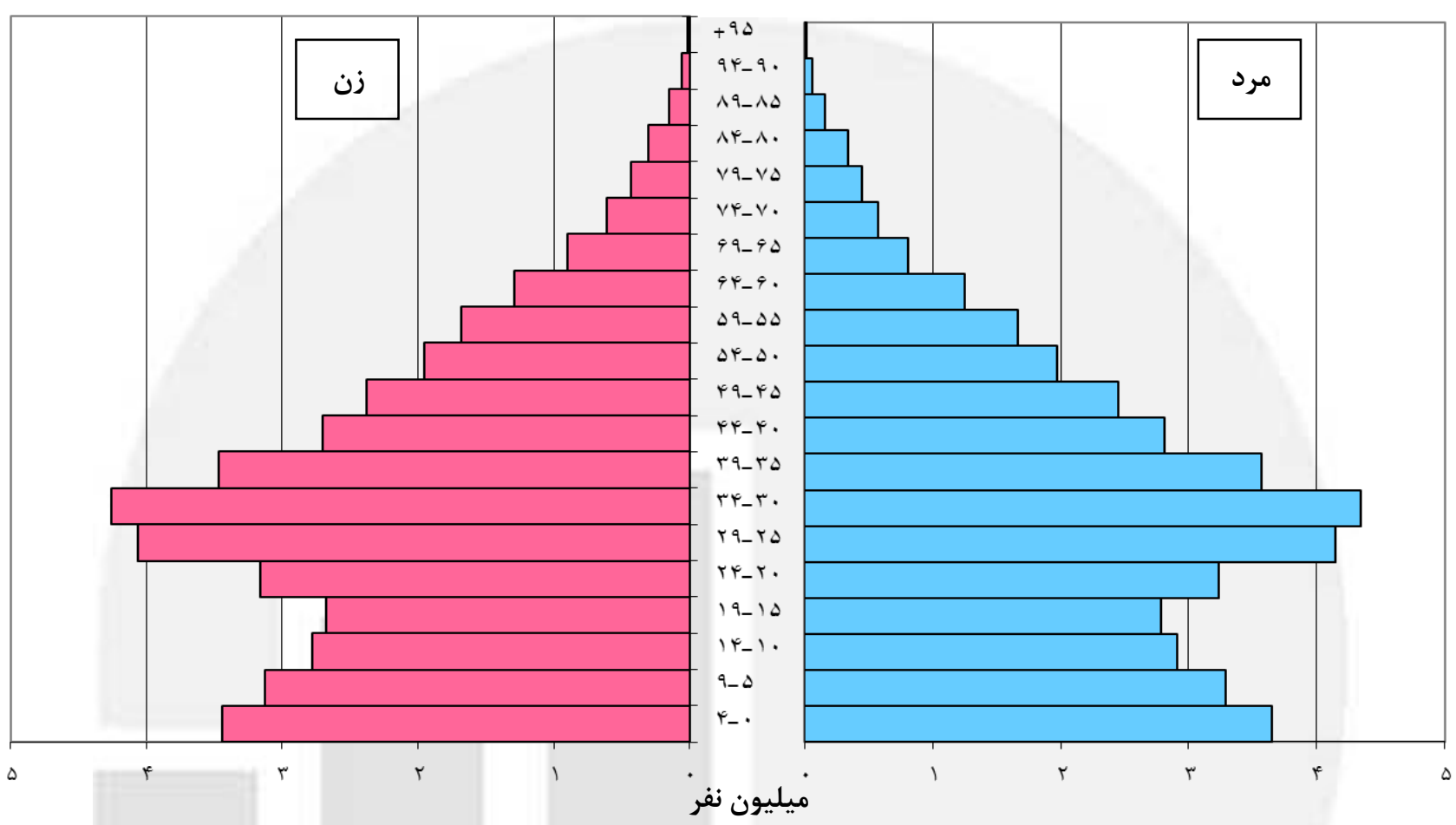

نمودار F - هرم سنى - جنسى جمعيت نقاط شهرى
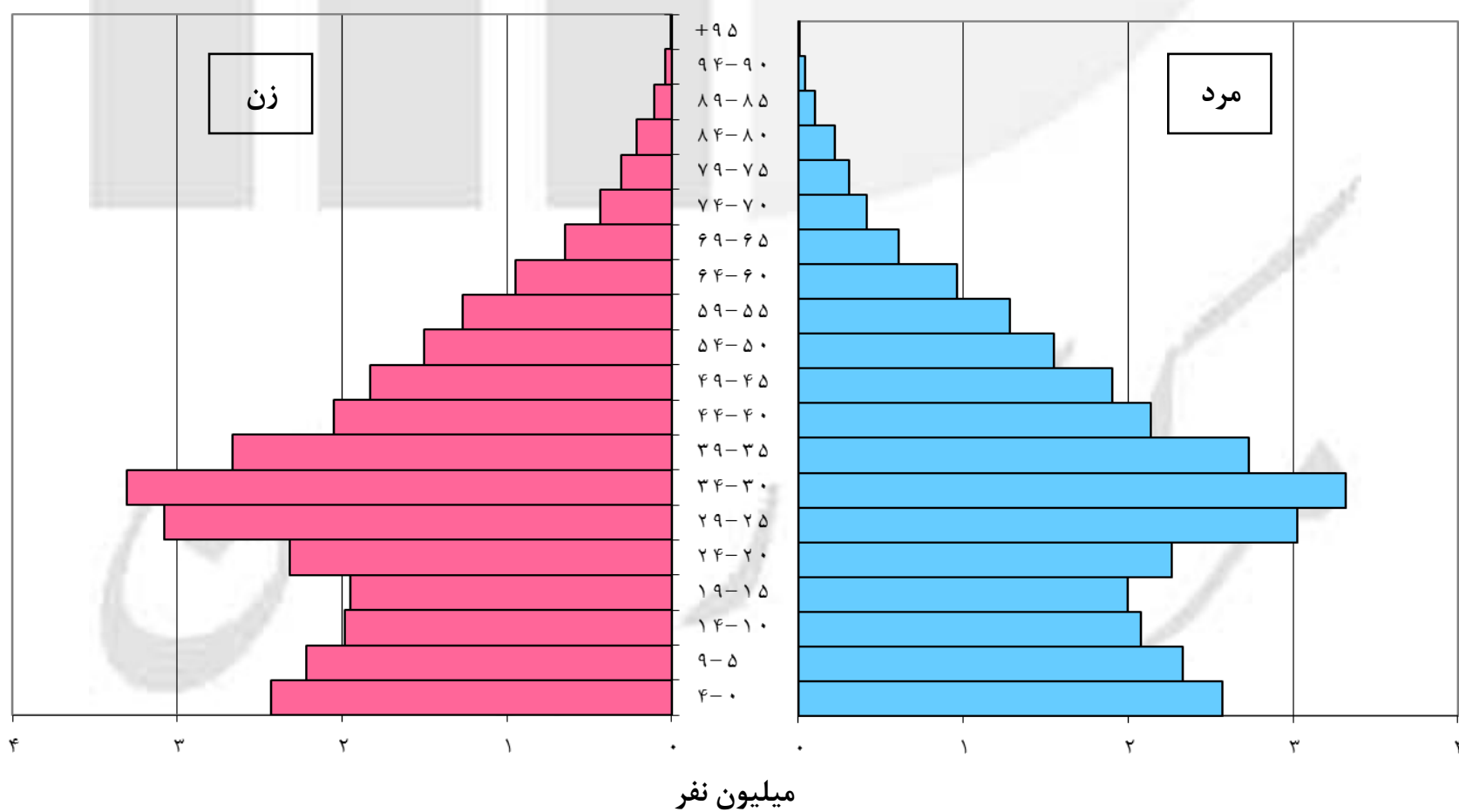


\section{نمودار ه- هرم سنى - جنسى جمعيت نقاط روستايى}

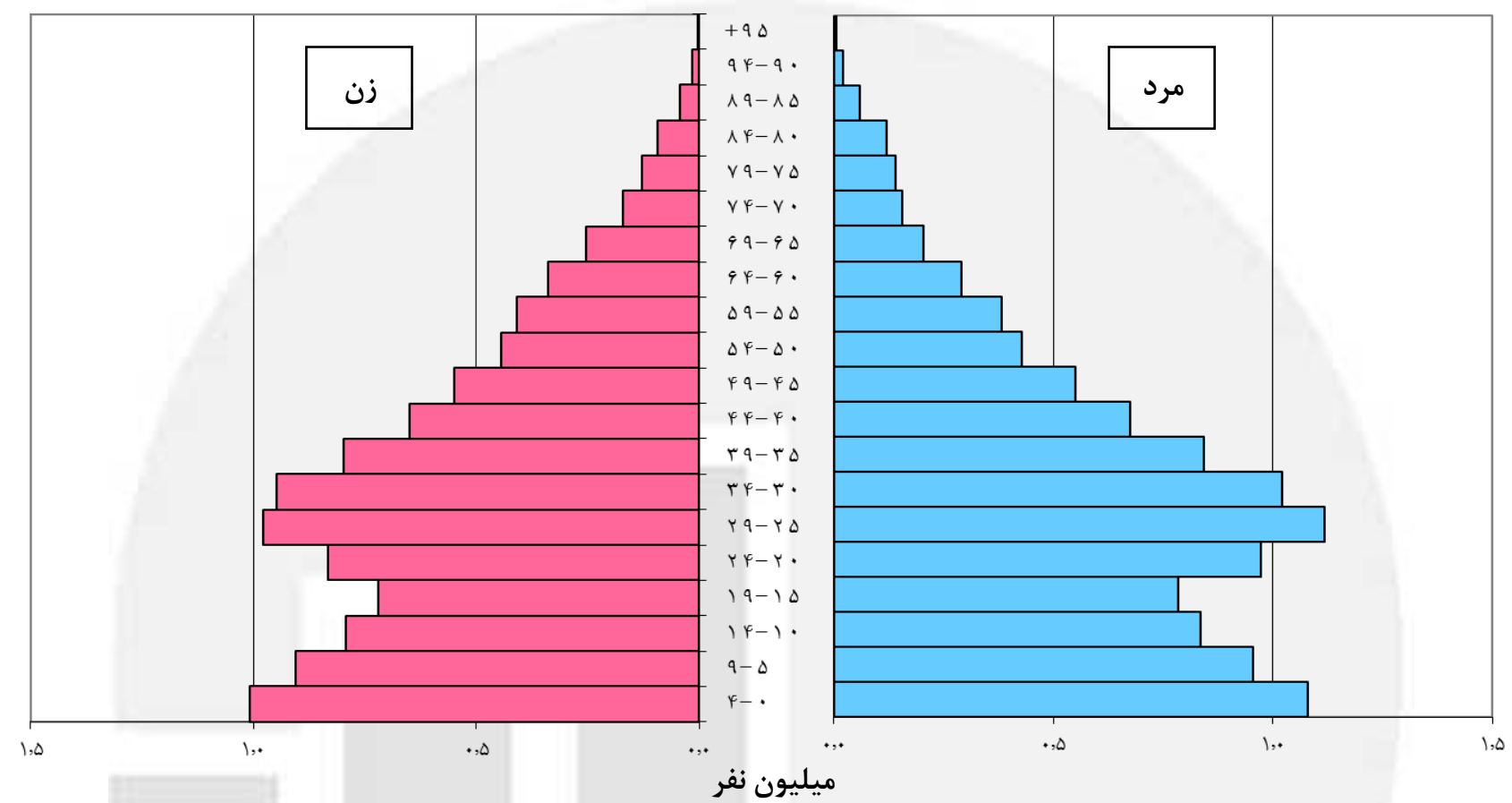

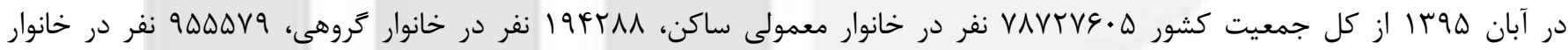
مؤسسهاى و FAV91 نفر در خانوار معمولى غير ساكن بودهاند.

ت- جمعيت برحسب جنس و نوع خانوار

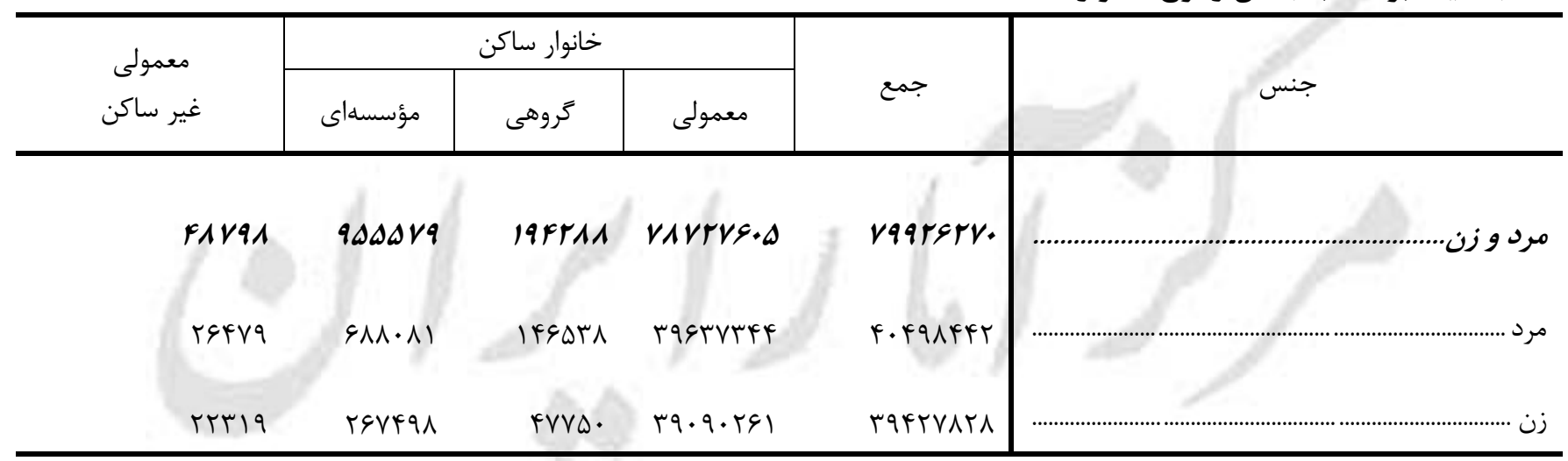




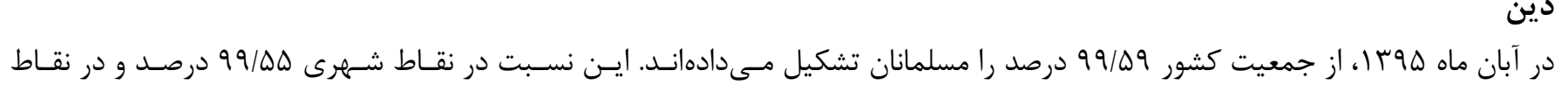
روستايى • •9/V درصد بوده است.

ث - توزيع نسبى جمعيت برحسب دين و وضع سكونت

\begin{tabular}{|c|c|c|c|c|}
\hline \multirow{2}{*}{ 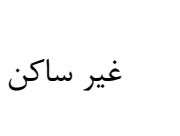 } & \multicolumn{2}{|c|}{ 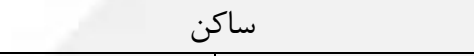 } & \multirow{2}{*}{ 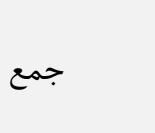 } & \multirow{2}{*}{ 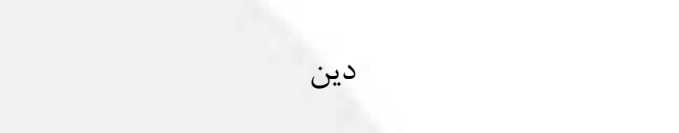 } \\
\hline & نقاط روستايى & نقاط شهرى & & \\
\hline $1 \cdots \cdot \cdot$ & $1 \cdots \bullet$ & $1 \cdots \%$ & $1 \cdot ., \cdot$ & 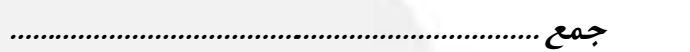 \\
\hline $99 / \bullet \wedge$ & $99, \vee$. & $99 / \Delta 6$ & $१ १ / \Delta १$ & مسلمان ................ \\
\hline$\cdot 10$ & $\cdot, 14$ & $\cdot / 1$ & $\cdot 19$ & بحى : \\
\hline$\cdot / \cdot$ & $\cdot \%$ & $\cdot 1 \cdot 1$ & $\cdot / \cdot 1$ & كليمى ......... \\
\hline$\cdot 1 \cdot 1$ & $\cdot / \cdot r$ & $\cdot \cdot \cdot r$ & $\cdot / \cdot r$ & زرتشتى ....................... \\
\hline$\cdot, \nabla \Delta$ & $\cdot 10$ & $\cdot r r$ & $\cdot, r 1$ & ساير و اظهار نشده ......... \\
\hline
\end{tabular}

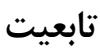

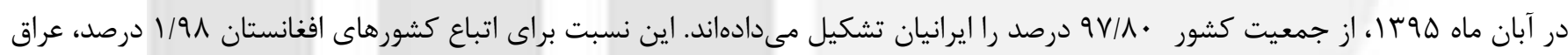

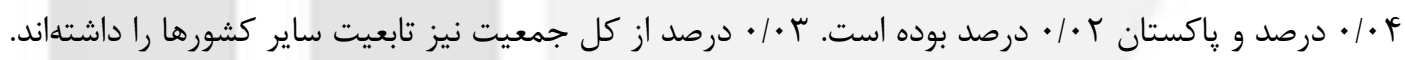

ج- توزيع نسبى جمعيت برحسب تابعيت و وضع سكونت

\begin{tabular}{|c|c|c|c|c|}
\hline \multirow{2}{*}{ 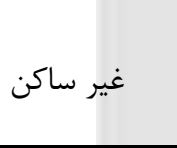 } & \multicolumn{2}{|c|}{ ساكن } & \multirow[b]{2}{*}{ 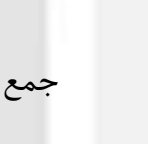 } & \multirow{2}{*}{ تابعيت } \\
\hline & نقاط روستايى & نقاط شهرى & & \\
\hline $1 \cdots, \cdot$ & $1 \cdots, \cdot$ & $1 \cdots, \cdot$ & $1 \cdots, \cdot$ & جمع........ \\
\hline $9 \Lambda, 1 \vee$ & $9 \Lambda, r$. & $9 \vee, 94$ & $9 \vee / \wedge$. & 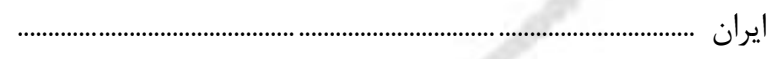 \\
\hline $1, \pi 9$ & 1,94 & $r, 1$. & 1,91 & 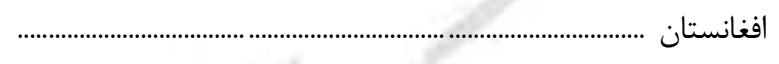 \\
\hline$\cdot \cdot \cdot$ & $\cdot / \cdot 1$ & $\cdot / \cdot \Delta$ & $\cdot \cdot \cdot r$ & 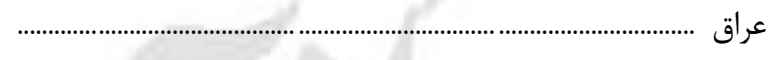 \\
\hline$\cdot / \cdot \Delta$ & $\cdot / \cdot 1$ & $\cdot \cdot \cdot r$ & $\cdot / \cdot r$ & 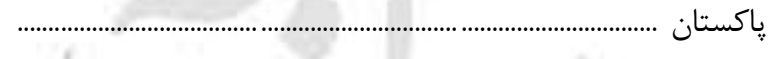 \\
\hline$\cdot \cdot \cdot$ & $\cdot, \cdot$ & $\because \cdot \cdot$ & $\cdot \cdot \cdot$ & 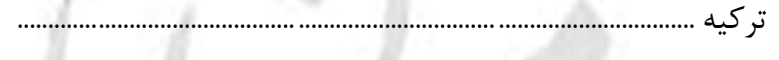 \\
\hline$\cdot . \cdot 1$ & .1 .1 & & $\cdot \cdot r$ & 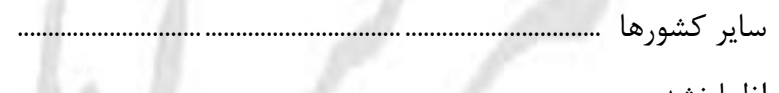 \\
\hline 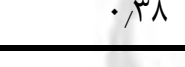 &.$/ 14$ & $\cdot / 14$ & $\cdot$ & اظهارنشده ....................... \\
\hline
\end{tabular}




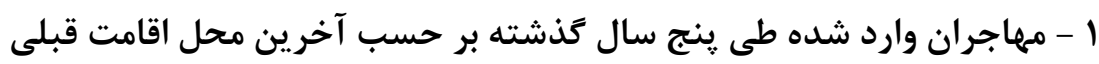

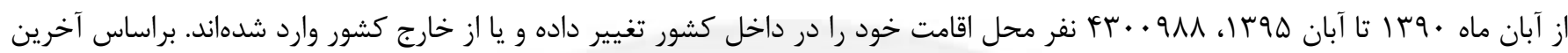

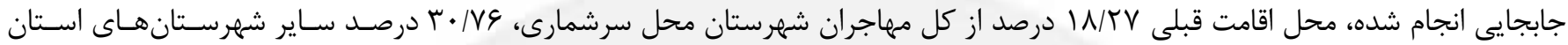

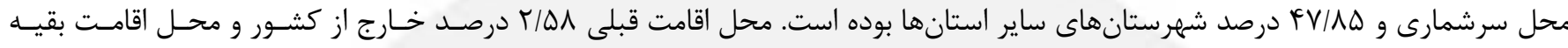

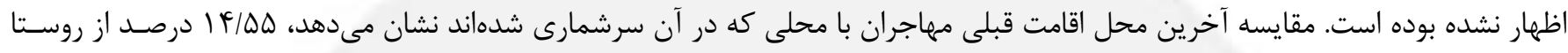

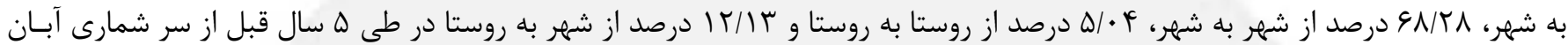

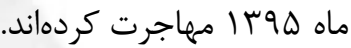

ج - مهاجــران وارد شده طى ه ســال كذشته بـر حسب آخرين محل اقـامت قبلى به تفكيك جنس، نقاط شهرى و روستايى

\begin{tabular}{|c|c|c|c|c|c|c|c|c|c|}
\hline \multicolumn{3}{|c|}{ ساكن در نقاط روستايى } & \multicolumn{3}{|c|}{ ساكن در نقاط شهرى } & \multicolumn{3}{|c|}{ 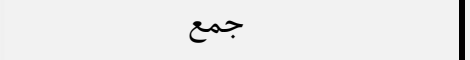 } & \multirow{2}{*}{ آخرين محل اقامت قبلى } \\
\hline 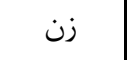 & 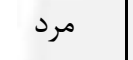 & | ا مرد و زن & زن & 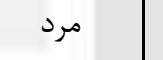 & 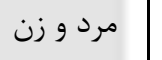 & زن - ت ان & مرد & 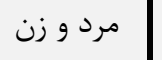 & \\
\hline requer & $r \cdot v \cdot 11$ & vrerar & IVeIferq & $11 \cdot r \mu \cdot q$ & raserra & $r \cdot q \cdot 9 \cdot 1$ & rrl.rar & $k r . .911$ & \\
\hline $19 \cdot v 9 \Delta$ & 109949 & rivrif & treVGe & rrTITA & 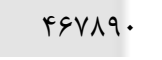 & 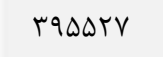 & rq..vv & $\checkmark \wedge \Delta \varphi \cdot \varphi$ & شهرستان مـ \\
\hline 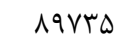 & 19Vrq & IVq4at & NFqIr & AMTE. & $191 \mathrm{Q}$ & IVFEFA & IVrq99 & TFVGIV & شهر ............ \\
\hline$V I \cdot r \cdot$ & SVIT. & IrNTA. & $149 \wedge<9$ & $1+9111$ & rq৭४rr & $r r \cdot \wedge V q$ & $r|v| \cdot \Lambda$ & rrva८v & آبادى ...................... \\
\hline ৩৭৭४^ & 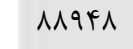 & $19 \wedge 1 \wedge 9$ & $\Delta \wedge \vee r \wedge$. & $\Delta \& \& \Delta G$. & llarqf. & GQVTIN & $9 \Delta \Delta \Delta \cdot \Lambda$ & Irtrats & ساير شهرستانهاى استان ..... \\
\hline$\Delta 9 \Lambda \cdot r$ & 99119 & Iraदqr & D. TYYY & FAFTIF & 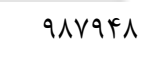 & DGTOTY & $\Delta \Delta F I \cdot T$ & IIIVGe. & 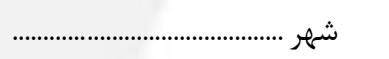 \\
\hline t.ird & $19 \cdot \Delta 9$ & rq19q & Nrets & ATHES & 190999 & $1 \cdot r \vee \wedge 1$ & $1 \cdot 14 \cdot 0$ & $r \cdot \Delta \backslash \wedge \varphi$ & آبادى ............ \\
\hline rq & $\Delta q F$ & GTr & NQT & $11 \Delta F$ & $r \cdot .4$ & ^१1 & IVFA & rquq & اظهارنشده شهر ستان.............. \\
\hline rF & $\Delta \vee \wedge$ & G.r & var & $1 \cdot v e$ & 11499 & 119 & I $9 \Delta T$ & r\&s & شهر .................. \\
\hline 10 & 19 & r & 4. & $\wedge$. & if. & VD & १९ & $|v|$ & آبادى ............ \\
\hline$\Lambda r \cdot r \Lambda$ & $\mid F \Delta \cdot r \Lambda$ & rTA. GQ & 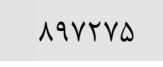 & 9MTGGT & IArq9тr & $9 \Lambda \cdot r \cdot r$ & I.rvr.. & $r \cdot \Delta \Lambda \cdot \cdot r$ & شهرستان . \\
\hline VITra & $M F \cdot F$. & $190 r 99$ & ArqrqV & $\wedge \Delta \wedge \vee \Delta \Lambda$ & 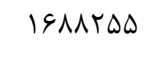 & $9 \cdot \cdot v r q$ & १८५V१८ & MAMATF & شهر ................ \\
\hline 11899 & $r \cdot 991$ & rTVqV & GVVVA & $v r q \cdot r$ & IFIGAT & 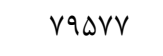 & $q \notin q \cdot r$ & IVEFVa & آبادى ........................ \\
\hline vq & IDTK & 1914 & ir.t & $r \cdot r_{4}$ & 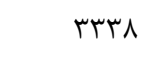 & $|r \wedge|$ & rov. & 4901 & اظههارنشده \\
\hline sV & $10 \cdot r$ & 1099 & ITrV & 19.9 & MikT & $1 r \cdot r$ & $r \mu \cdot \Lambda$ & Fit & شهر ....... \\
\hline ir & rt & Fe & 90 & $1 r$. & 190 & VV & 194 & rrq & آبادى ........................... \\
\hline 89 & rel & rav & $|\Delta r|$ & 1991 & rreq & lert & $r \cdot 19$ & rqDF & اظهارنشده /ستان و شهرستان \\
\hline ro & $r \wedge \Delta$ & $r$ r. & lfr. & $1 Q \Delta F$ & rqAץ & 1990 & $1 \wedge r q$ & $r \mu \varphi$ & شهر .................. \\
\hline r & एद & $9 V$ & $|+|$ & IFF & rAQ & IVT & $1 \wedge \cdot$ & rar & آبادى ........... \\
\hline erel & $1 r \cdot 9 \pi$ & $|\& F| f$ & reIAT & e.rrr & gFfID & $r \wedge \Delta \cdot r$ & vrrus & $11 \cdot 1 r 9$ & خارج از كشور. \\
\hline 948 & $18 \cdot 4$ & raf. & $\Leftrightarrow 1 \cdot \Delta$ & aAra & qqf. & $\Delta \cdot+1$ & verq & ITFA. & اظهار نشده محل اقامت قبلى \\
\hline
\end{tabular}




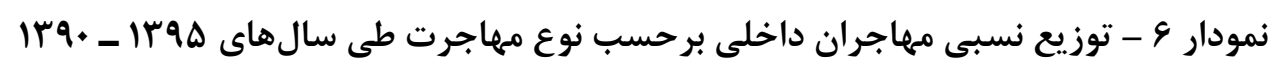
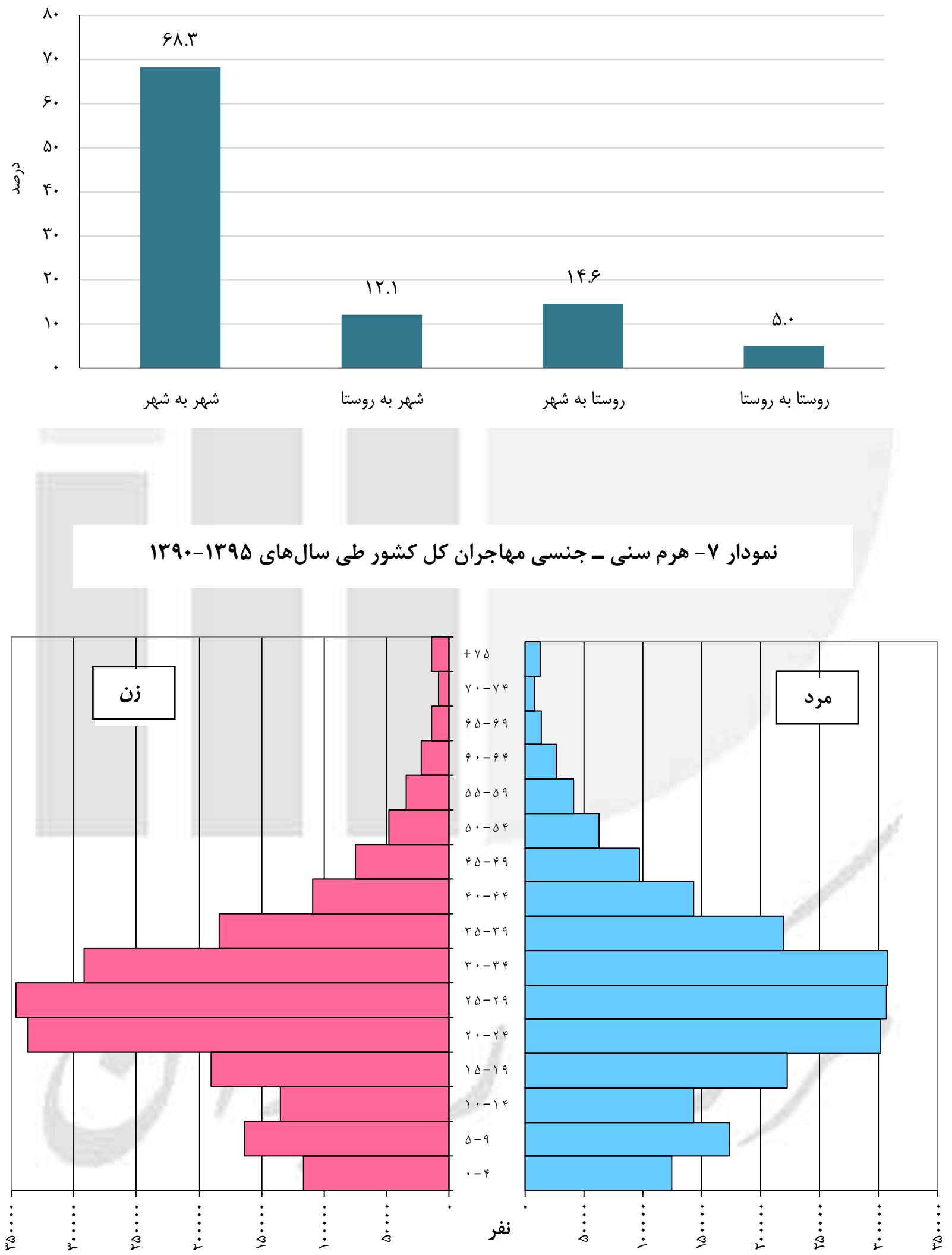


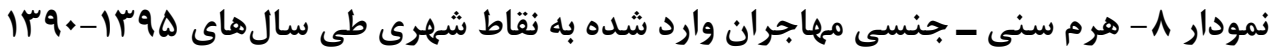
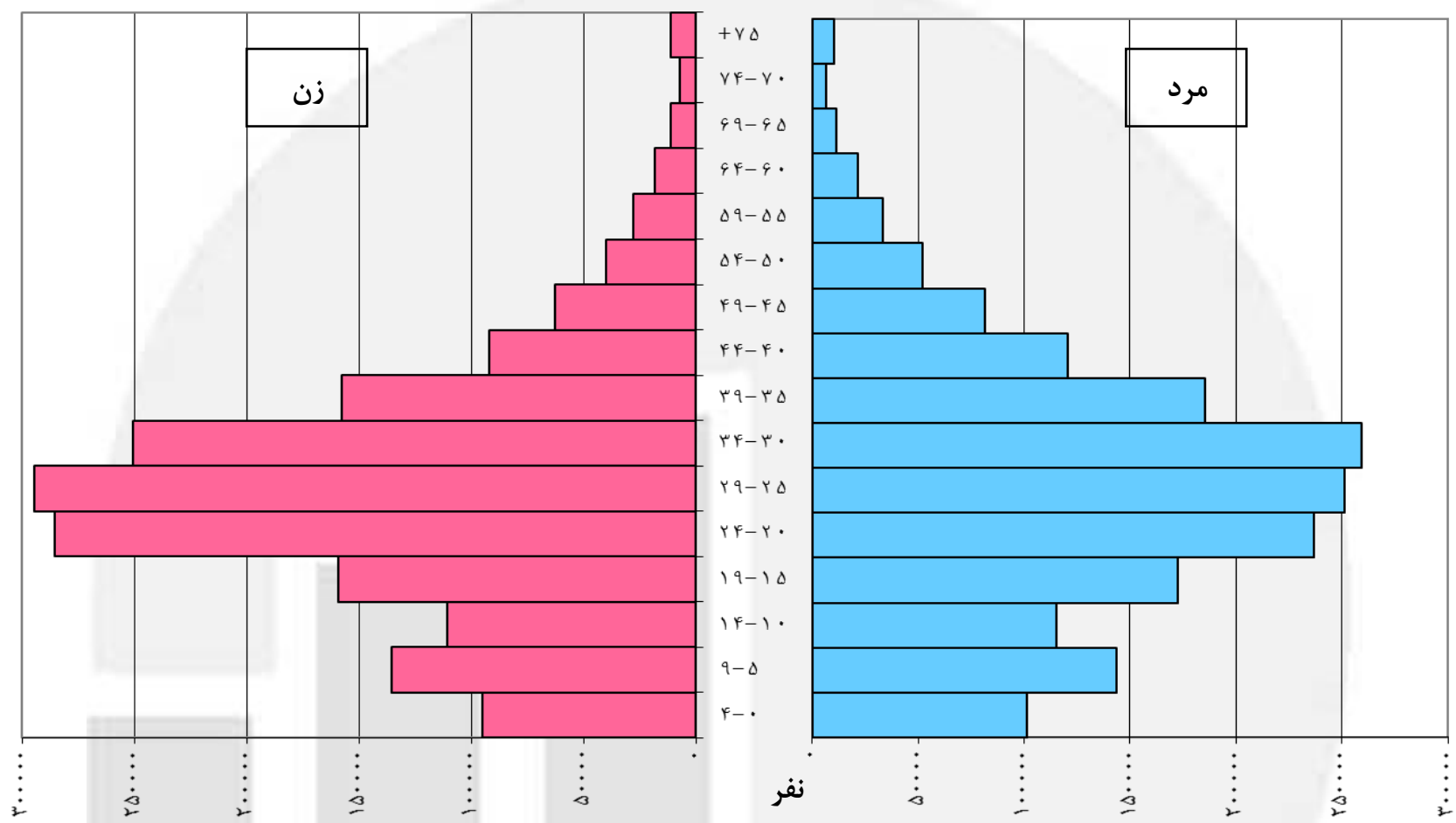

نمودار 9 - هرم سنى - جنسى مهاجران وارد شده به نقاط روستايى طى سالهاى هوس|-•qس||

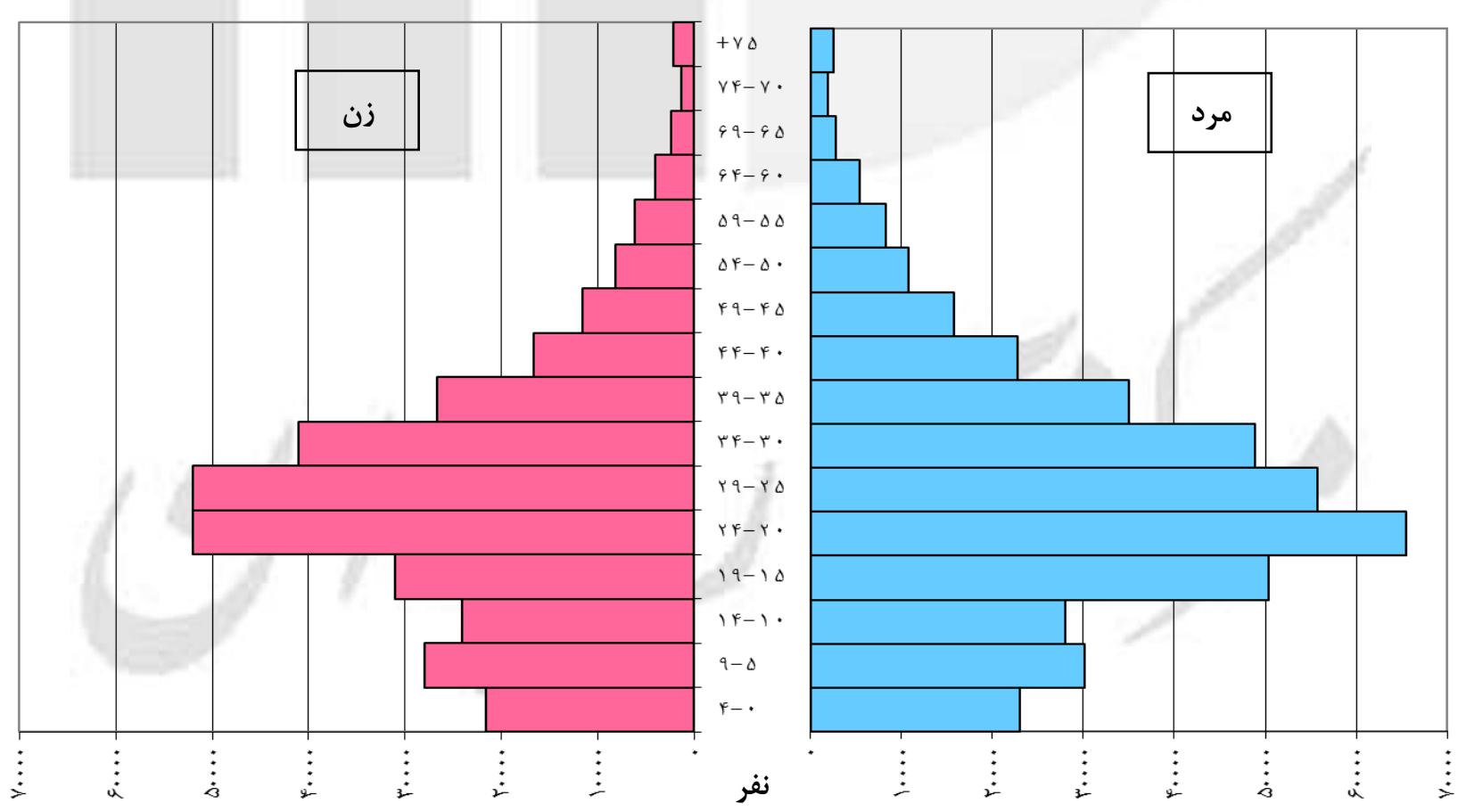


r - مهاجران وارد شده طى پينج سال كذشته برحسب مدت اقامت در محل سرشمارى

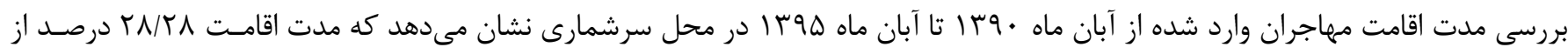

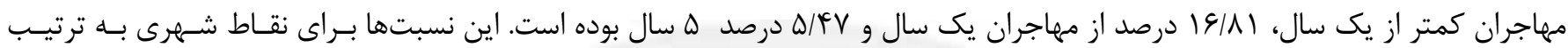
| |

ح - مهاجــران وارد شده طى ينج سـال كذشته بـر حسب مدت اقـامت در محل سرشمارى به تفكيك نقاط شهرى و روستايى

\begin{tabular}{|c|c|c|c|c|c|c|}
\hline \multicolumn{2}{|c|}{ ساكن در نقاط روستايى } & \multicolumn{2}{|c|}{ ساكن در نقاط شهرى } & \multicolumn{2}{|c|}{ جمع } & \multirow{2}{*}{ مدت اقامت در محل سرشمارى } \\
\hline درصد & تعداد & مرصد & تعداد & درصد & تعداد & \\
\hline $1 \cdots, \cdot$ & vrerar & $1 \cdots, \cdot$ & raserra & $1 \cdots, \cdot$ & $4 r \cdot .911$ & جمع ................ \\
\hline$r r_{1} \cdot F^{c}$ & 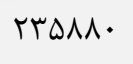 & $\langle V / \Delta|$ & 91.94. & $r \Lambda, r \Lambda$ & $|r| \& \Delta \ldots$ & كمتر از يك سال ............... \\
\hline$I V, g r$ & IrqArV & 19,84 & LqTIII & $|8 / 1|$ & VTrQD. & | سال ........................... \\
\hline $11,1 T$ & ITMETA & $19, \nabla \Delta$ & V.FITS & $19,4 V$ & $\Lambda T V \Delta G K$ & r سال ....... \\
\hline $\mid \Delta, r \Lambda$ & IITFA & $11, \cdot \cdot$ & $9419 \cdot 1$ & $I V / \Delta T$ & $V \Delta F \cdot q G$ & r سال ................ \\
\hline $1 \cdot 1 \cdot$ & VETAT & IT,KT & FTDFDQ & $11, \wedge \Delta$ & $0.911 \%$ & F \\
\hline $8, T^{F}$ & $p \Delta q \cdot q$ & $\Delta, \pi$ & MAqKFF & $0, p V$ & THOMF. & 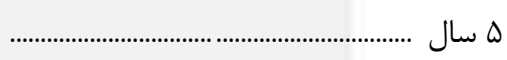 \\
\hline$\cdot / 09$ & frel & $\cdot \Delta V$ & $r \cdot$ r\&q & $\cdot \Delta V$ & TFVTY & اظهار نشده .... \\
\hline
\end{tabular}

وضع سواد

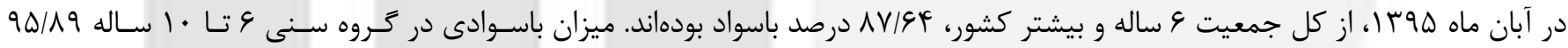

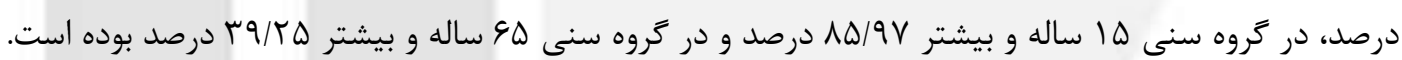

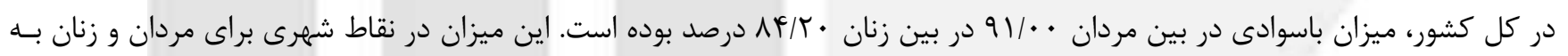

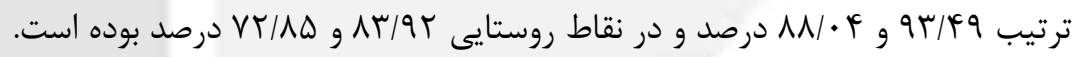

خ- ميزان باسودى جمعيت 9 ساله و بيشتر بر حسب سن به تفكيك جنس و وضع سكونت

\begin{tabular}{|c|c|c|c|c|c|c|c|c|c|}
\hline \multirow{2}{*}{\multicolumn{2}{|c|}{ غير ساكن }} & \multicolumn{4}{|c|}{ ساكن } & \multirow{2}{*}{\multicolumn{3}{|c|}{ جمع }} & \\
\hline & & \multicolumn{2}{|c|}{ نقاط روستايى } & \multicolumn{2}{|c|}{ نقاط شهرى } & & & & \\
\hline زن & مرد & 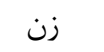 & 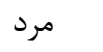 & 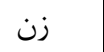 & 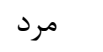 & 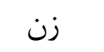 & مرد & مرد و زن & \\
\hline$\Delta \& / 9$ & $g g, V F$ & $V T / \Lambda \Delta$ & $1 r, 95$ & $M M \cdot F$ & $q r, p q$ & $\Delta E, r$. & $91, .$. & $A V, q F$ & جمعيت و ساله و بيث \\
\hline$\wedge \kappa, \lambda$. & $\wedge \Delta, \wedge \Delta$ & $q q, q 4$ & $q \xi, v V$ & १९, ४А & $q \varepsilon, \Gamma q$ & $9 \Delta, \lambda V$ & 90,91 & $90 / \wedge 9$ & • ا-9 ساله (كو. \\
\hline$q \cdot \Delta \Delta \Delta$ & $9 \cdot, 99$ & 97,49 & $q \vee, \vee \wedge$ & $99, \cdot r$ & $99, \cdot 9$ & $9 \Lambda / \Delta V$ & 91,99 & 91,94 & ץ||-1|| ساله (نوجواز \\
\hline$<q, q q$ & $s r, 11$ & $81 / 18$ & $11, \% \Delta$ & $1 \in, F A$ & $9 r / 1$. & 11,99 & 19,91 & $10,9 \gamma$ & جمعيت ها ساله و \\
\hline 11,99 & $\Delta r / \Lambda T$ & $q q, q v$ & $9 \Delta, \wedge \wedge$ & $91, \pi 9$ & $91,1 \vee$ & $9 \vee, r q$ & $q \vee, \uparrow q$ & $9 \vee, r \wedge$ & \\
\hline $\mathrm{kr} / \wedge \mathrm{F}$ & $81,4 \Delta$ & $\varepsilon \Lambda, V \Delta$ & $\lambda F, \lambda$ & $\Lambda \Lambda, \Lambda T$ & $q 4,4 q$ & $\Delta r, \cdot v$ & 91,99 & $\Lambda \Lambda_{j} \cdot v$ & \\
\hline r,ve & $q, p v$ & 9,41 & $r \Delta, r T$ & $r \Delta, \Delta \varphi$ & $g T, g r$ & $r V, T$ & $\Delta 1,99$ & $r q, r \Delta$ & ه9 ساله و بيشتر (بزر \\
\hline
\end{tabular}


نمودار •1 - ميزان باسوادى جمعيت 9 ساله و بيشتر به تفكيك جنس و وضع سكونت

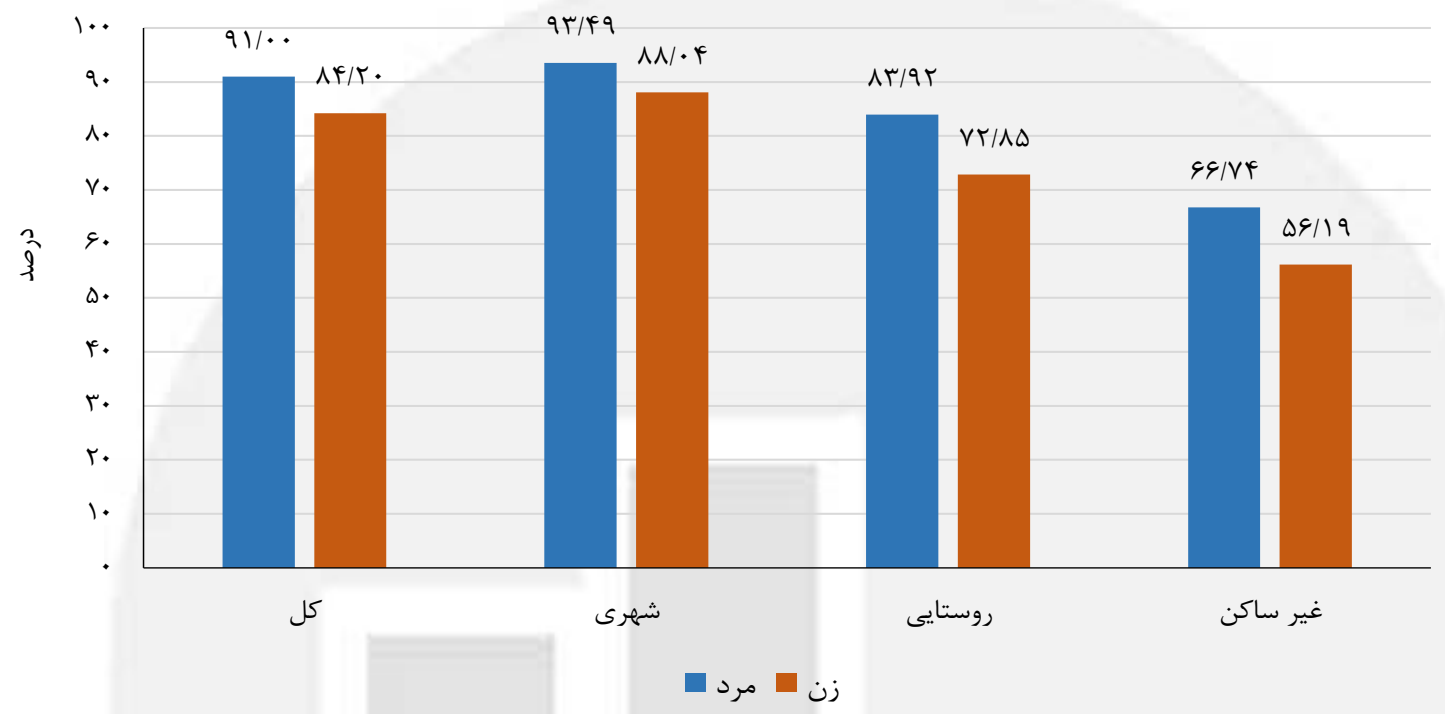

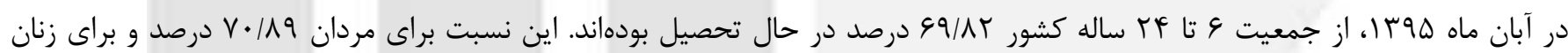
(9N/VI

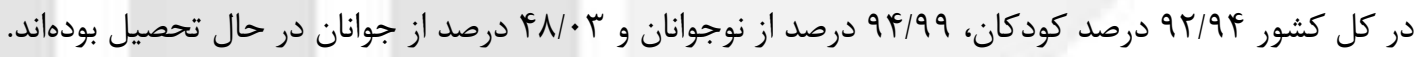

د- توزيع نسبى جمعيت \& تا YF ساله در حال تحصيل بر حسب سن به تفكيك جنس و وضع سكونت

\begin{tabular}{|c|c|c|c|c|c|c|c|c|c|}
\hline \multirow{2}{*}{\multicolumn{2}{|c|}{ غير ساكن }} & \multicolumn{4}{|c|}{ ساكن } & \multirow{2}{*}{\multicolumn{3}{|c|}{ 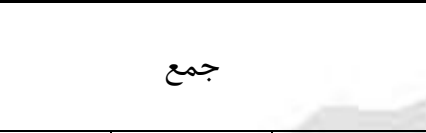 }} & \multirow{3}{*}{ سن } \\
\hline & & \multicolumn{2}{|c|}{ نقاط روستايى } & \multicolumn{2}{|c|}{ نقاط شهرى } & & & & \\
\hline زن - ت ان & مرد & 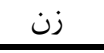 & مرد & زن - ان & مرد & 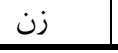 & 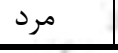 & 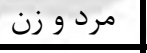 & \\
\hline$F F, q F$ & $\varepsilon V, r f$ & $\Delta \Lambda, \& \Delta$ & st,IT & $V T / \Delta A$ & $V E, F q$ & $s \wedge, \gamma \mid$ & $r \cdot 19$ & 89,15 & جمعيت و تا FF سا \\
\hline$v \& / \Delta r$ & $\Lambda \cdot, \mu$ & $9 \cdot 94$ & 91,17 & $q \mu, V F$ & $q \mu, v$. & 94,91 & $9 \%, १ ९$ & $q r, q 4$ & • ا-צ ساله (كودكان) \\
\hline $9 \Lambda, \Delta r$ & $v(x, 4)$ & $\wedge 9,91$ & $9 \uparrow, 9$. & $98,9$. & $9 \vee, r \Delta$ & $9 \leftrightarrow, \wedge \varphi$ & $१ ९ / \bullet \vee$ & 94,99 & 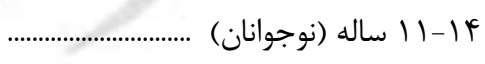 \\
\hline 19,01 & $T F, \Delta F$ & $r \Lambda, \Lambda F$ & $r \Delta, r)$ & $\Delta r, 99$ & $\Delta \Delta, \mu$. & $r \varepsilon, \Delta T$ & $p q, 4 q$ & $r \wedge, \cdot r$ & 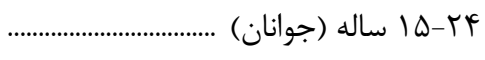 \\
\hline
\end{tabular}




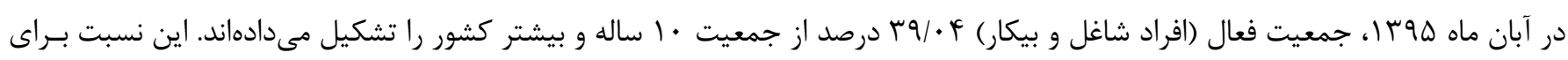

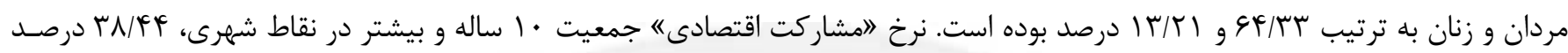

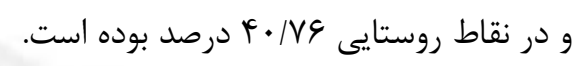

ذ - توزيع نسبى جمعيت •ا ساله و بيشتر بر حسب وضع فعاليت، به تفكيك جنس و وضع سكونت

\begin{tabular}{|c|c|c|c|c|c|c|c|c|c|c|c|c|}
\hline \multirow{2}{*}{\multicolumn{3}{|c|}{ غير ساكن }} & \multicolumn{6}{|c|}{ ساكن } & \multirow{2}{*}{\multicolumn{3}{|c|}{ جمع }} & \multirow{3}{*}{ وضع فعاليت } \\
\hline & & & \multicolumn{3}{|c|}{ نقاط روستايى } & \multicolumn{3}{|c|}{ نقاط شهرى } & & & & \\
\hline زن & مرد & | مرد و زن & زن & مرد & مرد و زن & 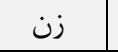 & مرد & | مرد و زن & 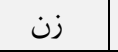 & مرد & مرد و زن & \\
\hline $1 \cdots, \cdot$ & $1 . \cdots, \cdot$ & $1 \cdots, \cdot$ & $1 \cdots, \cdot$ & $1 \cdots, \cdot$ & $1 \cdots, \cdot$ & $1 \cdots, \cdot$ & $1 \ldots, \cdot$ & $1 \cdots, \cdot$ & $1 \cdots, \cdot$ & $1, ., \cdot$ & $1 \cdots, \cdot$ & 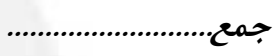 \\
\hline MY,TA & $V V, 19$ & $\Delta \mathrm{V}, \mathrm{V \Lambda}$ & 11,49 & $91,9 \Delta$ & $r \cdot v \varepsilon$ & $I r, V V$ & $G r, \lambda r$ & $r \Lambda, F \psi$ & $|r, r|$ & g4, r & $r q, \cdot r$ & جمعيت فعال............ \\
\hline rT, & $V r, r$ & $\Delta F / \Delta$. & $9, \pi$ & $9 T, 14$ & re, rv & $|\cdot| \Delta \mid$ & $\Delta \Delta, q q$ & ع צr, & $1 \cdot \pi r$ & $\Delta V / \Delta F$ & $r F, \| r$ & شاغل..... \\
\hline$T, T V$ & $4,1 \pi$ & r, & $r / D$ & $9, \Delta 1$ & $\varphi, \pi \wedge$ & r, & 8,19 & $\Delta, \cdot 1$ & $r, 91$ & $9, \sqrt[9]{ }$ & 4,91 & بيكار .... \\
\hline $9 \Delta, r)$ & 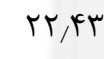 & $\{1,1\}$ & $M 1, k r$ & $r \cdot,+1$ & $\Delta \wedge, \gamma\rangle$ & 18,10 & $r \varepsilon, \Delta V$ & $91, \pi)$ & $\Lambda \varepsilon, \nu$. & $r F, q \Lambda$ & $\varepsilon \cdot \Delta V$ & فعال. \\
\hline $1 \cdot \pi r$ & $11, \lambda r$ & 11,1 & $|f, v|$ & $18,9 \mathrm{~V}$ & $1 \Delta / \wedge V$ & $19, \pi r$ & $19,9 \mathrm{~V}$ & $19, \mu F$ & $11, \cdot 9$ & $\mid \Lambda / \wedge r$ & $11, * 4$ & محصر \\
\hline $0 \cdot, \cdot \varphi$ & $\cdot,+4$ & $r r, q$. & $Q V, \Delta Q$ & • & T & $q \cdot, 4 q$ & $\cdot \pi v$ & $r \cdot r \cdot$ & GT,IV & $\cdot|+|$ & $r \cdot, 99$ & خانهدار ...... \\
\hline$\cdot, r \wedge$ & $\cdot, 99$ & $\cdot, 9 \mathrm{~V}$ & $1, \cdot 1$ & $r, \mathrm{vr}$ & T, ter & $r / \cdot \Delta$ & $1 \cdot, r \Lambda$ & 9,99 & $r / \Delta F$ & 1,91 & 0,91 & داراى درامد بدون كار .. \\
\hline$f, 90$ & $9, \%$. & V,lf & 0,10 & 9,14 & $v / 19$ & $r, p q$ & $\varepsilon, 4 \Delta$ & $p, 91$ & $r, 91$ & $V, 1 f$ & $\Delta, \Delta F$ & ساير ....... \\
\hline$\cdot \mid+1$ & $\cdot|+|$ & $\cdot|+|$ & $\cdot, 11$ & - 94 & - $\Delta f$ & .1 .9 & $\cdot, 9$. & • & .1 .9 &., 99 & $\cdot, \pi q$ & اظهار نشده ....... \\
\hline
\end{tabular}

نمودار Iا - توزيع نسبى جمعيت +ا ساله و بيشتر بر حسب وضع فعاليت

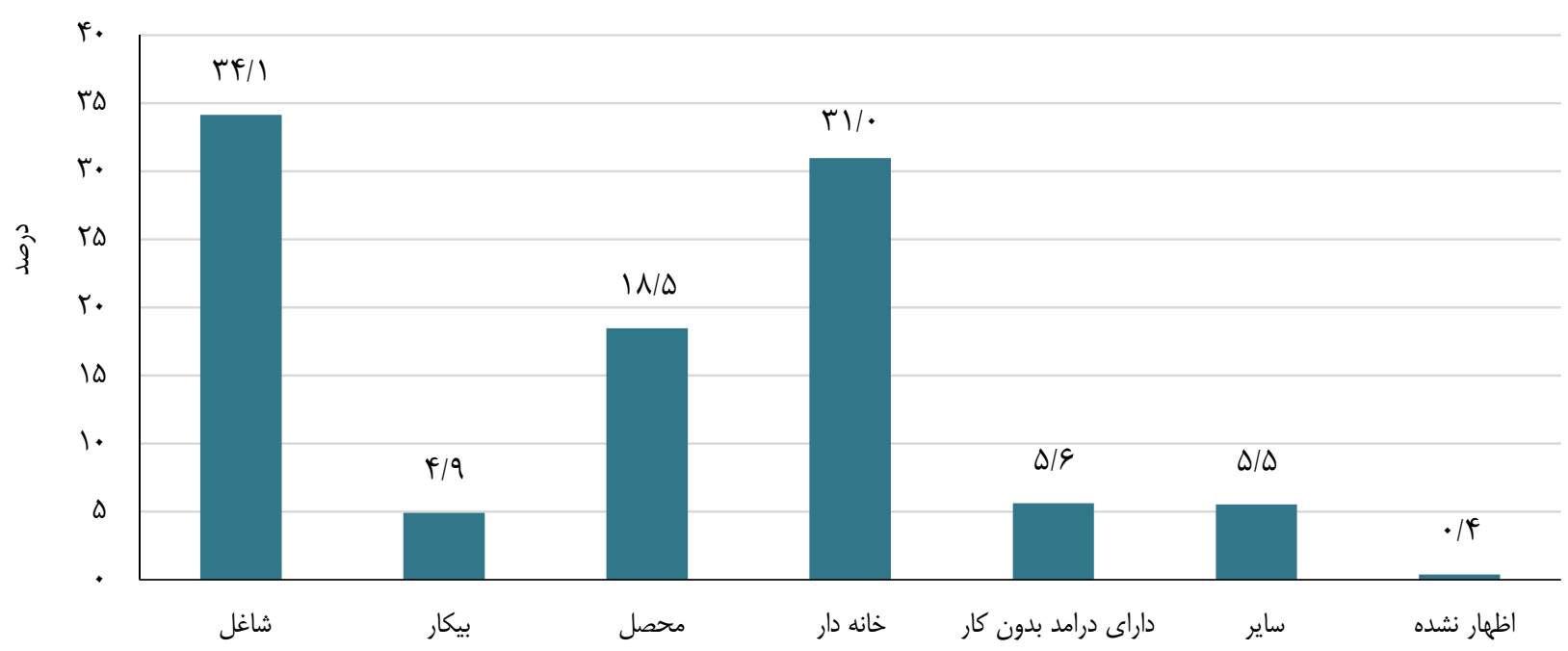


نمودار Ir - توزيع نسبى جمعيت +ا ساله و بيشتر بر حسب وضع فعاليت به تفكيك جنس

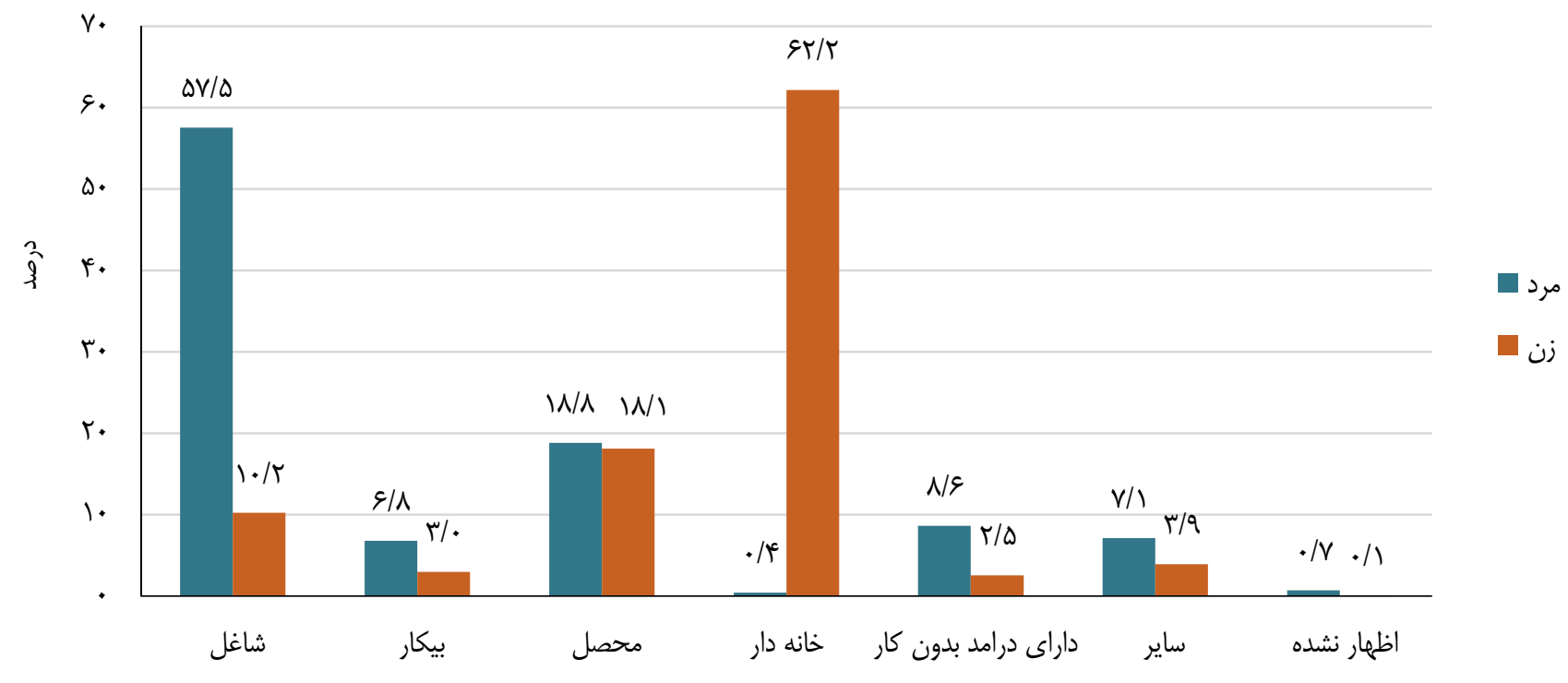

وضع زناشويى

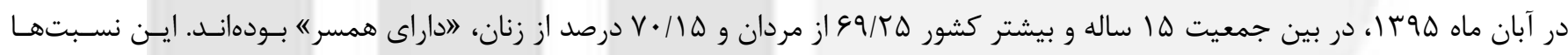

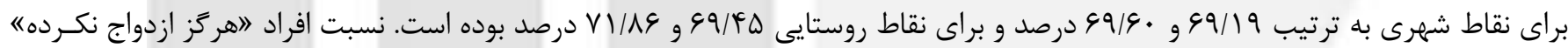

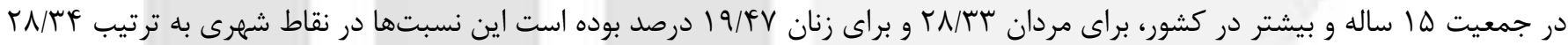

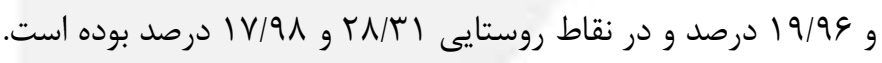

ر - توزيع نسبى جمعيت ها ساله و بيشتر برحسب وضع زناشويى به تفكيك جنس و وضع سكونت

\begin{tabular}{|c|c|c|c|c|c|c|c|c|}
\hline \multirow{2}{*}{\multicolumn{2}{|c|}{ غير ساكن }} & \multicolumn{4}{|c|}{ ساكن } & \multicolumn{2}{|c|}{ جمع } & \multirow{3}{*}{ وضع زناشويى } \\
\hline & & \multicolumn{2}{|c|}{ نقاط روستايى } & \multicolumn{2}{|c|}{ ل نقاط شهرى } & \multirow{2}{*}{ 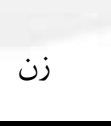 } & \multirow{2}{*}{ 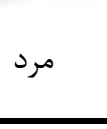 } & \\
\hline زن - ت ا & مرد & زن - ت ن & مرد & زن - ت ن & مرد & & & \\
\hline $1 \cdots \%$ & $1 \cdots \%$ & $1 \cdots \%$ & $1 \cdots$ & $1 \cdots$ & $1 \cdots \%$ & $1 \cdots$ & $1 \cdots$ & جمع.. جمع \\
\hline$V F / \backslash \Lambda$ & GM/A & $\Lambda T / \cdot 1$ & $V 1 / 90$ & N./.t & $v \mid / 91$ & $\Lambda \cdot|\Delta|$ & $V I / G T$ & حداقل يك بار ازدواج \\
\hline $9 V / 99$ & $\Delta Q / \Lambda T$ & $\checkmark / / \Lambda 9$ & $99 / 4 \Delta$ & $99 / 9$. & $99 / 19$ & $v \cdot / / \Delta$ & $99 / \pi \Delta$ & داراى همسر \\
\hline$\Delta / v \cdot$ & & N/VG & $1 / r 4$ & V/VT & $\cdot / 9 \mathrm{~V}$ & $V / 9 V$ & $1 / \cdot v$ & بى همسر بر اثر فوت \\
\hline$\cdot 191$ & 1/99 & $1 / \pi v$ & • & $r / 99$ & $1 / \% \Delta$ & $r / T V$ & $1 / \pi$. & بـ مهمس \\
\hline$\cdot 11$ & $.1 \cdot 9$ & $.1 \cdot 1$ & 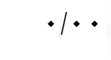 & & $\cdot 1 \cdot \cdot$ & $\cdot 1 \cdot 1$ & $\cdot 1 \cdot$ & اظهار نشده ... \\
\hline$r \Delta / \Delta \Delta$ & $r \Delta / \Lambda \Lambda$ & $1 V / 9 \Lambda$ & TN/TI & 19/99 & TN/TY & $19 / 4 V$ & r T/R & 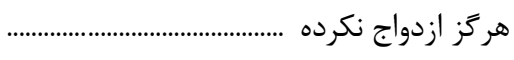 \\
\hline . 149 & ואן. &.$/ \cdot r$ & $.1 \cdot 4$ & $\cdot / \cdot r$ & $\cdot / \cdot \Delta$ & $\cdot 1 \cdot r$ & $\cdot 1 \cdot \Delta$ & اظهار نشده ..................................................... \\
\hline
\end{tabular}


نمودار سا ـ توزيع نسبى مردان ها ساله و بيشتر بر حسب وضع زناشويى در كل كشور (درصد)

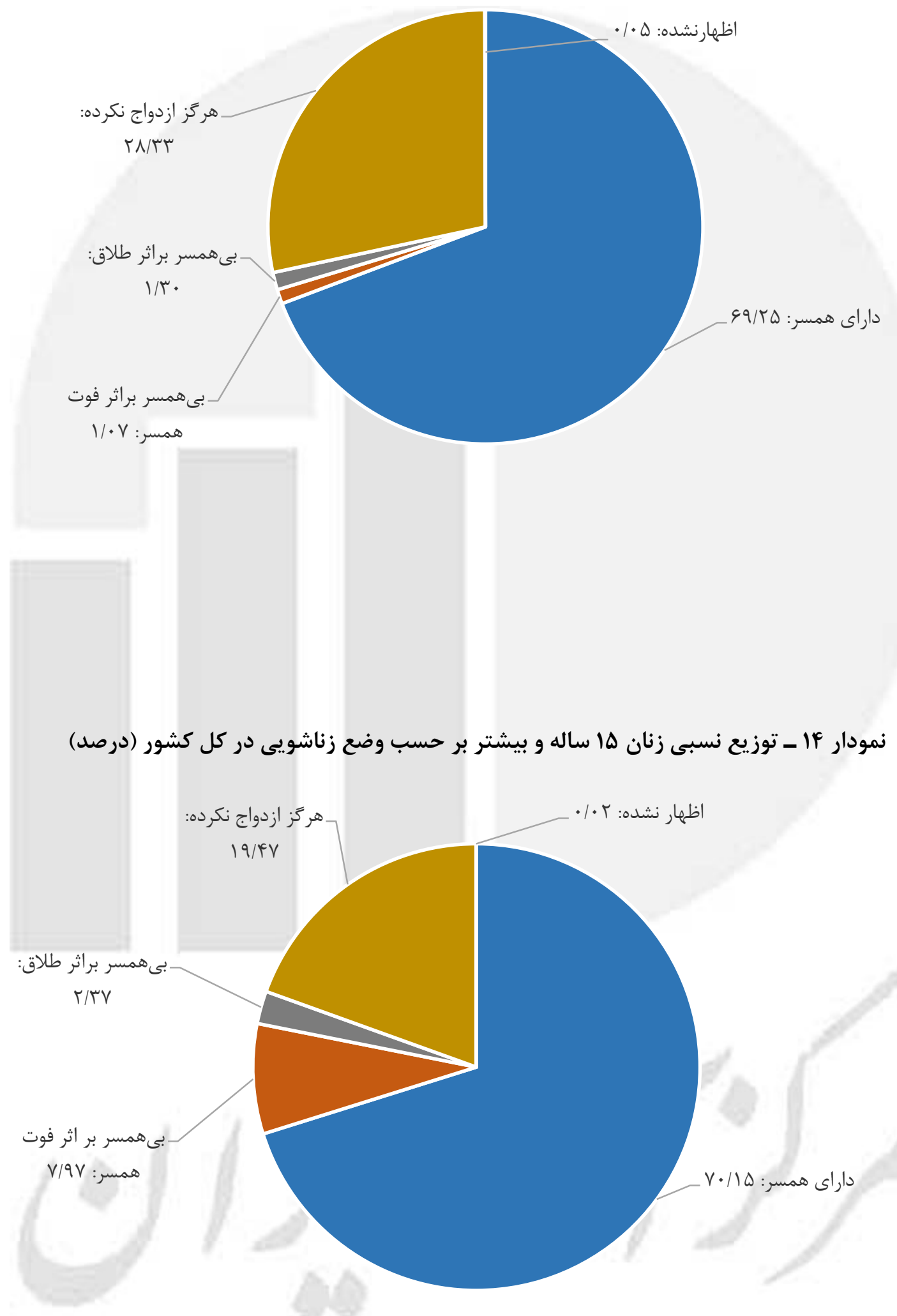




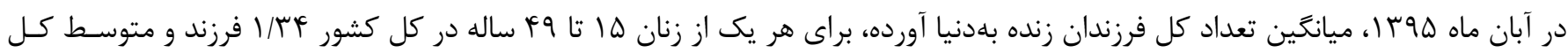

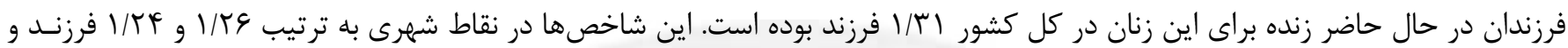

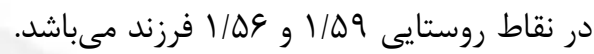

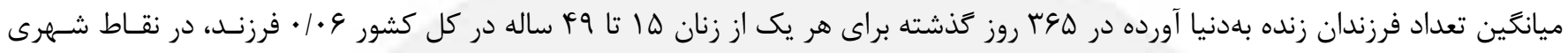

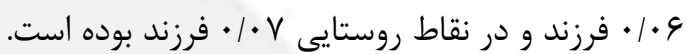

ز - جمعيت زنـان ها تا qq ساله بر حسب سن و تعداد فرزندان زنده بلددنيا آورده، تعداد فرزندان در حال حاضـر زنــده و تعــداد

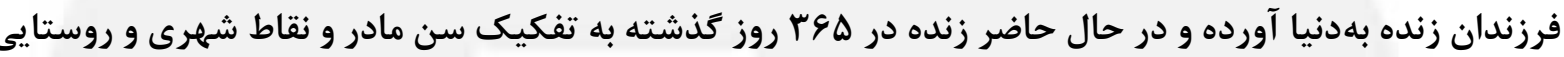

\begin{tabular}{|c|c|c|c|c|c|}
\hline \multicolumn{2}{|c|}{ تعداد فرزندان در ه هץ روز كذشته } & \multicolumn{2}{|c|}{ تعداد كل فرزندان } & \multirow[b]{2}{*}{ جمعيت زنان } & \multirow[b]{2}{*}{ سن } \\
\hline در حال حاضر زنده & زنده به دنيا آورده & در حال حاضر زنده & زآنده به دنيا & & \\
\hline IFrgDIA & Iferit. & rasterrere & $r \cdot F F \cdot q \cdot V$ & rreqDFVF & \\
\hline $9991 f$ & G৭人r. & $1 V+119$ & IVEsA. & TEVTr.q & ....... $10-19$ \\
\hline reQVA. & 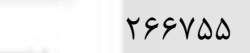 & IrN.rAT & ITqKID. & rIQDQ.F & $\ldots \ldots . . . r \cdot-r F$ \\
\hline FTATFA & $F T \cdot V \varepsilon D$ & TAFTIIT & roVVquF & $r \cdot \Delta V G \Lambda \Lambda$ & ......... $r \Delta-r q$ \\
\hline$r \cdots \Delta q$ & $F \cdot 101 V$ & $\Delta V T \Delta 9 q Y$ & $\Delta \vee q \Delta \& q \Lambda$ & FYG. 490 & $\ldots \ldots \ldots . . . r \cdot r \mu$ \\
\hline r. V৭८ & r. ^१T. & gTFTAIq & SFFVADG & TFEDI9D & .......... r山 -rq \\
\hline$\Delta \Delta १ १ ५$ & $\Delta G M I F$ & GI GFYFF & GTFTAVT & TV. FEIV & $\ldots \ldots \ldots . f \cdot-f f$ \\
\hline $1 \cdot \wedge \varepsilon F$ & 11.19 & 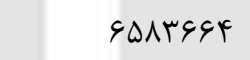 & $9 \wedge \cdot 919 \vee$ & 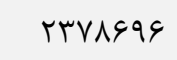 & $\ldots \ldots .+r q-r q$ \\
\hline $1 . r 9192$ & $1 \cdot r f \cdot 1$. & ritef. & rISYOAAA & IVIagraf & 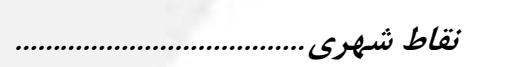 \\
\hline rघ911 & $r v \cdot r \Delta$ & 9rद9V & $q \mu \Delta q \mathcal{F}$ & $190 \cdot r \cdot r$ & $\ldots \ldots . .10-19$ \\
\hline IVEDFE & IVDI99 & Vqтатr & $\Lambda \cdot 1 r \cdot 9$ & TrIGVTA & $\ldots \ldots \ldots . . . r \cdot-r \digamma$ \\
\hline MITF.D & mitara & TFTYTEI & TFDIFFA & r.vefif & $\ldots \ldots \ldots \ldots$ \\
\hline r. F\&\& & $r \cdot \Delta \vee \wedge$. & $4 \mid 0.901$ & fr...pr & rr.q1r. & $\ldots \ldots \ldots . . . r \cdot-r F$ \\
\hline loF^9T & IQDGT & Fब99919 & FEVTRIT & rяवrquя & $\ldots . . . . . \mu \Delta-r q$ \\
\hline rq। $\Delta V$ & татал & FFrg.re & FarVES. & $r \cdot \Delta I \Delta F$. & $\ldots \ldots \ldots \ldots+F \cdot r$ \\
\hline VTrD & VEr & FVGrG.. & 4919018 & INTAr.r & $\ldots \ldots+\ldots q-i q$ \\
\hline$F \cdot \Delta \wedge \wedge \Delta$ & $r \cdot v r r r$ & 1DaArqr & AVFriar & DFATAIT & 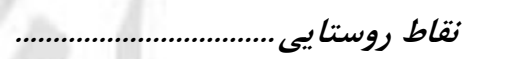 \\
\hline rqgkr & rqYro & $\Lambda \cdot r<q$ & $1 \cdot 91$. & $V T \| 191$ & $\ldots .10-19$ \\
\hline $91 \cdot \vee \wedge$ & $914 \cdot 1$ & FNDGYA & pq..rr & ArFisa & $\ldots \ldots \ldots . . . r \cdot-r Y$ \\
\hline $\mid 19941$ & $|l V \cdot r|$ & 111 rV91 & lltyrat & १マ१५^. & $\ldots . . . . . r \Delta-r q$ \\
\hline QDTF. & $9 \Delta \Delta \wedge$. & IOVTIET & IDQTFID & $q \uparrow q \Delta \vee$. & $\ldots \ldots \ldots . r \cdot r \cdot r$ \\
\hline$\Delta Y 9 \Delta 1$ & $\Delta M I \& \Delta$ & IVrq\&人9 & $I V R \cdot A T V$ & V৭१५द & 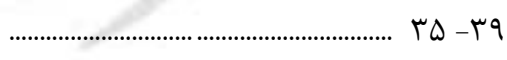 \\
\hline $19 \vee 99$ & ISAVE & IVATYAD & $11 \cdot \cdot 191$ & $9011 \% \cdot 9$ & $\ldots \ldots \ldots \ldots \ldots+\ldots$ \\
\hline rate & $r \Delta \wedge \Delta$ & $1 \wedge \mid F Y \wedge q$ & INAFFEV & DFへ१९D & $\ldots \theta-F q$ \\
\hline
\end{tabular}




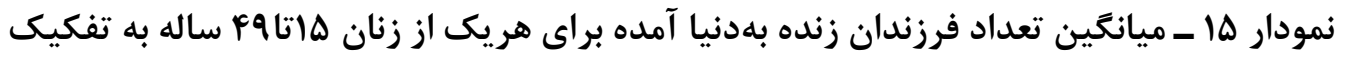
كل كشور، نقاط شهرى و نقاط روستايى

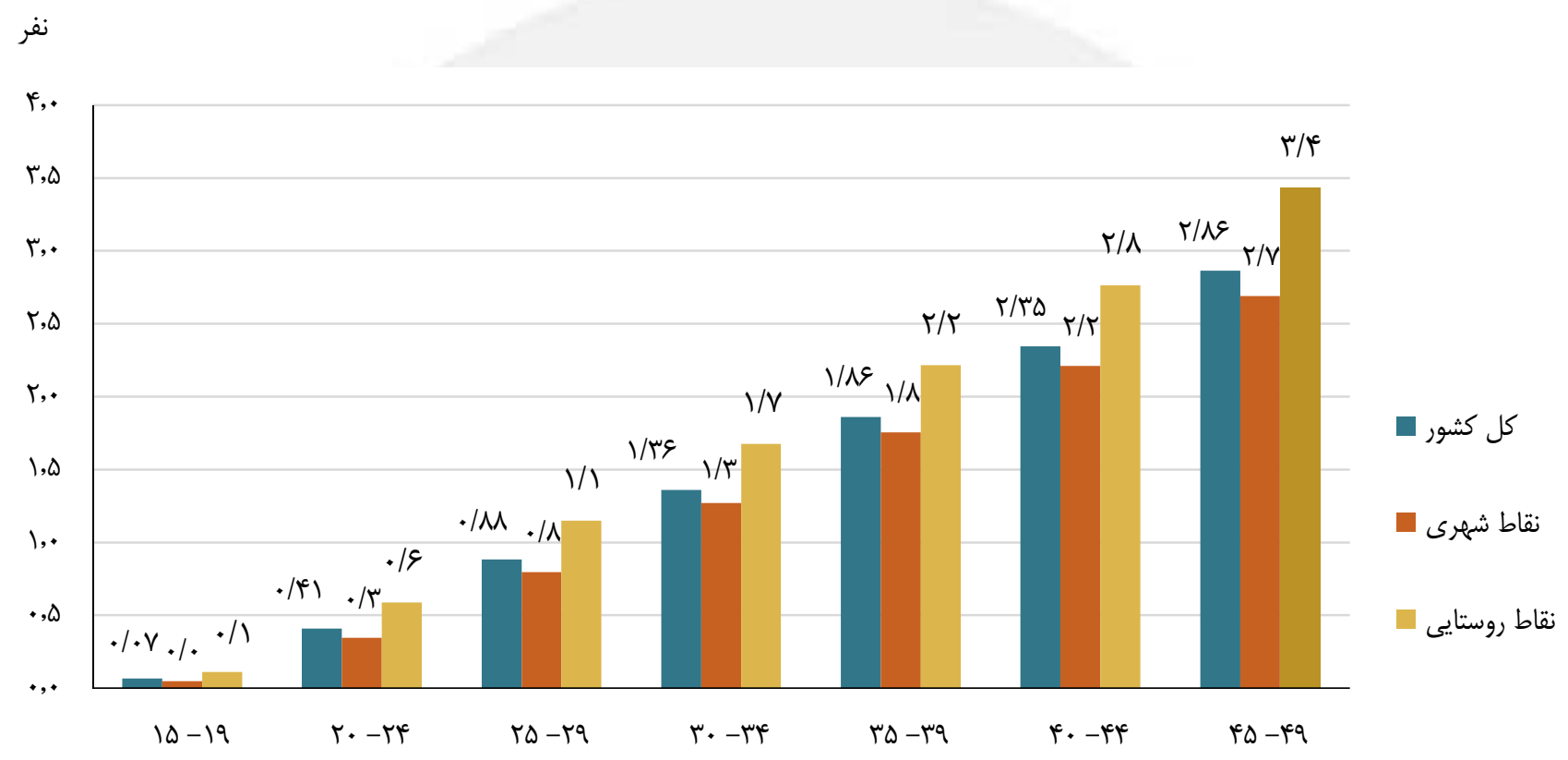

نوع خانوار و يراكندكى آن

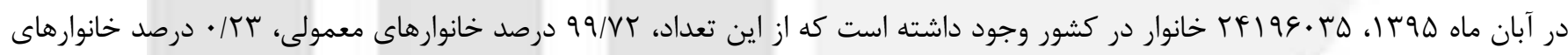

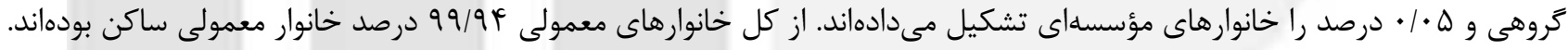

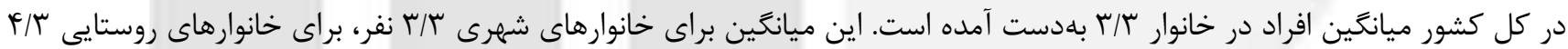
نفر و براى خانوارهاى غيرساكن ب/ا نفر بوده است.

ز - خانوار بر حسب نوع و به تفكيك وضع سكونت

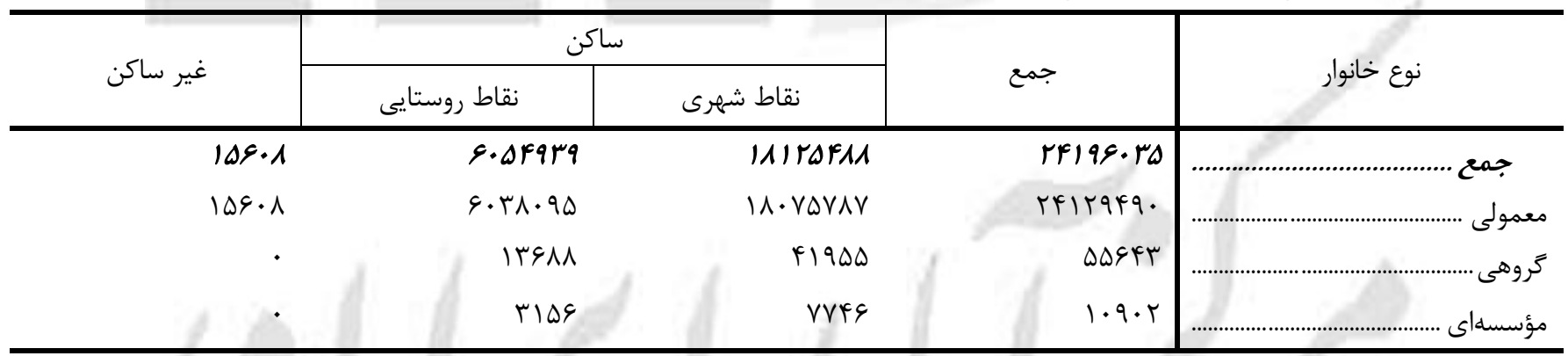

سريرست و تعداد اعضاى خانوار

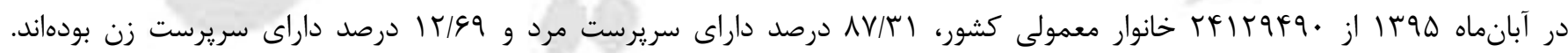

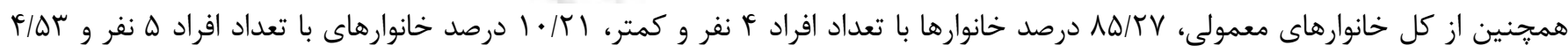

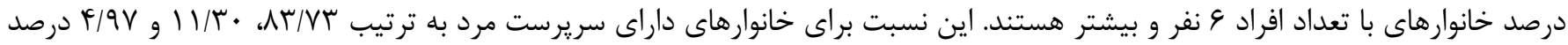

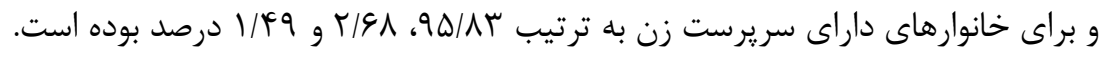


س - خانوارهاى معمولى بر حسب جنس سريرست و تعداد افراد در خانوار

\begin{tabular}{|c|c|c|c|c|c|c|c|c|c|c|c|}
\hline • بيشتر & 9 نفر & 1 نفر & نفر V & 9 كنر & ل ل لفر & لا نفر & ك انفر & ك نفر & ا نفر & جمع & جنس سريرست \\
\hline$r \cdot \Delta \Delta A$ & $r \cdot v 99$ & Ararr & rrurfa & vrralf & TFqT. IT & sevrlld & sı\&gqT. & rqurqry & r. FqRIV & rfirqfq. & مرد و زن .... \\
\hline 19941 & 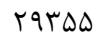 & V9v9 & TrrTaq & SqF9AF & $r r \Lambda .9 \Delta r$ & GFaTqTo & GKFGK & $F \mid \Delta F \cdot \wedge \Delta$ & G\GVGY & $r 1.9 V V T V$ & אرد........................ \\
\hline QTV & $|f F|$ & TVGQ & $1 . k 49$ & rq19. & $\Delta T \cdot \Delta q$ & $r T \cdot I \Lambda T$ & DT. TTV & 人rזیqז & $1 r \Delta q \Delta \Delta r$ & $r .91 V \Delta r$ & \\
\hline
\end{tabular}

نوع محل سكونت خانوار

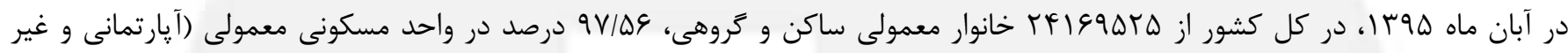

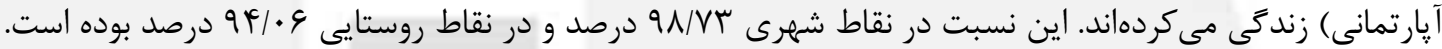

ش - خانوار هاى معمولى ساكن و تروهى بر حسب نوع محل سكونت و به تفكيك نقاط شهرى و روستايى

\begin{tabular}{|c|c|c|c|}
\hline ساكن در نقاط روستايى & ساكن در نقاط شهرى & جمع - اع & نوع محل سكونت \\
\hline g.divar & IAIIVVFr & rFIEqATA & 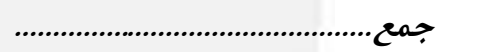 \\
\hline TYADSA & Aマ..rیז & $9.4 \wedge 9 \Delta 1$ & 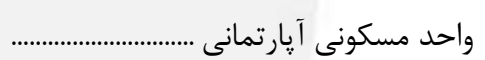 \\
\hline DTFTVTS & qIAVDFF & IFATITV. & واحد مسكونى غير آيارتمانى (خانههاى \\
\hline$\Lambda \cdot 1 v 9$ & $r \cdot \Delta r \Lambda$ & $1 \cdots v \mid f$ & קادر،كير آلونك، زاغه يا موارد مشابه ...... \\
\hline$r Y \Lambda \cdot \Delta F^{\prime}$ & T. YADQ & FAYqIT & 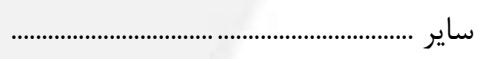 \\
\hline IrQ9 & FFIN & $\Delta \& V V$ & 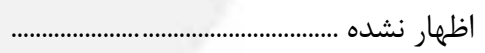 \\
\hline
\end{tabular}

نحوه تصرف محل سكونت خانوار

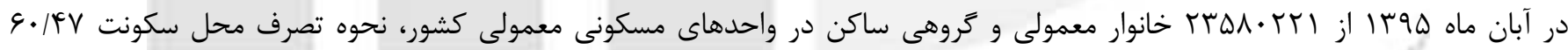

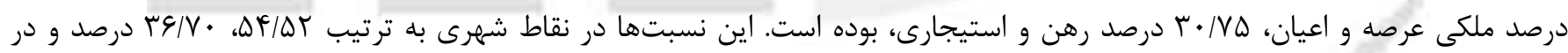

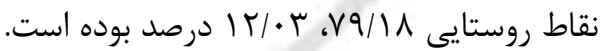

ص - توزيع نسبى خانوارهاى معمولى و كروهى ساكن در واحدهاى مسكونى معمولى بر حسب نحوه تصرف محل سكونت به

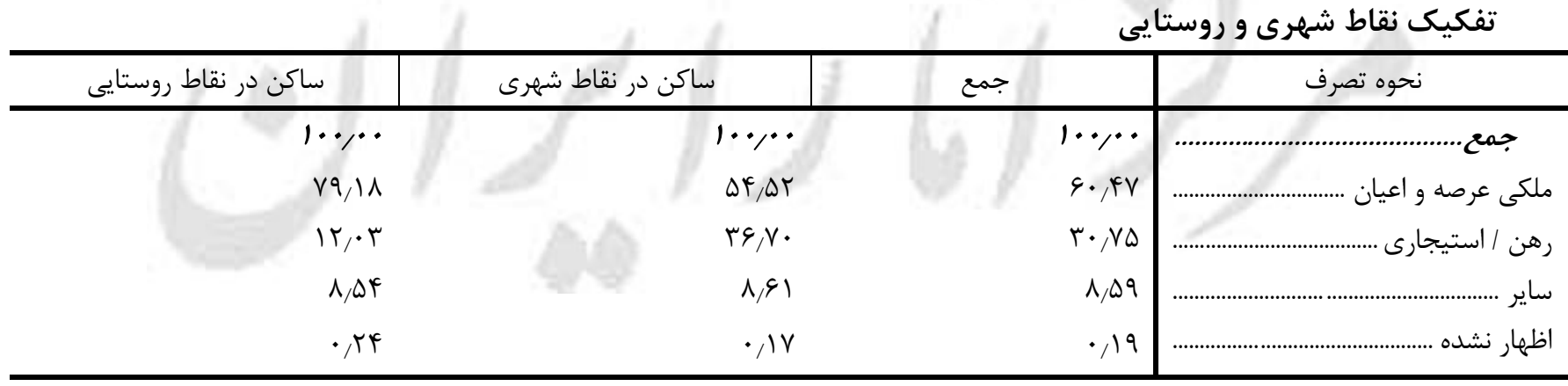


نمودار عا ـ توزيع نسبى خانوارهاى معمولى و گروهى ساكن در واحدهاى مسكونى معمولى بر حسب نحوه تصرف محل سكونت

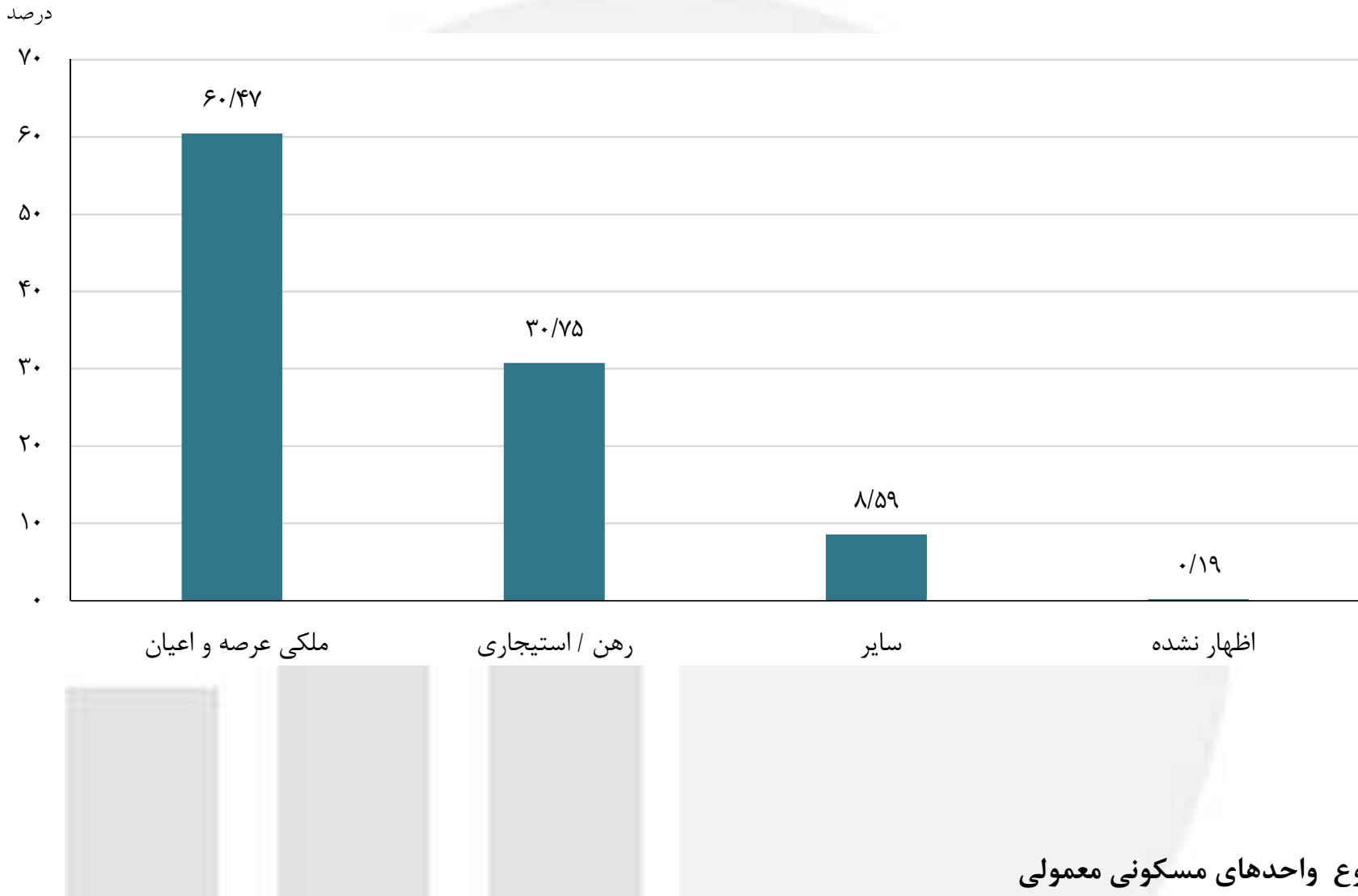

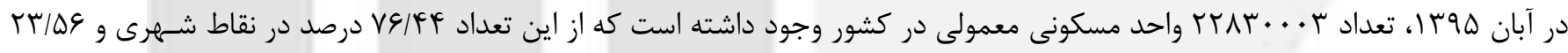

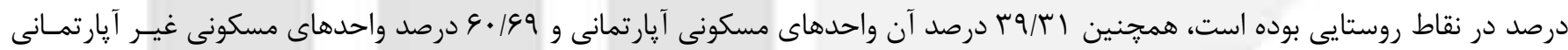

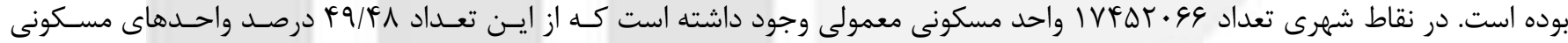

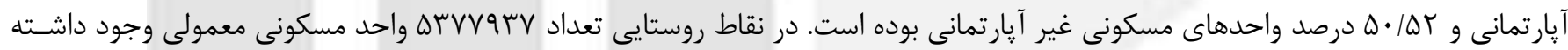

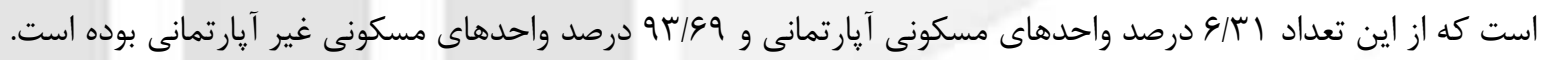

ض - واحدهاى مسكونى معمولى بر حسب نوع به تفكيك نقاط شهرى و روستايى

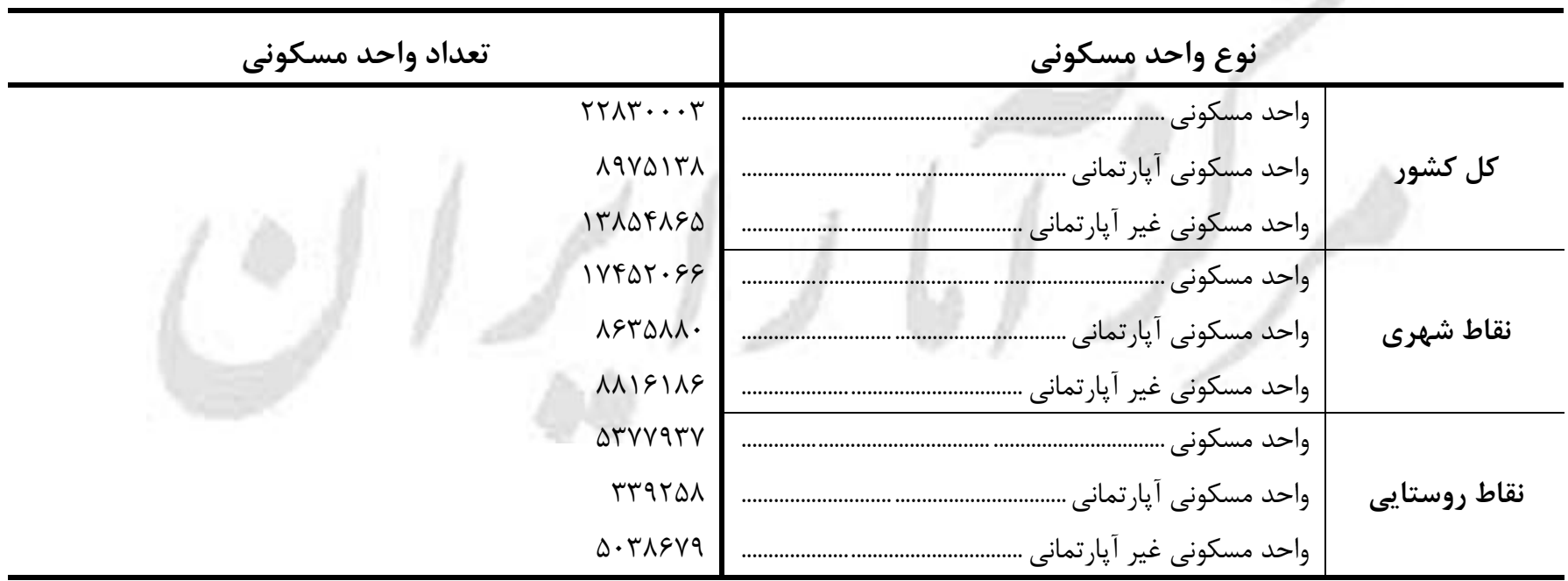


mq

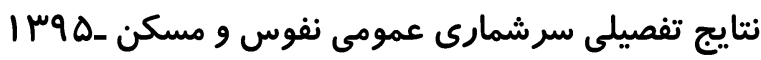

نمودار VIV - توزيع نسبى واحدهاى مسكونى معمولى بر حسب نوع - كل كشور (درصد)

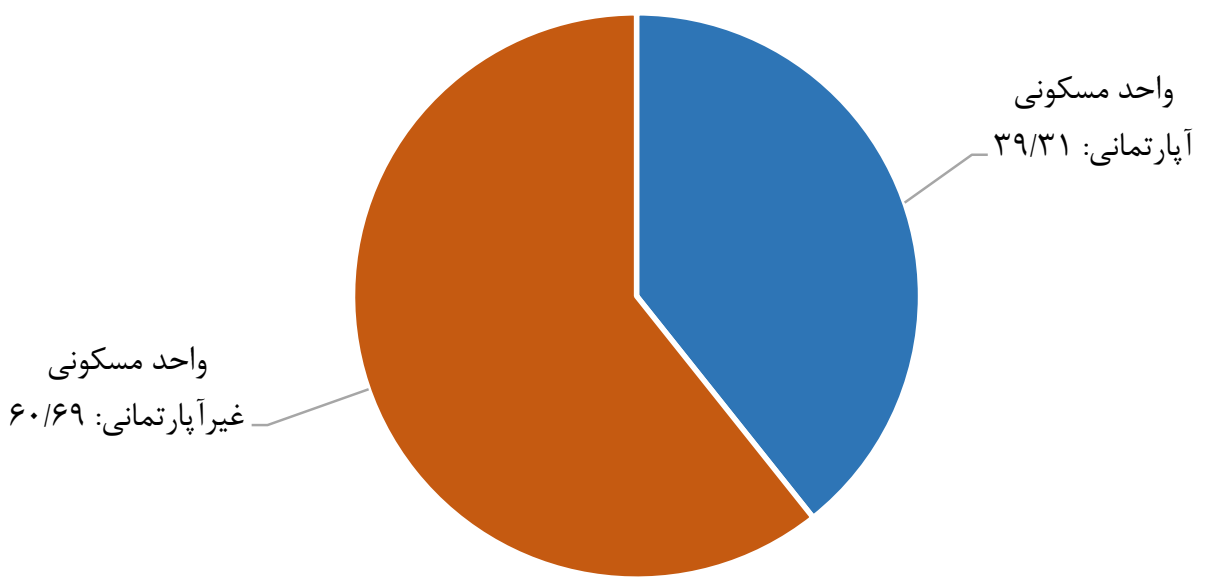

نمودار 11 ـ توزيع نسبى واحدهاى مسكونى معمولى بر حسب نوع - نقاط شهرى (درصد)

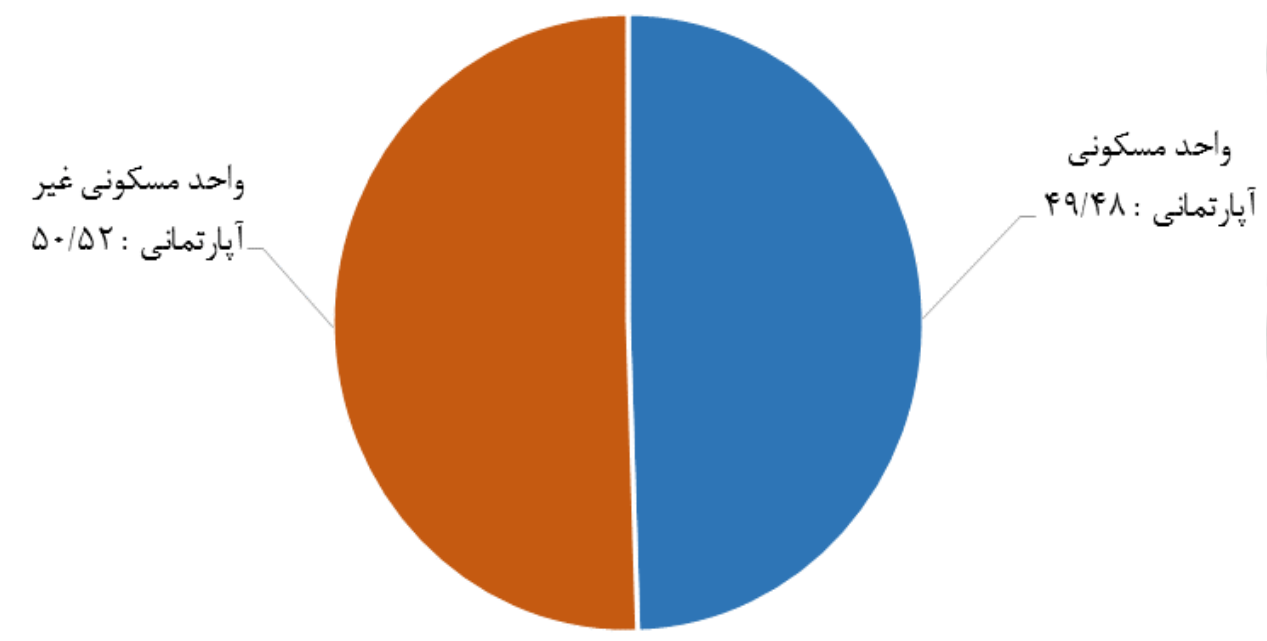


نمودار 19 ـ توزيع نسبى واحدهاى مسكونى معمولى بر حسب نوع - نقاط روستايى (درصد)

واحد مسكونى غير : بونمير

آهارتمانى : 9 :

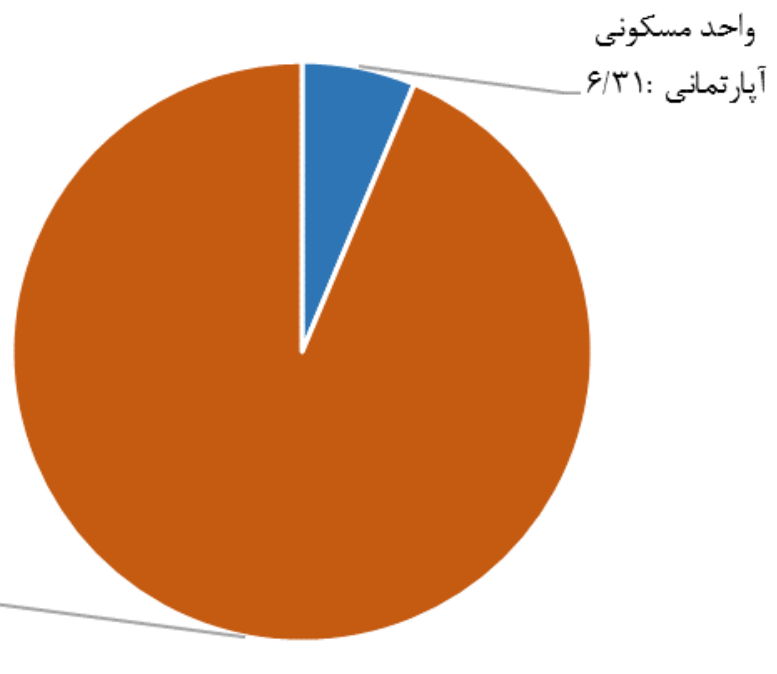

مساحت زيربناى واحدهاى مسكونى معمولى

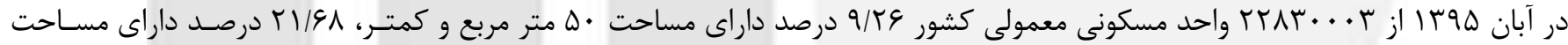

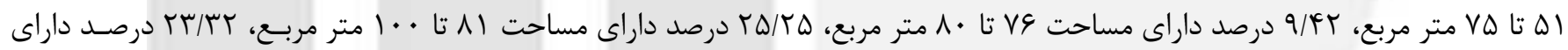

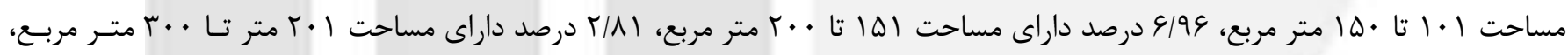

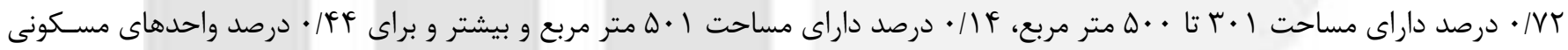

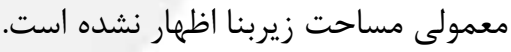

ط - واحدهاى مسكونى معمولى بر حسب مساحت زيربنا به تفكيك نقاط شهرى و روستايى

\begin{tabular}{|c|c|c|c|c|c|c|c|}
\hline 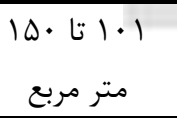 & 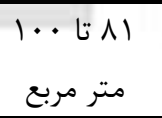 & 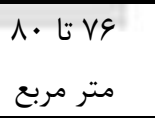 & $\begin{array}{l}\text { I اه تا متر مربع } \\
\text { متر }\end{array}$ & • له متر مربع و & جمع & \multicolumn{2}{|c|}{ واحد مسكونى معمولى } \\
\hline DTTRVVF & $\Delta V G T \Delta \Delta F$ & rIfqQ9V & 490.999 & Tll4809 & rTAr...r & واحد مسكونى........................ & \\
\hline $1911 \% \cdot 1$ & FETTVYY & NFrqDF & $r \Delta \cdot G \wedge r I$ & $Q \cdot \Delta F \ldots$ & NQVDITA & $\ldots$ & 15 \\
\hline TMYTAVT & rrF.人IV & I TKGGKT & TFETAFA & $10 \cdot 94 \Delta 9$ & 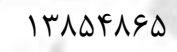 & مانى .. & \\
\hline FFFINIS & FFYG।91 & IFAFTHD & rNFF्S99 & $|F| \Delta \vee \wedge q$ & IVFAT.GG & واحد مسكون & \\
\hline $1911 \Delta \Delta F$ & TrTIAqF & VAFIAT & TFTI9IT & DVGTFT & $\Lambda \varsigma r \Delta \Lambda \Lambda$. & واحد مسكوني آيار تمانى.................... & \\
\hline THt & T. rFqqV & $V \cdots \Delta r$ & IFTTVAV & NTGQFG & 1419119 & واحد مسكونى غير آيار تمانى.. & سهرى \\
\hline $1 \cdot 119 \Delta \wedge$ & |fle994 & GQATGY & $11.099 V$ & squ^v. & Drrvarr & 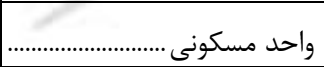 & \\
\hline 9941V & $1 \cdot \lambda \kappa r$ & rAVVT & $\wedge<q . q$ & TEIDV & 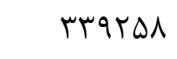 & واحد مسكونى آيار تمانى.......... & \\
\hline $1 .|T M F|$ & $|r| \Delta \wedge r$. & $9 r 909$. & $|\cdot r| \cdot \Delta \lambda$ & SVTVIr & D. rर\&VQ & واحد مسكو & \\
\hline
\end{tabular}




\begin{tabular}{|c|c|c|c|c|c|c|}
\hline اظظهارنشده & بيشتر 1 مـ مربع و & 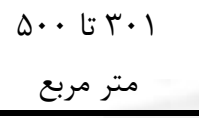 & 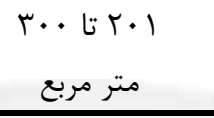 & 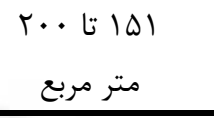 & \multicolumn{2}{|l|}{ سال اتمام } \\
\hline $99 \Delta ९ V$ & ए广А१९ & ISYANA & SYI9DT & $I \Delta \Lambda \Lambda F \Delta$. & 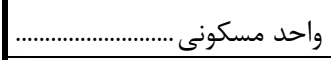 & \\
\hline firt. & $\Delta r .$. & TFITV & ITATYT & $\psi \psi \cdot \Delta \varphi$ & واحد مسكونى آيار تمانى.......... & كشي كل \\
\hline$\Delta \wedge r q \vee$ & TVQQQ & $|f \cdot V \varepsilon|$ & 01991. & lIFAFqF & واحد مسكونى غير آيار تمانى .. & \\
\hline$\Lambda T G \cdot \Delta$ & 19041 & ITEKGV & $\Delta F \vee \wedge Q \Delta$ & ITETIOA & 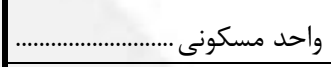 & \\
\hline ragfa & FVG & $r r \Lambda \cdot \Lambda$ & ITITAF & FrNDGT & 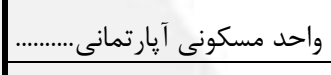 & نقاذ \\
\hline FrqG. & IFVVD & $1 . r \varepsilon \Delta 9$ & 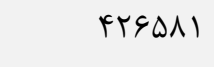 & $91 \% \Delta 99$ & واحد مسكونى غير آيار تمانى .. & سهرى \\
\hline 19995 & ITrod & TAFt & $q \uparrow \cdot \wedge V$ & TrETqT & 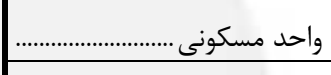 & \\
\hline $19 r \Delta$ & $\Delta r F$ & 1519 & ra१1 & $114 q 4$ & واحد مسكونى آيار تمانى........... & ن فاط \\
\hline IQTHV & |rAT| & $r r \mid \cdot r$ & $9 \cdots 99$ & rmFVqA & واحد مسكونى غير آيار تمانى .. & \\
\hline
\end{tabular}

نمودار • + - توزيع نسبى واحدهاى مسكونى معمولى بر حسب مساحت زيربنا - كل كشور (درصد)

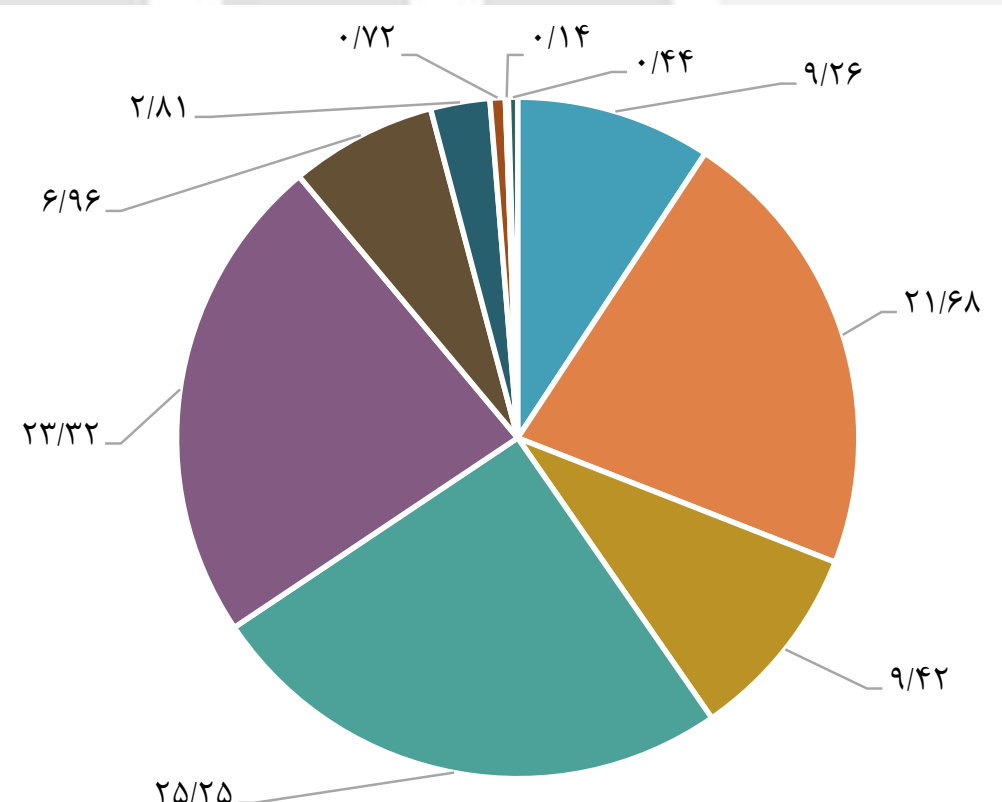

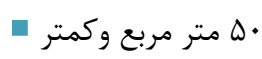

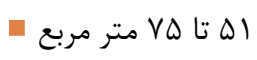

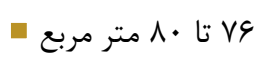

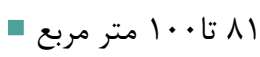

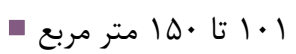

|

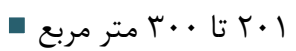

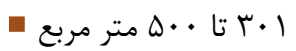

| 1 | متر مربع و بيشتر

| اظهارنشده

$r \omega / T \omega$ 
نمودار الr ـ توزيع نسبى واحدهاى مسكونى معمولى بر حسب مساحت زيربنا - نقاط شهرى (درصد)

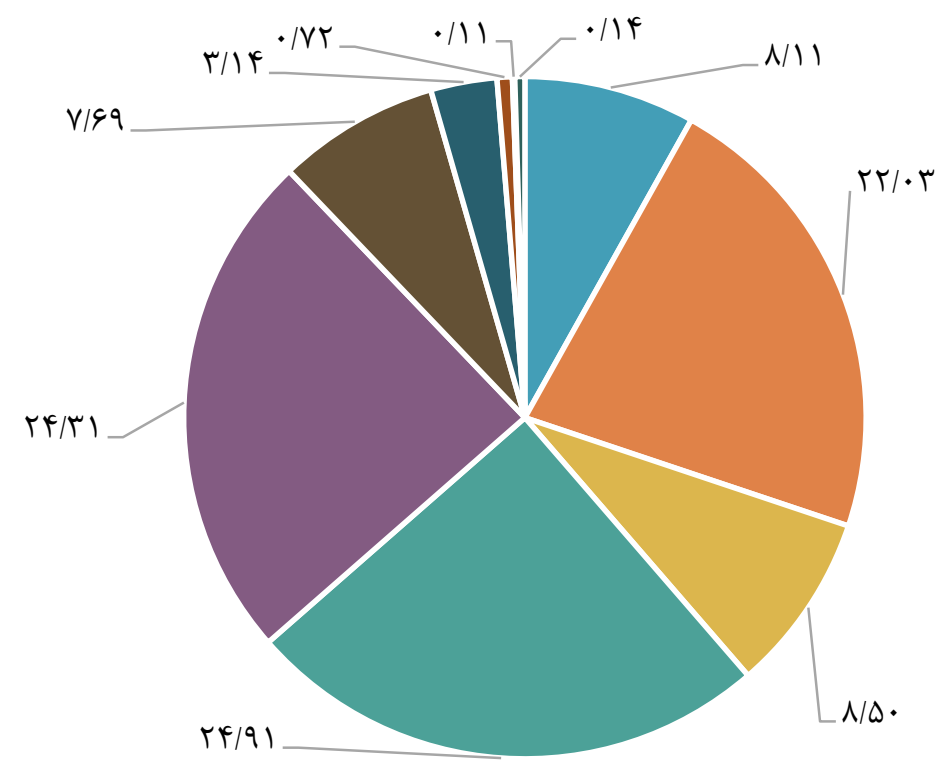

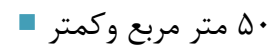

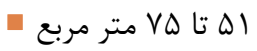

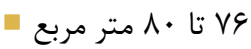

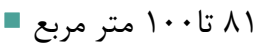

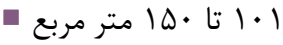

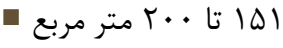

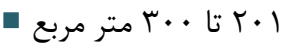

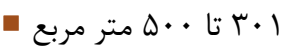

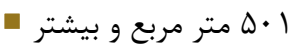

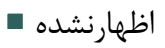

نمودار r ـ - توزيع نسبى واحدهاى مسكونى معمولى بر حسب مساحت زيربنا - نقاط روستايى (درصد)

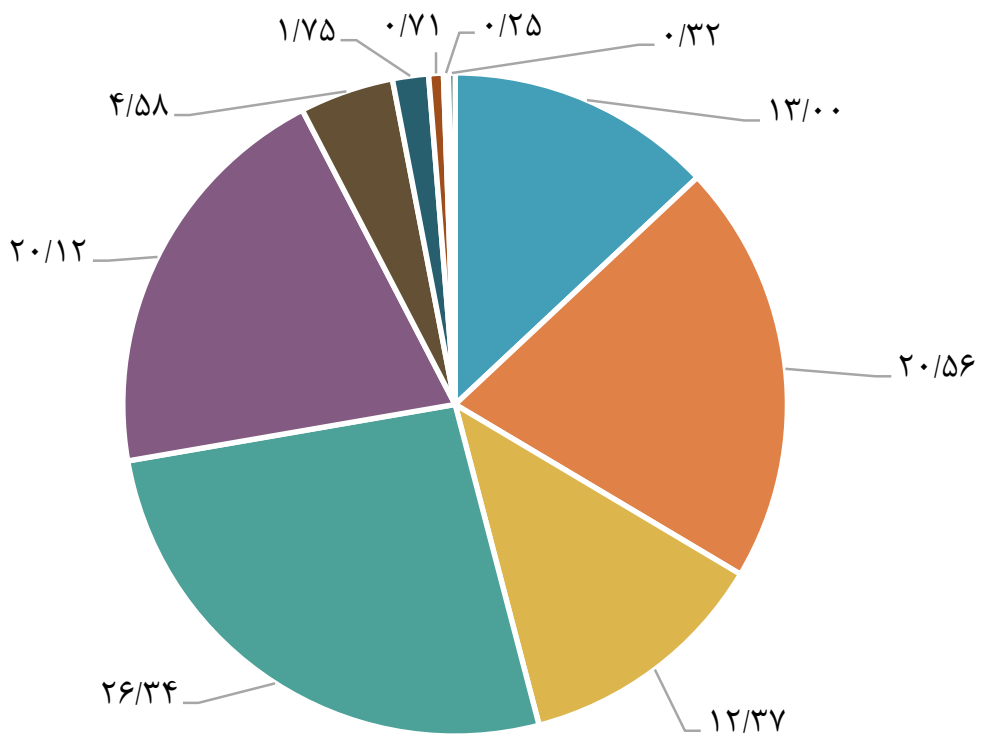

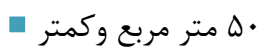

" اله تا V V متر مربع

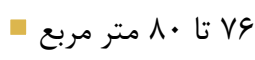

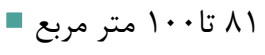

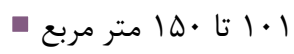

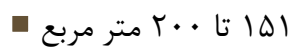

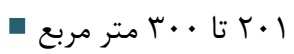

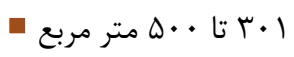

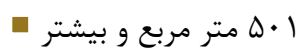

| اظهارنشده 


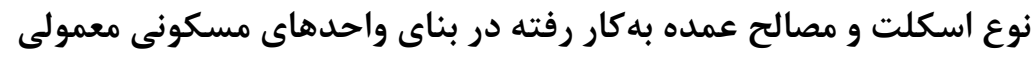

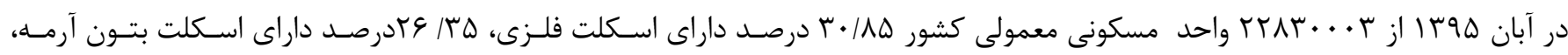

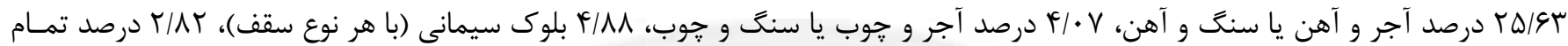

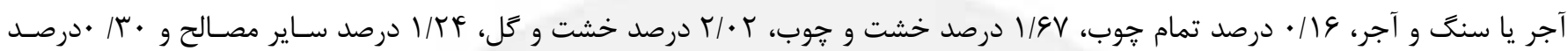
نوع اسكلت آنها اظهارنشده است.

ظ - واحدهاى مسكونى معمولى بر حسب نوع اسكلت بنا و مصالح عمده بهكار رفته در بنا به تفكيك نقاط شهرى و روستايى

\begin{tabular}{|c|c|c|c|c|c|c|c|c|}
\hline \multicolumn{4}{|c|}{ ساير اير } & \multirow[b]{2}{*}{ بتون آرمه } & \multirow[b]{2}{*}{ فلزى اسكلت } & \multirow[b]{2}{*}{ جمع } & \multirow{2}{*}{\multicolumn{2}{|c|}{ واحد مسكونى معمولى }} \\
\hline $\begin{array}{c}\text { بلوك سيمانى (بر نوع } \\
\text { سقف) }\end{array}$ & سنح و جوب & آجر آ سنَ آهن & جمع & & & & & \\
\hline 1114811 & 9 q... & $\Delta \wedge \Delta \cdot \wedge \vee q$ & $9 \gamma \cdot r \wedge 10$ & Q. IETrt & V.FTrAN & rrAr...r & 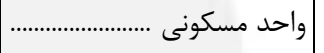 & \\
\hline$\Delta V Y \wedge \Delta$ & ror^q & 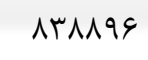 & I. DIVVV & rᄉv^.rq & $r \cdot r \Delta q \Lambda F$ & 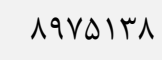 & |واحد مسكونى آيارتمانى ...... & كل \\
\hline س & $q . p \vee<q$ & 0.11914 & $\wedge \varepsilon \Delta 1 \cdot r \wedge$ & TITAT.D & $r \cdot \cdot v r \cdot r$ & IrADFAGD & |واحد مسكونى غير آيارتمانى & \\
\hline 0.991. & $|\mu \cdot| r \mid$ & FTIATAD & G.VFFAD & $\Delta \cdot \Lambda \Lambda \cdot \Lambda r$ & GYFI911 & IVFAT.GG & 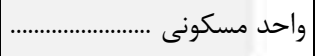 & \\
\hline FANT. & $19 V 1 \%$ & V१५११९ & १९V९१र & TVFAG. & TqIFTIq & 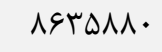 & واحد مسكونى آيارتمانى ...... & \\
\hline fervi. & TEMFIA & roTQTAq & $\Delta 1.9 \vee 94$ & ITFTFAT & rrTVVGq & M119119 & واحد مسكونى غير آيارتمانى & شهرى \\
\hline $9 \cdot \Delta \cdot \cdot 1$ & $\Delta \vdash q q \cdot V$ & IOTKQQF & тятАнт. & $9 Y \wedge \mid 01$ & $\Lambda \cdot 1 r . \cdot$ & DTVVqTY & 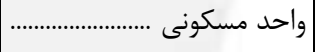 & \\
\hline 11490 & 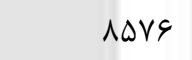 & $r \Delta q \ldots$ & $\wedge F \cdot \wedge \Delta$ & I TTETg & ITIVED & 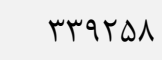 & |واحد مسكونى آيارتمانى ...... & \\
\hline DqTDFr & DFITI & 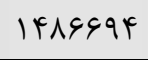 & TAFFTES & VQDVTr & 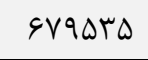 & 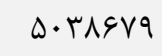 & |واحد مسكونى غير آيارتمانى & \\
\hline
\end{tabular}

\begin{tabular}{|c|c|c|c|c|c|c|c|}
\hline \multirow{2}{*}{ اسكلت و مصالح الظهار نشده نوع } & \multicolumn{5}{|c|}{ 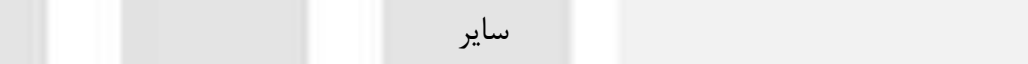 } & \multirow{2}{*}{\multicolumn{2}{|c|}{ واحد مسكونى معمولى }} \\
\hline & ساير & خشت و كل & خشت و جوب & تمام جوب & سنَ و آجر آجر & & \\
\hline $9 \vee 949$ & $r \Lambda F \cdot G r$ & \&QIQVV & $r \Lambda \cdot 9 \wedge r$ & TVQDT & GFrF.F & 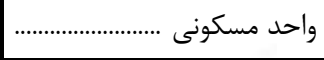 & \\
\hline quFA & ब१९९. & $\Lambda D F V$ & GNDT & שתזו & $\Delta r V \Delta \Delta$ & واحد مسكونى آيارتمانى ....... & \\
\hline$\Delta \wedge r I \Lambda$ & THFIFA & FQT.r. & rVTATI & एदा & $\Delta \wedge q \& 4 q$ & واحد مسكونى غير آيار تمانى . & \\
\hline$F \vee \Delta I$. & $11 \cdot+r 4$ & $I V \Delta \cdot \wedge \Lambda$ & $1 \cdots 10$ & 19711 & $r q 1 \cdot \wedge r$ & واحد مسكونى ........................................... & \\
\hline ( & DGTYF & rrAs & TVGV & NF & prapt & واحد مسكونى آيار تمانى ....... & \\
\hline rq|q| & ITFT. & $I V \cdot V \cdot r$ & qVR & IMMAN & TETIFI & واحد مسكونى غير آيار تمانى . & سهرى \\
\hline$r \cdot \mid \Delta G$ & ו 1.rGY & 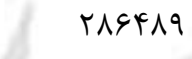 & $r \Lambda \cdot \Delta r r$ & IVAFI & TATMT. & 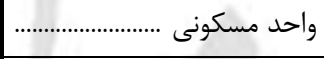 & \\
\hline $9 \vee 9$ & rघ9९ & (19) & $\varphi \cdot \wedge \Delta$ & rq. & $\Delta N I T$ & واحد مسكونى آيارتمانى ........ & لعاط \\
\hline $191 \mathrm{VV}$ & १९৭४५ & TATHTA & TVGFYA & $|V F \Delta|$ & $r \ll \& D \cdot \Lambda$ & واحد مسكونى غير آيار تمانى .. & \\
\hline
\end{tabular}


نمودار بr ـ توزيع نسبى واحدهاى مسكونى معمولى برحسب نوع اسكلت و مصالح عمده به كار رفته در بنا ـ كل كشور (درصد)
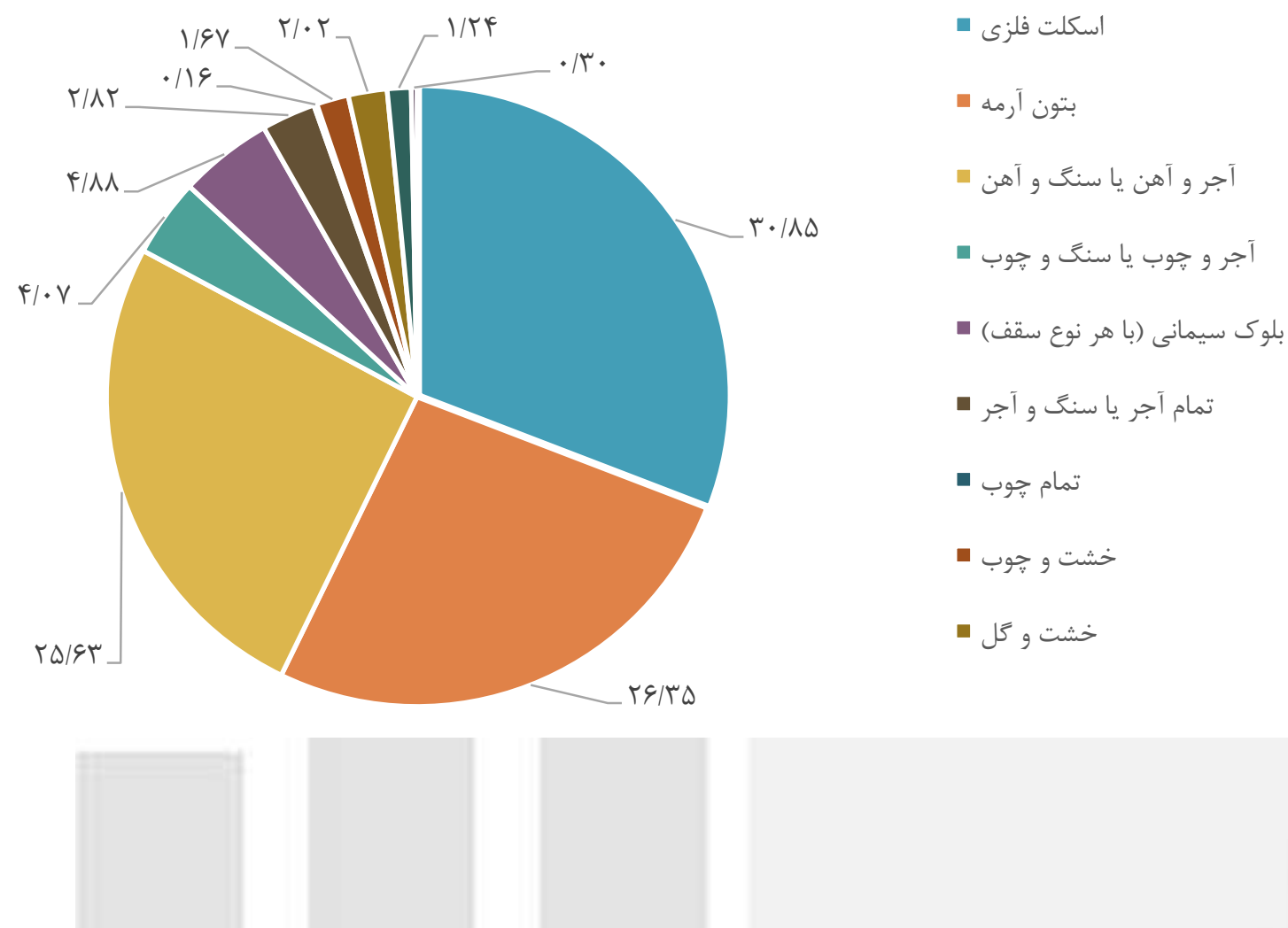

نمودار FF ـ توزيع نسبى واحدهاى مسكونى معمولى برحسب نوع اسكلت و مصالح عمده به كار رفته در بنا ـ نقاط شهرى(درصد)

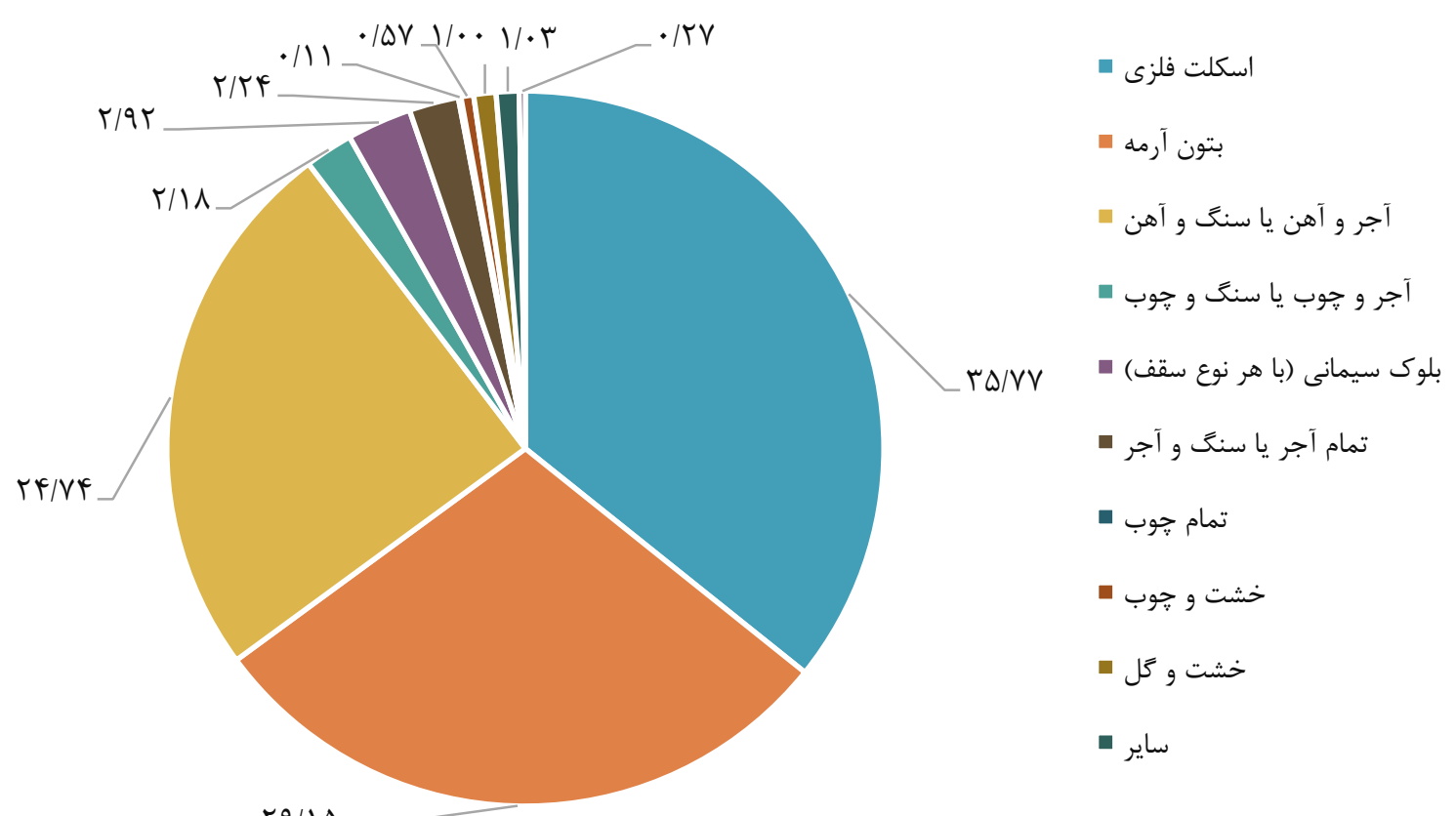

$r q / 10$ 
نمودار ها ـ توزيع نسبى واحدهاى مسكونى معمولى بر حسب نوع اسكلت و مصالح عمده بهكار رفته در بنا ـ نقاط روستايى (درصد)
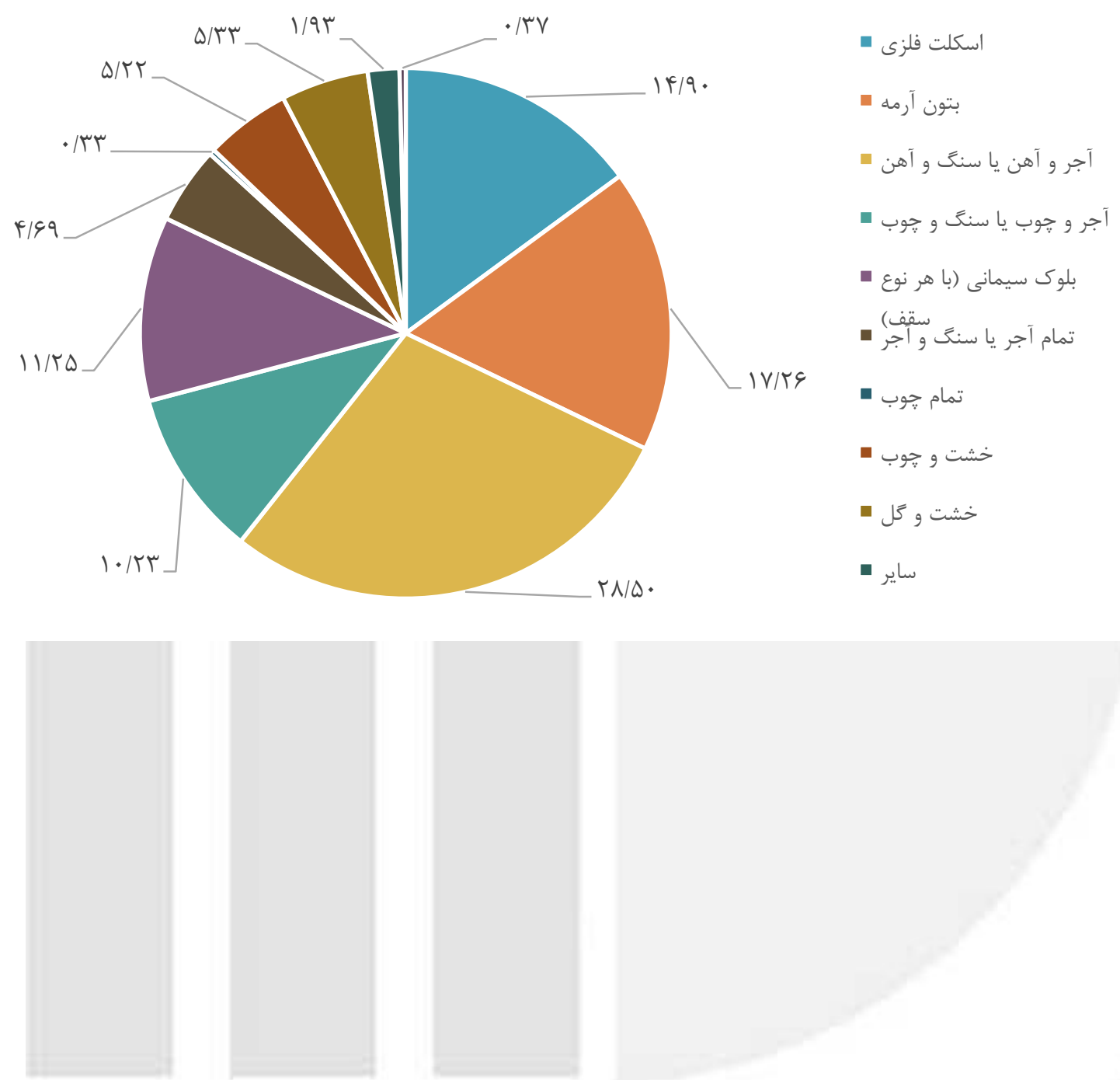
ط ـ جمعيت و خانوار شهرستانهاى كشور به ترتيب استان

\begin{tabular}{|c|c|c|c|c|}
\hline خانوار & 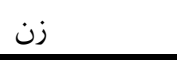 & 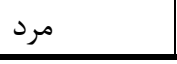 & جمعيت & 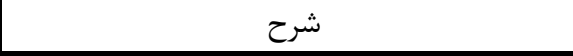 \\
\hline$r F \mid q \varepsilon \cdot r a$ & rafrrara & F. FqAFFT & raqrerr. & 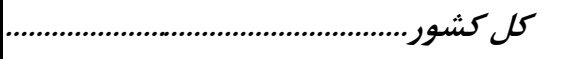 \\
\hline INITAFAN & rQT. DFrr & rqAfifif & DQIFEAFV & ساكن در نقاط شهرى ............. \\
\hline$q \cdot \Delta$ \&qrq & $1 \cdot 1 \cdots v 9$ & $1.8 T \cdot \Delta \& q$ & $r \cdot V r \cdot q r \Delta$ & 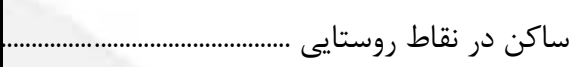 \\
\hline $109 \cdot 1$ & trtid & requa & FAY৭A & 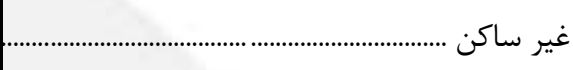 \\
\hline $1 r r r \cdot r A$ & 19T.rat & $19194 \ldots$ & $r q .98 \Delta \mathrm{r}$ & 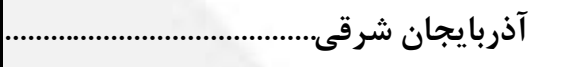 \\
\hline MAVIFr & $\mid r \wedge \wedge q \cdot r$ & $I F T \cdot \Delta T \cdot$ & TA. QFTY & 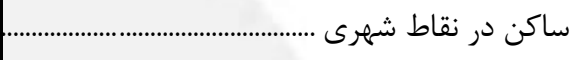 \\
\hline 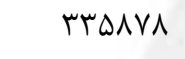 & DTIFFA & $\Delta G \wedge \wedge \vee \Delta$ & 11 ..rr. & ساكن در نقاط روستايى ............ \\
\hline$v$ & r & $\Delta$ & $\wedge$ & 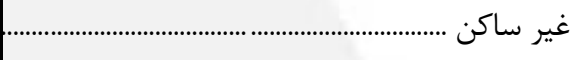 \\
\hline rorgF & DFTAT & $\Delta q \cdot r \Lambda$ & $11 \cdot r 11$ & 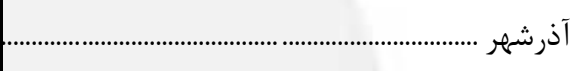 \\
\hline rra९A & rqтат & rVQ.r & Vัヘ৭९ & ساكن در نقاط شهرى ....... \\
\hline 11490 & IVAMA & INATA & rafir & ساكن در نقاط روستايى ... \\
\hline 1 & r & & r & 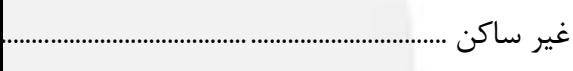 \\
\hline$\Delta \cdot q V F$ & $V r v \cdot q$ & $\Lambda \cdot \Delta \& 1$ & IQATV. & 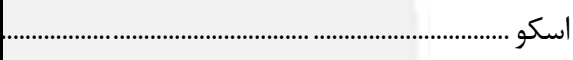 \\
\hline rVGIr & $\Delta V A F \Lambda$ & $\Delta ৭ \& \vee १$ & IIVATV & ساكن در نقاط شهرى \\
\hline $\mid r \cdot 91$ & 19181 & $r \cdot \Lambda \Lambda T$ & $F \cdot V k r$ & ساكن در نقاط روستايى .. \\
\hline FqT.r & VeVvF & VVVQS & lQFAT. & غير ساكن ............................................................. \\
\hline rIFAI & DTDIA & DTVAI & $1 \cdot \Delta r 99$ & ساكن در نقاط شهرى \\
\hline$|F V Y|$ & TFTAS & rFqVa & FqrTा & ساكن در نقاط روستايى .... \\
\hline tratr & FAVYr & $q q . q v$ & qצvaq & غير ساكن ...................................... بسان \\
\hline VRrI & 11941 & ITVEV & $r F V \cdot \Lambda$ & ساكن در نقاط شهرى \\
\hline$r \cdot F i d$ & rrvi. & rerk. & $\nabla \cdot c \cdot$ & ساكن در نقاط روستاي \\
\hline 1 & 1 & & 1 & غير ساكن ........................ \\
\hline FTMTD & geYro & GAFDV & IrYAQT & 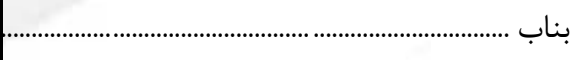 \\
\hline r9919 & FTrGV & rrq.V & NDTVF & ساكن در نقاط شهرى \\
\hline $10 F \cdot 9$ & $T F \cdot 9 \Lambda$ & $r \Delta \Delta \omega \cdot$ & 99911 & ساكن در نقاط روستاي \\
\hline$\cdot$ & $\cdot$ & $\cdot$ & · & 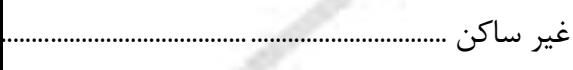 \\
\hline DGrGG. & $\wedge \vee \Delta \wedge \vee \varepsilon$ & ^৭४।QV & IVVT.rr & 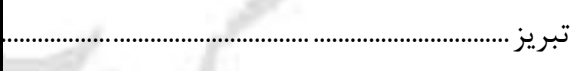 \\
\hline DIAIAV & $\Lambda \cdot r \Delta G 9$ & $1190 \mathrm{H}$ & $19 \pi \% \cdot 99$ & ساكن در نقاط شهرى ....... \\
\hline FDFVT & VYril. & VVGTG & lf9949 & ساكن در نقاط روستايى .... \\
\hline 19k4 & rqvas & $\begin{array}{l}1 \\
\text { rIDar }\end{array}$ & 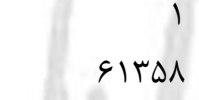 & 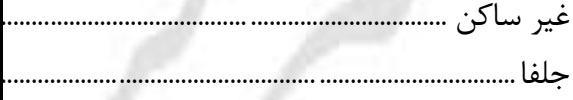 \\
\hline$|r v a|$ & TIDFA & rrIDQ & 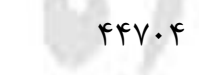 & 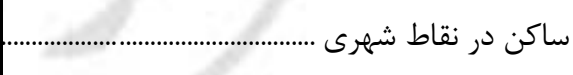 \\
\hline$\Delta \& \wedge T$ & $\Lambda T \Delta I$ & $\Lambda F \cdot r$ & $199 \Delta F$ & 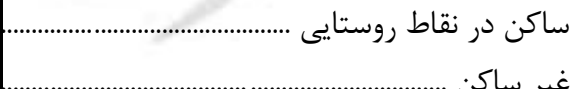 \\
\hline
\end{tabular}


ط - جمعيت و خانوار شهرستانهاى كشور به ترتيب استان (دنباله)

\begin{tabular}{|c|c|c|c|c|}
\hline خانوار & 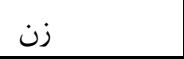 & 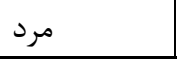 & جمعيت & 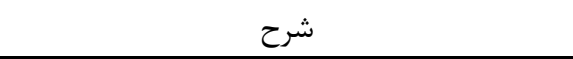 \\
\hline $9 \cdot 19$ & $10 \cdot 19$ & lo91r & $m_{1} \cdot v_{1}$ & 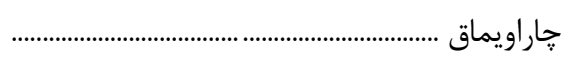 \\
\hline 1994 & $r \cdot \Delta r$ & $r \cdot \varphi q$ & 91.4 & 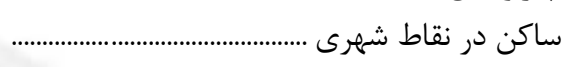 \\
\hline VTOF & $1 T \cdot r 4$ & 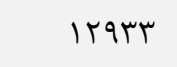 & rFq৭q & 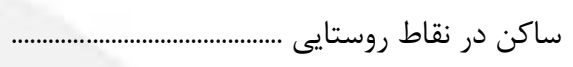 \\
\hline & . & - & & غير ساكن .................................................... \\
\hline 1.199 & IETFF & $|\& V \Delta|$ & rrq9D & 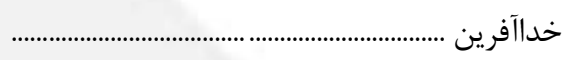 \\
\hline$\Delta \varphi$. & 949 & १९५ & $19 \cdot r$ & 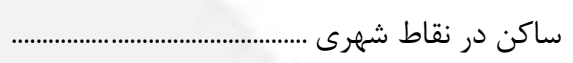 \\
\hline १\&४९ & $1 \Delta \mu \cdot \Delta$ & $ı \Delta \vee \wedge \Lambda$ & r).9r & 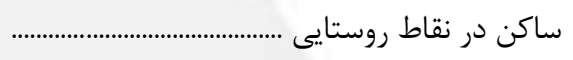 \\
\hline · & · & $\cdot$ & & 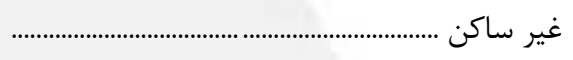 \\
\hline rAfrs & g.ver & grarı & $|r \Delta T F|$ & 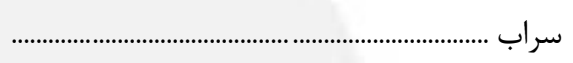 \\
\hline IAFT. & ra.rt & $r \cdot r \wedge \Delta$ & $\Delta q r \cdot V$ & 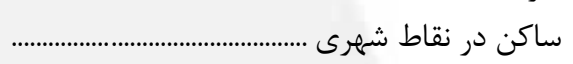 \\
\hline$r \cdot r \Delta$ & rivel & TFtqT & 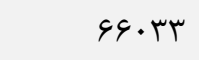 & 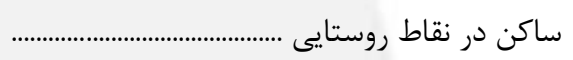 \\
\hline 1 & & 1 & 1 & 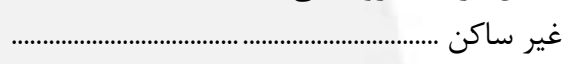 \\
\hline rquk & svrrl & $\varepsilon \wedge \cdot \Delta \cdot$ & $\mid T \Delta F T$ & 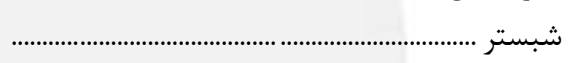 \\
\hline rtqle & raral & $r \Delta \& \wedge \Lambda$ & $V \cdot १ ९ ৭$ & ساكن در نقاط شهرى .......... \\
\hline$r 1 \cdot 91$ & $r r \cdot q$. & Trtat & SFALT & 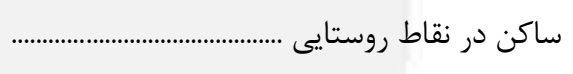 \\
\hline$r \cdot 4 \cdot 1$ & reger & 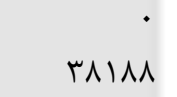 & $V \cdot \wedge \Delta r$ & 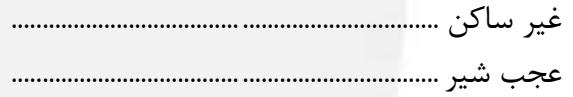 \\
\hline 1.NAT & IV.re & IVrA. & rer.G & 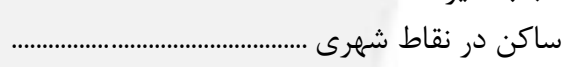 \\
\hline$q \vee \Delta \Delta$ & IDFr & $r \cdot 9 \cdot 1$ & reDFG & 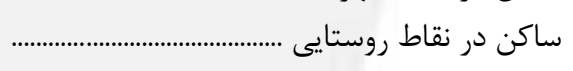 \\
\hline & & & & 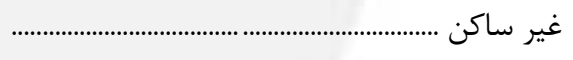 \\
\hline IfIfS & rras. & rTAFA & F्IITD & 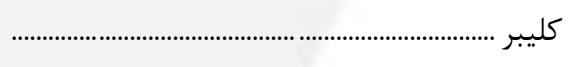 \\
\hline r६६9 & D91T & 9ITV & Ir.rq & ساكن در نقاط شهرى ..... \\
\hline 1. PVG & 19991 & $|V F| \Lambda$ & $M F \cdot 1 q$ & ساكن در نقاط روستايى \\
\hline $1 \cdot 491$ & IrAMEF & irrvte. & TETG. r & 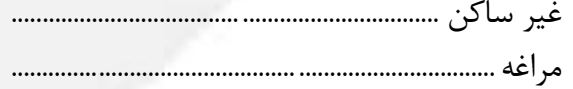 \\
\hline$\Delta \Delta \Delta r$. & 11тrq & $\Lambda \wedge \vee F$. & $1 V v \cdot v q$ & 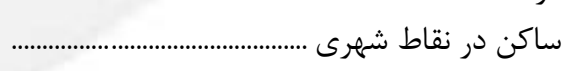 \\
\hline rFYr. & $r \cdot \Delta r \Delta$ & prqq9 & $\Lambda \Delta \Delta Y F$ & 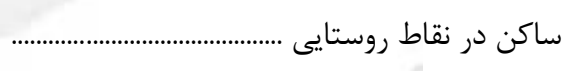 \\
\hline 1 & & & 1 & 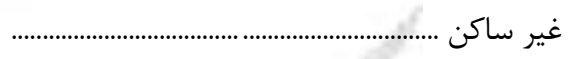 \\
\hline VarII & IT. Tra & ITESTE & TEFqVI & مرند...................................... \\
\hline FArQG & $v 91 \cdot r$ & vara. & $1 \Delta \varphi \cdot \Delta r$ & ساكن در نقاط شهرى ... \\
\hline trfite & erater & farqd & $\wedge \wedge 91 \vee$ & ساكن در نقاط روستايى \\
\hline 1 & $\cdot$ & 1 & 1 & غير ساكن ......................... \\
\hline rroqA & $\Delta r \varepsilon \Delta \mu$ & DV\&\&4 & 111419 & 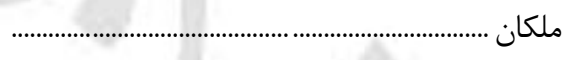 \\
\hline IIVTV & $11 \mathrm{~V} \cdot r$ & $190 F$ & ThkT & 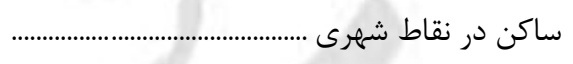 \\
\hline rIAVI & $\mu<q \Delta$. & rNITS & $V r \cdot V \varepsilon$ & 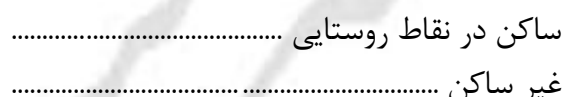 \\
\hline$\Delta V \& 9 \Delta$ & $11<q 4$ & $q \leftrightarrow r \Delta \Delta$ & INTAFA & 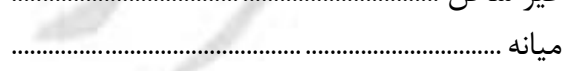 \\
\hline 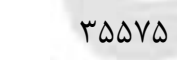 & $\Delta \varphi \cdot V v$ & $0 \wedge 919$ & 114999 & 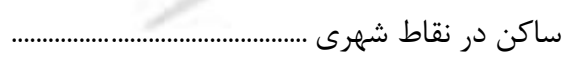 \\
\hline$r r \cdot 19$ & refig & raFto & 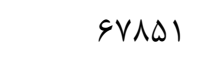 & 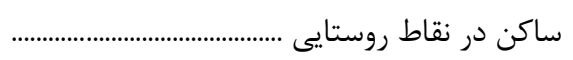 \\
\hline 1 & $\cdot$ & 1 & 1 & 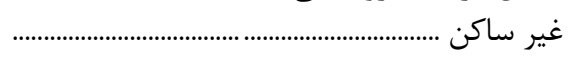 \\
\hline
\end{tabular}


ط - جمعيت و خانوار شهرستانهاى كشور به ترتيب استان (دنباله)

\begin{tabular}{|c|c|c|c|c|}
\hline خانوار & 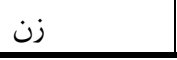 & 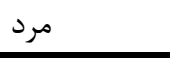 & جمعيت & شرح \\
\hline$r \cdot q \mu q$ & rervl & TEVTT & 99.94 & 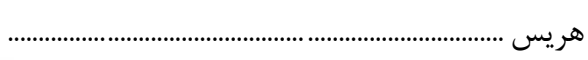 \\
\hline 994. & 19vra & $19 V \cdot V$ & rmete & ساكن در نقاط شهرى .............. \\
\hline 1.999 & IVET & $11 \cdot 10$ & $r \Delta S \Delta V$ & ساكن در نقاطروستايى ........ \\
\hline & & $\cdot$ & & 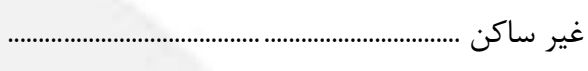 \\
\hline IVIVT & rraql & 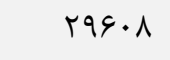 & $\Delta \vee 199$ & 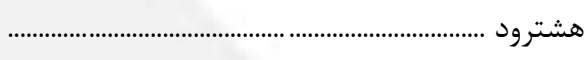 \\
\hline$q 4 \cdot F$ & $1.9 \Delta \pi$ & 111rr & tIVAV & ساكن در نقاط شهرى ............ \\
\hline $1 \cdot \operatorname{vaq}$ & 19941 & INFE & rQFit & ساكن در نقاط روستايى .................. \\
\hline & & $\cdot$ & & غير ساكن .......................... \\
\hline ISTVY & raqrq & $r v \cdot .1$ & DTSD. & ورزقان ........................................ \\
\hline TFE & 19119 & FaIt & $\wedge \vee \cdot 1$ & 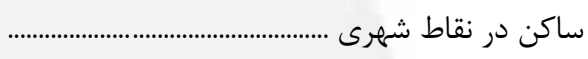 \\
\hline IrNHY & rlks. & TrYAQ & rrqpq & ساكن در نقاط روستايى ...... \\
\hline$q \pi \Delta q \Delta \varepsilon$ & $19.99 .$. & 19DAria & regaria & 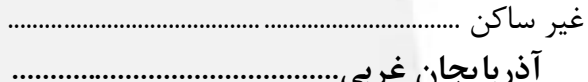 \\
\hline gmाl.r & $1 . \Delta 99 \mu 1$ & $1 \cdot V 9 \Delta \& \Delta$ & 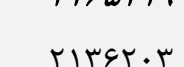 & ساك. د. نقاط شبع تربى \\
\hline r. FArt & DFVTET & $\Delta \Lambda I V T \Lambda$ & $11 \% 9 \ldots$ & ساكن در نقاط روستاط سهرى \\
\hline 19 & & 19 & 19 & 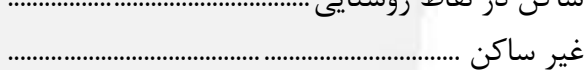 \\
\hline$r \cdot \kappa r \cdot \varphi$ & DITTAV & DTVTVA & $1 \cdot F \cdot \Delta 9 \Delta$ & اروميه .................................. \\
\hline trat. & rVtrav & TVGFYA & $V \Delta \cdot \Lambda \cdot \Delta$ & ساكن در نقاط شهرى ....... \\
\hline$v \Delta 1 \ldots$ & 1т人я. & $1 Q \cdot \wedge r \Delta$ & 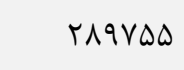 & ساكن در نقاط روستاير \\
\hline$\Delta$ & & $\Delta$ & $\Delta$ & 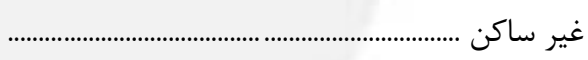 \\
\hline 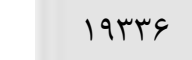 & req91 & rVIAN & 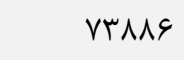 & 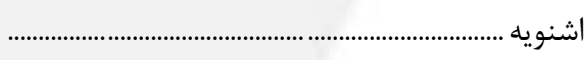 \\
\hline llFts & ritra & rIfFq & errVte & ساكن در نقاط شهرى . \\
\hline マ^११ & larrr & lQVrq & rIII & ساكن در نقاط روستايم \\
\hline VETQ. & $\mid r F \cdot r$. & IrVrVq & $r \Delta / F \cdot q$ & 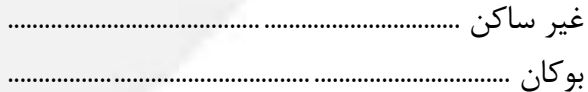 \\
\hline DVTIY & $99 \Delta T 1$ & qATrब & $194 \lambda+8$ & 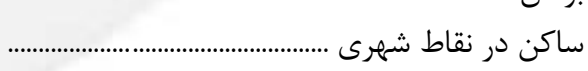 \\
\hline 19941 & $r v a \cdot q$ & $r q \cdot r \wedge$ & $\Delta \varphi \Delta \Delta V$ & 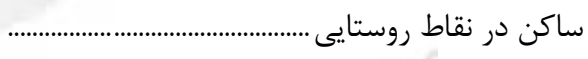 \\
\hline 4 & & 9 & 4 & 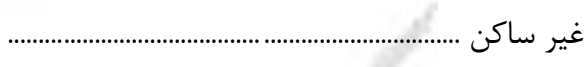 \\
\hline llarV & $r \cdot \Delta \& \Lambda$ & $r \mid 9 \cdot r$ & FTIV. & 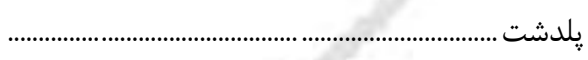 \\
\hline Gr. G & $r \cdot r \mu$ & vils & lfirq & ساكن در نقاط شهرى . \\
\hline 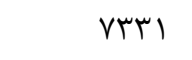 & Irata & IFYAS & $r \Lambda \cdot r \mid$ & ساكن در نقاط روستايي \\
\hline · & $\cdot$ & $\cdot$ & $\cdot$ & 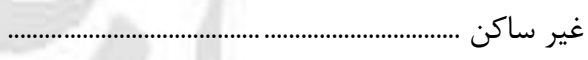 \\
\hline rFaG. & sV^ar & $V \cdot 94 V$ & IrMAG4 & 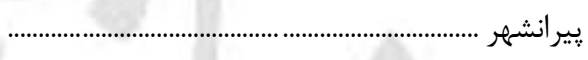 \\
\hline TYQYI & Fratl & $4 \wedge 190$ & $9 \Delta \vee 19$ & 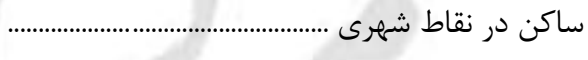 \\
\hline $1 \cdots 19$ & $r \cdot r v e$ & TTVRT & FIFA & ساكن در نقاط روستايى...... \\
\hline tritat & $r \cdot r+1$ & L. rTa & $\Lambda \cdot \Delta \Delta \varphi$ & $\ldots \ldots \ldots \ldots \ldots \ldots \ldots$ \\
\hline IFrqq & revaq & TFAVA & kq৭V & 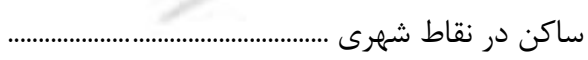 \\
\hline $911 \%$ & IDATr & larav & $r \cdot \wedge v q$ & 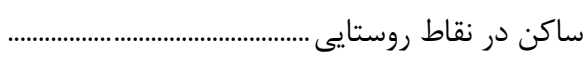 \\
\hline & . & & & غير ساكن ......... \\
\hline
\end{tabular}


ط ـ جمعيت و خانوار شهرستانهاى كشور به ترتيب استان (دنباله)

\begin{tabular}{|c|c|c|c|c|}
\hline خانوار & 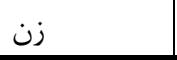 & 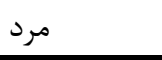 & جمعيت & 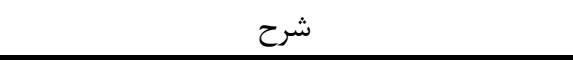 \\
\hline 1198. & TH. Tr & 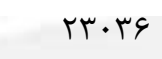 & $\varphi \Delta \cdot \varepsilon$. & 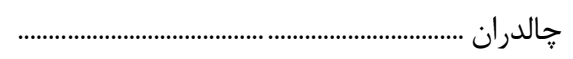 \\
\hline 0.94 & gert & $1 \cdots r$. & $1948 V$ & 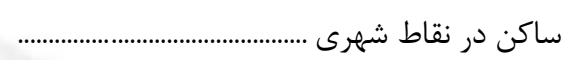 \\
\hline sАV & $15 \Delta 9 \mathrm{~V}$ & וгव9 & $r \Delta \Delta q$. & 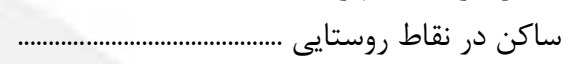 \\
\hline r & & r & r & 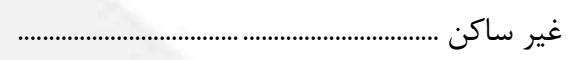 \\
\hline IrRIN & trets & $r F \cdot V I$ & pVrqu & 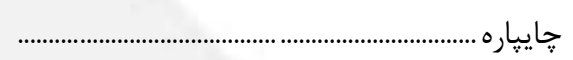 \\
\hline V119 & $|\pi| \cdot 1$ & 14949 & T\&VGV & 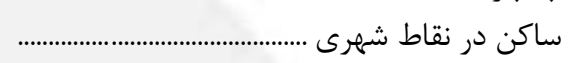 \\
\hline$\Delta \wedge 99$ & 1.15 & $1 \cdot r \cdot \Delta$ & $r \cdot \Delta T \Delta$ & 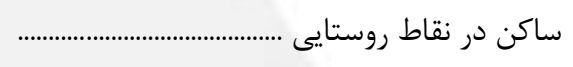 \\
\hline & & & & 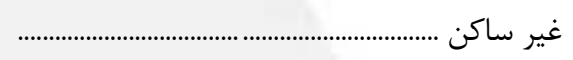 \\
\hline $1.11 r$. & IVr.r. & IVGGTF & MFAGGY & 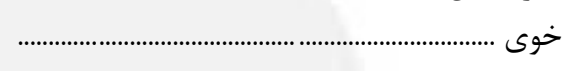 \\
\hline GVFAF & $11 \pi r 99$ & $11 \pi \Delta 9 \Delta$ & TRDQTI & 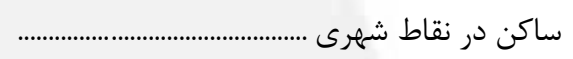 \\
\hline MrgFy & $\Delta 9994$ & $\Delta r \cdot s V$ & ITrVTI & ساكن در نقاط روستايى ........ \\
\hline r & . & r & r & 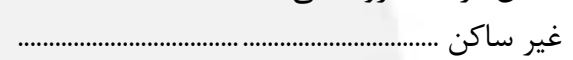 \\
\hline m. & $\Delta \Lambda r^{c} \cdot r$ & G. FFV & $1114 k 9$ & سردشت .................................... \\
\hline $\mid$ | & rmatr & TFATQ & 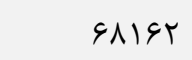 & ساكن در نقاط شهرى ........ \\
\hline $1 r 911$ & rerra & rQQIT & $0 \cdot 9 \Lambda \mathrm{V}$ & 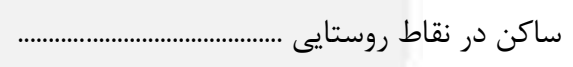 \\
\hline$\Delta \mu q \cdot V$ & $9 \Delta v r q$ & $1 \cdots 11 V$ & $199 \Delta F 9$ & 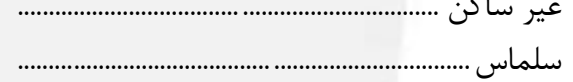 \\
\hline$r 9 \Delta \ldots$ & eqrag & DTIFF & $1.1 \mathrm{kF}$. & ساكن در نقاط شهرى . \\
\hline TFY.V & keferr & FA\&VK & $901 \cdot 9$ & ساكن در نقاط روستايى ............ \\
\hline & & & & 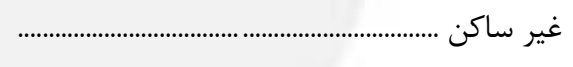 \\
\hline rV\&૬q & $F \Delta 99 \Delta$ & faral & GTFAS & 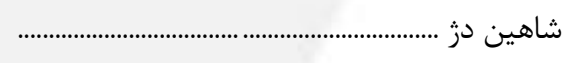 \\
\hline $194 \cdot 9$ & rq991 & TVISV & $\Delta F I T \Delta$ & ساكن در نقاط شهرى ..... \\
\hline $11 F 9$. & $19 \cdot r V$ & 19Y9F & rArti & ساكن در نقاط روستايى . \\
\hline lQVQS & repar & r^rq. & DQSAT & غير ساكن .......................................................... \\
\hline V^s। & IMGK. & $\mid f \cdot r \Delta$ & TVGVD & 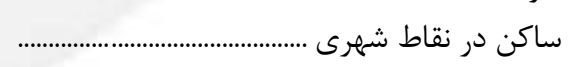 \\
\hline$\vee \wedge 9 \Delta$ & meat & IFrad & $r \wedge \cdot \cdot v$ & 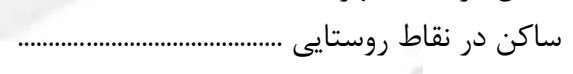 \\
\hline$r r \cdots q$ & kqIrs & FASTH & qYVDI & 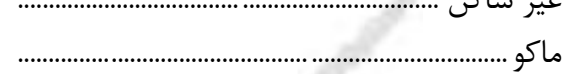 \\
\hline 19914 & rras. & rq... & $\Delta \varphi \Delta \varphi$. & ساكن در نقاط شهرى .... \\
\hline $1 \ldots r s$ & $11 \Delta 91$ & 1994T & rی191 & ساكن در نقاط روستايى \\
\hline & $\cdot$ & · & · & 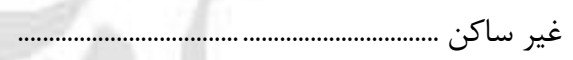 \\
\hline 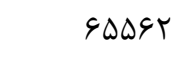 & ||$V \Delta F \mid$ & $1194 \cdot 1$ & rmeNFq & مهاباد ..................................... \\
\hline $4 \lambda \cdot q 4$ & 1kreg & AFVY & $1991 \% 4$ & ساكن در نقاط شهرى ....... \\
\hline $1 V+49$ & rriva & TFATT & $q V V \cdot V$ & 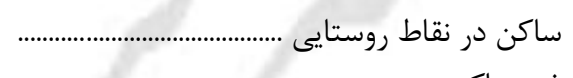 \\
\hline NMrme & Iregar & IfIrag & rVrqpq & 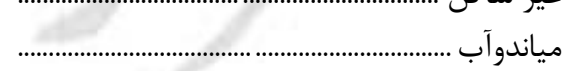 \\
\hline$F \Delta \Delta q \vee$ & VTFIT & VDGFT & $\mid \psi \lambda \cdot \Delta s$ & 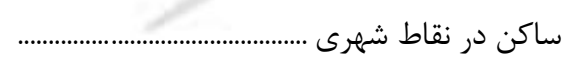 \\
\hline rVGry & G. rk. & gDGQT & 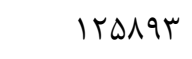 & 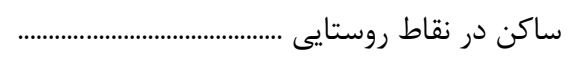 \\
\hline$\cdot$ & $\cdot$ & & & 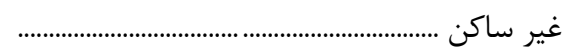 \\
\hline
\end{tabular}


ط - جمعيت و خانوار شهرستانهاى كشور به ترتيب استان (دنباله)

\begin{tabular}{|c|c|c|c|c|}
\hline خانوار & 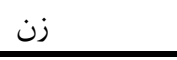 & 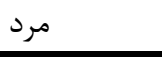 & جمعيت & شرح \\
\hline rVYAl & $9 \mu \cdot 1 r^{c}$ & 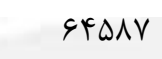 & $|r V G V|$ & نقده ................................ \\
\hline TVTAV & Farrs & 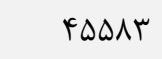 & 9.911 & 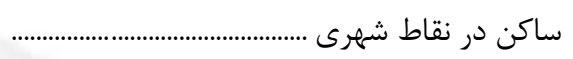 \\
\hline 1.TYK & Irras & $19 . .4$ & revG. & 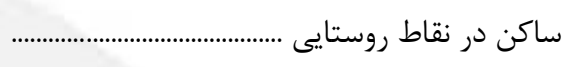 \\
\hline & & & & 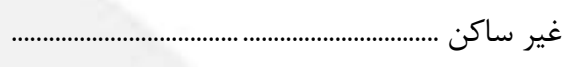 \\
\hline rYVFrt & \&r. 19d & QQ. TAD & IrY.Fr. & 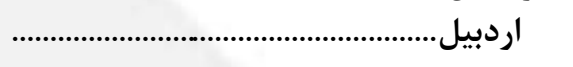 \\
\hline 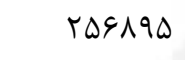 & cra.l. & FFI. TF & $\Lambda \notin 9 \cdot \mu \mathrm{K}$ & 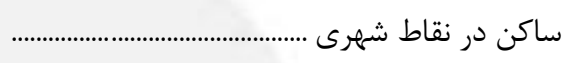 \\
\hline$|r \cdot Y \lambda|$ & $190 \cdot 10$ & $r .9101$ & f. erre & ساكن در نقاط روستايى ............ \\
\hline iv & $r$. & $\wedge$. & 10 . & 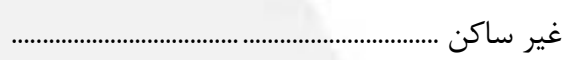 \\
\hline $11 \cdot 9 \vee \Delta$ & ragris & $r \cdot 9 \Delta \cdot r$ & G. & 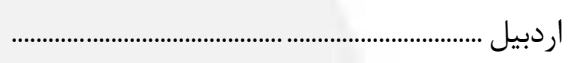 \\
\hline $1 \Delta 9 r \cdot \Lambda$ & $r 91.1 r$ & 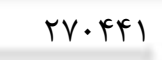 & DHIFAF & 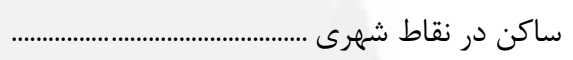 \\
\hline rI\&90 & raFVa & rq. & VFarg & 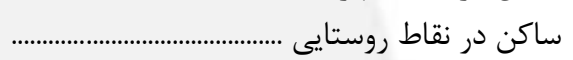 \\
\hline r & & r & r & 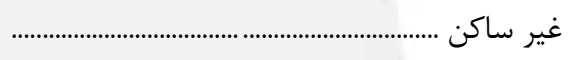 \\
\hline $1011 \%$ & reqge & reft. & $\Delta \mid F \cdot F$ & 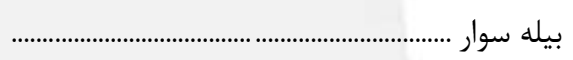 \\
\hline gAve & ||$\Delta r \mid$ & $11 \wedge 94$ & trmile & 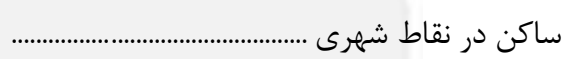 \\
\hline 1199 & irrver & IFEV. & trAkt & 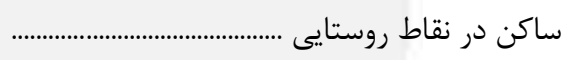 \\
\hline fr & $r$ & VV & IfV & 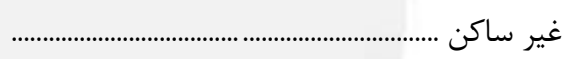 \\
\hline$\Delta \cdot \cdots$ & 1D\&Fa & $919 \Delta 9$ & IVVG.। & 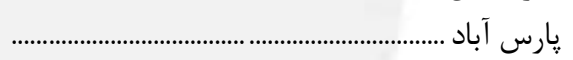 \\
\hline$r a 1 \cdot 4$ & DITAD & $\Delta F \cdot q r$ & $1 \cdot \Delta r V \Lambda$ & 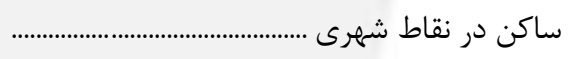 \\
\hline$r \cdot r \Lambda \cdot$ & rete. & rVAGT & VTYTT & 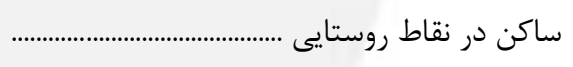 \\
\hline & & 1 & 1 & 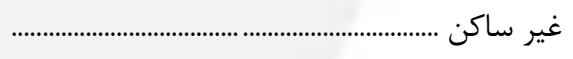 \\
\hline reVVq & erge. & frrql & A\&VTI & 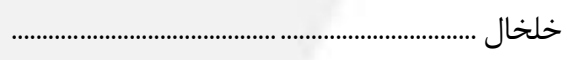 \\
\hline If. & Trgat & rrgqF & prrve & ساكن در نقاط شهرى ... \\
\hline $14 V I 9$ & $19 r \Delta 1$ & $r \cdots q V$ & rqтыd & 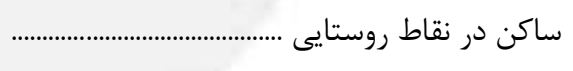 \\
\hline & & & & غير ساكن ............................... \\
\hline QrTh & $194 \mathrm{~F}$ & $9 \Delta \Delta T^{2}$ & $M \Lambda T^{\prime} \cdot$ & 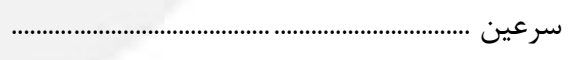 \\
\hline IDAT & $r \Delta \Lambda 1$ & rAVA & $\Delta F \Delta q$ & 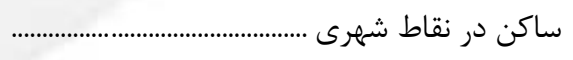 \\
\hline TVDS & 9.99 & GQVD & $|r V F|$ & 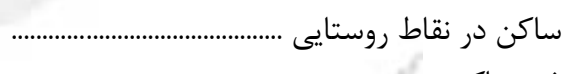 \\
\hline $9 \Delta \wedge \varphi$ & $1 \cdot 1+1$ & $11 \pi \cdot 9$ & tTITV & كوثر ................................................. \\
\hline tINT & roFA & radr & $\checkmark 1 \cdot 1$ & ساكن در نقاط شهرى .... \\
\hline fF. & vrVt & VVAT & $10 \cdot r q$ & ساكن در نقاط روستايى . \\
\hline & $\cdot$ & $\cdot$ & • & 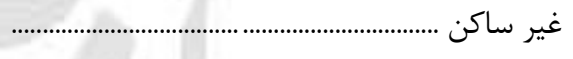 \\
\hline rtrkq & rvasq & r人१५ه & v9q.1 & 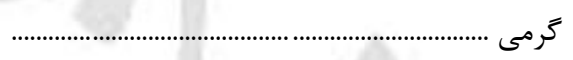 \\
\hline $9 \cdot 94$ & lakit & 19119 & migit & 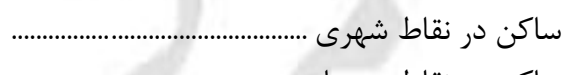 \\
\hline ITTOV & rTKAT & $r r \Lambda \cdot 9$ & FarAq & غاكن در نقاط روستايى ...................................................... \\
\hline TFF. F & ra1ra & fIVVo & $119 \cdot 4$ & 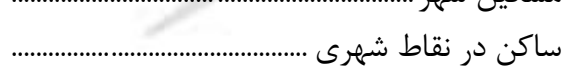 \\
\hline r)०90 & rertis & $r \Delta \cdot 9 \varphi$ & 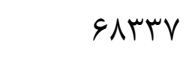 & 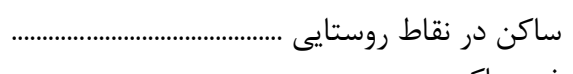 \\
\hline & & & & 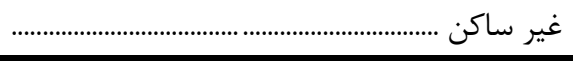 \\
\hline
\end{tabular}


ط ـ جمعيت و خانوار شهرستانهاى كشور به ترتيب استان (دنباله)

\begin{tabular}{|c|c|c|c|c|}
\hline خانوار & 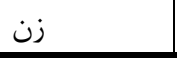 & مرد & جمعيت & شرح \\
\hline IVArs & rasva & $\mu \cdot \lambda r$ & 9.909 & 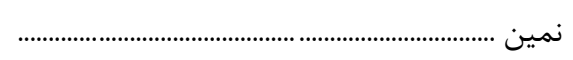 \\
\hline vgky & Irvas & IrItes & rDQTT & 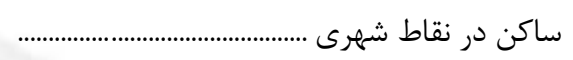 \\
\hline 1.197 & $19 V 19$ & IVqrA & TFVTV & 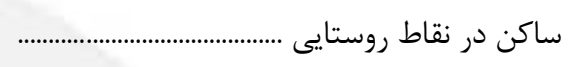 \\
\hline & & & & 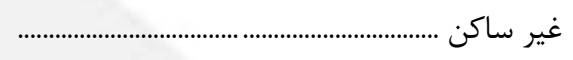 \\
\hline GTGF & $1 \ldots 19$ & $1 \cdot \wedge r \Delta$ & $r \cdot \Lambda \varepsilon q$ & 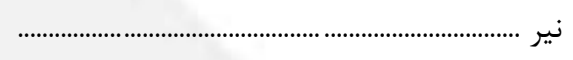 \\
\hline $194 \mathrm{~F}$ & reat & TETT & $q V \cdot r$ & 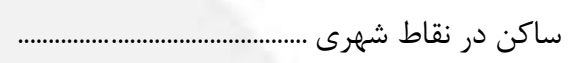 \\
\hline FeIV & svrV & VETr & 1419. & 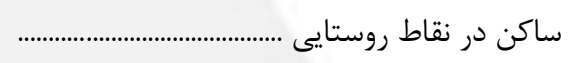 \\
\hline & & & & 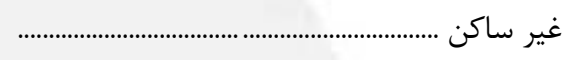 \\
\hline 19.VFAT & rarirrr & roqqqVV & $\Delta / r \cdot 1 \Delta$. & 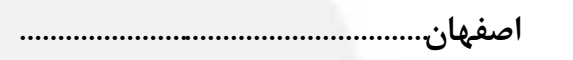 \\
\hline IFUIGTF & rrta.r. & TrAKTAQ & $r \Delta \cdot V r \cdot q$ & 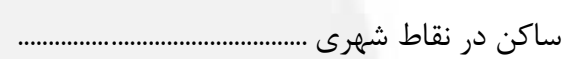 \\
\hline $190 \mathrm{~V} \cdot 1$ & ragirt & r19901 & $91 r \cdot V r$ & 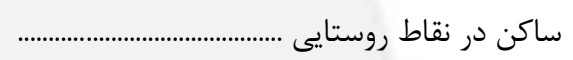 \\
\hline $1 \Delta V$ & rel & tru & $\forall \& \Lambda$ & 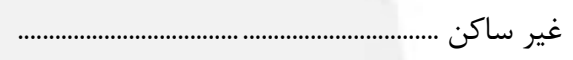 \\
\hline$r r^{\prime} \Delta \cdot$ & $\Delta \cdot \Lambda \vee \mu$ & DYGFE & I.rDIV & 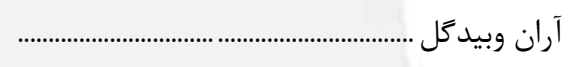 \\
\hline TVD.G & $\mu q . . r$ & 80.19 & Na.tr & 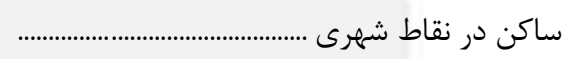 \\
\hline FQFF & sır. & VAYD & IFFqD & 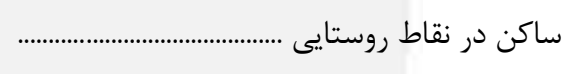 \\
\hline$|f| k$. & $r \cdot 1 r^{r}$ & rITAI & $\mid F Y l \cdot D$ & اردير ساكن ............................................................ \\
\hline Nart & Irrat & $\mid f \cdot . v$ & rrVqI & ساكن در نقاط شهرى ....... \\
\hline$\Delta r I \Lambda$ & $V \cdot \kappa \cdot$ & VTVE & IfTIF & 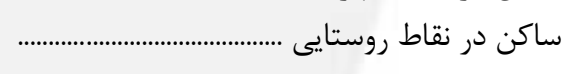 \\
\hline & & & & غير ساكن ........................... \\
\hline$\vee \cdot \vee \wedge \vee \cdot$ & $11 \cdot 91 \cdot r$ & llrmfte & FYFMYTA & 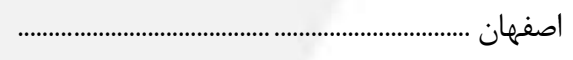 \\
\hline G94ATK & 1.4999. & $1 \cdot 94 \cdot V \mathrm{~V}$ & TIITVGV & ساكن در نقاط شهرى ...... \\
\hline (I) ru & $9 \mu l \cdot v$ & GVTOF & $|r \cdot 4 \varepsilon|$ & 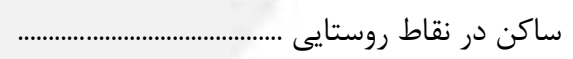 \\
\hline 11 & 9 & 10 & rI & 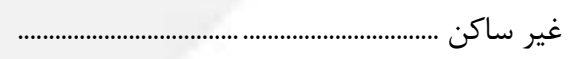 \\
\hline rVGrt & $\Delta 9 \pi /$. & $941 \cdot 9$ & ITTFI9 & 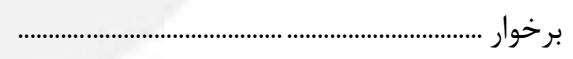 \\
\hline rFqrA & DarAT & $\Delta \wedge \Delta 9 T$ & IIrAva & ساكن در نقاط شهرى ..... \\
\hline r990 & $r \cdot r v$ & FOIV & NQFF & 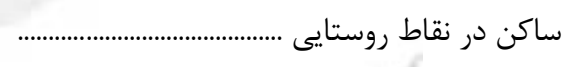 \\
\hline$\Lambda \cdot r q$ & $111 \mathrm{Vr}$ & $|r r q|$ & TYIST & بويين و مياندشت...................... \\
\hline FrqD & sVVF & 9111 & $\mid r \Delta \wedge \Delta$ & ساكن در نقاط شهرى .. \\
\hline एदा & $\Delta \cdot 91$ & $\Delta F \wedge$. & $1 \cdot \Delta V \wedge$ & 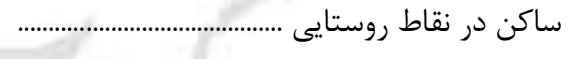 \\
\hline & & & $\cdot$ & 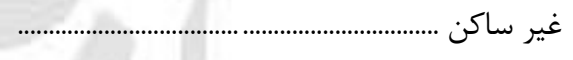 \\
\hline$T T R \cdot t$ & MFAVF & $r \varepsilon V \cdot 1$ & VIDVA & 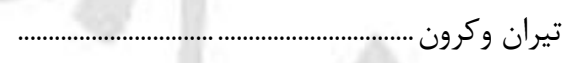 \\
\hline $9 \Delta \Delta \Delta$ & IFAFV & IOHT. & $r \cdot 19 \mathrm{~V}$ & ساكن در نقاط شهرى ........ \\
\hline$|M| F \lambda$ & $r \cdots r v$ & rirva & $4 \mid f \cdot \varphi$ & ساكن در نقاط روستايى .... \\
\hline 914r & $109 r \Delta$ & $19 \Delta \Delta F$ & rTEVQ & حادگان .......................... \\
\hline FTVA & $V \cdot q V$ & $\vee 1 \wedge 9$ & IFTAG & 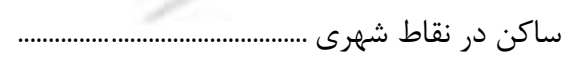 \\
\hline$\Delta \Delta \Delta \Delta$ & $1 \wedge \Delta \Lambda$ & $94 \& \Delta$ & INYTr & 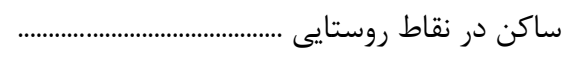 \\
\hline$\cdot$ & $\cdot$ & $\cdot$ & & غير ساكن ............... \\
\hline
\end{tabular}


ط ـ جمعيت و خانوار شهرستانهاى كشور به ترتيب استان (دنباله)

\begin{tabular}{|c|c|c|c|c|}
\hline خانوار & 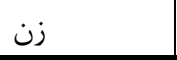 & 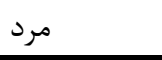 & 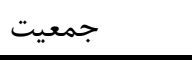 & 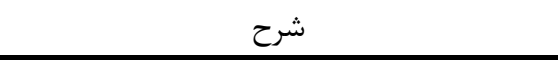 \\
\hline $914 \% 9$ & lakqk. & IGFVAV & MIQVTV & 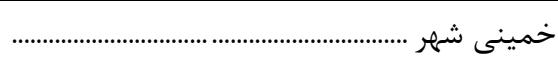 \\
\hline १९৯५ & IargVV & IGTrVD & 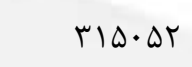 & 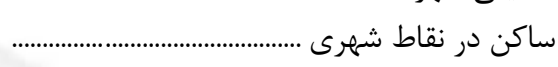 \\
\hline Ifre & rrat & TFIT & E\&Va & 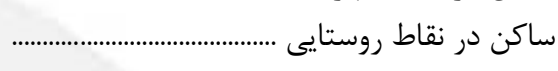 \\
\hline & . & - & & 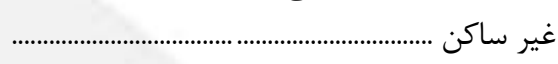 \\
\hline $1.9 \pi 4$ & $199 \cdot r$ & IEFYs & $r$ req & 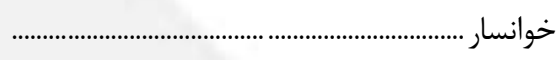 \\
\hline$V \cdot 94$ & 11199 & $1.91 \mathrm{~F}$ & TIANY & 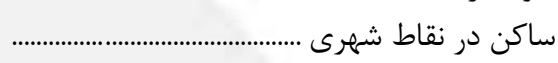 \\
\hline ז人ז & $\Delta F \cdot F$ & DVGT & 11199 & 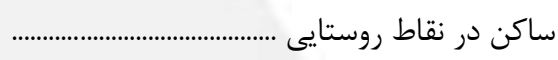 \\
\hline & & • & & 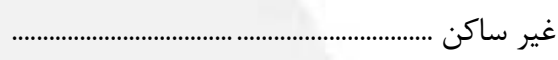 \\
\hline gFt. & qrat & १९४ & 19v81 & 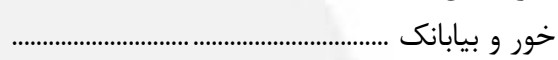 \\
\hline FaqF & $V 199$ & VTrq & $\mid k r q 1$ & 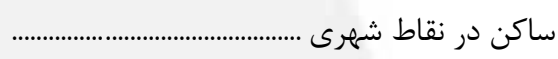 \\
\hline INTE & rela & TYYA & DrGT & ساكن در نقاط روستايى ............. \\
\hline & $\cdot$ & • & & 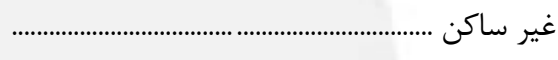 \\
\hline 11111 & leqk. & $|V \Delta V|$ & rFall & 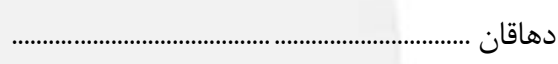 \\
\hline VATS & $11 \mathrm{krr}$ & 11949 & trrat & ساكن در نقاط شهرى .......... \\
\hline rQqT & $\Delta \Delta \cdot V$ & DGT & 11119 & 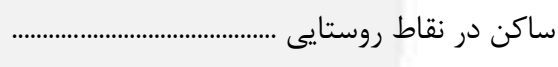 \\
\hline rrar. & 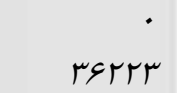 & 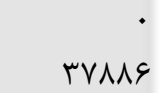 & $V \times 1.9$ & 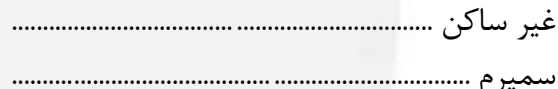 \\
\hline 11.99 & IVane & INITV & raVIr & 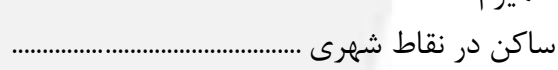 \\
\hline llTar & $\mid \Lambda F \Delta r$ & $199 .$. & $r \Lambda \cdot \Delta r$ & 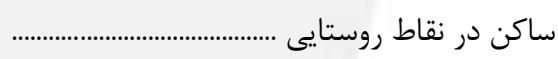 \\
\hline $1 \cdot 1$ & $111^{F}$ & 109 & ret & 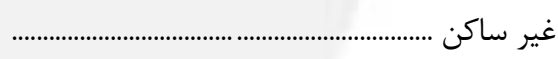 \\
\hline VrqAI & $11 \mathrm{Vr} \cdot$. & IIVESV & THESGV & شاهينشهروميمه ....................... \\
\hline gqfil & 11.991 & $11 \cdot 419$ & $T T \cdot \Lambda \Lambda V$ & ساكن در نقاط شهرى ....... \\
\hline FATI & garl & VTFD & IrVVe & ساكن در نقاط روستايى ........... \\
\hline r & 1 & r & r & 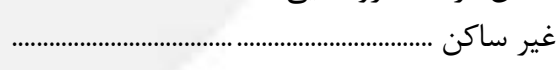 \\
\hline 0.914 & $r \wedge \mid \Delta V$ & NIsk. & lo9v9V & 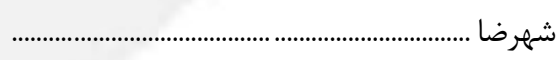 \\
\hline FAVTr & $v \cdot \mu \mu$. & VIVAs & $\mid$ ETIIS & 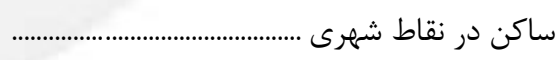 \\
\hline$\Delta T \Delta \Delta$ & vara & $9 \wedge \Delta 1$ & IVGVG & 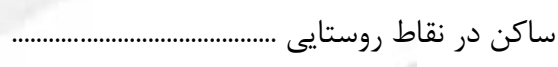 \\
\hline 1 & & r & $\Delta$ & 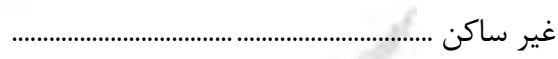 \\
\hline IQDFV & TKT.D & 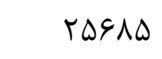 & pq८q. & 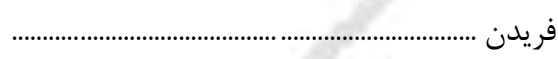 \\
\hline VTET & 11194 & ITADT & TfFet & ساكن در نقاط شهرى .. \\
\hline$\Lambda T \& \Lambda$ & ITrVa & $14 \cdot \wedge 9$ & TDHGF & ساكن در نقاط روستايم \\
\hline 19 & r & fr & NT & 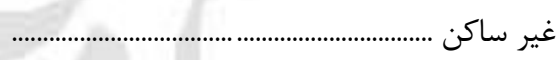 \\
\hline 1.911 & IVANT & $|\Lambda| V \mid$ & $r \Delta G \Delta F$ & 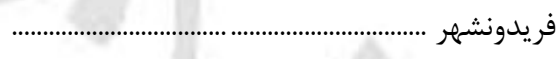 \\
\hline$\Delta q r$. & $q \mu k V$ & १९५ & $1 \wedge 9 \wedge 0$ & ساكن در نقاط شهرى ...... \\
\hline FVaA & $11 \pi 8$ & rar & 19999 & ساكن در نقاط روستايى .... \\
\hline RVTIT & $|r| \cdot r q$ & ITAVAD & rFq1IF & فلاورجان ........................................... \\
\hline DIFFT & $1111 \mathrm{~V}$ & NATTD & ISVTFT & 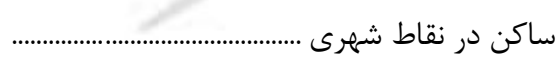 \\
\hline rovr. & rag1r. & FTAG. & NTFVT & 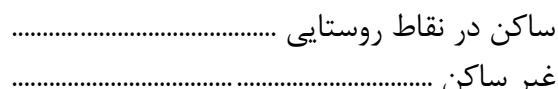 \\
\hline
\end{tabular}


ط - جمعيت و خانوار شهرستانهاى كشور به ترتيب استان (دنباله)

\begin{tabular}{|c|c|c|c|c|}
\hline خانوار & 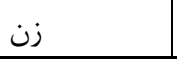 & 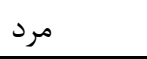 & جمعيت & 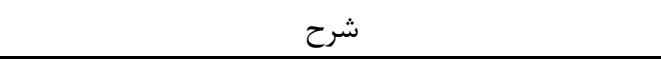 \\
\hline IITTQA & IV99V9 & $\mid \Lambda F \lambda \cdot 9$ & TEFANT & 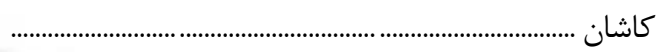 \\
\hline $99 \Delta ९ 9$ & 191099 & $19 \Delta \& F V$ & TTYTET & ساكن در نقاط شهرى .......... \\
\hline IrGAS & $11 \cdot 1$ & $191 \Delta 9$ & rVTre & ساكن در نقاط روستايى ........ \\
\hline r & · & r & r & 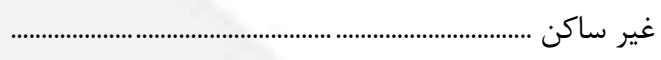 \\
\hline$r \cdot 419$ & FFIVI & 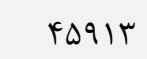 & $9 \cdots \wedge \varsigma$ & 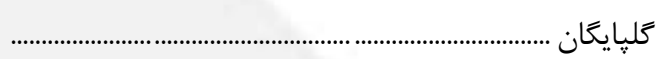 \\
\hline rFq\&A & rял1r & rV৭९৭ & $V F \wedge \Delta T$ & ساكن در نقاط شهرى . \\
\hline DFFV & vrq. & var. & IOTR. & ساكن در نقاط روستايى ............... \\
\hline r & $\cdot$ & r & r & 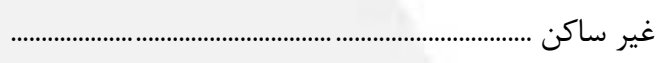 \\
\hline $111 \cdot 1$ & Irarab & IrTSQV & rबrqाז & 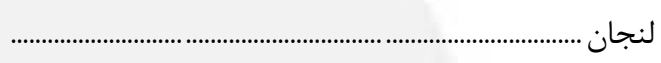 \\
\hline VTDVV & $11091 \%$ & $119 \Delta \mathrm{H}^{\circ}$ & TrQFFA & (2) \\
\hline NQTK & I MEFT & $|r \cdot r|$ & TVEAT & ساكن در نقاط روستايم \\
\hline 1 & & 1 & 1 & 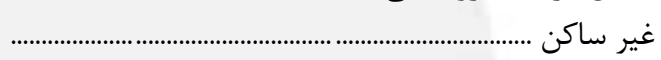 \\
\hline feqre & Vufir & $V V \cdot r q$ & $\mid Q \cdot F+1$ & 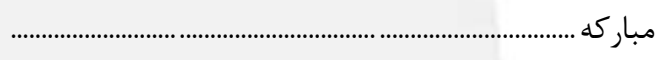 \\
\hline ґА१১৯ & $91 \cdot V \Delta$ & GrADF & IFFqTq & ساكن در نقاط شهرى \\
\hline v911 & Irerg & ITIVD & $r \Delta \Delta I T$ & ساكن در نقاط روستاي \\
\hline irrvi & 19яke & 19911 & rqrqi & غير ساكن ............................................................ \\
\hline 1.rq. & $1 \Delta \Delta V \mu$ & IDSAV & TITS. & ساكن در نقاط شهرى \\
\hline$r \cdot \wedge v$ & $r \cdot v$. & ган. & $\wedge \cdots$ & ساكن در نقاط روستاير \\
\hline 1 & & 1 & 1 & 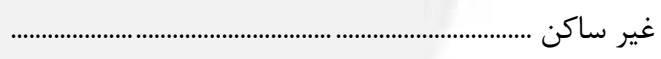 \\
\hline 9АD। & $\left.\left|\Delta V F^{\prime}\right|\right|^{\prime}$ & $|\varepsilon| V 9 \mid$ & 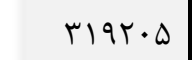 & 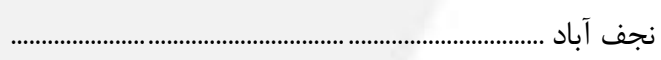 \\
\hline$q \cdot \wedge+\Delta$ & IFATAS & $|f \wedge 9|$. & rqYTQD & ساكن در نقاط شهرى . \\
\hline Vฯฯ4 & $15 \cdot r 9$ & IrAvq & $r r q \cdot \Lambda$ & ساكن در نقاط روستايم \\
\hline r & & r & $r$ & غير ساكن ........................... \\
\hline $1 F 909$ & rI\&sa & TrMtt & ктq४у & نطنز ........................................... \\
\hline $11 \cdot \wedge \mathrm{V}$ & $19 v+9$ & $19 \wedge 11$ & Treiv & ساكن در نقاط شهرى . \\
\hline rAVt & kare & DFHF & $1 \cdot r 4$. & ساكن در نقاط روستايم \\
\hline 1DFाl & Irrg.ed & Irverta & roirfe. & عير سالب............................................... \\
\hline$V q \mu \cdot r F$ & ITFIGMA & $|r V| \cdot 99$ & TAITVRY & ساكن در نقاط شهرى \\
\hline 9५990 & qFrre & $1 . \Delta 1 \Lambda 1$ & $199 \Delta \Delta 9$ & ساكن در نقاط روستايي \\
\hline १४ & $k q$ & $\Delta \Delta$ & $1 \cdot r$ & 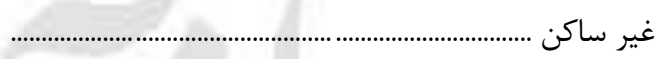 \\
\hline$|1 V r|$ & $|14 r|$ & $199 \cdot 0$ & rVAVG & 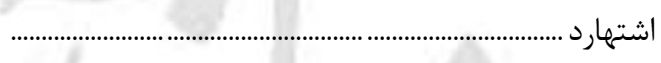 \\
\hline$q \pi \Delta V$ & $\mid F \Delta \Delta \Lambda$ & IDFTE & ५१९१५ & ساكن در نقاط شهرى ... \\
\hline & reir & 4199 & VANT & ساكن در نقاط روستا \\
\hline$\Lambda \cdot 9 \Delta \mu$ & lregr. & 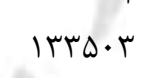 & rब११७r & $\ldots$ \\
\hline DTEYQ & 1rval & $\wedge V \Delta \cdot 9$ & ivir.. & 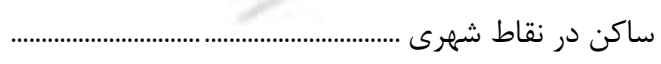 \\
\hline rArA. & ererg & $F \triangle 9 \wedge \Lambda$ & MAৎT১ & 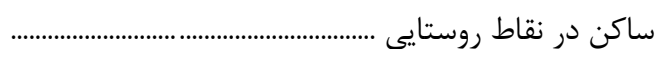 \\
\hline if & kr & 4 & $i \wedge$ & $\ldots \ldots \ldots \ldots \ldots \ldots \ldots \ldots \ldots \ldots \ldots \ldots \ldots \ldots \ldots \ldots . . . \cdots \cdots$ \\
\hline
\end{tabular}


ط - جمعيت و خانوار شهرستانهاى كشور به ترتيب استان (دنباله)

\begin{tabular}{|c|c|c|c|c|}
\hline خانوار & 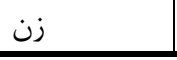 & 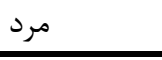 & جمعيت & شرح \\
\hline graF & 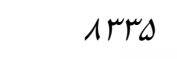 & $\wedge \uparrow \wedge$. & 19110 & 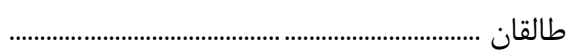 \\
\hline$|r F|$ & IVra & 1119 & rafa & ساكن در نقاط شهرى .................................. \\
\hline DIIT & $99 \cdot 9$ & 9994 & IrTr. & 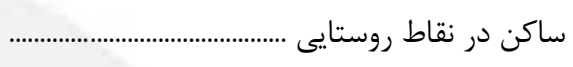 \\
\hline · & . & • & & 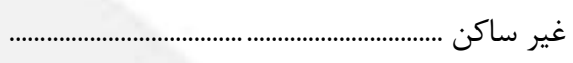 \\
\hline 19919 & $|r a| k V$ & IrGGAT & TRINTQ & 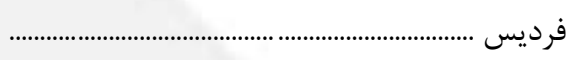 \\
\hline VVD१V & $15 \cdot 991$ & |TTtII & TFTIV & 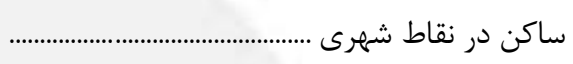 \\
\hline Q.rt & $141 \times 9$ & $|f \& V|$ & r^९D. & ساكن در نقاط روستايى ............ \\
\hline & . & • & & 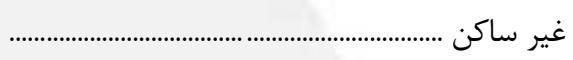 \\
\hline grru. & avrsi. & 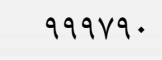 & 19VrFV. & كرج \\
\hline GIFTH & 909941 & $91 \cdot 9 \cdot 9$ & $19 F \cdot \Delta \Delta F$ & ساكن در نقاط شهرى ............ \\
\hline $9 \Delta q^{\prime}$ & Irvra & $191 \% 1$ & TrAGT & 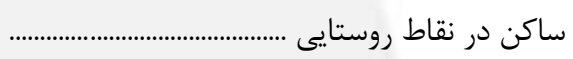 \\
\hline$\Delta 1$ & $r$ & is & $\Delta r$ & 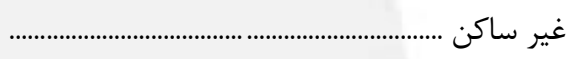 \\
\hline 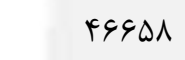 & VeIgr & VATVQ & DQTFTY & 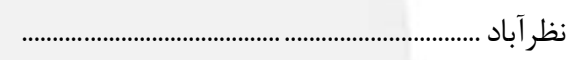 \\
\hline rvqva & G. GFF & GTATT & $|r F| 94$ & 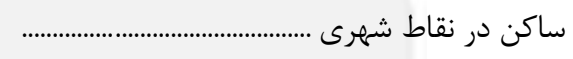 \\
\hline$\wedge \& \vee \wedge$ & $1 \mathrm{raIA}$ & $|F V \Delta|$ & rArsq & 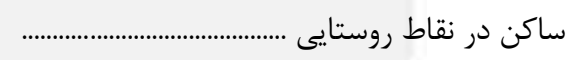 \\
\hline 1 & & r & r & 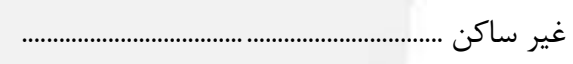 \\
\hline$|099|$. & rAFqD9 & r94199 & $\Delta \Lambda \cdot 1 \Delta \Lambda$ & 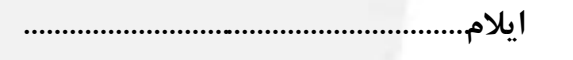 \\
\hline $1.994 \wedge$ & I IFAKF & $r \ldots+19$ & rqDTGK & 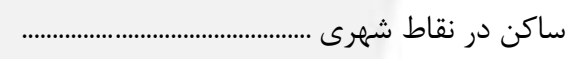 \\
\hline FqDFT & 19190 & $q F \Delta F q$ & IAFFFE & 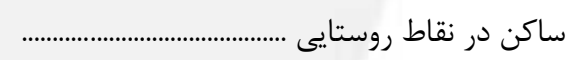 \\
\hline $1 \%$. & $r r$. & ו & $F \Delta I$ & 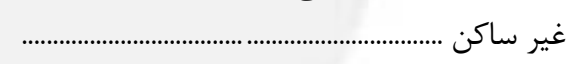 \\
\hline IrINA & refeqa & TFtat & FYADI & آبدانان ..................................... \\
\hline NFFy & l kqve & IDrqV & $r \cdot r v r$ & ساكن در نقاط شهرى ... \\
\hline fref & Aarr & $\wedge 9 \Delta \Delta$ & IVFVA & 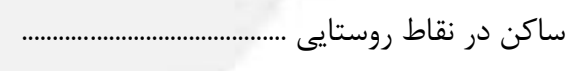 \\
\hline sष\&VI & $\| \Delta \wedge \Delta \mid$ & 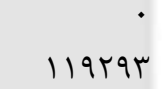 & THDIFY & 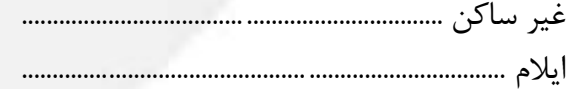 \\
\hline$\Delta Q I F T$ & $919 \mathrm{VF}$ & $1.111 \mathrm{~V}$ & 199191 & 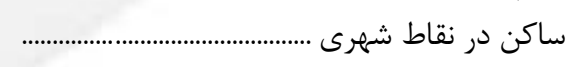 \\
\hline $9 \Delta / f$ & IVIar & $1 \Lambda \cdot V V$ & TLYT. & 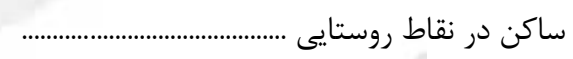 \\
\hline If & re & rq & $\Delta r$ & 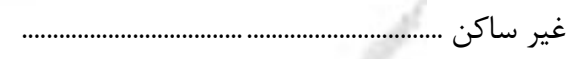 \\
\hline IrNT. & TEGTE & TFASV & $4 q 4 q 1$ & 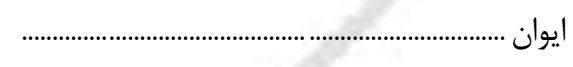 \\
\hline $9 \Delta 94$ & $18 \cdot .9$ & IVTDQ & TETED & ساكن در نقاط شهرى ..... \\
\hline Gt.r & rarı & $\vee \Delta \Delta \Lambda$ & 10148 & ساكن در نقاط روستايى . \\
\hline ry & r. & $\Delta \cdot$ & 9 . & 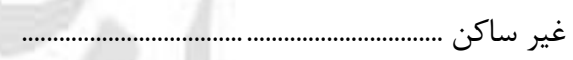 \\
\hline साl & rasq & VYFa & $|\Delta q| F$ & بدره \\
\hline IrFq & rinr & $r \cdot 9 \Delta$ & FrVA & 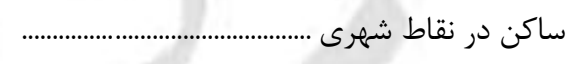 \\
\hline$r \cdot 9 r$ & $\Delta 919$ & $\Delta \varphi \Delta \cdot$ & 111re & 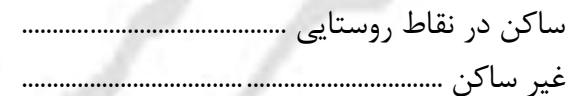 \\
\hline $\mid \Delta \wedge \& \vee$ & $r 1 \cdot 19$ & rqugr & $\Delta \vee r \wedge I$ & 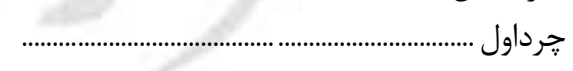 \\
\hline qヘF. & $|r| k \lambda$ & 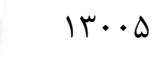 & TQIQT & 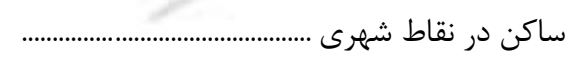 \\
\hline$q \cdot r \Delta$ & lo19V & IETof & TTtTI & 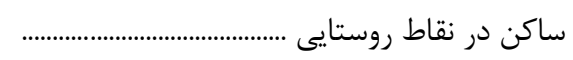 \\
\hline r & c & r & $v$ & 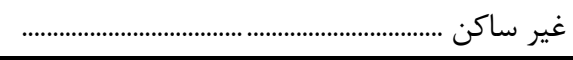 \\
\hline
\end{tabular}


ط ـ جمعيت و خانوار شهرستانهاى كشور به ترتيب استان (دنباله)

\begin{tabular}{|c|c|c|c|c|}
\hline خانوار & 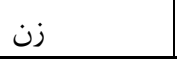 & 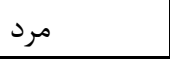 & جمعيت & 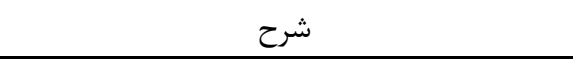 \\
\hline$M \cdot I r$ & riras & rtrie. & $k r v \cdot \Lambda$ & 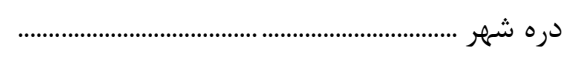 \\
\hline 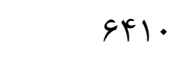 & ll ker & 11999 & trATIt & 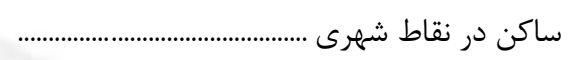 \\
\hline$\Delta G \cdot r$ & $99 \Delta \Delta$ & $1 \cdot r k 1$ & r.ras & 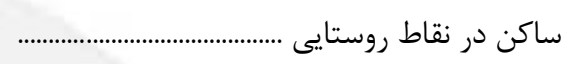 \\
\hline$\cdot$ & $\cdot$ & $\cdot$ & & 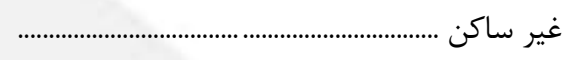 \\
\hline 19909 & rlagr & $r F \cdot q \Lambda$ & 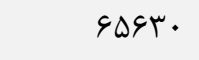 & 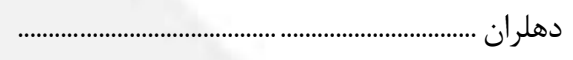 \\
\hline $11 k r$. & $r \cdot r l l$ & $r \cdot \wedge V r$ & fillk & 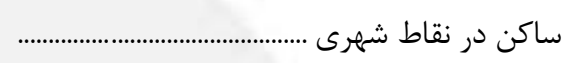 \\
\hline$\Delta \Delta I V$ & IITrV & 14199 & TFYG & 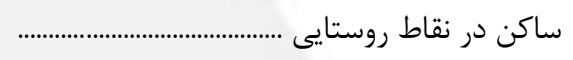 \\
\hline it & re & rV & $\Delta 1$ & 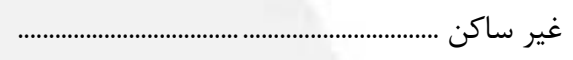 \\
\hline r919 & $v \cdot \Delta \Delta$ & VrFq & lFF. F & 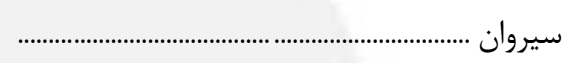 \\
\hline var & Ires & irv. & r৭१९ & 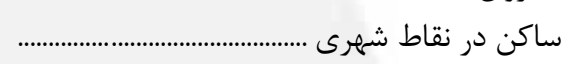 \\
\hline Trta & avrq & ఎq४q & $11 V \cdot \Lambda$ & ساكن در نقاط روستايى ............ \\
\hline & · & $\cdot$ & & 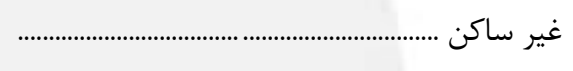 \\
\hline G.tr & 1.091 & $1 \cdot \Delta F V$ & thro & 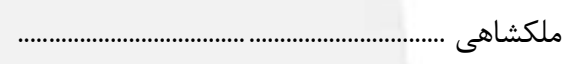 \\
\hline$p r \cdot q$ & $V \& V q$ & Vrrv & IFADS & ساكن در نقاط شهرى .......... \\
\hline$|9 V|$ & $r \cdot r \mu$ & $r \cdot 90$ & GITV & 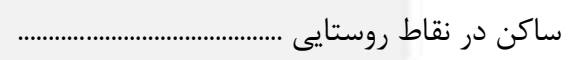 \\
\hline et & 1. & VQ & $10 \Delta$ & 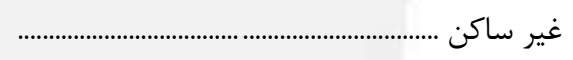 \\
\hline 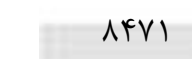 & $|k| q \mid$ & $1 \Delta r \cdot \varphi$ & rq४จ & 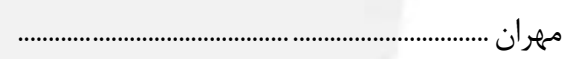 \\
\hline DFGS & $9 r 91$ & $9 \wedge \wedge \wedge$ & 19119 & 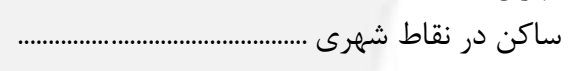 \\
\hline rqทq & $\Delta / F \Delta$ & $\Delta r Y$ & $1 \cdot 019$ & 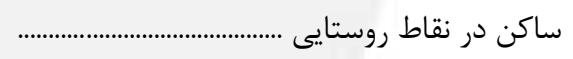 \\
\hline rq & \&A & iv & 90 & 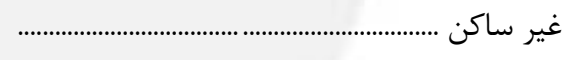 \\
\hline relate & DFYGVA & st.vrr & llert.. & 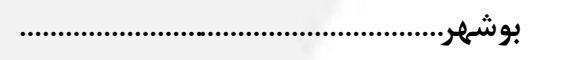 \\
\hline$r r v \cdot r \Delta$ & rq1krq & FTVDIS & $\wedge r \Delta q \Delta \Delta$ & ساكن در نقاط شهرى ... \\
\hline NFred & I fatef & |AYTYI & TrQFqD & 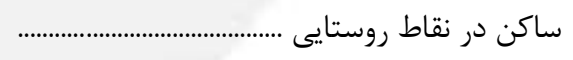 \\
\hline Drs & 990 & $9 \wedge \Delta$ & 190 & غير ساكن .......................... \\
\hline NDQTH & $14 a \cdot 1 T$ & IOTAIT & 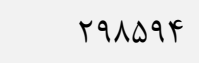 & بوشهر .................................... \\
\hline VArr. & |rTral & $14 \cdot$ Vq9 & rVTUVY & 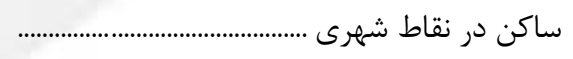 \\
\hline$V Y \wedge 1$ & irtra & IT\&99 & TFQVD & ساكن در نقاط روستايى ... \\
\hline it & tr & $r \cdot$ & kt & 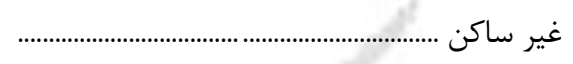 \\
\hline$r r \cdot \Lambda \cdot$ & rovre & ґ^৭. & $V \& V \cdot \varphi$ & تنگستان ................................. \\
\hline qDVq & 11911 & $118 r q$ & THETV & ساكن در نقاط شهرى .... \\
\hline IDFAV & $r g \cdot 1 r$ & rVIQV & QTTII & ساكن در نقاط روستايى \\
\hline $1 f$ & $r \boldsymbol{c}$ & re & 91 & 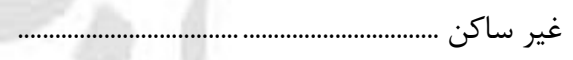 \\
\hline 1999V & rrakr & $r \varphi \Delta \cdot \Lambda$ & $V \cdot \Delta l$ & 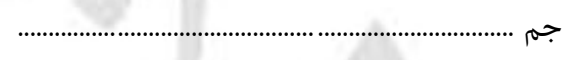 \\
\hline $11 r \cdot r$ & $114 v a$ & 1994 & rیו11 & 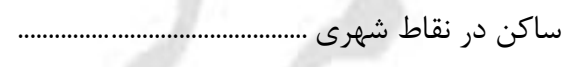 \\
\hline$\wedge \vee V V$ & $10 \cdot F_{1}$ & $191 F F$ & riN9t & 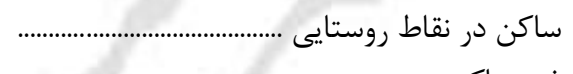 \\
\hline $\begin{array}{l}19 \\
\text { TFFYF }\end{array}$ & $\begin{aligned} r \cdot r \\
|\mu| \cdot r\end{aligned}$ & $\begin{array}{l}\text { rl } \\
\text { RTrIS }\end{array}$ & $\begin{array}{l}41 \\
\text { N\&TIQ }\end{array}$ & 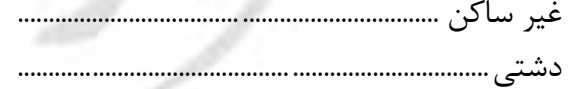 \\
\hline$|घ 94|$ & rav19 & tQATr & 09919 & 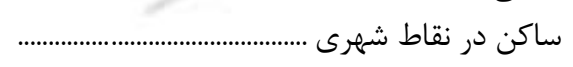 \\
\hline Vq. 9 & 14910 & 14991 & rब१וr & 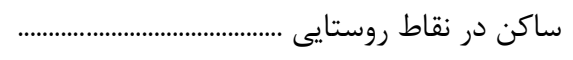 \\
\hline rMF & r99 & rq1 & vq. & 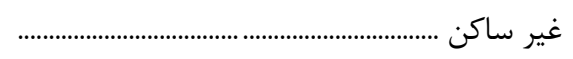 \\
\hline
\end{tabular}


ط ـ جمعيت و خانوار شهرستانهاى كشور به ترتيب استان (دنباله)

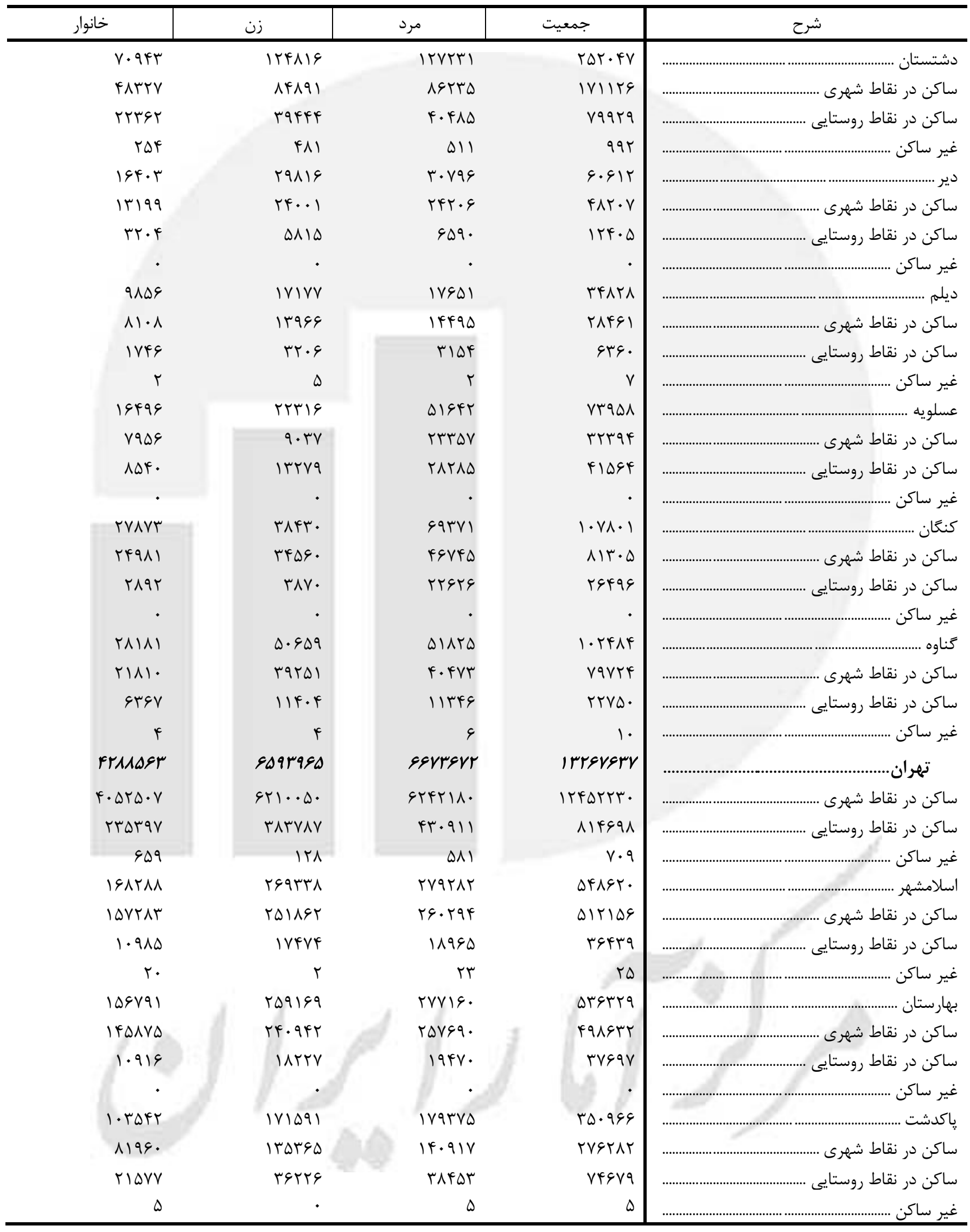


ط - جمعيت و خانوار شهرستانهاى كشور به ترتيب استان (دنباله)

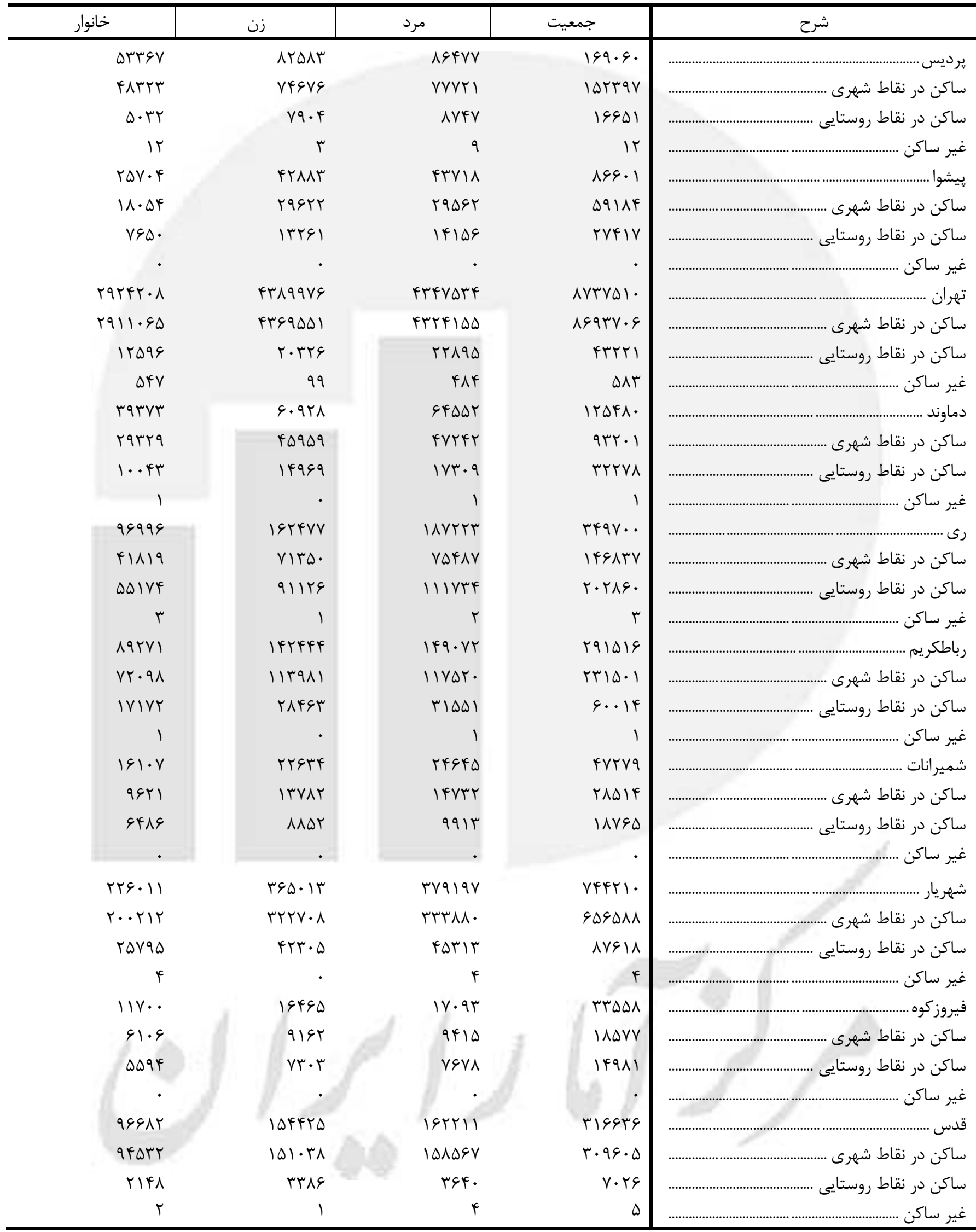


ط - جمعيت و خانوار شهرستانهاى كشور به ترتيب استان (دنباله)

\begin{tabular}{|c|c|c|c|c|}
\hline خانوار & 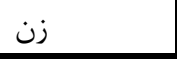 & 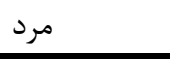 & جمعيت & 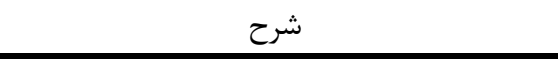 \\
\hline 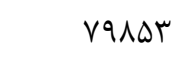 & $1 r \cdot \wedge 19$ & IrATFq & rबqाrर & 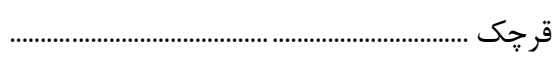 \\
\hline $99 \cdot 49$ & $\| r \Lambda 1 \Delta$ & I1ArG. & TMI.VD & 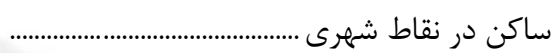 \\
\hline $1 \cdot N T T$ & $I A \cdot V k$ & $1991 \mathrm{~V}$ & $\lceil\wedge \cdot 9\rangle$ & 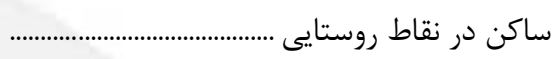 \\
\hline r & $\cdot$ & r & r & 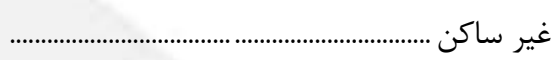 \\
\hline$\|Q\| \Delta F$ & MA.r. & IQTTYVT & rVVrat & 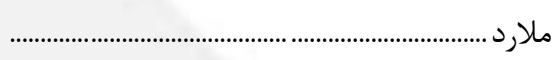 \\
\hline $9901 \mathrm{~V}$ & IDTEAT & $|9 \cdot . r|$ & 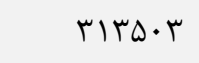 & ساكن در نقاط شهرى .......... \\
\hline $1 \wedge \Delta \wedge \Delta$ & $r \cdot \Delta r r$ & Trtif & grVTs & ساكن در نقاط روستايى ........ \\
\hline$\Delta r$ & 19 & rv & Q & 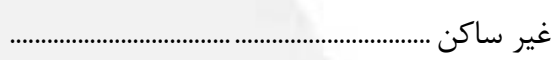 \\
\hline$\wedge \Delta \Delta \backslash €$ & |rqाr. & $|F \& E| T$ & tATYKT & 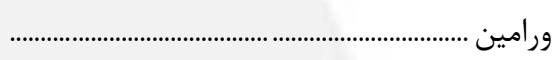 \\
\hline$V \cdot 9 \wedge \mathrm{r}$ & $11 r v \Delta \Delta$ & $119 \mathrm{VIV}$ & $T r \cdot k V t$ & 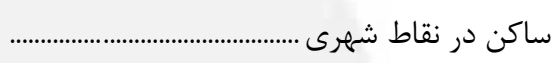 \\
\hline IFATK & rQHGQ & rVAMS & $\Delta r T \Delta \Delta$ & 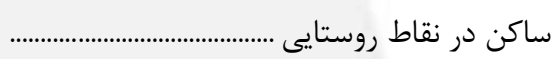 \\
\hline 1 & 4 & 9 & 10 & 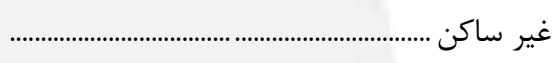 \\
\hline$r \gamma \cdot k r \mu$ & rear.V & ratras & grvyer & 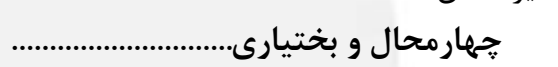 \\
\hline IVQAFT & r৭१९४९ & $r \cdot \vee \vee q \Lambda$ & G.VFFF & 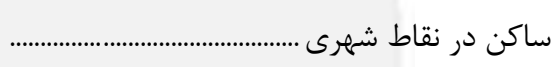 \\
\hline GFFTV & $|9 \Delta F \Delta|$ & IVETIS & एт৭६яV & 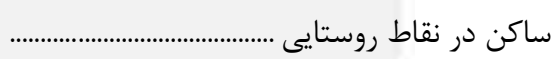 \\
\hline 190 & щ. & MFT & gQT & 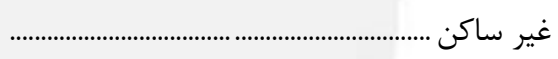 \\
\hline 11.99 & $r F \cdot \Delta r$ & TFATA & $\uparrow \wedge \Lambda \Lambda$. & 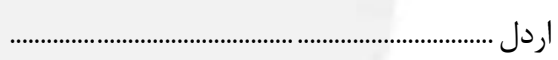 \\
\hline$\Delta \vee q 1$ & $1 \cdot|r|$ & 1. ras & r. YAV & ساكن در نقاط شهرى ... \\
\hline VQVF & וтqז9 & IfFe. & หヘґ^৭ & ساكن در نقاط روستايي \\
\hline 1 & r & r & f & 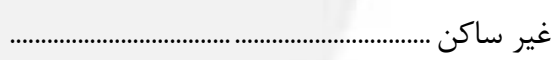 \\
\hline retru & G. MET & gr|f| & ITTFAT & 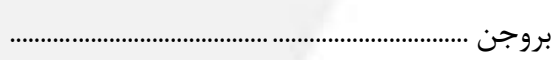 \\
\hline$r \cdot v q 1$ & DIFVF & $\Delta r \Delta V q$ & $1 \cdot r \cdot \Delta r$ & ساكن در نقاط شهرى \\
\hline DFFV & $\wedge \wedge \Lambda_{1}$ & १Q९Y & IAFr. & ساكن در نقاط روستاي \\
\hline 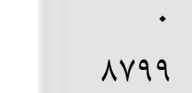 & 1rqu. & Ifrag. & 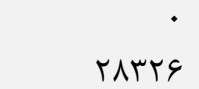 & …................... ن \\
\hline DrVA & ^८९V & $\wedge \wedge r$. & IVETV & 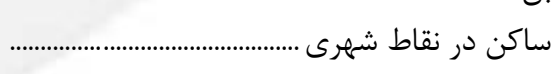 \\
\hline TEYI & 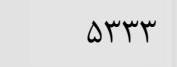 & $\Delta \Delta ९ \varphi$ & $1 \cdot 199$ & 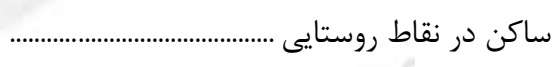 \\
\hline $11 \cdot 1$ & $1994 \Delta$ & $|v 99|$ & rFs|s & 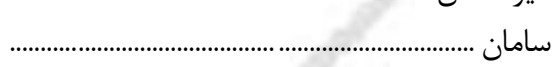 \\
\hline$F \Delta Q F$ & $V \cdot r v$ & VIDQ & $|F| 9 T$ & ساكن در نقاط شهرى \\
\hline GQTS & $9 \wedge 1 \wedge$ & $1 \cdot \Delta r \varepsilon$ & T.FYF & ساكن در نقاط روستايي \\
\hline & & · & $\cdot$ & 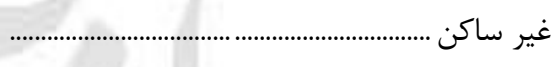 \\
\hline $941 \cdot r$ & IDEKTD & $109 \Delta \Delta \Delta$ & rI091. & 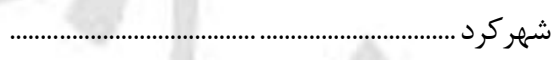 \\
\hline$\Lambda \notin \varepsilon \Delta \Lambda$ & $\mid F T \lambda \cdot 1$ & lfarqu & rAN199 & 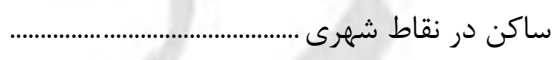 \\
\hline NFFr & IrGTF & IFIQF & trVVA & ساكن در نقاط روستايى .... \\
\hline r\$9/4 & 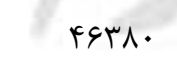 & $4 \wedge 9.9$ & 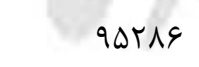 & 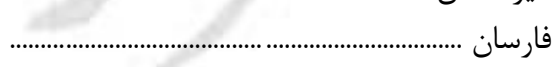 \\
\hline r|rq) & $r v \cdot r \Lambda$ & rMarF & VQ৭\&Y & 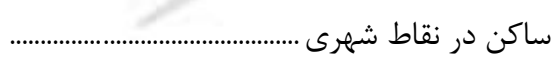 \\
\hline$\Delta \Delta r r$ & QMFT & $991 \mathrm{r}$ & IQTTY & 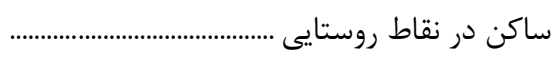 \\
\hline$\cdot$ & · & $\cdot$ & $\cdot$ & 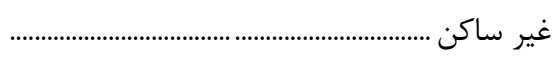 \\
\hline
\end{tabular}


ط - جمعيت و خانوار شهرستانهاى كشور به ترتيب استان (دنباله)

\begin{tabular}{|c|c|c|c|c|}
\hline خانوار & 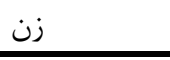 & 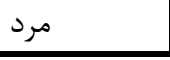 & جمعيت & 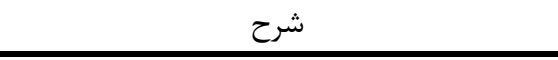 \\
\hline $1 \cdot 1 \Delta 9$ & $r \cdots v q$ & rIFAS & FIDTA & 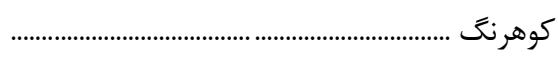 \\
\hline $1 f \Delta \Delta$ & r\&AD & $r \cdot r \varphi$ & $\Delta V I I$ & ساكن در نقاط شهرى ............... \\
\hline arFy & $I V \cdot \wedge V$ & $11 \cdot 99$ & r & 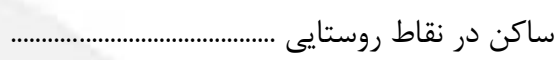 \\
\hline 19. & $r \cdot v$ & rur & sq1 & 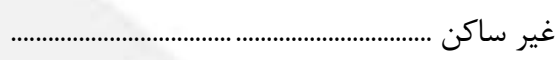 \\
\hline $1 \Delta \Delta \& q$ & TFArT & TEIFr & $0.9 \vee 9$ & 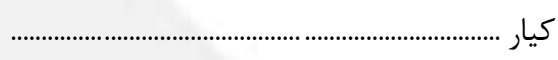 \\
\hline$V \in E V$ & l1ג人r & ITEFV & TfFer. & ساكن در نقاط شهرى ............ \\
\hline$\Lambda \cdot \wedge 1$ & Irq49 & iroqr & TEDFT & ساكن در نقاط روستايى ............. \\
\hline 1 & 1 & r & r & 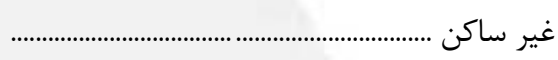 \\
\hline DFATD & 1. TEYI & 1.VYF. & $r \cdot 9911$ & 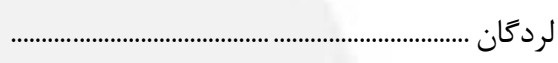 \\
\hline $149 \Delta V$ & $r \Lambda \cdot 1 \cdot$ & 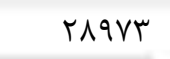 & $\Delta 99 \Lambda \mu$ & 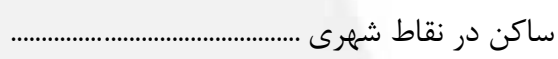 \\
\hline f. 191 & VFFI & VATEV & 10YGQ1 & 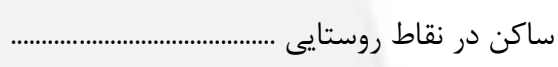 \\
\hline & & & & 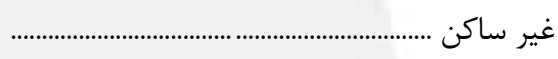 \\
\hline reraste & rraqui & raq9ir & VE1191 & خراسان جنوبى.. \\
\hline Irq.rq & THTTAF & $r+\mathcal{k T H}$ & FATATV & 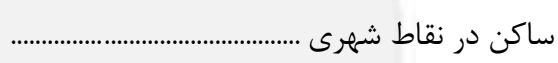 \\
\hline$q \leftrightarrow q \leftrightarrow V$ & IDQGTV & lQqFFY & ria.v. & 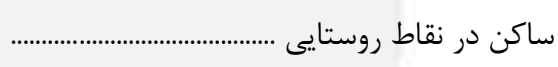 \\
\hline 1 & & 1 & 1 & 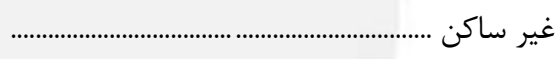 \\
\hline$\Lambda T \Delta \Delta$ & Irq4A & $|r| 19$ & TG. Gr & بشرويه .............................................. \\
\hline$\Delta 9 \Delta r$ & 9बr & $9 \vee \Delta \wedge$ & $194 \wedge 1$ & 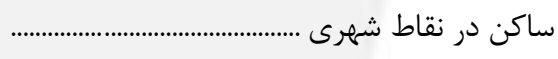 \\
\hline$r+r$ & rrTs & 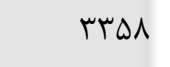 & 99^r & 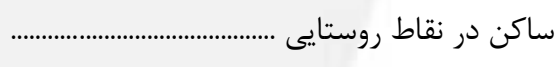 \\
\hline & & & & 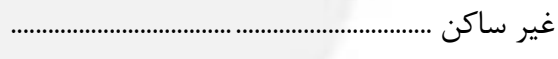 \\
\hline$V \ll \& \Delta V$ & $|r q| k T$ & ITtMIN & TEITTF & بيرجند............................... \\
\hline$\Delta V Y F \Delta$ & $1.1 r r V$ & 1. rrqq & T.rदKG & ساكن در نقاط شهرى ....... \\
\hline 19911 & $r \vee q \cdot \Delta$ & rqท人ץ & $\Delta \vee G \wedge \Lambda$ & ساكن در نقاط روستايى ...... \\
\hline & & & & 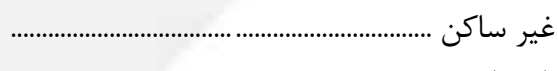 \\
\hline VFqT & $1190 \Delta$ & IDSFD & rVG.. & 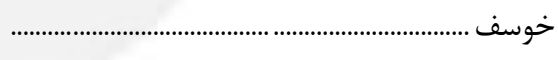 \\
\hline 109 . & rara & stri & $94 \cdot 4$ & ساكن در نقاط شهرى ........ \\
\hline$\Delta 9 \cdot 1$ & $q \cdot r \cdot$ & qrVT & lArqu & 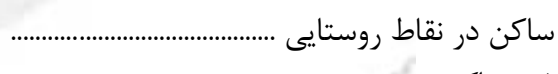 \\
\hline 1 & rack & 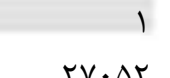 & $\begin{aligned} 1 \\
1\end{aligned}$ & غير ساكن ........................ \\
\hline 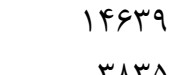 & $\begin{array}{l}\text { ra994 } \\
\text { vmy }\end{array}$ & 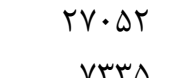 & $\begin{array}{l}\text { DHVIF } \\
\text { LEEVT }\end{array}$ & دريان ............................. \\
\hline rNid & VTrV & vrta & 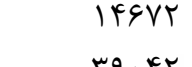 & ساكن در نقاط شهرى .................. \\
\hline $1 \cdot \lambda \cdot r$ & 19TrD & $1981 V$ & rq.kr & ساكن در نقاط روستايى ... \\
\hline$\| 11 v^{\circ}$ & 19Vrr & $r \cdot r \mid \Lambda$ & $f \cdot 1 \Delta \Delta$ & 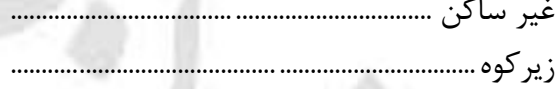 \\
\hline IVAF & ratr & reqq & VYAS & 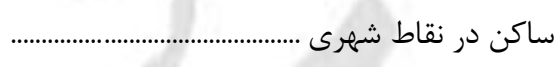 \\
\hline GFYF & 191. & $19 \vee 99$ & TrAGQ & 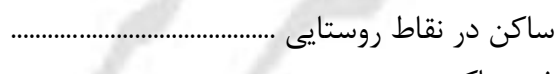 \\
\hline 1.rrq & 1991r & 19949 & (זוזrr & 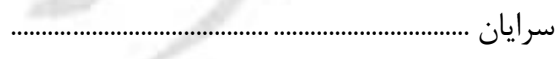 \\
\hline$V \cdot \Delta 9$ & $119 \wedge \mu$ & 11991 & trute & 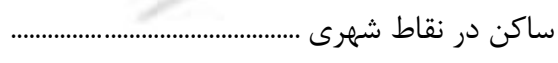 \\
\hline TrV. & $\Delta \cdots$ & 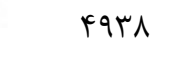 & १९५८ & 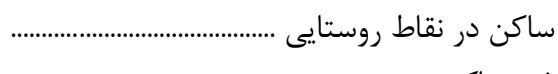 \\
\hline & - & $\cdot$ & & غير ساكن ....................... \\
\hline
\end{tabular}


ط - جمعيت و خانوار شهرستانهاى كشور به ترتيب استان (دنباله)

\begin{tabular}{|c|c|c|c|c|}
\hline خانوار & 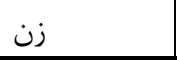 & 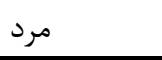 & جمعيت & 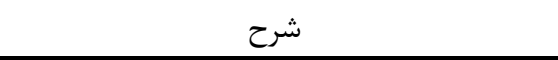 \\
\hline$|r \cdot| 1$ & $r \cdot \Delta \varphi \Delta$ & r.rqr & $r \cdot 9 \Delta 9$ & 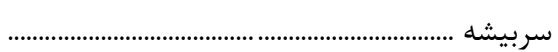 \\
\hline TETT & $9 \cdot 14$ & sivq & $\operatorname{lr} 194$ & 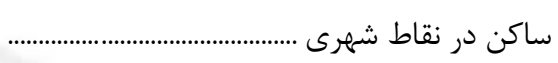 \\
\hline$\wedge \Delta \wedge \Lambda$ & IFDQT & IFTID & rAVEV & 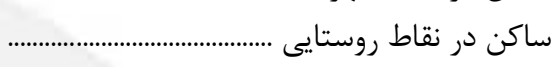 \\
\hline$\cdot$ & - & • & & 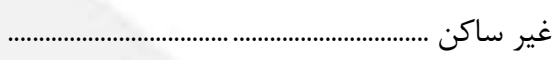 \\
\hline TTIFT & rogIV & $r v \ldots$ & VTEIV & 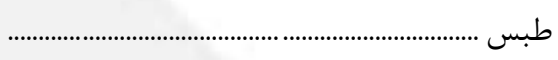 \\
\hline $\mid F \cdot r \cdot$ & rrqu. & trgt. & \&\&4.. & 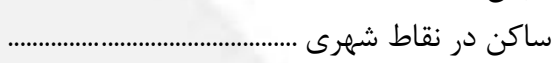 \\
\hline NITr & ITETV & irrk. & $r G \cdot I V$ & 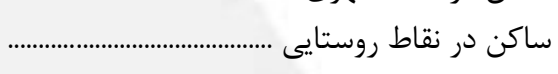 \\
\hline . & & & & 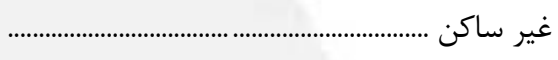 \\
\hline $\mid q \mu \cdot r$ & TrVF. & trtat & FADTK & 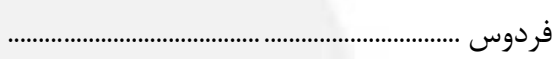 \\
\hline 1.945 & I $\vee \wedge \wedge 9$ & $|v q| f$ & $r \Delta \Lambda \cdot r$ & 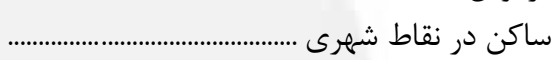 \\
\hline 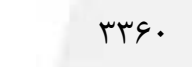 & $\forall \wedge \Delta \mid$ & 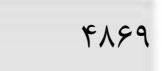 & qrr. & 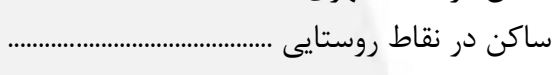 \\
\hline & · & & & 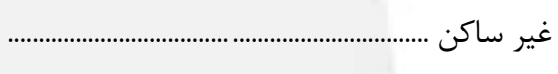 \\
\hline mprqf & $\Delta \vee \vee \& 1$ & DAFT. & 119111 & قاينات .................................. \\
\hline$|V \cdot \wedge|$ & rqهr. & $r \cdot \Delta S T$ & 9..9r & ساكن در نقاط شهرى ............. \\
\hline irrir & thrti & 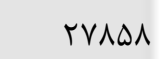 & $\Delta 9 \cdot 19$ & ساكن در نقاط روستايى ........... \\
\hline$\cdot$ & & · & & 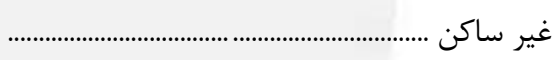 \\
\hline$|F| \wedge \Delta$ & raIVI & tatra & DIFFq & 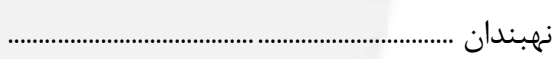 \\
\hline DQTH & $1.4 q$. & 1.990 & tIFAD & 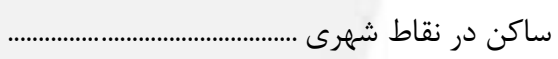 \\
\hline$\wedge \Delta \Delta 1$ & $|\forall \& \wedge|$ & IDTAK & r৭१९५ & ساكن در نقاط روستايى .... \\
\hline & & & & 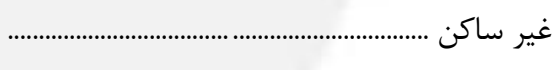 \\
\hline 19rav.r & rIAqrig & TrFAIAS & serea. & خراسان رضوى.......... \\
\hline |FTr|.9 & TrMANTV & rHGT. QV & FV.. qTF & 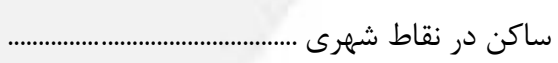 \\
\hline 019419 & $1 \Delta \cdot r \cdot 9$ & NAYAIQ & IVTrITI & 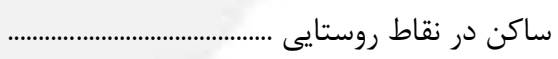 \\
\hline IVQ & lর & rVT & $f \Delta \varphi$ & 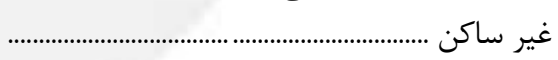 \\
\hline $1 \Delta \Delta T \Delta$ & $r V \cdot r \Delta$ & TYQA. & $\Delta \& \& \mid \Delta$ & 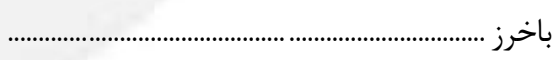 \\
\hline rate & Frtr & friv & $q \cdot k 4$ & ساكن در نقاط شهرى .......... \\
\hline 14919 & $r r r \cdot \Lambda$ & TYA\&T & $f \Delta \Delta V \mid$ & ساكن در نقاط روستايى ..... \\
\hline $1 \cdots 11$ & IDQTF & losAr & 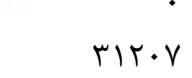 & 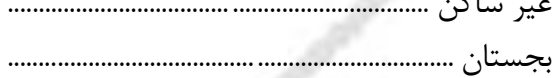 \\
\hline$\forall \wedge \Lambda$ & vat. & VATV & $|Q| \& V$ & ساكن در نقاط شهرى . \\
\hline هIr. & VMAF & $\wedge 1 \Delta \varphi$ & $19 \cdot 4 \cdot$ & ساكن در نقاط روستاير \\
\hline$\cdot$ & & . & y & 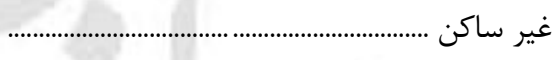 \\
\hline trutr & rVrqq & זrז & VDGT & 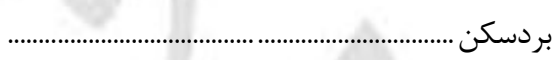 \\
\hline $11 \cdot v a$ & 18909 & INDFT & red.r & 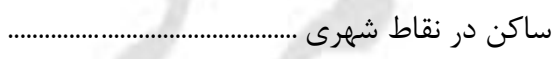 \\
\hline ITSOV & 19FK. & $19 \vee \wedge 9$ & rq1 & 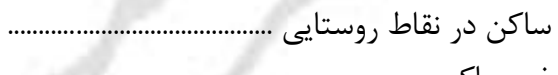 \\
\hline r|人⿻| & 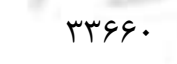 & 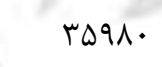 & qq94. & 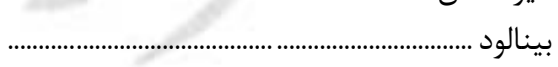 \\
\hline $1.9 \Delta F$ & $|V| r \mid$ & IVAG4 & rFqAD & 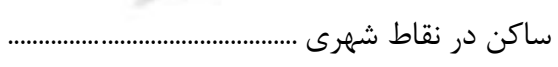 \\
\hline $1 \cdot 9 \cdot \Delta$ & 19arq & 11114 & regar & 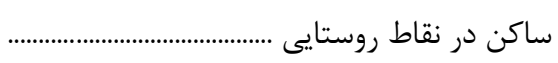 \\
\hline r & $\cdot$ & r & r & 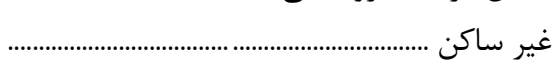 \\
\hline
\end{tabular}


ط - جمعيت و خانوار شهرستانهاى كشور به ترتيب استان (دنباله)

\begin{tabular}{|c|c|c|c|c|}
\hline خانوار & 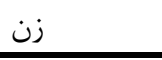 & 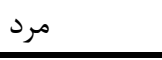 & جمعيت & شرح \\
\hline$r \cdot v i \Lambda$ & $\Delta V \Delta \Delta V$ & $9 \cdots v$ & $\| V \Delta G Y$ & 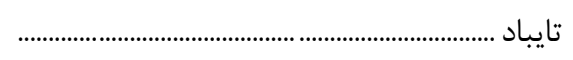 \\
\hline$r \cdot \Delta 99$ & rVQAv & rqv^r & VVVGq & ساكن در نقاط شهرى ............ \\
\hline $1 \cdot|r|$ & 19099 & t. trte & ५৭จ१५ & 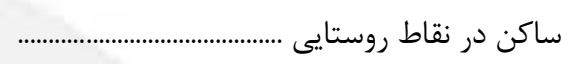 \\
\hline 1 & 1 & 1 & r & 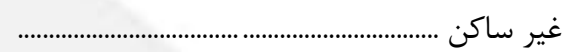 \\
\hline$v \backslash \Lambda \cdot r$ & $|r r| q 4$ & ITSFV & r\&V\&VI & 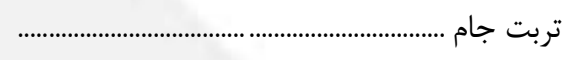 \\
\hline$r \Delta f l$. & gaTIT & 99919 & | & 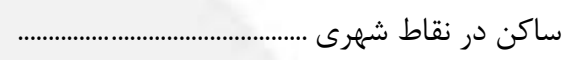 \\
\hline rदтqт & GANAT & $\varepsilon \wedge \Delta \Delta \Lambda$ & IrdFF. & 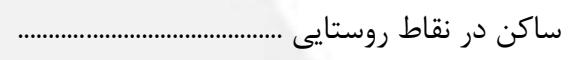 \\
\hline · & - & · & & 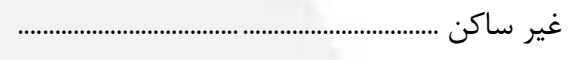 \\
\hline Gヘ9TV & 1.9901 & 114991 & TYEATE & 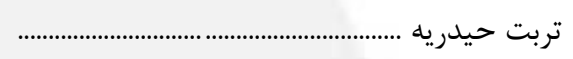 \\
\hline$f \Delta \Lambda \cdot f$ & VК৭১. & $V \Delta \Lambda \Lambda F$ & IFMATF & 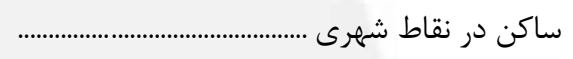 \\
\hline 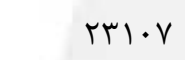 & rघタAr & $r q \cdot \Delta V$ & VQVY. & 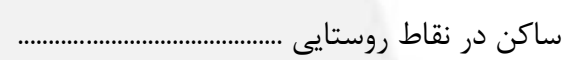 \\
\hline 19 & $r \Delta$ & tr & Qr & 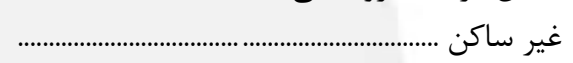 \\
\hline Ifart & rF. qF & $r \Delta \cdot \Lambda 1$ & FqIVQ & جغتاى ................................... \\
\hline r\&V. & fDSI & $q v \cdot v$ & $9 r \& \wedge$ & ساكن در نقاط شهرى ............ \\
\hline IrTAK & 1904T & $r \cdot r V e^{2}$ & rq৭•v & ساكن در نقاط روستايى .................. \\
\hline & & & & 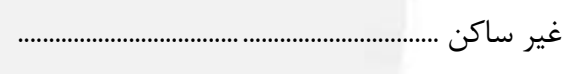 \\
\hline IEVYA & 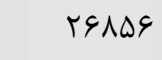 & TVGTT & DFFAM & 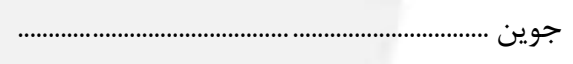 \\
\hline fept & VYGA & $V \Delta I Q$ & IFVAr & ساكن در نقاط شهرى ........... \\
\hline Irtry & 19490 & 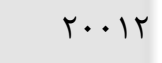 & $r 9 \Delta \cdot V$ & 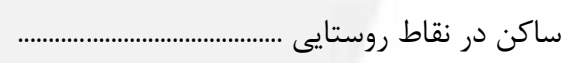 \\
\hline$\Delta \Lambda$ & 9 & $1 \cdot 0$ & 191 & 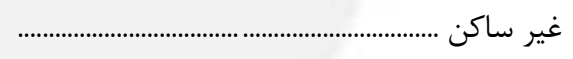 \\
\hline$\forall \Delta l \cdot \Delta$ & $V \psi \cdot \Delta V$ & $\wedge \cdot 9 \Delta \varphi$ & $100 \cdot 1 \pi$ & 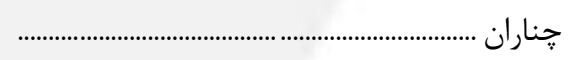 \\
\hline tqTrF & FAFGA & 0.991 & $991 \% 9$ & ساكن در نقاط شهرى ...... \\
\hline IQVDF & TDQFT & $r \cdot r r \cdot$ & $\Delta \Delta V V r$ & ساكن در نقاط روستايى .. \\
\hline rV & iq & 90 & 111 & 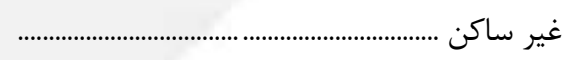 \\
\hline I99AF & TAFA. & ratol & $\Delta I V \cdot 1$ & 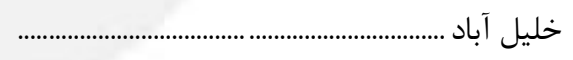 \\
\hline GTYK & १९ा & $9 \Delta \Lambda$. & 19511 & 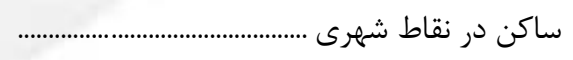 \\
\hline 1.49. & 10119 & $199 \mathrm{~V}$ & rTFq. & 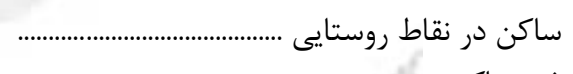 \\
\hline ५६ч৭q & sısty & $V \cdot r t \Lambda$ & Ir人avr & 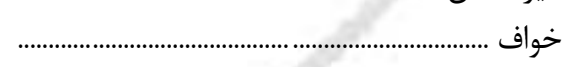 \\
\hline IVANY & rrTsq & MFTEq & $G \vee \Delta \cdot \Lambda$ & ساكن در نقاط شهرى . \\
\hline$|\Lambda \Delta| \&$ & raTAa & rq.vq & VIFEF & ساكن در نقاط روستايى .. \\
\hline & - & & • & 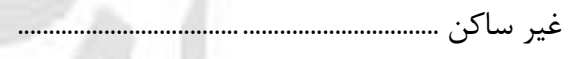 \\
\hline $11 \wedge \Lambda \mathrm{H}$ & INFT. & $|\wedge \vee \Delta|$ & rRINi & خوشاب ............................. \\
\hline$|V \Delta|$ & rی९9 & $r \cdot q r$ & DQYT & 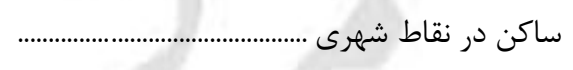 \\
\hline $1.1 \% r$ & $1 \Delta \Delta 91$ & $\mid \Delta \& \wedge \Lambda$ & MITFq & 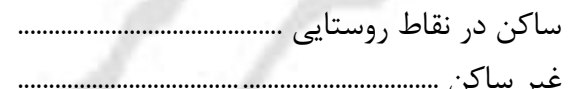 \\
\hline Vavi & سب & $11 \cdot V r$ & 11911 & داورزن ........................................................... \\
\hline qVq & $94 \Delta \varphi$ & $\begin{array}{l}1491 \\
9711\end{array}$ & $\begin{array}{l}\text { TVFF } \\
1919 V\end{array}$ & 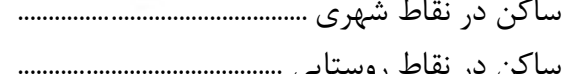 \\
\hline • & - & • & & 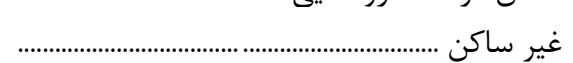 \\
\hline
\end{tabular}


ط - جمعيت و خانوار شهرستانهاى كشور به ترتيب استان (دنباله)

\begin{tabular}{|c|c|c|c|c|}
\hline خانوار & 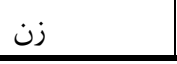 & 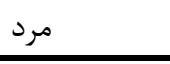 & جمعيت & شرح \\
\hline trVRA & $r \Delta \wedge \Delta \cdot$ & $r \varphi \Delta \cdot \Delta$ & VTrDa & دركز \\
\hline IrGAF & rIVIN & rig1V & 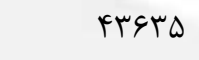 & 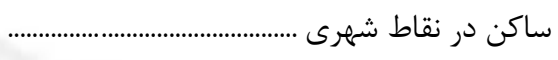 \\
\hline 9.94 & IFITK & $\mid \uparrow \Delta \wedge \Lambda$ & TAVT. & 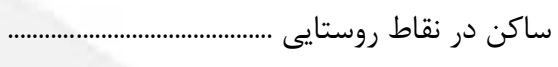 \\
\hline . & . & . & · & 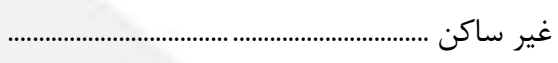 \\
\hline IVDGG & rQAVt & $r \cdot \wedge i v$ & 9.919 & 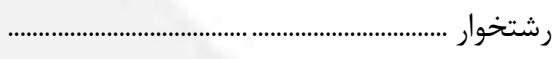 \\
\hline 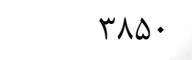 & $v \cdot v \cdot$ & $V \cdot 94$ & Iflek & ساكن در نقاط شهرى ................ \\
\hline irvis & $r$ ru.r & trutr & FEDTA & ساكن در نقاط روستايى ............. \\
\hline$\cdot$ & $\cdot$ & $\cdot$ & & 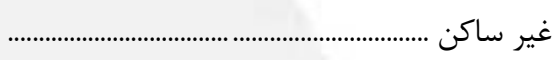 \\
\hline$r . . q r$ & 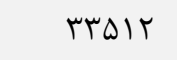 & rFiNr & बУ९9D & زاوه \\
\hline หqтq & FVrI & $49 \cdot 1$ & qrरq & 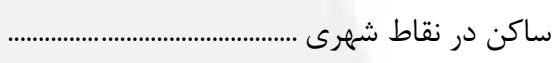 \\
\hline IVITK & r^マq. & rqQVT & DArGT & 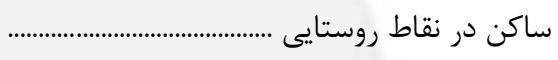 \\
\hline r & 1 & r & r & 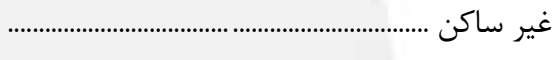 \\
\hline $9 \Delta \Delta \Delta \mathrm{r}$ & IDTIKT & IQTIAV & $r \cdot q r l$. & 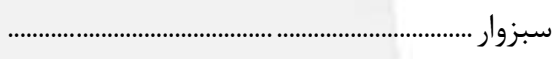 \\
\hline Vदqu। & $|r \Delta \Delta| \mid$ & ITATTS & $r \Delta \cdot \wedge r \varepsilon$ & ساكن در نقاط شهرى ............... \\
\hline$|\Lambda G T|$ & tVAIT & rY^\&l & $\Delta \Delta F V Y$ & 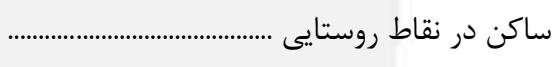 \\
\hline 1 & & 1 & 1 & 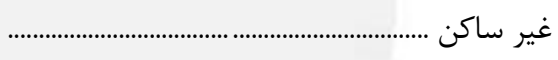 \\
\hline T\&QTT & FVV.q & rq1।r & १४४।१ & 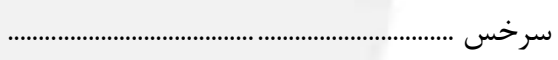 \\
\hline$|r| F \mid$ & rITUA & $r t \cdot G$ & Fret. & 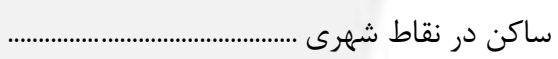 \\
\hline IFv. & TETFV & TVVDI & $\Delta F \cdot 9 \Lambda$ & 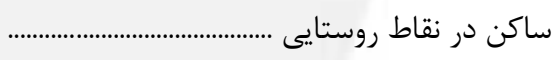 \\
\hline & 1 & & 1 & 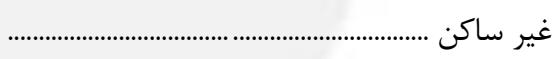 \\
\hline TA\&4 & $\uparrow \wedge १ \Delta \vee$ & $\Delta \cdots r q$ & $99 . .1$ & 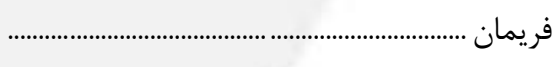 \\
\hline IVTVE & $r q .91$ & 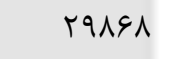 & $\Delta \wedge 9 \hookrightarrow 4$ & ساكن در نقاط شهرى ..................... \\
\hline $11 r 90$ & 19109 & $r \cdot I V 4$ & r..ro & ساكن در نقاط روستايى .. \\
\hline & & & & غير ساكن ........................ \\
\hline lIVAr & INFVD & 19.94 & TVQYq & 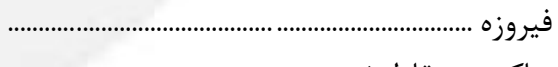 \\
\hline rllv & TATr & rqस & $v \backslash \Delta \Lambda$ & 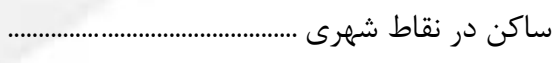 \\
\hline १९९४ & I $F q \Delta r$ & IDFYA & r.r人 & ساكن در نقاط روستايى ..... \\
\hline$\Delta T \wedge \Delta I$ & 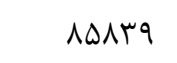 & 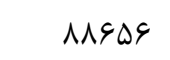 & IVFFqD & قو خان .............................. \\
\hline$r \cdot r \wedge V$ & D.rat & $\Delta 1 \Lambda \cdot \varphi$ & 1.5191 & ساكن در نقاط شهرى ... \\
\hline TTDGT & TAFEV & reAFA & VTYQD & ساكن در نقاط روستايى \\
\hline r & & r & r & 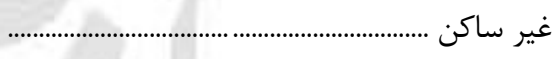 \\
\hline DrVYA & ᄉr६६. & $\wedge \Delta \cdots+$ & 191994 & 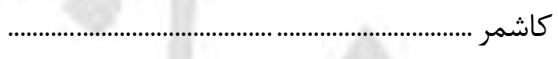 \\
\hline rufve & बrrqq & $\Delta F \Delta V$. & $1 \cdot \sqrt{9} 99$ & 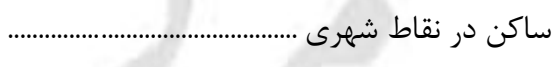 \\
\hline $194 \cdot r$ & $r \cdot r 41$ & $r \cdot k r \mu$ & $\begin{array}{r}9.990 \\
.\end{array}$ & غاكن در نقاط روستايى ......................................... \\
\hline TTSV & $\Delta \& 49$ & aVsr & llfert & 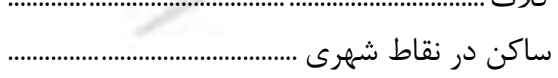 \\
\hline$V F \Delta l$ & IrINK & ITETT & $r F \Lambda \cdot D$ & 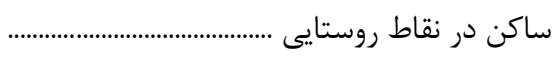 \\
\hline$\cdot$ & · & $\cdot$ & & 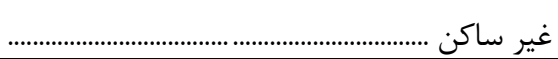 \\
\hline
\end{tabular}


ط ـ جمعيت و خانوار شهرستانهاى كشور به ترتيب استان (دنباله)

\begin{tabular}{|c|c|c|c|c|}
\hline خانوار & 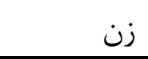 & 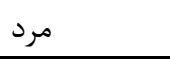 & جمعيت & 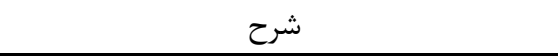 \\
\hline TVG.V & $|f| l \cdot 9$ & FFEFV & MAVDT & ₹ \\
\hline $\mid \Delta r \cdot \Delta$ & TQR⿴Qq & $r \Delta \Delta F \cdot$ & $0 \cdot 199$ & ساكن در نقاط شهرى ........... \\
\hline Irr.r & IAVFV & $191 \cdot V$ & rVADF & 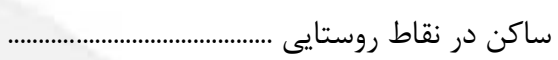 \\
\hline · & $\cdot$ & $\cdot$ & & 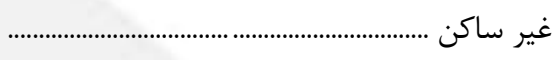 \\
\hline $\mid \cdot r 1 \cdot 9 \Lambda$ & $19 \vee 9 \cdot \Delta \Lambda$ & 19949.r & rTrYGG. & 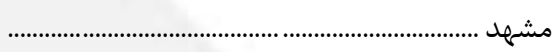 \\
\hline qIVTat & $10 \cdot r \wedge 9 \vee$ & 10.9194 & $r \cdot \mid r \cdot q$. & 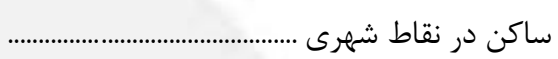 \\
\hline $1 . r \varepsilon \Delta V$ & IVEIFV & $\mid$ |NFdi & rq. 491 & 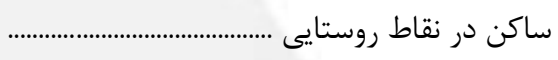 \\
\hline$\Delta 9$ & If & $\Delta \Lambda$ & VT & 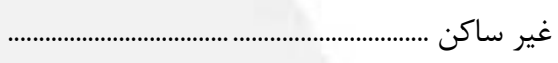 \\
\hline IDAFF & TATAT & TG. TV & $\Delta 14 \cdot q$ & 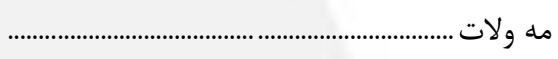 \\
\hline GGFV & $1 \cdot V \Delta V$ & 11111 & rI9YA & 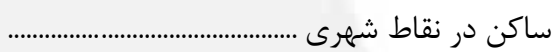 \\
\hline $919 \vee$ & IFETD & IFArq & raps4 & ساكن در نقاط روستايى ....................... \\
\hline & & & & 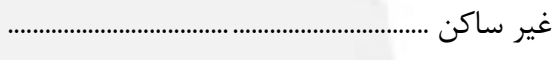 \\
\hline IFTAFA & THEATV & ThITIT & FoIVA. & 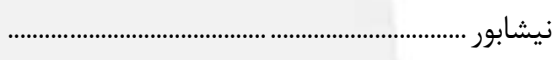 \\
\hline 9YFII & $\mid$ |\&\&4| & Ifrits & rquVVs & ساكن در نقاط شهرى . \\
\hline$\Delta \cdot \mid r \Lambda$ & $\vee \wedge \cdot r$ & 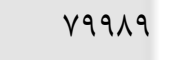 & lQV৭१५ & ساكن در نقاط روستايى ..................... \\
\hline 4 & r & 9 & 11 & 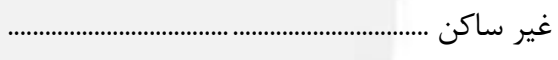 \\
\hline rafyer & FrqFaq & errerer & 19r.9r & خراسان شمالى..... \\
\hline IFTrI9 & $r F \cdot q \cdot r$ & TEMETT & fNerfe & 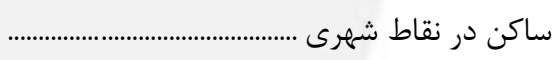 \\
\hline 111191 & INV৭DT & $\mid \wedge 9 \Delta \wedge 1$ & rVVATr & 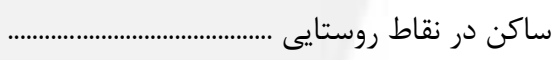 \\
\hline rrv & 4.r & 91. & TIK & 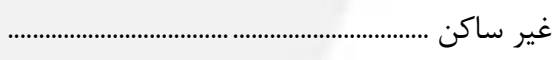 \\
\hline rघD19 & 9.119 & G.rmY & $\mid r \cdot \Delta I T$ & 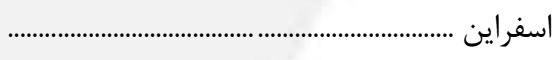 \\
\hline INFAS & MIISO & rIVVT & sraाv & ساكن در نقاط شهرى ........ \\
\hline$M \cdot r F$ & $r q \cdot r t$ & $r \wedge \Delta \Delta \mid$ & QVQVT & ساكن در نقاط روستايى ... \\
\hline 9 & it & 11 & r & 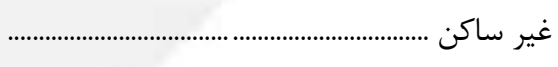 \\
\hline qFYDV & $191 \pi \cdot 0$ & IGTrVA & rTF.人t & بنورد ............................... \\
\hline GAVAr & 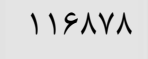 & llब9rर & rrral. & 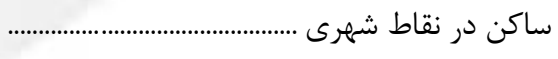 \\
\hline$r \Delta V \cdot r$ & FFETY & 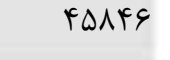 & Q.rVr & ساكن در نقاط روستايى ... \\
\hline$\| 11 \Delta F$ & $|\Lambda T|$. & MNGK & rGQVT & جاجرم .................................. \\
\hline$V \cdot 9 r$ & 11194 & $I T \cdot V G$ & rrqv. & ساكن در نقاط شهرى ... \\
\hline r.9T & gris & GTAV & IrV.r & ساكن در نقاط روستايى \\
\hline$\cdot$ & & & . & 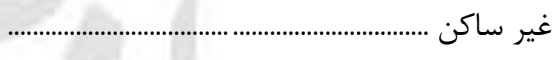 \\
\hline $109 \cdot r$ & rqAVr & ramr & $\Delta 9 Y 1$. & 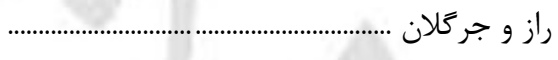 \\
\hline lara & TFV. & $r \Delta \Delta q$ & $\Delta \cdot r q$ & 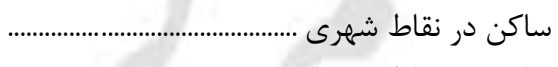 \\
\hline $1 F r 41$ & $T V F \cdot r$ & reVVq & $\Delta F|\Lambda|$ & ساكن در نقاط روستايى ........ \\
\hline rrAvr & VTYAT & 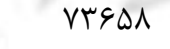 & $|f \&| f$. & 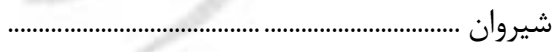 \\
\hline TEQVT & FFr人q & $\varphi \Delta \cdot \Delta \varphi$ & AqMFd & 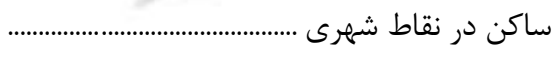 \\
\hline 18199 & r人।91 & r^১৭৭ & $\Delta \& \vee q$. & 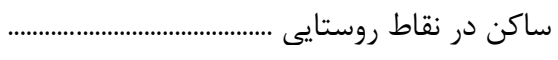 \\
\hline r & r & r & $\Delta$ & غير ساكن ........ \\
\hline
\end{tabular}


ط ـ جمعيت و خانوار شهرستانهاى كشور به ترتيب استان (دنباله)

\begin{tabular}{|c|c|c|c|c|}
\hline خانوار & 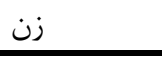 & مرد & جمعيت & 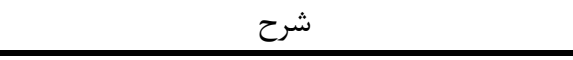 \\
\hline lof\&q & rFa.. & TEVYI & FqTVI & فاروج ................................. \\
\hline prrq & VAl. & $\wedge \cdot \wedge \varphi$ & ।४८१९ & ساكن در نقاط شهرى .......................... \\
\hline I.VTr & $199 \mathrm{VF}$ & $199 \mathrm{VT}$ & 每 & 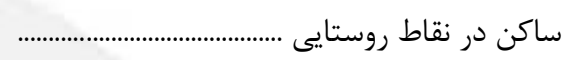 \\
\hline$\wedge$ & 19 & it & ru & 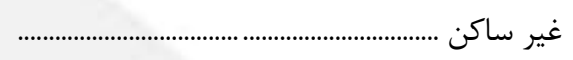 \\
\hline VYFA & ITDQT & ITANT & TDFVD & 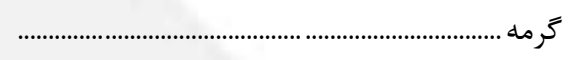 \\
\hline 9.r1 & 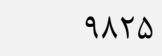 & $1 \cdots r \Lambda$ & $19 \wedge \Delta \mu$ & ساكن در نقاط شهرى ................ \\
\hline IVIV & TVGA & rADF & DGTT & ساكن در نقاط روستايى ............. \\
\hline$\cdot$ & - & - & & 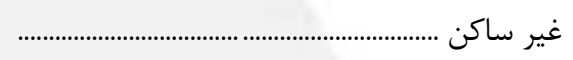 \\
\hline TQGTF & $\Delta \cdot r i \Lambda$ & $\Delta 1 f \cdot q$ & $1.1 \mathrm{VTV}$ & 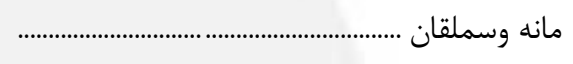 \\
\hline 9941 & $19 \Delta 94$ & س 1994 & rutg & 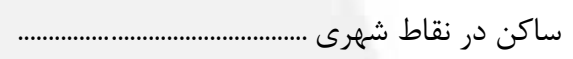 \\
\hline 19480 & 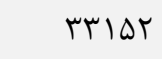 & rщкат & $q V \cdot$ GF $^{-}$ & 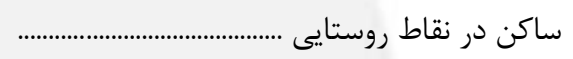 \\
\hline Mil & $\Delta V r$ & $\Delta \wedge F$ & $\| \Delta V$ & 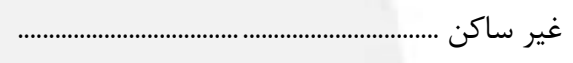 \\
\hline$I r A \cdot G F \Delta$ & reriata & rrAseve & $F V l \cdot 0 \cdot q$ & 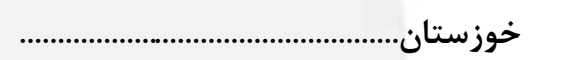 \\
\hline $9 \wedge \Delta \sim)_{1}$ & $1 \vee \Delta 9 . .9$ & $1 V 90199$ & $r \Delta \Delta F \cdot \cdot \Delta$ & 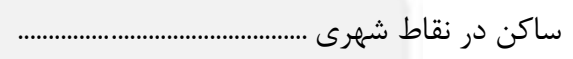 \\
\hline rquivr & $\Delta G \cdot 9 \mu r$ & $\Delta 9.9 \& 4$ & 1101099 & 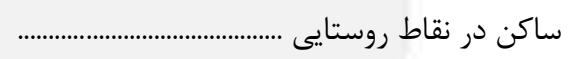 \\
\hline $11 \cdot v$ & r & TQID & $q v \cdot \Lambda$ & 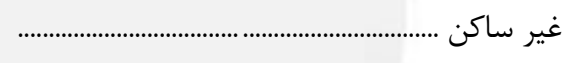 \\
\hline $10 \cdot 10$ & $\mid \digamma \wedge \Delta \Lambda$. & $|\notin 90|$. & $r 9 \Lambda \cdot 9$. & 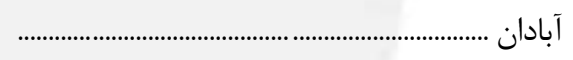 \\
\hline VIVTe & IrATSq & $|r \Delta| \wedge ⿻$ & $r \Delta \cdot \Delta \Delta \Delta$ & 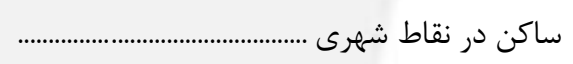 \\
\hline Irt人F & trte & TFMIQ & FVATA & 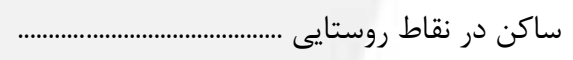 \\
\hline$\Delta$ & r & $\Delta$ & v & غير ساكن .......................... \\
\hline (9६1 & 1945 & NVIT & IVGDF & آغاجارى ...................................... \\
\hline reVV & G.rی & $\Delta \wedge V^{F}$ & 11914 & ساكن در نقاط شهرى ... \\
\hline likr & $r q \cdot r$ & rATs & $\Delta V Y V$ & ساكن در نقاط روستايى ........ \\
\hline 1 & r & r & $\Delta$ & 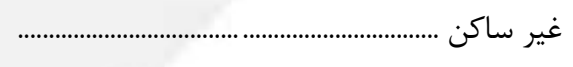 \\
\hline TAITH & FDQVF & |FV४। & 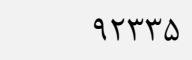 & 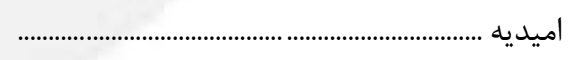 \\
\hline 19rrF & THYAT & $r \Delta \Delta \cdot 1$ & gqVAF & ساكن در نقاط شهرى .... \\
\hline$\Delta \wedge \wedge 9$ & $11 \% 91$ & 11re. & rTDDI & ساكن در نقاط روستايى . \\
\hline$\| \Delta \vee \wedge$ & 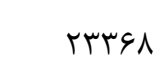 & TFYEI & FVGTq & 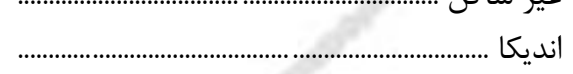 \\
\hline $1 . r 4$ & $r \cdot r r$ & $r \cdot r \Lambda$ & $r \cdot 11$ & ساكن در نقاط شهرى . \\
\hline $1 \cdot \Delta \Delta Y$ & TITTS & TTYTH & rrofA & 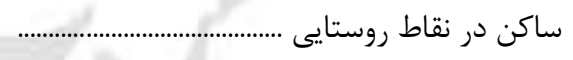 \\
\hline$\cdot$ & - & $\cdot$ & ? & 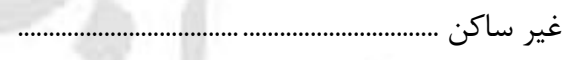 \\
\hline 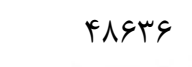 & ATVG & AV\&\&q & IVIfIT & 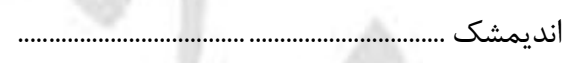 \\
\hline pritg & $v F \cdot v q$ & VDSFV & IfqVYe & 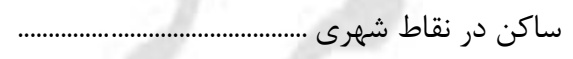 \\
\hline $\begin{array}{l}\text { DTVE } \\
\text { rrT }\end{array}$ & 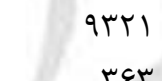 & $\operatorname{llDGT}_{k K}$ & $r \cdot \Lambda \wedge r$ & 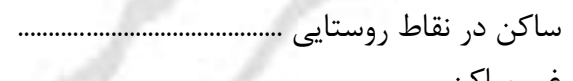 \\
\hline $\begin{array}{l}\text { LETHA. } \\
\text { retr }\end{array}$ & 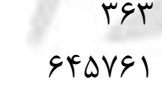 & $\begin{array}{l}\text { rF. } \\
\text { gDSNr. }\end{array}$ & 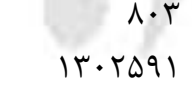 & 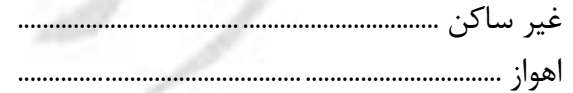 \\
\hline TrMEgl & $\Delta 91119$ & 9.94. & llarkrq & 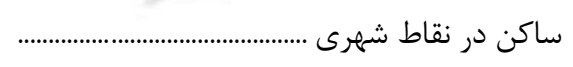 \\
\hline$r q \cdot 1 r$ & DrqFT & $\Delta G Y \cdot T$ & 11.148 & 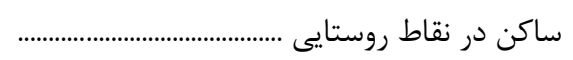 \\
\hline 9 & - & 4 & 4 & 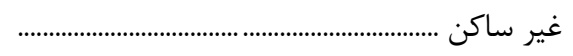 \\
\hline
\end{tabular}


ط ـ جمعيت و خانوار شهرستانهاى كشور به ترتيب استان (دنباله)

\begin{tabular}{|c|c|c|c|c|}
\hline خانوار & 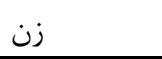 & 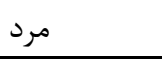 & جمعيت & 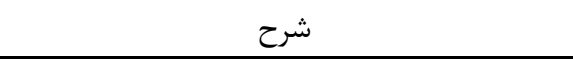 \\
\hline FヘタヘT & १৭९०. & $99 \Delta T 1$ & $1914 \mathrm{VI}$ & 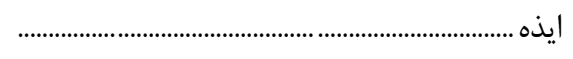 \\
\hline mirki & GKYGV & GTFTT & $\operatorname{IrF\wedge \Lambda 9~}$ & ساكن در نقاط شهرى ............ \\
\hline$I V r \cdot r$ & 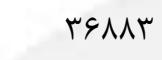 & $r v \cdot 99$ & vrqut & 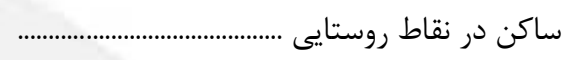 \\
\hline . & - & • & & 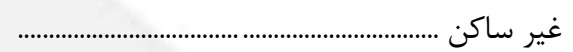 \\
\hline$r \Delta \wedge \vee T$ & DIV9V & $\Delta r \Delta \Lambda V$ & $1 \cdot \Delta r \wedge F$ & 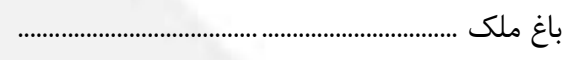 \\
\hline 11910 & r r & TYG. & FAT. F & 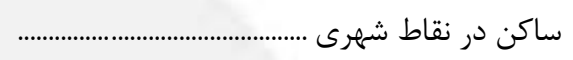 \\
\hline $1 r 9 \Delta \Delta$ & rAlq. & r^৭^। & arivi & 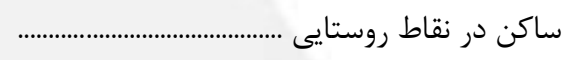 \\
\hline r & r & $\Delta$ & 9 & 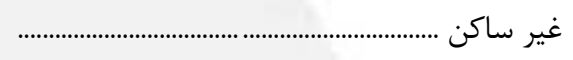 \\
\hline rबڤ१V & FVATt & rAG9T & १G广AF & 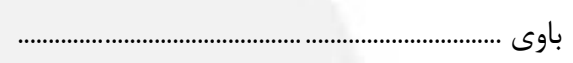 \\
\hline ।ヘґ৭я & retry & MFEFS & $99 \cdot \pi 4$ & 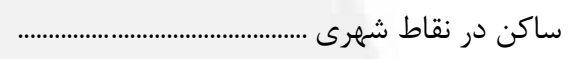 \\
\hline VT. & I THFa & $14 \cdot 10$ & rYFe. & ساكن در نقاط روستايى .......... \\
\hline 1 & - & 1 & 1 & 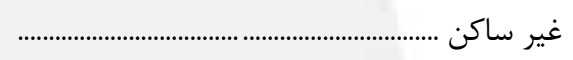 \\
\hline NITII & $1494 \cdot V$ & lfq६ब4 & rQGYYI & 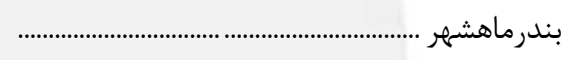 \\
\hline Ve. kT & 1 1r9.4 & $1 r \Lambda \cdot r q$ & TVY\&DO & ساكن در نقاط شهرى ......... \\
\hline 0191 & $1 \cdots 1$ & 11810 & ris19 & ساكن در نقاط روستايى ........ \\
\hline DIATA & $\Lambda \mu v \cdot{ }^{*}$ & $91 \wedge \wedge 9$ & $\mid \Lambda \cdot \Delta q r$ & 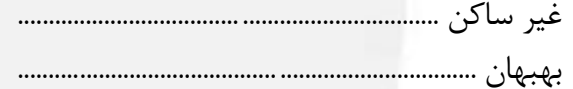 \\
\hline$r \cdot \Delta I V$ & gAvF. & $V \cdot r 91$ & וrqurk & ساكن در نقاط شهرى ........... \\
\hline $11 \pi 11$ & $199 \Delta \wedge$ & TITNA & FITKK & ساكن در نقاط روستايى .......... \\
\hline r & \& & \& & it & 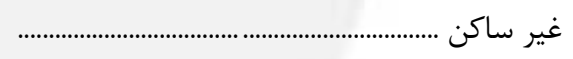 \\
\hline $1 r \Delta 9 \Lambda$ & r\&199 & TVAGT & DTVGT & 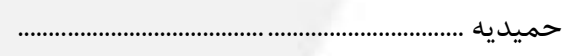 \\
\hline$\Delta F 19$ & $1 \cdot V H F$ & IITr & $r T \cdot \Delta V$ & ساكن در نقاط شهرى .... \\
\hline 1IV9 & $10 \% 90$ & IETF. & $M I V \cdot \Delta$ & ساكن در نقاط روستايى . \\
\hline & & & & 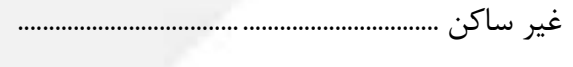 \\
\hline Frra. & NQVYI & NATFA & $18 \cdot 9 v 9$ & 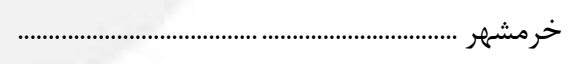 \\
\hline TVVAT & 9111. & GVYIA & IraTrA & 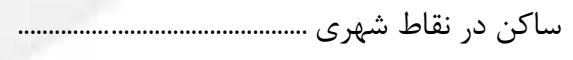 \\
\hline १९५८ & IVGTI & $M \cdot r \Delta$ & rosks & 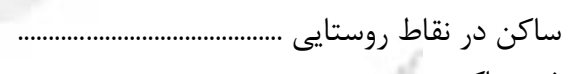 \\
\hline$r$ & & $r$ & $r$ & غير ساكن ......................... \\
\hline$|T \Delta T \Delta|$ & rIfIVI & $r r q \Lambda$. & ferqu & دزفول ............................ \\
\hline qY्ar & losqra & $199 \cdot 14$ & rrr. 19 & 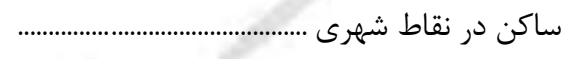 \\
\hline r..rr & $\Delta \Delta \wedge \backslash \Delta$ & GrI. r & 118919 & ساكن در نقاط روستايى \\
\hline $49 \mathrm{~V}$ & $|F T|$ & 1814 & $r \cdot r r$ & 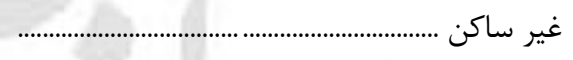 \\
\hline$r \varepsilon \Delta \Delta \Lambda$ & QTYAI & $\Delta F V \cdot \Lambda$ & $1 \cdot \vee 9 \wedge 9$ & 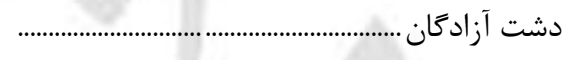 \\
\hline$|V M F|$ & rFGVT & rQTAl & $999 \Delta F^{\circ}$ & 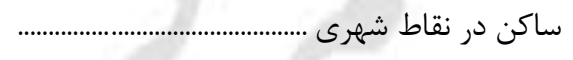 \\
\hline 9riv & $114 \cdot 1$ & I9FTV & rᄉ.r山 & 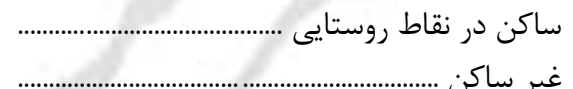 \\
\hline Iflir & rG\&Tr & rVYAl & $\Delta F \cdot . \varphi$ & 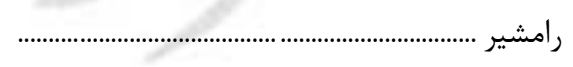 \\
\hline vi.. & $|r \Delta \Delta|$ & IraDr & trI. t & 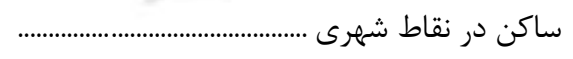 \\
\hline$v \cdot 1 r$ & $1 r \cdot v r$ & IrATA & rq9.. & 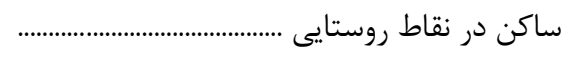 \\
\hline$\cdot$ & - & $\cdot$ & & 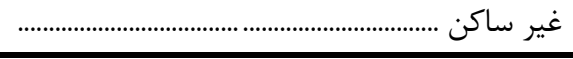 \\
\hline
\end{tabular}


ط ـ جمعيت و خانوار شهرستانهاى كشور به ترتيب استان (دنباله)

\begin{tabular}{|c|c|c|c|c|}
\hline خانوار & 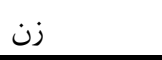 & 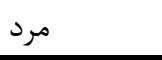 & جمعيت & 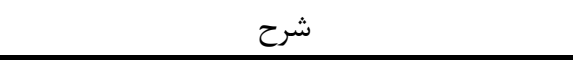 \\
\hline$r \cdot \Delta q 1$ & $\Delta G I M Y$ & DVGFT & llrvve & 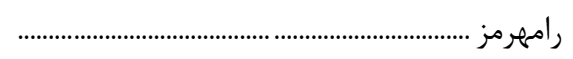 \\
\hline$t \cdot I r V$ & rGQHA & rVVrv & VETAD & ساكن در نقاط شهرى ................ \\
\hline $1 \cdot x+q$ & $19 \Delta \% 4$ & 1918. & rapis & 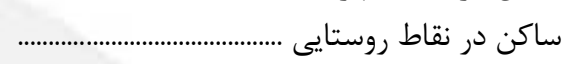 \\
\hline 10 & r. & ro & VQ & غير ساكن .......................................................... \\
\hline rq.r। & 91199 & V.rIf & IrAFA. & 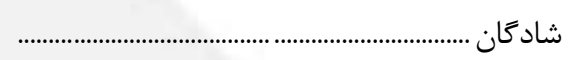 \\
\hline IrNT. & TATrq & $r q \cdot 1 T$ & $\Delta|Y Y|$ & 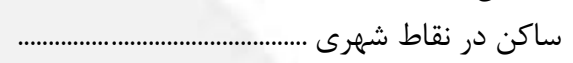 \\
\hline Trt. F & rTqu & fergy & AVTrt & 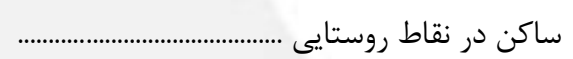 \\
\hline$v$ & r & $\Delta$ & $v$ & 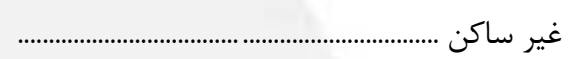 \\
\hline$\Delta \Delta / 9 F$ & $1 \cdot 1 \cdot 10$ & $1 \cdot k V \cdot \Delta$ & $r \cdot \Delta V T$. & 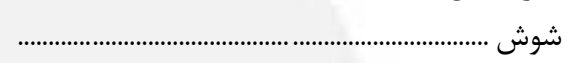 \\
\hline rqlis & Q19V^ & $\Delta r \cdot \mid r$ & 1.4991 & 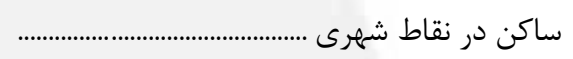 \\
\hline TQ. TI & F^९ท9 & DI\&YD & 1.9914 & ساكن در نقاط روستايى ....... \\
\hline rV & $\Delta \wedge$ & $\Delta V$ & 110 & 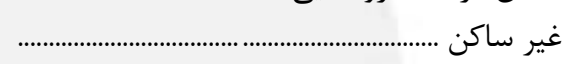 \\
\hline$\Delta \cdot \wedge \vee \wedge$ & qreqY & 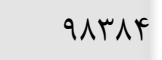 & $19 T \cdot r \Lambda$ & شوشتر ............................. \\
\hline 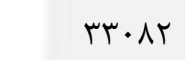 & $\Delta Q \Lambda \Delta T$ & 91914 & ITIVED & ساكن در نقاط شهرى ....... \\
\hline IVVGF & Tris & एят৭У & $v \cdot 11 r$ & 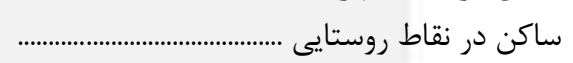 \\
\hline rt & Ve & VD & 101 & 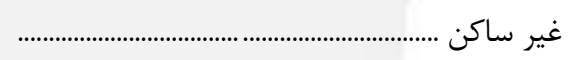 \\
\hline rrVFq & $\Delta 19 \cdot 1$ & $\Delta r q G F$ & $1 \cdot \Delta \wedge V Y$ & 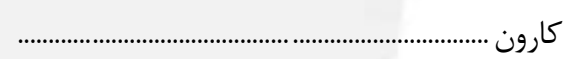 \\
\hline IFVIF & TYYAS & r^१९५ & DGYAT & ساكن در نقاط شهرى ... \\
\hline ir & TFETT & rFq91 & pqq. & ساكن در نقاط روستايى .......... \\
\hline 199.1 & rivis & rrVQr & $\varepsilon \Delta F \& \Lambda$ & غير ساكن ............................................................ \\
\hline$|1 \wedge 9|$ & 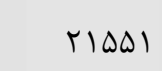 & $r T \Lambda \cdot Q$ & fretor & ساكن در نقاط شهرى .... \\
\hline FqFT & १९८५ & $1 \cdot V r r$ & $r \cdot V \cdot \varphi$ & ساكن در نقاط روستايى . \\
\hline 91 & $|1|$ & TrF & $r \cdot \Delta$ & 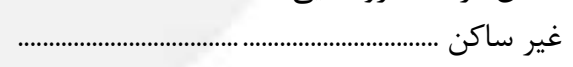 \\
\hline $94 \cdot$. & १४५ & $19 \Delta 9 F$ & rV৭৭r & 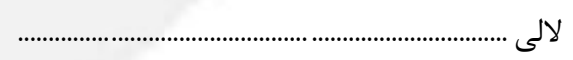 \\
\hline FAtr & $9 \cdot 94$ & 941. & IAFVT & ساكن در نقاط شهرى ..... \\
\hline frrv & 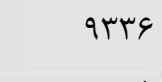 & $1.1 \Delta F$ & 1949. & ساكن در نقاط روستايى .................................... \\
\hline$r \cdot 110$ & $\Delta \Delta \vee G$. & $\Delta \vee \& \Delta q$ & $11 K 419$ & مسجدسليمان ............... \\
\hline reVq. & $\Delta \cdots r$ & $\Delta I \Delta \Lambda T^{\prime}$ & $1 \cdot 10 \wedge 9$ & ساكن در نقاط شهرى ... \\
\hline r.V & $\Delta V 19$ & q.rV & IIVDS & ساكن در نقاط روستايى \\
\hline 11 & щ & rq & VV & 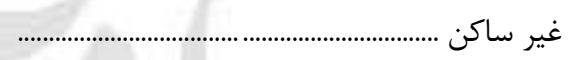 \\
\hline$\Delta 9 \cdot 1$ & 1.948 & 11194 & Tr119 & 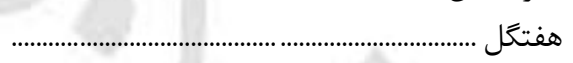 \\
\hline FrAT & VYA & $\Lambda \cdot r l$ & $1 \Delta \Lambda \cdot r$ & ساكن در نقاط شهرى ..... \\
\hline ISTD & mifo & TIVT & Griv & ساكن در نقاط روستايى ...................... \\
\hline 1.949 & $191 \% 4$ & 19949 & TAVGT & 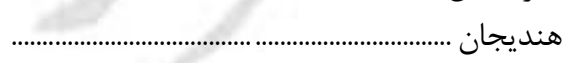 \\
\hline Nrrq & IFArT & IOTVE & $r \cdot r \cdot v$ & 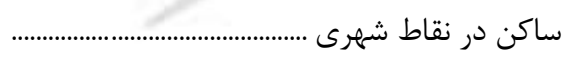 \\
\hline$r F \cdot V$ & rr. & FrAT & $\Lambda \Delta \Delta \Delta$ & 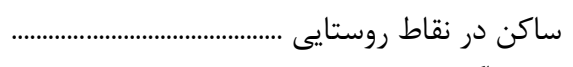 \\
\hline$\cdot$ & - & • & • & 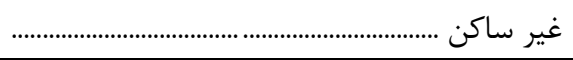 \\
\hline
\end{tabular}


ط - جمعيت و خانوار شهرستانهاى كشور به ترتيب استان (دنباله)

\begin{tabular}{|c|c|c|c|c|}
\hline 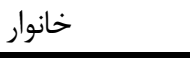 & زن - ت - ت & 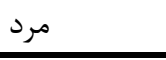 & جمعيت & شرح \\
\hline qpeq & $1 \wedge \vee \Delta q$ & $T \cdot I T V$ & 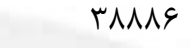 & 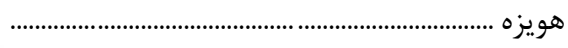 \\
\hline$\Delta 91 \cdot$ & $11 F \Delta V$ & $\| \wedge r \mid$ & trtra & ساكن در نقاط شهرى .. \\
\hline rorq & $V r \cdot r$ & $\Lambda r \cdot \varphi$ & $1 \Delta \varphi \cdot \Lambda$ & 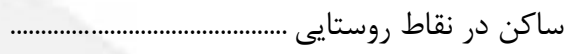 \\
\hline . & · & · & · & 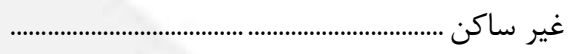 \\
\hline rriqur & Drreir & DrFAFq & 1. DVFEI & 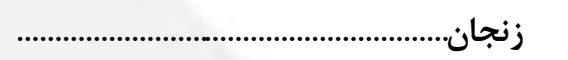 \\
\hline tivit & 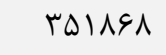 & $r \Delta q r \cdot q$ & VIIIV & ساكن در نقاط شهرى ... \\
\hline $1 \cdot \operatorname{trgq}$ & $I V \cdot V F F$ & IVDQTq & MFGTAK & ساكن در نقاط روستايى \\
\hline 1 & $\cdot$ & 1 & 1 & 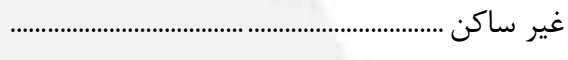 \\
\hline FVrrq & $V F \wedge \Delta$ & 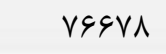 & IDIDTA & 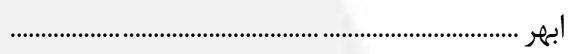 \\
\hline rqr人q & Grr.V & $q \mu \Lambda \cdot V$ & $|r G \| 1| F$ & ساكن در نقاط شهرى . \\
\hline$\Lambda \cdot r \cdot$ & ITDFT & $|r \wedge V|$ & TDFIF & ساكن در نقاط روستايح \\
\hline - & - & & - & 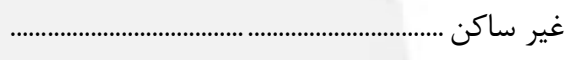 \\
\hline IIrIV & $11 \cdot 94$ & $\curlywedge \wedge \Delta \vee \wedge$ & rGG4I & 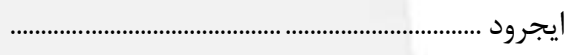 \\
\hline 99 . & س & $199 \mathrm{~V}$ & 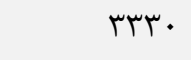 & ساكن در نقاط شهرى ...... \\
\hline $1 \cdot r \Delta V$ & left. & $19 \wedge \wedge 1$ & 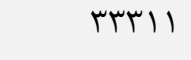 & ساكن در نقاط روستايى \\
\hline & & & - & 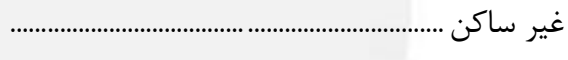 \\
\hline 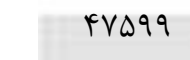 & $11 T \cdot 1$ & Arrqt & leffqu & 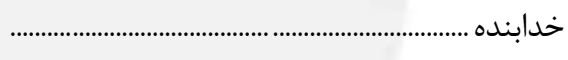 \\
\hline 119V9 & TrTDI & rtqit & 901द & ساكن در نقاط شهرى .. \\
\hline r人৭r. & $\uparrow \wedge १ \Delta$. & $\Delta \cdot r \wedge \cdot$ & ११५r. & ساكن در نقاط روستايح \\
\hline י & • & · & बV१Q। & 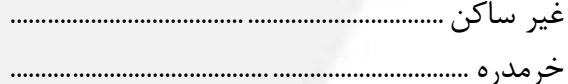 \\
\hline IVTFE & TVFT. & rvark & $\Delta \Delta r \varepsilon \Lambda$ & ساكن در نقاط شهرى .. \\
\hline r^V. & G) & gr.. & 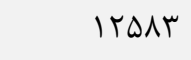 & ساكن در نقاط روستايح \\
\hline & & & & 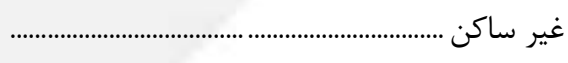 \\
\hline $1 \Delta q \cdot r \cdot$ & 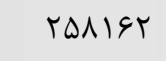 & TEMIF. & $\Delta T I T \cdot T$ & 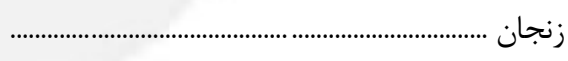 \\
\hline وهاسM & rIfG.r & rINAVT & FrmfVD & ساكن در نقاط شهرى ........ \\
\hline rه人⿻ & FrDDq & FFTEV & AVArs & 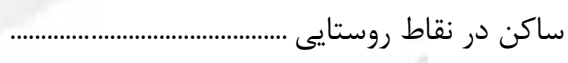 \\
\hline 1 & $\cdot$ & & 1 & 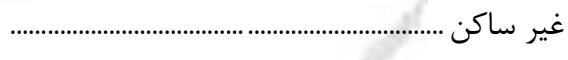 \\
\hline 911. & lFor. & 1490 & rq४^. & 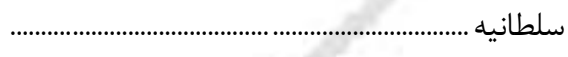 \\
\hline 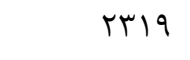 & TVTV & एq। & 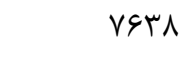 & ساكن در نقاط شهرى . \\
\hline $9 \wedge 11$ & $1 \cdot \lambda \cdot r$ & $11 \cdot 4 q$ & TINFT & ساكن در نقاط روستايح \\
\hline • & · & · & & 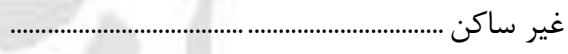 \\
\hline IFFr & TYATV & $r r \Lambda \cdot r$ & F\&\&4I & 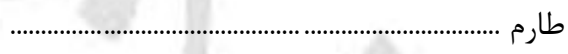 \\
\hline$r \cdot r q$ & FAFG & rqv^ & qArr & ساكن در نقاط شهرى .. \\
\hline$\| F \mid r$ & |V११| & IAMrE & rGNIV & ساكن در نقاط روستايي \\
\hline 11940 & $19 r \Delta 9$ & $r . .99$ & rqFTa & 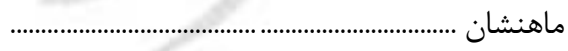 \\
\hline rqтq & $\Delta \cdot V I$ & 0194 & $1 \cdot r 90$ & 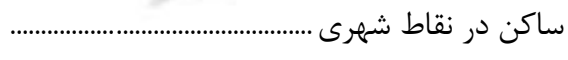 \\
\hline ८९९६ & $I F Y \wedge D$ & IFAVQ & rq19. & 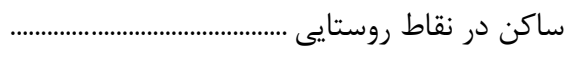 \\
\hline$\cdot$ & $\cdot$ & $\cdot$ & $\cdot$ & 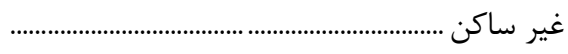 \\
\hline
\end{tabular}


ط - جمعيت و خانوار شهرستانهاى كشور به ترتيب استان (دنباله)

\begin{tabular}{|c|c|c|c|c|}
\hline خانوار & 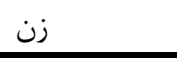 & 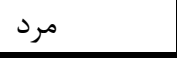 & جمعيت & شرح \\
\hline rIDAVI & $r F \Delta V \cdot F$ & rDS\&DS & $r \cdot r \mu s$. & 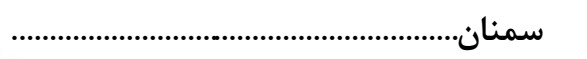 \\
\hline $199 \vee \Delta \Delta$ & rVYaqu & rATQ.r & $\Delta \varphi \cdot \Delta \cdot r$ & 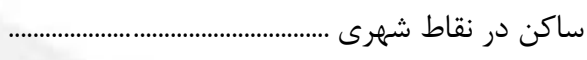 \\
\hline ra八 & $9 V V \cdot 9$ & VFIOT & $|F| \wedge \Delta \Lambda$ & 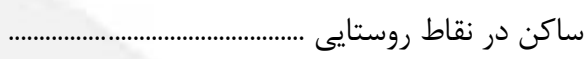 \\
\hline . & . & & $\cdot$ & 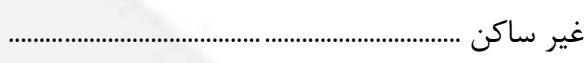 \\
\hline 4919 & 911V & $V \cdot 9 V$ & IrAMF & 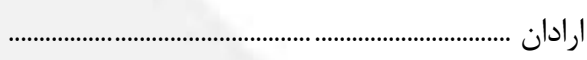 \\
\hline TQFT & reVt & rVvV & verq & ساكن در نقاط شهرى .......... \\
\hline rrve & rifs & rrq. & grto & ساكن در نقاط روستايى ...... \\
\hline & & • & & 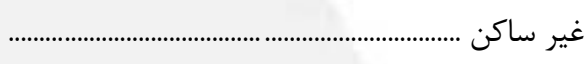 \\
\hline r. r৭६ & $q V \cdot 9 \Lambda$ & FVITK & 9419. & 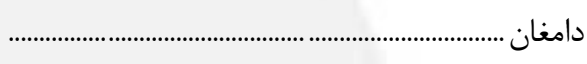 \\
\hline 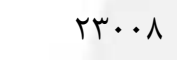 & rGqVG & reTFq & VTaro & 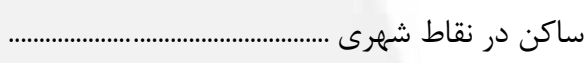 \\
\hline VYAM & I.rar & $1 \cdot \wedge V r$ & rIT\&D & 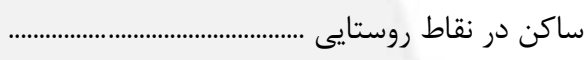 \\
\hline . & & & & 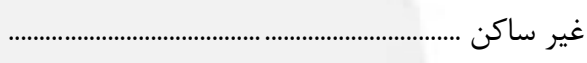 \\
\hline Drr. & VबDG & 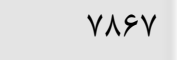 & IDQTK & 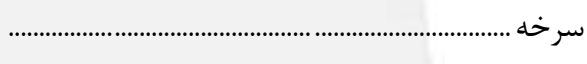 \\
\hline rrak & fqrq & $D \cdot r t$ & 9901 & ساكن در نقاط شهرى ..... \\
\hline $19 F$ & TVTV & rAFQ & $\Delta \Delta V T$ & ساكن در نقاط روستايى . \\
\hline$\Delta r \cdot 11$ & $१ \Delta \Delta \vee \wedge$ & $1 \ldots q q \mu$ & $199 \Delta T \mid$ & 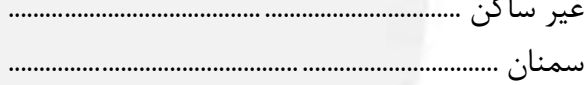 \\
\hline FqITF & $q \cdot \vee \backslash 1$ & qFyוl & INDIYq & ساكن در نقاط شهرى .. \\
\hline rAMV & 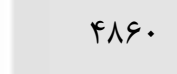 & gQTr & l1rar & ساكن در نقاط روستايى. \\
\hline & & & & 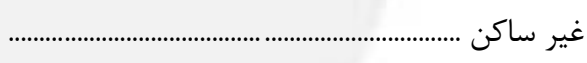 \\
\hline gqVTr & 1. verv & 111191 & rIAGYA & 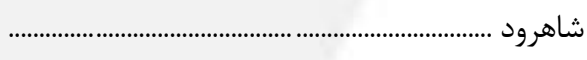 \\
\hline DGMTT & AVEFA & MMqYF & $1 V 9919$ & ساكن در نقاط شهرى ... \\
\hline $\mid r F \cdot 1$ & 19Y9r & TTHIV & fr.. q & ساكن در نقاط روستايى \\
\hline & & & & 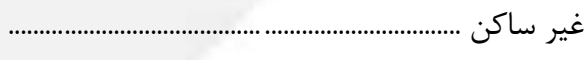 \\
\hline$r \Delta \Delta \wedge \Delta$ & TATFq & rqIVr & VYETI & 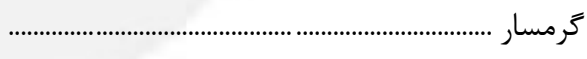 \\
\hline$r \cdot 99 r$ & 11191 & r. १९r & 9rig. & ساكن در نقاط شهرى .... \\
\hline ४^११ & $v \cdot \Delta l$ & $\wedge 1 \wedge$ & $\mid$ DST & ساكن در نقاط روستايى . \\
\hline IDTRE & THGT & rmAFF & FYEVD & 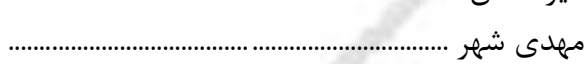 \\
\hline ITTED & $r \cdot \wedge v \wedge$ & $r \cdot \vee 9 \Delta$ & fisvr & ساكن در نقاط شهرى ... \\
\hline 1911 & TVQT & $r \cdot k q$ & $\Delta \Lambda \cdot r$ & ساكن در نقاط روستايى \\
\hline & & $\cdot$ & · & 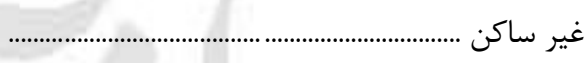 \\
\hline$|T F A|$ & 19481 & 1940 & rAVIA & 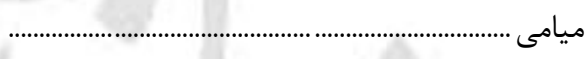 \\
\hline$|F \mu|$ & TTAT & rrAF & fD\&G & ساكن در نقاط شهرى ...... \\
\hline $11 \cdot \Delta \cdot$ & 19919 & IVIG9 & MFIOT & نقاط روستايى . \\
\hline$r \cdot$ FA11 & $1 r r r \cdot 1 r$ & $|f \cdot| 94 \mid$ & $r r r a \cdot I f$ & 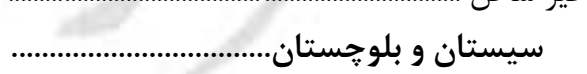 \\
\hline$r m 4 \cdot \Lambda$ & $94 \cdot 4 V q$ & GNDIGT & IMFDGFT & 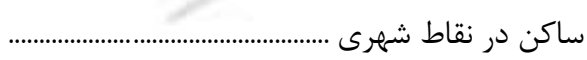 \\
\hline rGarts & VIIVIF & $\vee \backslash \Delta \& \mid \Lambda$ & IFTHMT & 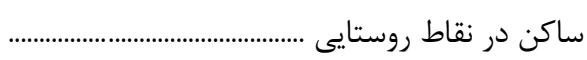 \\
\hline$\Lambda \Delta F$ & $\wedge 9$. & 110 & $r \cdot r \cdot$ & غير ساكن ................. \\
\hline
\end{tabular}


ط ـ جمعيت و خانوار شهرستانهاى كشور به ترتيب استان (دنباله)

\begin{tabular}{|c|c|c|c|c|}
\hline خانوار & 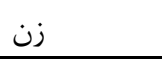 & 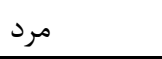 & جمعيت & شرح \\
\hline GTSTD & ITEGTY & ITVGqT & TAFTIF & 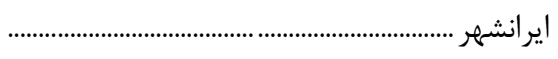 \\
\hline TFTVE & $991 \Delta$. & VI911 & $|f| \leqslant \varepsilon \mid$ & ساكن در نقاط شهرى ............ \\
\hline TATHA & $\Delta \& V Y I$ & $\Delta \varphi \cdot \Lambda \cdot$ & $\| r \wedge \Delta \mid$ & 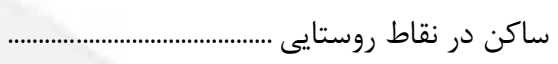 \\
\hline 1 & 1 & 1 & r & 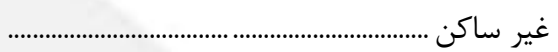 \\
\hline GNIFV & IrAVTr & IFFAN & TAKT. F & 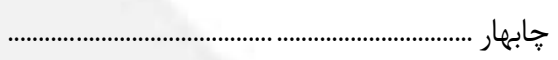 \\
\hline TYYIS & DFATD & $\Delta V \Delta V F$ & $11 r k \cdot q$ & 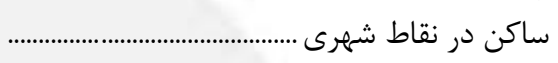 \\
\hline 4.911 & ArAMF & ヘ๕ヘ१ฬ & $I V \cdot V V \Lambda$ & ساكن در نقاط روستايى .................... \\
\hline r & r & if & iv & 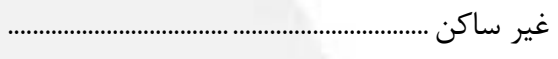 \\
\hline अAr१९ & $\wedge 9 \Delta 91$ & AVTr. & IVRATI & 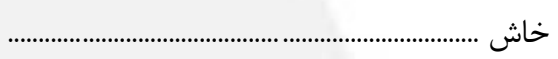 \\
\hline lQVQA & $r \cdot V r \Lambda$ & mIIV & GINFs & ساكن در نقاط شهرى ............. \\
\hline rita & $\Delta \Delta T Y I$ & $\Delta \Delta F \& \Lambda$ & $11 \cdot \operatorname{vrq}$ & 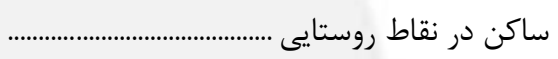 \\
\hline$\Delta \cdot r$ & DQT & sta & IrrV & 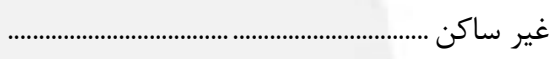 \\
\hline$|9 \Delta \Delta|$ & TFTAT & rTOVQ & GVADV & 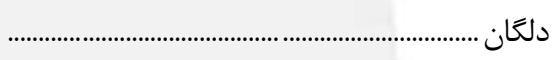 \\
\hline TYQ. & DIT. & DIVT & 1. rq4 & ساكن در نقاط شهرى ........ \\
\hline$|f| \cdot \mid$ & rq19र & $r \Lambda F \cdot r$ & $\triangle Y \triangle Q \Delta$ & ساكن در نقاط روستايى ... \\
\hline Frve & ATEV. & ^५१९९ & 190994 & 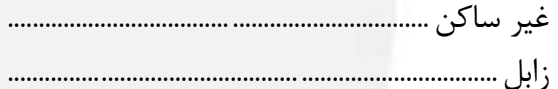 \\
\hline rGFTA & 99194 & $99 \Delta F \wedge$ & $\mid$ ruvi. & ساكن در نقاط شهرى .... \\
\hline VTGK & irkat & Thte & TSQTF & 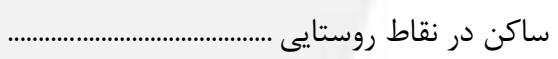 \\
\hline 1 . & 19 & 19 & rt & 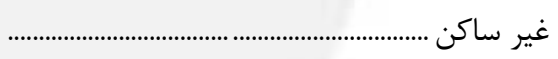 \\
\hline $19 \wedge \uparrow \wedge$. & r...90 & METATE & 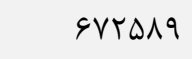 & زاهدان ................................ \\
\hline IFVqVT & $r q \cdot \wedge V r$ & $r \cdot r \cdot 9 \Delta$ & DQT१९八 & ساكن در نقاط شهرى ... \\
\hline r. $९ q 9$ & ५9191 & F. Fr. & V१९ाI & 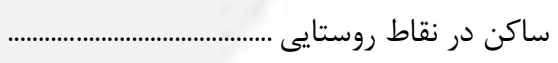 \\
\hline & 1 & 9 & 1. & غير ساكن ................................. \\
\hline$r \cdot \Delta \Delta$ & שrוt & rVVG & 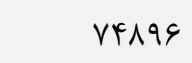 & زهك \\
\hline rTHA & gDST & qVqF & IrTaV & ساكن در نقاط شهرى ....... \\
\hline $1911 \mathrm{~V}$ & $r \cdot \Delta V$. & $r \cdot 999$ & बIQTq & 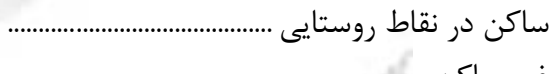 \\
\hline$\Delta \cdot \Delta T F$ & $9 \Delta \cdot v r$ & $99 \Delta \wedge १$ & 191991 & 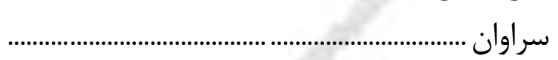 \\
\hline$r F \cdot V \varepsilon$ & $+4 \lambda \cdot 1$ & $|49| \cdot \Delta$ & $9 \cdot 9 \cdot 9$ & ساكن در نقاط شهرى ... \\
\hline TGMIF & $0.1+9$ & $\Delta \cdot r \cdot V$ & 1..rar & ساكن در نقاط روستايى \\
\hline rme & iro & TVV & $r \cdot r$ & 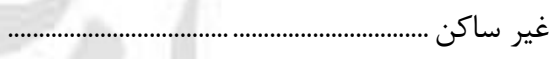 \\
\hline (9Q9). & QTrYI & qYএ१४ & $\mid \wedge 9190$ & سرباز ...................................... \\
\hline grtr & $\mid r q 1 \%$ & IFTrF & rNIFS & 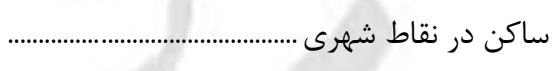 \\
\hline rqQVर & v१५०१ & $\begin{aligned} V \wedge G \Delta G \\
\epsilon\end{aligned}$ & $101 \cdot 10$ & ساكن در نقاط روستايى ..... \\
\hline rI990 & หr人१९ & FTIQS & $\wedge \Delta \cdot 9 \Delta$ & 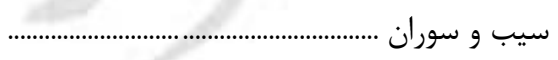 \\
\hline rVF. & VATF & VVr. & IDTAF & 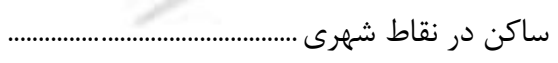 \\
\hline IVATF & rarva & rFYG & 99人ץ^ & 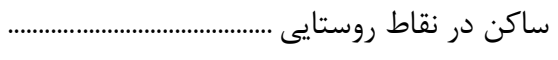 \\
\hline 1 & . & r & r & 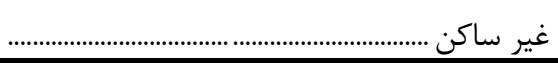 \\
\hline
\end{tabular}


ط - جمعيت و خانوار شهرستانهاى كشور به ترتيب استان (دنباله)

\begin{tabular}{|c|c|c|c|c|}
\hline خانوار & 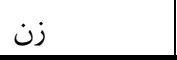 & 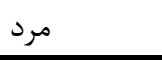 & 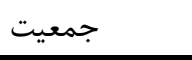 & شرح \\
\hline $1 K \varepsilon \cdot 4$ & 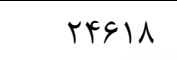 & TFAFT & $\mid 99181$ & 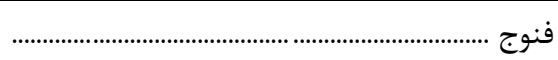 \\
\hline ryl. & gQFI & garq & $\mu \cdot v \cdot$ & 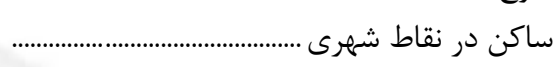 \\
\hline 9194 & $M \cdot v V$ & $1 \lambda \cdot||^{\mathrm{F}}$ & re.91 & 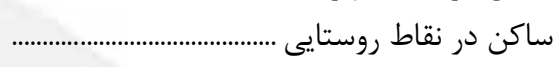 \\
\hline & - & - & & 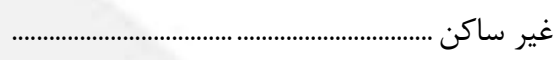 \\
\hline IDQTF & $r \cdot v \Delta I$ & $r \cdot r r \Delta$ & $91 \cdot \sqrt{9}$ & 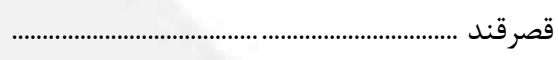 \\
\hline reqq & $\Delta \wedge \vee$. & $\Delta V r \Delta$ & $119 \cdot \Delta$ & ساكن در نقاط شهرى ................ \\
\hline ITAVD & TYAMI & rFDq. & FqFV & 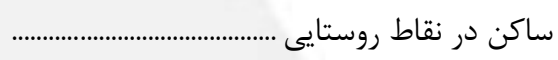 \\
\hline · & & • & & 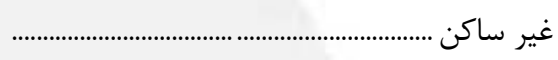 \\
\hline rrg.. & FafFF & DTVGA & QATIT & 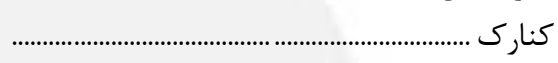 \\
\hline $1 \cdot \wedge r \cdot$ & $r \cdot v r q$ & TEQTT & FYrel & 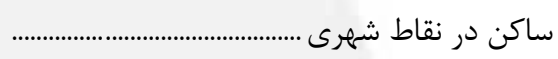 \\
\hline ITVR. & $r F V \cdot \Delta$ & TETFE & $\Delta \cdot 901$ & ساكن در نقاط روستايى ........... \\
\hline$\cdot$ & • & & & غير ساكن ................................. \\
\hline $\begin{array}{l}I V F \cdot V \\
r g c a\end{array}$ & rDDFA & 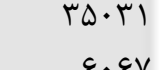 & $\begin{array}{l}V \cdot \Delta V q \\
1 r r k \Delta\end{array}$ & 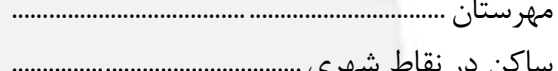 \\
\hline $\begin{array}{l}\text { rag9 } \\
\text { rexp }\end{array}$ & 9IV^ & $4.9 \mathrm{~V}$ & 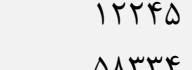 & \\
\hline IFFTA & rqur. & rА१दץ & DATHF & 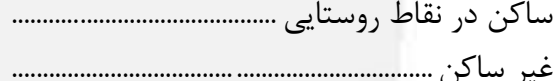 \\
\hline $11 \wedge \Delta r$ & rtrig & rravA & roruV & 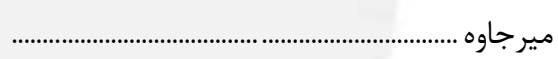 \\
\hline$r 1 \cdot r$ & 49.9 & FVD. & $q \mu \Delta q$ & ساكن در نقاط شهرى .............. \\
\hline qYFe & IVVr. & IATrA & rЬ৭१^ & 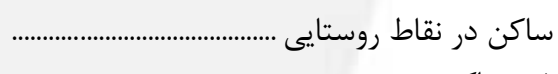 \\
\hline & & & & 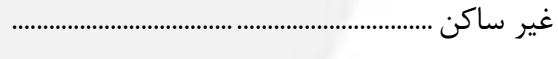 \\
\hline$r V t \cdot V$ & $V \cdot 91 V$ & $V \cdot 9 \vee V$ & $141 \wedge 94$ & 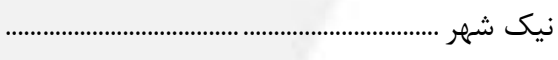 \\
\hline $9 \vee \wedge 9$ & Irর\&A & $\mid F F \cdot \Delta$ & tATVt & ساكن در نقاط شهرى ...... \\
\hline$r \cdot f \backslash 1$ & $\Delta V \cdot r \wedge$ & $\Delta Q \Delta \Delta T$ & $\mid 1 r \Delta q 1$ & 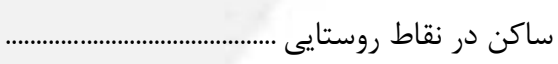 \\
\hline $1 \cdot$ & 11 & 19 & r. & 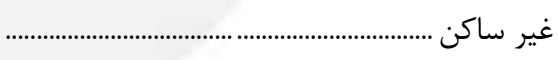 \\
\hline ITV.. & rrqזq & TFAFT & FAFVI & 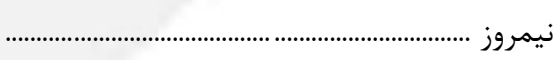 \\
\hline ᄉAT & 1949 & $199 \mathrm{~V}$ & r & 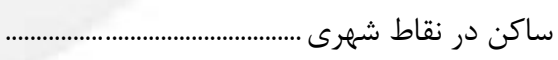 \\
\hline $111 \cdot 9$ & r1911 & trVqR & feVIt & ساكن در نقاط روستايى ....................................... \\
\hline rq & 90 & 11 & life & 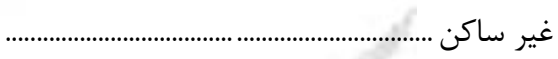 \\
\hline$\| r \wedge$ & $r \cdot \Delta \Delta \cdot$ & $r \cdot r \& V$ & $41.1 \mathrm{~V}$ & 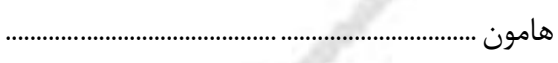 \\
\hline$r r \cdot 1$ & Firt & $f \| f$ & NTFV & ساكن در نقاط شهرى ... \\
\hline$q \cdot r q$ & $|\& M y|$ & IGTVY & TrGIT & ساكن در نقاط روستايى \\
\hline r. & Ve & 11 & $i \Delta V$ & 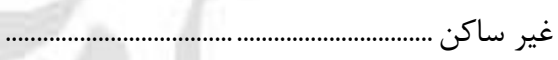 \\
\hline $19 \Delta \Delta 9$ & MIST. & rTHQQ & ятq४q & 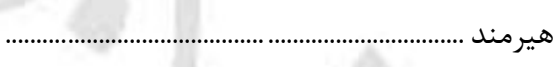 \\
\hline Ifit & Trtr & rrqu & G94 & 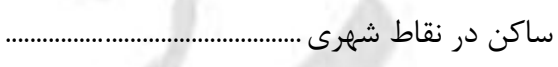 \\
\hline IDIFV & rیrqu & r८৭९८ & $\Delta V r \Delta \Lambda$ & 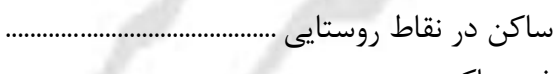 \\
\hline IFFr. rV & rrq...r & rFeIraI & FADITVE & 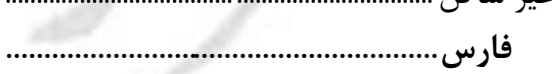 \\
\hline D. TYK.t & $|9 \wedge \uparrow| \Delta \Delta$ & IVIVAT. & $M F \cdot 19 V D$ & 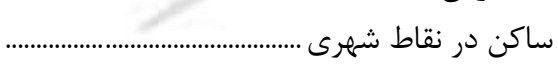 \\
\hline$f \mid Q \cdot \wedge \Delta$ & 99४^91 & Vrefer & IFrTrad & 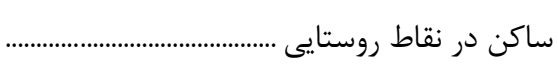 \\
\hline$\Delta \Delta Y$. & vavv & $94 \& V$ & IVTFY & غير ساكن ........... \\
\hline
\end{tabular}


ط - جمعيت و خانوار شهرستانهاى كشور به ترتيب استان (دنباله)

\begin{tabular}{|c|c|c|c|c|}
\hline خانوار & 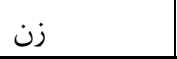 & 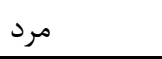 & جمعيت & شرح \\
\hline rISVT & pq人ץ. & $\Delta \cdot 991$ & $|\cdots \wedge r|$ & 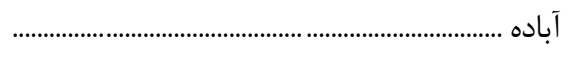 \\
\hline$r \Lambda \cdot \Lambda r$ & $k F \cdot 14$ & FFTIT & MATrG & ساكن در نقاط شهرى ........... \\
\hline$r \Delta \wedge F$ & $\Delta \wedge r \mid$ & gVVr & IrQqF & 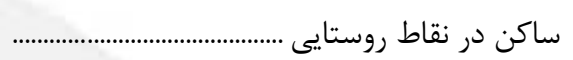 \\
\hline$\Delta$ & 9 & $\Delta$ & 11 & 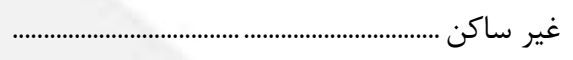 \\
\hline ITAVA & $r l \cdot r \Delta$ & tive. & FTVTD & 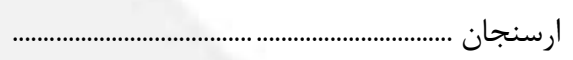 \\
\hline DTAF & $\wedge \vee \notin q$ & $\wedge १ \Delta \vee$ & $1 V V \cdot \varphi$ & 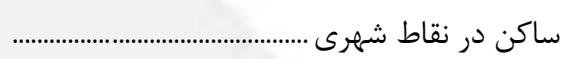 \\
\hline VDQT & ITYKT & $|r V F|$ & $r \Delta \cdot I r$ & 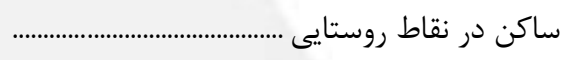 \\
\hline r & r & r & \& & 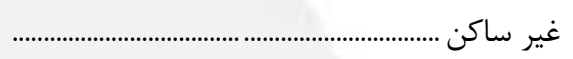 \\
\hline$r \cdot \wedge 9$. & rr人fq & $r \Delta \cdot \cdots l$ & $\Leftrightarrow \wedge \Lambda \Delta$. & 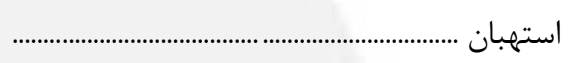 \\
\hline$|\notin 9|$. & rrqu & TEFVA & FAFIS & 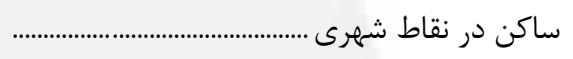 \\
\hline Gr\&q & 9194 & $1 \cdot \Delta \cdot F^{c}$ & $r \cdot r 9 \Lambda$ & ساكن در نقاط روستايى ....... \\
\hline 11 & iv & 19 & r & 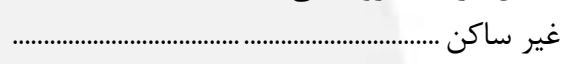 \\
\hline TVYTI & FEIrA & eVGro & qrVदr & اقليد.................................. \\
\hline $1991 \pi$ & TATVF & rAVAr & $\Delta V \cdot \Delta V$ & ساكن در نقاط شهرى ....... \\
\hline $1 \cdot r \cdot \Delta$ & $\operatorname{lVr\Delta \Delta }$ & $|A T \lambda|$ & 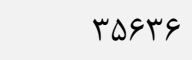 & ساكن در نقاط روستايى ... \\
\hline$r \cdot r$ & $<99$ & $\Delta V I$ & $1 \cdot v \cdot$ & 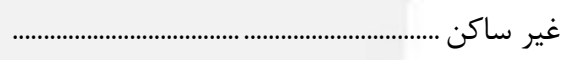 \\
\hline IDAVF & TFFA. & 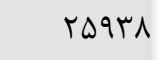 & $\Delta \cdot+\mid \Lambda$ & 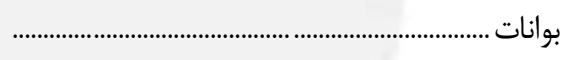 \\
\hline GFrV & $99 \cdot \wedge$ & $1 \cdot \Delta r$. & terth & ساكن در نقاط شهرى ....... \\
\hline grev & IFAVT & IDFIA & ५११९. & 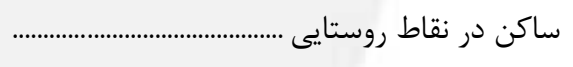 \\
\hline & & & & غير ساكن ......................... \\
\hline NAIr & IFVFS & IQRVR & $r \cdot 11 \Lambda$ & 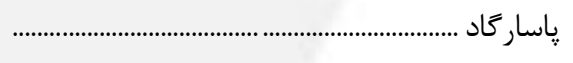 \\
\hline DFVT & 9191 & 9019 & I $\ \& V$ & ساكن در نقاط شهرى .... \\
\hline 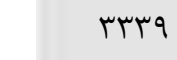 & $\Delta \Delta \wedge \mu$ & $\Delta \wedge \Delta \varphi$ & 11 \&rq & ساكن در نقاط روستايع \\
\hline 1 & 1 & 1 & r & 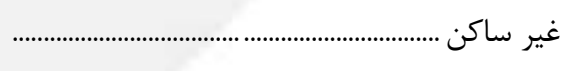 \\
\hline$v \cdot 1 \wedge V$ & $1.9 F F T$ & 119.9. & trADTt & جهرم .............................. \\
\hline rqurr & $V V V \cdot V$ & NFIFF & $|\&| \wedge \Delta \mid$ & 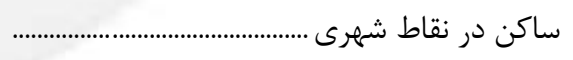 \\
\hline$r \cdot 1 \cdot r$ & MITIF & TFFET & GQVVG & 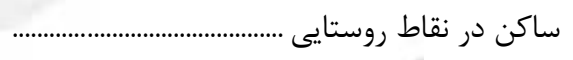 \\
\hline rII & FTI & FAF & $q \cdot \Delta$ & 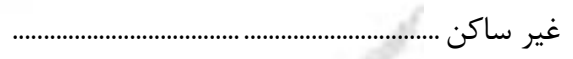 \\
\hline IGNVF & TENFT & $r \Lambda \cdot r \mid$ & DFAGF & خرامه .................................. \\
\hline gril & $1 \cdots v f$ & 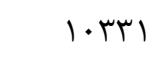 & $r \cdot r \cdot \Delta$ & ساكن در نقاط شهرى .... \\
\hline 1.994 & $19 \vee 99$ & IV99. & TEYAq & ساكن در نقاط روستايى \\
\hline - & $\cdot$ & · & $\cdot$ & 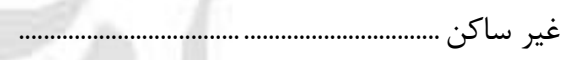 \\
\hline $10 \cdot \Lambda \cdot$ & TYA\&Y & $r \Delta \& \Delta q$ & $\Delta \cdot \Delta T r$ & خرم بيد ................................. \\
\hline$|r \Delta| Q$ & $r .999$ & $r I r \cdot V$ & 419.9 & 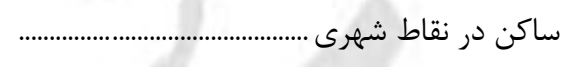 \\
\hline TDGF & figf & FEAT & & غاكن در نقاط روستايى ................................................... \\
\hline $1 \cdot v \cdot \Lambda$ & $r \cdot V T I$ & $r \cdot G r \Lambda$ & firda & خنج \\
\hline 4990 & $9 \Leftrightarrow 4 \wedge$ & $9 \Delta ९ 9$ & I9YIV & 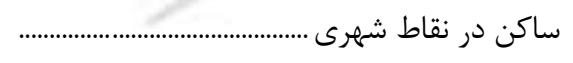 \\
\hline G. PT & $11 \cdot V r$ & 11.91 & TrIT. & 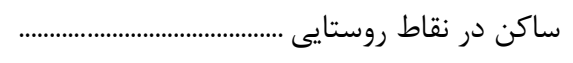 \\
\hline 1 & 1 & 1 & r & 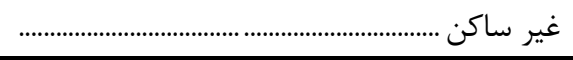 \\
\hline
\end{tabular}


ط ـ جمعيت و خانوار شهرستانهاى كشور به ترتيب استان (دنباله)

\begin{tabular}{|c|c|c|c|c|}
\hline خانوار & 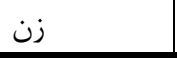 & 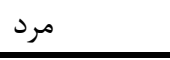 & جمعيت & 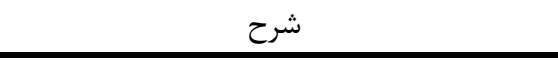 \\
\hline$\Delta 9 \Delta \Gamma \Delta$ & १८৭९१ & 1. TAT. & $r \cdot \mid r \wedge q$ & داراب ....................................................................... \\
\hline TVYSV & frq19 & $r \Delta \Lambda F \wedge$ & $q \cdot \wedge r r$ & 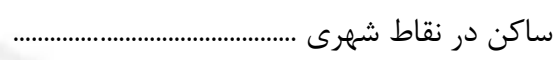 \\
\hline rtוr & DrGqF & $\Delta G r \Lambda \Lambda$ & $11 \cdots \wedge r$ & 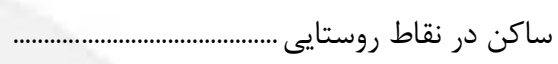 \\
\hline $14 \Delta$ & rیq & rAY & $\Delta V r$ & 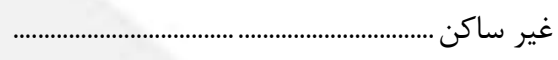 \\
\hline 1 ITSA & tTAIt & rIAVF & ferke & 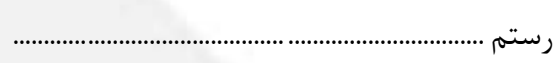 \\
\hline$r \Delta \cdot 1$ & grqv & $\Delta q \vee 1$ & ITTSN & ساكن در نقاط شهرى ............ \\
\hline $91 \Delta \mathrm{V}$ & $19 r \cdot r$ & $10 \wedge 9$. & rt. Th & ساكن در نقاط روستايى .......... \\
\hline $1 \cdot$ & it & ir & TQ & 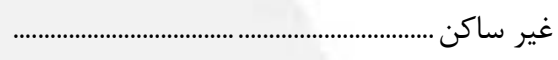 \\
\hline t.rth & rद. ^9 & rril. & VrI99 & 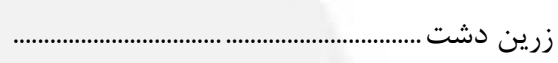 \\
\hline ITKID & TIVEV & TrGGY & FFil & ساكن در نقاط شهرى ............ \\
\hline$\Lambda \cdot \Delta 1$ & IFTIV & Ifrte & rADF. & ساكن در نقاط روستايى ..... \\
\hline ar & ira & Irr & TFA & 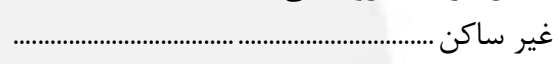 \\
\hline TEYAI & ferve & FETVK & 91.49 & 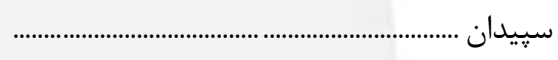 \\
\hline 1191 & 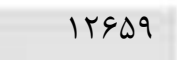 & $\| r \cdot v \wedge$ & TQVTV & ساكن در نقاط شهرى ...... \\
\hline 19111 & rTाI & (TI9T & $9 \Delta r \cdot \Delta$ & ساكن در نقاط روستايى .... \\
\hline$r$ & r & r & $\checkmark$ & 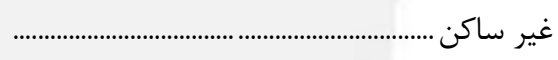 \\
\hline $119 \Delta r$ & 119.9 & $19 \Delta \cdot \Delta$ & rNIIF & 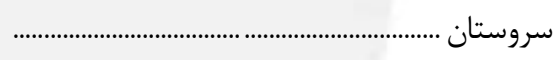 \\
\hline (494 & $1.9 r V$ & $1 \cdot \lambda+1$ & rIFen & ساكن در نقاط شهرى ... \\
\hline 0.19 & ท৭ท & NG૬Y & $|994|$ & ساكن در نقاط روستايى .... \\
\hline 1 & r & r & $\Delta$ & 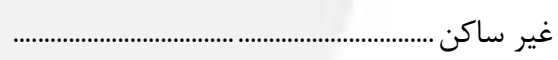 \\
\hline$\triangle S Y \triangle Q V V$ & 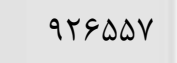 & gFYFFE & $1 \wedge 99 . .1$ & 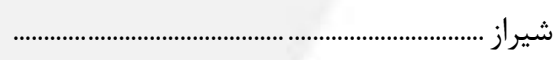 \\
\hline DrTIGq & NATYYT & Ne..trt & IVITVEA & ساكن در نقاط شهرى ... \\
\hline pq..r & VTrVt & $\wedge 1 \wedge \Delta 9$ & |DQTH| & ساكن در نقاط روستايى \\
\hline r१ه & FGT & 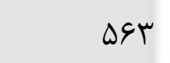 & $1 \cdot r \Delta$ & 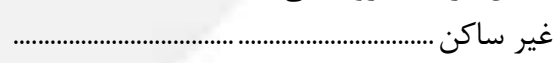 \\
\hline $1 K G \cdot F$ & TTATR & rTQYG & $F \Delta F \Delta q$ & فراشبند .................................... \\
\hline V^^9 & IrATA & IrVrq & TVDQV & ساكن در نقاط شهرى ...... \\
\hline $\operatorname{tg} \Delta \Lambda$ & $\Lambda T \Delta \varphi$ & $\wedge \vee{ }^{\prime}$. & 19999 & ساكن در نقاط روستايح \\
\hline$r \Delta V$ & pqq & YAV & (9) & 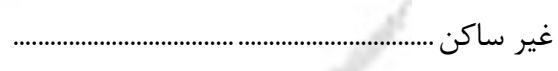 \\
\hline 910.9 & $1 \ldots q 41$ & 1. FYFE & $r \cdot \Delta I A V$ & 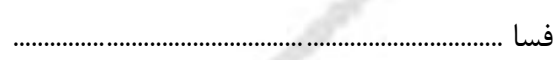 \\
\hline FTG. F & $V \cdot r \cdot r$ & VIrqs & 141091 & ساكن در نقاط شهرى \\
\hline $1 \wedge \Lambda \Delta \Delta$ & $r \cdot \varphi \Delta r$ & TTVDS & GMF. $q$ & ساكن در نقاط روستايي \\
\hline$\Delta \cdot$ & $\wedge \varphi$ & 94 & 11 & 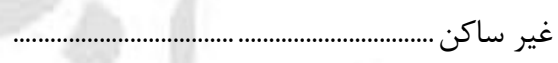 \\
\hline TVFAT & $9 \cdot|V|$ & SITYS & IrIFIV & 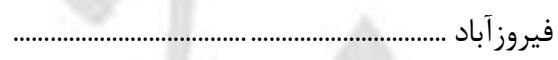 \\
\hline rmpl. & rVrqq & rیוr & VDQTY & ساكن در نقاط شهرى ..... \\
\hline $\mid$ IFTI & $r \cdot r \mid r$ & $r \cdot \Delta \wedge \varphi$ & 4.999 & ساكن در نقاط روستايي \\
\hline IS1T & TrDQ & TATY & FMAI & غير ساكن ................................................................. \\
\hline$r \cdot \Delta \cdot \Lambda$ & rFark & rद940 & RIt.r & 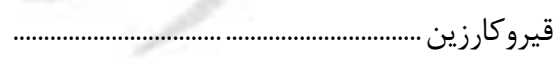 \\
\hline IIATV & $r \cdot 911$ & $r \mid r \cdot V$ & FT. IN & 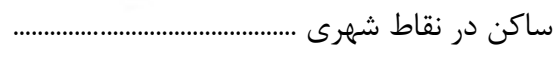 \\
\hline N1.r & $1 \pi r 90$ & וrq1 & TVTAK & 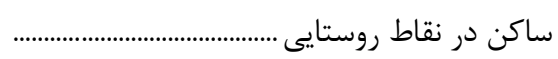 \\
\hline$\Delta \vee q$ & Grt & irv. & $19 \cdot r$ & غير ساكن ........ \\
\hline
\end{tabular}


ط - جمعيت و خانوار شهرستانهاى كشور به ترتيب استان (دنباله)

\begin{tabular}{|c|c|c|c|c|}
\hline خانوار & 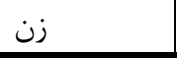 & 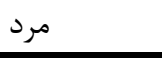 & جمعيت & 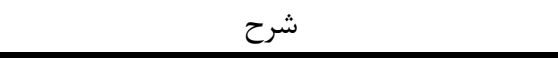 \\
\hline VATTV & Irাध人 & ITFATF & TGGTIV & 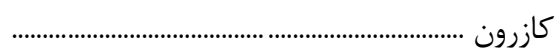 \\
\hline 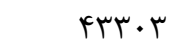 & vrvv. & VFTVD & $\| F \Lambda \mid F \Delta$ & ساكن در نقاط شهرى. \\
\hline rTAIT & $\Delta V Y r q$ & ఎ११VT & $118 v \cdot 1$ & 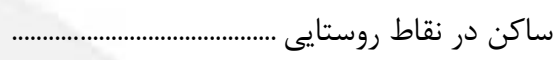 \\
\hline 111 & INF & IAV & rvi & 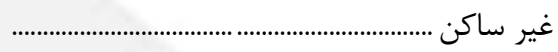 \\
\hline rון & r. \&rq & FrtpF & NrAMr & 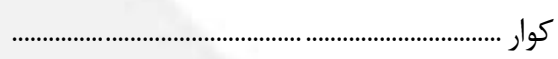 \\
\hline$\Lambda \Delta V \nabla$ & $10 \Delta \cdot 9$ & $194 \cdot \Delta$ & mIVII & 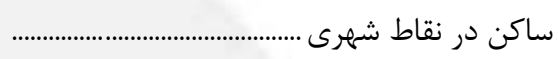 \\
\hline IfFet & TAITQ & $r r^{2}$ & DTIGT & ساكن در نقاط روستايى ........ \\
\hline r & r & 4 & 1. & 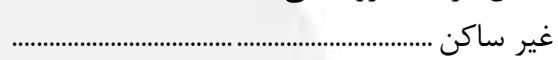 \\
\hline$|\Delta| \Delta \Delta$ & $r \varepsilon r \cdot \Delta$ & TVG. T & $\Delta r q \cdot V$ & 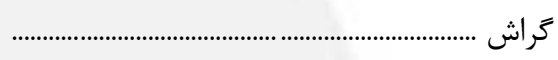 \\
\hline$I \cdot r \cdot V$ & $199 \cdot 4$ & IVDSD & MFYGQ & ساكن در نقاط شهرى ............ \\
\hline rqłA & $94 \cdot 1$ & $1 . . r V$ & $194 r 1$ & 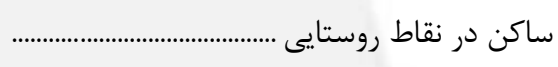 \\
\hline & $\cdot$ & & & 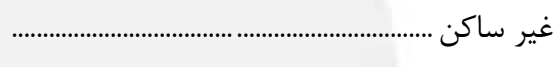 \\
\hline q. 4 l. & 1.4199 & 1. $9 V \Delta F$ & rirqr. & 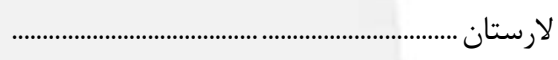 \\
\hline rova. & $9 \cdot \mathrm{qq}$ & serqu & ITATAT & 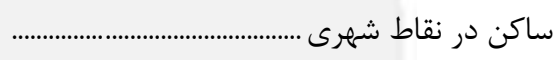 \\
\hline TFYeD & $k r \cdot \Lambda \Lambda$ & FYAMA & 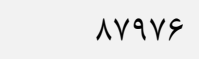 & 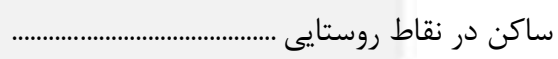 \\
\hline 190 & rAF & rqA & GDT & 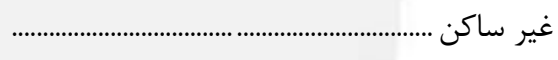 \\
\hline TDATV & FETTI & $\{\Delta\{9\}$ & qIVAr & 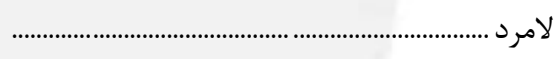 \\
\hline $\mid r q 14$ & $r r \cdot 9 \Lambda$ & TrGFF & FAVFT & 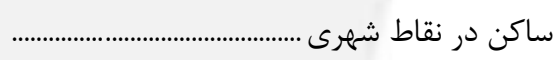 \\
\hline IrqTr & trtik & trNIF & HE.rt & 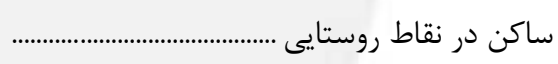 \\
\hline 1 & $\Delta$ & r & $\wedge$ & غير ساكن ............................. \\
\hline 94999 & lQVrVq & $199 \cdot \Delta \Delta$ & remerte & 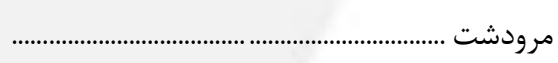 \\
\hline FAVAr & NIIsr & $\Lambda \Delta \Delta \Delta T$ & $199 V 10$ & ساكن در نقاط شهرى .... \\
\hline FANTT & $V 9.99$ & $\lambda \cdot r<q$ & IDEFIA & ساكن در نقاط روستايى \\
\hline 94 & lev & lQF & $r \cdot 1$ & 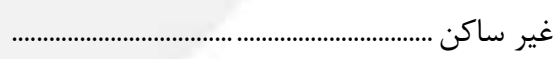 \\
\hline$r \Delta \cdot \varphi \cdot$ & बV११५ & ఎ१०น० & IIVATV & 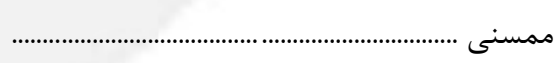 \\
\hline 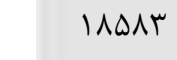 & rIAqF & rTVGT & s4ৎDV & 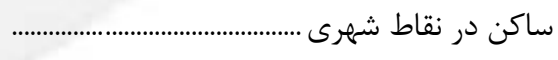 \\
\hline $10 \cdot 11$ & $r F \| Q$ & TFGSV & ravat & 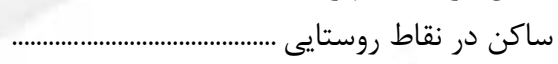 \\
\hline $1 \% \wedge 9$ & $194 r$ & $r l \cdot \Delta$ & $\varphi \cdot \Lambda \Lambda$ & 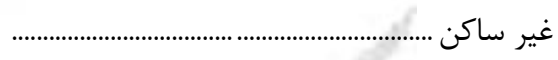 \\
\hline IVTET & mIgve & MTADT & SFATV & 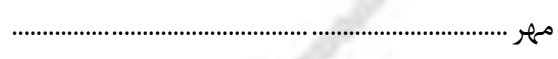 \\
\hline $1 \& 49$ & $|\Delta \& Y|$ & $19 \Delta Y$. & MTIFI & ساكن در نقاط شهرى \\
\hline 191\% & IEMor & 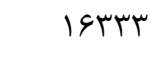 & 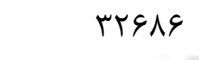 & ساكن در نقاط روستايح \\
\hline & & & · & 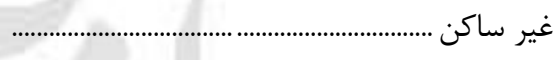 \\
\hline reVVI & $\Delta \Delta q \mu r$ & $\Delta V r \Delta \Lambda$ & $\mid 1 r r q 1$ & 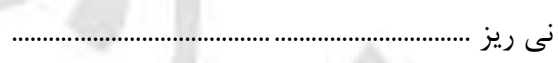 \\
\hline 1997. & rTIDD & rTANS & gPVFI & ساكن در نقاط شهرى ...... \\
\hline $1+\lambda \cdot \mid$ & TrVYA & TFVVT & YNDQ. & غداكن در نقاط روستايى ..................................... \\
\hline ravisd & erreter & $9 \Delta \cdot 4 q 9$ & |rrreges & 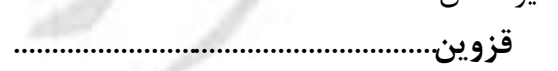 \\
\hline$r 90 \cdot 19$ & FANITt & FAK.TV & $q \Delta r \mid F q$ & 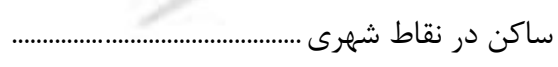 \\
\hline $1 \cdot r \mid F Y$ & $|\Delta \Delta| f$. & 1944. & rTIS1. & 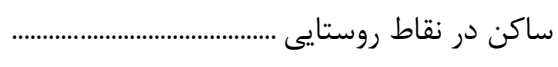 \\
\hline r & & $r$ & $r$ & غير ساكن ......... \\
\hline
\end{tabular}


ط - جمعيت و خانوار شهرستانهاى كشور به ترتيب استان (دنباله)

\begin{tabular}{|c|c|c|c|c|}
\hline خانوار & 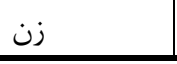 & 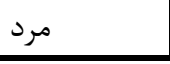 & جمعيت & 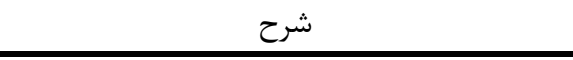 \\
\hline ratru & $F \Delta F \cdot V$ & kq1rq & qFATS & 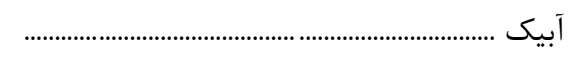 \\
\hline $190 T 1$ & 1.99 & rTIAS & GTTDD & 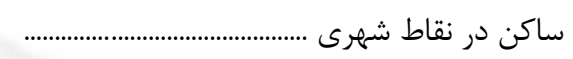 \\
\hline qvir & Ifruk & $19 q 4 \pi$ & TIYNI & 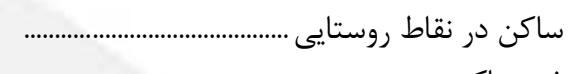 \\
\hline VQqTK & $11 \wedge 9 \Delta V$ & $\operatorname{lrmq\cdot 1}$ & TFTASD & 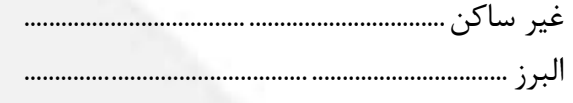 \\
\hline 99014 & $1.95 \Delta 1$ & $11 r \Delta \cdot \Delta$ & TTTVDS & ساكن در نقاط شهرى ......... \\
\hline $94 \cdot 1$ & $9 \vee \cdot 9$ & $1 \cdot r \cdot r$ & $r \cdot 1 \cdot 9$ & ساكن در نقاط روستايى .. \\
\hline · & $\cdot$ & & & 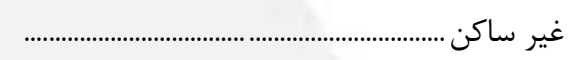 \\
\hline$|r \wedge| \Lambda$ & tIt & rTDQG & erval & 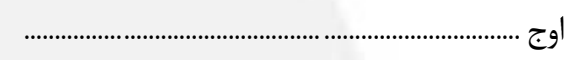 \\
\hline TATF & $\Delta \Delta T_{1}$ & $\Delta 9 \Delta V$ & $\| F \vee \wedge$ & ساكن در نقاط شهرى \\
\hline 1.rqu & $|\Delta \& \wedge|$ & Iघqra & 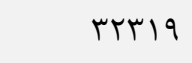 & ساكن در نقاط روستاير \\
\hline 1 & $\cdot$ & 1 & 1 & 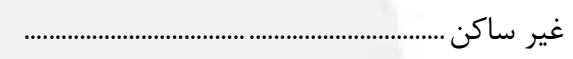 \\
\hline 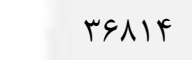 & $\Delta 991 F$ & $q r \cdot \wedge \cdot$ & IrTq94 & 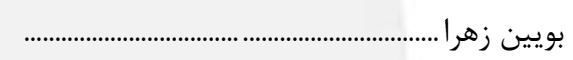 \\
\hline IEFVE & TVDDQ & TADTV & $\Delta \varphi \cdot \lambda r$ & ساكن در نقاط شهرى ... \\
\hline r.ru & rTHDq & rFDQT & $9991 \mathrm{r}$ & ساكن در نقاط روستايى \\
\hline DrqIV & $\Lambda F \vee \Delta \Delta$ & $\wedge \vee \wedge \Lambda 1$ & IVTGKG & 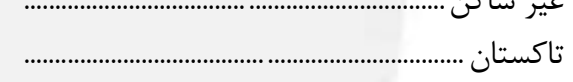 \\
\hline TFMAK & $\Delta \Delta G \cdot G$ & DVFAF & $11 r \cdot 9$. & ساكن در نقاط شهرى \\
\hline INQLr & rqIFq & r. rqv & DQDF\& & ساكن در نقاط روستايد \\
\hline & & & & 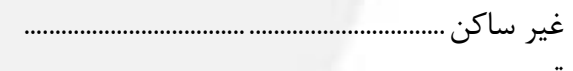 \\
\hline IMAFE. & $r q r \cdot r V$ & $r \cdot r q \cdot \Delta$ & DQGवसT & قزوين ................................... \\
\hline $1019 .$. & rтqाт. & TYGMEA & FADFAM & ساكن در نقاط شهرى .. \\
\hline 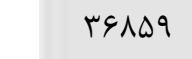 & $\Delta r q \cdot V$ & DVATS & IIIfKT & ساكن در نقاط روستايى \\
\hline & & 1 & 1 & 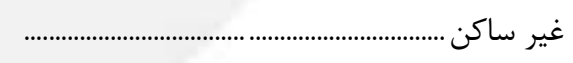 \\
\hline rararr & stryer & gDADF. & irarrat & قم............................ \\
\hline reDrTY & $G \cdot \Delta F \Delta \Delta$ & GYFQ. q & IrYq9G4 & ساكن در نقاط شهرى \\
\hline 11199 & TAYAA & $r r \cdot r q$ & GTriv & ساكن در نقاط روستايم \\
\hline$r$ & & $r$ & $r$ & \\
\hline TATOTr & grTVFT & 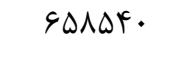 & ITATrAT & قم ............................... \\
\hline reDrTF & $G \cdot \Delta F \Delta D$ & GKFD. 9 & Irr99G4 & ل مبر نقاط شهر \\
\hline 11199 & TATAN & $r r \cdot r q$ & GTHIV & ساكن : \\
\hline r & $\cdot$ & r & $r$ & غير ساكن ................... \\
\hline frirl. & ra.rra & Alrvre & $\mid 8 \cdot r \cdot 11$ & 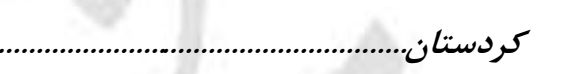 \\
\hline TrVTF. & $\Delta Q 1 \cdot \lambda r$ & DVYIFV & IITEYTq & ساكن در نقاط شهرى \\
\hline $\begin{aligned} 1 H 4.99 \\
k\end{aligned}$ & 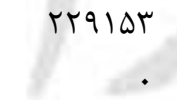 & $\begin{aligned} \text { rMqGTQ } \\
r\end{aligned}$ & $\begin{aligned} \text { reAVVA } \\
r\end{aligned}$ & 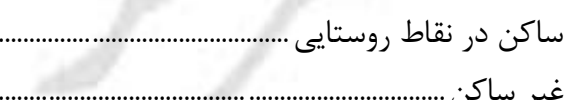 \\
\hline frvgr & $V \Lambda \cdot 9 \Lambda$ & N.GTr & $10 \wedge 99$. & 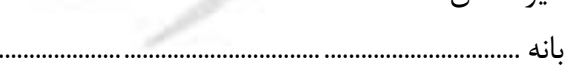 \\
\hline TrITV & $\Delta V \cdot G q$ & $\Delta \wedge r \varepsilon \mid$ & llarTa & 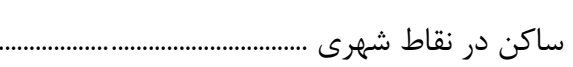 \\
\hline $1184 \Delta$ & $r) \cdot r$ & rrtgl & prred & 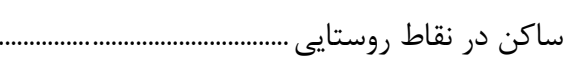 \\
\hline$\cdot$ & $\cdot$ & & & غير ساكن......... \\
\hline
\end{tabular}


ط ـ جمعيت و خانوار شهرستانهاى كشور به ترتيب استان (دنباله)

\begin{tabular}{|c|c|c|c|c|}
\hline خانوار & 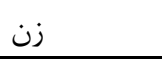 & 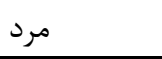 & جمعيت & شرح \\
\hline TVVDq & fert. & FFArt & 19194 & 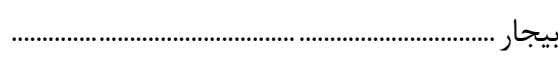 \\
\hline IVArd & TATGS & r^ఎ१। & $\Delta \& \Lambda \Delta V$ & 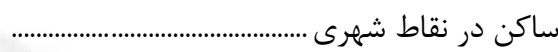 \\
\hline $99 \% 4$ & 19.94 & |ETY| & 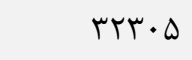 & 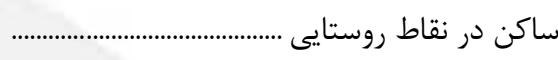 \\
\hline • & - & • & & 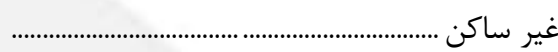 \\
\hline $194 \wedge 1$ & r11199 & rTAKS & $94 \cdot 10$ & 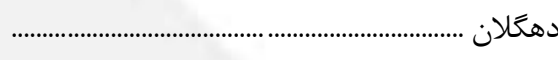 \\
\hline AVAr & |FTi. & IFAVQ & r৭1^ब & 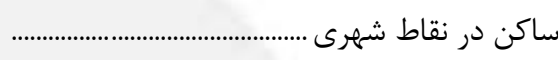 \\
\hline $1 \cdot 9 \cdot 0$ & $191 \mathrm{~V} 9$ & $|\vee 9 \Delta|$ & rFAr. & 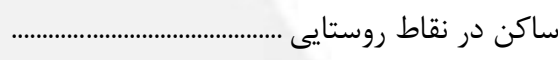 \\
\hline & - & & & 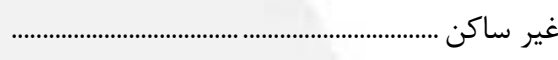 \\
\hline TITIS & rqтr. & $r \cdot 11$. & $\Lambda \cdots r$. & 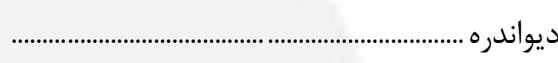 \\
\hline $999 \%$ & $1 V 119$ & IATVQ & ra.91 & 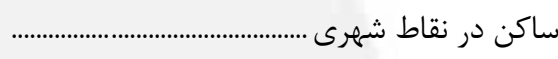 \\
\hline IITrK & rifll & TRAT. & prqpi & 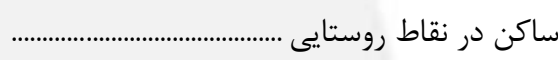 \\
\hline 1 & & 1 & 1 & 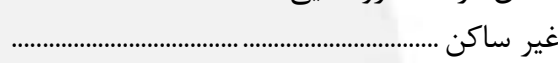 \\
\hline IrFVD & $r T \cdot \Delta \varphi$ & TrAMF & prqf. & 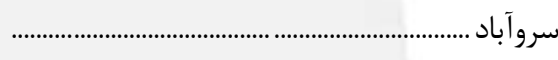 \\
\hline$r F \cdot q$ & $f \cdot q_{1}$ & FTDS & Arqv & ساكن در نقاط شهرى ......... \\
\hline 11.99 & $11 \cdot 10$ & INAYA & MGGKT & ساكن در نقاط روستايى ..... \\
\hline gFrof & IIrATS & IIrard & THEFAI & 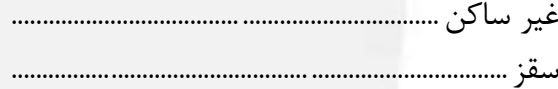 \\
\hline PqTAM & NrArs & NFDIT & $19 \wedge \mu \Delta 9$ & ساكن در نقاط شهرى ... \\
\hline $10 \cdot 99$ & 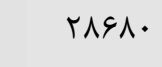 & rafir & $\Delta \Lambda \cdot 9 r$ & 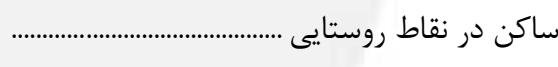 \\
\hline DQTATr & $r<\mu \cdot \Delta \Delta$ & TOHEFV & $\Delta \cdot \mid r \cdot r$ & 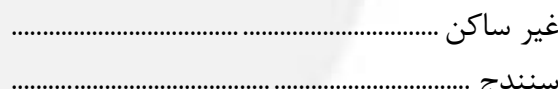 \\
\hline Ir\&qr. & $r \cdot \Delta r \cdot I$ & $r \cdot \wedge v \& \Lambda$ & $4 \mid 4 \cdot 9 q$ & ساكن در نقاط شهرى ... \\
\hline$r \Delta q \ldots$ & FrVQF & risur & AVrTI & ساكن در نقاط روستايى \\
\hline & & r & r & 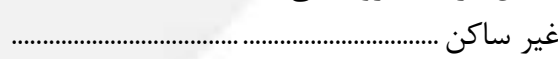 \\
\hline Frq. D & GqTrV & $\vee \cdot \wedge ९ \Delta$ & $14 \cdot 194$ & قرو \\
\hline$r q .94$ & 4999. & preff & $q k F \cdot F$ & ساكن در نقاط شهرى ...... \\
\hline IrNFt & THES & THETI & FAVAM & 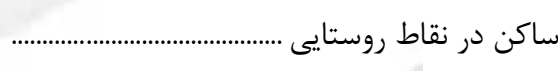 \\
\hline r.rVg & $\Delta \cdot 1 F$ & $\Delta T V \cdot q$ & 1.rNDS & 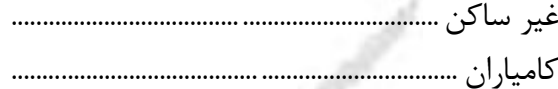 \\
\hline IVQqF & rqqi. & rl.rv & G. FFV & ساكن در نقاط شهرى ... \\
\hline ITEAT & $r \cdot V T r$ & TISVT & FTF. & ساكن در نقاط روستايى \\
\hline • & $\cdot$ & & • & غير ساكن ........................ \\
\hline$\Delta \Delta \varphi \cdot r$ & $9 \Delta \Gamma \cdot V$ & $999 \Delta 9$ & 19DTET & 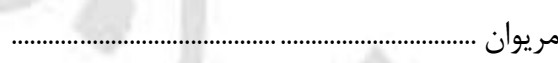 \\
\hline Fro19 & $V F \cdot 90$ & RVITH & 1011111 & 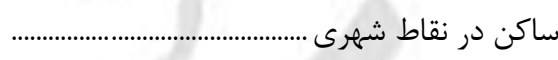 \\
\hline 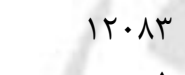 & TITET & trAtrt & $F q \cdot V q$ & 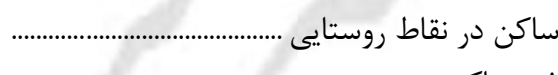 \\
\hline arrerl & $\mid \Delta F V \cdot r$. & IEIVEAM & rigrevid & 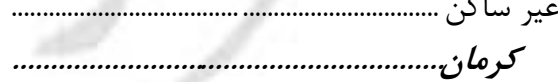 \\
\hline$\Delta \Delta|| F \mid$ & $91 . .19$ & $q \uparrow \wedge \Delta \vee 1$ & $\backslash \wedge \Delta \wedge \Delta \wedge \mathrm{V}$ & 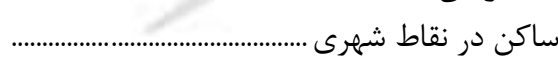 \\
\hline rA. TAV & GTOTIV & GQVTY. & $I r \cdot r \Delta \Delta V$ & 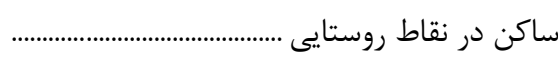 \\
\hline r & $199 \mathrm{~V}$ & IAVV & $r \Delta V V^{c}$ & 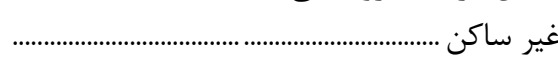 \\
\hline
\end{tabular}


ط ـ جمعيت و خانوار شهرستانهاى كشور به ترتيب استان (دنباله)

\begin{tabular}{|c|c|c|c|c|}
\hline خانوار & 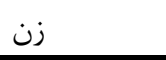 & 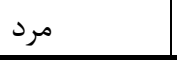 & جمعيت & شرح \\
\hline $111 \mathrm{kr}$ & $19 \cdots 1$ & $190 \cdot r$ & rADI. & 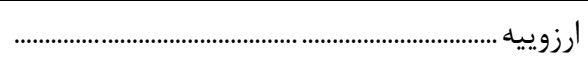 \\
\hline 1901 & rrva & ryqu & $9 \wedge 9 \wedge$ & ساكن در نقاط شهرى ............... \\
\hline $91 \wedge \mathrm{k}$ & logrT & $19 \cdot 99$ & MIEFT & 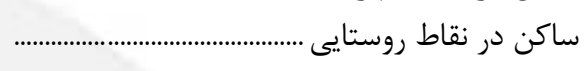 \\
\hline$\cdot$ & · & • & & 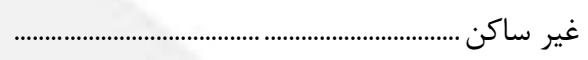 \\
\hline 1.911 & IVVT. & $191 \mathrm{VV}$ & 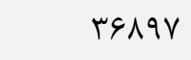 & 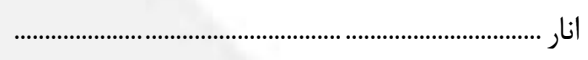 \\
\hline$\Delta 9+\lambda$ & qVTr & D. Trt & $1994 \Delta$ & 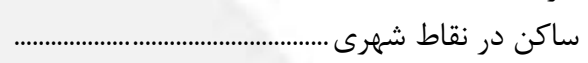 \\
\hline kqv. & マ৭१४ & $\wedge १ \Delta \Delta$ & $1990 \mathrm{r}$ & ساكن در نقاط روستايى .......... \\
\hline$\cdot$ & & & & 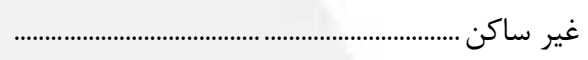 \\
\hline TQDFT & fisqf & FrF. $q$ & $\lambda+1 \cdot r$ & 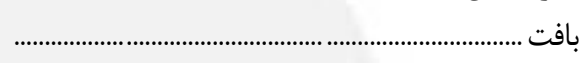 \\
\hline $11 F v q$ & 194Ta & $199 \cdot 0$ & $r q \cdot r q$ & ساكن در نقاط شهرى .............. \\
\hline IFADT & r/911 & TTQI. & frpqu & ساكن در نقاط روستايى ...... \\
\hline rit & trV & rqu & $\Delta V_{1}$ & 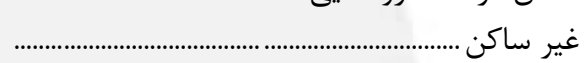 \\
\hline TQTIQ & $r \cdot r \cdot \Lambda$ & FI\&VD & 11914 & 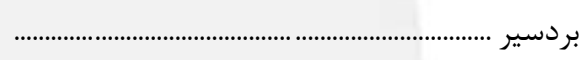 \\
\hline$|F| r \Delta$ & 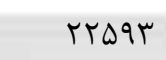 & trteV & 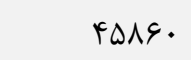 & ساكن در نقاط شهرى ......... \\
\hline $1 \cdot \wedge V V$ & IVrs9 & $1 \vee 9 \Delta \Lambda$ & TATTV & 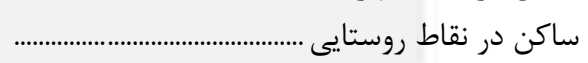 \\
\hline rir & kis & ra. & १९९ & 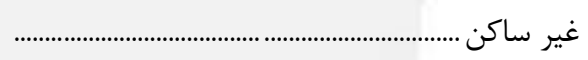 \\
\hline VIrru & $11 \cdot r v r$ & 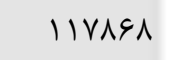 & TTATEI & 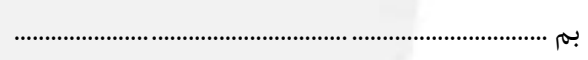 \\
\hline Fefrg & VHrGA & $\vee ९ \vee \wedge 9$ & $1 Q \cdot 1 Q V$ & ساكن در نقاط شهرى . \\
\hline TYG.V & rGGTA & $k \cdot q r V$ & VVRGD & 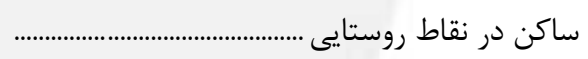 \\
\hline$r \cdot r$ & rVV & fFr & 119 & 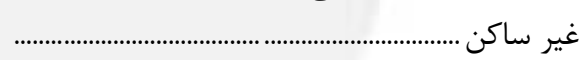 \\
\hline q५จฺ & $10 \cdot 9 \pi r$ & 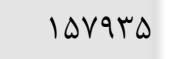 & $r \cdot \Lambda \Lambda \Delta \Lambda$ & جيرفت .............................. \\
\hline FeDFT & vedro & 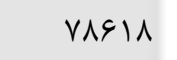 & IOTIQT & ساكن در نقاط شهرى... \\
\hline स्स & VEYAF & Vquाf & $10 \Delta \& 91$ & ساكن در نقاط روستايى \\
\hline & r & r & $v$ & 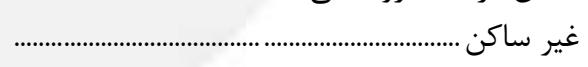 \\
\hline$\|\Delta\|$ & IVG.. & IVVGY & rargr & 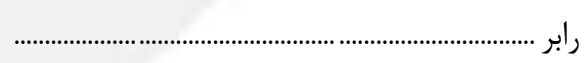 \\
\hline fall & VMFT & VrVr & $\mid F V I D$ & ساكن در نقاط شهرى ...... \\
\hline ६9९V & $1 \cdot r \cdot r$ & $1 . r T \Lambda$ & $r \cdot \Delta T_{1}$ & ساكن در نقاط روستايى \\
\hline ra & $\Delta \Delta$ & 91 & 119 & 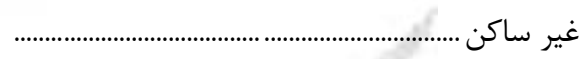 \\
\hline$|r T \Lambda|$ & TIOHT & ri\&49 & Frias & 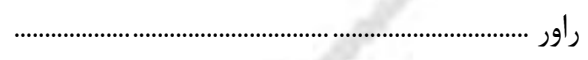 \\
\hline VIAV & $11 \wedge \& V$ & 11199 & trute & ساكن در نقاط شهرى... \\
\hline 9.94 & 9990 & १ทจท & I949T & ساكن در نقاط روستايي \\
\hline & $\cdot$ & - & • & 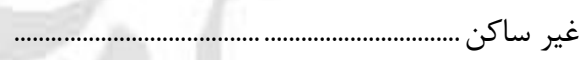 \\
\hline 91011 & $|\& \wedge \notin q|$ & IGTVKT & MUKIF & رفسنجان ............................ \\
\hline G & MATAF & q૯qvq & INHKGY & ساكن در نقاط شهرى..... \\
\hline$r v q \cdot r$ & $\Delta ৭ \wedge \vee$. & gVTat & ITKTY & 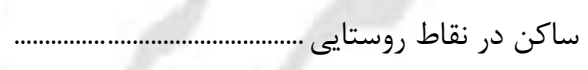 \\
\hline $\begin{array}{l}\text { TQI } \\
\text { TYETA }\end{array}$ & $\begin{array}{l}r T V \\
\text { QrVVA }\end{array}$ & $\begin{array}{l}\text { rqT } \\
\text { DrTIF }\end{array}$ & $\begin{array}{r}V T q \\
1 . \Delta 99 T\end{array}$ & 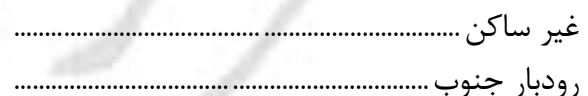 \\
\hline$\Delta \Delta \vee \varepsilon$ & $1 \cdot \sqrt{99}$ & $1 \cdot 119$ & rIDAr & 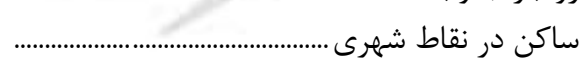 \\
\hline TINAT & RTEIT & frrqu & 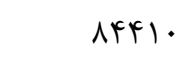 & 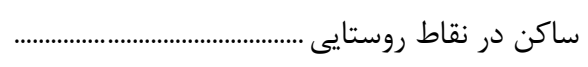 \\
\hline${ }^{\circ}$ & $\cdot$ & - & $\cdot$ & 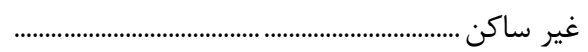 \\
\hline
\end{tabular}


ط - جمعيت و خانوار شهرستانهاى كشور به ترتيب استان (دنباله)

\begin{tabular}{|c|c|c|c|c|}
\hline 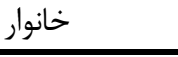 & 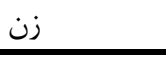 & 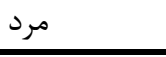 & جمعيت & شرح \\
\hline rrqAr & prtat & $F \Delta \| 11$ & $M|\wedge|$. & 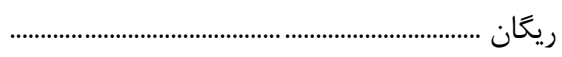 \\
\hline $999 \mathrm{~V}$ & $|r \Delta| \mid$ & $|F F| 9$ & rVqr. & ساكن در نقاط شهرى .......... \\
\hline$I V Y \wedge D$ & rqマ^। & $r .991$ & $9 \cdot 4 \vee q$ & 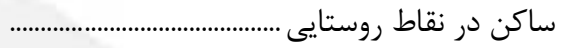 \\
\hline 1 & $\cdot$ & 1 & 1 & 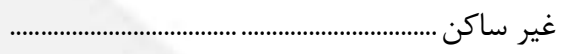 \\
\hline rqYQI & \&NFDI & g৭૬人t & 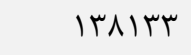 & زرند ......................................... \\
\hline$r \cdot r \Lambda F$ & rGIधV & $r v \cdot \mid \Lambda$ & VTIAD & ساكن در نقاط شهرى \\
\hline $19.9 V$ & TrTAF & rrgGY & gFqFi & ساكن در نقاط روستايي \\
\hline • & - & · & • & 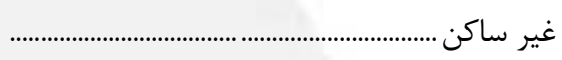 \\
\hline qQTUV & IOS\&VV & IEVTES & rteI.r & 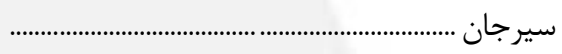 \\
\hline$V T \Delta \cdot \Delta$ & 119911 & IrgrqD & Tr\&T. & ساكن در نقاط شهرى ......... \\
\hline THAFF & r\&Vघl & $F I \cdot r F$ & $\vee \vee \vee \wedge \Delta$ & ساكن در نقاط روستايى ..... \\
\hline$\wedge$ & $\cdot$ & 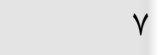 & $1 \cdot$ & 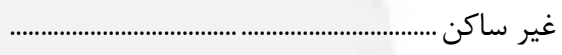 \\
\hline rIFAr & FquाQ & DFGG. & I. rqvd & 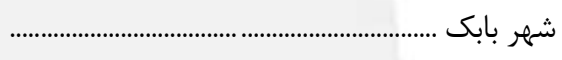 \\
\hline$r t \cdot Q V$ & rorq. & rNQHF & VHATF & ساكن در نقاط شهرى \\
\hline 9419 & $\mid r \cdot r \Delta$ & 19119 & $r \cdot|\Delta|$ & ساكن در نقاط روستايي \\
\hline & & & • & 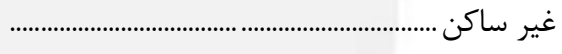 \\
\hline$r m p \cdot q$ & $r \cdot q 4 \wedge$ & fikq. & NTFTA & 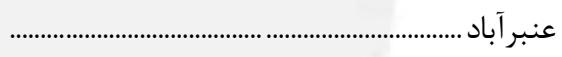 \\
\hline VTSD & $|r \Delta F|$ & ITEFF & $r \Delta \backslash \wedge \Delta$ & ساكن در نقاط شهرى \\
\hline$|9| \mathrm{FF}$ & $r \Lambda F \cdot V$ & rNAFE & $\Delta V T \Delta K$ & ساكن در نقاط روستاي \\
\hline & & & & 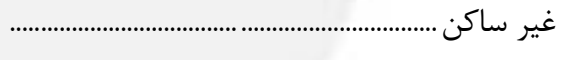 \\
\hline $9 \wedge 18$ & $199 \mathrm{VF}$ & $I V \cdot r q$ & $r r \ldots$ & 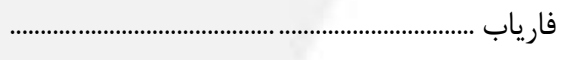 \\
\hline MFT & THAF & rmvq & Fへ૬r & ساكن در نقاط شهرى .. \\
\hline NFVF & IFF. & IfEFV & rqIrV & ساكن در نقاط روستايي \\
\hline & & & & 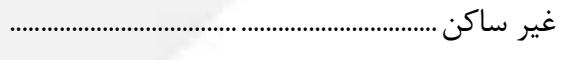 \\
\hline 17190 & rTHE & TFVD. & $9 V \cdot 99$ & 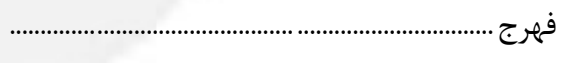 \\
\hline $1 \wedge \Delta \cdot$ & rofq & 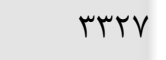 & G৯VG & ساكن در نقاط شهرى \\
\hline IDTFF & TA\&Yq & ritrv & Q१^९९ & ساكن در نقاط روستايي \\
\hline $1 \cdot 1$ & 191 & 119 & rof & 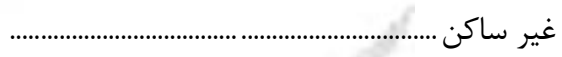 \\
\hline$r \cdot \Delta T_{1}$ & $\longleftrightarrow \wedge \Delta \cdot \varphi$ & 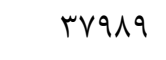 & V\&YqD & 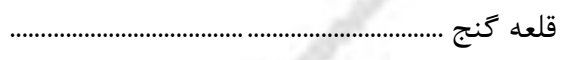 \\
\hline 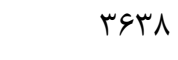 & GGYV & GDFT & $|r| 99$ & ساكن در نقاط شهرى \\
\hline $19 \Lambda \wedge r$ & 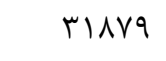 & MIFFV & 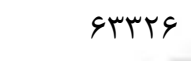 & 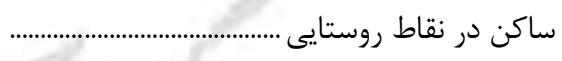 \\
\hline$\cdot$ & $\cdot$ & $\cdot$ & & 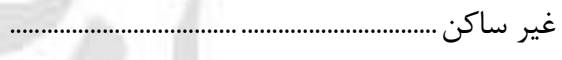 \\
\hline TrtTAG & rGYA.G & rVDq1^ & VTAVTY & 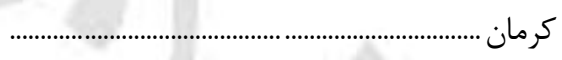 \\
\hline 191119 & MI. rV & 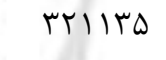 & GTrIGT & ساكن در نقاط شهرى \\
\hline 11191 & DIVAD & DFVG. & $1 \cdot 9 \Delta T \Delta$ & ساكن در نقاط روستايى ................ \\
\hline $\begin{array}{l}19 \\
\text { retVG }\end{array}$ & $\begin{array}{l}\text { If } \\
\text { frreq }\end{array}$ & 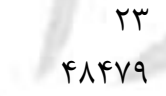 & $\begin{array}{r}r \vee \\
q \Delta \Lambda F \wedge\end{array}$ & 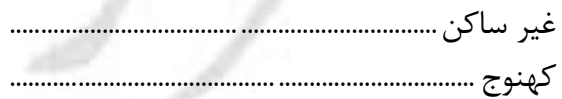 \\
\hline Ifrqf & TQVIV & $r q 9 \cdot V$ & DTETF & 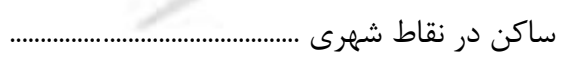 \\
\hline $11 \wedge \Lambda t$ & rIsat & rIQVT & FTrtF & 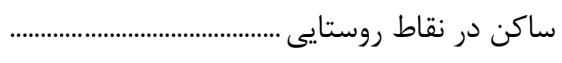 \\
\hline • & · & · & • & 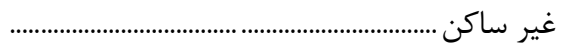 \\
\hline
\end{tabular}


ط ـ جمعيت و خانوار شهرستانهاى كشور به ترتيب استان (دنباله)

\begin{tabular}{|c|c|c|c|c|}
\hline خانوار & 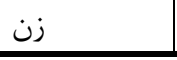 & 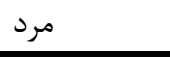 & جمعيت & 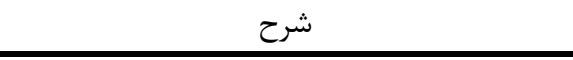 \\
\hline squtr & $1 \cdot F \Delta F$ & $1 \cdot V \Delta 1$ & $r \mid r \cdot a$ & كوهبنان .......................... \\
\hline rabr & vQV. & VVrY & $1 Q \mu \cdot \psi$ & ساكن در نقاط شهرى .. \\
\hline INAT & rAvi & $r \cdot \omega$ & $\Delta \wedge \vee \varepsilon$ & 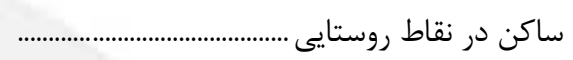 \\
\hline v & ir & it & ra & 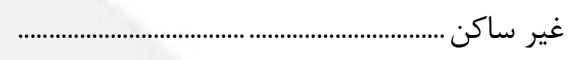 \\
\hline INTLY & TTAVT & 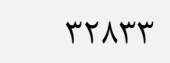 & $\varphi \Delta V \cdot \Delta$ & منوجان .......................................... \\
\hline DqFध & $1 . \operatorname{kr}$ & $1 \cdot \Delta \Delta r$ & r1199 & ساكن در نقاط شهرى ........... \\
\hline $\mid K F \cdot F$ & TTYTY & TtrVt & $\operatorname{rea} .$. & ساكن در نقاط روستايى ........ \\
\hline r & r & \& & 9 & 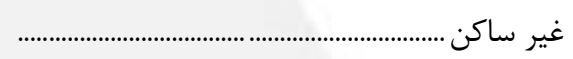 \\
\hline 19114 & rबD१ & tVGTA & DFTYA & 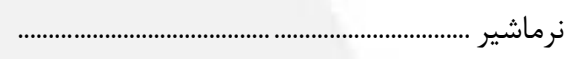 \\
\hline rTMA & ए९९९ & rqQT & VaYA & 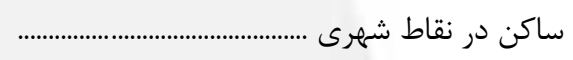 \\
\hline Ir^৭ץ & rイ^৭ท & rrGAr & $\uparrow \notin \Delta \Lambda$. & ساكن در نقاط روستايى .... \\
\hline & & & & 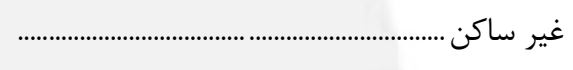 \\
\hline DV\&A\&I & qefelq & $911 \cdot 10$ & 19DKFTF & 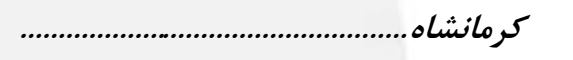 \\
\hline$F F \cdot G \cdot F$ & Vrirqu & VTVRTY & $|\notin 9 \wedge 9| Q$ & ساكن در نقاط شهرى .......... \\
\hline $\mid r \& q 10$ & $r r \cdot q 4$. & rFVA.r & frsffy & 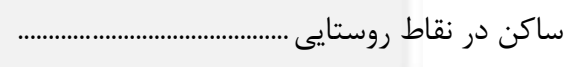 \\
\hline ITKT & rFAS & rMAq & arva & 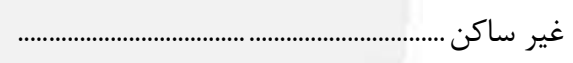 \\
\hline $4 \cdot 911$ & $990 \cdot V$ & VIrsq & $\mid f \cdot \wedge v \varepsilon$ & اسلام آباد غرب ........................ \\
\hline 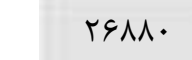 & FAFVT & $r q r \cdot r$ & ११^४९ & ساكن در نقاط شهرى ........ \\
\hline Ir人⿻. & TrVAF & TFDAG & FArF. & 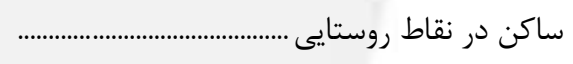 \\
\hline$|V|$ & rAl & rVq & 94. & 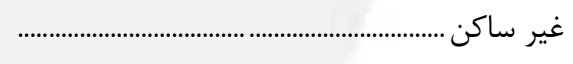 \\
\hline$|A F V|$ & ५৭१४ & $r \cdot r \Delta q$ & G.4TI & ياوه .......................................... \\
\hline $111 r \wedge$ & $|\vee q 4|$ & INIVT & rel.r & ساكن در نقاط شهرى ...... \\
\hline Vrre & $|r \cdot r|$ & ITYAV & TFrth & 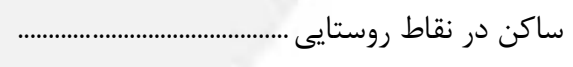 \\
\hline & & & & 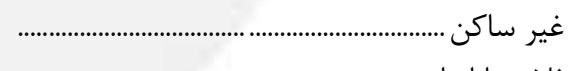 \\
\hline$q r V \cdot$ & $|V T M|$ & $\operatorname{I\vee q\Lambda \Lambda ~}$ & TUTIQ & 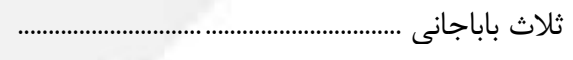 \\
\hline fill & $\checkmark \wedge \Delta \wedge$ & ATFQ & 19Y.r & 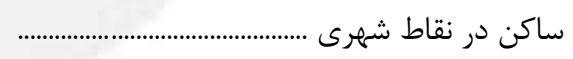 \\
\hline FAr. & $94 \cdot r$ & $9 \Delta ९ ६$ & 14199 & ساكن در نقاط روستايى ..... \\
\hline rq & v. & vV & lif & 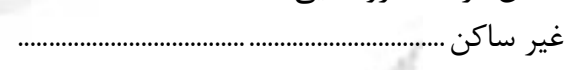 \\
\hline$r \cdot \Delta q r$ & r\&AVQ & rNTqY & VD199 & 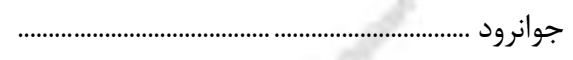 \\
\hline $10 \cdot 1$ & rqAIr & TVDFI & DFTUF & ساكن در نقاط شهرى ... \\
\hline$\Delta \Delta \wedge r$ & $1 . .9 r$ & $1 \cdot V \Delta r$ & $r \cdot \Lambda 10$ & ساكن در نقاط روستايح \\
\hline$\cdot$ & $\cdot$ & $\cdot$ & & 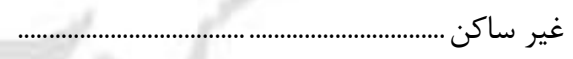 \\
\hline $1 \cdot$ T\&4 & $111 \cdots$ & IVAAV & 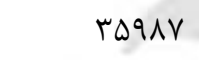 & 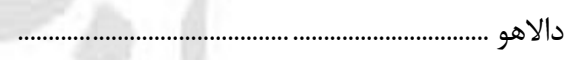 \\
\hline teq & Vqur & VArt & $1 \Delta \vee \Delta \Delta$ & 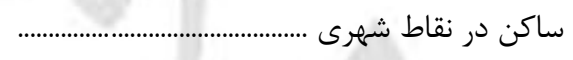 \\
\hline$\Delta \Delta G \mu$ & $1 \cdots 19$ & $99 \vee V$ & $r .994$ & 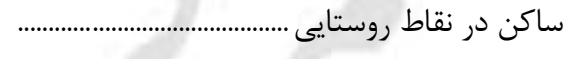 \\
\hline $\begin{aligned} 4 \mid \\
\mid r v q .\end{aligned}$ & 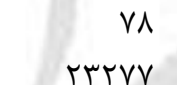 & $\begin{aligned} 11 \\
\text { rers. }\end{aligned}$ & $\begin{array}{r}198 \\
\text { EV }\end{array}$ & غير ساكن ............................................................. \\
\hline $1|v|$ & IrVAs & IFra9 & $r \Lambda \cdot \Lambda \Delta$ & 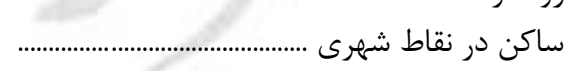 \\
\hline$\Delta \& 1$. & $9 \% \wedge$. & $1 . .94$ & $190 \% 9$ & 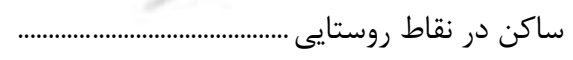 \\
\hline 9 & 11 & 10 & rq & 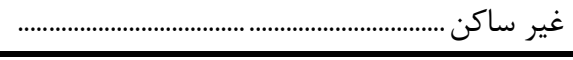 \\
\hline
\end{tabular}


ط ـ جمعيت و خانوار شهرستانهاى كشور به ترتيب استان (دنباله)

\begin{tabular}{|c|c|c|c|c|}
\hline خانوار & 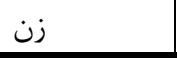 & 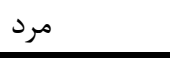 & جمعيت & شرح \\
\hline rrsqs & FTFGA & FTAVF & NDTKT & 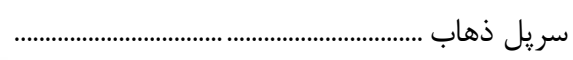 \\
\hline $\mid r \wedge \Delta \cdot$ & rTQ9D & TrAMG & $F \Delta F \lambda$ & ساكن در نقاط شهرى ............... \\
\hline $1 \cdot 1 \cdot 9$ & 19111 & 19910 & rqvrs & 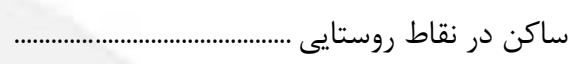 \\
\hline rV & gr & vr & $1 r \Delta$ & 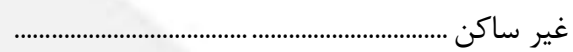 \\
\hline$r \Delta \Delta \Delta F$ & $f \cdot r V q$ & $f \backslash \wedge \Delta$ & 11991 & 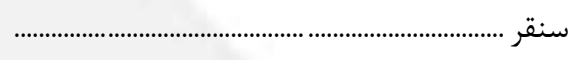 \\
\hline $\mid$ Frt & TTQTK & trYAI & $r \Delta r \cdot r$ & 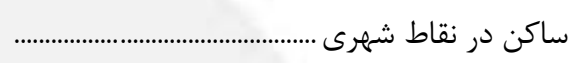 \\
\hline $11 r \pi$. & IVquV & lیrag & TGMTK & 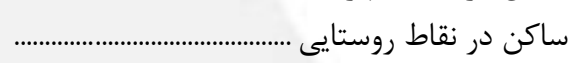 \\
\hline r & 9 & $\wedge$ & 14 & غير ساكن ........................... \\
\hline rivAN & ra. Et & roVIQ & $V \cdot V \Delta V$ & 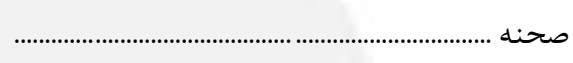 \\
\hline 11191 & IV৭০V & INTES & raT.r & 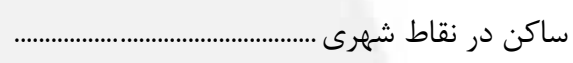 \\
\hline $1 \cdot \Delta F_{1}$ & $199 \vee V$ & IVTFA & TFTtS & 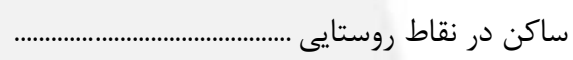 \\
\hline$\Delta \varphi$ & $1 \cdot 1$ & $|r|$ & rrq & 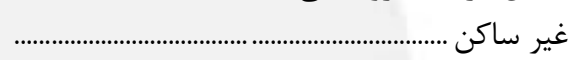 \\
\hline $99 \cdot r$ & $111 \wedge r$ & ITVEV & rrqrq & 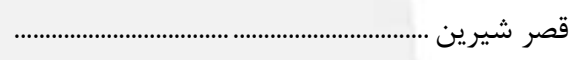 \\
\hline DFAT & $19 \uparrow q$ & $9 \vee \cdot{ }^{4}$ & 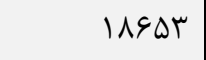 & ساكن در نقاط شهرى ......... \\
\hline$|r \Delta|$ & 1941 & reVA & 49.9 & ساكن در نقاط روستايى ..... \\
\hline iv. & $r \cdot \Delta$ & rथd & sV. & 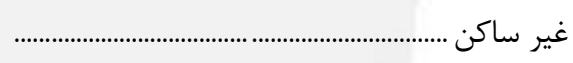 \\
\hline rrtrql & $\Delta T \Delta \Delta \cdot V$ & DFATYS & 1.人rkrr & 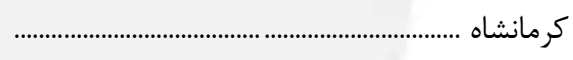 \\
\hline rMAl. 9 & FVATVA & erv. 1 . & QDTYND & ساكن در نقاط شهرى ... \\
\hline TEVTH & ఎqTVV & V. MET & 1 1rqV19 & 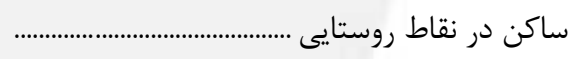 \\
\hline FDq & $\wedge \Delta \Delta$ & $9 v F^{f}$ & inrq & 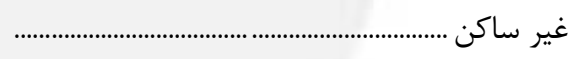 \\
\hline rrtar & rマvq৭ & rAFIV & VATIG & 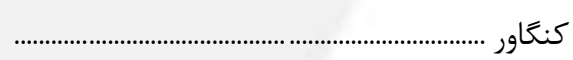 \\
\hline $1909 \mathrm{~V}$ & $r \notin 9 \Delta$. & $r R \cdot r$ & बrqAI & ساكن در نقاط شهرى ....... \\
\hline gFVF & $1 \cdot \operatorname{trg}$ & 1.919 & rIfar & ساكن در نقاط روستايى \\
\hline IAT & $r v r$ & r.. & VVr & 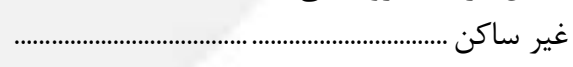 \\
\hline $19 \Delta \mathrm{V}$ & TAIV & rیAт. & $\Delta v \cdots v$ & 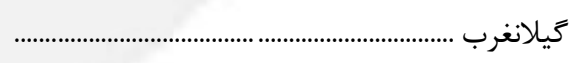 \\
\hline VeVr & $1 Y 90 \cdot$ & ITDQF & TATFY & ساكن در نقاط شهرى .... \\
\hline$\wedge १ \Delta \vee$ & IATVK & १०१५^ & rIrII & 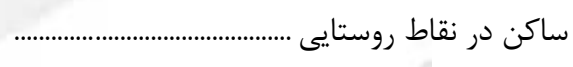 \\
\hline lf. & rQF & ra1 & $\Delta \Delta T$ & 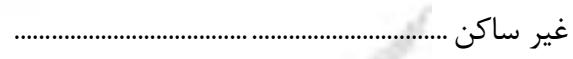 \\
\hline$r T \Delta \cdot G$ & $r \wedge \cdot \varphi$ & rqDFF & vAra. & 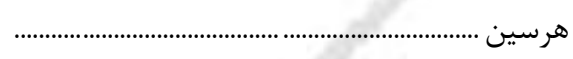 \\
\hline $1 k r \cdot q$ & TFE. & TEYAV & $r q \cdot \wedge \mu$ & ساكن در نقاط شهرى .. \\
\hline NIQT & IFITK & 14949 & $r q \cdot \wedge \Lambda$ & ساكن در نقاط روستايح \\
\hline$i \Delta$ & ^r & 91 & IVF & 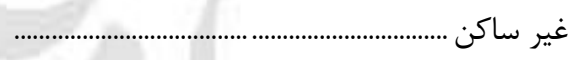 \\
\hline IAqre. & ral\&ge & 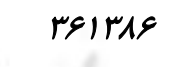 & vir.ar & 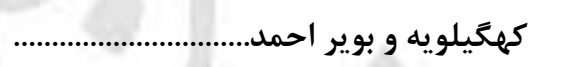 \\
\hline $1 . r T V$. & $190 \mathrm{VA}$ & $r \cdot 1911$ & rqves & ساكن در نقاط شهرى .. \\
\hline$\Lambda T \Delta \Delta \Lambda$ & $|\Delta \Delta| F \Lambda$ & $|\Delta \wedge \wedge 9|$ & rIf..q & ساكن در نقاط روستايى ... \\
\hline QVNI & $1 \cdot 194$ & 1. Arg & $\begin{array}{l}\text { lo1r } \\
\text { ris9. }\end{array}$ & 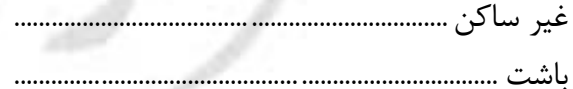 \\
\hline rATI & $\Delta$ QrAs & $\Delta r V \Lambda$ & $1 \cdot v a t$ & 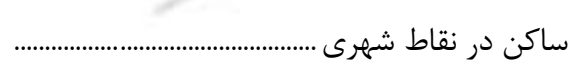 \\
\hline rars & DFFI & $\Delta F \cdot r$ & $1 \cdot \wedge k t$ & 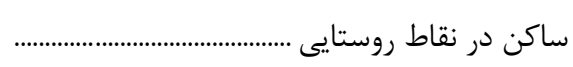 \\
\hline rF & rv & is & $\Lambda r$ & \\
\hline
\end{tabular}


ط - جمعيت و خانوار شهرستانهاى كشور به ترتيب استان (دنباله)

\begin{tabular}{|c|c|c|c|c|}
\hline خانوار & زن & 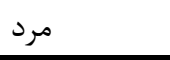 & جمعيت & شرح \\
\hline $1 \cdots r \Lambda$ & $1 \wedge V \Psi \cdot$ & $194 \cdot 9$ & rNIrG & 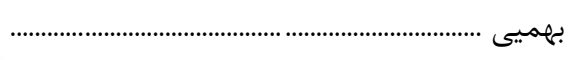 \\
\hline 0.91 & q४९V & $1 \cdots 9$ & $1910 \mathrm{~V}$ & ساكن در نقاط شهرى ........ \\
\hline 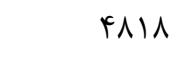 & 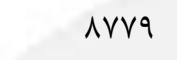 & 9.9. & IV^ৎq & ساكن در نقاط روستايى ......................... \\
\hline 119 & INF & Trs & il. & 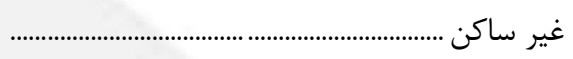 \\
\hline$V \vee \Delta \varphi q$ & $148 \wedge 19$ & 10T999 & ५৭৭१८० & 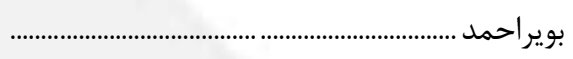 \\
\hline l. & $V V \cdot q r$ & $1 \cdot r 41$ & IOVFAF & ساكن در نقاط شهرى ............ \\
\hline rVI91 & qqVrF & VTDGY & IFtras & ساكن در نقاط روستايى .......... \\
\hline (i) & GT & vi & | & 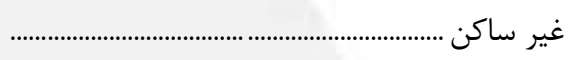 \\
\hline$\wedge \wedge$. & IEVTr & 19111 & rTaFt & 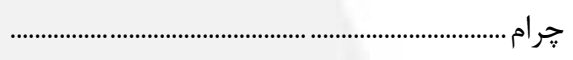 \\
\hline fFed & AGTI & $\Lambda \Delta Q T$ & IVTIT & ساكن در نقاط شهرى ........... \\
\hline fFta & $\wedge 111$ & ArI9 & 19rr. & ساكن در نقاط روستايى .. \\
\hline & & & & 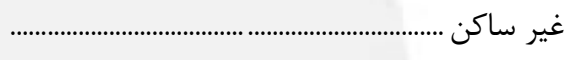 \\
\hline $118 \cdot 9$ & $r 1 \cdot V r$ & rIfeV & frorq & دنا.............................................. \\
\hline rArq & rqQT & DIAV & 1.149 & ساكن در نقاط شهرى ............ \\
\hline М২૬ & 19119 & 19rvq & rrmas & ساكن در نقاط روستايى .......... \\
\hline 1 & 1 & 1 & $r$ & 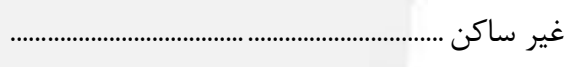 \\
\hline TTFAV & gDIFA & घq4.r & | & 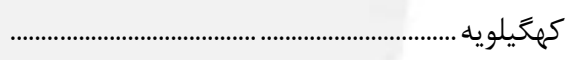 \\
\hline IVVEA & ravit & TENTt & VTOTY & ساكن در نقاط شهرى .............. \\
\hline IFEFT & rqтr & rqTa. & $\Delta \wedge \Delta \wedge \Lambda$ & ساكن در نقاط روستايى .. \\
\hline GV & 91 & $|r|$ & rtq & 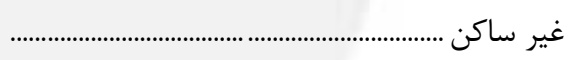 \\
\hline merga & GIrkr & GTVIr & $\mid K F \cdot 94$ & 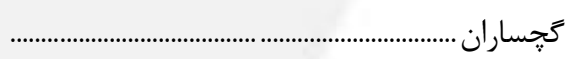 \\
\hline r\&VV. & kvq.r & FAMYF & १९VYA & ساكن در نقاط شهرى ...... \\
\hline Vria & שוזו & $1 \% \Delta 19$ & TGGKT & ساكن در نقاط روستايى . \\
\hline TF. & $r \Delta \varphi$ & $r v \cdot$ & VYG & 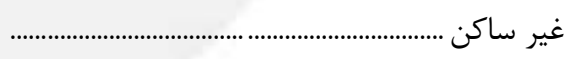 \\
\hline$\Delta \Delta \varphi$. & $1 \cdot \lambda+\Lambda$ & 1.994 & rINIT & 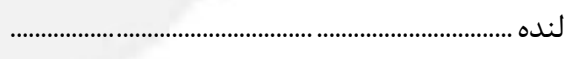 \\
\hline MT.G & GTED & GKY & ITVVT & ساكن در نقاط شهرى ... \\
\hline rTaF & ra.r & Farv & $q \cdot k \cdot$ & 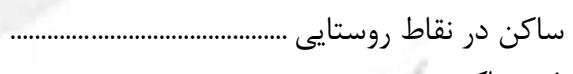 \\
\hline$\Delta \Delta \cdot r<q$ & $q u \cdot f q r$ & grarrs & 1191119 & 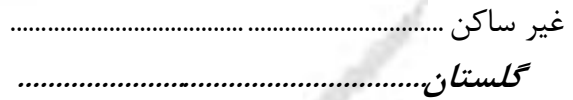 \\
\hline$r \cdot \mid r V r$ & kqvя.1 & $491.1 f$ & $99 \Delta \& 1 \Delta$ & ساكن در نقاط شهرى \\
\hline TFNFT & Frtivr & rmqur & AVIDFS & ساكن در نقاط روستا \\
\hline$\Delta \Delta F$ & $\vee \curlywedge$ & 94 . & 1901 & 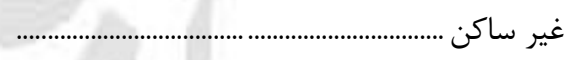 \\
\hline ২^৭९D & FAFI9 & FArAF & $99 \Lambda \cdot r$ & 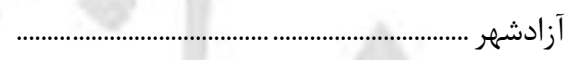 \\
\hline $190 \cdot 9$ & TVEST & TYETT & DFAAV & ساكن در نقاط شهرى ... \\
\hline & $r \cdot 9 \Delta \Delta$ & r.१९. & $\begin{array}{r}41910 \\
1\end{array}$ & 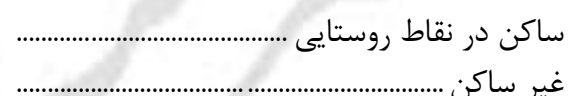 \\
\hline 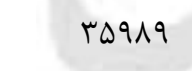 & 99191 & gqura & (1) & 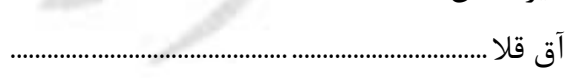 \\
\hline$\| F \Delta \Lambda$ & r. qry & rIIVD & FrII9 & 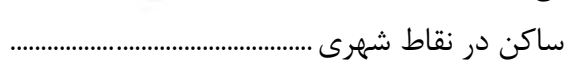 \\
\hline TFATI & FaTDF & FATG. & 9.914 & 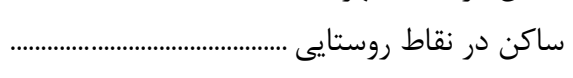 \\
\hline$\cdot$ & $\cdot$ & $\cdot$ & $\cdot$ & غير ساكن ...................... \\
\hline
\end{tabular}


ط ـ جمعيت و خانوار شهرستانهاى كشور به ترتيب استان (دنباله)

\begin{tabular}{|c|c|c|c|c|}
\hline خانوار & 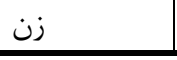 & مرد & جمعيت & 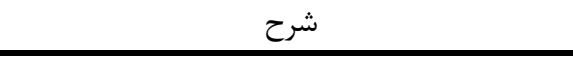 \\
\hline IDTEV & 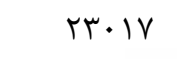 & 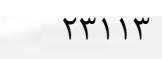 & ध्वाr. & بندركز \\
\hline$q \cdot r)$ & $1 \pi 4 \cdot 9$ & Irv^s & trutat & ساكن در نقاط شهرى .............. \\
\hline 9ris & $9+11$ & qTrV & IAVrA & ساكن در نقاط روستايى ............. \\
\hline & - & • & & 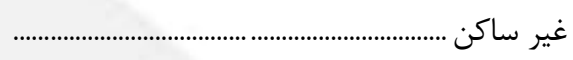 \\
\hline 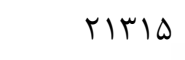 & rqveV & L.t & マ৭৭マ^ & 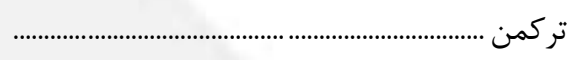 \\
\hline IFDIT & T\&VGI & $r V r \cdot q$ & $\Delta r q \vee$. & 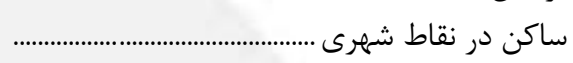 \\
\hline $9 \Lambda \cdot r$ & Irq19 & ir.tr & $r \varphi \cdot \cdot \Lambda$ & 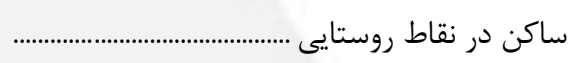 \\
\hline · & & & & 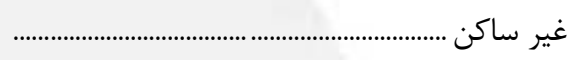 \\
\hline 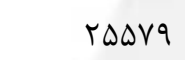 & FTITV & $r r \cdot \wedge r$ & A૬YI. & 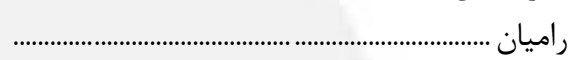 \\
\hline $1 \cdot \wedge \vee \cdot$ & $11 \cdot v 9$ & 11194 & rGTV. & 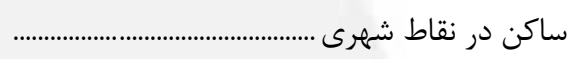 \\
\hline $\mid q V \cdot \Lambda$ & $r \Delta \cdot \Delta l$ & TYANA & १११९q & ساكن در نقاط روستايى ...... \\
\hline 1 & . & 1 & 1 & 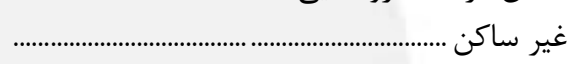 \\
\hline FTVTD & V.rTY & $\nabla \cdot r \wedge \Delta$ & $1 f \cdot v \cdot q$ & 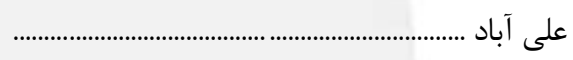 \\
\hline וTIT & F. Frd & $r \cdots \wedge \varphi$ & $\Lambda \cdot \Delta 11$ & ساكن در نقاط شهرى ............ \\
\hline IVQ৭Y & rq199 & $r \cdot r q \Lambda$ & 9.197 & ساكن در نقاط روستايى ......... \\
\hline 1 & & & 1 & 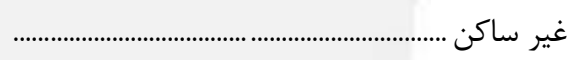 \\
\hline TrQDI. & rar.. & rЬqV. & VITV. & 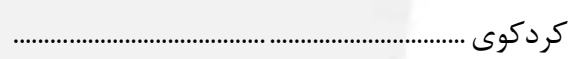 \\
\hline$|r q v|$ & 19GTr & $r \cdot r \Delta Q$ & rq\А। & ساكن در نقاط شهرى .. \\
\hline $1 \cdot \Delta r q$ & $1 \Delta 9 V \wedge$ & $|\Delta V| \mid$ & mIr人q & ساكن در نقاط روستايى \\
\hline rrqq1 & DAFAr & 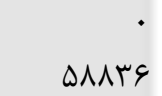 & $11 V r 19$ & 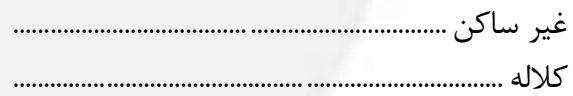 \\
\hline 11909 & $r 1 \cdot 0 q$ & $r \cdot 19 q$ & flqdr & ساكن در نقاط شهرى \\
\hline TI. Fr & TVETF & ryqFe & VATGG & ساكن در نقاط روستايي \\
\hline & & & & 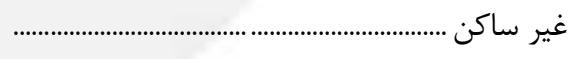 \\
\hline$|A V T|$ & rid. & mISG4 & GTIVT & 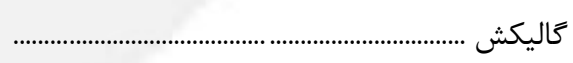 \\
\hline 9999 & $119 \Delta \mathrm{V}$ & IIVTr & rmpqf & ساكن در نقاط شهرى . \\
\hline IIVTa & 19人ar & 199TV & rqvvq & ساكن در نقاط روستاير \\
\hline 10.949 & rrMAki & TFIV.. & $\langle\lambda \cdot \Delta F\rangle$ & كرَان \\
\hline||$\Delta \Delta+\mid$ & INTrNer & MArr.. & TEDGAT & ساكن در نقاط شهرى ... \\
\hline reVqu & DQFFV & ఎqrq. & llFArV & ساكن در نقاط روستايي \\
\hline 1. & ir & 1. & Tr & 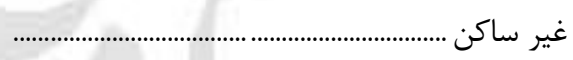 \\
\hline IAFVF & $r \mu \cdot \Delta \Lambda$ & reVID & GAVVT & كميشان ............................ \\
\hline QGTT & IV৭AV & $1 \lambda k \cdot q$ & 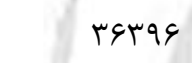 & ساكن در نقاط شهرى ...... \\
\hline$\Lambda \Lambda Q I$ & $|9 \cdot v|$ & $19 \% \cdot \Delta$ & rtrve & 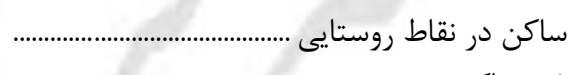 \\
\hline qVIFV & IVTrge & IVDFA. & $\begin{array}{l}1 \\
\text { rFAVFF }\end{array}$ & 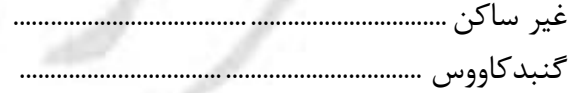 \\
\hline FATTE & VVrat & $V V \cdot r \cdot$ & lQFF.F & 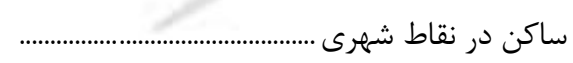 \\
\hline DIDFV & $9 \Delta \& \mu 1$ & $9 \Lambda \cdot \kappa \cdot$ & $|9 r 8 V|$ & 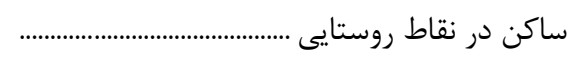 \\
\hline TVG & r99 & f.. & 999 & غير ساكن.................. \\
\hline
\end{tabular}


ط - جمعيت و خانوار شهرستانهاى كشور به ترتيب استان (دنباله)

\begin{tabular}{|c|c|c|c|c|}
\hline خانوار & 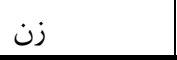 & 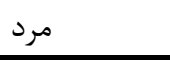 & 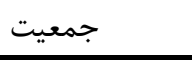 & شرح \\
\hline $\mid 9 \pi 11$ & $r \cdot \Delta r q$ & r.FTV & $9 \cdot 9 \Delta 4$ & مراوه تيه .............................................................. \\
\hline$r \cdot v t$ & pert & frrq & 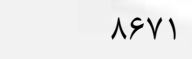 & ساكن در نقاط شهرى ............... \\
\hline IrNVD & $r \Delta \varphi \Delta V$ & TDSGT & Q DIrI9 & 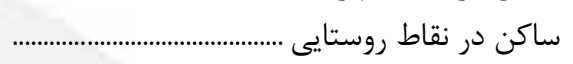 \\
\hline r\&Y & erv & DrG & १६r & 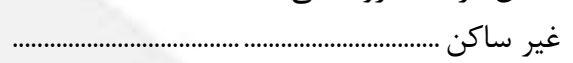 \\
\hline trVIT & rVavq & $r \vee \wedge \cdot q$ & VDFAT & مينودشت ................................ \\
\hline ^९^. & IFATK & IDTGK & $r \cdot{ }^{\prime} \cdot \Lambda \Delta$ & ساكن در نقاط شهرى ............... \\
\hline irrra & TrADV & TTQFI & ForqA & ساكن در نقاط روستايى .......... \\
\hline - & $\cdot$ & $\cdot$ & & 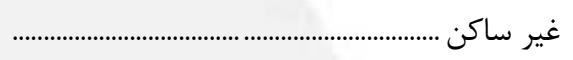 \\
\hline haIrat & $149 r \cdot 99$ & IreVaqr & rar.sqg & 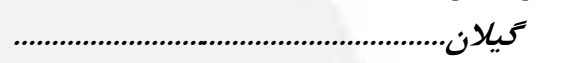 \\
\hline DrVFIV & $\Lambda \cdot \Delta \Delta \Delta \varphi$ & vaver. & $19 \cdot r \cdot r 4$ & 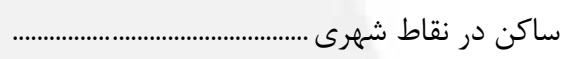 \\
\hline 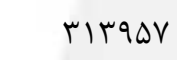 & FAVQFT & $\mathrm{FV} \cdot 11 \mathrm{~V}$ & qTVG9. & ساكن در نقاط روستايى ....... \\
\hline$\wedge$ & & $1 \cdot$ & 1. & 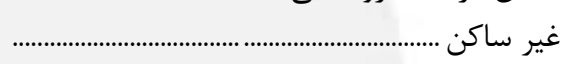 \\
\hline TAVFT & farqq & $\varphi \Delta \wedge \Delta \wedge$ & qITDV & 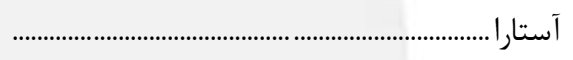 \\
\hline$r \cdot \cdot l^{r}$ & MIMr & rIFA. & gr人if & ساكن در نقاط شهرى .............. \\
\hline$\Lambda \vee r \Lambda$ & $14 \cdot 9 \Delta$ & IFrVA & TAFFt & 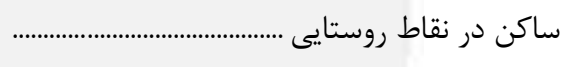 \\
\hline rMATF & DrVGr & DFTEV & $1 \cdot \Lambda 1 r$. & 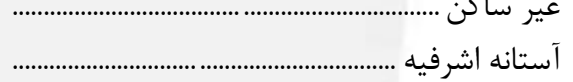 \\
\hline$r \cdot V I T$ & 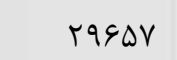 & rq५. & $\Delta \wedge १ \& r$ & ساكن در نقاط شهرى ........... \\
\hline $1 M 114$ & $\langle F| \cdot G$ & $r \Delta \cdot 91$ & FqI\&V & 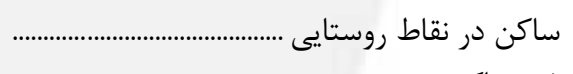 \\
\hline 10r.9. & rIsq4 & r|Ds| & FTrta & 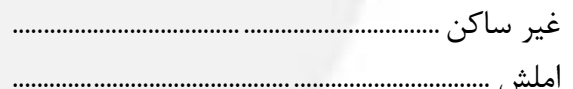 \\
\hline $4.1 \mathrm{~V}$ & $M 1 I^{f}$ & AVAF & IVQ9A & ساكن در نقاط شهرى... \\
\hline 9 9४१ & $I T \wedge \Delta \cdot$ & ITrVV & TDSTV & ساكن در نقاط روستايى. \\
\hline & & & & 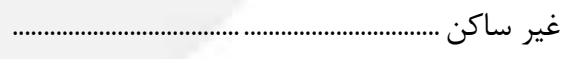 \\
\hline FNIqT & 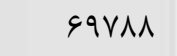 & GqTrA & 149.19 & 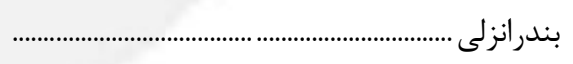 \\
\hline$F l \cdot \Delta r$ & DqVar & $\Delta \Lambda \Lambda \cdot r$ & $11 \wedge \Delta G 4$ & 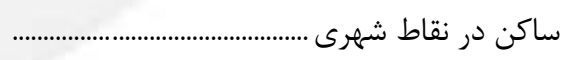 \\
\hline virq & $1 \cdots r 4$ & $1 \cdot$ rta & $r \cdot Y Q D$ & 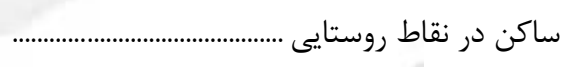 \\
\hline 1 & . & 1 & 1 & 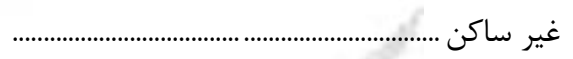 \\
\hline rtiV.r & evNrqu & 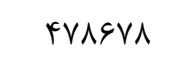 & $9 \Delta 99 \vee 1$ & 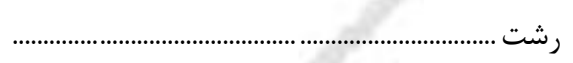 \\
\hline TQIQ1T & 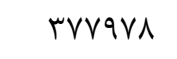 & $r v \cdot V r r$ & VEAVII & ساكن در نقاط شهرى ... \\
\hline 99v19 & $1 \cdot . r \mid \theta$ & $1 \cdot$ vq41 & $r \cdot \Lambda T \Delta S$ & ساكن در نقاط روستايى \\
\hline r & & r & r & 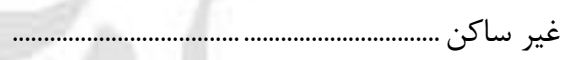 \\
\hline THTKE & rF^q1 & reqVF & $99 \wedge 90$ & 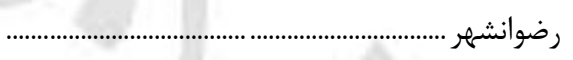 \\
\hline AVFA & IrVTe & $14 \lambda \cdot 9$ & TVATA & ساكن در نقاط شهرى ..... \\
\hline $14 \% 91$ & rII90 & r1190 & & ساكن در نقاط روستايى .... \\
\hline mllks & r\&VAF & fVqug & gqVT. & 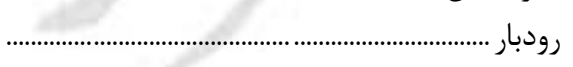 \\
\hline INGTY & rMN19 & 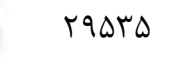 & $\Delta \wedge r \Delta F$ & 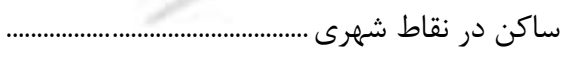 \\
\hline ITATH & IV৭९D & $1 \wedge k \ldots$ & rदrGD & 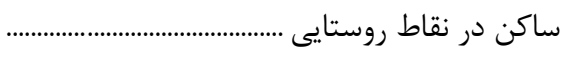 \\
\hline 1 & $\cdot$ & 1 & 1 & 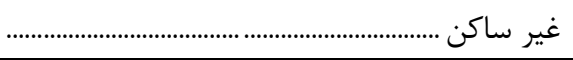 \\
\hline
\end{tabular}


ط ـ جمعيت و خانوار شهرستانهاى كشور به ترتيب استان (دنباله)

\begin{tabular}{|c|c|c|c|c|}
\hline خانوار & 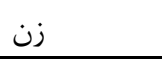 & 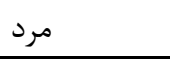 & جمعيت & شرح \\
\hline$\Delta \mid \Delta \wedge A$ & vreAN & Vrril & $14 \vee r q 9$ & 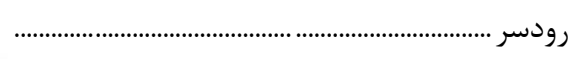 \\
\hline TATH. & $r v \cdot r \cdot$ & r६६Vq & $V r V \cdot q$ & ساكن در نقاط شهرى ......... \\
\hline TETFD & r $99 \Delta \Lambda$ & rq & V५G八9 & 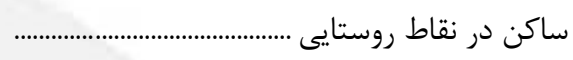 \\
\hline 1 & · & 1 & 1 & غير ساكن ن. \\
\hline$|94 \Delta|$ & rrsqV & trtid & reqva & 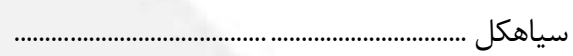 \\
\hline Vrg. & 1.90. & $1 \cdot v \cdot r$ & rlgar & ساكن در نقاط شهرى .......... \\
\hline ^९9. & ITYFV & ITSVF & TARTI & 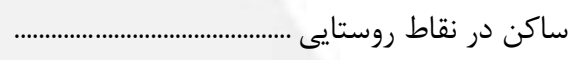 \\
\hline 1 & · & 1 & 1 & 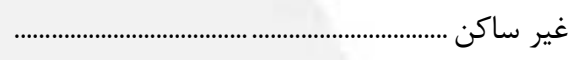 \\
\hline |NFIs & $r v \cdot 14$ & TRTIT & DFTTE & 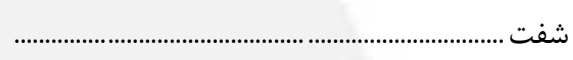 \\
\hline reIA & DIGT & $\Delta / Q \cdot$ & (t) & 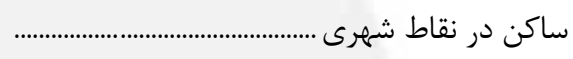 \\
\hline 14991 & rINAT & $t r \cdot G t$ & frqlf & ساكن در نقاط روستايى ..... \\
\hline fiqvo & gTVQV & GTriv & $I r \Delta \cdot V G$ & 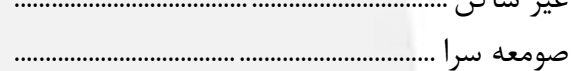 \\
\hline $191 \wedge \Delta$ & ratra & rq५^. & $\Delta \wedge \varsigma \Delta \wedge$ & ساكن در نقاط شهرى ...... \\
\hline rrvq. & rufva & rrqug & 94419 & ساكن در نقاط روستايى ... \\
\hline $81 \cdot \Delta \Delta$ & 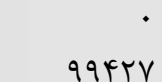 & 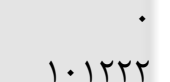 & $r . . q<q$ & غير ساكن ............................... \\
\hline 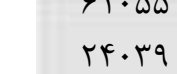 & rАqभT & rqfrs & VArq. & ساكن در نقاط شهري. \\
\hline$r v \cdot 19$ & 9.190 & gIVqF & ITTYNG & ساكن در نقاط روستايى ... \\
\hline & & & & 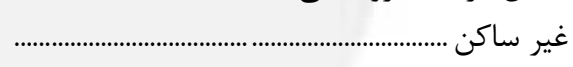 \\
\hline rir.q & $|\varphi| \Lambda \mid$ & relrq & arrা. & فومن ................................. \\
\hline ITATT & 11999 & 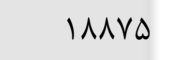 & rV^ৎq & ساكن در نقاط شهرى ...... \\
\hline INAVD & rVIAV & TVTOT & DFFrq & ساكن در نقاط روستايى . \\
\hline r & & r & r & 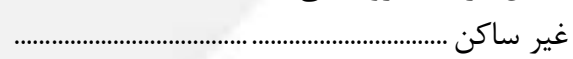 \\
\hline DATVA & Nrreq & 14190 & IEVAFF & 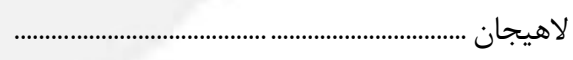 \\
\hline roviv & DTGTE & $\Delta \backslash \wedge \Lambda \Lambda$ & $1 . F \Delta / F$ & ساكن در نقاط شهرى ......... \\
\hline rrצ91 & $r \cdot V r r$ & $r t r \cdot v$ & qr.r. & ساكن در نقاط روستايى ..... \\
\hline fqral & $v \ldots 11$ & $v \cdot 9 V \Delta$ & $\mid F \cdot 919$ & لنَّر ود .............................................................. \\
\hline TATtr & 0.99. & DIITK & 1. IVAr & ساكن در نقاط شهرى ..... \\
\hline IFITF & $|9 \pi \Delta|$ & $19 \Delta \Delta r$ & 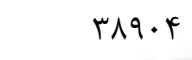 & ساكن در نقاط روستايى . \\
\hline . & . & $\cdot$ & • & 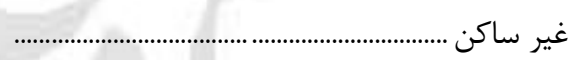 \\
\hline 199.1 & rqयа & TETDG & DrGKq & 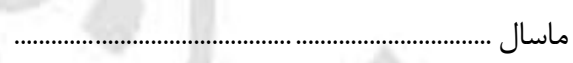 \\
\hline VDTI & llNTr & 11899 & 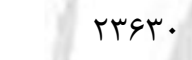 & 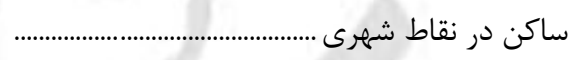 \\
\hline qщ^. & IF $\$ \Delta Q 9$ & IfFe. & $r 9.19$ & ساكن در نقاط روستايى ....................................... \\
\hline$\Delta \cdot q \cdot r \Delta$ & A\&VVE. & 194119 & $1 v 8.9 \times 9$ & 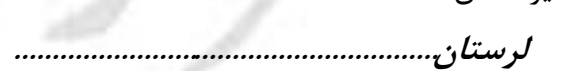 \\
\hline rrrqDF & DqFVQ & $\Delta V \cdot 11 r$ & $11 r r q \cdot 1$ & 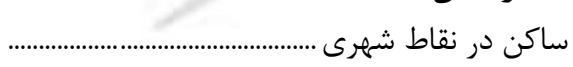 \\
\hline IVEATA & $r \cdot r l l$. & rTIVAS & ятr人৭9 & 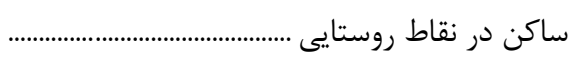 \\
\hline DrG & $\wedge \Delta \Delta$ & १९. & $\mid \wedge F \Delta$ & غير ساكن .................. \\
\hline
\end{tabular}


ط - جمعيت و خانوار شهرستانهاى كشور به ترتيب استان (دنباله)

\begin{tabular}{|c|c|c|c|c|}
\hline خانوار & 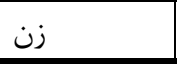 & 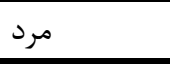 & 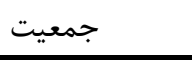 & 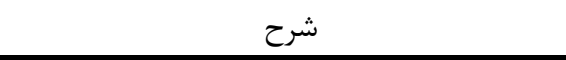 \\
\hline TrYII & 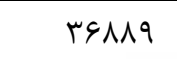 & $r \Lambda \cdot r V$ & VFqug & 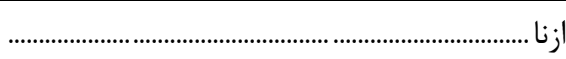 \\
\hline IfVDA & TFEYA & TFA૬T & |वशा. & 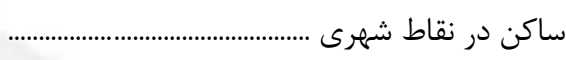 \\
\hline VaYG & ITFTV & $|r| 99$ & TФఎ१ & ساكن در نقاط روستايى ......... \\
\hline$v$ & If & 19 & rr & 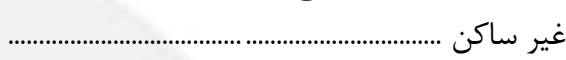 \\
\hline$r \wedge \Delta \cdot r$ & $9990 \Delta$ & $v \cdot \Delta \vee q$ & ITVOHF & 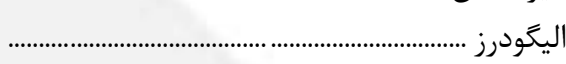 \\
\hline$r 9.91$ & FFFar & FETfE & 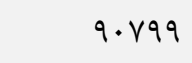 & ساكن در نقاط شهرى \\
\hline IrrAf & TYYIA & TFITA & redre & ساكن در نقاط روستاي \\
\hline Q) & $\Lambda F$ & $1 \cdot \Delta$ & 119 & 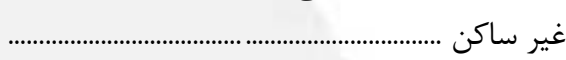 \\
\hline $1 \cdot r r \Delta \Lambda$ & IETETE & IGTATA & TrGFAT & 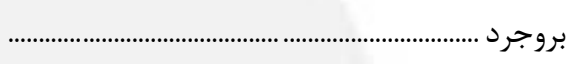 \\
\hline VQqIf & $\mid r \cdot \Delta \Delta r$ & 119994 & 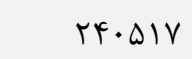 & ساكن در نقاط شهرى \\
\hline TEMFY & kr.VI & FrAGY & АЬ१९ & ساكن در نقاط روستاي \\
\hline & & & & 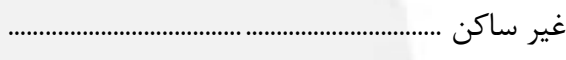 \\
\hline rir.r & TETAt & ryfer & VTrEF & يلدختر ................................. \\
\hline $99 \cdot V$ & $19 \wedge 94$ & IVIFA & $r r \cdots \Lambda$ & ساكن در نقاط شهرى \\
\hline $11 \% \wedge 9$ & $19 r 49$ & $r \cdot 1 \cdot 9$ & 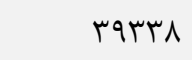 & ساكن در نقاط روستاي \\
\hline $1 \cdot V$ & 19. & $r \cdot \Lambda$ & rq1 & 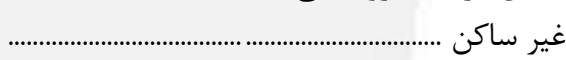 \\
\hline $\mid F \& q \Delta \Lambda$ & $r \Delta \cdot 9 q$. & rQDVAI & $0.94 V I$ & 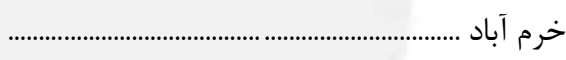 \\
\hline פ & $19 \cdot \Delta V F$ & $19 \cdot r \Delta \Delta$ & $r \Lambda \cdot \wedge r q$ & ساكن در نقاط شهرى \\
\hline rTrQI & $\Delta q \Delta F q$ & 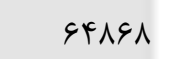 & ITFFIV & ساكن در نقاط روستاي \\
\hline rAl & $\Delta \varphi V$ & $9 \Delta \Lambda$ & ITTD & 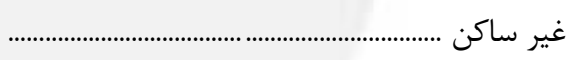 \\
\hline$F \cdot r \& V$ & 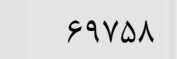 & VETID & Ifrqvr & 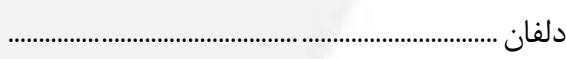 \\
\hline IMMAS & rTQqV & rrরi. & gefir & ساكن در نقاط شهرى \\
\hline rIDAI & rV|al & $\varphi \cdot r q \Delta$ & $\checkmark V \Delta \Delta Q$ & ساكن در نقاط روستاي \\
\hline & & & & 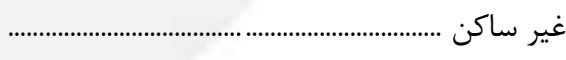 \\
\hline 11941 & $r \cdot r \wedge q$ & rIFEV & FIVAS & 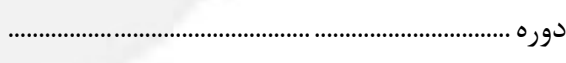 \\
\hline $1.9 V$ & 1191 & $19 \cdot r$ & $\mu \wedge$. & ساكن در نقاط شهرى ............ \\
\hline $1 \cdot \wedge \Delta 1$ & $|\wedge r q|$ & $1909 \Delta$ & rVqDQ & 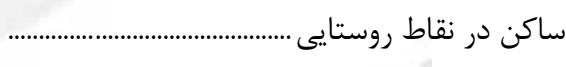 \\
\hline$\Delta \cdot 14$. & $\Lambda \Delta F I \Lambda$ & 19.9. & $\mid V E \Delta \cdot \Lambda$ & دورود ................................. \\
\hline 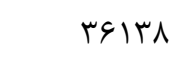 & girvV & GTFAF & $|r r \wedge \varepsilon|$ & ساكن در نقاط شهرى \\
\hline If..r & $Y F \cdot F i$ & r\$9.9 & $0.9 \mathrm{kV}$ & ساكن در نقاط روستاي \\
\hline & & & · & 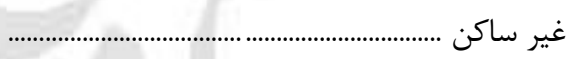 \\
\hline 1.VKT & $|9 \pi r|$ & $19 v r v$ & $r q \cdot \Delta \Lambda$ & 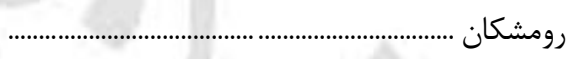 \\
\hline$|8| 4$ & $r \cdot r q$ & r.१९ & qIro & ساكن در نقاط شهرى .... \\
\hline $91 \% \wedge$ & 1949T & $|994|$ & & غن ساكن در نقاط روستايى . \\
\hline rille. & IV & TATET & $\vee \Delta \Delta \Delta q$ & 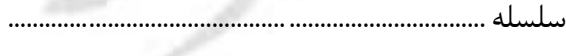 \\
\hline 1. TAY & $|\wedge r q|$ & 111999 & r५9QV & 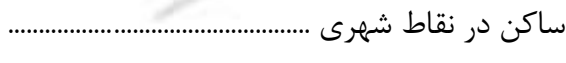 \\
\hline $1 \cdot 11 \wedge$ & $19 \cdot r 8$ & $190 \vee 9$ & rNG.r & 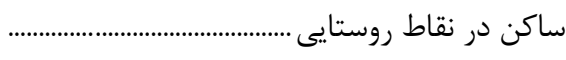 \\
\hline - & · & $\cdot$ & & 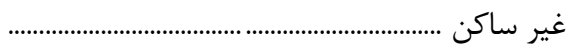 \\
\hline
\end{tabular}


ط ـ جمعيت و خانوار شهرستانهاى كشور به ترتيب استان (دنباله)

\begin{tabular}{|c|c|c|c|c|}
\hline خانوار & 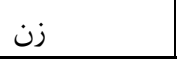 & 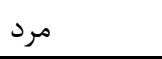 & جمعيت & شرح \\
\hline$F \Delta \mid \Delta \Delta$ & NTYIV & NFFFi & 199901 & 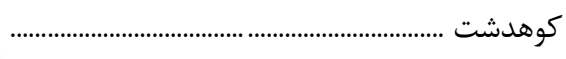 \\
\hline rVqqF & $\Delta \cdot V I T$ & $\Delta I \Delta V T$ & I. TYNA & ساكن در نقاط شهرى \\
\hline$|V| 9 \mid$ & $r \mid \Delta \cdot \Delta$ & TrAGA & getry & ساكن در نقاط روستايى ..................... \\
\hline$\cdot$ & - & · & & غير ساكن ............................... \\
\hline $1 \cdot 1 \mathrm{Fva1}$ & IerqaAf & 18arq94 & rratast & 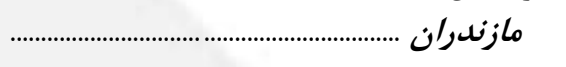 \\
\hline GYY991 & qFVGGT & $q \uparrow q \Delta \vee q$ & I AqVYrی & ساكن در نقاط شهرى ....... \\
\hline $49 \cdot 141$ & 9119T. & $V \cdot F \& I V$ & IrMgrty & ساكن در نقاط روستايى ....... \\
\hline 9 & r & $\Delta$ & $\checkmark$ & 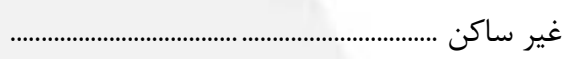 \\
\hline Irr.re & 1991\%v & $r \cdot r \Delta \cdot r$ & r. $19 \mu q$ & 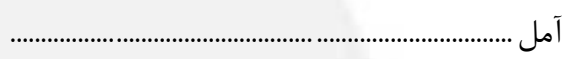 \\
\hline rifle & |rTाqV & $|r M| \Delta \Lambda$ & TE\&TAD & ساكن در نقاط شهرى \\
\hline $019 \cdot 1$ & 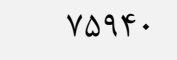 & VquFF & IDQTAF & ساكن در نقاط روستا \\
\hline$\cdot$ & & & & 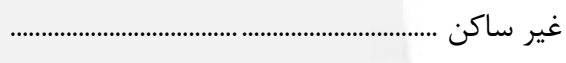 \\
\hline IVFTaI & rEFIQT & reVVVV & QHIQY. & بابل .................................... \\
\hline १९६४৯ & IDTGTr & IDTEDQ & $r \cdot \Delta \Delta V \Lambda$ & ساكن در نقاط شهرى \\
\hline VEAG & $111 \% \pi$. & ||$\Delta|Y|$ & TYGTAI & 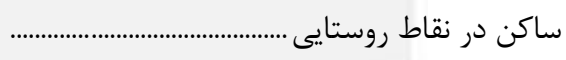 \\
\hline 1 & & 1 & 1 & 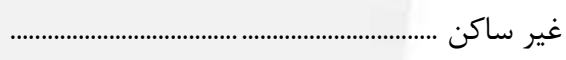 \\
\hline FEFAT & SVVEA & GVFFT & $1 \pi \Delta 191$ & بابلسر .............................. \\
\hline TF\&49 & rAFII & rVTa. & VDVध & ساكن در نقاط شهرى \\
\hline 19119 & rqurV & $r . .9 r$ & DqFT. & ساكن در نقاط روستاي \\
\hline & & & & 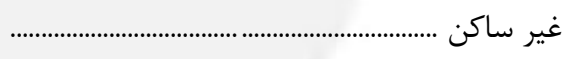 \\
\hline$\Delta \Delta / F$. & NTFD. & NQTIQ & $19 \wedge \vee 99$ & 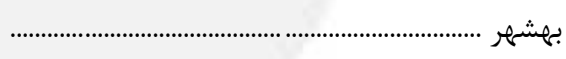 \\
\hline ए人rq9 & $\Delta \wedge \backslash \wedge q$ & DQTH। & IIVET. & ساكن در نقاط شهرى \\
\hline$|9 \wedge| F \mid$ & TATSI & $r \varepsilon \cdot \Lambda \Lambda$ & $\Delta I r F q$ & ساكن در نقاط روستاي \\
\hline & & & & 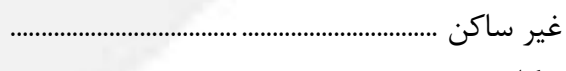 \\
\hline D९GYG & $19^{\prime} 99$ & אזTIT & IG91MT & 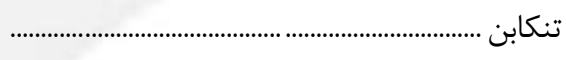 \\
\hline rAVk. & FTATE & FTtMI & AFVEV & ساكن در نقاط شهرى \\
\hline TV^৭ด & r.rqu & F.991 & NIrAF & ساكن در نقاط روستا \\
\hline 1 & $\cdot$ & 1 & 1 & 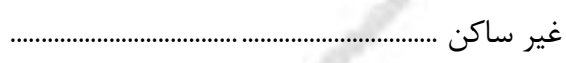 \\
\hline TATrA & 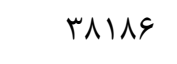 & гqтя. & VVDVG & 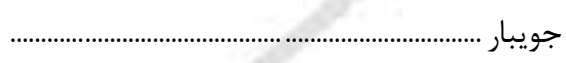 \\
\hline$\| r \mid 9$ & $I V r \cdot r$ & IVAGT & rDIधq & ساكن در نقاط شهرى \\
\hline $14 \cdot G r$ & $r \cdot \Lambda \Lambda T$ & TIOTA & FYFI. & ساكن در نقاط روستايح \\
\hline$r q 1 \cdot \Delta$ & DVFYD & $\Delta q .9 V$ & llgDFT & حالوس ................................ \\
\hline TYEYA & $F \cdot g r$. & FIGVT & NrTar & 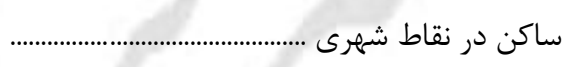 \\
\hline IISTV & I $9 \wedge T \Delta$ & IVETD & TYTQ. & ساكن در نقاط روستايى \\
\hline TATIT & r८९०१ & TRTt. & veIvq & رامسر ................................................................ \\
\hline 19419 & TAYVF & r人rrq & DQVIT & 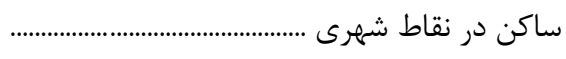 \\
\hline ४१९९ & $\wedge \Delta \wedge \Delta$ & $\wedge \wedge \Lambda 1$ & IVtse & 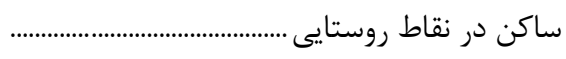 \\
\hline$\cdot$ & • & $\cdot$ & & 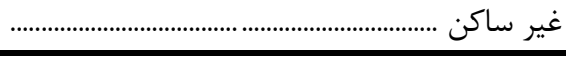 \\
\hline
\end{tabular}


ط ـ جمعيت و خانوار شهرستانهاى كشور به ترتيب استان (دنباله)

\begin{tabular}{|c|c|c|c|c|}
\hline خانوار & 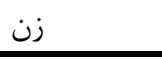 & 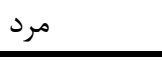 & جمعيت & 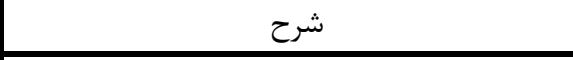 \\
\hline $19 \Delta \& \varepsilon V$ & $r \Delta \cdot \wedge F V$ & TATFAI & $\Delta \cdot \operatorname{crq\Lambda }$ & 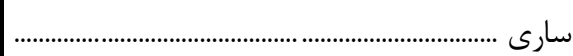 \\
\hline $1 . \mu F V \Delta$ & $10 \wedge r q \Lambda$ & $|\Delta S| \mu \mid$ & MIFATq & 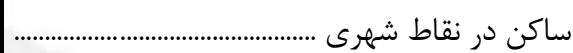 \\
\hline 9199. & GTFFA & $9 \vee 411$ & 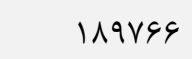 & 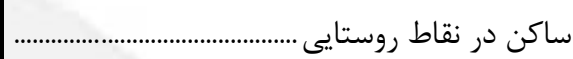 \\
\hline r & 1 & $r$ & r & 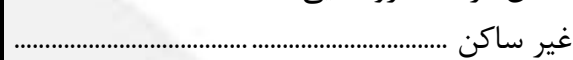 \\
\hline IfqD૬ & rivis & TrIQY & सrqा & 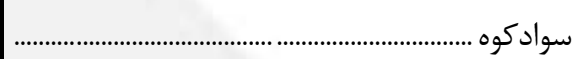 \\
\hline N\&\&s & ITAS. & $|r \wedge| \Lambda$ & rDSVA & ساكن در نقاط شهرى . \\
\hline 901. & $\Lambda \wedge \Delta \varphi$ & $q r \vee q$ & IATra & ساكن در نقاط روستايى .......... \\
\hline . & . & . & & 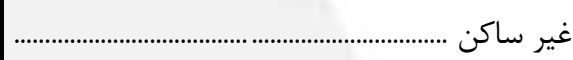 \\
\hline NFV & $1 \pi r \Delta q$ & ITFVD & TFATK & 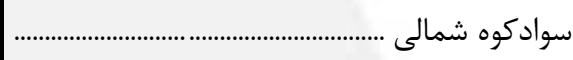 \\
\hline rی\&9 & rra. & FFrl & 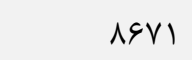 & ساكن در نقاط شهرى ..... \\
\hline$\Delta \varphi \cdot V$ & $11 \cdot 9$ & $\Lambda \cdot \Delta F$ & 19194 & ساكن در نقاط روستايح \\
\hline & & & & 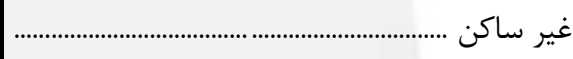 \\
\hline 9949 & 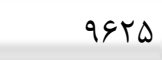 & १VD। & lquve & 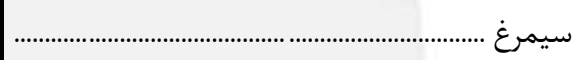 \\
\hline r\$91 & rq८9 & $f \cdot \Delta 1$ & $\Lambda \cdot r \cdot$ & 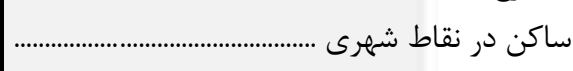 \\
\hline rqpa & DGHG & $\Delta \vee \cdots$ & 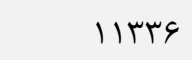 & ساكن در نقاط روستايي \\
\hline & & & & 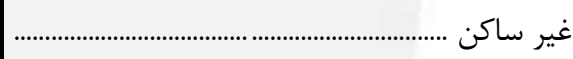 \\
\hline IVrFa & rब१९V & 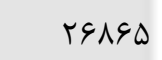 & DrArt & 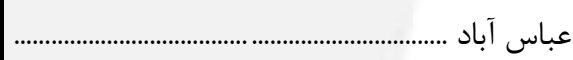 \\
\hline $99 \Delta 9$ & IFrM & $10 \cdot 1 \mathrm{~V}$ & $r q r \cdot \Delta$ & ساكن در نقاط شهرى . \\
\hline V\&19 & $11 \Delta v 9$ & $\| \Lambda F \wedge$ & THETV & ساكن در نقاط روستايح \\
\hline & & & & 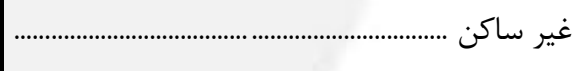 \\
\hline$r . .94$ & rqD... & $r \cdot \Delta r$ & G..ru & فريدونكنار ......................... \\
\hline 114.9 & IAVTr & I9FIV & rAIDF & ساكن در نقاط شهرى . \\
\hline VFe. & $1 \cdot$ Vबr & 11114 & TIAVV & ساكن در نقاط روستايح \\
\hline & & & & غير ساكن ....................... \\
\hline $1 \cdot r 9 \Delta \cdot$ & IOT9QT & IDQTFV & $r \cdot 9199$ & قايم شهر ......................... \\
\hline$\vee I V \cdot \Lambda$ & $1 \cdot 1 \cdots 9$ & $1 \cdot V T V 1$ & rIDTA. & 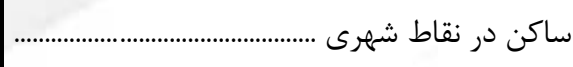 \\
\hline TIKFI & FoqRT & FVqvo & १५११^ & ساكن در نقاط روستايى \\
\hline 1 & - & 1 & 1 & 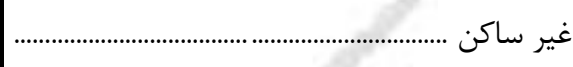 \\
\hline $1 \cdot 9 \mathrm{~V}$ & $1199 \mathrm{~V}$ & 11911 & trath & 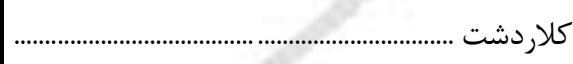 \\
\hline$f \Delta s \Delta$ & $9 \Delta \wedge 9$ & 9NIT & $\mid r F \cdot 1$ & ساكن در نقاط شهرى \\
\hline$r \Delta \cdot r$ & $\Delta \cdot \vee \wedge$ & 0199 & 1. TEV & ساكن در نقاط روستايي \\
\hline & & & & 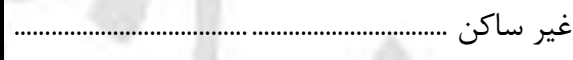 \\
\hline ITIFV & 19149 & T. TYq & $r \cdots v \wedge$ & كلو كاه .............................. \\
\hline 9191 & 1.495 & $1 \cdot 14$ & tirat & 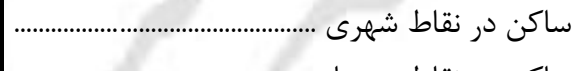 \\
\hline rthl. & FArsi & $\Delta \cdots+\varphi$ & $q \Lambda \uparrow \cdot V$ & 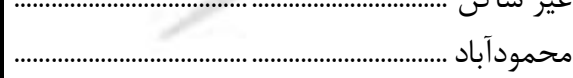 \\
\hline ITEFV & INATT & |9941 & rNDFT & 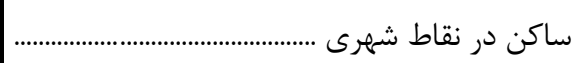 \\
\hline$r \cdot 19 r$ & rqłrq & $r \cdot F T \Delta$ & Dq८९े & 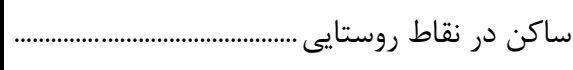 \\
\hline & . & & & غير ساكن ......... \\
\hline
\end{tabular}


ط - جمعيت و خانوار شهرستانهاى كشور به ترتيب استان (دنباله)

\begin{tabular}{|c|c|c|c|c|}
\hline خانوار & زن - ت & 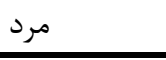 & جمعيت & شرح \\
\hline INTDK & $r V F \cdot G$ & TVEFV & $\Delta \Delta \cdot \Delta r$ & 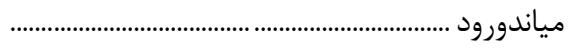 \\
\hline$r \cdot \Lambda V$ & ravs & FET & $9 r \cdot \Lambda$ & ساكن در نقاط شهرى . \\
\hline 10199 & rTAr. & $r+10$ & $F \Delta \wedge F \Delta$ & ساكن در نقاط روستايى ... \\
\hline · & - & · & - & 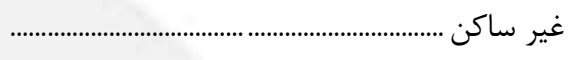 \\
\hline rAIVA & DqFiV & 9.99 & 119011 & 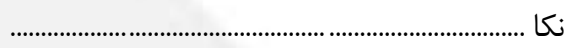 \\
\hline $19 r \Delta V$ & r.tra & $r \cdot V \Delta \varphi$ & 9.991 & ساكن در نقاط شهرى .. \\
\hline$|\Lambda \Lambda T|$ & rq1人r & (19ז & $\Delta \wedge \Delta T$. & ساكن در نقاط روستايـ \\
\hline · & · & $\cdot$ & · & 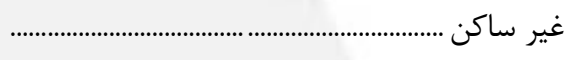 \\
\hline rqud. & $q \cdot r \cdot r$ & SITYA & | & 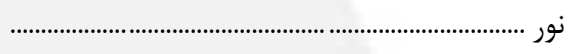 \\
\hline IVFIV & $r V \cdot 11$ & TVTGT & $\Delta F Y \wedge I$ & ساكن در نقاط شهرى ... \\
\hline سחו & TrTAD & rmąd & SVTD. & ساكن در نقاط روستايح \\
\hline & & & - & 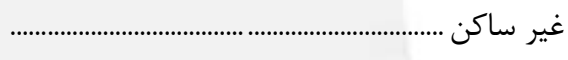 \\
\hline$r \Delta V \Delta q$ & 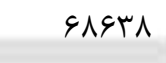 & $V \cdot r V D$ & |r人q|r & 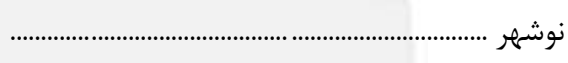 \\
\hline $\mid \wedge k \cdot r$ & rV@DD & $r \Lambda \cdot \mid \Lambda$ & $\Delta \Delta \Phi V$ & ساكن در نقاط شهرى \\
\hline TVTDS & $r \cdot 91 r$ & FTrAV & רrrtq & ساكن در نقاط روستايى \\
\hline 1 & 1 & · & 1 & 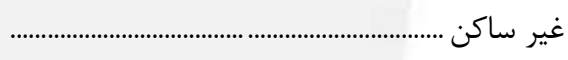 \\
\hline$F \Delta \Delta A \& G$ & $\gamma \cdot r v r f$ & rraral & IFrgfre & 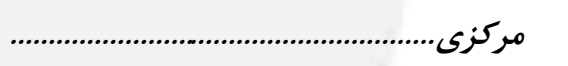 \\
\hline mFGFGA & DFTGMT & $\Delta \Delta V I r$. & $1.99 \vee \varepsilon f$ & ساكن در نقاط شهرى \\
\hline I. 9rVA & $191 \cdot 19$ & $19 \wedge 9 \cdot 1$ & rrq६q. & ساكن در نقاط روستايح \\
\hline$r \cdot$ & 1 & $r \cdot$ & rl & 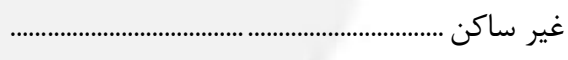 \\
\hline$|\wedge \Lambda| \wedge$ & $r 91011$ & r..rFd & $\Delta 91 V \Delta \varphi$ & 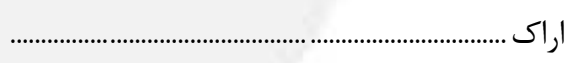 \\
\hline I99ITA & $r \varepsilon T \cdot F V$ & TGAFVG & MTIDTH & ساكن در نقاط شهرى .... \\
\hline $19 \cdot \mu f$ & TAYET & rIVDI & G.rIf & ساكن در نقاط روستايى ..... \\
\hline 11 & 1 & 11 & 19 & 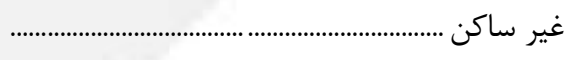 \\
\hline$\Delta \Delta \wedge \mathrm{r}$ & 1119 & NTr人 & IsToV & 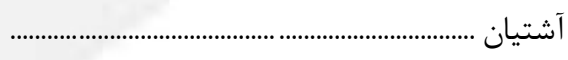 \\
\hline tVAN & frg. & $F \Delta \cdot r$ & AVGr & 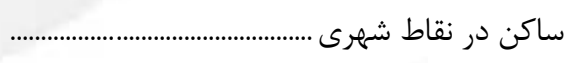 \\
\hline trqu & 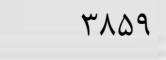 & rVMd & VQqF & ساكن در نقاط روستايى \\
\hline$\cdot$ & $\cdot$ & $\cdot$ & $\cdot$ & 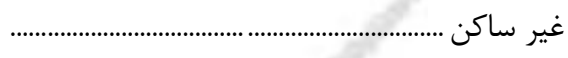 \\
\hline$\wedge \Delta \wedge \Lambda$ & ITSTH & lrma. & rFqIT & 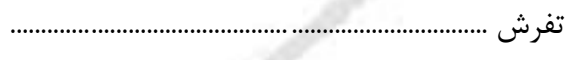 \\
\hline DTHT & NTEV & NTrG & 19494 & ساكن در نقاط شهرى .. \\
\hline 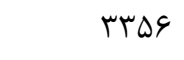 & Fras & figt & AFr. & ساكن در نقاط روستايي \\
\hline$\cdot$ & $\cdot$ & $\cdot$ & $\cdot$ & 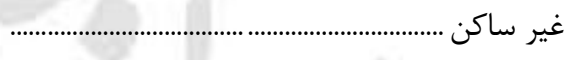 \\
\hline meqII & $\Delta T \cdot Y_{1}$ & Drqve & $1 \cdot 0 \cdot 1 \mathrm{~V}$ & 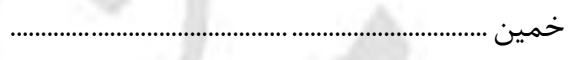 \\
\hline rmVt. & reVVG & rVYA. & VFTDS & 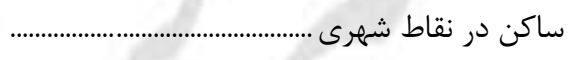 \\
\hline $1 \cdot \lambda F^{* 1}$ & $10 T \& \Delta$ & lofqG & $r \cdot \vee \& l$ & 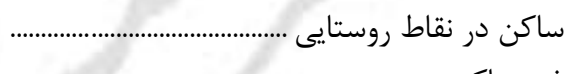 \\
\hline 19V9T & rqIDG & tVAGT & $\Delta F \cdot 11$ & 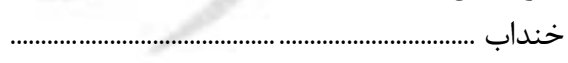 \\
\hline ५११^ & grq1 & $9 \Delta \cdot \Delta$ & $\mid r \Lambda \cdot r$ & 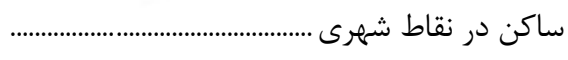 \\
\hline IrVqF & 19101 & rITUV & FITID & 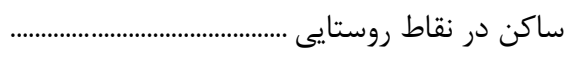 \\
\hline$\cdot$ & . & $\cdot$ & $\cdot$ & 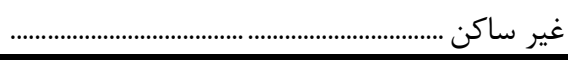 \\
\hline
\end{tabular}


ط - جمعيت و خانوار شهرستانهاى كشور به ترتيب استان (دنباله)

\begin{tabular}{|c|c|c|c|c|}
\hline خانوار & 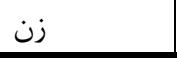 & 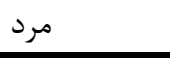 & جمعيت & شرح \\
\hline IsFar & TATYq & TETVT & $\Delta|\& T|$ & 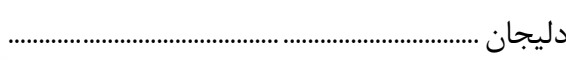 \\
\hline IFYAF & rirqu & trte & preqf & 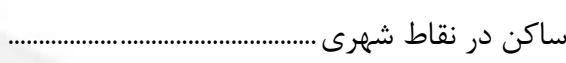 \\
\hline r৭९q & rqه९ & fivi & NITV & ساكن در نقاط روستايى ........ \\
\hline & $\cdot$ & . & & 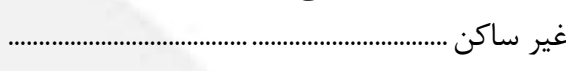 \\
\hline r. FAr & rIfa. & TTFAV & qщq.V & 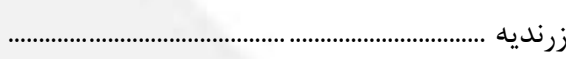 \\
\hline ITAVY & $r \cdot 199$ & $r \cdot G \cdot r$ & 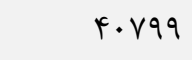 & ساكن در نقاط شهرى \\
\hline Vq. & IITDF & $\| \wedge \Delta F$ & ו ו & ساكن در نقاط روستايي \\
\hline · & & · & · & 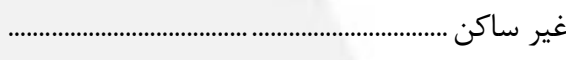 \\
\hline AvfFe & Irরৎ9V & |FFAVI & TATarA & 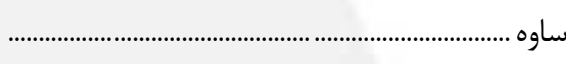 \\
\hline VIlQf & 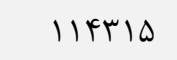 & 119.94 & 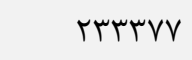 & ساكن در نقاط شهرى \\
\hline ISTAN & TFTat & $r \Delta \Lambda \cdot V$ & $0 \cdot 109$ & ساكن در نقاط روستاي \\
\hline r & & r & r & 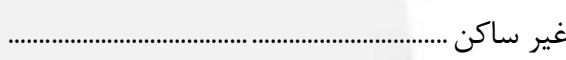 \\
\hline TATIF & DARTr & $\Delta 91 r \wedge$ & $|l v \Delta V|$ & 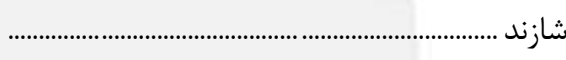 \\
\hline 1199. & rqAVV & $r \cdot \Delta V r$ & $q \cdot k p q$ & ساكن در نقاط شهرى. \\
\hline 19TAF & $r \wedge \Delta \Delta Q \varphi$ & r^D९৭ & DVITT & ساكن در نقاط روستاي \\
\hline - & & & & 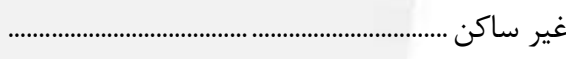 \\
\hline qYYF & IFry. & lfest & r८१९Y & 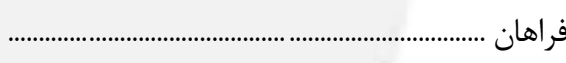 \\
\hline r^१४ & Frul & $|4|$. & 1991 & ساكن در نقاط شهرى \\
\hline GNFV & $99 \Delta 9$ & $1 \ldots k t$ & $r \cdots r$ & ساكن در نقاط روستاي \\
\hline & & & & 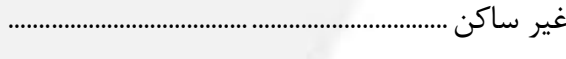 \\
\hline 11rrq & IV9D9 & INFAD & reffi & 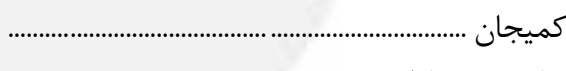 \\
\hline DFAV & $M A V$ & 9TIV & $11 \cdot 94$ & ساكن در نقاط شهرى \\
\hline$\Delta \wedge \Delta T$ & 91.9 & $9 T \& \wedge$ & INTVV & ساكن در نقاط روستايد \\
\hline Inkte & rVTVq & $r \Lambda \cdot q r$ & DQYKT & محلات ........................... \\
\hline 19994 & $r \Delta \cdot V V$ & $r \Delta S V \Delta$ & $\Delta \cdot V Q T$ & ساكن در نقاط شهرى .... \\
\hline IVFT & 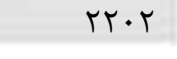 & THMA & $r \Delta q$. & ساكن در نقاط روستايي \\
\hline . & $\cdot$ & $\cdot$ & & 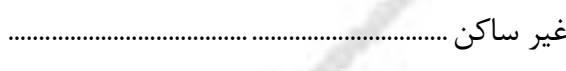 \\
\hline farge. & 1998.1 & $9 \cdot 81)^{F}$ & Irverid & 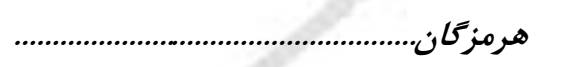 \\
\hline TVDSIQ & FVratr & fq४^१q & QVINTY & ساكن در نقاط شهرs \\
\hline TIVTrI & rquprr & $r \cdot v V r q$ & $\Lambda \cdot r \Delta I T$ & ساكن در نقاط روستاي \\
\hline VT. & $9 \cdot 0$ & $11 V 9$ & $r \cdot \Lambda 1$ & غير ساكن ....................................... \\
\hline $\begin{array}{l}9 T F^{f} \\
\Lambda \Delta V\end{array}$ & $\begin{array}{l}10 \cdot r \\
\text { IFTD }\end{array}$ & $\begin{array}{l}\Delta \wedge 99 \\
r \vee \wedge \Lambda\end{array}$ & $\begin{array}{l}\text { VE. } \\
\text { FTIT }\end{array}$ & ساكن در نقاط شهرى .................................. \\
\hline TISAK & татq४ & (4). 90 & N. kqT & بستك \\
\hline Fald & $\wedge r T \Delta$ & $\Lambda \Delta F F$ & 19199 & 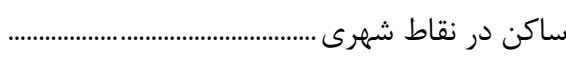 \\
\hline$|V| 9 \mid$ & $r 1 \cdot 9 \Lambda$ & rrorq & Grs.V & ساكن در نقاط روستايى ........................................ \\
\hline$\wedge$ & r & ir & 19 & 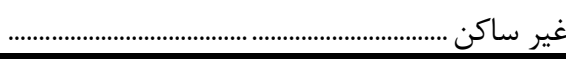 \\
\hline
\end{tabular}


ط - جمعيت و خانوار شهرستانهاى كشور به ترتيب استان (دنباله)

\begin{tabular}{|c|c|c|c|c|}
\hline خانوار & زن - ت & 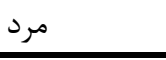 & جمعيت & شرح \\
\hline$q \mu \Delta q$ & IVFVT & $|V \&| r$ & $r \Delta \cdot \wedge \Delta$ & 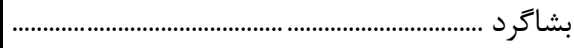 \\
\hline$V I f$ & IFT. & $I F V D$ & rی9० & ساكن در نقاط شهرى ... \\
\hline NAFD & $19 \cdot \Delta r$ & 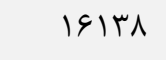 & rTI9. & ساكن در نقاط روستايى \\
\hline · & $\cdot$ & $\cdot$ & • & 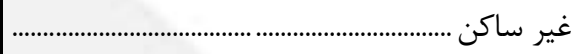 \\
\hline 19GTr. & & TFVT. T & $\varphi \wedge \cdot r \varphi \varphi$ & 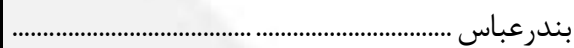 \\
\hline IDVDG & TEDVTF & TVVFAF & DFTTIA & ساكن در نقاط شهرى .. \\
\hline refqu & sVr.. & $990 \ldots$ & IrGA.. & ساكن در نقاط روستايح \\
\hline 109 & וr. & YIN & mî & 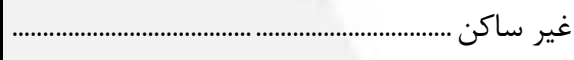 \\
\hline fFrqu & VFEVA & $\Lambda F \& \Lambda$. & । & 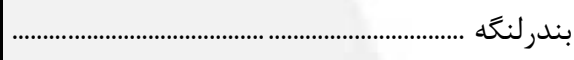 \\
\hline rAFVI & fFqar & $\Delta / T \Delta \cdot$ & वबाँ & ساكن در نقاط شهرى \\
\hline IDQYT & rqVif & אזrسז & Gr.rV & ساكن در نقاط روستاي \\
\hline r & r & v & 9 & 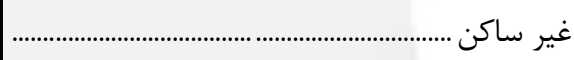 \\
\hline Ir人Is & TFAS. & roVrG & $\Delta \cdot \Delta 99$ & 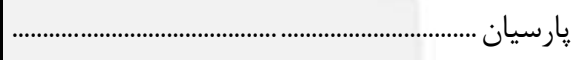 \\
\hline$V \cdot p q$ & $1 r V \cdot q$ & |rrq| & rq... & ساكن در نقاط شهرى \\
\hline GVৎV & $|r| \Delta \mid$ & ITFFE & TFDQG & ساكن در نقاط روستاي \\
\hline - & & & - & 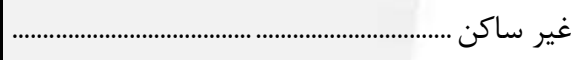 \\
\hline$|\Delta r| \mid$ & TAVVF & r. & $\Delta \Lambda \Lambda \Lambda F$ & 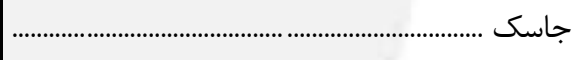 \\
\hline FFID & 1.人 & $\wedge \vee \vee v$ & 1919. & ساكن در نقاط شهرى. \\
\hline $1 . \vee 99$ & $r .991$ & אחזוץ & FT. TF & ساكن در نقاط روستاي \\
\hline & & & & 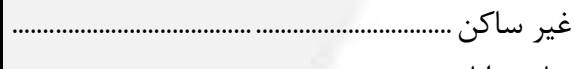 \\
\hline$r \cdot v \cdot \cdot$ & MFTTI & $r \Delta F \cdot r$ & घq૯Td & 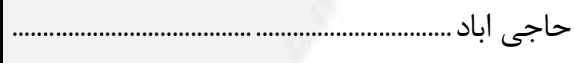 \\
\hline$q \cdot r r$ & IDSTD & IETAT & $r 19 \cdot V$ & ساكن در نقاط شهرى \\
\hline IIrT. & $|\vee 9 \Delta|$ & 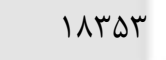 & rqr. & ساكن در نقاط روستاي \\
\hline fru & sto & V९q & $|f| f$ & 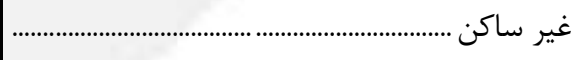 \\
\hline$|q \cdot V|$ & rVqDT & rی190 & $\Delta G \mid F \wedge$ & 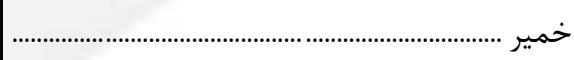 \\
\hline$q \cdot \Delta V$ & $1 \cdot 1 r \varepsilon$ & $11 \cdot \Delta r$ & YIAVA & ساكن در نقاط شهرى ......... \\
\hline $1 \cdots \mid f$ & IVITV & IVIFT & MFTV. & ساكن در نقاط روستايا \\
\hline$\cdot$ & · & $\cdot$ & $\cdot$ & 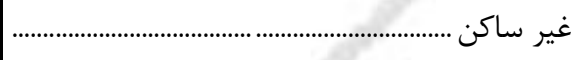 \\
\hline rFDGI & $q K F \cdot \Lambda$ & GTIIF & ITFATY & 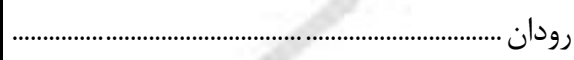 \\
\hline$|r| q \mid$ & אשחמז & rT\&DA & F्व & ساكن در نقاط شهرى \\
\hline r) & ऍА१マ & سזسوץ & $\vee \wedge \mu \cdot \varphi$ & ساكن در نقاط روستاي \\
\hline vi & $1 \cdot r$ & r - 5 & TrG & 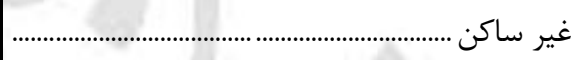 \\
\hline $11 r \cdot f$ & rTANK & rTAF. & FAVTK & 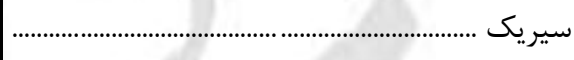 \\
\hline rAVI & $9 \cdot \Delta 9$ & 9149 & $M T \cdot \Delta$ & ساكن در نقاط شهرى. \\
\hline Trta & IENTF & 19994 & MTLIN & 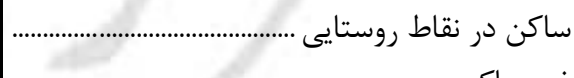 \\
\hline$\varphi \cdot 0 \cdot \varepsilon$ & Vra19 & $V q \cdot V V$ & 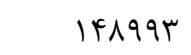 & 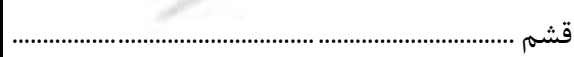 \\
\hline $19 \cdot r V$ & rrmq1 & mpy & $991 \cdot 1$ & 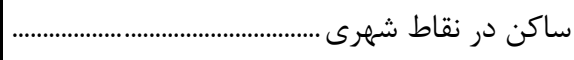 \\
\hline TIFFV & $r \cdot \Delta I V$ & FIsfer & NTIG. & 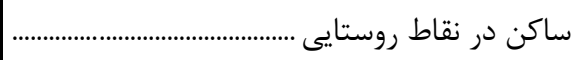 \\
\hline rt & 1 & 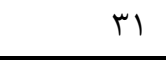 & rt & 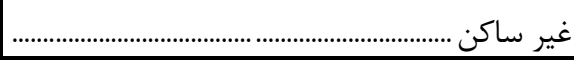 \\
\hline
\end{tabular}


ط - جمعيت و خانوار شهرستانهاى كشور به ترتيب استان (دنباله)

\begin{tabular}{|c|c|c|c|c|}
\hline خانوار & 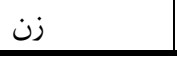 & مرد & جمعيت & 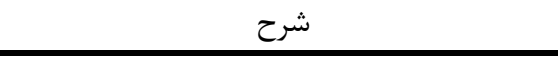 \\
\hline $9 \wedge 9.9$ & Irqur & irqurq & TDQTKI & 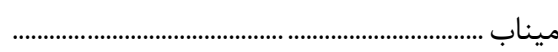 \\
\hline TTSDV & cr. ra & prepq & $\Lambda \notin \varsigma V V^{F}$ & 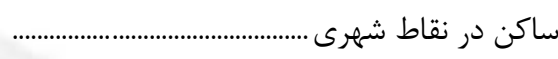 \\
\hline FATKI & NGTTV & $\wedge \& \mid \wedge \uparrow$ & IVTAII & 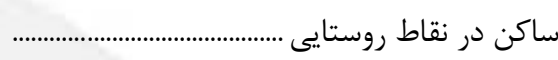 \\
\hline$\wedge$ & r. & 19 & rs & 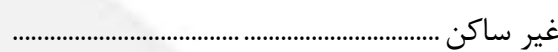 \\
\hline$\Delta r A 1 \cdot r$ & 1avals & $11 \cdot r 11$ & ivrarre & 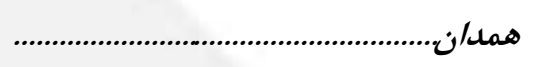 \\
\hline refG. & DFGGT. & $\Delta \Delta \cdot \Delta \wedge \vee$ & $1.9 V Y I V$ & 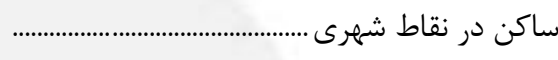 \\
\hline 194991 & MI. TFY & rイヘ૬૬T & $\varepsilon r q \cdots \Delta$ & ساكن در نقاط روستايى ........ \\
\hline 499 & qqe & 1.91 & $r \cdot I r$ & 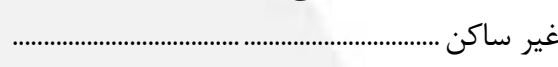 \\
\hline$r \cdot r \wedge V$ & 19q1. & 0.991 & $1 \cdot .9 \cdot 1$ & 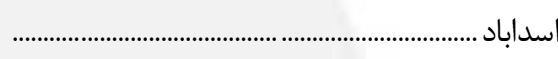 \\
\hline$I V \Delta \wedge V$ & rی१19 & TAQTT & 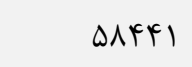 & 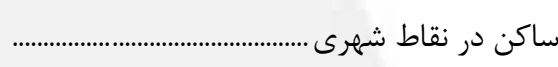 \\
\hline$|T V T|$ & $r \cdot \wedge \Delta \varphi$ & $r \mid r \cdot t$ & GTIOA & 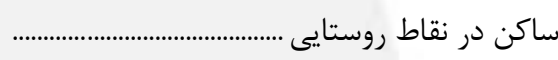 \\
\hline vq & ira & $19 \mathrm{~V}$ & $r \cdot r$ & 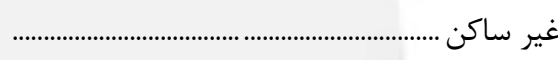 \\
\hline rGAFF & $\Delta \wedge 1 \cdot 9$ & $9.9 \vee 9$ & $119 \cdot 1 r$ & 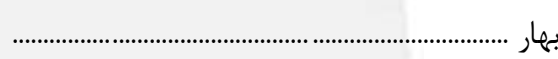 \\
\hline $\mid \Lambda F \varepsilon \Lambda$ & rMArq & Т৭१९५ & $\Delta \wedge \Lambda \mu_{1}$ & 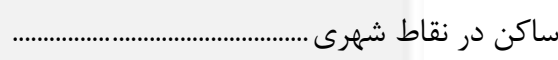 \\
\hline IArVG & ratgV & $r \cdot 9 \Lambda \mathrm{F}$ & $Q \cdot Y \Delta I$ & 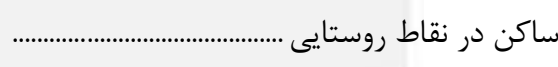 \\
\hline$\cdot$ & & & & غير ساكن ......................... \\
\hline rrart & $0.8 Y 9$ & $\Delta 1 \cdot r V$ & 1.1994 & 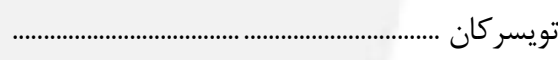 \\
\hline IATF. & rA.re & $r \Lambda \cdot r q$ & $\Delta G \cdot G T$ & 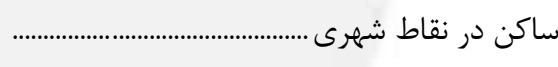 \\
\hline largr & TTATS & tratr & FDFAT & $\ldots \ldots \ldots \ldots \ldots \ldots \ldots \ldots \ldots \ldots \ldots \ldots \ldots \ldots \ldots$. \\
\hline 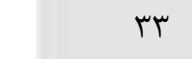 & qV & Af & 101 & 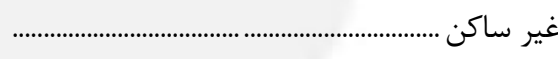 \\
\hline Ttr. & Drqv. & $\Delta F \& I V$ & $1 \cdot V \Delta \wedge \vee$ & رزن ........................................... \\
\hline N. kt & ITIVT & IrAve & $t r \cdot f Q$ & ساكن در نقاط شهرى. \\
\hline TYISD & rqท৭^ & $F \cdot V F r$ & $\Lambda \cdot \Delta F I$ & ساكن در نقاط روستاي \\
\hline IrINT & 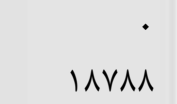 & $r \cdot \Delta V I$ & 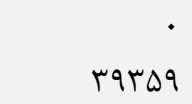 & غير ساكن ............................................................ \\
\hline rqqu & 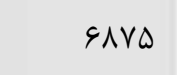 & r & $I F T \cdot \Lambda$ & ساكن در نقاط شهرى. \\
\hline vast & 11914 & ITtKA & $r \Delta|\Delta|$ & ساكن در نقاط روستاي \\
\hline & . & & & 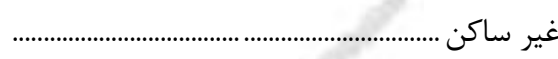 \\
\hline rVDSV & 9.949 & gDFTr & $1 T G .94$ & 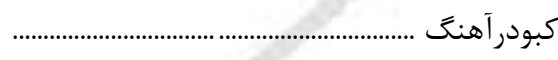 \\
\hline VQT. & $|r| V \Delta$ & $\mid r \wedge \Delta \wedge$ & rQ TL & ساكن در نقاط شهرى \\
\hline$r . . p v$ & FAFAF & $\Delta T \Delta V \Delta$ & $1 \cdot 1 \cdot 49$ & ساكن در نقاط روستاي \\
\hline NGYGr & IFrFAs & 190199 & rMASND & 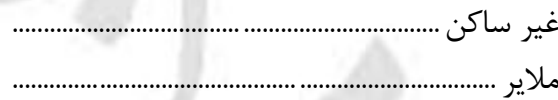 \\
\hline$\Delta \Lambda T \cdot \Delta$ & $q r \Delta q \Lambda$ & qADGT & $|\wedge \Lambda| s$. & 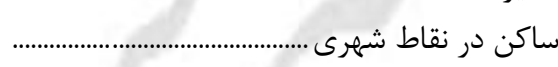 \\
\hline riars & 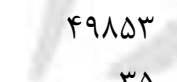 & $\Delta \cdot \Delta 9 r_{x \in}$ & $1 \ldots+k \notin$ & ساكن در نقاط روستايى . \\
\hline DQDFT & MNTIS & $q \cdot \Delta V 1$ & IVAVAV & 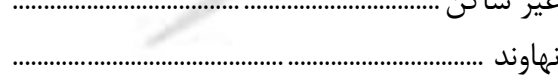 \\
\hline$r \Lambda \Lambda \cdot q$ & $r \Delta \& \wedge 1$ & fergr & 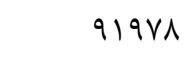 & 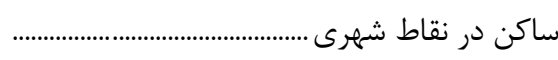 \\
\hline TEMVI & FINTA & $r r \Delta \cdot \Delta$ & (1) & 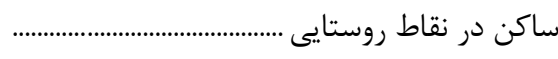 \\
\hline rar & $v \cdot v$ & v\&9 & IfVs & 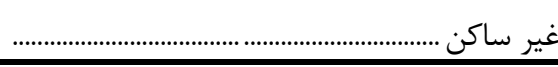 \\
\hline
\end{tabular}


ط ـ جمعيت و خانوار شهرستانهاى كشور به ترتيب استان (دنباله)

\begin{tabular}{|c|c|c|c|c|}
\hline خانوار & 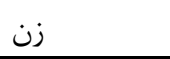 & 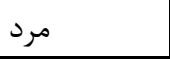 & جمعيت & 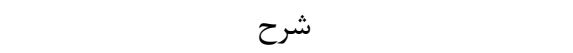 \\
\hline TI.VVD & TMDINT & rF. qTr & $9 \vee 91 \cdot \Delta$ & 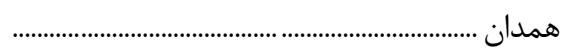 \\
\hline IATKTV & rAqHTD & TANITK & $\Delta V Y F \Delta \Lambda$ & ساكن در نقاط شهرى ........... \\
\hline TNQTF & $F \Delta A F V$ & DTVQS & 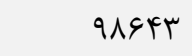 & 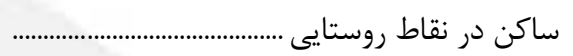 \\
\hline r & $\cdot$ & f & f & 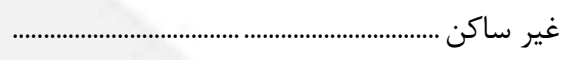 \\
\hline$r F \cdot q \Delta V$ & DATAT. & $\Delta \Lambda 9 \cdot 1 r$ & Irratr & 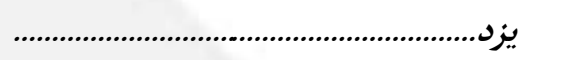 \\
\hline$r 9.991$ & FVDI. 1 & FqGTQF & 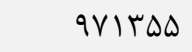 & 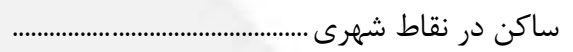 \\
\hline 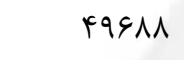 & VVYGA & $194 \Delta \varphi$ & IGQVTF & 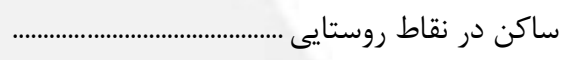 \\
\hline$r \cdot 1$ & $|0|$ & $r \cdot r$ & Faf & 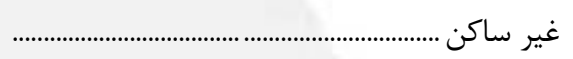 \\
\hline $19 \cdot r 9$ & TYAMS & rৎ৭૬૬ & $\Delta I \Delta \Delta T$ & 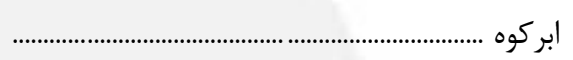 \\
\hline $1 \cdot \Lambda r V$ & IVTEF & IATVV & TDGTI & 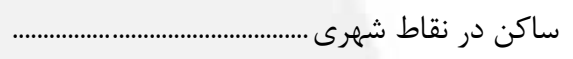 \\
\hline$\uparrow q .$. & vrar & $\wedge \cdot 9$. & IDFAT & ساكن در نقاط روستايى ... \\
\hline r१९ & 10 & r৭9 & kqq & 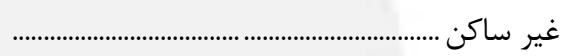 \\
\hline TATIS & fefey & מTDIT & १४१९. & 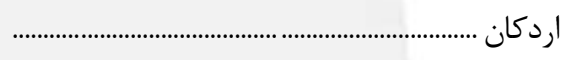 \\
\hline rFq৭૬ & r৭^६1 & kets. & $\Lambda r \cdot v i$ & ساكن در نقاط شهرى \\
\hline rtr. & $F \Delta \wedge \varphi$ & $1 \cdot r \cdot r$ & $1 F \wedge \wedge 9$ & ساكن در نقاط روستايد \\
\hline qघाए & 1019. & $\mid V k \cdot 9$ & rTDGQ & |شير ساكن ........................................................ \\
\hline DQदर & $9 \Delta \Delta \wedge$ & $1.1 \ldots$ & $199 \Delta \Lambda$ & ساكن در نقاط شهرى...... \\
\hline r\&QI & $\Delta G \cdot r$ & $V r \cdot 9$ & $1 r q \cdot 1$ & ساكن در نقاط روستايح \\
\hline & & & & 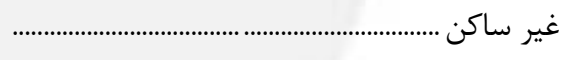 \\
\hline$|\Delta| \Delta \varphi$ & rFq99 & 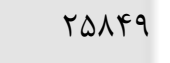 & $\Delta \cdot \lambda \uparrow \Delta$ & بافق ............................................ \\
\hline IMFDF & THTt & (4TIT & FAFAT & ساكن در نقاط شهرى... \\
\hline IV.r & TEVD & TVIV & Drat & ساكن در نقاط روستاي. \\
\hline$\Delta r \dot{\theta}^{\circ}$ & ᄉ\&Y & $\Lambda \Delta q r^{\circ}$ & IVTYI & 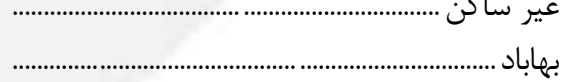 \\
\hline trVA & $p q \cdot r$ & far. & QTrT & ساكن در نقاط شهرى ... \\
\hline re.r & rarv & f.qr & จ१८१ & 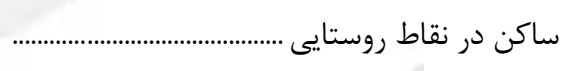 \\
\hline $148 \Delta 9$ & rIfFe & TYFEV & • & غير ساكن ............................................................ \\
\hline$G T \Delta \Delta$ & १人५q & $1 \cdot r \varepsilon \Delta$ & $r \cdot r \cdot r$ & ساكن در نقاط شهرى. \\
\hline$\Lambda F \cdot r$ & $119 \cdot V$ & $I T \cdot \wedge r$ & rா\&人9 & ساكن در نقاط روستايي \\
\hline$\cdot$ & $\cdot$ & • & • & 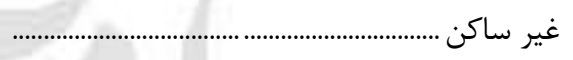 \\
\hline $1 \cdot 111$ & $|V F| 9$ & 19148 & TSDGT & 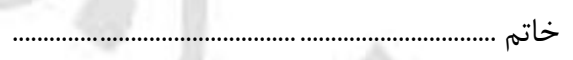 \\
\hline G9T & I. Nkt & 11099 & TrFII & ساكن در نقاط شهرى ........ \\
\hline FiM & GQVR & $V \Delta V F$ & $|f| f V$ & ساكن در نقاط روستايى ... \\
\hline loqv^ & ratar & reri. & DIVTr & 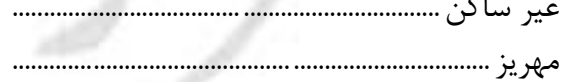 \\
\hline $1 \cdot r k F$ & 19V9V & IVEF. & TETTY & 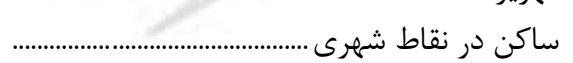 \\
\hline$\Delta G r F$ & $\wedge F \Delta S$ & $q \cdot 4 \cdot$ & IVFag & 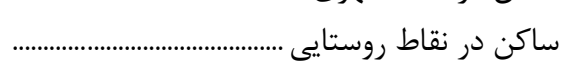 \\
\hline & · & . & & 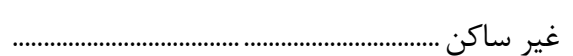 \\
\hline
\end{tabular}


| نتايج تفصيلى سرشمارى عمومى نفوس و مسكن _ه

\begin{tabular}{|c|c|c|c|c|}
\hline خانوار & زن & مرد & جمعيت & شرح \\
\hline rqGAF & FASQA & $\Delta 1 \cdot V 1$ & १९Y५ & \\
\hline rEANT & 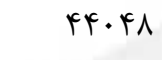 & $F \Delta q \Delta F$ & $q \cdots r$ & ساكن در نقاط شهرى ... \\
\hline$r \Lambda \cdot r$ & $4 \varepsilon \cdot 1$ & $\Delta \| 1 V$ & qYTQ & ساكن در نقاط روستايى. \\
\hline & - & & & 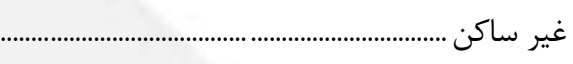 \\
\hline $1901 M F$ & TrISTI & rmeNer & gDGFVE & يزد د.............. \\
\hline INTDFA & 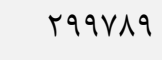 & rllबV & 911494 & ساكن در نقاط شهرى ........... \\
\hline ITANA & TINFT & TrISD & is..v & ساكن در نقاط روستايى ........... \\
\hline 1 & - & 1 & 1 & غير ساكن ........ \\
\hline
\end{tabular}




\begin{tabular}{|c|c|c|c|c|}
\hline خانوار & زن & 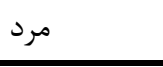 & جمعيت & 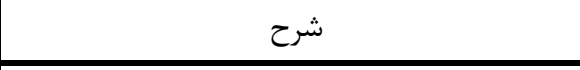 \\
\hline 1AVIFr & $1 r 119 \cdot r$ & 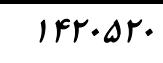 & rA. qFTF & 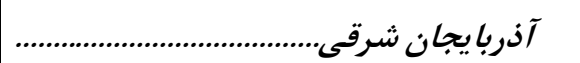 \\
\hline マ^9 & $14 \cdot r$ & זוr & TVID & آبش احمد ..... \\
\hline IFTET & $r t \cdot 19$ & rTAVI & FYANV & 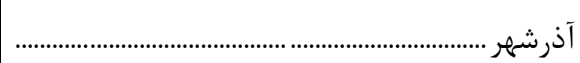 \\
\hline 914 & $\mid 4 \cdot 1$ & $10 \cdot 1$ & $r q \cdot r$ & آقكند .......... \\
\hline 119 & וNIT & $\mid \Lambda r F$ & reft & آجاجى .......... \\
\hline 9411 & qrтq & $91 \%$. & $1 \wedge F \Delta q$ & اسكو .................... \\
\hline$r \cdot 1 r q$ & $\Delta \cdot r \Delta \Delta$ & $\Delta \cdot r \wedge \varphi$ & $1 . .941$ & اهر ................ \\
\hline$\Delta \Delta \cdot \cdot$ & NTYF & $\wedge r \Delta \cdot$ & $19 \Delta V Y$ & ايلخجى .................... \\
\hline ґ^৭. & $9 \cdot \wedge r$ & $49 \cdot 9$ & Ir\&9T & باسمنج........... \\
\hline $11 \cdot 1$ & $r \cdot 99$ & r.rq & $91 . r$ & بخشايش........... \\
\hline GTIA & $1 \cdot \Delta T F$ & $\||r| \cdot$ & TIVTF & بستان آباد .............. \\
\hline r\&919 & frrev & Frq.V & NDYVF & بناب ........ \\
\hline$|+4|$ & trt. & $r \cdot \Lambda I$ & साl & بناب مرند ....... \\
\hline 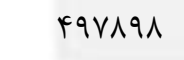 & VRT. rT & V^ৎ991 & 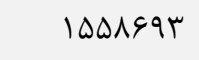 & تبريز ........ \\
\hline G.r & 1.49 & $99 \%$ & $r \cdot r)$ & ترك ......................... \\
\hline TrGG & rqDS & rVAv & vetr & تركمانجاى ........ \\
\hline tolf & rVA. & TVET & VATT & تسوج .................... \\
\hline 914 & IfIV & $I \Delta \Delta V$ & rave & تيكمه داش ............ \\
\hline IV99 & TQAT & TVQT & DrVD & تيمورلو................... \\
\hline TQFV & $r \cdot r q$ & FVAl & $\wedge \wedge 1$. & 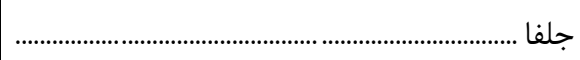 \\
\hline rir & MFF & ros & $\vee \cdot \cdot$ & جوان قلعه .......... \\
\hline $1 \cdot r \Delta$ & 1099 & IVAF & Trat & 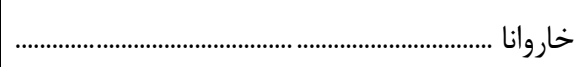 \\
\hline $1 \cdots 9$ & LQFF & $101 T$ & $r \cdot \Delta \varphi$ & 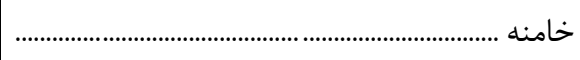 \\
\hline$\Delta V T$ & $9 \Delta \mathrm{T}$ & AVT & IAYY & خداجو(خراجو) ......... \\
\hline 9^V. & $111 r \Delta$ & $1 \cdot \Lambda F V$ & rI9VT & 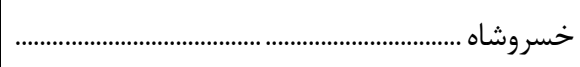 \\
\hline$\Delta \varphi \cdot$ & 949 & 994 & $19 . r$ & 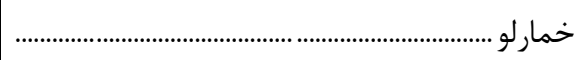 \\
\hline $1 \pi 90$ & 1997 & $r \cdot 14$ & $k \cdot 11$ & 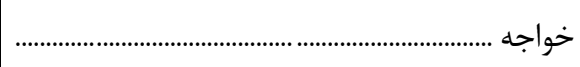 \\
\hline 1.90 & IVTr & 11990 & TGTV & دوزدوزان ........... \\
\hline 1949 & TQVT & TVVI & DTFT & 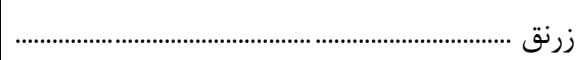 \\
\hline NFr & 11499 & 1.99 & TFED & 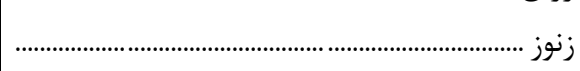 \\
\hline וrqDT & TrIFA & rTMMS & $\mid r \Delta \cdot r)$ & سراب..................................... \\
\hline$q \Delta T Q$ & Ifres & $|\Delta F| T$ & rqvrq & 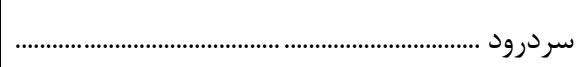 \\
\hline$r \Delta \Lambda \cdot T$ & $r \cdot r q \Delta$ & FTI99 & ATFqF & 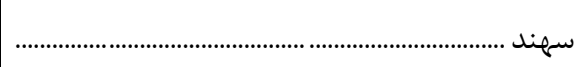 \\
\hline $19 T \wedge$ & & $r \cdot q \cdot$ & 91.4 & ............. \\
\hline iv. & VTr & $\wedge 10$ & $\mid D F \Lambda$ & سيه رود .................. \\
\hline$v \cdots c^{c}$ & $11 \cdots 4$ & $111 V 0$ & rTIAI & بستر ...... \\
\hline
\end{tabular}


ظ ـ جمعيت و خانوار شهرهاى كشور به ترتيب استان (دنباله)

\begin{tabular}{|c|c|c|c|c|}
\hline خانوار & 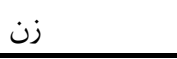 & 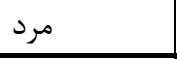 & جمعيت & شرح \\
\hline lQT. & TMFY & Tart & FAVV & 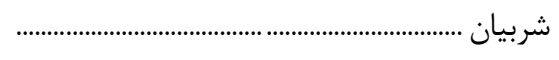 \\
\hline lefs & rIf. & rl. r & FTEF & 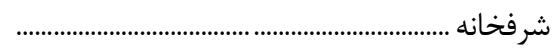 \\
\hline$r V \cdot r$ & fiar & 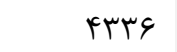 & $\wedge \uparrow \wedge q$ & 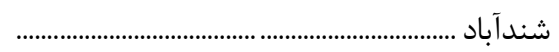 \\
\hline rTr & 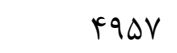 & $0 . .9$ & 9994 & 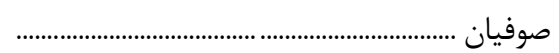 \\
\hline 1.94. & $199 \wedge 1$ & $199 Y 4$ & TrG.9 & عجب شير ................................ \\
\hline I995 & $r \cdot \Delta r$ & $r \cdot \varphi q$ & $91 . r$ & 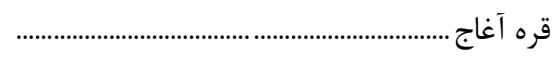 \\
\hline$r \Delta \cdot q$ & अवा^ & FIFt & $\Lambda \cdot 9 \cdot$ & 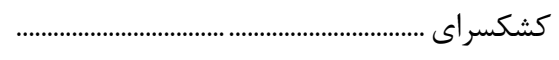 \\
\hline r111 & $r V \cdot r$ & rVal & $V \notin \varepsilon \Delta$ & 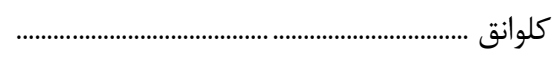 \\
\hline rMA. & Fal. & FAlF & QTYY & 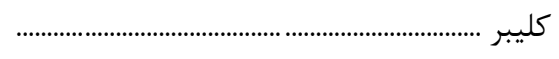 \\
\hline late & rmes & trak & fVr. & 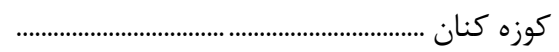 \\
\hline rی৭r & $\Delta V V r$ & ब१९९ & IIVFT & 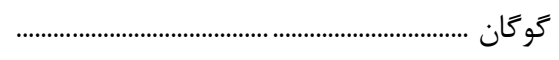 \\
\hline $194 \mathrm{Fr}$ & $r \cdot F \Delta$ & 莏 & 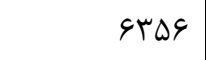 & 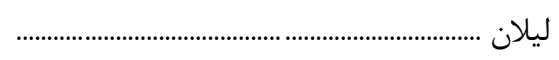 \\
\hline iriv & rIQ. & $r r \cdot \varphi$ & 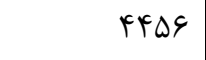 & 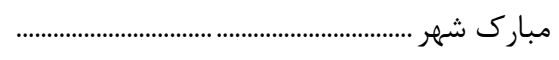 \\
\hline$\Delta r q \Delta \Lambda$ & AVYAV & $\wedge \vee \wedge ९ \wedge$ & IVATDQ & 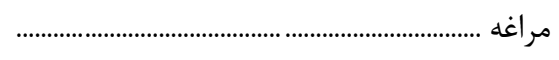 \\
\hline$F \cdot r V \Delta$ & GFIDF & $999 \mathrm{VI}$ & $\mid r \cdot \wedge r \Delta$ & 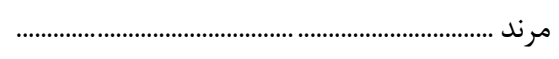 \\
\hline$\Lambda \notin \& V$ & $1 r \Delta \cdot \Lambda$ & וrark & TVET & 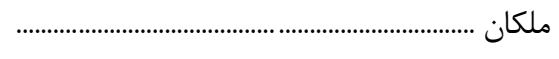 \\
\hline rqu & G.rT & $\Delta \wedge \vee \cdot$ & $11 \wedge 95$ & 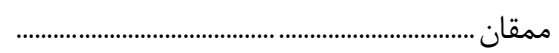 \\
\hline IMAT & $r \wedge \cdot 1$ & rqvi & $\Delta V V T$ & مهربان ............................... \\
\hline$r \cdot \Delta \cdot r$ & $\forall \wedge 19 \Lambda$ & $\Delta \cdot \Lambda \cdot \Delta$ & $9 \wedge 9 \vee \%$ & 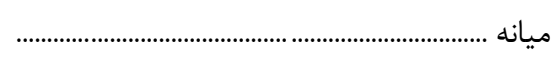 \\
\hline rFA & $\Delta 91$ & $91 \mathrm{~V}$ & $1 r 10$ & 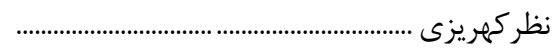 \\
\hline $10 \cdot 1$ & 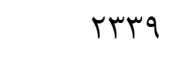 & 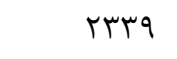 & 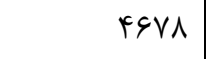 & وايقان ............................... \\
\hline $14 \cdot 1$ & roq. & 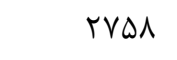 & DHFA & ورزقان ................................. \\
\hline $1 \cdot$ VFF & IEVAr & IVDST & retes & 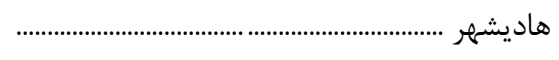 \\
\hline mIle & drq. & $\Delta / T \Delta$ & $1 \cdot 010$ & 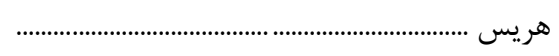 \\
\hline$\varphi \cdot \Delta \varphi$ & $1 \cdots \Delta \Delta$ & $1 \cdot \Delta I V$ & $r \cdot \Delta V T$ & 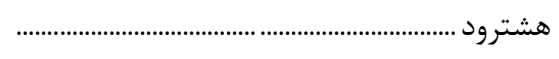 \\
\hline Irat & TrgT & $r T 9 \Delta$ & $\varphi \otimes \Delta \wedge$ & 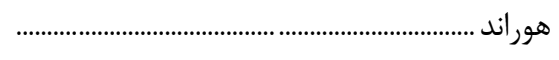 \\
\hline$r r \cdot \Lambda$ & $\Delta 1 \cdot r$ & arq. & $1 \cdot r q 5$ & 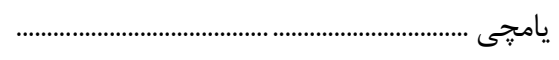 \\
\hline s rll.r & $1 . \Delta 99 r 1$ & $1 \cdot V \& \Delta \& \Delta$ & rirgr.r & آذربا يجان غربى... \\
\hline$\forall \wedge 9$ & $\Delta r \cdot$ & NFr & $199 \pi$ & 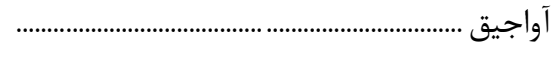 \\
\hline$r r \Delta \cdot \Delta \cdot$ & rqVINI & rqq. kr & VTGYTF & 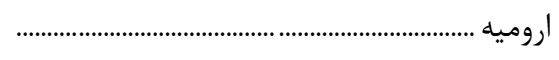 \\
\hline $1.99 \mathrm{~V}$ & 19人ץq & 19984 & $r 9 \Lambda \cdot 1$ & $\ldots \cdots \cdots \cdots \cdots \cdots \cdots$ \\
\hline 999 & 1911 & $18 \cdot 9$ & Trt. & 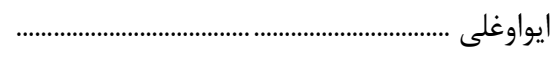 \\
\hline ITFQ & $r \cdot V \cdot$ & $r \backslash \Delta \Delta$ & FrTS & باروق ......................................................................... \\
\hline$r \cdot k r$ & $4 q .1$ & $\Delta \cdot \vee \wedge$ & १९४१ & بازركان ..-1) \\
\hline$\Delta q q F F$ & QDAFT & 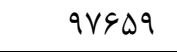 & $19 \pi \Delta \cdot 1$ & 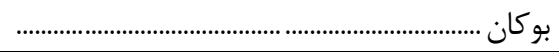 \\
\hline
\end{tabular}


ظ - جمعيت و خانوار شهرهاى كشور به ترتيب استان (دنباله)

\begin{tabular}{|c|c|c|c|c|}
\hline خانوار & 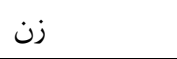 & 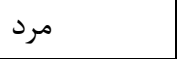 & جمعيت & 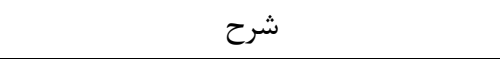 \\
\hline rrv & $\Delta \& \vee \Delta$ & बV৭Y & llFV & يلدشت ............................................................ \\
\hline TMESA & rDQRE & Faqvq & 91010 & 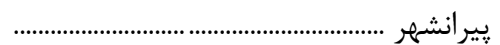 \\
\hline rung & Frar & g & 19५9 & تازه شهر ......................................................... \\
\hline Ifreq & rFVqq & TFAVA & Fq9VV & تكاب..................... \\
\hline rVqT & FQq & $4 \lambda \cdot q$ & $94 \cdot 9$ & 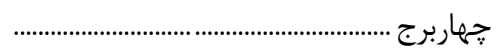 \\
\hline 119 & TFY & $\Delta \cdot \omega$ & $V \notin q$ & 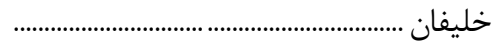 \\
\hline$\Delta 9994$ & 991\% & $99 \vee 15$ & $19 \Lambda \wedge F \Delta$ & خوى ..1.1. \\
\hline rMGY & $r \cdot v r$ & kr.q & NTAT & ديزج ديز .......................................................... \\
\hline$\mu \cdot r$. & VVFA & $\Lambda \cdot \cdot r$ & $1 Q \vee \Delta \cdot$ & 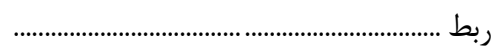 \\
\hline rTY & $9 \cdot \Delta$ & DFT & $11 \mathrm{FV}$ & 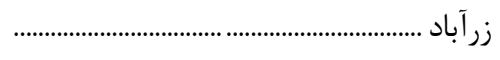 \\
\hline$|r \Delta \Delta|$ & 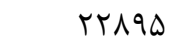 & tratr & fefit & سرد \\
\hline $4 \& 9$ & 194 & 9.9 & $11 \cdot \cdot$ & سرو ...................... \\
\hline trIIO & $r \Delta \cdot r$ & $F \vee \wedge \cdot \Lambda$ & $94 \wedge 11$ & سلماس ..................... \\
\hline pre & $\Lambda \cdot \Delta$ & $1 \cdot 9$ & 1914 & سيلوانه ..................... \\
\hline rदq & $9 \vee 9$ & 999 & IFYA & سيمينه ........... \\
\hline $48 \cdot 1$ & $\wedge \varphi \cdot \vee$ & $919 \vee$ & $I V \lambda \cdot r$ & سيه קشمه ............................ \\
\hline ITAKG & TIDFE & $r \backslash \Delta \wedge \Delta$ & 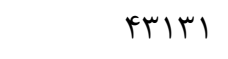 & شاهين دز ........................................................ \\
\hline VYI9 & $|T \Delta T|$ & $I T \wedge \Delta \cdot$ & TOHAI & 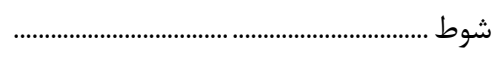 \\
\hline TGY. & rea. & FVF. & 919. & فيرورق ....................................................... \\
\hline$V \wedge 19$ & $|r| \cdot \mid$ & 1 1r994 & TEVGV & 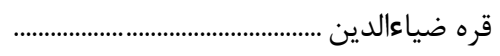 \\
\hline 1194 & rFqF & reQT & DIFV & 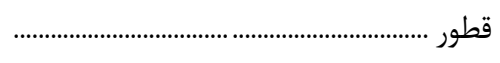 \\
\hline quळ & $1 r \Delta \cdot$ & lefr & TVAV & 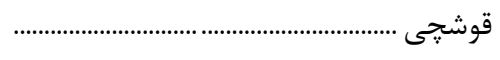 \\
\hline ITFA & 1994 & rlfe & FIrA & 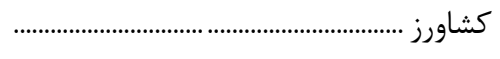 \\
\hline $1 \cdot V r$ & 1910 & rtle & Fr. 1 & كردكشانه ....................................................... \\
\hline Irq4. & rT\&DQ & rratr & $r \notin \Delta \wedge 1$ & 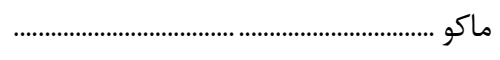 \\
\hline TVVD & ravq & Frur & 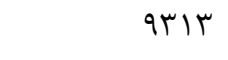 & محمديار .................................................... \\
\hline rita & TFYA & rFis & ધヘ૬9 & 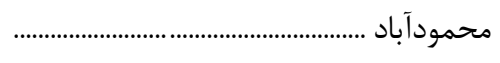 \\
\hline GFT & $11 \cdot 9$ & $111 \mathrm{a}$ & trat & 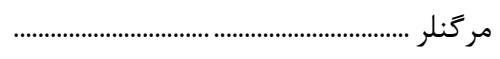 \\
\hline fVqVe & NFITT & NFrVI & 19人ঙq & 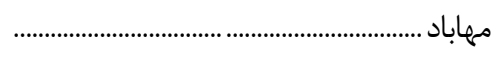 \\
\hline$f \mid F \Delta q$ & GDVFG & 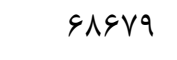 & ITFETS & 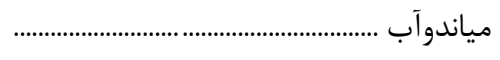 \\
\hline $1 \Delta \Delta \cdot$ & rqAF & $r \cdot 19$ & $4 \ldots$ & ميرآباد............................................................ \\
\hline$\wedge r q$ & IrFA & 1419 & T\&9V & نازك عليا.......................................................... \\
\hline VVA & $\mid F \wedge 9$ & IFAV & rqv & 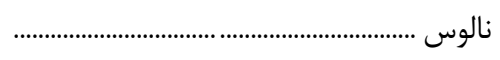 \\
\hline TFYAT & $r \cdot v \& q$ & $r \cdot \wedge r q$ & $\wedge 1091$ & 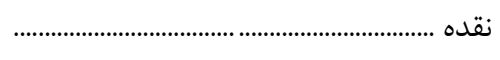 \\
\hline rm & FITV & Frat & $\wedge ґ \wedge$. & 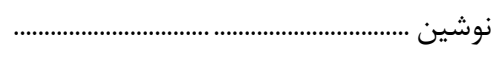 \\
\hline 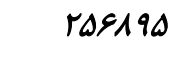 & Fra. 1. & $F F I \cdot r F$ & $1 \& 9 \cdot \mu F$ & 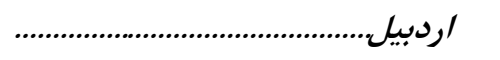 \\
\hline $1 \vee 99$ & $m \cdot v$ & $M F \cdot q$ & 9019 & 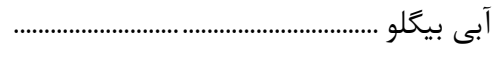 \\
\hline IOAGTV & rЬ৭9AV & К९૧૯АV & DTqTVF & |ربيل ............................... \\
\hline
\end{tabular}


ظ - جمعيت و خانوار شهرهاى كشور به ترتيب استان (دنباله)

\begin{tabular}{|c|c|c|c|c|}
\hline خانوار & 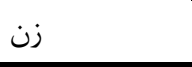 & 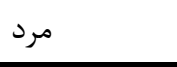 & جمعيت & شرح \\
\hline Arq & $1 \Delta T \Lambda$ & $1 Q F$. & $r \cdot 9 \Lambda$ & 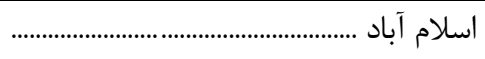 \\
\hline IVe. & $r \cdot \wedge \cdot$ & rT\&A & GryA & 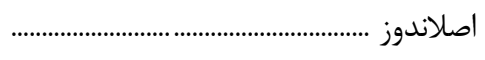 \\
\hline FArV & 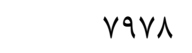 & $\Delta r{ }^{\prime}$. & 19111 & 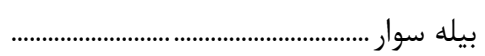 \\
\hline$r \& \Delta \cdot \Delta$ & FAFTH & FVQDF & qTruv & 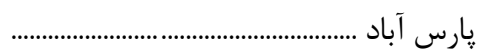 \\
\hline$v \cdot \Lambda$ & ITFF & | & rQVD & 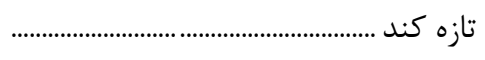 \\
\hline VIV & IrIT & 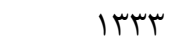 & reta & تازه كندانكَوت .................. \\
\hline$r \cdot r r$ & Takr & 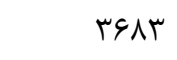 & VTTE & 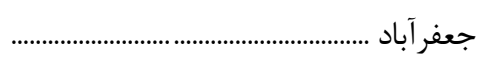 \\
\hline $110 \cdot 1$ & $\mid 9941$ & 19994 & rq५. & 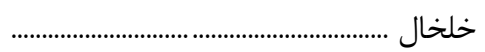 \\
\hline fVr & vVq & $\lambda \cdot r$ & $|\Delta \Lambda|$ & 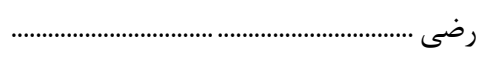 \\
\hline $1 \Delta \wedge r$ & 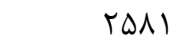 & rAVA & $\Delta F \Delta q$ & سرعين ..................... \\
\hline IVV. & TADT & $r q \cdot \Delta$ & $\Delta V \Delta V$ & عنبران ...................... \\
\hline ref & kqv & $\Delta \cdot r$ & 999 & 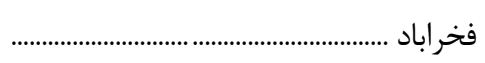 \\
\hline sar & $1 \cdot \varphi_{\Delta}$ & $1 \cdot \Delta \cdot$ & $r \cdot 9 \Delta$ & قصابه .................. \\
\hline VAr & $1 \% \cdot 9$ & $\| 4 \mid$ & trut & 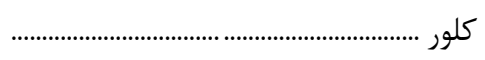 \\
\hline tht & $c \cdot \Delta$ & Frg & NM & 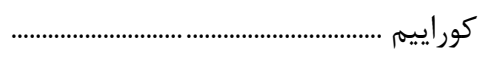 \\
\hline 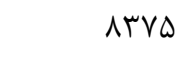 & $|f| V \mid$ & Ifvas & r৯৭९V & 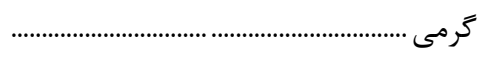 \\
\hline TINT & TLFA & rQDL & $v 1 \cdot 1$ & 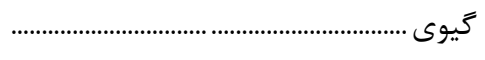 \\
\hline Var & 1.99 & $1 \cdot \Delta \cdot$ & rIfq & 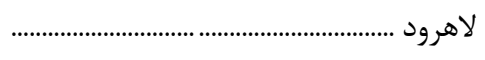 \\
\hline riN & roq & TIT & $9 V 1$ & 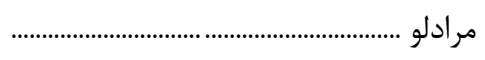 \\
\hline TI9TE & $r \varphi \cdot \Delta \cdot$ & $r \Lambda \cdot \Delta q$ & $V \notin 1.9$ & مشخين شهر .................... \\
\hline $41 \cdot 0$ & GATV & sArT & 14809 & 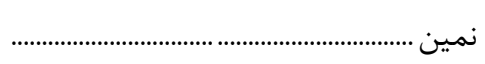 \\
\hline IVIO & rAVV & ५१९९ & $\Delta \wedge V T$ & نير ........................................... \\
\hline IVVD & rAta & rیq. & $\Delta V T \Delta$ & 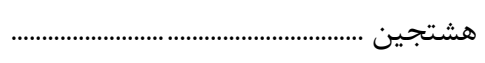 \\
\hline 911 & $1 \cdot r 4$ & $1 \cdot \Delta F$ & $r \cdot \Lambda \cdot$ & 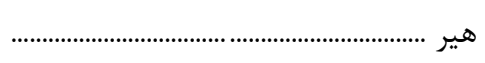 \\
\hline IFllere & rrta.r. & rrarrag & $r \Delta \cdot V r+q$ & اصفهان....... \\
\hline$r \cdot r \mid Q$ & $r r \Delta \cdot 1$ & $r$ rq.r & $9 Q F \cdot F$ & 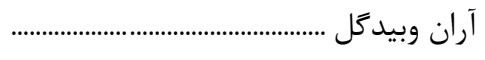 \\
\hline$V \cdot q r$ & 1.991 & IIFrA & TrFTG & 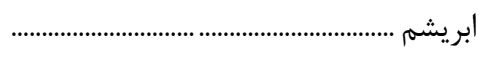 \\
\hline IVAF & rAfF & trte & Q१Vद & ابوزيدآباد ........................................................ \\
\hline$\Delta \cdot 9 \pi$ & $\checkmark Y \wedge \Delta$ & $\vee १ \Delta 9$ & lovfF & اردستان ................................................................. \\
\hline $1 \cdot 11$ & leqr & 1994 & r & 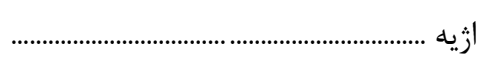 \\
\hline$r \cdot 99$ & TrtA & rQFA & GAVG & اصغرآباد .......................................................... \\
\hline 919.91 & $9 V T \cdot 94$ & 919191 & 1981 (19. & 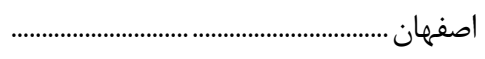 \\
\hline $\mid r \Delta \Lambda$ & $1 \wedge \Delta \cdot$ & INFS & ए९९९ & افوس .............................................................. \\
\hline 999 & $9 \Delta 9$ & qfF & $19 \cdot r$ & انارك ........................ \\
\hline FOIO & $V \cdot 4 q$ & VDAF & I I I T & | ايمانشهر ...................................................... \\
\hline fVer & VTAT & VFV. & IFrr & 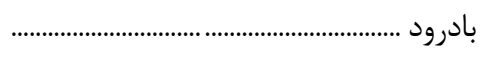 \\
\hline rtru & 1911 & Drsi & $1 \cdot$ rVq & 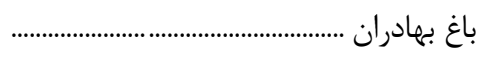 \\
\hline $14 \cdot 1$ & $r \cdot 99$ & trAV & rros & باغشاد ................................................................ \\
\hline
\end{tabular}


ظ ـ جمعيت و خانوار شهرهاى كشور به تر تيب استان (دنباله)

\begin{tabular}{|c|c|c|c|c|}
\hline خانوار & 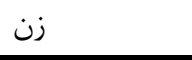 & 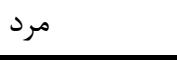 & جمعيت & شرح \\
\hline $9 \wedge \Lambda$ & $1 \cdot r$ & qVD & 1971 & 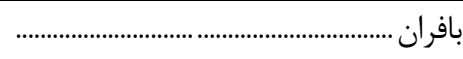 \\
\hline 1491 & TTQV & 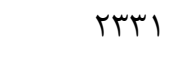 & $F \Delta \Lambda \Lambda$ & 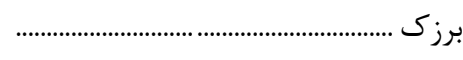 \\
\hline left & roVV & $r \Lambda \cdot \Delta$ & DHAT & 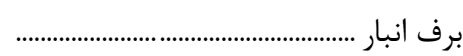 \\
\hline rur & FaYF & 4990 & $9 \wedge \wedge 9$ & 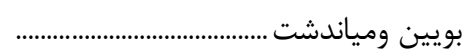 \\
\hline rGFV & DFFT & $\Delta \Lambda F T$ & MrAF & بهاران شهر ........................... \\
\hline rQIIN & rquदq & r৭९ठV & Vq. rr & بهار ستان ..................................................... \\
\hline kr. 9 & QQT. & sq4q & Irfsa & يربكران ........................................................ \\
\hline irk. & rITr & TIOT & ETVD & تودشك ..................................................... \\
\hline $9 \Lambda \Lambda$. & $1 \cdot V T \Delta$ & $1.9 \vee \wedge$ & $r I V \cdot r$ & 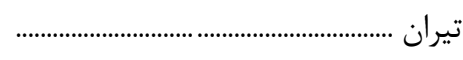 \\
\hline IFV & THEV & rtal & 1990 & 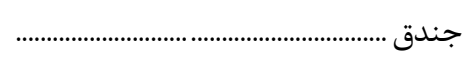 \\
\hline$r l \cdot \Delta$ & MFYF & rave & 9991 & 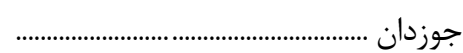 \\
\hline 1499 & $r \cdot q r$ & rIIN & $|4| \Lambda \mid$ & جوشقان قالى ............................................... \\
\hline ratr & kqfr & 4911 & $99 \% F$ & 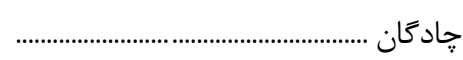 \\
\hline rqur & 9711 & $V \cdot r)$ & IrVtr & جرمهين .......................... \\
\hline $0.1 V$ & V\&Q. & Vart & $1 \Delta \Delta V F$ & 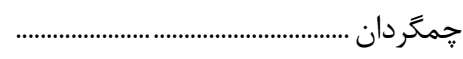 \\
\hline$r \cdot \Delta$ & $4 \& v q$ & FNIT & 9491 & حبيب آباد ............................... \\
\hline $149 \mathrm{~V}$ & $r t \cdot G$ & trRt & EEVA & 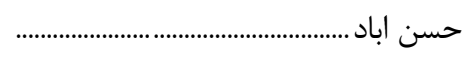 \\
\hline LOTA & TFAT & TFF. & Fart & 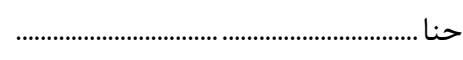 \\
\hline $1 . r f$ & TrL & 149. & rer & 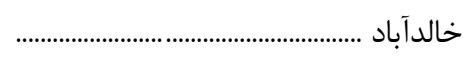 \\
\hline$\vee \Delta \backslash \Lambda$. & $1199 \vee \wedge$ & IrVEA. & TEVITA & 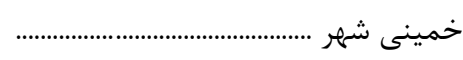 \\
\hline$V \cdot 9 r$ & 11199 & $1.9 \Lambda \mathrm{F}$ & rIANK & 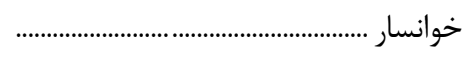 \\
\hline$t r \cdot \Lambda$ & rrq9 & rFeg & \&V\&D & 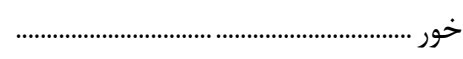 \\
\hline 9.11 & $|f| \cdot \Delta$ & $10 \cdot 49$ & rq1QF & 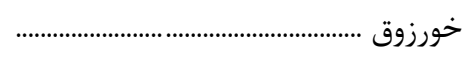 \\
\hline$\Delta \wedge \Lambda 1$ & $9 Y 41$ & (1) & $r \cdots v \wedge$ & 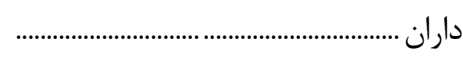 \\
\hline IrNT & $r|\Delta|$ & trig & fres & 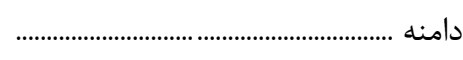 \\
\hline$|\Delta F| \mid$ & Trtad & TFred & $r \vee \wedge .$. & 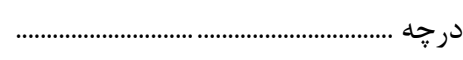 \\
\hline$\Delta r \cdot \Lambda$ & NDST & qrit & IVVVD & دستخر د....................................................... \\
\hline ITHO. & 1999. & $r \cdot 910$ & $4 \cdot q \uparrow \Delta$ & دولت آباد.................................................. \\
\hline$\Delta \vee q$. & $\wedge \vee \wedge \wedge$ & $919 \mathrm{~V}$ & IVqFa & دهاقان ............................................................ \\
\hline r\&VG & $r \cdots v$ & Fred & NTVt & 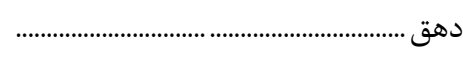 \\
\hline 9.11 & GTYT & qVir & 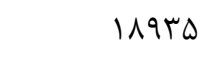 & 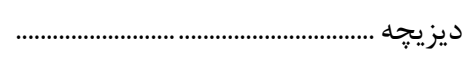 \\
\hline$|r \Delta|$ & TIYK & $r t \cdot \Lambda$ & (1) & رزوه ...................... \\
\hline IrIT & $18 v 9$ & IATV & rद. & 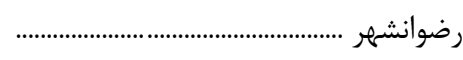 \\
\hline TFAT & tArt & fif. & V৭दर & 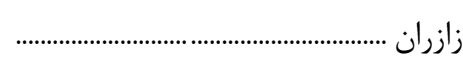 \\
\hline$r \cdot \Lambda \cdot$ & 49.9 & FADF & q4\& & 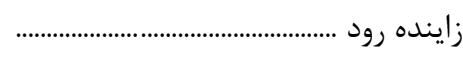 \\
\hline$|V A r|$ & TVATA & r^r^৭ & $\Delta \Delta \wedge I V$ & 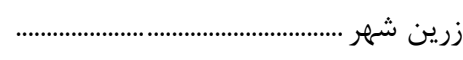 \\
\hline rEVI & FIOT & 4191 & 人rt. & 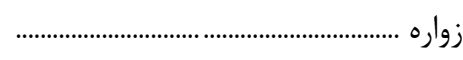 \\
\hline $1 r \cdot 9$ & $1 M \Lambda \Lambda$ & $r \cdot r \cdot$ & r911 & زيار . . \\
\hline
\end{tabular}




\begin{tabular}{|c|c|c|c|c|}
\hline 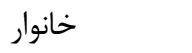 & 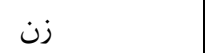 & 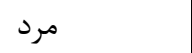 & جمعيت & 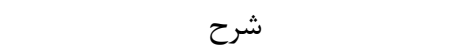 \\
\hline MIST & $\Delta \cdot r$ & 0199 & $1 \cdot r \cdot$. & 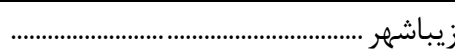 \\
\hline 1911 & taIt & $r \Delta \Delta l$ & $0.9 \pi$ & 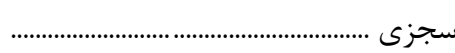 \\
\hline$\Delta 99 \Delta$ & $q \vee q 1$ & १९१. & $191 \cdot 1$ & 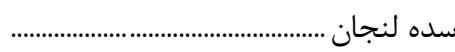 \\
\hline IV.. & rVYI & r tr & $\Delta \Lambda \cdot r$ & 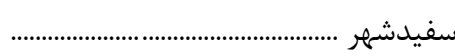 \\
\hline$\Lambda \mu \cdot r$ & 14191 & IrVFe & rgqRT & 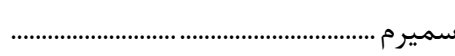 \\
\hline$I V \Delta \Delta$ & TETA & TA\&V & $\Delta F q \Delta$ & 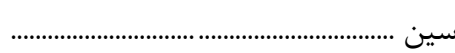 \\
\hline $11 \cdot 1$ & rAF. & $r \cdot v \Delta$ & $\Delta 910$ & 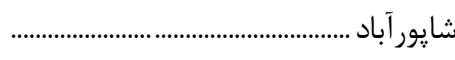 \\
\hline$\Delta \& r .$. & AVMrI & $\wedge 9 \cdot 1$ & IVTrTa & شاهين شهر .................... \\
\hline freve & घ9V9l & 91191 & ITFQDT & 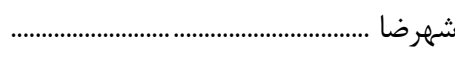 \\
\hline m. & FAVr & $\Delta \cdot \Delta 1$ & $99)^{4}$ & 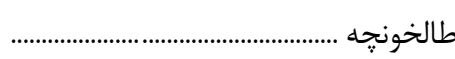 \\
\hline VTS & MAF & $\wedge \notin \Delta$ & IVEq & 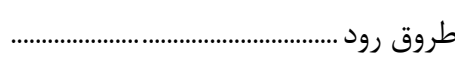 \\
\hline IfGT & tret & rola & $\uparrow \wedge \Delta \Lambda$ & 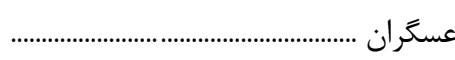 \\
\hline T\&11 & ५१९८ & $r \cdot v r$ & $\Lambda \cdot 9 V$ & 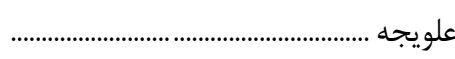 \\
\hline $9 \cdot 9$ & $10 \cdot r$ & 1490 & rQ९८ & 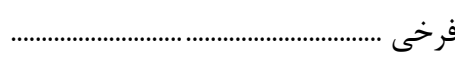 \\
\hline FrAS & sVv. & g人r & $1 r 4 \cdot r$ & 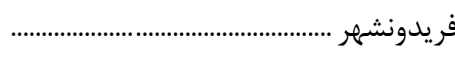 \\
\hline $1.97 \wedge$ & $114 q$. & $19 T 1 F$ & $r v r \cdot q$ & 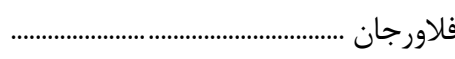 \\
\hline 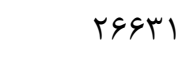 & Fruls & fisl. & MAFE & فولادشهر ................................................. \\
\hline$|r M|$ & IMAr & 1990 & rAvV & 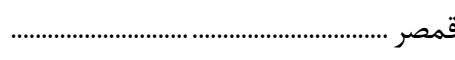 \\
\hline ५৭१० & pre. & fqve & qVir & 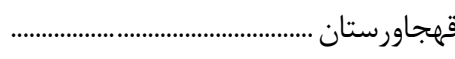 \\
\hline $1 \cdot k f$. & $194 \cdot 9$ & IVAT. & TFTYG & 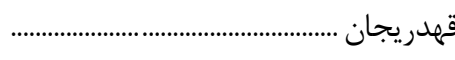 \\
\hline १ו१९ه & $10 \cdot r \wedge \gamma$ & $|\Delta F| .$. & T.FYAV & 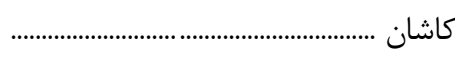 \\
\hline 199 & Irtr & $|r| \mid$ & TEMF & 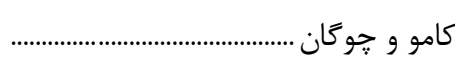 \\
\hline TTIV & reit & rata & $v \cdot \Delta \Lambda$ & 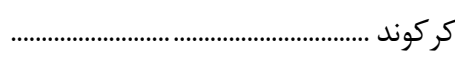 \\
\hline 1119 & IrrqV & 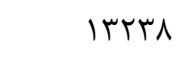 & rQSTL & 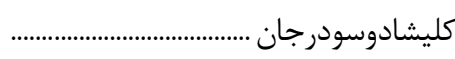 \\
\hline 1091 & $r \Delta \cdot q$ & roq1 & $\Delta 1 \cdots$ & 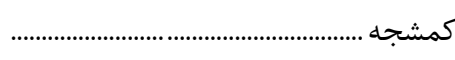 \\
\hline 991 & $1 \cdot v 1$ & $111 \pi$ & rMAF & 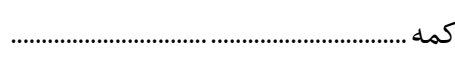 \\
\hline five & grre & $R \cdot 1 r$ & IrTFA & 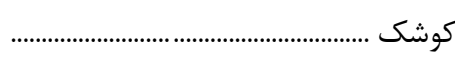 \\
\hline $1 V 90$ & rYIQ & rV৭q & $\Delta \Delta \backslash \Lambda$ & 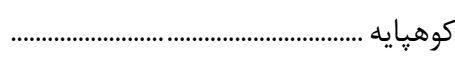 \\
\hline$r \cdot 90$ & $\Delta \cdot \vee \wedge$ & DrG & D. Fet & 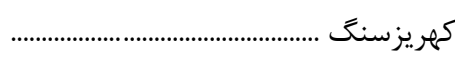 \\
\hline rar. & fVar & fqur & १९१. & 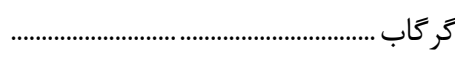 \\
\hline VVAA & $119 \cdot 1$ & ITOKT & TFET & كزبرخوار ........................................... \\
\hline $19 \Delta F \bar{C}$ & rqIr & rqvq1 & $\Delta \wedge q 49$ & 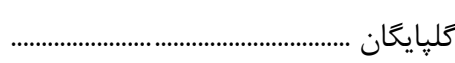 \\
\hline VDAT & $|r \pi|$. & IrqTa & TATrL & 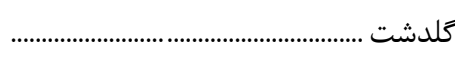 \\
\hline IVRG & $r q \Delta \Delta$ & trAt & DFrV & 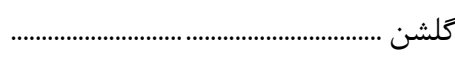 \\
\hline rrql & pyeq & $\Delta \backslash \Delta \Delta$ & $99 \cdot 4$ & كلشهر ......................................................... \\
\hline 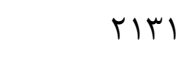 & ५१९९ & $r \cdot 19$ & $4 \cdot 1 r$ & كو حد \\
\hline$\Delta V_{1}$ & १५. & $q \cdot r$ & INTr & 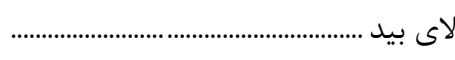 \\
\hline TISVG & $M F \cdot T \cdot$ & TDFTG & gqfeq & مبار كه ................... \\
\hline
\end{tabular}


ظ - جمعيت و خانوار شهرهاى كشور به ترتيب استان (دنباله)

\begin{tabular}{|c|c|c|c|c|}
\hline خانوار & 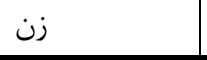 & 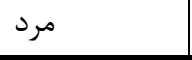 & جمعيت & 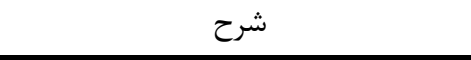 \\
\hline trAY & FAFT & FAr. & (9) & 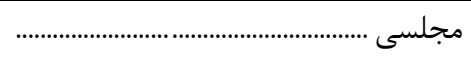 \\
\hline IFAT & TFA. & TAQT & $\Delta \cdot r r$ & 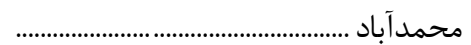 \\
\hline $19 \wedge \mathrm{V}$ & rఎ१ & trGG & $\Delta r \Delta V$ & 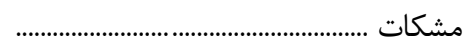 \\
\hline rTYq & rఎ९q & $r \Delta q \Delta$ & VISF & 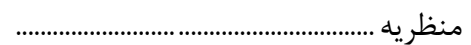 \\
\hline $11 \Delta \Lambda$ & $1 \Lambda F V$ & $1 M \Lambda$. & TYYV & 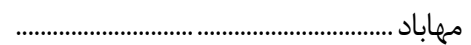 \\
\hline 19.9 & rAVD & TYVE & $\Delta 9 \Delta 1$ & 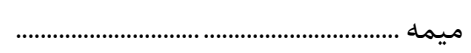 \\
\hline 19.9 & $|r s| 1$ & IrVGA & rVrvq & 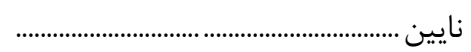 \\
\hline VTV৭q & $\| 9 \Delta V 1$ & $\|\wedge \mathrm{N}\|$. & rTATAl & 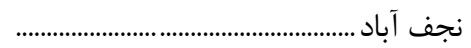 \\
\hline IVGA & miVe & rTAl & sqTa & نصر آباد .......................................................... \\
\hline FAGY & $V \cdot \Delta q$ & $V \cdot q r$ & IFITK & نطنز \\
\hline$r v \cdot v$ & $\Delta \Lambda \Lambda \vee$ & Q9०1 & $\| \wedge \mu \wedge$ & 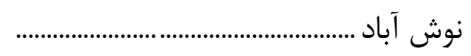 \\
\hline$\vee \wedge$. & 1191 & $11 r \wedge$ & r & نياسر ............................... \\
\hline IFFT & $r I \cdot \Delta$ & rTQQ & Frge & 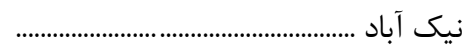 \\
\hline rq.. & $\varepsilon \cdot V_{1}$ & g94T & ITVIF & 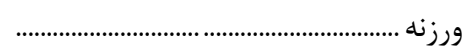 \\
\hline$\Delta V V F$ & $9 \cdot 91$ & $99 \cdot 9$ & $1 \wedge \vee \cdots$ & 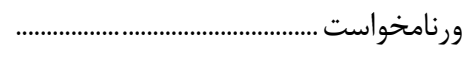 \\
\hline 191. & rAMA & $r \cdot g r$ & $\Delta 9 \Delta \mathrm{T}$ & 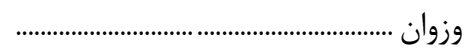 \\
\hline$\Delta \vee G$ & $\wedge \mu \Delta$ & $\wedge r$. & 1990 & 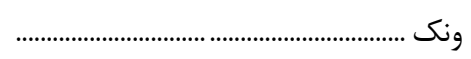 \\
\hline TFVA & trtr & Fi. & VArq & هرند ................................. \\
\hline var.re & IrFIgra & $|r r| .99$ & ralrrrr & 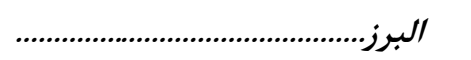 \\
\hline Far & gry & 990 & 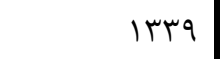 & اسارا ا........................................................... \\
\hline$q r \Delta V$ & $\mid f \Delta \Delta \Lambda$ & IDFTa & г৭१९५ & 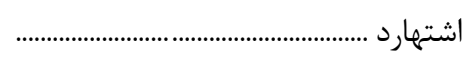 \\
\hline $1 F \Delta q$ & $T t \cdot \varepsilon$ & TFYA & FqAF & تنكمان .................................................... \\
\hline IFrk. & rTats & $r \Delta T \cdot r$ & FMATA & 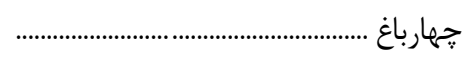 \\
\hline ITETT & $r \cdot \Lambda \varepsilon r$ & TITAF & FTIFV & 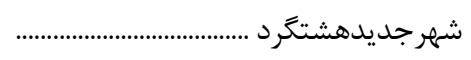 \\
\hline$|Y Y|$ & IVTq & 1119 & rafo & طالقان ...................................................... \\
\hline$\Delta \wedge 9 \Delta r$ & $9 \cdot 9 \cdot 1$ & $q \cdot \Delta V r$ & $|A| I V F$ & 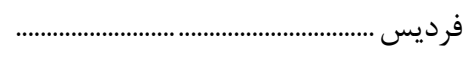 \\
\hline$\Delta \cdot \lambda \& r$. & $v q . .9 q$ & $\Lambda \cdot r r q \Lambda$ & IDATYGT & كرج \\
\hline privi & $99 \cdots 1$ & VYG9I & 141999 & كمال شهر ................................................. \\
\hline ( & QYqI & $\Delta \& \& q$ & $1.94 \cdot$ & كوهسار ................................................... \\
\hline VIrq & 11109 & $\| \Delta \& V$ & TTVTS & 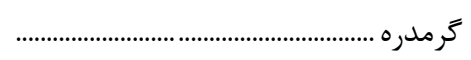 \\
\hline (1. r & 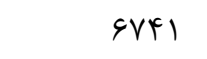 & $v \cdots r$ & IrVFa & 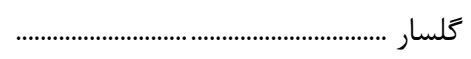 \\
\hline $191 \mathrm{FV}$ & $r \cdot 91 r$ & rTrqV & s५91. & 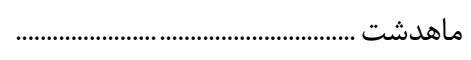 \\
\hline$r \Delta q \cdot r$ & $\Delta \wedge \& r$. & 9.911 & 119411 & 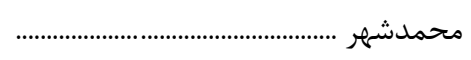 \\
\hline Inste & $r \cdot r \in V$ & mIsra & sr.. $\Delta$ & 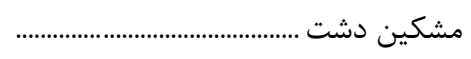 \\
\hline TEDT. & $\Delta \Lambda F r \Lambda$ & q1. VF & $11901 \%$ & نظر آباد ......................................................... \\
\hline$I V T \cdot r$ & TVYr. & TATV. & $\Delta \Delta \& Y$. & 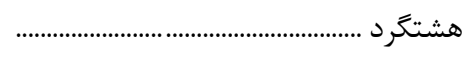 \\
\hline 1.9841 & I IFAFF & $r . . p 19$ & rqargr & 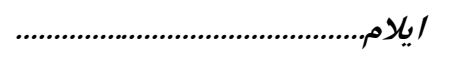 \\
\hline $99 \Delta \mathrm{r}$ & $\| \vee \wedge \Delta$ & $|r| 9 \mid$ & rmq4s & 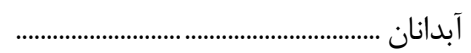 \\
\hline
\end{tabular}




\begin{tabular}{|c|c|c|c|c|}
\hline خانوار & 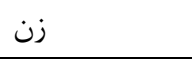 & 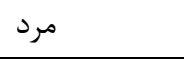 & جمعيت & 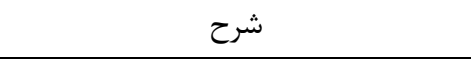 \\
\hline 199. & $r \cdot \mu \psi$ & (4TG & GYA. & 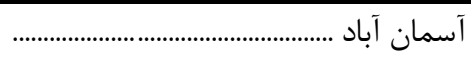 \\
\hline rqq1 & $9 \cdot 1$. & $\Delta 99 V$ & $1198 \mathrm{~V}$ & 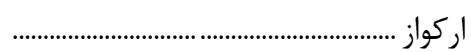 \\
\hline$\Delta r \Delta \Lambda I$ & $q \Delta V \Delta F$ & qATV\& & $194 \cdot r$. & 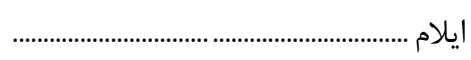 \\
\hline$\Lambda \Lambda \cdot \Lambda$ & IDQFT & lQVDS & rirq9 & 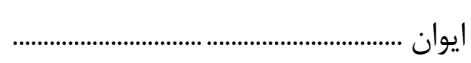 \\
\hline IrFq & rIAr & $r \cdot 90$ & grVA & بدره ............ \\
\hline va & 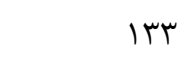 & $\mid$ & req & بلاوه .................................................. \\
\hline $1 \cdot 10$ & 1994 & 19.9 & rAv. & يهله ....................... \\
\hline $9 \cdot 1$ & 1.49 & 1.99 & rITA & توحيد ............... \\
\hline IDST & rar. & rq11 & $\Delta \wedge \mu 1$ & جوار ..................... \\
\hline$\Delta 9 \wedge \Lambda$ & 1.994 & $11 r \cdot 9$ & r19.. & دره شهر ................... \\
\hline Q1. & qr. & 199 & 1119 & 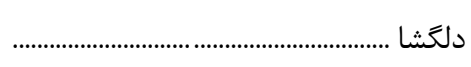 \\
\hline $9 T \cdot 4$ & 19199 & $19 \mathrm{VVO}$ & rrqui & دهلران .................................................... \\
\hline 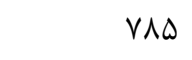 & IF\& & $10 \cdot r$ & r৭६४ & 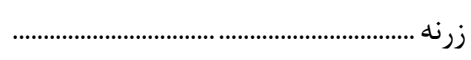 \\
\hline VII & $|\pi| s$ & Irfr & $r \varphi \Delta q$ & سراب باغ ................................................... \\
\hline MFIV & $\Delta 9 \vee \Delta$ & $9+11$ & מזq & 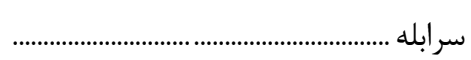 \\
\hline $1 \cdot \wedge r$ & $199 \mathrm{~V}$ & $|r| r \mid$ & $\mu \cdot \Lambda \Lambda$ & 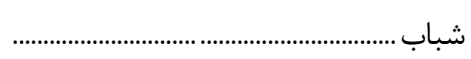 \\
\hline fqv & 11. & $9+1$ & $|V \Delta|$ & 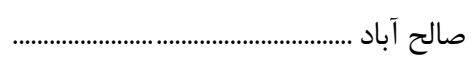 \\
\hline Vat & gre & irv. & rৎ৭૬ & 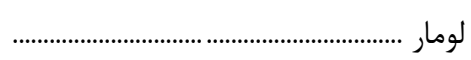 \\
\hline Frt & $V \ll q$ & VAr & IDIT & 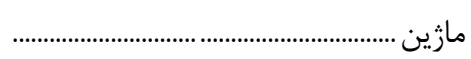 \\
\hline 1.9. & IAVD & $1 \wedge 94$ & rVGA & 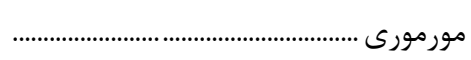 \\
\hline GKT & irrq & IrT. & TYDQ & 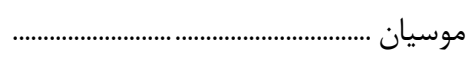 \\
\hline$r \cdot 1$ & $\Delta<q$ & Q11 & 1.9 . & 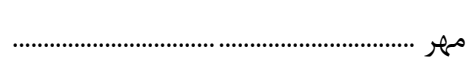 \\
\hline 0.19 & $\Lambda F M$ & 19\%V & ivera & 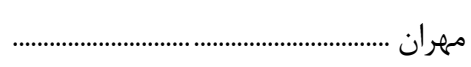 \\
\hline$\Delta \& 9$ & gFt & 971 & 1914 & 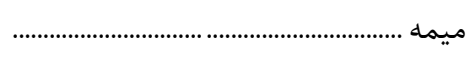 \\
\hline$r r v \cdot r a$ & rqukrq & errale & $1 r \Delta q \Delta \Delta$ & 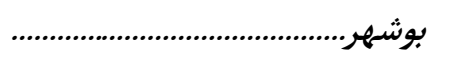 \\
\hline$\Delta T \Delta \cdot$ & 9Y\&V & 9\&49 & 14914 & آب يخش .................................................. \\
\hline $1 \cdot \vee \wedge$ & 1948 & $|\wedge \Delta|$ & rVAV & 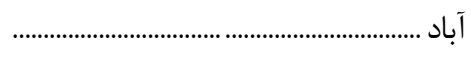 \\
\hline 1119 & refa & trat & SATV & 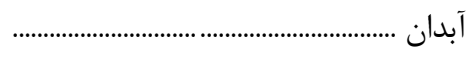 \\
\hline$V<q$ & IrVV & Irof & TRM & امام حسن ............................................... \\
\hline$q \cdot 4$ & IOVT & IATA & $r \mu .$. & انارستان ..................................................... \\
\hline FTER & Ve.r & $V \Delta 9 \Delta$ & 10191 & اهرم م......................................................... \\
\hline $1.9 V$ & 1990 & rer & $r \cdot r \Lambda$ & بادوله .................................................... \\
\hline MIrgl & DF^१T & $\Delta \Delta \& \vee \Delta$ & $11 \cdot \Delta 9 V$ & 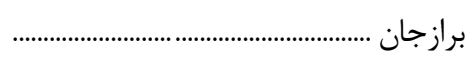 \\
\hline 1494 & $r q \cdot V$ & TVYS & אחזם & 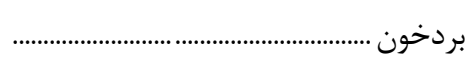 \\
\hline invr & 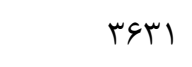 & rFAl & VIIT & بردستان .................................................... \\
\hline 991. & $|\| \Lambda T|$ & ITKGT & $r F \cdot \Lambda r$ & بندردير ........................................................ \\
\hline$V r \Delta q$ & $1 r \Delta \wedge 9$ & $|r| q \mid$ & rQVY. & بندرديلم .......................................................... \\
\hline r & $r \cdot 9 \Delta$ & MIAv & GTOT & بندر ريخ ....... \\
\hline
\end{tabular}


ظ ـ جمعيت و خانوار شهرهاى كشور به ترتيب استان (دنباله)

\begin{tabular}{|c|c|c|c|c|}
\hline خانوار & 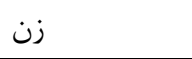 & 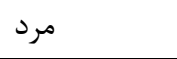 & جمعيت & 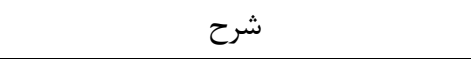 \\
\hline IITTO & TFEAS & $r \Delta \Delta \cdot 1$ & $4 \cdot 11 \mathrm{~V}$ & 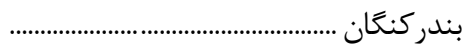 \\
\hline $199 \mathrm{VV}$ & 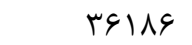 & rVTAS & VMFVT & بندر \\
\hline$r \Lambda \cdot v$ & GNFF & VTAT & $|F| r s$ & 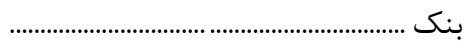 \\
\hline 4.r & 1.90 & $1 \cdot v \cdot$ & rirs & 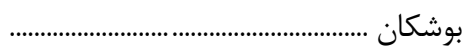 \\
\hline GMAT. & $1 \cdot$ ATFY & 11QTE. & rTrQ.F & 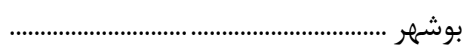 \\
\hline$\Lambda V \Delta$ & 1948 & 1099 & MTEY & 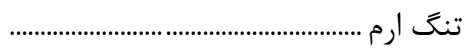 \\
\hline 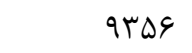 & IDTFF & $19 \cdot 9 r$ & MIfrs & جم ......................... \\
\hline DIFV & $91 \% 4$ & १४V५ & $M \wedge \vee \cdot r$ & جغادى .................... \\
\hline thrt & एव९ा & GTH & 119 & خارك \\
\hline IIOHV & t.ttt & $r \cdot \Delta \cdot \cdot$ & R.VTr & خورموج ................... \\
\hline 1N48 & TTEV & rila & squs & 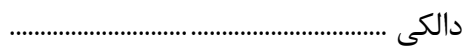 \\
\hline Irro & rIfq & rTq4 & fFET & 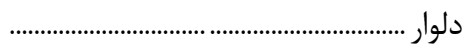 \\
\hline$|148|$ & TFqV & $r T \Delta \Delta$ & FADT & 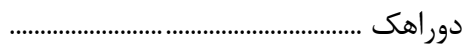 \\
\hline qkF & $10 \Delta 9$ & IVTK & rTAT & 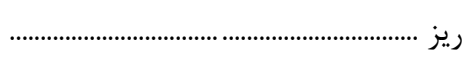 \\
\hline tMAL & 4.99 & fiva & $\Lambda T Y \Lambda$ & سعد آباد ..................................................... \\
\hline 1949 & $r \cdot r \cdot$ & ragr & 9995 & سيراف.............................................................. \\
\hline trat & ए人१५ & $\uparrow \cdots \wedge$ & vq.. & 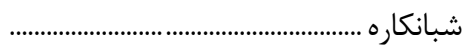 \\
\hline Ve. & list & ITAK & TYEV & 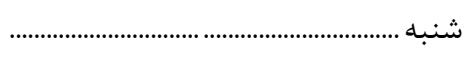 \\
\hline 99५ & 1140 & IIVTA & rmivi & 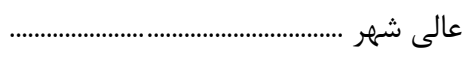 \\
\hline TMtY & raYA & $99 ५ 9$ & $1 r \Delta \Delta V$ & 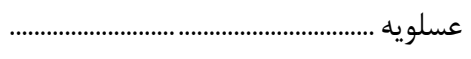 \\
\hline rtrt & $91 \cdot 1$ & 9.11 & 14119 & 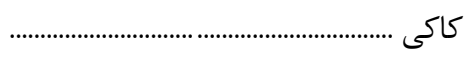 \\
\hline Vre & ITF. & ITr & TFET & 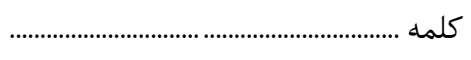 \\
\hline Fatr & $\Delta F \cdot q$ & IrFTA & IMArV & 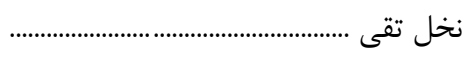 \\
\hline MIGT & $\Delta \Delta V r$ & $\Delta \& \& q$ & IITrT & 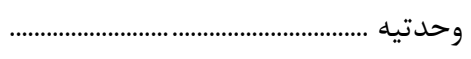 \\
\hline$r \cdot \Delta r \Delta \cdot V$ & srl... D. & ererid. & irfartr. & 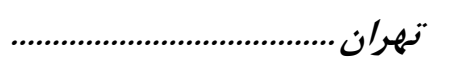 \\
\hline आ1. & 0119 & $\Delta \Delta r T$ & $1.94 \lambda$ & آبسرد ........................................................... \\
\hline$\wedge V \Delta$ & $|r|$ & $\mid F Y \lambda$ & $r V \Delta \Lambda$ & آبعلى ........................................................... \\
\hline Fras & 9949 & VIYA & $\mid f \cdot V V$ & 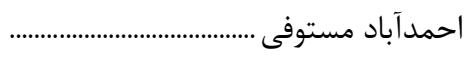 \\
\hline $4 \cdot 4$ & $\Delta \Delta F$ & $\Delta V \cdot$ & $11 K F$ & ارجمند \\
\hline IrVGr & Tt. rti & $r T V A \cdot \Lambda$ & rFAirq & 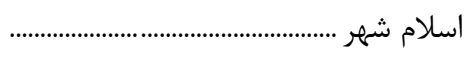 \\
\hline$r \Delta \Delta V r$ & $\Delta Y M Y \Delta$ & $\Delta \wedge \vee \backslash \vee$ & 119.95 & 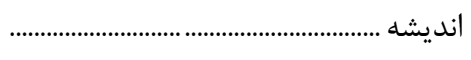 \\
\hline rrVAV & r.rir & Frat & NrquF & 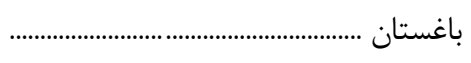 \\
\hline $1 M N \cdot r$ & rIqpV & MrFYI & GDHAN & باقرشهر ............................................................... \\
\hline TFMAD & rATFE & $r \cdot \vee \wedge \Lambda$ & $V q \cdot r F$ & 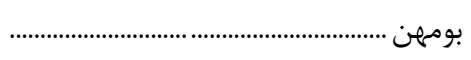 \\
\hline$V \cdot r T \cdot$ & $110 \wedge 9$. & $1 T \cdot Y \Delta Q$ & rMGTI9 & 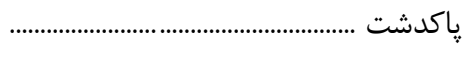 \\
\hline rrq५^ & requ. & r & VMrG & 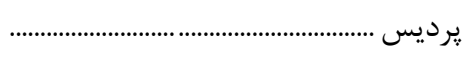 \\
\hline r।घ9 & FAFAV & 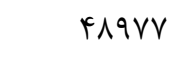 & qVeq4 & 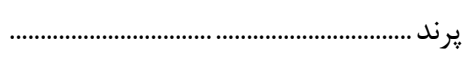 \\
\hline $\mid \Lambda \cdot \Delta F$ & TQ८Tा & rqه & $\Delta q 1 \wedge F$ & بيشوا .......................................................... \\
\hline
\end{tabular}


ظ ـ جمعيت و خانوار شهرهاى كشور به تر تيب استان (دنباله)

\begin{tabular}{|c|c|c|c|c|}
\hline خانوار & 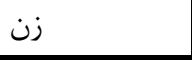 & 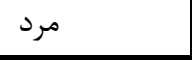 & جمعيت & 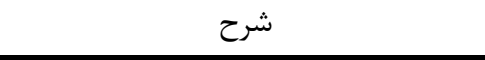 \\
\hline 4911.90 & FrsqDDI & FTTFIDD & 19qrV. & تهران ................................................................. \\
\hline leqf & thet & $r \Delta \cdot r$ & FAfF & جوادآباد ................................................ \\
\hline $10 T \Delta q$ & TYDQT & ror $\Delta \Lambda$ & 4990. & جهاردانكه ......................................................... \\
\hline |rris & rITAV & rTard & frgrt & حسن آباد ........................................................ \\
\hline IDTEV & tratet & TFors & FArی. & دماوند .................................................... \\
\hline$r \backslash \Lambda \cdot r$ & DIVES & DrGFV & 1. बrq & 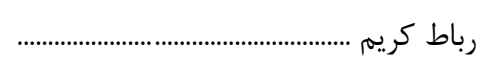 \\
\hline 910. & IFTAV & IFTES & TMUT & 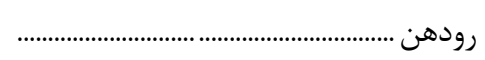 \\
\hline VAFr & (THE & $1 r t \cdot \Lambda$ & TDSFF & 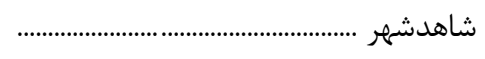 \\
\hline DrGA & М११r & 9 १४^ & $|\wedge r \wedge|$ & 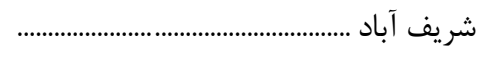 \\
\hline 1198 & $19 V \pi$ & IVa. & TRt & شمشك................. \\
\hline qYaV. & IDTATr & $1 \Delta \varphi \cdot \wedge \Delta$ & $r \cdot १ \varphi \cdot v$ & 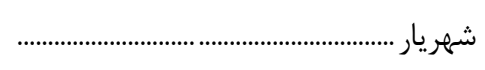 \\
\hline IVTVR & TATAV & r. ५৭६ & $\Delta \wedge \& \wedge r$ & 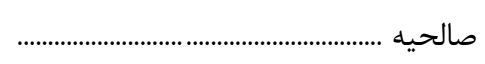 \\
\hline $1 \Delta \wedge \Delta \cdot$ & TET.Q & TVYGS & QrqVI & 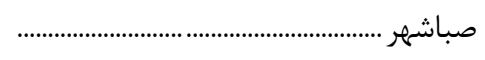 \\
\hline १९৯૪ & IQVRT & IEVFT & mTFV & 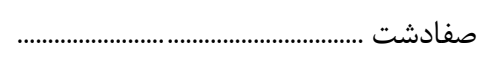 \\
\hline $1 \cdot r q$. & $1 \& V T$. & $|V| q \mid$ & TETTI & 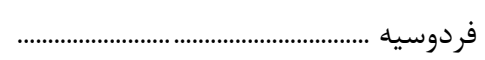 \\
\hline grVT & 1.911 & $11 \cdot v \cdot$ & rISAT & 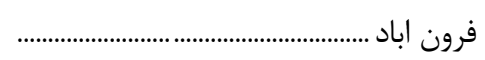 \\
\hline trat & TrMI & rG94 & 9940 & 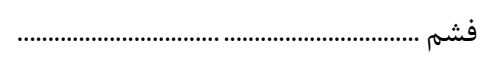 \\
\hline$\Delta \vee \cdot$. & $19 \cdot 1$ & $M \wedge F \Delta$ & IVEAT & 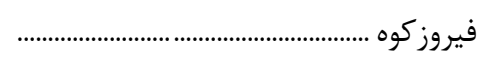 \\
\hline qRDTr & $|0| \cdot r \Lambda$ & $\mid \Delta \wedge \Delta \& V$ & $r \cdot 9 \varphi \cdot \Delta$ & قدس ................................. \\
\hline $9 q \cdot 4 q$ & $\| r \wedge 10$ & llkre. & $r m \cdot V \Delta$ & قر קك \\
\hline $1 \cdot v \cdot 1$ & $11 \cdot 19$ & 19011 & TVATY & كهريزك . \\
\hline $94 \mathrm{~T}$ & $\mid f \cdot F$ & 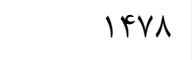 & TAMT & 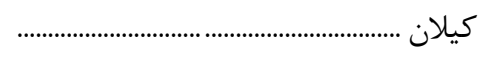 \\
\hline$v \cdots v r$ & llهgrr & Irtart & r & كلستان ........................................................ \\
\hline sir. & MArA & $9 \pi / 1$ & $|1| \notin 4$ & 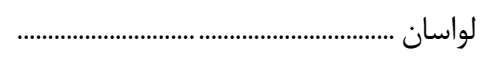 \\
\hline ヘя^ґ. & irvreq & IFrTVA & $r \Lambda 1 \cdot T V$ & 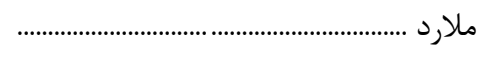 \\
\hline$\Delta \wedge F+1$ & $q V \cdot r r$ & $1 \cdot r r v 1$ & r..rq Tr & 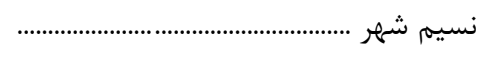 \\
\hline$\Lambda q \cdot r$ & IrVFA & IF^99 & TAGFF & نصيرشهر ...................................................... \\
\hline $94 .$. & 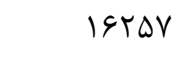 & 19995 & TrtYq & 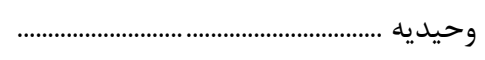 \\
\hline 9919. & 111414 & $\|$ FTID & TrOSA & ورامين ............................................................ \\
\hline IVAAFT & raq949 & $r \cdot v v q 1$ & G.VFFF & 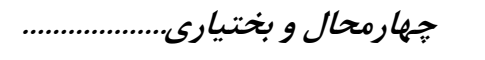 \\
\hline IrAT & rolr & rVTa & DYFA & 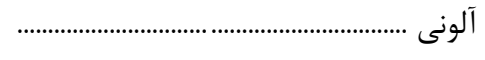 \\
\hline TEKT & Q.r & $\Delta \cdot \wedge \cdot$ & 1.114 & اردل ............................................................... \\
\hline TTVE & $\Delta F \mid$. & DVar & $11 r \cdot r$ & باباحيدر ............................................................ \\
\hline rrv & $\checkmark \cdot$ & $1 \cdot 9$ & 1019 & بازفت .................. \\
\hline IVTYA & 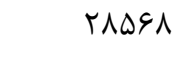 & $r \wedge \Delta \cdot r$ & $\Delta V \cdot V I$ & بروجن ............ \\
\hline rafe & $\Delta \wedge \Delta \Delta$ & GITd & $1191 \cdot$ & 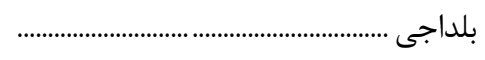 \\
\hline $4 \cdot k q$ & grru & gqur & $|r q V|$ & بن ..-1) \\
\hline rma & $f 110$ & 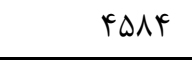 & ^६99 & 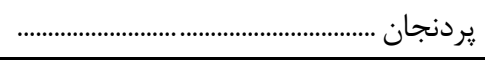 \\
\hline
\end{tabular}


ظ ـ جمعيت و خانوار شهرهاي كشور به ترتيب استان (دنباله)

\begin{tabular}{|c|c|c|c|c|}
\hline خانوار & 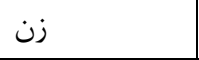 & 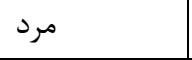 & جمعيت & 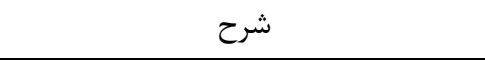 \\
\hline FIOF & $V \cdot 9 v$ & VRre & IFFTr & 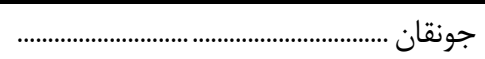 \\
\hline var & IrAv & $19 \cdot r$ & rq१९ & 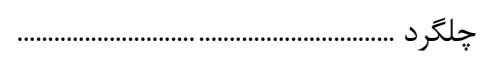 \\
\hline$|4| r$ & rTAs & $r \Delta \Delta q$ & Fq4Q & 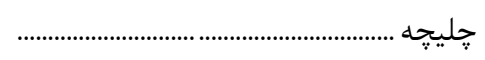 \\
\hline 1910 & rFqF & reqq & DIFT & دستنا ............................................... \\
\hline 111. & $r \cdot . q$ & $r \cdots r$ & 4.19 & 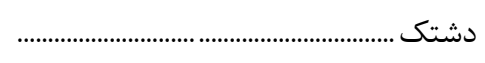 \\
\hline$F \Delta \Delta F$ & $V \cdot r V$ & $\checkmark \backslash \Delta Q$ & $14 \backslash 95$ & 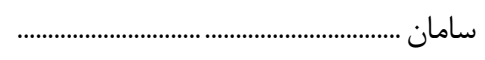 \\
\hline$\Delta V r$ & 1.19 & 1110 & 吾 & 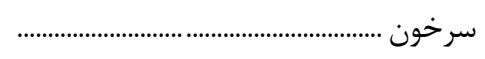 \\
\hline $11 \wedge F$ & TVG. & ( I & $\Delta 991$ & 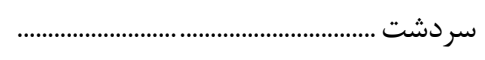 \\
\hline IDFT & rq৭. & rVAl & $\Delta \& V I$ & 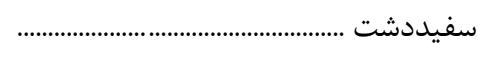 \\
\hline $19 \Delta \Lambda$ & TVDA & rAYr & $\Delta \Delta \wedge 1$ & 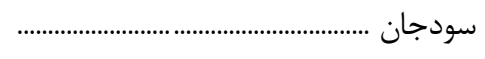 \\
\hline$r \Delta 9 \Delta$ & $\Delta 910$ & ятат & $1 r r \cdot \Lambda$ & 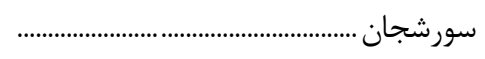 \\
\hline rlle & 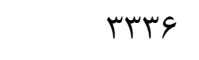 & ragr & 9199 & 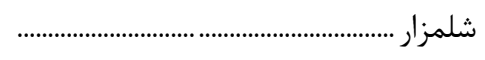 \\
\hline$\Delta \Delta F q Y$ & $9 \Delta \& \Delta T$ & $q \ngtr \vee \wedge q$ & $19 . x+1$ & 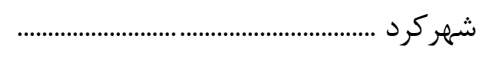 \\
\hline red & $\Delta \wedge \Lambda$ & 910 & $M \cdot r$ & صمصامى ................ \\
\hline IgFt & $r \cdot \Delta l$ & $r 119$ & siv. & 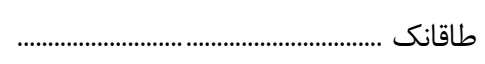 \\
\hline$\wedge \uparrow$. & $10 \cdot r 9$ & IDFVQ & $r \cdot \Delta \cdot r$ & فارسان ............................................................ \\
\hline$r \wedge \cdot \Lambda$ & gQVF & gVkT & (tV & 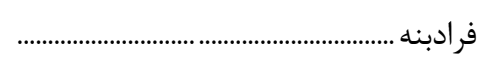 \\
\hline qrar & $\mid \Delta \cdot r \Lambda$ & $18 \times 11$ & rIVrq & 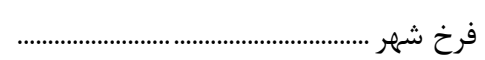 \\
\hline $119 \mathrm{~V}$ & $r \cdot 9 r$ & rIGY & FTrV & 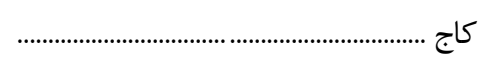 \\
\hline r^q. & qra. & 9091 & Irq4A & 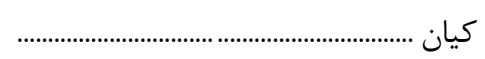 \\
\hline INAT & $r \cdot \varphi q$ & TMET & sॅ91 & Fندمان ................................ \\
\hline$i v \wedge$. & $r \cdot . l$ & rivi & 91va & گوجان ...................................................... \\
\hline $1 / 94$ & $r \cdot 9 \Lambda$ & r190 & GTGT & گَ) \\
\hline l. FAr & $r \cdot . q 1$ & T. Frr & $r \cdot \Delta r \Lambda$ & لردكان ............................................................ \\
\hline IrTA & 1940 & $r \cdot v q$ & $F \cdot r F$ & 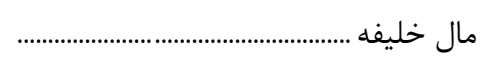 \\
\hline rیl & $v \cdot 1$ & V91 & leqr & 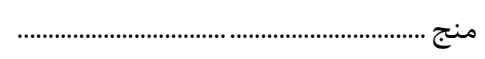 \\
\hline MAKT & rQAD & rif. & GITQ & 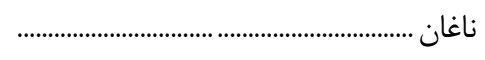 \\
\hline $119 \Lambda$ & 197. & $r \cdot 19$ & $r \cdot \Delta q$ & 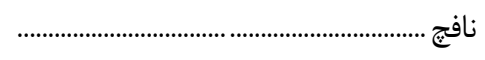 \\
\hline TAID & eVru & $\Delta / \wedge \Delta$ & 99५ & 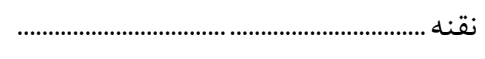 \\
\hline Irra & rTQq & rı१V & FEDS & 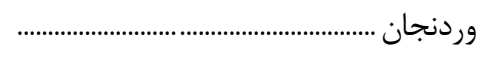 \\
\hline 999 & 1919 & $191 \%$ & 49.1 & 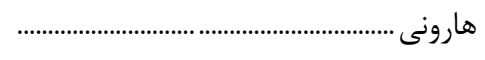 \\
\hline $99 \Delta \Delta$ & $1 \cdot r \wedge \Lambda$ & 1.994 & rITAT & 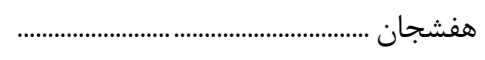 \\
\hline $1 r q . r g$ & rerraf & $r r \cdot k v r$ & rarary & 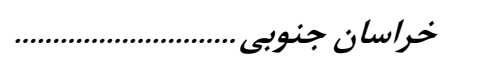 \\
\hline $1 \cdot 9$ & $1 \wedge 94$ & 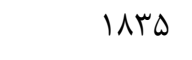 & rVTq & آرين شهر ......................................................... \\
\hline $19 \mu 9$ & TDST & rQA. & DIF & آيسك ....................................................... \\
\hline $9 \wedge \cdot$ & IFA9 & 1499 & $r q \Delta \Delta$ & 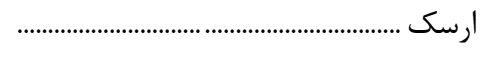 \\
\hline Ir人 & r९99 & tYGY & $\Delta F G$. & 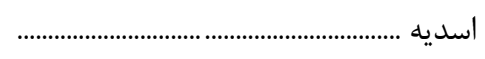 \\
\hline $1 \cdot v \cdot$ & $11 \cdot V$ & $|\vee 9|$ & roqA & $\ldots \ldots \ldots \ldots \ldots \ldots \ldots \ldots \ldots \ldots \ldots \ldots \ldots$ \\
\hline
\end{tabular}


نتايج تفصيلى سرشمارى عمومى نفوس و مسكن _ه |

$1 \cdot{ }^{c}$

ظ ـ جمعيت و خانوار شهرهاى كشور به ترتيب استان (دنباله)

\begin{tabular}{|c|c|c|c|c|}
\hline خانوار & 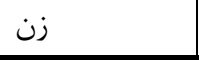 & 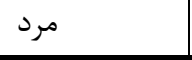 & جمعيت & 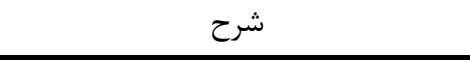 \\
\hline r/9r & $r \Delta q q$ & rolf & $\checkmark 1 \cdot 1$ & 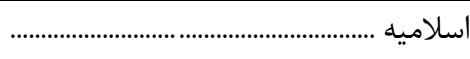 \\
\hline fqvr & NIrv & 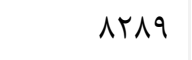 & IETtE & 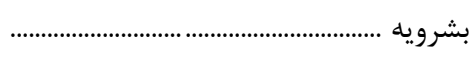 \\
\hline$\Delta V Y F \Delta$ & $1.1 \% T r$ & 1. זчq9 & r. Tद्व & 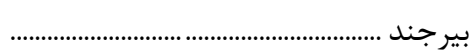 \\
\hline legt & mIIV & $r \cdot \Delta l$ & 9191 & 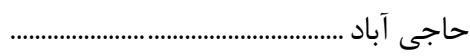 \\
\hline 1999 & 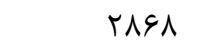 & rNIT & $\Delta \& \Lambda$. & 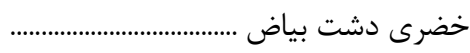 \\
\hline IDFF & TAVT & TAFF & $\Delta V \backslash S$ & 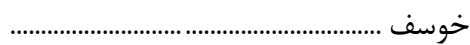 \\
\hline$\Lambda 9 V$ & IDIT & lefr & $r q \Delta 9$ & 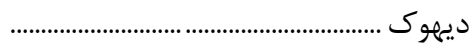 \\
\hline rq. & $\Delta T$. & Q91 & 1111 & 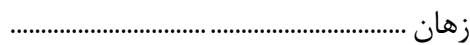 \\
\hline fir. & $9 \wedge \Delta$. & 9990 & $1 \pi v 90$ & 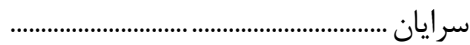 \\
\hline TMGT & Fraq & pefes & AVID & سربيشه ............ \\
\hline $1 \% q$. & TrV. & r199 & fare & سه قلعه ........... \\
\hline$\wedge \vee q$ & lQTr & left & MIN| & شوسف ............................ \\
\hline l11ve & 19499 & $r \cdot \mid \Lambda \cdot$ & rq६Vद & 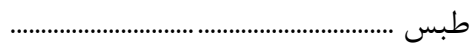 \\
\hline $1 \cdot V r$ & rTIQ & rYAl & FDQ & 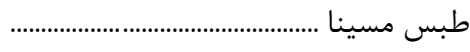 \\
\hline IrVV & $19 V r$ & 1994 & ra९d & 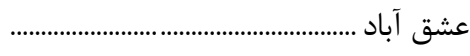 \\
\hline AVEq & $1 F r 90$ & IfF.. & r^९9D & 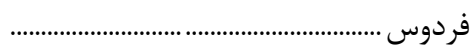 \\
\hline 1199. & $r \cdot 4 \cdot 1$ & TIVID & (19TM & 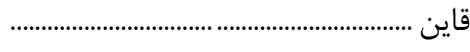 \\
\hline$v \cdot 1$ & $119 \mathrm{~V}$ & $11 \Delta \Delta$ & TMTt & 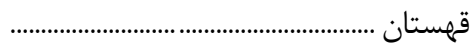 \\
\hline $9 \vee 9$ & 1109 & $111 \pi$ & rrqF & 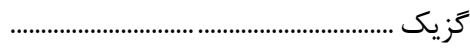 \\
\hline kq & \& & TQTV & roq. & 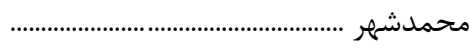 \\
\hline 1.91 & IVFF & IVTr & TFV & 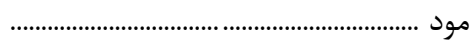 \\
\hline$\notin \vee \Delta \Delta$ & $\wedge 9 \Delta \mathrm{r}$ & qral & $1 \wedge r \cdot r$ & 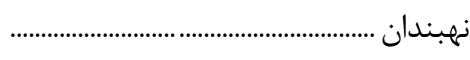 \\
\hline 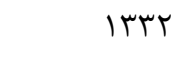 & rTar & $r F \cdot q$ & fVer & 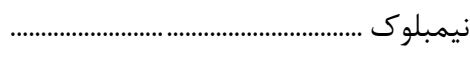 \\
\hline $\mid$ frr|.q & rrTatry & rrer.ar & $F r . .9 T F$ & 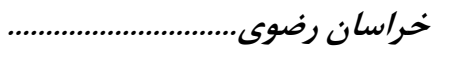 \\
\hline$r 110$ & $k \cdot v F^{k}$ & FrAT & Nrre & 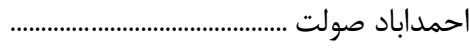 \\
\hline$|\wedge 9|$ & $r \cdot \Lambda r$ & 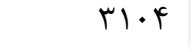 & 9119 & انابد .................................................................. \\
\hline 111 & r^9 & $r \cdot \Delta$ & $\Delta 9 F$ & 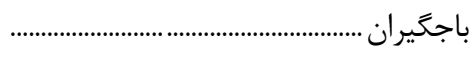 \\
\hline Targ & Retr & eriv & $q \cdot k q$ & 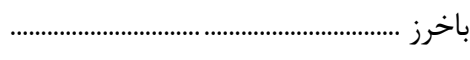 \\
\hline $11 \pi r$ & $1 \Lambda \cdot r$ & 1995 & rVAD & 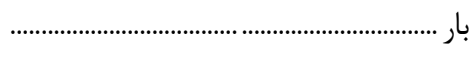 \\
\hline $11 Q F$ & MNT & IVTr & TAFD & 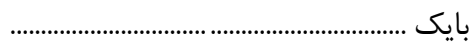 \\
\hline rV৭A & $\Delta \wedge \vee \Delta$ & $\Delta \wedge 99$ & ||$V \mid$ & 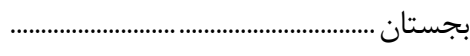 \\
\hline$\Lambda \Delta \vee \cdot$ & Ir人⿻r & lfrv. & TAYTH & 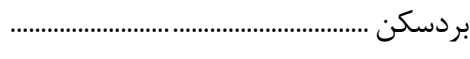 \\
\hline 1719 & TVVV & TYYF & $\Delta \Delta \cdot 1$ & بيدخت ............................ \\
\hline 14999 & rVQA & r^৭^। & $\Delta 9 \Delta \& Y$ & تايباد ..................... \\
\hline TVIDS & Fq९V & $\Delta \cdot V V T$ & $1 \ldots+4 q$ & تربت جام.................................................... \\
\hline$r r \cdot r q$ & 9NF19 & $V 19 \cdot r$ & $14 \cdot .19$ & 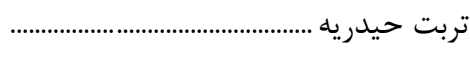 \\
\hline rqv. & Fosi & $i v \cdot v$ & $949 \Lambda$ & 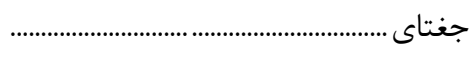 \\
\hline IVTV & 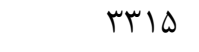 & 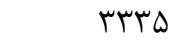 & 990. & 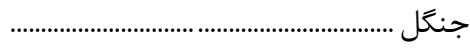 \\
\hline
\end{tabular}


ظ ـ جمعيت و خانوار شهرهاى كشور به ترتيب استان (دنباله)

\begin{tabular}{|c|c|c|c|c|}
\hline خانوار & 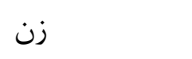 & 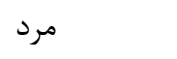 & 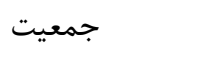 & 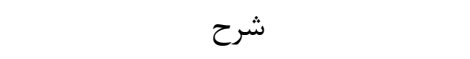 \\
\hline va9 & $11 \Delta V$ & $|K| V$ & rmVF & 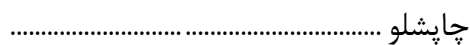 \\
\hline kq. & VAT & 949 & $|r \lambda|$ & 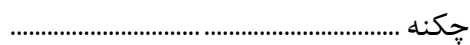 \\
\hline $109 \cdot 9$ & r\&494 & TRMAT & DrAVq & קناران .................................... \\
\hline frve & 9919 & 9919 & Irord & 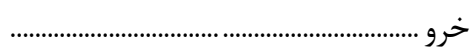 \\
\hline $4 \cdot 94$ & 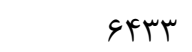 & बril & $\mid$ ITVDI & 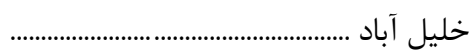 \\
\hline 1999 & $\mid$ |qr人| & $19 \Lambda \cdot \Lambda$ & 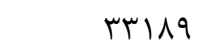 & 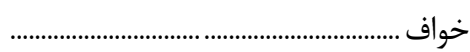 \\
\hline$\Lambda \wedge \Delta$ & Ir人 & $\mid$ & TrFY & 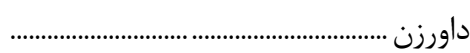 \\
\hline llFy & INTAD & IAFV & HGVGY & دركز \\
\hline lNks & TADT & TASD & $\Delta V I V$ & درود........................... \\
\hline rqтq & FVTI & $49 \cdot 1$ & qrrq & 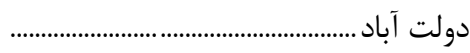 \\
\hline FaV & 119 & VTr & $|\Delta \Delta|$ & رباط سنگ ........ \\
\hline rוाr & $r V \Delta \Delta$ & $r \vee \Delta q$ & VDIF & 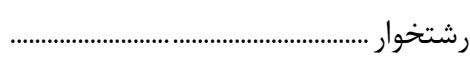 \\
\hline rQ\ৎ & Fart & Fris & $\wedge \wedge \Delta$. & 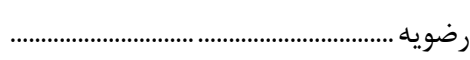 \\
\hline ITQF & $r \cdots \Lambda$ & $r \cdot r \cdot$ & $r \cdot r \Lambda$ & روداب ............. \\
\hline $1 V \cdot 1$ & TrRT & rqDF & $\Delta G \wedge V$ & 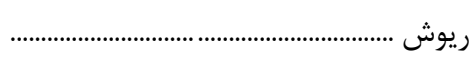 \\
\hline VFVOV & שrtrot & $|r| 99 \mathrm{~V}$ & retr. & 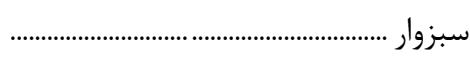 \\
\hline$\| 114$ & $r \cdot \wedge V r$ & $r \mid r \cdot v$ & FTIVq & 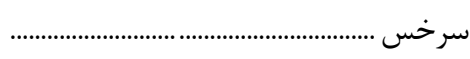 \\
\hline IVTa & rave & $r \Delta \Delta$ & 9119 & 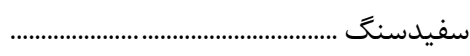 \\
\hline 1901 & rris & r人r & $V \Delta \Delta \Delta$ & سلامى ..................... \\
\hline$|V \Delta|$ & r^६9 & $r \cdot q \mu$ & DQTT & 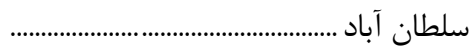 \\
\hline rIIV & $4.9 \mathrm{~V}$ & Gres & ITFET & سنغان ................................... \\
\hline 1101 & iıv. & $19 \Delta \Delta$ & rATd & شادمهر ............ \\
\hline RTET & GAVT & $v 110$ & IrqAV & شانديز .............. \\
\hline 95. & lev. & $19 \mu 1$ & r) & شتمد .................. \\
\hline gkt & 1.14 & 1.99 & $r \cdot \wedge r$ & 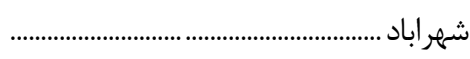 \\
\hline $11 \mathrm{FV}$ & $1 \wedge 99$ & $1 \wedge \vee 9$ & rVFa & 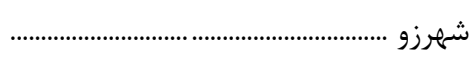 \\
\hline r191 & Fil. & prid & NATD & صالح آباد .................................................. \\
\hline 9911 & $1 \cdot r+q$ & $1 \cdot v<q$ & $r \cdot 991$ & 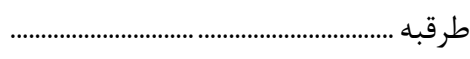 \\
\hline DqT & $9 \vee r$ & $1 \cdot r \cdot$ & 1994 & عشق آباد ...................................................... \\
\hline rr人. & $419 \Lambda$ & FTVE & NFFT & فرهاد \\
\hline$\| v \Delta \Delta$ & $19 \Delta F \Delta$ & 1998. & rqه। & فريمان ....................................................... \\
\hline IVE. & ratr & rQ⿻ & $\Delta \Lambda \Lambda F$ & فيروز ........................................................ \\
\hline$\Delta \& q \varphi$ & MAMV & 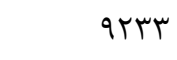 & $M \| T$. & فيض آباد .................................................... \\
\hline $1 \% q$. & TATS & TETr & $\Delta I F \Delta$ & قاسم آباد .................................................... \\
\hline 194 & DQFT & I $\&$ V & $r \cdot 1 \cdot$ & 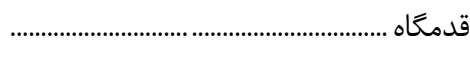 \\
\hline $14 \cdot 9$ & TYII & TFEq & YMA. & قلندر آباد ...................................................... \\
\hline r...9 & $\Delta \cdot 1 \cdot r$ & $\Delta / \Delta \cdot 1$ & $1 \cdot 19 \cdot 4$ & 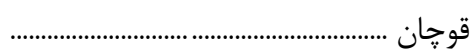 \\
\hline
\end{tabular}


نتايج تفصيلى سرشمارى عمومى نفوس و مسكن _ه | $1 \cdot 8$

ظ ـ جمعيت و خانوار شهرهاى كشور به ترتيب استان (دنباله)

\begin{tabular}{|c|c|c|c|c|}
\hline خانوار & 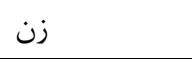 & 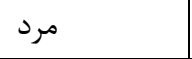 & جمعيت & 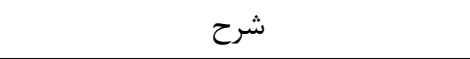 \\
\hline $1 \Delta F q$ & שזسז & r rat & FATD & 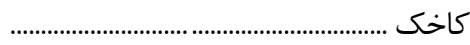 \\
\hline rA19 & DFVT & DQT. & $111 \cdot r$ & 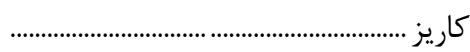 \\
\hline MIVVD & 0.949 & 01919 & I.TTAT & كاشمر ................... \\
\hline 1194 & 1194 & IATY & rVIq & 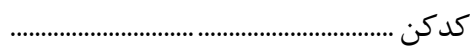 \\
\hline rII. & rVAr & $r q \cdot r$ & VAAV & كلات ................ \\
\hline rir. & 4191 & TrAT & s49. & 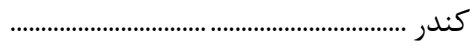 \\
\hline $1 \cdot \Lambda \Delta F$ & $1 A T \cdot 1$ & 11999 & rqAVV & 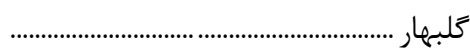 \\
\hline r\८) & rVGY & 49.9 & ArVr & 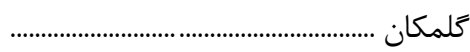 \\
\hline$M \cdot r V$ & $r \cdot r<q$ & $r \cdot \Delta T F$ & $r \cdot V V r$ & كناباد...................... \\
\hline $9 \cdot 0$ & 919 & $q 4 q$ & $1 \wedge 90$ & لطف آباد ........... \\
\hline rrq & Fイ९ & $v \Delta \Delta$ & $|r F|$ & 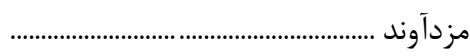 \\
\hline 914149 & IfqVre. & ID. rNTF & $r \cdot .1114$ & مشهد ..................... \\
\hline TYAI & fqut & $\Delta|V|$ & $1 \cdot 1 \cdot 0$ & 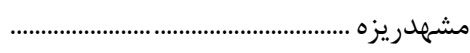 \\
\hline sr. & 1. r & $1 \cdot \Delta r$ & $r \cdot \Delta \varphi$ & ملك آباد ........... \\
\hline TFYS & $F \Delta F \mid$ & FqTa & $91 \vee 9$ & نشتيفان ................... \\
\hline$r \cdot r \Delta$ & ratg & rArr & ves. & نصر آباد ............................... \\
\hline peter & VYGA & VQIQ & IFVAT & 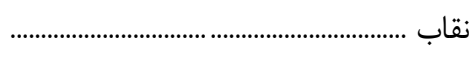 \\
\hline A\&T & 149. & IrVF & rark & 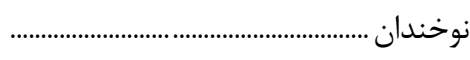 \\
\hline NTIFT & $\mid r t \cdot r$ & ITTKYT & reFrVD & 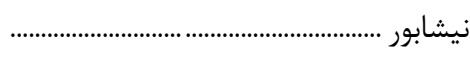 \\
\hline 1919 & rata & ryes & VrVI & نيل شهر ........................................................... \\
\hline rVV & $4 .$. & sVF & ITVF & 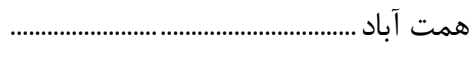 \\
\hline $111 r$ & IV\&D & 1991 & MFTE & 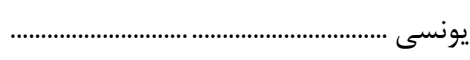 \\
\hline 1 erria & $r F \cdot q \cdot r$ & refueter & FAFres & 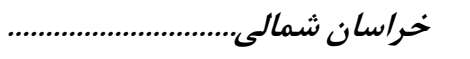 \\
\hline VYFS & ITEG & $|r G 4|$ & $r \Delta I \cdot F$ & آشخانه .......................................................... \\
\hline $1 r \varepsilon \Lambda$ & 1999 & $r \cdot T r$ & 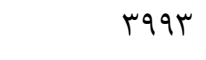 & آوا \\
\hline IVESG & $r q 4 \cdot r$ & $r \cdots \wedge v$ & $\Delta q \& q$. & اسفراين ........................................................ \\
\hline $11 \mathrm{VI}$ & 1994 & $r \cdots$ & ५१९६ & 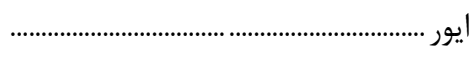 \\
\hline GVMTL & 11449. & IIfFE & rイヘ৭r। & بجنورد ........................... \\
\hline 911 & $9 \vee V$ & $1 \cdot$ TF & $r \cdot \cdots$ & ييش قلعه ........................................................ \\
\hline 1191 & $1 \wedge \vee \wedge$ & $19 \Delta \mathrm{V}$ & rard & تيتكانلو ........................................................... \\
\hline$\Delta 919$ & $9 \Delta ९ \wedge$ & $1 \cdot \cdot 1 r$ & 1901 & جاجرم ............................................................. \\
\hline $1 \cdot 10$ & $19 \mathrm{VV}$ & $I V \cdot r$ & rт人. & 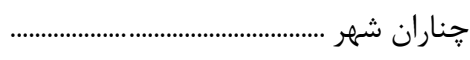 \\
\hline$r \cdot r$ & vil & $\vee \wedge \Lambda$ & 1499 & 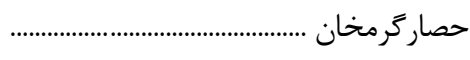 \\
\hline lerg & TYOV & r\&9q & fars & 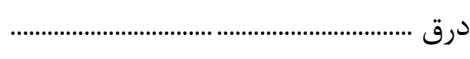 \\
\hline lard & reV. & $r \Delta \Delta q$ & $\Delta \cdot r q$ & راز . . \\
\hline ITAF & rilr & r.99 & fivq & زيارت .............................................................. \\
\hline $9 \Lambda \Lambda$ & 1114 & १९५ & $r \cdot V V$ & 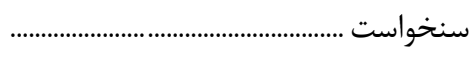 \\
\hline$\checkmark \Delta \Lambda$ & IrIT & $11 \cdot 1$ & שוT & شوقان ........... \\
\hline
\end{tabular}


نتايج تفصيلى سرشمارى عمومى نفوس و مسكن _ه 11 |

ظ ـ جمعيت و خانوار شهرهاى كشور به ترتيب استان (دنباله)

\begin{tabular}{|c|c|c|c|c|}
\hline خانوار & 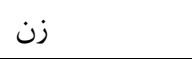 & 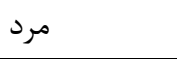 & 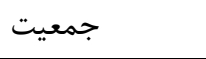 & 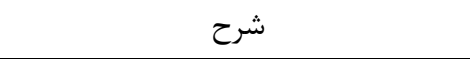 \\
\hline TFYG. & 41.99 & fioq. & $\wedge r \& \wedge 9$ & شيروان...................................................... \\
\hline $1 \cdot r \cdot$ & IVET & $19 \wedge \Delta$ & TETV & 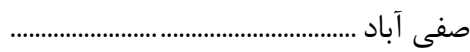 \\
\hline rQFi & DQTT & 9149 & $|r \cdot 9|$ & فاروج ............................................................ \\
\hline AIV & $111 \mathrm{~V}$ & $|T F|$ & TFYA & قاضى ...................... \\
\hline rq. & FAV & $\Delta \cdot 9$ & 999 & 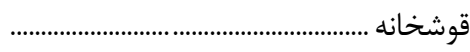 \\
\hline TसM & $\Delta r V F$ & $\Delta \Delta \Delta q$ & 1. & ₹رمه \\
\hline 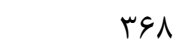 & $\Delta q$. & १९१ & $|\uparrow \lambda|$ & 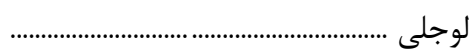 \\
\hline $91 \Delta \mu \varepsilon 1$ & $18 \Delta 9 . .9$ & 1890199 & TADFT. D & 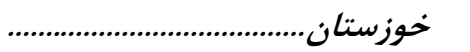 \\
\hline gefv. & ||$\Delta V H \mid$ & $\| \Delta V F \Delta$ & THIFVE & آبادان ........................................................... \\
\hline fr. & $\wedge r v$ & ع & $19 V \pi$ & آبزدان ............................................................. \\
\hline Iraf & TFES & roll & FqQV & 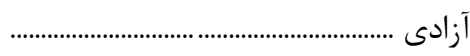 \\
\hline reVt & $9 \cdot r \wedge$ & $\Delta \wedge V F$ & 11914 & 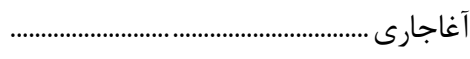 \\
\hline IrVD & TVQ. & TVAS & $\Delta \Delta \cdot 9$ & ابوحميظه .......................... \\
\hline rIDS & $\Delta \& V I$ & $\Delta \Delta \cdot r$ & $111 \mathrm{Vr}$ & اروندكنار ................... \\
\hline IATF & rTQV & rogr & 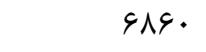 & 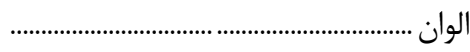 \\
\hline $19 \cdot 0$ & $r \Lambda \cdot \Delta$ & rAfs & VEDI & 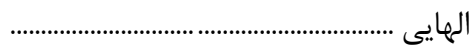 \\
\hline INDVF & 童新. & MFr.V & GVETV & 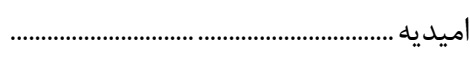 \\
\hline rq|४। & 99191 & GATIA & 1 rol19 & انديمشك ........... \\
\hline 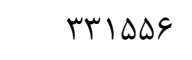 & $\Delta \Lambda \Lambda \cdot \mid f$ & $\Delta Q \& V V F$ & WNFVAN & 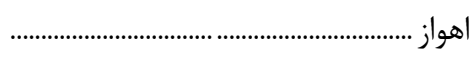 \\
\hline$r . .94$ & $\Delta q V r F$ & $\Delta 9990$ & 119499 & 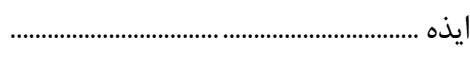 \\
\hline \&4\& & $\mid r \wedge \Delta \Lambda$ & ITYAD & TEMTK & 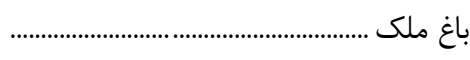 \\
\hline$r l \cdot 1$ & pigf & FrAT & AFV & 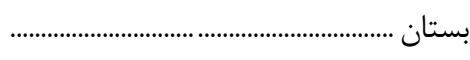 \\
\hline$r|\Lambda| \cdot$ & $r 9.91$ & rqтат & VAror & 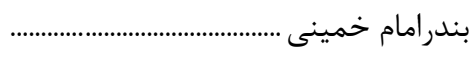 \\
\hline$Y \Delta T \cdot \Lambda$ & $\wedge 1 \cdot \wedge \cdot$ & NIVIV & IGTV9V & 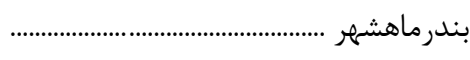 \\
\hline raArs & G.4A. & GTITF & ITrG.4 & 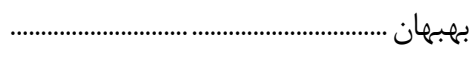 \\
\hline אז & 1199 & IrT. & rr人e & 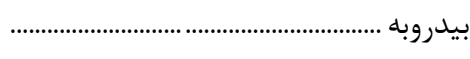 \\
\hline $1 \Delta \wedge \Delta$ & TVVr & rq1Q & $\Delta \& \Lambda \Lambda$ & تركالكى ............ \\
\hline 1109 & TIYA & 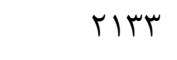 & FrAl & 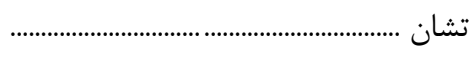 \\
\hline 99. & 1194 & 1194 & rTUV & جايزان ................................................................ \\
\hline IFVD & relr & TVYA & DrG. & 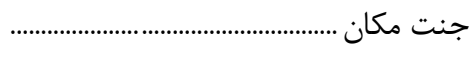 \\
\hline$\Delta \cdot \Delta$ & 948 & $1.9 \mathrm{~V}$ & $r \cdot 1 r$ & 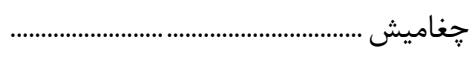 \\
\hline 1481 & reAr & TVE & DFFE & בֶم كلك................. \\
\hline$q \cdot r \Delta$ & 19490 & $I V \cdot r \cdot$ & $r r \Delta \cdot \Delta$ & 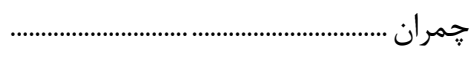 \\
\hline rl.. & ragV & rqщq & $\vee 9.9$ & 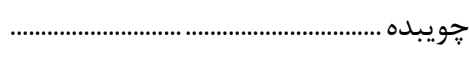 \\
\hline tolt & $F \Delta \cdot r$ & rqVa & $91 \mathrm{VV}$ & 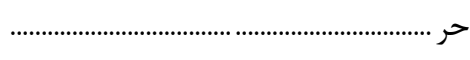 \\
\hline Tr & १ᄉ९ & $9 \mathrm{al}$ & $|A r|$ & حسينيه ....................... \\
\hline$|f \Delta|$ & raAv & rl. & 9.91 & 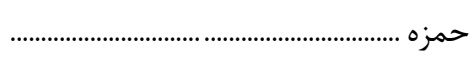 \\
\hline$\Delta F 19$ & $1 \cdot V \mu F$ & L & $T r \cdot \Delta V$ & حميد \\
\hline
\end{tabular}


ظ - جمعيت و خانوار شهرهاى كشور به ترتيب استان (دنباله)

\begin{tabular}{|c|c|c|c|c|}
\hline خانوار & 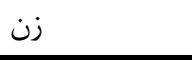 & مرد & جمعيت & 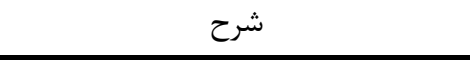 \\
\hline TVITE & $9991 \mathrm{~F}$ & $9911 \pi$ & |rr.qV & 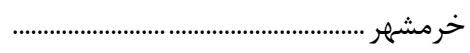 \\
\hline $9 \Delta \wedge$ & IAgT & 1991 & rADT & خنافره ه..................................................... \\
\hline $1 F \Delta \Lambda$ & 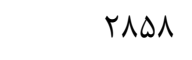 & rVqV & $\Delta \& \Delta \Delta$ & 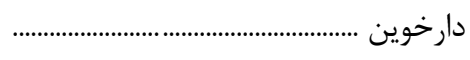 \\
\hline VArYA & IrAVAF & ITDQTD & $r q \varphi v \cdot q$ & دزفول............................................................. \\
\hline imit & זrV & TVOV & $\Delta F q$. & 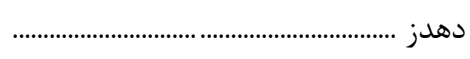 \\
\hline garg & $\mid r \Delta \Delta \Lambda$ & $|T F D|$ & $r \Delta \cdot \cdot q$ & 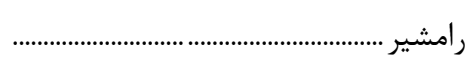 \\
\hline$r \cdot I T V$ & reDFA & rVVrv & VETAD & 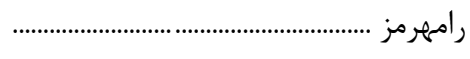 \\
\hline 1.94 & 1191 & $1 \wedge 99$ & rVq & 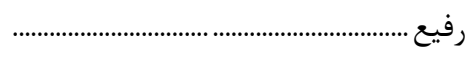 \\
\hline rTS & $\Delta 9 \Delta$ & จqV & 1194 & زهره \\
\hline $99 \mathrm{~V}$ & $M I V$ & ITK & TQG. & 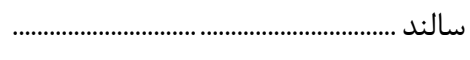 \\
\hline IrTA & TATY & $r V \cdot \varphi$ & DYF. & 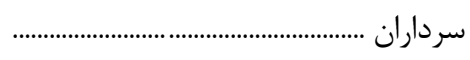 \\
\hline$r \cdot r$ & $r F \cdot \Delta$ & $r \Delta \cdot v$ & $991 \%$ & 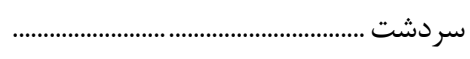 \\
\hline kru & $\lambda \cdot r$ & 911 & IVAF & 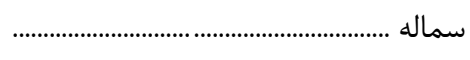 \\
\hline IrGGY & rQDYI & $r \Delta q 1$. & $\Delta|F T|$ & 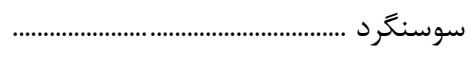 \\
\hline 1410 & $r 4.9$ & tYqV & $\Delta F \cdot \varphi$ & 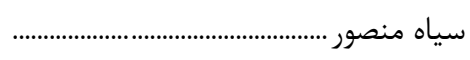 \\
\hline $11 k \cdot r$ & $r \cdot \Delta \cdot q$ & TITYK & FIVTr & 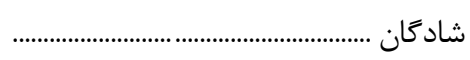 \\
\hline TRM & kMfF & 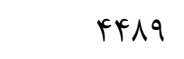 & MArr & شاوور ........................................................... \\
\hline reAF & $\Delta \wedge r \Lambda$ & DqTa & IIVAV & 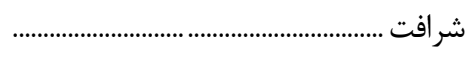 \\
\hline migt & DrTV & $\Delta G Y I$ & $1 \cdot \wedge \Delta \wedge$ & 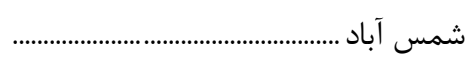 \\
\hline rista & r人rqя & TAVQT & VVIFA & 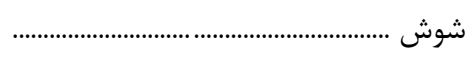 \\
\hline TAYrT & 0.119 & DIVGT & $1 \cdot \operatorname{l\wedge } \wedge$ & شوشت ............................... \\
\hline 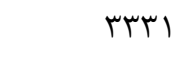 & $\Delta \Delta \cdot r$ & $\Delta \wedge 91$ & 11rqr & 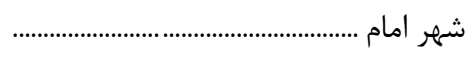 \\
\hline qqu & IVITr & INFF & rerVF & 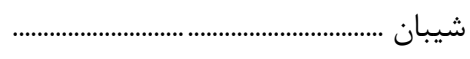 \\
\hline$|\Lambda|^{F}$ & ragr & rVte & $v r \cdot 9$ & 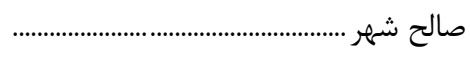 \\
\hline rAqF & priq & DIG. & 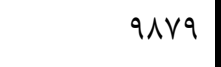 & 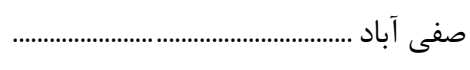 \\
\hline $1 \Lambda \cdot r$ & rVru & rqוr & Vबa. & 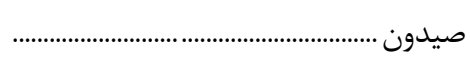 \\
\hline VTr & $14 r q$ & lare & rqvr & 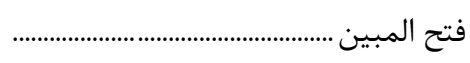 \\
\hline TVIS & $\Delta r \cdot 1$ & DrqV & 1.991 & قلعه تل ........................................................... \\
\hline $9 \cdot 9$ & $1 r \cdot 9$ & $M \cdot r$ & $r F \cdot \Lambda$ & 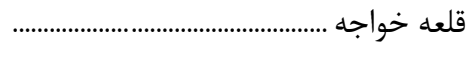 \\
\hline $1 r \cdot 1$ & $r t \cdot 1$ & 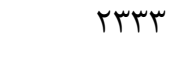 & Fafi & كوت سيد نعيم ......................................... \\
\hline $\mid F V I F$ & TVYAS & r^৭६9 & DGTAT & 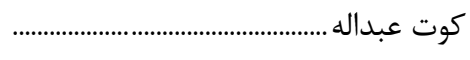 \\
\hline qDFq & $111 \ldots$ & $|T F| Q$ & TETIS & 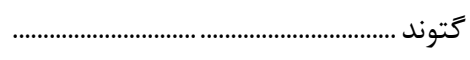 \\
\hline TMN & $\Delta T \Delta$ & $\Delta G F$ & $1 \cdot 19$ & 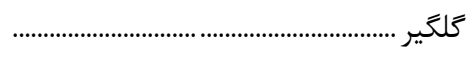 \\
\hline 99v & Irva & 1010 & r^q. & 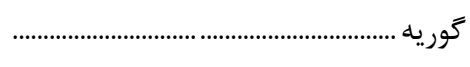 \\
\hline FATr & $9 \cdot 94$ & 941 . & IAFr & 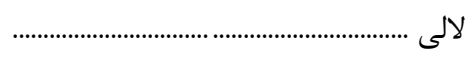 \\
\hline$r \varepsilon \Delta \cdot r$ & rqpVA & $01 \cdot 19$ & $1 \ldots+q 9$ & 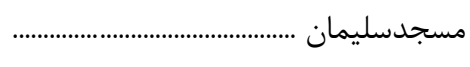 \\
\hline$\Delta G F$ & 994 & $11 \cdot r$ & $r \cdot 90$ & مشراكه................................................................. \\
\hline 4990 & $11 \cdot 9$ & $\Lambda \Delta M_{1}$ & IVTrV & 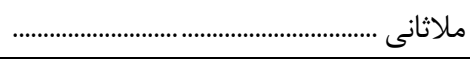 \\
\hline
\end{tabular}


نتايج تفصيلى سرشمارى عمومى نفوس و مسكن _هوس|

ظ ـ جمعيت و خانوار شهرهاى كشور به ترتيب استان (دنباله)

\begin{tabular}{|c|c|c|c|c|}
\hline خانوار & 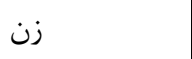 & 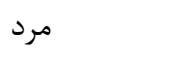 & جمعيت & 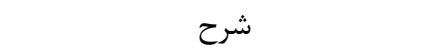 \\
\hline IQTA & $r V \cdot V$ & TVMF & $\Delta F F I$ & 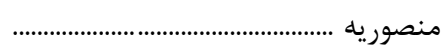 \\
\hline rAYV & pqup & DIVG & 1.11 . & 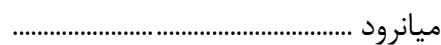 \\
\hline זسף & $1 V \cdot 9$ & $M \cdot V$ & 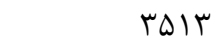 & 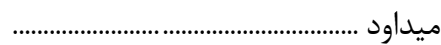 \\
\hline 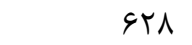 & 11149 & $11 \cdot 0$ & וTr & مينوشهر .....……………………………‥ \\
\hline$k \cdot 94$ & Vदrq & VEVT & IQTIK & 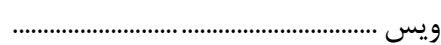 \\
\hline FTAK & VYAI & $\Lambda \cdot r)$ & $10 \Lambda \cdot T$ & هفتگل .................................................. \\
\hline vq. t & IFTMA & IFVV & $r 9 \cdot 10$ & 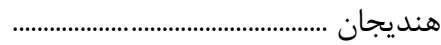 \\
\hline$k q .4$ & $9 \Delta \Delta १$ & 99५ & 19401 & 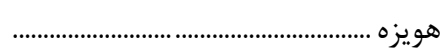 \\
\hline rivgir & ralase & $r \Delta q r \cdot q$ & v111rv & 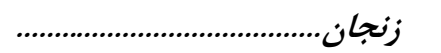 \\
\hline rfqk & ra人d & 41.9 & $1 \cdot 91$ & 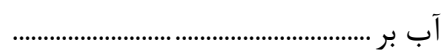 \\
\hline r.qur & Fq19V & $0 \cdot 111$ & १৭५^৯ & 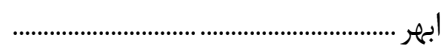 \\
\hline$\Delta V T$ & 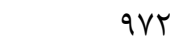 & $11 \mathrm{VV}$ & rIFq & ار رغانخانه ....................................................... \\
\hline DrT & $\wedge 81$ & AVT & IVTr & جورزق ............................ \\
\hline$r \Delta q$ & FeV & $\Delta \cdot 9$ & $9 \Delta \varphi$ & 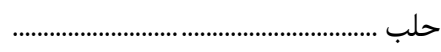 \\
\hline IVTFA & TVET. & tVara & $\Delta \Delta r G \Lambda$ & خرمدره ................... \\
\hline rוा & thet & TETD & FVVA & 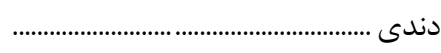 \\
\hline$v \cdot 1$ & 1119 & 1114 & rrVte & 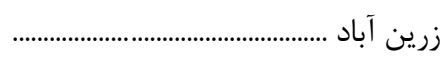 \\
\hline lQ9F & rAfi & tArt & $\Delta \& \& F$ & 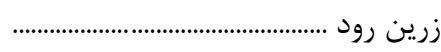 \\
\hline IrTyeq & rITESD & TIVF.4 & $F r \cdot \wedge V I$ & 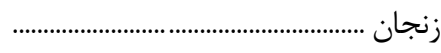 \\
\hline$r \cdot r \wedge$ & rYGQ & $r \Delta V$ & $V \cdot r V$ & سجاس ....................................................... \\
\hline rmIa & TVTV & rq11 & VArA & 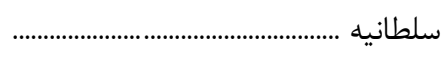 \\
\hline 1991 & tatr & req9 & 9991 & 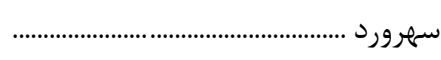 \\
\hline$\varphi \cdot \varphi \wedge$ & gr人t & $9 V \cdot 9$ & $1 \% 919$ & 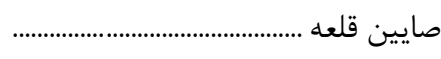 \\
\hline $1 \cdots r \wedge$ & $1 V 194$ & IVYTV & rFqYI & 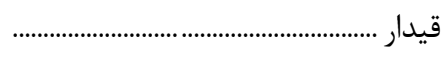 \\
\hline $99 \Delta$ & 1099 & $101 V$ & $r \cdot \Lambda r$ & 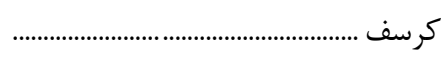 \\
\hline $1 \cdot r v$ & $1 M \Lambda 9$ & $19 \mathrm{Vr}$ & rArt & 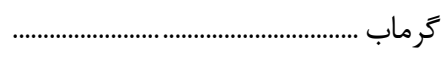 \\
\hline lare & TVYA & TVDQ & DFAV & 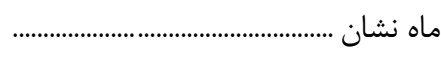 \\
\hline $1 \cdot \Delta \varphi$ & IVVe & $\mid \wedge \& \wedge$ & reft & 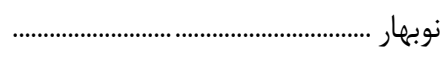 \\
\hline 110 & 199 & r^৭ & $\uparrow \Delta \Delta$ & 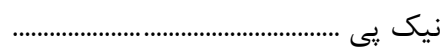 \\
\hline pr.q & 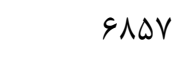 & 9914 & IrNk. & 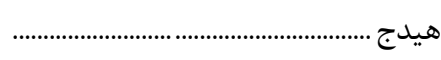 \\
\hline IEqYad & rrvaqu & rATa.r & $\Delta \varepsilon \cdot \Delta \cdot r$ & 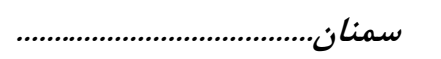 \\
\hline$r \cdot 9 r$ & $r \cdot q r$ & MI9F & GTOV & 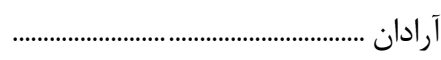 \\
\hline $11 \Delta T$ & IV.r & $1 \wedge \Delta \wedge$ & rosl & 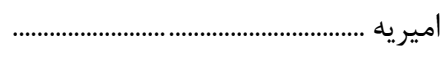 \\
\hline 4819 & svrq & sVVq & IraIA & 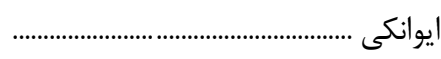 \\
\hline ritr & FYFq & prg. & $19 \cdot 9$ & 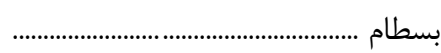 \\
\hline Nis & ITVD & ITUK & TATA & 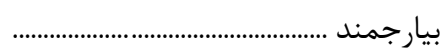 \\
\hline INFIV & ५৭१४r & ralru & $091 \cdot 9$ & 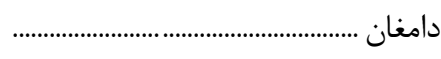 \\
\hline IVVV & rq). & $r \cdot \Lambda V$ & ४९१४ & درجزين ............... \\
\hline
\end{tabular}


ظ - جمعيت و خانوار شهرهاى كشور به ترتيب استان (دنباله)

\begin{tabular}{|c|c|c|c|c|}
\hline خانوار & 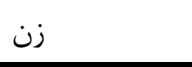 & 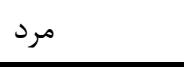 & جمعيت & شرح \\
\hline 199. & TVGq & rAVA & $\Delta G Q V$ & 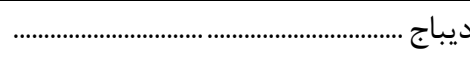 \\
\hline ITKN & $1 \wedge<q$ & 1941 & $r v r \cdot$ & 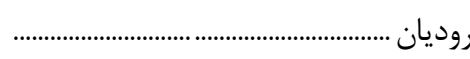 \\
\hline rrik & fqrq & $D \cdot r t$ & 9901 & 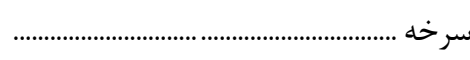 \\
\hline$F q I F r$ & $q \cdot \vee \backslash 1$ & $9 F+11$ & $|\wedge \Delta| r q$ & 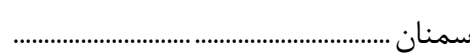 \\
\hline FVG. & VFFVR & $V \Delta \varphi \Delta \varphi$ & $10 \cdot 1 \% 9$ & 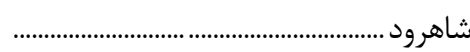 \\
\hline rV^q & $\Delta G r V$ & $\Delta \Delta \Delta F$ & 11191 & 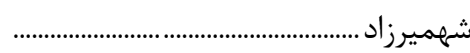 \\
\hline levq & 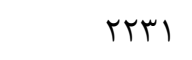 & rт人. & 4911 & 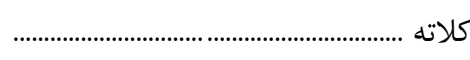 \\
\hline Fa. & 9.9 & $\Delta \wedge \mu$ & 1195 & 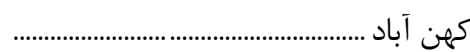 \\
\hline$M \cdot r$ & rAv. & trul & $\Delta 9 \Delta 1$ & 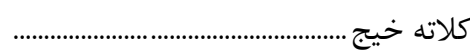 \\
\hline $19 \cdot V \Delta$ & TFYAQ & TFTIT & FASVT & كرمسار ................................................ \\
\hline TITV & rq५ & $r \cdot r$ & DQTT & 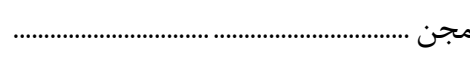 \\
\hline V\&Vq & | (1TM & $|r| \Delta F$ & TFYAD & 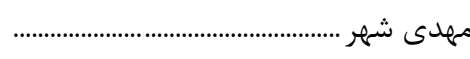 \\
\hline $\mid$ |Ft & trAt & trAF & FDSG & 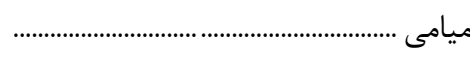 \\
\hline$r m F \lambda \cdot 1$ & $98 \cdot 4 r q$ & \&ADI\&r & IrFDFFT & 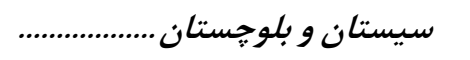 \\
\hline ヘ\&Y & 1948 & $199 \mathrm{~V}$ & r & 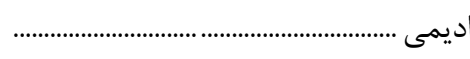 \\
\hline $11 \mathrm{rV}$ & Trt. & rrqa & eriq & 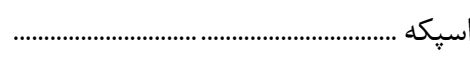 \\
\hline TYTYA & $\Delta \Delta \varphi \cdot V$ & $\Delta \Lambda I F r$ & $11 \% \mathrm{ra} \cdot$ & 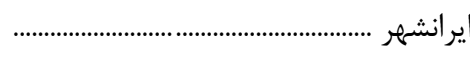 \\
\hline $1 r \Delta \Delta$ & TVET & TYA. & DI9T & 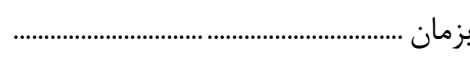 \\
\hline ritr & grru & 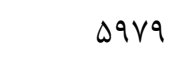 & ITTIV & 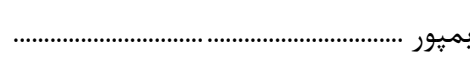 \\
\hline $10 \cdot r$ & TQTI & $r q .1$ & DATr & 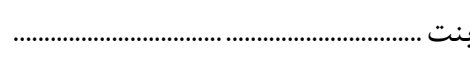 \\
\hline $1 \cdot T V$ & $19 \cdot r$ & $\backslash \wedge \Delta V$ & rVq. & 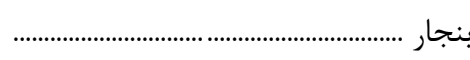 \\
\hline TFYG & V৭rq & $\Lambda \cdot \Lambda t$ & $19 \cdot 11$ & 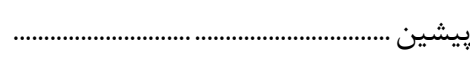 \\
\hline Friq & $q \cdot v r$ & $q \cdot r \Delta$ & $11 \cdot 91$ & 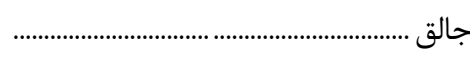 \\
\hline rQ८१९ & $\Delta r \cdot \Delta r$ & $\Delta F \& \Delta V$ & $1.9 \vee r 9$ & جاه بهار ................................................ \\
\hline IFrAF & $r \wedge \cdot q$. & rAFqF & $\Delta \& \Delta \wedge F$ & 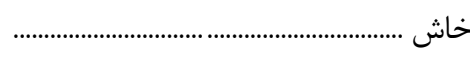 \\
\hline IFIT & TrTV & ruqf & 9951 & 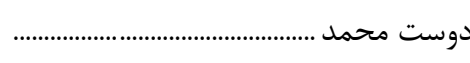 \\
\hline TYII & ध9६^ & DIFV & 1.110 & 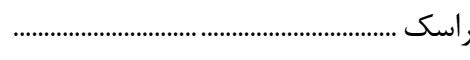 \\
\hline$r \Delta F \cdot 1$ & SVTDQ & बV991 & $1 \%<q \Delta$. & 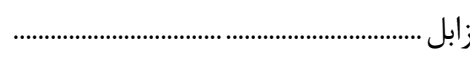 \\
\hline IfEVIV & 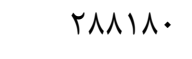 & 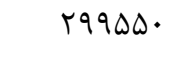 & $\Delta \wedge \vee V \cdot$ & 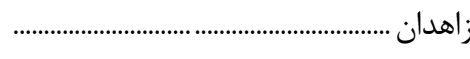 \\
\hline ^Vฯ & lNTd & rISA & $r \cdot r$ & زرآباد ............................................................. \\
\hline rTrA & $9 \Delta 9 \mu^{2}$ & qVar & IrTaV & 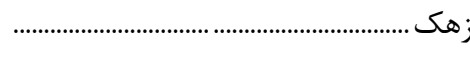 \\
\hline 10979 & rqTrD & $r \cdot 9 \wedge 9$ & $9 \cdot .14$ & 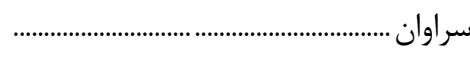 \\
\hline 490 & 1.10 & $1 \cdots 0$ & $r \cdot r \cdot$ & 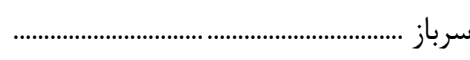 \\
\hline rTaV & GVDS & GAYK & $1 r \Delta \Lambda \cdot$ & 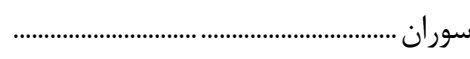 \\
\hline$\Delta \Delta V$ & $1 \cdot \wedge$ & 1119 & r/99 & 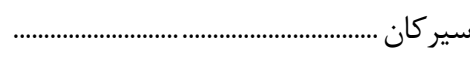 \\
\hline Irar & rrVV & rF. & erva & 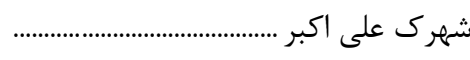 \\
\hline ryl. & gDFI & gQTq & $\pi \cdot v \cdot$ & 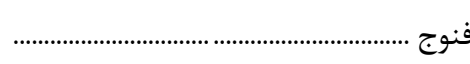 \\
\hline rqYq & $\Delta \wedge \vee \cdot$ & $\Delta V T \Delta$ & $119 \cdot \Delta$ & قصرقند ..................... \\
\hline
\end{tabular}


ظ - جمعيت و خانوار شهرهاى كشور به ترتيب استان (دنباله)

\begin{tabular}{|c|c|c|c|c|}
\hline خانوار & 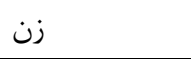 & 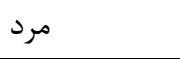 & جمعيت & 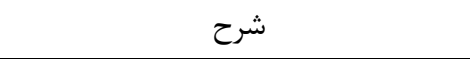 \\
\hline $99 \Delta F$ & $119 \cdot q^{f}$ & TFTOF & FTrOA & كنارك \\
\hline Irrq & TQQT & TFF. & rq95 & گشت ..................... \\
\hline rFa. & DIT. & DIVT & I. rqr & كلمورتى ............ \\
\hline$r \Delta \Delta \cdot$ & DTGK & $\Delta \cdot r q$ & $1 \cdot r \cdot r$ & 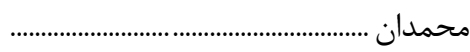 \\
\hline $9 \cdot 9$ & IVDS & IVIT & rFs & 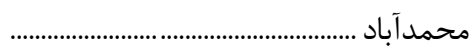 \\
\hline IGKT & TVRI & rATS & $\Delta 9 \cdot 9$ & محمدى .......... \\
\hline r৭९9 & GIVA & $9 \cdot 9 V$ & ITTED & مهر ستان ......................................................... \\
\hline$r I \cdot V$ & 49.9 & FVD. & $q \mu \Delta q$ & 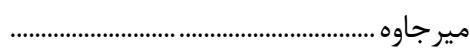 \\
\hline$I T \Delta \Delta$ & rदq & TAFD & DTHA & 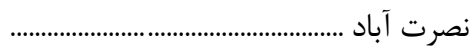 \\
\hline Irt. & TVAT & rqIV & $\Delta q V$. & نكور ............................... \\
\hline irv. & Taru & TET & DrEl & نوك آباد .................... \\
\hline fiQS & ヘAYV & $91 \cdot 0$ & IVVTr & نيك شهر ................................. \\
\hline rar & VबA & $9 \cdot 9$ & $19 V F$ & 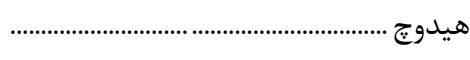 \\
\hline 1.ref.r & $|\& A F| \Delta D$ & IVIVAT. & $r F \cdot 18 V \Delta$ & 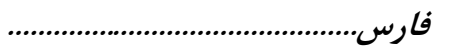 \\
\hline 11990 & rqDF^ & 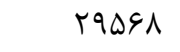 & 09119 & آباده ............................. \\
\hline TTVR & rघQI & TVYA & vrva & آباده طشك ......... \\
\hline filv & $V T I N$ & $V F i d$ & سחצואו & اردكان ...................... \\
\hline DrAF & $1 Y<q$ & $\wedge 9 \Delta \vee$ & $I V V \cdot q$ & ارسنجان ........... \\
\hline $1 \cdot 9 v \cdot$ & $M \cdot V V$ & 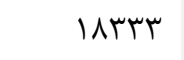 & rafi. & استهبان ............................... \\
\hline$\wedge \varepsilon \Delta$ & $|F \Delta|$ & 1091 & $r \cdot k t$ & 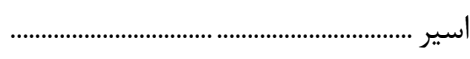 \\
\hline$T F \cdot G$ & feiv & eqqu & 9110 & 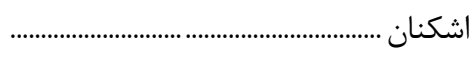 \\
\hline$V r_{1}$ & IraF & $1 r \cdot r$ & 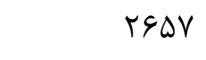 & 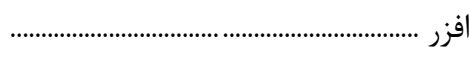 \\
\hline$|r r| \cdot$ & $r \backslash \wedge \Delta V$ & TYFAF & fFrfi & 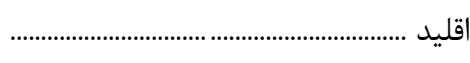 \\
\hline $19 \cdot V$ & rAGY & rqтq & $\Delta \Lambda \cdot r$ & 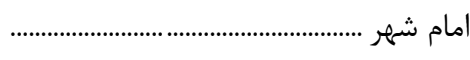 \\
\hline$\Delta T V R$ & $999 \mathrm{~V}$ & $1 \cdots r \cdot$ & $1991 \mathrm{~V}$ & 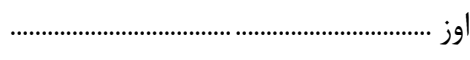 \\
\hline ^rq & $19 \wedge 9$ & lequ & riva & اهل ............................. \\
\hline INVS & $r \cdot v \cdot$ & rive & GTES & ايج \\
\hline lNKF & rart & rqท^ & Q91. & 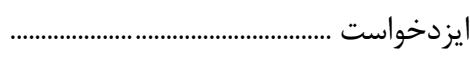 \\
\hline rrr. & $r \Delta \Lambda 1$ & rFA. & $v \cdot 91$ & 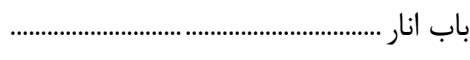 \\
\hline rM & 994 & $9 \wedge \Delta$ & irva & بابامنير ........................................................... \\
\hline 1919 & rqه & $r \cdot 19$ & $\Delta Q V T$ & 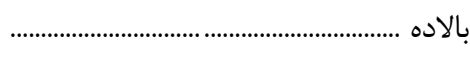 \\
\hline$r \Delta \Lambda \cdot$ & FFFa & FETr & $q \cdot v \vee$ & 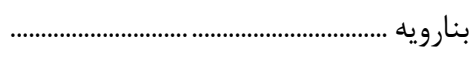 \\
\hline rqva & FVed & $0 \cdot 11$ & qVVद & 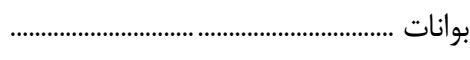 \\
\hline TMTS & rVIq & rAkq & $V \Delta G \Lambda$ & بهمن ................... \\
\hline TITD & r $4 \cdot 0$ & reqd & $v r \cdot$. & بيرم ...................................... \\
\hline $190 \mathrm{r}$ & $r \Delta \cdot r$ & $r \vee \Delta \cdot$ & VTAT & 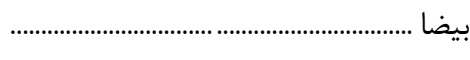 \\
\hline ragt & 9ヘrG & GVGT & $1 r \Delta 91$ & 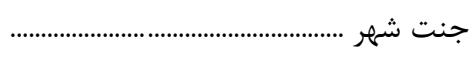 \\
\hline TEMT & req. & Far. & $\wedge \cdot 1$. & جويم ........... \\
\hline
\end{tabular}


ظ - جمعيت و خانوار شهرهاى كشور به ترتيب استان (دنباله)

\begin{tabular}{|c|c|c|c|c|}
\hline خانوار & 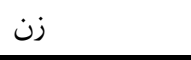 & مرد & جمعيت & 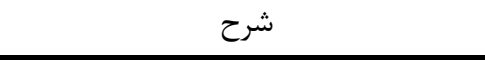 \\
\hline prrpq & 9४११५ & VHGFI & IFIGHF & 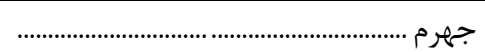 \\
\hline 9.91 & $1 \cdot \Delta H V$ & IIIN & rISVD & 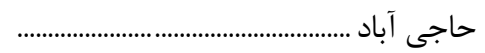 \\
\hline $1 \cdots$ & 1484 & 1990 & 萑 & 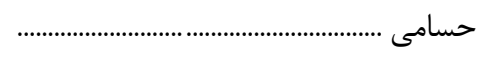 \\
\hline$\Delta \Lambda T$ & $1 \cdot r \wedge$ & $1 \cdots v$ & $r \cdot r \Delta$ & حسن اباد........................................................ \\
\hline $11 \% 9$ & $r \cdot 9 \Delta$ & 1995 & $r \cdot r v$ & خانه زنيان ........................................................ \\
\hline 919 & leVk & lofG & $r \cdot r \cdot$ & 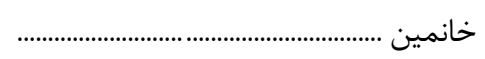 \\
\hline אזט1 & $r \cdot \Delta r$ & trVa & | l & 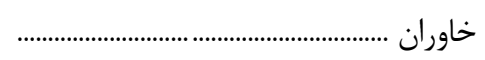 \\
\hline$\Delta G H \Delta$ & $91 \mathrm{kF}$ & 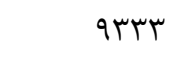 & IAFV & خرامه .......................................................... \\
\hline TVYr & reqv & rqDT & 9099 & خشت ........ \\
\hline 4990 & 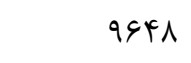 & $9 \Delta 99$ & $19 T I V$ & 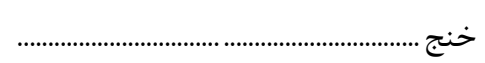 \\
\hline MArq & rFis & ratr & Vrre & 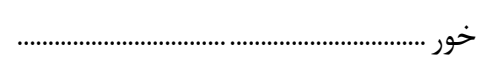 \\
\hline VTr & $\mu \cdot v$ & 1941 & TrFa & 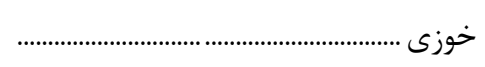 \\
\hline $\mid V 9 \Delta$ & Mr. & $r \cdot 19$ & Gr. & 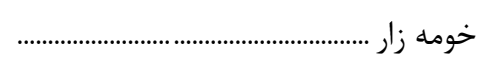 \\
\hline$r \mid r \cdot \Lambda$ & megkt & $r \Delta \Delta \wedge q$ & $V \cdot r \mu r$ & 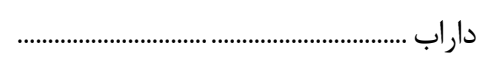 \\
\hline$r \cdot r)$ & YA\&V & DIV. & $1 \ldots r v$ & 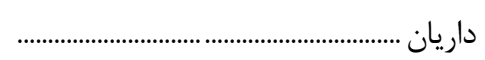 \\
\hline 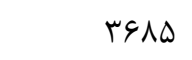 & gVVT & $V \cdot r v$ & $1 \% \Lambda \cdot 9$ & 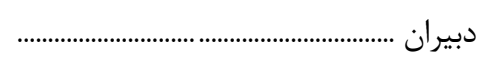 \\
\hline 1191 & 1901 & 1999 & rqTF & 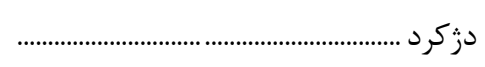 \\
\hline$\Lambda \Delta 9$ & $1 F \Delta$ & If $F V$ & rq. & 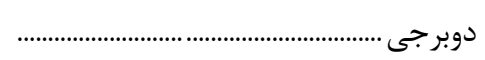 \\
\hline (i). & 941 & $v \cdot v$ & $\mid r F \lambda$ & دوزه \\
\hline $1 \cdot \varphi_{\Delta}$ & IVTS & IVTr & res & دهرم \\
\hline vir & $|r \&|$ & $1 r \wedge 9$ & $r \Delta \Delta \cdot$ & 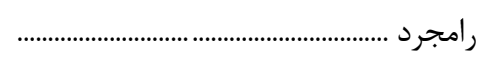 \\
\hline IVeF & TVqI & r৭६9 & $\Delta \vee \varepsilon \cdot$ & 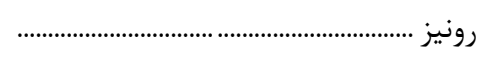 \\
\hline r人\&9 & prei & rqv^ & $9 \vee 19$ & 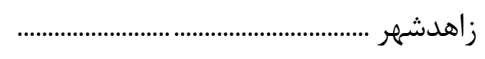 \\
\hline $9 \Delta 91$ & IDGFY & I991V & rTrGl & 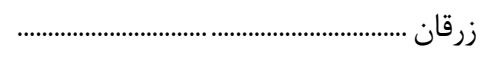 \\
\hline $19 \pi r$ & TFYI & ( & SVEV & 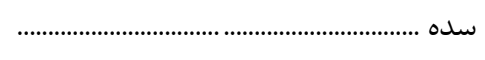 \\
\hline$\Delta \Delta Q T$ & $q \cdot 4 \wedge$ & $91 r q$ & $1 \wedge \backslash \wedge V$ & سروستان ........................................................ \\
\hline$\Delta \cdot r)$ & ᄉrیs & $\wedge V \& \Delta$ & $|V| r \mid$ & سعادت شهر .................................................. \\
\hline QVG & 94 . & 991 & $194 \wedge$ & سلطان شهر .................................................. \\
\hline $1 \cdot \Delta T$ & $|0|$ & IQF. & $r \cdot \Delta \cdot$ & 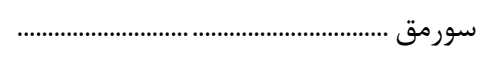 \\
\hline rDSG & FIAT & FET & $\Lambda \Delta V A$ & سيدان .......................................................... \\
\hline IVVA & rArA & TITt & Q99. & 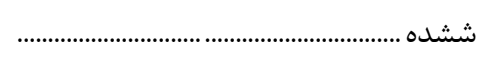 \\
\hline resq & fers & $\operatorname{cr} \wedge q$ & ^৭r & شهر \\
\hline rAVAl & FDSqT & reiv. & ११人ब५ & شهرصدرا ....................................................... \\
\hline frvq19 & $R N \cdot I t r$ & VADFA. & IDSDQVY & 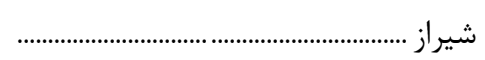 \\
\hline rq. & $q \mu \cdot r$ & grVA & ITAAT & صغاد .................................................... \\
\hline$\Lambda \cdot r 4$ & פחשrו & $1 r \Delta q \Lambda$ & r TqM & صفاشهر .......................................................... \\
\hline $11 r 9$ & $r \cdot \Delta \cdot$ & $r \cdot 1 \Lambda$ & $r \cdot 9 \Lambda$ & 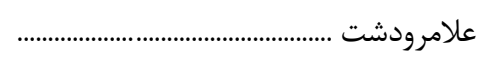 \\
\hline 1.19 & TIDT & $r \cdot \Lambda r$ & erta & عمادده ........................................................ \\
\hline
\end{tabular}


ظ - جمعيت و خانوار شهرهاى كشور به ترتيب استان (دنباله)

\begin{tabular}{|c|c|c|c|c|}
\hline خانوار & 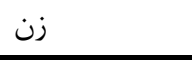 & 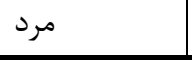 & جمعيت & 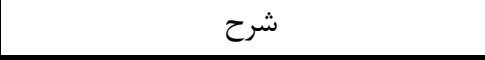 \\
\hline $11 \pi 4$ & $r \cdot \Delta V$ & r. F. & $k \cdot 9 V$ & 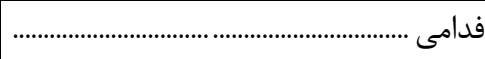 \\
\hline$\Delta V I V$ & 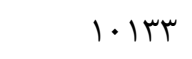 & $1 \cdot 1 \wedge \mathrm{V}$ & t.rte. & 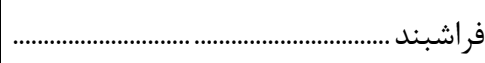 \\
\hline 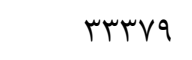 & $\Delta \Delta I V \Delta$ & $\Delta \Delta 9 \Delta$ & $11 \cdot \wedge r \Delta$ & 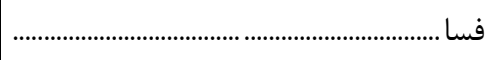 \\
\hline$r \cdot \mid \Lambda r$ & rtral & $r r \cdot \Delta 9$ & GQFIV & 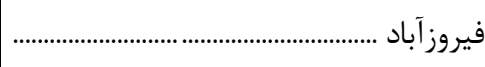 \\
\hline F\&A. & Vrat & $\sqrt{ } \varepsilon \cdot 9$ & liqur & قادراباد ................................................................. \\
\hline VTa1 & Irfte & ITEVT & rब911 & 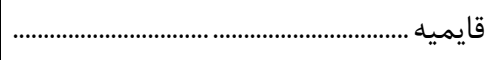 \\
\hline 1914 & rTqD & TFV & GVVT & قره بلاغ......................................................... \\
\hline rta. & rerq & f.rv & VEVG & قطب آباد .......................................................... \\
\hline ^९v & 1490 & $10 \cdots$ & r^१० & قطرويه ................................ \\
\hline$\Delta \varphi \Delta \cdot$ & $97 \cdot 9$ & $1 \cdot r \cdot 4$ & $r \cdot . l \cdot$ & 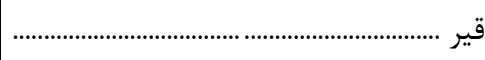 \\
\hline TAT. & ra.r & 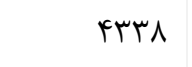 & MAFI & 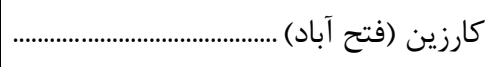 \\
\hline 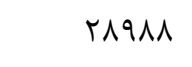 & FATID & FAFA & 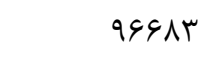 & 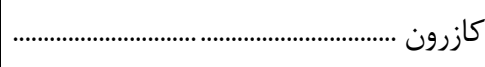 \\
\hline $1 \cdot \Delta V$ & $|V \wedge|$ & 1945 & rvir & 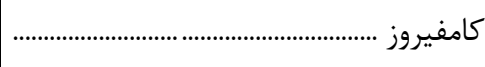 \\
\hline $1 r \Delta 9$ & $194 \pi$ & $r \cdot r$ & rqQ४ & 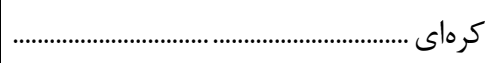 \\
\hline IVGF & $r \cdot r \cdot$ & $r \cdot p l$ & $9 \cdot 11$ & كنار تخته ............................................................. \\
\hline$\wedge \Delta \vee V$ & $1 \Delta \Delta \cdot 9$ & $194 \cdot \Delta$ & rIVII & 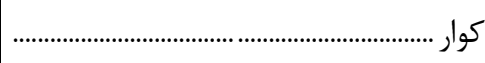 \\
\hline $9 \cdot 9$ & $19 \Delta 1$ & $10 \vee 9$ & rtrt & كوين .................................... \\
\hline $1 \cdot+1$ & lovq & $I V \cdot r$ & TrNI & 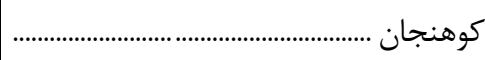 \\
\hline$I \cdot r \cdot V$ & $199 \cdot 4$ & 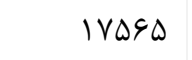 & MFYG & 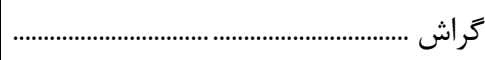 \\
\hline$r \Delta \wedge q$ & $99 V \mathrm{~V}$ & sVVD & ITFYA & 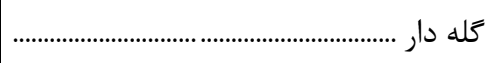 \\
\hline$\backslash \wedge \Delta \vee \wedge$ & $r \cdot \mid \wedge \Delta$ & MMA. & $G T \cdot F Q$ & 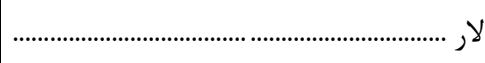 \\
\hline ^DYq & IFVED & IF\&Ta & rqu^. & 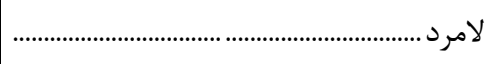 \\
\hline TVQI & tht & Fas & $\wedge ৭ \wedge \Delta$ & 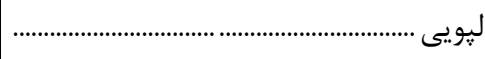 \\
\hline 1910 & roHF & rVGG & $v r$. & 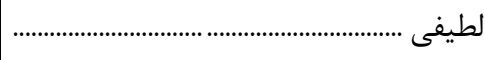 \\
\hline Far & VVQ & VVI & lQFe & 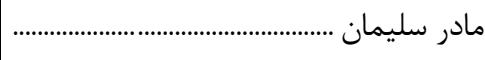 \\
\hline 1419 & rIAF & TATT & $k v \cdot v$ & 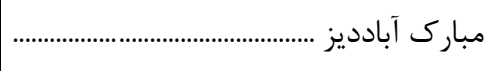 \\
\hline rtark & VYFqD & VArgr & $\mid \& \wedge \Lambda \Delta \Lambda$ & مرودشت ........................................................... \\
\hline 1194 & IVQF & MN & TDSV & مزايجان ........................................................... \\
\hline $1 \& \Delta \Lambda$ & TMTA & rr^৭ & Filv & مشكان .............................................................. \\
\hline TQAT & kqrq & rmat & $9 \cdot r 1$ & 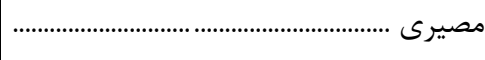 \\
\hline rive & rی९l & rarr & VYAF & مهر ................................... \\
\hline IVVD & rq4. & rqvr & Dqार & 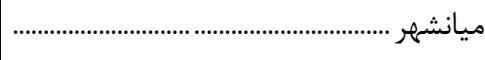 \\
\hline rTrs & $\Delta \cdot F_{1}$ & $\Delta \cdot \vee 9$ & $1 \cdot 1 r$ & 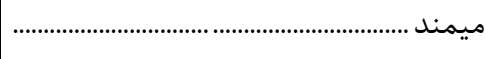 \\
\hline Arr & $|r| r$ & $119 \mathrm{~V}$ & $|Y| T_{0}$ & 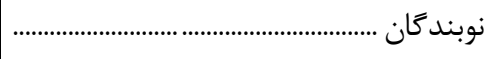 \\
\hline $11 r v$ & 1909 & $|\wedge|$ & rV९q & 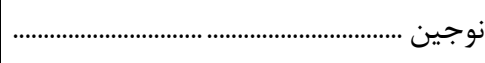 \\
\hline$\Delta+1$ & 1499 & IFrT & rی⿱ & نودان ............................................................ \\
\hline lekt. & Tマ৭৭९ & $r q .9 r$ & $\Delta V \cdot \Delta \Lambda$ & ن................................................................. \\
\hline IQTH & TFYAI & $r \Delta .99$ & $\uparrow q \wedge \Delta$. & 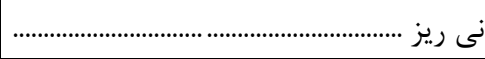 \\
\hline
\end{tabular}


نتايج تفصيلى سرشمارى عمومى نفوس و مسكن _ه |

ظ ـ جمعيت و خانوار شهرهاى كشور به ترتيب استان (دنباله)

\begin{tabular}{|c|c|c|c|c|}
\hline خانوار & زن - ت ان & 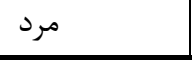 & جمعيت & 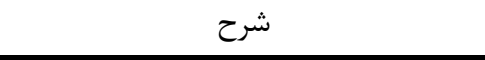 \\
\hline $1 \pi \cdot r$ & rrtq & rTqT & FATr & 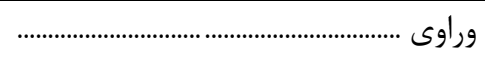 \\
\hline $11 r 9$ & 1949 & 1914 & rNAT & 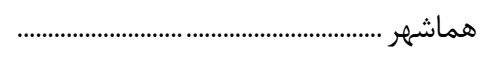 \\
\hline$r 90.19$ & FenITr & FAF. rV & $9 \Delta r I F q$ & 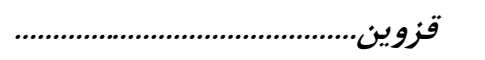 \\
\hline $19 \cdot r$ & $r \cdot r v$ & rт৭q & ( - la & 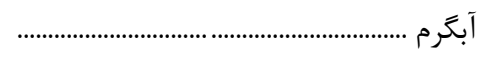 \\
\hline INQT. & rqDrV & $r \cdot \Delta V \cdot$ & $9 \cdot 1 \cdot v$ & آبيك ................................................................... \\
\hline$|G T|$ & rFAF & 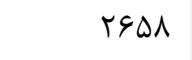 & DIFT & 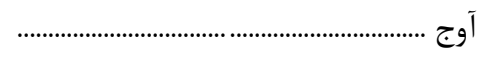 \\
\hline 1099 & rFG. & rQAT & $\Delta \cdot \mu r$ & 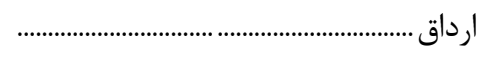 \\
\hline rrqu & 9199 & $G T \cdot T$ & $|r m|$ & |س..................................................... \\
\hline$|\varepsilon| \Delta F$ & T\&GTD & TAFEI & $\Delta \Delta \cdot 94$ & اقباليه ................................. \\
\hline rА१५s & FaqFV & $\uparrow \vee \wedge \wedge q$ & qr人ץя & 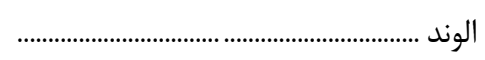 \\
\hline GT91 & $1 \cdot r V 1$ & $1 \cdot \Delta \Delta T$ & $r \cdot \Lambda r t$ & 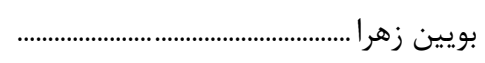 \\
\hline$\Delta \Delta \wedge 1$ & $\Lambda V T V$ & QTr & $11 \cdot 9$. & 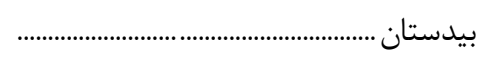 \\
\hline$T F \Delta 9 \Delta$ & rqurf & $\varphi \cdot q \vee \Delta$ & $1 \cdot r 99$ & تاكستان ..................................................... \\
\hline $1 \cdots 1$ & lart & 1919 & mIFA & 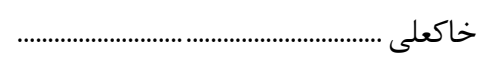 \\
\hline 1998 & Trt. & rrme & $9 \Delta \Delta F$ & خرمدشت .................................................... \\
\hline$r \vee \cdot 1$ & 4911 & FArT & qurf & 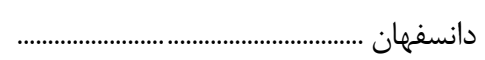 \\
\hline$r \cdot \Delta$ & $\Delta 91$ & sqr & ITAK & رازميان........................................................ \\
\hline 1994 & $r V \cdot \Lambda$ & trAe & Drar & 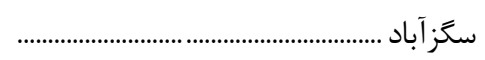 \\
\hline r.. & rAV & Fil & $\Lambda \cdot \Delta$ & سيردان ............................................................ \\
\hline FTIV & $V \Delta \cdot \Delta$ & $\checkmark V \wedge \Delta$ & lorq. & 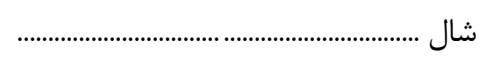 \\
\hline q.VF & १人५ & 1.019 & T. rTY & 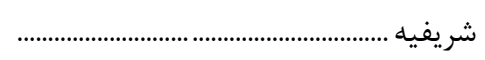 \\
\hline rVTr & fifq & 4lir & NTET & 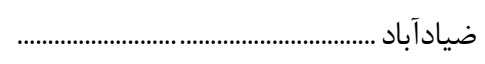 \\
\hline ITYIAF & 199.48 & $r \cdot r V \cdot r$ & K. TYYA & 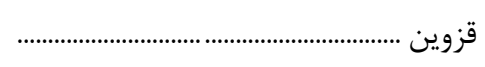 \\
\hline Fil & 990 & VES & $|4| \mid$ & 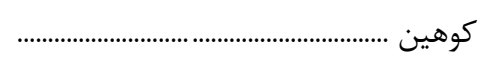 \\
\hline rA9YT & fFres & rarrV & $q \cdot \Delta 1 r$ & 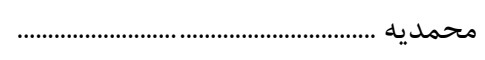 \\
\hline 9481 & $1 \cdot V r q$ & llrar & rI9Ar & 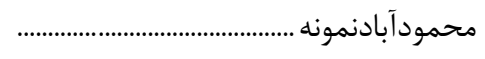 \\
\hline$v \cdot 1$ & $1 \cdot v V$ & 1149 & trtr & 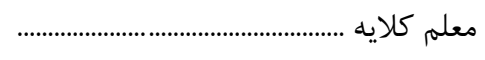 \\
\hline 1991 & trFe & r^९. & $\Delta G \cdot F$ & 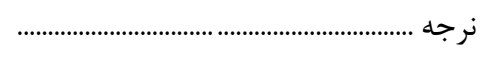 \\
\hline rearrf & G.DFAD & erFa.q & Irraggr & 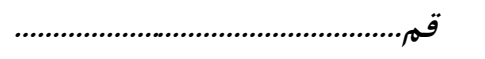 \\
\hline TAQT & $r \Delta \cdot r$ & FMAF & ૧૯АV & 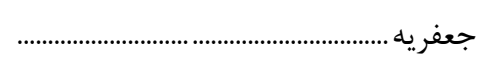 \\
\hline DIV & VQF & vVI & IDTD & 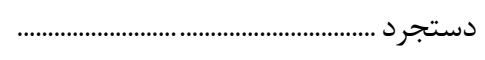 \\
\hline k\&q & $9 \Delta \varphi$ & VHF & $1 r q$. & 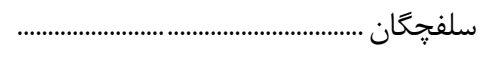 \\
\hline rogqve & Q9191V & $9 \cdot 9 \Delta 41$ & $|r \cdot| \mid \Delta \Lambda$ & 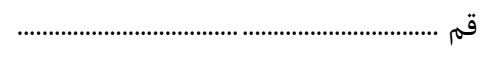 \\
\hline r g g. & $\Delta \Delta V \cdot$ & $9 \cdot 9 V$ & $1199 \mathrm{~V}$ & قنوات ............................................................ \\
\hline $14 \lambda$ & $r T \Delta \Delta$ & tiAt & FArV & 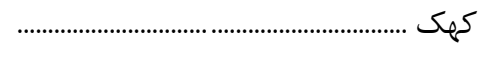 \\
\hline rrVre. & $\Delta \& 1 \cdot 1 T$ & avrlev & lirereq & 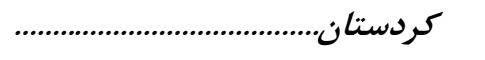 \\
\hline riा & 1111 & 1194 & $r+\Delta$ & 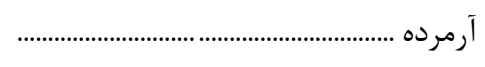 \\
\hline 911 & IQFA & $19 Y \Lambda$ & rive & اورامان تخت .............. \\
\hline
\end{tabular}


ظ - جمعيت و خانوار شهرهاى كشور به ترتيب استان (دنباله)

\begin{tabular}{|c|c|c|c|c|}
\hline خانوار & 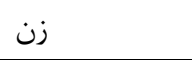 & 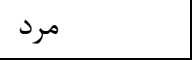 & جمعيت & 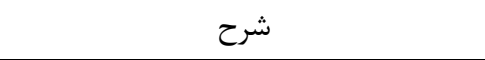 \\
\hline 19. & TAS & TAT & 0.9 & 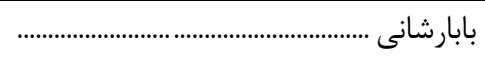 \\
\hline$r \cdot v \notin r$ & $\Delta \& G \cdot q$ & $\Delta \Delta G \cdot q$ & $11 \cdot r 11$ & 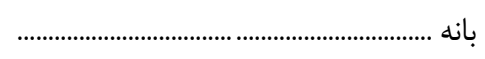 \\
\hline TrI & $\psi_{\wedge}$. & $\Delta F$. & $1 \cdot r \cdot$ & 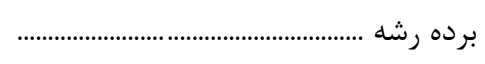 \\
\hline $1 \cdot V \Delta$ & $\mid \Delta G \Lambda$ & IsTa & r & 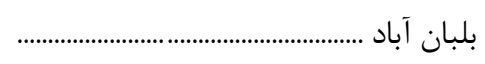 \\
\hline$r \cdot r$ & VIV & $\Lambda \cdot 1$ & 1011 & 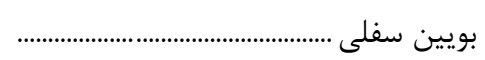 \\
\hline $\mid \Delta V \cdot \Delta$ & rFAVq & TQITL & $\Delta \cdot \cdot l f$ & 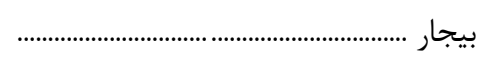 \\
\hline rgt & $\Delta 91$ & $9 \cdot 1$ & 1199 & 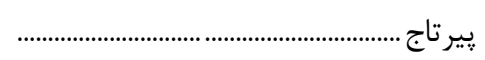 \\
\hline$\Delta F_{1}$ & 114 & ^ז & 1940 & توף آغاج ................................................... \\
\hline lre & 194 & rघl & $\varepsilon \Delta \Delta$ & جناره .................................. \\
\hline 999 & $11 r 9$ & $1 \cdot 9$ & rTIQ & دزج..................................... \\
\hline 1974 & TrGA & TFED & gVIT & 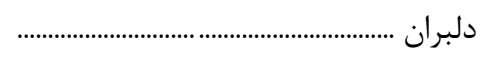 \\
\hline$v V \cdot \Lambda$ & ITVET & Irra. & rDQ9T & 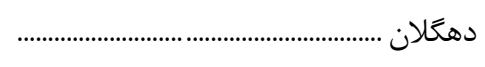 \\
\hline qศqv & $19 \vee \wedge 9$ & IVTrI & $r r \cdots v$ & 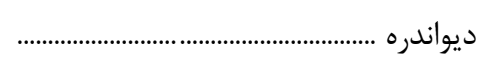 \\
\hline 490 & r & $1 \cdot \Delta \Lambda$ & $r \cdot 91$ & 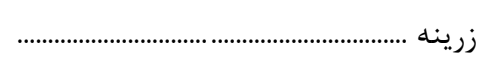 \\
\hline 1491 & rFqu & raYA & $\Delta|r|$ & سروآباد ............................................................... \\
\hline trit & $r \Delta \Lambda \mu$ & rqו & ११९s & 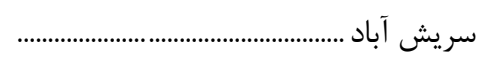 \\
\hline FAFAM & NTtYF & Arqur & $19 \Delta T \Delta \Lambda$ & 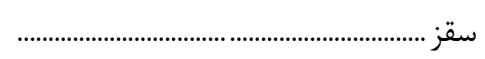 \\
\hline ITGTK. & $r \cdot r V \cdot \Lambda$ & $r \cdot \Lambda \cdot \Delta q$ & FITVGV & 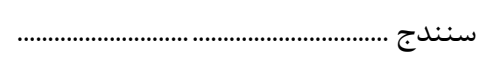 \\
\hline rq. & טqT & $v \cdot 9$ & ir.t & 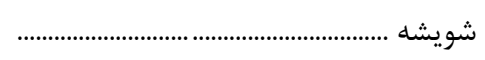 \\
\hline$\wedge \cdot \cdot$ & IDVT & $10 r 9$ & $r 1 \cdot 1$ & صاحب........... \\
\hline rFIII & ґ^৭^. & тат৭я & VATVG & قروه ..................................... \\
\hline $19 \Delta F V$ & TVYF. & rqurv & $\Delta V \cdot V V$ & 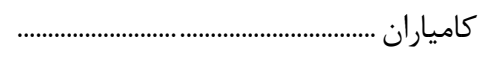 \\
\hline TVQF & 9419 & 994 & $1 r \cdot 09$ & 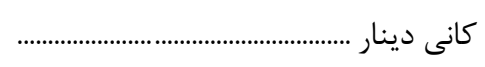 \\
\hline ra八 & arv & $9 \Delta V$ & IrAF & 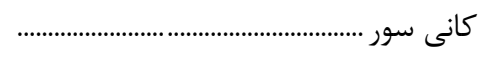 \\
\hline rquя & ध99VD & 999V१ & 1 ITSQAF & 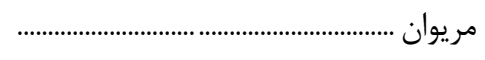 \\
\hline $1 \cdot k V$ & $19 V$. & $1 V^{\prime} \cdot$ & rrv. & مو جش ....................................................... \\
\hline $1.9 \mathrm{~V}$ & 1819 & $|V V|$ & req. & ياسوكند ............................................................ \\
\hline$\Delta \Delta|| F \mid$ & $91 \cdot .18$ & qFADVI & IADASAT & 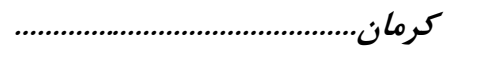 \\
\hline rAIF & FAFD & 4990 & $9 \wedge \mathrm{F}$. & اختيار آباد ................................................... \\
\hline 1901 & rrva & requ & $9 \wedge 9 \wedge$ & ارزوييه.......................................................... \\
\hline$I r M \Lambda$ & rite & rTV & Fatr & امين شهر ....................................................... \\
\hline iq4. & VQAV & vaps & IDSTr & 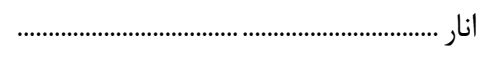 \\
\hline $1 T \Delta \Delta$ & 1981 & $r \cdot v \cdot$ & $F \cdot F_{1}$ & 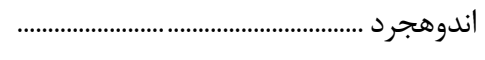 \\
\hline 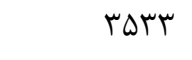 & rqr. & GYAV & $1 \cdot r \cdot v$ & 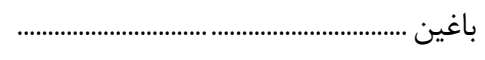 \\
\hline l.ru & IVIFF & IVTrR & MFDIV & بافت ..................... \\
\hline$v V \cdot q^{c}$ & ITFES & $1 T V \cdot 9$ & TQIDT & 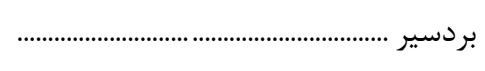 \\
\hline VนヘS & $111 \ldots$ & 11991 & TYYAI & بروات ............................................................. \\
\hline lfFF & rTAD & TMTt & FoIV & 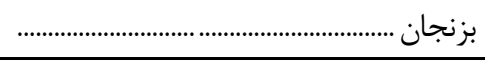 \\
\hline
\end{tabular}


ظ ـ جمعيت و خانوار شهرهاى كشور به ترتيب استان (دنباله)

\begin{tabular}{|c|c|c|c|c|}
\hline خانوار & 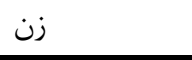 & 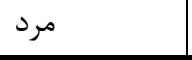 & جمعيت & شرح \\
\hline $11 \cdot 9$ & IVG. & IVVF & rark & بلورد.................................................................... \\
\hline Ifrq & TATV & TVVV & $\Delta r \cdot r$ & 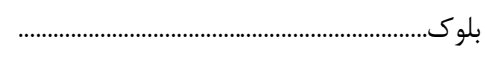 \\
\hline$r q \cdot k r$ & GTTGN & GDITA & irvrqs & 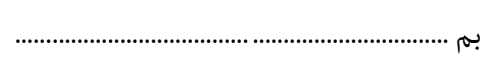 \\
\hline IFVF & TFYD & rAt. & $\Delta T \& \Delta$ & 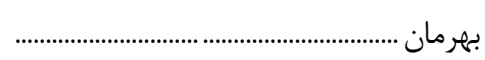 \\
\hline rब१९ & r१я & G. Ft & $\wedge \cdots \Delta$ & 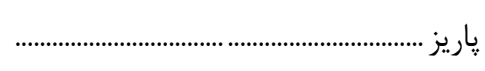 \\
\hline 198. & TrED & rFAD & GVa. & 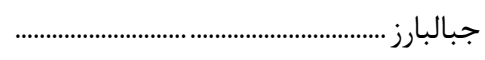 \\
\hline $11 \Delta T$ & $1 \wedge V$ & IVFF & $r q \cdot v$ & 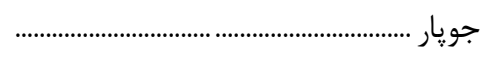 \\
\hline 994 & $19 \Delta \Delta$ & $|V \wedge|$ & rete & 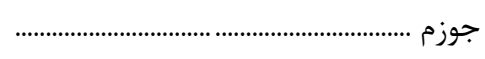 \\
\hline 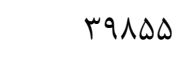 & $q \pi \Delta \Delta \Delta$ & GQAVE & Ir.krq & 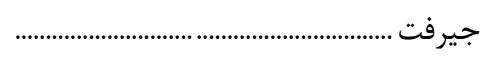 \\
\hline IVr. & rی१९ & T৭९। & $\Delta \wedge \varepsilon$ & جترود ................ \\
\hline IEFT & TQYI & rq०. & $\Delta \& V I$ & 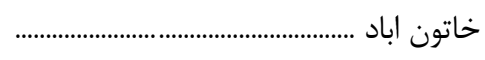 \\
\hline$\vee \wedge 9$ & 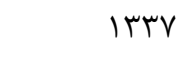 & $\mid r q 1$ & TETA & 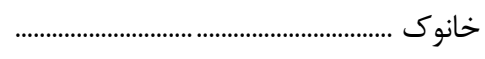 \\
\hline VVV & $I r \cdot V$ & $|r V|$ & rEVA & 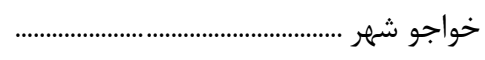 \\
\hline Teta & 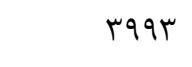 & Froq & NTAT & 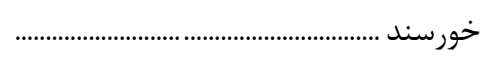 \\
\hline rrsq & $\Delta 1 M$ & DFAT & $1.9 V \cdot$ & درب بهشت ........................................................... \\
\hline $9 \Delta \Delta$ & 1099 & 1991 & MTME & دشتكار ............................................................. \\
\hline ITrK & $r \cdot v \wedge$ & $r \cdot \Delta r$ & fir. & 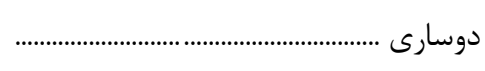 \\
\hline$|9 T|$ & 1901 & $r \cdot q q$ & $\Delta \cdot F \Delta$ & دهج .......................... \\
\hline$r \cdot \Delta l$ & 99.9 & $99 \Delta \mathrm{V}$ & 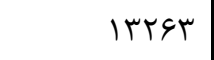 & 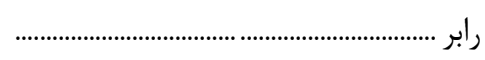 \\
\hline gNVE & lirk. & $11 r k 9$ & trkta & 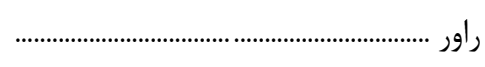 \\
\hline$r \cdot \varphi l$ & 0191 & $\Delta \cdot 90$ & $1 . r \wedge S$ & 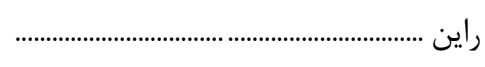 \\
\hline$k V \cdot 1 r$ & $V \wedge r \cdot r$ & $\Lambda r G \cdot V$ & 1919.9 & رفسنجان ............................................... \\
\hline rVAT & VMFT & $V F \cdot \Delta$ & IfYeV & 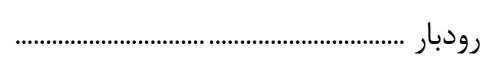 \\
\hline $1 r \cdot 1$ & TYAT & rMIN & $r \Delta \Lambda$. & ريحان -...-1) \\
\hline IEVTT & raArF & $r \cdot \Delta r \varphi$ & $q \cdot r v \cdot$ & 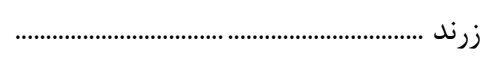 \\
\hline TFYG & FrND & FrAT & $\wedge \Delta ९ \wedge$ & 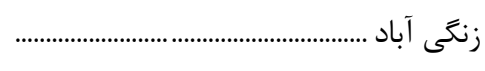 \\
\hline IVqT & MFTF & rell & sヘra & زهلكوت ............................................................ \\
\hline 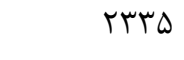 & ergl & FNIF & 9115 & زيدآباد............................................................... \\
\hline$\Delta \wedge \vee \Delta \varphi$ & $9 V \cdot \varphi \wedge$ & $1 \cdot r 9 \Delta 9$ & $1997 \cdot F^{4}$ & سيرجان ......................................................... \\
\hline$|94|$ & rबAr & TATF & DTIV & 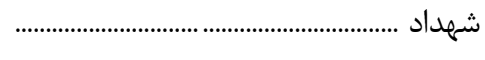 \\
\hline IQTVQ & TQIV. & reYQ. & DIST. & 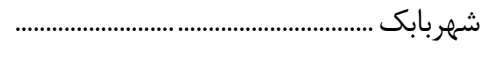 \\
\hline$\vee \Delta \Lambda$ & Ir.r & ITVD & reVA & صفاييه .............................................................. \\
\hline QT^D & ^৭८ & $9 r \cdot 1$ & $|\wedge| \wedge \Delta$ & عنبر آباد .............................................................. \\
\hline IrFT & TYAF & rrva & FA\& & 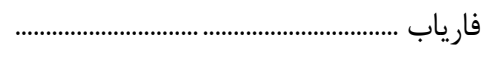 \\
\hline $1 \wedge \Delta$. & rafq & rrty & GヘVG & فهرج ........................................................... \\
\hline Taru & GATV & GQFT & 14199 & قلعه كنج ................................................... \\
\hline 1101 & 1990 & $r \cdot 9 \Delta$ & $4 \cdot 9$. & 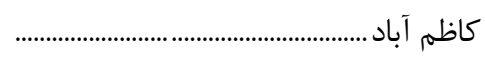 \\
\hline IETEVV & $r 90 \cdot r$ & TYYYID & DrVYIA & 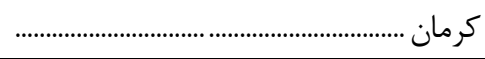 \\
\hline
\end{tabular}


ظ ـ جمعيت و خانوار شهرهاى كشور به ترتيب استان (دنباله)

\begin{tabular}{|c|c|c|c|c|}
\hline خانوار & 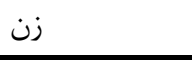 & مرد & جمعيت & 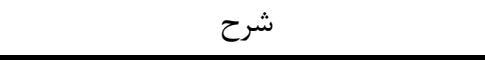 \\
\hline$r T \cdot q$ & rqVF & rqv. & VGFY & 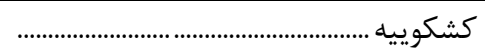 \\
\hline rTas & $\Delta r \cdot q$ & DFAT & $1 \cdot \sqrt{ } \& 1$ & 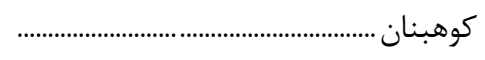 \\
\hline Ifraf & roVIV & $r \& 9 \cdot V$ & DTETF & 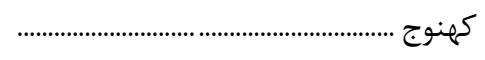 \\
\hline ITSV & rT\&l & trAT & FAFT & كيانشهر ......................................................... \\
\hline r^६q & kq4q & $\varepsilon \Delta \Delta \varphi$ & $9 T \cdot \Delta$ & 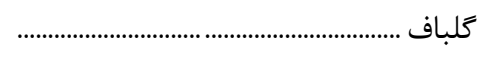 \\
\hline $\mid V I I$ & $r r^{2}$ & tret & DFFD & 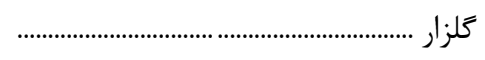 \\
\hline 1199 & metr & rVQV & 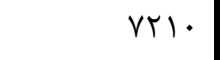 & كنبكى ...................... \\
\hline$|r| f$ & rlle & 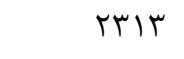 & ferg & 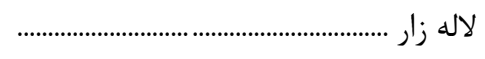 \\
\hline QVIr & q४वर & १६फा & 19FT & ماهان ....................................................... \\
\hline FAYA & $1 . .91$ & $1.9 \Delta r$ & $r \cdot V \cdot \cdot$ & 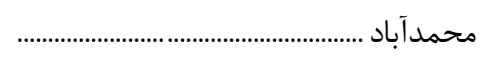 \\
\hline 1109 & 1901 & $19 \vee 9$ & rqт. & محى آباد .................... \\
\hline VFe & $14 V q$ & 1491 & rAv. & 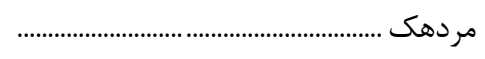 \\
\hline IAGT & 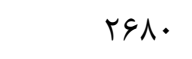 & TYAV & ఎ१९V & 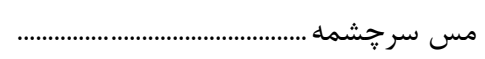 \\
\hline frif & VAYF & V^l. & IDSTK & منوجان ..................................................... \\
\hline$\Delta \wedge q \uparrow$ & 9901 & I.rIT & $r \cdot \mid 94$ & نجف شهر ........................ \\
\hline IDFD & TAFF & reVA & DTrT & نرماشير ............................ \\
\hline ver & $11 \Delta T$ & IrVF & TFte & نظام شهر ............. \\
\hline TEY & rVar & rیґی & ve.. & 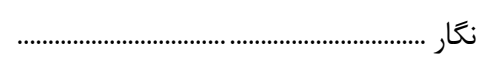 \\
\hline lemt & rAIA & treF & $\Delta \Delta \& Y$ & 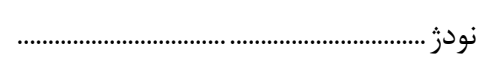 \\
\hline rוז & FAV & $\Delta r$. & $1 \cdots v$ & هجدى \\
\hline $1 \cdot r k$ & 1919 & IETD & 吾 & هماشهر .................... \\
\hline iq. & Vre & VIe & lfar & 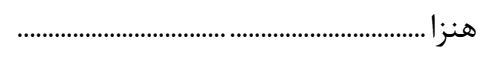 \\
\hline IOVT & tYFF & rA\& & $\Delta \varphi \cdot v$ & 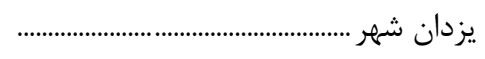 \\
\hline$F F \cdot q \cdot F$ & vrirar & vrrerrer & $|F \& 1 \&| \Delta$ & 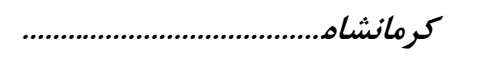 \\
\hline rVt & grv & $\wedge \notin \Delta$ & $10 \cdot r$ & 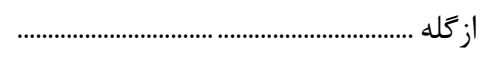 \\
\hline$r \varepsilon \Delta \cdot r$ & fFras & FDVGl & $q \cdot \Delta \Delta q$ & 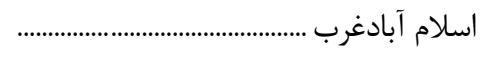 \\
\hline 191 & 1949 & $|\Delta F|$ & riAv & بانوره \\
\hline$r \Delta V$ & VET & VVI & 1014 & 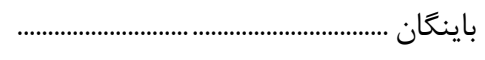 \\
\hline 11990 & TFY & TQID & pqut & بيستون .......................................................... \\
\hline Vart & ITVYF & $I r \cdot r V$ & rQVVI & ياوه ................................................................ \\
\hline$r \cdot r q$ & VTrI & $v \notin \lambda$. & $\mid F v \cdot 1$ & تازه آباد ............................................................ \\
\hline $10 \cdot 1$ & r\&AIr & TVQFI & $\Delta F T \Delta F$ & جوانرود .......................................................... \\
\hline rVV & gVF & gसr & iriv & 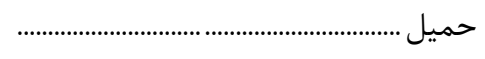 \\
\hline TQT & rq1 & prt & NTr & 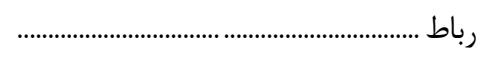 \\
\hline VITr & 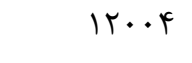 & ITATR & TYATY & روانسر ......................................................... \\
\hline $11 \cdot 1$ & 1990 & 1945 & rq.v & ريجاب ........................................................ \\
\hline$I T \wedge \Delta \cdot$ & rTD9D & TrAMG & FOFAI & سريل ذهاب ................................................. \\
\hline 111 & lete & $14 v q$ & rqוז & سرمت.......................................................... \\
\hline
\end{tabular}


نتايج تفصيلى سرشمارى عمومى نفوس و مسكن _ه |

\begin{tabular}{|c|c|c|c|c|}
\hline خانوار & 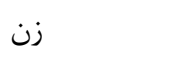 & 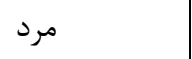 & جمعيت & 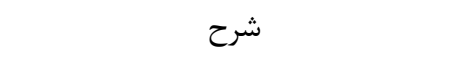 \\
\hline TrQ & $\Delta G Y$ & FAF & $1.4 \lambda$ & 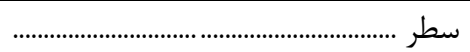 \\
\hline 14999 & $r 1909$ & rtrqu & FFTOS & سنقر ......................................................... \\
\hline 9 & r & IVV & $1 \wedge \cdot$ & 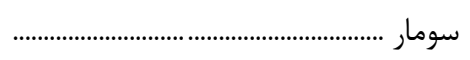 \\
\hline 1.49 & IVAT & IVVe & $r \Delta \Delta \Lambda$ & 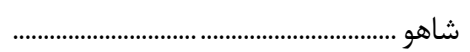 \\
\hline $1.9 \wedge 0$ & $I V G \cdot \Delta$ & IVq.r & $r \Delta \Delta \cdot \wedge$ & صحنه .................... \\
\hline DFV & 1949 & QDTV & 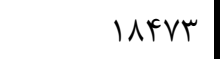 & قصرشيرين ............... \\
\hline rAGYAF & FVTAVA & $k V k \cdot V r$ & 944901 & 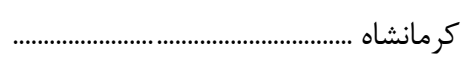 \\
\hline rmpq & rq১. & rAץA & 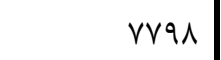 & 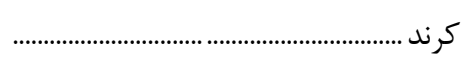 \\
\hline IDVGT & rDЬ१९ & $r \Delta V \Delta Q$ & DITAT & كنگَاور .................................. \\
\hline 114. & 1975 & $r \cdot \Lambda \Delta$ & $r \cdot . v$ & 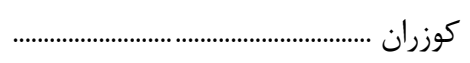 \\
\hline ^r山 & Iraf & ITVD & rяTq & كودين ..................................................... \\
\hline$I T \cdot \Delta$ & $r \cdot 11$ & t.rt & $r \cdot \Delta \cdot$ & 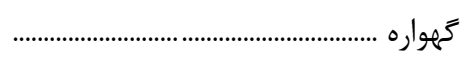 \\
\hline 9994 & $\| r \mid 9$ & 11110 & 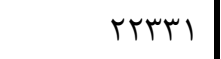 & كيلانغرب................................................... \\
\hline$r \cdot 9$ & rar & ret & 990 & 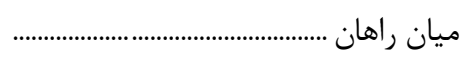 \\
\hline irra & INAT & וגז. & 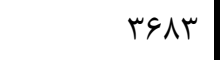 & نودشه ...................................................... \\
\hline grq & $9 \Delta \varphi$ & १९ा & 1949 & 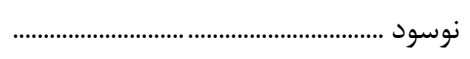 \\
\hline$|r \wedge| F$ & THIVE & rIGYT & fFIfS & 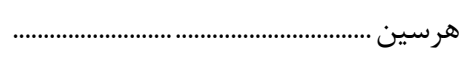 \\
\hline 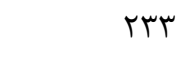 & rAF & FT. & $\Lambda \cdot F$ & 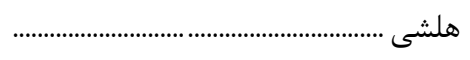 \\
\hline $1 \cdot r r v$. & $19 \Delta r A$. & $r \cdot|81|$ & ravkgi & 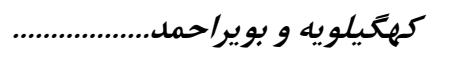 \\
\hline rATI & QrAG & DrVA & $1 \cdot \operatorname{Var}$ & 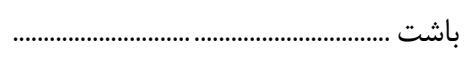 \\
\hline grq & $11 \cdot v$ & $11 \mathrm{Vr}$ & TrAF & 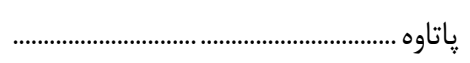 \\
\hline एव५q & VATI & Vด৭V & $\mid \Delta T I \Lambda$ & 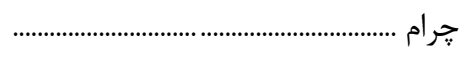 \\
\hline 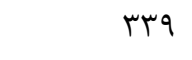 & $\Delta \Delta V$ & $4 \cdot v$ & 1194 & جيتاب ................... \\
\hline reVV. & $p \vee q \cdot r$ & FANTF & १९VरА & 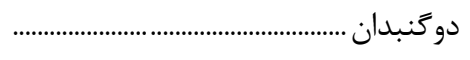 \\
\hline $14 . .9$ & $r \Lambda \cdot \Delta \Delta$ & r८৭1। & $\Delta V \cdot r q$ & 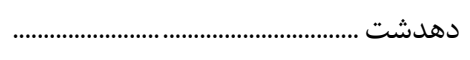 \\
\hline irat & TVVT & $r \cdot 19$ & $\Delta \vee 91$ & ديشموك .................... \\
\hline QHe & $1 \cdots$ & 990 & 1990 & 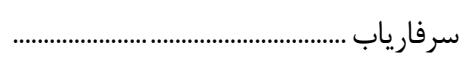 \\
\hline 1990 & rTAl & rIQV & grts & 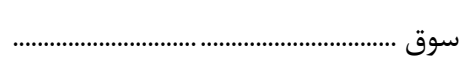 \\
\hline rt.. & rAFQ & f.l. & $\vee \wedge \Delta \Delta$ & 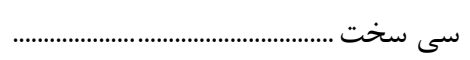 \\
\hline$v \Delta \cdot$ & $19 \cdot 4$ & 1990 & rrsq & 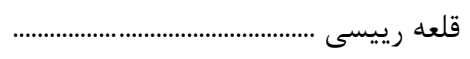 \\
\hline ITS & $r \wedge \cdot$ & red & $\Delta F \Delta$ & 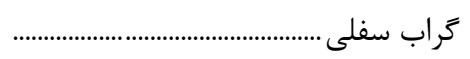 \\
\hline rT.G & gMTA & GKTV & ITVRT & 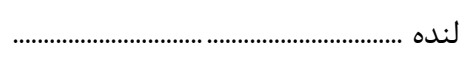 \\
\hline 0.91 & qVฯV & $1 \cdots 9$ & $19 \wedge \Delta \vee$ & 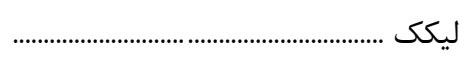 \\
\hline FTIQ & $\wedge \Delta 9 \Delta$ & qצAr & $1 \Lambda \cdot \vee \wedge$ & مادوان .......................................................... \\
\hline vav & $1 \Delta \Delta \varphi$ & $1 \Delta \vee q$ & rira & 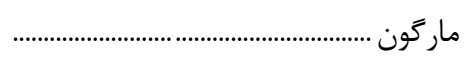 \\
\hline MYAD. & $991 \cdot 0$ & GAFTV & IrFart & 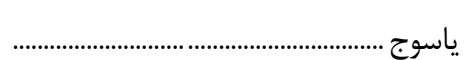 \\
\hline r. Irvr & fqvq. 1 & $f 91 \cdot 1 f$ & $99 \Delta \& 10$ & 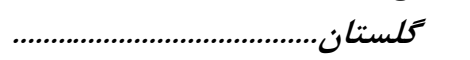 \\
\hline $1 \pi r \cdot 9$ & rI99r & rivas & erve. & 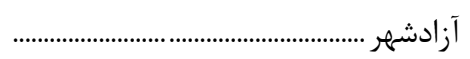 \\
\hline
\end{tabular}


ظ ـ جمعيت و خانوار شهرهاى كشور به ترتيب استان (دنباله)

\begin{tabular}{|c|c|c|c|c|}
\hline خانوار & 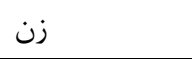 & 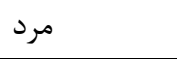 & جمعيت & 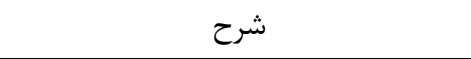 \\
\hline$q \uparrow q 1$ & IVrq. & IVVTS & rQI19 & 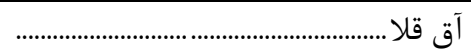 \\
\hline 199. & $r \Delta \Delta F$ & repq & $v \cdot r$ & 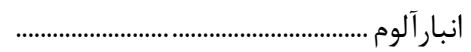 \\
\hline ט१ & IrUT & ||$f \mid$ & rFqF & 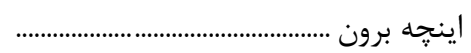 \\
\hline$|F \Delta| r$ & T\&VAI & TVT. & $\Delta \mu q \nabla$. & 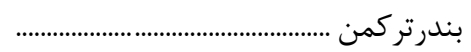 \\
\hline sVia & $1 \cdot r \cdot \Delta$ & 1. \&rV & T.VAT & بندر ز ز.................................................... \\
\hline ITIV & rMgV & TYID & FVAT & تاتارعليا ........................................................ \\
\hline TRE. & rदar & TVTD & VAIV & 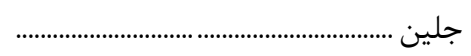 \\
\hline Trta & DFrD & DFFT & $1 \cdot \wedge \vee \wedge$ & 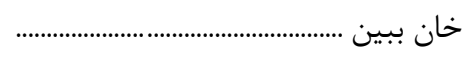 \\
\hline TFAT & (1).. & $f \cdot \lambda f$ & $11 \wedge \mathrm{F}$ & 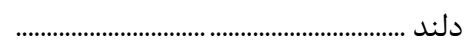 \\
\hline trVt & GIVF & GTAT & ITFYE & 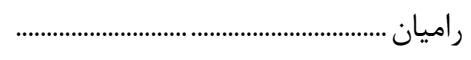 \\
\hline TFNT & rیוl & rVYA & $\vee \Delta \wedge १$ & 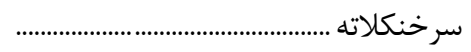 \\
\hline$I T \Delta \Delta$ & rIIF & $r \cdot \wedge 9$ & FT. r & 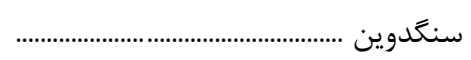 \\
\hline kqqu & $\Lambda F \wedge$ & AVIV & $I V T \cdot \Delta$ & 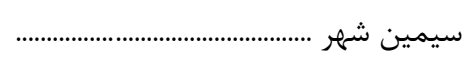 \\
\hline 19900 & TGGTD & TATIT & DrATA & 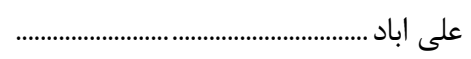 \\
\hline$\Delta \wedge 9 q$ & $99 \wedge \wedge$ & qVVr & 19481 & 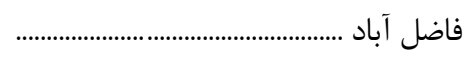 \\
\hline 191. & ravr & $r \Lambda \cdot \Delta$ & $\Delta V V V$ & 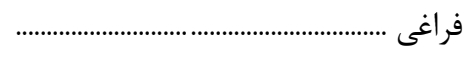 \\
\hline $\mid r q 4$ & I9GTT & $r \cdot r \Delta Q$ & rq11। & 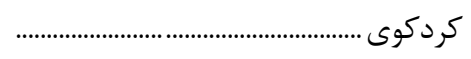 \\
\hline $1 \cdot$ rke & $1 \Lambda \cdot \Lambda V$ & $11 \cdot 19$ & ralve & 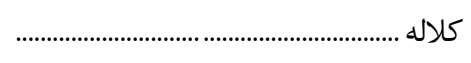 \\
\hline 9999 & $119 \Delta V$ & IIVTr & rmat & 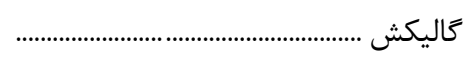 \\
\hline 111.99 & IVDAVq & IVFVqV & $r \Delta \cdot q V G$ & 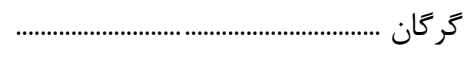 \\
\hline$\Delta 1 r^{\prime}$ & $q 49 q$ & 9995 & 19191 & كميش تيه ............................................... \\
\hline FFVYI & ve.11 & $\vee \Delta \wedge १ 9$ & 10191. & 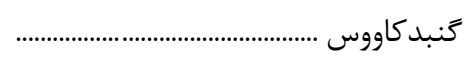 \\
\hline$r \cdot V t$ & FATt & frrq & $\wedge \& \vee 1$ & 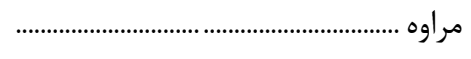 \\
\hline ITUT & 1991 & $r \cdot 11$ & $4 \cdot . q$ & 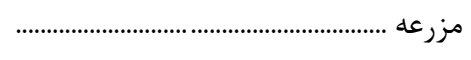 \\
\hline$\wedge 9 \wedge$. & IFATT & IOTEK & $r \cdot \wedge \Delta$ & مينودشت .................... \\
\hline TMFY & ra९d & fivr & $\wedge ו r \wedge$ & 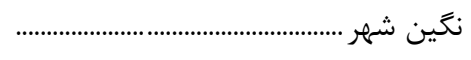 \\
\hline $9 \Delta 9$ & larV & IFAT & rq८9 & 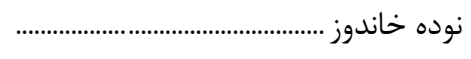 \\
\hline rmIS & rr. & rryq & 990. & 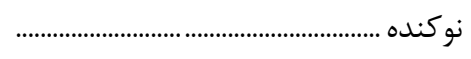 \\
\hline arveir & $1 \cdot \Delta \Delta \Delta \&$ & raver. & $18 \cdot r \cdot r \varepsilon$ & 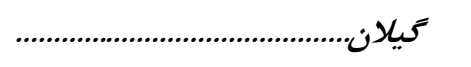 \\
\hline 19999 & $r \Delta V \cdot \varphi$ & raAVr & $\Delta 1 \Delta \vee q$ & 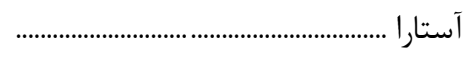 \\
\hline IDSVQ & TrDQY & ThteF & fqqfi & 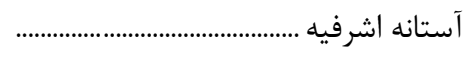 \\
\hline VTV & $1 .+4$ & $1 \cdot \lambda r$ & TIYA & احمدسر \\
\hline TTVI & 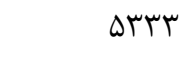 & DrAV & $1 \cdot V T \cdot$ & 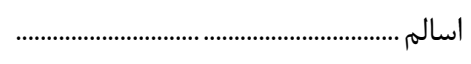 \\
\hline sar & q४. & $99 \wedge$ & 1941 & 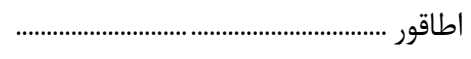 \\
\hline DTEA & VVGV & VAVV & IDFFF & 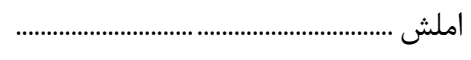 \\
\hline IVAT & TANV & TAFT & $\Delta V r q$ & 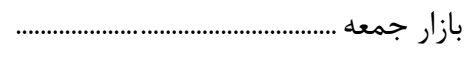 \\
\hline$\Delta \Delta 9$ & NIV & $\vee 90$ & 1814 & 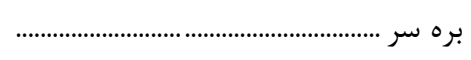 \\
\hline$\langle l \cdot \Delta r$ & DqVGT & $\Delta M \Lambda \cdot r$ & $11 \wedge \Delta \& F$ & 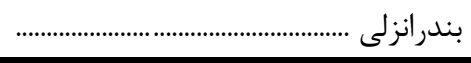 \\
\hline
\end{tabular}


نتايج تفصيلى سرشمارى عمومى نفوس و مسكن _ه |

ظ - جمعيت و خانوار شهرهاى كشور به ترتيب استان (دنباله)

\begin{tabular}{|c|c|c|c|c|}
\hline خانوار & 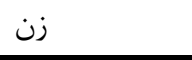 & مرد & جمعيت & 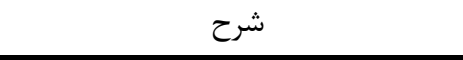 \\
\hline TATS & ragr & $r \cdot \Delta r$ & $1 \cdot 19$ & 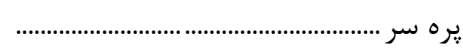 \\
\hline fqr & VVG & VrF & $|0|$ & 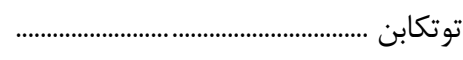 \\
\hline v91 & 1199 & llar & ret. & 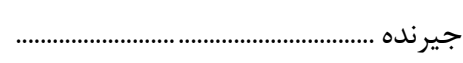 \\
\hline TVQ. & $r \cdot \wedge r$ & fif. & ATrF & 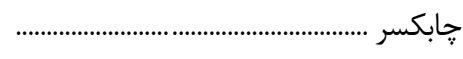 \\
\hline rirv & grra & Fa. 1 & MAF. & 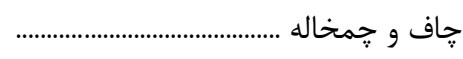 \\
\hline $19 \cdot 4$ & TVGT & tVat & $\Delta \Delta \Delta F$ & 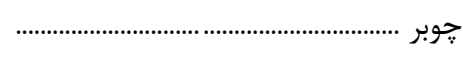 \\
\hline 1199 & 1994 & rrqa & Fral & 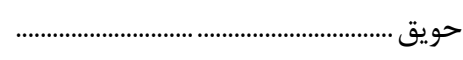 \\
\hline TEV. & rఎ१९ & rets & VTFS & 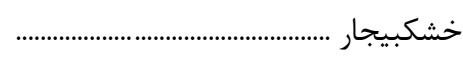 \\
\hline VIfr & $1 \cdot 4 \cdot 1$ & $1.4 \wedge 9$ & $r \cdot \wedge 9 \vee$ & 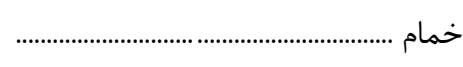 \\
\hline$\Delta G Y$ & $\wedge \Delta \varphi$ & Avr & IVra & 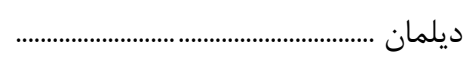 \\
\hline$v \notin q$ & $1 \cdot k V$ & $11 \cdot v$ & TIOF & رانكوه ............................... \\
\hline$r \Delta \cdot v$ & $\Delta r \cdot q$ & DTET & $1 \cdot \Delta V I$ & 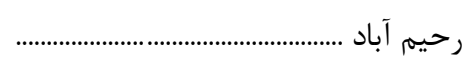 \\
\hline th & gVrF & $V \cdot I T$ & IrVte & رستم آباد ................................................. \\
\hline trNIFt & mergat & (1) & $9 \vee 9990$ & رشت \\
\hline GTIT & qVदr & $q \vee \Delta \varphi$ & 19019 & 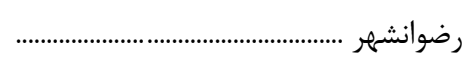 \\
\hline$r \Delta \Delta q$ & $\Delta T \Delta q$ & DTFD & $1 \cdot \Delta \cdot e^{f}$ & رودبار ............................................................. \\
\hline ITr. & $19 V 9$ & $1 V 90$ & ryal & 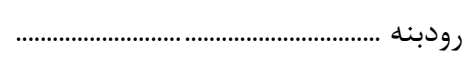 \\
\hline 14191 & $19 \cdot 01$ & INqץV & 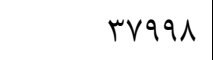 & 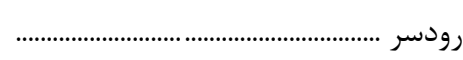 \\
\hline FTMA & Grद9 & grif & $\operatorname{Ir\Delta \Lambda T}$ & 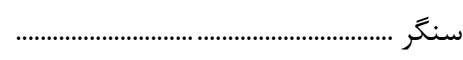 \\
\hline \&V१९ & $1.99 k$ & १人५. & 19954 & 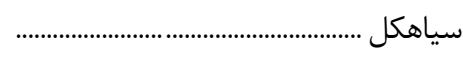 \\
\hline r\$91 & 4119 & $4 \cdot 91$ & $\wedge 1 \wedge F$ & شفت ............................... \\
\hline $1 \wedge \Delta \Delta$ & TOIV & $r \Delta \wedge \Delta$ & $\Delta 1 \cdot r$ & 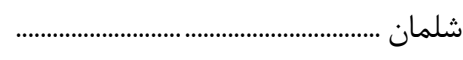 \\
\hline $\mid$ DrT & rrole & rTDSV & $q v \cdot \wedge r$ & 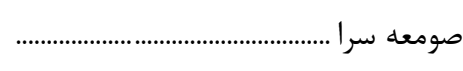 \\
\hline $111 \times 99$ & $|v 9 v|$ & ivAv. & $r \Delta \wedge \& \mathbf{l}$ & 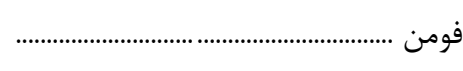 \\
\hline prrq & GTYA & s|r| & IrrVq & 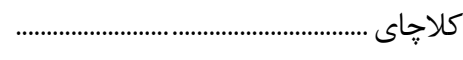 \\
\hline rFa. & $\Delta \cdot V r$ & $r q \Delta F$ & $1 \cdots r q$ & 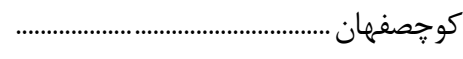 \\
\hline$r T \Delta \Delta$ & TTIT & MTYD & GYOV & 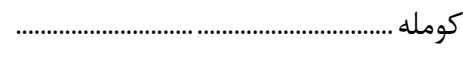 \\
\hline $0 \cdot r v$ & $V \cdot 9$. & 9995 & IK.Tr & 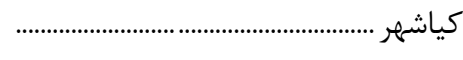 \\
\hline 191. & $T F \cdot 1$ & rerq & FAF. & 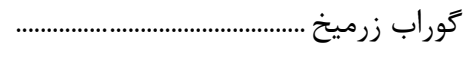 \\
\hline myYqV & $\Delta \cdot 9 \Delta \cdot$ & $\Delta \cdot 1 r r$ & $1 \cdot 1 \cdot V r$ & 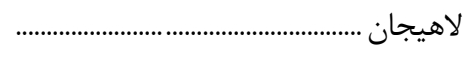 \\
\hline trat & $\Delta r \cdot r$ & Drre & $1 \cdot \Delta r q$ & 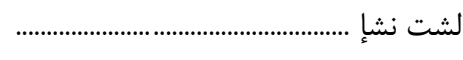 \\
\hline TRTIN & ragrर & rqArт & vafys & 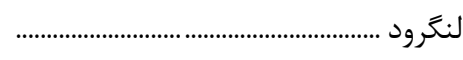 \\
\hline$r 9 \Delta \wedge$ & GMr & 9994 & Ir.rt & 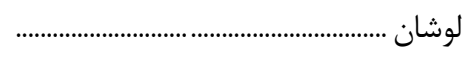 \\
\hline rqVV & refa & rYAl & vers & لولمان ....................................................... \\
\hline Aוג & DGTA & $\Delta q \cdot V$ & l1rra & لوندويل ..................................................... \\
\hline 1194 & IVqF & INAT & raty & 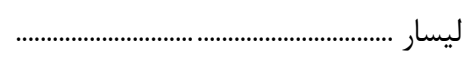 \\
\hline$\Delta \vee \Delta q$ & 19FV & $\wedge 9 \Delta F$ & $1 \vee 9 \cdot 1$ & ماسال ............................................................ \\
\hline IfV & $r \cdot r$ & 191 & r & ماسوله .................... \\
\hline
\end{tabular}


ظ - جمعيت و خانوار شهرهاى كشور به ترتيب استان (دنباله)

\begin{tabular}{|c|c|c|c|c|}
\hline خانوار & 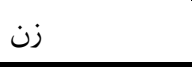 & 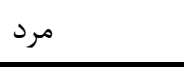 & جمعيت & شرح \\
\hline Drs & $\Delta T_{1}$ & 114 & $19 \pi \Delta$ & 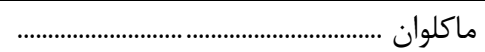 \\
\hline TMEF & 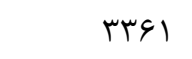 & rrve & gVra & 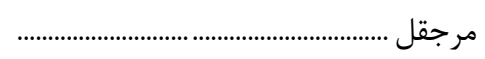 \\
\hline 490 . & VVrq & $\vee q \cdot 1$ & lDST. & 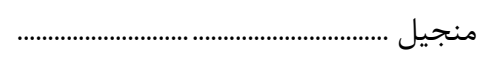 \\
\hline 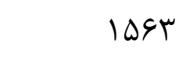 & 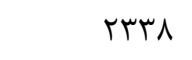 & r199 & Farv & واجار كاه ....................................................... \\
\hline IGArt & $r V \cdot \Lambda l$ & $r V \cdot q V$ & DFIVA & 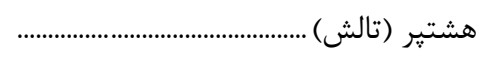 \\
\hline rrmabf & $\Delta \& F V q \Delta$ & $\Delta r \cdot 11 r$ & $11 r<q \cdot 1$ & 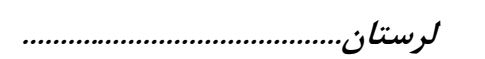 \\
\hline $\mid F T \cdot \Lambda$ & rMDSt & rrqpV & eVFis & 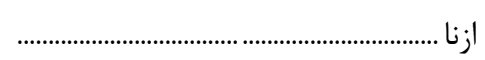 \\
\hline IVen & rیו1 & $r V \cdot q$ & $\Delta \Delta T$. & 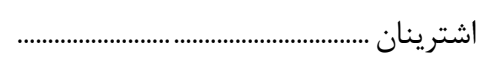 \\
\hline 9 qq4 & $199 \Delta T$ & 199.9 & $r r \Delta \Delta \Lambda$ & 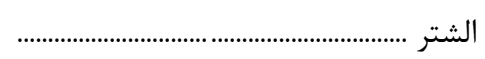 \\
\hline rDSts & Frvil & $r \Delta \Delta r V$ & 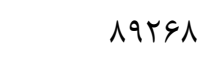 & 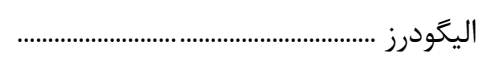 \\
\hline velis & IIVYKT & 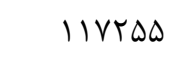 & rrFqqV & 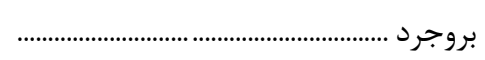 \\
\hline erl & $\Lambda \Delta F$ & $\wedge ९ 9$ & IVT. & 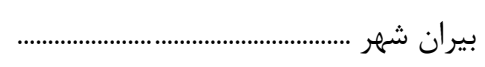 \\
\hline VDGY & מזוTו & Irtra & TETAT & يلدختر ........................................................ \\
\hline 4.9 & $11 \% F$ & $1 \cdot 19$ & THt & 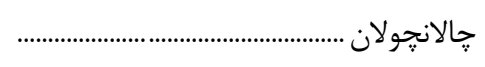 \\
\hline$|\varepsilon| f$ & $r \cdot r q$ & r.१९ & qIro & جقابل ......................................... \\
\hline $1.9 r \pi 1$ & 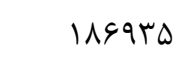 & $|\wedge 9 \uparrow \wedge|$ & TVMFIS & 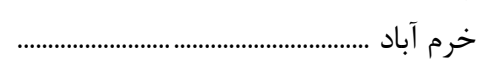 \\
\hline grt & $1 . \Delta F$ & $1 \cdot v V$ & ITIT & درب كنبد ................................................... \\
\hline$r \Delta \Delta r_{q}$ & G. TFt & 91490 & ITISHA & دورود ....................... \\
\hline 110 & 1 IrG & $14 \cdot 9$ & TVVG & 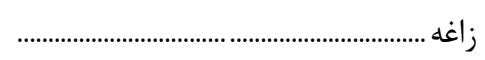 \\
\hline $1 \cdot 9$ & $|4| 1$ & 11499 & rqIV & 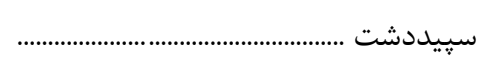 \\
\hline FVA & $\Lambda \Delta S$ & $\Lambda \Delta \vee$ & IVIT & 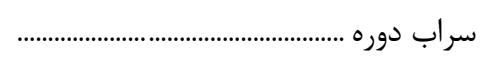 \\
\hline FTt & VTT & $1 \cdot 9$ & $|\Delta M|$ & شول آباد ...................................................... \\
\hline $9 \Delta \wedge$ & 19т9 & IVe. & 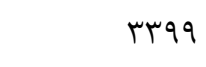 & فيروزآباد ................................................... \\
\hline TFTEV & fyilq & fqq. & 19.91 & كوهدشت...................................................... \\
\hline$r \cdot \Delta V$ & rAvı & ґ^q. & VVGA & كوهنانى ................................................... \\
\hline 994 & 1091 & $I V \cdot r$ & rrqD & 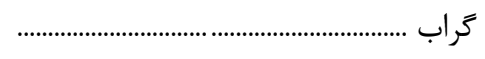 \\
\hline TMFY & rVF. & एवाद & V\&DG & 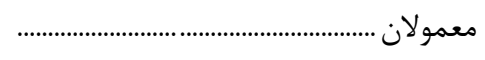 \\
\hline$\Delta \Delta \cdot$ & $9 \cdot 9$ & 910 & $|\wedge r|$ & مومن آباد .............................................................. \\
\hline $1 \wedge 9 \cdot V$ & rTIG & rmak & $9 \Delta \Delta F V$ & نور آباد ............................................................ \\
\hline 819 & $1 .+4$ & $1.4 \Delta$ & $r \cdot \wedge V$ & 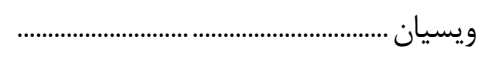 \\
\hline rVq & Fre & fre & $\wedge \vee$. & هفت حشمه ............................................... \\
\hline sTreql & qfyegr & $q F q \Delta V \varepsilon$ & IAqvrre & 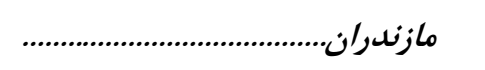 \\
\hline krs & 910 & $\Delta \vee \wedge$ & 1194 & 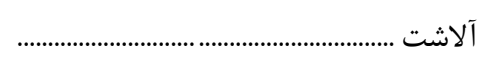 \\
\hline 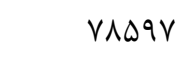 & INMTK & $111 \mathrm{v} \cdot 9$ & THVATA & آمل ................................................................ \\
\hline 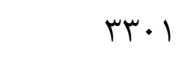 & $\Delta \cdot \Delta \Delta$ & DTVT & 1. TrV & ارطه ................................................................. \\
\hline $11 \cdot 9$ & TAVt & rی99 & $\Delta \vee 9 \Lambda$ & 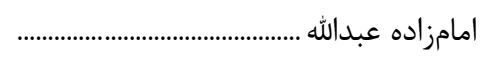 \\
\hline $1 \cdot 1 r$ & $\mid \Delta T \cdot \Delta$ & IOTVR & $r \cdot r V \Lambda$ & امير كلا ..................................................... \\
\hline
\end{tabular}


ظ - جمعيت و خانوار شهرهاى كشور به ترتيب استان (دنباله)

\begin{tabular}{|c|c|c|c|c|}
\hline خانوار & 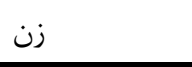 & 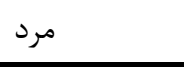 & جمعيت & شرح \\
\hline TQIF & re八D & TVQF & verq & 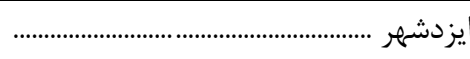 \\
\hline NIDVT & ITQTAF & ITFAGK & TQ. TIV & 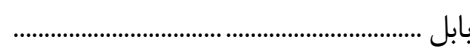 \\
\hline $19 \Delta \vee 4$ & r.qVG & rqтq. & 099५४ & بابلسر ل.*-1) \\
\hline rar & fVF & 199 & q४. & 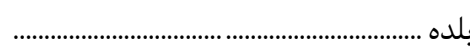 \\
\hline m. & FVIIF & FVrAh & $q q v \cdot r$ & 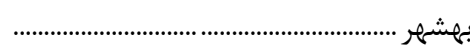 \\
\hline TQFi & rAVr & rer & $\vee 9.4$ & بهنمير .. \\
\hline 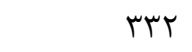 & kq & fqK & $9 \Delta 9$ & 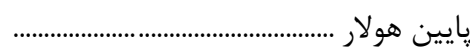 \\
\hline rघ人. & Firk & FIDG & NrqF & 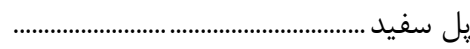 \\
\hline 1.94 & $10 V 9$ & $|\Delta V|$ & ma. & بول .................... \\
\hline IMAVA & rAl19 & tRMIN & $\Delta D F T F$ & تنكابن .................................. \\
\hline $1 \cdot \hat{\uparrow} \wedge$. & 19199 & $19 \vee \Delta \Delta$ & rTqTF & 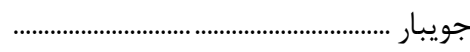 \\
\hline TrIG4 & TrVA. & TYYIS & 90199 & جالوس ................................ \\
\hline reqT & DGTT & $\Delta \Delta V T$ & 11194 & جمستان .................................. \\
\hline$r q \cdot r$ & $\Delta V \& q$ & QVवr & IIDFT & 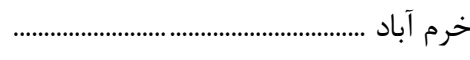 \\
\hline rrqu & $\Delta I \Delta V$ & $\Delta \wedge \vee \Delta$ & II. & 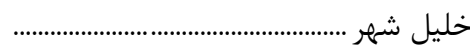 \\
\hline $19 \cdot 9$ & rᄉrq & $r q \cdot r$ & DVFT & 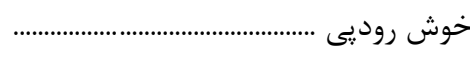 \\
\hline$\Delta V T$ & 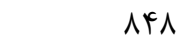 & 91. & $I V \Delta \Lambda$ & 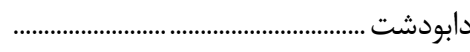 \\
\hline$|r| \Delta K$ & $\mid \vee 911$ & $11 \cdot \vee 9$ & rЬ११V & 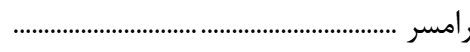 \\
\hline rqvq & $\Delta V I \Lambda$ & $\Delta 99 \Lambda$ & $119 \wedge 9$ & 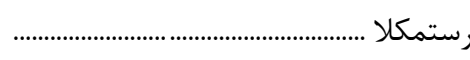 \\
\hline TY\&l & ґ^६. & rAvi & VVMI & 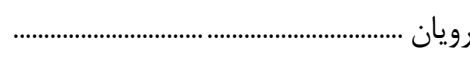 \\
\hline TaT & FAV & 190 & 9人र & 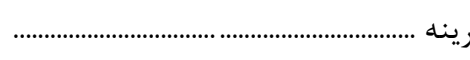 \\
\hline 1411 & $19 \cdot 1$ & $r \cdot \wedge r$ & ५११। & 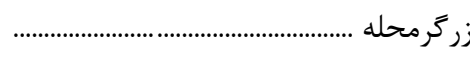 \\
\hline Drr. & $\wedge 1 \cdot V$ & $\Lambda \cdot \Lambda F$ & 19191 & 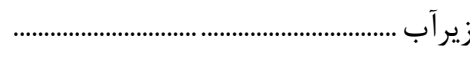 \\
\hline $1.194 \pi$ & ।४Ь११V & IDTAKr & $r \cdot 9 \Lambda r$. & 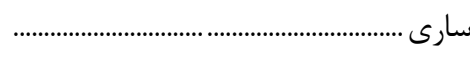 \\
\hline TYYA & rTVA & TEYI & 9999 & 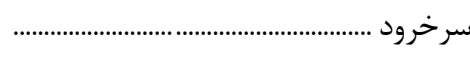 \\
\hline$r \cdot \Delta V$ & $\operatorname{l999}$ & pq9. & $१ ९ \Delta ९$ & 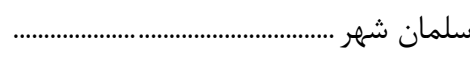 \\
\hline$r \cdot \Lambda v$ & FAVG & GETr & $9 r \cdot 1$ & سورك ............................................................. \\
\hline rی९9 & FTD. & FFY & $\wedge \& \vee 1$ & شير كاه ....................... \\
\hline rADI & $\Delta \& \mid \varphi$ & $\Delta \vee 91$ & IIrvV & 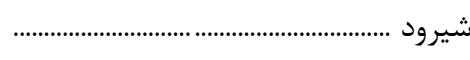 \\
\hline$r a .$. & 9910 & Gヘ\&V & ITFAT & 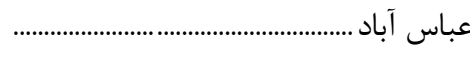 \\
\hline $1 \pi 4 \cdot 9$ & IAVTr & IgFiv & rNIDF & 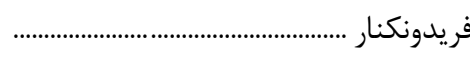 \\
\hline ITV & 189 & 19. & rद9 & 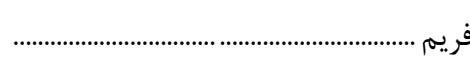 \\
\hline $9 \wedge F \cdot V$ & $1 . r 9 \Delta F$ & 1.1999 & $r \cdot \varphi q \Delta r$ & قايم شهر ...................... \\
\hline $1 \cdot \Delta r$ & $1 \Delta \Delta r$ & IDSV & TIr. & كجور .................................. \\
\hline$r \cdot 99$ & $r \cdot v V$ & riq. & GTEV & 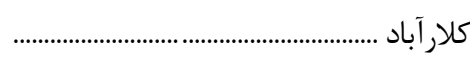 \\
\hline$F \Delta G \Delta$ & $90 \wedge 9$ & $9 \Lambda 1 T$ & $1 r F \cdot 1$ & كلاردشت .......... \\
\hline r\$91 & rq19 & $f \cdot \Delta l$ & $\Lambda \cdot r$. & كياكلا................. \\
\hline
\end{tabular}


ظ ـ جمعيت و خانوار شهرهاى كشور به ترتيب استان (دنباله)

\begin{tabular}{|c|c|c|c|c|}
\hline خانوار & 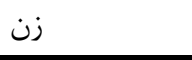 & مرد & جمعيت & 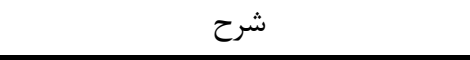 \\
\hline VI\& & $1 \cdot 4 \Delta \varphi$ & $1 \cdot r \varepsilon$. & $r \cdot V I S$ & 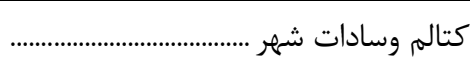 \\
\hline Vre & $11 \pi \Delta$ & $11 \cdot v$ & TMET & 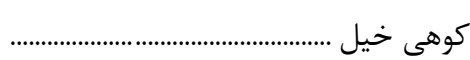 \\
\hline $1 \cdot \wedge f$ & IVrq & $19 \Delta \Delta$ & rMAF & 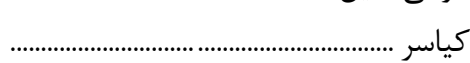 \\
\hline rme. & $r v \cdot \Lambda$ & rद५ & VrVF & كَتاب ............... \\
\hline $1 \cdot r$ & 191 & $|0|$ & r19 & 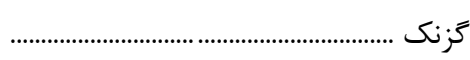 \\
\hline rirs & teAt & MFTE & $99 \cdot 1$ & 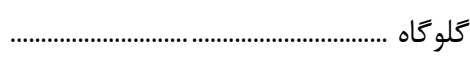 \\
\hline $9 \wedge 91$ & 1.495 & $1 \cdot 19$ & TITAT & 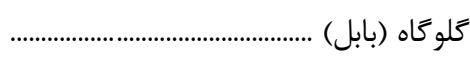 \\
\hline 1.499 & IDSFY & $194 .$. & MINFF & محمودآباد .................... \\
\hline$|A F|$ & $T V \Delta I$ & rqp & 9991 & 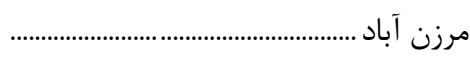 \\
\hline$r \cdot 1$ & FrV & 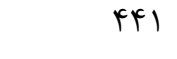 & $\wedge 9 \wedge$ & 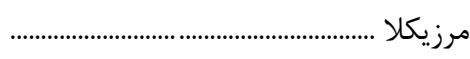 \\
\hline $51 \cdot 9$ & $r \cdot \varphi_{\Delta}$ & rmeq & grqf & نشتارود ............................ \\
\hline I $9 \mathrm{r} \Delta \mathrm{V}$ & r.rta & $r \cdot V \Delta \varphi$ & 9.991 & 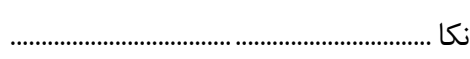 \\
\hline$\wedge$ ^९V & IrrvV & Irov. & r\&qYV & نور ........................ \\
\hline IEYAV & TEDTK & TYMA. & $q q 4 \cdot r$ & نوشهر ..................... \\
\hline TAFq & rAgr & $Y \cdot r V$ & 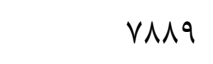 & هادى شهر ......... \\
\hline reVI & $\Delta \cdot \wedge 9$ & $\Delta r \cdot q$ & $1 . r 91$ & هيجرود ..................... \\
\hline regres & DFrere & $\Delta \Delta r I T$. & $1.99 \mathrm{Vef}$ & 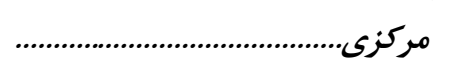 \\
\hline TETV & roAr & rQAS & VI94 & آستانه .......................... \\
\hline TVMA & Frg. & ra.r & AVGr & آشتيان .............. \\
\hline $11 \cdot 1$ & 194. & 1919 & rq. & آوه .............................. \\
\hline $19 \Delta V \cdot 9$ & $r \Delta V \wedge \cdot 1$ & TETIKT & $\Delta T \cdot q F F$ & 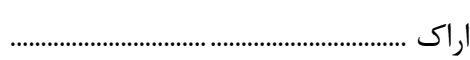 \\
\hline r।qr & rTAD & $r \Delta \cdot 1$ & $9 \Lambda \Lambda 9$ & يرندى .............. \\
\hline DTH & NT\&V & NTrG & I\&4q4 & 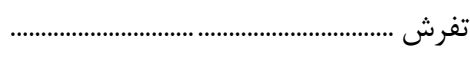 \\
\hline VTr & $11 \Delta F$ & $\| F \wedge$ & $r \mu \cdot r$ & توره \\
\hline lef. & TYYI & TAQT & एव१ & 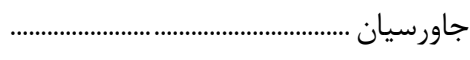 \\
\hline IDSV & rYqV & rVFq & DrFS & 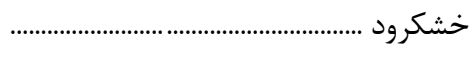 \\
\hline trmte & rellर & reVV. & VTANT & 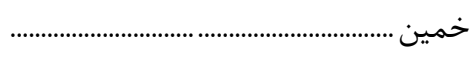 \\
\hline $1 \cdot+1$ & lDG & $19 \mathrm{VT}$ & rTM & خنجين .................. \\
\hline rroA & 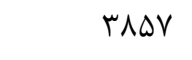 & rqه & $\vee \wedge l$. & خنداب .................. \\
\hline IATF & $r V \cdot \Lambda$ & rVAr & $\Delta \& q 1$ & 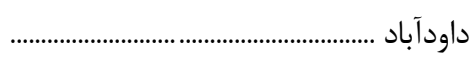 \\
\hline IrgIr & $t \cdot r t$ & $r \cdot \Lambda \Lambda$. & $r \cdot q \cdot r$ & 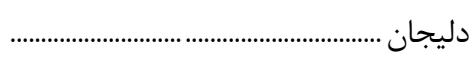 \\
\hline rq. & $4 \mid \Lambda$ & $4 \cdot 1$ & Ars & 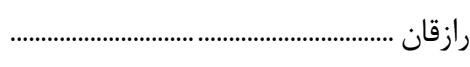 \\
\hline $1 \wedge \Lambda$ & rQAD & $r \cdot f r$ & G.TV & 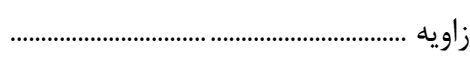 \\
\hline$\varphi q V$ & $9 V r$ & gVr & ITES & 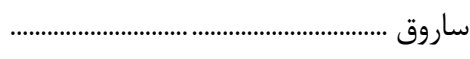 \\
\hline SVTr. & $1 \cdot \Lambda \cdot r \cdot$ & IITVET & Tr.VAT & 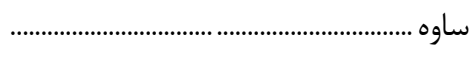 \\
\hline q9VV & 1.099 & $1 \cdot \Delta \wedge r$ & $r \mid 1 \Lambda$ & 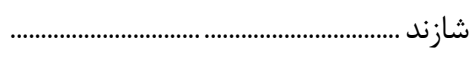 \\
\hline trVD & $r v \cdot q$ & TATV & VATS & شهباز ................... \\
\hline
\end{tabular}


| نتايج تفصيلى سرشمارى عمومى نفوس و مسكن _MD

ظ - جمعيت و خانوار شهرهاى كشور به ترتيب استان (دنباله)

\begin{tabular}{|c|c|c|c|c|}
\hline خانوار & 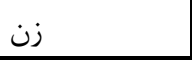 & 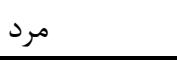 & جمعيت & شرح \\
\hline $11 \cdot 0$ & r\&\1 & rqq4 & DrVa & 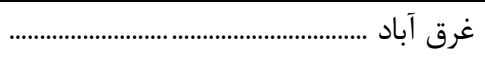 \\
\hline $1 \wedge \Delta S$ & rA19 & rquV & $\Delta V \Delta S$ & 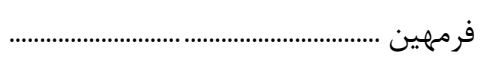 \\
\hline pre & sq4 & vi. & irve & 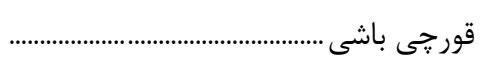 \\
\hline $11 r \Lambda$ & $1 \wedge 9 \Delta$ & IAVA & ryer & 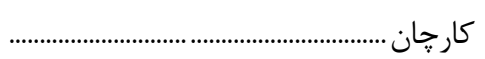 \\
\hline rYFq & FF.F & ervt & AVVS & 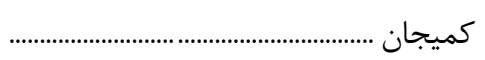 \\
\hline sq4V & 1.911 & $1 \cdot q \cdot r$ & rMAIF & مامونيه ........................... \\
\hline IFTGS & rifir & TINTt & FTrFa & 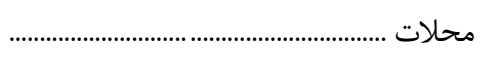 \\
\hline $91 \Delta \Delta$ & १८१९ & $1 \cdot F \Delta F$ & t.rks & مهاجران ......... \\
\hline TVMA & Feft & FAFS & $9 T \wedge \Lambda$ & 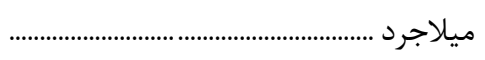 \\
\hline AVT & $|r r|$ & $\mid$ & rQQT & 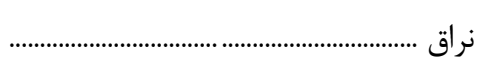 \\
\hline 1.11 & 1994 & 194. & 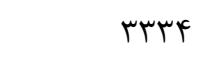 & نوبران .................................................. \\
\hline TETV & rघ94 & rakr & $V \Delta \cdot V$ & 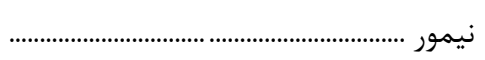 \\
\hline $4 \cdot 4$ & १५ & q४१ & 1911 & هندودر .............................. \\
\hline rVD\&Iq & errarr & rqv19q & ariarr & 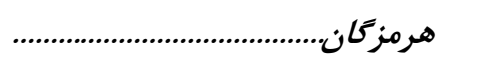 \\
\hline$\Lambda \Delta V$ & IFTD & tYMA & RTIT & 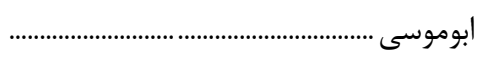 \\
\hline r991 & r^q. & 0.99 & $99 \Delta 9$ & بستك ............................................................. \\
\hline eqID & $\Lambda \cdot \wedge r$ & $\Lambda V V V$ & $19 \wedge 9$. & 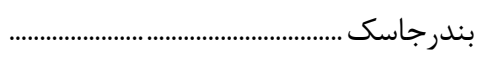 \\
\hline IDTAGT & TAVGIQ & r r & DTGGYA & بندرعباس ......................................................... \\
\hline NFAT & 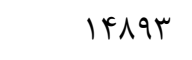 & IDQFT & 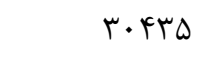 & بندر لنَهه ..................................................... \\
\hline t. Fa & rVMr & rFAS & 119. & 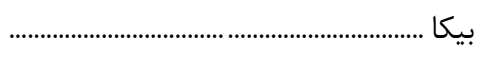 \\
\hline 1990 & $\wedge \wedge 1$. & arro & $M \cdot F \Delta$ & 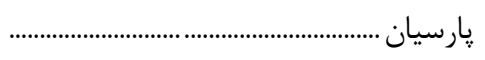 \\
\hline $1 T \cdot 9$ & rifq & rIIf & FTE & 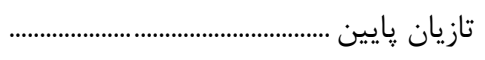 \\
\hline 194 & $\mid k \cdot r$ & 191 & $r \cdot \Lambda t$ & تخت ................................... \\
\hline 1480 & rrVV & rqqF & FAVI & تيرور ................................. \\
\hline INDF & TFto & reVa & 991. & جناح ................................. \\
\hline 1.19 & IArq & rerv & $4 \cdot 99$ & حارك \\
\hline 1.qr & $|F| F \lambda$ & IFATq & T^৭マV & 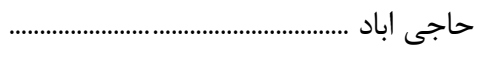 \\
\hline$|4| 9 \mid$ & VDSF & VVAS & IQTY. & 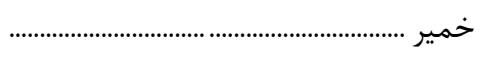 \\
\hline rAFQ & gVAT & VVAT & IFDTD & 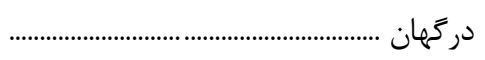 \\
\hline$I r \cdot V$ & 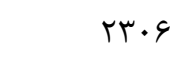 & rr人q & 4990 & 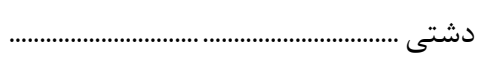 \\
\hline qVrr & INTA. & |rAvI & ra|r| & 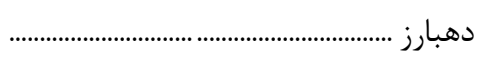 \\
\hline 1199 & TrGT & rTQ9 & $9 \Delta \Delta \wedge$ & 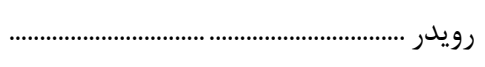 \\
\hline VIr & IrFA & | (1) & reva & $\ldots \ldots \ldots \ldots \ldots \ldots \ldots \ldots \ldots$ \\
\hline rq1 & $1<q$ & 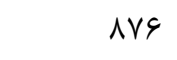 & IVTD & سردش ............................. \\
\hline rar & $\Delta \& \Lambda$ & $\Delta \wedge 9$ & $11 \Delta V$ & سركز . \\
\hline$r \Delta q$ & १९५ & qrr & 1910 & سندرك ............................................................. \\
\hline lorq & rAfF & TA\& & $\Delta V \cdot V$ & سوز \\
\hline
\end{tabular}


ظ ـ جمعيت و خانوار شهرهاى كشور به ترتيب استان (دنباله)

\begin{tabular}{|c|c|c|c|c|}
\hline خانوار & 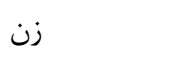 & 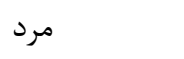 & جمعيت & 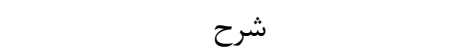 \\
\hline $11 \wedge r$ & $r \Delta \cdot q$ & TGYA & DITV & سيريك ................................................................... \\
\hline$\Delta \wedge \varphi$ & $9 \cdot 9$ & 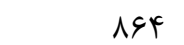 & IVVT & 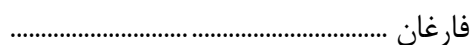 \\
\hline 1191 & $r \cdot \Delta r$ & IMAV & чqчq & فين ...-1) \\
\hline 11940 & $19 \wedge \Delta \mu$ & $r \cdot \Lambda T \Delta$ & $r \cdot 9 \vee \wedge$ & 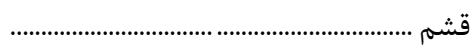 \\
\hline life. & TQIS & TVV. & DrAS & قلعه قاضى ....... \\
\hline ves & $\left.|Q|\right|^{F}$ & lote & $r \cdot 9 \cdot$ & 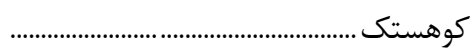 \\
\hline FqTI & 9495 & 9941 & $19 \pi 1 \%$ & كنگ \\
\hline$\Lambda \notin v$ & 1ه9 & $199 \mathrm{~V}$ & rrg. & 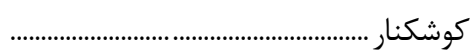 \\
\hline $\mid r k \cdot r$ & IVGVD & trIVA & 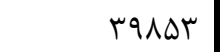 & 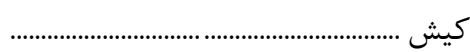 \\
\hline q4 & r. re & $19 V \mathrm{r}$ & 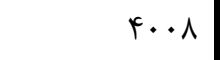 & 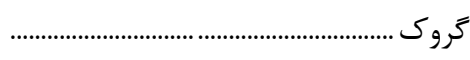 \\
\hline Trt & $\Delta V_{1}$ & $\Delta 99$ & 118. & كوهران..................... \\
\hline s4s & ITVK & leVt & $r V F \Delta$ & 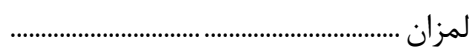 \\
\hline 19.rr & rदrGD & $r \varepsilon \Lambda \cdot \Delta$ & VIVIV. & 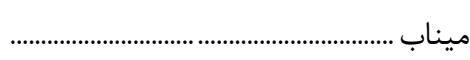 \\
\hline 1991 & rqه人 & 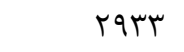 & $\Delta \wedge 91$ & 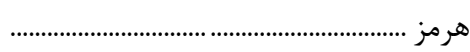 \\
\hline$|v|$. & rरq1 & METV & $\operatorname{sil\Lambda }$ & هشتبندى ........... \\
\hline rerg.q & Dregr. & $\Delta \Delta \cdot \Delta A r$ & $1.9 \mathrm{rrir}$ & 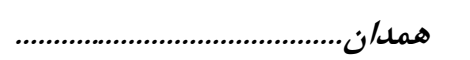 \\
\hline NTr & Irks & irat & rRru & 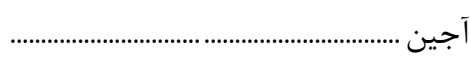 \\
\hline 1 & DFV & $\Delta 9 q 4$ & $111 \mathrm{~V}$ & ازندريان ................................. \\
\hline $19 \vee 90$ & TVQVT & TAIr. & $\Delta \Delta V \cdot r$ & 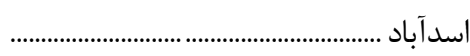 \\
\hline VVF & 1190 & ITGT & rFaV & برزول ......................................................... \\
\hline এ१८५ & $14 \cdot 94$ & $|f \Delta q|$ & 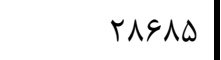 & 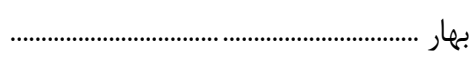 \\
\hline $\mid \varepsilon r 91$ & $r \Delta \cdot G V$ & TOTAM & $\Delta \cdot r \Delta \Delta$ & 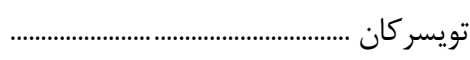 \\
\hline r. Ft & $F \Delta 9 \Delta$ & вqтq & qrre & جورقان .................................................... \\
\hline gVF & $1 \cdot v r$ & 1110 & rtQA & 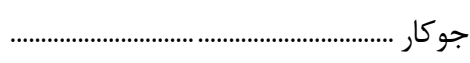 \\
\hline $9 \wedge \vee$ & $199 \mathrm{~V}$ & lagk & ו וזrז & 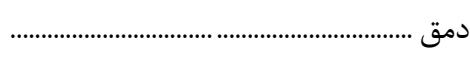 \\
\hline$r \cdot \wedge r$ & 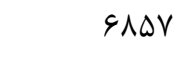 & $V F i \Lambda$ & IFrVD & 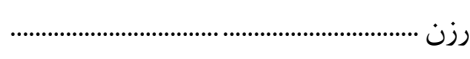 \\
\hline rma & rIf & $r \cdot v$ & gri & زنحنه ........................ \\
\hline 1 1ra & $191 \%$ & 1419 & rAvr & سامن ........................................................... \\
\hline leqr & r19. & $1 \wedge 91$ & $f \cdot \wedge 1$ & سر كان \\
\hline 901 & IrVq & 1111 & rFe. & شيرين سو ................................................... \\
\hline TQY. & rqkF & $r 9 \Delta \Delta$ & マ^৭१ & صالح آباد .................................................... \\
\hline eqq1 & GAVD & 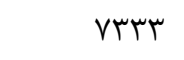 & $1 F T \cdot \Lambda$ & فامنين ............................................................ \\
\hline rov & vVq & $V E V$ & lare & فرسفج .................................................. \\
\hline IQTE & raVr & rq.. & DIVT & 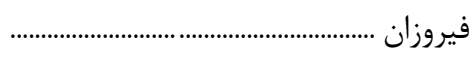 \\
\hline rqv & FqYA & rA9T & $q \Delta F$. & 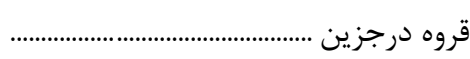 \\
\hline$\Delta F \Delta$ & IFED & IDTD & rqv. & 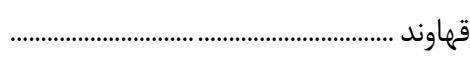 \\
\hline GTrI & qVar & $1 \cdot \Delta \wedge r$ & G & كبودراهنَ ....... \\
\hline
\end{tabular}


نتايج تفصيلى سرشمارى عمومى نفوس و مسكن _ه |

ظ ـ جمعيت و خانوار شهرهاى كشور به ترتيب استان (دنباله)

\begin{tabular}{|c|c|c|c|c|}
\hline خانوار & 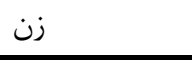 & مرد & جمعيت & شرح \\
\hline $94 \lambda$ & $114 T$ & 1.90 & trTV & 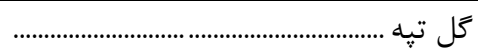 \\
\hline TQDT & rq1ब & FTrI & $\wedge 1 \wedge 9$ & گ \\
\hline eVID & VTAV & $\vee \vee \Delta Q$ & $\mid 4919$ & لالجين ..................................................... \\
\hline r819 & DHFF & $\Delta \Delta \cdot f$ & $1 \cdot \wedge+\wedge$ & 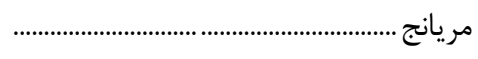 \\
\hline DrGQV & NFVD. & ADFAV & IV.rTV & ملاير .......................................................... \\
\hline TrG. & rafF & rVAv & VIrI & 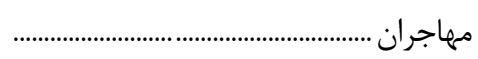 \\
\hline rrqpr & rV৭৭1 & rNIEF & VAIGT & نهاوند ..................... \\
\hline IVEVTI & TVYQDI & TVGYAD & $\Delta \Delta F Y \cdot G$ & همدان ........................................................ \\
\hline$r 9.981$ & rval. 1 & FqgTAF & qvirad & 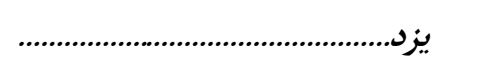 \\
\hline$\wedge ץ \wedge q$ & Irfar & $|k \cdot r|$ & TVQTF & ابركوه .................................................... \\
\hline 1919 & r^\&l & rIAD & $4 \cdot 49$ & احمدآباد .................... \\
\hline TTFVD & rघIrq & rqlft & VQTYI & 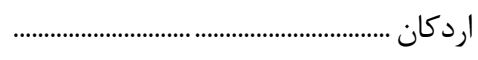 \\
\hline$\Delta \vee 99$ & $q \mu \cdot 4$ & 9119 & $191 \pi$ & اشكذر ..................... \\
\hline ITFDF & TMt & Tוtוt & Fafar & بافق ...................... \\
\hline$r \cdot \Delta$ & 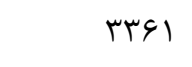 & ravı & я৭rq & بفروييه ه...1.1.1. \\
\hline trVA & FV.r & far. & qrrt & 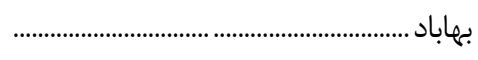 \\
\hline$\Delta \& \& q$ & 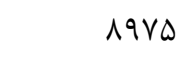 & $94 \wedge 9$ & $\mid \Lambda F \& 4$ & تفت .................... \\
\hline IDTGA & TATHE & TEFYY & DIVq & 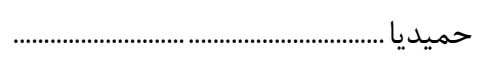 \\
\hline 194 & TQF & rAl & Dra & 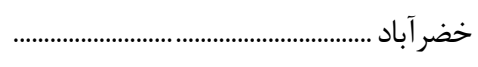 \\
\hline rrak & $\Delta \Delta \cdot r$ & 9119 & 11991 & زارج ...................................... \\
\hline$\Delta \Delta Y F$ & $q \ldots$ & $94 \cdot 9$ & $1 \wedge r \cdot q$ & 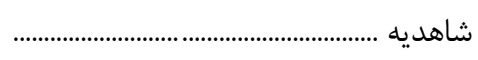 \\
\hline G.r & $\wedge \vee 1$ & мᄉ & IVDF & 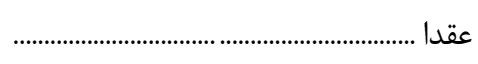 \\
\hline rvq. & $f \Delta \Lambda$ & cras & $q$ qrq & 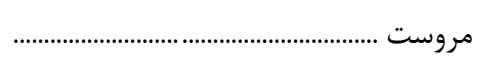 \\
\hline 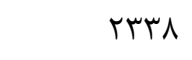 & rADI & Fres & $\Lambda \cdot 9 \vee$ & 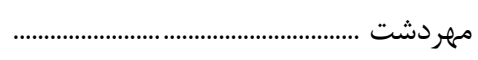 \\
\hline $1 \cdot$ rFF & $19 \vee 97$ & IVFF. & TFtrt & 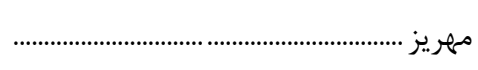 \\
\hline rrq19 & rqQ & FIIAT & $\Lambda \cdot v i r$ & 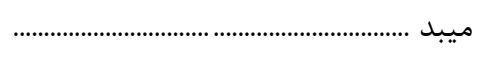 \\
\hline v91 & $11 T V$ & ITYF & tral & 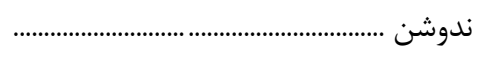 \\
\hline $9 \cdot 9$ & 194 & Ave & IVF. & 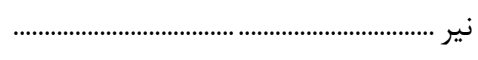 \\
\hline rert & sT41 & 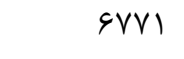 & Ir. & هرات ....................................................... \\
\hline $\mid \Delta \wedge r \varepsilon \Lambda$ & rDQqYi & reqVTr & DTQ\&VT & يزد ي.................. \\
\hline
\end{tabular}




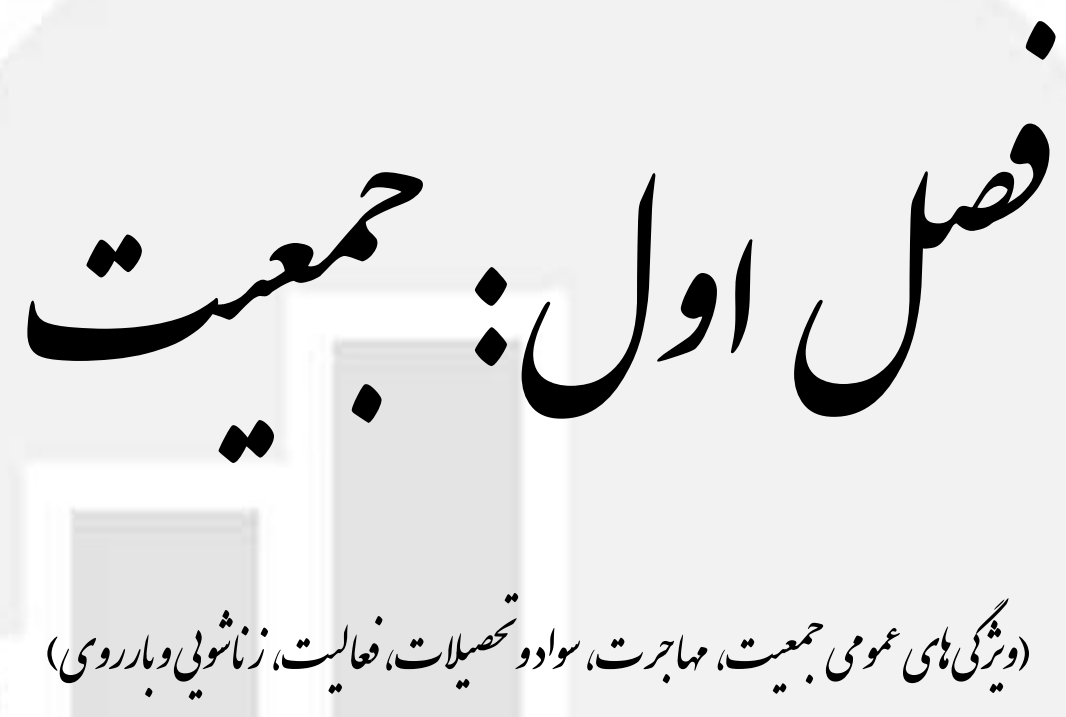




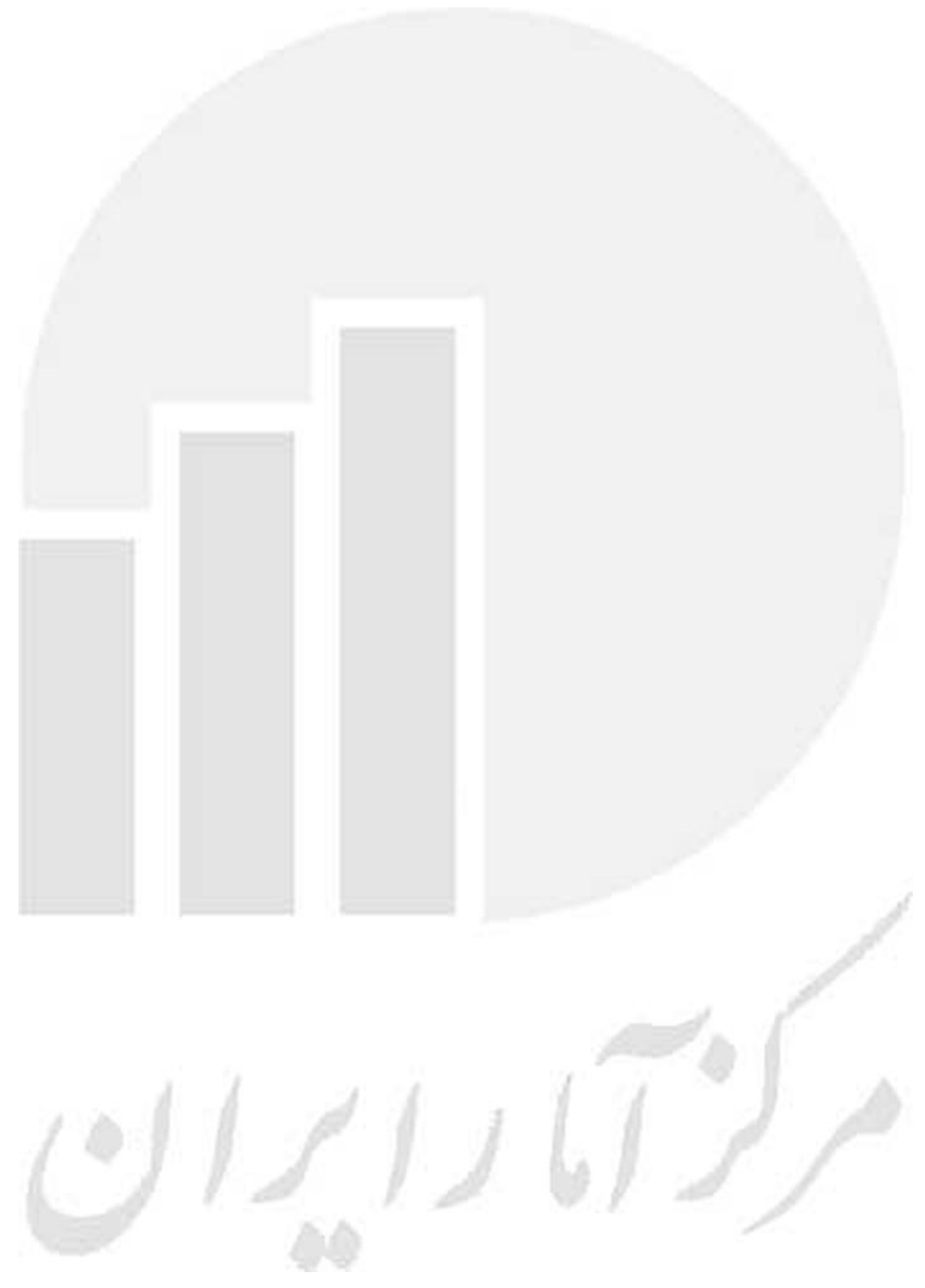


1 - 1 - جمعيت بر حسب سن، جنس و وضع سكونت

\begin{tabular}{|c|c|c|c|c|c|c|}
\hline \multicolumn{3}{|c|}{ ساكن در نقاط شهرى } & \multicolumn{3}{|c|}{ 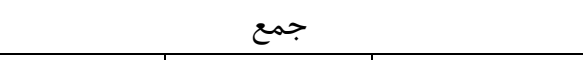 } & \multirow{2}{*}{ 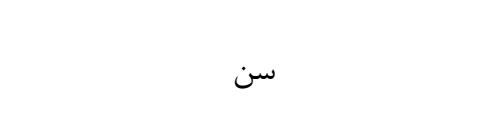 } \\
\hline 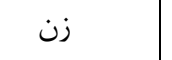 & 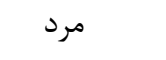 & مرد و زن & 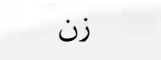 & 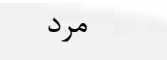 & مرد و زن & \\
\hline$r q r \cdot \Delta F r r$ & rqAfifir & DqIF\&AFV & rqfervara & F. FqAfFr & raqrerr. & 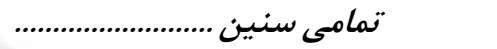 \\
\hline TFTtg.t & rDS9ITV & $\Delta \cdot \operatorname{lV} r \cdot$ & HFFTt F & rgłq1.. & $v \cdot q r \ldots r$ & 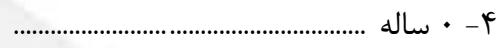 \\
\hline FV9194 & $\Delta \cdot \Delta|f|$ & $q \wedge F \mu \cdot V$ & sVrqIV & VITGIF & $|r A V \Delta r|$ & 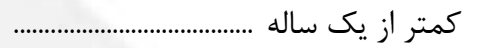 \\
\hline DITANT & $\Delta F T V D q$ & $1 \cdot \Delta \& \& \varphi_{1}$ & VTATGD & RVTYGT & I fqV $\Delta \Delta V$ & 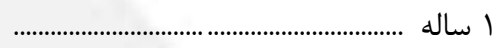 \\
\hline pqr... & $\Delta T \Delta G \Delta \Lambda$ & 1. rr\&Q1 & $V \cdot \Delta \& T \Delta$ & $V F q \cdot F d$ & IFDF\&V. & 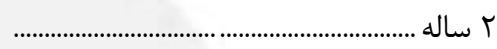 \\
\hline FVA. Ir & $\Delta \cdot r \Delta \Delta \cdot$ & $9 \Lambda 1 \Delta \& Y$ & 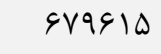 & VIVTAN & IrqV.r & 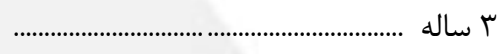 \\
\hline$F \& \Delta D F T$ & 1991.19 & १ఎ९D\&Y & 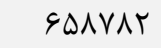 & $99 \vee+81$ & ITDGYFT & 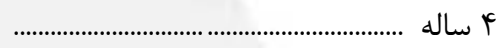 \\
\hline TTIGTDS & מזr שrזr & $F \Delta F \& \Delta \wedge \Lambda$ & TITATFV & rr^G.r. & GYIITVV & 9 ه ساله .................... \\
\hline FASDTD & $F \wedge 1.9 V$ & $q r V q \cdot r$ & 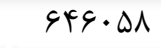 & $91 \cdot 119$ & ITTGAVF & ه ساله .......... \\
\hline FDTr. & FVGDGG & १५१VदV & ятVqяq & $q V \cdot \Delta \wedge q$ & $\| r \cdot \wedge \Delta \Delta \Lambda$ & 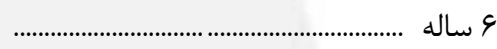 \\
\hline 40.999 & pVrrvq & $q Y F \cdot F \wedge$ & 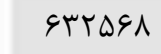 & g9YAIS & IrqVTAF & 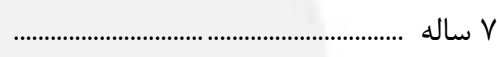 \\
\hline FTrTAF & FDF\&qI & 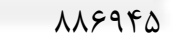 & צחז. & GFIVDT & $1 T \Delta T \cdot \Lambda \Lambda$ & 1 ساله ................ \\
\hline FrrsqV & FEFATG & NGNTTE & Q9ATाब & $G Y \Lambda \cdot \Delta V$ & ITYGTV & 9 ساله ................... \\
\hline $19 \Lambda 1 \cdot \Delta V$ & $r \cdot V \Delta \mid \wedge \varepsilon$ & $F \cdot \Delta G Y F T$ & TVY\&9\&I & Tq1IFr & 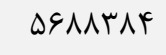 & 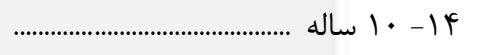 \\
\hline fIVTre & frqugs & NDGVFT & DQTATr & $g r r \cdot \Delta \Lambda$ & $|r| \& \wedge 9$. & • • ساله ......... \\
\hline$F \cdot r \& V I$ & FTrTgl & ArGqTr & $\Delta G Y F \wedge F$ & $\Delta q F \Delta \wedge \varepsilon$ & $119 r \cdot V \cdot$ & 11 ساله ......... \\
\hline$r q . \Delta q$ & $p \cdot \vee q \vee q$ & $\vee १ \wedge \cdot r \wedge$ & $\Delta F \Delta \backslash 91$ & $\Delta \vee \backslash 9 \wedge \Delta$ & IIVIVE & זاله .......... \\
\hline rAVIAF & $\varepsilon \cdot \Delta \mid \Delta q$ & Varru. & DHQTrV & DGFVGT & $11 \cdot 4999$ & או ساله ......... \\
\hline rATVGV & rqqFTF & VAYI9I & DHTYIV & $\Delta \Delta G \cdot r r$ & 1. NAYFq & ץ ساله ........................ \\
\hline $190 \cdot r \cdot r$ & $r \cdot \ldots r r r$ & $r 9 \Delta \cdot 9 r \Lambda$ & r\&VRT. & 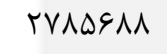 & $\Delta F \Delta \wedge १ १ \vee$ & 19 - ها ساله .............. \\
\hline TATVGT & $F \cdot \mid \wedge V$. & VAFETT & $\Delta T \Delta V V V$ & $\Delta \Delta r \cdot \wedge \varepsilon$ & 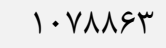 & ها ساله ............. \\
\hline rᄉrఎq. & rq9\&4V & VArtry & DTAFFq & DQTTIA & 1.VVDGV & 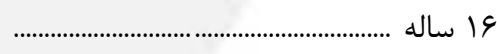 \\
\hline гА१тrq & f.rqvq & V9TrIA & $\Delta M F \Delta G \Lambda$ & $\Delta G T \cdot I T$ & 1.9901. & 1V ساله .......... \\
\hline rqvor. & $r \cdot r \cdot r$ & $\Lambda \cdot \Delta M^{F}$ & DFTDGG & $\Delta G M Y \cdot r$ & 11.9999 & 1) ساله .................... \\
\hline rqv.^r & rqIArF & マ^^৭।V & $\Delta F F \cdot F q$ & $\Delta \Delta F q \& q$ & $1.99 \cdot 11$ & 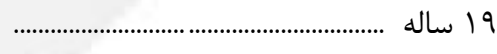 \\
\hline THIQVTA & TYSIT.D & 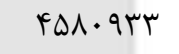 & $r 1 \Delta \Delta q \cdot r$ & rTrGqVD & grqY^vq & ץ \\
\hline FIr. IN & F. TFET & $\Lambda \mid F F \Lambda$. & $\Delta \varphi \Delta \cdot q F$ & $\Delta \vee \varepsilon \mid \cdot \Delta$ & 1141199 & 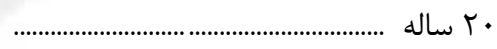 \\
\hline FrqRTr & $f \backslash 99 \cdot 1$ & AFqur. & $\Delta \wedge V \vee \Delta r$ & G.rGIr & $119 \cdot r G V$ & ا آ ساله \\
\hline FEIFFV & FFVqTI & 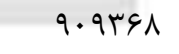 & q & GForva & I TVATAK & r T ساله ............. \\
\hline Fq.rrk & $F V V \cdot V V$ & qGVF.. & GGDSTD & $\varphi \wedge \Delta \cdots+$ & $1 r \Delta \cdot G r q$ & 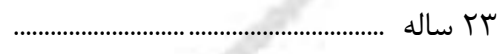 \\
\hline DTGT. & DIFITV & $1 \cdot F \cdot r F \Delta$ & V.VATR & VYVAVA & IFrar. & 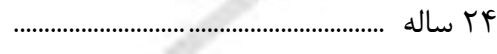 \\
\hline r.VGfIf & T. TFT.. & $91 \cdot .914$ & $f \cdot \Delta \vee \& \wedge \Lambda$ & FIFTEFD & NT. & \\
\hline$\Delta \Lambda \cdot F \backslash \Lambda$ & $\Delta G \Delta G Y q$ & $\| F G \cdot F V$ & VVADQY & 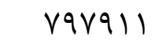 & $1 \Delta V G \Delta \cdot r$ & صاله ............ \\
\hline G. IV & $\Delta q \cdot 9 V \cdot$ & س & VqVDr. & N|N|r| & $|9| 0991$ & 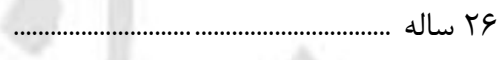 \\
\hline $94 . . .9$ & Gr.VTd & $|r \Delta \cdot V A|$ & NTEVQV & $1 F \&|1|$ & IEVTqVA & TV TV \\
\hline GTATrT & GTYOV. & 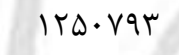 & $\Lambda T \Delta \cdot r \cdot$ & NFFETD & 1999990 & 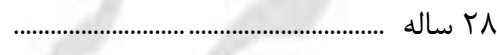 \\
\hline GTG..F & GTYDQG & $1 \pi 9 \cdot 9 .$. & 1rqVrq & 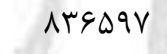 & 1999TYG & ج \\
\hline r & 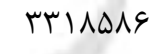 & G9TVVIS & FYG. FED & FHF. FFA & $\Lambda \varepsilon . .91 \%$ & 1......................... \\
\hline gqTFIN & 9q4qT. & 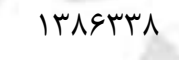 & $9 \cdots \vee 91$ & $q T \cdot \Delta r \Lambda$ & INTIrTq & 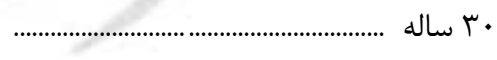 \\
\hline GNTrDQ & $91 . .99$ & ITETrTA & AVqFVr & 1919VF & IVRIFEV & آس ساله.................. \\
\hline $9 \wedge 9109$ & $99.99 V$ & $1 r \lambda \cdot I r \mu$ & $\wedge M \Delta 191$ & $\wedge 99 \wedge \Delta 1$ & $I V \wedge \Delta \cdot \operatorname{Fr}$ & 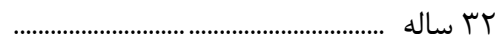 \\
\hline 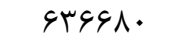 & GFIMF. & $I T V \Lambda \cdot r \cdot$ & $\wedge 1 \vee \Delta \wedge 9$ & NHFGG & 19OTRAT & 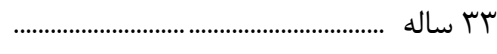 \\
\hline G.VGIV & 9lrrq. & $1 r r \cdot q \cdot V$ & BVYETI & VQTFTI & $1 \Delta V \cdot \Lambda F T$ & 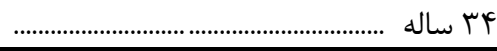 \\
\hline
\end{tabular}


|- 1 - جمعيت بر حسب سن، جنس و وضع سكونت (دنباله)

\begin{tabular}{|c|c|c|c|c|c|c|}
\hline \multicolumn{3}{|c|}{ غير ساكن } & \multicolumn{3}{|c|}{ ساكن در نقاط روستايى } & \multirow{2}{*}{ 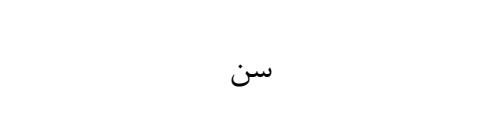 } \\
\hline زن & 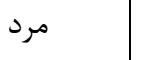 & 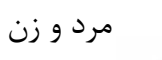 & 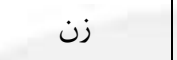 & 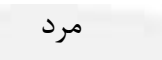 & 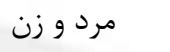 & \\
\hline reria & refra & raval & $1 \cdot 1 \ldots v 8$ & $1 \cdot q r \cdot \Delta F q$ & $r \cdot v r \cdot q r \Delta$ & 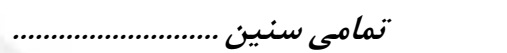 \\
\hline $11 \cdot 9$ & $19 \Delta 1$ & rVat & $1 \cdots \wedge \vee 9 \Delta$ & $1 \cdot \vee \wedge \vee \backslash \Delta$ & $r \cdot \wedge \vee \Delta I \cdot$ & 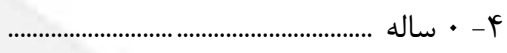 \\
\hline r19 & r & 909 & I gFFer & $r \cdot 11 r \varphi$ & $F \cdot T \Delta F \Lambda$ & 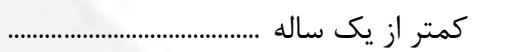 \\
\hline rM & rgF & VAT & $r 11990$ & TrMI99 & FF. IGF & | ساله ......................... \\
\hline raf & FTY & VVS & $r \cdot \Lambda T V I$ & rYTQGD & FTITHE & ץ ساله ............................ \\
\hline raf & 419 & VVr & r.ITrq & TITFIq & FIFG91 & 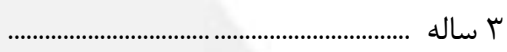 \\
\hline rq1 & FIs & $\Lambda \cdot V$ & $19 T \lambda F \wedge$ & $r \cdot \varphi \cdot r q$ & 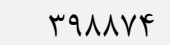 & ץ ساله ................... \\
\hline 19Tr & $r \cdot v \cdot$ & ५११९ & 9.9999 & १QTVYA & $119.99 \mathrm{~V}$ & - \\
\hline GTV & fil & $\Lambda F \Delta$ & 119.99 & | 1994r| & rANFTV & ه ساله ................. \\
\hline ґ. & Fir & var & INFrAג & $|948|$. & 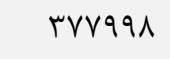 & 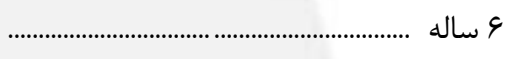 \\
\hline rVF & frq & $\Lambda \cdot r$ & INIQTA & $191 \cdots 1$ & TVTATr & Vاله ............................... \\
\hline$r 9 \Lambda$ & rat & $\vee \Delta \cdot$ & IVVVIF & I $₫ 9 \vee 9$ & тектqт & 1 ساله............... \\
\hline rVr & FrA & $\Lambda \cdot 1$ & IVETES & $|\wedge T| .$. & roVres & 9 ساله ............................. \\
\hline ।19४ & rI. & ५१११ & vq५..v & ATFITD & IGYAIFT & 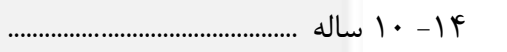 \\
\hline rYA & FAT & १५. & $I V \Delta \cdot \cdot \Lambda$ & $\mid$ AETI. & rDQTIA & • ا ساله ....... \\
\hline rav & per & 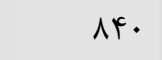 & ISTYIS & $I V \cdot \Lambda \Lambda T$ & rmetqA & اله ساله ...................... \\
\hline Tar & TTM & $V V \Delta$ & IQFVA. & 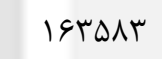 & r|রזद & ז ساله ......................... \\
\hline$r \Delta \Delta$ & ґ^८ & 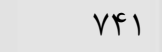 & 101991 & IDQTY. & 41.911 & ץا ساله ......................... \\
\hline MFQ & ren & VIr & $|f q| \cdot \Delta$ & lDGTF. & $r \cdot \Delta r F \Delta$ & | / ساله ........................... \\
\hline INFF & rTQD & firq & 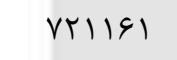 & $V \wedge r \cdot \Delta q$ & ID. FTT. & 19- ها ساله ................. \\
\hline$r \Delta q$ & (1). & Vब9 & IFTEAS & $10 \cdot 1 \cdot 9$ & TqMFET & 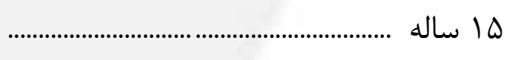 \\
\hline rov & $k \cdot 1$ & $V \& \Delta$ & $|f| f \cdot r$ & |QTIGK & rqTDSD & 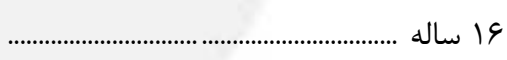 \\
\hline rv. & $\forall \& \Lambda$ & $\Lambda$ ᄉ & IFFADq & $1 \Delta V \Delta \varphi \Delta$ & T. TEYY & Vاله ................... \\
\hline raf & DFT & 199 & IFDSAT & IQ৭१०V & $r \cdot \Delta \Delta r q$ & \ ساله ......................... \\
\hline f. F & FEV & $\wedge \vee 1$ & IFGDST & 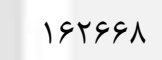 & r.qrr. & 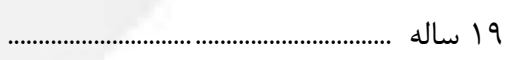 \\
\hline$r \cdot 11$ & rq०. & $\mid 9991$ & NTFISD & qVTAT. & 11.9910 & 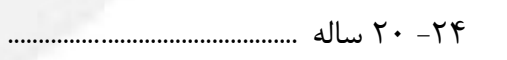 \\
\hline Dlf & $\Delta 91$ & $11 \cdot 0$ & IDTAST & $I V T \cdot \Delta T$ & rTDGIY & • r ساله ......................... \\
\hline r.. & $\Delta r$. & qщ. & IDVGTY & IATFVD & rF..qV & 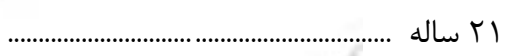 \\
\hline reQ & DQT & $9 \Delta V$ & 191199 & 198人૬र & $r \varphi \Delta \cdot \Delta \Lambda$ & r \\
\hline rQV & GrA & 990 & IVFqTa & $r \cdot V r q 9$ & TATTME & 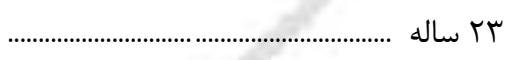 \\
\hline red & 9.9 & $q y^{4}$ & $1 \Lambda \cdot \wedge \Delta \cdot$ & אזוTוT & тqт৭人 & 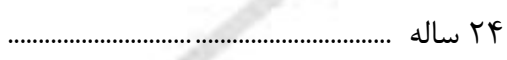 \\
\hline 1994 & r\&\&V & 1981 & १४१५^. & $111 \varepsilon \Delta \vee \wedge$ & $r \cdot 9 \Delta \wedge \Delta \Lambda$ & q - ه \\
\hline$\uparrow M$ & $99 V$ & $11 \Delta \Delta$ & 19V914 & THISID & दrqr. & 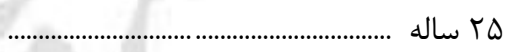 \\
\hline$r 9 \Lambda$ & $\Delta F Y$ & 915 & 190\%१9 & rYGQIV & FTYMIS & 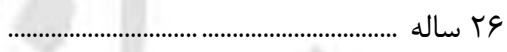 \\
\hline$k \cdot \Lambda$ & $\Delta T^{\prime}$ & qrV & 19янКк & TYFqIV & FTIT.. & Y Tاله .......................... \\
\hline rqV & eva & Net & 19940. & rTIDA. & 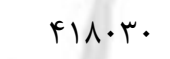 & 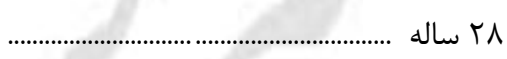 \\
\hline 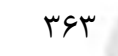 & FAT & 110 & I ITHET & rllarq & f. +9911 & q باله ................ \\
\hline IV9D & $r \cdot r \Lambda$ & $r \wedge \cdot r$ & $q \uparrow q \Delta V$. & $1.191 \mathrm{Tr}$ & 1999494 & 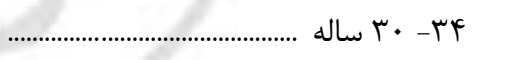 \\
\hline GIT & $\Delta \Delta F$ & 999 & $r \cdot 9991$ & $T T V \cdot G T$ & FTK. TD & 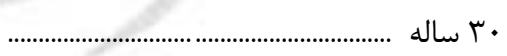 \\
\hline rFA & rq1 & vrq & 199199 & rMQIF & $r \cdot \wedge r \wedge$. & 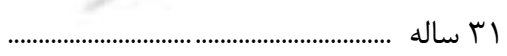 \\
\hline reQ & rq1 & Vबr & 19D९V. & $r \cdot \Lambda F \wedge G$ & $F \cdot F \mid \Delta \varphi$ & r ساله ............................. \\
\hline ryl & 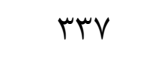 & sVA & $\mid \Lambda \cdot \Delta \xi \Lambda$ & $19491 \mathrm{~V}$ & 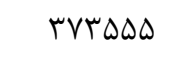 & 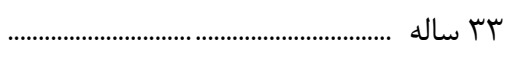 \\
\hline ५१९ & $r \Delta \Lambda$ & $9 \Delta V$ & $1990 \cdot \Delta$ & IVqVVr & rFqTVA & F ساله ........ \\
\hline
\end{tabular}


|- 1 - جمعيت بر حسب سن، جنس و وضع سكونت (دنباله)

\begin{tabular}{|c|c|c|c|c|c|c|}
\hline \multicolumn{3}{|c|}{ ساكن در نقاط شهرى } & \multicolumn{3}{|c|}{ جمع } & \multirow{2}{*}{ سن س } \\
\hline 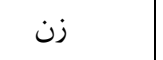 & 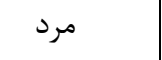 & مرد وزن & 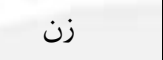 & 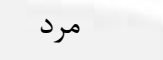 & مرد و زن & \\
\hline Тяятq४я & TVYArTd & DrqTrVI & TFEDI9D & rUVYF.r & $V \cdot r V \Delta 9 \Lambda$ & qץ- טץ ساله .................. \\
\hline 819人r1 & GMYATr & ITAFGGF & V१マ।A। & $\Lambda T \Delta V I$. & |รTY^9| & ه س ساله ................................. \\
\hline DSVGYA & $\Delta \Lambda \cdot 9 \Delta \cdot$ & IIFATVA & VTYADG & VDGYT. & IF^৭|VG & 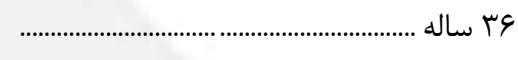 \\
\hline DTGTDS & DTqFFI & $1.9 \Delta 99 \mathrm{~V}$ & $9 \Lambda \Lambda \cdot r \Lambda$ & $v \cdot \wedge \wedge \vee \wedge$ & |rqव91द & 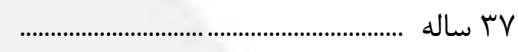 \\
\hline $49.9 r F$ & $\Delta \cdot r \Delta \wedge F^{\prime}$ & १q५r।^ & GA4EIT & 991914 & $1 \mu \cdot 9 r 9 \Delta$ & 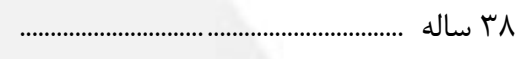 \\
\hline 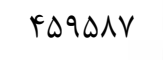 & FV.ATV & $9 F \cdot F \mid f$ & $\varphi \cdot r \Delta \cdot \Lambda$ & 919114 & ITYTYT. & q ساله .............................. \\
\hline$r \cdot \Delta \mid \Delta T$. & TIrgTKE & FIAVAイ\& & TV.FFIV & 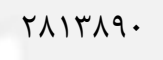 & $\Delta \Delta \backslash \Lambda Y \cdot V$ & fr \\
\hline FAFTAT & kV.qkr & १५०।१९ & 091.91 & qr...11 & $|r| 1 \mid \cdot q$ & 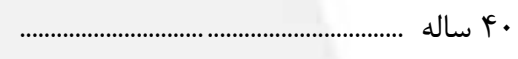 \\
\hline FTITID & 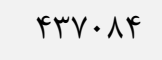 & 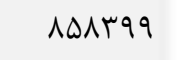 & $\Delta \Delta \Delta \Delta \varphi$. & $\Delta V V I 9 \Lambda$ & IITrVDA & أ ساله ................ \\
\hline$f \cdot k+49$ & FrIT. & NTAVr. & $\Delta T \Delta \cdot G r$ & $\Delta \Delta \Delta r G q$ & $1 \cdot 9 \cdot k+1$ & Y Fاله .............. \\
\hline rqDF६. & FITEAV & $\Lambda \cdot \wedge 91 \vee$ & $\Delta T \cdot \wedge \& V$ & DFrAVq & 1. EqVFe & זع ساله ........ \\
\hline rVG. Tr & 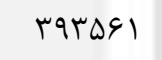 & Vदq9.F & FqFAT. & DIVKr & 1.ITrGK & ............. fy ساله \\
\hline INTAr.r & $19 \cdot r \cdot 9 V$ & rVr. ५৭q & rrV^ৎqя & TFAFFTV & אוזוTIT & \\
\hline F. GArq & frq119 & NTGGSD & DTEGED & $\Delta G H T \cdot G$ & $1.9 \vee \wedge \Delta 1$ & هi ساله ......... \\
\hline$r V F \cdot F Q$ & $r q \cdot \wedge \wedge \Delta$ & VG\&qT. & rAVI.r & $\Delta \cdot V F V \Delta$ & 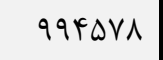 & \& \& ساله ............... \\
\hline reVIFG & rATAIT & $V \Delta \cdot 9 \Delta 9$ & frrv.. & FqDTG. & १४५৭द. & FV ساله ............. \\
\hline rQVDTA & rя९१q1 & $V T \Delta \Delta 19$ & |FGTAGI & F९9०VI & TrTITr & ^^ ساله ................ \\
\hline TrTVAF & rrqAqr & GATEYS & FIG9AV & $41 \wedge 910$ & $\Delta r \Delta G \cdot r$ & q \\
\hline $10 \cdot F V \nabla \mid$ & IOFGDTA & $r \cdot \Delta I r \cdot \varphi$ & 190.r9V & I9VDQVYF & rqYब१V। & 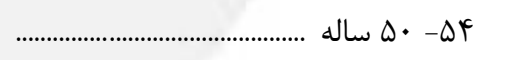 \\
\hline rTMGVV & TETTVY & $91190 \mathrm{~F}$ & frvqur & FrVVDQ & $\Lambda \vee \Delta ૬ \Lambda \Lambda$ & 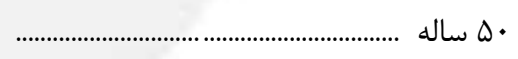 \\
\hline rq14qq & $r \cdot \Delta I \Delta T$ & 9.4901 & 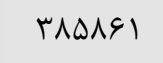 & rAYkq9 & VVRTG. & 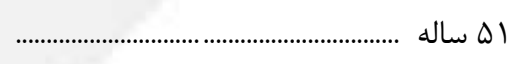 \\
\hline rqDIFQ & $r \cdot q \cdot r \Delta$ & $9.11 \mathrm{~V}$. & 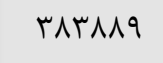 & rq19द4 & $V V \Delta \wedge \Delta T^{\prime}$ & .................... \\
\hline TQT\&QI & $r \cdot r<91$ & DQDTFT & rVAV·D & rAGAFI & $V \varphi \Delta \Delta F \varepsilon$ & 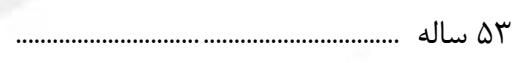 \\
\hline rVqvaq & гАqтq. & $\Delta 991 \wedge 9$ & rgF..q & TVIDIA & $V T \Delta \Delta Y^{F}$ & 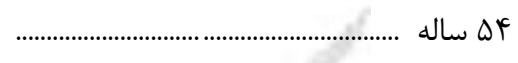 \\
\hline$|r \varepsilon \wedge \Lambda \Lambda|$ & $|r \wedge \Delta q T|$ & TODFAIT & 191.909 & Iद9994 & $r r \Delta \cdot \Delta q r$ & \\
\hline TAGQTT & rq1V99 & $\Delta \vee \wedge r \cdot I$ & $r V V \cdot 90$ & rVVArr & VQFqYA & ه هاله ................. \\
\hline TETIVI & reDQVT & DTVYFT & TEESTV & Thtr.r & 9ヘV१Y. & وه ساله ................. \\
\hline 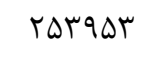 & TAGFIV & $\Delta 1 \cdot r V \cdot$ & TMGGTF & 的. & $q V \cdot r \cdot r$ & هV ساله ................ \\
\hline TFFEDT & rFAkrq & kqr.qr & TrQqTr & TrMADV & q4qYq. & ه \\
\hline TYIQVT & TrTVMF & FAST. & т৭янА. & rq|r\&l & $\Delta \Lambda V E A I$ & 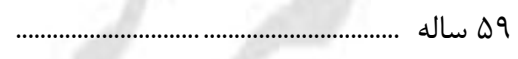 \\
\hline $90 \cdot 111$ & $9 q \cdot k r$. & $19 \mid \cdot \Delta F A$ & $|r \wedge 99|$. & ITATGG & TOFTAVT & ب ع- •ع ساله \\
\hline TrITGS & TMFAT & FFANFA & rq०Q.1 & rq1/4s & $\Delta \Lambda V \cdot F V$ & . 9 ساله ... \\
\hline 1999r1 & $r \cdot v \wedge q$. & $F \cdot V \times q l$ & $r Y I \cdot T s$ & TVTIQV & DFTYTH & 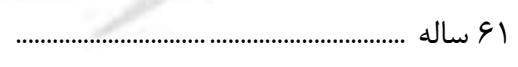 \\
\hline IArVAq & $\mid \wedge \Delta 9 \Delta \Lambda$ & requeV & $r Q \cdot q R V$ & THATH & Fqq4A. & 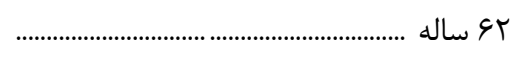 \\
\hline ivлrqa & |V९qT| & TQDHTY & rerATq & THITE & $\varphi v \Delta \cdot \Delta \Delta$ & ץ \\
\hline $19 \times 199$ & $19 \Delta \& 99$ & rrTs9d & TMAT.V & TIFDS| & FETVEA & 19 \\
\hline
\end{tabular}


1 - 1 - جمعيت بر حسب سن، جنس و وضع سكونت (دنباله)

\begin{tabular}{|c|c|c|c|c|c|c|}
\hline \multicolumn{3}{|c|}{ غير ساكن } & \multicolumn{3}{|c|}{ ساكن در نقاط روستايى } & \multirow{2}{*}{ سن } \\
\hline 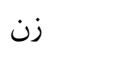 & 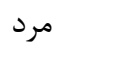 & 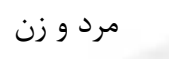 & 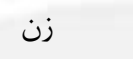 & 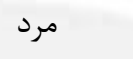 & 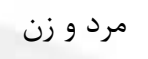 & \\
\hline $119 \vee$ & $r \cdot r$ & rq.. & V११४⿻ & NFT. 90 & IEFIFTV & \\
\hline וT & iv. & $9 \cdot 1$ & $1 V 9919$ & $19 \cdot 4 \cdot V$ & reVTrg & 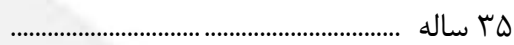 \\
\hline rAT & $r \cdot \Delta$ & VAV & ISFAFE & IVATED & $r F .111$ & عب ساله ................... \\
\hline TQF & rVA & VTr & ISIFTA & 199.09 & זT. FAV & 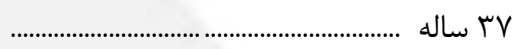 \\
\hline rq & rqq & VAV & $\mid \Delta r \Delta \wedge \Delta$ & $|\Delta \wedge\rangle \cdot \Delta$ & rirrq. & يץ ساله ........... \\
\hline Vזr & raq & $99 \pi$ & IFrQAF & IFAGTq & rqIrIT & q ب ساله ........ \\
\hline $109 \Lambda$ & laTr & r19ब & $901 r \cdot 9$ & GVQqIV & ITTVYTS & ......... \\
\hline$f \cdot r$ & $r \cdot r$ & $\Lambda \cdot V$ & $\mid$ FEFF| & $\mid \& \wedge \Leftrightarrow 9 \Delta$ & rqr।. & r............ \\
\hline ז. & rit & GTr & 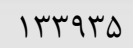 & $1 r q 1 \cdot r$ & TVRYTV & أf ساله .......... \\
\hline rqf & MTY & GTI & $1 r \cdot r q 9$ & $\mid$ MrVFi & rGY.Y. & ץ א ساله ...... \\
\hline$r \cdot r$ & TAT & $\Delta G F$ & $|r \Delta| \cdot \Delta$ & $1 \% \cdot 19$. & TADTED & بع ساله .... \\
\hline$r \Delta \Lambda$ & זr & $\Delta \wedge 1$ & $11 \wedge \Delta T_{9}$ & ITrDFq & TFT.VA & 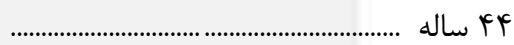 \\
\hline IFrg & $19 \cdot V$ & $r \cdot r q$ & $\Delta F \wedge १ ९ \Delta$ & $\Delta \Delta \cdot V T r$ & $1.999 \wedge \wedge$ & \\
\hline rat & rqq & $V \Delta \Lambda$ & ITVFAT & Irrq99 & TG. FYA & له أ ساله ..... \\
\hline rq. & $r \Delta V$ & GFV & IIrVEA & IIETrM & rrq..l & צ \\
\hline rDQ & וזץ & $\Delta \wedge \vee$ & $11 . r 91$ & $\|1\| f \mid 9$ & TYIVIF & VV F \\
\hline TVG & TAV & Q & 1. FVDV & 1.1rqr & $r \cdot 4 \cdot \Delta$. & يץ ساله ..... \\
\hline TF & ג & FAl & q५яq. & $\Lambda \wedge \vee \wedge \Delta$ & IAYEVD & q q ساله ........ \\
\hline Irrq & $1 Y \cdot 9$ & TFMA & feprap & FrVAr. & AVTrTY & ........ \\
\hline MFF & ५ १९ & Ger & $9 \wedge 91 \%$ & qFivq & 194.91 & • ه ساله ....... \\
\hline זrז & TIV & Fa. & AVIrq & ArIT. & $1995 \Delta 9$ & اله ساله .. \\
\hline 199 & raT & FAT & $M N D F \Delta$ & $\wedge \Delta \& \wedge \&$ & IVETHI & ماله .......... \\
\hline r tra & q & fre & 10119 & 人rq)। & $199 \mathrm{Vr}$. & ץه ساله ......................... \\
\hline$r \mid \Lambda$ & $r \cdot 1$ & 419 & 人rq9 & N19TF & 190919 & 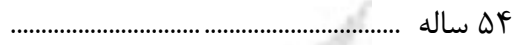 \\
\hline $1 \cdot 0$. & 1109 & Tr. & $F I \cdot V T \Lambda$ & TAYAFE & VQTOVT & \\
\hline$r \Delta V$ & $r \Delta q$ & 019 & $q \cdot r \cdot q$ & $\Lambda \Delta \Lambda \cdot \Delta$ & $\mid V 9111$ & ( $ه$ ساله .... \\
\hline r19 & TrQ & FED & ATrug & $V V Q \cdot \Delta$ & IDQYFT & هو ساله ........ \\
\hline 1199 & TMT & FTI & ATFAT & $V V \cdot r l$ & $10901 \%$ & هاله ........... \\
\hline rIT & גזr & $F \Delta$. & 11.91 & VQIA. & IDGKFA & Q \\
\hline IVT & $r \cdot r$ & rVV & VFATd & GVTKK & $|F| 901$ & ه ساله ................... \\
\hline 111 & $99 \wedge$ & IV^S & rr人qve & rq1red & $q r \cdot r r q$ & 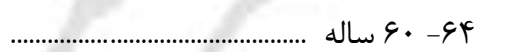 \\
\hline T\&9 & TrI & $\Delta \wedge \vee$ & VETEQ & GGTKR & $|r \cdot 9| r$ & 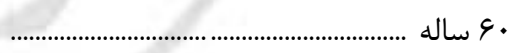 \\
\hline IQT & 194 & rls & $V I D \cdot r$ & gFIFT & IrDSFE & ا9 ساله ............. \\
\hline 10 . & 114 & 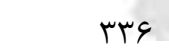 & $9 \vee \cdots 1$ & $\Delta \vee \& \wedge q$ & IrFegV & r \\
\hline Ir & IVT & щ. & GQTQD & DFITK & 119411 & 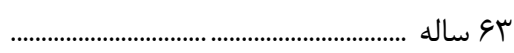 \\
\hline 114 & ira & r & $9 \cdot 199$ & ४イ৭९V & 1.91499 & 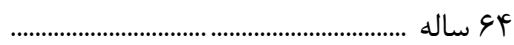 \\
\hline
\end{tabular}


|- 1 - جمعيت بر حسب سن، جنس و وضع سكونت (دنباله)

\begin{tabular}{|c|c|c|c|c|c|c|}
\hline \multicolumn{3}{|c|}{ ساكن در نقاط شهرى } & \multicolumn{3}{|c|}{ جمع } & \multirow{2}{*}{ 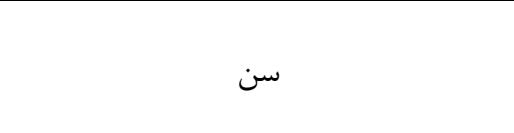 } \\
\hline 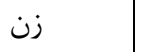 & 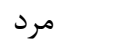 & 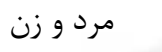 & زن - ان & 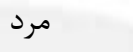 & مرد و زن & \\
\hline G\&VqD. & $G \cdot \Delta \cdot V \Lambda$ & $I T \Delta r \cdot r \Lambda$ & $q \cdot r \Delta \Delta F$ & $\Lambda \cdot \wedge 91$. & IVIIFEF & 1................. \\
\hline 1994.4 & lOQTAF & TMIOAV & rrqq1. & 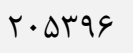 & Frar.G & 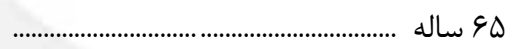 \\
\hline$|r| \ldots$ & ITYAVq & rorAvq & IAYF. & 1янтя. & MFDVqQ & צ \\
\hline IrAV৭q & ITTG.Y & $r \Delta I F \cdot r$ & 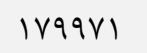 & IETEVE & Temef & 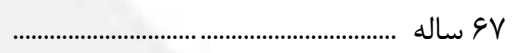 \\
\hline llraVt & $1 . F F V$ & $r \mid \Lambda \cdot k q$ & 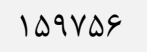 & IFINTK & $r \cdot \mid \Delta \Lambda \Lambda$ & 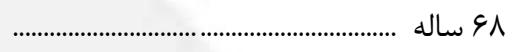 \\
\hline $1 \cdot \Lambda V_{F}$ & ११४४५ & $r \cdot \Lambda 11$. & $10 \cdot 011$ & $\mid$ IFAls & TADTTV & 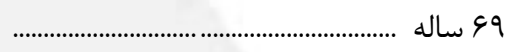 \\
\hline FTETTY & FIDTAT & $\Lambda \uparrow q \Delta \cdot \Delta$ & $9.901 \pi$ & $\Delta V \| 11 r$ & IIVVEYD & ساله ............... \\
\hline $11 . \mathrm{kF}$. & qvqץ. & $r \cdot \wedge r \wedge$. & 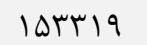 & $1 \% T \Delta 19$ & 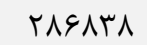 & 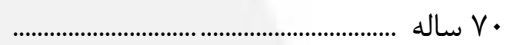 \\
\hline qrTVD & $M M N I T$ & $1 \Lambda T \cdot \Lambda V$ & Irq9.r & $1 T \cdot 991$ & $r \Delta \cdot r \cdot l$ & اله ساله \\
\hline AVVYI & $\Delta V \cdot \Delta r$ & IVEVVT & IrTs & $I T \cdot \Delta r V$ & rerqIT & Vاله ................................ \\
\hline VATEV & VTVGq & IFA|re & $1 \cdot r \Delta \Delta \Lambda$ & 1.rrrv & r.99TD & ساله ................................ \\
\hline 91419 & sVVI. & 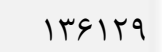 & QDSTV & $q q \cdot r 1$ & $1 \wedge 994 \wedge$ & ساله ........................... \\
\hline$r \cdot \Delta \wedge r q$ & $\Pi 11 \cdot \wedge \Delta$ & 9199TF & Frfqur & Falfiq & 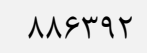 & ساله ............. VQ -Vq \\
\hline$V F \cdot . q$ & $V \cdot I K F$ & IfFir. & $1 \cdot F \Delta \cdot 4$ & $9 \wedge \wedge \wedge \Delta$ & r.rrql & ساله ................................ \\
\hline GKITI & gFIVT & ITVYar & $1 M \wedge F q$ & 91499 & $|\Lambda \cdot r| \Lambda$ & ساله .............................. \\
\hline$\Delta \wedge \cdot 99$ & 09909 & $\| V V \Delta \Lambda$ & NYqIV & 19909 & $1991 v 9$ & 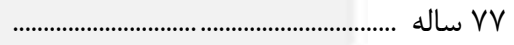 \\
\hline DVTrq & $\Delta q \cdot Y I$ & l1बrv. & $\wedge 1 \Delta \& \Delta$ & NAVYI & $19 \Lambda \mu \cdot 9$ & ساله .................... \\
\hline DTRAF & $\Delta \Lambda \cdot \wedge 9$ & $111 \pi v r$ & VVIrs & AVrGa & $1940 \cdot 1$ & 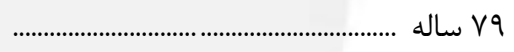 \\
\hline$T I \cdot F \Delta I$ & rTrQADa & Frefte & $r \cdot r \Delta \cdot r$ & I & GKGVTr & 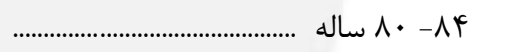 \\
\hline$\Delta \& \wedge \Delta \Delta$ & GIVA9 & ||$\Lambda \& Y \mid$ & $119 \cdot r$ & $q \mu \Delta \vee \Delta$ & IVDFVq & • ^ ساله ................................ \\
\hline frrq. & $\forall q \cdot \wedge V$ & MAFVV & sT. If & $V \cdot \Delta V \Delta$ & 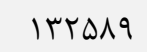 & 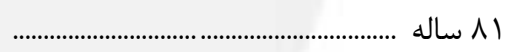 \\
\hline$\psi_{1} \cdot$ r & FTVTV & ArVGr & $\Delta q \cdot \Delta V$ & $9 \Delta r \cdot 9$ & ITFrgG & 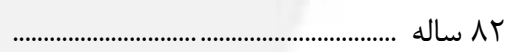 \\
\hline$r V V \cdot r$ & rqmוg & $V V \cdot r_{I}$ & $\Delta F \mid F \wedge$ & $9 \cdot 019$ & $11499 \mathrm{~V}$ & ץ ساله ................................ \\
\hline MTFGA & $\mu r \cdot \wedge q$ & $9 \varphi \Delta \Delta F$ & fervq & DrTQT & १९९ार & ^^ ساله ......................... \\
\hline $1.9 T \Delta 1$ & 1. TVTS & $r \cdot 1919$ & $|0| \cdot r G$ & ISIFFA & TITFAF & 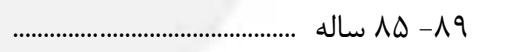 \\
\hline . & MrG9D & $90 \wedge 90$ & FVrAr & $\Delta 1 \cdots r$ & 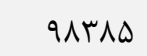 & 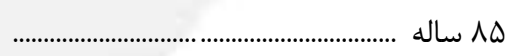 \\
\hline TrVVT & $r \cdot I V$ & perq. & TTFAT & MFG. F & $s V \cdot \wedge V$ & ع ساله .............................. \\
\hline 19119 & $11 \cdot r q$ & rVIQA & TVIVE & rADGY & $\Delta \Delta V Y V$ & 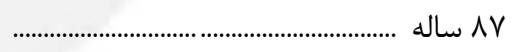 \\
\hline IVTqR & $18 r \cdot 9$ & rra. & TFTER & $r \Delta F \Delta D$ & 99111 & 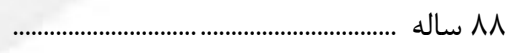 \\
\hline Ir人ז & $\| \mu \cdot \Delta$ & TVEFT & 19Gr & TIATE & FIFAV & 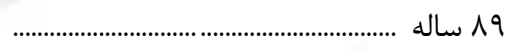 \\
\hline ए人९ा૬ & rVDG & VGIVq & $\Delta r \wedge \Delta q$ & $\Delta V Y i s$ & $\| 11 \Delta V \Delta$ & 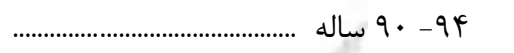 \\
\hline 1 1тrq & $|M| 9 V$ & $r \& \Lambda \cdot \varphi$ & $19 \cdot 19$ & $r \cdot r \cdot \varphi$ & rqpqr & 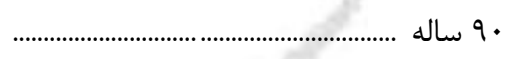 \\
\hline १९V४ & १^६ & $|9 \Delta F|$ & IrFTF & IDT.. & TAGTY & 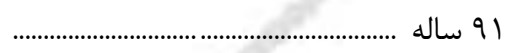 \\
\hline $99 \cdot 0$ & G94N & Irofr & $q 4 .$. & $1 \ldots 98$ & 19499 & 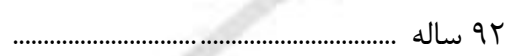 \\
\hline D. & evqv & qА५. & VIrV & VTrI & $14 r 91$ & ץو ساله .................. \\
\hline | & $r \cdot 91$ & sfQq & FNIT & eVtr & $9 \Delta \Delta \Delta$ & 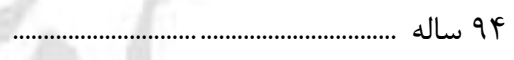 \\
\hline gq4V & $\Delta \& \& 1$ & $M F \cdot \Lambda$ & १९४४ & $\Lambda \vee r$. & IAqVV & .............. \\
\hline ( ) & rAfr & $94 \cdot 9$ & r^a. & FOIN & $94 \cdot 1$ & ه \\
\hline IDTD & 1195 & TVIV & $r 1.9$ & INTD & rq4i & 9 9 ساله ................... \\
\hline 911 & 99. & $19 V 1$ & irva & $11 K \Lambda$ & $r \Delta \cdot V$ & 9اله ................... \\
\hline 914 & FVV & 1.91 & 191 & VVI & 1994 & 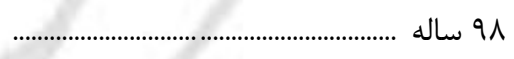 \\
\hline$r \Delta V$ & $r \Delta q$ & VIS & $9 \wedge 1$ & EVA & 1109 & 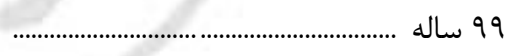 \\
\hline$r \cdot I V$ & 191. & reqv & r & rive & $9 \Delta \& \Lambda$ & 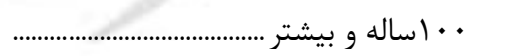 \\
\hline$r / / 9$ & $r \mid / r$ & ri/d & $r \mid r$ & $r \cdot / 9$ & $r / / 1$ & 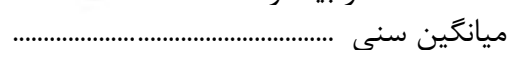 \\
\hline$r$. & r. & $r$. & $r$. & r. & r. & ميانه سنى ..................................................... \\
\hline
\end{tabular}


|- 1 - جمعيت بر حسب سن، جنس و وضع سكونت (دنباله)

\begin{tabular}{|c|c|c|c|c|c|c|}
\hline \multicolumn{3}{|c|}{ 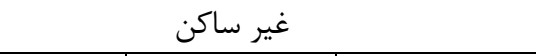 } & \multicolumn{3}{|c|}{ ساكن در نقاط روستايى } & \multirow{2}{*}{ سن } \\
\hline 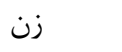 & 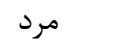 & 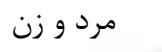 & 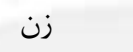 & 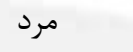 & 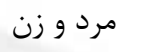 & \\
\hline faq & GrA & $1 \cdot 1 \mathrm{~V}$ & TAFIFD & $T \cdot r \cdot T \cdot F$ & FAVYFq & 99- $9 \mathrm{a}$ ساله ................. \\
\hline Ir. & 191 & TrI & gravr & FQATा & 111\%91 & ه \\
\hline VV & 119 & 194 & Q DIrT & $r \cdot r 9 \Delta$ & QIVTF & 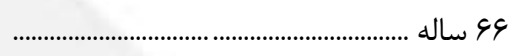 \\
\hline AT & $1 \cdot r$ & $1 \wedge \Delta$ & $\Delta 1 \cdot 9$. & $r \cdot v \Leftrightarrow q$ & $91 \wedge 09$ & VV \\
\hline ז & $1 \cdot 1$ & $r \cdot 1$ & $49 \cdot 19$ & TVRFq & גוזואו גו & ^ عاله ..................... \\
\hline VV & 11. & IAV & Fr. & reqv. & $V V \cdot r \cdot$ & 99 ساله .................................................. \\
\hline rAG & זri & 119 & $I V T \cdot \sigma$ & ।DQT৭Q & THYF. I & ساله $V \cdot-V F$ \\
\hline 9 . & 109 & rFq & FrVAq & TDFT. & VAr. $q$ & ساله ............................ \\
\hline$\Delta \varphi$ & Ve & IrT & TETVT & 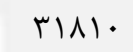 & $9 \Lambda \cdot \Lambda r$ & 1 اله .............................. \\
\hline L & $\checkmark \cdot$ & rr & $r \Delta \varphi \cdot r$ & rrFid & $99.1 V$ & ساله .............................. \\
\hline$\forall \wedge$ & $\checkmark \cdot$ & 111 & $r \cdot I V \mu$ & 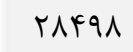 & $\Delta \wedge \subseteq \vee 1$ & ساله ..................... \\
\hline rq & $\Delta \Lambda$ & १७ & rVIsq & TETAT & DHFTY & ساله ............................. \\
\hline 109 & rq & pqq & 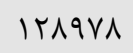 & $|f \ldots q|$ & $r 99.19$ & ساله .................... V VQ Vq \\
\hline FV & VQ & rז & $r \cdot r \Delta r$ & 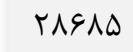 & $\Delta 91 \% \wedge$ & ساله ................................ \\
\hline TF & $\Delta 9$ & $\wedge r$ & $r \Delta V \cdot r$ & TVTHA & DTQRT & ساله ............................ \\
\hline tr & Lr & VQ & TFYqG & TVYFY & $\Delta T \cdot F T$ & ساله .................................. \\
\hline tr & $\Delta \Lambda$ & $\Lambda \Delta$ & TFY. & TVEFT & $\Delta|\wedge \Delta|$ & 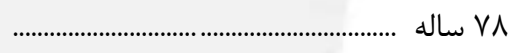 \\
\hline re & FV & $\Lambda \mu$ & rrals & rarrq & $\Delta r \cdot F \Delta$ & ساله ........................... \\
\hline 114 & TrV & एव) & q५वाV & 1119999 & 5119.9 & ץ • • • ساله ............. \\
\hline ro & qv & Trt & $r \Delta \cdot \mid r$ & rivit & DSVTS & 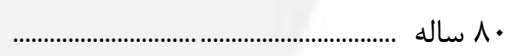 \\
\hline r & $\Delta T$ & $v \Delta$ & $198 \cdot 1$ & TFETS & $F F \cdot r V$ & 1 1 ساله ................... \\
\hline 10 & $i \wedge$ & ז & $11 \cdots 9$ & TrATF & $f \cdot \Delta f$. & ז \\
\hline$r \cdot$ & ET & GT & IETtE & $r M \Delta \Lambda$ & rVDAF & 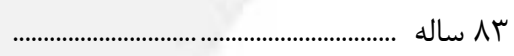 \\
\hline rI & ऍ人 & $\Delta q$ & 1т人я. & 19179 & 19. & 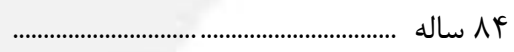 \\
\hline $4 q$ & lff & 194 & FEVTE & $\Delta \wedge \Delta \varphi q$ & D. D. & .................................................. \\
\hline 11 & rی & $\Delta \varphi$ & IfIro & $14 r 99$ & ThFTE & (............................ \\
\hline 9 & FV & $\Delta \varphi$ & $9 \vee \cdot 1$ & ITAF. & THTEI & 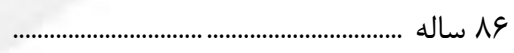 \\
\hline If & re & c. & $\Lambda \cdot+1$ & $1 .+91$ & INQTq & N ساله ............................. \\
\hline r & TF & tr & $v \cdot 9 \Lambda$ & TTYT & 19r9. & 1 ساله ....................... \\
\hline$\Delta$ & 9 & 14 & $\Delta \vee 91$ & $\wedge \cdot 1$. & $\mid r \Lambda \cdot 1$ & 19 ساله .................. \\
\hline 19 & fF & 4. & IDTTV & $r \cdot 1.9$ & g & 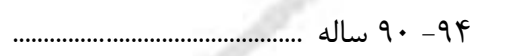 \\
\hline r & 19 & 19 & DFFF & VTRT & IT\&GV & • 9 ساله .................. \\
\hline f & $1 \cdot$ & 14 & TVAT & QTY & $9 \cdot v 9$ & 19 91 ساله ................. \\
\hline r & 9 & ir & tFqT & refq & $\Delta q F i$ & ז 9 ساله .................... \\
\hline$\Delta$ & \& & 11 & $r \cdot 19$ & TFAN & $r \Delta \Delta V$ & بو ساله ............... \\
\hline 1 & r & f & $1 \notin \Delta$. & IETT & $r \cdot 9 r$ & ץ q qاله .......................... \\
\hline$\wedge$ & $\Delta$ & ir & r৭9 & rTGY & GTDG & 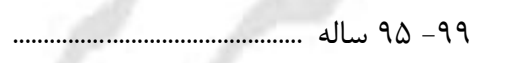 \\
\hline$\Delta$ & r & V & IOTK & $19 V \pi$ & m190 & ه9 ساله ....... \\
\hline 1 & 1 & r & $\Delta \wedge$ & GKT & ITTK & 9 9 ساله ................. \\
\hline 1 & 1 & r & rq. & fry & ATV & ף \\
\hline 1 & 1 & r & TVG & ra & $\Delta \varphi q$ & 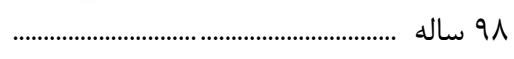 \\
\hline$\cdot$ & · & $\cdot$ & TME & r19 & fer & 9 ساله ........................................................ \\
\hline$r \cdot / q$ & $r 1 / 1$ & $r \cdot / \Lambda$ & $r \cdot 10$ & rq/V & $r \cdot / 1$ & 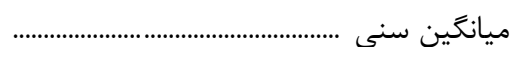 \\
\hline rq & $r \Lambda$ & $r \Lambda$ & ru & TA & rA & ميانه سنى ......................... \\
\hline
\end{tabular}


r - 1 - جمعيت بر حسب جنس، سن و تابعيت

\begin{tabular}{|c|c|c|c|c|c|c|c|c|}
\hline 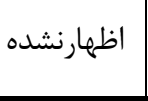 & كشورها & 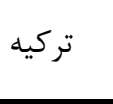 & 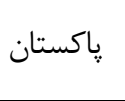 & 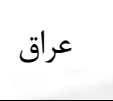 & افغانستان & 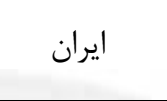 & 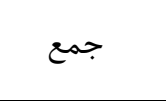 & جنس و سن \\
\hline $1 \cdot \Delta \cdot \varepsilon$. & $r \cdot \Lambda F F$ & vir & Ifrer. & reart & lastarg & raisgarr & raqugrr. & 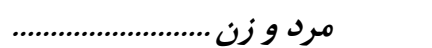 \\
\hline$q \Delta \gamma$. & trut & $\wedge \Delta$ & $19 \cdot V$ & TFT. & IVDTYA & $99.99 r$ & $v \cdot q r \cdot r$ & F \\
\hline NFrs & rוt & $\Delta F$ & 1110 & 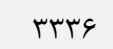 & 191 rAV & $g r \cdot f I T g$ & GFIITVV & 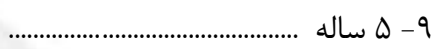 \\
\hline VTYA & IFYA & fF & 1191 & $r \cdot r q$ & IAYVDD & $\Delta \& q \cdot V \cdot r$ & $\Delta \& \Lambda \Lambda Y \wedge F$ & 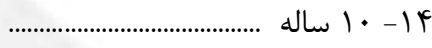 \\
\hline 9999 & 1491 & q. & 1119 & FrVA & $\mid V r \cdot \Lambda \cdot$ & DYVI৭१९ & $\Delta F \Delta \wedge १ १ \vee$ & 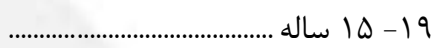 \\
\hline$\wedge V{ }_{\Lambda}$ & $r V \cdot G$ & $9 \Delta$ & I\&r人 & 190 & 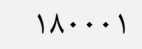 & 9199011 & 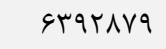 & 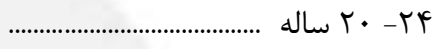 \\
\hline 11114 & 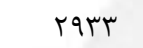 & VI & ।Vq1 & trith & $19 T \cdot V \Delta$ & $\Lambda \cdot r \cdot r q r$ & سזוI & 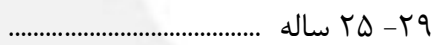 \\
\hline $1 \cdot \Lambda T_{1}$ & trVA & 99 & $1 \Delta \Delta \varphi$ & ו וזrז & ITIFT & NFETFTV & $\wedge \varepsilon \cdot .911$ & 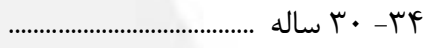 \\
\hline 1999 & $10 \Delta 9$ & 9) & Mr & trRi & $1 \cdot \Delta F \Delta \Delta$ & 991人fru & $V \cdot r V \Delta q \Lambda$ & 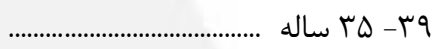 \\
\hline Grst & 1.49 & $9 V$ & VTG & titt & VVGFT & DFT. & $\Delta \Delta \backslash \wedge \mu \cdot V$ & ساله \\
\hline DATV & Arr & r山 & DTr & $r \cdots \wedge$ & \&r人\&s & FVGI. Fr & שTMTITR & 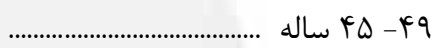 \\
\hline$\Delta 111$ & $\Delta G F$ & ry & TTV & $1 \wedge \wedge \Delta$ & $\Delta r \Lambda \cdot r$ & rAGDTF. & rarఎqVI & ..................... \\
\hline pret & fif & 10 & 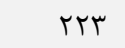 & Iras & $r F V \cdot \Lambda$ & m.qpqf & rrd. & 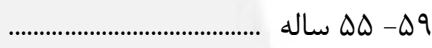 \\
\hline$r \Delta \Delta V$ & $r \cdot r$ & 1. & 190 & llgt & سוקוצr & TDIITFT & TAFTOVT & ...................... 94 ساله \\
\hline rDSQ & 190 & r & $\Lambda r$ & Drt & $10 \cdot 8 r$ & $1994 \cdot 19$ & IVIIfGF & ..................... 90 - 99 \\
\hline$r \cdot q$. & irq & $\Delta$ & $9 \wedge$ & rva & $1 \cdot+10$ & llEFDFT & IIVVGTA & ساله ...................... -VF \\
\hline raIV & $|r|$ & r & $\Delta \Delta$ & fFY & l1גrV & 1999Tar & 19NTFYq & 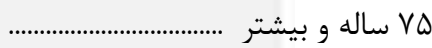 \\
\hline$\Delta 9\|\|$ & $|r| \varepsilon \mid$ & frg & Arry & I9rra & AFATEV & rqDDqfTr & F. Fq1FFr & 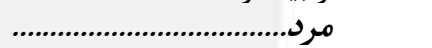 \\
\hline $0 \cdot 1 f$ & $|4 \varepsilon|$ & $\uparrow \wedge$ & $1 \cdots 1$ & Irar & $q \cdot I r F$ & $r \Delta \Delta \cdot \wedge \Delta T$ & rgYqA.. & ץ \\
\hline rrqd & 1.90 & rr & qfF & IVFA & 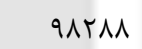 & 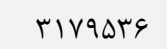 & 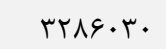 & 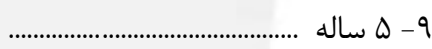 \\
\hline rAFd & Vrr & rt & 919 & $r \cdot \Delta V$ & qfVVq & $r \Lambda \cdot q r V \cdot$ & rqIIfTr & f| \\
\hline r५99 & VYI & r) & $\Delta V V$ & TTET & $\wedge 99 \cdot 1$ & 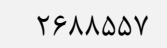 & 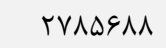 & 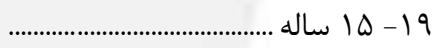 \\
\hline $\mid \notin \Phi \Delta l$ & IFFA & זی & $9 \Delta \Lambda$ & IVrq & $9 r \cdot r \wedge$ & TITDITE & TrMGQVD & .................... \\
\hline $9 \cdot 9 \wedge$ & IVFe & fi & $1 \cdots f$ & IDQT & 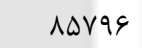 & F. FVTrL & fIFTfFS & .................... \\
\hline 9.90 & $\mid f \wedge \Delta$ & iv & $99 \Delta$ & 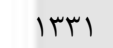 & $991 V 9$ & FTEFTFE & $F T F \cdot F F \Lambda$ & 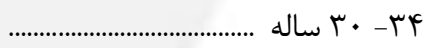 \\
\hline FATK & $1 \cdot \Delta \Lambda$ & is & $V F V$ & $|r R|$ & Q991. & ru.vQTq & rQVYF.r & 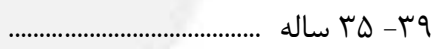 \\
\hline reqG & $R \cdot r$ & $\Delta F$ & $\Delta \cdot r$ & Itrat & $F F \cdot V V$ & rVATVVV & rᄉIr^q. & ساله \\
\hline TrAT & $\Delta \Delta V$ & tr & rFA & ITFD & rFANK & FFIF. IF & TFDFFTV & ساله . fq \\
\hline T\&M & 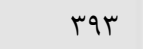 & rV & rma & $1 \pi \cdot 1$ & $r \cdot \mu \gamma f$ & $194 \cdot 0 \cdot 9$ & 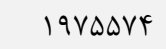 & 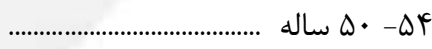 \\
\hline trRi & TrF & ir & 109 & qVF & $r \cdot 9 V T$ & $1 \& F \Delta \Delta V \Delta$ & 199994F & - \\
\hline$|\wedge|$. & $r \cdot$. & V & $11 \mathrm{~V}$ & 119 & IETAV & פ & ITATGG & 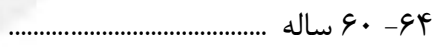 \\
\hline س & ع & r & $\Delta V$ & $r \Delta \cdot$ & q4re & V৭VArळ & $\wedge \cdot \wedge 91$. & 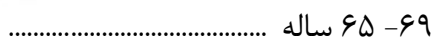 \\
\hline $9 \wedge \mathrm{F}$ & vq & $\Delta$ & $\Delta F$ & $r \cdot V$ & 9019 & $\Delta G T 19 F$ & $\Delta V \| 11 r$ & ساله V..................... -V \\
\hline$M \cdot r$ & VQ & 1 & rq & Trta & VVFF & $1 \cdot 1 \Delta \Lambda \mu F$ & $1 \cdot T \Delta V T \cdot$ & 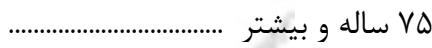 \\
\hline FAqqq & $1 \notin 1 \%$ & raf & D99\% & $\mid F A \cdot V$ & rravir & $r(\varepsilon) \cdot r_{.}$. & rqfrrara & 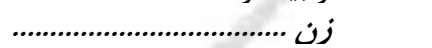 \\
\hline$F \Delta \Delta \varphi$ & $|r v|$ & rv & 199 & IITV & $\Lambda \Delta Y \cdot T$ & 吾 & TEFTt. F & ץ · שاله ...1. \\
\hline$r \cdot \Delta l$ & $1 \cdot 11$ & tr & $\wedge \vee 1$ & $|\Delta 9|$ & 94.99 & $r \cdot r F \Delta q$. & MITATFV & 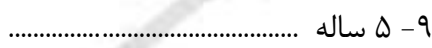 \\
\hline 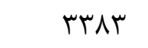 & 994 & rt & $\Delta \wedge T$ & I9VT & 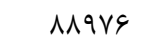 & (9) & TrVG৭\&l & f \\
\hline (ب.. & VVV & rq & Qrq & r.re & NrIVq & rDArFrq & TEVRT. q & 19 1 1 1 ساله ......... \\
\hline$r \cdot \Lambda$. & $|r \varepsilon|$ & $\Delta V$ & 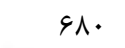 & If9s & 199V & r. GIrAV & $r \mid \Delta \Delta q \cdot r$ & 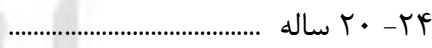 \\
\hline $0 \cdot 49$ & $11 \wedge \mathrm{V}$ & rV & vqf & 1199 & VATVq & rqVTIDq & $r \cdot \Delta \vee \& \wedge \Lambda$ & qr \\
\hline FVre & var & rt & $\Delta 91$ & $1 \cdots$ & $\Delta \Delta T \Delta T$ & $4 \mid 91 \cdot 11$ & FTG. FGD & ץ \\
\hline rAGY & $\Delta \cdot 1$ & 10 & rVG & $1 \cdots$ & $F \wedge \Delta F \Delta$ & $m|4| \cdot \wedge 9 q$ & MYGDI9D & q \\
\hline 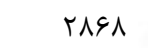 & rFV & r & TrF & $\Lambda F$. & rMAGG & 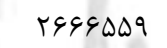 & tr.FFIV & 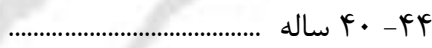 \\
\hline rQVF & r৭9 & $\wedge$ & IVF & घq4 & rVqAr & THFV. rA & rrVAৎ9я & 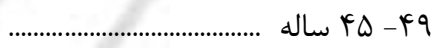 \\
\hline TFAV & $|v|$ & v & qr & $\Delta V V$ & trmtg & I9TFVMF & 19Q.r१V & 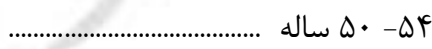 \\
\hline$r \cdot V t$ & If. & r & $9 V$ & FTr & $\mid f \cdot r q$ & 1994919 & 191.909 & ـ \\
\hline IVFV & $1 \cdot r$ & r & $\uparrow \wedge$ & rFA & qVic & $\mid r V V q 19$ & $|r \wedge 99| \cdot$ & 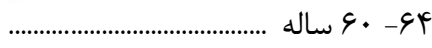 \\
\hline ITVG & $\Delta 9$ & 1 & rG & INT & DGTS & १९DrیF & $q \cdot r \Delta \Delta F$ & . \\
\hline 11.9 & $\Delta \cdot$ & . & if & 191 & TATS & $q \cdot 1 r 4 q$ & $9.9 \Delta 1 \pi$ & ساله $V \cdot V{ }^{c}$ \\
\hline 1114 & is & r & 19 & 419 & $f \cdot q r$ & $90 \cdot 019$ & $9 \Delta 9 V \cdot q$ & ساله و بيشتر ..................... سل \\
\hline
\end{tabular}


r - ا - جمعيت بر حسب جنس، استان و تابعيت

\begin{tabular}{|c|c|c|c|c|c|c|c|c|}
\hline نشده اظهار & كشورها & تركيه & " پاكستان & عراق & افغانستان & ايران & 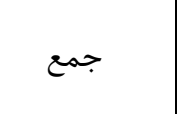 & جنس و استان \\
\hline $1 \cdot \Delta \cdot q$ & $r+\Lambda F F$ & vir & Ifret. & rFArr & los rava & VAIESATr & vaqugrv. & 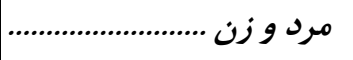 \\
\hline$\Delta \Delta \Delta q$ & 119 & $4 q$ & - & ra & 1149 & rq.rVDl & rq. $99 \Delta r$ & آذربايجان شرقى ................... \\
\hline SYAF & $\Delta \Delta$ & $\wedge r$ & f & $V \cdot r$ & $1 \cdot v$ & rTAVVAY & rrgarIq & آذربايجان غربى \\
\hline rmeA & r. & $\Delta$ & · & If & ra & IrgVqท^ & IrV.kT. & 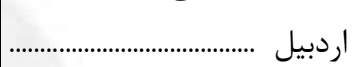 \\
\hline FryA & vFF & 10 & एव९ & TrII & IATIYF & $k q r \cdot 11 r$ & $\Delta I T \cdot \wedge \Delta \cdot$ & اصفهان . \\
\hline$|r v|$ & $|f|$ & 19 & $11 \mathrm{~V}$ & rl. & NFrt & TETETYF & TYITE.. & البرز ......... \\
\hline Q9V & 11 & · & · & 1994 & rq & DVYATV & $\Delta \Lambda \cdot 1 \Delta \Lambda$ & ايلام ...... \\
\hline 1940 & rAV & 1 & 194 & Ifr & r৭९91 & 1141199 & \|GMF.. & بوسهر : ..... \\
\hline TMTEY & TEYA & lQF & 1999 & 9990 & $\Delta \mid \triangle \Delta \& V$ & ITVT.rY. & IrYGVGTV & تهران ................. \\
\hline १दा & v & - & r & 9 & 91 & 949994 & qAVVGT & جهارمحال و بخ \\
\hline ra & 1. & · & r & 19 & $\Delta \cdot i \Delta$ & VGTYQA & 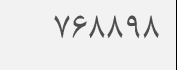 & خراسان جنوبـ \\
\hline 991. & $0.9 \Lambda$ & iv & IVFF & sq.. & rlakfr & 919194. & grres. 1 & خراسان رضوى . \\
\hline TET & v & - & r & rQ & $9 \pi$ & AGYV.r & $19 r \cdot 9 r$ & خراسان شمالى . \\
\hline IDSVA & If9 & 1 & זr & rqve & srq. & 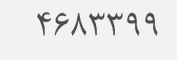 & $|v| \cdot \Delta \cdot q$ & خوزستان \\
\hline INF & IrF & 9 & 1 & IV & r. & $1 \cdot \Delta V \cdot V q$ & $1 \cdot \Delta V|\varepsilon|$ & زنجان ........... \\
\hline FrA & Fa & 1 & 11 & n & $r \Delta F \cdot q$ & 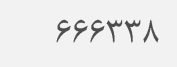 & V.rMG. & منان ............. \\
\hline r人৭1 & 191 & 1 & reIV & 14 & reAYS & TYFIFY. & $r V \nabla \Delta \cdot 1 F$ & سيستان و بلو \\
\hline lQF. & $r \cdot \Lambda$ & 1 & vq & $\Delta q \mu$ & 1.9KFV & FVragrs & YNQITVE & فارس . \\
\hline MIS & $1 F \Delta$ & 9 & Tr & $11 r$ & $1 A k \cdot 1$ & ITDFVDq & $\mid$ |rVYG| & قزوين ........... \\
\hline pqpA & $\Lambda F I r$ & me. & gDFT & $\Lambda \mu \varepsilon \Delta$ & Q⿻ॄ⿰V & $\| \varepsilon V r \cdot V$ & IrqTrAr & قم ....................... \\
\hline $19 \mathrm{~V}$ & $\wedge$ & . & - & FTE & 11 & $19 . r$ rqf & $19 \cdot r \cdot 11$ & كردستان ..... \\
\hline $1 . r 9 r$ & $\Delta \cdot \Lambda$ & $\Delta$ & 1.9 & Ve & $|F Q F| \mid$ & r. TArT. & rIsFVIN & كرمان . \\
\hline $19 \cdot v$ & $\Delta$ & 1 & . & $\wedge r$. & iv & l949844 & 19DTFME & كرمانشاه ..... \\
\hline 19 & $\Delta r$ & . & . & r & $10 \cdot r$ & VIIr.r & $V I T \cdot \Delta T$ & كهيليلويه و بويراخ \\
\hline$\wedge r q$ & fr. & 1 & 14 & $\Delta F$ & MTVR & $\mid 14 q 191$ & $119 \wedge 119$ & كَلستان \\
\hline$r \wedge 1$ & vr & · & r & kr & $r \cdot q$ & rarq99. & $r \Delta r \cdot 999$ & كيلان .. \\
\hline 19. & r & . & r & rTs & 99 & $1 V G \cdot 1 T A$ & $1 V 9.949$ & لرستان . \\
\hline rVEV & $\Delta \varphi$ & - & if & $\Delta \varphi$ & rgrt & TTVV.19 & rTArDAr & مازندران .. \\
\hline 1190 & 11 & 1 & r & rی9 & rqTaV & 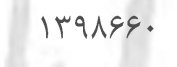 & IFTGEVD & مركزى .. \\
\hline krt & $1 \cdot \wedge r$ & $r$ & & qv & $r F 190$ & IVFqAVD & IVYGYID & مزكان \\
\hline 941 & rq & r & r & IAV & riv & $\mid \vee r G \wedge \& 9$ & IVTNTmE & همدان ................ \\
\hline $18 \wedge 9$ & 94 & r & $9 r$ & IVIr & DIVFr & $1 \cdot \wedge r \mid \cdot 1$ & WH人LH & \\
\hline
\end{tabular}


r - ا- جمعيت بر حسب جنس، استان و تابعيت (دنباله)

\begin{tabular}{|c|c|c|c|c|c|c|c|c|}
\hline نشده اظهار & كشورها & 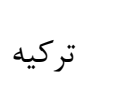 & 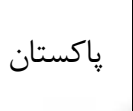 & 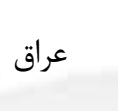 & | افغانستان & ايران & جمع & جنس و استان \\
\hline$\Delta \mathscr{q} \| l \prime$ & $15|9|$ & erg & artr & 19VTd & AFATEV & 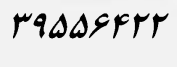 & F+FqAFFT & 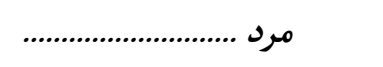 \\
\hline$r \cdot 99$ & $\wedge \vee$ & ra & $\cdot$ & tr & Ve & 19191.9 & $19194 \ldots$ & آذربايجان شرقى ....................... \\
\hline TMEt & ra & $\Delta \omega$ & r & rFa & dr & ISDFYAS & $190 \wedge r 19$ & آذربايجان غربى ....... \\
\hline IrGA & $1 \cdot$ & r & $\cdot$ & $\checkmark$ & 10 & s4^901 & $9 \Delta \cdot T \Delta \Delta$ & اردبيل ............................................... \\
\hline 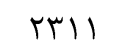 & kis & v & IVe & ITYK & qurvr & $r \Delta \ldots r q$. & 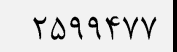 & اصفهان ......... \\
\hline vvq & $v \Delta$ & it & $\vee \wedge$ & ITd & $F \Delta \Delta F A$ & IrrqviN & IrVGrrd & 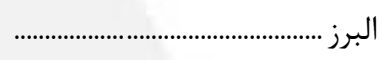 \\
\hline ( ) & \& & · & $\cdot$ & $1 \cdot r \cdot$ & ir & rQTATt & r90199 & ايلام ............... \\
\hline $11 \mathrm{rV}$ & $r \cdot r$ & 1 & (14) & Ar & $19 \mu \wedge 8$ & 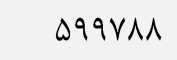 & GT.VTT & بوشهر ......... \\
\hline l1V99 & 1999 & 1.9 & $1 . r 9$ & r^१५ & rVYYA. & GrNIFrr & GSVTGVY & تهران .................. \\
\hline 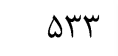 & r & · & r & r & 4. & FNIVAT & FATTAS & جهارمحال و بختيارى .............. \\
\hline ir & $\Delta$ & · & r & 9 & r819 & rAVr\&9 & एА१९१V & 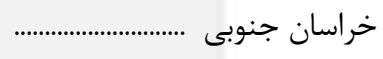 \\
\hline DIVV & $r r^{2}$ & 11 & 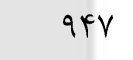 & rVa. & 1111499 & TIYIT. & TYYAIND & خراسان رضوى ....... \\
\hline ع & r & • & r & 19 & $\Delta \Delta$ & GMTETI & (1) & خراسان شمالى ...... \\
\hline ᄉr & १४ & 1 & iv & r\&A. & ravi & rrVr人av & rrMASVF & 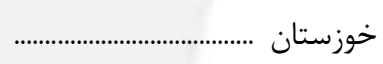 \\
\hline 11. & $\mid r \Lambda$ & v & 1 & 9 & r & DHFAVI & DrFAFq & زنجان ........................ \\
\hline rk. & ry & . & ir & is & INATL & rrvVıe & 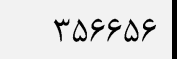 & 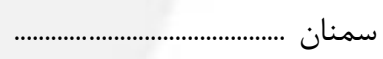 \\
\hline$r \cdot 1 r$ & ع & . & $1 \Delta \wedge \mathrm{V}$ & v & $|f| g r$ & $I r N F \cdot r \Delta$ & $|4 \cdot| 94 \mid$ & سيستان و بلو \\
\hline $9 r V$ & $|r|$ & . & ه & rrv & 91191 & 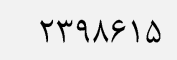 & TYEITDI & فارس ............................. \\
\hline 189 & is & $\Delta$ & 19 & $\checkmark \cdot$ & 9095 & $q F \cdot \Delta q T$ & 90.499 & 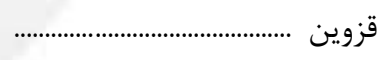 \\
\hline rarq & FoqF & IVe & rFA. & priq & FAVQq & DqfINT & GQNAT. & قم .................... \\
\hline 94 & $\Delta$ & . & . & $r \cdot \Lambda$ & ir & NIFFAN & AIrVVe & 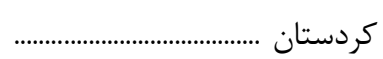 \\
\hline$\Delta \Delta \& 1$ & rVA & r & $v^{r}$ & rq & 999.9 & IOFIVTG & IEIVEAN & 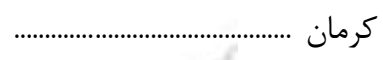 \\
\hline 1.94 & 1 & 1 & $\cdot$ & fro & re & 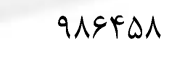 & $911 \cdot 10$ & كرمانشاه ... \\
\hline $1 \ldots$ & is & · & $\cdot$ & $r$ & 199 & TE. MFT & r & كهخيلويه و بوب \\
\hline erv & rir & 1 & 9 & rT & $99 \cdot r$ & $9 r \lambda \cdot r r$ & qH人rтV & Fلستان ... \\
\hline $14 \Delta$ & $\Delta \cdot$ & . & r & r & rM & $\mid$ TEVIDI & ITEVQqV & Fيلان ........ \\
\hline $1 . r$ & 1 & . & r & IrF & qr & 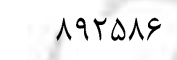 & 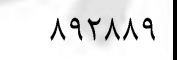 & لرستان .... \\
\hline 1914 & ry & $\cdot$ & ir & r & $|1| \Lambda$ & $19 \Delta \cdot 11 \mathrm{~V}$ & 190r991 & مازندران ... \\
\hline gri & VD & 1 & 19 & 110 & larq. & $\checkmark \cdot 9 \Delta \Delta$. & VTAVAI & 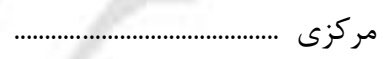 \\
\hline rAr & $\wedge \Delta$. & 1 & $\Delta \wedge \varphi$ & $\Delta q$ & $1 F r \cdot 1$ & $\Lambda q \cdot V \mu F$ & 9.9114 & هرمزكان . \\
\hline$\Delta T \Delta$ & rt & r & r & $q 4$ & ira & NVqATq & $M \cdot r \mid \Lambda$ & همدان .............................................. \\
\hline 909 & vq & 1 & V & r & TATAS & $\Delta \Delta \Delta \varepsilon \cdot \Lambda$ & $\Delta \wedge \varepsilon \cdot 1 r$ & يزد .................. \\
\hline
\end{tabular}


ץ- ا- جمعيت بر حسب جنس، استان و تابعيت (دنباله)

\begin{tabular}{|c|c|c|c|c|c|c|c|c|}
\hline اظهار نشده & كشورها & 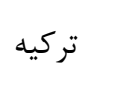 & 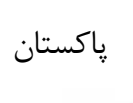 & 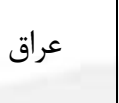 & افغانستان & ايران & جمع & جنس و استان \\
\hline$F \wedge q q q$ & 191T & taF & $\Delta 99 \pi$ & $\mid F \Lambda \cdot V$ & vravir & rAsl.F.. & rafrVAtA & زن.... \\
\hline rFq. & re & if & $\cdot$ & $\wedge$ & r & I91VEFA & 19T. TQY & 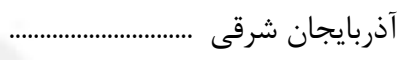 \\
\hline mift & $r \cdot$ & $r \wedge$ & · & rav & $\Delta \Delta$ & 19.rrq1 & $19.99 .$. & 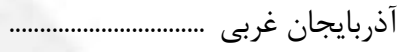 \\
\hline $11 \cdots$ & 1 . & 1 & · & $v$ & $r \cdot$ & G19.rV & $9 T \cdot 190$ & اردبيل ........ \\
\hline$r \cdot r V$ & rq1 & $\wedge$ & 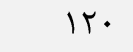 & $\wedge \wedge \vee$ & MNHol & TETAGVT & TATITYY & اصفهان ............... \\
\hline DQT & 99 & c & rq & $\wedge \Delta$ & rAVVr & Irq9a. & ( & 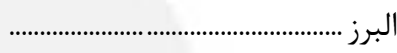 \\
\hline 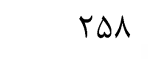 & $\Delta$ & $\cdot$ & $\cdot$ & sVF & iv & rAF.DD & rAFqดQ & ايلام .................... \\
\hline 111 & $\wedge \Delta$ & $\cdot$ & rᄉ & 81 & $1 \cdot r \cdot \Delta$ & $\Delta r \mid r \Lambda I$ & DFTEVA & بوشهر .......... \\
\hline 1.491 & 914 & i^ & $9 V$. & $r \cdot v r$ & $r F \cdot V \wedge V$ & qтr人q.V & 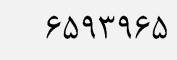 & تهران .............. \\
\hline qr. & r & . & · & r & r & feqq4i & $\forall \& \Delta F \cdot V$ & جهارمحال و بخ \\
\hline ir & $\Delta$ & . & 1 & v & FETE & rVGATq & rV^৭1। & خراسان جنوبى \\
\hline FVrr & DG & 9 & vqv & reQ. & $1 \cdot 1 \cdot 49$ & $r \cdot v \cdot v 19$ & MIA9Mाब & خراسان رضوى \\
\hline$I T V$ & f & · & · & 9 & rı & FTAYAI & FrqFoq & خراسان شمالى .... \\
\hline VREV & pq & . & 9 & rTAT & re19 & $r r \cdot 9 \Delta \cdot r$ & TMTIATA & خوزستان ...... \\
\hline VF & 9 & r & · & $\wedge$ & IV & $\Delta T Y \Delta \cdot \Delta$ & DTREIT & زنجان ............. \\
\hline rru & 11 & 1 & $\Delta$ & r & IEAVF & TYNDQL & $r F \Delta V \cdot F$ & سمنان ........................ \\
\hline $1 M \Lambda \Delta$ & Gr & 1 & $1 \cdot r \cdot$ & $v$ & ITEAT & 1 IroVFID & $1 \pi V r \cdot \Lambda r$ & سيستان \\
\hline 9וr & $\wedge \vee$ & 1 & re & rTs & $4 \lambda \cdot 4 q$ & TrYYI. TI & rrq...r & فارس .............. \\
\hline Irv & $1 \ldots$ & 1 & 9 & GT & $11 \cdot 9$ & GIfISV & GTMTEY & 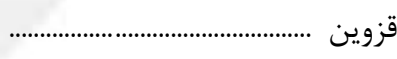 \\
\hline r & rᄉ19 & lef & $r \cdot q r$ & refG & FVG. & DVTIYY & gruVkT & قم ...................... \\
\hline$V \Delta$ & r & · & · & rle & $\Delta$ & V^৭१४६ & Vq.rra & كردستان ....... \\
\hline fVrl & $1 \pi$. & r & זr & rv & $\Delta \Delta \Delta \cdot \Delta$ & $|F \wedge 9 \Delta 9|$ & IQFV.r. & كرمان \\
\hline 11r & r & . & . & $r 9 \Delta$ & rI & QGTाNG & qsfyiq & كرمانشاه ......... \\
\hline 9. & 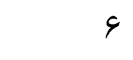 & $\cdot$ & $\cdot$ & $r$ & $4 \cdot V$ & $r \Delta .941$ & rol994 & كهخيلوي \\
\hline$r \cdot r$ & TrV & $\cdot$ & $\Delta$ & rt & 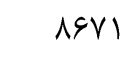 & 971190 & $q r \cdot 4 q r$ & كلستان \\
\hline ع & tr & . & . & 11 & 91 & IrGTArq & 1 1KG. 99 & كيلان . \\
\hline$\wedge \vee$ & r & . & 1 & 94 & ع ب & NEVAFT & NeVVG. & لرستان . \\
\hline INTF & rt & $\cdot$ & 1 & r & $\Lambda \cdot \Delta$ & 1948199 & IGY9DAF & مازندران ... \\
\hline$\Delta M Y$ & \& & & $r$ & 1.4 & IrqवV & . & $V \cdot r Y Y Y$ & مركزى . \\
\hline 10 & זr & 1 & lfF & r & $9 \wedge 94$ & $1 \Delta q|F|$ & 1999.1 & هرمزكان ...... \\
\hline एवя & f & . & & $q 4$ & Ar & $\Lambda \Delta V \mu Y$. & NQVq।द & 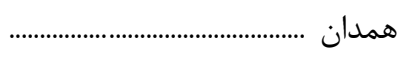 \\
\hline$\wedge r$. & 10 & 1 & 10 & $v \cdot 9$ & TMYAV & DrVEqT & DQTQT. & يزد .............. \\
\hline
\end{tabular}




\begin{tabular}{|c|c|c|c|c|c|c|c|c|}
\hline نشده & كشورها & 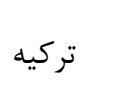 & 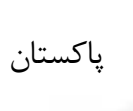 & 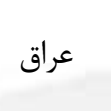 & | افغانستان & ايران & 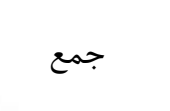 & جنس و استان \\
\hline $1 \cdot 1 v 9$ & lafve & sVF & llar. & riql. & Irerert & DVYEIVFE & DqIFEAFV & 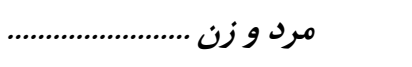 \\
\hline ETVE & 110 & is & $\cdot$ & ro & 19 & rA. FA\&T & TA. QFTF & 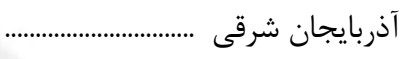 \\
\hline rм^. & rA & 81 & · & $F \Delta \Delta$ & $\Delta V$ & TIMIVTT & rIrgr.r & آذربايجان غربى \\
\hline$\Delta 91$ & 11 & $\Delta$ & $\cdot$ & Ir & 19 & 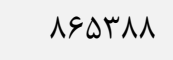 & $199 \cdot r 4$ & 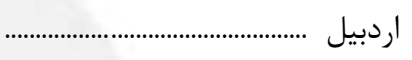 \\
\hline five & ver & 10 & tAT & rIVI & $199 \mathrm{V9V}$ & 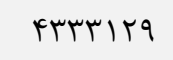 & $f \Delta \cdot v r \cdot q$ & اصفهان ........ \\
\hline$q 90$ & $1 \pi$. & 19 & $\wedge \varsigma$ & $1 \wedge 1$ & $\Delta 91 \% 1$ & TFATTEA & TAITVTY & البرز ...................... \\
\hline IV9 & 11 & . & . & ITrE & $r \Delta$ & rqMATd & TQDTER & ايلام ......... \\
\hline MK. & 4. & 1 & Ar & ITD & TEVEA & $1 \cdot 9 \cdot 99$ & $\wedge r \Delta 9 \Delta \Delta$ & بوشهر .......... \\
\hline 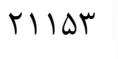 & TARq & lifF & $9 \Delta 9$ & FAGF & rVr... & $|r \cdot r q \Delta V|$ & IFFATYK. & 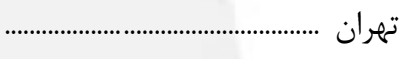 \\
\hline$\Delta \wedge \cdot$ & f & · & r & 9 & $\Delta r$ & $9.9 \vee 99$ & G.VFFF & جهارمحال و بختيارى \\
\hline$r \cdot$ & f & · & f & 19 & ev.r & $p q q \cdot \Lambda$. & FATATV & خراسان جنوبى ... \\
\hline$\Delta \wedge \Delta \vee$ & $r \cdot \varphi_{1}$ & 10 & $19 V$ & ब१९१ & $\mid \wedge \Delta \vee \wedge \cdot$ & FFqVQqV & FV..qYF & خراسان رضوى ........... \\
\hline $1 \cdots$ & r & . & 1 & rF & $\Delta \Lambda$ & FAFI\&I & FAfres & خراسان شمالى ..... \\
\hline $1 r+9 \Delta$ & (re & 1 & 1. & $F \backslash \wedge \Delta$ & raVt & rorrA.G & $r \Delta \Delta F r \cdot \Delta$ & خوزستان .... \\
\hline 91 & $\wedge$ & 9 & 1 & 9 & r^ & $V \| l \cdot r e$ & vIIIV & زنجان ........... \\
\hline fef & بq & 1 & 11 & $9 \Lambda$ & rq८१V & $\Delta r \cdot . r \Lambda$ & $\Delta \varphi \cdot \Delta \cdot r$ & سمنان .......... \\
\hline rrदq & 109 & . & ITAN & 9 & IfFrg & ITTVYAI & IMFDGFT & سيستان و بلو. \\
\hline qा & 19. & 1 & $\Delta T$ & $\Delta F_{1}$ & TRAFI & $r r \cdot V F \mid 9$ & $M F \cdot 19 V \Delta$ & فارس ........... \\
\hline IVT & IfS & 9 & rI & $1 \cdot 1$ & $|\Delta T \Delta|$ & QTEKYAD & $q \Delta T I F q$ & 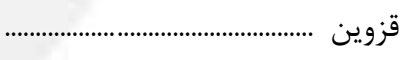 \\
\hline $\mid<911$ & $\Delta F \cdot r$ & rF. & GQIF & (זrז & M1919 & WITAFV & Irrq9яF & قم ............................. \\
\hline$|r|$ & v & · & · & $r \Delta \Delta$ & ir & מ & DIMFTYG & كردستان ....... \\
\hline $1 \cdots 9$ & 4^9 & r & VQ & $\Delta V$ & 199.9 & IVG..t ts & $\backslash \wedge \Delta \wedge \Delta \wedge \vee$ & 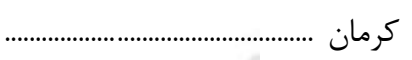 \\
\hline NYF & r & 1 & . & $v \Delta$. & rq & $\mid f \& V \cdot . V$ & $|F \& \wedge \&| Q$ & كرمانشاه ..................................... \\
\hline १४ & v & $\cdot$ & · & f & ITET & एव९.11 & rqv\&s1 & كهخيلويه و بويراح \\
\hline TVQ & TMt & 1 & Ir & id & N\&VI & 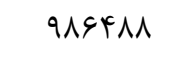 & $99 \Delta 910$ & كلمتان \\
\hline 149 & 91 & · & 1 & זr & $r \cdot \Delta$ & $19 \cdot r \Delta \Lambda$. & $19 \cdot r \cdot r 4$ & كيلان ........ \\
\hline Tr & r & $\cdot$ & r & $1 \cdot 9$ & 4. & IIrfelr & $11 r k q \cdot 1$ & لرستان .... \\
\hline$r q . r$ & $\Delta \cdot$ & . & 9 & tr & Ifiv & INATATV & IAqVYTA & مازندران . \\
\hline$r \Delta \varphi$ & $\wedge 1$ & 1 & IV & $T \Delta \varphi$ & rIGVF & 1. VVFVq & $1.99 \vee 94$ & 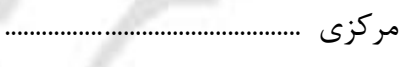 \\
\hline (זוr & 119 & $r$ & rqq & $\wedge$. & $I V V \cdot r$ & QDTGGV & qVIATR & هرمزكان ... \\
\hline ryq & ry & r & r & $1 \wedge r$ & 10. & 1.94497 & I. QVYIV & همدان ...... \\
\hline 1991 & TV & 1 & V^ & IENT & FYFDQ & QTDFFV & qVITQD & يزد ....... \\
\hline
\end{tabular}


r - ا- جمعيت بر حسب جنس، استان و تابعيت (دنباله)

\begin{tabular}{|c|c|c|c|c|c|c|c|c|}
\hline اظهار نشده & كشورها & تركيه & 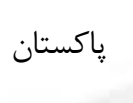 & عراق & افغانستان & ايران & جمع & جنس و استان \\
\hline reave & $1.9 \Delta \Delta$ & $f \cdot r$ & gDFV & $11 r \cdot 1$ & $9 \Delta 9 \cdot 19$ & rq1. \&qra & rqAFIFIF & 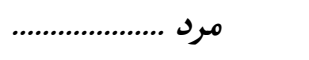 \\
\hline THIN & $\wedge \Delta$ & rF & . & rV & r & IfINIIK & $I F T \cdot \Delta T \cdot$ & آذربايجان شرقى .............. \\
\hline 1940 & If & 41 & · & TrD & ra & $1 \cdot V \& M 1 Q$ & $1 \cdot \vee 9 \Delta \& \Delta$ & 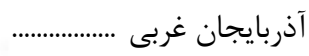 \\
\hline$r \Delta \Delta$ & 9 & r & · & $\checkmark$ & it & $F F \cdot G T V$ & $\mid F(1 . T F$ & اردبيل .................... \\
\hline rt.. & ifs & v & $|V|$ & $1 \% 90$ & $\wedge \Delta \Delta \wedge r$ & TIQTSAM & TYATYAQ & اصفهان .................. \\
\hline DGT & 99 & it & Q & 1.9 & rIVAI & ITHADIS & $|r V| .99$ & البرز .......... \\
\hline $1 \cdot f$ & \& & $\cdot$ & · & VTr & 1. & $1990 \mathrm{VV}$ & $r \ldots+19$ & ايلام ............... \\
\hline 1.48 & is & 1 & $\Delta 9$ & 99 & IDFTE & FY. 909 & FrVDIS & بوشهر .......... \\
\hline 11194 & $10 \wedge 9$ & 91 & $4 .$. & TATT & 199098 & G. T\&Y. & GTETIN. & تهران ............................... \\
\hline טגו & r & $\cdot$ & r & f & 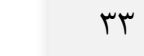 & $r \cdot v \& 19$ & $r \cdot \vee V q \Lambda$ & جهارمحال و بختيارى ...... \\
\hline 11 & r & $\cdot$ & r & 9 & TFFF & rTA..F & $r T \cdot F V T$ & خراسان جنوبى ............... \\
\hline ( & rIVV & 9 & $q \cdot V$ & rFAA & $94 \wedge 19$ & 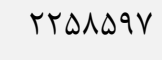 & TrGT. १V & خراسان رضوى .... \\
\hline$\Delta V$ & - & · & 1 & 10 & ro & Ferme & temete & خراسان شمالى ............... \\
\hline 9091 & צ & 1 & 9 & THAT & rISA & $I V A F \cdot F Y$ & 1890199 & 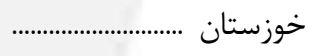 \\
\hline$\Delta \Lambda$ & r & v & 1 & r & 11 & TQ9TIA & 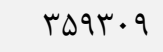 & زنجان .................... \\
\hline rle & $r \Delta$ & · & ir & id & $10 F \& 9$ & T\&QVYG & TATA.r & سمنان ...................... \\
\hline irt. & $1 \cdot 1$ & · & V৭४ & r & Vৎ९D & GVATYI & $9 \Lambda 019 \pi$ & سيستان و بلو٪ \\
\hline$\Delta \varphi \Delta$ & $1 \cdot 1$ & . & r. & rr. & $\Delta \cdot F \mid \Lambda$ & 1999.99 & IVIVAT. & فارس ...................... \\
\hline 90 & ro & $\Delta$ & 10 & $8 V$ & VAre & $F V \Delta q \Delta F$ & FAF. TV & قزوين ............................ \\
\hline relf & FAAV & IVE & HEA & <я9. & FFG.F & DGFrVD & GTFD. 9 & 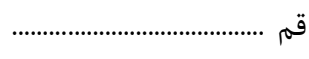 \\
\hline 49 & r & . & · & INQ & 1. & DVTAMT & $\Delta V T I F V$ & كردستان ................. \\
\hline erv. & rदq & r & $\Delta F$ & rA & FANIF & $\wedge 9 \Delta \cdot \mu q$ & qYADVI & كرمان ............... \\
\hline 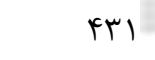 & 1 & 1 & • & f.. & 10 & VRGYVE & VTVRTT & كرمانشاه ........... \\
\hline $4 q$ & $\Delta$ & $\cdot$ & · & r & Vद9 & $r \cdot \wedge \Delta Q$ & $r \cdot \mid 911$ & كهَيلويه و بويراحمد ....... \\
\hline 419 & 111 & 1 & 9 & $r \omega$ & FFAF & FqM।धQ & $k 91 \cdot 1 k$ & كلستان .... \\
\hline$v \Delta$ & rr & · & 1 & re & lis & V9V।A। & VqVFV. & كيلان .... \\
\hline 41 & 1 & . & r & 90 & rی & D९q9४Q & $\Delta V \cdot 11 T$ & لرستان .... \\
\hline$|199|$ & r. & $\cdot$ & 9 & r. & $9 \vee v$ & $q 4 V \cdot+q$ & $q \uparrow q \Delta \vee \varepsilon$ & مازندران ..... \\
\hline$|f|$ & Va & 1 & 10 & $10 \Lambda$ & lIrTF & $\Delta F \Delta D \cdot \varphi$ & $\Delta \Delta V I T$. & 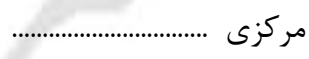 \\
\hline 199 & DQ1 & 1 & raq & 48 & $1.10 F$ & 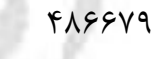 & 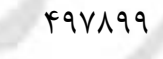 & هرمزكان ................................. \\
\hline$r \cdot$. & rt & r & $r$ & १. & 19 & $\Delta \Delta \cdot I V T$ & $\Delta \Delta \cdot \Delta \wedge\rangle$ & 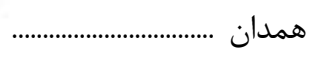 \\
\hline$\wedge \vee V$ & ir & 1 & \& & 910 & THFDQ & FVINAV & FQGTQF & يزد ............................................. \\
\hline
\end{tabular}




\begin{tabular}{|c|c|c|c|c|c|c|c|c|}
\hline اظههار نشده & كشورها & تركيه & ياكستان & عراق & افغانستان & ايران & جمع & جنس و استان \\
\hline$r \gamma s \cdot r$ & rarl & $r r$. & fqAr & $1 r r \cdot r$ & DAETFT & rA\&DFAII & $r q r \cdot \Delta F r r$ & 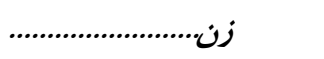 \\
\hline$r \cdot \Delta \varphi$ & r. & 14 & • & $\wedge$ & iq & Ir^SVQ. & $1 r \wedge \wedge q \cdot r$ & آذربايجان شرقى ................ \\
\hline 1940 & If & $r \cdot$ & · & r & re & $1 \cdot \Delta V \psi \cdot V$ & 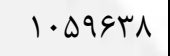 & آذربايجان غربى .................. \\
\hline בצr & 9 & 1 & · & 4 & $\checkmark$ & FTEVDI & rra. 1. & 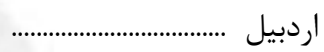 \\
\hline $19 V T$ & rq1 & $\wedge$ & 111 & AvG & NITIF & $r|F \cdot \Delta F|$ & TYTQ.T. & اصفهان ................. \\
\hline rی & 91 & r & 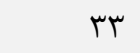 & $v \Delta$ & TRTa. & ITITVTr & ITFIGTA & 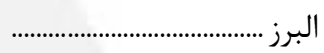 \\
\hline VT & $\Delta$ & • & • & $\Delta \cdot F^{F}$ & 10 & I IFFFA & lqFAFF & ايلام ............... \\
\hline Vqf & If & • & r & $\Delta \varphi$ & qfir & rANIF. & rq人सrq & بوشهر ................ \\
\hline ११११ & $9 \Delta \mathrm{r}$ & is & roq & t.rt & IVTF. G & G.THTET & GrI..D. & تهران ............................... \\
\hline TFT & r & · & - & r & $r \cdot$ & г৭१५^. & r৭१९४९ & جهارمحال و بختيارى ....... \\
\hline 9 & r & - & 1 & v & rTQQ & rTI.VG & trmTAF & خراسان جنوبى ................. \\
\hline TVYT & In\&t & 9 & V\&\& & $r \Delta \cdot r$ & 91984 & rrrq... & THTANTV & خراسان رضوى ..... \\
\hline r & r & $\cdot$ & · & 9 & r & $T F \cdot \Lambda T V$ & $r F \cdot q \cdot F$ & 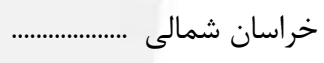 \\
\hline$\Delta \wedge 9 \vee$ & kr & · & 1 & $19 \cdot r$ & $1 F \cdot F$ & IVFqVGT & $1 V \Delta q \ldots 9$ & 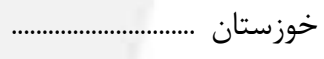 \\
\hline 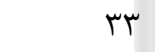 & f & r & · & r & $1 \cdot$ & roINIS & 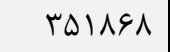 & زنجان ...................... \\
\hline rTA & 11 & 1 & $\Delta$ & r & IFFTA & rgrr.r & 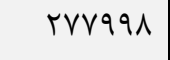 & سمنان ........... \\
\hline 1149 & $\Delta 1$ & $\cdot$ & fqr & 4 & sVrI & $9 \Delta T \cdot 1$. & $99.4 V q$ & سيستان و بلوج \\
\hline rq9 & $\wedge r$ & 1 & ir & rTI & FTITK & Isfira. & $|\varepsilon \wedge F| \Delta \Delta$ & فارس .......................................... \\
\hline $\mathrm{v \wedge}$ & 1. & 1 & 9 & (i) & $V \Delta \cdot \Delta$ & |q. rq1 & r\&AITr & قزوين ........................... \\
\hline trqV & rᄉls & lat & $r \cdot \Delta l$ & refr & $F F \cdot I r$ & DFAFVT & $G \cdot \Delta F \Delta \Delta$ & 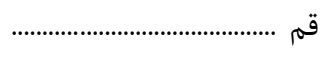 \\
\hline$\Delta \Delta$ & r & - & $\cdot$ & IV. & r & $\Delta \varphi \cdot \wedge \Delta I$ & $\Delta \varepsilon 1 \cdot \Delta r$ & 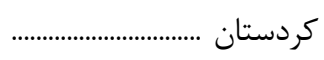 \\
\hline rVrq & $1 r$. & 1 & rl & rq & 41.90 & $\wedge 9 \Delta \cdot 11$ & $91 \cdots 19$ & كرمان ............... \\
\hline r & r & . & • & ra. & If & 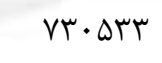 & ( & كرمانشاه . \\
\hline is & $r$ & · & · & r & $\Delta V r$ & $19 \Delta 1 \Delta \Delta$ & 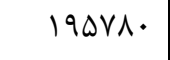 & كهَّيلويه و بويراحمد ......... \\
\hline lQS & 111 & · & r & $r \cdot$ & raAv & (19Trt & fqve. 1 & علستان ... \\
\hline vi & 11 & · & . & 9 & $\Delta 9$ & $\Lambda \cdot \Delta r q 9$ & $\Lambda \cdot \Delta \Delta \Delta \varphi$ & 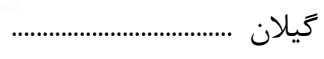 \\
\hline Gr & $r$ & - & 1 & (i) & rt & DSFGQV & D\&FVQD & لرستان .... \\
\hline IfIT & $r \cdot$ & $\cdot$ & . & ir & pr. & qFQVVA & qFVGar & 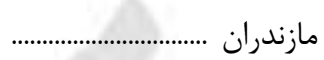 \\
\hline 110 & 9 & . & $r$ & $9 \wedge$ & $1 \cdot k y$. & $\Delta r / 9 V T$ & DFTEMF & مركزى .. \\
\hline 114 & 101 & 1 & ᄉ. & $\mu F$ & VQFA & $4909 \wedge 1$ & FVrqur & هرمزحان .................. \\
\hline 149 & r & • & & q & 91 & DFETTD & DHGQT. & 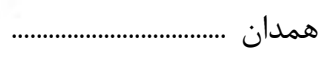 \\
\hline VAF & 10 & • & 10 & $99 \mathrm{~V}$ & $r \cdots$ & Fordq. & FVDI.1 & يزد ...................... \\
\hline
\end{tabular}




\begin{tabular}{|c|c|c|c|c|c|c|c|c|}
\hline اظهار نشده & كشورها & تركيه & ياكستان & عراق & افغانستان & ايران & جمع & جنس و استان \\
\hline TF\&q1 & rred & rq & rYea & reti & $r F . q 91$ & $r \cdot r \Delta r \mid q q$ & $r \cdot v r \cdot g r d$ & مرد و زن .............. \\
\hline ITND & f & 1 & $\cdot$ & - & $\Delta \cdot$ & $1.9 \wedge 1 \wedge$. & 11 ..rr. & آذربايجان شرقى ................. \\
\hline TG. T & TV & tr & r & TEV & $\Delta \cdot$ & $11 r 4.48$ & $1119 \ldots$ & 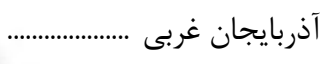 \\
\hline IVVV & r & $\cdot$ & $\cdot$ & 1 & 19 & F. TFY. & F. Frrs & اردييل ........................ \\
\hline$I V \Delta$ & 1 & . & If & r. & |ETr| & DQ९DTK & $91 \mu \cdot v r$ & اصفهان ................. \\
\hline rro & 11 & $\cdot$ & r & rq & TOIVD & IVrAMA & $199 \Delta \Delta 9$ & البرز ............... \\
\hline FTI & . & . & . & $\forall \& 1$ & r & IATADT & MFFFY & 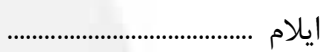 \\
\hline $1 \cdot 4$ & TrV & $\cdot$ & $\Lambda r$ & 11 & fakr & $r T \cdot|r|$ & THQFqD & بوشهر ......... \\
\hline $11 \cdot 4$ & $1 \cdot 1$ & 1. & vrq & $1 \cdots$ & IFTFA9 & $9 V \cdot \mid F_{1}$ & 114991 & 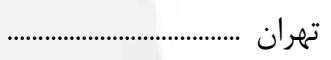 \\
\hline rᄉr & r & · & • & · & ऍی & Tratkr & rra६बV & جهارمحال و بختيارى ......... \\
\hline$\Delta$ & \& & . & · & · & TFT & rIFVIV & rID. & خراسان جنوبى . \\
\hline$r \cdot r \wedge$ & $1 . r \Delta$ & r & n & prq & 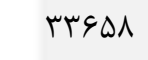 & 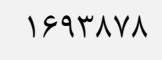 & IVTrITI & خراسان رضوى ... \\
\hline 14 & $\Delta$ & · & 1 & 1 & ro & TVVTrA & TVVATT & خراسان شمالى ... \\
\hline$r .99$ & 1. & $\cdot$ & ir & VAv & TRIT & llfFqVD & 1101099 & خوزستان ...... \\
\hline 94 & ITS & · & · & 11 & ir & TYG. YI & TFETAT & 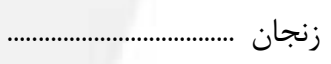 \\
\hline rF & 9 & . & . & r & $\Delta \Delta I T$ & 1тян.. & $|F| \wedge \Delta \Lambda$ & 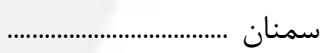 \\
\hline 1011 & rq & 1 & $15 \cdot 9$ & $\Delta$ & $\mid r F \cdot q$ & $|r| r \cdot \Delta \Lambda$ & IFTVRTY & سيستان و بلو \\
\hline$\Delta \Delta r$ & iN & · & rq & tr & ISIFV & $|f| \Delta \Delta \wedge q$ & IFTrTDQ & فارس ............. \\
\hline Tr & - & $\cdot$ & 1 & f & $r \cdot \Delta \cdot$ & TINFIT & Mr|S|. & قزوين .............. \\
\hline rv & 1. & $\cdot$ & rq & rt & VVDI & $\Delta F F \Delta \Lambda$ & GTrIV & قم ..................... \\
\hline pq & 1 & $\cdot$ & · & 99 & $\Delta$ & 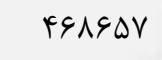 & r\&AVVA & كردستان ...... \\
\hline TTNI & 19 & r & r & 19 & $r \Delta \Delta$. & ITEFV.D & $I T \cdot r \Delta \Delta V$ & 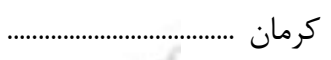 \\
\hline $1 \cdot \lambda r$ & 1 & · & $\cdot$ & $\wedge$. & 11 & FVVTGY & Fraffy & كرمانشاه .... \\
\hline 94 & is & · & $\cdot$ & · & 191 & rirvil & rlf..q & كهخيلويه و بو \\
\hline fET & riN & $\cdot$ & 1 & 9 & $9 \vee १ \wedge$ & $\wedge \varepsilon 1 \cdot \Delta \Lambda$ & AVIDFS & كلستان .... \\
\hline irs & 11 & $\cdot$ & 1 & 9 & $1 \cdot 4$ & qTVK.. & 9TVG9. & 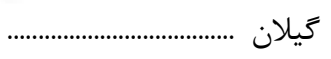 \\
\hline 49 & 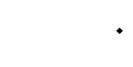 & . & . & ir. & rq & GTrGVI & 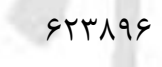 & لرستان ................. \\
\hline NFY & & · & $\Delta$ & TY & $1 T \cdot 4$ & ITNFTAT & IrAgrTV & مازندران ....... \\
\hline $9 \cdot 9$ & & . & $\Delta$ & rr & $V \Delta \Lambda$. & rTIIST & rrqsq. & مركزى .......................................... \\
\hline 119 & rGF & - & ५^9 & IV & grat & VQDITF & N.TAIT & 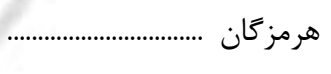 \\
\hline$\Delta V T$ & r & · & & r & $9 V$ & Gr人ঙя. & \& q... & 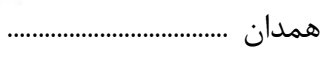 \\
\hline$I T A$ & SV & 1 & $1 f$ & r. & qRAF & IQVT.. & IESVTF & يزد .................... \\
\hline
\end{tabular}




\begin{tabular}{|c|c|c|c|c|c|c|c|c|}
\hline اظطهار نشده & كشورها & تركيه & 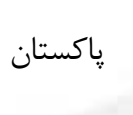 & عراق ل & افغانستان & ايران & جمع & جنس و استان \\
\hline Ireti & $10 \cdot F$ & ra & IVer & 1018 & IA1AD. & 1. Frryr. & $1 \cdot \& r \cdot \Delta F q$ & 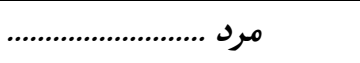 \\
\hline$\wedge \Delta 1$ & r & 1 & $\cdot$ & - & r & $\Delta \& \vee 9 \wedge \Lambda$ & DSAMVQ & 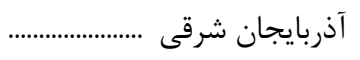 \\
\hline 1498 & rI & If & f & ir. & $r v$ & $\Delta \Lambda \cdot 1 \Delta \Delta$ & $\Delta \wedge I V T \Lambda$ & 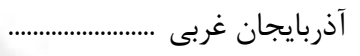 \\
\hline $91 \pi$ & 1 & - & $\cdot$ & · & r & $r \cdot A K T K$ & $r \cdot 9101$ & 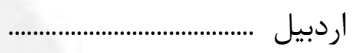 \\
\hline 11. & 1 & . & $\Delta$ & rq & $91 \wedge \mathrm{F}$ & r.VATr & r|ब9व1 & اصفهان ................. \\
\hline ris & 4 & · & ra & 19 & ITVDF & 91191 & $1 \cdot \Delta|\Lambda|$ & 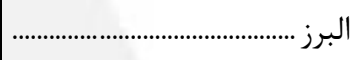 \\
\hline rTD & - & . & · & ra1 & 1 & $94 \cdot 10$ & $q F \Delta F q$ & 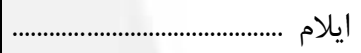 \\
\hline$\wedge$. & 109 & • & VV & Ir & $\varphi \cdot \Delta$. & IVVAFs & IATTYI & بوشهر ............ \\
\hline$\Delta 99$ & vq & $\wedge$ & frq & $\Delta 9$ & VDIIf & TAFETR & $k r \cdot 911$ & تهران ...................... \\
\hline 190 & r & · & $\cdot$ & · & TV & IVrq9T & IVFTIS & جهارمحال و بختيارى ............ \\
\hline 1 & r & • & $\cdot$ & · & IVD & lQ9TEY & IDQFET & خراسان جنوبى ... \\
\hline$r \cdot r$. & $\Delta T \Delta$ & r & r. & Tar & IVDVV & 19rrrq & MATAIQ & خراسان رضوى .... \\
\hline vq & r & • & 1 & 1 & $r \cdot$ & l119FV & $\mid \wedge 9 \Delta \wedge 1$ & خراسان شمالى ... \\
\hline $199 \mathrm{~V}$ & f & - & $\wedge$ & rqv & $10 \cdots$ & DAVTAV & $\Delta 9.994$ & خوزستان ...... \\
\hline$\Delta T$ & ITF & • & $\cdot$ & 4 & $\Delta$ & IVATAT & IVDQTq & 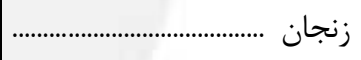 \\
\hline$r F$ & 9 & - & · & r & $r .99$ & $\nabla 1 \cdot \Delta$. & VFIOT & 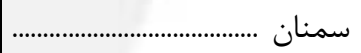 \\
\hline VVA & rᄉ & • & VVV & f & grqu & V.VATH & $V|\Delta \&| \Lambda$ & سيستان و بلو \\
\hline res & 14 & . & ir & IV & $1 . r \Delta q$ & VTrATY & VTEEST & فارس ............ \\
\hline$\Delta F$ & • & - & 1 & r & IVte & 1Eस्सG & leq4V. & 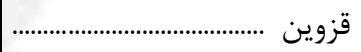 \\
\hline 10 & v & - & IV & rq & $f \backslash \Delta \Delta$ & $r 9 \Lambda \cdot 9$ & $r r \cdot r q$ & 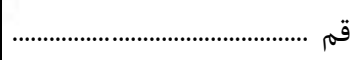 \\
\hline re & 1 & · & $\cdot$ & r & r & rrqDVT & rTqGTD & 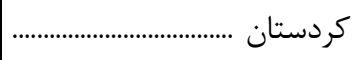 \\
\hline $1 r q$. & 9 & . & 19 & 11 & $r) \cdot q$. & GFYATI & GEVTF. & كرمان .......... \\
\hline ब94 & & . & $\cdot$ & ro & 11 & $T F V \cdot q \Delta$ & rFVA. F & كرمانشاه ................ \\
\hline DI & (1) & - & $\cdot$ & · & ITV & IONGFT & $|\Delta \Lambda \wedge \varepsilon|$ & كهخيلويه و بويراحمد \\
\hline TIV & $1 \cdot r$ & . & $\cdot$ & v & 0110 & איו & krqur & كلستان ....... \\
\hline v. & v & - & 1 & v & VT & 14999. & $\mathrm{FV} \cdot 11 \mathrm{~V}$ & كيلان ........... \\
\hline et & · & - & $\cdot$ & 99 & ro & rrIsa. & rTIVAS & لرستان. ...... \\
\hline GTY & ${ }^{f}$ & 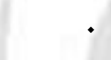 & f & זו & $\lambda F_{1}$ & V.r & V.FYIV & مازندران ... \\
\hline$k$ & & • & r & tr & $r \cdot \Delta r$ & $194 \cdot T V$ & 1919.1 & 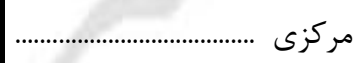 \\
\hline$\wedge 1$ & rیq & & rTd & ir & fils & $F \cdot Y \wedge \wedge \Delta$ & $r \cdot v r r q$ & هرمزكان .... \\
\hline rTa & & $\cdot$ & & $r$ & 48 & TYATAq & 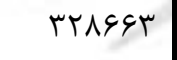 & 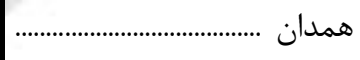 \\
\hline NT & GV & . & If & 11 & $\Delta \wedge T V$ & NMFYA & $194 \Delta 9$ & يزد ..................... \\
\hline
\end{tabular}


| نقايج تفصيلى سرشمارى عمومى نفوس و مسكن _ه |

\begin{tabular}{|c|c|c|c|c|c|c|c|c|}
\hline | اظهار نشده & كشورها & تركيه & 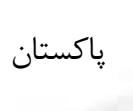 & عراق ل & افغانستان & ايران & جمع & جنس و استان \\
\hline $11 \mathrm{rrV}$ & 191 & If & $1 . . r$ & $11 \cdot 0$ & IOTFIA & 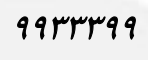 & $1 \cdot 1 \ldots v g$ & 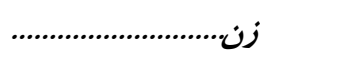 \\
\hline fre & r & - & - & • & IV & $\Delta r \cdot 19 T$ & DTITFD & آذربايجان شرقى ................... \\
\hline $1 T \cdot V$ & 4 & $\wedge$ & . & ITV & r & $\Delta F \Delta \wedge q 1$ & DFVTGY & آذربايجان غربى ..................... \\
\hline 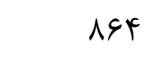 & 1 & - & - & 1 & r & $19 k T \cdot 9$ & $19 \Delta \cdot 1 \Delta$ & اردبيل ........................................ \\
\hline 90 & · & · & 9 & 11 & virv & r^^q.. & TQGIT & اصفهان ................ \\
\hline$r \cdot q$ & $\Delta$ & - & 4 & 1. & $\| F T \mid$ & ATVTV & qFrv & 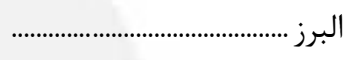 \\
\hline $1 \wedge 9$ & · & . & - & iv. & r & А१८นV & $\wedge 9190$ & 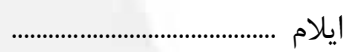 \\
\hline rF & vi & · & $\Delta$ & $\Delta$ & 19ז & IFTTVE & IFTtVF & بوشهر ........... \\
\hline$\Delta \cdot \Delta$ & rq & r & r. & (i) & GVYVQ & rIDQTD & rArvAv & 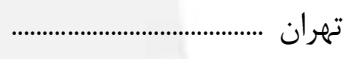 \\
\hline $1 M 1$ & 1 & - & · & $\cdot$ & 11 & $|\varepsilon \Delta T \Delta|$ & $19 \Delta F \Delta \mid$ & جهارمحال و بختيارى ............. \\
\hline r & r & - & - & · & $19 \mathrm{~V}$ & IDQFAT & IDDGTV & خراسان جنوبى . \\
\hline$r \cdot \Lambda$ & $\Delta \cdots$ & · & r & IFV & $19 \cdot 11$ & NrIArq & $\Lambda \Delta \cdot r \cdot \varphi$ & خراسان رضوى \\
\hline$\Delta f$ & r & - & · & $\cdot$ & 10 & IAVADI & INVQDT & خراسان شمالى .................... \\
\hline IfTr & 9 & - & r & rq. & ITIK & $\Delta \Delta V \Delta \Lambda \Lambda$ & $\Delta \varphi \cdot q r r$ & خوزستان .................... \\
\hline il & r & · & · & $\Delta$ & v & $18 \cdot 919$ & $I V \cdot V F F$ & 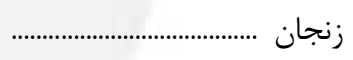 \\
\hline 1. & - & - & · & · & TFYe & GQTD. & $q V V \cdot \varphi$ & سمنان ............. \\
\hline VTr & 11 & 1 & DTT & 1 & $\Delta 911$ & V. FATA & vIVIf & سيستان و بلو \\
\hline trV & $\Delta$ & - & If & $\Delta$ & $\Delta \wedge \Lambda \Lambda$ & GQIVAT & 99४^१1 & فارس .............. \\
\hline$\Delta 9$ & · & - & - & 1 & $1 r \cdot q$ & lorVVG & $|\Delta \Delta| F$. & قزوين ........................................ \\
\hline rt & r & · & ir & r & rब१९ & TEQAT & TATAN & قم ...................... \\
\hline$r \cdot$ & · & - & - & kq & r & $r r q \cdot \wedge D$ & rTQIQT & 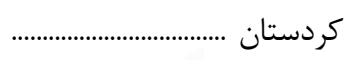 \\
\hline 991 & 1. & r & it & $\wedge$ & $|f F|$. & $91914 F$ & GTATIV & كرمان ........... \\
\hline kT. & 1 & - & - & id & v & $T r \cdot 19 \mathrm{~V}$ & $r \mu \cdot q 4$. & كرمانشاه ...... \\
\hline (i) & r & · & · & · & rr & $100 \cdot 99$ & $|\Delta \Delta| \& \Lambda$ & كهيكيلويه و بو \\
\hline TFQ & 119 & · & 1 & r & F्A & FTVITE & FTIVT & علستان ........ \\
\hline 90 & r & - & - & r & rt & FAVFF. & FAVAFT & 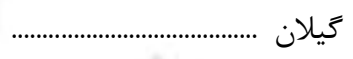 \\
\hline ry & . & 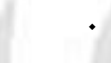 & . & $\Delta 1$ & If & $r \cdot r \cdot r)$ & $r \cdot r l l$. & لرستان ........... \\
\hline Frt & r & . & & 11 & red & 911119 & 9119T. & مازندران ......... \\
\hline$r \Delta$ & VQ & - & 44 & r & THES & rarrfa & rquVVr & 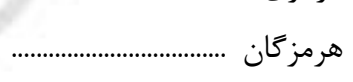 \\
\hline TEV & r & - & & 1 & YI & $r l \cdot v r$ & MI.MFT & همدان ........................................... \\
\hline is & . & 1 & . & ir & TrAV & VTVAT & VVYGA & يزد ...................... \\
\hline
\end{tabular}


F - I - جمعيت بر حسب جنس، سن و دين

\begin{tabular}{|c|c|c|c|c|c|c|c|}
\hline 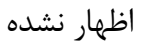 & ساير & زرتشتى & كليمى & مسيحى & 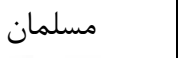 & 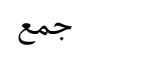 & جنس و سن \\
\hline IrFAYT & $F \cdot \Delta \Delta I$ & rrl.q & q1TE & $14 \cdot 101$ & $r q \Delta q 1 \cdot \Delta F$ & vaqrerv. & مرد و زن ............ \\
\hline 19949 & pret & FVF & per & FrAs & $V \cdot G M F \cdot q$ & $v \cdot q r \cdot . r$ & 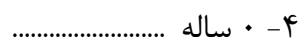 \\
\hline gpfy & rVIF & IFTD & $\Delta \wedge \vee$ & $\Lambda T \Delta q$ & 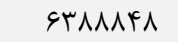 & SFIITVV & 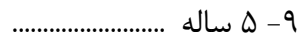 \\
\hline VTrA & TFDA & irv. & $\Delta r V$ & VqFA & 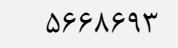 & $\Delta G \Lambda \Lambda r \Lambda F$ & f|- •| ساله ....................... \\
\hline VMFI & r\&10 & lkr. & 49. & ArFq & DFrAG.r & $\Delta F \Delta \wedge 9 q V$ & 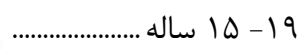 \\
\hline qGYF & rANr & $|94|$ & SFA & 9Vr। & \&TGATDT & grqrAvq & 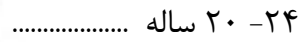 \\
\hline (rוा & 竞 & $19 \Delta F$ & VAF & $111 \cdot 9$ & $\Lambda \mid \nabla \cdot 1 \cdot \Delta$ & سזו & ج r \\
\hline 14991 & rFa. & rTSA & NFt & IrVTq & 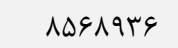 & 19..91 & 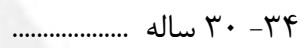 \\
\hline $1.11 r$ & tVDA & IAVr & gqi & $1 \cdot \operatorname{VAT}$ & $V \cdot 11$ far & $V \cdot r V \Delta q \Lambda$ & 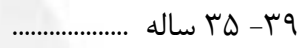 \\
\hline VTAT & tTAL & Iord & $\varphi \wedge$. & $91 \% \wedge$ & DFqVदql & $\Delta \Delta I \Lambda r \cdot V$ & 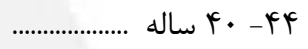 \\
\hline gra. & rmi & IFAF & $\Delta F \Delta$ & $q \cdot v{ }^{4}$ & भ人Iтrqq & 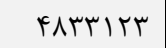 & ................... $r Q$ \\
\hline DIrN & ( & IDTF & $\Delta F_{1}$ & $14 \notin 9$ & rq. vq८ & rqrఎqVI & 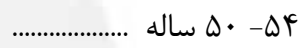 \\
\hline FTAT & 4190 & IFV. & 919 & $V \wedge \cdot \Delta$ & DTMTAD & r & ..................... \\
\hline$r \Delta \Delta$. & 190 & $1 r \Delta$. & 901 & $9 \Delta \cdot r$ & TAYADV. & TAFTOVT & ..................... -9f ساله • \\
\hline roqV & IDFS & 1.97 & $\Delta F \Delta$ & 0.19 & $18 \cdot .94$ & IVIIfGF & ........................ 99 - \\
\hline$t \cdot \Lambda T$ & 11149 & $V \Delta F$ & fVe & rघ99 & $11990 \cdot 1$ & IIVVGTD & ساله ................. -VY \\
\hline rvat & rIVE & lev. & $\wedge r$. & gQTq & 19GVGTT & I9ATFTG & VD ساله و بيشتر .................. \\
\hline gAFr. & $r / r \cdot 1$ & I TAFY & $\Delta 111$ & $q q \cdot v \Delta$ & $r \cdot r r \Delta \cdot v g$ & $F \cdot$ FqAFFr & 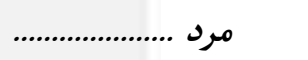 \\
\hline 1. TrG & rrq. & TIS & rTd & rrq. & TGTFFAT & rqqq1.. & 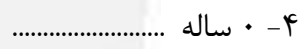 \\
\hline Fへ૬ & ||$r \mid$ & vet & rrq & FrAD & TYVFFFA & тr人⿻.r. & 9- ه ساله ............................... \\
\hline r^ৎV & $\mid r \cdot 1$ & $V \Delta \cdot$ & ५१९ & f. 9 . & $r q .11 k 9$ & rqIIfrr & 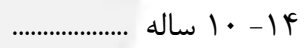 \\
\hline rVAl & $|r|$ & $V \Delta q$ & $r \Delta q$ & FTID & TVVDI.r & 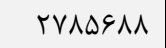 & 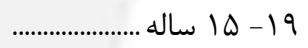 \\
\hline fquv & IFVF & $\Lambda F \Delta$ & $r \Delta \Delta$ & $\Delta \cdot \Delta V$ & TTYFT.V & rrmGqVD & 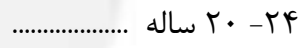 \\
\hline RIT & $|\wedge \Delta|$ & $1 \cdot \wedge \varepsilon$ & $4 \cdot 9$ & GTVD & FIrGV.r & FIFTFFA & Y....................... \\
\hline$V \cdot 9 T$ & 19.9 & ITVD & FTV & GAVV & Frrtq. & FTFEFFA & 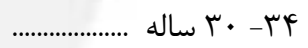 \\
\hline$\Delta \varepsilon \cdot \mathcal{F}$ & IDFT & $11 \cdot v$ & 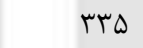 & G. FY & $r \Delta \Delta V \nabla V I$ & TAVTF.r & 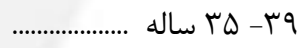 \\
\hline ए१८९ & ITHV & $q \cdot r$ & $r F$. & DIV. & rN. trAT & 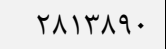 & 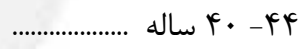 \\
\hline ref. & TKT & $\Lambda \uparrow \wedge$ & TGF & $\Delta \cdot q \pi$ & TFFroßя & TFAFFTV & .................... $r Q$ \\
\hline TGMF & $\| \Delta T$ & 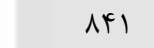 & rII & FFAF & 19997人1 & $19 V \Delta \Delta V F$ & 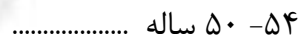 \\
\hline TIFe & 1.99 & $V \Delta V$ & $r q \Lambda$ & $f 1 \cdot 4$ & س & $199994 \mathrm{TF}$ & 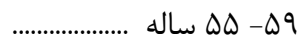 \\
\hline IVVA & gFt & vi. & ( ) & meVt & ITFAFYV & ITATGGK & ..................... - 94 ساله \\
\hline$|r| \Delta$ & NIT & DFG & rid & rTa & A. raTV & $\wedge \cdot \wedge 91 \cdot$ & 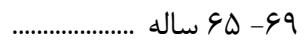 \\
\hline$q \cdot r$ & DदG & $r \cdot 1$ & TFt & $19 \cdot 4$ & $\Delta S V \cdot 9 \Delta$ & $\Delta V \| 11 r$ & ساله ................. -VY \\
\hline $1 \vee 9 \Delta$ & $1 \cdot 11$ & $v \Delta \Delta$ & frr & ו l. & $1 \cdot 1 \wedge r \cdot 9$ & 1. TQVT. & ساله و بيشتر .............. VD \\
\hline$\Delta q / f r$ & I grer & $1 \cdot \Delta \& V$ & frid & $91 \cdot 1 r$ & rarvrqve & rqfrrara & 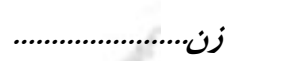 \\
\hline १९५r & $r \cdot \Delta r$ & $r \Delta \Lambda$ & TIN & r.99 & MFY人৭DG & TFYTr. F & 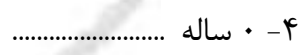 \\
\hline$F \Delta \wedge \mid$ & Irar & GAT & $r \Delta \Lambda$ & rqve & एा सrqq & TITATEV & 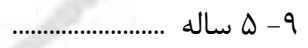 \\
\hline roll & $11 \Delta V$ & Gr. & r h & rMAN & TVGVDFV & TrVAq9I & 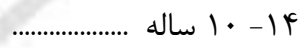 \\
\hline ras. & ITFF & $9 \times 1$ & $r \cdot l$ & F.rF & T\&GrYqq & reVrr. & 19 هاله س......................... \\
\hline r\&AV & $14 \cdot q$ & Vas & rqu & FqVF & MIFF. FD & $r / \Delta \Delta q \cdot r$ & 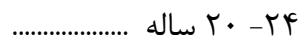 \\
\hline ८१९. & $|\Delta| V$ & $\wedge \notin \wedge$ & rvi & $\Delta \Delta r F$ & F. Frk. I & $F \cdot \Delta V \& \wedge \Lambda$ & \\
\hline DGTG & IDFF & $9 \wedge r$ & fid & $\Delta \wedge \Delta T$ & FTFG. TD & FTG. FGD & 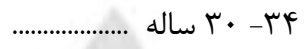 \\
\hline$i \Delta \cdot \Lambda$ & $|r| S$ & VदG & $r \cdot q$ & $F V \cdot \Lambda$ & MFATGqI & TYGDI90 & 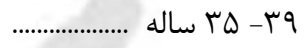 \\
\hline rrqs & $1 \cdot 1 f$ & GrT & rF. & $r q \Delta \wedge$ & T\&QDTVV & KV.FFIV & 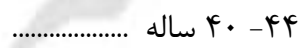 \\
\hline rیl. & 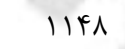 & Grs & rAl & $4 \cdot 11$ & rrgq11. & rrVAsqs & 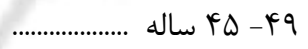 \\
\hline$r \Delta \cdot r$ & $111 F$ & GNr & 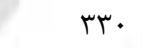 & $f \cdot 10$ & 1941911 & $190 \cdot r 9 V$ & 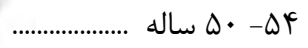 \\
\hline 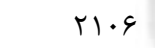 & 1.99 & VIr & rin & $r v \cdot 1$ & IEVTVTY & $191 \cdot 909$ & - \\
\hline IVVT & 1.94 & st. & r19 & $r \cdot r$. & ITAMIFT & $|r \wedge 99|$. & 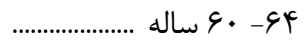 \\
\hline ITAT & VMr & $\Delta \Delta I$ & rr. & TGYY & ヘ৭V·rr & $q \cdot r \Delta \Delta F$ & 99-.................... 99 ساله \\
\hline 1189 & $\Delta V \cdot$ & rar & 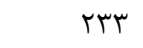 & IVED & G. TFIT & $9.901 \%$ & ساله . - $V$ • \\
\hline 1998 & 1.90 & vid & $r \Delta V$ & TrI9 & qfarts & $9 \Delta 9 V \cdot 9$ & ساله و بيشتر ..................... س VD \\
\hline
\end{tabular}


F - ا - جمعيت بر حسب جنس، سن و دين (دنباله)

\begin{tabular}{|c|c|c|c|c|c|c|c|}
\hline اظهار نشده & ساير & 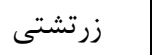 & 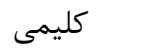 & مسيحى & مسلمان & جمع & جنس و سن \\
\hline $91 \cdot v 9$ & relkg & 19999 & qDrq & 1. reg. & $\Delta 111 \cdot F \& V$ & DqIFEAFV & مرد و زن .......... \\
\hline IfFyq & rall & krq & qr. & rI9V & $q q \vee q \vee \cdot r$ & $\Delta \cdot \cdot I V r^{\prime}$ & 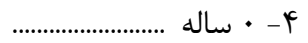 \\
\hline$V \forall \wedge 1$ & rmag & $11 \cdot V$ & $\Delta \varphi$. & $\Delta G \wedge F$ & FDYqRVI & $F \Delta F \subseteq \Delta \wedge \Lambda$ & 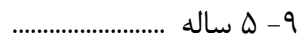 \\
\hline$\Delta \Lambda / F$ & rIgr & 1.人 & $\Delta \cdot 9$ & $\Delta \varphi \wedge \varphi$ & $f \cdot r \cdot q \Delta V$ & $F \cdot \Delta G Y F r$ & 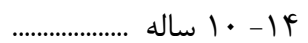 \\
\hline$\Delta V F V$ & THFt & $11 V V$ & sts & $9 \backslash \wedge \Delta$ & rqTFDQI & $r ৭ \Delta \cdot 9 \mu \wedge$ & 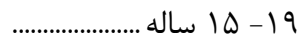 \\
\hline$\vee \Delta \Delta \cdot$ & TFAT & ITTD & Grt & VT१६ & 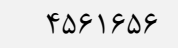 & 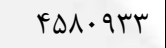 & 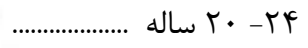 \\
\hline $1 \cdot \Delta \cdot V$ & ravV & $19 \Delta \Delta$ & $V \Delta F$ & $q \cdot r q$ & G.VDGqT & 91.9414 & ج \\
\hline 1. Fer & $m \cdot \Delta$ & IgfF & 119 & $1 \cdots V V$ & | & geTrVIS & 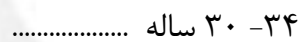 \\
\hline ATVV & TFVE & (1911 & 910 & 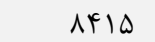 & $\Delta r V \cdot \wedge V \Delta$ & DrqTrVI & 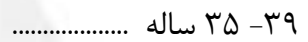 \\
\hline$\Delta \wedge \varepsilon Y$ & $r \cdot \cdot v$ & Irqf & fGr & V।qr & FIVI. $9 \mathrm{~V}$ & 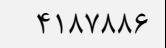 & 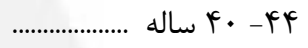 \\
\hline$\Delta \cdot \Lambda F$ & rIVT & (זוזו & $\Delta T V$ & VFAr & rVIr人iq & rV.r.११ & ................... $r Q$ \\
\hline 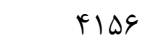 & rI91 & ITAV & $\Delta r \Lambda$ & VIGK & $r \cdot r \Delta q \cdot r$ & $r \cdot \Delta / r \cdot \varphi$ & 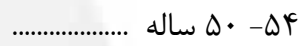 \\
\hline mpVF & $r \cdot r_{1}$ & Irfe & 91. & $99 \cdot V$ & $r \Delta F \cdot V F F$ & rDDFAIr & .................... \\
\hline TVAV & $|\wedge| r$ & ITFD & grt & $\Delta \Delta F \wedge$ & 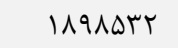 & $191 \cdot \Delta F \wedge$ & 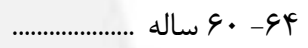 \\
\hline$r \cdot q r$ & $|f F|$ & 1..r & Drs & pref & ITFMGFI & $\mid r \Delta r \cdot r \Lambda$ & ........................ 99 - \\
\hline $19 \cdot r$ & $1 \cdot 09$ & 99. & 194 & mIV & AFTOI. & $\Lambda \mp q \Delta \cdot \Delta$ & ساله ..................... -VY \\
\hline rマ৭q & 1911 & IrFA & NIr & $\Delta \Delta \vee \varepsilon$ & $\|r F \cdot\| 1 \pi$ & ITATGT. & ساله و بيشتر ................. VD \\
\hline$\Delta 1199$ & liste & $1.9 v V$ & fqpr & Drafr & rqv. refq & raAfIfIf & 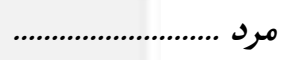 \\
\hline VFAF & IA૬V & 199 & r19 & 1901 & rQDVVT. & rD\&qITV & ץ • • ساله ....................... \\
\hline rATs & 1191 & $\Delta V r$ & Mle & 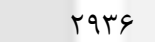 & grrirq. & משrtrrtr & 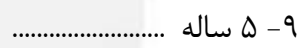 \\
\hline r.r & 1199 & $\Delta 9 r$ & rVV & TMNI & T.GVTHD & $r \cdot V \Delta I \wedge \varphi$ & f \\
\hline r৭९९ & $I T \cdot V$ & GTs & mpF & m|ध| & 199५.r. & r...rmf & 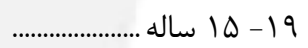 \\
\hline TVAT & ITIN & GVT & ( ) & rVTr & THDIFVE & $r$ rSIT.D & 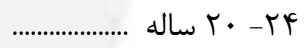 \\
\hline$\Delta \Delta \varepsilon$. & I09V & 918 & rat & FETT & $r \cdot 11 \cdot 9 r$ & T. TFY.. & Q................... \\
\hline$\Delta V \Delta \varphi$ & $19 V \pi$ & 1.90 & $f \backslash \Lambda$ & l l & 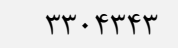 & 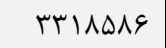 & 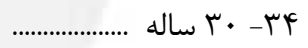 \\
\hline FAVT & IrfT & qur & שTr & F९9D & TVIEYqD & TVTATMA & 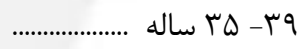 \\
\hline आヘя & $1 \cdot V \Delta$ & $V \notin q$ & rrq & ए৭९१ & tITVITA & TIMGTEG & 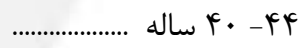 \\
\hline rVVA & 1.90 & VET & $r \Delta \cdot$ & $f \mid \cdot 1$ & IAqTITF & $19 \cdot r \cdot 9 V$ & 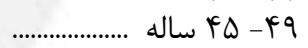 \\
\hline TITA & 1.94 & $V \Delta \cdot$ & $r \cdot 1$ & TVTr & IDrیGG & IDFGDTD & 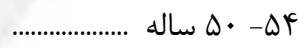 \\
\hline IVFF & $1 \cdots v$ & gVF & $r 9 \Delta$ & $M F \cdot \Lambda$ & IrVAN·r & $|r \wedge \Delta q T|$ & ه \\
\hline IfIV & $\Lambda \vee v$ & qrq & rrq & ratr & QDFTFI & q५. सr. & ...................... -9f ساله \\
\hline qVT & $V \Delta q$ & far & आI & $r \cdot \Delta F$ & $q \ldots q q$. & $\varepsilon \cdot \Delta \cdot \vee \wedge$ & 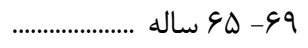 \\
\hline 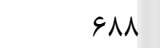 & DYF & reV & rra & 1910 & $f|| \wedge \Delta \mid$ & FIDTAK & ساله .................. -VF \\
\hline$|r T|$ & 999 & GNT & far & TVTV & GVGTYA & GNTD. 9 & ساله و بيشتر ................ VD \\
\hline$r q q \cdot r$ & IVAIT & qrar & FDAF & 19911 & ralrs.11 & $r q r \cdot \Delta F r r$ & 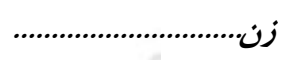 \\
\hline 9990 & lefF & rF. & $r 11$ & lQTq & TFYIQYY & TFrtg.r & ץ- • ساله .......................... \\
\hline reda & 1198 & $\Delta M F$ & TFF & TVEA & Tr. VQNI & THIGTDS & 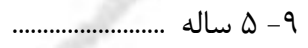 \\
\hline rVAr & $1 \cdot r \Delta$ & kq. & Trt & $r \Lambda \cdot \Delta$ & I9VRVTr & $1911 \cdot \Delta V$ & 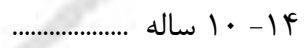 \\
\hline rVAI & IIro & $\Delta \Delta 1$ & rar & $r \cdot r F$ & |qFTOTI & $190 \cdot r \cdot r$ & 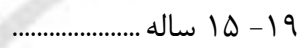 \\
\hline rVAV & ITSD & gar & rAY & $r \Delta \Delta q$ & 亗.11. & rmIgrta & 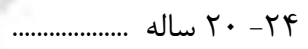 \\
\hline FqFV & Ir⿲. & Vrی & rat & FrNV & r.q4G.. & $r \cdot v a f i f$ & ج r \\
\hline F\&AV & Ifre & $\wedge \vee q$ & rqu & pres & rт৭\&911 & (r.qाr. & 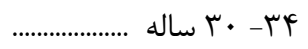 \\
\hline$r V \cdot \Delta$ & 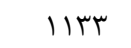 & GVG & rat & rVD. & TSOFTA. & TЯяसqRG & 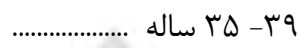 \\
\hline T\&VG & qur & $\Delta F \Delta$ & rmy & MTtF & r. prqrq & $r \cdot \Delta \mid \Delta r$. & 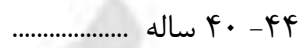 \\
\hline$r \mu \cdot \varphi$ & $1 \cdot v \wedge$ & $\Delta V_{1}$ & TVV & 要 & 111.990 & INTAK·r & ................... \\
\hline$r \cdot r_{1}$ & $11 \cdot \Delta$ & grv & rtr & mpF. & $|F q V Y F|$ & $10 \cdot F \vee V \mid$ & .................... \\
\hline IVr. & $1 \cdot T F$ & GVT & (هו & ए199 & $|r \varepsilon| 94 \mid$ & $|r G \wedge \Lambda \Lambda|$ & 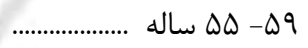 \\
\hline $1 \pi \Delta \cdot$ & 948 & 4.9 & mif & TETI & qfFYqI & $90 \cdot 111$ & ...................... -9f ساله \\
\hline 1.91 & GAT & 011 & rTd & rrq. & GFTIDI & GFVqD. & 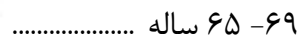 \\
\hline 910 & QTD & Tra & trA & IOST & $F r \cdot 9 \Delta 9$ & FTFTYT & ساله • - -VY \\
\hline$I F V A$ & 1.14 & 999 & ral & rApq & GGTVGD & $9 V \cdot|T|$ & ساله و بيشتر ................ VD \\
\hline
\end{tabular}




\begin{tabular}{|c|c|c|c|c|c|c|c|}
\hline 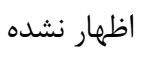 & ساير & 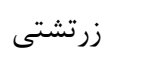 & 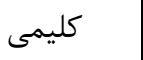 & مسيحى & 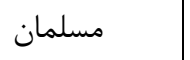 & جمع & جنس و سن \\
\hline reIfT & fral & rira & rag & rVEFf & r.sequrr & $r \cdot v r \cdot s r \Delta$ & مرد و زن ............ \\
\hline$\Delta F V$ & NMt & $r \Delta$ & r & 1119 & r. V११४द & $r \cdot \wedge \vee \Delta I$. & 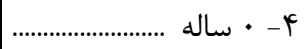 \\
\hline latr & rrq & Mा & rV & raV. & $|\wedge \Delta \Delta \Delta| \mid$ & $119.99 \mathrm{~V}$ & 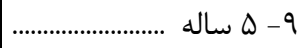 \\
\hline$|\Delta F|$ & TGF & r^s & $r \wedge$ & TrOA & IATRVED & IGTAIFT & 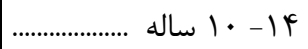 \\
\hline lQSF & $r v$. & ror & TF & rIDQ & । $₹ 999 \Delta$. & ID.FYT. & 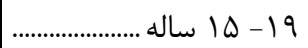 \\
\hline t.re & rqu & mis & $r \Delta$ & TFt. & $1 \Lambda \cdot \mid V \wedge F$ & $11.991 \Delta$ & 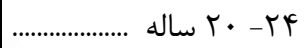 \\
\hline$r \Delta V V$ & ґА & $r q \Lambda$ & r. & TVVT & r. ^१९१r & $r \cdot 9 \Delta \wedge \Delta \Lambda$ & ...................... \\
\hline trta & MFD & mif & re & TERT & I9GrNTr & 1999494 & 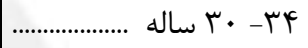 \\
\hline $11 \cdot r$ & $r \wedge$. & rq. & re & trth & |GrgVT| & IEFIFTV & 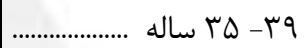 \\
\hline Irov & TFF & $\mid\langle| T_{1}$ & iv & $19 r$. & ITrTFY & ITTVTTE & 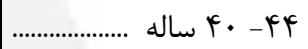 \\
\hline$\| F \Delta$ & 198 & $|V|$ & 11 & IDAr & $1.99 \Delta V F$ & $1.999 \wedge 1$ & .................... $r Q$ \\
\hline 994 & 191 & IrV & Ir & 11999 & 199449 & AVTTYV & 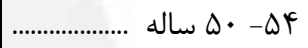 \\
\hline VG. & I & מזו & \& & 1194 & V9IrTs & VqTUVT & - \\
\hline$V \& \Delta$ & irv & $1 \cdot \Delta$ & $\wedge$ & $9 \Delta r$ & GTATRT & qr.rrq & ...................... -9f ساله \\
\hline$\Delta r \Lambda$ & $1 \cdot f$ & 94 & 9 & $\varepsilon \vee \Delta$ & 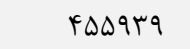 & FDVRFq & 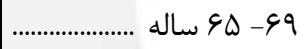 \\
\hline FrA & VV & q & 1. & fqr & TTEYAI & TrVF.l & ساله .................. -VY \\
\hline $9 \wedge \vee$ & 190 & $|r|$ & 19 & $9 \Delta r$ & GYGFIA & 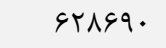 & ساله و بيشتر ................ VD \\
\hline$I f \cdot 1 \cdot$ & rasr & $|19|$ & $19 V$ & laFqT & 1. Dqqrar & $1 \cdot q r \cdot \Delta F q$ & 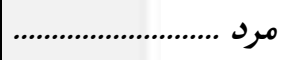 \\
\hline$r \wedge \Delta \Delta$ & FTH & IV & 4 & \&тq & $1 \cdot V F \vee \wedge D$ & $1 \cdot V \wedge \vee \backslash \Delta$ & 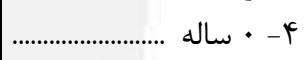 \\
\hline $1 \cdot r \Lambda$ & IV. & $\mathrm{IV}$ & r & IrFV & $901 \ldots$ & 9DYVTA & 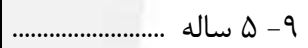 \\
\hline$\Lambda T \Delta$ & IrT & 109 & rt & $11 \mathrm{VV}$ & שTוM & NTFITD & 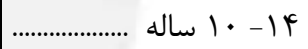 \\
\hline$\vee १ \Delta$ & I & 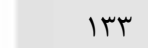 & 10 & IIOT & $\vee \wedge \cdot \wedge \cdot 1$ & $\vee \wedge r \cdot \Delta q$ & 19 - هاله س......................... \\
\hline IIOT & $r \Delta \Delta$ & IV & 19 & irid & १९৭१•V & QYTAT. & 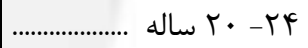 \\
\hline IDFV & ror & 191 & If & 1949 & 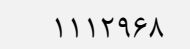 & $1119 \Delta \mathrm{VA}$ & .................... \\
\hline IrqF & 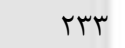 & r). & 9 & $I D F \Delta$ & س 19Dו 1. & $1.191 \mathrm{TF}$ & 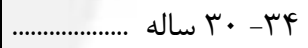 \\
\hline $1 \cdot 10$ & 199 & IV. & it & IrVte & Аrवr৭D & $A F T \cdot G \Delta$ & 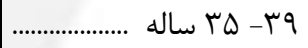 \\
\hline$V \Delta S$ & IST & lQF & 11 & 1199 & GVTGKA & GVDqIV & 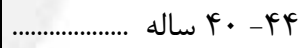 \\
\hline 90. & IrA & 1.9 & If & $94 \wedge$ & DFAAVV & $\Delta \Delta \cdot V T r$ & ................... \\
\hline qqf & 19 & 91 & 1 . & Vrq & FTEFIV & FrVAr. & ...................... • • \\
\hline rqf & $\Lambda \Lambda$ & N & r & 99r & rNIDAF & TATAFY & 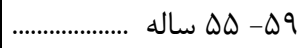 \\
\hline$r \Delta \cdot$ & GV & VI & r & $\Delta F F$ & rq. rr. & rqIr\&D & 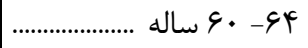 \\
\hline ruq & $\Delta r$ & $\Delta F$ & r & 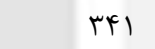 & T. TAIF & T.rT. & 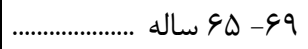 \\
\hline rIf & pr & 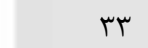 & $\Delta$ & r^৭ & IDFAIT & 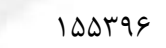 & ساله ................... -VY \\
\hline FVT & 115 & VT & 1. & $\Delta \wedge r$ & rFII9V & METfFe & ساله و بيشتر ................ VD \\
\hline Ir.gr & IATF & IrVF & 159 & 11945 & $1 \ldots$ VrADa & $1 \cdot 1 \ldots v \varepsilon$ & 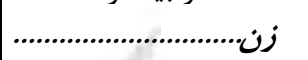 \\
\hline TS19 & $r \cdot \Lambda$ & 11 & $\checkmark$ & $\Delta \Delta V$ & $1 \cdots 0119$ & $1 \cdots \wedge \vee 9 \Delta$ & ץ- • ساله ............................. \\
\hline $91 f$ & 109 & $\mid \& \lambda$ & If & מTו & $q \cdot F \Delta 11$ & 9.9999 & 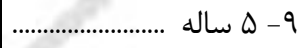 \\
\hline VIs & IrT & 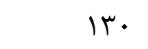 & $\varepsilon$ & $1 \cdot 11$ & Vqlafr & Vqץ. $\cdot V$ & f \\
\hline V\&q & $1 \cdot V$ & Ir. & 9 & $1 \cdots v$ & VI9149 & $V T \| 91$ & 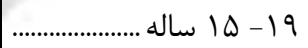 \\
\hline 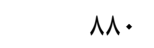 & I F & IFr & 9 & 1111 & 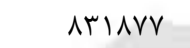 & NFFI\&D & 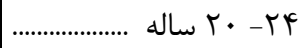 \\
\hline $1 \cdot r \cdot$ & Irv & 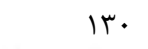 & 19 & $11 \mathrm{kr}$ & QVEATF & 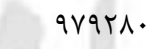 & ج \\
\hline qro & 115 & $1 \cdot e^{f}$ & IV & 1.91 & $q F V r \cdot f$ & $q \uparrow q \Delta V$. & 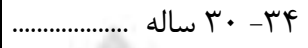 \\
\hline$\vee \wedge \vee$ & 11 & 9. & if & $9 \Delta F$ & VAVFre & Vq94 & 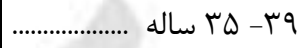 \\
\hline $9 \cdot 1$ & NT & $\wedge \vee$ & 4 & VMF & я४q४qq & $901 \% \cdot 9$ & 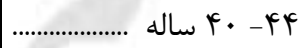 \\
\hline 490 & 99 & 90 & f & $\varepsilon r \Delta$ & DFVGqV & $\Delta F \wedge 99 \Delta$ & . \\
\hline$q V$. & vq & is & r & $\Delta V \cdot$ & FFTrTg & FFfT & ..................... • • \\
\hline rदG & $v \Delta$ & r. & r & $\Delta \cdot r$ & F. qVFr & FI. VTA & 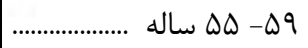 \\
\hline fid & $\checkmark \cdot$ & me & $\Delta$ & $\uparrow \cdot \Lambda$ & rru. tr & 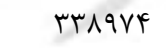 & 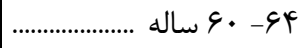 \\
\hline r^9 & $\Delta T$ & r. & $\Delta$ & ( & TATFTD & TQFIFD & 99-1.................... \\
\hline rgF & ro & r. & $\Delta$ & $r \cdot r$ & $|V| F \& \Lambda$ & $I V T \cdot \Delta$ & ساله • - VY \\
\hline$\Delta / \Delta$ & $\Lambda r$ & pq & $\varepsilon$ & rv. & TADTKI & TAGTFY & ساله و بيشتر VD \\
\hline
\end{tabular}


ه- 1 - جمعيت بر حسب سن، جنس و نوع خانوار

\begin{tabular}{|c|c|c|c|c|c|c|c|}
\hline \multicolumn{6}{|c|}{ خانوار ساكن } & \multirow{3}{*}{ جمع } & \multirow{3}{*}{ سن } \\
\hline \multicolumn{3}{|c|}{ تروهى } & \multicolumn{3}{|c|}{ معمولى } & & \\
\hline 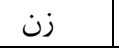 & 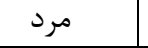 & مرد و زن & 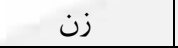 & 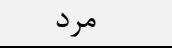 & مرد و زن & & \\
\hline FVVD. & IFEDTA & I IFFMA & $r q \cdot q \cdot r q l$ & rqgrVrFF & rAVrVg.d & vaqrerr. & 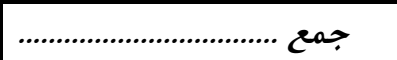 \\
\hline rFAD & rAFt & VTrV & TATrIDT & TETTtT & $V \cdot \Lambda \cdot r \Lambda F$ & $v \cdot q r \ldots q$ & ץ-................................. س • \\
\hline$r \cdot v \cdot$ & (1) & gfir & $m 119 \cdot \wedge V$ & rTVА१९т & $q 4 q 1 \cdot \vee q$ & GFIITVV & 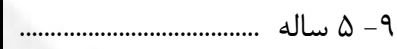 \\
\hline rQDI & merk & $9 \cdot 19$ & TVDTI. F & $r \Lambda \Lambda \cdot \Delta r q$ & 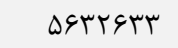 & $\Delta S \Lambda \Lambda \mu \wedge F$ & f 1 ساله . \\
\hline ५१९จ & 10999 & 19999 & $r \Delta q T Y \cdot \Delta$ & rदITrqG & $\Delta T \cdot \Delta V \cdot 1$ & $\Delta F \Delta \wedge 99 \vee$ & 19 اله اله 19 \\
\hline Vqu। & $r F \cdot F r$ & fiqve & $r \cdot r F \cdot r \Delta$ & $r \cdot . \wedge V V r$ & $G \cdot F r \Lambda \cdot \Lambda$ & ятqr人vq & 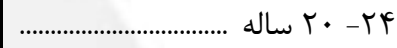 \\
\hline SVD. & КА१९T & TDVET & F. TIVTT & f. Ispqk & A.rNTIG & r & ساله \\
\hline DIMI & $19 F \Delta T$ & rFaAr & FTFMI9D & FTFVTIT & $\Lambda k q \cdot r \cdot \Lambda$ & 19..91r & ץ \\
\hline roגv & $|r V A|$ & $18 \pi 8 \Lambda$ & MFAFVII & TA. TrtT & 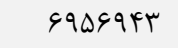 & $V \cdot r V \Delta q \Lambda$ & q \\
\hline TFV. & $1 \cdots 9$ & $1.4 \vee q$ & rqqVY.r & TVGATIV & DFGDVT. & $\Delta \Delta \backslash \wedge \mu \cdot V$ & ساله \\
\hline$r) \cdot \Delta$ & $\Delta \Delta \wedge \Delta$ & V\&q. & THVTVAN & TFTH.IT & $F \vee 9 \Delta \wedge \cdot 1$ & שTITIT & 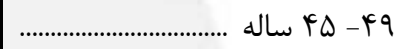 \\
\hline IVAS & rq^ג & $\Delta V V F$ & $194 \Delta G \cdot \Lambda$ & $19 \Delta 9 \Delta \wedge \Delta$ & rq. r।qr & 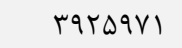 & 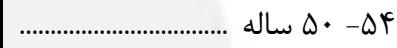 \\
\hline larV & tVAF & FTt & ISVGGG & IGDVFA & TrmfldI & سو & و - \\
\hline $1 T \cdot 4$ & $11 \cdot 9$ & $r \cdot 10$ & 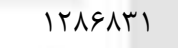 & IYFDGG & TDTrFqF & TAFTAVT & ماله . 94 \\
\hline NIT & $9 ९ V$ & IVvq & $q \cdots+\Delta q$ & $\Lambda \cdot \Delta r \Delta q$ & $|V \cdot \Delta \Lambda| \Lambda$ & IVIIfGF & .................................. $9 \Delta$ - 99 \\
\hline FVA & 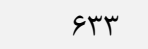 & 1111 & 9.499. & $\Delta 9 \wedge 91$. & $11 \vee r q .$. & IIVVGTD & ساله \\
\hline$V \Delta F$ & $11 \mathrm{Vr}$ & I9TV & $9011 \cdot 1$ & D.TITFA & I9VTHDS & I9ATFTQ & ساله و بيشتر ................................ \\
\hline$r f q \cdot q$ & $1 \cdot \Delta 111$ & $I F \cdot V A r$ & $r q \cdot r k r r r$ & $r q r A \cdot r F q$ & DArIfrar & DqIFEAFV & ساكن در نقاط شهرى....... \\
\hline rig. & TFIV & $r q \cdot V$ & TFTQGGY & 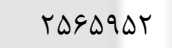 & 4990919 & $\Delta \cdot \cdot I V r \cdot$ & ץ • ساله . \\
\hline $19 V F$ & rirs & fil. & TTITTAI & THYGDST & ForqAir & 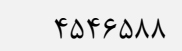 & 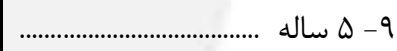 \\
\hline $199 \mathrm{~V}$ & riva & rAfs & 199DIDT & $r \cdot \Delta \vee \wedge l \cdot$ & F. rrast & $F \cdot \Delta G Y K T$ & 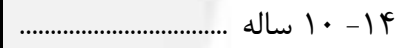 \\
\hline rq91 & IIFVT & IfFer & $111 \cdot v 19$ & INVAFFA & TVDqI\&V & $r 9 \Delta \cdot 9 \mu^{\prime}$ & 19 - هاله س......................... \\
\hline GQVI & TETVG & rTqFV & $r r \cdot 9 \wedge 91$ & $r \cdot q$ PVDq & $F r \cdot F \varphi \Delta$. & $F \Delta \Lambda \cdot q \mu r$ & • • اله سال. \\
\hline$\Delta F \cdot \Lambda$ & TIEFT & $t R \cdot a \cdot$ & $r \cdot r q \cdot r$. & rqfiNkT & $\Delta q \wedge \vee \wedge \Delta F$ & 41.914 & ساله \\
\hline rq. & |r११| & IV^qท & 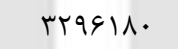 & rTETAGT & $q \Delta \Delta q \cdot V q$ & gervile & \\
\hline TETI & $\wedge \vee 9 \wedge$ & 11419 & TEDVTAT & 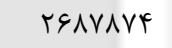 & DTFATTE & DHQTYVI & q \\
\hline IVTK & $\Delta r q 1$ & vilr & $r \cdot r \vee \Delta \wedge r$ & 511.914 & F) $0119 V$ & 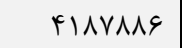 & 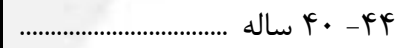 \\
\hline 1490 & rvav & DTGT & $1 \wedge r \Delta \cdot V q$ & IMAFVDS & rV. qArd & r r. ५ qq & 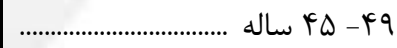 \\
\hline ITFF & rRII & r৭ఎ & DD. TMTK & larg..r & r.rATrG & $r \cdot \Delta ו r \cdot \varphi$ & (.............................. \\
\hline $1 \cdot r \cdot$ & 1918 & $r \cdot I V$ & $1 Y \& \& \wedge \Delta 9$ & ITVATTK & TQFG. $1 I$ & rDQFAIT & ساله $\Delta$ - $\Delta 9$ \\
\hline VAr & $1 \pi 4$. & $r \cdot k r$ & qFADFA & $9 \Delta 9 ৭ \cdot V$ & $19 \cdot \Delta 1 \Delta \Delta$ & $191 \cdot \Delta F \wedge$ & . 9 ساله . \\
\hline Q & gri & IIFF & $\operatorname{sq} \& \Lambda \cdot 4$ & G. TIVD & IrFq9Vq & $I T \Delta K \cdot r \Lambda$ & .................................... 99 - \\
\hline שוץ & rq1 & vil & Frmtge & $f\|f\| f$ & AFVKAN & $\Lambda \mp q \Delta \cdot \Delta$ & ساله $V \cdot-V F$ \\
\hline$\Delta \cdot \Lambda$ & 990 & $M \cdot r$ & GGDVTR & SVANTE & ITFDQAFq & IrATGK. & ساله و بيشتر ................................ VD \\
\hline I TAFF & $f \cdot \varepsilon \Delta r$ & $\Delta r \Delta \cdot 1$ & $1 \cdot \Delta \Delta a q 1$ & $1 \cdot r \Delta \& 19 \Delta$ & r.firarr & $r \cdot v r \cdot q r \Delta$ & ساكن در نقاط روستا ييى... \\
\hline $1 \% 90$ & IFTD & TVT. & $1 \cdots V F \wedge \Lambda$ & $1 \cdot V V r \Lambda \cdot$ & $r \cdot \Lambda F V \& \Lambda$ & $r \cdot \wedge \vee \Delta \mid \cdot$ & 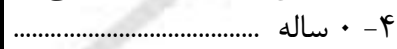 \\
\hline 1.99 & $I T \cdot V$ & r r tra & $9 \cdot \Delta \wedge \mu \varepsilon$ & QDTFY. & INDATGG & $119.99 \mathrm{~V}$ & 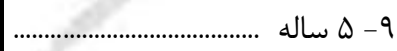 \\
\hline$q \wedge \mathrm{F}$ & $1 T \Delta 9$ & THET & VAৎ৭DT & ATTVI9 & $19.99 V 1$ & IETAIFT & ץ • اله ساله . \\
\hline 1.94 & GTrV & TrTH & WIsরe & VTYAFA & IFFGDTF & DQ.FTT. & 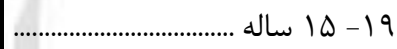 \\
\hline 1re. & V\&9V & $q \cdot r V$ & NTFIFF & $91 f \cdot 1 f$ & $|V T \wedge| \Delta \Lambda$ & 11.9910 & 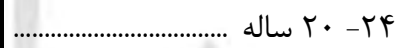 \\
\hline ITET & Vra. & 人९9T & $q V \Delta V \cdot r$ & 1. V\&\&G. & $r \cdot \Delta \cdot r G r$ & $r \cdot 9 \Delta \wedge \Delta \wedge$ & 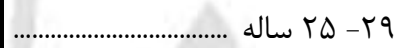 \\
\hline ITTD & $\Delta<\& \mid$ & 99人૬ & $94 V \cdot 10$ & $914 T 19$ & I9mIrrt & 1999494 & 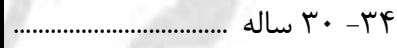 \\
\hline 994 & rq人 & pqpq & $\vee q \vee r \Delta q$ & $\Lambda I F r \Delta \Lambda$ & $1911 \mathrm{VIV}$ & IEFIFTV & q \\
\hline 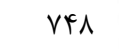 & rघIN & 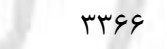 & grqur. & 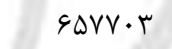 & IT.VDTH & ITTVTTE & | \\
\hline st. & IVAM & TFTA & $\Delta F V V \cdot q$ & DTNTSV & $1 \cdot 10949$ & $1.998 \wedge \Lambda$ & ................................. \\
\hline DFT & ITVV & 1119 & fermpt & $F T \cdot \Delta \Lambda \mu$ & Аรพ $9 \Delta \vee$ & AVTTYV & ( $\Delta$ ساله . \\
\hline$\Delta \cdot V$ & V9V & $1 r \cdot r$ & $f \cdot 91 \cdot r$ & rVArgs & $\vee \wedge \Lambda \cdot V \cdot$ & VqTuVT & 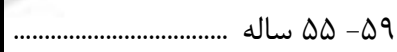 \\
\hline Frt & $\Delta F q$ & qVर & rrATNT & $r \wedge q \cdot \Delta \varphi$ & grVmrq & $q \mu \cdot r r q$ & 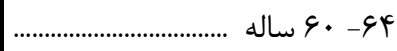 \\
\hline r99 & פח & $\varepsilon r \Delta$ & 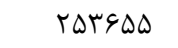 & $r \cdot r \mid \Lambda F$ & $r \Delta \Delta \wedge r q$ & FDVrFq & |.................................. 90 - 99 \\
\hline 190 & rta & r.. & IVIVIe & IDFVqG & TTEDIT & mTVR. I & ساله \\
\hline rFG & Fru & VTY & rADHAD & MFIFTt & 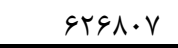 & 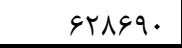 & ساله و بيشتر ................................ \\
\hline
\end{tabular}


ه- 1 - جمعيت بر حسب سن، جنس و نوع خانوار (دنباله)

\begin{tabular}{|c|c|c|c|c|c|c|}
\hline \multirow{2}{*}{\multicolumn{3}{|c|}{ خانوار معمولى غير ساكن }} & \multicolumn{3}{|c|}{ خانوار ساكن } & \multirow{3}{*}{ سن } \\
\hline & & & \multicolumn{3}{|c|}{ مؤسسهاى } & \\
\hline زن & مرد & 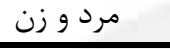 & زن & مرد & 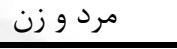 & \\
\hline reria & refra & raval & revequ & $811 \cdot 11$ & $q \Delta \Delta \Delta V q$ & جمع ........... \\
\hline $11 \cdot 9$ & 1901 & rvas & val & V\&A & $10 Y 9$ & 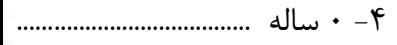 \\
\hline 1945 & $r \cdot v \cdot$ & एव१५ & 1191 & 19T0 & TVQT & |.................................. \\
\hline $119 \mathrm{~V}$ & rI. T & ५१११ & $r \cdot r \cdot q$ & TATAF & FAGAT & 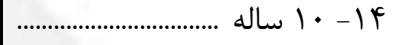 \\
\hline INFF & rT9D & Firq & $V Q .9 T$ & IDFrqA & rTq4al & 19 اله س............................... \\
\hline$r \cdot 11$ & ras. & (99) & $11194 \mathrm{~V}$ & $191 r \cdot 9$ & r.rirs & ............................ \\
\hline 1994 & rघ9V & 4991 & TYYTY & QDTqR & ITTAIF & q............................. \\
\hline IV9D & $r \cdot r \wedge$ & $r \Lambda \cdot r$ & 1.rVk & VIVES & Ar 119 & 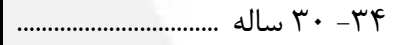 \\
\hline ।१9v & $r \cdot . r$ & rq.. & $\Delta \cdots$ & $\Delta \Delta T \wedge V$ & G. rAV & q \\
\hline 1091 & IGTV & r190 & rav9 & rबqTV & гА१וr & ..1.1.1.1.1.1.1.1.1.1....... \\
\hline IFrq & $19 \cdot \mathrm{V}$ & r.re & rTVE & TFYTY & rबQ99 & .............................. \\
\hline ITrq & $15 \cdot 9$ & TFYA & IVVE & IrVar & 10Q99 & 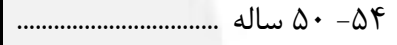 \\
\hline $1 \cdot \Delta \cdot$ & 1109 & $r \cdot q$ & $14 \cdot 9$ & $\Lambda \Delta \cdot r$ & $991 \%$ & 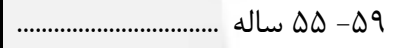 \\
\hline 111 & $94 \wedge$ & IVAS & $1 \cdot \Delta \Delta$ & FTt & DTVA & ............................... \\
\hline FQq & Gru & $1 \cdot 1 \mathrm{~V}$ & ATF & 1909 & TVA. & 1............................. \\
\hline TAS & אזי & 119 & $V Q 9$ & 11149 & 1190 & 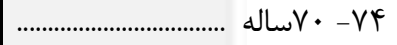 \\
\hline myF & V\&D & $11 \cdot 9$ & $F \Delta \cdot r$ & TATF & $v \cdot r v$ & 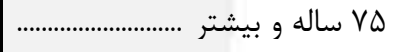 \\
\hline - & . & . & rrgigf & $F \Delta \Delta \cdot 1 F$ & sq1rra & ساكن در نقاط شهرى .... \\
\hline 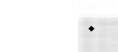 & - & & $v \notin q$ & $v \Delta \Lambda$ & $10 \cdot V$ & ץ- • ساله .................................. \\
\hline . & . & & $11 \pi 1$ & lark & r\$90 & 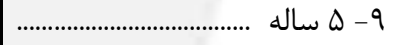 \\
\hline . & - & & IFTHA & $1019 V$ & rapro & 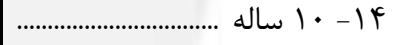 \\
\hline . & - & & 99094 & $11 \cdot 4 \mid f$ & $\operatorname{lV} \cdot \cdots 1$ & 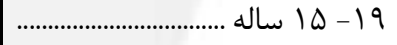 \\
\hline 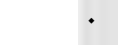 & - & & 1. MYGQ & $14 \cdots v$. & TFTHE & 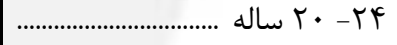 \\
\hline . & . & & rFq19 & G.VYF & $\Lambda \Delta V 1$. & q............................ \\
\hline . & - & & $q \cdot k r$ & fiv.1 & $\Delta \cdot V \leftarrow \Delta$ & 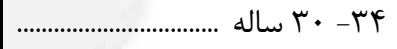 \\
\hline . & . & 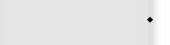 & एव९ा & M1994 & TASTS & q \\
\hline 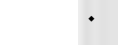 & - & & rTrQ & $r \cdot r+1$ & TrQVG & 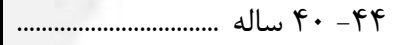 \\
\hline - & - & & $I V \Delta \Lambda$ & ITAFF & $\mid \Delta T \cdot T$ & ................................... \\
\hline . & - & & וrqז & VATt & 9110 & ................................. \\
\hline - & - & & 995 & FVTr & DVIF & ................................. $ه \Delta-\Delta q$ \\
\hline - & - & & VAV & rAGY & ז" & .............................. \\
\hline - & - & & दזr & ITrT & $19 \cdot \Delta$ & |.................................... \\
\hline - & - & & sTo & vil & 14.9 & 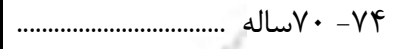 \\
\hline$\cdot$ & . & & ґА१. & 1911 & $\Delta \wedge \vee \wedge$ & Vاله و بيشتر ................................ \\
\hline - & - & - & $r i r \cdot r$ & reraqr & repr. I & ساكن در نقاط روستا يي.... \\
\hline . & . & - & ir & 1 . & r & ץ · • ساله ......................................... \\
\hline - & - & . & rV & 9) & irs & …………….................. \\
\hline . & - & • & $4 \cdot \sqrt{1}$ & $1.1 \Delta V$ & IGTrA & ז \\
\hline . & - & & $1 \notin 99$ & Fra人k & DYFAT & 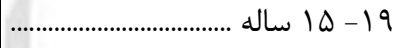 \\
\hline - & . & & 1991 & Q1)ra & $\Delta 9 \Lambda .$. & 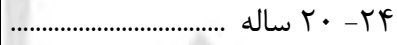 \\
\hline - & - & & FYMG & TFDGA & rqA.4 & 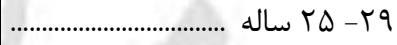 \\
\hline . & - & & וrr. & $r \ldots q \mu$ & MITYF & 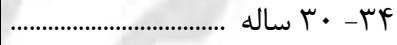 \\
\hline & • & & I. rV & TrVTF & rFVal & q \\
\hline & & & V*1 & $10 \Delta 99$ & 19TYV & 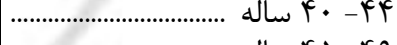 \\
\hline & & & 919 & $1.9 \mathrm{VA}$ & $11 r 94$ & $\ldots$ \\
\hline & & & FAl & DqV. & s401 & 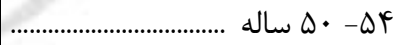 \\
\hline & - & & fiv & rYA & 4191 & ............................... $\Delta \Delta$ - $\Delta 9$ \\
\hline - & 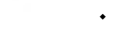 & - & 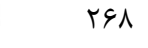 & 199. & $194 \Lambda$ & ............................... \\
\hline - & - & - & 191 & sAF & $\Lambda \vee \Delta$ & \\
\hline - & - & - & ITF & red & $4 \wedge 9$ & 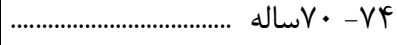 \\
\hline$\cdot$ & - & . & $91 \%$ & $\Delta+\varepsilon$ & 1109 & ساله و بيشتر ......... \\
\hline
\end{tabular}




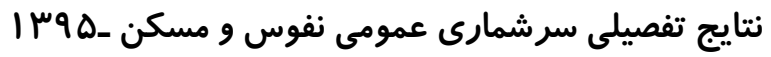

צ- (- مهاجران وارد شده طى ه سال كذشته بر حسب جنس، سن و محل اقامت قبلى (بر اساس آخرين جابجايى انجام شده) (كل)

\begin{tabular}{|c|c|c|c|c|c|c|c|}
\hline \multicolumn{6}{|c|}{ استان محل سرشمارى } & \multirow{3}{*}{ جمع } & \multirow{3}{*}{ 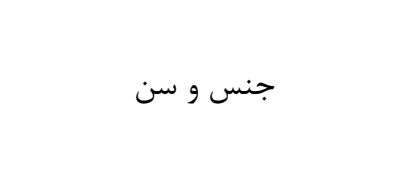 } \\
\hline \multicolumn{2}{|c|}{ اظهار نشده شهرستان } & \multicolumn{2}{|c|}{ ساير شهرستانهاى استان } & \multicolumn{2}{|c|}{ شهرستان محل سرشمارى } & & \\
\hline آبادى & شهر & آبادى & شهر & آبادى & شهر & & \\
\hline$|v|$ & TKEA & $r \cdot \Delta 119$ & lllvgr. & frrqur & reveIV & fr...q11 & مرد و زن ............ \\
\hline lf & $10 \Delta$ & $\| 114$. & $44 \Delta \wedge 9$ & rTEYA & rTata & TEITTI & ץ- • ساله ..................................... \\
\hline rq & rif & $19 \cdot V 4$ & 94.90 & $r \Delta \cdot \Delta q$ & rryil & rrVGVV & 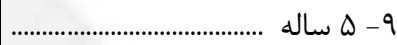 \\
\hline r & 189 & Irav. & VIDII & pqvq. & rQDAV & TVATAV & ץ \\
\hline rq & (4) & 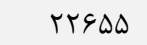 & QAQGF & GGTFV & tFqAT & FITTLD & 19 اله ............................... \\
\hline$r_{1}$ & $9 \Delta \mathrm{V}$ & rrTAl & $|\Delta V| \Delta \mid$ & raTYA & rMFVD & 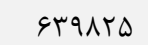 & 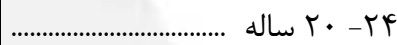 \\
\hline 19 & $r \cdot r$ & rTITs & DQTATq & DqFTS & fralv & GQTAT. & \\
\hline ir & $19 \pi$ & TrIlQ & $|\Delta V Y| \mid$ & DFEST & DITAN & Q৭৭९৯९ & ץ · \\
\hline 9 & 190 & IVTEY & DIMETt & rgATF & एध११९ & F. Frג. & q \\
\hline$\Delta$ & vr & $11 \cdot \Delta V$ & $v r \cdot v 1$ & THAGT & rせरqT & TQTHYV & (................. \\
\hline r & fi & $v \cdot r \Delta$ & $\Delta \cdot 10$. & 1490. & ISVTr & IVTITE & 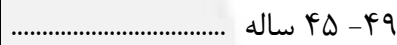 \\
\hline c & kr & FI91 & $r r \cdot \Lambda$. & 1990 & $1.9 . r$ & $111 \cdot \wedge 1$ & . \\
\hline . & rᄉ & $r \Lambda \cdot \Delta$ & TITYY & GTAV & VYTY & VQ.rt & 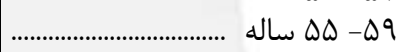 \\
\hline r & 19 & IArq & IrTqD & riga & fval & $494 \cdot 1$ & •q. \\
\hline . & 19 & 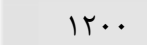 & $V T \Delta \Delta$ & $r V \Delta q$ & rEVT & rAlAr & q 9 ساله ............................... \\
\hline r & 11 & $\Lambda \mu \Lambda$ & FrTa & 19v9 & $19 \cdot 4$ & $|v \cdot \Delta|$ & 다. \\
\hline 1 & 1. & T. Tr & $94 \cdot r$ & rug. & THYA & reVVF & Vاله و بيشتر ............................. \\
\hline 99 & IEAT & $1 \cdot 1 \% \cdot \Delta$ & $\Delta \Delta F I \cdot r$ & $r|v| \cdot 1$ & IVraga & rrl.rar & 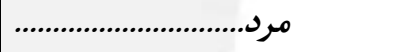 \\
\hline 1. & १४ & $\Delta V r$. & $r r \cdot q$. & | & $|r| 94$ & IFFT. & ץ- • • ساله ................................ \\
\hline ir & $11 r$ & ArVF & FVADI & 11.19 & ivras & IVrq99 & 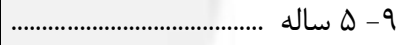 \\
\hline 11 & q. & $V \cdot \mu q$ & rबqvץ & TQAVT & Irr.1 & IFHEDV & ץ \\
\hline ir & raی & $11 \% 48$ & pqper & rrTqQ & llArr & rrratry & 19 اله اله ـ............................... \\
\hline 9 & QTq & Irive & $9 \Delta \Delta 999$ & leque & $1 T Y \cdot q$ & T. TTYD & 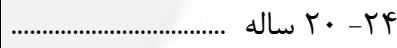 \\
\hline$\wedge$ & Irr & 10901 & 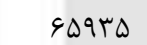 & rVYrq & r.VKG & $r \cdot 9 \Lambda r q$ & q \\
\hline $\mathrm{v}$ & 90 & 149. & VATTS & rqlev & TETFE & $r \cdot \Lambda ו V \wedge$ & 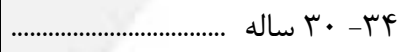 \\
\hline $\mathrm{v}$ & $\mathrm{v} \wedge$ & GTFD & 91.re & r.IVT & 19149 & $r r \cdot I V q$ & q \\
\hline$\Delta$ & re & G.rT & FIral & Frrer & ITFED & IFTERV & 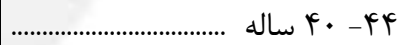 \\
\hline 1 & r & rATr & rAQVYF & NTGF & $q \pi \Delta \varphi$ & १VQTQ & . \\
\hline f & rI & TTQV & IAr.. & FVFi & ८१९९ & \&T990 & 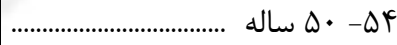 \\
\hline . & 11 & leks & IIVTr & rт人t & kry. & $+\mid \Lambda \cdot \Delta$ & 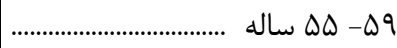 \\
\hline . & 4 & AVV & VISD & $r .94$ & rela & revrq & . \\
\hline . & 9 & EVA & rat. & 1110 & 1r4. & IFTr. & 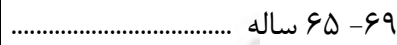 \\
\hline r & $\Delta$ & g & $r T \cdot V$ & $\Lambda \Delta \Delta$ & NTr & N9וז & 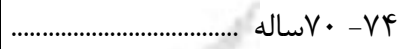 \\
\hline . & r & $1 . .1$ & TQT) & rIFT & 1.99 & Irवq & ساله و بيشتر .............................. \\
\hline Va & 118 & $1 \cdot r r a 1$ & aqrarr & $r r \cdot 1 r q$ & IVFefA & $r \cdot q \cdot q \cdot 1$ & 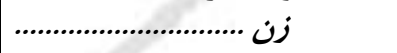 \\
\hline r & $\Delta \wedge$ & $\Delta \psi 1$. & rाषq9 & IIrIf & $11 r \Delta q$ & $\mid 19941$ & ץ- • ساله ..................................... \\
\hline ir & $1 . r$ & $v \vee \cdot$. & Farle & IV.F. & 19110 & $\mid$ |QrVI| & (9 \\
\hline ir & 19 & gQTS & rFaTA & rrqוג & Irras & ITFAT. & 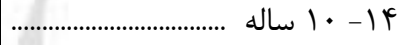 \\
\hline if & qr & 11419 & $4 q . q 4$ & TYADT & ITIFA & 19.411 & اله 19 \\
\hline ir & 111 & $r \cdot 1 \cdot \Delta$ & $91 \Delta \wedge \Delta$ & $r \cdot F r F$ & r.VAS & rrVq.. & ץ \\
\hline$\wedge$ & $\wedge 1$ & IVFYF & $\wedge \vee q \cdot \varphi$ & rT. YS & rYIVI & re9991 & \\
\hline$\Delta$ & $9 \wedge$ & $|T \Delta| \Delta$ & vapve & TAHIQ & $r \Delta \cdot 14$ & $r 910 \cdot 1$ & ץ \\
\hline r & $\wedge \mathrm{V}$ & $1 \cdot 1 \mathrm{~V}$ & DrTqG & $1990 \mathrm{r}$ & $1 V \cdot 94$ & MFT. I & 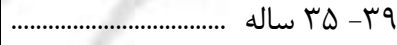 \\
\hline . & rq & $\Delta \cdot r \Delta$ & rive. & $1 .+\mathrm{Fq}$ & $1 . F F$ & $1 \cdot \wedge \vee \Delta$. & (1............ \\
\hline 1 & rI & & rIQVe & $94 \wedge 9$ & vrrv & VFD9 & ........................... \\
\hline 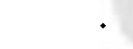 & rt & 1911 & Irм. & rqDF & $p q \cdot v$ & FAFTH & …....................... \\
\hline . & 1. & $1 r \Delta q$ & 949. & $r \ldots q$ & TFAV & TFETY & $ه$ ساله ............................ \\
\hline r & 1. & १९५ & 91\%. & r/99 & rive & FTETQ & ק. \\
\hline . & v & VTr & rets & IGFY & & 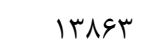 & 99 90 ساله ........................... \\
\hline . & 9 & $\Delta \cdot r$ & rIIN & IIKF & VVT & AFrq & ................................ \\
\hline 1 & $\Lambda$ & $1 . r_{1}$ & mFAt & THIN & llar & $\mid$ IrVAl & ساله و بيشتر ............................ \\
\hline
\end{tabular}


צ- (- مهاجران وارد شده طى ه سال كذشته بر حسب جنس، سن و محل اقامت قبلى (بر اساس آخرين جابجايى انجام شده) (كل)

(دنباله)

\begin{tabular}{|c|c|c|c|c|c|c|c|c|}
\hline \multirow{3}{*}{ محل اقامت } & \multirow{3}{*}{ خارج از } & \multirow{2}{*}{\multicolumn{2}{|c|}{ اظهار نشده استان و }} & \multicolumn{4}{|c|}{ استانهاى ديخر } & \multirow{3}{*}{ جنس و سن } \\
\hline & & & & \multicolumn{2}{|c|}{ اظهار نشده شهرستان } & \multicolumn{2}{|c|}{ شهرستان } & \\
\hline & & آبادى & شهر & آبادى & شهر & آبادى & شهر & \\
\hline$I F F A$. & $11 \cdot 149$ & rar & 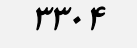 & req & fyit & IVFFYq & IANTATF & 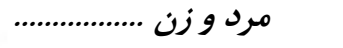 \\
\hline MTI & $V \cdot \wedge \varepsilon$ & rq & $\mid F \wedge$ & rI & IOT & I. rTA & $1 \cdots \Delta \Lambda$ & 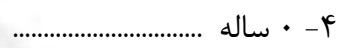 \\
\hline $11 \% 4$ & 9491 & \& & rTA & 11 & $I V \Delta$ & $|r \Delta F|$ & IKGT·^ & 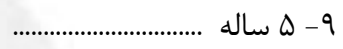 \\
\hline 1191 & $99 \wedge \Delta$ & $\Delta 9$ & ITr & If & 149 & $\wedge \wedge \wedge \cdot$ & $1 \cdots \Delta r q$ & 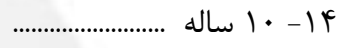 \\
\hline$|A T|$ & IrrqA & rt & erq & r & $\| r \wedge$ & $|\wedge ब \Delta|$ & $19 \Delta 9 \cdot r$ & 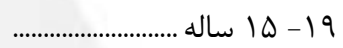 \\
\hline trAF & $19 T V K$ & 91 & $1 \cdot \Delta \Lambda$ & 91 & $1 f \Delta \Delta$ & TFIAD & MIFAD & 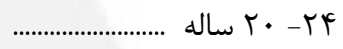 \\
\hline IFFA & $19 V \cdot \Lambda$ & rF & $\Delta \Delta I$ & rF & 499 & rrI. 9 & $r \cdot V 911$ & \\
\hline 1114 & Irorr & 19 & T T & ra & rG. & rrqFF & rVI\&9D & F \\
\hline$\Lambda \cdot 1$ & qrवा & 11 & 194 & If & $r \cdot \Lambda$ & $1 r r \Delta \Delta$ & IVDqFD & 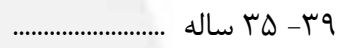 \\
\hline$\Delta \wedge F$ & $\Delta \varphi \cdot G$ & $1 \cdot$ & $q \uparrow$ & v & IFT & VAT. & $1.91 \Delta F$ & ........................ \\
\hline prr & rq६द & $\Delta$ & $9 \Delta$ & $\Delta$ & TEY & FVAT & Vrsqr & ............. \\
\hline rᄉr & TVTV & f & $4 q$ & r & vr & $r q .9$ & $p q \cdot \Delta l$ & \\
\hline TVD & $|1|$. & $\Delta$ & rl & 1 & Fa & 1919 & rrat. & 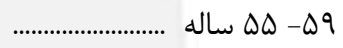 \\
\hline rla & Irr. & 1 & ir & · & rq & $I r \wedge \Lambda$ & TYYIF & 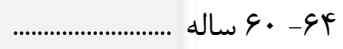 \\
\hline 191 & $\wedge \cdot$. & 1 & 9 & r & IV & NTr & $|r| q \mid$ & 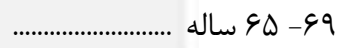 \\
\hline 110 & $\Delta \Delta \Delta$ & 1 & ir & r & r & $\Delta 99$ & $V \cdot r s$ & ساله $V$ • $-V{ }^{4}$ \\
\hline rII & $\Delta 91$ & $\cdot$ & 11 & 1 & ir & $|r| \Delta$ & १९人T & 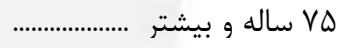 \\
\hline Verq & vrrug & 11. & 1149 & Ifr & $r F \cdot 1$ & $q f q \cdot r$ & q1rvas & مرد.............................. \\
\hline 189 & TEFT & rI & $v r$ & 10 & vq & $\Delta r \Delta V$ & $\Delta \backslash \Delta \cdots$ & 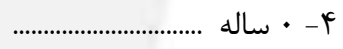 \\
\hline GFT & fars & tr & $11 r$ & 9 & $\wedge 1$ & Gł91 & V...r & 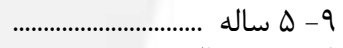 \\
\hline$\varphi \cdot \Delta$ & rदा9 & re & 91 & 9 & VT & $F \Delta \wedge \varphi$ & DITEF & 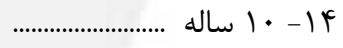 \\
\hline ITAV & 9194 & Ir & met & r & 991 & $11 \cdot \Delta \Delta$ & $9 \mu \mathrm{G} \cdot \mathrm{V}$ & 19 اله ساله............................. \\
\hline 1099 & ITETK & rq & $\Delta \vee \wedge$ & is & $11 K r$ & $11 \cdot F F$ & IG. TFT & • • שاله . \\
\hline$\wedge \notin \wedge$ & 11491 & r & tAr & r. & rqV & $I V \cdot V \wedge$ & IF्9T^ & 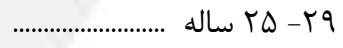 \\
\hline$\Delta \wedge 9$ & ATFT & v & IFD & 11 & 19. & $\| r \cdot \wedge \Delta$ & ITVFVT & 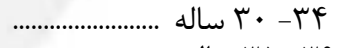 \\
\hline FTV & $9 \cdot 14$ & 9 & 94 & $1 \cdot$ & $|r|$ & VFIT & $१ \Delta \& \Delta \varphi$ & q \\
\hline mis & rVD. & $\Delta$ & $\Delta \cdot$ & r & $9 \uparrow$ & FYAI & $9.9 \vee \Delta$ & 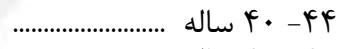 \\
\hline$r$ r. & rEFV & 1 & fr & r & ITI & TVQF & fiQVA & 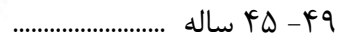 \\
\hline$r \cdot 1$ & IVAT & r & r & 1 & 91 & 1019 & TVVヘS & 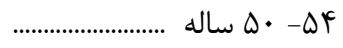 \\
\hline IFr & $|r| \Lambda$ & r & ir & 1 & rV & 111 & INDTr & 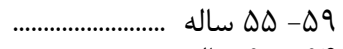 \\
\hline$|r|$ & NTr & 1 & $\Delta$ & · & 10 & GVG & $1 K 4 \cdot 9$ & 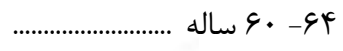 \\
\hline v9 & pq4 & 1 & r & 1 & 9 & $r \Delta V$ & 9091 & 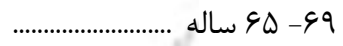 \\
\hline$\Delta \varphi$ & 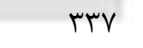 & 1 & 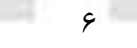 & $\cdot$ & r & rAl & एद्र & 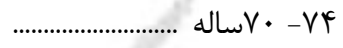 \\
\hline $1 \cdots$ & TFT & · & r & 1 & 4 & $\Delta \vee \Delta$ & FArT & ساله و بيشتر ...................... VD \\
\hline$\Delta \cdot F_{1}$ & $r \Lambda \Delta \cdot r$ & IVr & $I F \& D$ & $r v$ & $I r \cdot f$ & $r q \Delta r \gamma$ & $9 \ldots$ vrg & 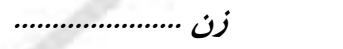 \\
\hline IFT & MFFF & 11 & $V \Delta$ & 4 & Vr & FqVI & $\uparrow \wedge \Delta \Delta \wedge$ & ץ- • ساله . \\
\hline pqr & FATD & re & 119 & 9 & $q 4$ & $4 \cdot \Lambda \cdot$ & \&\&IVD & 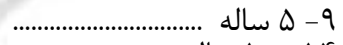 \\
\hline$\Delta \Delta \varphi$ & $r .99$ & r & gr & $\Delta$ & $V V$ & frqf & FaTVD & f \\
\hline$\Delta M F$ & $r t \cdot \Delta$ & 19 & (re & $\wedge$ & irv & Vด৭Q & VTrag & 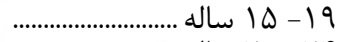 \\
\hline $9 \wedge \Lambda$ & $\Delta \varphi \Delta \cdot$ & rt & $\psi_{\wedge}$. & ir & זמז & $|9| 4 \mid$ & IDITFK & r \\
\hline$\Delta \wedge \cdot$ & DTIV & 11 & rq9 & If & $r \cdot r$ & $|Q \cdot r|$ & $19.9 \wedge \mathrm{H}$ & \\
\hline$\Delta r V$ & 419. & ir & 111 & v & IV. & $9 \wedge \Delta 9$ & $|r F| q \pi$ & F \\
\hline TVF & $r t \cdot \Lambda$ & 9 & vi & f & $\wedge \mathrm{V}$ & DQFT & $\wedge \cdot r \wedge 9$ & q \\
\hline rqA & $11 \Delta Q 9$ & $\Delta$ & FF & r & $4 q$ & ( & FAFVQ & ( \\
\hline$r \cdot r$ & ITIV & f & r & r & r & $r \cdot r \wedge$ & rrIIF & 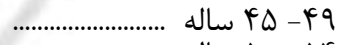 \\
\hline INT & $99 \Delta$ & 1 & rq & r & 11 & ITIV & rITED & 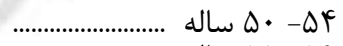 \\
\hline Irt & Q9T & r & 9 & $\cdot$ & $\wedge$ & AVG & IOTAN & 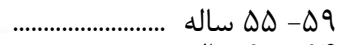 \\
\hline 94 & DIV & $\cdot$ & $\wedge$ & $\cdot$ & 14 & VIt & $9 \wedge \cdot \Delta$ & 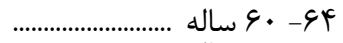 \\
\hline 19 & $r \cdot \varphi$ & $\cdot$ & $\Delta$ & 1 & $\wedge$ & 199 & $\Delta \wedge \vee \cdot$ & 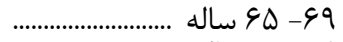 \\
\hline$\Delta 9$ & TIN & $\cdot$ & V & r & r & rAD & mef & ساله . \\
\hline 111 & rFq & $\cdot$ & if & $\cdot$ & 4 & $q 4$. & rAfq & 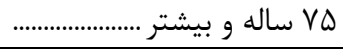 \\
\hline
\end{tabular}


\& - ا- مهاجران وارد شده طى ه سال كذشته بر حسب جنس، سن و محل اقامت قبلى (بر اساس آخرين جابجايى انجام شده) (نقاط شهرى)

(دنباله)

\begin{tabular}{|c|c|c|c|c|c|c|c|}
\hline \multicolumn{6}{|c|}{ استان محل سرشمارى } & \multirow{3}{*}{ 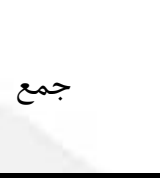 } & \multirow{3}{*}{ جنس و سن } \\
\hline \multicolumn{2}{|c|}{ اظهار نشده شهرستان } & \multicolumn{2}{|c|}{ ساير شهرستانهاى استان } & \multicolumn{2}{|c|}{ شهرستان محل سرشمارى } & & \\
\hline آبادى & شهر & آبادى & شهر & آبادى & شهر & & \\
\hline 14. & 1199 & 19D99F & $q \Lambda V q F A$ & raqvrr & IEAIAr & rAGFVHA & 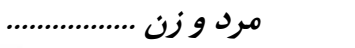 \\
\hline 1. & IfT & 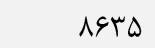 & $\Delta V \cdot 91$ & IOKTA & $1 \cdot r \Delta \Delta$ & $1999 \cdot 1$ & 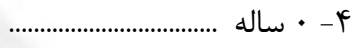 \\
\hline$r \cdot$ & $r \cdot r$ & IrAK. & $\Delta r \cdot \Delta V$ & TFTF. & IDSTY & $r \vee 9 \Delta \cdot V$ & 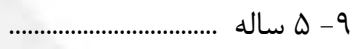 \\
\hline Ta & IVD & $1 \cdot \Lambda \wedge V$ & $9 r \Lambda \cdot q$ & 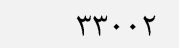 & iror. & TrETED & 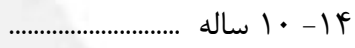 \\
\hline r. & rif & INTFY & $\Lambda \Delta \wedge \vee F$ & $r q \cdot i \Delta$ & IrFYq & 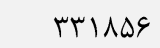 & 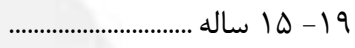 \\
\hline 11 & fis & r\&DIF & IrSAFG & rAFAl & $|\Delta| V \Lambda$ & DTrTQA & 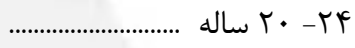 \\
\hline 10 & $\mid \Delta F$ & $r V \cdot \Delta \Lambda$ & |rATt & $\uparrow \cdots \wedge$ & TTDST & $\Delta F \Delta V \cdot F$ & rQ $r$ \\
\hline 1. & IVF & trmina & $|F| \Lambda F$. & rरrqץ & $r \Delta \Delta \wedge \vee$ & $\Delta \cdot q V F V$ & 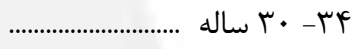 \\
\hline 9 & Ifq & IFIDT & 1.4190 & reIrA & 119.9 & ThtVTL & 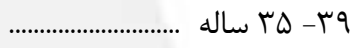 \\
\hline$\Delta$ & vi & $9 \cdot 1 \cdot$ & $9 \Delta G \cdot 9$ & IVTrA & ITKGT & rIrqIV & q f - fl \\
\hline 1 & er & DVAT & $\forall \notin \lambda \cdot \Delta$ & $1 \cdot v \cdots$ & $1 \Delta \cdot 9$ & IFFETA & 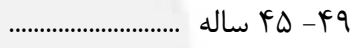 \\
\hline r & fr & rrVA & TAIVI & $q \cdot V 1$ & $\Delta T \Delta F$ & $97 \cdot 19$ & • • \\
\hline · & ru & $r t \cdot \Lambda$ & $11 \mid F \Delta$ & prty & rove & SIOSV & 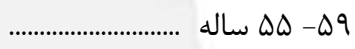 \\
\hline 1 & 10 & IfEV & IITFS & $r \cdot I V$ & tIAT & 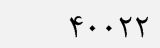 & 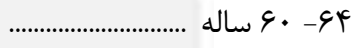 \\
\hline · & 19 & q४r & GIAV & 191 & IrFq & rtqFe & 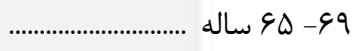 \\
\hline 1 & 11 & 999 & rsq4 & lfye & $v \Delta \Lambda$ & IrNIr & 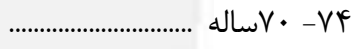 \\
\hline 1 & 1. & IVIT & DFVE & mTVt & IITD & Lttr & 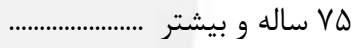 \\
\hline 1. & $1 \cdot V F$ & Arreg & FAFTIF & IFq111 & Arte. & و.r. & 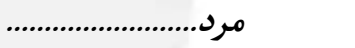 \\
\hline$\wedge$ & 9 . & FFY & raYsT & VarV & $\Delta M q F$ & $1 \cdot|K F|$ & 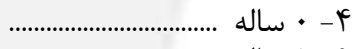 \\
\hline 11 & $1 \cdot 1$ & GAYq & FTVRV & ITFT & AIrd & IFrVqd & 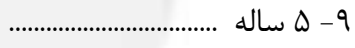 \\
\hline if & $\wedge \vee$ & $\Delta G F V$ & rrarl & ISTIV & spfy & IIDFVT & f \\
\hline$\wedge$ & IOT & $q \cdot \Delta r$ & FINDH & rTIVD & $9 \cdot 94$ & IVTD.G & 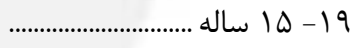 \\
\hline$\checkmark$ & r११ & 1. Fet & DrAAV & $q \wedge \Delta \vee$ & $\Delta \Delta G T$ & rrgVDQ & 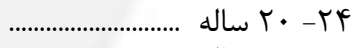 \\
\hline$\wedge$ & Ve & Ir. & DGGTG & $191 K F$ & qpar & $r \Delta l \cdot \Delta V$ & ساله $r \Delta$ - \\
\hline v & vq & ITTKA & sq1FA & $r \cdot q \mu$. & ITQTV & TDQTYA & 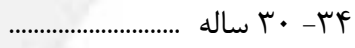 \\
\hline v & 99 & VDqT & $\Delta F \wedge \backslash \Lambda$ & $|f F T|$ & १११८ & $|\Lambda \Delta| G Y$ & q \\
\hline$\Delta$ & بq & Fqq४ & mVIFt & $91 \cdot 1$ & 9949 & Ir.NTS & f · fl \\
\hline & tr & TIVT & $r \Delta \Delta \Delta I$ & $\Delta q 4 \varphi$ & FArF & 11999 & 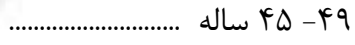 \\
\hline r & r. & IArV & $19 \cdot r$ & 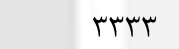 & tAVT & $01 \wedge 99$ & 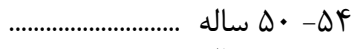 \\
\hline . & 11 & 1119 & $1 \cdots r \Delta$ & 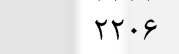 & 1909 & $r r \Delta \Delta q$ & (.......................... $ه 9$ \\
\hline · & $\Delta$ & $9 \wedge$. & G. re & $|F| \Lambda$ & $\| r \Delta$ & מוז & F \\
\hline . & 9 & rat & TLIN & vrl & spq & 11498 & 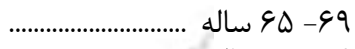 \\
\hline 1 & $\Delta$ & roq & IArV & ब१r & rul & sVDV & ساله $V Y Y$ \\
\hline - & r & Aft & TFDI & $1 \Delta V$ & $\Delta \cdot V$ & $1 \cdot$ fFy & 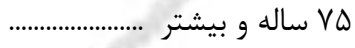 \\
\hline c. & var & Argpg & $\Delta \cdot r v \mu r$ & IFqAFq & Afqur & Ivelpra & 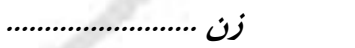 \\
\hline r & $\Delta r$ & $G T \cdot V$ & rVVqq & vrol & 4991 & QDHGV & 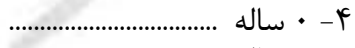 \\
\hline 9 & 99 & $9|1|$ & G.rt. & $111 \cdot V$ & VDIT & iravit & 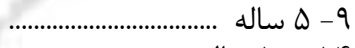 \\
\hline 11 & $\Lambda$ & 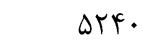 & $r \cdot \wedge \Lambda \Lambda$ & 19910 & $9 \cdot 19$ & $11 \cdot$ var & f • اله ساله . \\
\hline ir & GT & 919. & $F Y \cdot r_{1}$ & rTAY. & sqid & $1 \Delta 9 \mu \Delta$. & 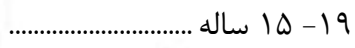 \\
\hline 11 & $11 \mathrm{~V}$ & $19 \cdot V r$ & $\Lambda \| \Delta \vee \Delta$ & IAGTF & 9919 & 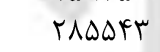 & 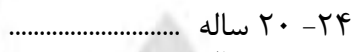 \\
\hline$\checkmark$ & V^ & $14 \cdot 10$ & $\vee \wedge \Delta ৭ \Delta$ & $r \cdot 9 \Delta \varphi$ & $|r \cdot v|$ & rqfar & rd \\
\hline r & 90 & $1 \cdot 10$ & V199r & IVEsk & IT\&G. & $r \Delta \cdot r q q$ & 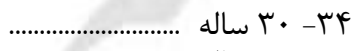 \\
\hline r & N & $q \Delta \varphi$. & FrrYV & 11998 & ^११। & $|\Delta V \Delta V|$ & q \\
\hline - & ra & $4 \cdot 19$ & TAFEY & VFY. & אسMט & $94 \cdot 91$ & f · flf \\
\hline 1 & r. & $|\varphi|$. & 19TDF & FVDF & reVD & GTafr & ........................ $q Q$ \\
\hline · & tr & $|\Delta F|$ & $|r| 99$ & TVRA & rril & $4 \cdot 194$ & • $\Delta$ ساله . \\
\hline . & 1. & $1 \cdot 19$ & 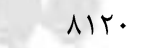 & $r|r|$ & 194. & $r \Lambda \cdot \cdots$ & 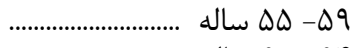 \\
\hline 1 & 1. & ৩৯৩ & $\Delta \mu \cdot q$ & 1099 & $1 \cdot k V$ & INATq & 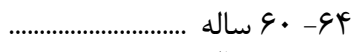 \\
\hline - & $\checkmark$ & 911 & r৭९9 & $1 r \cdot q$ & q.. & $11 k 4 q$ & (9D - 99 \\
\hline . & 4 & fry & $\backslash \Lambda \Delta V$ & NDT & $r \cdot v$ & $V \cdot \Delta \varphi$ & ساله $V / F$ \\
\hline 1 & $\Lambda$ & $\Lambda V$. & $r \cdot r \Delta$ & $I V \cdot r$ & 911 & $110 \vee q$ & 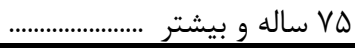 \\
\hline
\end{tabular}


\& - ا- مهاجران وارد شده طى ه سال كذشته بر حسب جنس، سن و محل اقامت قبلى (بر اساس آخرين جابجايى انجام شده) (نقاط شهرى)

(دنباله)

\begin{tabular}{|c|c|c|c|c|c|c|c|c|}
\hline \multirow{3}{*}{ محل اقامت } & \multirow{3}{*}{ خشور } & \multirow{2}{*}{\multicolumn{2}{|c|}{ اظهار نشده استان و }} & \multicolumn{4}{|c|}{ استانهاى ديخر } & \multirow{3}{*}{ جنس و سن } \\
\hline & & & & \multicolumn{2}{|c|}{ اظهار نشده شهرستان } & \multicolumn{2}{|c|}{ شهرستان } & \\
\hline & & آبادى & شهر & آبادى & شهر & آبادى & شهر & \\
\hline 994. & IFFID & rAd & rasf & 190 & rifr & IFIEAT & 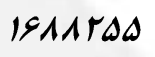 & مرد و زن ................ \\
\hline$r$ r. & 9.90 & ו & IrV & 10 & ird & NTAT & $9 \cdot 1 k T$ & 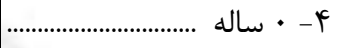 \\
\hline$\wedge \varphi \wedge$ & $\Lambda \cdot \Lambda f$ & $\Delta \Delta$ & TII & $1 \cdot$ & $1 \Delta F$ & I. & ITHATT & 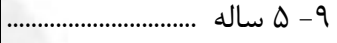 \\
\hline 1 १ & $\Delta V \Delta r$ & $\Delta r$ & r & וr & IFF & VTAT & 91911 & 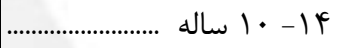 \\
\hline lQVV & $1.1 \cdot 9$ & re & 419 & r & $\Delta r V$ & IMGFE & IFTEFD & 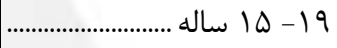 \\
\hline 1994 & $1 \Delta \wedge q f$ & $\Delta \cdot$ & $9 \vee \cdot$ & 01 & 999 & r\&AG. & reqfFl & r • • ساله ..................... \\
\hline $11 \cdot 9$ & $|F| \Lambda$. & $r \wedge$ & $0 \cdot 4$ & rA & fis & $r V \cdot 99$ & TVVTFY & 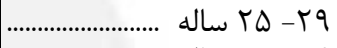 \\
\hline 19. & $1.9 V T$ & 11 & rmi & r & $r q 1$ & 19011 & TFAFAT & 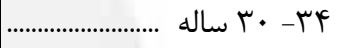 \\
\hline$\varphi \cdot \Delta$ & NITV & If & $|f|$ & it & $1 \wedge F$ & $11 \cdot V r$ & $|9| \cdot r V$ & q \\
\hline FYA & fars & $\checkmark$ & N & 4 & 90 & sq. 1 & १९९৭४ & 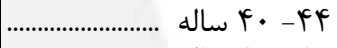 \\
\hline MIs & MFEF & $\Delta$ & $\Delta \varphi$ & $\Delta$ & $V F$ & ५q. & 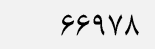 & 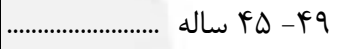 \\
\hline שוץ & trut & r & f. & r & r^ & 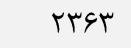 & $f q \cdot v q$ & 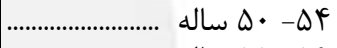 \\
\hline$r \cdot q$ & 1091 & r & 19 & 1 & ro & IDFG & 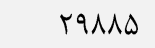 & ه \\
\hline IVT & 1189 & 1 & 9 & . & Tr & $11 \mathrm{k}$ & $194 \mathrm{k}$ & 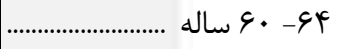 \\
\hline 1r & $\sqrt{11}$ & $\cdot$ & $\wedge$ & r & 19 & $9 \wedge$. & 1.919 & 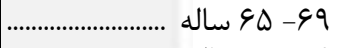 \\
\hline 94 & YAM & · & ir & r & r & $Y \in V$ & GIfr & ساله . \\
\hline 19. & DTr & . & 11 & 1 & $1 \cdot$ & $1 \cdot V V$ & 1ятq & 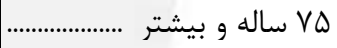 \\
\hline$\Delta \wedge r \Delta$ & g.trur & IFF & $\mid \Delta \Delta F$ & 14. & $19 \cdot 9$ & $V r q+f$ & $\Lambda \Delta \Lambda V \Delta \Lambda$ & مرد................................ \\
\hline Irt & mif & 19 & $9 \wedge$ & it & $\checkmark \cdot$ & prrq & FATd & 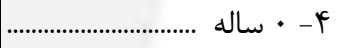 \\
\hline$p q$. & FI9T & re & $1 \cdot 1$ & $\Delta$ & $V F$ & DTQG & $s \mathbb{\Delta \Delta \Delta .}$ & 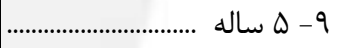 \\
\hline$\varphi \Delta q$ & $r \cdot \Delta q$ & r t & G & $\wedge$ & 99 & TVTF & FGGYA & f ا ساله ....................... \\
\hline 1111 & VTFV & 11 & TAF & iv & $r \cdot \Delta$ & vifs & $v \Delta \wedge \vee V^{F}$ & 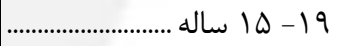 \\
\hline ( & $1.99 \wedge$ & r & pqV & щᄉ & SVI & ITADT & $I r \cdot r \Lambda \Lambda$ & r • שاله .............................. \\
\hline arq & $9 \Delta T$. & 19 & 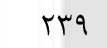 & 10 & tri & 114999 & $\mid r \Lambda \cdot F \varphi$ & 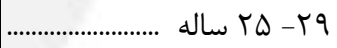 \\
\hline$r .$. & $V \cdot q \mu$ & r & ir. & IV & IFT & $11 \cdot 11$ & ITFTEV & ץ \\
\hline आ & $\Delta \backslash \Delta \Delta$ & $\checkmark$ & (1) & 9 & $1 \cdot 1$ & $G \cdot \operatorname{cr}$ & $\wedge \varepsilon \Delta \Delta \varphi$ & q \\
\hline rmo & mTIS & f & rq & r & fr & $r q \cdot \Delta$ & DFVG & F \\
\hline $\mid \Delta F$ & trRI & 1 & mp & r & fr & THII & TVFAS & 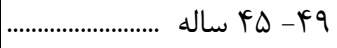 \\
\hline IQV & $10 \cdot 0$ & r & 19 & 1 & 19 & IrFq & TFAVA & 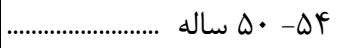 \\
\hline $1 \cdot 9$ & $1 \cdot \Delta V$ & r & $\wedge$ & 1 & 19 & NHF & $194 \cdot 0$ & 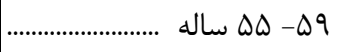 \\
\hline $1 \cdot r$ & VTr & 1 & 1 & $\cdot$ & 11 & $\Delta T \Delta$ & $1 \cdot V \Delta S$ & \\
\hline 99 & fre & · & r & 1 & $\wedge$ & tAr & $\Delta \xi q 4$ & 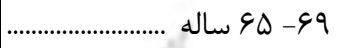 \\
\hline pF & rMA & $\cdot$ & 4 & $\cdot$ & r & rrג & mift & ساله ............. \\
\hline Ve & rq1 & $\cdot$ & r & 1 & $\Delta$ & pqu & Gr. r & 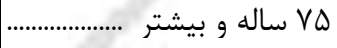 \\
\hline$F+\Delta$ & reIAr & $|f|$ & Ifr. & $9 \Delta$ & Irro & svVrA & Arapar & 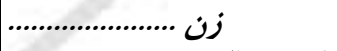 \\
\hline 91 & rqDI & 10 & 99 & r & 90 & r.r & frrvi & ץ- • ساله ................. \\
\hline rVA & r人१r & ו & 11. & $\Delta$ & $\Lambda \cdot$ & $0 \cdot 19$ & G. TVY & 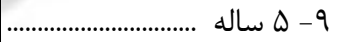 \\
\hline pr. & raqf & $r \cdot$ & 4. & $\Delta$ & $V \Delta$ & rarA & FqqAK & f|- • | ساله .......................... \\
\hline$\varphi \Delta q$ & TVET & 10 & ird & 4 & Irt & $90 \ldots$ & GSVVI & 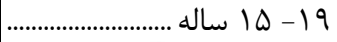 \\
\hline $9 \cdot 1$ & pqra & tr & Frr & Ir & rth & $\mid f \cdots v$ & |rq|QT & 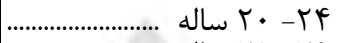 \\
\hline$r \wedge$. & F99. & 9 & TEV & ir & 190 & $|r| \cdots$ & $\mid f q r \cdot 1$ & q \\
\hline f4. & r^vq & 9 & 114 & 4 & 109 & AFTD & $1 T \Delta \cdot \Lambda \varepsilon$ & 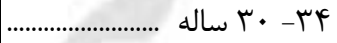 \\
\hline rqf & ravr & $\checkmark$ & $v \cdot$ & r & $\wedge r$ & $\Delta \cdot r)$ & VFFAI & 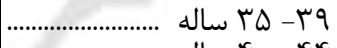 \\
\hline rוt & ivit & r & pF & r & $\uparrow \wedge$ & rVqG & fIqMF & 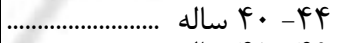 \\
\hline lat & 1194 & f & tr & r & rt & 199. & TQDTT & 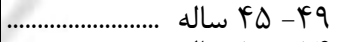 \\
\hline 109 & ArG & $\cdot$ & TY & r & 9 & 1114 & $19 r \cdot 1$ & 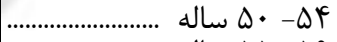 \\
\hline $1 \cdots$ & $\Delta F_{1}$ & 1 & $\wedge$ & $\cdot$ & 4 & vir & $\mid r G \Lambda$. & \\
\hline$\vee \cdot$ & FDG & $\cdot$ & $\wedge$ & $\cdot$ & Ir & 910 & $A V I F$ & F............................. \\
\hline vr & TVV & $\cdot$ & $\Delta$ & 1 & $\wedge$ & rq^ & DrqT & 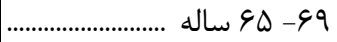 \\
\hline$\hat{~} \wedge$ & $r \cdot$. & · & $\checkmark$ & r & r & rrq & ห११९ & ساله ........................ \\
\hline$\wedge F$ & Mr & $\cdot$ & If & $\cdot$ & $\Delta$ & $\Delta \Lambda F$ & fFrt & 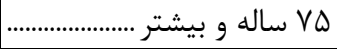 \\
\hline
\end{tabular}


\& - 1 - مهاجران وارد شده طى ه سال كذشته بر حسب جنس، سن و محل اقامت قبلى (بر اساس آخرين جابجايى انجام شده) ( نقاط روستايى)

(دنباله)

\begin{tabular}{|c|c|c|c|c|c|c|c|}
\hline \multicolumn{6}{|c|}{ استان محل سرشمارى } & \multirow{3}{*}{ جمع } & \multirow{3}{*}{ جنس و سن } \\
\hline \multicolumn{2}{|c|}{ اظهار نشده شهرستان } & \multicolumn{2}{|c|}{ ساير شهرستانهاى استان } & \multicolumn{2}{|c|}{ شهرستان محل سرشمارى } & & \\
\hline آبادى & شهر & آبادى & شهر & آبادى & شهر & & \\
\hline$\mu$ & e.r & rq19f & Ira995 & IrATA. & IVqFeF & vretar & 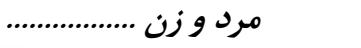 \\
\hline r & ir & $r \Delta \cdot \Delta$ & VDTA & Niv & IrIV. & fisir & 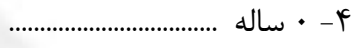 \\
\hline 4 & V & MTFY & $1 \cdots 1$ & $1 \cdot 119$ & IVrVe & $\Delta \wedge 1 \vee \cdot$ & 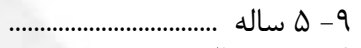 \\
\hline \& & r & TGAT & $V V \cdot r$ & $19 \vee \wedge \Lambda$ & $\| r \cdot \Delta V$ & $\Delta T \cdot T r$ & f \\
\hline 4 & TFV & ffir & ITGSV & $r \cdot r \cdot T^{2}$ & $1 r \Delta \cdot r$ & 11499 & 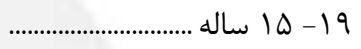 \\
\hline r & 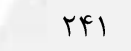 & SVGV & rI9^9 & $1919 \vee$ & IArqV & IIVATV & 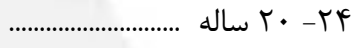 \\
\hline 1 & $\Delta \cdot$ & $4.9 V$ & $|\wedge 9| 1$ & $19 \pi \mathrm{F}$ & rorof & $1 \cdot \vee \wedge 19$ & ساله $r \Delta$ س \\
\hline r & 19 & frrv & $|\Delta \wedge \vee|$ & 19.91 & rDSVI & А११५१ & 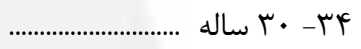 \\
\hline$\cdot$ & 19 & щו. & $11 \pi r v$ & 1.999 & ivaAr & SIE4D & 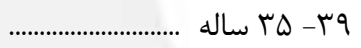 \\
\hline$\cdot$ & 1 & $198 \mathrm{~V}$ & $V \notin \notin \Delta$ & GGMF & $119 \mu$. & rqłя. & 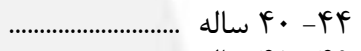 \\
\hline 1 & r & ITAT & DrFD & Fro. & ATYF & TVYAS & ........................... \\
\hline$\cdot$ & 1 & vq. & rq.q & TGTF & $\Delta S F q$ & 11999 & 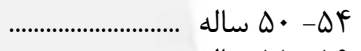 \\
\hline · & · & $\Delta 9 \vee$ & $r \cdot \gamma \nabla$ & 199. & $F|\Delta|$ & Ifred & ساله - $\Delta$ - $\Delta 9$ \\
\hline 1 & 1 & rVT & 190. & ITEN & rs. 9 & ૧૯ヘ૬ & 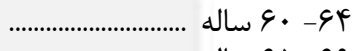 \\
\hline$\cdot$ & · & rtr & 1.91 & VVq & IFTr & DrTV & 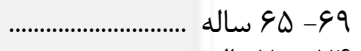 \\
\hline 1 & • & IfT & 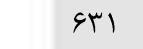 & $\Delta r \Delta$ & 14s & 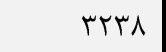 & ساله • -VY \\
\hline$\cdot$ & · & r). & qrV & $1 \cdot \wedge \Lambda$ & Mr & FVDI & 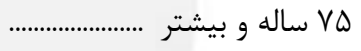 \\
\hline 19 & $\Delta V A$ & $19 \cdot \Delta 9$ & 99119 & grtr. & $19 v+9$ & $p \cdot v \cdot 11$ & 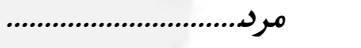 \\
\hline r & $\checkmark$ & iret & rArs & Frof & SVVY & $r r \cdot r q$ & 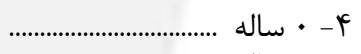 \\
\hline r & r & IVTA & $\Delta \| l f$ & $\Delta \Delta \wedge \varsigma$ & 9181 & $r \cdot|v|$ & 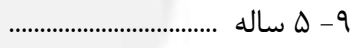 \\
\hline c & r & IrqV & $r \cdot \Delta T$ & $१ \Delta \Delta \Delta$ & sVDV & rVQAD & 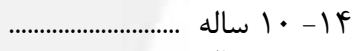 \\
\hline c & TFE & trAT & VDqF & 1.r. & $\Delta V V r$ & $0 \cdot 4 T_{1}$ & 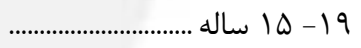 \\
\hline r & $r F$. & trut & $119 \vee 9$ & $\Delta \cdot \wedge V$ & VIFV & sQFV. & 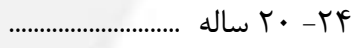 \\
\hline · & FV & $r G \cdot \Lambda$ & $94 \cdot 9$ & $\Lambda T \Delta \Delta$ & Mrof & $\Delta \Delta V V T$ & 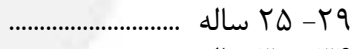 \\
\hline$\cdot$ & 19 & trut & ᄉґیv & NTIV & 童 & ґ^१५. & 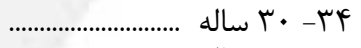 \\
\hline$\cdot$ & it & $19 \Delta T$ & GTIN & $\Delta V F_{1}$ & $9 \wedge r 1$ & $r \Delta \cdot 10$ & q \\
\hline . & · & $1 \cdot r \wedge$ & Fr. q & rava & 9019 & rTA. I & f · f \\
\hline 1 & 1 & $9 \Delta \cdot$ & ret & 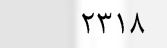 & FATT & $10 \wedge r q$ & 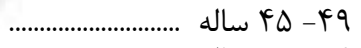 \\
\hline · & 1 & Fr. & r191 & $1 f \cdot 1$ & 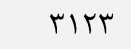 & $1 \cdot \sqrt{1} 99$ & F \\
\hline . & . & rtv & $I V \cdot V$ & $1 \cdot V V$ & thit & ATFS & ه \\
\hline$\cdot$ & 1 & 198 & $11 r 9$ & s4A & $1 F \wedge$. & DrAG & 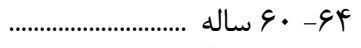 \\
\hline . & . & 118 & G.r & mpF & Vil & TAtr & 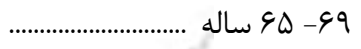 \\
\hline 1 & - & VV & rv. & TAT & $\forall \wedge 1$ & $1 \wedge \Delta \Delta$ & ساله • -VY \\
\hline$\cdot$ & • & 109 & iv. & $\Delta V Y$ & $\Delta \Delta q$ & rofq & ساله و بيشتر VD \\
\hline 10 & FF & $r+1 r \Delta$ & $\Delta q 1+\mu$ & $v 1 . r$. & 19vrd & requr & 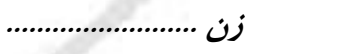 \\
\hline r & $\varepsilon$ & $M \cdot r$ & rq. & 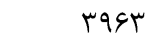 & grqu & rIDSF & f \\
\hline r & r & 1019 & Fイ१४ & ( ) & $\Lambda \varepsilon \cdot r$ & rV৭99 & 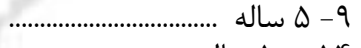 \\
\hline r & 1 & ITAS & rqa. & VTrt & 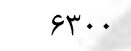 & $T F \cdot r V$ & 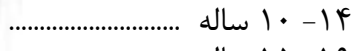 \\
\hline r & 1 & ritg & $\Delta \cdot V r$ & १৭人र & sVr. & $m .9 \Lambda$ & 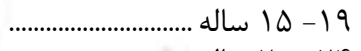 \\
\hline 1 & 1 & r r & $1 \cdots 1$ & 1111 & 1110 & $\Delta r \cdot \Delta V$ & • • שاله \\
\hline 1 & r & rFDQ & $94 \cdot 9$ & $11 \cdot 9$. & $|4| \ldots$ & $\Delta Y \cdot F Y$ & ......................... \\
\hline r & r & rmed & VFAF & $\checkmark \wedge \Delta \mid$ & IrTUK & $4_{1} \ldots q$ & 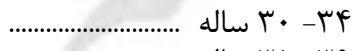 \\
\hline$\cdot$ & r & lfor & $0 \cdot 19$ & $49 \Delta \Delta$ & NIDT & T\&GT. & 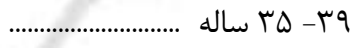 \\
\hline$\cdot$ & 1 & १५१ & TTDS & $r \cdot \Delta q$ & $\Delta 11 F$ & 19909 & 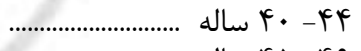 \\
\hline · & 1 & G.r & tht & 19Tr & $r r \cdot r$ & $119 \Delta \mathrm{V}$ & 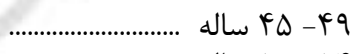 \\
\hline · & & rv. & $|V| 1$ & $|r| 9$ & TATE & Arr. & • • \\
\hline$\cdot$ & · & $r v \cdot$ & $1 \pi v$. & 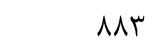 & IArV & sरा9 & 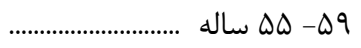 \\
\hline 1 & $\cdot$ & $I V \Delta$ & ArI & $4 .$. & 1119 & $f \cdots$ & 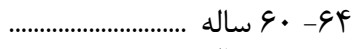 \\
\hline$\cdot$ & • & 111 & 494 & rro & VIr & TFIF & 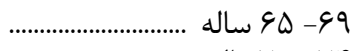 \\
\hline . & . & $9 \Delta$ & rQ1 & trT & rad & سمرا & ساله • -VY \\
\hline$\cdot$ & $\cdot$ & 101 & raV & 019 & $\Delta \varphi q$ & $r T^{\prime} \cdot{ }^{2}$ & 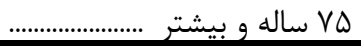 \\
\hline
\end{tabular}


\& - ا- مهاجران وارد شده طى ه سال كذشته بر حسب جنس، سن و محل اقامت قبلى (بر اساس آخرين جابجايى انجام شده)

\begin{tabular}{|c|c|c|c|c|c|c|c|c|}
\hline \multirow{3}{*}{ محل اقامت } & \multirow{3}{*}{ خارج از كشور } & \multirow{2}{*}{\multicolumn{2}{|c|}{ اظهار نشده استان و }} & \multicolumn{4}{|c|}{ استانهاى ديكر } & \multirow{3}{*}{ جنس و سن } \\
\hline & & & & \multicolumn{2}{|c|}{ اظهار نشده شهرستان } & \multicolumn{2}{|c|}{ شهرستان } & \\
\hline & & آبادى & شهر & آبادى & شهر & آبادى & شهر & \\
\hline raf. & $|e f| f$ & sv & rr. & FF & 1099 & rerar & $190 \mathrm{rq9}$ & 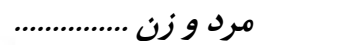 \\
\hline 1.1 & $1 \cdot r 1$ & $\Lambda$ & 11 & 4 & IV & $19 \vee 9$ & ११५५ & ץ- • ساله ........................... \\
\hline r99 & ITVV & $\Lambda$ & IV & 1 & rl & TrTq & ITrAs & -9 هاله .................................. \\
\hline TYK & qur & $\mathrm{v}$ & 9 & 1 & a & 1941 & १९५ & 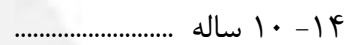 \\
\hline TFF & rTAq & 4 & 4. & $\wedge$ & Q91 & $\Delta \cdot \omega$ & THTOA & 9 \\
\hline rr. & rTVq & 11 & $1 \wedge$ & 1. & Fas & VTrQ & KT.FY & ץ \\
\hline r"q & TQTA & 4 & FQ & 4 & $\Lambda \mathrm{r}$ & $0 \cdot 1$. & $r \cdot r a q$ & q \\
\hline r99 & $|\Delta 9|$ & $\wedge$ & rq & r & GT & ret & TMTIT & \\
\hline 199 & 1190 & i & tr & r & TF & THAT & $14 q \cdot 1$ & q \\
\hline 149 & sVA & r & 11 & 1 & is & 1419 & qYQV & . \\
\hline $11 \mathrm{~V}$ & $\Delta \cdot$. & . & 9 & . & 19. & $1 \wedge 1$ & GVIF & q \\
\hline v. & r^९ & r & 9 & . & Ff & DFT & kqVr & ץ \\
\hline 99 & rIT & r & $\Delta$ & . & r. & Fi. & rq५० & \\
\hline rr & 191 & . & r & . & a & rFA & TVFY & ץ \\
\hline r. & 19 & 1 & 1 & . & 1 & ler & $I F V D$ & 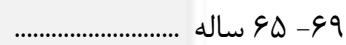 \\
\hline ז & SV & 1 & . & . & - & 99 & 194 & ........................... \\
\hline DI & 99 & . & . & . & r & Ir & $1 . \mathrm{kr}$ & V ساله و بيشتر, ............................ \\
\hline $19 . F^{f}$ & $1 \pi \cdot 9 \pi$ & re & rAS & re & $10 . r$ & $r .991$ & ITF.F. & 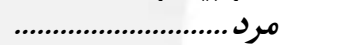 \\
\hline$\Delta V$ & DTA & $\Delta$ & a & r & 9 & $1 \cdot r \Lambda$ & DIFq & ץ • שاله ............................... \\
\hline lar & VFF & r & 11 & r & $\mathrm{r}$ & 1190 & GKAT & Q \\
\hline 149 & $\Delta \varphi$. & i & $\Delta$ & 1 & $r$ & NGT & Fars & 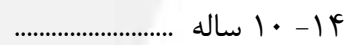 \\
\hline 199 & INFE & r & $\Delta q$ & 9 & $\Delta \wedge \varphi$ & $r q \cdot q$ & IVVTr & 9 - 19 اله ............................. \\
\hline זTr & 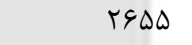 & 4 & 11 & 1. & Yal & 0191 & 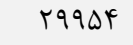 & 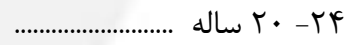 \\
\hline rqq & 1971 & t & kr & $\Delta$ & ve & $r \cdot v q$ & IAMAT & q \\
\hline 1199 & ira. & $\Delta$ & TQ & 1 & is & 1998 & $|r| \cdot \Delta$ & ץ \\
\hline 119 & $9 \% 9$ & r & rl & 1 & r. & $|r v|$ & $91 .$. & 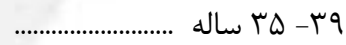 \\
\hline$\wedge 1$ & DHF & 1 & 11 & 1 & iv & AVG & Q9/T & ……………....... \\
\hline ve & TVG & . & $\wedge$ & . & 119 & DFT & FITK & q \\
\hline Fe & TVY & 1 & $\mathrm{v}$ & . & Fr & MF. & $r q \cdot 1$ & ץ \\
\hline ry & 191 & 1 & r & . & 11 & TVG & TMTV & 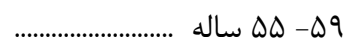 \\
\hline 19 & $1 \ldots$ & . & r & . & r & $|0|$ & $19 \Delta \pi$ & ץ \\
\hline ir & GT & 1 & 1 & . & 1 & va & $19 \mathrm{~V}$ & 99 90 \\
\hline ir & pq & 1 & . & . & . & $\Delta r$ & $\Delta F A$ & .......................... \\
\hline rF & ه1 & $\cdot$ & $\cdot$ & $\cdot$ & 1 & $\wedge r$ & Gr & VD Vاله و بيشتر .................. \\
\hline 948 & frel & ו & ra & it & sv & 11899 & virra & 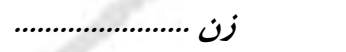 \\
\hline fr & pqr & r & 9 & r & $\wedge$ & $9 \uparrow \wedge$ & FVAV & ץ- • ساله ........................................ \\
\hline $114 \mathrm{f}$ & Gب & $\Delta$ & 9 & r & If & 1.94 & $\Delta q \cdot r$ & ه هاله .......................... \\
\hline 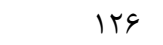 & TVT & r & r & . & r & v99 & Frat & ץ \\
\hline$v \Delta$ & Fer & r & 1 & r & $\Delta$ & 1.99 & $\Delta \Delta T \Delta$ & 19 - هاله .............................. \\
\hline$\wedge \mathrm{v}$ & VTF & a & $\mathrm{v}$ & . & $\Delta$ & rime & $1 T \cdot q$. & ץ \\
\hline $1 \ldots$ & $\Delta \Delta V$ & r & r & 1 & $\mathrm{v}$ & 1941 & IIFAT & q \\
\hline vV & आI & r & r & 1 & If & lekr & $91 \cdot V$ & r \\
\hline ᄉ. & THE & r & 1 & 1 & f & 911 & $\Delta \Lambda \cdot \Lambda$ & q q \\
\hline$\Delta \Delta$ & lFF & r & - & & 1 & DFT & TAFQ & 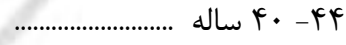 \\
\hline il & IKF & . & & . & 1 & גז & TDQT & 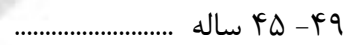 \\
\hline rq & 1.9 & 1 & r & . & r & $r \cdot r$ & $r \cdot 94$ & ...................... \\
\hline rr & ه) & 1 & 1 & - & r & 194 & $19 \cdot 1$ & 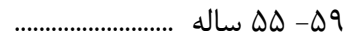 \\
\hline re & 91 & . & . & - & 1 & qv & 1.91 & q............................ \\
\hline IV & TV & . & . & . & . & 91 & $\Delta \vee \Lambda$ & 99 - 99....................... \\
\hline 11 & 11 & $\cdot$ & $\cdot$ & $\cdot$ & $\cdot$ & is & $r F \Delta$ & .......................... \\
\hline TV & 11 & . & . & . & 1 & $\Delta \varphi$ & FIr & Vه ساله و بيشتر .................. \\
\hline
\end{tabular}


V - ا - مهاجران وارد شده طى ه سال كذشته بر حسب جنس، استان محل اقامت قبلى و سن (بر اساس آخرين جابجايى (كل)

\begin{tabular}{|c|c|c|c|c|c|c|c|c|c|}
\hline 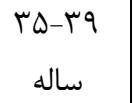 & $\begin{array}{l}\text { ساله } \\
\text { ساله }\end{array}$ & 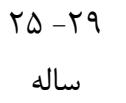 & $\begin{array}{l}\text { ساله } \\
\text { ساله }\end{array}$ & $\begin{array}{l}19 \\
19 \\
10\end{array}$ & ساله & $\begin{array}{l}\text { ساله } \\
\text { ساله } 9\end{array}$ & ساله & جمع & محل اقامت قوبلى \\
\hline f. Fra. & D9981F & sarar. & srasta & FIrrad & rrarar & rrverv & TEITHI & $4 r . .911$ & مر \\
\hline IVEVT & TFDIT & TETTR & TFETT & $10 T \cdot 9$ & $1 \cdot r \cdot 9$ & IrGAr & $9 \cdot r r$ & IVIA9T & آذربايجان شرقى .......... \\
\hline $1199 \mathrm{~V}$ & $I V \Delta \cdot r$ & rTQAI & $r \Delta \Delta \varphi \Delta$ & $\mid F V \|$ & мᄉrq & $1 \cdot \Delta \wedge 9$ & $V G \cdot \Delta$ & $1 T V 9 \Delta F$ & آذربايجان غربى ........ \\
\hline 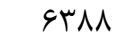 & $1.1 \% \Delta$ & Irrget & $|M| \Delta \varphi$ & 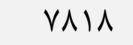 & fVar & DFTD & $\mu \cdot r \Lambda$ & $V 9.91$ & اردبيل ..... \\
\hline T\&T. D & ґА৭৭. & 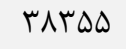 & TYT.G & $r \Delta \Delta \Delta I$ & 10191 & $r \cdots v q$ & Irata & TEATAN & اصفهان .............. \\
\hline $1 \vee 9$. & THVAT & 19971 & $|\Delta| T$. & १人ץ^ & qDFS & $|r \Delta| \Lambda$ & NTID & lfqArq & 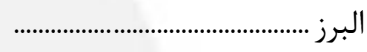 \\
\hline rV^a & $\Delta \Lambda \cdot r$ & $8 \wedge \Delta \Delta$ & 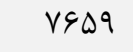 & rrle & rIAr & TASV & 1999 & $r \cdot r \cdot r$ & ايلام .................. \\
\hline VRr. & I. 941 & $1.1 T V$ & $q \cdot \Delta \varphi$ & $\Delta 9 \Delta T$ & ४994 & gqVT & FeVt & 99101 & 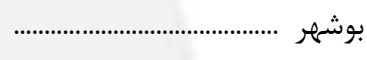 \\
\hline マ।९८9 & qrTAF & ᄉ.rqV & GTrro & FIrAD & rqmF^ & $\Delta \cdot \wedge \notin 9$ & rF.ro & ו & تهران ........ \\
\hline$\Delta \wedge \varepsilon$. & $\wedge 91$. & איז 1. & IIETF & $V F \wedge D$ & FVG & $\Delta r \Delta \Lambda$ & TVGG & GNIr山 & جهارمحال و بخ \\
\hline$r \& \Delta \Lambda$ & VAGT & १६५. & $1 \cdot \Delta V r$ & $1 \cdot \Delta \Lambda F$ & $\Delta F A F$ & fqть & rq4A & spriq & خراسان جنوبى . \\
\hline 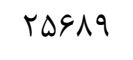 & 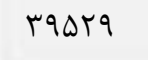 & FD।98 & FVqTV & rqDVG & $r \cdot r l \cdot$ & TFFAV & $19 \cdot \Delta \cdot$ & $r \cdot 19 \Delta F$ & 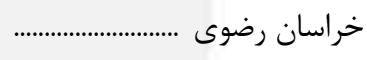 \\
\hline 1910 & $\Lambda \cdot r \varphi$ & 1. THE & $1 \cdot \Lambda \Delta F$ & q४rq & FNAV & DITV & $f \cdot b$ & gFVIF & خراسان شمالى ........ \\
\hline TIFVT & THFOA & ry^91 & TVDFT & TIV9Q & $10 \Delta 9$. & 19449 & 14199 & $T F \cdot \wedge \Lambda q$ & خوزستان ........... \\
\hline FVVV & VVFF & $1 \cdot r \cdot \Delta$ & 1.099 & $\Lambda \Delta F q$ & FqT. & FrTd & r... & $919 \vee 9$ & 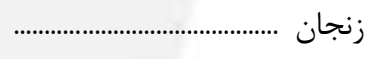 \\
\hline TVQF & DVET & GYAV & $\Delta 9 \Delta V$ & TVYF & r\&ᄉ. & Tht & TITV & $r \cdot \Delta r$ & 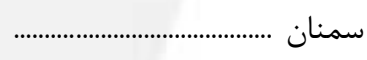 \\
\hline $9 T \cdot r$ & $1 r 9 \Lambda 1$ & IDTGG & IV\&9 & 4419 & $9 \& \& V$ & (TrTr & $\wedge ৭ \vee \wedge$ & ITKAF & سيستان و بلوجستان .... \\
\hline rTUVG & rद५ बD & FIFAF & Fr人 & TVQVT & IVDVF & IAVTA & ITFAQ & QDFIT & فارس ........... \\
\hline $1 \cdots \vee \wedge$ & Ifrse & ITAYA & lIrVt & VEVE & $9 \Delta \Delta \varphi$ & 119 & $\Delta G \cdot F$ & qFDFA & 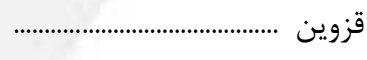 \\
\hline FNIF & VIIV & $V \cdot \lambda r$ & 9491 & FIVT & MryF & FYYF & TUQT & FATIF & 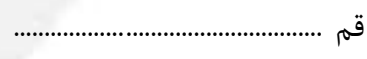 \\
\hline $1 \cdots 1$ & 19190 & TITVR & TrII9 & IrVDr & NFTE & AGTI & GIOT & ITrGM & كردستان ......................... \\
\hline $91 \% V$ & $\mid F \cdot r \Lambda$ & ISTAS & $r \mid r \cdot r$ & ITVED & VQFV & ^\&VG & ячq. & $11 r q \cdot 0$ & 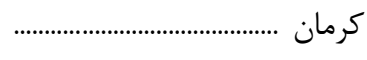 \\
\hline $1 \cdot \wedge \& 4$ & $11 \cdot 49$ & rTIIF & TIT & 1 won & wi & 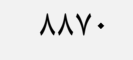 & 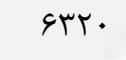 & $1 r \wedge q .$. & 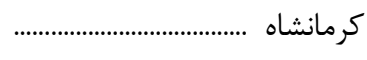 \\
\hline DFAF & $M N \cdot r$ & 1. T9V & $1 \cdot \Delta r$ & grif & Frise & $\Delta \Delta \Lambda$. & FTVA & GQVAV & كهخيلويه و بويراح \\
\hline AFqr & |fFY & INGG & IArA. & $\| \Delta \wedge F$ & GAIV & AFi. & $V F \cdot r$ & 1.9114 & 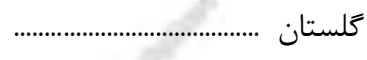 \\
\hline$|F| \& 4$ & TrDQS & $r G \cdot r \Lambda$ & Tr. FQ & $11 \cdot 1$ & VKG9 & Q.rT & $44 \cdot 1$ & IFTVDq & كيلان ....... \\
\hline 1.94. & IVIVq & TIST. & $r \cdot \wedge 99$ & १९९८ & 9919 & $9 \cdot r \wedge$ & VTGT & $|r| \wedge \Lambda \mid$ & 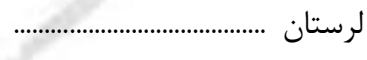 \\
\hline ITIVE & TrMGT & TFIOT & $r \cdot r \Lambda$ & $I T \cdot F V$ & VTrV & $9 \cdot 11$ & $9 \cdot 19$ & IrGYVD & مازندران .............. \\
\hline ^५৭৭ & ITrIN & IrFDA & ITTEV & 1190 & $9 \ldots$ & $94 \cdot 9$ & rrqD & 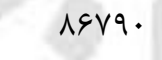 & 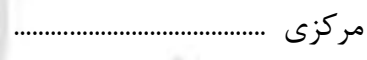 \\
\hline 9T^S & ITOYA & ITF.. & ITGTT & $119 \Delta \Lambda$ & VFFG & $\wedge 919$ & GTMT & १QYA. & هرمزكان ..................... \\
\hline$q T \Delta \varphi$ & lQDHF & $194 \cdot \Delta$ & IVq49 & $1 \pi r \cdot \Delta$ & $V F 19$ & v991 & $\Delta V+1$ & $111 \mathrm{Vr}$. & 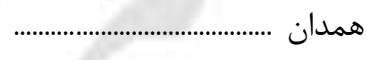 \\
\hline$r V \Delta \Delta$ & $4 \cdot V \wedge$ & $99 \cdot 4$ & GNFV & $r a \cdot r$ & YAVI & rars & TMAI & FHFIQ & يزد ............................ \\
\hline$|1|$ & rNT & $\Delta \wedge \Delta$ & 1119 & $\Delta 11$ & 191 & rq1 & $1 \wedge \mathrm{V}$ & rqDS & اظهار نشده استان ...... \\
\hline 9r9T & ITLTK & $19 V \cdot 1$ & $19 T V R$ & Irras & $99 \wedge 0$ & $9+41$ & $\vee \cdot \wedge 9$ & $11 \cdot 1 r q$ & 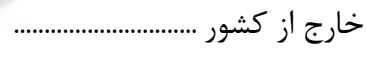 \\
\hline$\Lambda \cdot 1$ & 1114 & IFFA & TrAF & $|A T|$ & 1191 & $11 \% F$ & MTI & ITFA. & اظهار نشده محل \\
\hline
\end{tabular}


V - ا - مهاجران وارد شده طى ه سال كذشته بر حسب جنس، استان محل اقامت قبلى و سن (بر اساس آخرين جابجايى انجام شده) (دنباله)

\begin{tabular}{|c|c|c|c|c|c|c|c|c|}
\hline بيشتر & $\begin{array}{l}V \cdot-V F \\
\text { ساله }\end{array}$ & $\begin{array}{l}90-99 \\
\text { ساله }\end{array}$ & $\begin{array}{l}9 \cdot-9 f \\
\text { ساله }\end{array}$ & $\begin{array}{l}\Delta \Delta-\Delta 9 \\
\text { ساله }\end{array}$ & $\begin{array}{l}\Delta \cdot-\Delta F \\
\text { ساله }\end{array}$ & $\begin{array}{l}F a-1 q q \\
\text { ساله }\end{array}$ & $\begin{array}{l}\text { F.-FF } \\
\text { ساله }\end{array}$ & محل اقامت قبلى و استان \\
\hline reVVF & $|V \cdot \Delta|$ & ral1r & $k q f+1$ & $V q \cdot r r$ & $111 \cdot 11$ & IVTITE & rarrvV & 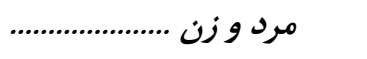 \\
\hline ITAV & $\wedge 1$. & $1 . t y$ & $|\wedge r|$ & rیar & FAat & VTAF & $111 \mathrm{r}$ & 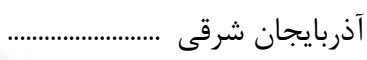 \\
\hline 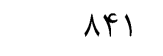 & $4 \cdot 1$ & gqf & IIrT & IVVV & rAFQ & frat & SVTI & آذربايجان غربى ............ \\
\hline DrF & rیq & rat & Q91 & 949 & IOTV & TVIF & $f \cdot p q$ & 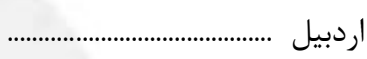 \\
\hline$|9 T|$ & 1.94 & $19 \mathrm{YF}$ & rFAr & DrVF & VAVA & $11 \Delta 9 \Lambda$ & $1994 \lambda$ & اصفهان ............................ \\
\hline I. TF & $\wedge r y$ & $1 r \Delta \Lambda$ & TMQF & MEFV & DIV & vefr & $111 \cdot v$ & 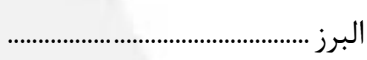 \\
\hline 191 & یr & $11 \mathrm{D}$ & $r \cdot \Lambda$ & $\Delta \Delta \varphi$ & $\Lambda \cdot r$ & lQDK & rmif & 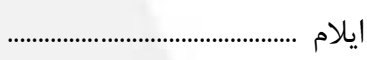 \\
\hline trV & 101 & raf & DQT & $\Lambda 9 \Delta$ & $1 \pi 19$ & TFIV & $f \cdot \wedge f$ & 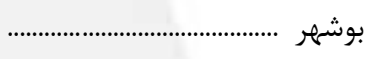 \\
\hline$\Delta \Delta 1$. & fapi & VAIT & $119 \vee \wedge$ & IVrq9 & ( & וזוזו & $\forall \& \mid 11$ & تهران ................................... \\
\hline 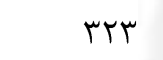 & r & $r \Delta$. & pqf & 199 & ligk & TFAI & rqQर & جهارمحال و بختيارى .. \\
\hline rq৯ & $1 \Delta \Delta$ & TFF & rMA & VTS & 1.91 & IVFA & 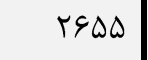 & 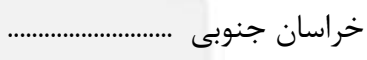 \\
\hline $109 \Lambda$ & $9 \wedge 1$ & lfar & rצAF & FYAD & GTYA & $\cdots r \Delta$ & IDQTV & خراسان رضوى .......... \\
\hline rm & 119 & IVG & mif & sta & qVT & 1914 & $r \Lambda \cdot r$ & خراسان شمالى .......... \\
\hline$|F|$ & $\wedge \vee \cdot$ & ivq & rیו1 & DITE & VIrt & 1.rr. & $1 \% 99 \Delta$ & 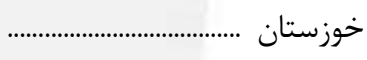 \\
\hline$\psi_{\wedge}$. & ra. & mTF & $F \Delta \Lambda$ & ver & १९৯ & IVAr & $r \cdot F q$ & زنجان ................................... \\
\hline 199 & IrV & 191 & rat & 919 & 999 & 1091 & trat & 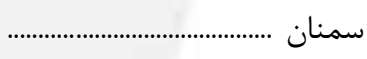 \\
\hline rvq & TFt & FFV & 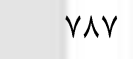 & Irar & $r \cdot V \varphi^{q}$ & 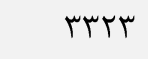 & $\Delta r V F$ & 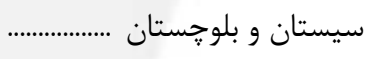 \\
\hline lffy & $\checkmark v \Delta$ & $1 \notin 80$ & r\&AD & FFED & GFAV & $1 \cdot r V \Delta$ & $14 r \wedge 9$ & 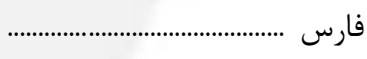 \\
\hline QHG & rri & $\Delta \cdot V$ & 9.9 & lefr & reIF & G.et & sqAF & 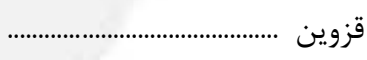 \\
\hline rtq & Ire & 199 & kis & 911 & $1 \cdot 01$ & $19 \Delta \mathrm{r}$ & rVAI & 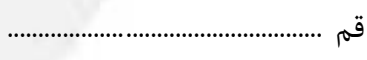 \\
\hline$\Lambda \cdot \vee$ & fif & 990 & IITF & 1011 & TYFF & $r \cdot I r$ & 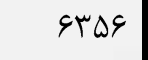 & كردستان ................................. \\
\hline$\Delta T \wedge$ & TVV & $\Delta \wedge$. & 1.91 & IVF. & $r 9 D 1$ & FIre & $\Delta \wedge r \mid$ & كرمان .................................. \\
\hline$q \cdot r$ & $\Delta \cdot r$ & 948 & $19 .$. & $r \Delta \cdot q$ & 49.9 & $\Delta \Delta \cdot 9$ & VINT & كرمانشاه ................................ \\
\hline $49 q$ & rif & $r \Delta \Delta$ & V৭V & $11 \mathrm{FF}$ & IrVA & & rosq & كهخيلويه و بويراحمد . \\
\hline rᄉ. & 199 & $\mathrm{r \Delta \Lambda}$ & grq & $11 \cdot v$ & 1199 & $r \cdot \varphi \Delta$ & $\Delta T \cdot T$ & 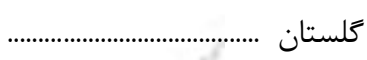 \\
\hline $11 \Delta \Lambda$ & GYF & 199 & IVTe & TYIO & r৯QV & $\Delta 999$ & NDIT & 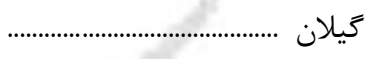 \\
\hline GTD & rTA & $\Delta G F$ & 1.91 & 1949 & TET. & kquq & $9 \Delta \Delta T$ & 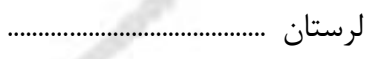 \\
\hline vVq & FAT & (r & | & TIAV & TrAI & DFTE & $\wedge \cdot \vee \varepsilon$ & مازندران .......................... \\
\hline VIN & (t & $4 \notin 9$ & $\wedge \vee \wedge$ & $1 F \Delta \Delta$ & rт人. & TVET & $\Delta \& 9 \Lambda$ & 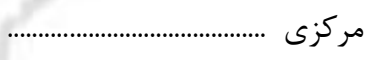 \\
\hline rvq & Irr & $r \Delta \cdot$ & $9 \wedge \Delta$ & IrT. & $19 \vee 9$ & rFqu & $\Delta \Delta \Delta \Delta$ & 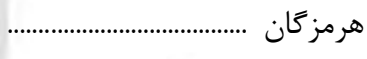 \\
\hline 90. & ry. & $\Delta r \cdot$ & $9 \Delta r$ & 1911 & r×qq & $r \cdot I r$ & $\Delta \wedge \vee \wedge$ & 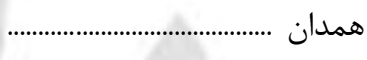 \\
\hline MIN & ITr & $r \cdot r$ & r & Q91 & $9 \Delta \Lambda$ & $10 \Delta 9$ & Trte & 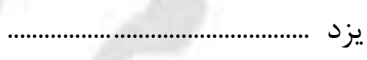 \\
\hline 11 & If & 1. & If & re & $\Delta r$ & $\vee \cdot$ & 1.4 & اظهار نشده استان . \\
\hline$\Delta 91$ & $\Delta \Delta \Delta$ & $\wedge .$. & IrF. & & TVTV & ras4 & $\Delta \varphi \cdot \varphi$ & 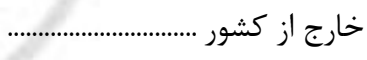 \\
\hline rII & 110 & 191 & rID & TVD & rیr & rre & $\Delta \Lambda F^{\prime}$ & اظهار نشده محل اقامت قبلى.... \\
\hline
\end{tabular}


V - ا - مهاجران وارد شده طى ه سال كذشته بر حسب جنس، استان محل اقامت قبلى و سن (بر اساس آخرين جابجايى (كل)

\begin{tabular}{|c|c|c|c|c|c|c|c|c|c|}
\hline 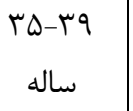 & 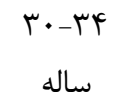 & 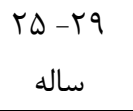 & $\begin{array}{l}\text { W.-YF } \\
\text { ساله }\end{array}$ & ساله 19 - 19 & ساله & 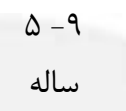 & ساله & جمع & محل اقامت قبلى و استان \\
\hline$r r \cdot I v q$ & $r \cdot 1 / v 1$ & $r \cdot s 1 r q$ & r.rrta & rrrary & IFrFar & IVrags & Irerg. & rrl. rar & 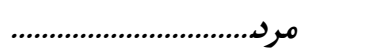 \\
\hline 9401 & ITEYF & $|K F| \Lambda$ & $119 \Delta \pi$ & $\Lambda \cdot \Delta r$ & QTHY & $V \cdot 9 V$ & FATD & MATr. & آذربايجان ش \\
\hline . rזg. & 9.49 & 1.4T & ITESG & Аঙ৭^ & Fofq & $\Delta \Delta r V$ & rqIf & $V \cdot 99$. & آذربايجان \\
\hline MFVG & $\Delta \Delta / F$ & GAFT & 0919 & ५११४ & rrVV & rAVA & $r \cdot 90$ & rANrv & اردبيل \\
\hline 14991 & $19 r \Delta \Lambda$ & 19919 & IVIIV & ITATY & NTGG & $|\cdot T \Delta|$ & $V \cdot \Delta q$ & Irrq.r & اصفهان ..... \\
\hline$q \vee \cdot \Delta$ & $\| \Delta \Lambda$. & $\Lambda T \cdot V$ & grid & $\Delta \cdot r q$ & YAVQ & 9490 & frqq & VF्व & \\
\hline rif. & rQDV & $r \cdot \wedge r$ & rTaV & $1 V \cdot 9$ & 1191 & lfqf & $1 . r q$ & T. FVT & ايلام \\
\hline FTYA & $\Delta \Delta \cdot \Lambda$ & FEYA & Fr. 9 & $r \mu \cdot \varphi$ & rq.. & rTat & rrAd & rGlst & \\
\hline rAvq1 & fध9人১ & $r v \cdot v r$ & rqт.r & r. ११V & 19109 & relrq & IVrsa & rI991f & \\
\hline TrFe & $\forall \& \Delta \Lambda$ & 1999 & DYFI & rAGF & Y|q| & TrVI & 1194 & MYGqV & ج \\
\hline TQFA & rqDF & $k q .1$ & $\Delta \cdots \wedge$ & DVGT & rVq & $r \Delta V I$ & $r \cdot \Delta T$ & MTGS & خراس \\
\hline $1 r \lambda \cdot 9$ & $r \cdot \Delta \wedge r$ & TYITF & TYYFA & $r \cdot q r$. & $1 \cdot r \wedge$. & ITETV & 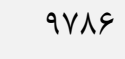 & IDSF.V & خراسان رض \\
\hline TGMT & FrAT & DIOT & FAl. & $\Delta \cdot \Delta \varphi$ & rTVQ & $r \varphi \cdot \Delta$ & $r \cdot q V$ & TrATt & خراسان شمالى ... \\
\hline $11 \Delta r$. & $109 \Delta 9$ & IDTar & $1 V 9.9$ & $|r| \wedge \Delta$ & $\Lambda \cdot(4)$ & १९८र & $9 \Lambda \cdot r$ & $|r K| \wedge q$ & خوزستان ............. \\
\hline TAFq & FITK & ४१९६ & $F v \cdot v$ & FAFA & rFAT & $r 190$ & $|g \pi|$ & $\mu I V \cdot \Lambda$ & زنجان ........ \\
\hline$r \cdot \cdot r$ & rqD & $r \cdot 9 \Delta$ & $r \ldots$ & 1Аrq & IrG & 1999 & $1 \cdot V \varepsilon$ & $r \cdot \Delta \Delta \cdot$ & سمنان . \\
\hline$\Delta \backslash \Delta \Delta$ & GAFV & จ११९ & 1.199 & $v \cdot \wedge r$ & FMAF & GMET & FATr & GIrvq & سيستان و بـ \\
\hline ITVVV & |র\&|r & $|M \Lambda \Delta|$ & $r \cdot \Delta \Delta G$ & $\mid \Delta F \Delta \Lambda$ & GYEV & १९V. & द99. & $|r 4| .9$ & فارس \\
\hline$\Delta \Delta r$. & VrVG & q. r. & FAls & rVAS & TFMF & Friq & rqDS & PVDGF & قزوين . \\
\hline rrII & TAYT & $r \cdot r \cdot$ & r. Fr & THTH & IV.. & TEMA & IVAV & TFOAT & قم ......... \\
\hline$\Delta \Delta V T$ & NQ१Y & $|\cdot r|$. & 1. & VYle & FDQI & Frat & rive & GrAFV & كردستان \\
\hline FAY & VIV. & VVYA & 9991 & GAIV & r MaT & fraf & rrqI & $\Delta \& \& \Delta r$ & كرمان \\
\hline$\Delta \wedge 91$ & qfqr & I.rqV & $1.4 r \Lambda$ & $\Delta G F F$ & r99D & feQV & rr. & $\varphi \Delta \varphi \Delta \varphi$ & كرمانشا \\
\hline TITT & eVrq & FMAs & $01 \wedge 9$ & 促 & TIT & rی氏 & rID. & MFF. r & كهيَيلوي \\
\hline fert & $v F \cdot 1$ & $\wedge \notin q \Delta$ & VFid & DqTV & rmpl & fras & rNTV & $\Delta r \| \Lambda$ & كلستان ........... \\
\hline$V \Gamma \wedge \Delta$ & $11 r 91$ & سזAאו & 9.11 & DTrT & rVVe & f994 & . & sqg41 & \\
\hline G.rT & qTVF & $1 \cdot 4 \cdot 9$ & $99 \Delta F$ & 0.90 & rQVQ & fVar & rvi. & $949 \cdot 1$ & لرستان ..... \\
\hline gq4T & $111 \Delta 9$ & $1 \cdot \Delta r q$ & MATD & GTVT & rVIS & FAVD & $\mu \cdot \Lambda$ & $9 V \cdot 90$ & مازندران . \\
\hline Find & 9.94 & grr. & DTEF & rquF & $r \cdot \Delta r$ & q & TrVD & FrIls & مركزى .. \\
\hline DIGT & sTaA & $\Delta 9 \wedge r$ & gqur & \&V9V & rNTA & FESV & TrAV & $D 1 \cdot T T$ & هرمزكان \\
\hline$\Delta \cdot F \lambda$ & NTrq & qRT & VVEV & GTAT & raqu & rqvq & $r 901$ & $\Delta \varphi \mid \Delta \Delta$ & همدان \\
\hline$T \cdot A r$ & MISV & TINT & TFAV & rTQD & $10 \cdot 9$ & $|V \Lambda|$ & IOTK & TrQAS & يزد ............. \\
\hline 1.1 & IOT & $r \cdot \Delta$ & $q \cdot V$ & $r \Delta \varphi$ & 1.4 & 149 & 94 & $r \cdot 19$ & استان.......... \\
\hline $9 \cdot 1 F$ & NFr & 11491 & ITETr & $919 \pi$ & 4919 & pqug & rate & VTrTS & خارج از \\
\hline FTV & $\Delta \wedge 9$ & $\wedge \& \Lambda$ & 1099 & ITNV & $9 \cdot 0$ & GKT & 189 & verq & محل اقامت قبلى . \\
\hline
\end{tabular}


V - 1 - مهاجران وارد شده طى ه سال كذشته بر حسب جنس، استان محل اقامت قبلى و سن (بر اساس آخرين جابجايى انجام شده)(دنباله)

\begin{tabular}{|c|c|c|c|c|c|c|c|c|}
\hline بيشتر VD ساله و & $\begin{array}{l}V \cdot-V F \\
\text { ساله }\end{array}$ & $\begin{array}{l}90-99 \\
\text { ساله }\end{array}$ & $\begin{array}{l}9 \cdot-94 \\
\text { ساله }\end{array}$ & $\begin{array}{c}\Delta \Delta-\Delta 9 \\
\text { ساله }\end{array}$ & $\begin{array}{l}\Delta \cdot-\Delta F \\
\text { ساله }\end{array}$ & $\begin{array}{l}F \Delta-r q \\
\text { ساله }\end{array}$ & $\begin{array}{l}\text { f.-pf } \\
\text { ساله }\end{array}$ & محل اقامت قبلى استان \\
\hline 1 1r994 & relr & Ifrer. & rerrq & $F \mid 1 \cdot \Delta$ & greqd & 9vara & Ifrept & 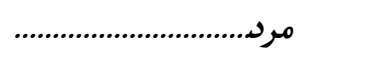 \\
\hline$\Delta \wedge \vee$ & red & FAF & qRT & 109 . & TAKA & firs & STrI & 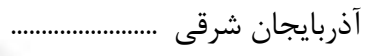 \\
\hline f.. & 111 & TAV & $\Delta r$. & $94 \wedge$ & $1 \Delta \Delta \Delta$ & TQAT & $r \wedge \cdot \Delta$ & 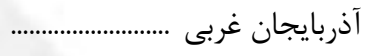 \\
\hline rqq & $|r|$ & 199 & rat & 019 & $\wedge \varepsilon t$ & ID\& & rTQI & 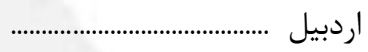 \\
\hline V\&4 & $\Delta \&$ & 1119 & $191 \mathrm{~V}$ & rی१९ & fr.d & 90.9 & que. & اصفهان ................... \\
\hline 499 & fr. & gAr & $1 T \Delta 9$ & INAT & rNID & FTrV & GMET & 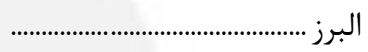 \\
\hline 91 & re & 1.9 & 191 & 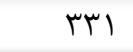 & FAT & $9 \Delta 9$ & 1 1rad & ايلام .......... \\
\hline 1.9 & 91 & Ir. & $r \Delta V$ & $\Delta T_{1}$ & 11. & IFVG & TDTV & بوشهر ................ \\
\hline TAVG & TFAF & f.. l & Gr人r & $9|\uparrow|$ & IrrTq & $|\wedge \&| r$ & TEYAI & 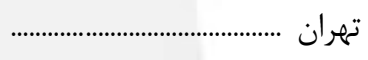 \\
\hline let & v9 & $|r|$ & $r \cdot 1$ & $\Delta 11$ & $91 \mathrm{~V}$ & $14 \wedge 9$ & rrqq & جهارمحال و بختيارى \\
\hline 119 & $\wedge$. & 119 & 197 & rq1 & GIV & 941 & $10 \cdot r$ & خراسان جنوبى ........................... \\
\hline vrq & Fへ૬ & VTA & IFVA & TFIQ & rFql & $\Delta 999$ & AVIr & 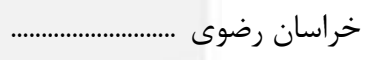 \\
\hline 94 & $\Delta \Lambda$ & $9 V$ & 199 & rVV & $\Delta \Delta \cdot$ & 990 & 1090 & 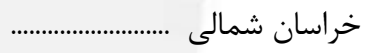 \\
\hline 99. & frt & $9 \vee \Delta$ & TTOV & TVEI & एव१ & $\Delta V \wedge \vee$ & var. & 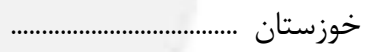 \\
\hline TTD & $1 \cdot 1$ & ITD & rID & rND & $\Delta T_{q}$ & १४४ & (פTI & 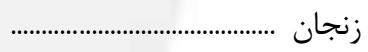 \\
\hline ᄉr & VA & $1 \cdot \Delta$ & 194 & red & $\Delta F A$ & $9 .$. & ITVA & سمنان ........................ \\
\hline$r \cdot q$ & ITV & TFE & fat & V१ & 1199 & 194. & TrIF & سيستان و بلوجستان ..... \\
\hline$v \cdot 1$ & rq4 & 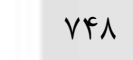 & leV & rDAM & rvv. & $\Delta q F$. & NTAT & فارس ................................ \\
\hline rrv & 189 & rIA & kq & $q \cdot r$ & ITrV & TYGG & rVAF & 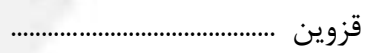 \\
\hline 111 & द. & 1.9 & req & rदq & 099 & qf. & $19 \cdot 4$ & قم ............................. \\
\hline FID & IVF & ref & $\Delta F \Lambda$ & $\Lambda T \Delta$ & ITIV & TYAS & 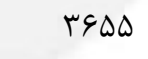 & 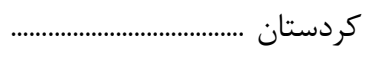 \\
\hline TQF & 148 & MIS & $\Delta 9 \Lambda$ & $9 \Delta F$ & $10 r 9$ & TMYG & ए199 & 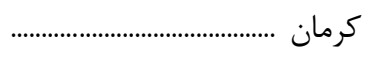 \\
\hline rro & TIN & $r \cdot r$ & Nis & Irar & $191 \mathrm{r}$ & $r . r$ & 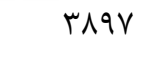 & كرمانشاه ..................... \\
\hline tAr & 114 & $1 \wedge \Delta$ & far & 901 & $V \Delta \Delta$ & ( - l & $r \cdot \Delta T$ & كهيَيلويه و بويراحمد \\
\hline 149 & 99 & $|V|$ & mis & 919 & $1 \cdot \sqrt{ } 9$ & $19 V T$ & rAVr & علستان .......... \\
\hline $4 \wedge q$ & $r 91$ & Fil & $\Lambda F V$ & $\| T \Delta \Lambda$ & T.GT & rt. & FATV & كيلان.................. \\
\hline rq1 & 191 & $r V \cdot$ & $\Delta \Delta \Lambda$ & $11 \%$. & $1 F \wedge \Lambda$ & r\&AV & $r v \cdot 1$ & 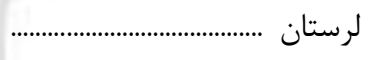 \\
\hline rat & אזr & fir & 999 & $11 \wedge F$ & IVVT & rQYV & FEIT & مازندران .......................................... \\
\hline Trt & $1 F \Delta$ & rma & faV & $\wedge 1 \%$ & IrAF & t. Ft & $r \cdot f r$ & 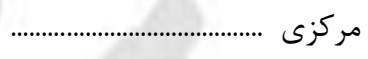 \\
\hline 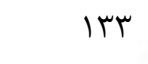 & vr & $r \cdot r$ & ref & VMr & lrma & TIYI & ThET & 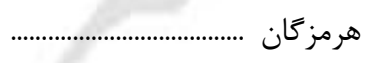 \\
\hline$r \cdot \Delta$ & $|f|$ & rru & $\mid 4 q 1$ & $\wedge 9 \Delta$ & $|F \Delta|$ & rIVI & Tret & 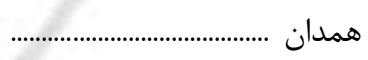 \\
\hline ITV & 90 & $11 r$ & rIT & ral & $\Delta \&$ & $q \cdot v$ & ITAF & 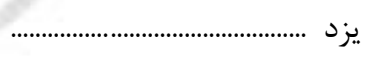 \\
\hline r & v & $\Delta$ & 4 & 10 & rq & kr & $\Delta \Delta$ & 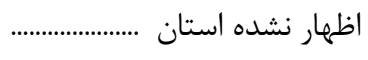 \\
\hline MFt & rrv & 199 & NTr & $|r| \Lambda$ & IVAT & TAYV & $r V \Delta \cdot$ & 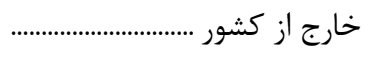 \\
\hline $1 \cdots$ & $\Delta \varphi$ & v9 & $|r|$ & Ifr & $r \cdot 1$ & rr. & MIS & اظهار نشده محل اقامت قبلى... \\
\hline
\end{tabular}


V - 1 - مهاجران وارد شده طى ه سال كذشته بر حسب جنس، استان محل اقامت قبلى و سن (بر اساس آخرين جابجايى انجـام (كل)

\begin{tabular}{|c|c|c|c|c|c|c|c|c|c|}
\hline 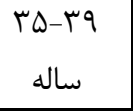 & $\begin{array}{l}r \cdot-r F \\
\text { ساله }\end{array}$ & $\begin{array}{l}r \Delta-r q \\
\text { ساله }\end{array}$ & $\begin{array}{l}r \cdot-Y Y \\
\text { ساله }\end{array}$ & $\begin{array}{l}19-19 \\
\text { ساله } 10\end{array}$ & $\begin{array}{l}\text { ساله } \\
\text { ساله }\end{array}$ & 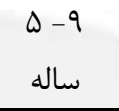 & ساله & جمع & محل اقامت ق قبلى استان \\
\hline $1 A F+1$ & $r 910 \cdot 1$ & reqsql & rrve.. & 19.411 & IrFar. & $\mid$ err|| & $\mid 1994$ & $r \cdot 9 \cdot 9 \cdot 1$ & زن. \\
\hline$N \cdot r t$ & $1 r \cdot 19$ & $\mid r \Lambda \cdot \Delta$ & Ir\&VQ & VIQV & $\Delta \cdot \vee q$ & 9919 & frqu & NHGGY & 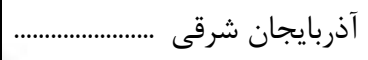 \\
\hline$\Delta H g V$ & $\Lambda F \Delta \Lambda$ & $|r| \Delta \cdot$ & $11 \% \cdot 99$ & (4) & FrA. & $\Delta \cdot \Delta r$ & एव91 & 99994 & 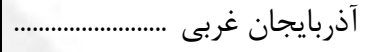 \\
\hline rqाr & FATI & 9941 & VISV & rATI & rrAd & $r \Delta \Delta V$ & 194 & TVTAF & 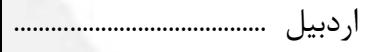 \\
\hline ITMIF & $19 V \cdot r$ & rIVrq & $r \cdot \cdot 19$ & $1 T V 19$ & VATT & १人ץ^ & $\varphi \Delta V$. & I TrMAg & اصفهان ................. \\
\hline 1190 & ITIVT & IIVIF & $\Lambda \notin \vee \Delta$ & pVqq & $r \notin V$. & TIT & $f \cdot 19$ & VQIFV & البرز ................. \\
\hline 1940 & TAFS & TVVT & $r+r$ & $|0|$. & I. Tr & IrVr & $94 V$ & 19人rर & ايلام .......... \\
\hline 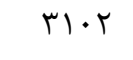 & هir. & DFVq & FAFV & refG & r & MIN. & rT人9 & rrq94 & بوشهر ......... \\
\hline 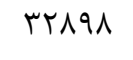 & र्र१9 & FMTTF & rTqTD & $r \cdot r \wedge \Lambda$ & $194 \wedge 9$ & rFVF. & 19999 & $r \cdot r d i$ & 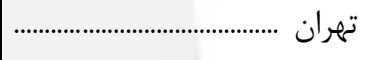 \\
\hline relf & Frts & DVTV & GKM & |दTा & $r r \cdot r$ & TFAV & IAVT & rrfre & جهارمحال و بختيارs \\
\hline rll. & $r q \cdot 1$ & prrq & $\Delta \Delta \& \Delta$ & FATI & T\&\& & TrGY & 1199 & $r 1.94$ & خراسان جنوبى . \\
\hline l1ANr & l11949 & $r r \cdot V r$ & rQIVQ & loq49 & १८५. & 1114. & qTEY & IFATFV & خراسان رضوى ... \\
\hline rTAT & rVFF & $\Delta \cdot \wedge F$ & q. pq & re八r & TFAT & TART & 1941 & r।人9r & خراسان شمالى ..... \\
\hline 9945 & $190 \cdot r$ & 19099 & $1994 \mathrm{~V}$ & १९१. & VDFq & QYAV & \&rqV & 111998 & 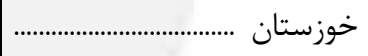 \\
\hline TrMA & TETr & DrTq & $\Delta \wedge 9 T$ & $r v \cdot 1$ & TIYV & rir. & 1489 & $r \cdot r r$ & زنجان .... \\
\hline$|V D|$ & TVAS & (rmar & $r 9 \Delta V$ & $1 M \Lambda \Delta$ & IMIV & $1 \Delta \Delta F$ & $1 \cdot \Delta 1$ & $190 \cdot r$ & 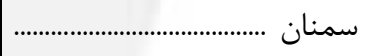 \\
\hline$F \cdot \uparrow \wedge$ & $9|4|$ & VTGV & $V \notin q \Delta$ & ( & ra人 & $\Delta 911$ & FraD & $\Delta 1 \cdots \Delta$ & سيستان و بلوجستان \\
\hline $1 \cdot \vee 99$ & $1 N \cdot t^{2}$ & TrצTr & TMTK & ITDIF & ArTV & $q \cdot \Delta \Lambda$ & \&4qq & Irqr.r & 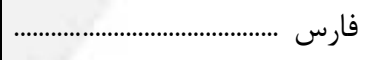 \\
\hline FAFA & 999. & VYA & $9 \Delta \Delta \Lambda$ & r६q. & TITT & rqve & rGYA & rq9人F & 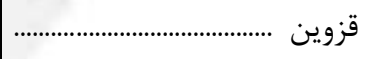 \\
\hline$r 1 \cdot r$ & rDqF & f. Gr & 9 ורזי & lNFq & lefy & TYAS & IVED & THRT & قم ............................... \\
\hline FETA & VQVT & 11.94 & $111 \Delta \Delta$ & G.rV & rیAr & frrq & rqve & DQAFI & كردستان . \\
\hline$k r \cdot 9$ & 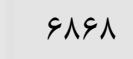 & $\Lambda \Delta \Delta \Lambda$ & $\| \varepsilon 41$ & GMTA & 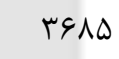 & frat & $r \cdot 99$ & DSTOT & كرمان ..... \\
\hline FqVY & $\Lambda \Delta \Delta V$ & IIVIV & $11 \lambda \& V$ & FquV & rrgF & FrIT & $r \cdot 11$ & GMTFF & كرمانشاه \\
\hline TrGT & f & $\Delta F \|$ & DTH & rMA & ry & TrIV & rITA & rIrAf & كهخيلويا \\
\hline 4.91 & $V \cdot r$. & $1.19 \mathrm{~V}$ & 1.190 & $\Delta \& \& V$ & rFV & r & rova & DF\&QG & كلستان \\
\hline sVVA & $11 r \cdot \Delta$ & $\mid$ IFID & $1 r \cdot r \mu$ & DVAV & r & frv & $r \cdot \Delta \Lambda$ & 11 & كيلان . \\
\hline $49 \cdot 1$ & $v q \cdot \Delta$ & $\| r \mid F$ & IITFA & FAVT & MTYI & GTVE & TUQT & $\Delta \Lambda$ QVर & لرستان ........ \\
\hline grrT & $11 r \cdot 9$ & IMGTF & $11 r \cdot r$ & $\Delta V V \Delta$ & rar & pFFY & rq11 & gq4^. & مازندران ....... \\
\hline rq1F & GITD & VTrA & $v \cdots r$ & FTOI & rqqV & $r \cdot v V$ & rIT. & rrgve & مركزى ................... \\
\hline FITF & giv. & GFIV & $99 \wedge \Delta$ & ‘\९। & MFY & FIOT & rqfa & FYTOA & هرمزكان ........ \\
\hline$r r \cdot \Lambda$ & $V r \cdot \Delta$ & $1 \cdots v F$ & I.r.T & G.rT & rVv & TrIT & rVq. & $\Delta \Delta \& \mid \Delta$ & همدان ... \\
\hline $19 V \pi$ & r911 & MET. & rrq. & $r r \cdot q$ & IrgT & $I V \Delta \Delta$ & $1 r \Delta 9$ & $r \cdot \Lambda r r$ & 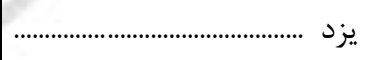 \\
\hline$\wedge \cdot$ & $1 \pi$. & $r \wedge \cdot$ & DIT & 100 & $\wedge \vee$ & IQT & $9 \mu$ & $19 \mathrm{Tr}$ & 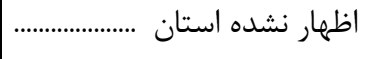 \\
\hline$r T \cdot \Lambda$ & 419. & DTIV & $\Delta 9 \Delta$. & $M T \cdot \Delta$ & $r \cdot 94$ & FATQ & MFYY & $r \wedge \Delta \cdot r$ & 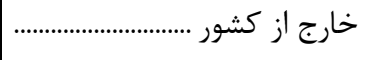 \\
\hline rVF & $\Delta r V$ & $\Delta \Lambda$. & $9 \Lambda 1$ & $\Delta M F$ & $\Delta \Delta \varphi$ & far & IFT & $\Delta \cdot+4$ & اظهار نشده محل اق \\
\hline
\end{tabular}




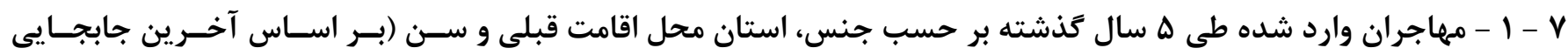
انجامشده)(دنباله)

\begin{tabular}{|c|c|c|c|c|c|c|c|c|}
\hline بيشتر & $\begin{array}{l}V \cdot-V F \\
\text { ساله }\end{array}$ & $\begin{array}{l}\text { ساله 90-99 } \\
\text { ساله }\end{array}$ & $\begin{array}{l}9 \cdot-94 \\
\text { ساله }\end{array}$ & $\begin{array}{l}\Delta \Delta-09 \\
\text { ساله }\end{array}$ & $\begin{array}{l}\Delta \cdot-\Delta f \\
\text { ساله }\end{array}$ & $\begin{array}{l}F \Delta-\& q \\
\text { ساله }\end{array}$ & $\begin{array}{l}\text { س. Ff } \\
\text { ساله }\end{array}$ & محل اقامت قبلى و استان \\
\hline$|r r a|$ & 1frq & Irasr & rreta & refry & FAFrt & $v F \Delta q q$ & $1 \cdot 1 \mathrm{ra}$. & زن................ \\
\hline$\vee \cdot$. & fis & $\Delta \varphi$. & $\wedge \wedge 9$ & Ir.t & lagt & rITA & FAFq & 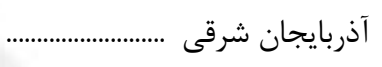 \\
\hline FYl & tr. & rVv & DQT & 1rq & irq. & 19.9 & rवYद & آذربايجان غربى ........................ \\
\hline rqD & $1 \Delta \Lambda$ & 194 & ५१९ & $\mid f_{1}$. & 994 & 1101 & $I V \Delta \Lambda$ & اردبيل .................................... \\
\hline$\wedge \Delta \Delta$ & 499 & $\wedge \Delta \Delta$ & 1099 & TFVA & rTV & $\Delta \cdot \Delta q$ & $V T \cdot \Lambda$ & 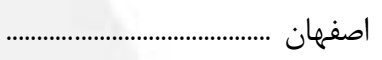 \\
\hline$\Delta T \Delta$ & $r \cdot f$ & sVद & 1.90 & 1090 & 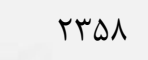 & 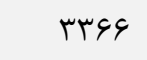 & pVef & 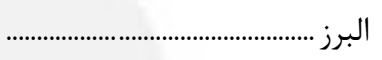 \\
\hline vV & FV & v9 & 14. & rTA & Trt & ఎ१४ & $q 4 q$ & ايلام ................ \\
\hline 111 & ז & lef & rma & ryF & 0.9 & 941 & $1 \Delta \Delta V$ & بوشهر ............ \\
\hline TEMY & TIQV & ratr & $\Delta \Delta १ \Delta$ & $\wedge \backslash \Delta \Lambda$ & $1 \cdot v \cdot 4$ & $|f \Delta| \Lambda$ & 191. & 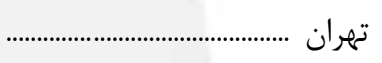 \\
\hline$|\wedge|$ & $\wedge F$ & 179 & 194 & ral & $\Delta F V$ & १९ा & $19 \Delta \mathrm{r}$ & جهارمحال و بختيارى ..... \\
\hline $1 V 9$ & $V \Delta$ & $1 \pi \Delta$ & 191 & rma & FVF & $\Lambda \cdot V$ & $11 \Delta T$ & خراسان جنوبى ...... \\
\hline 1rq & 490 & VHF & $1 Y \cdot 9$ & r. kq & TVAV & FTOS & $9 \wedge 14$ & خراسان رضوى ........ \\
\hline 149 & $\Delta \Lambda$ & $1 \cdot 9$ & Ifs & r\&৯ & GTY & V19 & ITET & خراسان شمالى ....... \\
\hline VQI & Fru & $\wedge 1 \wedge$ & $1 \Delta \Delta F$ & rrsa & 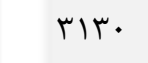 & FAFT & $G \cdot V \Delta$ & 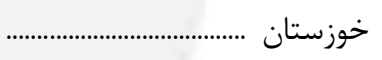 \\
\hline$r \Delta \Delta$ & IfT & 199 & TFY & $r \Delta \Lambda$ & rqq & V१९ & $|f| \mid$ & 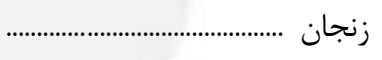 \\
\hline 119 & pq & १५ & IV. & ral & ris & 991 & $9 \wedge \Delta$ & 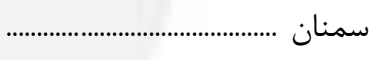 \\
\hline IV. & 110 & $r \cdot r$ & Trt & $\Delta \varphi$. & $\wedge \vee \Delta$ & r & ris. & سيستان و بلوجستان ..... \\
\hline Vre & rیl & viv & $1 Y \cdot \Lambda$ & IAvV & trit & ferd & q.rV & 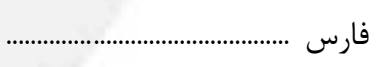 \\
\hline r৭q & 195 & rAq & fir & $v k$. & $1 \cdot 1 V$ & IVVe & TAV. & قزوين ..................... \\
\hline 111 & vı & ז & 19V & rir & rat & vir & $11 \mathrm{kV}$ & 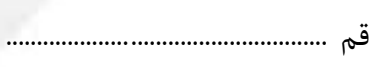 \\
\hline rat & TF. & (F) & $\Delta \vee \varepsilon$ & 994 & I. TV & IVTe & $r v \cdot 1$ & 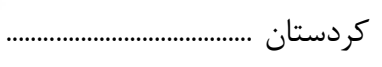 \\
\hline TVE & $|r|$ & rgF & rer & V^ৎ & IIrT & $1 \wedge \cdots$ & raTa & كرمان ........................... \\
\hline 190 & rAD & DFT & VDF & $11 \Delta 9$ & IETF & $r \Delta \cdot G$ & rTAD & 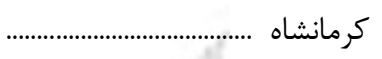 \\
\hline riv & $1 \cdots$ & IV. & ref & kqu & GTr & q७Q & $101 \mathrm{~V}$ & كهخيلويه و بويراحمد ... \\
\hline $\mid 01$ & $1 \cdots$ & IAV & rqr & $<q 1$ & $\Lambda T$. & IrVr & rma & كلستان ......... \\
\hline 999 & TrG & $\{\wedge 1$ & $\wedge \vee q$ & $11 \Delta r$ & $1 \vee 90$ & TVAV & ५৭८ब & كَيلان ......... \\
\hline TrV & 19. & rat & Tr & $1 \cdot 9$ & Tr & $190 T$ & TADT & 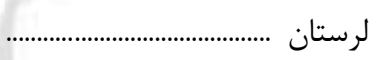 \\
\hline fiv & 519 & FTI & GqT & $1 \cdot \cdot r$ & $10 \cdot 9$ & rFqq & rGG4 & 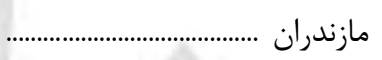 \\
\hline r90 & $19 V$ & THF & FTI & GFT & 999 & IV.. & TFAF & 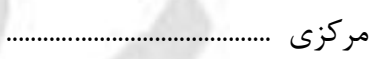 \\
\hline 148 & $\Delta 1$ & 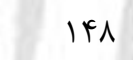 & TrI & $\uparrow \wedge$ & $V k$. & IrVV & TIT & 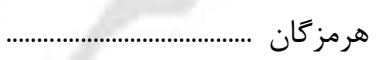 \\
\hline rFS & 199 & rqT & FAT & VTr & $1 \cdot \psi_{1}$ & $|A| F \mid$ & rolf & همدان .................. \\
\hline 191 & $\Delta v$ & 90 & $1 \notin \lambda$ & TFV & rqD & 949 & qvT & 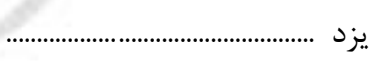 \\
\hline If & v & $\Delta$ & $\wedge$ & 11 & rV & tr & $4 q$ & 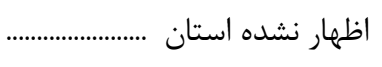 \\
\hline rYq & riN & $r \cdot r$ & DIV & DqT & 990 & IrIV & $1 \wedge \Delta 9$ & 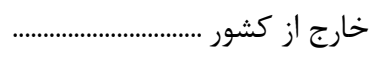 \\
\hline 111 & $\Delta 9$ & 19 & 94 & Irr & INT & $r \cdot r$ & 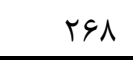 & اظهار نشده محل اقامت قبلى ... \\
\hline
\end{tabular}


V - 1 - مهاجران وارد شده طى ه سال كذشته بر حسب جنس، استان محل اقامت قبلى و سن (بر اساس آخرين جابجايى (نقاط شهرى)

\begin{tabular}{|c|c|c|c|c|c|c|c|c|c|}
\hline 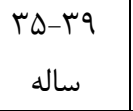 & 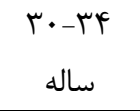 & 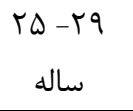 & $\begin{array}{l}\text { ساله } \\
\text { ساله }\end{array}$ & $\begin{array}{l}190-19 \\
\text { ساله } 19\end{array}$ & $\begin{array}{l}\text { ساله } \\
\text { ساله }\end{array}$ & $\begin{array}{l}\text { س -9 } \\
\text { ساله }\end{array}$ & ساله & جمع & محل اقامت قبلى و استان \\
\hline rervra & $\Delta \cdot q V F V$ & $\Delta F \Delta V \cdot F$ & arreas & rriabs & rretga & $r r q a \cdot r$ & $1999 \cdot 1$ & rasfrra & مرد و زن ....... \\
\hline $\mid \Delta F T$ & rivra & TrVGG & $r \cdot r \cdot r$ & $1 K G \cdot 1$ & $91 F 4$ & $|r \cdot| r$ & マ^१८ & $\mid F \wedge 910$ & آذربايجان شرقى ...... \\
\hline$\wedge q . F^{f}$ & Irrq. & 19999 & IVArq & $1 \cdots \Delta \Delta$ & G95. & VQq. & DFFI & $1 \cdots 991$ & آذربايجان غربى .. \\
\hline$\Delta \& \Lambda 1$ & १९८९ & 11991 & $1111 r$ & GFAF & 411 . & $\{\wedge \Delta 1$ & re.1 & GSTIV & اردبيل ......... \\
\hline$r r \Delta \cdot \Lambda$ & $r \Delta \cdot v \Lambda$ & 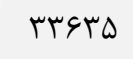 & TrAYI & TYAAV & $14 \cdot 9 V$ & IVVRF & $119 \cdot V$ & rTLYA & اصفهان ............... \\
\hline $\mid 9191$ & rIrAs & IVGGV & ITADV & 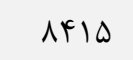 & $\Lambda F \Delta \varphi$ & 1.994 & $V_{1}$. & r & 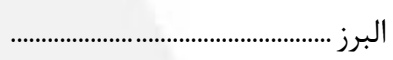 \\
\hline (זr. & $0 \cdot 19$ & DQT. & GVTr & rArq & $191 \mathrm{~V}$ & 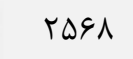 & $|V| \overline{\mid}$ & $r \Delta \Delta \Delta q$ & 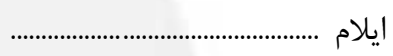 \\
\hline (4) & $M \Lambda I^{F}$ & $\Lambda \cdot r t$ & VrVq & rqv & $r \cdot 9 r$ & $\Delta F I$. & $r \wedge \cdot q$ & DGVGY & بوشهر ....... \\
\hline GTr. G & ATFTV & 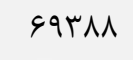 & $\Delta \backslash \wedge \Delta V$ & 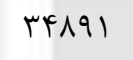 & тrqч. & frque & r^৭マ\% & $\Delta r G \wedge \Delta q$ & تهران ......... \\
\hline DI9T & ৩৭९। & $q \cdot r r$ & I.rIr & $901 \mathrm{~V}$ & fivi & FVGr & אוזr & G..rA & جهارمحال و بختي \\
\hline ratr & $\Delta \vee \wedge I$ & $V \notin q D$ & NFIr & ATrA & $r q .9$ & rogk & rA\& & FMMSD & خراسان جنوبى \\
\hline 19498 & $r \cdot I \Delta F$ & TFAIT & rVI.r & ५६११५ & IFTGY & IVFFF & ITLIV & TRATYE & خراسان رضوى ....... \\
\hline$r \cdot \Lambda \Lambda$ & SVYI & ヘAYD & 1999 & VVQ. & rV^q & Frto & TIT & DrYI. & خراسان ش \\
\hline IgFto & rqfar & $r \cdot q \Lambda$. & riqr. & גזrוגו & $|f| \mid 0$ & $|V \Delta V|$ & 11899 & TIFTIS & خوزستان .. \\
\hline FTGF & 9990 & 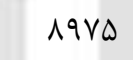 & NFTD & $99 \Delta \Delta$ & 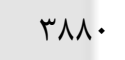 & $r q . r$ & rVVq & DTQGD & 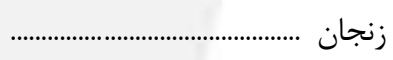 \\
\hline rivi & $r \lambda \cdot v$ & DFTI & 0.19 & rq. & $t \cdot i t$ & relit & $18 \cdot 9$ & TYGDS & سمنان ............ \\
\hline VTYT & $1 \cdots v f$ & 110rs & $|r| \cdot r$ & 199 & g^VI & $.9 \Lambda$ & GDFG & भ१ו & سيستان و بلوجستان ... \\
\hline $1997 \mathrm{~V}$ & LITHI & rolsq & TVEIA & TFTGG & IFVG & IDQTY & $11 \cdot \Delta V$ & TrATVE & فارس ......... \\
\hline qTVY & Irr.k & ITFEA & $9 \Delta \Delta \varphi$ & GTYA & $\Delta \wedge 11$ & VQFA & $\Delta|f|$ & אוTrt & 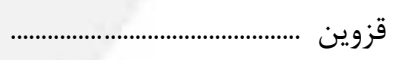 \\
\hline firt & GTFA & $9 \cdot V r$ & DH & rrak & TVDV & ५१११ & r৭६9 & $r \cdot \Delta \& 9$ & قم ..................... \\
\hline 1191 & $1 \pi r \cdot 9$ & IVTIA & IVATQ & 1.914 & GITt & gqur & Fへ૬૬ & 91990 & 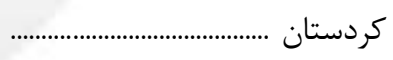 \\
\hline 9994 & $1.4 q 4$ & $|r F| 9$ & $1 V 9 \cdot 1$ & $1 \cdot r \cdot r$ & ه & GTYD & FATS & iqve & 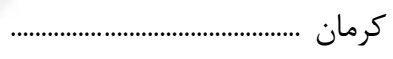 \\
\hline $9 \times 1$. & $181 \mathrm{FF}$ & 1944 & $|M N F|$ & N\&IT & GTYG & $\checkmark \wedge \Lambda$. & $\Delta \Delta r$. & IIrGAV & 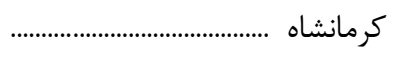 \\
\hline$r \Lambda \cdot r$ & बसाI & vrq. & AITS & FYYF & TQTr & $r V \cdot \Delta$ & TYVE & 49811 & كهيَيلويه و بويراحم \\
\hline GTqT & $1 \cdot \Lambda T V$ & I & IrqFa & vrq. & FDIS & $\Delta 9 \Delta V$ & DIVT & VDADT & كلستان \\
\hline IIrVT & INDFA & r|s|r & $I V \& \Delta \Delta$ & 1 & DFVG & 9991 & $\forall \wedge \Delta 1$ & 114109 & كيلان ....... \\
\hline qqVT & IDFYA & $19.9 V$ & IVrrg & ᄉ\⿻コ & 9.94 & $1 \cdot 91$ & grs. & $1 . \Delta 994$ & لرستان ... \\
\hline 9119 & $18 \cdot 19$ & INFIV & $|F \wedge V|$ & $\wedge v \cdot q$ & FANT & SFAF & fraq & १९९८र & مازندران ... \\
\hline$V \Delta \cdot \Delta$ & 1.991 & $1 r \cdot r q$ & 1.Grr & 9914 & DTF. & $\Delta \& \wedge \Lambda$ & rAAv & VGY৭q & مركزى .............................. \\
\hline VVYT & 1.114 & 90.9 & $1 \cdot 01$ & $\wedge \vee \wedge I$ & $\Delta \Delta Y I$ & 9901 & FA91 & VDINF & هرمزكان .... \\
\hline NFtr & $14 \cdot 9$. & $|V| \varepsilon \mid$ & $1 \Delta r \cdot 1$ & १९१९ & GIQT & 9910 & $\Delta 1 \cdot 1$ & $q \Lambda T \cdot r$ & همدان ................. \\
\hline$r \cdot \omega$ & pqrF & DFAT & DqF. & rیזם & rIIF & TVAT & rtrq & quוp & يزد ......................... \\
\hline $1 \Delta \Delta$ & TYD & $\Delta r F$ & $1 \cdot r$. & Fid & $I V D$ & rघ9 & 191 & rT\&q & اظهار نش \\
\hline NITV & $1.9 V r$ & IFIN. & $10 \wedge 98$ & 1.1 .9 & QVQT & $\Lambda \cdot \wedge \kappa^{k}$ & 9.90 & affid & 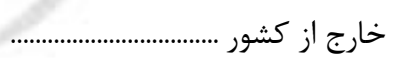 \\
\hline $4 \cdot 0$ & $\wedge \varepsilon$. & 11.9 & 1994 & $1 \Delta V V$ & 119 & $\wedge \varepsilon \Lambda$ & rt. & 994. & اظهار نشده محل اقامت قبلى ..... \\
\hline
\end{tabular}


V - ا - مهاجران وارد شده طى ه سال كذشته بر حسب جنس، استان محل اقامت قبلى و سن (بر اساس آخرين جابجايى (نقاط شهرى)

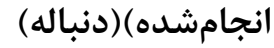

\begin{tabular}{|c|c|c|c|c|c|c|c|c|}
\hline بيشتر VD ساله و & $\begin{array}{l}V \cdot-V F \\
\text { ساله }\end{array}$ & $\begin{array}{l}90-99 \\
\text { ساله }\end{array}$ & $\begin{array}{l}9 \cdot-94 \\
\text { ساله }\end{array}$ & $\begin{array}{l}\Delta \Delta-\Delta 9 \\
\text { ساله }\end{array}$ & $\begin{array}{c}\Delta \cdot-\Delta F \\
\text { ساله }\end{array}$ & 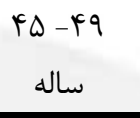 & 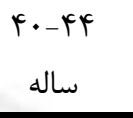 & محل اقامت قبلى استان \\
\hline rterr & Iralr & rrafe & $r . . r r$ & gla\&v & $99 \cdot 19$ & IFFerA & rirgir & 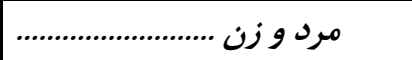 \\
\hline 111. & 991 & $\wedge \vee$. & $1 \Delta V$ & requ & rqG4 & GFTD & १८১। & 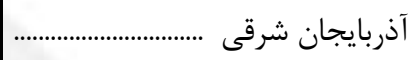 \\
\hline $9 \wedge \Delta$ & $r \cdot r$ & Q1. & $\wedge \vee r$ & Irat & $r t \cdot r$ & TYDQ & $\Delta I V A$ & آذربايجان غربى ............... \\
\hline FAF & TFI & $r \cdot \Lambda$ & $\Delta \cdot V$ & var & IrGT & tett & rq. F & 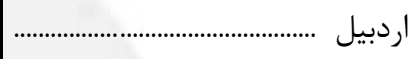 \\
\hline lifes & $94 \Delta$ & IVF. & $r \cdot r$. & \&qV. & gVrq & 1.rar & $I F \wedge \Delta \Lambda$ & 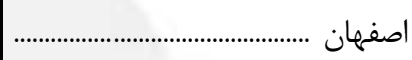 \\
\hline 人 & $9 \Lambda \Lambda$ & $11 \mathrm{kT}$ & $190 \mathrm{r}$ & r८१८ & Fra. & gVr. & 9919 & 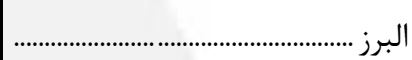 \\
\hline (148 & 90 & IOT & 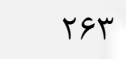 & $\Delta \cdot r$ & VII & $14 \cdot 1$ & $r \cdot \Lambda \Delta$ & ايلام ....................... \\
\hline IV9 & ir. & 194 & FAT & 8^4 & $1 \cdot V F$ & 1997 & ret. & بوشهر ..................... \\
\hline FqVF & rAFl & GTGT & 9115 & IFTrg & T. TFT & TAV৭V & $r \cdot r \Delta \Delta$ & تهران ....................... \\
\hline rat & 10 . & rIf & frv & $v \notin q$ & ITVT & TTYT & $r \Delta \cdot \Delta$ & جهارمحال و بختيارى .. \\
\hline rel & ג & 194 & riN & fet & VTO & $|r| \Lambda$ & $199 \mathrm{~V}$ & خراسان جنوبى ............ \\
\hline 1194 & 999 & 1. & IAVF & rוl. & F\&AT & $V \Delta \cdot V$ & $\| V T \mid$ & خراسان رضوى ........... \\
\hline 194 & vT & $\mid$ & trt & FrA & vq. & irvi & trqG & خراسان شمالى ......... \\
\hline $1 \% \cdot 9$ & V৭9 & lqar & TQFi & f\&V & GDFD & $9 \pi 9 \Delta$ & ITSDF & 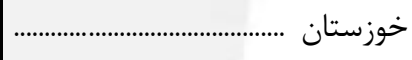 \\
\hline fir & TTV & rat & $k \cdot 1$ & $9 \Delta \Delta$ & $\wedge \Delta$. & IQVY & TVTA & زنجان ............................. \\
\hline 10 & $\wedge \vee$ & If. & $r \Delta V$ & fre & VबD & ITVT & INAT & 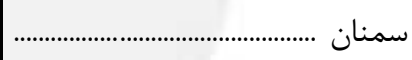 \\
\hline TFF & lQT & r.. & $\Delta H^{\prime}$ & १९८ & lQTE & $r \Delta \cdot G$ & FIT. & سيستان و بلوجستان ...... \\
\hline IrTq & gar & $|K T|$ & TRAT & rVTq & $\Delta \Delta \Delta F$ & MAF. & IrIFF & 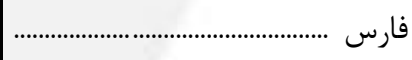 \\
\hline FaV & $r \cdot 1$ & $r \cdot r$ & Vru & 1rq9 & $r \cdot \Delta F$ & roßs & $q \cdot V V$ & 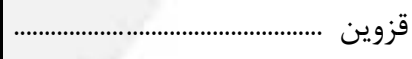 \\
\hline IV. & $1 \cdot c^{4}$ & 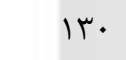 & r.. & $\Delta \cdot \Lambda$ & NIT & (1) & וIוT & قم ................................. \\
\hline $8 \wedge \Lambda$ & אזr & $\Delta \& V$ & 911 & & $11 \cdot r$ & TrAS & 0190 & 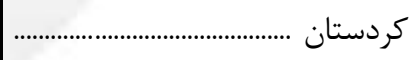 \\
\hline$r \cdot \Delta$ & $I \Delta V$ & ra. & st. & $1.4 \Delta$ & IVAT & r^१० & fiAt & 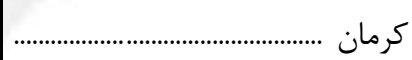 \\
\hline マ৭9 & Fre & NFV & $\| F \mid T$ & Trta & rTDQ & f9६4 & grvo & 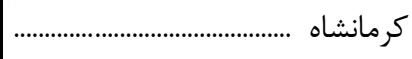 \\
\hline זעז & lis & Trt & $\Delta \& 1$ & VEV & $9 Y \wedge$ & 1099 & $r F \cdot q$ & كهيَيلويه و بويراحمد \\
\hline$r \cdot r$ & Irv & rtq & Fil & VAM & ira. & TrGS & rVAG & كلستان ..................... \\
\hline$\wedge \Delta 1$ & $|49|$ & 995 & Q & MN. & rq\&4 & 1494 & 9949 & كيلان .................................. \\
\hline$\Delta r \cdot$ & rAD & 190 & $9 \Delta \Delta$ & $19 \wedge \mathrm{V}$ & $r \cdot \Delta$ & अवार & $\Delta \vee V \wedge$ & 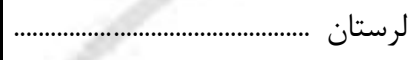 \\
\hline DTr & rMA & DHS & $\wedge \Delta 9$ & 149. & $r I \cdot r$ & rVIr & $\Delta \Lambda \cdot \Delta$ & مازندران ........................ \\
\hline จ१९ & rब9 & ґ१q & VTS & $I T \cdot \Delta$ & $T \cdot F T$ & rer & Fイ⿻ & 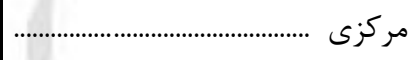 \\
\hline$I V F^{c}$ & $\wedge \varepsilon$ & rar & $\Delta \cdot r$ & $9 \Delta F$ & 1919 & एव६ & ref & 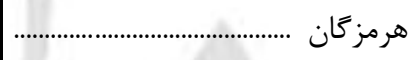 \\
\hline טqT & rII & prq & $\wedge \notin \wedge$ & 1480 & rTqD & reQT & $\Delta Y q F$ & همدان ........................ \\
\hline r99 & $1 \Delta$ & 149 & TYA & frv & 999 & ITr. & IVAT & يزد ................................................... \\
\hline 11 & ir & $\wedge$ & $1 \cdot$ & 19 & rt & 91 & $q$. & 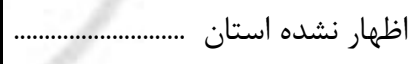 \\
\hline DrT & $F \wedge$ & VII & 1189 & 1091 & TMYI & MEGF & rarA & 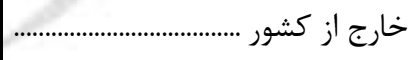 \\
\hline 19. & 95 & 1 Ir & IVT & $r \cdot 9$ & r & MIS & FrA & اظهار نشده محل اقامت قبلى ........ \\
\hline
\end{tabular}


V - ا - مهاجران وارد شده طى ه سال كذشته بر حسب جنس، استان محل اقامت قبلى و سن (بر اساس آخرين جابجايى

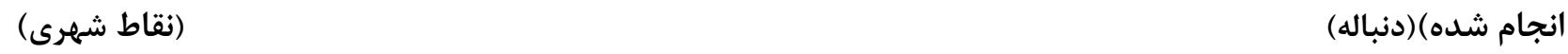

\begin{tabular}{|c|c|c|c|c|c|c|c|c|c|}
\hline 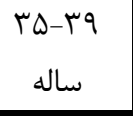 & $\begin{array}{c}\text { ساله } \\
\end{array}$ & $\begin{array}{c}r \Delta-r q \\
\text { ساله }\end{array}$ & $\begin{array}{l}r \cdot-\text { rF } \\
\text { ساله }\end{array}$ & $\begin{array}{c}19-19 \\
10 \\
\end{array}$ & 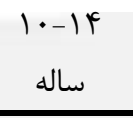 & $\begin{array}{l}\Delta-9 \\
\text { ساله }\end{array}$ & $\begin{array}{l}\cdot-f^{\prime} \\
\text { ساله }\end{array}$ & جمع & محل اقامت قبلى واستان \\
\hline$|A \Delta| \& F$ & TAqTFA & $r \Delta l \cdot \Delta r$ & rrgvad & IVTA. & llaFVr & I frrqd & $1 .|r F|$ & $11 \cdot r \mu \cdot q$ & 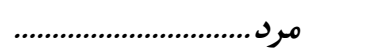 \\
\hline NTIF & $11 \ldots$ & $1 . q \mu V$ & १५rq & GAYG & F\&AV & GIVe & $\varphi \cdot r \wedge$ & VDTF. & آذربايجان شرقى \\
\hline FATr & 9991 & $V V \Delta \Lambda$ & ᄉrV. & DFIT & TrTD & $r 909$ & rVVq & DIrG & آذربايجان غربى ........... \\
\hline$r \cdot \wedge \varphi$ & F्99 & DGTH & FVAF & r190 & 194 & $r \Delta \& \Delta$ & IAVT & THYGT & 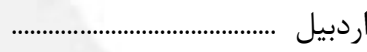 \\
\hline IrHAF & IVIVq & $|f| 8 \mid$ & IfGGF & IITFA & VTVD & $9 \cdot 01$ & 9191 & 1194.1 & اصفهان ............... \\
\hline AVIV & $1 \cdot r \wedge$. & VITK & 0199 & FrII & kr.r & $\Delta \Delta q \mu$ & rVAF & 94999 & البرز .......... \\
\hline IAVE & roTq & TAFF & TVT & lfr. & $1 \cdot \Delta \varphi$ & אזrו & 911 & IVDGY & ايلام ........... \\
\hline rFAI & FFIF & rFqV & rF. I & rVFq & Tा19 & TVQV & I gFt & rqY\&q & بوشهر ......... \\
\hline$r \mu \cdot \Lambda$. & fir.q & 41.91 & rTADQ & $|V| \cdot 1$ & IV.rt & rTDqF & $1+\lambda \cdot \varphi$ & TVITET & تهران ............... \\
\hline TrVA & ५११९ & rAkq & frvr & . & $t t \cdot r$ & TATY & 1990 & rq119 & جهارمحال و بختيارى \\
\hline 194. & ravr & ryfF & rVAF & FTMt & 1114 & 1149 & $\mid r \wedge$. & TFETT & خراسان جنوبى .. \\
\hline $1 \cdot r \cdot 9$ & IDFA. & $19 \vee 9$. & I\&^\&V & IFIr & VTFF & 190. & 9911 & 114194 & خراسان رضوى .... \\
\hline r।9r & rq. & FTMA & TETI & $r \Lambda \cdot \Delta$ & 1909 & rIQF & 1915 & रघтq। & خراسان شمالى .. \\
\hline $1 \cdot r \wedge \Lambda$ & $|F| A T$ & גזוזו & Ir人৭ณ & 9991 & VTar & $\Lambda 9 \Delta F$ & 91.1 & $1 \cdot \Delta \wedge F$ & خوزستان ... \\
\hline rTat & TVET & FETT & rब1ץ & rar. & 1990 & 1911 & IFr & rदqTद & زنجان ..... \\
\hline 1994 & Trtr & TOMF & TFIT & ITFD & $1 \cdot Y k$ & 1 1r49 & $\Lambda \Delta F$ & $\mid \varepsilon F \Delta \Lambda$ & سمنان ......... \\
\hline$f \cdot 11$ & $01 \wedge 9$ & $\Delta \wedge r V$ & VI.r & هIr. & TDIT & FATA & ג & frA.. & سيستان و بلو \\
\hline $1 \cdot \Delta V r$ & IDFVG & $|\Delta \Delta \varphi|$ & IVTqV & גוזrו & VAYV & $1 r \cdot q$ & DVFY & $11 F \cdot r V$ & فارس ............. \\
\hline 0.90 & 9111 & $\Delta M F I$ & rNFV & mIlf & र१९T & rave & $r V$. & FT. 99 & قزوين .................... \\
\hline THOV & $r \cdot q r$ & TAT. & TEYG & IATA & $1 r \wedge 9$ & $r \cdot \Delta q$ & 1499 & $r \cdot r \Delta r$ & 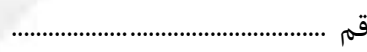 \\
\hline FATA & $V \cdot 4 q$ & 人זیז & V৭१১ & $\Delta V I F$ & $r \cdot r_{1}$ & roIV & $r \Delta \ldots$ & $\Delta \cdot r \Delta F$ & كردستان .. \\
\hline TYAI & $\Delta T \Delta F$ & $\Delta V \Delta I$ & VArI & 4919 & TVF. & rIVe & rrr & $4 \backslash 19$. & كرمان ... \\
\hline DTTV & $\Lambda F \vee \wedge$ & 1911 & Arva & FTET & rTr. & $F|r|$ & ТА१ & DGHT & كرمانشاه ...... \\
\hline rIDT & TMTD & MFYI & ra9 & $r \Delta V$. & $|Q F|$ & 119. & $1 \% 90$ & TFYTY & كهيَيلويه \\
\hline זוזr & $\Delta \Delta q \mu$ & GMGV & Drsq & TDGF & T199 & $r \cdot \Lambda l$ & r\&AD & TVYFq & كلستان .. \\
\hline$\Delta \wedge \Delta 1$ & 9191 & $q \vee \cdot \Delta$ & 991. & rVAq & rArd & rell & rolA & DFFVI & كيلان ..... \\
\hline זrTH & NTEV & $q \cdot r q$ & VAVG & rAVF & MTFF & FTFT & TrMT & DrDSG & لرستان ............................ \\
\hline אזוه & $\Delta F \cdot \Delta$ & VATV & GrTa & FAIN & TQMY & TrVD & TIFT & FATAD & 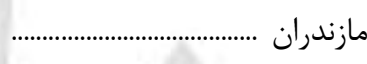 \\
\hline rq७^ & DFqF & $\Delta \Delta \|$ & frav & MIN & relf & rq\&D & $r \cdots v$ & rvrv. & 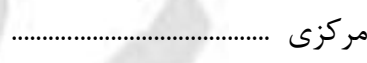 \\
\hline Frg. & $\Delta \cdot r q$ & feva & $\Delta \Delta \cdot \Delta$ & $\Delta T \cdot T$ & rAfF & $r \Delta \vee q$ & $r \Delta \Lambda r$ & $4 \cdot 191$ & هرمزكان .......................... \\
\hline$F \Delta \Delta V$ & $V \Delta \cdot r$ & ATKF & 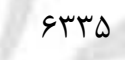 & eVve & rqvq & $r \Delta \Delta \phi$ & TEYA & FAvrq & 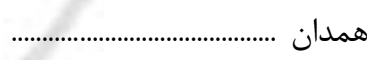 \\
\hline$|94|$ & TATI & TQFV & $r q \cdot q$ & IMAF & 1114 & $|r N|$ & 1110 & IV9IV & 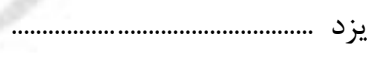 \\
\hline$\vee \wedge$ & IrT & $r \Delta \Lambda$ & $\Delta T \cdot$ & $r 90$ & 90 & $I T \Delta$ & NF & 1991 & 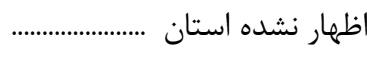 \\
\hline$\Delta \backslash \Delta \Delta$ & $v \cdot q r$ & $9 \Delta \mathrm{Tr}$. & 1.991 & VTEV & $r \cdot \Delta q$ & figr & mIlf & G.rmT & 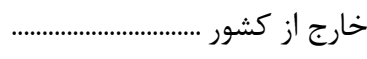 \\
\hline r11 & f.. & \&रq & ( & 1111 & $F \Delta 9$ & pq. & ITT & $\Delta \wedge r \Delta$ & اظهار نشده محل اق \\
\hline
\end{tabular}


V - 1 - مهاجران وارد شده طى ه سال كذشته بر حسب جنس، استان محل اقامت قبلى و سن (بر اساس آخرين جابجايى انجـام (نقاط شهرى)

شده)(دنباله)

\begin{tabular}{|c|c|c|c|c|c|c|c|c|}
\hline بيشتر & $\begin{array}{l}V \cdot-V F \\
\text { ساله }\end{array}$ & $\begin{array}{l}90-99 \\
\text { ساله }\end{array}$ & $\begin{array}{l}9 \cdot-94 \\
\text { ساله }\end{array}$ & $\begin{array}{l}\Delta \Delta-\Delta q \\
\text { ساله }\end{array}$ & $\begin{array}{l}\Delta \cdot-\Delta F \\
\text { ساله }\end{array}$ & $\begin{array}{l}r \Delta-r q \\
\text { ساله }\end{array}$ & $\begin{array}{l}\text { W.-Ff } \\
\text { ساله }\end{array}$ & محل اقامت ق قبلى استان \\
\hline $1 \cdot F_{F F}$ & svar & $1189 \mathrm{r}$ & rirar & rradq & $\Delta 1198$ & 11998 & Ir.1TE & 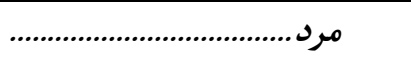 \\
\hline$\uparrow \wedge \Lambda$ & $r \cdot r$ & ral & Var & 1 Ira & rrmq & r\&\&V & $\Delta \Delta \& \Lambda$ & 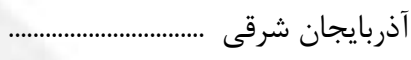 \\
\hline r19 & $1 \pi q$ & tre & rqf & VTr & ITIT & $r \cdot 1 \cdot$ & एवदर & 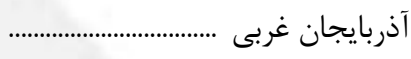 \\
\hline 198 & $1 \cdot V$ & Ifr & Tet & fro & Vq. & Irqv & $r \cdot r \Delta$ & 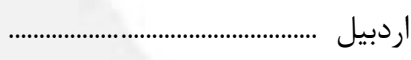 \\
\hline sVD & FAF & १४१ & $19 \Delta F$ & rFq. & rVqI & $\Delta \vee \Delta I$ & NTQF & اصفهان ............................. \\
\hline GTV & TE & $\Delta \Delta r$ & $1 . r t$ & $1 \Delta \Delta$. & rrq. & TVQI & $\Delta \& V F$ & 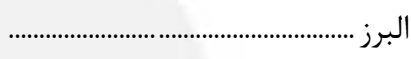 \\
\hline vi & TQ & $\wedge \Delta$ & 149 & rq9 & prt & $\Lambda \Delta V$ & ITTA & 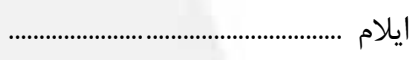 \\
\hline$\Delta c^{f}$ & $\Delta V$ & 19 & rVT & (i). & 990 & ITTS & rI.9 & بوشهر ................... \\
\hline rrvi & $191 \%$ & TrAT & $\Delta 1 \cdot V$ & VEa. & MITES & 19111 & rT৭9४ & تهران ....................... \\
\hline 1K4 & Vr & $1 \cdot \Delta$ & r\&l & FrA & V^v & IrTE & 1990 & جهارمحال و بختيارى .... \\
\hline 149 & 41 & $\wedge 1$ & $1 \cdot r$ & TYG & fis & 991 & 1111 & خراسان جنوبى ......................... \\
\hline DFF & rTS & $\Delta \cdot \Delta$ & 999 & 1919 & $r \varphi \cdot \Delta$ & Fr. $q$ & GQVD & خراسان رضوى ..... \\
\hline VV & זr & iv & 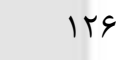 & TVG & fiq & V१९ & IrAT & خراسان شمالى ....... \\
\hline $9 \cdot 0$ & ras & 9ाז & $r I \cdot r$ & rF\&D & rGT. & $\Delta / \Delta \cdot$ & $V \cdot r \Lambda$ & خوزستان ...................... \\
\hline$r \cdot \Delta$ & 91 & 11. & INT & ref & $F \Delta \Lambda$ & 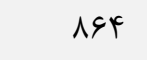 & leve & زنجان ....................... \\
\hline$\Delta \Lambda$ & $\Delta \varphi$ & $\mathrm{v} \cdot$ & 159 & TEV & Er. & $V k$. & $1 \cdot \Delta \varphi$ & سمنان .................... \\
\hline IrF & Ve & 109 & rl. & $\Delta V I$ & $\Lambda \wedge \vee$ & lfre & TFAN & سيستان و بلوجستان ...... \\
\hline$\Delta \vee q$ & rTV & 919 & ITr & TIrI & r & $\Delta \cdots$ & 990. & 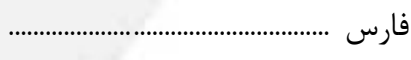 \\
\hline 199 & 1rq & $|V|$ & एव) & VबD & $11 T V$ & $r \cdot r q$ & rysq & قزوين ............................. \\
\hline VV & rV & \& & 191 & TVV & fVr & Vब9 & $|r \Delta|$ & 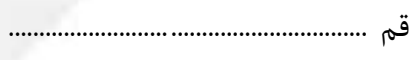 \\
\hline$r r \wedge$ & Ire & rle & Fra & gru & $9 \wedge \mathrm{r}$ & IAVF & r৭१९ & 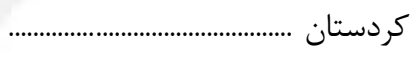 \\
\hline IrF & $\wedge$. & 119 & rgF & $\Delta \wedge 1$ & 1.r & $19 V \pi$ & TrAT & 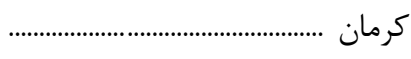 \\
\hline rAT & INF & rav & VTS & 1198 & IVqF & rघ9T & & 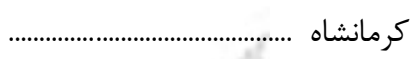 \\
\hline 191 & 99 & $|r|$ & r & Fid & $\Delta 11$ & 191 & $1 F \cdot V$ & كهيكيلويه و بويد \\
\hline 94 & 4 . & $11 \pi$ & TrA & fis & VVT & ITAT & r119 & علستان ........... \\
\hline Gru & TTV & mif & qr. & 919 & IQAT & $r \Delta \cdot \varphi$ & raf. & كيلان .. \\
\hline$r F \wedge$ & (re & rma & FAr & 994 & $1 r \wedge 9$ & riva & rutg & لرستان ..... \\
\hline gre & TF & TET & fir & שr & (11T & $r \cdot g r$ & MTIF & مازندران .... \\
\hline TrY & אזו & 194 & rVA & 499 & 1191 & $M \cdot r$ & rद৭9 & مركزى ....... \\
\hline VF & $\Delta \cdot$ & $|f|$ & ral & $\Delta V I$ & 1.1. & 1891 & TRIO & 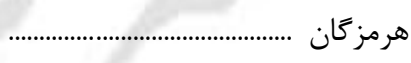 \\
\hline TAT & ITV & $r \cdot 9$ & FFV & $\vee १ \wedge$ & ITTA & 1998 & $r \cdot 19$ & همدان.................. \\
\hline $1 \cdot r$ & iv & ^ז & $|f|$ & T\&4 & fis & $V \cdot \Delta$ & $9 \vee r$ & 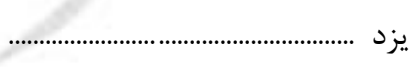 \\
\hline r & 4 & $r$ & r & 1. & 11 & $r \Delta$ & kr & 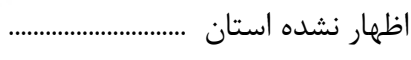 \\
\hline rq1 & TMA & Fry & VTr & $1 \cdot \Delta V$ & $10 \cdot 0$ & rTY & rTIS & 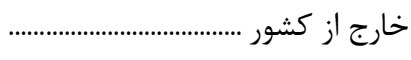 \\
\hline ve & ky & 99 & $1 \cdot r$ & 1.9 & $I \Delta V$ & lQF & STM & اظهار نشده محل اقامت قبلى .......... \\
\hline
\end{tabular}


V - 1 - مهاجران وارد شده طى ه سال كذشته بر حسب جنس، استان محل اقامت قبلى و سن (بر اساس آخرين جابجايى انجـام (نقاط شهرى)

شده)(دنباله)

\begin{tabular}{|c|c|c|c|c|c|c|c|c|c|}
\hline 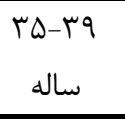 & 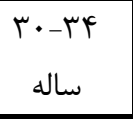 & 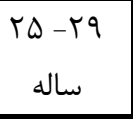 & $\begin{array}{l}\text { W.-YF } \\
\text { ساله }\end{array}$ & $\begin{array}{l}19-19 \\
\text { ساله } 10 \\
\end{array}$ & $\begin{array}{l}\text { ساله } \\
\text { ساله }\end{array}$ & $\begin{array}{l}\Delta-9 \\
\text { ساله }\end{array}$ & ساله & جمع & محل اقامت قبلى استان \\
\hline$|\Delta V \Delta V|$ & $r \Delta \cdot r q q$ & rqfert & TADAFT & Iه9ra. & $11 . \mathrm{var}$ & irarit & $9 \Delta r q v$ & IVEIFra & زن.......... \\
\hline vIIV & $1 \cdot \vee \vee q$ & IrITq & 11.90 & GIAT & FFAV & $\Delta \wedge r \wedge$ & 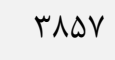 & VTOVQ & 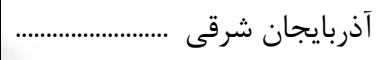 \\
\hline $4 \cdot 11$ & Gтrq & ^९५^ & 9499 & reft & rTQD & I I I I & T\&GT & 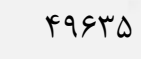 & آذربايجان غربى ........................... \\
\hline TQ9Q & $f \cdot q$. & 9.91 & 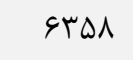 & rrAq & TIEV & TYAS & IVTA & rTqDD & 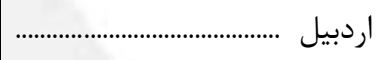 \\
\hline $111 Y F$ & IV^99 & $194 V F$ & $M \Lambda \cdot V$ & 11बrq & gVar & 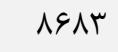 & DVFe & $119 \cdot 18$ & اصفهان ................. \\
\hline$V F \Delta I$ & $11 \cdots 9$ & $1 \cdot \Delta F \Delta$ & 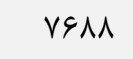 & GT. F & fiar & $\Delta F \cdot 1$ & TAYG & $9991 \pi$ & البرز .................... \\
\hline 1494 & rQG. & rrve & ५१११ & $14 \cdot 9$ & 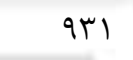 & Irto & r & IV99У & ايلام .............. \\
\hline TEQT & fi.. & Fata & rqv^ & trth & 1978 & rgar & IA\&V & rVFqT & بوشهر ....... \\
\hline rq1rद & FIrIA & r人rqV & rی१९८ & IVYAr & $199 \cdot 1$ & rIrA. & $|F| \& V$ & rqDFqV & تهران ..................... \\
\hline TFIF & एव६ & DIAT & $\Delta \wedge \mu$. & TIAV & 1991 & TRYI & $19 V \pi$ & $r \cdot r \cdot q$ & جهارمحال و بختيارى \\
\hline $109 V$ & $r \Lambda \cdot q$ & rVDI & FETA & ए१९६ & $r \cdot 9 r$ & 1991 & IrNH & TFTH & خراسان جا \\
\hline $9 \cdot 1 v$ & IFEVF & $1 \Lambda \cdot \Delta r$ & r. rrd & $\mid r \& \Lambda$. & $V \cdot \varphi \wedge$ & NFqF & $9 \Delta 99$ & III1Ar & خراسان رضوز \\
\hline 1190 & (rirq & 促 & $\Delta \cdot \vee \wedge$ & rafs & lAr. & $r \cdot \Lambda I$ & lQY. & T\&सוQ & خ خراسان ش \\
\hline $91 \Delta V$ & IOTAT & IVAFT & $11 \cdot F V$ & Nq4. & GATt & 1૬IV & $\Delta 991$ & 1. ArVG & خوزستان .. \\
\hline $19 V T$ & rt. & FAQT & gVEt & $T \cdot r \Delta$ & 1910 & $194 \pi$ & $1 \pi \cdot 4$ & rq. rq & زنجان .......... \\
\hline IFAF & rrVFe & r^१V & rq. r & $1 \Delta \Delta V$ & $9 \wedge 1$ & ITFA & NAT & 19191 & سمنان .......... \\
\hline 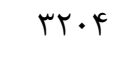 & $F \wedge \Lambda$ & $\Delta 999$ & ब११९ & f. 19 & rraq & FFF. & rIMA & rq11V & سيستان و بلو. \\
\hline$q T \Delta F$ & $1 \Delta V \Delta \Delta$ & $199 \cdot 1$ & $r \cdot|r|$ & $1.94 \lambda$ & 9949 & VVIT & אוזם & $111 r 49$ & فارس ..... \\
\hline FINT & \&4qT & $v 1 \cdot v$ & $\Delta V \cdot q$ & mIIf & rA19 & r\$99 & TYYI & FTTAV & قزوين ...... \\
\hline$I V \wedge$. & MIAD & rabr & rMAq & $10 \Delta 9$ & 1481 & 19r5 & IFV. & $r \cdot r \mid q$ & 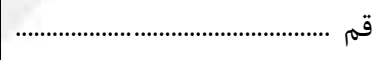 \\
\hline raf. & 919. & MNזם & qQTF & ४^१9 & $r \cdot 91$ & rFiQ & TצG & FATII & كردستان ........ \\
\hline TTET & DrTq & 9991 & १४^. & DTIF & 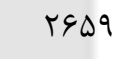 & $r \cdot r q$ & TrEY & $\mu r \cdot \Lambda q$ & كرمان ...... \\
\hline FANT & V999 & $1 \cdot+\Delta$. & 1.494 & fra. & ए१९६ & rVDq & reTV & $\Delta G T \Delta \Delta$ & كرمانشاه . \\
\hline 1949 & rq19 & ५१९१ & FITT & rIDF & IrNT & 1110 & $|r N|$ & TyfFY & كهيلو \\
\hline rqA. & DTMF & VYqQ & VAVG & rVT & Trt. & rAVG & TFAV & 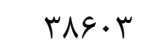 & حَلستان \\
\hline DFT & queV & $119 \cdot V$ & $1 \cdot V F \Delta$ & for. & rapi & rrav & אזrז & ब१९१M & كيلان \\
\hline fif. & VIब1 & $1 \cdots v 1$ & qVQT & Fr人q & rAFq & r $\wedge \Delta \Delta$ & TIYA & DTFYA & لرستان ... \\
\hline 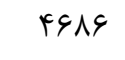 & 1911 & 1.09. & NDFG & frql & TMYA & riv & TITV & $\Delta \mid F \cdot V$ & مازندران ... \\
\hline TATV & DFqV & gQTA & و & rry & TETG & Inti & $1 \wedge \Lambda$. & ५А१५ & مركزى ... \\
\hline THEY & 7. & $\Delta \cdot r$. & $\Delta \cdot \cdot \Delta$ & rovq & reV & q & TTVA & r $4 q \wedge q$ & هرمزكًان . \\
\hline rA\&D & GQAV & $q \cdot r V$ & १৭९९ & DTr. & MIVF & rroq & reV. & \&qץ9D & همدان . \\
\hline Irat & TFIT & $r q .9$ & $r \cdot r l$ & 1901 & $1 \cdots$ & IrVT & $1 \cdot \Delta F$ & IVTYY & يزد ........................ \\
\hline VV & $1 \pi r$ & TVG & $\Delta \cdot \cdot$ & 10 & $\wedge \cdot$ & $|f|$ & $\Delta F$ & $|\Delta V|$ & 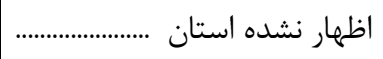 \\
\hline ravr & rAvq & F\&9. & fqre & TVAT & rqqF & ए人१५ & rQDI & THINT & 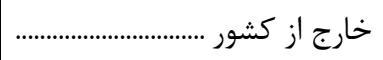 \\
\hline raf & iq. & $\dot{\mu}$. & 9.1 & FQq & qr. & rVA & 91 & 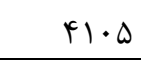 & اظهار نشده محل اقامت قبلى.... \\
\hline
\end{tabular}


V - 1 - مهاجران وارد شده طى ه سال تذشته بر حسب جنس، استان محل اقامت قبلى و سن (براساس آخرين جابجايى (نقاط شهرى)

انجام شده (دنباله)

\begin{tabular}{|c|c|c|c|c|c|c|c|c|}
\hline 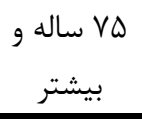 & $\begin{array}{c}V \cdot-V F \\
\text { ساله } \\
\end{array}$ & $\begin{array}{l}90-99 \\
\text { ساله }\end{array}$ & $\begin{array}{c}9 \cdot-9 f \\
\text { ساله } \\
\end{array}$ & $\begin{array}{c}\Delta \Delta-\Delta 9 \\
\text { ساله }\end{array}$ & $\begin{array}{c}\Delta \cdot-\Delta F \\
\text { ساله }\end{array}$ & $\begin{array}{c}F \Delta-F q \\
\text { ساله }\end{array}$ & $\begin{array}{l}\text { س.jpf } \\
\text { ساله }\end{array}$ & محل اقامت قو استان \\
\hline $110 V 9$ & $r \cdot \Delta \varphi$ & IIFFq & $119 r 9$ & $r \Lambda \cdot \cdot 1$ & $r \cdot 19 r$ & graft & $94 \cdot 91$ & زن..................... \\
\hline Grt & rNA & FVT & vrA & $11 K \Delta$ & IVTD & tVQA & Rtor & 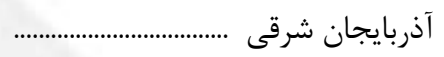 \\
\hline rद६ & IVT & rAY & fvq & 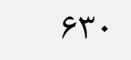 & 991 & IFFq & tris & 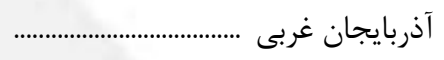 \\
\hline$r \Delta V$ & ITF & 190 & rat & $r \Delta \Lambda$ & $G \cdot r$ & $1 \cdot r \Delta$ & $10 \Delta 9$ & اردبيل ................. \\
\hline Vri & $F \Delta \mid$ & VQI & ITVG & rIN. & rq४^ & FQFT & $\varphi \Delta \cdot f$ & اصفهان ........ \\
\hline 149 & MFA & $\Delta \wedge 9$ & 95. & ITFS & $r \cdot \varphi$. & rq9q & FTFD & 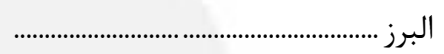 \\
\hline 90 & f. & $9 V$ & 114 & $r \cdot r$ & rVq & $\Delta \Delta I$ & $\Lambda \Delta V$ & ايلام ................. \\
\hline $9 \Delta$ & q & $1 \cdot f$ & 189 & tVe & $4 \cdot q$ & V\&V & ||$_{1}$ & بوشهر ...... \\
\hline rtqg & $1 \wedge \Delta V$ & $r \cdot 1 \cdot$ & $r V \cdot \Delta$ & srvq & ८९१८ & $|r q| 9$ & IVTDQ & تهران .............. \\
\hline 199 & VV & 1.9 & IVE & ITI & $\uparrow \wedge \Delta$ & १९९ & 101. & جهارمحال و بك \\
\hline 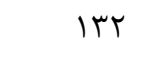 & pr & $\Lambda \mu$ & 110 & $19 V$ & $r \cdot q$ & $\Delta \omega \cdot$ & $14 q$ & خراسان جنوبى \\
\hline sr. & rve & $\Delta r \cdot$ & $\wedge \vee \Delta$ & $|F T|$ & $r \cdot r \wedge$ & rrqA & DIfG & خراسان رضوى \\
\hline 118 & ५q & $\Lambda f$ & $1 \cdot 9$ & $r \cdot r$ & MFl & $\Delta \wedge r$ & (1) - (1) & خراسان شمالى \\
\hline$v \cdot 1$ & $f \cdot 1$ & $V F$. & IfrV & $r r^{\prime} G$ & rard & FTFD & $\Delta \varphi \mid \varphi$ & خوزستان ....... \\
\hline$r \cdot \Lambda$ & Irq & INT & r) & आI & rqr & $v \cdot \wedge$ & ITAT & زنجان ....... \\
\hline 94 & 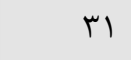 & $v \cdot$ & $I T \Lambda$ & 199 & rFa & DHT & ArV & سمنان .... \\
\hline 11 & VG & IFF & TrG & rqf & qrq & $1 \cdot v \cdot$ & le9r & سيستان و بلوجستان ...... \\
\hline $90 \cdot$ & ( ) & $q \cdot r$ & $1 \cdot r \cdot$ & 1091 & | lel & rAץ. & $\Delta 19 F$ & فارس ................ \\
\hline$r \Delta \Lambda$ & Igr & שחז & MFV & | ( & qrV & $1 \Delta \Delta V$ & $r q \cdot \Lambda$ & قزوين ...... \\
\hline q & $9 V$ & $q V$ & Trt & וזr & qur & $\Delta q{ }^{c}$ & 99. & قم .................. \\
\hline Mr. & 194 & rol & FN & $\Delta \vee \Delta$ & $\Lambda r$. & IfIT & r) & كردستان .......... \\
\hline$|V|$ & VV & 191 & rQS & feq & 819 & ITTK & $19 \cdot 1$ & 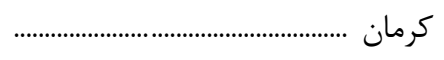 \\
\hline fiv & TFT & $q q$. & $\varphi \wedge \varphi$ & rer & 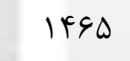 & TrVF & rqfT & كرمانشاه .............. \\
\hline IFT & VV & 111 & וזr & Trm & $\mid i_{1}$. & SVI & $1 \cdot r$ & كهخيلويه \\
\hline 1.9 & VV & 119 & $r \cdot r$ & MFT & $\Delta \vee \wedge$ & $1 \cdot 11$ & $19 V$ & علستان ................ \\
\hline$\Delta / D$ & TGF & rVA & $\Leftrightarrow \wedge \Delta$ & $9 \cdot 1$ & IrNT & $r \backslash \Delta \Delta$ & פוr & تيلان ............ \\
\hline TAT & 149 & rG. & FVT & VYI & $1 \cdot 19$ & IVrq & TDFT & لرستان ..... \\
\hline rAs & 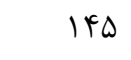 & rAY & fys & GQV & $9 \vee \cdot$ & 190 & $r \Delta q 1$ & مازندران .... \\
\hline rTV & سF & 198 & rFA & QHG & $\wedge \Delta ।$ & $10 \cdots$ & rISV & مركزى ......... \\
\hline $1 \cdots$ & re & $11 r$ & $|0|$ & rیr & $9 \cdot 9$ & 1190 & 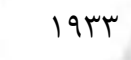 & هرمزكان .............. \\
\hline आI & MA & r & FYI & $99 V$ & $9 \& V$ & $19 \wedge 9$ & trVA & همدان .......... \\
\hline 190 & r & 99 & $1 \cdot V$ & $|V|$ & rᄉ. & $\Delta / \Delta$ & $\vee \wedge 9$ & يزد ...................................... \\
\hline If & V & $\Delta$ & $\Lambda$ & 9 & $r F$ & TG & EV & 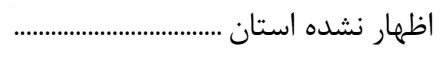 \\
\hline 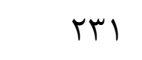 & $r \cdot$. & rVV & $F \Delta \varphi$ & $\Delta F_{1}$ & Nrs & 1194 & IVIT & 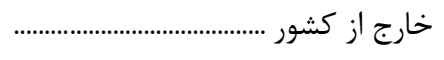 \\
\hline NF & is & VT & $\mathrm{V} \cdot$ & $1 \cdots$ & $10 \varphi$ & 194 & מוץ & اظهار نشده محل اقامت قبلى ............ \\
\hline
\end{tabular}


V - ا - مهاجران وارد شده طى ه سال كذشته بر حسب جنس، استان محل اقامت قبلى و ســن (بـر اســاس آخــرين جابجـايى (نقاط روستايى)

انجام شده)(دنباله)

\begin{tabular}{|c|c|c|c|c|c|c|c|c|c|}
\hline 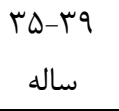 & $\begin{array}{l}\text { ساله } \\
\text { ساله }\end{array}$ & 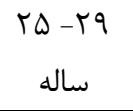 & $\begin{array}{l}\text { ساله } \\
\text { س. TF }\end{array}$ & $\begin{array}{l}19-19 \\
\text { ساله } 10\end{array}$ & 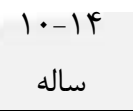 & 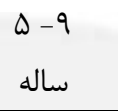 & ساله & جمع & محل اقامت قبلى و استان \\
\hline FIFFA & 19949 & 1. VAls & llvarr & $11 F 99$ & $\Delta r \cdot r r$ & DAIV. & FFiा & vretar & مرد و زن ...... \\
\hline T. FT & TVMY & TFAV & RTM & $r q .1$ & ITET & 1999 & $11 r \wedge$ & rrqVV & آذربايجان شرقى ........ \\
\hline TVQT & FTIF & $\Delta \wedge \wedge \Delta$ & VVYS & $\Leftrightarrow Q \Delta \varphi$ & $r t \cdot q$ & r৭99 & rISY & ए৭१०९ & آذربايجان غربى ........... \\
\hline$v \cdot v$ & 1149 & $19 V \pi$ & $r \cdot k r$ & IrrF & gDT & $\Delta \wedge F$ & frv & qAVF & 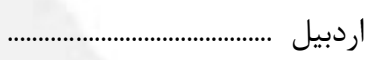 \\
\hline TVqV & TANT & FVr. & Drta & rGG4 & $|\wedge r|$ & trita & 1819 & rq9.. & اصفهان ........ \\
\hline IVTr & TrGS & TRAF & TRGT & Ifir & $1 \cdot 19$ & IDTF & $1 \cdots \Delta$ & IVqTV & البرز ............. \\
\hline fid & VIr & פחם & 948 & rVV & 199 & ५९9 & rTS & FVES & ايلام ......... \\
\hline $119 \mathrm{~V}$ & IATE & 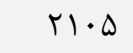 & $19 \mathrm{VV}$ & $9 \vee \Delta$ & 9.1 & 1.94 & 190 & Iтrवद & بوشهر ................ \\
\hline NFAr & $1 \cdot \Lambda \Delta V$ & $11 \cdots 9$ & $1 \cdot r \wedge 1$ & grqf & $\Delta F I \Lambda$ & $9 \wedge 90$ & $0 \cdot 9 T$ & NGFV & تهران .............. \\
\hline 991 & 1.19 & $\mid f \cdot 1$ & $|f| \mid$ & $9 ९ \wedge$ & DqT & 490 & FrA & $11 \cdot V$ & جهارمحال و بختيارى \\
\hline$\| 1 r \mid$ & $|V \wedge|$ & מItS & r|ब1 & TrDS & IDFA & $|r v|$ & $1 \cdot \wedge \Delta$ & $I \Delta \wedge \Delta F$ & خراسان جنوبى . \\
\hline दा & qrVD & I.r人ץ & $1 \cdot \wedge r \Delta$ & $9 \Delta \wedge r$ & $\Delta 911$ & $V \cdot k r$ & $\Delta \Delta r r$ & VGYA. & خراسان رضوى ....... \\
\hline$\Lambda T V$ & IrAD & 1911 & rIQD & 1919 & 1.91 & $q \cdot r$ & var & $M r \cdot r$ & خراسان شمالى ................ \\
\hline$T \cdot T V$ & raq4 & एवा1 & $\Delta G \cdot r$ & TFAV & IFVD & $1 \wedge \vee \wedge$ & $1 f \ldots$ & r\&\&V. & خوزستان ......... \\
\hline DIr & V৭9 & Irr. & rIVF & 1194 & $v \Delta \cdot$ & FTI & TrI & 9.14 & 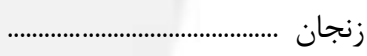 \\
\hline$\Delta V Q$ & qזם & $1 \cdot \Delta \varphi$ & 941 & NTr & 991 & 9.9 & FTI & vrav & سمنان ...................... \\
\hline 1911 & rqIf & rVr. & $\varepsilon \Delta \Delta q$ & rTV. & TDQG & rTDQ & TEMT & rArGV & سيستان و بلوج \\
\hline rapq & DFTF & GTID & s481 & $r V \cdot \varphi$ & rNII & $r \Lambda \cdot G$ & TF.T & r..rq & فارس ................ \\
\hline$\Lambda \cdot 1$ & 1.95 & $1 r \Lambda$. & $|\wedge| 1$ & IFFA & VEA & stu & ret & I. TTD & 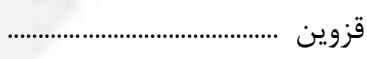 \\
\hline GVV & 199 & $1 \cdots 9$ & 1.49 & $\checkmark \wedge \Lambda$ & $\Delta \wedge \vee$ & Tru & $\Delta \wedge \varphi$ & VYFa & 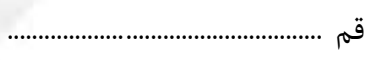 \\
\hline ( & rqه & $f \cdot \Delta \Delta$ & 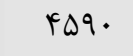 & rif. & rter & 1919 & IrAS & $r \Delta \cdot r$ & كردستان ......... \\
\hline TFMt & TAFA & rA\&V & $r v \cdot 1$ & TAFT & TIFA & TFAI & $I V \Delta \Delta$ & rVqTq & كرمان ............... \\
\hline $11 \Delta F$ & $19 \cdot 0$ & rEAr & MFFF & 1999 & (זr & १९. & vq. & ISTIY & كرمانشاه \\
\hline I9AT & r<ql & $r q \cdot V$ & एभ१९ & $14 q$. & IFTr & IAVD & 1499 & 191.9 & كهَيلويه \\
\hline rt.. & relf & 4999 & 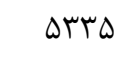 & frqF & $r+1$ & TFAT & TrT. & r. ब\& & كلستان \\
\hline r^q. & $f \cdot \Delta l$ & pers & स्वा & rधq1 & ivar & $r \cdot q 4$ & $1 \Delta \Delta V$ & rq4.. & كيلان .. \\
\hline $119 \mathrm{~V}$ & $|V \Delta|$ & TATR & $r \Delta v \cdot$ & $1 \Lambda \cdot \Delta$ & Arr & 94 . & $q \cdot r$ & $I \Delta \Lambda \Lambda V$ & لرستان ....................... \\
\hline rTaV & DHFS & $\Delta V r G$ & $\Delta / \Delta V$ & 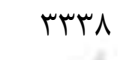 & $r T \Delta \Delta$ & TAGY & IAr. & ra八IT & مازندران ....... \\
\hline 194 & ITYV & $14 \cdot 9$ & lgrt & $|r \wedge|$ & ve. & 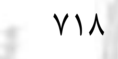 & $\Delta \cdot \Lambda$ & $1 .+991$ & 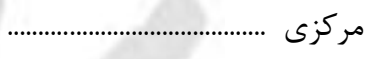 \\
\hline lDGF & $T Y \cdot T$ & r^१। & riाr & rAVV & IVTS & 1991 & $|r v|$ & r..१६ & هرمزكان ............... \\
\hline 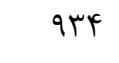 & lFFY & r. kF & rGFA & $r+q$ & ITG4 & VVe & 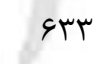 & Irogs & همدان ............... \\
\hline$v \Delta \cdot$ & $11 \mathrm{FF}$ & 11199 & $q \cdot v$ & 499 & $V \Delta V$ & VAr & gFt & $\Lambda T \Lambda$. & 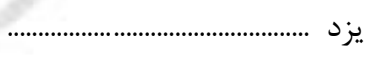 \\
\hline rq & rV & $\Delta 1$ & 99 & 99 & 19 & Ta & 19 & rAv & 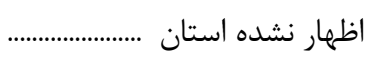 \\
\hline 1190 & $|09|$ & TATA & rrvq & rイ^q & qur & IrVV & 1.41 & $|s 4| f$ & 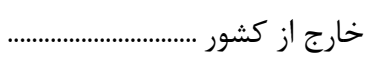 \\
\hline 199 & rब9 & ( & rT. & TFE & TVT & rø9 & 1.1 & TQF. & اظههار نشد \\
\hline
\end{tabular}


V - 1 - مهاجران وارد شده طى ه سال كذشته بر حسب جنس، استان محل اقامت قبلى و سن (بر اساس آخرين جابجايى انجـام (نقاط روستايى)

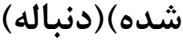

\begin{tabular}{|c|c|c|c|c|c|c|c|c|}
\hline بيشتر VQ ساله و & $\begin{array}{l}\text { V•-VF } \\
\text { ساله }\end{array}$ & $\begin{array}{l}90-99 \\
\text { ساله }\end{array}$ & $\begin{array}{l}4 \cdot-9 f \\
\text { ساله }\end{array}$ & $\begin{array}{l}\Delta \Delta-\Delta 9 \\
\text { ساله }\end{array}$ & $\begin{array}{l}\Delta \cdot-\Delta F \\
\text { ساله }\end{array}$ & $\begin{array}{l}F \Delta-f q \\
\text { ساله }\end{array}$ & $\begin{array}{l}\text { W. Ff } \\
\text { ساله }\end{array}$ & محل اقامت و استان \\
\hline fral & rere & arrr & 9 qras & IFFed & 11999 & rVFAs & rqqe. & مرد و زن ....... \\
\hline IVV & 119 & IVF & rQ1 & ५१९ & $\Delta 11$ & 149 & $1 r \& 9$ & 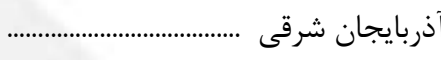 \\
\hline 109 & 99 & IOF & rfq & FTF & GAT & r & $1 \Delta \Delta T^{2}$ & آذربايجان غربى ....................... \\
\hline$\wedge$. & is & $\Delta F$ & $\wedge F$ & 149 & 190 & rAT & rqQ & 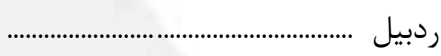 \\
\hline IVD & IrV & rme & Far & $v \cdot c^{c}$ & $1 \notin q$ & ITVD & $1 \vee q$. & صفهان ...................... \\
\hline |r| & lif & ris & $r \cdot r$ & $\Delta \Delta r$ & VTr & זr & 1111 & لبرز ............. \\
\hline rT & 11 & זr & id & $\Delta F$ & 9 & ifa & rrq & يلام ........... \\
\hline$i \wedge$ & ऍ & VI & If. & 189 & TFT & FTD & GQF & لوشهر .......... \\
\hline Arq & $\wedge \cdot$. & $|T Q|$ & rI99 & $r \cdot v \cdot$ & एяq. & frup & $\Delta \wedge Y G$ & تهران ....... \\
\hline r & ז & re & $\Delta V$ & ir. & 195 & rtq & frV & جهارمحال و بخ \\
\hline $1 \cdot v$ & VT & $\wedge$. & IV. & rAT & ए99 & $\Delta r$. & $9 \wedge \Lambda$ & خراسان جنوب \\
\hline$f \cdot r$ & TAT & FTV & 1). & $1 \% \Delta \Delta$ & $19 T 0$ & rQIA & $r \Lambda \cdot \varphi$ & خراسان رضوى . \\
\hline rV & Fe & ia & NT & $19 \mathrm{~V}$ & IAT & $r \cdot \varphi$ & Q11 & خراسان شمالى \\
\hline 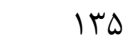 & vi & If. & Tr. & $F \Delta \Delta$ & $\Delta \vee \wedge$ & מד & $|r F|$ & 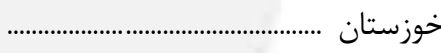 \\
\hline $9 \mathrm{~V}$ & זr & r & $\Delta V$ & $\Lambda \Lambda$ & 111 & rII & ris & زنجان ..................... \\
\hline $4 q$ & r. & $\Delta \Lambda$ & $1 \cdot 0$ & $1 \Lambda$. & וTr & res & rی. & سمنان ...................... \\
\hline $1 \Gamma \Delta$ & 9. & IFV & ral & r $\Lambda$ & DFA & NIV & ITSF & سيستان و بلوخستان ..... \\
\hline rIQ & ITr & TKY & FTt & Vre & זr & IQTU & TYYD & فارس ............... \\
\hline vq & $v$. & $1 \cdot r$ & 191 & TFV & rq. & FAS & $\Delta V V$ & فزوين .................. \\
\hline$\Delta 9$ & MF & 99 & lfe & IVT & rTq & rq. & kq. & 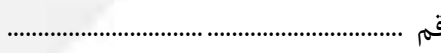 \\
\hline 119 & Ar & ITA & $r \cdot \varphi$ & $r \cdot \omega$ & FET & VYG & 1191 & كردستان .................... \\
\hline TrM & $\pi$. & r. & $F+1$ & 990 & 199 & |r|r & $194 V$ & كرمان ..................... \\
\hline 1.4 & VV & 99 & 111 & rA. & MEV & $\Delta F$ & $\Lambda \cdot V$ & كرمانشاه .... \\
\hline 199 & $4 \Lambda$ & r & מצ & rqv & is. & VFT & 119. & كهَيلويه و بو. \\
\hline VV & ar & 149 & $r \cdot \Lambda$ & M19 & DFS & VVq & $|f| 9$ & كلمتان ... \\
\hline$r \cdot v$ & 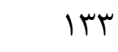 & $r \cdot V$ & 411 & $\Delta 9 \Delta$ & 人 & מזrו & lats & كيلان .... \\
\hline 90 & זי & 99 & (re & TAT & TlQ & VTI & VVQ & لرستان .... \\
\hline$r \Delta V$ & 194 & TAV & EVT & vav & 1189 & IVIT & THR & مازندران ... \\
\hline 119 & is & $\wedge$. & IOT & ra. & 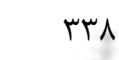 & rq. & sTa & مركزى ... \\
\hline $1 \cdot 0$ & rv & q४ & IN & rब9 & 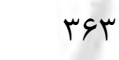 & DT & $q \cdot v$ & عرمزكان ......... \\
\hline$\Delta V$ & rq & (i) & $\Lambda \Delta$ & IDT & $r \cdot r$ & roq & $\Delta \Lambda F$ & 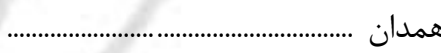 \\
\hline $4 q$ & $r v$ & $\Delta \Lambda$ & 111 & 191 & TET & 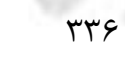 & rqt & بزد ..................... \\
\hline • & 1 & r & r & $v$ & 11 & 9 & if & ظهار نشده استان .............. \\
\hline 99 & $9 V$ & 19 & 191 & rir & rی9 & $\Delta \cdot \cdot$ & $9 \vee \Lambda$ & 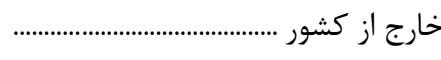 \\
\hline DI & r & $r \cdot$ & fr & 49 & $v$. & $11 \mathrm{~V}$ & g & 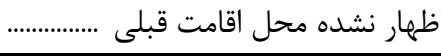 \\
\hline
\end{tabular}


V - 1 - مهاجران وارد شده طى ه سال كذشته بر حسب جنس، استان محل اقامت قبلى و سن (بر اساس آخرين جابجايى انجـام (نقاط روستايى)

شده)(دنباله)

\begin{tabular}{|c|c|c|c|c|c|c|c|c|c|}
\hline 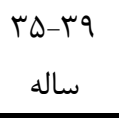 & $\begin{array}{l}r \cdot-r F \\
\text { ساله }\end{array}$ & $\begin{array}{c}r \Delta-r q \\
\\
\end{array}$ & $\begin{array}{l}\text { ساله } \\
\end{array}$ & $\begin{array}{c}19-19 \\
\text { ساله } \\
\end{array}$ & $\begin{array}{l}1 \cdot-1 f \\
\text { ساله } \\
\end{array}$ & $\begin{array}{l}\Delta-9 \\
\text { ساله }\end{array}$ & ساله & جمع & محل اقامت قبلى واستان \\
\hline$r a \cdot 1 a$ & FAqr. & $\Delta \Delta V V r$ & safr. & $\Delta \cdot \mid F+1$ & rVana & $r \cdot|v|$ & $r r \cdot f q$ & $f \cdot v \cdot 11$ & 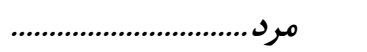 \\
\hline $11 \pi v$ & IFYF & $|V \wedge|$ & rVIF & 1949 & st. & १९१ & $\Delta 9 V$ & $1 \% \wedge 9$. & آذربايجان شرقى ..... \\
\hline $10 \cdot V$ & $r \cdot \wedge \Delta$ & revr & f.१९ & TQ10 & ITYE & $I \Delta \vee \wedge$ & $11 \pi 0$ & $1909 \mathrm{~V}$ & آذربايجان غربى ...... \\
\hline rq. & 911 & $\wedge r$. & IrTa & $\lambda \cdot r$ & fre & (זוץ & rtr & $\Delta \Delta \vee \Delta$ & 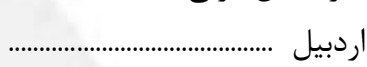 \\
\hline $19 \cdot V$ & $r \cdot v q$ & $r \Psi \Delta \Delta$ & TFAT & $\mid \Delta \Lambda F$ & १११ & $1 \mu_{*}$ & 190 & 199.1 & اصفهان ... \\
\hline $9 \wedge 1$ & 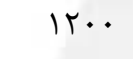 & $1 \cdot 1 \Delta$ & ITVE & 111 & $\Delta V T$ & $\lambda \cdot r$ & $\Delta / \Delta$ & १९१५ & البرز ..... \\
\hline rघ9 & FrA & Drq & GTD & TVE & $1 \cdot 0$ & 191 & $|r|$ & rq1. & ايلام .... \\
\hline$V E V$ & 1.94 & 1101 & $\Lambda \cdot \Lambda$ & $\Delta \Delta V$ & FAF & $\Delta r \Delta$ & pFt & $9 \wedge 90$ & بوشهر \\
\hline FVII & QVVe & D৭Ar & grte & rیAq & rArr & rata & TDST & FATAT & تهران .......... \\
\hline$\forall \& \Lambda$ & 49. & $\Lambda \& V$ & $\wedge \& \Lambda$ & $\Delta M F$ & $r \Delta \Lambda$ & rFq & rrq & FAVA & جهارمحال و بختيا \\
\hline $9 \cdot 1$ & qAT & $11 \Delta V$ & ITrF & $|\Delta r|$ & १४१ & $V \cdot \Delta$ & $\Delta V T$ & ८९१५ & خراسان جنوبى \\
\hline roqv & $\Delta 1 \cdot r$ & DHGF & $\Delta \Lambda \Lambda 1$ & GTIV & 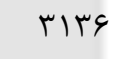 & revV & 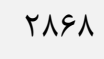 & FTrID & خراسان رضوى .. \\
\hline frq & $8 \Lambda$. & NGF & 1119 & $|r \Delta|$ & Fis & Fal & rAd & GATI & خراسان شمالى ... \\
\hline ITET & IVYF & TIQF & rir & TFAV & VFA & $1 \cdots 1$ & $v \cdot 1$ & IETFq & خوزستان ............ \\
\hline raV & ґ^. & DFT & $1 . r F$ & $|r| \Lambda$ & 011 & rif & 101 & FVAT & 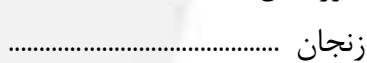 \\
\hline$r \cdot q$ & DrT & $\Delta \& 1$ & $\Delta \Lambda \Lambda$ & pqp & quq & $r \cdot r$ & Trt & r.9r & 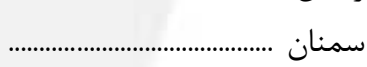 \\
\hline $11 r v$ & 1991 & rIGT & $r \cdot q \mu$ & $19 \Delta r$ & IrVT & $|V| F$ & Ired & lefva & سيستان و بلو \\
\hline 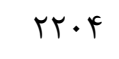 & rוrv & rTq & rTDQ & rIf. & IFT. & $|49|$ & $|r| s$ & $r T \cdot \Lambda T$ & فارس .. \\
\hline Fra & $\Delta \varphi \Delta$ & 999 & १९१ & GVT & FET & TF & TQS & $\Delta F q \Lambda$ & قزوين ......... \\
\hline raf & fq. & $\Delta . \cdot$ & 919 & 190 & rII & rVq & rq1 & Frtq & 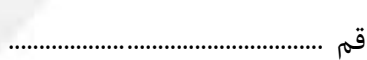 \\
\hline $1.4 \Delta$ & lofG & IATV & TrGA & $r \cdot r$ & $|0|$. & $\wedge \notin \Delta$ & sVG & Irkq & كردستان \\
\hline irv. & 1919 & I9VV & INF. & IFTA & IITr & $1 r \cdot 1$ & qT. & IFVG & كرمان ........ \\
\hline 994 & 1.14 & $|f| s$ & $r \cdot q r$ & ITAT & $1 \& 0$ & DrG & $4 \cdot q$ & qrTF & كرمانشاه \\
\hline १९१ & $14 \cdot 4$ & $1 \leqslant 90$ & 1194 & $V \Delta G$ & VVI & qVर & $V \Delta \Delta$ & 1.199 & كهيَيلو. \\
\hline $111 r$ & $11 \cdot 1$ & TITA & T. FG & TrVTr & $\| f \Delta$ & IrID & $11 F$ & $14 \wedge 99$ & Fلستان .................... \\
\hline lorF & $r \cdot q r$ & TITA & $r \cdot r$ & lfry & 941 & 1.01 & Trt & $101 V$. & كيلان ................. \\
\hline 999 & $1 \cdots v$ & $1 \mu \wedge$. & $r \cdot V \wedge$ & $|r T|$ & Fil & 019 & FVA & QRFT & لرستان ..... \\
\hline$|1|$. & TVDI & $r V \cdot r$ & $r \Delta .$. & $M A Q F$ & IINT & $1 r$. & 999 & IMAK. & مازندران .... \\
\hline$\Delta \cdot V$ & $\Delta 99$ & 119 & QQV & VAT & prq & ref & T\&A & $\Delta V \& S$ & 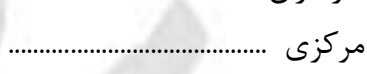 \\
\hline$q \cdot r$ & ITrT & $10 \cdot r$ & IFTr & 1090 & 911 & $M \Lambda$ & $v \cdot r$ & $1 \cdot A T F$ & هرمزكان .... \\
\hline $\mid 991$ & VTS & $1 \cdots v$ & IFIT & $10 \cdot V$ & GqT & Frt & זוץ & VFIS & همدان ......... \\
\hline$F+1$ & 949 & qro & $\Delta F \wedge$ & 411 & r9d & f.. & V & 4999 & 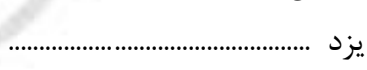 \\
\hline זr & $\mu$. & FV & AV & 91 & 9 & 14 & 1. & TrI & 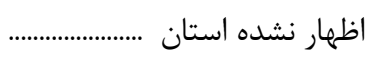 \\
\hline 949 & ITQ. & 1971 & $r \varphi \Delta \Delta$ & Mks & $\Delta \varphi$. & VeF & $\Delta T \Lambda$ & $15 \cdot 94$ & 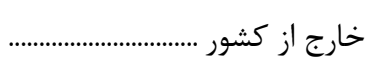 \\
\hline 119 & 119 & ruq & זri & 199 & 148 & LQT & $\Delta V$ & $19 \cdot 4$ & اظهار نشده محل اقامت قبلى.... \\
\hline
\end{tabular}


V - 1 - مهاجران وارد شده طى ه سال كذشته بر حسب جنس، استان محل اقامت قبلى و سن (بر اساس آخرين جابجايى انجـام (نقاط روستايى)

شده)(دنباله)

\begin{tabular}{|c|c|c|c|c|c|c|c|c|}
\hline بيشتر & $\begin{array}{l}V \cdot-V F^{F} \\
\text { ساله }\end{array}$ & $\begin{array}{l}90-99 \\
\text { ساله }\end{array}$ & $\begin{array}{l}9 \cdot-94 \\
\text { سالد }\end{array}$ & $\begin{array}{l}\Delta \Delta-\Delta 9 \\
\text { ساله }\end{array}$ & $\begin{array}{l}\Delta \cdot-\Delta F \\
\text { ساله }\end{array}$ & 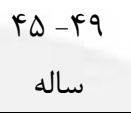 & $\begin{array}{l}\text { ساله } \\
\text { fy }\end{array}$ & محل اقامت قبلى استان \\
\hline raFq & $11 \Delta \Delta$ & rarr & ards & ATFE & $1 \cdot v \& 9$ & IDArq & $r r a \cdot 1$ & مرد...... \\
\hline 99 & st & $\wedge \varsigma$ & 10 & trt & ห१९ & $F \Delta q$ & $V \cdot r$ & 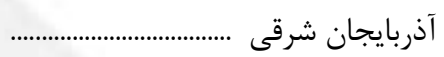 \\
\hline 11 & $\Delta T$ & (1) & (r) - (1) & TrD & Trt & $\Delta V r$ & NFr & 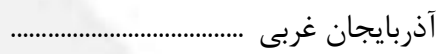 \\
\hline et & Tr & rq & pq & $\Lambda F$ & $1 \cdot e^{r}$ & 199 & TFE & اردبيل ................................. \\
\hline 91 & vq & $1 f$. & 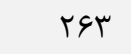 & $f \cdot q$ & $\Delta / F$ & $\vee \Delta \Lambda$ & $1 \cdot 19$ & اصفهان ................. \\
\hline VT & $\wedge \vee$ & lrq & trR & $r \cdot r$ & Frd & $\Delta T G$ & 999 & 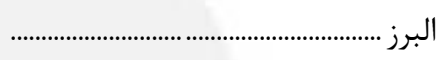 \\
\hline$r \cdot$ & 11 & YI & 19 & ret & $\Delta \cdot$ & 99 & itr & 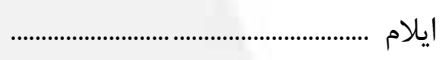 \\
\hline ro & 11 & 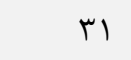 & Af & 111 & Ifd & $r \Delta \mid$ & $f \backslash 1$ & بوشهر ............ \\
\hline pqu & $\Delta \cdots$ & VFq & ITVE & 1991 & $191 \mathrm{~F}$ & TFTt & Dגזr & تهران ............... \\
\hline 19 & 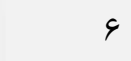 & 19 & f. & 9 . & r & س & $r \cdot r$ & جهارمحال و بختيارى .. \\
\hline q. & rq & r^ & 94 & IfD & $r \cdot 1$ & rVt & r^d & خراسان جنوبى ............. \\
\hline 190 & 191 & Trt & FVq & Vr. & $\Lambda \wedge$ & 148. & אוr & خراسان رضوى ........... \\
\hline 10 & ro & $r \cdot$ & r & $1 \cdot 1$ & $1 \cdot 1$ & 199 & rAT & خراسان شمالى ................ \\
\hline$\Lambda \Delta$ & re & gr & lar & rqG & rV & qrV & MAr & خوزستان ....... \\
\hline$r$. & 1 . & 10 & 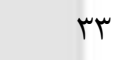 & (i) & vi & או & $1 \Delta V$ & زنجان ................... \\
\hline ro & Tt & ra & q & 91 & ITA & 19. & trt & 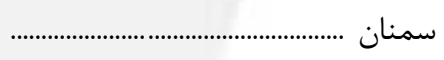 \\
\hline Va & QI & $\wedge \Lambda$ & IDF & trt & rit & pqp & $V \Delta \varphi$ & سيستان و بلوجٍ \\
\hline $1 r q$ & QV & $1 r 9$ & TQF & fQV & $\Delta V V$ & $q 4$. & $\mid r \cdot r$ & 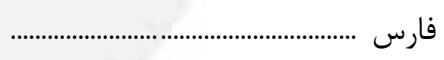 \\
\hline rی & f. & FV & $1 \cdot r$ & ו 1 & $r \cdot \cdot$ & rtr & صاس & قزوين .................. \\
\hline my & r & Fr & 11 & 94 & ITS & $|V|$ & rQT & قم .................... \\
\hline$q V$ & rq & $\forall \wedge$ & 111 & $1 \wedge V$ & rta & fir & $\varphi \Delta \varphi$ & كردستان ................ \\
\hline$\pi$ & 99 & ITV & TMF & rV & pq9 & GQH & 911 & 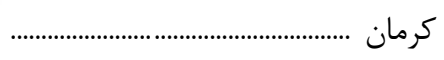 \\
\hline$\Delta \varphi$ & re & is & IT. & 109 & $1 \wedge 1$ & (II & pqp & 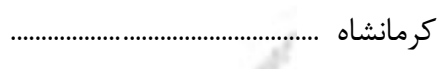 \\
\hline 91 & $i \Delta$ & $g f$ & או1 & (tre & rre & prq & gro & كهخيلويه و بويراحمد ... \\
\hline ro & rq & $\Delta \wedge$ & 111 & IV. & $r \cdot r$ & 419 & $V \Delta V$ & 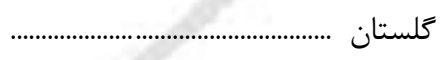 \\
\hline س & vi & $1 \cdot t$ & TIV & و & $\uparrow \wedge$. & $V \cdot r$ & $9 \wedge \mathrm{V}$ & كيلان .................... \\
\hline$\Delta \cdot$ & re & r & $\vee v$ & lat & 199 & $\Delta \cdot \Lambda$ & f\&9 & لرستان ........... \\
\hline ITS & 9 . & 10 & $r \Delta \varphi$ & $F \Delta l$ & $q 4$. & 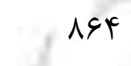 & 1191 & مازندران ........ \\
\hline DI & Tt & qH & vq & IfF & 194 & re. & mFA & 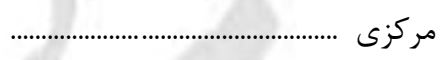 \\
\hline$\Delta 9$ & Tr & 91 & 111 & 191 & rrq & מזr & $\Delta T \Lambda$ & 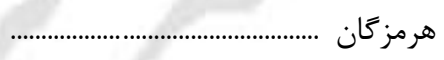 \\
\hline r & if & rt & FF & १४ & מזו & $r \cdot r$ & mFA & 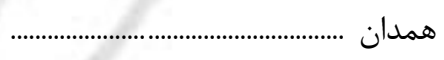 \\
\hline r & 11 & rq & VI & $\wedge \Delta$ & IFV & $r \cdot r$ & rAl & 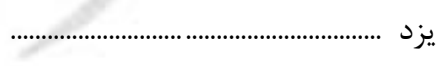 \\
\hline$\cdot$ & 1 & r & f & $\Delta$ & $\wedge$ & $\Lambda$ & it & 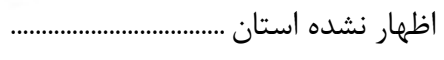 \\
\hline DI & pq & gr & $1 \cdots$ & 191 & rVV & rVe & 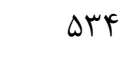 & 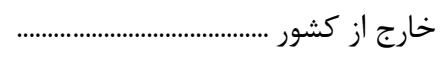 \\
\hline TF & it & 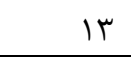 & 19 & rr & fF & Vq & $\wedge 1$ & اظهار نشده محل اقامت قبلى ............ \\
\hline
\end{tabular}


V - - - مهاجران وارد شده طى ه سال كذشته بر حسب جنس، استان محل اقامت قبلى و سن (بر اساس آخرين جابجايى انجـام (نقاط روستايى)

\begin{tabular}{|c|c|c|c|c|c|c|c|c|c|}
\hline 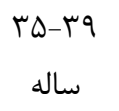 & 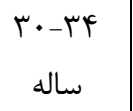 & 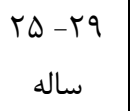 & $\begin{array}{l}\text { W.-YF } \\
\text { ساله }\end{array}$ & $\begin{array}{l}19-19 \\
10\end{array}$ & ساله & $\begin{array}{l}\Delta-9 \\
0 \text { ساله }\end{array}$ & ساله & جمع ( ) جم & محل اقامت و استان \\
\hline req. & $f 1 \ldots q$ & $\Delta T \cdot F F$ & $\Delta r \cdot \Delta r$ & $r 1.81$ & $r F \cdot r V$ & rvaqq & rIDEF & rralvr & زن.............................. \\
\hline$q \cdot \Delta$ & $|r|$. & I9V9 & $\mid 914$ & 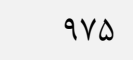 & GTr & VVA & $\Delta F_{1}$ & $1 \cdots \wedge V$ & آذربايجان شرقى .............. \\
\hline IrAS & rirq & ThIT & rar. & $|9 V|$ & $9 \wedge \Delta$ & $|F T|$ & $1 \cdot r q$ & $I V T \Delta Q$ & 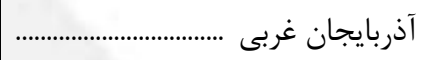 \\
\hline MIV & DI & $\Lambda \Delta T$ & $1 \cdot 9$ & DrT & ris & TrI & ria & Frqq & 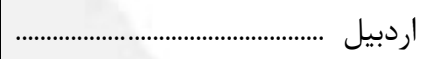 \\
\hline 119. & $M \cdot r$ & rTSD & IMAT & $1 \cdot \Lambda \cdot$ & $\Delta r$. & $11 f \Delta$ & ATF & Irrq9 & 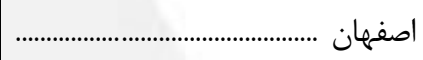 \\
\hline ver & 1199 & 1199 & १९४ & $\Delta 9 \Delta$ & DIV & VTr & kq. & ATrK & 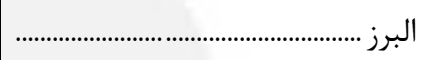 \\
\hline $14 q$ & rAD & ए१९ & m & $1 \cdot 1$ & १) & Irk & $1 \cdot 4$ & IAro & ايلام ................... \\
\hline ra. & $v r$. & $9 \Delta F$ & $\wedge \notin 9$ & Fil & fiv & DTV & FTr & $\Delta \Delta \cdot 1$ & بوشهر ............. \\
\hline rVVr & $\Delta \cdot \wedge 1$ & $\Delta \cdot r V$ & rqu & $r \Delta \cdot \Delta$ & $r \Delta \Lambda 1$ & ( ) & rFqq & TAtr. & تهران ................ \\
\hline$r \cdot$. & $r \Delta q$ & $\Delta Q F$ & DFT & pre & tre & TYG & 199 & rTrq & جهارمحال و بختيارى . \\
\hline TIT & ४९१ & $9 \vee \wedge$ & q ४ & NTS & $\Delta \varphi q$ & 999 & DIT & $9 \wedge 91$ & خراسان جنوبى . \\
\hline rVqG & FTVT & 0.19 & kqfF & rTGG & TVAT & (9צ & rब90 & $M F \cdot 9 D$ & خراسان رضوى .... \\
\hline 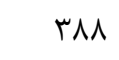 & $9 \cdot 0$ & $V \notin V$ & १९५ & Vru & gQT & Fal & $k \cdot 1$ & $\Delta \Delta V T$ & خراسان شمالى ........ \\
\hline$\vee \wedge \Delta$ & IrT. & IVQV & 119. & q४. & VTV & $\wedge \vee$. & 999 & 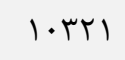 & خوزستان ............. \\
\hline rQS & 419 & g^V & 110 & qVe & THt & $r \cdot V$ & 194 & FTrt & زنجان ................ \\
\hline$T \& V$ & fir & 190 & rar & TrA & rTq & $r \cdot \varphi$ & 199 & D. & 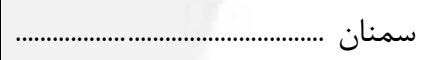 \\
\hline$\Delta F r$ & ITAT & $\operatorname{lQg} \Lambda$ & 1499 & ITIV & ITTF & $|\Delta F|$ & $119 \mathrm{~V}$ & $11 \mathrm{MM}$ & سيستان و بلوجستان \\
\hline IFFa & TrAV & $r \cdot r \Delta$ & rT.r & 1099 & $\mid r q 1$ & ITFA & 1119 & IVqDF & فارس ................................ \\
\hline rघ9 & fqv & 911 & $\wedge \notin q$ & $\Delta \vee Q$ & $r \cdot r$ & $r \cdot \Delta$ & $r \cdot V$ & FVTV & 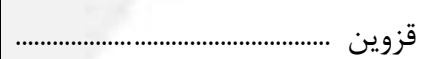 \\
\hline שTr & .9 & 0.9 & rr. & ra & TVG & rof & r90 & rols & قم ........................... \\
\hline$\checkmark \wedge \Lambda$ & Ifir & THYA & Tht & $11 r \wedge$ & Var & $\Delta T^{\prime}$ & घ). & llQT. & 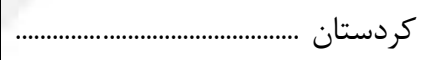 \\
\hline 1.94 & 1949 & 119. & $|\wedge 9|$ & 1114 & $1 \cdot r 4$ & ITET & ヘזڤ & IrIs9 & 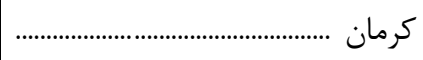 \\
\hline $4 q$. & 191 & IreV & $|r \wedge|$ & $\Delta \wedge \vee$ & rqA & $f \Delta F$ & rیl & $9 \wedge 19$ & كرمانشاه ................... \\
\hline vir & $1 \cdot \wedge V$ & IFFT & $M \cdot r$ & $V M r$ & GQT & $q \cdot r$ & ver & ^яץ. & كهيكيلويه \\
\hline $1 \cdot \Lambda$ & $11 \cdot 9$ & rAvi & rTAq & 1941 & 1109 & ITHA & $1 \cdot 11$ & 19.94 & Fلستان .... \\
\hline Iros & 1901 & $r r \cdot \Lambda$ & TrMA & ITOV & NAT & 1.14 & VTD & lfet. & عيلان ..... \\
\hline 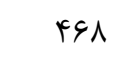 & VeF & $11 \mathrm{Fr}$ & l 491 & $\Delta \wedge{ }^{r}$ & rar & Frl & FrF & GDFD & لرستان ..... \\
\hline IDFV & rब१Q & $r \cdot r r$ & 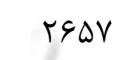 & liskF & $11 \mathrm{Vr}$ & ITEY & $\Lambda \Delta F$ & IVqVT & مازندران ... \\
\hline rAv & 1 & 99. & $99 V$ & $\Delta 11$ & MI & $r \Delta F$ & TY. & eris & 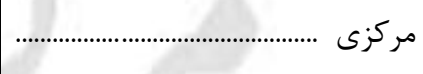 \\
\hline Gar & & IrAv & 191. & ITAT & VyF & VVr & $99 V$ & qrVT & 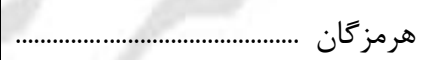 \\
\hline per & マ१ & 1.rv & (rTE & $\lambda \cdot r$ & G. & rar & r. & 910. & همدان ............. \\
\hline$r \cdot q$ & 191 & DIf & roq & $r \Delta \Lambda$ & rat & r r & $r \cdot \Delta$ & (4) & يزد .................................... \\
\hline r & V & r & ir & $\Delta$ & v & 11 & 9 & 49 & 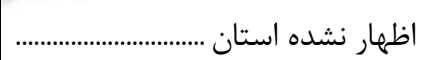 \\
\hline ع th & rll & $\Delta \Delta V$ & VYF & fer & rVT & 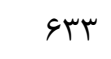 & kqr & RTt & 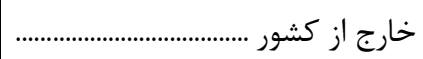 \\
\hline$\wedge$. & vV & $1 \ldots$ & $\wedge \vee$ & VQ & irs & 114 & pq & 948 & اظهار نشده محل اقامت قبلى ........ \\
\hline
\end{tabular}


V - 1 - مهاجران وارد شده طى ه سال كذشته بر حسب جنس، استان محل اقامت قبلى و سن (بر اساس آخرين جابجايى انجـام (نقاط روستايى)

شده)(دنباله)

\begin{tabular}{|c|c|c|c|c|c|c|c|c|}
\hline 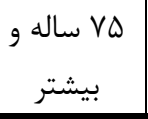 & $\begin{array}{l}V \cdot-V Y \\
\text { ساله }\end{array}$ & $\begin{array}{l}9 \Delta-99 \\
\text { ساله }\end{array}$ & $\begin{array}{c}9 \cdot-9 f \\
\text { ساله } \\
\end{array}$ & $\begin{array}{c}\Delta \Delta-\Delta 9 \\
\text { ساله }\end{array}$ & $\begin{array}{c}\Delta \cdot-\Delta F \\
\text { ساله }\end{array}$ & $\begin{array}{l}F \Delta-F q \\
\text { ساله }\end{array}$ & $\begin{array}{l}\text { س._fy } \\
\text { ساله }\end{array}$ & محل اقامت قو استان \\
\hline$r+r$ & Irar & rfif & f... & 9419 & Arr. & $119 \Delta V$ & 19809 & 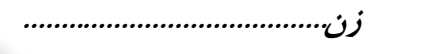 \\
\hline VA & $\Delta V$ & $\wedge \wedge$ & 111 & IVV & r19 & rve & $\Delta \varphi \varphi$ & 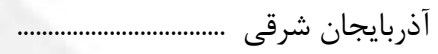 \\
\hline Va & iv & 94 & 111 & 199 & ५१९ & fq. & vi. & 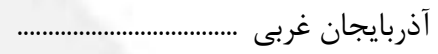 \\
\hline r人 & TF & $r \wedge$ & ra & $\Delta r$ & 91 & 119 & 199 & 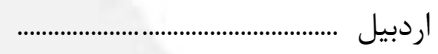 \\
\hline$\Delta F$ & $\forall \wedge$ & 94 & 19. & rq1 & ( ) & DIV & $v \cdot r$ & اصفهان ........... \\
\hline$\Delta 9$ & $\Delta 9$ & $\wedge \vee$ & IVD & $r \Delta \cdot$ & rqu & rqv & 019 & 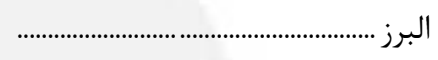 \\
\hline ir & V & it & rq & rt & Fr & is & 94 & 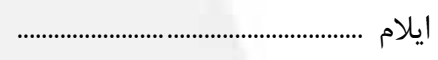 \\
\hline r & $r \cdot$ & $f$. & $\Delta \varphi$ & $9 \wedge$ & १V & IVF & (צr & بوشهر .......... \\
\hline 1 1 & r.. & $\Delta \cdot r$ & 19. & irva & $1 V \cdot 4$ & $19 \cdot r$ & TFYI & تهران ................... \\
\hline 10 & V & $r \cdot$ & IV & r. & Gr & 94 & IFT & جهارمحال و بختيارى ... \\
\hline qV & 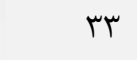 & fr & VQ & Ir & 190 & $r \Delta V$ & r.r & خراسان جنوبح \\
\hline$r \cdot q$ & $|r|$ & $r \cdot r$ & 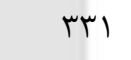 & sto & Vrq & $1 \cdot \Delta \Lambda$ & 1991 & خراسان رضوى .......... \\
\hline$r T$ & 19 & $r \Delta$ & rq & 99 & 11 & Irv & rrq & خراسان شمالى .......... \\
\hline$\Delta \cdot$ & rv & $\vee \wedge$ & 118 & 109 & $r \cdot \Delta$ & rq1 & $F \Delta q$ & خوزستان ....... \\
\hline FV & 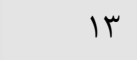 & IV & TF & FV & FV & $\Lambda \Lambda$ & 109 & 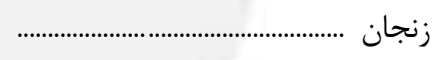 \\
\hline TY & 11 & 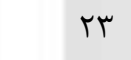 & pr & NT & $1 \cdot r$ & 199 & $\mid \Delta \Lambda$ & 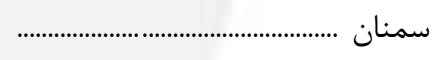 \\
\hline 4. & rq & $\Delta 9$ & $9 \vee$ & 199 & reg & 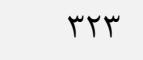 & $4 q 1$ & سيستان و بلوج \\
\hline$\wedge \varepsilon$ & $\Delta \Delta$ & 110 & $I V \wedge$ & rvq & ras & $\Delta 9 \Delta$ & NFT & 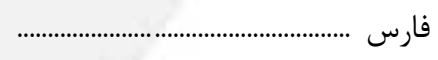 \\
\hline (4) & r. & $\Delta \varphi$ & 99 & $1 \cdot 9$ & 19 & rI9 & rat & 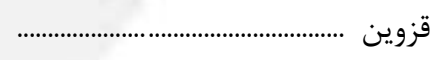 \\
\hline ra & 11 & rq & $9 \Delta$ & 11 & 111 - - & 119 & 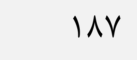 & قم ........................ \\
\hline$\Delta T$ & fq & $\wedge$ & 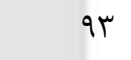 & 111 & $r \cdot V$ & MIF & $\Delta \cdot \Delta$ & كردستان. ........ \\
\hline r & $\Delta F$ & $1 \cdot r$ & $r \cdot V$ & Trt & $F \cdot r$ & $\Delta \vee \wedge$ & VMr & 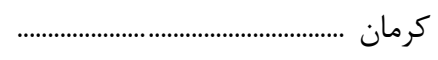 \\
\hline$\uparrow \wedge$ & r & 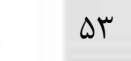 & $9 \wedge$ & IrF & 109 & tht & MFt & كرمانشاه ......... \\
\hline$\vee \Delta$ & r & $\Delta 9$ & 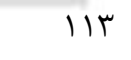 & 191 & rit & $r \cdot \xi$ & $\Delta / \Delta$ & كهخيلويه و بويراحمد ... \\
\hline fr & 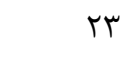 & vi & 9 . & $14 q$ & TFT & rq. & 909 & كلستان .......... \\
\hline $\mid \Delta F$ & st & $1 \cdot r$ & 194 & ras & FIT & Grt & $\wedge \Delta 9$ & عيلان ........ \\
\hline id & 11 & my & 91 & $\Lambda \Lambda$ & 119 & TIT & $r \cdot q$ & لرستان .... \\
\hline اسו & Vy & IrV & ris & mis & D & $1 F q$ & $1 \cdot V r$ & مازندران ..... \\
\hline $9 \Lambda$ & ry & rV & $V^{\mu}$ & $1 \cdot 9$ & $I F \Delta$ & $r \cdot$ & rAV & 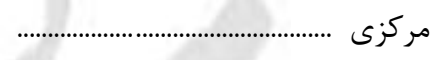 \\
\hline \&q & 10 & (ب & V. & $1 \cdot 0$ & IMF & tit & rvq & 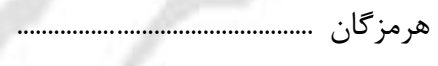 \\
\hline ry & 10 & 19 & (i) & $\Delta \varphi$ & $\wedge 1$ & $10 \Delta$ & reg & 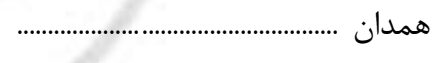 \\
\hline re & 19 & $r q$ & (i) & Ve & 110 & IrF & INr & 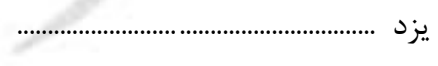 \\
\hline - & . & • & & r & r & 1 & r & 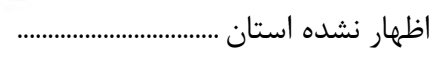 \\
\hline 11 & 11 & rV & 9) & $\Delta 1$ & $1 \cdot 9$ & ITF & lfF & 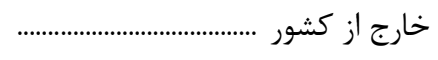 \\
\hline TV & 11 & IV & re & ret & rq & $\psi_{1}$ & $\Delta \Delta$ & اظهار نشده محل اقامت قبلى .......... \\
\hline
\end{tabular}


^ - 1 - مهاجران وارد شده طى ه سال كذشته بر حسب جنس، استان محل اقامت قبلى و فعلى (بر اساس آخرين جابجايى (كل)

\begin{tabular}{|c|c|c|c|c|c|c|}
\hline \multicolumn{6}{|c|}{ استان محل اقامت فعلى } & \multirow{2}{*}{ محل اقامت قبلى استان } \\
\hline 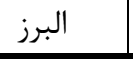 & اصفهان & 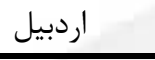 & آذربايجان غربى & آذربايجان شرقى & جمع - ا & \\
\hline$r q \cdot k q \mu$ & ragraf & $\Delta \varepsilon|f|$ & |raral & IAFTYA & $k r \cdot .911$ & 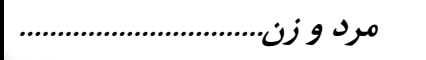 \\
\hline vets & $1.9 \mathrm{~V}$ & rvqr & $\| A Y \mid$ & 1.rarf & IVIA9T & 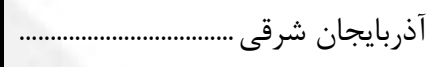 \\
\hline TEוT & $v \cdot 1$ & $r \cdot \Delta l$ & 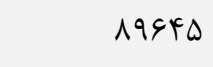 & 10191 & IrVqDF & 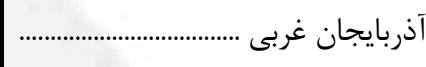 \\
\hline FTDI & $r \Delta s$ & miles & $19 \wedge \mathrm{V}$ & rAMA & $V 9.91$ & 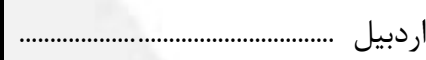 \\
\hline$\forall \& \wedge d$ & $|G T| F A$ & TrV & $\Delta q Y$ & q७. & TEDTAM & اصفهان ............................... \\
\hline EqK.r & TEM & $1 r \cdot \Delta$ & 1199 & $r \Delta \cdot q$ & 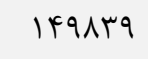 & 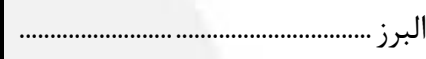 \\
\hline 1014 & $V * 1$ & $4 q$ & ITV & Ire & $k \cdot r \cdot k$ & ايلام ................... \\
\hline Var & TVOV & $11 \mathrm{~V}$ & riv & rq. & 99101 & بوشهر ...................... \\
\hline 1919V & INKGF & QTFV & GDTD & Ifrat & ( & 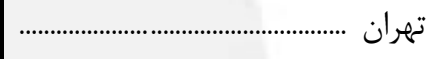 \\
\hline 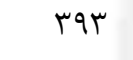 & T.TrG & rI & $1 \cdots$ & v9 & GヘIrब & 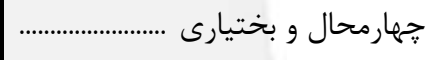 \\
\hline pqv & 9ヘr & $r \cdot$ & 99 & $\Delta 1$ & s4VI9 & 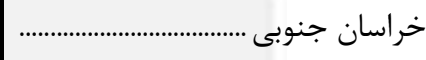 \\
\hline ret人 & $r \cdot \mu r$ & r人q & VYq & 941 & $r \cdot 19 \Delta F$ & 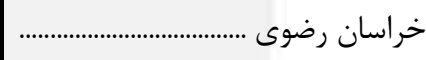 \\
\hline IDTV & fef & tt & $\Lambda r$ & 114 & gFvif & 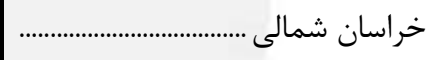 \\
\hline 11811 & $r q \Lambda \cdot v$ & TFD & vrv & Var & $T F \cdot \Lambda \Lambda \varphi$ & 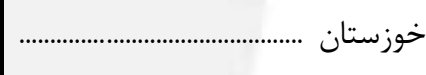 \\
\hline$\Delta T V$. & kq1 & Frs & $V \cdot r$ & 111 & $919 \vee 9$ & 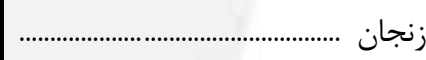 \\
\hline 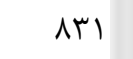 & EVD & $\wedge \vee$ & $19 \mathrm{~V}$ & 191 & $r \cdot \Delta r$ & 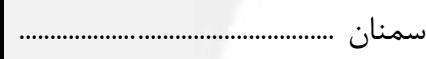 \\
\hline (t) & r\&Q. & Ire & $i \Delta V$ & TTE & IITYAF & سيستان و بلوجستان ......... \\
\hline$r \mid \Delta \Lambda$ & $\Lambda \cdot r q$ & INT & 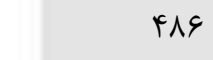 & $\Delta F \Delta$ & TEQFIT & 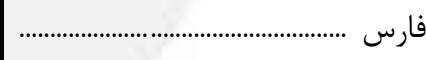 \\
\hline GqAF & $\Delta V \Delta$ & 194 & 99. & $9 \vee 9$ & QFDFA & قزوين .................................... \\
\hline (1) & rquF & reT & $\Delta \varphi$. & $1 \cdot 4 \lambda$ & FATIF & 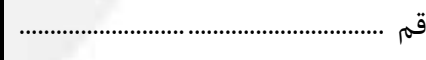 \\
\hline FqTI & $91 \%$ & $r \Delta q$ & एवाद & 1Ars & ITHGM & كردستان ............................................. \\
\hline $1 F \cdot V$ & TVID & Ira & rrq & r. & $11 r 9 \cdot \Delta$ & 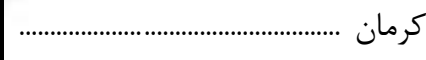 \\
\hline$|4| 49$ & TATt & MIS & $\lambda \uparrow$. & $\Delta T^{\prime}$ & $1 r \wedge q$. & 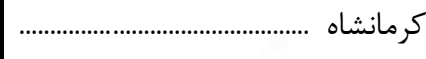 \\
\hline Trt & rqFV & $r v$ & vi & et & GDVAV & كهيلويه و بويراحمد . \\
\hline IV^9 & VAr & Irr & rFA & rAY & $1.911 \mathrm{~F}$ & 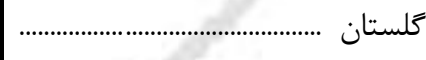 \\
\hline VATF & $10 \cdot 9$ & $r \cdot 94$ & $\Delta r \mathrm{~V}$ & AGT & IFrVDq & 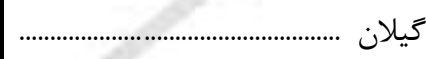 \\
\hline $919 V$ & $V \cdot r F$ & TIF & T\& & $19 \pi$ & $|r| \Lambda N \mid$ & لرستان .............. \\
\hline Fr. 1 & 1994 & $\Lambda T \Delta$ & f\&4 & $\Delta \varphi$. & IrefVa & 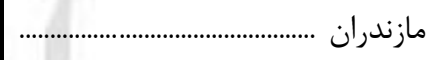 \\
\hline ryte & 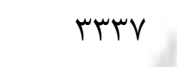 & 91 & r৭9 & rme & 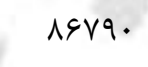 & 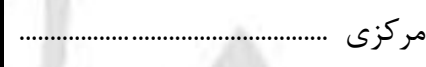 \\
\hline $10 \cdot F$ & TYFV & 149 & rVe & grq & qQTA. & هرمزكان ............................................ \\
\hline qVYG & 1NK4 & זr & FVF & F99 & $111 \mathrm{Vr}$. & همدان ............................................ \\
\hline 1419 & $r \Lambda \cdot q$ & qท & 19 & IAV & FHFI9 & 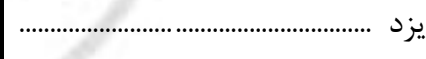 \\
\hline py & $r \Delta \Lambda$ & $1 \cdot$ & 19 & 114 & reQs & اظهار نشده استان ............................... \\
\hline 9119 & NHrF & IAV & $\Lambda r$. & qMI & $11 \cdot 1 r q$ & 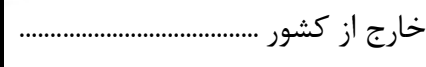 \\
\hline rTq & $\Delta F_{1}$ & 94 & FTA & $v \cdot r$ & ITFA. & اظهار نشده محل اقامت قبلى ........... \\
\hline
\end{tabular}


^ - 1 - مهاجران وارد شده طى ه سال كذشته بر حسب جنس، استان محل اقامت قبلى و فعلى(بر اساس آخرين جابجايى (كل)

انجام شده) (دنباله)

\begin{tabular}{|c|c|c|c|c|c|}
\hline \multicolumn{5}{|c|}{ استان محل اقامت فعلى } & \multirow{2}{*}{ محل اقامت قبلى و استان } \\
\hline خراسان جنوبى & و تجهارمحال & ت ت تهران & بوشهر & 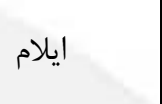 & \\
\hline srrea & fV|ql & AFrata & Arrul & ralak & 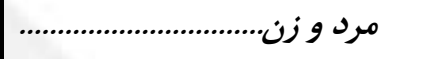 \\
\hline 149 & 99 & TEGTF & $4 \cdot 1$ & $1 \wedge \cdot$ & آذربايجان شرقى ................................................. \\
\hline$q 4$ & r. & $119 \cdot r$ & FrA & $r \cdot 1$ & آذربايجان غربى ............................................ \\
\hline er & re & 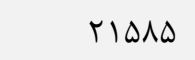 & ivr & iv & 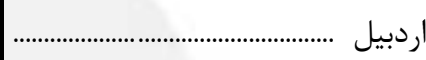 \\
\hline 1.9. & $\wedge \& \mid \vee$ & rVarq & rArq & $\Delta \cdot r$ & 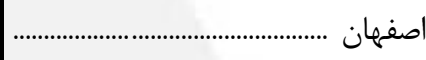 \\
\hline$f \cdot F$ & 11. & $\Delta \cdot \wedge \wedge \Delta$ & mו & rYA & 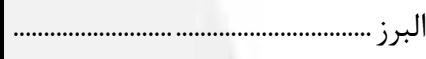 \\
\hline rl & $\wedge r$ & $\Lambda \Delta \cdot 1$ & TFV & IVTrA & 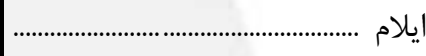 \\
\hline $1 \Delta \Delta$ & FAF & rFAT & rATrT & IKF & بوشهر .......................... \\
\hline 191. & $\wedge \Delta \Lambda$ & TVYG99 & 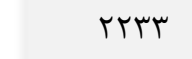 & $19 \cdot v$ & تهران ............................... \\
\hline 11. & rq५वा & $r V \cdot \Delta$ & THET & IfT & 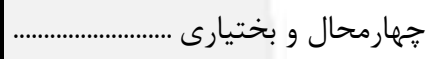 \\
\hline rMYDQ & r & rquF & $1 \cdot{ }^{4}$ & ir & 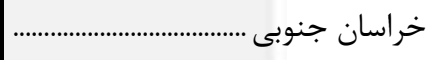 \\
\hline IrFQA & IVV & MrFIF & $q 4$. & $1 r \Delta$ & 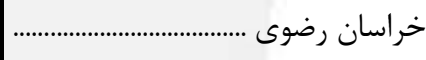 \\
\hline 1119 & rl & IIVYF & $|V|$ & If & 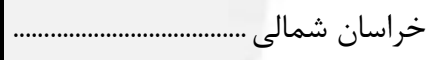 \\
\hline rVr & Tra. & tTETA & 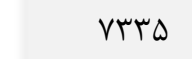 & $r+\Lambda$ & 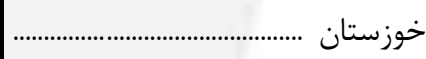 \\
\hline r & TF & $1 \cdot \Lambda T 1$ & \& & 4. & زنجان .................................. \\
\hline rir & EQ & VVYF & $v \Delta$ & $r \wedge$ & 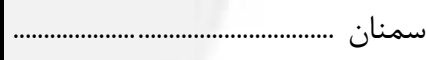 \\
\hline FETT & $r \cdot \cdot$ & $\Delta \Delta V \Lambda$ & $q 4 \Delta$ & rv & 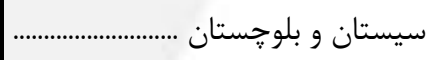 \\
\hline DrT & 919 & ITVRY & $19 \cdot 14$ & riv & 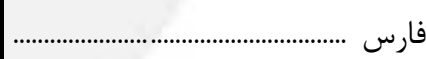 \\
\hline$\wedge 9$ & (i) & $119 \vee 9$ & $\wedge \vee$ & $\Delta V$ & قزوين .................................... \\
\hline 194 & rVD & ITITK & FAF & 199 & 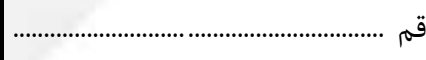 \\
\hline rq & rv & IEFTY & rrq & $\Delta \cdot \Delta$ & 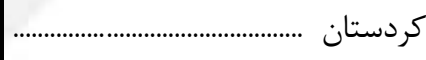 \\
\hline$\wedge \vee r$ & $1 \wedge 9$ & 9N1ז & 411 & ev & 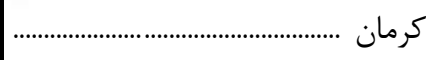 \\
\hline$\lambda T$ & 1.9 & TADTI & $4 \& 9$ & $r \cdot r$ & 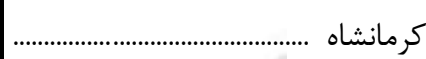 \\
\hline$\Delta V$ & $\Delta \wedge \Delta$ & tITE & TVYG & 91 & كهيَيلويه و بويراحمد ...... \\
\hline $1 \cdot \Delta F$ & $\vee \cdot$ & $r \cdot r \Delta \Lambda$ & $1 \pi \Delta$ & $\Delta \wedge$ & 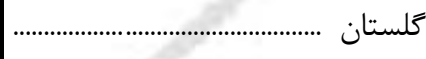 \\
\hline $1 \cdot r$ & 91 & TFF. F & $\Delta 9 \Delta$ & 110 & 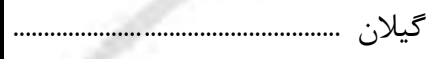 \\
\hline vV & 101 & fllrs & v9० & lisk & 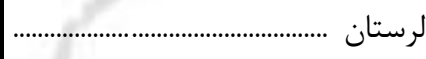 \\
\hline 110 & IfT & rIASV & r. & $11 \mathrm{~V}$ & 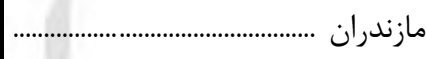 \\
\hline 90 & 10 & rr人⿻l & r4. & rl. & 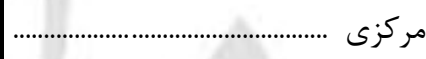 \\
\hline FrA & 491 & $V F \cdot V$ & $1 F \Delta q$ & rI & هرمز \\
\hline 111 & 19 & MMGA & VVA & rیl & همدان ................................................... \\
\hline D19 & MYF & FAN & 190 & $r v$ & 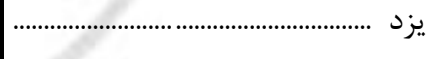 \\
\hline r & r & I. ra & 119 & $r$ & 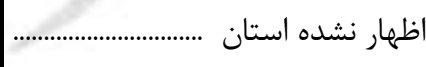 \\
\hline$v \wedge$ & rle & 0119. & $\varphi \varphi \cdot \Delta$ & q & 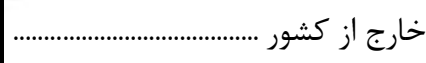 \\
\hline ऍ & $v^{e}$ & $r \cdot v q$ & 4र9 & $\Delta \Delta$ & اظهار نشده محل اقامت قبلى ........... \\
\hline
\end{tabular}


^ - 1 - مهاجران وارد شده طى ه سال كذشته بر حسب جنس، استان محل اقامت قبلى و فعلى (بر اساس آخرين جابجايى (كل)

انجامشده) (دنباله)

\begin{tabular}{|c|c|c|c|c|c|c|}
\hline \multicolumn{6}{|c|}{ استان محل اقامت فعلى } & \multirow{2}{*}{ محل اقامت قبلى و استان } \\
\hline | سيستان و بلوجستان & 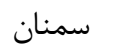 & 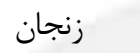 & 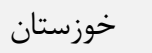 & خراسان شمالى & خراسان رضوى & \\
\hline arrar & VIFEA & $\Delta \Delta V q \varepsilon$ & IeIVIa & $<q 9 q 9$ & rIFADq & مرد و زن.................... \\
\hline 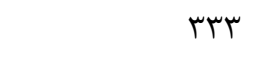 & rt. & IVIS & $9 \cdot \Delta$ & 99 & $11 \cdot 1$ & 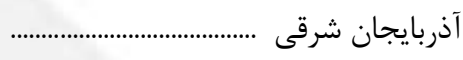 \\
\hline 19. & $\Delta F$. & IQT. & fre & vi & $\Delta \Delta \varphi$ & 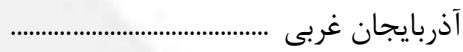 \\
\hline $1 \cdot 1$ & r & s49 & r & fF & rAl & |ربيل ................................... \\
\hline ITYF & $r|Q|$ & rev & VquV & TrI & $r \varepsilon \cdot v$ & اصفهان ...................... \\
\hline TrF & $r \cdot v e$ & 1. & $|\Lambda| F$ & $\Delta F q$ & TQF. & 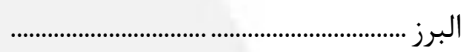 \\
\hline$i \Delta$ & 9ाr & VT & rQIA & $r$. & 119 & ايلام ....................................... \\
\hline FVF & 0.9 & 94 & rig. & 99 & ve. & بوشهر ........... \\
\hline I $९ 90$ & $I V \Delta \Delta \varphi$ & sтq. & $\Delta F A F$ & FFAV & TITHI & تهران ............................... \\
\hline 194 & FEV & 94 & r & $\Delta \varphi$ & rel & جهارمحال و بختيارى .......... \\
\hline$r \Delta \cdot V$ & ( & 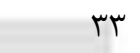 & $\wedge$. & pqf & IVTDA & 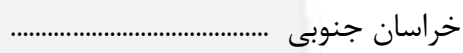 \\
\hline GTAF & $v \cdot v q$ & ret & $1 r \cdot r$ & १९५८ & 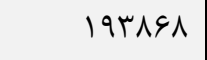 & 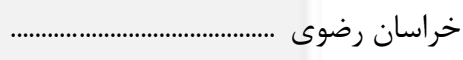 \\
\hline$\Delta \cdot r$ & IFAV & $\wedge 4$ & 118 & $r V V \cdot r$ & ITATT & خراسان شمالى ............ \\
\hline 918 & $\wedge 99$ & rVe & $1 . \Delta r q \Delta$ & $r \Delta \Lambda$ & DFTq & 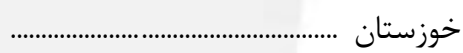 \\
\hline st & ra. & mifis & $14 q$ & rt & mFl & 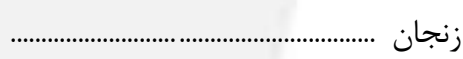 \\
\hline rir & IVET & $|r|$ & irq & 999 & $r y \cdot r$ & 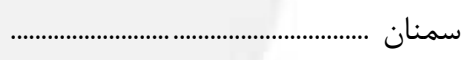 \\
\hline DTEQV & lif. & $|r|$ & vr & ז9 & $\mid$ ISA| & سيستان و بلوجستان ...... \\
\hline$r \cdot \Delta l$ & 991 & זrז & frva & TFY & $t \cdot r t$ & فارس ................................... \\
\hline$\Lambda r$ & Fへ૬ & $r \wedge \cdot$. & 191 & DI & $\Delta V$. & 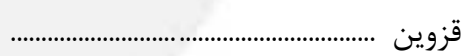 \\
\hline 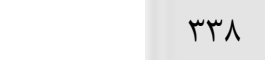 & $q \cdot r$ & & 1199 & 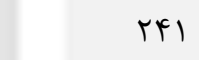 & $11 \cdot 9$ & 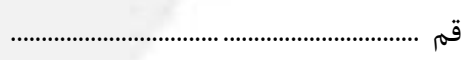 \\
\hline$\lambda F^{\mathrm{F}}$ & rAr & IVFa & $\Delta \wedge \Delta$ & $V F$ & rVq & 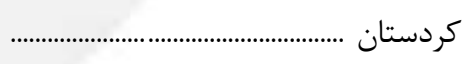 \\
\hline TEFF & Tr & $q$. & $q \cdot r$ & rma & raIt & 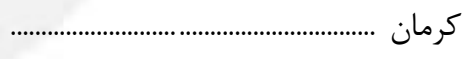 \\
\hline 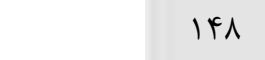 & $\Delta \Delta r$ & 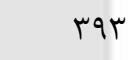 & IVIT & $\checkmark \cdot$ & $V \Delta I$ & 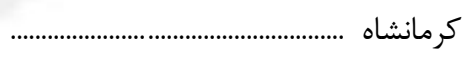 \\
\hline 119 & 190 & fF & fqri & tr & 149 & كهيليلويه و بويراحمد ......... \\
\hline 1918 & Giv. & IFT & $r \cdot v$ & $\mid \wedge ब V$ & $\Delta 1 \cdot r$ & 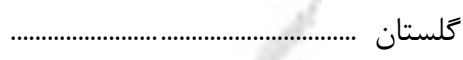 \\
\hline$\Delta 1$. & DFT & $1 \cdot 11$ & 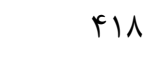 & 191 & $|\Delta r|$ & 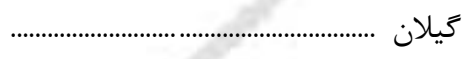 \\
\hline$r \cdot$. & $\Delta V^{\prime}$ & rir & $v \cdot 94$ & GT & $\Delta V \nabla$ & لرستان ........ \\
\hline $9 \Delta V$ & एя१९ & EED & $\Delta \vee q$ & १९४ & rVre & مازندران ..................... \\
\hline rrt & ve. & tTV & 1199 & VA & 919 & 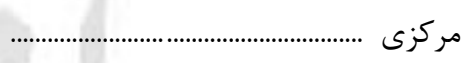 \\
\hline IVTF & r^s & 94 & ITFE & 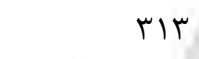 & reYA & 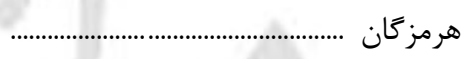 \\
\hline rri & $\{\wedge 1$ & far & IQVT & q. & $\Delta r q$ & همدان ............................ \\
\hline «q. & rQq & $\Delta \Lambda$ & 11 . & $\wedge$. & $19 \Delta r$ & 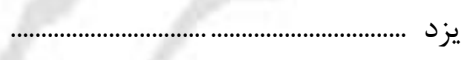 \\
\hline Gr & זוץ & 19 & 118 & v & rघq & اظهار نشده استان ........... \\
\hline NQT & rqf & rqV & IGTF & 1.1 & VVG. & 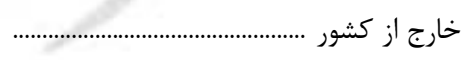 \\
\hline 191. & GT & ry & $q u \mathrm{~V}$ & If. & $\Lambda \mathrm{s}$ & اظهار نشده محل اقامت قبلى ................ \\
\hline
\end{tabular}


^ - 1 - مهاجران وارد شده طى ه سال كذشته بر حسب جنس، استان محل اقامت قبلى و فعلى (بر اساس آخرين جابجايى (كل)

انجام شده) (دنباله)

\begin{tabular}{|c|c|c|c|c|c|}
\hline \multicolumn{5}{|c|}{ استان محل اقامت فعلى } & \multirow{2}{*}{ محل اقامت قبلى واستان } \\
\hline 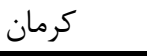 & 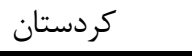 & قم & قزوين & فارس & \\
\hline$q F q G F$ & IITral & rrair & qser. & rariva & مرد و زن............. \\
\hline$r \cdot$. & $1 \wedge \Delta \cdot$ & $r \cdot r$ & $10 \cdot 9$ & אז & 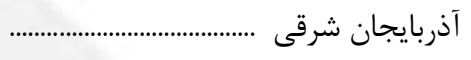 \\
\hline tru & FET. & $\wedge \vee \&$ & $1 \cdot 11$ & $\Delta \cdot \Lambda$ & آذربايجان غربى ............... \\
\hline $1 \wedge 9$ & riv & FAr & fiv & rq1 & 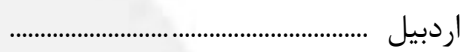 \\
\hline $11 \cdot 0$ & VIr & $0.9 F$ & ब9 & gFIf & اصفهان ............... \\
\hline$\Delta G Y$ & 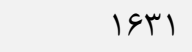 & r\^q & מTH & $9 \wedge$. & 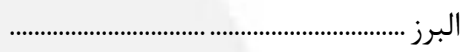 \\
\hline VV & $\vee q$. & $\Delta \Delta F$ & $1 \wedge \Delta$ & rtq & 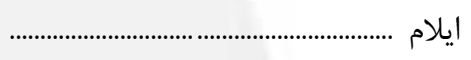 \\
\hline FAF & 14. & $\checkmark M$ & 90 & $1 \cdot \Delta T V$ & بوشهر ................... \\
\hline T\&\& & ArVF & ITFT & $95 \cdot 4$ & $v \cdot 11$ & 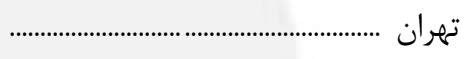 \\
\hline rघ9 & $11 \%$ & 901 & $9 \vee$ & $|f 8|$ & 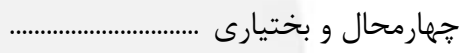 \\
\hline Tt & 11 & FAF & is & $r \Delta \Delta$ & 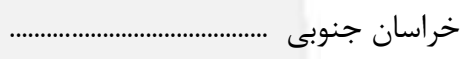 \\
\hline If\& & זr & 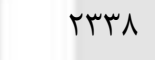 & G.r & lat9 & 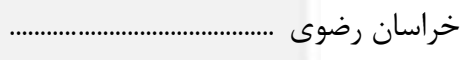 \\
\hline rtq & rq & rTS & 111 & $1 \wedge F$ & خراسان شمالى .......... \\
\hline $11 \wedge \mathrm{V}$ & 1111 & DVGT & $9 \wedge 1$ & qVTF & 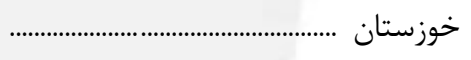 \\
\hline 94 & irkt & $r \cdots \Delta$ & TTDS & IVT & زنجان ................................... \\
\hline 11. & 199 & s4s & IVF & trt & سمنان .............................. \\
\hline TAVT & 19. & g9t & r৭९ & 5111 & سيستان و بلوجستان ......... \\
\hline rFE & far & TAIT & rQ1 & IVTEVA & فارس .................................. \\
\hline $1 \mathrm{k}$ & १४६ & $9 T F$ & D१९ा. & TYI & قزوين ............................... \\
\hline$V \Delta S$ & $\Delta V I$ & $9 V \cdot 9$ & 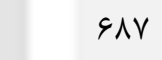 & 1.94 & قم ....................................... \\
\hline IrA & $V r \cdot V \cdot$ & $\Delta \Delta T$ & 1.94 & $\Delta q$. & 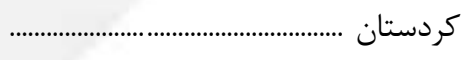 \\
\hline G4SM & 190 & 1941 & $l Q V$ & rrAd & 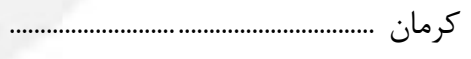 \\
\hline 194 & VISF & lQVT & $I V D$. & $1 \cdot 9$ & 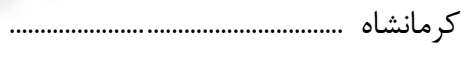 \\
\hline IVe & iA & V.r & id & VATI & 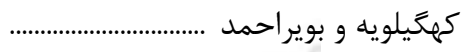 \\
\hline trt & מד & vef & DL & req & 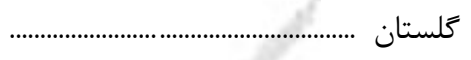 \\
\hline rథ9 & $\Delta \vee \wedge$ & IMTF & $\Delta \cdot r r$ & $9 \wedge$. & 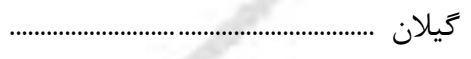 \\
\hline ( ) & $|f F|$ & rqve & $\Delta \wedge 9$ & 1109 & لرستان .................. ل ل \\
\hline rrq & 919 & 1イ9V & VET & NF & 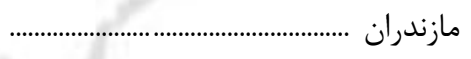 \\
\hline$|1|$ & FAT & fart & $\Delta T V$ & V१९ & 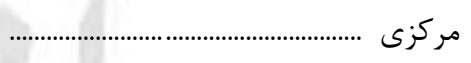 \\
\hline FDG & MFT & DFV & TDS & 1D૬G & 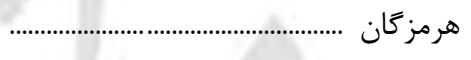 \\
\hline taT & rà. & pref. & 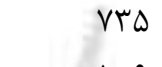 & ITVD & همدان ................ \\
\hline TFAT & 91 & $1 \cdots$ & $1 \cdot 9$ & $r \wedge \Delta \Lambda$ & يزد ..................... \\
\hline$r \cdot 91$ & $\wedge 91$ & sVVA & GYI & viाr & 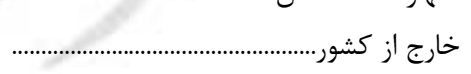 \\
\hline sta & $r \Delta$ & rAV & $\Delta T$ & $r \Delta V$ & 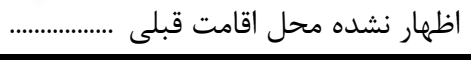 \\
\hline
\end{tabular}


| نتايج تفصيلى سرشمارى عمومى نفوس و مسكن _هQ

^ - 1 - مهاجران وارد شده طى ه سال كذشته بر حسب جنس، استان محل اقامت قبلى و فعلى (بر اساس آخرين جابجايى (كل) انجام شده) (دنباله)

\begin{tabular}{|c|c|c|c|c|c|}
\hline \multicolumn{5}{|c|}{ استان محل اقامت فعلى } & \multirow{2}{*}{ محل اقامت ق قبلى استان } \\
\hline 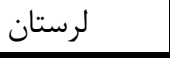 & 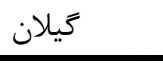 & كلستان & كهيَيلويه و بويراحمد & 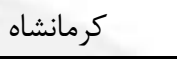 & \\
\hline arara & laVAAF & AqTar & $\Delta r q \cdot 1$ & 94911 & 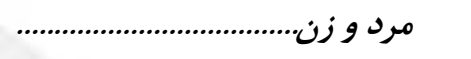 \\
\hline le. & $11 \Delta r$ & rVA & rی & $\wedge \cdot$. & 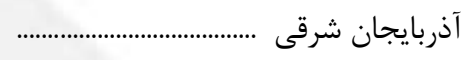 \\
\hline $1 \vee 9$ & VrV & $r \cdot \cdot$ & rv & 111. & 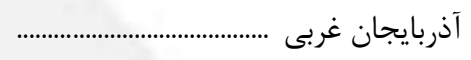 \\
\hline is & $\Delta \wedge \Lambda \varphi$ & $1 \cdot V$ & $\Delta r$ & $r \cdot$. & 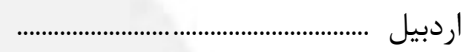 \\
\hline TFAD & $r \cdot 91$ & $V \Delta \Delta$ & lev. & $1 V \cdot 1$ & اصفهان ............................. \\
\hline$I r \wedge \Delta$ & VTIT & $\Lambda T$. & vT & rTVG & البرز .............................................. \\
\hline$\wedge \cdot$. & 191 & $\Lambda$ & rq & rq10 & 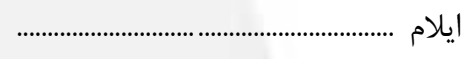 \\
\hline r19 & q४ब & IQV & ११५ & rFA & بوشهر ...................... \\
\hline GKTV & TADTI & VMTF & ४99 & $\Lambda \cdot \Delta l$ & تهران ................................ \\
\hline TET & 194 & 9 & $9 \Delta V$ & ret & 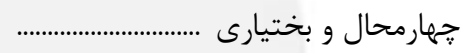 \\
\hline re & 111 & (t) & 19 & $\Delta \cdot$ & 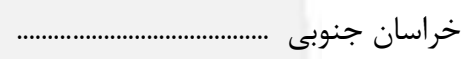 \\
\hline rq4 & $r \cdot 1$ & krq. & $11 \mathrm{~V}$ & $\wedge \notin \vee$ & 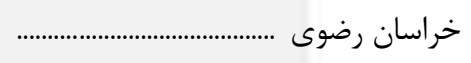 \\
\hline 10 & rIT & IAVT & $\wedge$ & FV & خراسان شمالى ............. \\
\hline 9\&^V & $1 \pi 11$ & FEV & trVt & rн. & 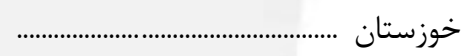 \\
\hline 1.9 & $10 \Delta 9$ & If. & ir & fer & 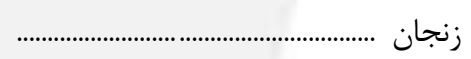 \\
\hline irv & rVI & rQDT & ro & r & 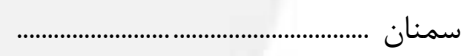 \\
\hline 195 & $9 \Delta \Delta$ & $\Delta Q V T$ & 110 & rin & سيستان و بلوجستان ............. \\
\hline s49 & $9 \Delta \Delta$ & rat & DrTG & 991 & 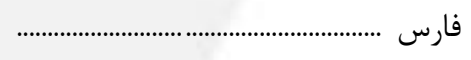 \\
\hline 149 & FATI & IVe & r. & $9 \wedge \Delta$ & قزوين ........................................ \\
\hline NHF & IrIV & $\Delta M F$ & rF. & 0.9 & 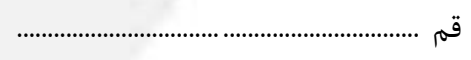 \\
\hline $1 \cdot V \Delta$ & $1 \cdot 9$ & rAF & is & $\Delta \wedge F I$ & 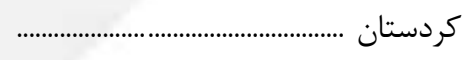 \\
\hline $1 \wedge \Delta$ & kq9 & rq1 & ITS & $r 90$ & 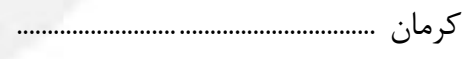 \\
\hline life. & VrF & TAT & $\mathrm{VA}$ & DITFV & 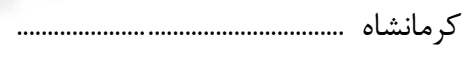 \\
\hline 190 & v^ & rA & rq६६4 & 109 & كهَيلويه و بويراحمد ...... \\
\hline NT & Vre & DFq६६ & ra & rq1 & 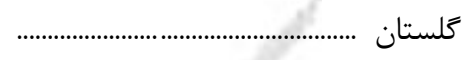 \\
\hline lar & $N T r \cdot F$ & $8 \vee 9$ & $\Delta \Lambda$ & Fre & 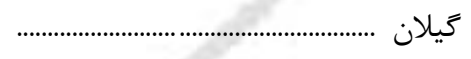 \\
\hline$r \cdot r \cdot q$ & rGF & 1149 & 114 & MEAT & 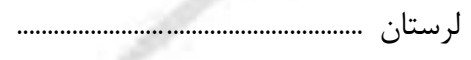 \\
\hline TEV & DIVe & r৭० & 94 & $\Delta 99$ & 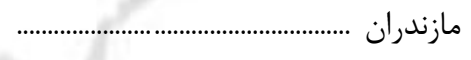 \\
\hline 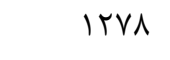 & lQFF & 199 & 19 & 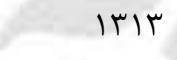 & 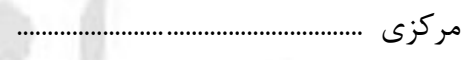 \\
\hline $4 \cdot 1$ & rı.. & str & MTY & $\wedge V F$ & 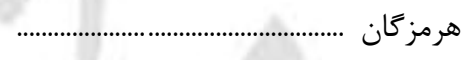 \\
\hline qr. & vi. & Irr & tra & mete & همدان ................. \\
\hline r99 & r9D & rqQ & Trt & 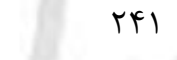 & 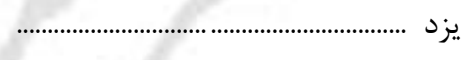 \\
\hline $\begin{array}{l}1 \\
91\end{array}$ & $\begin{array}{l}r T \\
q \Lambda \Lambda\end{array}$ & $\begin{array}{ll}\Delta \\
k \mid f\end{array}$ & $\begin{aligned} r \\
r V q\end{aligned}$ & $\begin{array}{l}1 \cdot 1 \\
k V 1\end{array}$ & 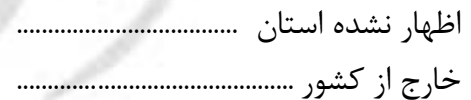 \\
\hline sV & V9 & 191 & ri & irv & 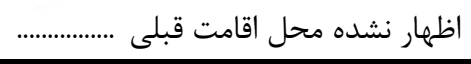 \\
\hline
\end{tabular}


1- 1 - مهاجران وارد شده طى ه سال كذشته بر حسب جنس، استان محل اقامت قبلى و فعلى (بر اساس آخرين جابجايى (كل) انجام شده) (دنباله)

\begin{tabular}{|c|c|c|c|c|c|}
\hline \multicolumn{5}{|c|}{ استان محل اقامت فعلى } & \multirow{2}{*}{ محل اقامت ق قبلى } \\
\hline 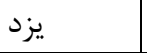 & 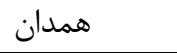 & هرمزكان & 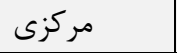 & مازندران & \\
\hline $1 T r \cdot r$ & varas & 119 rra & $1 T \& 19$ & IFArga & 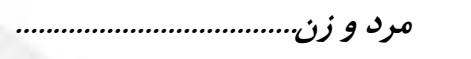 \\
\hline TFF & $|4|$ & $1 \cdot 99$ & rVQ & 111 & 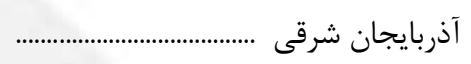 \\
\hline TAT & Grs & $\Delta T_{1}$ & Fol & 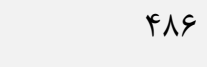 & آذربايجان غربى ........ \\
\hline$r \cdot 1$ & 14 . & rat & $1 \Delta \Delta$ & $19 \vee 9$ & 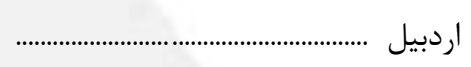 \\
\hline$\gamma \cdot .4$ & 149. & mete & $r \cdot \Delta r$ & rI91 & اصفهان ........................ \\
\hline ITFV & $r V \cdot G$ & $1 \cdots \omega$ & IVET & rVal & 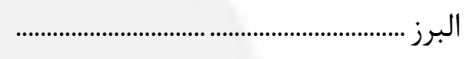 \\
\hline lar & $\Delta \wedge \vee$ & VTr & $\Delta 9 \Delta$ & rFa & ايلام ........................... \\
\hline$r \cdots$ & FAT & $r \cdot \wedge \Delta$ & rఎq & kqq & بوشهر ........... \\
\hline$\Delta V Y \wedge$ & $1 \cdot \Delta 1 r$ & G. YI & IrEFE & Trgtr & تهران ........................ \\
\hline $11 \cdot 9$ & re. & ו & rrv & $r \cdot \Delta$ & جهارمحال و بختيارى ...... \\
\hline 1990 & 19 & Fis & vq & $r \Delta \Delta$ & خراسان جنوبى ............ \\
\hline rTAF & rیs & TAFT & $9 \mathrm{VV}$ & $\Delta r \cdot l$ & خراسان رضوى ....... \\
\hline TVA & $\Delta V$ & $\Delta r q$ & TqT & TAT. & خراسان شمالى ........ \\
\hline DS१S & rTVE & $r \cdot 91$ & r|⿱一| & $1 F \lambda$. & 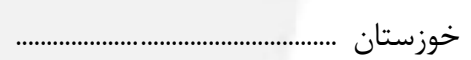 \\
\hline 91 & Frt & rra & $r \Delta \Delta$ & GQY & 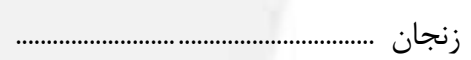 \\
\hline 191 & IAV & TYA & 190 & TQYI & 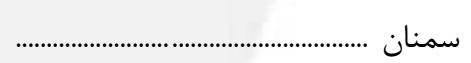 \\
\hline$\Delta 9 \wedge 9$ & rTA & rarg & rq. & leve & سيستان و بلوخستان .. \\
\hline$\Lambda \Delta Q T$ & ^९V & IDFVT & $\checkmark \wedge \Delta$ & $1 \cdot \Delta r$ & فارس ................ \\
\hline 101 & QTD & TIT & ए৭9 & $q \mathrm{qr}$ & 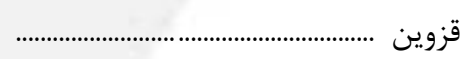 \\
\hline $1 \cdot \sqrt{ } 9$ & $19 \cdot r$ & FrT & TOTI & $10 \cdot 1$ & 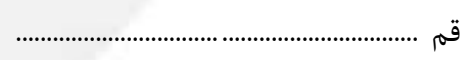 \\
\hline$r \cdot$. & FADT & FYI & $\Delta 99$ & $\vee \wedge 9$ & كردستان ...................... \\
\hline $1 \cdot+4$ & ו ו & 1.194 & rFq & gry & 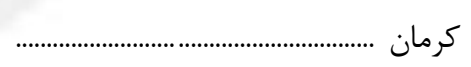 \\
\hline$\Delta \backslash \Lambda$ & 4.91 & 1481 & rqด9 & $1 \cdot F T$ & كرمانشاه ...................... \\
\hline GYT & IAV & 94. & PQq & אזו & كهخيلويه و بويراح \\
\hline$\Delta r F$ & 114 & $\wedge 91$ & Fed & sprq & كلستان ............ \\
\hline$f \mid f$ & ev. & rmeN & $1 \cdot 1 \mathrm{~V}$ & fer. & 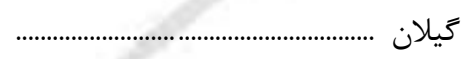 \\
\hline $19 \cdot 4^{4}$ & $r \cdot v q$ & $1 r \cdot r$ & $0 \cdot 11$ & $V \cdot \Delta$ & لرستان ............... \\
\hline$|<|$ & 491 & $19 \cdot r$ & $\Lambda \Delta r$ & VVFIT & مازندران ............... \\
\hline TYD & $r \cdot \Delta \cdot$ & $\Delta \wedge \Lambda$ & ra494 & VVr & 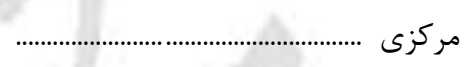 \\
\hline$r \Delta V$. & GFT & FVVYA & rqq & 1991 & هرمزكان ......... \\
\hline $\begin{array}{l}\text { rTG } \\
\text { IgMGe }\end{array}$ & $\begin{array}{l}\text { F. IrF } \\
\text { IVA }\end{array}$ & $\begin{array}{l}1119 \\
1.1\end{array}$ & $\begin{array}{l}\text { TKF. } \\
\text { TrG }\end{array}$ & 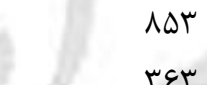 & همدان ..................... \\
\hline$\Delta 9$ & $r \cdot$ & ir & 19 & $r_{1}$ & 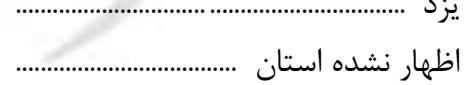 \\
\hline $11 \cdot r$ & $r 90$ & rAGG & $|r v|$ & V91 & 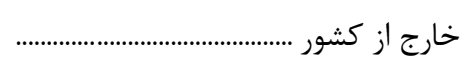 \\
\hline IVE & 149 & 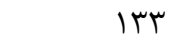 & 90 & MrI & اظهار نشده محل اقامت قبلى ................ \\
\hline
\end{tabular}


| نتايج تفصيلى سرشمارى عمومى نفوس و مسكن _هD

^ - 1 - مهاجران وارد شده طى ه سال حذشته بر حسب جنس، استان محل اقامت قبلى و فعلى (بـر اســاس آخــرين جابجـايى (كل)

انجام شده)(دنباله)

\begin{tabular}{|c|c|c|c|c|c|c|}
\hline \multicolumn{6}{|c|}{ استان محل اقامت فعلى } & \multirow{2}{*}{ محل اقامت قبلى استان } \\
\hline 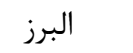 & اصفهان & 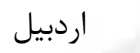 & آذربايجان غربى & آذربايجان شرقى & جمع & \\
\hline$\| \mu \cdot . \mu F$ & $|\Delta| A V \mid$ & raAkr & sarev & valra & rTI.rAv & 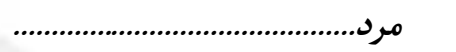 \\
\hline$r \vee \cdot 1$ & $q \cdot 4$ & r|\&1 & garq & $\Delta \backslash \Delta \Delta \varphi$ & MArr. & 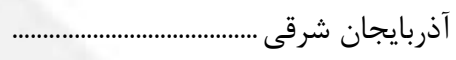 \\
\hline $1 \pi \Delta \Delta$ & ETD & leVA & FMFAT & NIVV & $\vee \cdot 94$. & آذربايجان غربى ........................ \\
\hline$r \cdot V k$ & rIf & IDFAM & $1 r \cdot 1$ & 195. & rАArV & 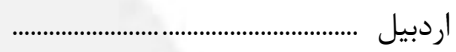 \\
\hline Tht & $\Lambda \cdot \Delta / F$ & $|V|$ & Tre & $\Delta \cdot{ }^{r}$ & Irrq.r & |صفهان ................... \\
\hline rmtes & ITIT & sVV & srq & ITET & veqar & 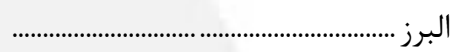 \\
\hline VYA & rAv & rF & 90 & SV & $r \cdot F V t$ & 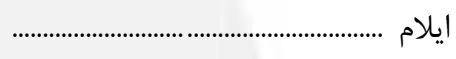 \\
\hline rAF & IFTF & ve & 19. & 199 & relgF & بوشهر ........... \\
\hline FFars & $901 V$ & DrF. & एदा & VFIV & r।9914 & تهران ............................. \\
\hline 194 & qVD. & $1 \cdot$ & VF & iv & rF्वqV & جهارمحال و بختيارى .......... \\
\hline rQq & rیv & IT & $\Delta \varphi$ & re & l mata & 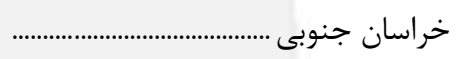 \\
\hline TrgV & let. & 111 & $\Delta r$. & 019 & $1 \Delta G F \cdot V$ & 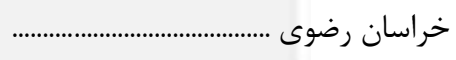 \\
\hline V^I & TFT & 19 & $\Delta V$ & 99 & TrATt & 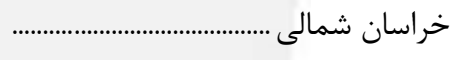 \\
\hline$\Delta V \cdot \varphi$ & $1 \notin 4 \Delta \Delta$ & Ifr & FeV & Fir & ITTIA9 & 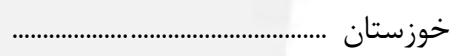 \\
\hline rovV & rAl & r৭9 & 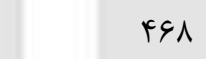 & FrA & $r I V \cdot \Lambda$ & 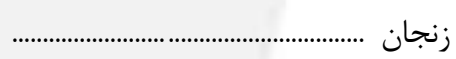 \\
\hline$k \cdot 1$ & TAI & $\Delta V$ & $1 \cdot 0$ & 9. & $r \cdot \Delta \Delta \cdot$ & سمنان ................................. \\
\hline $9 \Delta \Delta$ & $|\wedge \Delta|$ & $\wedge 9$ & 11. & lfF & GIrvq & سيستان و بلوجستان ..... \\
\hline 1.01 & $f \cdot \varphi \Delta$ & 111 & rat & rVq & $|r 4| \cdot 9$ & 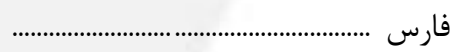 \\
\hline$r \cdot V \varphi$ & $r \cdot 1$ & $11 \pi$ & f.. & rQq & FVDGF & قزوين ........................ \\
\hline $1 \cdot v 9$ & TITS & $|f|$ & ra1 & $\Delta r \cdot$ & TFOAT & قم .................................... \\
\hline rar. & $\Delta V G$ & TAT & $191 \mathrm{~V}$ & ITVF & GrAFV & 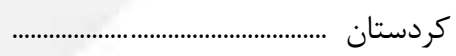 \\
\hline $8 \wedge 1$ & IroF & 91 & IVF & lgF & $\Delta \& 9 \Delta \Gamma$ & 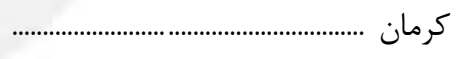 \\
\hline VIrT & $|\Delta| T$ & TYF & FAr & rAD & $\varphi \Delta \varphi \Delta \varphi$ & 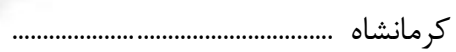 \\
\hline 119 & $|\Delta \Lambda|$ & ra & FV & rq & MFF. r & كهيَيلويه و بويراحمد ........ \\
\hline$\wedge \vee \wedge$ & rیr & qr & 19. & 101 & $\Delta T \| \Lambda$ & كلستان ....................................... \\
\hline raVs & $v F$. & 1011 & GIV & $r \cdot \Lambda$ & gq941 & كيلان ...................... \\
\hline pget & rosq & IVV & 194 & $9 \Delta$ & $8 r q \cdot \Lambda$ & لرستان ........................... \\
\hline 1949 & $\wedge 9$. & fet & rqu & TVT & $9 V \cdot 90$ & مازندران ........... \\
\hline INא & $19 \vee 9$ & $\Delta \Delta$ & IVD & $\pi$ & Frlls & 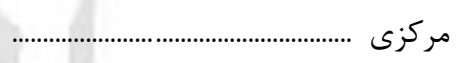 \\
\hline vqf & IFVD & $\wedge$ & 190 & rI9 & DI.tt & 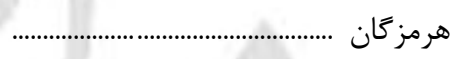 \\
\hline FATS & qVr & iNr & rit & rTq & $\Delta \varphi \mid \Delta \Delta$ & همدان ..................... \\
\hline Gq & $1 \Delta \Delta \Lambda$ & $\Delta 9$ & $\Delta r$ & $1 \cdot 1$ & rTDAS & 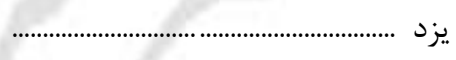 \\
\hline 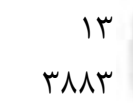 & $\begin{array}{l}1 F \Delta \\
\Delta r \cdot q\end{array}$ & Ir. & $\stackrel{-1}{\wedge}$ & $\begin{array}{ll}11 \\
r V r\end{array}$ & $\begin{array}{l}r \cdot 19 \\
\text { VTHYG }\end{array}$ & 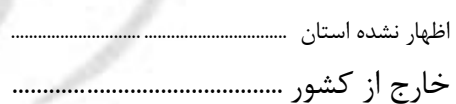 \\
\hline 114 & $r \cdot r$ & $\Delta 1$ & rFF & rV. & Verq & اظهار نشده محل اقامت قبلى ............ \\
\hline
\end{tabular}


^ - 1 - مهاجران وارد شده طى ه سال حذشته بر حسب جنس، استان محل اقامت قبلى و فعلى (بـر اســاس آخــرين جابجـايى (كل)

انجام شده)(دنباله)

\begin{tabular}{|c|c|c|c|c|c|}
\hline \multicolumn{5}{|c|}{ استان محل اقامت فعلى } & \multirow{2}{*}{ محل اقامت قبلى } \\
\hline خراسان جنوبى & جهارمحال و بختيارى & 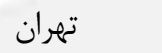 & 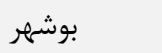 & 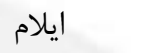 & \\
\hline rarar & $r r \cdot \varepsilon r$ & frevar & $\Delta r V Y I$ & $1 \Delta \Delta \Delta \Delta$ & 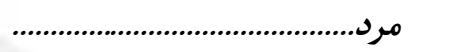 \\
\hline $11 \mathrm{~V}$ & rᄉ & irtir & rat & irv & 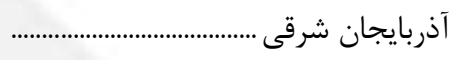 \\
\hline$\Delta r$ & TV & GFVT & r^s & IfV & 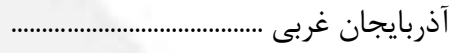 \\
\hline rF & r. & $1.94 \wedge$ & 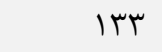 & re & 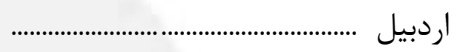 \\
\hline var & rq. & | (1) & $1 \wedge \Delta \Delta$ & 490 & 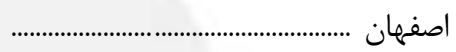 \\
\hline TrA & q & rYql. & 119 & $10 \Lambda$ & 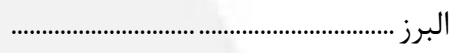 \\
\hline 10 & $4 q$ & FEAT & 190 & $\Lambda F \Delta q$ & 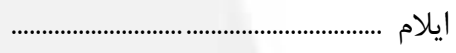 \\
\hline 9 . & $r 90$ & $11 \cdot F^{c}$ & 19人ץ^ & $\wedge \cdot$ & بوشهر ........................... \\
\hline 1199 & pVq & ITVEDV & $|r q|$ & 1.19 & تهران ............................... \\
\hline$v^{c}$ & $|F| a$. & ler. & INTS & 94 & 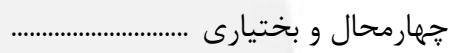 \\
\hline IVrr. & if & rI. & GV & $\checkmark$ & خراسان جنوبى ............................... \\
\hline $1 \cdot 91$ & $9 \Delta$ & $199 \vee \Delta$ & reA & $\wedge f$ & 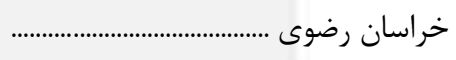 \\
\hline $1 \cdot 10$ & $1 \cdot$ & $9 \cdot 94$ & $11 \mathrm{~V}$ & $1 \cdot$ & 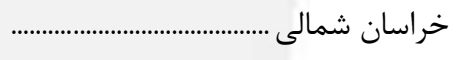 \\
\hline $1 \Delta V$ & 199. & $11 r q 4$ & $\Delta|f|$ & $1 \% q$. & 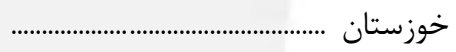 \\
\hline TI & le & $\Delta F \cdot 1$ & pq & 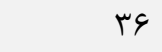 & 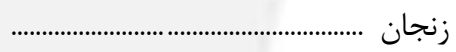 \\
\hline Trt & rq & rAve & $\Delta r$ & 11 & 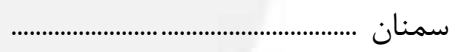 \\
\hline TFYA & r & $r \cdot r \cdot$ & $V \Delta I$ & $r v$ & 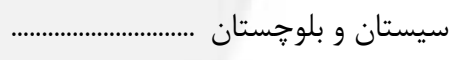 \\
\hline$r \cdot 1$ & rII & qDVq & qVरद & 149 & 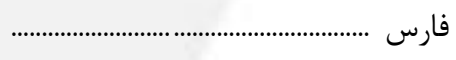 \\
\hline Ve & r) & $4 \cdot 19$ & $\Delta F$ & r & 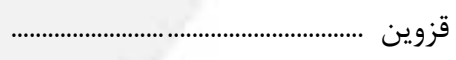 \\
\hline 94 & 19. & $\Delta q V F$ & rrq & $1 \cdot 1$ & قم ....................................... \\
\hline$r \cdot$ & זr & $\Lambda \Delta \Lambda T^{2}$ & ler & rid & 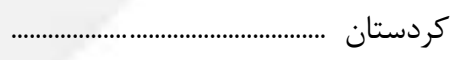 \\
\hline FAl & $9 \mathrm{~T}$ & rDAt & TVF & $r \Delta$ & 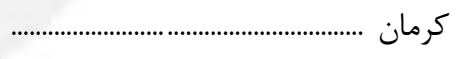 \\
\hline et & ve & IFNIT & $r \cdot r$ & 1111 & 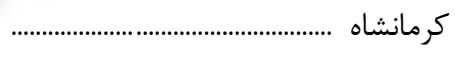 \\
\hline ra & rVr & irrq & IVed & 4 . & كهيلويه و بويراحمد ..... \\
\hline $9 T F$ & f. & 1.rq1 & $\wedge \vee$ & rq & 5لستان ...................... \\
\hline qf & $\Delta r$ & l1st. & rघ9 & Gr & 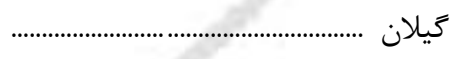 \\
\hline (4) & 19 & Tाls. & $\Delta \& V$ & $99 \wedge$ & 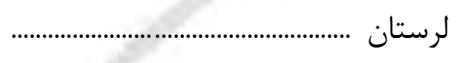 \\
\hline VIT & va & $1 \cdot V \Delta T$ & rฯ9 & VT & مازندران ......................... \\
\hline is & $\wedge$. & 119. & MFD & 149 & 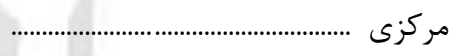 \\
\hline 199 & $r \cdot r$ & rNAT & $M \mathrm{~F}^{\prime}$ & 149 & 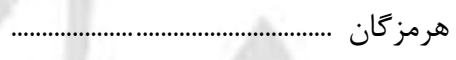 \\
\hline SV & kr & $|9 \wedge \Delta|$ & $\Delta \cdot \Delta$ & rq. & همدان ..................... \\
\hline r৭9 & IAT & $\begin{array}{l}\text { TFF. } \\
\text { TFE }\end{array}$ & $11 \pi$ & rt & 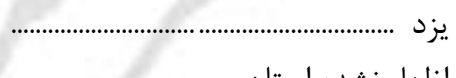 \\
\hline r & $10 \Lambda$ & rit & 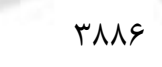 & $4 q$ & 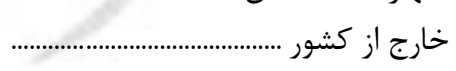 \\
\hline r. & kT & 1014 & k99 & rq & اظهار نشده محل اقامت قبلى ................ \\
\hline
\end{tabular}


| نتايج تفصيلى سرشمارى عمومى نفوس و مسكن _ه

^ - 1 - مهاجران وارد شده طى ه سال حذشته بر حسب جنس، استان محل اقامت قبلى و فعلى (بـر اســاس آخــرين جابجـايى (كل)

انجام شده)(دنباله)

\begin{tabular}{|c|c|c|c|c|c|c|}
\hline \multicolumn{6}{|c|}{ استان محل اقامت فعلى } & \multirow{2}{*}{ محل اقامت قبلى و استان } \\
\hline |سيستان و بلوجستان & سمنان & 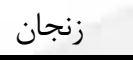 & خوزستان & خراسان شمالى & خراسان رضوى & \\
\hline refir & $r v \cdot q v$ & rAr.q & 1.909 & rFqดq & $19 \cdot v a r$ & 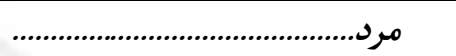 \\
\hline$r \cdot 4$ & 194 & $\wedge \wedge 9$ & एद५ & FV & 9.r & 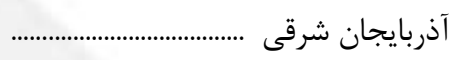 \\
\hline ITF & rFA & 911 & tAr & $\Delta F$ & $r \Delta \cdot$ & 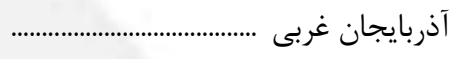 \\
\hline$\Lambda$ & $r \cdot r$ & rq. & 99 & 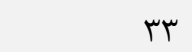 & IFr & اردبيل ................... \\
\hline $9 \Delta 9$ & 1.49 & ivr & $k \cdot r t$ & IVT & $1 M \Lambda 9$ & اصفهان ................. \\
\hline 110 & $9 \wedge 9$ & levq & $9 \wedge 1$ & r人 & ITVD & 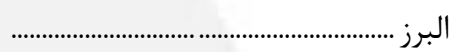 \\
\hline ب & rT. & re & $11 \mathrm{Vr}$ & זו & $q$. & ايلام .................................. \\
\hline rAd & TET & r & 1191 & $9 \Delta$ & $f \cdot r$ & 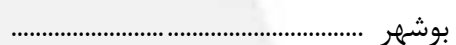 \\
\hline 1114 & $\Lambda \varepsilon V \bar{T}$ & $r \cdot v \vee$ & rqv & rTLF & $11 \cdot 19$ & 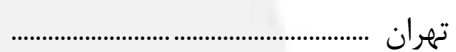 \\
\hline rז & IAT & 90 & $19 V 9$ & rı & IAV & جهارمحال و بختيارى ........................ \\
\hline $11 \mathrm{Vr}$ & GTH & 19 & $\Delta F$ & TVT & $\wedge 99 \Delta$ & خراسان جنوبى ...................... \\
\hline$F \cdot \Delta r$ & 4111 & 191 & 991 & rtal & $9 \wedge r \wedge$. & خراسان رضوى ...................... \\
\hline 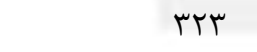 & Vri & Vr & VD & ITETF & GIOD & خراسان شمالى .......... \\
\hline ATF & $r \Delta \Lambda$ & ris & $\Delta \cdot \Delta \Delta \varphi$ & 109 & rV९q & خوزستان ....................... \\
\hline f. & 190 & $10 \Lambda \cdot \varphi$ & 11 & 19 & $M F$ & 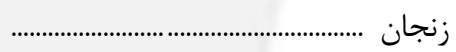 \\
\hline 114 & AVEV & $\Delta V$ & $\varepsilon \wedge$ & 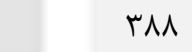 & 1119 & 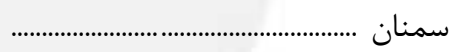 \\
\hline$r \vee \cdot 4$. & $\wedge \varphi$. & vr & TFA & $\Delta V V$ & ^१५ & سيستان و بلوجستان .................. \\
\hline IOTV & FAF & ITt & $T F \cdot r$ & ع & $9 \wedge \mathrm{F}$ & 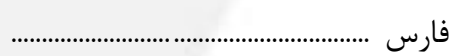 \\
\hline$\Delta F$ & TAT & Irrq & $11 \mathrm{r}$ & rq & r৭9 & 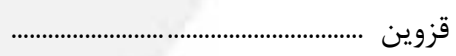 \\
\hline 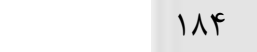 & Fal & $\Delta T$. & GTr & IrF & arr & 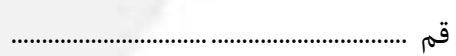 \\
\hline$\Delta \varphi$ & IVr & $9 \& 4$ & MIN & pq & TYI & 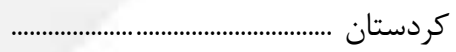 \\
\hline$|g F|$ & IVT & fr & q4q & 1re & IEFV & 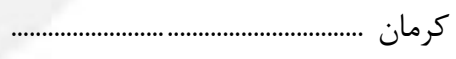 \\
\hline Ve & $r \cdot q$ & $r \cdot r$ & 991 & $\Delta 1$ & f.l & 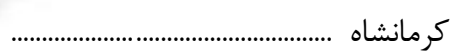 \\
\hline 99 & $1 \cdot V$ & tr & TFE & Ir & VT & كهخيلويه و بويراحمد ......... \\
\hline vvq & MefF & $\mathrm{v}$. & 119 & $\wedge \vee$. & rब१V & 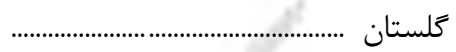 \\
\hline שTr & TEV & FMA & rin & 91 & VET & 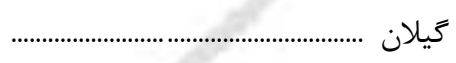 \\
\hline ir. & $r \cdot r$ & 111 & rvqq & rᄉ & Ter & لرستان .......... \\
\hline Fra & $194 \wedge$ & rta & rir & drq & $r \cdot 1 \cdot$ & 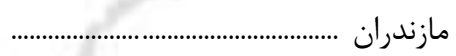 \\
\hline ivq & GTt & 11. & gVF & rq & rTa & 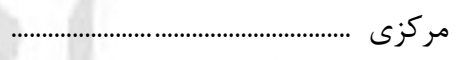 \\
\hline$|r V|$ & 1 ira & pq & VAT & 191 & If.r & 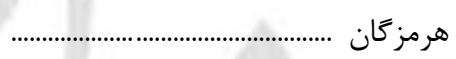 \\
\hline IVV & rтq & TET & 94 & 90 & TVT & 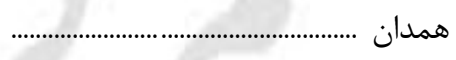 \\
\hline rNI & $14 \lambda$ & ro & fry & is & 994 & يزد ......................... \\
\hline (i) & rTI & If & $\Delta \varphi$ & r & מוd & اظهار نشده استان ......... \\
\hline Grr & ra. & rid & $1 \cdot 1 \cdot$ & $\Delta V$ & FIG & 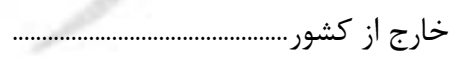 \\
\hline IVAD & rr & 19 & FVa & 19 & $F \cdot v$ & 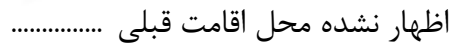 \\
\hline
\end{tabular}


^ - 1 - مهاجران وارد شده طى ه سال كذشته بر حسب جنس، استان محل اقامت قبلى و فعلى (بـر اســاس آخــرين جابجـايى (كل)

انجام شده)(دنباله)

\begin{tabular}{|c|c|c|c|c|c|}
\hline \multicolumn{5}{|c|}{ استان محل اقامت فعلى } & \multirow{2}{*}{ محل اقامت ق قبلى استان } \\
\hline 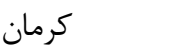 & 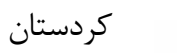 & قم & 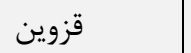 & 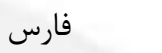 & \\
\hline$\Delta \cdot 1 r$. & $\Delta 1919$ & rarad & fAfqg & $I \mu \cdot . r F$ & 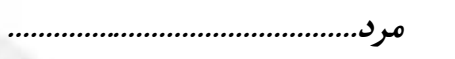 \\
\hline 195 & $|r R|$ & $1 \cdot v r$ & 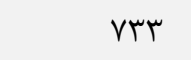 & ref & 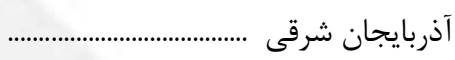 \\
\hline IVA & trut & rrq & $\Delta 91$ & rT. & 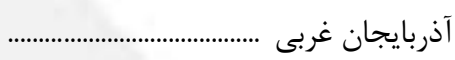 \\
\hline 119 & $10 \Delta$ & TFY & rtq & 19. & 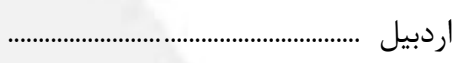 \\
\hline 1191 & FAT & rF.. & red & 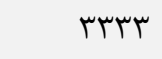 & اصفهان .............................. \\
\hline mes & 人r) & $1 . r v$ & TQSV & |N1 & البرز .................................... \\
\hline rq & Fa. & raT & १भ & $|r|$ & ايلام ............................................................. \\
\hline$r \Delta \cdot$ & $\wedge 1$ & 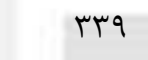 & $4 q$ & DTYV & بوشهر ....................... \\
\hline $1 \Delta \Delta T^{2}$ & FEV & 91re & FVQq & 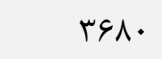 & تهران ................................ \\
\hline rus & $q V$ & $r \cdot 1$ & $\Delta T$ & М८ & 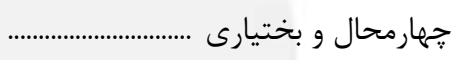 \\
\hline 19. & 11 & rTV & rq & 194 & 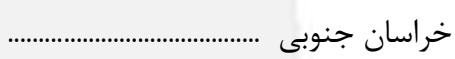 \\
\hline VEA & זrז & $11 \mathrm{VI}$ & r19 & M1 & 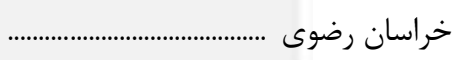 \\
\hline 111 & tr & 119 & $9 \Lambda$ & $1 \cdot v$ & 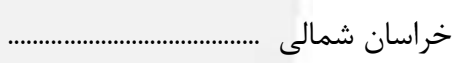 \\
\hline Arf & gQF & TAKT & ry. & DYTA & 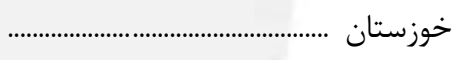 \\
\hline kq & $\Lambda \wedge \Delta$ & $1 . . r$ & lQ9T & VA & زنجان ............................... \\
\hline$\Delta 9$ & 114 & rt. & 94 & ITF & 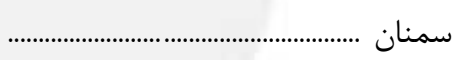 \\
\hline 1094 & $11 \pi$ & ras & IVD & Irar & 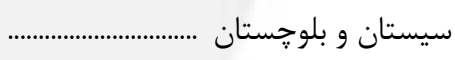 \\
\hline 1911 & ra & ITr. & 19. & $\wedge \Delta q \hookrightarrow Y$ & 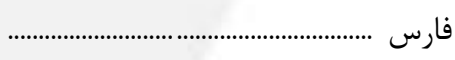 \\
\hline$\wedge \cdot$ & $\Delta T F$ & fer & rq८. & (re & 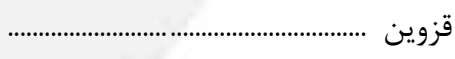 \\
\hline reV & एव९ & MFFA & Tre & $\Delta \Delta V$ & 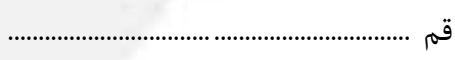 \\
\hline$\wedge \Lambda$ & reVtr & rVV & $\Delta \Lambda \Lambda$ & rیl & 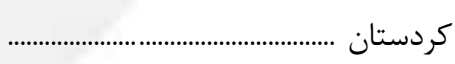 \\
\hline T1919 & 111 & $\wedge \notin 9$ & $\Delta F$ & $\mid \wedge \mu \wedge$ & 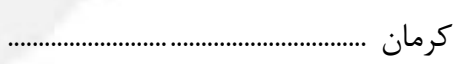 \\
\hline 110 & $r v \cdot \varphi$ & Var & 9.9 & 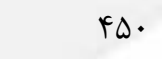 & كرمانشاه .............................. \\
\hline $\mid r \Lambda$ & rr & myF & re & rquk & كهَيلويه و بويراحمد .. \\
\hline $11 \pi$ & $r \cdot q$ & red & 19. & 191 & كلستان ................................. \\
\hline 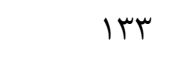 & 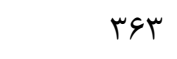 & sq. & rFIF & 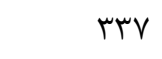 & 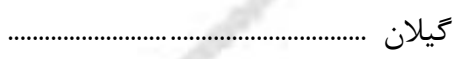 \\
\hline rIs & $9 \cdot 9$ & 199. & $r \cdot 1$ & $9 \Delta 9$ & 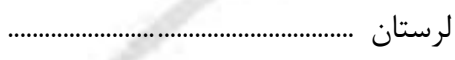 \\
\hline 191 & reA & $\wedge १ \wedge$ & r^. & fre & 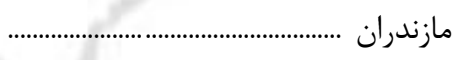 \\
\hline $1 \cdot 0$ & T\&V & rire & TYQ & $r \Delta V$ & 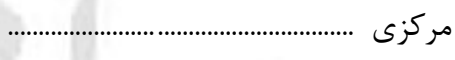 \\
\hline rVYA & $r \cdot$. & rq. & 149 & FAVT & 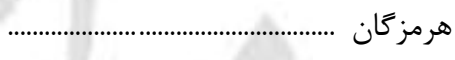 \\
\hline 10 & $19 V T$ & r|NI & rq. & VIf & 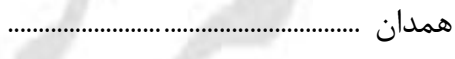 \\
\hline mer & $\Delta 9$ & $\Delta / F$ & $\Delta \varphi$ & IfFr & 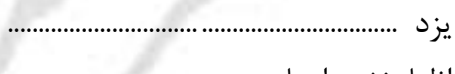 \\
\hline rmql & $\Delta r \Lambda$ & rrru & 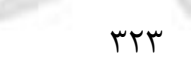 & Frus & 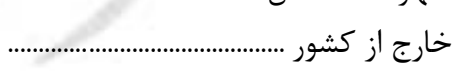 \\
\hline meF & 11 & TrF & tr & TIO & اظهار نشده محل اقامت قبلى ............... \\
\hline
\end{tabular}


| نتايج تفصيلى سرشمارى عمومى نفوس و مسكن _هD

^ - 1 - مهاجران وارد شده طى ه سال حذشته بر حسب جنس، استان محل اقامت قبلى و فعلى (بـر اســاس آخــرين جابجـايى (كل)

انجام شده)(دنباله)

\begin{tabular}{|c|c|c|c|c|c|}
\hline \multicolumn{5}{|c|}{ استان محل اقامت فعلى } & \multirow{2}{*}{ محل اقامت قبلى استان } \\
\hline 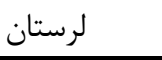 & 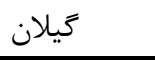 & كلستان & كهيَيلويه و بويراحمد & كرمانشاه & \\
\hline rAstr & rar.. & F194. & reres & alrar & 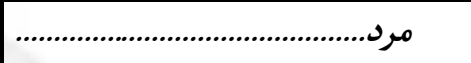 \\
\hline NT & 819 & 14 . & rI & gri & آذربايجان شرقى .......... \\
\hline ITt & ivi & 1.9 & TQ & 918 & آذربايجان غربى ............................................... \\
\hline rq & r911 & $9 V$ & rq & 149 & 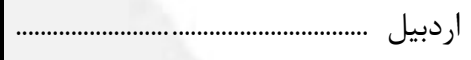 \\
\hline ITYT & 1.94 & rq. & VTD & १ی५ & اصفهان .................... \\
\hline Gq & 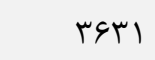 & ill & kr & $19 \Lambda \mathrm{F}$ & 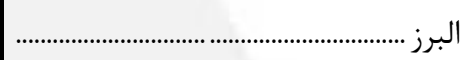 \\
\hline rat & 91 & $\Delta F$ & 19 & $19 \cdot 0$ & 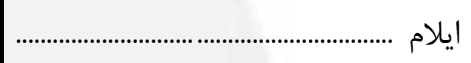 \\
\hline$|V|$ & 011 & 11 & $\Delta \cdot f^{2}$ & INF & 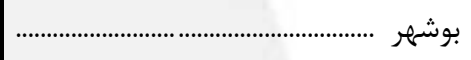 \\
\hline TTVT & 14911 & rNIF & ras & $F F \cdot V$ & 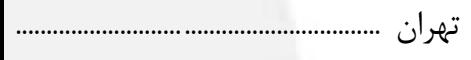 \\
\hline ITA & גז & $\psi_{\wedge}$ & rघ4 & TVT & 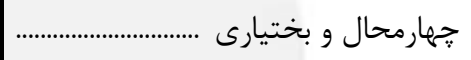 \\
\hline$r \cdot$ & 99 & tru & 11 & $r F$ & خراسان جنوبى ................. \\
\hline 189 & $1 . r_{9}$ & TI19 & vq & 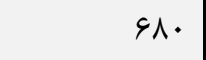 & خراسان رضوى ............ \\
\hline 1. & $1 \cdot 1$ & $q \cdot r$ & $\Delta$ & ri & 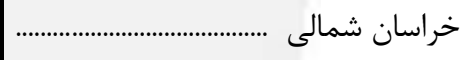 \\
\hline ( & $v \cdot 4$ & rtq & IreV & 酒. & 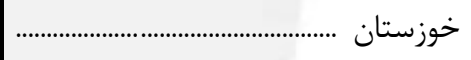 \\
\hline st & $\checkmark v \wedge$ & VT & $\wedge$ & res & 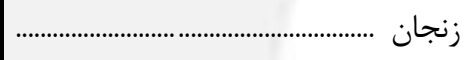 \\
\hline Vr & 19V & $10 \cdot r$ & iv & $\wedge 1$ & 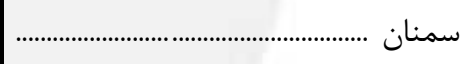 \\
\hline 110 & $\Delta q^{\prime}$ & rN19 & 98 & 149 & سيستان و بلوجستان ......... \\
\hline r19 & $\forall \wedge F$ & 189 & TEYA & FVF & فارس ............................................... \\
\hline$\wedge \varepsilon$ & TTAT & 90 & $\wedge$ & Frq & 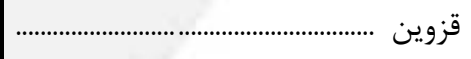 \\
\hline FTT & $9 \vee \Delta$ & $r 9 \Lambda$ & ITr & TAT & 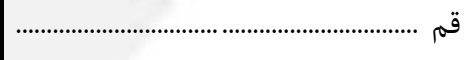 \\
\hline ब१९ & fqr & $|0|$ & ri & TrTI & 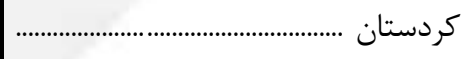 \\
\hline 11. & trR & $\mid F \wedge$ & 91 & INT & 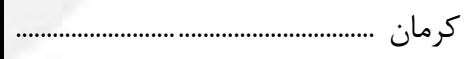 \\
\hline 990 & rq1 & irv & is & rQDSV & 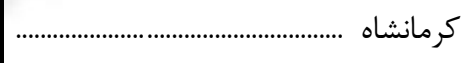 \\
\hline $1 r$. & $\Delta 1$ & 10 & 19901 & $11 r$ & كهخيلويه و بويراحمد ...... \\
\hline$\Delta r$ & rی. & TFASD & rq & rm & كلستان ..................... \\
\hline ᄉr & ए৭९.। & MIS & $4 q$ & $r V \cdot$ & 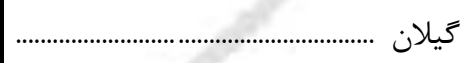 \\
\hline IfVET & 191 & $9 V$ & v^ & $r 1 \cdot 9$ & 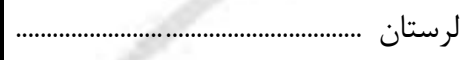 \\
\hline Irt & TFFY & $1 \vee 90$ & q & fis & 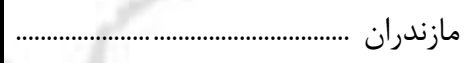 \\
\hline $9 \Delta 9$ & VAF & $1 \cdots$ & 91 & VTF & 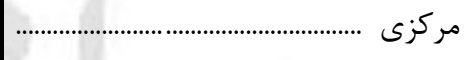 \\
\hline TTV & $r \cdot r \mu$ & mi & $1 \wedge F$ & 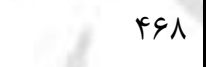 & 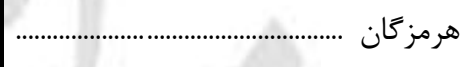 \\
\hline 411 & $r \Delta \Lambda$ & $\Delta V$ & 111 & INTK & 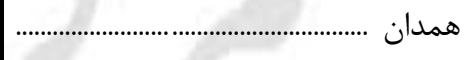 \\
\hline 100 & 101 & $|0|$ & ITF & IrF & يزد .................................... \\
\hline$\Delta r$ & FrA & rIT & tri & rq. & 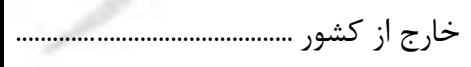 \\
\hline et & $r \Delta$ & $\Lambda F$ & $r \cdot$ & vQ & 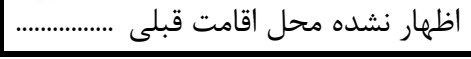 \\
\hline
\end{tabular}


^ - 1 - مهاجران وارد شده طى ه سال كذشته بر حسب جنس، استان محل اقامت قبلى و فعلى (بـر اســاس آخــرين جابجـايى (كل)

انجام شده)(دنباله)

\begin{tabular}{|c|c|c|c|c|c|}
\hline \multicolumn{5}{|c|}{ استان محل اقامت فعلى } & \multirow{2}{*}{ محل اقامت ق قبلى } \\
\hline 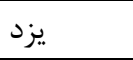 & همدان & هرمزكان & مركزى & مازندران & \\
\hline$F \varphi \cdot r \Delta$ & rA19r & $s \mu r \cdot r$ & FTAFT & vratr & 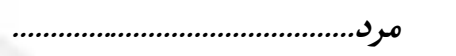 \\
\hline lar & r^৭ & $\Delta \Delta \Delta$ & TAT & fis & 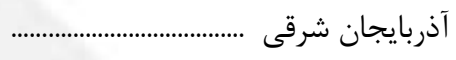 \\
\hline 194 & FTD & $r$ & rq1 & rघ9 & آذربايجان غربى ...................... \\
\hline rl. & 94 & TYF & $\wedge 1$ & $1 . r \Lambda$ & 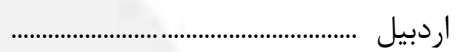 \\
\hline reqK & sqa & 1991 & IFVA & $1 \cdot \Delta V$ & 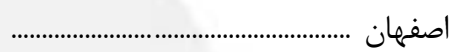 \\
\hline $9 \Delta \cdot$ & $|r| F$ & $\Delta F q$ & AVT & IATY & البرز ........................................................... \\
\hline 1.9 & rV. & rvq & r৭९ & 19. & 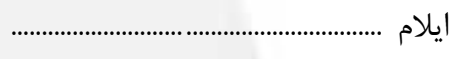 \\
\hline TTV & 519 & ITrK & $1 F \Delta$ & rol & بوشهر ....................... \\
\hline$r \Delta 99$ & QTVQ & rtVA & GQFV & 11945 & تهران ................................. \\
\hline 990 & $1 \cdot r$ & Art & rAD & 195 & 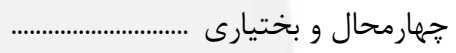 \\
\hline $1 \cdot V r$ & rV & 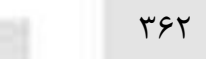 & pq & IVV & 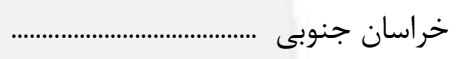 \\
\hline IVF. & rII & IDTK & ris & $r V \cdot \varphi$ & 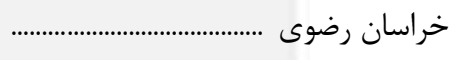 \\
\hline 19. & ro & $r \cdot 1$ & ira & IrFs & 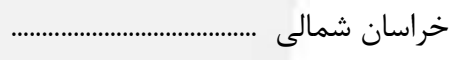 \\
\hline rq८9 & $11 \mathrm{Fr}$ & rI. & $1 F \Delta$. & $v \notin q$ & 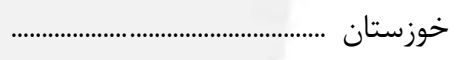 \\
\hline$\Delta 9$ & TAT & 101 & IOF & rqq & 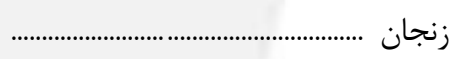 \\
\hline 94 & $q$. & 19. & $11 f$ & $\mid r \cdot r$ & سمنان ............................... \\
\hline ( & Ire & TATT & $r \cdot r$ & $1 \cdot 9$ & سيستان و بلوجستان ......... \\
\hline FTIA & fq. & NFF. & FTV & $\Delta V r$ & فارس ................................. \\
\hline$\checkmark \Delta$ & TVE & $|r|$ & TIF & $|4|$ & 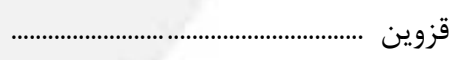 \\
\hline$\Delta \Delta I$ & VVV & Tr. & $19 \cdot 1$ & 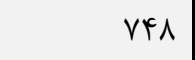 & قم ..................................... \\
\hline 148 & TAFT & $r \Delta \Delta$ & rq. & iq. & 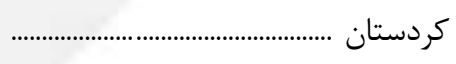 \\
\hline rqМ & $|r|$ & DTTY & If. & rrF & 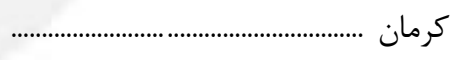 \\
\hline rᄉr & IV99 & VIr & $109 \Delta$ & $\Delta r \Delta$ & 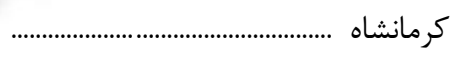 \\
\hline$\Delta 9 \Lambda$ & 91 & $\Delta q$. & roג & $v r$ & 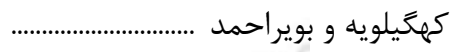 \\
\hline FAS & $\Delta r$ & Faq & TAT & r191 & كلستان ................................................... \\
\hline$r$ r. & riv & $\mid r \| 1$ & $\Delta G Y$ & $r \cdot 9 T$ & كيلان ........................... \\
\hline ^৭r & 911 & 491 & rQSA & rVF & 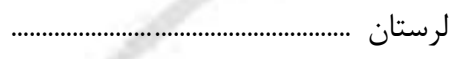 \\
\hline TQV & r\&4 & NrF & Dq & TGATF & 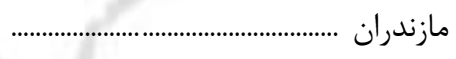 \\
\hline$|f|$ & $9 \mu \wedge$ & MIS & 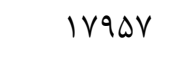 & $f \cdot 9$ & 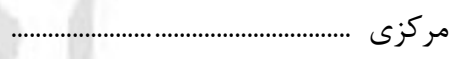 \\
\hline ITFT & rFa & TFAGD & trt & 19ז & 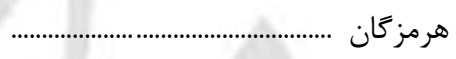 \\
\hline 195 & $191 \times 9$ & $\Delta \wedge \varphi$ & 190. & pq. & همدان ............................. \\
\hline ky & $1 \cdots$ & $\begin{array}{r}\Delta Q \cdot \\
\end{array}$ & 11 & $\begin{array}{l}19 V \\
\text { rF }\end{array}$ & 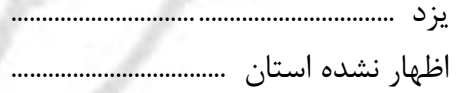 \\
\hline r & 191 & $r \cdot r \Lambda$ & $\wedge \vee \wedge$ & $0 \cdot 1$ & 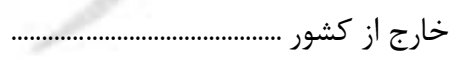 \\
\hline 19 & vq & $V \Delta$ & Tr & IVE & 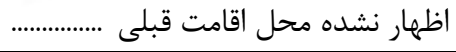 \\
\hline
\end{tabular}


| نتايج تفصيلى سرشمارى عمومى نفوس و مسكن _ه

^ - 1 - مهاجران وارد شده طى ه سال حذشته بر حسب جنس، استان محل اقامت قبلى و فعلى (بـر اســاس آخــرين جابجـايى (كل)

انجام شده)(دنباله)

\begin{tabular}{|c|c|c|c|c|c|c|}
\hline \multicolumn{6}{|c|}{ استان محل اقامت فعلى } & \multirow{2}{*}{ محل اقامت قبلى استان } \\
\hline البرز ال & اصفهان & 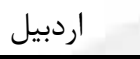 & آذربايجان غربى & آذربايجان شرقى & جمع - جم & \\
\hline Ir.krq & Ifrefr & rerga & slfiff & veirq & $r \cdot q \cdot q \cdot 1$ & زن ....................... \\
\hline TyFe & r\& & IGTT & $019 T$ & DrTGA & NrGG & آذربايجان شرقى ... \\
\hline $1 r \Delta \Lambda$ & rAT & $\Delta V r$ & FAT.r & $V \cdot r I$ & 99994 & آذربايجان غربى ............. \\
\hline TIVV & IFT & । $Q 9 \vee \wedge$ & F^s & 1991 & TVTAY & 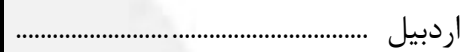 \\
\hline TFET & NISTF & 1.9 & TQI & 194 & I TrMAS & |صفهان ........ \\
\hline THIDS & $1 \% 19$ & Gru & $\Delta F$. & ITEV & VDIFV & 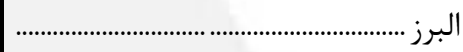 \\
\hline vra & TAF & ra & GT & $\Delta 9$ & 19Arr & 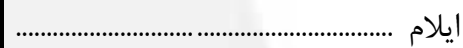 \\
\hline rVA & זrזr & (i) & $10 \mathrm{~V}$ & $|4|$ & rrq94 & بوشهر ......... \\
\hline r\&\&V & 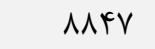 & $r \cdots v$ & rیM9 & 9940 & r.rRiV & تهران .................... \\
\hline 199 & 1. FV & 11 & rq & rt & 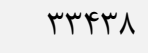 & جهارمحال و بختيارى ........ \\
\hline ris & TQ9 & $\wedge$ & ir & 19 & rl.qf & 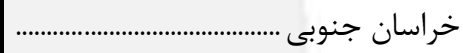 \\
\hline rMNI & $1 F \cdot r$ & $1 \cdot 1$ & $r \cdot q$ & $r \cdot r$ & IFATFV & خراسان رضوى ....... \\
\hline VDS & t. & 4 & re & is & ए।人१५ & خراسان شمالى ........ \\
\hline DQAT & $|\Delta| \Delta T$ & $1 \cdot r$ & rq. & req & $11199 \mathrm{~V}$ & 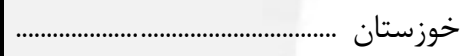 \\
\hline rघ9 & rl. & ITV & tra & rq. & r.tri & زنجان ...................... \\
\hline FTr & THF & $r \cdot$ & GT & V^ & $190 \cdot r$ & 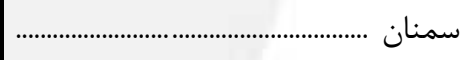 \\
\hline $9 \Delta V$ & จ१९ & rv & iv & Ar & $\Delta 1 \cdots \Delta$ & سيستان و بلوجستان ... \\
\hline $11 \cdot v$ & एव१९ & vi & Trt & r@9 & וrqr.r & 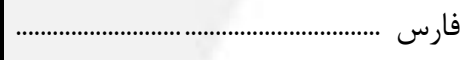 \\
\hline rrvi & TVF & $\wedge 1$ & rq. & re. & F्9वर & 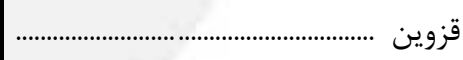 \\
\hline llaF & $11 \cdot 9$ & $|r|$ & teT & $\Delta 11$ & TrRtr & قم ............................. \\
\hline r"ql & rTV & $1 \cdot v$ & 1979 & $\Delta G T$ & $\Delta q \wedge F\rangle$ & كردستان .................. \\
\hline VKG & $|r 9|$ & fF & 90 & 199 & $\Delta G Y \Delta T$ & 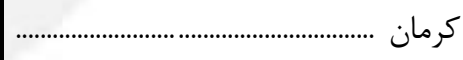 \\
\hline$V \cdot r q$ & $|r| \cdot$ & 94 & $r \Delta V$ & TFF & GMTFF & 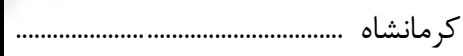 \\
\hline Ifr & 1 1r49 & ir & TF & r & MIrAF & كهخيلويه و بويراحمد ......... \\
\hline 911 & rᄉ. & 4. & $\Lambda$ & שrו & DF्व & 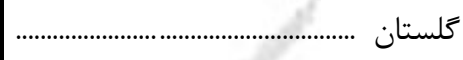 \\
\hline FYFA & v99 & $\mid \Delta \wedge 1$ & $r$ r. & FAF & $V F \| 1$ & كيلان ....................... \\
\hline FATr & $r F \Delta \Delta$ & rV & 99 & $9 \wedge$ & $\Delta \wedge q \vee r$ & 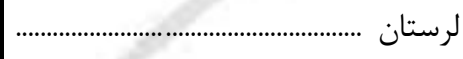 \\
\hline TrAT & $\Lambda \cdot r$ & rᄉl & 191 & rMA & 99५^. & مازندران ........... \\
\hline $191 \pi$ & $19 \Delta 1$ & re & IrF & 119 & frgve & 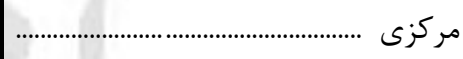 \\
\hline vi. & ITVT & 41 & $|1|$ & r. & FETOA & هرمز \\
\hline $4 q \cdot 1$ & 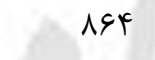 & $\Delta \cdot$ & ler & rrv & $\Delta \Delta \& \mid \Delta$ & 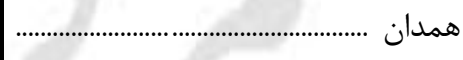 \\
\hline VQT & $|T \Delta|$ & ґ^ & re & $\wedge$ & $r \cdot \lambda \mu r$ & 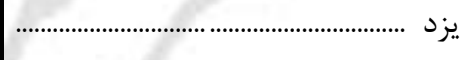 \\
\hline r & rir & i & $\wedge$ & $1 \cdot 1$ & $19 \pi \mathrm{V}$ & اظهار نشده استان ........ \\
\hline rres & $r \cdot r \Delta$ & $9 \mathrm{~V}$ & MFV & rQq & $r \wedge \Delta \cdot r$ & 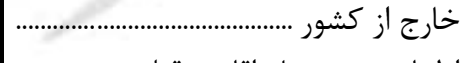 \\
\hline 110 & $r$ ru & Fr & $1 M F$ & זעז & $\Delta \cdot+1$ & اظهار نشده محل اقامت قبلى ............... \\
\hline
\end{tabular}


^ - 1 - مهاجران وارد شده طى ه سال حذشته بر حسب جنس، استان محل اقامت قبلى و فعلى (بـر اســاس آخــرين جابجـايى (كل)

انجام شده)(دنباله)

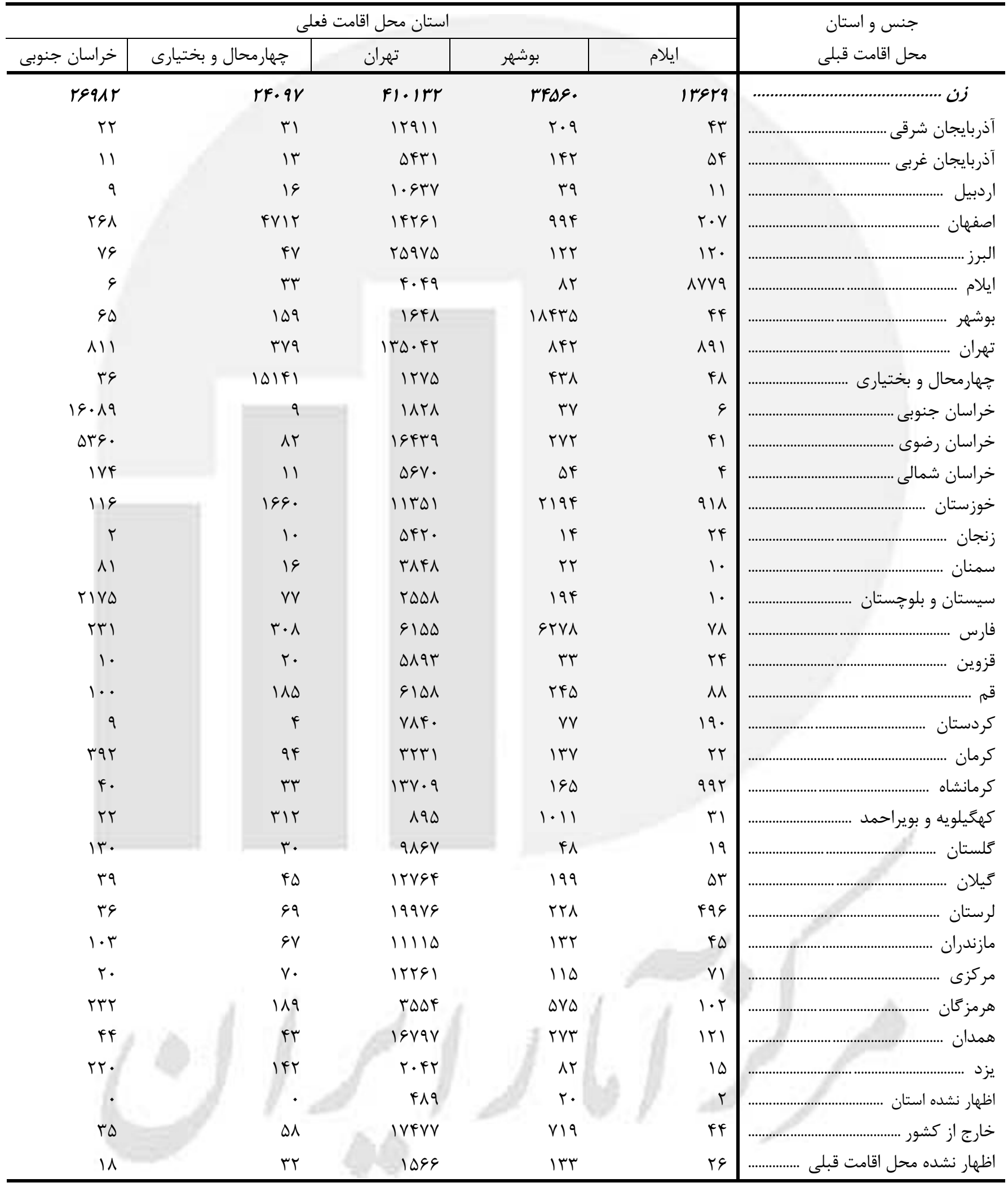


| نتايج تفصيلى سرشمارى عمومى نفوس و مسكن _هQ

^ - ا- مهاجران وارد شده طى ه سال حَذشته بر حسب جنس، استان محل اقامت قبلى و فعلـى (بــر اســاس آخــرين جابجـايى (كل)

انجام شده)(دنباله)

\begin{tabular}{|c|c|c|c|c|c|c|}
\hline \multicolumn{6}{|c|}{ استان محل اقامت فعلى } & \multirow{2}{*}{ جحل اقامت قوبلى } \\
\hline | سيستان و بلوجستان & سمنان & 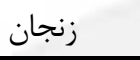 & 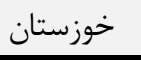 & خراسان شمالى & خراسان رضوى & \\
\hline ( - le & $r \mu q=1$ & rraAr & $1 \cdot V \Delta S$ & TFAFT & $|\Delta F| \cdot q$ & 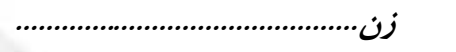 \\
\hline ITV & ITV & ATV & rTq & tr & 491 & 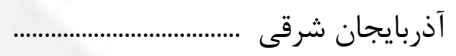 \\
\hline 99 & 195 & G.r & lQT & IV & $r \cdot 9$ & آذربايجان غربى ............... \\
\hline$r$. & r. & TDS & $\Delta F$ & 11 & Irk & 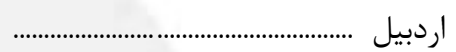 \\
\hline mid & $111 r$ & IVF & rq1ब & $14 q$ & $|V T|$ & اصفهان .................... \\
\hline 1.9 & 1.9 . & $19 \%$. & זrא & rq. & ITED & 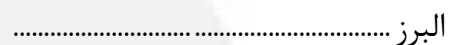 \\
\hline 9 & rat & r & ITFD & $\checkmark$ & 99 & 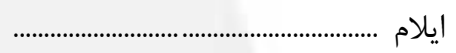 \\
\hline 19 & raf & rA & $1 . r T$ & re & $r \Delta \varphi$ & 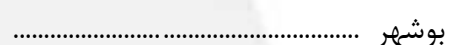 \\
\hline 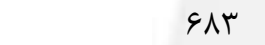 & MANT & & $r \Delta \cdot V$ & שזוז & I.TYT & تهران ....................... \\
\hline 99 & $r \wedge \Delta$ & rq & 19T4 & 11 & IVF & جهارمحال و بختيارى ...................... \\
\hline Irmy & Fir & If & re & TrT & $\Lambda \triangle Q K$ & 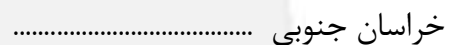 \\
\hline tr. & $r 9 \Delta \Lambda$ & IDT & $0 \cdot 9$ & FAVQ & $9 \Delta \Delta \wedge \Lambda$ & خراسان رضوى ............... \\
\hline $1 \wedge$. & VTE & ז & et & $1 F \cdot v q$ & $999 \mathrm{~V}$ & خراسان شمالى ...................... \\
\hline q & Q11 & 19. & DFATq & 99 & rq9. & خوزستان ......................... \\
\hline TF & $1 \wedge \Delta$ & $\mid \Delta \varphi \wedge$. & 91 & r & $I \Delta V$ & 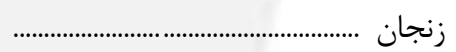 \\
\hline 1.1 & 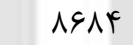 & q4 & 91 & TVA & $10 \Lambda \mathrm{r}$ & سمنان .................... سمن \\
\hline rबQQY & $4 .$. & \&A & 19 & MIs & VMFE & سيستان و بلوج \\
\hline$\Delta Y F$ & $\Delta \cdot V$ & 111 & $r \cdot V \varphi$ & $1 \cdot 1$ & $1 \cdot r \wedge$ & فارس .................................. \\
\hline rq & tru & $|09|$ & $\wedge$ & tr & TRI & قزوين .............................. \\
\hline $1 \Delta F$ & Far & هIT & $\Delta V \mathrm{~V}$ & $1 \cdot V$ & 119 & 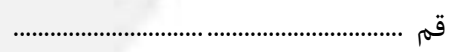 \\
\hline rA & 11. & V^I & reV & $r$. & אוr & 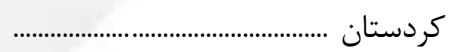 \\
\hline 19人r & $|V|$ & FA & TAF & 1.9 & 11190 & 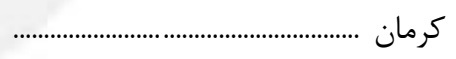 \\
\hline vT & TFE & 119 & VrI & 19 & ra. & كرمانشاه .......................... \\
\hline$\Delta \cdot$ & $\Delta \Lambda$ & tr & rata & 9 & $9 V$ & كمخَيلويه و بويرا- \\
\hline 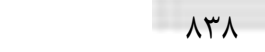 & TVTS & VT & 111 & १९४ & $r \Delta \cdot \varphi$ & كلستان \\
\hline IAV & $r 90$ & $\Delta T r$ & r.. & V. & vVq & 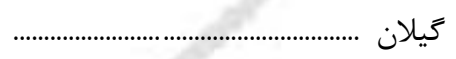 \\
\hline v. & r\&q & 90 & TREV & Tr & rre & لرستان ....... \\
\hline 519 & IVGA & rI. & rघ9 & krq & IVT. & مازندران ........ \\
\hline pr & גזr & $11 \mathrm{~V}$ & eqr & rq & rq1 & 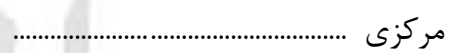 \\
\hline Far & $|\Delta|$ & ia & FAT & ITK & ITFE & 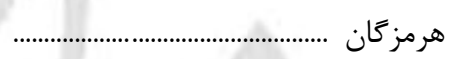 \\
\hline 94 & IDT & req & squ & ro & $r \Delta \varphi$ & همدان ......... \\
\hline$r \cdot q$ & 111 & rr & rV & rt & $१ ८ १$ & 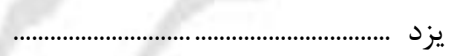 \\
\hline r) & 94 & $\Delta$ & 7 & r & TrF & اظهار نشده استان .................. \\
\hline rr. & IfF & ᄉr & $\Delta \Delta F^{F}$ & fr & roqV & 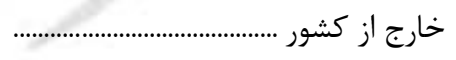 \\
\hline $1 F \Delta$ & rA & 10 & Far & $|r|$ & FrA & اظهار نشده محل اقامت قبلى .............. \\
\hline
\end{tabular}


^ - ا- مهاجران وارد شده طى ه سال كَذشته بر حسب جنس، استان محل اقامت قبلى و فعلـى (بـر اســاس آخــرين جابجـايى (كل)

انجام شده)(دنباله)

\begin{tabular}{|c|c|c|c|c|c|}
\hline \multicolumn{5}{|c|}{ استان محل اقامت فعلى } & \multirow{2}{*}{ محل اقامت و استان } \\
\hline 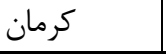 & كردستان & قم & قزوين & فارس & \\
\hline FFAIF & $\Delta F \cdot q \Delta$ & $r q \cdot r \mu$ & frate & $|r| f \mid$ & 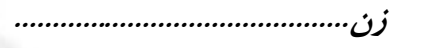 \\
\hline $1 \cdot 1$ & $\Delta \vee q$ & 1111 & VVG & rఎq & 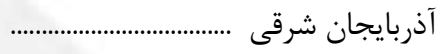 \\
\hline $1 \cdots$ & $r \cdot r \Lambda$ & FFV & $q q$. & $1 \wedge$ & 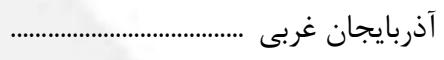 \\
\hline \&V & GT & ru & $1 \wedge \Lambda$ & $1 \cdot 1$ & 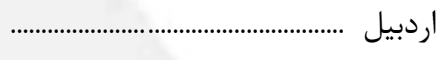 \\
\hline grv & r\&l & rqq4 & $r 9 \Lambda$ & $r \cdot \Lambda l$ & 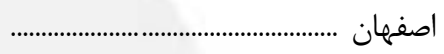 \\
\hline rin & $\wedge \cdot \cdot$ & $11 \Delta T$ & r999 & 499 & 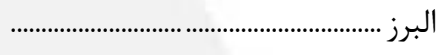 \\
\hline rᄉ & my. & rq1 & 94 & $1 \cdot 1$ & 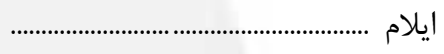 \\
\hline $1 \cdot r$ & $\Delta 9$ & rvq & is & $\Delta \mu^{\prime} \cdot$ & 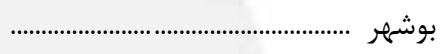 \\
\hline 111. & $r v \cdot 1$ & GMII & FFFV & 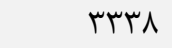 & 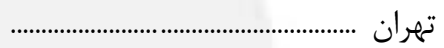 \\
\hline IrA & id & $r \Delta \cdot$ & $f \Delta$ & $\Delta \vee \Delta$ & جهارمحال و بختيارى ........ \\
\hline IfT & V & trd & IV & 94 & خراسان جنوبى .......................... \\
\hline $\operatorname{Vid}$ & $9 \cdot$ & $119 \mathrm{~V}$ & rAץ & VAD & 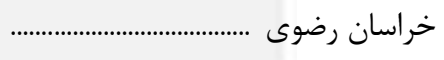 \\
\hline 111 & If & 11 & pr & V & 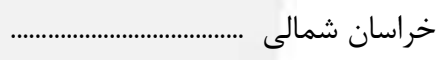 \\
\hline ror & $F \Delta V$ & rqr. & mFl & fras & خوزستان ....................... \\
\hline is & $4 q 1$ & $1 \cdots r$ & lq94 & 94 & زنجان ........................ \\
\hline$\Delta 1$ & $\wedge \Delta$ & reg & $\wedge$. & $1 \cdot 1$ & 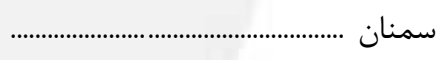 \\
\hline ITVA & VV & $r \cdot \wedge$ & $|r|$ & $\vee 19$ & 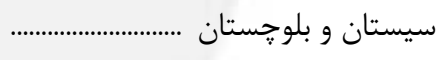 \\
\hline $\mid \Delta F \Delta$ & 199 & ITAK & Ir & $\wedge 9 \Delta / l^{k}$ & 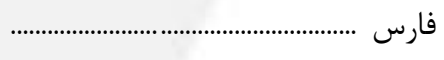 \\
\hline$\Delta \wedge$ & Far & $|\wedge \wedge|$ & rq४V. & $1 \cdot 0$ & 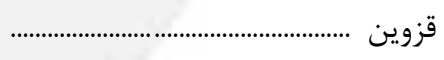 \\
\hline ऍ^9 & rVD & rtQA & एदा & $\Delta r V$ & 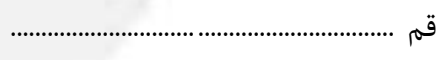 \\
\hline f. & 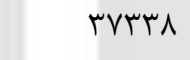 & rVD & $\Delta \cdot \Delta$ & $r \cdot q$ & 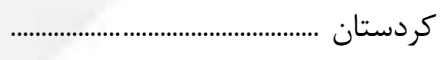 \\
\hline TTVRT & FV & $1 \cdot 94$ & $v r$ & IDFV & 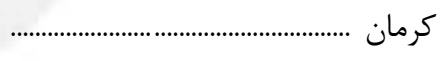 \\
\hline VV & $r \mu \Delta \Lambda$ & $\vee \wedge 1$ & NFI & ras & 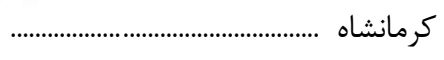 \\
\hline is & 10 & roq & 19 & rDFV & كهَيلويه و بويراحمد ........ \\
\hline 11 & IrG & rvq & IfD & $|\Delta|$ & 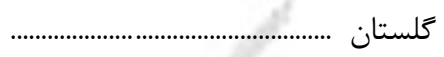 \\
\hline 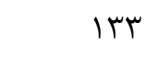 & $r / D$ & G人F & rqT. & מצr & 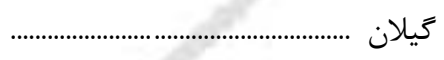 \\
\hline אוז & ( & 1919 & 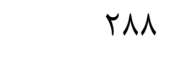 & fqv & 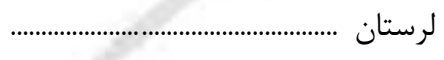 \\
\hline Ir & tiA & 999 & rat & $r \cdot v$ & 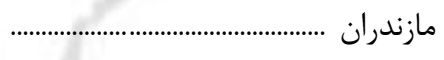 \\
\hline Vq & TIQ & tell & Tat & q q & 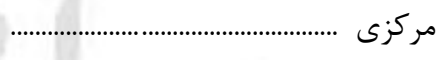 \\
\hline$I \vee \wedge \Delta$ & MF & $r \Delta V$ & 118 & ५१९ा & 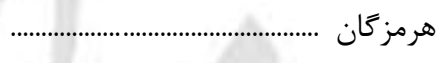 \\
\hline 115 & 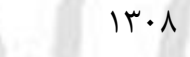 & r)Q9 & rFd & $\Delta 91$ & همدان ................ \\
\hline 1189 & rt & $\uparrow \wedge \varphi$ & $\Delta r$ & $|f| 0$ & 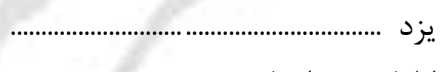 \\
\hline $2 \cdot v^{2}$ & 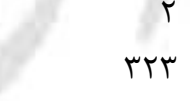 & 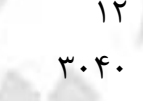 & $r$ & $\begin{array}{l}\text { tht } \\
\text { thI }\end{array}$ & 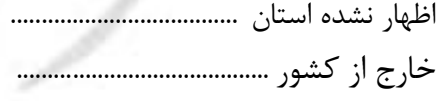 \\
\hline$r \cdot l$ & If & س & $r \Delta$ & Ift & اظهار نشده محل اقامت قبلى ............ \\
\hline
\end{tabular}


| نتايج تفصيلى سرشمارى عمومى نفوس و مسكن _ه

^ - ا- مهاجران وارد شده طى ه سال حَذشته بر حسب جنس، استان محل اقامت قبلى و فعلـى (بــر اســاس آخــرين جابجـايى (كل)

انجام شده)(دنباله)

\begin{tabular}{|c|c|c|c|c|c|}
\hline \multicolumn{5}{|c|}{ استان محل اقامت فعلى } & \multirow{2}{*}{ محل اقامت ق قبلى } \\
\hline 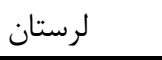 & 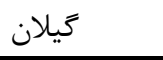 & كلستان & كهيَيلويه و بويراحمد & كرمانشاه & \\
\hline$r 9 \cdot 11$ & valuf & evrer & T\&\& & frerta & 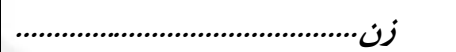 \\
\hline$\Delta \Lambda$ & $\Delta r V$ & 1 Ir & 1 & IV9 & 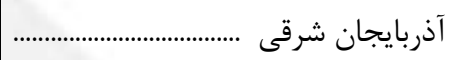 \\
\hline$\Delta V$ & rब9 & 91 & 1 & זוץ & 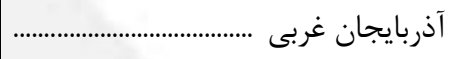 \\
\hline$r$. & rqVD & r. & r & sq & 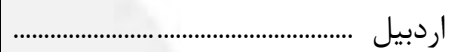 \\
\hline ITEK & $1 . r \Delta$ & $r 90$ & $V q$ & vis & 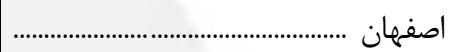 \\
\hline GTr & $r \Delta \Lambda 1$ & r.r & r & lQ9T & 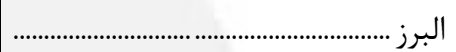 \\
\hline pre & $\vee \cdot$ & rq & 1 & | (1). & ايلام ..................................................... \\
\hline 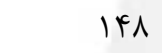 & fqf & Ve & is & 194 & بوشهر ................................ \\
\hline rQGF & ITET. & rol. & re & rept & تهران ............................. \\
\hline Irr & vq & is & rq & v) & 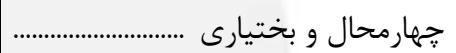 \\
\hline 19 & $4 q$ & 199 & 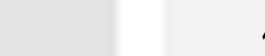 & 19 & 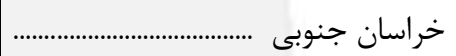 \\
\hline 110 & १४१ & trVte & r & IAV & 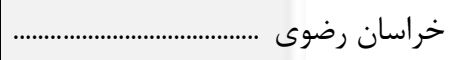 \\
\hline$\Delta$ & $1 \cdot f^{2}$ & $9 \vee 1$ & & 19 & خراسان شمالى .................... \\
\hline rTAג & 915 & או & If. & $1 \cdot v \cdot$ & 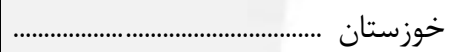 \\
\hline FV & V^। & 91 & 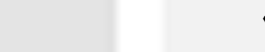 & $v \wedge$ & زنجان ................................. \\
\hline$\Delta f$ & IVF & lefq & & fr & 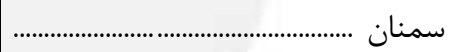 \\
\hline VV & fis & rADT & r & 49 & 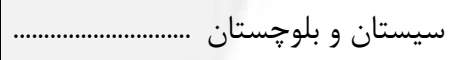 \\
\hline rtv & \&ri & IN & $r \wedge \cdot$ & rTK & فارس .................................... \\
\hline$\Delta r$ & rI99 & $\wedge$ & 1 & TAS & قزوين ............................... \\
\hline fir & GKT & r\$4 & 1. & TYV & 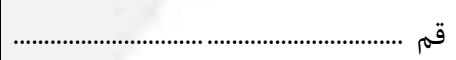 \\
\hline fVq & riv & 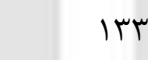 & 1 & reT. & 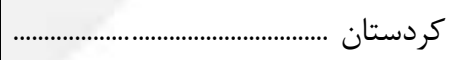 \\
\hline VQ & rघ9 & Ifr & 4 & $11 \pi$ & 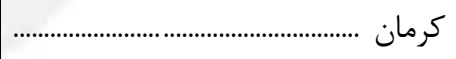 \\
\hline$\vee 9 \Delta$ & 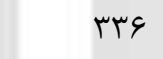 & 110 & r & rovA. & 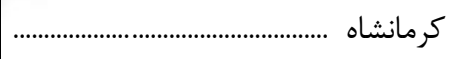 \\
\hline VD & Tr & r & 1971 & fq & كهخيلويه و بويراحمد .... \\
\hline rq & ras & $r \cdot 1 \cdot 1$ & & $\Delta \varphi$ & كلستان ....................... \\
\hline vq & FTG.r & 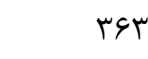 & & 109 & كيلان ................................. \\
\hline losts & 199 & VT & $r$ & $1 r \Delta \Delta$ & 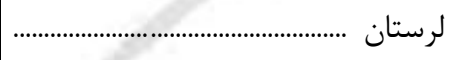 \\
\hline 114 & TVMT & rIOA & r & $1 \wedge$. & 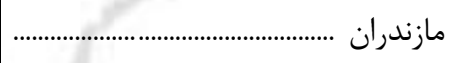 \\
\hline 919 & $\vee \wedge \cdot$ & 99 & r & $\Delta \vee q$ & 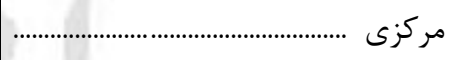 \\
\hline rAl & IVVV & rI9 & le & $f \cdot 9$ & 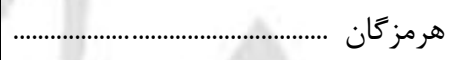 \\
\hline 019 & rat & 49 & $1 \cdot$ & IDTT & 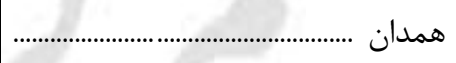 \\
\hline$|f|$ & irv & lFF & $q$ & $1 \cdot v$ & 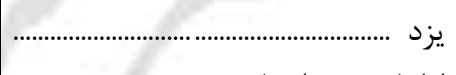 \\
\hline is & $\begin{array}{l}\text { If } \\
\text { rq. }\end{array}$ & $\begin{aligned} r \\
r \cdot 1\end{aligned}$ & $\Delta$ & $\begin{aligned} r \\
r I 1\end{aligned}$ & خارج از كشور .................................. \\
\hline rQ & rF & $\Delta F$ & 1 & GT & اظهار نشده محل اقامت قبلى ............ \\
\hline
\end{tabular}


191

| نتايج تفصيلى سرشمارى عمومى نفوس و مسكن _MD

^ - ا- مهاجران وارد شده طى ه سال تذشته بر حسب جنس، استان محل اقامت قبلى و فعلى (بر اساس آخرين جابجايى انجـام (كل)

شده)(دنباله)

\begin{tabular}{|c|c|c|c|c|c|}
\hline \multicolumn{5}{|c|}{ استان محل اقامت فعلى } & \multirow{2}{*}{ محل اقامت قبلى و استان } \\
\hline 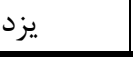 & همدان & هرمزكان & 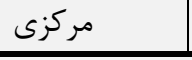 & مازندران & \\
\hline relas & $f \cdot 19 f$ & Drera & $f \cdot I F V$ & VAFFT & 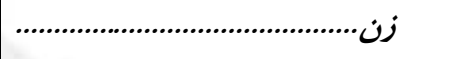 \\
\hline 91 & IVT & $\Delta F F$ & IrT & $r 90$ & 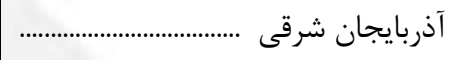 \\
\hline$\Delta 9$ & 511 & TIN & lar & riv & 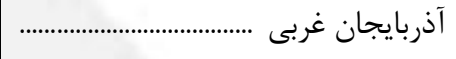 \\
\hline 91 & is & 14 . & $V v^{c}$ & 901 & 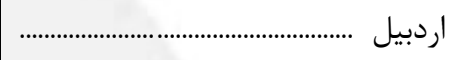 \\
\hline TAFT & 110 & 1481 & lQVFe & 1111 & اصفهان ................ \\
\hline ఎqV & irat & FAS & $\wedge \vee \cdot$ & $194 \mathrm{~F}$ & 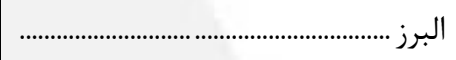 \\
\hline py & MIV & mFF & r\$9 & $1 \Delta \Delta$ & 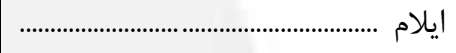 \\
\hline IVT & TrF & NAT & 114 & 191 & 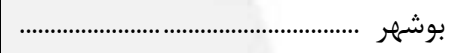 \\
\hline rivq & DIrA & TVAT & $9.9 \mathrm{~V}$ & 11811 & تهران ................................ \\
\hline NFF & IrV & 019 & IDT & Ifr & 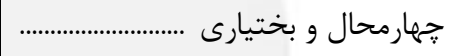 \\
\hline ^9т & rt & AF & $r$. & IVA & 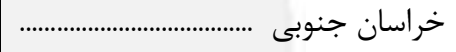 \\
\hline lofF & IVD & Irt. & rrq & TQ৭D & 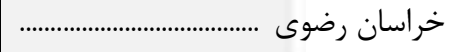 \\
\hline 111 & rt & rru & ITV & ITVD & خراسان شمالى ............ \\
\hline rq9V & $111 \%$ & १९९ & $|f| 1$ & Vri & 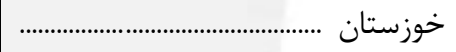 \\
\hline rq & $1 \wedge$. & $\wedge$. & $1 \cdot 1$ & טגו & 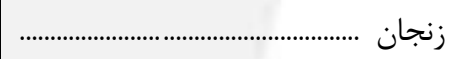 \\
\hline ve & १४ & $\Lambda$ & $\wedge 1$ & $|r| 9$ & 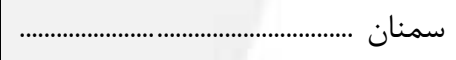 \\
\hline 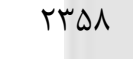 & $11 r$ & 1114 & $1 \Delta V$ & $99 \mathrm{~V}$ & 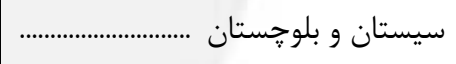 \\
\hline frry & frv & $V \cdot r t$ & $r \Delta \Lambda$ & rA. & 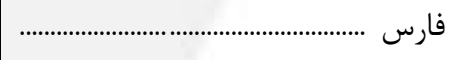 \\
\hline$\Lambda r$ & rFq & 91 & IDT & FVe & 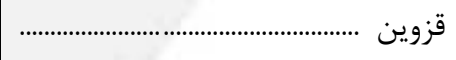 \\
\hline$\Delta T \Delta$ & NT\& & $r \cdot r$ & 19. & var & 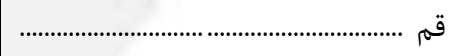 \\
\hline sq & rri. & 199 & rmq & rrq & 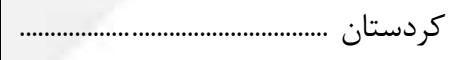 \\
\hline$r \cdot \Delta \Lambda$ & 11. & FAFt & 1.9 & $r \cdot$. & 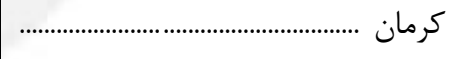 \\
\hline rTa & rmt & $9 \Delta \Delta$ & IrqF & $\Delta \cdot V$ & 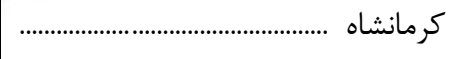 \\
\hline TaF & 19 & $r \Delta \cdot$ & $1 \cdot 1$ & 4. & كهيَيلويه و بويراحمد \\
\hline rV^ & 41 & erq & 194 & TrYi & 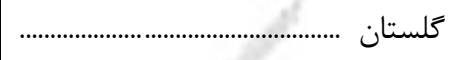 \\
\hline lAF & TQT & $11 \Delta V$ & $\Delta T \Delta$ & rmal & 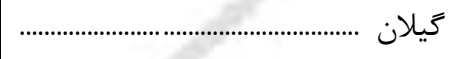 \\
\hline vil & 1191 & G4T & TFD. & 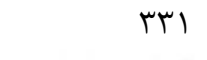 & 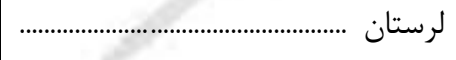 \\
\hline$r \cdot F$ & TrQ & V99 & rq. & $r \cdot \Delta \Lambda \Lambda$ & مازندران ................. \\
\hline $1 \cdot r$ & $111 r$ & TVT & $1 \wedge v \cdot V$ & reV & 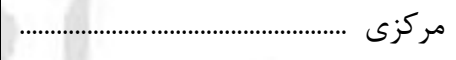 \\
\hline ITrV & rqv & TYAGT & 195 & $1 \cdot 9$ & 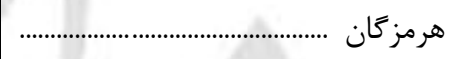 \\
\hline irf & $r \cdot 9 \wedge \Delta$ & 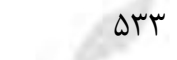 & 109. & fir & همدان ........................ \\
\hline $91 \cdot 9$ & VD & $\Delta r \cdot$ & 94 & 199 & يزد ......................................................... \\
\hline 10 & if & $r$ & $\Lambda$ & V & 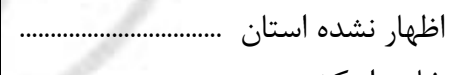 \\
\hline il. & $1 \cdot 4$ & 111 & kqr & rq. & خارج از كشور ........................................ \\
\hline$\Lambda \vee$ & $\vee \cdot$ & $\Delta \Lambda$ & 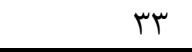 & $1 F \Delta$ & 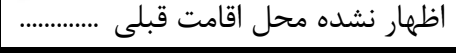 \\
\hline
\end{tabular}




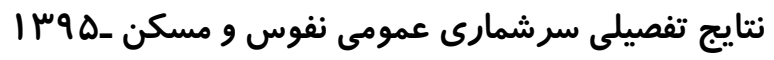

^ - ا- مهاجران وارد شده طى ه سال كذشته بر حسب جنس، استان محل اقامت قبلى و فعلى (بر اساس آخرين جابجايى انجـام (نقاط شهرى)

شده)(دنباله)

\begin{tabular}{|c|c|c|c|c|c|c|}
\hline \multicolumn{6}{|c|}{ استان محل اقامت فعلى } & \multirow{2}{*}{ محل اقامت ق قبلى } \\
\hline 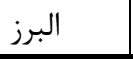 & اصفهان & 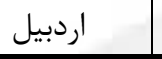 & آذربايجان غربى & آذربايجان شرقى & جمع - la & \\
\hline rFa. rq & revria & F\&A\&D & $A V F \Delta \Lambda$ & $14 \cdot 11 \mathrm{~V}$ & raffrra & 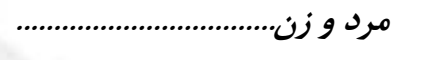 \\
\hline vrqu & qrr & TIMA & qHFV & $M N \cdot N r$ & $\mid F \wedge 910$ & 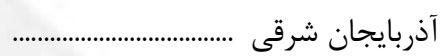 \\
\hline rall & gFt & 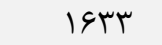 & $\Delta q \Delta F V$ & ITrVq & $1 . .991$ & آذربايجان غربى ............. \\
\hline firq & MFI & TEFTV & १४४ & rQFF & GGTIV & 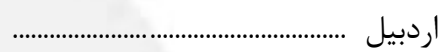 \\
\hline FeVt & $|f| g r t$ & TFA & $\forall \& \Delta$ & $\wedge \vee \wedge$ & rTarAh & اصفهان ................ \\
\hline rarto & rI9V & $11 \wedge \Delta$ & 948 & TIDF & 141914 & البرز ............................... \\
\hline lfqT & 919 & FV & $\wedge \Delta$ & 11. & $r \Delta \Delta \Delta q$ & 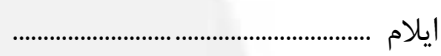 \\
\hline$v \Delta \Delta$ & $r \Delta \Delta \Lambda$ & 1.9 & TAY & rAl & DSVGT & بوشهر .................. \\
\hline$\Lambda \Delta q \cdot V$ & 109Я & VदYq & $\Delta \wedge V T$ & 11499 & 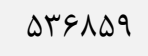 & 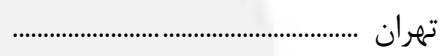 \\
\hline rvq & $19 \cdot \Delta \Lambda$ & 19 & $\Delta F$ & VT & $G \cdot r \Lambda$ & 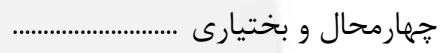 \\
\hline$|+|$ & ४१९ & IV & $\Delta \varphi$ & rq & 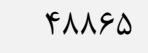 & 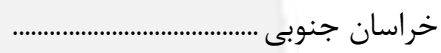 \\
\hline FrTV & $r \varphi \Delta \Lambda$ & rø9 & rVv & VVG & TRATVF & 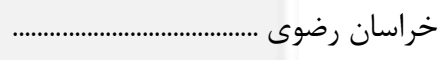 \\
\hline lfer & fif & rI & i^ & $1 \cdot 0$ & $\Delta T V I$. & خراسان شمالى ........... \\
\hline llfar & r^६91 & TrE & $\Delta I_{1}$ & $99 \mathrm{~V}$ & TIFTIS & 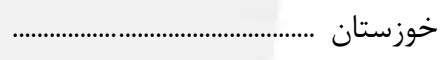 \\
\hline 0110 & $r 90$ & TMA & kq9 & VधA & $\Delta T Q 9 \Delta$ & 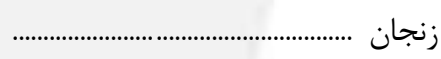 \\
\hline$\Lambda \cdot r$ & k\&q & VF & Iro & 194 & TrGDG & 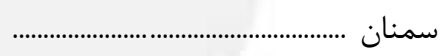 \\
\hline IrIT & $1 \wedge \vee 9$ & 114 & $1 \cdot 9$ & lNT & ArqIV & سيستان و بلوجستان ..... \\
\hline r.१९ & $V F \cdot F$ & 190 & ra & 499 & TrATVE & فارس .................................. \\
\hline GITQ & $\Delta \& q$ & ler & FAF & $9 .$. & איזאו & 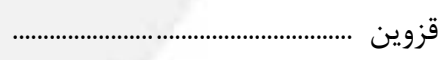 \\
\hline Tre & $r \varphi \cdot \Delta$ & TFD & $\Delta \cdot$ & NFV & $r \cdot \Delta \& q$ & 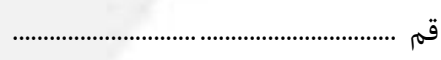 \\
\hline एव१९ & $\wedge \vee \Delta$ & tVF & rQG4 & ITFF & $9 \wedge \Leftrightarrow 9 \Delta$ & 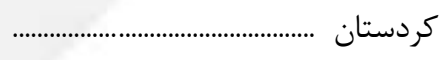 \\
\hline$|r v|$ & ro19 & $1 \cdot 1$ & IQT & $r \cdot 9$ & NFqve & 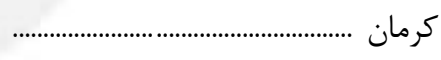 \\
\hline IrVAT & $r V \cdot \Lambda$ & $r \cdot r$ & $\Delta \Delta \varphi$ & FAD & IIrGAV & 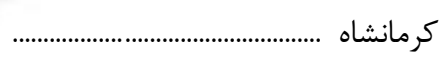 \\
\hline MTF & TEYV & re & pq & r. & r\&411 & كهَيلويه و بويراحمد ......... \\
\hline 1919 & VIf & 111 & IVT & THt & VDADT & 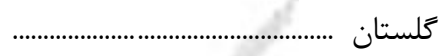 \\
\hline$\vee \Delta \wedge q$ & Ifrr & T\&\&4 & Fr. & V৭V & 114109 & 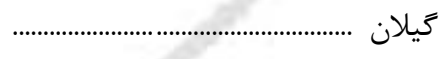 \\
\hline 19\%9 & 9494 & v. & IVV & lNr & $1 . \Delta 99 F$ & 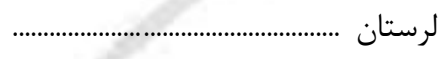 \\
\hline$f \cdot \Delta \Delta$ & IDST & VIV & rq४ & 019 & 99994 & 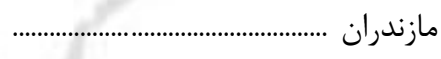 \\
\hline reqq & 4111 & VA & $r \Delta \varphi$ & TrI & VदY & 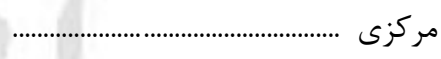 \\
\hline levr & ror. & (rt & rat & ఎq & VDIAF & هرمز \\
\hline$q 4 \vee q$ & 1991 & Irt & $r \cdot r$ & erg & $q \wedge r \cdot r$ & 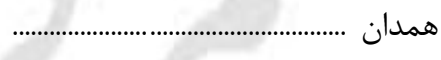 \\
\hline$|r \Delta|$ & rQAD & $\wedge f$ & Vr & 194 & rolrq & 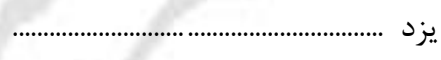 \\
\hline $\begin{array}{l}\text { Fr } \\
\text { DII. }\end{array}$ & $\begin{array}{l}\text { HKS } \\
\text { VIMA }\end{array}$ & $\begin{array}{r}\Delta \\
10 \Delta\end{array}$ & $\begin{array}{l}\text { ir } \\
\text { Vrr }\end{array}$ & $\begin{array}{l}111 \\
9.5\end{array}$ & $\begin{array}{l}\text { TrGq } \\
\text { qFYID }\end{array}$ & خارج از كشور .............. \\
\hline$r$ r. & एव9 & rq & $r \omega$. & DIT & 994. & اظهار نشده محل اقامت قبلى ............. \\
\hline
\end{tabular}


^ - ا- مهاجران وارد شده طى ه سال كذشته بر حسب جنس، استان محل اقامت قبلى و فعلى (بر اساس آخرين جابجايى انجـام (نقاط شهرى)

شده)(دنباله)

\begin{tabular}{|c|c|c|c|c|c|}
\hline \multicolumn{5}{|c|}{ استان محل اقامت فعلى } & \multirow{2}{*}{ محل اقامت قبلى استان } \\
\hline خراسان جنوبى & جهارمحال و بختيارى & 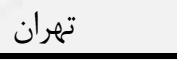 & 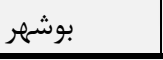 & 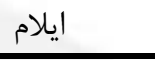 & \\
\hline frels & fl. rr & $r v \cdot r r q$ & garql & rrasa & 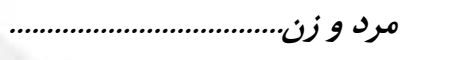 \\
\hline st & $9 V$ & ro190 & in & 191 & 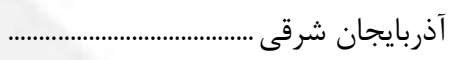 \\
\hline pr & r. & $11 r \cdot 1$ & 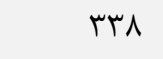 & IVT & 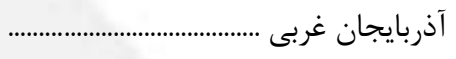 \\
\hline rq & r & $r \cdot \Delta r$ & $1 \cdots$ & ו & 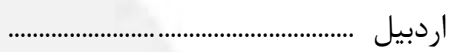 \\
\hline 915 & VTrQ & ra91r & rTQQ & krq & |صفهان ........................... \\
\hline rat & $1 \cdot 1$ & FATSD & rघ9 & TTE & 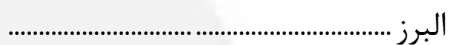 \\
\hline 19 & va & NTr. & $1 \wedge \Delta$ & IFETH & 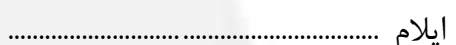 \\
\hline 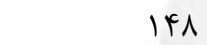 & ऍ१ & זqזr & TAFAK & 110 & 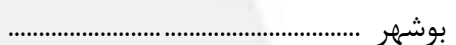 \\
\hline IF\& & 111 & 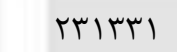 & IAv. & 1910 & 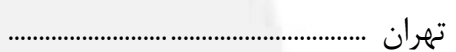 \\
\hline 99 & TQSM & TATV & 1 IrGA & $1 \cdot 9$ & 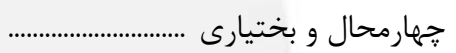 \\
\hline$r) \cdot r$ & tr & raps & $\Lambda$ & it & خراسان جنوبى ............... \\
\hline 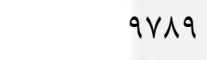 & IV. & TITAV & Dre & $\wedge 1$ & 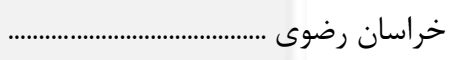 \\
\hline$\Delta \& \Lambda$ & 19 & سז1• & 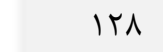 & 9 & خراسان شمالى .............. \\
\hline TFE & rVQI & $t r \cdot \pi$ & $\Delta F \cdot V$ & IVIS & خوزستان ....................... \\
\hline it & r & $1 \cdots \Delta V$ & i) & $\Delta \varphi$ & زنجان ........................ \\
\hline IVV & i) & VIFt & $\Delta V$ & rA & سمنان ...................... \\
\hline rFAl & IVV & сqтq & 9lf & IV & 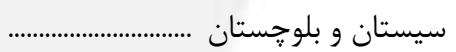 \\
\hline Fへ૬ & D\&N & $I T F \cdot \Delta$ & ITTFA & $1 \wedge 0$ & فارس ...................... \\
\hline AT & rᄉ & $\mid 1 r 1$. & vq & Fa & 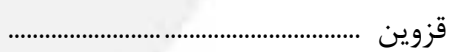 \\
\hline 199 & rFe & $11 r 91$ & ५१९ & $1 \vee 9$ & 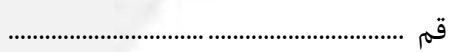 \\
\hline بs & me & $|\Delta \& \Delta|$ & rl. & fqV & 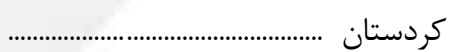 \\
\hline$V \cdot f$ & $1 \Lambda$. & gDrT & TQF & Fr & 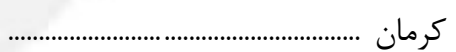 \\
\hline VQ & $1 \cdot e^{4}$ & TVTFY & ret & $I V \cdot V$ & 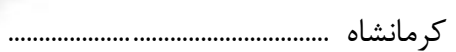 \\
\hline$f \Delta$ & ill & $r \cdot 9 V$ & $19 \vee 9$ & 90 & كهيَيلويه و بويراحمد ...... \\
\hline VFr & 94 & IVVGa & $1 \cdot r$ & (i) & كلستان ... \\
\hline 94 & 94 & $r r \Delta \varphi l$ & evr & $1 \cdot \Delta$ & 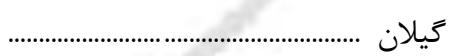 \\
\hline$q V$ & I T & $r q 1 \Delta$. & $\Delta \wedge 9$ & 910 & لرستان ................. \\
\hline 90. & $1 \mathrm{k}$ & $r_{1} \cdots r$ & ro & $1 \cdot 1$ & 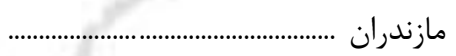 \\
\hline fF & If. & trVQN & rqv & 11. & مركزى ................................ \\
\hline r9ब & krq & VTDQ & ITKT & 199 & 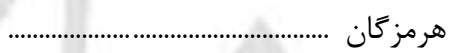 \\
\hline$\wedge \vee$ & ^ & rivVF & $9 \Delta \Delta$ & $r \cdot \Delta$ & همدان ................... \\
\hline FrF & $r \cdot r$ & rtar & 199 & Tr & 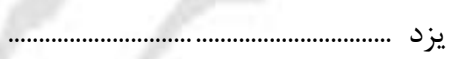 \\
\hline ra & IV & 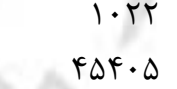 & 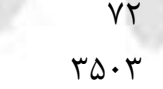 & r & 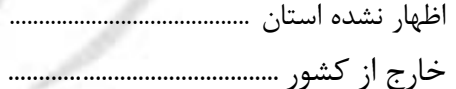 \\
\hline זr & 4. & TYYA & IAr & (4) & اظهار نشده محل اقامت قبلى .............. \\
\hline
\end{tabular}


| نتايج تفصيلى سرشمارى عمومى نفوس و مسكن _هQ

^ - ا- مهاجران وارد شده طى ه سال كذشته بر حسب جنس، استان محل اقامت قبلى و فعلى (بر اساس آخرين جابجايى انجـام (نقاط شهرى)

شده)(دنباله)

\begin{tabular}{|c|c|c|c|c|c|c|}
\hline \multicolumn{6}{|c|}{ استان محل اقامت فعلى } & \multirow{2}{*}{ محل اقامت ق قبلى } \\
\hline سيستان و بلوجستان & سمنان & 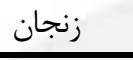 & خوزستان & خراسان شمالى & خراسان رضوى & \\
\hline spafi & $\Delta 9899$ & Frats & If.ITE & $r v r \cdot q$ & repres & 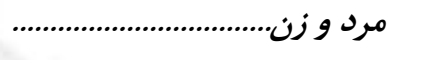 \\
\hline$r \cdot q$ & rAV & Irat & 019 & $\Delta r$ & $1 \cdot \Delta r$ & 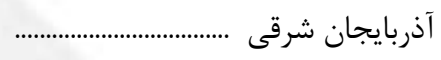 \\
\hline 199 & $F \Delta 1$ & ITFE & rat & هI & $\Delta T \Lambda$ & آذربايجان غربى .......................... \\
\hline$\wedge$ & מו & DI. & r & rی & rबQ & 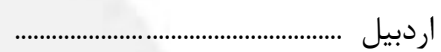 \\
\hline $1 T \cdot \Delta$ & 1990 & r & VM & r\$9 & rrta & اصفهان .......... \\
\hline rir & $190 \mu$ & r111 & 1994 & FYG & rYQA & 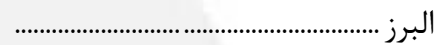 \\
\hline r. & $\Delta q$. & re & rMgV & 11 & iv9 & 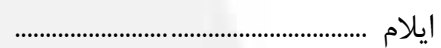 \\
\hline FET & $\Delta \cdots$ & $\Delta \varphi$ & 1911 & 90 & VTV & 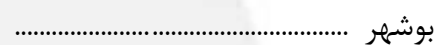 \\
\hline IVVe & IDFT. & FqQV & DIVF & TTVT & INGTS & تهران .............................. \\
\hline IAF & $F Q 1$ & זr & TEYA & fF & reF & جهارمحال و بختيارى ....................... \\
\hline rтq. & $V \Delta$. & ru & $9 \mathrm{~V}$ & Frt & $10 Y 9 \Delta$ & خراسان جنوبى ................. \\
\hline Drqq & $\Delta \wedge r T^{2}$ & rYe & $1 \cdot r \Delta$ & $V \cdot \Delta q$ & (1Trtge & خراسان رضوى ........... \\
\hline 419 & ITar & ve & 1.1 & $r . .90$ & $11 V \lambda 1$ & خراسان شمالى ........ \\
\hline$\Lambda 9 \Lambda$ & זr & $r \Delta \Delta$ & $q \cdot V \Delta r$ & rIT & $0|9|$ & خوزستان ............... \\
\hline$\Delta \Delta$ & r. & TATrT & IrF & rA & re & زنجان ................... \\
\hline $1 \wedge 9$ & 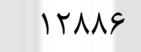 & $1 \cdot 0$ & IrA & DFF & $r \cdot . q$ & سمنان ................. \\
\hline ए૬D९q & $11 \mathrm{VV}$ & 99 & TFI & Vq. & ITNAD & سيستان و بلوج \\
\hline 1911 & 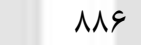 & $1 \Delta \omega$ & r৭৯ब & 190 & $190 \mathrm{~V}$ & فارس ............. \\
\hline$v \Delta$ & FOV & $r \cdot r q$ & INT & 14 & Dr. & قزوين .................................. \\
\hline$r \cdot r$ & 119 & 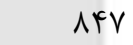 & 111. & $r \cdot r$ & $199 \mathrm{~V}$ & قم .............................. \\
\hline$\wedge r$ & rrv & IFAT & $\Delta \Delta r$ & 90 & rFq & كردستان ................... \\
\hline 覑 & $r \cdot r$ & $\Delta V$ & $\Delta \varphi$. & 119 & g פ & 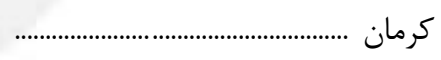 \\
\hline IFT & $F \Delta q$ & ras & Ifar & $\Delta V$ & 998 & 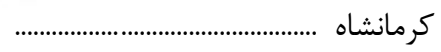 \\
\hline $11 r$ & $\mid \Delta F$ & r) & $r \cdot \Delta V$ & 10 & IrF & كهخيلويه و بويراحمد . \\
\hline lffes & FQq. & 115 & $r V$. & IQT. & FarA & 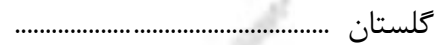 \\
\hline$<q$. & $\Delta \cdot V$ & 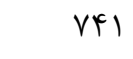 & $r \cdot r$ & 148 & IFAT & 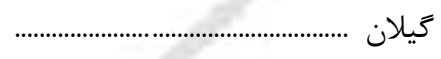 \\
\hline 195 & $\Delta T \Lambda$ & 140 & $\Delta 9 \Delta 9$ & $\Delta \cdot$ & DFD & لرستان ...... \\
\hline$\Delta \Lambda \Lambda$ & rTrq & $r \Delta v$ & $\Delta T$ & \&VV & TFTD & مازندران ..... \\
\hline rM & ( & 191 & $1 . r F$ & $\Delta \Delta$ & $\Delta q \mu$ & 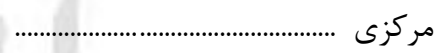 \\
\hline $19 \Delta 9$ & T\&A & VG & $1 \cdot 19$ & TAT & $r \Delta \Delta \mid$ & هرمزكان ............... \\
\hline$r \Delta \Delta$ & rmy & rat & Irrq & $\Delta \Delta$ & 0.9 & همدان ......... \\
\hline crq & TFY & $\forall \wedge$ & $9 \wedge F$ & qV & $19 \mathrm{VI}$ & 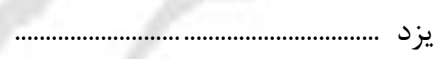 \\
\hline TF & rוr & 19 & 114 & $\Delta$ & THE & اظهار نشده استان ... \\
\hline$\Delta \Delta T$ & ( & $1 \wedge r$ & $1 \pi \Delta$. & 90 & VAT & 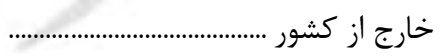 \\
\hline IVT. & 4. & TF & (19) & $1 T 4$ & 914 & اظهار نشده محل اقامت قبلى ............ \\
\hline
\end{tabular}


^ - ا- مهاجران وارد شده طى ه سال كذشته بر حسب جنس، استان محل اقامت قبلى و فعلى (بر اساس آخرين جابجايى انجـام (نقاط شهرى)

شده)(دنباله)

\begin{tabular}{|c|c|c|c|c|c|}
\hline \multicolumn{5}{|c|}{ استان محل اقامت فعلى } & \multirow{2}{*}{ محل اقامت قبلى و استان } \\
\hline 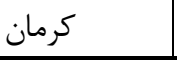 & كردستان & قم & قزوين & فارس & \\
\hline$\varepsilon V \cdot . \Delta$ & MADFT & vrrel & AFsAV & $r / v r \cdot r$ & 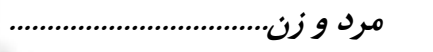 \\
\hline rVq & 1099 & rI9T & IfTK & VVF & 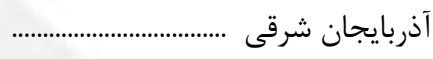 \\
\hline TET & rیrı & $\Lambda \Delta r$ & MN & fध4 & 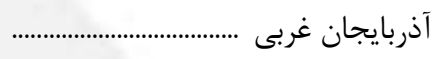 \\
\hline let & 10 & FAr & ґی & rrq & 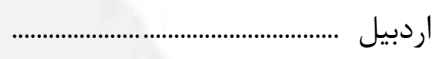 \\
\hline$|v|$. & gar & pq\&4 & $\Delta \vee q$ & $\Delta \wedge \Delta T$ & |صفهان ............................. \\
\hline DTr & leta & rIFV & FrAq & $q \uparrow \wedge$ & البرز ......................................... \\
\hline VT & 994 & $\Delta \Delta F$ & INT & TIT & ايلام ....................................................... \\
\hline FFT & irs & VIf & 9 . & $9 \Delta F$ & بوشهر ........................ \\
\hline TAT. & Vre. & 11918 & $V \cdot r \cdot$ & 8NIT & 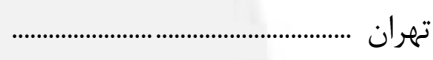 \\
\hline$r .$. & 99 & s4A & 94 & $15 \cdot 9$ & 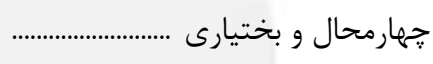 \\
\hline rVq & IV & FDl & rv & TFD & خراسان جنوبى ................................. \\
\hline$|r|$ & 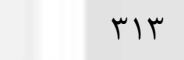 & THEF & Gr. & $1 \Delta \Delta \varphi$ & خراسان رضوى ............... \\
\hline rtr & rt & rt. & $\wedge \wedge$ & IVT & 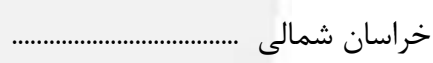 \\
\hline $1 \cdot 1$ & $9 \wedge 1$ & $\Delta V r V$ & sev & $9 \cdot 91$ & 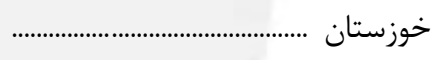 \\
\hline 94 & $11 \mathrm{kr}$ & $199 \mathrm{~V}$ & rq४^ & 194 & 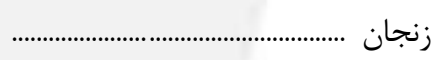 \\
\hline 91 & 191 & sqa & IfV & ris & 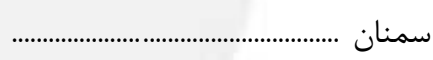 \\
\hline ris9 & 190 & gq. & IVQ & $1 \wedge \varepsilon \Lambda$ & 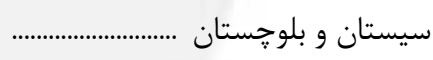 \\
\hline 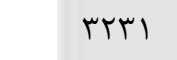 & FET & rFqG & ret & Ifrava & فارس .................................... \\
\hline Irr & $\wedge \vee r$ & $9 \cdot \Delta$ & QTDIV & 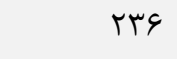 & 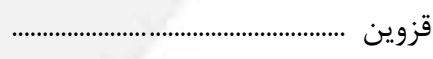 \\
\hline 909 & $\Delta T Y$ & rqRT & DQT & $9 \wedge 9$ & 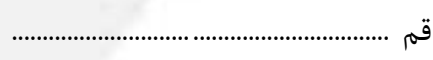 \\
\hline ITQ & DFFEQ & DFT & $1 \cdot r r$ & $\Delta r$. & 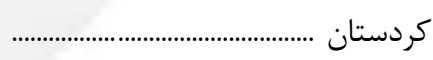 \\
\hline 41999 & lar & 1919 & $1 \cdot 1$ & rir. & 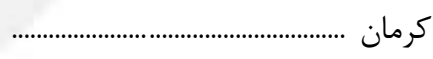 \\
\hline IVF & GTVD & lQST & 1090 & $v \notin q$ & 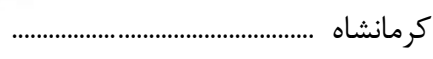 \\
\hline 191 & is & $R \cdot r$ & c. & sVav & كهَيلويه و بويراحمد ........ \\
\hline$|v|$ & $r \cdot q$ & VID & 199 & Tre & گَلستان ............................................ \\
\hline$r \Delta \varphi$ & $\Delta T \cdot$ & 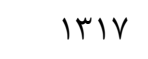 & fVar & gar & 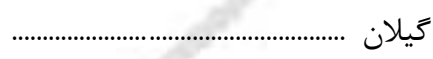 \\
\hline rl. & 1 1r9 & एव६ & pqf & 1.91 & 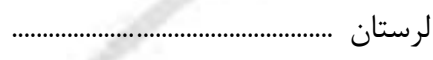 \\
\hline$r r \cdot$ & $\Delta 9 V$ & IAVG & qMa & VVq & 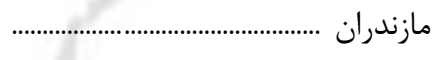 \\
\hline$|9|$ & 419 & FTDS & FQV & vrq & 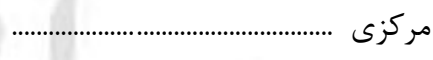 \\
\hline rNIT & Trt & Dre & TET & VघIT & 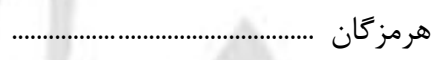 \\
\hline TFD & tQAT & qr. & 901 & ITIV & 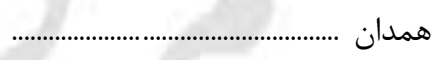 \\
\hline 194. & $\wedge 1$ & 9人 & 99 & rosG & 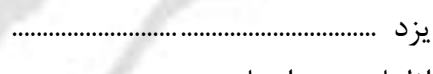 \\
\hline Iqra & $\begin{array}{r}9 \\
119\end{array}$ & $\begin{array}{l}\text { IVV } \\
\text { grt. }\end{array}$ & $\begin{array}{l}r \\
\Delta r r^{\prime}\end{array}$ & $\begin{array}{l}k T 1 \\
\Delta \wedge \Delta \Lambda\end{array}$ & 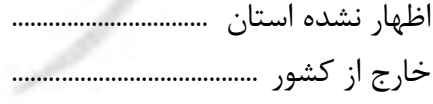 \\
\hline ful & $r \cdot$ & TAT & rv & rql & اظهار نشده محل اقامت قبلى ............... \\
\hline
\end{tabular}




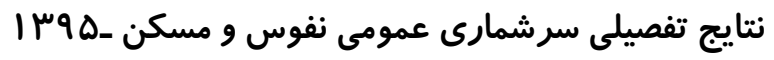

^ - ا- مهاجران وارد شده طى ه سال كذشته بر حسب جنس، استان محل اقامت قبلى و فعلى (بر اساس آخرين جابجايى انجـام (نقاط شهرى)

شده)(دنباله)

\begin{tabular}{|c|c|c|c|c|c|}
\hline \multicolumn{5}{|c|}{ استان محل اقامت فعلى } & \multirow{2}{*}{ محل اقامت ق قبلى } \\
\hline 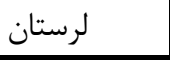 & كَيلان & كلستان & كهخيلويه و بويراحمد & كرمانشاه & \\
\hline felar & 111991 & sir.a & ravf. & vargr & 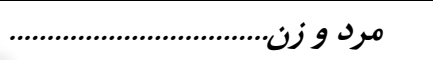 \\
\hline $11 \mathrm{~V}$ & १९V & rQq & rq & rیו & 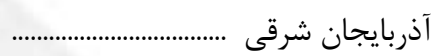 \\
\hline 111 & $\Delta \wedge 9$ & IAV & rt & $\Delta g F$ & 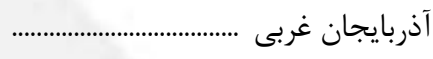 \\
\hline rv & kquा & 99 & rq & 119 & اردبيل ....................................... \\
\hline 1999 & IVID & $99 \mathrm{~V}$ & $11 \% 4$ & | & اصفهان ................... \\
\hline 1149 & $\Delta \Delta \backslash \Delta$ & 911 & $\Delta V$ & $r \cdot r q$ & 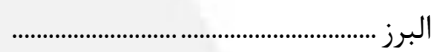 \\
\hline$\Delta r \Lambda$ & 10 & $\vee \wedge$ & r & rrq. & 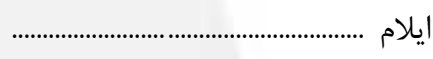 \\
\hline$r \wedge \Delta$ & MAT & 149 & VVr & re & 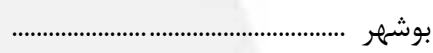 \\
\hline DrAF & TYGTY & $\Delta q F$. & $\Delta T \Delta$ & $v \cdot v \cdot$ & تهران ................................. \\
\hline 19. & $14 q$ & 91 & FAD & 199 & 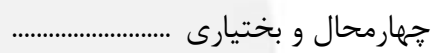 \\
\hline re & $1 \cdot 9$ & rFe & if & $r F$ & 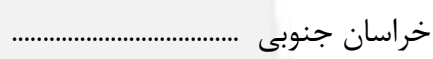 \\
\hline 197 & 1994 & rVvq & Ve & rq. & خراسان رضوى ............................. \\
\hline$\wedge$ & 119 & $1 \Delta \Delta V$ & 9 & rF & 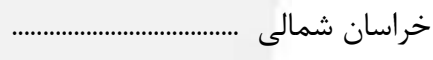 \\
\hline DTTI & $\| \Delta V$ & FrT & VעrV & TITF & 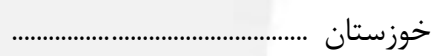 \\
\hline$\wedge \wedge$ & (rts & ir. & 11 & ris & 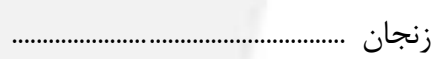 \\
\hline $1 \cdot 0$ & ris & rma. & rt & $9 \pi$ & 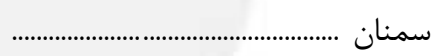 \\
\hline lQT & $\wedge \notin \Delta$ & rג隹 & 99 & 191 & 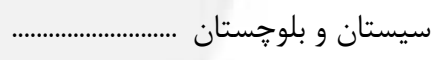 \\
\hline $0 \cdot 1$ & ATF & 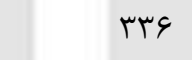 & FTAT & fFe & فارس ................................... \\
\hline ir. & rTII & $|f|$ & $\checkmark$ & $\Delta T r$ & 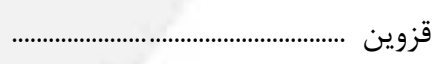 \\
\hline VTe & $1 \cdot \Delta r$ & FiA & rIf & ers & قم ............................................. \\
\hline$q \uparrow \Delta$ & 999 & rar & r. & fqr & كردستان ................................................ \\
\hline $1 \Delta \Delta$ & 419 & TET & $1 \cdot 0$ & $1 \wedge 9$ & كرمان ................................ \\
\hline $1 \cdot 11$ & qr. & rma & eV & $4 \| 1 r q$ & 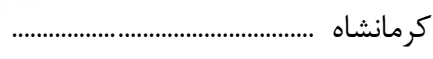 \\
\hline Irی & GT & rV & TFTYT & $1 \pi q$ & 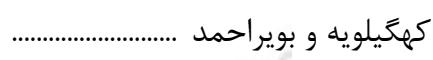 \\
\hline$\Delta V$ & grr & rmis. & if & lfF & كلستان ..................................................... \\
\hline $1 r 9$ & $\Delta V I G F$ & qr. & rq & ras & كيلان .................................. \\
\hline rINFF & 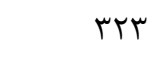 & $I K \Lambda$ & 91 & TERT & 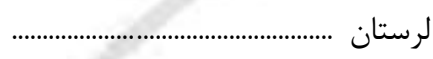 \\
\hline 19. & YIAD & reqf & Q & rV & 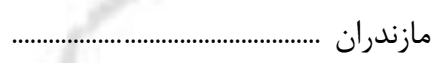 \\
\hline $1 \cdot \lambda r$ & $1 T \cdot r$ & IV. & ve & 1119 & 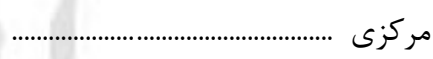 \\
\hline$\Delta F \Delta$ & rols & $\Delta \Delta F$ & rVT & $\wedge r$. & 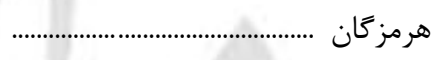 \\
\hline V^I & 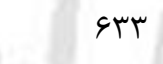 & $11 \cdot$ & $r \cdot \Lambda$ & rVQD & 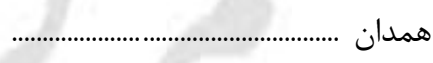 \\
\hline req & raf & $r \cdot \Delta$ & $19 V$ & $\begin{array}{l}\text { Gr } \\
\text { gre }\end{array}$ & يزد .................................... \\
\hline १. & ג & rAf & 194 & krt & 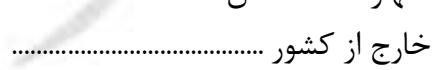 \\
\hline rt & 90 & $|r|$ & 1. & $1 \cdot 0$ & اظهار نشده محل اقامت قبلى ............ \\
\hline
\end{tabular}


^ - ا- مهاجران وارد شده طى ه سال كذشته بر حسب جنس، استان محل اقامت قبلى و فعلى (بر اساس آخرين جابجايى انجـام (نقاط شهرى)

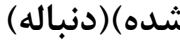

\begin{tabular}{|c|c|c|c|c|c|}
\hline \multicolumn{5}{|c|}{ استان محل اقامت فعلى } & \multirow{2}{*}{ محل اقامت و قبلى } \\
\hline 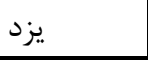 & همدان & هرمزكان & 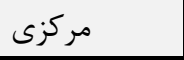 & 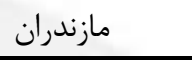 & \\
\hline svalt & 981.9 & 91118 & $81 \cdot 94$ & 914re & 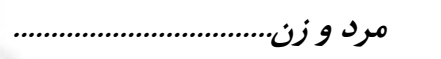 \\
\hline lar & $r \cdot \Delta$ & 1.19 & red & qDT & 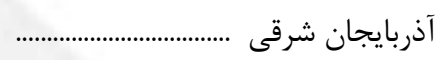 \\
\hline 199 & fAr & fqr & rTV & $r \Delta \Lambda$ & آذربايجان غربى ........................................... \\
\hline rII & 111 & rTD & ira & IGTF & 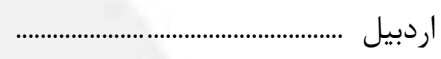 \\
\hline gerq & 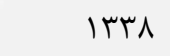 & rir. & TVq & lDST & اصفهان .............................. \\
\hline $111 \pi$ & $r \cdot \Lambda$ & qщ. & levr & trra & 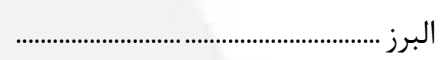 \\
\hline 111 & $\Delta 11$ & 991 & 190 & r\&q & ايلام ....................................................... \\
\hline$r \cdot \Delta$ & ५q1 & $|\Lambda| r$ & rma & rVT & 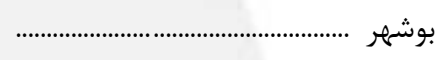 \\
\hline ४\M & 1994 & $\Delta \vee \wedge \Lambda$ & qqVर & IVAYF & تهران .................................. \\
\hline late & TrE & $1 \cdot 19$ & rیq & TrD & 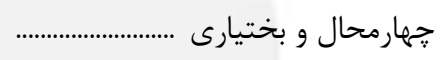 \\
\hline $1 V \Delta q$ & Fa & Mit & 90 & TFT & 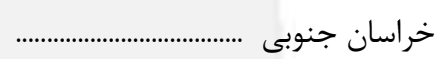 \\
\hline r৭९९ & meF & T991 & $\Delta r \cdot$ & $r R \cdot r$ & خراسان رضوى ................ \\
\hline TFG & (i) & 491 & r & $I \Lambda T \Lambda$ & 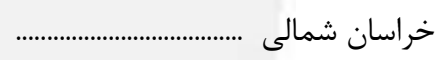 \\
\hline DrFq & 1994 & TFYF & relQ & $11 \% \Lambda$ & 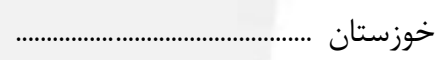 \\
\hline vq & rel & 191 & rit & 019 & 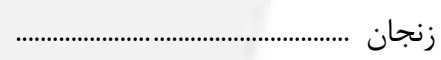 \\
\hline 148 & 101 & ris & IVe & । & 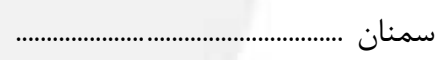 \\
\hline fefes & IVT & $r \Delta \cdot r$ & $r \cdot \Delta$ & वाז & 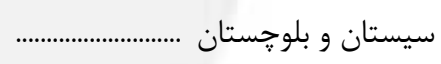 \\
\hline VQVV & $\checkmark \wedge \Delta$ & ITtrt & vif & $\Lambda \cdot \wedge$ & فارس ................................. \\
\hline$|f|$ & EVa & $r \cdot 1$ & $r \cdot v$ & Vr. & قزوين .................................. \\
\hline 919 & 1.94 & rıv & TrVD & $11 \Delta 9$ & قم .................................... \\
\hline lat & 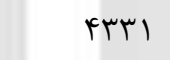 & ra & $\Delta 1$. & 011 & كردستان .............................................. \\
\hline$v r 9 \Delta$ & 191 & $\wedge \notin \Delta \Lambda$ & $r \cdot \Delta$ & $\Delta \cdot r$ & كرمان ............................................... \\
\hline$F \Delta \Delta$ & TEDQ & irt. & thrt & 111 & 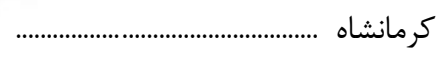 \\
\hline ג.r & IVD & vq. & rtq & $1 \cdot 0$ & كهخيلويه و بويراحمد ......... \\
\hline vr. & 9. & Nit & זr & F.re & 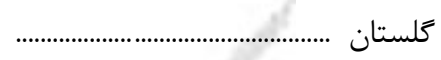 \\
\hline rद. & fre & THAV & 915 & $m F \cdot 1$ & 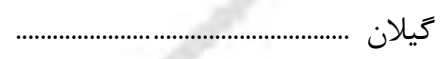 \\
\hline Iffq & $11 \cdot 1$ & |rir & Farl & $\Delta r$. & 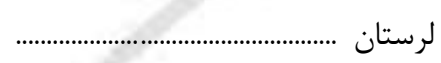 \\
\hline rVV & Faf & LQFF & rAF & FqIST & 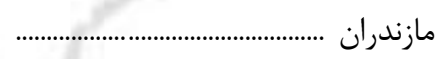 \\
\hline$r \cdot 1$ & IV99 & $\Delta \varphi$. & rqAev & $9 \cdot 1$ & 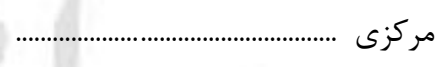 \\
\hline$r F \cdot \Lambda$ & 099 & riv.. & reV & irs. & 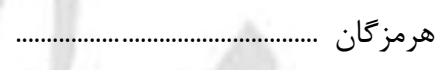 \\
\hline$r v \cdot$ & rt.re & $1 \cdot V \wedge$ & raYF & 911 & همدان ............ \\
\hline $14 \cdot 90$ & 19. & $1 \cdots 9$ & 195 & $r V r$ & 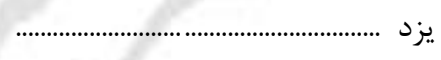 \\
\hline$q q$ & $\begin{array}{l}19 \\
\text { rq. }\end{array}$ & $\begin{array}{c}1 \\
I V \cdot r\end{array}$ & $\begin{array}{l}10 \\
1 \cdot \lambda r\end{array}$ & $\begin{aligned} r \Delta \\
q 4 \Delta\end{aligned}$ & 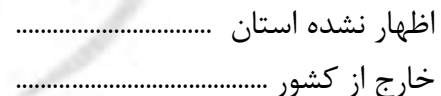 \\
\hline 191 & vV & $1 \cdot v$ & ه1 & rIf & اظهار نشده محل اقامت قبلى ........... \\
\hline
\end{tabular}




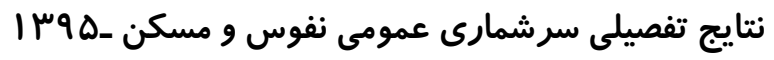

^ - ا- مهاجران وارد شده طى ه سال كذشته بر حسب جنس، استان محل اقامت قبلى و فعلى (بر اساس آخرين جابجايى انجـام (نقاط شهرى)

شده)(دنباله)

\begin{tabular}{|c|c|c|c|c|c|c|}
\hline \multicolumn{6}{|c|}{ استان محل اقامت فعلى } & \multirow{2}{*}{ جحل اقامت و قبلى } \\
\hline 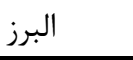 & اصفهان & 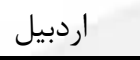 & آذربايجان غربى & آذربايجان شرقى & جمع - ا & \\
\hline 141194 & IrFTaf & rela. & rrasl & SFADF & $11 \cdot r \mu \cdot q$ & 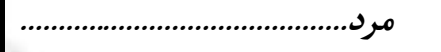 \\
\hline rGT. & 011 & $19 \vee \wedge$ & 4911 & eravt & VDTF. & آذربايجان شرقى .............. \\
\hline Irq9 & rVa & $1 \cdot \vee 9$ & TMMAF & GIVD & DITER & 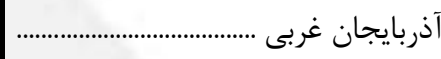 \\
\hline 1991 & $t \cdot r$ & IrqTV & $\Delta \Lambda$. & IVDq & 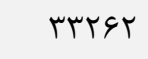 & |ردبيل .................................. \\
\hline r119 & $9994 \wedge$ & lfe & rar & fis & $1194 \cdot 1$ & |صفهان ............................... \\
\hline 19919 & $1 \cdot V F$ & 91. & req & $1 \cdot \Delta F$ & я४999 & البرز ........................................... \\
\hline VAV & $r \Delta \Delta$ & tr & rv & $\Delta 9$ & IVDGT & 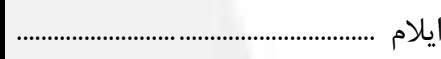 \\
\hline rNI & ITIV & 90 & Ifr & IfF & rq५धq & بوشهر ............ \\
\hline FTNIT & NIVT & RTM & riM & $\Delta \wedge \Delta \Delta$ & trITET & تهران ............................... \\
\hline 119 & $91 K 4$ & $\wedge$ & rq & f. & 49119 & 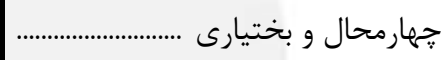 \\
\hline ו & . & 1 & r & $r \cdot$ & TFETT & 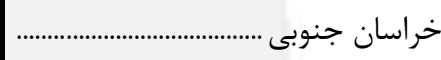 \\
\hline rl. r & 1 1r99 & 199 & $r \cdot r$ & ५१९ & 114195 & 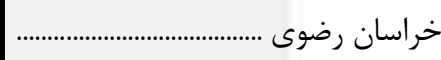 \\
\hline$\checkmark \Delta \cdot$ & rTS & 10 & re & 4. & र६भवा & 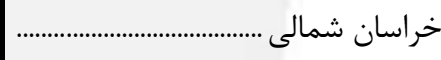 \\
\hline$\Delta \Delta V I$ & IrqAV & IrQ & $r v \cdot$ & red & $1 \cdot \Delta \wedge k$. & 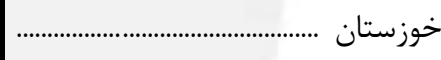 \\
\hline rFqr & 194 & IVT & rqq & r৭९ & र९९५૬ & زنجان ................................... \\
\hline rqf & res & is & $9 \wedge$ & 19 & $\mid q F \Delta \Lambda$ & 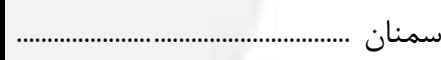 \\
\hline 9.9 & $119 \mathrm{~V}$ & v^ & אr & $11 r$ & ris.. & سيستان و بلوجستان ........... \\
\hline $1 \cdot 1 \pi$ & reQF & 91 & $r \cdot r$ & raV & $\| F \cdot r V$ & 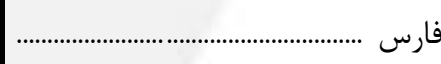 \\
\hline rqlf & rAr & 9. & $r \varepsilon \Delta$ & $r \cdot v$ & FT. GQ & 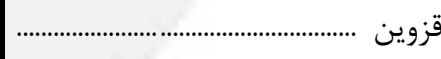 \\
\hline $1 . \mu r$ & 1959 & Irt & rq. & FTF & r r T & 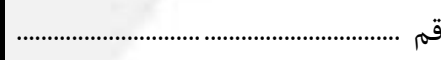 \\
\hline$T F \cdot r$ & $\Delta F F$ & $I V T$ & ITKT & VAT & $\Delta \cdot r \Delta F$ & 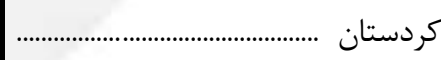 \\
\hline 991 & IrTA & vr & 94 & 149 & ४ा人q. & 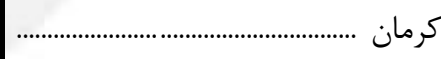 \\
\hline s9r1 & $14 \Delta$. & ITT & $r \Delta q$ & TDI & DGMTT & 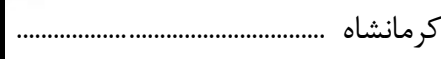 \\
\hline MF & 1419 & rt & rt & $r V$ & TFTHV & كهيَيلويه و بويراحمد ... \\
\hline var & rat & $\Delta \varphi$ & 98 & 111 & rVYFq & كلستان ............................ \\
\hline rFa. & VIN & ITFS & TrA & raq & DFFY & 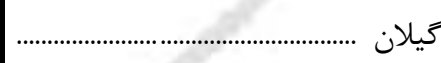 \\
\hline frqu & rmeq & r & 94 & 9. & $\Delta r \Delta \varphi \varphi$ & 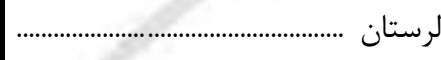 \\
\hline IMAT & 11. & rVG & IOT & TFA & FATDD & 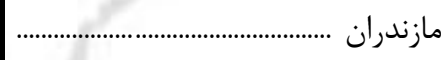 \\
\hline$|V \wedge|$ & $10 r q$ & pr & IFT & 11. & rVTr. & 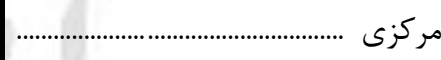 \\
\hline vVq & Irov & VV & 189 & r99 & $4 \cdot 191$ & 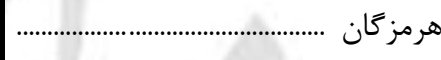 \\
\hline$\forall \& \wedge$ & AVa & 人 & $1 \Delta \Lambda$ & rit & fivrq & 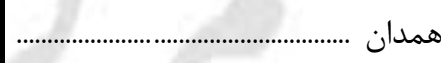 \\
\hline qr. & $\mid F Y$ & is & rq & $\wedge \vee$ & IVqIV & 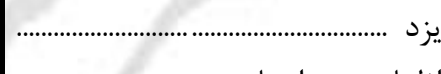 \\
\hline $\begin{array}{l}\text { IINV } \\
\text { it }\end{array}$ & $\begin{array}{l}\text { ITS } \\
\text { RTrD }\end{array}$ & 1. & $\begin{array}{ll}V \\
\text { rqq }\end{array}$ & $\begin{array}{l}11 \\
\text { rar }\end{array}$ & $\begin{array}{l}1991 \\
9 \cdot r \mu r\end{array}$ & 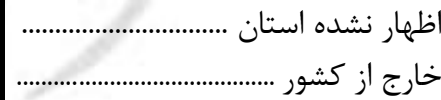 \\
\hline 111 & TVQ & re & If. & $r \Delta q$ & $\Delta \wedge r \Delta$ & اظهار نشده محل اقامت قبلى ............ \\
\hline
\end{tabular}


^ - ا- مهاجران وارد شده طى ه سال كذشته بر حسب جنس، استان محل اقامت قبلى و فعلى (بر اساس آخرين جابجايى انجـام (نقاط شهرى)

شده)(دنباله)

\begin{tabular}{|c|c|c|c|c|c|}
\hline \multicolumn{5}{|c|}{ استان محل اقامت فعلى } & \multirow{2}{*}{ محل اقامت قبلى واستان } \\
\hline خراسان جنوبى & جهارمحال و بختيارى & 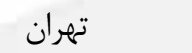 & بوشهر & ايلام & \\
\hline rrger & $r \cdot \Delta \Delta r$ & rafral & rviar & 11901 & 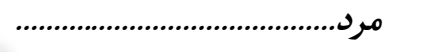 \\
\hline er & r & Irq49 & rVq & ir. & 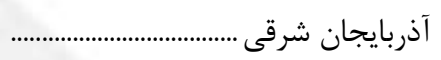 \\
\hline rV & rV & 9119 & rit & 111 & 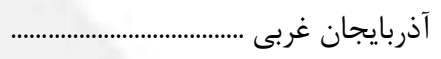 \\
\hline 11 & 19 & $1.114 q$ & 94 & rI & 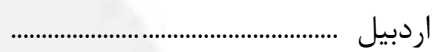 \\
\hline 994 & $r \mid \Delta \Delta$ & ItATt & ITES & TF. & 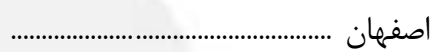 \\
\hline$r \cdot$. & gr & TrEV & lQF & ITt & 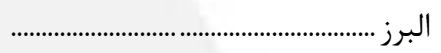 \\
\hline $1 \cdot$ & i^ & Rter & 119 & 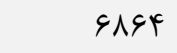 & ايلام ......................................................... \\
\hline$\Lambda$ & TAT & IVVV & $14 r q 0$ & $v^{f}$ & 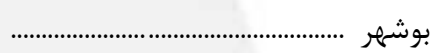 \\
\hline$\wedge r$. & Fa. & 119149 & $1 \cdot \vee \wedge$ & NFt & تهران ............................. \\
\hline$q r$ & IrDFq & Irیk & 19 & 4. & جهارمحال و بختيارى ..................... \\
\hline $1 \cdot r \Delta \Lambda$ & ir & 1999 & \&V & 4 & خراسان جنوبى ............. \\
\hline DYFq & 9 भ & $|\Delta \Lambda T|$ & rar & et & 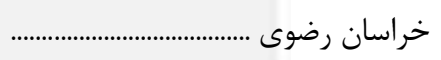 \\
\hline Fri & 9 & $\Delta \varphi \cdot 1$ & ve & $\Delta$ & 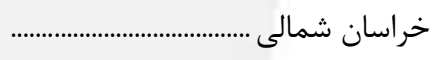 \\
\hline$|r|$ & $14 \cdot 9$ & 1.941 & regr & $\wedge \vee \Delta$ & 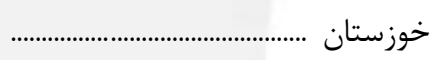 \\
\hline 1. & Ir & Fqva & $r \cdot$ & rt & زنجان ................................... \\
\hline $1 . r$ & rV & rafi & rv & 11 & 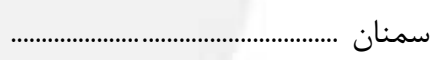 \\
\hline$|V T|$ & $1 \cdot 0$ & r\&gF & far & 9 & 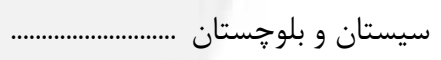 \\
\hline rVI & rVA & दावा & $99 . r$ & $11 \%$ & 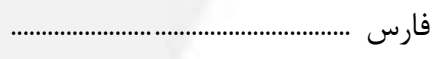 \\
\hline vr & r. & D\&TV & ץ^ & זr & قزوين ................................ \\
\hline$\wedge 1$ & IVe & DQTT & $1 \wedge 1$ & १ & 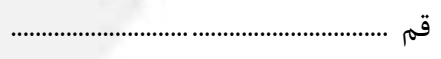 \\
\hline tr & $r \cdot$ & NIfr & 148 & trA & 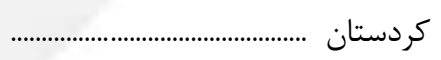 \\
\hline ros & $\wedge$ & rets & IfT & TY & 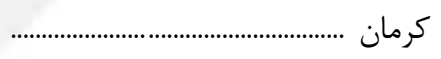 \\
\hline (i) & vi & IFITV & 194 & $\wedge / 4$ & 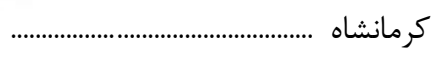 \\
\hline re & $1 \wedge \Delta$ & 119 & l1V9 & ra & كهيَيلويه و بويراحمد ....... \\
\hline gri & ro & $q \cdot r q$ & 4. & Tr & 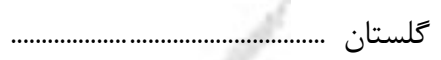 \\
\hline$\Delta \Lambda$ & iv & $1111 r$ & TVG & $\Delta F$ & 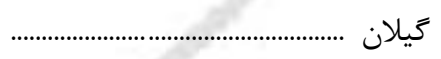 \\
\hline rV & $\wedge \Delta$ & $r \cdot I r$. & rq. & 490 & 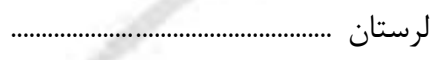 \\
\hline$\Delta \Delta \Delta$ & vr & $1 \cdot r \Delta \varphi$ & 194 & $\Delta V$ & 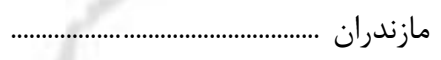 \\
\hline tr & $v^{e}$ & $11 \cdot r T$ & TAV & 111 & 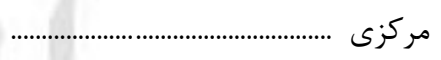 \\
\hline IVT & roq & rype & $R \cdot r$ & 1.9 & 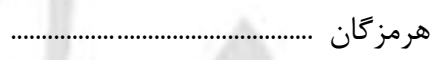 \\
\hline is & et & $\mid \Delta \wedge \Delta \wedge$ & 411 & 194 & 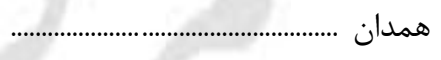 \\
\hline 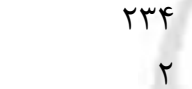 & 191 & $\begin{array}{l}\text { rmat } \\
\text { QHa }\end{array}$ & $\begin{array}{l}91 \\
\text { Q9 }\end{array}$ & $\begin{array}{l}\text { If } \\
1\end{array}$ & 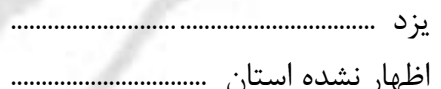 \\
\hline FT & $1 T \cdot$ & rqu19 & r৯৭マ & FT & 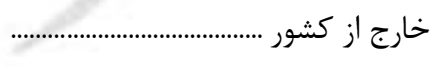 \\
\hline 11 & re & Irrs & 1.9 & r & اظهار نشده محل اقامت قبلى ........... \\
\hline
\end{tabular}




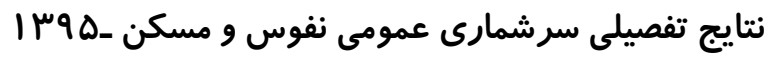

r..

^ - ا- مهاجران وارد شده طى ه سال حَذشته بر حسب جنس، استان محل اقامت قبلى و فعلى (بر اساس آخرين جابجايى انجـام (نقاط شهرى)

شده)(دنباله)

\begin{tabular}{|c|c|c|c|c|c|c|}
\hline \multicolumn{6}{|c|}{ استان محل اقامت فعلى } & \multirow{2}{*}{ محل اقامت قبلى واستان } \\
\hline سيستان و بلوجستان & سمنان & زنجان & خوزستان & خراسان شمالى & خراسان رضوى & \\
\hline ravrv & ragrt & TrFYA & sva1 & $11 \Delta V V$ & irtrel & 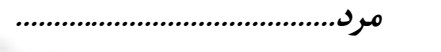 \\
\hline $1 \wedge \Delta$ & $19 \mathrm{~V}$ & $v \cdot \Delta$ & rq\ & rt & $\Delta \& V$ & 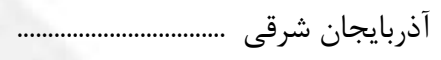 \\
\hline$\Delta F$ & tRt & $\checkmark \Delta \cdot$ & riv & rq & 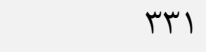 & 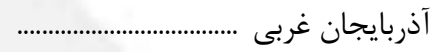 \\
\hline 4) & TAV & ו. & ar & ru & ITA & اردبيل .......... \\
\hline $9 \cdot 9$ & $1 \wedge 1$ & $|r|$ & raq & Ira & IVTS & اصفهان ......... \\
\hline $1 \cdot 1$ & $9 \cdot 1$ & 991 & NFr & TIQ & $11 \%$. & 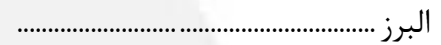 \\
\hline щ & $r \cdot q$ & 19 & 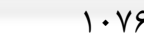 & it & $\Delta F$ & 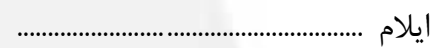 \\
\hline rq. & r & ry & $1 \cdot r 9$ & 9) & rAf & بوشهر .......... \\
\hline 1119 & VTAT & TETD & TRMS & $\mid \mathrm{VI}$. & 9911 & تهران ................ \\
\hline 119 & 199 & 11 & 1599 & rq & IV9 & جهارمحال و بختيارى ..................... \\
\hline 1.99 & TaT & 10 & i) & rrq & VAVG & 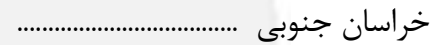 \\
\hline rra. & 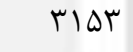 & lQF & QHT & rrvq & 49449 & 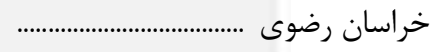 \\
\hline TFY & 919 & 91 & $\Delta^{9}$ & $991 \%$ & DGT. & خراسان شمالى ................... \\
\hline VVe & MTY & IMF & FrAIS & ITV & זעצץ & خوزستان ........................ \\
\hline ry & 10 . & $14 \cdot 14$ & $v \cdot$ & IV & IVF & 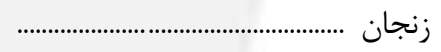 \\
\hline $1 \cdots$ & 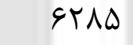 & 19 & 91 & raf & 19.9 & 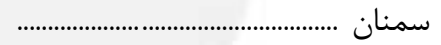 \\
\hline$|\wedge \Delta F|$ & qrq & $\Delta \Delta$ & $10 \Delta$ & $49 \Lambda$ & $V G \cdot 9$ & سيستان و بلوجستان .......... \\
\hline 1481 & ५ १९ & $v^{k}$ & 198. & 11. & 909 & 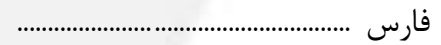 \\
\hline is & TrA & $9 \Delta F$ & 91 & re & TrV & 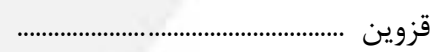 \\
\hline$|V|$ & rAv & Fil & $\Delta 91$ & $11 r$ & $\wedge \Delta \Lambda$ & 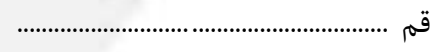 \\
\hline$\Delta F$ & Ira & 110 & rqY & rᄉ & $r$ r. & 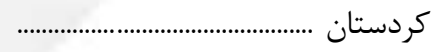 \\
\hline IFY & lQT & rq & HIT & $1 \cdots$ & $1 \Delta \Delta F$ & 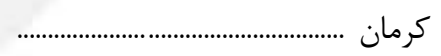 \\
\hline$V F^{e}$ & 519 & IFA & VAT & (4) & rVI & كرمانشاه ...................... \\
\hline G & 99 & $\pi$ & $19 \mathrm{rr}$ & $\Lambda$ & $\mathrm{v} \cdot$ & كهيكيلويه و بويراحمد \\
\hline glF & TETE & $\Delta F$ & $\mid \Delta V$ & GVG & rTQG & علستان ....... \\
\hline$r \cdot r$ & TYY & rVA & $r \cdot r$ & Ar & $v \cdot 9$ & 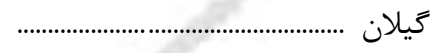 \\
\hline IrT & TVE & 11 & raf. & tr & r19 & 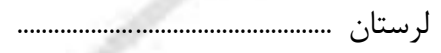 \\
\hline rی. & IDSV & $11 \Delta$ & $r \Delta \Lambda$ & Tr & IATV & مازندران ........ \\
\hline IVQ & $\mu \cdot$. & $\Delta \mu^{4}$ & $\Delta 9 \Delta$ & re & $r 90$ & 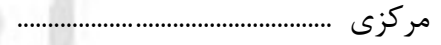 \\
\hline IrTs & Ire & rq & 919 & $|V|$ & Irke & هرمزكان ...................... \\
\hline 190 & 195 & inr & VTG & $r \cdot$ & $r \Delta \Lambda$ & 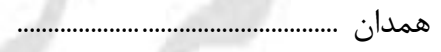 \\
\hline rrV & 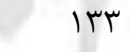 & rA & $r \Delta \cdot$ & rq & NFT & 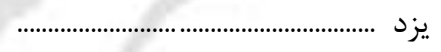 \\
\hline r) & TYI & If & $\Delta r$ & r & $|r|$ & اظهار نشده استان ... \\
\hline एव) & $|r|$ & $1 \cdot 0$ & $\Lambda$. & $\Delta F$ & $r \ldots r$ & 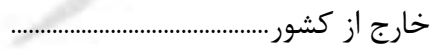 \\
\hline $190 \mathrm{~V}$ & me & Ir & Fre & 1. & r91 & اظهار نشده محل اقامت قبلى ........... \\
\hline
\end{tabular}


^ - ا- مهاجران وارد شده طى ه سال كذشته بر حسب جنس، استان محل اقامت قبلى و فعلى (بر اساس آخرين جابجايى انجـام (نقاط شهرى)

شده)(دنباله)

\begin{tabular}{|c|c|c|c|c|c|}
\hline \multicolumn{5}{|c|}{ استان محل اقامت فعلى } & \multirow{2}{*}{ محل اقامت قبلى و استان } \\
\hline 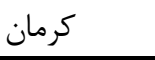 & كردستان & 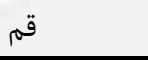 & قزوين & 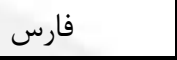 & \\
\hline rargr & raVar & reivr & $|f| 1 \mid \varepsilon$ & 111119 & 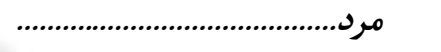 \\
\hline IVG & 1.91 & 1.94 & 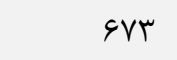 & FrF & 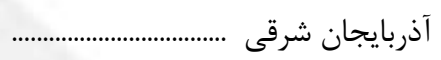 \\
\hline 194 & $r \cdot \Lambda \cdot$ & $k \cdot v$ & $|4|$ & $r M$ & 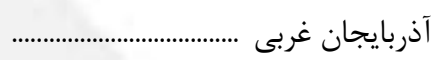 \\
\hline$\Lambda r$ & $1 \cdots$ & TFF & $r \cdot 9$ & $1 F \Delta$ & 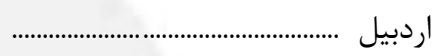 \\
\hline $11 \cdot 1$ & f.r & rmif & rqv & rqه & |صفهان .............................. \\
\hline זr & Vre & $1 \cdots 9$ & $r \cdot r$ & rav & البرز .................................... \\
\hline rv & reV & ra & 94 & $1 \cdot 1$ & ايلام ........................................................ \\
\hline MFI & vq & 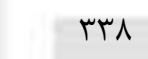 & iv & FYG & بوشهر .................................. \\
\hline If\&Y & $r \cdot r q$ & $\Delta \Lambda 1 T$ & rTAS & rata & 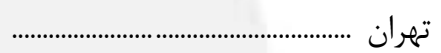 \\
\hline 11 . & $\Delta \Lambda$ & r৭१ & $\Delta \cdot$ & Var & 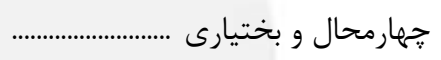 \\
\hline lat & 1 & TrQ & r. & lar & 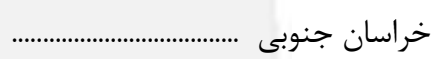 \\
\hline $9 \wedge \Lambda$ & rte & 1.91 & $r \cdot r$ & $\wedge 14$ & 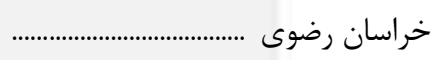 \\
\hline 114 & 19 & 111 & $\Delta \cdot$ & १७ & 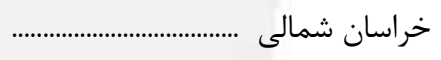 \\
\hline Vฯ६ & $\Delta \& V$ & tArA & ris & FVA & 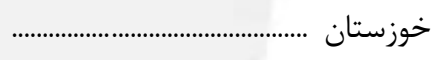 \\
\hline fr & 997 & १४. & life. & $v \Delta$ & 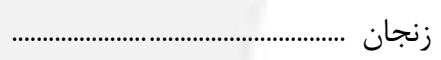 \\
\hline iv & 94 & r19 & $v \Delta$ & 114 & 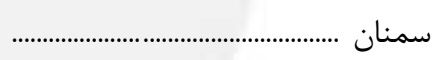 \\
\hline $\mid r \cdot 1$ & 94 & 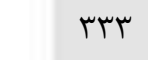 & $1 \cdots$ & 1119 & 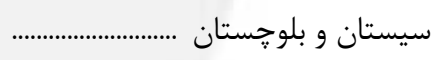 \\
\hline $11 \cdot 1$ & re. & 1419 & 119 & VIVV. & 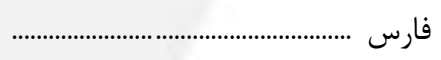 \\
\hline 99 & FAF & frq & TEVTF & זrו & قزوين ................................... \\
\hline rt. & $r V \cdot$ & $r \cdot 11$ & rVr & $\Delta \cdot \wedge$ & 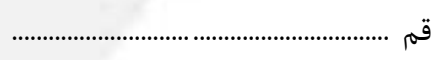 \\
\hline$\wedge \vee$ & r\&qAr & rV. & $\Delta F \Delta$ & 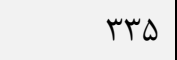 & 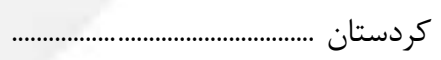 \\
\hline$r \cdot r q q$ & 11. & $\wedge \Delta \Lambda$ & $\Delta \varphi$ & IQVT & 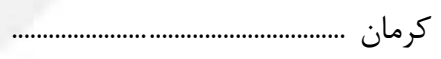 \\
\hline $1 \cdot 4$ & rIfA & VAF & $\wedge$. & $4 \cdot q$ & 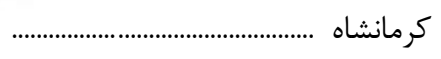 \\
\hline ITt & $r \cdot$ & ret & tr & $r \varphi \cdot \Delta$ & كهيلويه و بويراحمد ....... \\
\hline NT & lik & re. & 91 & $|\wedge|$ & 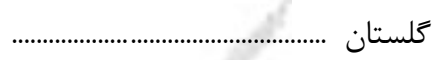 \\
\hline ira & rit & gre & rrtu & rTI & 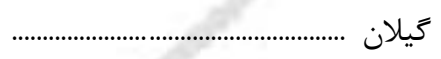 \\
\hline 190 & VrV & 1911 & TFt & $4 \cdot v$ & 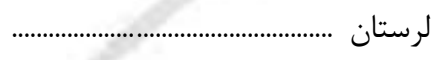 \\
\hline 114 & THF & $\wedge \vee \wedge$ & rqu & rar & 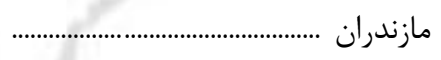 \\
\hline$\wedge \Delta$ & rTI & $t \cdot r t$ & rtr & fir & 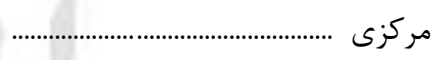 \\
\hline TETT & $1 \wedge \Delta$ & rNa & 149 & r..r & هرمزكان ............................ \\
\hline Irv & irva & rIDS & re. & sv. & همدان .............................. \\
\hline $\begin{array}{r}1.1 \\
19\end{array}$ & Q1 & $\begin{array}{l}\Delta \cdots \\
190\end{array}$ & $\begin{array}{c}\Delta \cdot \\
r\end{array}$ & $\begin{array}{l}|r N| \\
\mid A T\end{array}$ & يزد ............................................. \\
\hline 1199 & ه11 & reVt & Tar & rА૬ & 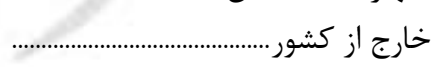 \\
\hline ri. & 1. & 191 & 11 & Iru & اظهار نشده محل اقامت قبلى ........... \\
\hline
\end{tabular}




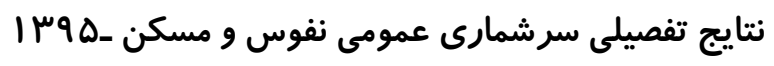

^ - ا- مهاجران وارد شده طى ه سال كذشته بر حسب جنس، استان محل اقامت قبلى و فعلى (بر اساس آخرين جابجايى انجـام (نقاط شهرى)

شده)(دنباله)

\begin{tabular}{|c|c|c|c|c|c|}
\hline \multicolumn{5}{|c|}{ استان محل اقامت فعلى } & \multirow{2}{*}{ محل اقامت ق استان } \\
\hline 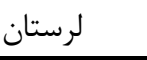 & 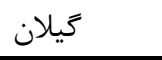 & كلستان & كهيَيلويه و بويراحمد & كرمانشاه & \\
\hline$r \mid 1 \cdot r$ & DAfrr & rqr.q & Irrar & rrare & 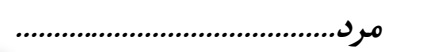 \\
\hline qV & $\Delta \cdot r$ & Trt & if & tin & 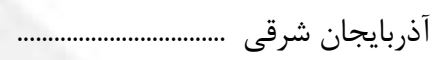 \\
\hline st & ras & $1 \cdot r$ & it & roq & 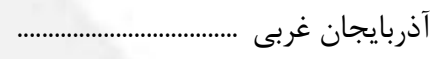 \\
\hline IV & TEYK & $4 \pi$ & 11 & 4 . & 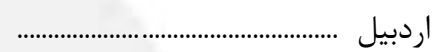 \\
\hline q४৩ & NQT & $r \cdot q$ & Drq & 991 & |صفهان ........................... \\
\hline DQT & $r V \cdot \Delta$ & TET & 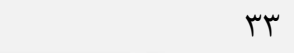 & $10 I V$ & 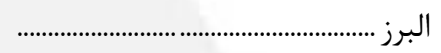 \\
\hline req & $\wedge \Delta$ & $\Delta \cdot$ & 19 & (11) & 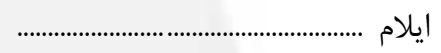 \\
\hline IDT & $\forall \Delta \Delta$ & 99 & rqf & $|V|$ & بوشهر ............................. \\
\hline tVAT & $\| \Delta \Delta \mid$ & $r \cdot r V$ & ras & rquq & تهران ....................... \\
\hline NT & vi & eV & $r \Delta \Lambda$ & ITV & 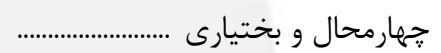 \\
\hline 11 & द. & 110 & 9 & 19 & 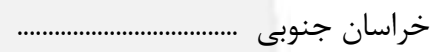 \\
\hline 1.9 & ᄉrv & $11 \cdot 1$ & r. & rin & 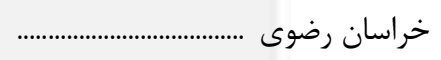 \\
\hline r & 94 & $\vee 19$ & r & $\wedge$ & 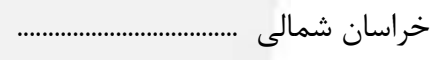 \\
\hline$r \Delta \Delta \Delta$ & $9 \cdot 9$ & 194 & 1.94 & $|1 r|$ & 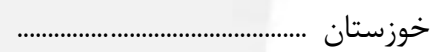 \\
\hline fF & s广d & $\Delta V$ & $\checkmark$ & IFT & زنجان ............................. \\
\hline$\Delta \varphi$ & 194 & iter & 10 & $\Delta f$ & 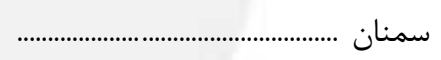 \\
\hline ᄉr & eVr & 19.9 & $\Delta \Lambda$ & $1 \cdots$ & 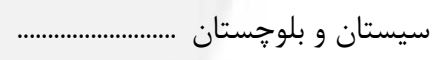 \\
\hline tTA & (i). & 199 & 19.9 & trat & فارس .................................. \\
\hline vr & $|\Delta \Lambda|$ & Ve & r & rAD & 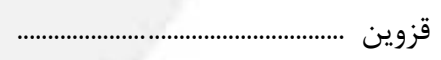 \\
\hline rel & $\Delta T V$ & TTI & 114 & TIS & 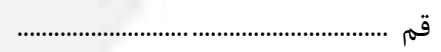 \\
\hline 491 & 411 & IrF & iv & TQFY & كردستان ................................................... \\
\hline$\wedge \Lambda$ & $1 M 1$ & 119 & $\psi_{\wedge}$ & AF & 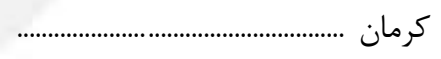 \\
\hline EEV & rrq & r & r & 19991 & 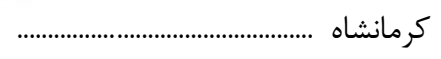 \\
\hline VV & rی & if & ITIVT & $\wedge \vee$ & كهيَيلويه و بويراحمد \\
\hline rA & $r \cdot \Lambda$ & $10 \Delta T_{q}$ & 9 & ar & كلستان ........................ \\
\hline 4. & TRMTI & trA & rI & 148 & 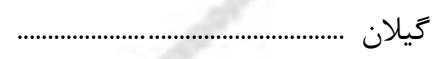 \\
\hline 1.914 & IV. & $\Delta 9$ & $\Delta V$ & . & 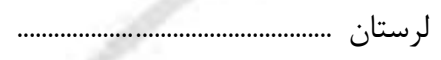 \\
\hline 91 & $19 T F$ & $10 \cdot 9$ & TQ & 199 & مازندران ........................... \\
\hline$\Delta \Delta F$ & $\Delta q F$ & $\wedge \vee$ & $\Delta 1$ & $\Delta \& 9$ & 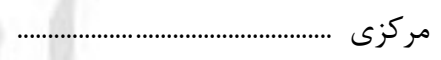 \\
\hline rat & INAT & TVG & lar & krq & هرمزكان .................. \\
\hline V & זוץ & D) & $1 \cdot 1$ & (rv & همدان .................. \\
\hline 149 & (r & $1 \cdot 1$ & 94 & 119 & يزد ................................ \\
\hline iA & rqv & 199 & $|4|$ & TY. & 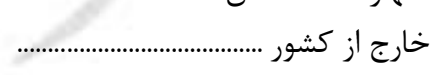 \\
\hline$r$. & $r v$ & $\Delta \varphi$ & 4 & $\Delta r$ & اظهار نشده محل اقامت قبلى .......... \\
\hline
\end{tabular}


^ - ا- مهاجران وارد شده طى ه سال كذشته بر حسب جنس، استان محل اقامت قبلى و فعلى (بر اساس آخرين جابجايى انجـام (نقاط شهرى)

شده)(دنباله)

\begin{tabular}{|c|c|c|c|c|c|}
\hline \multicolumn{5}{|c|}{ استان محل اقامت فعلى } & \multirow{2}{*}{ محل اقامت ق قبلى } \\
\hline 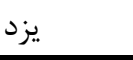 & 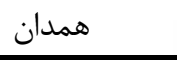 & هرمزكان & 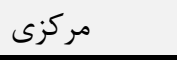 & 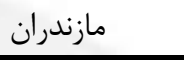 & \\
\hline$r F \cdot F v$ & rrr. 1 & Fisid & rre.d & frgre & 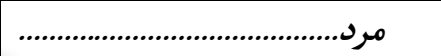 \\
\hline$q 4$ & 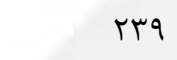 & 0.9 & $l \Delta V$ & זr & آذربايجان شرقى ....................................... \\
\hline $11 r$ & rqu & rA. & INT & $1 \wedge \Lambda$ & 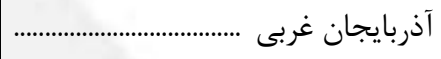 \\
\hline$|r|$ & Va & 194 & qV & $\Delta f y$ & 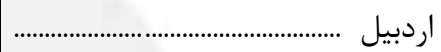 \\
\hline$r \cdot r \Lambda$ & $\Delta 99$ & ivir & Irav & vr. & اصفهان ................................. \\
\hline$\Delta \Delta V$ & 1119 & pqr & $V \cdot \Delta$ & 1499 & 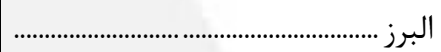 \\
\hline 99 & TFE & rar & 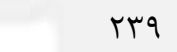 & 149 & 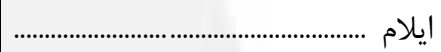 \\
\hline lQF & 19 & $1 \cdot r \Delta$ & $1 \mu$. & $r \cdot \Lambda$ & 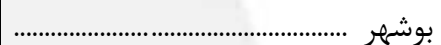 \\
\hline TIYA & FAF. & $r \cdot \wedge r$ & fref & MANT & تهران ................................ \\
\hline NIr & $1 \cdot r$ & $\Delta 99$ & IDT & 110 & 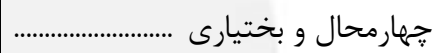 \\
\hline 91. & rq & rF. & r. & $|r|$ & 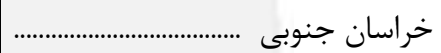 \\
\hline IOTD & 119 & $1 \% 90$ & TFA & IATV & 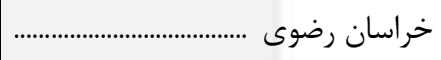 \\
\hline Irt & TY & TrT & $|r|$ & 918 & خراسان شمالى .............. \\
\hline TVRG & १人ץ & $\left.|0|\right|^{k}$ & ITVV & $\Delta 9 \Delta$ & 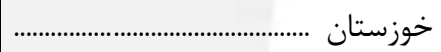 \\
\hline r. & $r \cdot 4$ & IrF & 119 & $r \Delta I$ & زنجان ................................. \\
\hline Vr & Vq & 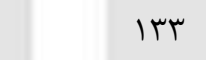 & १४ & $9 \wedge$. & 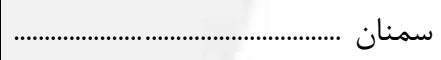 \\
\hline rस৭द & 94 & $19 \mathrm{Vr}$ & $19 \mathrm{~V}$ & iq. & سيستان و بلوجستان ......... \\
\hline rघ91 & rqf & $9 \wedge 99$ & ryf & rqq & 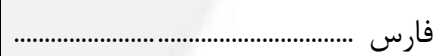 \\
\hline 91 & TFF & 111 & 199 & 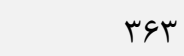 & 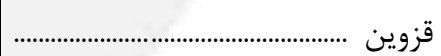 \\
\hline FYA & 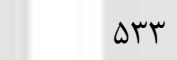 & 199 & IfTS & $\Delta \varphi$. & 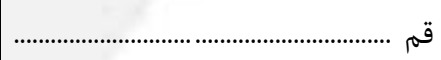 \\
\hline $1 \cdots$ & TrES & rta & rAF & rq४ & 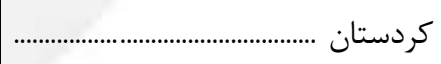 \\
\hline 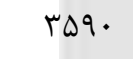 & 91 & ferv & $11 \mathrm{~V}$ & rq. & 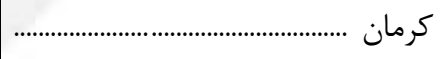 \\
\hline trt & $101 \mathrm{~V}$ & $8 \wedge \Delta$ & leVr & rr. & 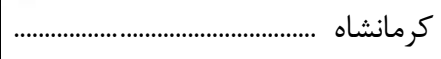 \\
\hline k\&9 & 90 & far & IrF & 91 & 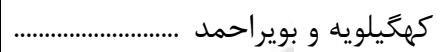 \\
\hline rAd & (i) & rqf & 191 & $191 \%$ & 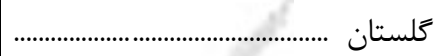 \\
\hline$M k$ & $r \cdot$. & $\| \Delta F$ & Fri & $19 \cdot 9$ & كيلان ................................ \\
\hline VQF & $\wedge \cdot 1$ & G.r & TIMA & rVq & 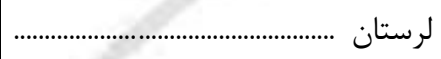 \\
\hline INT & TFD & $\vee \wedge \Lambda$ & tra & TIATF & 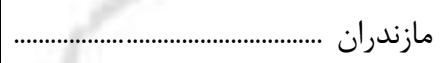 \\
\hline $1 \cdot 1$ & $\vee 9 \Lambda$ & r৭9 & IFYAD & $r \cdot q$ & 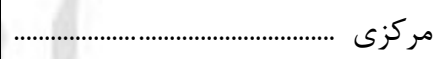 \\
\hline Irre & Trt & IEFDF & 190 & VTS & 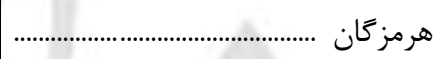 \\
\hline lfF & IDHEV & $\Delta \Delta \Delta$ & Ifro & $r \cdot v$ & 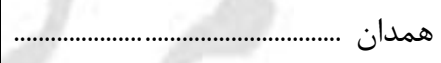 \\
\hline s\^९ & q. & $\Delta 1$. & v9 & IF & 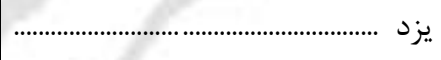 \\
\hline $\begin{array}{l}r G \\
\Delta V \Delta\end{array}$ & $\begin{aligned} r \\
101\end{aligned}$ & 1109 & $\begin{array}{ll}V \\
\text { sVA }\end{array}$ & $\begin{array}{l}r . \\
r 99\end{array}$ & 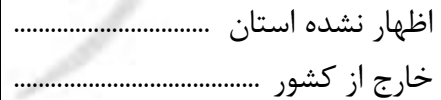 \\
\hline ᄉr & Fy & 90 & $r \Delta$ & $11 \%$ & اظهار نشده محل اقامت قبلى ........... \\
\hline
\end{tabular}




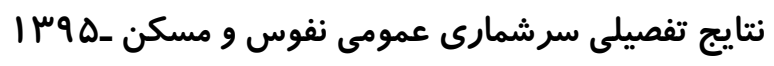

$r \cdot r$

^ - ا- مهاجران وارد شده طى ه سال حَذشته بر حسب جنس، استان محل اقامت قبلى و فعلى (بر اساس آخرين جابجايى انجـام (نقاط شهرى)

شده)(دنباله)

\begin{tabular}{|c|c|c|c|c|c|c|}
\hline \multicolumn{6}{|c|}{ استان محل اقامت فعلى } & \multirow{2}{*}{ محل اقامت ق قبلى استان } \\
\hline 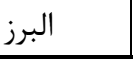 & اصفهان & 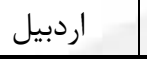 & آذربايجان غربى & آذربايجان شرقى & 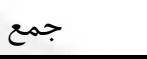 & \\
\hline irrita & | & rreva & rravr & sargl & IVeIfrg & 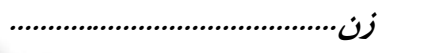 \\
\hline revr & $r \cdot \Delta$ & $|0|$. & ferg & FFol. & VTDVD & 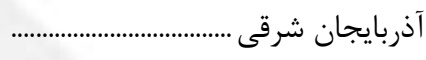 \\
\hline $1 \pi 10$ & r\$9 & $\Delta \Delta F$ & $r .99 \mu$ & $G T \cdot r$ & Fqяफे & آذربايجان غربى .......... \\
\hline r|r| & 1rq & Irkq. & $r \cdot v$ & $I \vee \wedge \Delta$ & rrqه & 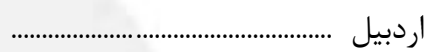 \\
\hline rTar & VIS19 & $1 \cdot r$ & TIT & Frt & $119 \cdot 1 \mathrm{~V}$ & |صفهان ................... \\
\hline 199.9 & r & $\Delta \vee \Delta$ & rAt & $11 \cdots$ & द्ववाr & 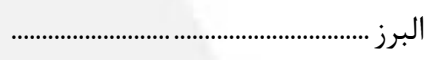 \\
\hline$V T \Delta$ & rmy & ra & is & QI & IV৭9V & 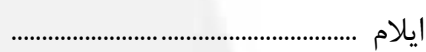 \\
\hline TVF & $|T F|$ & $f_{1}$ & 14. & Irv & TVFqT & بوشهر .......... \\
\hline$r r \cdot 9 \Delta$ & VVq1 & 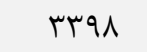 & 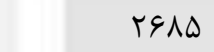 & $\Delta G Y_{1}$ & TEQFqV & تهران .......................... \\
\hline 194 & ११५ & 11 & TQ & rt & $r \cdot r \cdot q$ & جهارمحال و بختيارى ......... \\
\hline rl. & r\&4 & v & ז & 19 & TETHT & 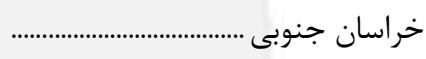 \\
\hline Trtr & ITET & १V & IVr & rVv & $1111 \wedge r$ & 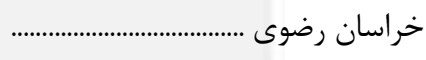 \\
\hline vir & 119 & 4 & tr & id & TETIQ & خراسان شمالى .......... \\
\hline$\Delta \Lambda \Lambda T$ & 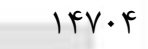 & 1.1 & $T Q 1$ & זrז & 1. ArV & 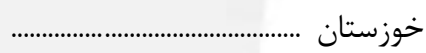 \\
\hline TETT & $r \cdot r$ & 119 & $t \cdot r$ & rVt & rq. rq & 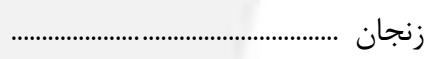 \\
\hline fl. & rit & rA & $\Delta V$ & VD & 19191 & 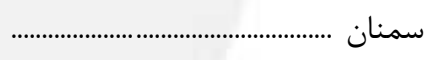 \\
\hline $9 \cdot 9$ & VIT & r & er & 99 & एवाIV & سيستان و بلو گجستان . \\
\hline $1 \cdot \wedge r$ & rVD. & qV & 191 & TET & $111 r 49$ & 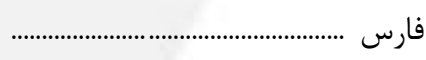 \\
\hline rrII & r\&4 & VT & r19 & ra & FTTAV & قزوين ......................... \\
\hline $11 \cdot r$ & l9V9 & 114 & Tr. & Tre & t.rIG & 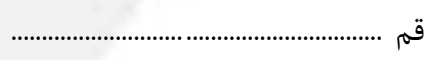 \\
\hline rTq & 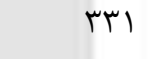 & $1 \cdot 1$ & latr & $0 \cdot 1$ & FAтII & 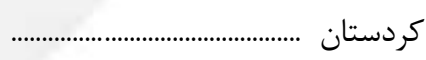 \\
\hline$V \cdot r$ & $\mid r q 1$ & rq & $\Delta 9$ & $1 \Delta V$ & $r r \cdot \wedge \varphi$ & 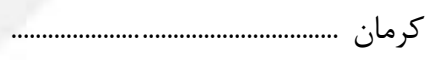 \\
\hline GNQF & $1 r \Delta \Lambda$ & $\wedge$. & rqV & rme & $\Delta q \Gamma \Delta \Delta$ & 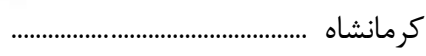 \\
\hline If. & ITYN & ir & rF & וr & TrFFY & كهيَيلويه و بويراحمد ...................... \\
\hline Nrr & rar & $\Delta \Delta$ & Ve & 114 & 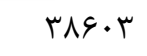 & 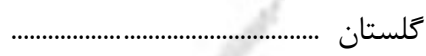 \\
\hline firq & $V \Delta \Delta$ & 1419 & 195 & Fil & $\Delta 99 \wedge \Lambda$ & كيلان ........................ \\
\hline Feft & 要 & rv & $\wedge f$ & $q$ & DTFYA & لرستان ........... \\
\hline rivr & VAT & MFI & lfF & TrI & $\Delta \mid F \cdot V$ & مازندران .............. \\
\hline $1 \wedge 9 \Lambda$ & IQVT & ra & 114 & 111 & ५А१५१ & 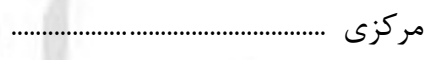 \\
\hline 994 & $11 \mathrm{Vr}$ & $\Delta \Delta$ & IVr & rqf & requs & هرمزكان ................................. \\
\hline 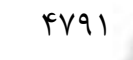 & $\vee \wedge \varphi$ & pq & lFF & TYY & rq49D & 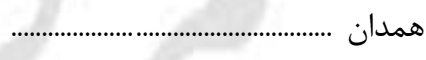 \\
\hline $\begin{array}{l}V+1 \\
r 1\end{array}$ & $\begin{array}{l}119 F \\
r 1 .\end{array}$ & $\begin{array}{c}r \\
r\end{array}$ & س & $\begin{array}{l}\text { ve } \\
1 \ldots\end{array}$ & $\begin{array}{l}\text { IVTYY } \\
\text { IQVI }\end{array}$ & 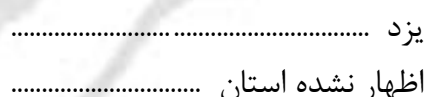 \\
\hline $194 \pi$ & rA\& & $\Delta \Delta$ & rqu & ra. & mEINT & 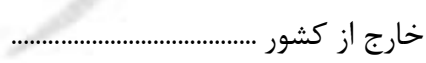 \\
\hline 1.9 & rt. & سו & 11. & TQR & $\mid+1 \cdot \Delta$ & اظهار نشده محل اقامت قبلى ............. \\
\hline
\end{tabular}


^ - ا- مهاجران وارد شده طى ه سال كذشته بر حسب جنس، استان محل اقامت قبلى و فعلى (بر اساس آخرين جابجايى انجـام (نقاط شهرى)

شده)(دنباله)

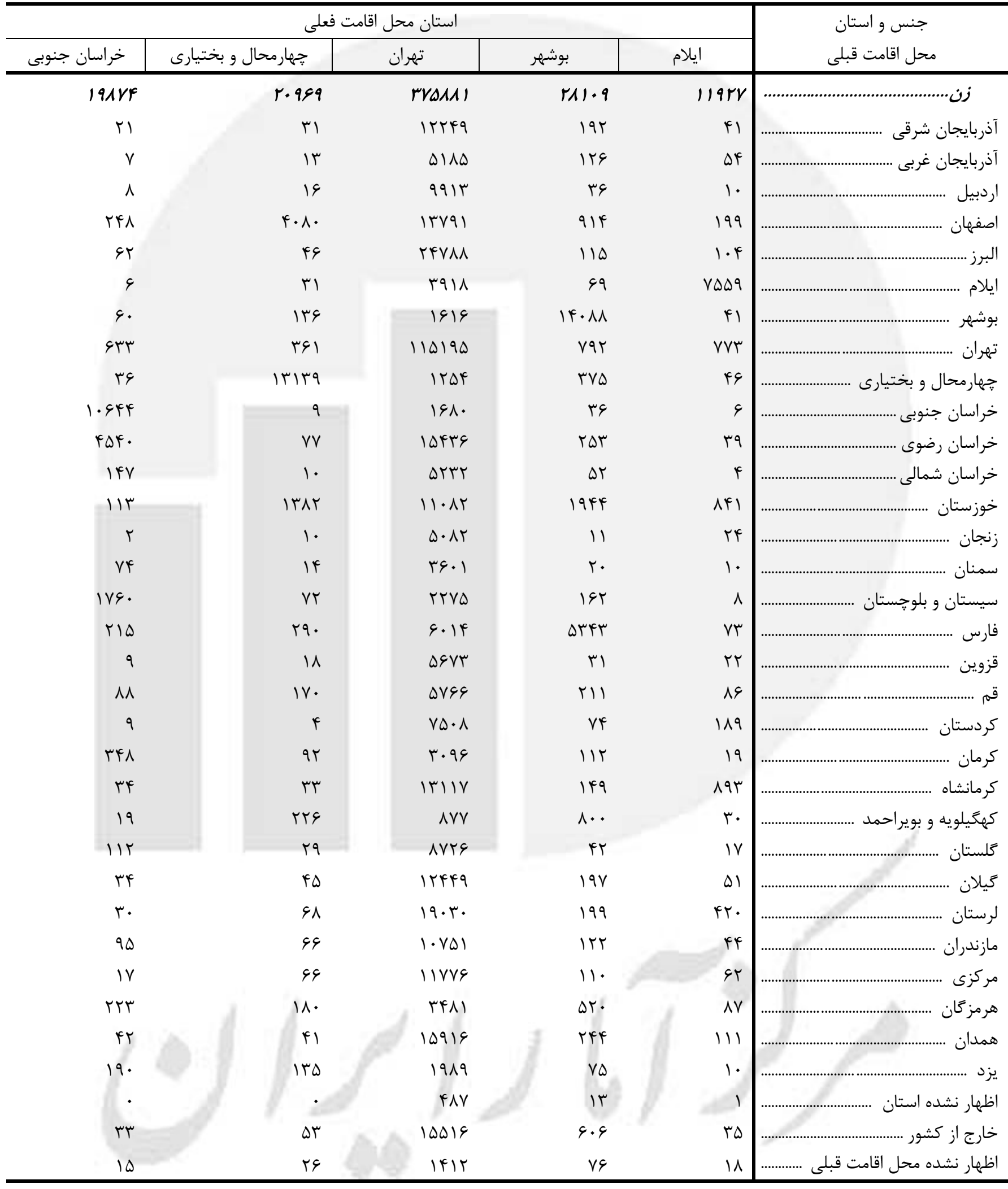




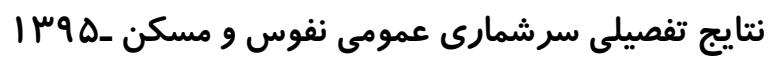

^ - ا- مهاجران وارد شده طى ه سال حذذشته بر حسب جنس، استان محل اقامت قبلى و فعلى (بر اساس آخرين جابجايى انجـام (نقاط شهرى)

شده)(دنباله)

\begin{tabular}{|c|c|c|c|c|c|c|}
\hline \multicolumn{6}{|c|}{ استان محل اقامت فعلى } & \multirow{2}{*}{ جنس اقامت قبلى } \\
\hline | سيستان و بلوجستان & سمنان & ز زنجان & خوزستان & خراسان شمالى & خراسان رضوى & \\
\hline TAIEF & $r \cdot r r r$ & rifli & vrirs & 1Agrt & 119810 & 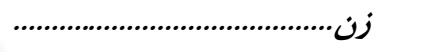 \\
\hline ITF & ir. & $9 \Delta 9$ & r19 & rI & FAS & آذربايجان شرقى .................................. \\
\hline 90 & 189 & 499 & IFV & 10 & 198 & آذربايجان غربى ................ \\
\hline$r$. & Trs & r.. & هI & 1. & 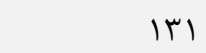 & اردبيل ..................................................... \\
\hline एव९ & $1 \cdot \wedge f$ & 114 & rVVT & ITA & $19 .$. & اصفهان .................... \\
\hline $1 \cdot 0$ & $1 \cdot \Delta r$ & $11 \%$. & 119 & राI & 111 & البرز ................................. \\
\hline 9 & rیl & 11 & $|r q|$ & 9 & 90 & ايلام ................................ \\
\hline$\Delta r$ & rqT & tr & १९५ & rF & ret & بوشهر .................... \\
\hline $9 \Delta \Lambda$ & $1 \| \hat{H}$ & TART & TFHA & IDGY & $9 \cdot T^{F}$ & تهران ................................. \\
\hline $9 \Lambda$ & tAr & it & Irat & 10 & 190 & 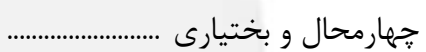 \\
\hline Irat & rq1 & r & re & $r \cdot r$ & V919 & 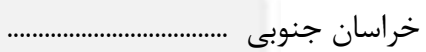 \\
\hline r119 & revq & ir. & fqr & r६A. & $9991 \mathrm{~V}$ & خراسان رضوى ........ \\
\hline IVV & gVr & 4 & et & $1 \cdot 1 \Delta r$ & 9191 & خراسان شمالى ............ \\
\hline 94 & 499 & $|r|$ & FVard & $\Lambda \Delta$ & TQTA & خوزستان ................................ \\
\hline rI & $1 \wedge$ & ITrG. & st & 11 & IDT & زنجان ................................ \\
\hline$\wedge \varphi$ & $99 \cdot 1$ & $\Delta \varphi$ & 91 & $r \Delta \cdot$ & $\mid f \cdot r$ & 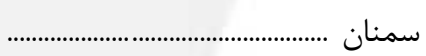 \\
\hline $\mid \Lambda \cdot r \Lambda$ & QH & (i) & $\wedge 9$ & rat & GTVG & سيستان و بلوجستان ..... \\
\hline QIT & FAV & 11 & $r \cdot 10$ & $\wedge \Delta$ & 991 & 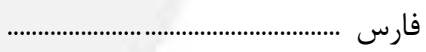 \\
\hline tr & rrq & 1.90 & $1 \Delta$ & $r \cdot$ & raT & 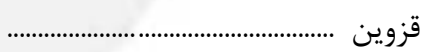 \\
\hline זrו & frq & Fis & $\Delta F q$ & 94 & $1 \cdot 9$ & 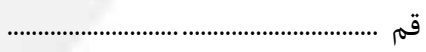 \\
\hline rA & $1 \cdot r$ & $99 \mathrm{~V}$ & rq. & rV & 149 & 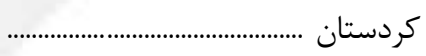 \\
\hline INAT & 149 & r & TFA & 19 & IVVD & 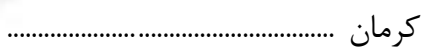 \\
\hline $9 \wedge$ & rF. & 10 . & $\vee \cdot$. & 19 & res & 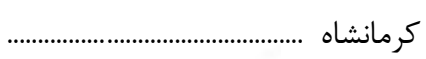 \\
\hline$\Delta$. & $\Delta \Lambda$ & $\wedge$ & $r \cdot \Delta r$ & v & $g F$ & كهخيلويه و بويراحمد ..... \\
\hline Vat & rI99 & $\Delta \Lambda$ & 111 & AFF & TMTT & 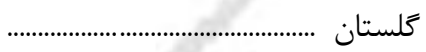 \\
\hline IAV & rᄉr & 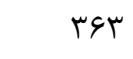 & $r \cdot$. & st & VFG & كيلان ...................... \\
\hline$\checkmark$. & TAT & st & $r \cdot 19$ & r & TrG & 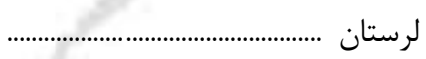 \\
\hline$r \cdot \Lambda$ & ISVT & IVT & Tצ & q פזr & 1091 & 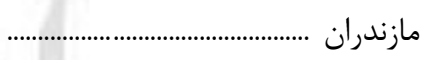 \\
\hline Fr & 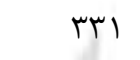 & $\Lambda F$ & $4 \notin q$ & rq & r\&A & 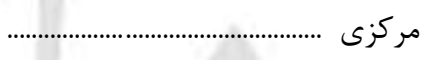 \\
\hline rr. & IFT & rv & ev. & 111 & $1 T \cdot \Delta$ & هرمزكان ................ \\
\hline 9. & Ift & $\mid 11$ & G.r & ra & TFA & 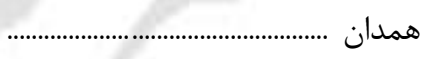 \\
\hline 194 & 1.9 & r. & rry & ra & $\Lambda T \Lambda$ & 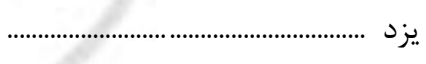 \\
\hline r & 94 & $\Delta$ & 91 & r & $r{ }_{T}$ & اظهار نشده استان............. \\
\hline 191 & 110 & VA & ev. & (i) & MFTY & 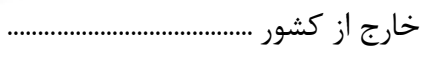 \\
\hline V & rq & 11 & FTV & 119 & r & اظهار نشده محل اقامت قبلى .......... \\
\hline
\end{tabular}


^ - ا- مهاجران وارد شده طى ه سال كذشته بر حسب جنس، استان محل اقامت قبلى و فعلى (بر اساس آخرين جابجايى انجـام (نقاط شهرى)

شده)(دنباله)

\begin{tabular}{|c|c|c|c|c|c|}
\hline \multicolumn{5}{|c|}{ استان محل اقامت فعلى } & \multirow{2}{*}{ محل اقامت قبلى واستان } \\
\hline 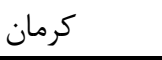 & كردستان & قم & قزوين & 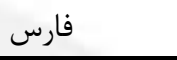 & \\
\hline rigkt & rerv. & $r v \cdot 19$ & reari & $1.81 V \Delta$ & 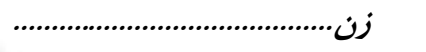 \\
\hline $1 \cdot r$ & $\Delta T \Lambda$ & $11 r 9$ & $v \Delta \cdot$ & $r \Delta \cdot$ & آذربايجان شرقى ............................. \\
\hline 91 & $I V \Delta \Lambda$ & fis & FTI & IVA & 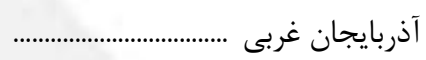 \\
\hline q. & $\Delta \cdot$ & ruq & MAT & 94 & 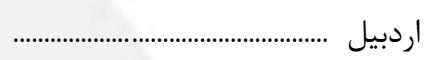 \\
\hline 9.9 & rFq & res. & tAr & К८१९ & 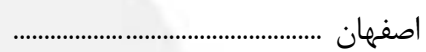 \\
\hline$r \cdot$. & $v \cdot 9$ & $11 r \wedge$ & rTAV & (9) & 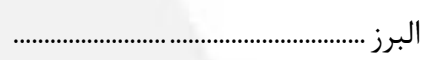 \\
\hline ro & rtV & rq1 & $q$. & $1 \cdot 4$ & ايلام ........................................................... \\
\hline $1 \cdot 1$ & $\Delta \varphi$ & rVe & fr & prvq & بوشهر ........................... \\
\hline $1 \cdot \Delta \varphi$ & | - آוזr & $91 \cdot 0$ & rqVF & TTVA & تهران .............................. \\
\hline ir. & 4) & req & er & DFV & جهارمحال و بختيارى ................... \\
\hline $11 \mathrm{~V}$ & V & tre & IV & 91 & 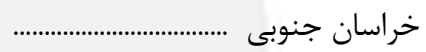 \\
\hline 9QT & $\wedge \vee$ & 1149 & TIV & VET & 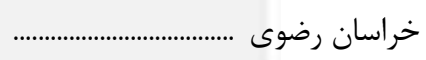 \\
\hline $1 \cdot 1$ & Ir & 1.9 & rی & VD & 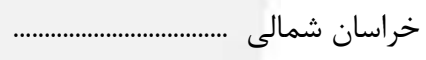 \\
\hline MIf & fif & rq. $q$ & זעr & (1). & 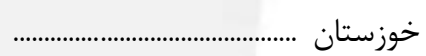 \\
\hline is & fFe & ११४ & IOHA & $\Lambda$ & 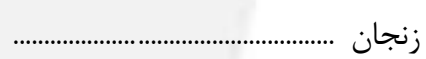 \\
\hline pq & qV & res & vT & $1 \cdot r$ & 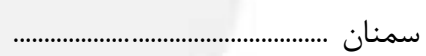 \\
\hline $99 \wedge$ & vi & $r \cdot v$ & $v \Delta$ & $q \vee q$ & سيستان و بلوحستان .................... \\
\hline IfTr & INT & ITVV & Irf & $V Y I \cdot \Delta$ & 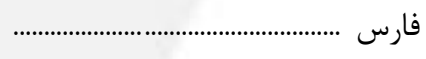 \\
\hline$\Delta F$ & 419 & fVe & r\&VqT & 1. r & 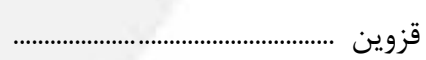 \\
\hline 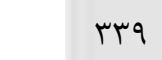 & TAT & |941 & r19 & 401 & 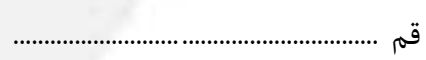 \\
\hline rı & TVFAD & TVT & FVA & 190 & 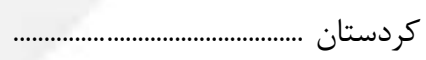 \\
\hline$r \mid F \cdot \Delta$ & er & $1 \cdot \Delta \Lambda$ & $\Delta r$ & IFrA & 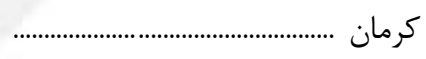 \\
\hline$\vee \cdot$ & TTtV & $\checkmark \vee \wedge$ & $\vee \wedge \Delta$ & re. & 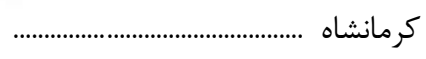 \\
\hline f\& & 10 & roq & 11 & rI9r & كهخَيلويه و بويراحمد \\
\hline 19 & Ira & rVa & 91 & Ifo & 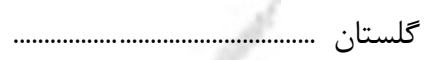 \\
\hline $\mid$ & $r \cdot \Lambda$ & 9ヘr & TATS & 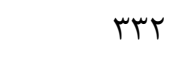 & 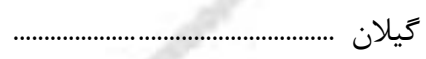 \\
\hline 110 & $\Delta r q$ & 1911 & TAT & FAF & 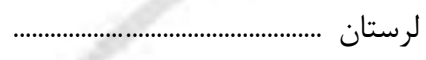 \\
\hline 1re & TFt & 991 & rrv & Ґی⿱ & 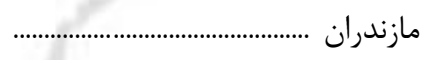 \\
\hline Ve & 191 & 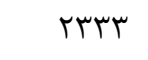 & TMF & TrG & 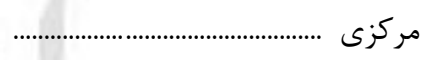 \\
\hline $\mid r q 1$ & Irv & ral & $11 \pi$ & एदा & 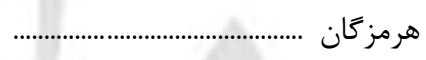 \\
\hline $1 \cdot 1$ & Ir.r & ria. & 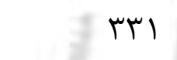 & $\Delta F V$ & همدان ....................... \\
\hline $94 \cdot$ & $r \cdot$ & FAY & $4 q$ & 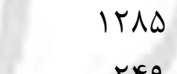 & يزد .......................................... \\
\hline pre & $r \cdot \Lambda$ & rA\&A & TrI & 1990 & 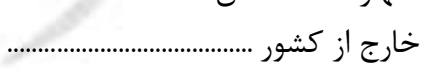 \\
\hline TrI & 1. & 91 & 19 & rr & اظهار نشده محل اقامت قبلى ......... \\
\hline
\end{tabular}




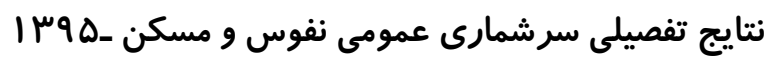

^ - ا- مهاجران وارد شده طى ه سال كذشته بر حسب جنس، استان محل اقامت قبلى و فعلى (بر اساس آخرين جابجايى انجـام (نقاط شهرى)

شده)(دنباله)

\begin{tabular}{|c|c|c|c|c|c|}
\hline \multicolumn{5}{|c|}{ استان محل اقامت فعلى } & \multirow{2}{*}{ محل اقامت ق قبلى } \\
\hline 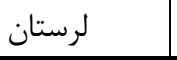 & كَيلان & كلستان & كهيَيلويه و بويراحمد & كرمانشاه & \\
\hline rrmar & c.rra & $r \mu \cdot q q$ & 18911 & rrviv & 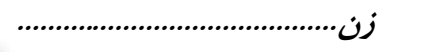 \\
\hline$\Delta \cdot$ & kqF & $i r V$ & 10 & 194 & آذربايجان شرقى ................ \\
\hline FV & זrז & $\Lambda F$ & 1. & $r \cdot \Delta$ & 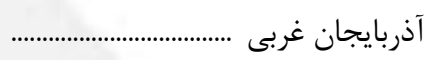 \\
\hline$r$. & $r \Delta \cdot V$ & rq & rl & $\Delta \varphi$ & 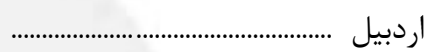 \\
\hline $1.1 r$ & $\Lambda \varepsilon r$ & $r \Delta \Lambda$ & $\Delta \wedge \vee$ & 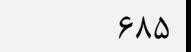 & اصفهان .................... \\
\hline$\Delta \Delta V$ & rAl. & 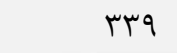 & re & IDTT & 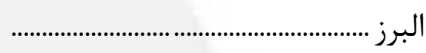 \\
\hline rی9 & 90 & $r \wedge$ & 10 & $\mid r \Delta \Lambda$ & ايلام ....................................................... \\
\hline rr & FrV & $9 \mathrm{~V}$ & rVq & $1 \Delta \Delta$ & 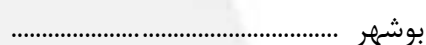 \\
\hline$r \varphi .1$ & $11 \cdot v 1$ & rqוr & rTq & TFו & تهران ..................... \\
\hline$\vee \wedge$ & V^ & pq & TrV & 99 & جهارمحال و بختيارى ...................... \\
\hline 19 & pq & 191 & $\Delta$ & 10 & خراسان جنوبى ............... \\
\hline 91 & $\wedge \Delta \varphi$ & $197 \wedge$ & re & IVT & 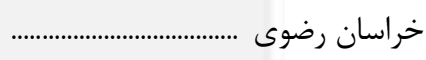 \\
\hline r & १४ & $\wedge ґ \wedge$ & r & 19 & خراسان شمالى .................... \\
\hline r949 & $\Delta F \Lambda$ & rtq & IFFF & $1 . r$ & 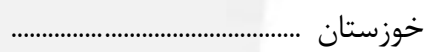 \\
\hline fr & $9 \wedge 1$ & qr & r & vr & 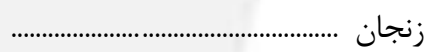 \\
\hline $4 q$ & IOT & $114 \lambda$ & $v$ & rq & 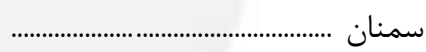 \\
\hline 99 & rar & $19 T \Delta$ & rı & $8 \Lambda$ & 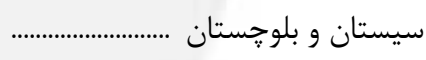 \\
\hline TVE & fif & IV. & treV & rit & فارس ................................... \\
\hline iv & lqr. & 90 & $\Delta$ & rrv & 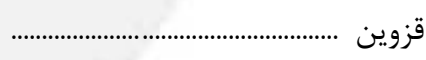 \\
\hline rqD & $\Delta T \Delta$ & rTr & $1 \ldots$ & $r \cdot q$ & 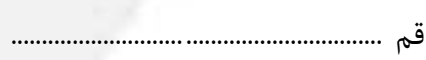 \\
\hline FAF & rMN & 119 & ir & ruvq & 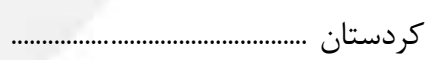 \\
\hline $9 V$ & ו & Ir & $\Delta V$ & $1 \cdot r$ & 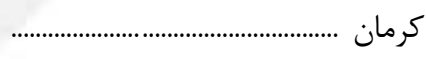 \\
\hline$\Delta q F$ & $r \cdot 1$ & 111 & rF & rIISA & كرمانشاه ............................... \\
\hline 91 & TF & ir & $|r| Q \cdot$ & GT & كهخيلويه و بويراحمد .. \\
\hline rq & rid & $|V \vee \Delta|$ & $\Delta$ & $\Delta r$ & كلستان ....................... \\
\hline 99 & rqAkr & Tar & $\wedge$ & $1 \Delta T$ & 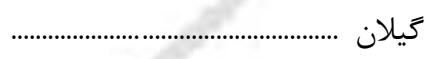 \\
\hline $11 r r$. & lor & 99 & re & irtr & 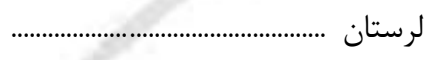 \\
\hline 99 & TYQI & 1910 & rی & IVF & 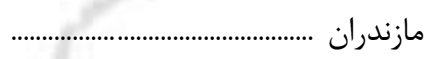 \\
\hline$\Delta Y \Lambda$ & 91. & $\Lambda$ & r & $\Delta F V$ & 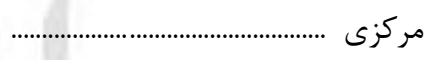 \\
\hline TQR & 1994 & rVA & $i r \cdot$ & rq1 & 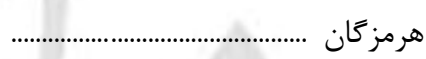 \\
\hline FFF & rt. & $\Delta q$ & $1 \cdots$ & $1 F \Delta \Lambda$ & 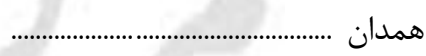 \\
\hline ITV & $|r|$ & १४ & VQ & $1 \cdot 4$ & 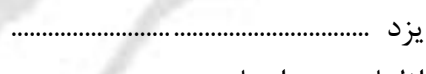 \\
\hline er & TFI & $1 \wedge 1$ & $\Delta T$ & 195 & 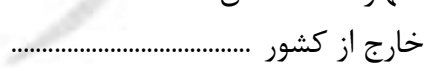 \\
\hline IT & ru & 90 & r & $\Delta r$ & اظهار نشده محل اقامت قبلى ............. \\
\hline
\end{tabular}


^ - ا- مهاجران وارد شده طى ه سال كذشته بر حسب جنس، استان محل اقامت قبلى و فعلى (بر اساس آخرين جابجايى انجـام (نقاط شهرى)

شده)(دنباله)

\begin{tabular}{|c|c|c|c|c|c|}
\hline \multicolumn{5}{|c|}{ استان محل اقامت فعلى } & \multirow{2}{*}{ جحل اقامت ق قبلى } \\
\hline 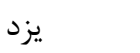 & 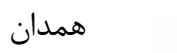 & هرمزكان & مركزى & مازندران & \\
\hline rrred & $r \mu q \cdot 1$ & rTa. I & RFFAq & $\Delta \cdot F \Delta F$ & 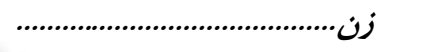 \\
\hline 19 & 199 & rاه & $1 \cdot 1$ & • & 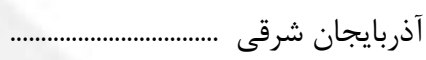 \\
\hline$\Delta F$ & $1 \wedge \Delta$ & TIT & IFS & IV. & 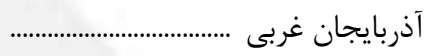 \\
\hline$q$. & re & אזו & $9 \Lambda$ & vq. & 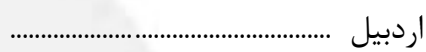 \\
\hline rrql & VET & $|f| V$ & $10 \cdots$ & Nrt & 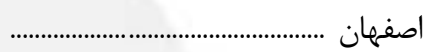 \\
\hline$\Delta \Delta G$ & 1119 & Fru & 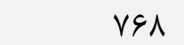 & lers & 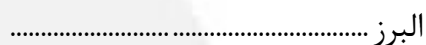 \\
\hline GT & TRT & 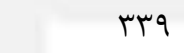 & TAS & ir. & ايلام .................................................... \\
\hline 101 & 191 & VVA & $1 \cdot 0$ & 190 & 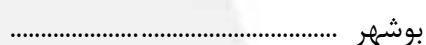 \\
\hline T. F. & FFAF & $T V \cdot G$ & kqr. & 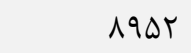 & تهران ................................ \\
\hline $11 f$ & ITF & $\forall \wedge$. & irv & 11. & 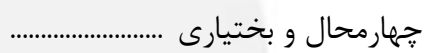 \\
\hline NFq & 19 & VT & ra & $|r|$ & 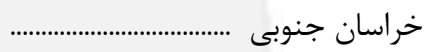 \\
\hline$|F F|$ & $10 \Delta$ & 1 1r94 & tAL & IAVD & 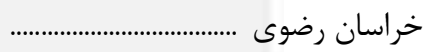 \\
\hline 114 & IV & Tre & 111 & $91 \%$ & 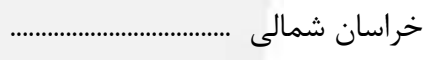 \\
\hline rबוr & 1.11 & १९. & 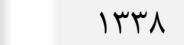 & $\Delta V r$ & 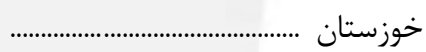 \\
\hline rq & $1 \Delta \Delta$ & VF & q & red & زنجان .............................. \\
\hline V & NT & $1 \Delta$ & vq & 914 & 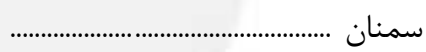 \\
\hline$r \cdot \Delta \cdot$ & $\wedge$. & $\wedge r$. & Irی & Frt & سيستان و بلوجستان ........ \\
\hline rq. & rq1 & gTaT & re. & rदq & 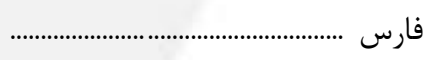 \\
\hline$\wedge$. & ודי & 19 & $\mid r \Lambda$ & reV & 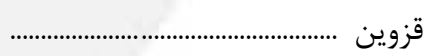 \\
\hline 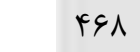 & $\Delta 91$ & 191 & Ireq & $\Delta 99$ & 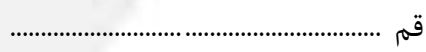 \\
\hline at & $r \cdot \wedge \Delta$ & $1 \Delta 1$ & Tre & TIY & 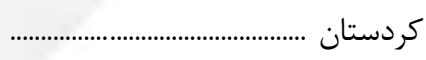 \\
\hline$r \wedge \cdot \Delta$ & $1 \cdots$ & $|4| 1 \mid$ & $\wedge$ & TET & 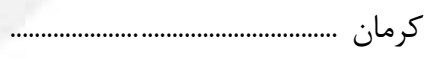 \\
\hline זr & I IFY & gra & Irtes & rq1 & 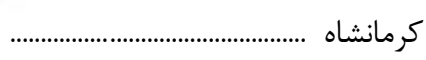 \\
\hline Vעr & $\wedge$. & TrA & 90 & fr & كهيليلويه و بويراحمد \\
\hline rFa & pq & fin & 195 & TITF & حلستان ......................... \\
\hline IVE & rme & (1ו1 & 491 & 1890 & 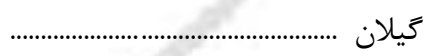 \\
\hline 990 & $1 \cdots v$ & 911 & 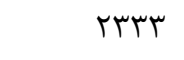 & TQI & 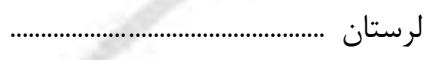 \\
\hline 190 & $r \cdot q$ & $V \Delta S$ & rkq & TFte. & 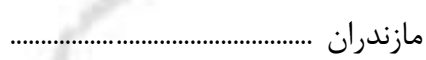 \\
\hline $1 \cdots$ & 971 & T\&l & IDTqY & rar & 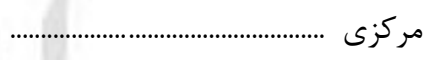 \\
\hline $11 V r$ & TVV & IDTFE & IOT & $9 \Delta \Delta$ & 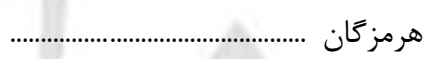 \\
\hline ITS & 19999 & DT & IFAs & $r \cdot r$ & همدان ........................ \\
\hline$V T \cdot 9$ & v. & 499 & ^r & ir. & 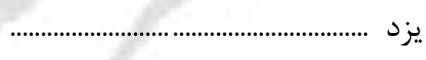 \\
\hline rea & $1 . r$ & $\Delta F V$ & $\begin{array}{r}\lambda \\
k \cdot \Delta\end{array}$ & $\begin{array}{l}\Delta \\
\text { rFS }\end{array}$ & 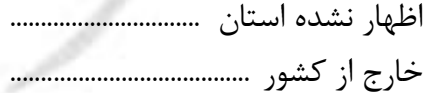 \\
\hline vq & سب & Gr & rq & $1 \cdot r$ & اظهار نشده محل اقامت قبلى .......... \\
\hline
\end{tabular}




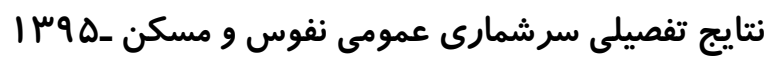

^ - ا- مهاجران وارد شده طى ه سال كذشته بر حسب جنس، استان محل اقامت قبلى و فعلى (بر اساس آخرين جابجايى انجـام

\begin{tabular}{|c|c|c|c|c|c|c|}
\hline ط ط ط روس & & & & & & شده)(دنباله) \\
\hline & & 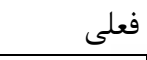 & استان محل اقامت & & & جنس و استان \\
\hline البرز ال & اصفهان & 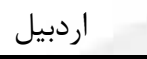 & آذربايجان غربى & آذربايجان شرقى & جمع - ا & محل اقامت قبلى \\
\hline LOFTF & rlasq & qrve & rarrer & relsi & vretar & 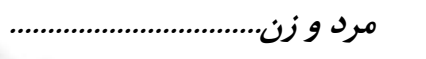 \\
\hline IQT & lkF & $9 \cdot 0$ & reVF & IDAFT & rrqv & 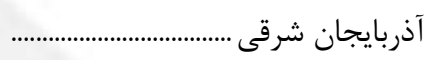 \\
\hline $1 \cdot r$ & $q 4$ & Fil & $r \ldots q \Lambda$ & rN19 & ए৭৭०८ & 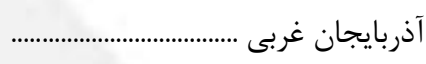 \\
\hline ITt & 10 & $\Delta \cdot r q$ & $v \cdot$. & mfY & Q१४५ & 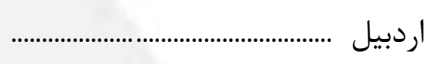 \\
\hline rit & $r \cdot \Delta I F$ & rq & $1 r q$ & 9र & rq৭.. & اصفهان ................... \\
\hline VIVV & rme & ir. & trt & $r \Delta \Delta$ & IVQTV & 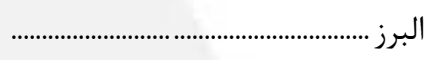 \\
\hline r) & $\Delta r$ & r & et & 19 & eVES & 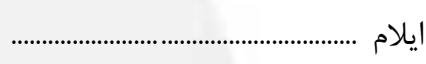 \\
\hline$v$ & 199 & 11 & me & 9 & Irras & 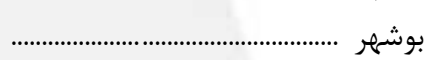 \\
\hline rrq. & $r F \cdot 1$ & 1911 & gQT & rی९9 & NGFVT & 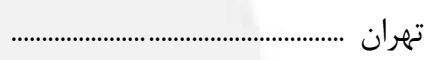 \\
\hline If & 1191 & r & सq & v & $\wedge 1 \cdot v$ & جهارمحال و بختيارى ..................... \\
\hline$\Delta \varphi$ & $\wedge \vee$ & r & r & ir & $\mid \Delta \wedge \Delta F$ & 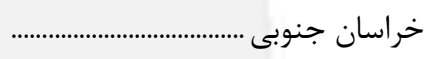 \\
\hline Trו & rAd & r & rat & $1 F \Delta$ & VAYA. & خراسان رضوى ............. \\
\hline VF & r. & 1 & ra & 9 & $\mid r \ldots r$ & خراسان شمالى ........... \\
\hline tra & 1119 & 19 & rIS & 90 & r\&9V. & 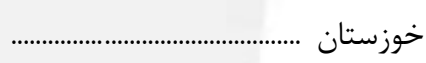 \\
\hline $10 \Delta$ & 99 & $1 \mathrm{in}$ & $r \cdot V$ & $\Delta \cdot$ & $9 \cdot 1 f$ & 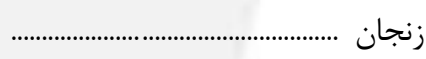 \\
\hline Tr & rq & Ir & kT & i & vrqv & 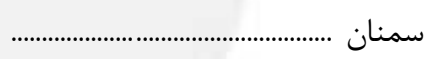 \\
\hline $1 \cdots$ & VVI & it & $\Delta 1$ & fr & TArGV & سيستان و بلوجستان ........ \\
\hline ar & grt & iv & q & is & r..rs & فارس .................................. \\
\hline rrq & re & tr & IVe & vq & $1 \cdot r T \Delta$ & 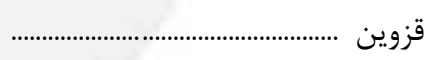 \\
\hline $9 \vee$ & rrq & IV & 4. & $r \cdot 1$ & VVFS & 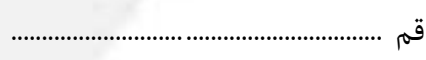 \\
\hline TTS & rᄉ & $\wedge \Delta$ & १QT & DQT & $r \Delta \cdot r r$ & 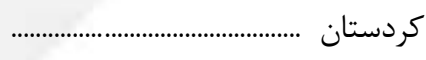 \\
\hline rq & 198 & rV & $\wedge \varphi$ & TF & rVqrq & 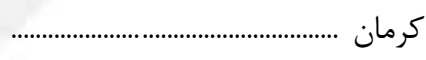 \\
\hline rqV & $11 \mathrm{~F}$ & 114 & rAF & pr & ISTIK & 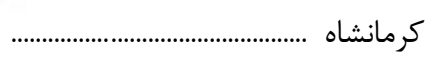 \\
\hline$\wedge$ & $r \cdot$. & r & ra & r & 191.9 & 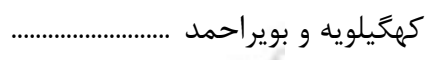 \\
\hline IVr & pq & it & Ve & $\Delta r$ & r.१८ & 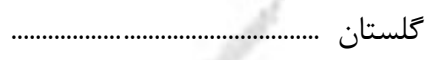 \\
\hline tra & re & FrA & fiv & 90 & rq9.. & كيلان ....................... \\
\hline ו ו & rel & lef & $\wedge \varsigma$ & 1. & $I \Delta \wedge \wedge \vee$ & 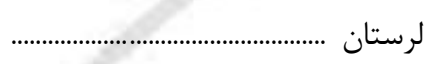 \\
\hline 148 & $|r|$ & $1 \cdot 1$ & IV. & il & rघ八Ir & 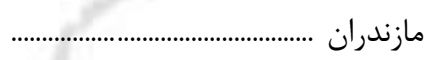 \\
\hline 9४ & TrE & ir & Fr & 10 & 1.491 & 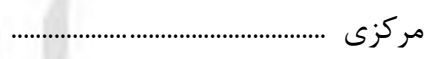 \\
\hline r & riv & IV & rF & rq & r..१९ & 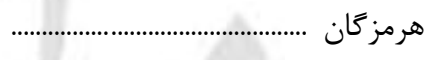 \\
\hline TFV & IVD & $1 \cdot 1$ & IVT & $r \cdot$ & IrDSG & 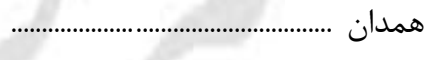 \\
\hline 90 & THF & ir & iv & te & $\wedge\ulcorner\wedge$. & 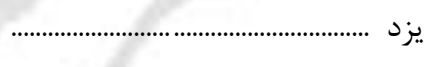 \\
\hline $1 \ldots 9$ & $\begin{array}{l}\text { rr } \\
1148\end{array}$ & Q & $\begin{array}{l}v_{V} \\
\wedge r\end{array}$ & $\begin{array}{c}1 \\
r q\end{array}$ & $\begin{array}{l}\text { rAV } \\
|S T| Y\end{array}$ & 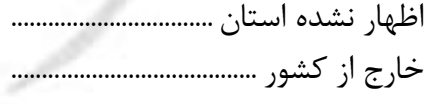 \\
\hline 9 & is & $\Delta \Delta$ & $I V \Lambda$ & 191 & TAF. & اظهار نشده محل اقامت قبلى ............. \\
\hline
\end{tabular}


^ - ا- مهاجران وارد شده طى ه سال حَذشته بر حسب جنس، استان محل اقامت قبلى و فعلى (بر اساس آخرين جابجايى انجـام (نقاط روستايى)

شده)(دنباله)

\begin{tabular}{|c|c|c|c|c|c|}
\hline \multicolumn{5}{|c|}{ استان محل اقامت فعلى } & \multirow{2}{*}{ محل اقامت قبلى استان } \\
\hline خراسان جنوبى & | جهارمحال و بختيارى & ت ت تهران & بوشهر & ايلام ام & \\
\hline $19 V F 9$ & sirq & VF\&AS & rr.e. & arq9 & 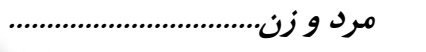 \\
\hline VQ & r & Ifra & $1 r$. & 19 & 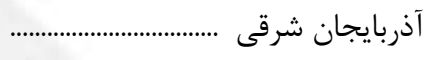 \\
\hline$r \cdot$ & · & G.r & 9. & rq & 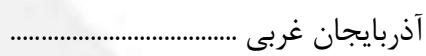 \\
\hline IV & 1 & (טTI & vr & 19 & 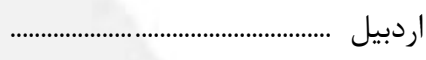 \\
\hline $\mid F \lambda$ & ITAT & 1.19 & $\Delta q$. & Gr & 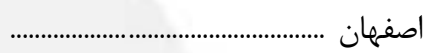 \\
\hline kt & r & rat. & fr & $\Delta r$ & 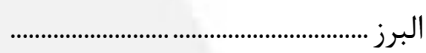 \\
\hline$\Delta$ & r & rAl & ar & $r \wedge 10$ & 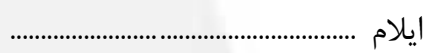 \\
\hline v & 90 & $\Delta 9$ & १४१. & 9 & بوشهر ......................................... \\
\hline DIV & iv & FIrGA & 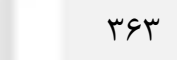 & rat & تهران ................................................. \\
\hline 11 & $r \varepsilon \cdot r$ & $8 \Lambda$ & 990 & بq & جهارمحال و بختيارى .................... \\
\hline ITFOV & 1 & rMA & rl & 1 & 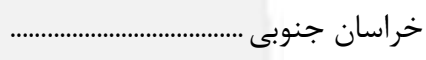 \\
\hline r৭৭9 & v & rIOV & $1 \cdot{ }^{4}$ & fit & خراسان رضوى ................. \\
\hline Gri & r & $9 \cdot 1$ & kr & $\Delta$ & 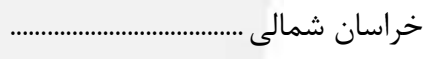 \\
\hline rq & $\Delta \Delta q$ & GTr & $19 r \wedge$ & DQT & 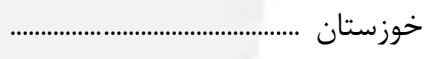 \\
\hline 11 & 1 & vat & tr & f & زنجان ............................... \\
\hline rq & r & $\Delta \wedge r$ & 11 & . & 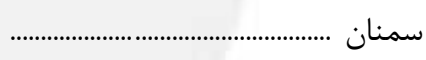 \\
\hline $11 \mathrm{KT}$ & r & ятq & 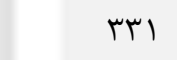 & r. & 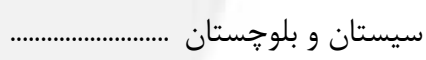 \\
\hline \&\& & $\Delta 1$ & rTq & rVGq & rt & 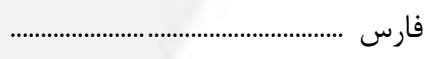 \\
\hline f & r & 999 & $\wedge$ & it & قزوين ................................. \\
\hline rQ & rq & NMF & $\wedge \Delta$ & IV & 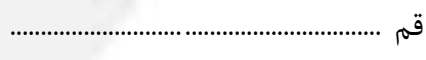 \\
\hline r & r & vVI & rq & rی & 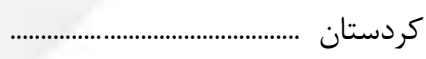 \\
\hline 199 & 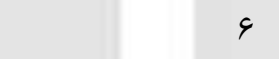 & rAl & $i \Delta V$ & r & 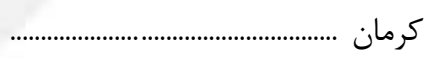 \\
\hline v & $\Delta$ & ITVV & 1re & ए१९ & 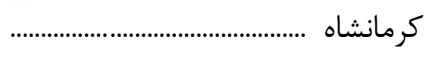 \\
\hline ir & IVF & $\Delta V$ & $\wedge \cdots$ & rq & كهيَيلويه و بويراحمد ........ \\
\hline r11 & 4 & rfqr & זr & IV & 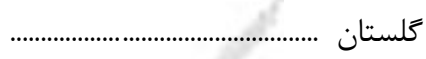 \\
\hline 11 & 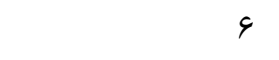 & Ner & 94 & $1 \cdot$ & 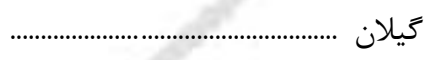 \\
\hline $1 \cdot$ & $\Delta$ & 1919 & $r \cdot 9$ & $\Delta F q$ & 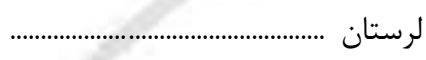 \\
\hline 190 & r & $\wedge \varepsilon$. & $\wedge \varsigma$ & 19 & 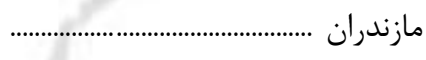 \\
\hline rl & 1. & 1.94 & \& & r. & 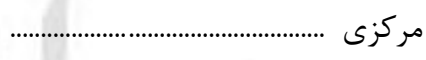 \\
\hline r & $\Delta T$ & lQT & rrv & ro & هرمز \\
\hline Tr & r & INVF & r & ve & 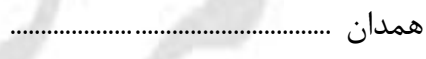 \\
\hline 94 & $\begin{array}{r}r \\
r\end{array}$ & $\begin{array}{l}149 \\
14\end{array}$ & $\begin{array}{l}r q \\
r q\end{array}$ & $\begin{array}{l}14 \\
1\end{array}$ & 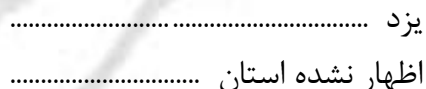 \\
\hline r & kr & $\Delta \vee \wedge \Delta$ & $11 \cdot r$ & 19 & 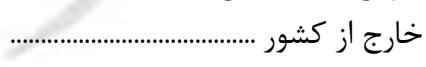 \\
\hline$\Delta$ & if & ו ו & FeV & if & اظهار نشده محل اقامت قبلى ............ \\
\hline
\end{tabular}




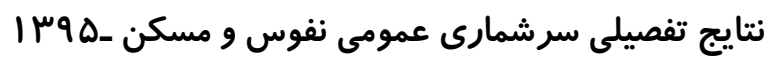

^ - ا- مهاجران وارد شده طى ه سال حذذشته بر حسب جنس، استان محل اقامت قبلى و فعلى (بر اساس آخرين جابجايى انجـام

\begin{tabular}{|c|c|c|c|c|c|c|}
\hline \multicolumn{6}{|c|}{ استان محل اقامت فعلى } & \multirow{2}{*}{ محل اقامت قبلى استان } \\
\hline سيستان و بلوجستان & سمنان & زنجان & خوزستان & خراسان شمالى & خراسان رضوى & \\
\hline IAAFT & 11999 & 1191. & ris19 & irra. & vratr & 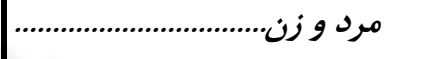 \\
\hline rF & 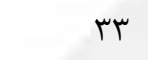 & rat & 19 & 19 & iへ & 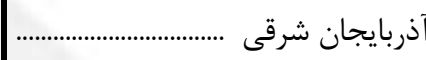 \\
\hline il & 19 & TVF & $v$. & $r \cdot$ & rA & 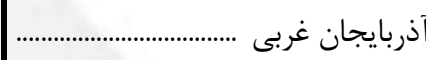 \\
\hline rV & $r \cdot$ & Irs & r. & 4 & rt & ردبيل ...................................................... \\
\hline 99 & $1 \wedge 9$ & 114 & $\Delta V F^{c}$ & $\Delta \Delta$ & tAT & صفهان ............................. \\
\hline 11 & Tr & 991 & lar & ITr & trt & 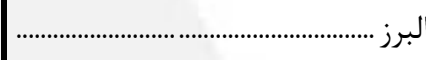 \\
\hline$\Delta$ & tr & rی & $|0|$ & r & 1. & 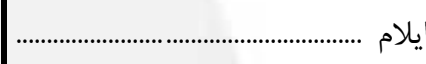 \\
\hline rr & 4 & 1. & $r \cdot r$ & f & r & 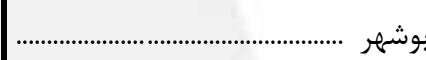 \\
\hline 91 & TITS & 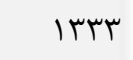 & щ. & IrID & rq.4 & تهران ............................ \\
\hline$\wedge$ & 19 & VI & qVY & ir & IV & 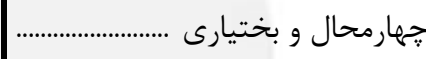 \\
\hline 118 & $\wedge \varphi$ & $\Delta$ & Ir & \&T & 1984 & 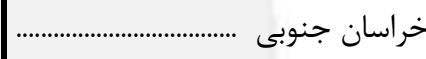 \\
\hline$\vee \wedge \Delta$ & ITFF & 99 & $1 \vee 9$ & $1 \wedge \& V$ & $4 \cdot 9 \cdot r$ & خراسان رضوى .............. \\
\hline$\Delta F$ & 190 & it & 19 & VAru & 1.41 & خراسان شمالى .................... \\
\hline $4 q$ & re & $|r|$ & IFGFT & is & r\&A & 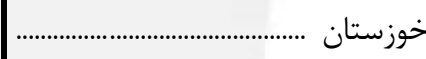 \\
\hline 9 & r. & 9114 & 10 & r & 10 & 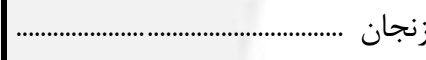 \\
\hline rV & FAFA & 19 & 1 & ITt & 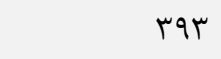 & 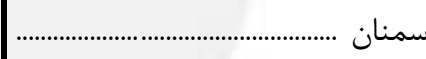 \\
\hline $19 \cdot 11$ & rAr & ro & 94 & אזו & rras & سيستان و بلوحستان ......... \\
\hline v. & VQ & VA & kqf & $p q$ & $9 \Delta$ & 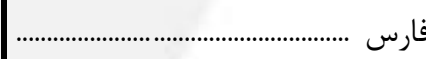 \\
\hline$\wedge$ & rq & VDI & 10 & $\Delta$ & $r$. & فزوين ................................... \\
\hline re & $\Lambda$ & $1 \wedge 9$ & 19 & rv & IFT & 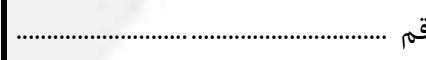 \\
\hline r & is & 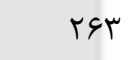 & tr & 9 & r. & كردستان .............................................. \\
\hline 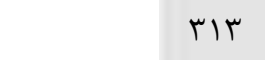 & (i) & זr & 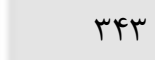 & pq & lᄉr & كرمان .................................................. \\
\hline \& & q & 90 & roq & ז & $\Delta r$ & 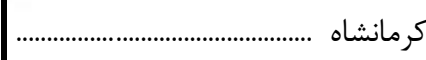 \\
\hline 4 & 11 & rr & 914 & $\checkmark$ & $\Delta$ & 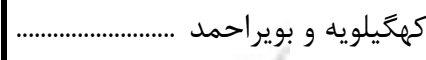 \\
\hline$|V|$ & $10 \Lambda$ & $r \cdot$ & rv & TFV & $\Delta \vee \Delta$ & كلستان ......................... \\
\hline r. & ra & rr. & 10 & rt & 99 & 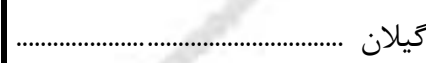 \\
\hline$\wedge$ & kr & $9 \Lambda$ & $11 \cdot v$ & ir & rT & 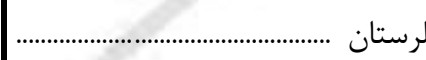 \\
\hline 99 & fov & $\Lambda \Lambda$ & $\Delta \Lambda$ & rql & $r \cdot \Delta$ & 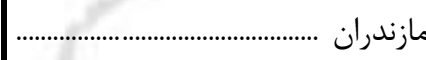 \\
\hline r & $1 r q$ & $\Delta 9$ & Irt & r & $\Delta r$ & 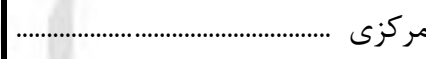 \\
\hline 91 & 11 & 11 & $1 \Delta \Lambda$ & ri & qV & 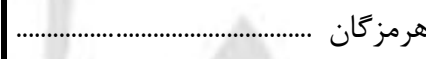 \\
\hline 19 & IFV & 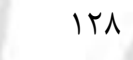 & TFT & ro & r & 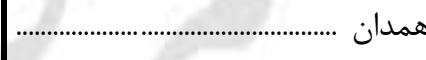 \\
\hline $\begin{array}{l}91 \\
r \Lambda\end{array}$ & & 1. & ITE & $e^{i r}$ & $\frac{r}{r k i}$ & 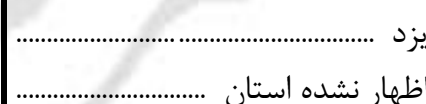 \\
\hline$r \cdot 1$ & 101 & 114 & rAY & 4 & rrq & 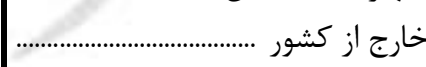 \\
\hline $1 \Lambda$. & $r$ & 1. & Vq & if & TrI & 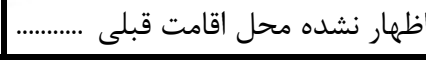 \\
\hline
\end{tabular}


^ - ا- مهاجران واردشده طى ه سال كذشته بر حسب جنس، استان محل اقامت قبلى و فعلـى (بـر اســاس آخــرين جابجـايى (نقاط روستايى)

انجامشده)(دنباله)

\begin{tabular}{|c|c|c|c|c|c|}
\hline \multicolumn{5}{|c|}{ استان محل اقامت فعلى } & \multirow{2}{*}{ محل اقامت قبلى واستان } \\
\hline 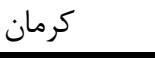 & كردستان & قم & قزوين & 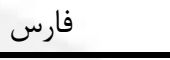 & \\
\hline ryara & reIA9 & raDT & $118 \pi$ & raAvi & 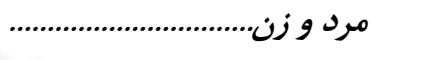 \\
\hline rI & TAF & it & $\wedge \varphi$ & $4 q$ & 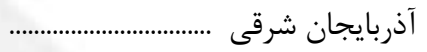 \\
\hline 19 & $\Delta \wedge r$ & r & 199 & et & 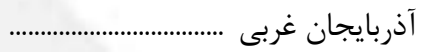 \\
\hline er & $9 V$ & . & rq & $\Delta r$ & 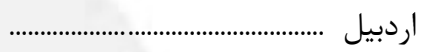 \\
\hline 90 & 4. & $1 \pi$. & $\Lambda F$ & $\Delta \& T$ & 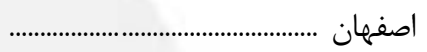 \\
\hline (i) & 199 & FT & qky & rT & 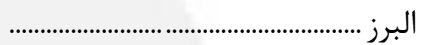 \\
\hline a & 99 & - & r & IV & ايلام ........................................................... \\
\hline ir & $\Delta$ & r & $\Delta$ & $9 \wedge \mathrm{F}$ & 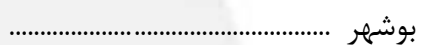 \\
\hline lfr & 1.14 & $\Delta r$. & rIVe & $r \cdot \Delta$ & 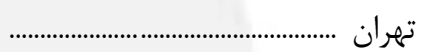 \\
\hline 94 & ז & r & $\Delta$ & IOT & 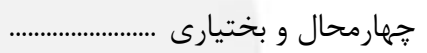 \\
\hline$\Delta r$ & 1 & r & 9 & $1 \cdot$ & 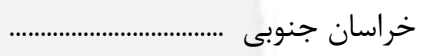 \\
\hline IrT & $1 \cdot$ & 94 & lır & 9 . & 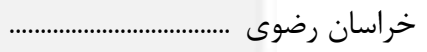 \\
\hline v & r & 4 & r & ir & خراسان شمالى .................... \\
\hline $1 \cdot V$ & $1 \pi$. & TQ & mF & GTE & خوزستان ............................ \\
\hline • & TF. & rᄉ & trA & 9 & زنجان ............................. \\
\hline 19 & rᄉ & 1 & TV & 19 & سمنان ................................ \\
\hline V.r & rQ & rF & $|r|$ & TET & 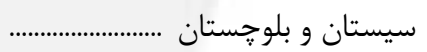 \\
\hline tra & $\Delta \cdot$ & 19 & ro & 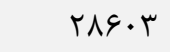 & فارس .................................. \\
\hline 10 & $1 \cdot r$ & 19 & $911 \pi$ & $\Delta$ & 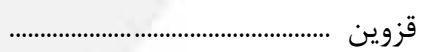 \\
\hline १V & kq & TVGY & 90 & $1 \cdot 0$ & قم ..................................... \\
\hline r & $199 \cdot 1$ & $1 \cdot$ & $\vee \cdot$ & 4. & 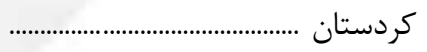 \\
\hline rrq19 & ir & 10 & $4 q$ & T\&D & 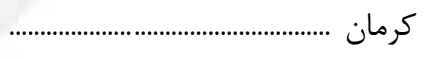 \\
\hline 11 & $\vee \wedge 9$ & 11 & $1 \Delta \Delta$ & $\Delta V$ & 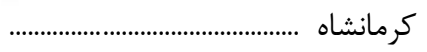 \\
\hline$\wedge$ & r & 1 & $\Delta$ & VrF & كهيليلويه و بويراحمد ........ \\
\hline$\Delta r$ & re & rq & 149 & r & كلستان ............................ \\
\hline $1 \cdot$ & $\Delta \Lambda$ & V & $r V \cdot$ & tr & 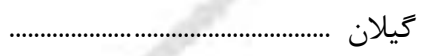 \\
\hline rq & IVD & If & 90 & 90 & 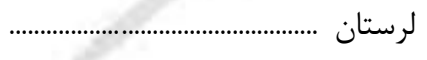 \\
\hline 9 & $4 q$ & rI & $1 \cdot V$ & st & مازندران ...................... \\
\hline r. & q & $|\wedge|$ & $\vee \cdot$ & $\Delta V$ & 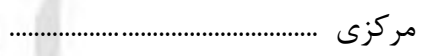 \\
\hline$\checkmark \Delta \cdot$ & rl & 11 & 14 & $9 \Delta \mathrm{r}$ & 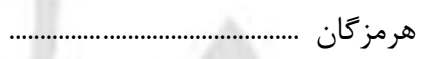 \\
\hline IV & rq1 & ry & $\wedge f$ & $\Delta \Lambda$ & 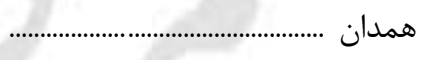 \\
\hline$\Delta \Delta r$ & $1 \cdot$ & IV & $1 \cdot$ & rat & يزد ..................................... \\
\hline If\& & et & Fru & 91 & ITSD & 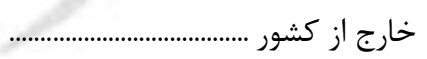 \\
\hline rIf & $\Delta$ & ra & 10 & 94 & اظهار نشده محل اقامت قبلى .......... \\
\hline
\end{tabular}


| نتايج تفصيلى سرشمارى عمومى نفوس و مسكن _هD

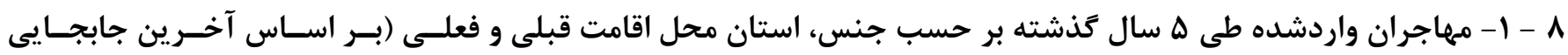
(نقاط روستايى)

انجام شده)(دنباله)

\begin{tabular}{|c|c|c|c|c|c|}
\hline \multicolumn{5}{|c|}{ استان محل اقامت فعلى } & \multirow{2}{*}{ محل اقامت قو استان } \\
\hline 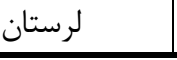 & 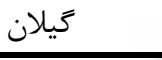 & 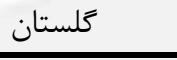 & كهخيلويه و بويراحمد & كرمانشاه & \\
\hline Irrre & ra148 & ryger & $|1| 81$ & 19FTa & 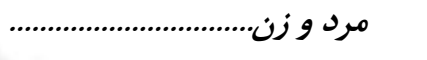 \\
\hline r & $1 \wedge 9$ & 19 & 9 & 419 & 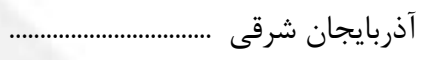 \\
\hline $8 \Lambda$ & 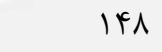 & M & is & $\Delta \& 9$ & 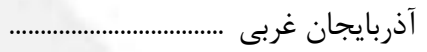 \\
\hline 9 & $9 \Delta \Delta$ & $\wedge$ & if & $\Lambda F$ & اردبيل ................................................ \\
\hline FAS & r r & $\Lambda$ & MFY & rFA & |صفهان ................. \\
\hline 148 & $199 \mathrm{~V}$ & & 10 & r & 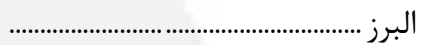 \\
\hline TAT & 11 & $\Delta$ & $\Delta$ & $\Delta T \Delta$ & 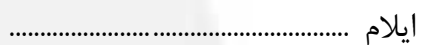 \\
\hline ry & q & rI & rr. & tr & بوشهر ........................ \\
\hline$\Lambda \Delta r$ & $\Delta 9 \cdot 9$ & IrAk & vi & 911 & تهران ..................................................... \\
\hline $1 \cdot r$ & ז & r & IVT & IFV & 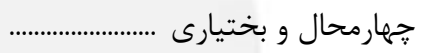 \\
\hline r & 9 & 9 . & $\Delta$ & 19 & 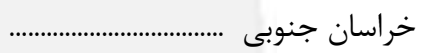 \\
\hline १७ & rid & 911 & i) & FVV & 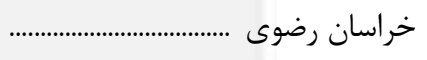 \\
\hline v & זr & Mlब & r & זr & خراسان شمالى ............. \\
\hline 1494 & 191 & fi & rev & ITSG & 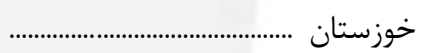 \\
\hline rl & 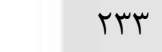 & $r \cdot$ & 1 & TTA & زنجان ............................. \\
\hline rt & $\Delta \Delta$ & G.r & r & r. & 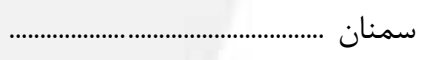 \\
\hline f. & 9 . & $|A F|$ & 19 & $\Delta \cdot$ & 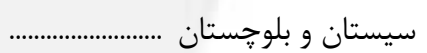 \\
\hline IfD & וזו & re & १人 & TQF & 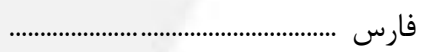 \\
\hline 19 & $|r| \cdot$ & ra & rו & r & 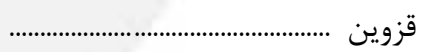 \\
\hline $1 \cdot 1$ & $r \varphi \Delta$ & 19 & re & $\Delta F$ & قم ........................................ \\
\hline $1 \%$ & 11. & ו & 11 & 911 & 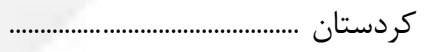 \\
\hline r. & VV & $4 q$ & $r$. & 1.9 & 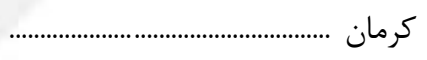 \\
\hline p\&q & $1 \cdot 4$ & IV & ו & I. TIN & 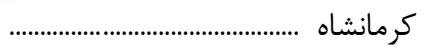 \\
\hline$\Delta V$ & 19 & 1 & IDTFT & tr & كهيَيلويه و بويراحمد ....... \\
\hline ro & $11 \%$ & TIGAS & rI & $14 V$ & كلستان ........................... \\
\hline ז & $r \Delta \cdot r \cdot$ & $4 q$ & rq & ITA & 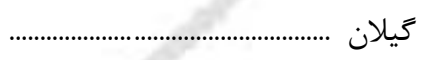 \\
\hline$\Lambda \Delta \& \Delta$ & (4) & 11 & r & ArT & 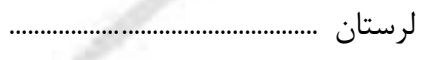 \\
\hline$\Delta V$ & 991 & Faq & il & rtr & 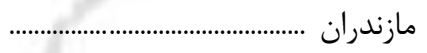 \\
\hline 199 & rF. & rq & 10 & 198 & 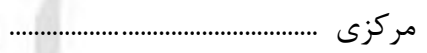 \\
\hline qr & rAY & $\Lambda r$ & $\Delta 1$ & pq & 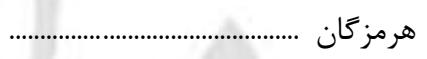 \\
\hline 149 & VV & Ir & iv & $\Delta F q$ & همدان ............................. \\
\hline 10 & (1) & q. & $\Delta \Delta$ & 11 & 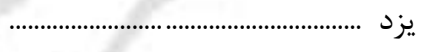 \\
\hline$\Lambda$ & & & & & 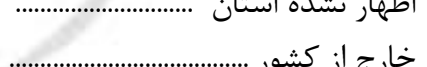 \\
\hline$r \Delta$ & if & qV & r) & rT & اظهار نشده محل اقامت قبلى ......... \\
\hline
\end{tabular}


^ - ا- مهاجران واردشده طى ه سال كذشته بر حسب جنس، استان محل اقامت قبلى و فعلـى (بـر اســاس آخــرين جابجـايى (نقاط روستايى)

انجامشده)(دنباله)

\begin{tabular}{|c|c|c|c|c|c|}
\hline \multicolumn{5}{|c|}{ استان محل اقامت فعلى } & \multirow{2}{*}{ محل اقامت قبلى و استان } \\
\hline 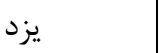 & همدان & هرمزان & مركزى & 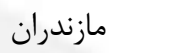 & \\
\hline$|k r q|$ & Irevg & ratrr & IFETA & (49191 & 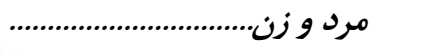 \\
\hline 91 & $\Delta \varphi$ & $\wedge \cdot$ & 11. & $1 \Delta \Lambda$ & 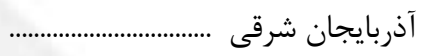 \\
\hline$\wedge \varphi$ & lor & rq & ITF & IrA & 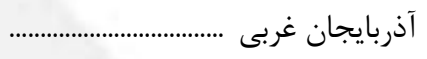 \\
\hline 9 . & rq & rq & $r \cdot$ & TFQ & اردبيل ................................................. \\
\hline$\Delta V V$ & irt & $r \cdot 9$ & $r \Delta \Delta$ & 9.9 & اصفهان .............................. \\
\hline IrF & ral & $\checkmark \Delta$ & rฯq & $1 \cdot T_{4}$ & 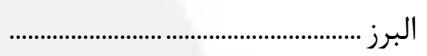 \\
\hline et & 99 & Tr & $\vee \cdot$ & VG & ايلام .................................................... \\
\hline 90 & $\Delta T$ & trr & rq & ve & 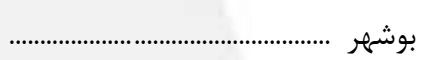 \\
\hline 109. & 1019 & זrז & rqv. & $\Delta \Lambda \cdot q$ & 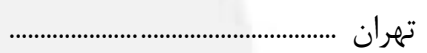 \\
\hline lır & $1 f$ & rQq & $14 \lambda$ & $\wedge$. & 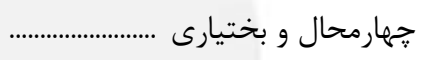 \\
\hline$r \cdot 4$ & r & IrF & if & 11 & 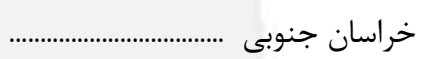 \\
\hline MIN & et & $|\wedge|$ & IFV & 1099 & 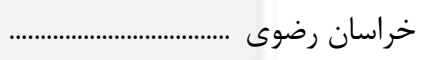 \\
\hline rt & 19 & (i) & r & Var & 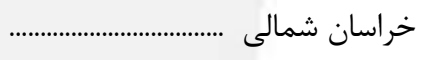 \\
\hline rrv & tAr & GTF & TYS & MFT & 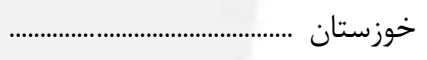 \\
\hline 19 & vi & r. & r & $\mid r \wedge$ & 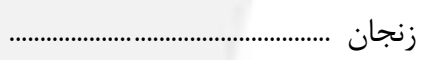 \\
\hline tr & rq & $r \cdot$ & 19 & GrA & 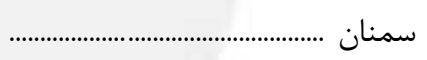 \\
\hline ITF. & 99 & 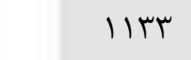 & $\Delta \Delta$ & $\Delta \& r$ & 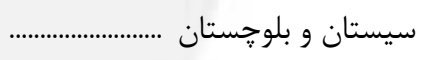 \\
\hline qva & 111 & rTA. & vi & TFA & 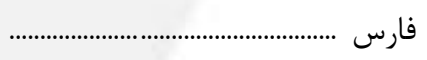 \\
\hline IV & $\Delta \cdot$ & 11 & $\Delta 9$ & $r \cdot V$ & قزوين ................................. \\
\hline 19. & $\Delta \cdot 9$ & re & Vis & rFa & 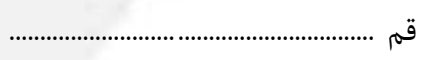 \\
\hline rی & $\Delta T_{1}$ & rA & $\wedge 9$ & rVA & كردستان ............................................. \\
\hline $9 \Delta 1$ & r & $10 \cdot 9$ & fF & Irt & كرمان ............................................... \\
\hline q & GMT & i^ & 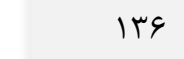 & וTr & 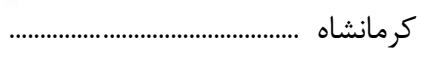 \\
\hline 119 & it & 10 & rr. & rA & كهيخيلويه و بويراحمد ........ \\
\hline 1.4 & rF & $\wedge 9$ & ITr & $T F \cdot r$ & كلستان ..................... \\
\hline$\Delta F$ & re & $\wedge$ & IVD & 1.49 & 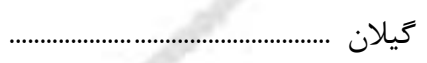 \\
\hline $10 \Delta$ & rVI & 91 & fqv & IVD & 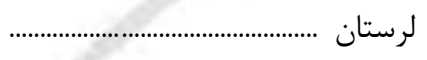 \\
\hline$\wedge f$ & rv & $\Delta 9$ & rघq & TIYFA & 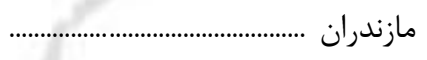 \\
\hline fr & rᄉl & rA & $9 \Lambda 1 V$ & IVT & 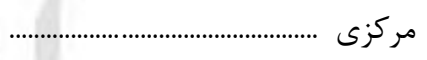 \\
\hline 194 & fr & $19 \cdot Y 1$ & iv & MIN & 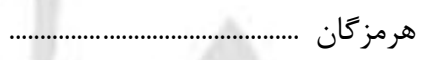 \\
\hline$\Delta \varphi$ & $1 \cdot 91$ & (i) & Mls & TFT & 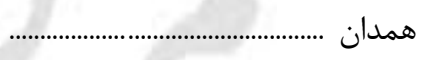 \\
\hline$\Delta \vee \wedge q$ & 10 & vi & $g r$ & 9. & 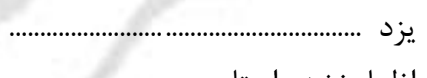 \\
\hline$\Lambda \notin \mu$ & $\Delta$ & 1194 & TMA & 148 & 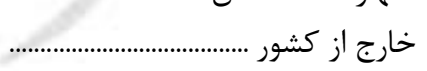 \\
\hline 10 & vr & rq & if & $1 \cdot v$ & اظهار نشده محل اقامت قبلى .......... \\
\hline
\end{tabular}


| نتايج تفصيلى سرشمارى عمومى نفوس و مسكن _ه

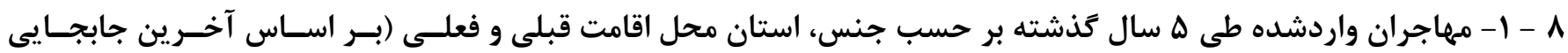
(نقاط روستايى)

انجامشده) (دنباله)

\begin{tabular}{|c|c|c|c|c|c|c|}
\hline \multicolumn{6}{|c|}{ استان محل اقامت فعلى } & \multirow{2}{*}{ محل اقامت قبلى استان } \\
\hline 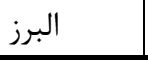 & اصفهان & 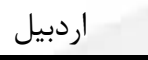 & آذربايجان غربي & آذربايجان شرقى & 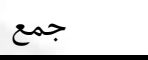 & \\
\hline $11 \%$. & IVDAV & $\Delta \& \Delta r$ & $r \cdot v \wedge s$ & irrar & $f \cdot v \cdot 11$ & مرد.......................... \\
\hline 11 & $\wedge 9$ & FAT & 1211 & V৭AF & 1 IrA. & 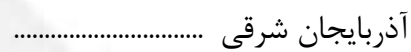 \\
\hline$\Delta 9$ & $\Delta \cdot$ & ५१९ & $\mid F \Delta \Delta \Lambda$ & $r \cdot r$ & 19098 & 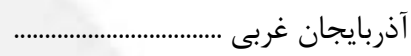 \\
\hline ve & it & $r \Delta \Delta l$ & GTI & 191 & $\Delta \Delta \vee \Delta$ & 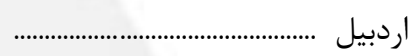 \\
\hline $1 \cdot r$ & $1 \cdot \Delta \varphi q$ & ra & 9 . & $\Delta \Lambda$ & $199 \cdot 1$ & 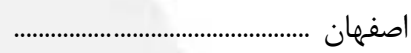 \\
\hline rqщ. & וrk & $9 V$ & 190 & $1 \wedge \Lambda$ & १९१९ & 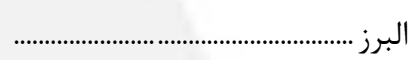 \\
\hline 11 & rT & r & rA & $\wedge$ & rq). & 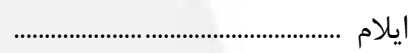 \\
\hline r & $1 \cdot v$ & 11 & IV & $\Delta$ & 9190 & 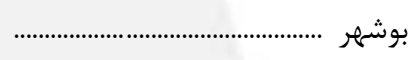 \\
\hline IVIf & ITFD & $1 \ldots 9$ & FFA & lQST & FATAT & تهران ............................... \\
\hline$\wedge$ & GTs & r & Fa & v & FAVA & جهارمحال و بختيارى ................... \\
\hline r山 & $\Delta V$ & r & ז & ir & ^৭9 & 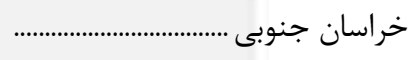 \\
\hline 194 & TFY & 19 & ris & $1 \%$ & RTMID & 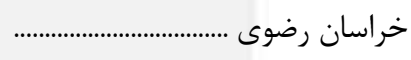 \\
\hline r & IV & 1 & r & 9 & gसt & خراسان شمالى ............ \\
\hline ira & 991 & 11 & IVV & is & IETrq & 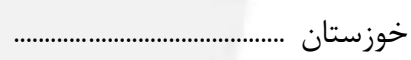 \\
\hline$\Delta f$ & $\wedge \Lambda$ & ITV & IVF & rt & FVAT & زنجان ........................................ \\
\hline If & 10 & 11 & rv & 1 & r.9r & سمنان ................................ \\
\hline 19 & gヘF & 11 & iv & r & IsFVq & سيستان و بلوجستان ................... \\
\hline ґ & rq1 & r & GT & tr & $t r \cdot \Lambda t$ & 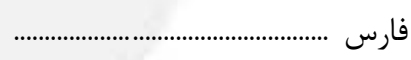 \\
\hline lar & 11 & r & iro & $\Delta T$ & $\Delta F q \Lambda$ & 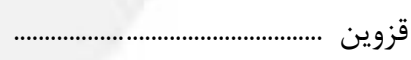 \\
\hline$r \Delta$ & 199 & 9 & rی & 1.9 & Frtq & قم ................................. \\
\hline IrV & rt & vq & gFa & $\Delta T_{1}$ & IrFqu & 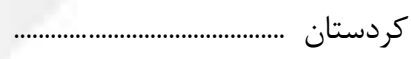 \\
\hline ir & 1re & 19 & $\wedge$. & 10 & IFVG & 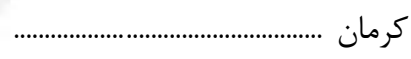 \\
\hline 190 & Gr & $1 \cdot r$ & THE & re & qrTF & كرمانشاه ........................................... \\
\hline$\Delta$ & ler & r & to & r & 1.199 & كهخيلويه و بويراحمد .................. \\
\hline$\wedge \Delta$ & rl & v & sf & r & $14 \wedge 99$ & 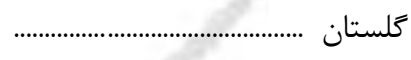 \\
\hline lre & rt & rब9 & ५^৭ & Gt & $101 \mathrm{~V}$ & 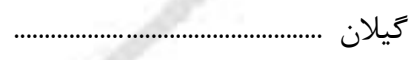 \\
\hline $\mid 01$ & $r r$. & lfF & vi & $\Delta$ & QMFT & لرستان ...................... \\
\hline $8 V$ & $\wedge \cdot$ & 81 & 148 & rF & IMAF. & 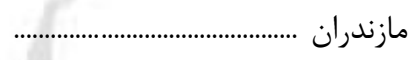 \\
\hline$\Delta T$ & 14. & ir & r & $1 \cdot$ & DVFe & مركزى ........................... \\
\hline 10 & 111 & 11 & 19 & r. & $1 \cdot \lambda r F$ & هرمزكان ..................... \\
\hline irv & १७ & $1 .$. & lQF & iv & vele & 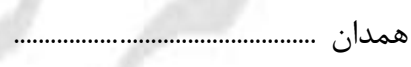 \\
\hline r & irv & 11 & If & If & 1499 & 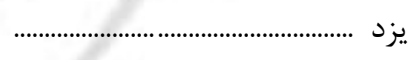 \\
\hline 1 & 19 & $r$ & $v^{f}$ & $\cdot$ & MrI & 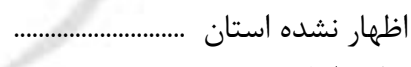 \\
\hline ४৭९ & $9 \wedge 4$ & $r \cdot$ & ry & r. & $1 r \cdot q 4$ & 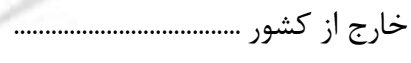 \\
\hline$r$ & tr & ra & $1 \cdot f$ & 111 & $19 \cdot 4$ & اظهار نشده محل اقامت قبلى ........ \\
\hline
\end{tabular}


^ - ا- مههاجران واردشده طى ه سال كذشته بر حسب جنس، استان محل اقامـت قبلـى و فعلى(بـر اســاس آخــرين جابجـايى

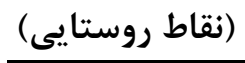

انجامشده)(دنباله)

\begin{tabular}{|c|c|c|c|c|c|}
\hline \multicolumn{5}{|c|}{ استان محل اقامت فعلى } & \multirow{2}{*}{ محل اقامت قبلى و استان } \\
\hline خراسان جنوبى & جهارمحال و بختيارى & تهران & بوشهر & 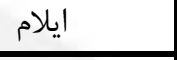 & \\
\hline |ref| & $r \cdot 11$ & r. Fra & $10 \Delta 19$ & raqr & 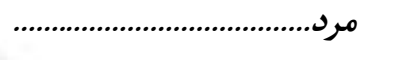 \\
\hline$V^{F}$ & $r$ & VAV & $11 \pi$ & IV & 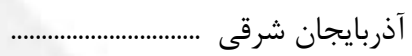 \\
\hline 19 & · & ros & $V F$ & rq & 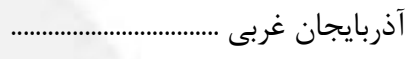 \\
\hline 19 & 1 & $1 \cdot 9$ & 99 & 10 & اردبيل ................................................... \\
\hline IrA & $\vee \Delta \cdot$ & DrG & $\Delta 1$. & $\Delta \Delta$ & اصفهان ............................................... \\
\hline ru & 1 & rre & ro & r & البرز .......................................................... \\
\hline$\Delta$ & 1 & 10 & $4 q$ & 1090 & ايلام ............................ \\
\hline r & Ft & rV & DFFT & 4 & بوشهر ............... \\
\hline 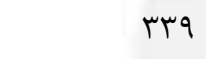 & rq & TIOT| & 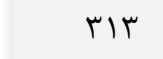 & IVF & 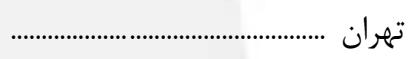 \\
\hline 11 & $19 \cdot 1$ & iv & qTr & re & جهارمحال و بختيارى ................... \\
\hline$V \cdot I T$ & 1 & 14 . & $r \cdot$ & 1 & 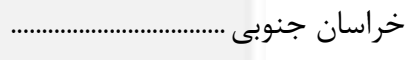 \\
\hline rArq & r & $11 Q F$ & $\wedge \Delta$ & Ft & 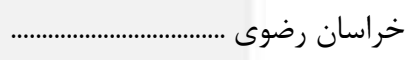 \\
\hline$\Delta 9 F$ & 1 & far & il & $\Delta$ & خراسان شمالى ................. \\
\hline re & rNI & 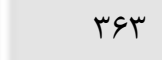 & $19 \vee \wedge$ & $\Delta / \Delta$ & 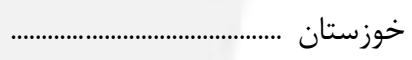 \\
\hline 11 & 1 & fre & 19 & r & زنجان ......................................... \\
\hline rq & r & 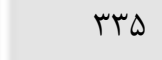 & 19 & $\cdot$ & سمنان ................................................. \\
\hline VTV & 11 & ros & ५१९ & 11 & 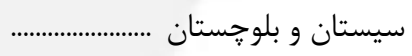 \\
\hline$r \cdot$ & 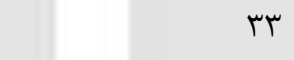 & $1 M \Lambda$ & rATr & rV & 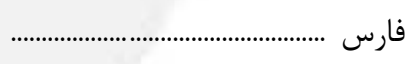 \\
\hline r & 1 & kqq & 9 & 1. & قزوين ..................................................... \\
\hline ir & If & fFt & $\Delta 1$ & 10 & 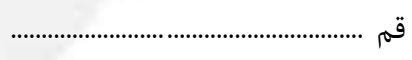 \\
\hline r & r & frq & rq & rv & 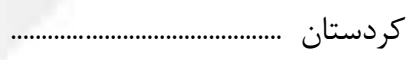 \\
\hline $1 T \Delta$ & f & lis & Irt & 1 & 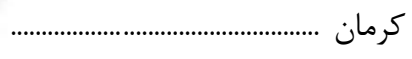 \\
\hline 1 & $\Delta$ & $9 \wedge \Delta$ & 11. & rqv & 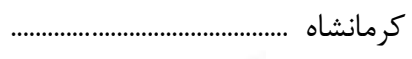 \\
\hline 9 & $\wedge \Lambda$ & rq & $\Delta \wedge 9$ & ra & كهَيلويه و بويراحمد .................... \\
\hline rar & $\Delta$ & ITUT & rr & 10 & 5لستان ................................. \\
\hline 4 & 4 & $\Delta r \Lambda$ & 9 . & $\wedge$ & 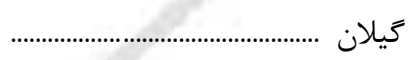 \\
\hline f & q & $1 \cdot 4$ & IVV & evr & 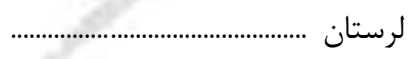 \\
\hline $1 \Delta V$ & r & lq9 & ve & 10 & 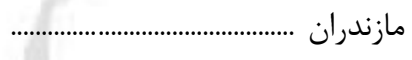 \\
\hline 11 & द & $\Delta \vee \wedge$ & $\Delta \Lambda$ & r) & 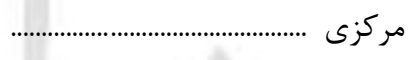 \\
\hline rY & Fr & Vq & INT & $r \cdot$ & 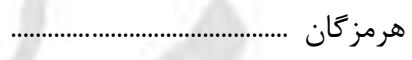 \\
\hline tr & 1 & ११५ & 94 & 49 & 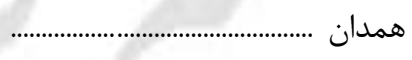 \\
\hline GT & li & ve & rt & $\wedge$ & 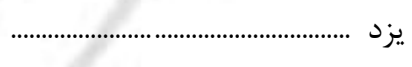 \\
\hline 1 & $r$ & 11 & r. & & 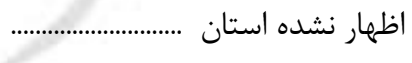 \\
\hline 1 & rı & rATY & 919 & $\mathrm{v}$ & 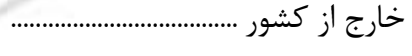 \\
\hline$r$ & $\wedge$ & IVV & rq. & 4 & اظهار نشده محل اقامت قبلى ......... \\
\hline
\end{tabular}


| نتايج تفصيلى سرشمارى عمومى نفوس و مسكن _هD

^ - ا- مهاجران واردشده طى ه سال كذشته بر حسب جنس، استان محل اقامت قبلى و فعلـى (بـر اســاس آخــرين جابجـايى (نقاط روستايى)

انجام شده)(دنباله)

\begin{tabular}{|c|c|c|c|c|c|c|}
\hline \multicolumn{6}{|c|}{ استان محل اقامت فعلى } & \multirow{2}{*}{ محل اقامت قبلى و استان } \\
\hline |سيستان و بلوجستان & سمنان & زنجان & خوزستان & خراسان شمالى & خراسان رضوى & \\
\hline 1.94. & $r v a d$ & $\Delta V H F$ & $|r a r|$ & srr & $r \lambda \cdot r r$ & 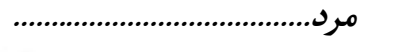 \\
\hline r) & re & $1 \wedge F$ & 99 & 10 & re & 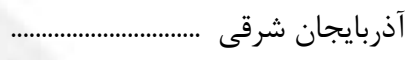 \\
\hline r. & VG & 191 & 90 & 11 & 19 & آذربايجان غربى ....................... \\
\hline tr & 19 & $\wedge$. & IV & a & 10 & اردبيل ............................... \\
\hline$\Delta \cdot$ & $10 \Lambda$ & QT & Fil & re & 191 & اصفهان ..................... \\
\hline $\mathrm{v}$ & $\Lambda \Delta$ & FMA & Ire & ve & IFA & 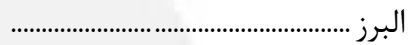 \\
\hline a & 11 & $r$. & १V & 1 & 4 & ايلام .............................................. \\
\hline ra & a & t & lFT & r & r. & بوشهر ........................ \\
\hline 94 & Irat & GQT & TFI & str & $1 f \cdot 1$ & تهران .................... \\
\hline $\mathrm{v}$ & Ir & $\Delta F$ & (i). & a & $\wedge$ & جهارمحال و بختيارى ..................... \\
\hline VV & vi & r & $\pi$ & pr & 1.19 & خراسان جنوبى ................ \\
\hline$V \cdot r$ & 990 & rv & 199 & $9 \vee r$ & MIGTा & 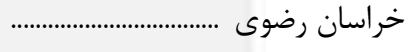 \\
\hline 11 & $11 \%$ & $\Delta$ & 19 & tRIT & QTL & خراسان شمالى .............................. \\
\hline$\uparrow \wedge$ & TF & $\Lambda T$ & VVre & r & 1re & 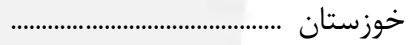 \\
\hline 9 & 10 & tVqF & 11 & r & 1 . & 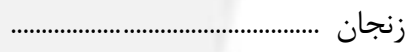 \\
\hline IT & TFET & $\wedge$ & 1 & 94 & TIT & سمنان ..................... \\
\hline$\wedge \Delta 19$ & TrI & 11 & q & 1.9 & IrTA & سيستان و بلوحستان .............................. \\
\hline$\Delta 9$ & $\Delta \Delta$ & is & אזי & rs & TQ & 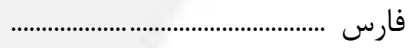 \\
\hline 9 & Tr & 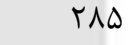 & if & r & Tr & 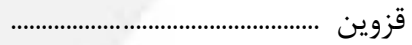 \\
\hline זו & sq & 19 & 9) & tr & 90 & قم ............................... \\
\hline r & ru & $1 F q$ & ra & 9 & rI & كردستان .............. \\
\hline rIT & 19 & 19 & Vזr & rq & q & 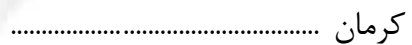 \\
\hline r & q. & $\Delta \varphi$ & rM & 1. & r. & كرمانشاه ................... \\
\hline 9 & 11 & 9 & FAY & a & r & كهيكيلويه و بويراحمد . \\
\hline 90 & I.r. & 19 & rt & 194 & $r \cdot 1$ & كلستان ........ \\
\hline$r$. & r & 11. & 10 & 19 & re & كيلان ..................... \\
\hline$\Lambda$ & re & rV & $\Lambda \Delta q$ & 11 & TY & 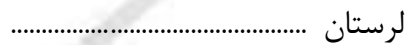 \\
\hline$\Delta \Lambda$ & rel & a. & $\Delta \Delta$ & $r \cdot l$ & IAr & مازندران ......... \\
\hline i & ITT & re & $1 \cdot 9$ & ir & r. & 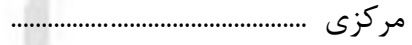 \\
\hline$i \Delta$ & 9 & 1 . & 148 & r. & $\Delta \varphi$ & هرمزكان ...................... \\
\hline IT & ITV & 4. & $r \cdot \Delta$ & ra & 10 & همدان ................... \\
\hline fr & 10 & V & $\wedge \mathrm{V}$ & 9 & 10. & 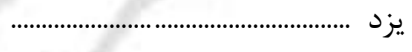 \\
\hline TrT & $1 r 9$ & 11. & $r \cdot \cdot$ & r & 109 & 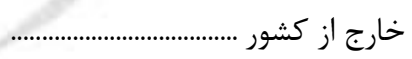 \\
\hline $1 \cdot 1$ & - & 4 & $i_{1}$ & o & 119 & اظهار نشده محل اقامت قبلى ....... \\
\hline
\end{tabular}


^ - ا- مهاجران واردشده طى ه سال كذشته بر حسب جنس، استان محل اقامت قبلى و فعلـى (بــر اســاس آخــرين جابجـايى (نقاط روستايى)

انجامشده)(دنباله)

\begin{tabular}{|c|c|c|c|c|c|}
\hline \multicolumn{5}{|c|}{ استان محل اقامت فعلى } & \multirow{2}{*}{ محل اقامت قبلى واستان } \\
\hline 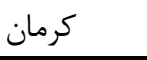 & كردستان & قم & قزوين & فارس & \\
\hline lever & IrAgF & 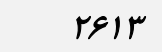 & 981 . & $119 \cdot 0$ & مرد.................................................... \\
\hline 19 & $r \cdot r$ & 1. & 4. & r. & 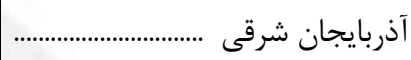 \\
\hline 14 & rat & rt & $1 \pi$. & rT & 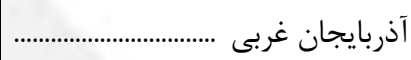 \\
\hline rद & $\Delta \Delta$ & . & r & $i \Delta$ & اردبيل .................................................. \\
\hline $9 V$ & $i \wedge$ & $\wedge 9$ & 91 & ґ^. & 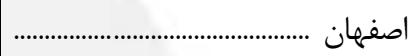 \\
\hline זr & $1 \cdot \Delta$ & r山 & $\Delta \varphi \Delta$ & TY & 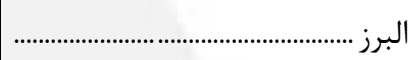 \\
\hline r & ^ & - & 1 & rו & ايلام ...................................................... \\
\hline 9 & r & 1 & r & Fq & 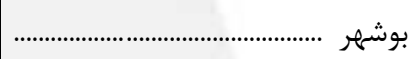 \\
\hline 19 & gFt & mif & $\mid f \cdot r$ & $1 F \Delta$ & تهران .............................. \\
\hline$\Delta \Lambda$ & 9 & r & $r$ & ITF & جهارمحال و بختيارى .................. \\
\hline ru & 1 & r & 9 & 9 & 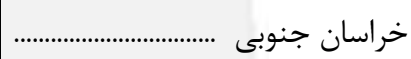 \\
\hline 4. & v & vr & 119 & sV & خراسان رضوى ............................. \\
\hline r & r & $\Delta$ & 11 & 1. & 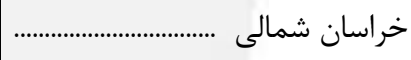 \\
\hline $9 \Lambda$ & $\wedge \vee$ & if & ro & is. & 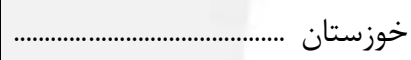 \\
\hline · & 111 & r & lQT & r & 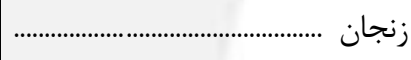 \\
\hline it & $r \cdot$ & 1 & 19 & 11 & 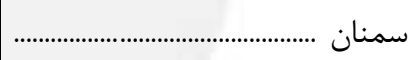 \\
\hline r & 19 & r & vo & $r \cdot r$ & سيستان و بلوجستان .................... \\
\hline 11. & 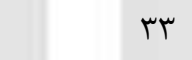 & 11 & r & lfiqf & فارس ..................................................... \\
\hline 11 & $\vee \cdot$ & lf & 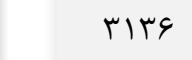 & r & قزوين .................................. \\
\hline FV & rq & Ifry & $\Delta r$ & $p q$ & قم ....................................... \\
\hline 1 & 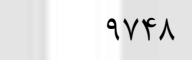 & v & r & iq & 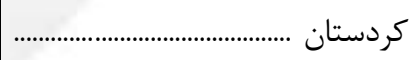 \\
\hline IIETr & $\wedge$ & 11 & rA & 194 & كرمان .............................................. \\
\hline 11 & $\Delta \Delta \Lambda$ & $\wedge$ & 99 & (i) & كرمانشاه ................................ \\
\hline 4 & r & 1 & f & rvq & كهگيلويه و بويراحمد .. \\
\hline r & to & $r \Delta$ & 94 & IV & 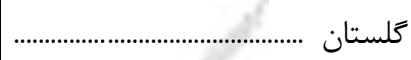 \\
\hline$\wedge$ & $\Delta 1$ & 4 & IVe & 19 & 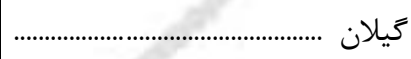 \\
\hline rI & IVT & 9 & $\Delta 9$ & $\Delta T$ & 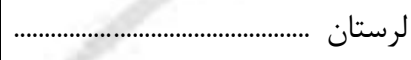 \\
\hline v & fr & $r$. & $\Lambda r$ & r & مازندران ................ \\
\hline r. & is & $1 \cdot r$ & et & pq & 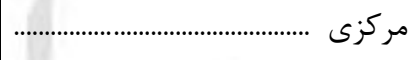 \\
\hline ras & 10 & $\Delta$ & 1. & $\Delta V I$ & 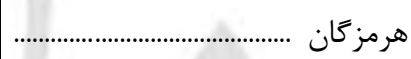 \\
\hline ir & r & $r \Delta$ & v. & ty & همدان ............................ \\
\hline f & r & r & 1 & kq & 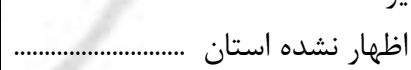 \\
\hline 1194 & rV & T\&4 & vi & 9rT & 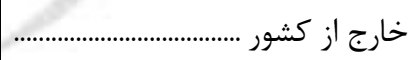 \\
\hline IKF & 1 & 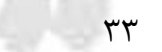 & 9 & VV & اظهار نشده محل اقامت قبلى ........ \\
\hline
\end{tabular}




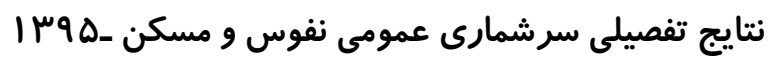

^ - ا- مهاجران واردشده طى ه سال كذشته بر حسب جنس، استان محل اقامت قبلى و فعلـى (بـر اســاس آخــرين جابجـايى (نقاط روستايى)

انجامشده)(دنباله)

\begin{tabular}{|c|c|c|c|c|c|}
\hline \multicolumn{5}{|c|}{ استان محل اقامت فعلى } & \multirow{2}{*}{ جحل اقامت ق قبلى } \\
\hline 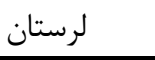 & 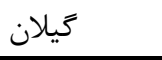 & كلستان & كهيَيلويه و بويراحمد & كرمانشاه & \\
\hline$v \cdot r \mu$ & $r \cdot r r v$ & $|r r r|$ & $q$ qqF & $1 \pi \lambda \cdot v$ & 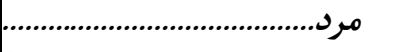 \\
\hline 10 & $11 \pi$ & $\wedge$ & v & $r \cdot r$ & 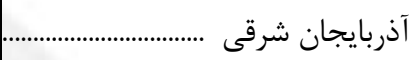 \\
\hline$\Delta \Lambda$ & 110 & 4 & ir & $\Delta \Delta \Lambda$ & 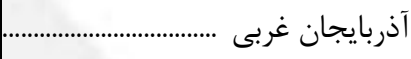 \\
\hline 9 & FAV & r & 11 & Ve & اردبيل ................................. \\
\hline rma & rII & هI & $1 \wedge 9$ & Mld & 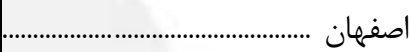 \\
\hline vi & 948 & ve & 1. & $19 V$ & البرز ........................... \\
\hline 110 & 4 & r & r & eVr & ايلام ...................................................... \\
\hline 19 & $\Delta \varphi$ & it & 11. & Ir & بوشهر ......................... \\
\hline \&q. & 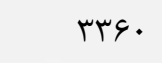 & VAV & 4. & VबA & تهران .......................... \\
\hline is & it & 1 & $1 \cdot 1$ & IfD & 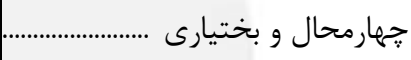 \\
\hline r & 9 & $\Delta r$ & r & 10 & 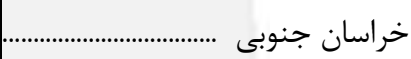 \\
\hline vr & 194 & rid & rq & fET & خراسان رضوى ............ \\
\hline 9 & 19 & IN & 1 & r & 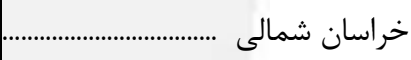 \\
\hline VVF & 9४ & ra & trF & 1119 & 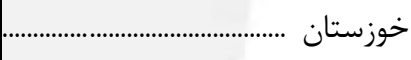 \\
\hline 11 & זrו & 10 & 1 & זrt & 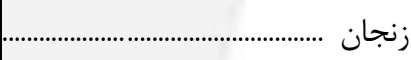 \\
\hline IV & זr & $r \cdot 1$ & r & TV & 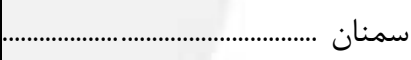 \\
\hline rt & 99 & 914 & $\wedge$ & pq & 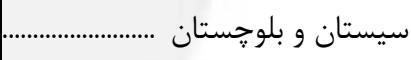 \\
\hline$q 4$ & ve & ז & DTT & TFT & 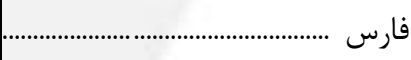 \\
\hline ז & qVI & 19 & \& & lfF & 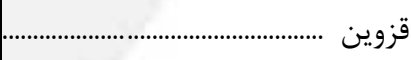 \\
\hline 9) & 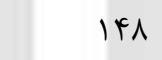 & FV & 11 & 99 & قم ............................. \\
\hline $1 \cdot 0$ & 11 & IV & if & qVV & 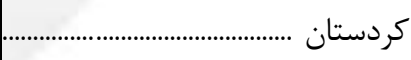 \\
\hline tr & rq & rq & r & 91 & كرمان ............................................... \\
\hline riی & 99 & 14 & TQ & $\Delta \varphi \cdot \varphi$ & 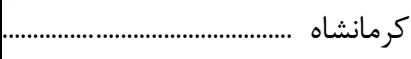 \\
\hline fr & ir & 1 & VVVq & $r \Delta$ & كهخيلويه و بويراحمد \\
\hline ra & vi & 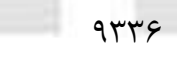 & iv & Ifr & كلستان ................... \\
\hline r & ITrA. & r & rA & ITE & 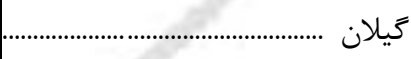 \\
\hline fifq & rᄉ & $\wedge$ & rI & vVq & لرستان ............... \\
\hline Fr & $\Delta T \cdot$ & 「^ৎ & rی & rIV & مازندران .............................. \\
\hline $1 \cdot 0$ & IV. & Ir & 1. & 190 & 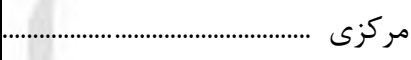 \\
\hline ro & $|V|$ & fr & r & rq & 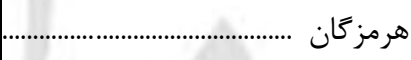 \\
\hline$v^{k}$ & ia & 4 & 1. & rNa & 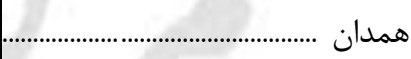 \\
\hline 19 & TQ & ז' & rt & 10 & يزد ...................................... \\
\hline$\Delta$ & r & IV & $\wedge \cdot$ & $r \cdot$ & 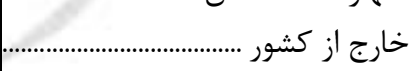 \\
\hline$r r$ & $\wedge$ & ru & if & rt & اظهار نشده محل اقامت قبلى ............................. \\
\hline
\end{tabular}


^ - ا- مهاجران واردشده طى ه سال كذشته بر حسب جنس، استان محل اقامت قبلى و فعلـى (بــر اســاس آخــرين جابجـايى (نقاط روستايى)

انجامشده)(دنباله)

\begin{tabular}{|c|c|c|c|c|c|}
\hline \multicolumn{5}{|c|}{ استان محل اقامت فعلى } & \multirow{2}{*}{ محل اقامت و استان } \\
\hline 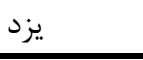 & همدان & هرمزكان & 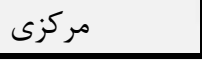 & مازندران & \\
\hline 9991 & 9991 & $10 \cdot 11$ & $19 r y$ & $r F q \cdot r$ & 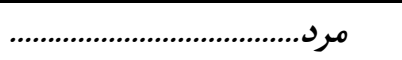 \\
\hline$\Delta 9$ & $\Delta \cdot$ & $4 q$ & $9 \Delta$ & q & 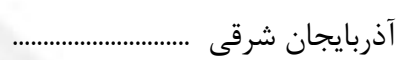 \\
\hline 11 & ITV & זr & 119 & $\wedge 1$ & 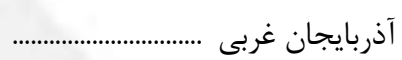 \\
\hline 19 & 19 & rt & If & 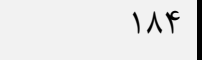 & 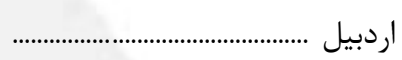 \\
\hline Fro & pq & $r \Delta \Delta$ & $|1|$ & rTV & اصفهان ................ \\
\hline q & 190 & $\Delta V$ & $19 V$ & $\Delta r \wedge$ & البرز ......................... \\
\hline$f \cdot$ & ri & tr & $\Delta V$ & i) & ايلام ................... \\
\hline$V^{\mu}$ & re & 111 & 10 & F & بوشهر ........ \\
\hline$|F \Delta|$ & $\wedge r \Delta$ & 199 & $1 \wedge \cdot r$ & $r \cdot \Delta \cdot$ & 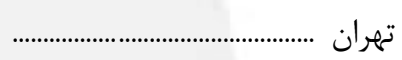 \\
\hline IDr & 1 & מדr & سזו & eV & جهارمحال و بختيارى . \\
\hline r & 1 & ITT & 9 & $\Delta \varphi$ & 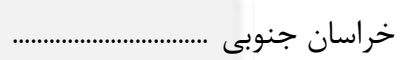 \\
\hline TID & rT & ITV & $1 \cdots$ & $\wedge \vee q$ & 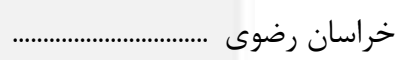 \\
\hline$r \wedge$ & 11 & rq & if & frq & خراسان شمالى ........... \\
\hline TQH & 109 & $\Delta \wedge \Lambda$ & IVT & 114 & 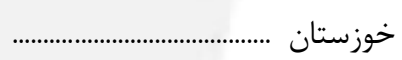 \\
\hline 19 & fq & re & $r \Delta$ & $\vee \wedge$ & 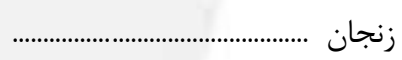 \\
\hline 19 & If & TV & IV & אז' & سمنان ......... \\
\hline qrर & re & $14 q$ & 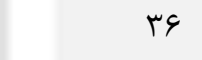 & r & سيستان و بلو. \\
\hline $9 \Delta$. & 99 & $|\Delta V|$ & L & IMF & فارس ............... \\
\hline If & rt & 9 & $f \Delta$ & 91 & 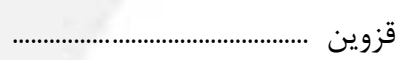 \\
\hline $1 \cdot r$ & TFY & te & $F \vee \Delta$ & $1 \wedge 1$ & 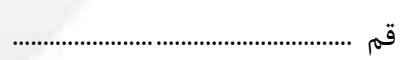 \\
\hline re & rqs & $r \cdot$ & VG & 194 & 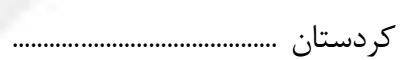 \\
\hline rq1 & r & $\Lambda F \Delta$ & r & $V F$ & كرمان .................... \\
\hline DI & roT & rh & $\wedge \wedge$ & 110 & كرمانشاه ....... \\
\hline $1 \cdot r$ & r & IrA & TTF & IT & كهخيلويه و بو \\
\hline VI & it & $9 \Delta$ & 94 & ITAS & كلستان ........ \\
\hline is & IV & $\Delta V$ & $|f|$ & Fas & گيلان .......... \\
\hline 1rq & 118 & $\Delta 9$ & ґ^. & 90 & 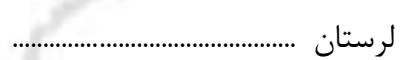 \\
\hline$v \Delta$ & TI & f\& & $r \Delta \Lambda$ & $10 \ldots$ & مازندران ....... \\
\hline f. & If. & IV & ra.r & $9 \vee$ & مركزى ........ \\
\hline $1 \cdot V$ & rr & $|F| \mid$ & rv & $19 \mathrm{~V}$ & 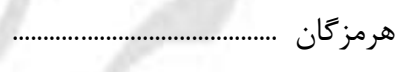 \\
\hline rigr & 1 & f. & $\Delta \Delta$ & $\Delta F$ & يزد .................. \\
\hline$\wedge$ & r & 9 & f & i & 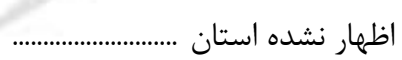 \\
\hline 111 & r & 195 & $r .$. & $1 \cdot r$ & 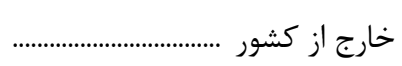 \\
\hline v & $r \Delta$ & $1 \cdot$ & V & $g t$ & اظهار نشده محل اقامت قبلى ...... \\
\hline
\end{tabular}




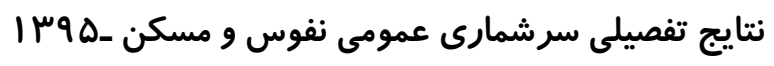

^ - ا- مهاجران واردشده طى ه سال كذشته بر حسب جنس، استان محل اقامت قبلى و فعلـى (بـر اســاس آخــرين جابجــايى (نقاط روستايى)

انجام شده)(دنباله)

\begin{tabular}{|c|c|c|c|c|c|c|}
\hline \multicolumn{6}{|c|}{ استان محل اقامت فعلى } & \multirow{2}{*}{ محل اقامت قاستان } \\
\hline 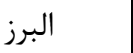 & اصفهان & 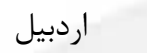 & آذربايجان غربى & آذربايجان شرقى & 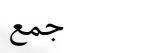 & \\
\hline vrqf & irast & repr & IVAFV & $1 \cdot 1 \mathrm{rA}$ & requer & 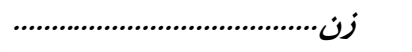 \\
\hline vi & $\Delta \Lambda$ & ITr & Vदr & $\vee \wedge \Delta \Lambda$ & $1 \cdot \wedge \vee$ & 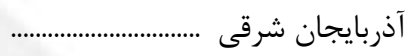 \\
\hline fr & if & 19 & $1 \Delta \Delta F$ & $\Lambda \mathrm{V}$ & IVTaq & 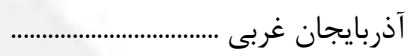 \\
\hline is & r & TFMA & vq & I & Frqq & 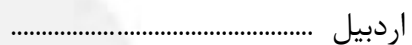 \\
\hline 11. & $994 \wedge$ & f & rq & ry & 1 1тrq9 & اصفهان ........................... \\
\hline TSAY & 99 & $\Delta r$ & $\Delta \Lambda$ & $19 \mathrm{~V}$ & ATrF & 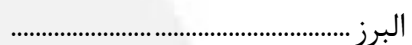 \\
\hline $1 \cdot$ & $r \cdot$ & - & 14 & $\wedge$ & lNrd & 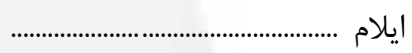 \\
\hline r & qr & . & IV & f & $\Delta \Delta \cdot 1$ & 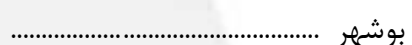 \\
\hline lQVQ & $1 \cdot \Delta 9$ & $4 \cdot 9$ & $r \cdot r$ & $\mu \cdot r$ & rAtt. & تهران ............................. \\
\hline 9 & DFT & - & 1 & . & Trtq & جهارمحال و بختيارى .................. \\
\hline$r \Lambda$ & r. & 1 & . & . & $9 \wedge 91$ & خراسان جنوبي ........................... \\
\hline 101 & $|f|$ & f & 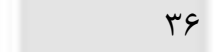 & ro & $M F \cdot \varphi d$ & خراسان رضوى ................ \\
\hline Fr & ir & · & r & r & $\Delta \Delta V r$ & 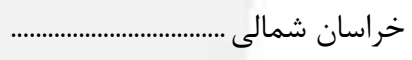 \\
\hline $1 \ldots$ & FYA & 1 & rq & IV & $1 \cdot r T 1$ & 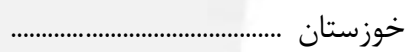 \\
\hline vi & $\wedge$ & 11 & 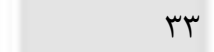 & 11 & FTHT & 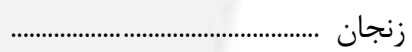 \\
\hline ir & 11 & r & $\Delta$ & r & 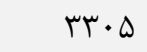 & 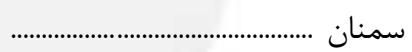 \\
\hline Q1 & $\wedge \vee$ & 1 & f & r & $11 \wedge \mathrm{A \Lambda}$ & 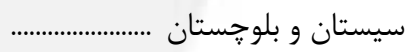 \\
\hline re & KAI & f & ו & Tr & IVqDF & 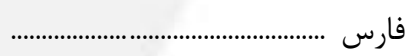 \\
\hline $19 \mathrm{~V}$ & $\wedge$ & 9 & (i) & TV & FVTV & 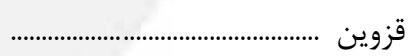 \\
\hline$\Delta T$ & אזו & $\wedge$ & tr & 90 & rols & قم ..................................... \\
\hline 91 & 4 & 4 & $r \cdot v$ & 9) & llQY. & 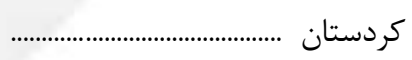 \\
\hline r & v. & $\wedge$ & 9 & 9 & 14199 & 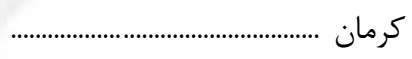 \\
\hline IVT & $\Delta T$ & it & 4. & 1 . & 9119 & 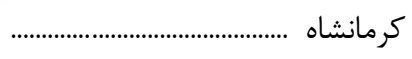 \\
\hline r & Irk & · & · & . & 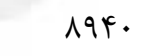 & كهيَيلويه و بويراحمد ..... \\
\hline$\wedge$ & rA & $\Delta$ & ir & 19 & 19.94 & Fلستان ......................... \\
\hline 1.9 & if & lat & rA & r & IfFer. & 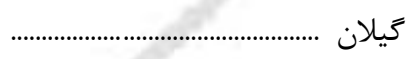 \\
\hline$\wedge \cdot$ & $|f|$ & $\cdot$ & 10 & $\Delta$ & GQFA & لرستان .............. \\
\hline vq & QI & r. & TY & iv & IVqVY & 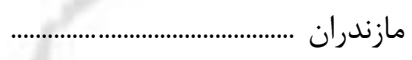 \\
\hline is & $\wedge \varepsilon$ & 1 & 1. & $\Delta$ & EVFa & 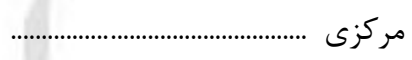 \\
\hline 19 & 99 & 4 & $\wedge$ & 19 & qTVT & 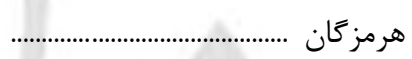 \\
\hline 11. & $\vee \wedge$ & 1 & 11 & Ir & 910. & 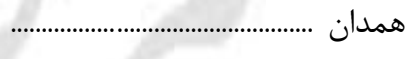 \\
\hline rT & 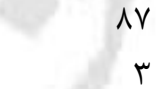 & $\begin{array}{r}r \\
r\end{array}$ & r & $1 \cdot$ & $\begin{array}{r}4911 \\
94\end{array}$ & 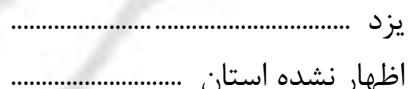 \\
\hline 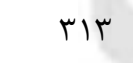 & IST & ir & pq & 9 & Fril & 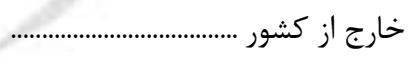 \\
\hline 9 & 11 & r. & VF & $\wedge$. & qus & اظهار نشده محل اقامت قبلى ........ \\
\hline
\end{tabular}


^ - ا- مهاجران واردشده طى ه سال كذشته بر حسب جنس، استان محل اقامت قبلى و فعلـى (بـر اســاس آخــرين جابجـايى (نقاط روستايى)

انجامشده)(دنباله)

\begin{tabular}{|c|c|c|c|c|c|}
\hline \multicolumn{5}{|c|}{ استان محل اقامت فعلى } & \multirow{2}{*}{ محل اقامت قاستان } \\
\hline خراسان جنوبى & جهارمحال و بختيارى & 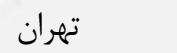 & بوشهر & 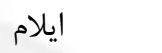 & \\
\hline$v 1 \cdot 1$ & rirs & retal & sfal & Ir.r & 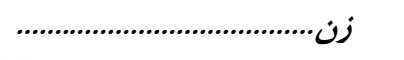 \\
\hline 1 & . & 995 & IV & r & 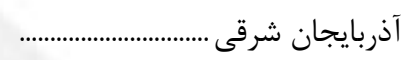 \\
\hline r & - & TYS & 19 & . & 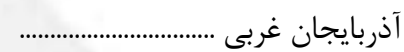 \\
\hline 1 & $\cdot$ & VYF & r & 1 & 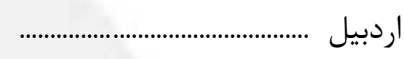 \\
\hline$r$. & grt & eq. & $\wedge \cdot$ & $\wedge$ & اصفهان ...................................................... \\
\hline if & 1 & $11 \wedge \mathrm{V}$ & v & 19 & 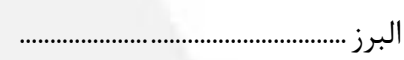 \\
\hline - & r & $|r|$ & ir & ITr. & ايلام ................................................ \\
\hline$\Delta$ & r & r & FTEV & r & 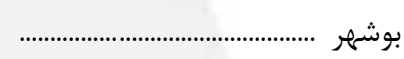 \\
\hline$I \vee \wedge$ & 11 & $191 \mathrm{FV}$ & $\Delta \cdot$ & 111 & تهران ............................................... \\
\hline - & $r \cdot r$ & rI & \& & r & جهارمحال و بختيارى ................. \\
\hline DFFD & . & 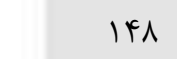 & 1 & . & 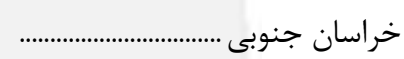 \\
\hline$\Delta r$. & $\Delta$ & $1 \cdot$ r & 19 & r & 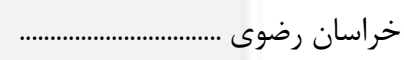 \\
\hline TV & 1 & kru & r & $\cdot$ & 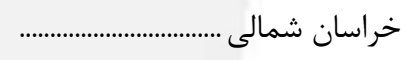 \\
\hline r & trA & r৭9 & ra. & VV & 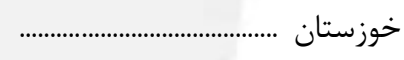 \\
\hline - & · & 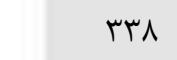 & r & . & 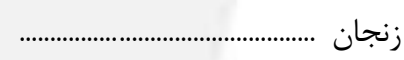 \\
\hline$\checkmark$ & r & TFV & r & . & 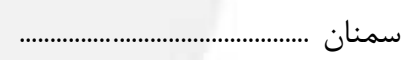 \\
\hline fio & $\Delta$ & rar & rt & r & 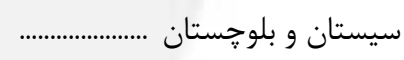 \\
\hline 19 & 11 & $|f|$ & qזه & $\Delta$ & فارس ............................................... \\
\hline 1 & $r$ & $r r$. & $r$ & r & 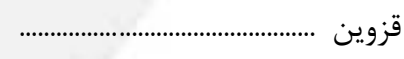 \\
\hline it & 10 & rat & re & r & قم ............................................ \\
\hline - & . & 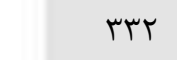 & r & 1 & 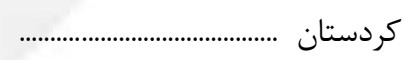 \\
\hline fr & r & ira & ra & r & كرمان ......................................... \\
\hline \& & $\cdot$ & DqT & 19 & 99 & كرمانشاه ........................................ \\
\hline r & $\wedge \varepsilon$ & 11 & rII & 1 & 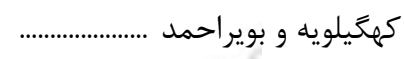 \\
\hline 11 & 1 & ||$k \mid$ & 4 & r & حلستان .............................................. \\
\hline$\Delta$ & · & rla & r & r & 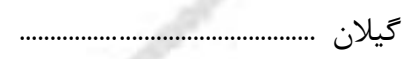 \\
\hline 4 & 1 & 949 & rq & Ve & 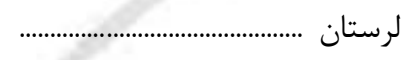 \\
\hline$\wedge$ & 1 & rgq & $1 \cdot$ & 1 & مازندران ............ \\
\hline r & r & $\forall \wedge \Delta$ & $\Delta$ & 9 & مركزى ............................................... \\
\hline 9 & 9 & $v^{r}$ & $\Delta \Delta$ & 10 & 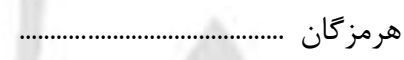 \\
\hline r & r & $\wedge \wedge$ & rq & 1. & 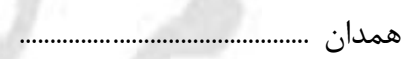 \\
\hline w & V & $\Delta r$ & v & $\Delta$ & يزد ........................................... \\
\hline r & $\Delta$ & 1991 & 111 & 9 & 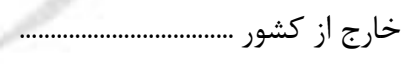 \\
\hline r & 9 & lQF & $\Delta V$ & $\Lambda$ & اظهار نشده محل اقامت قبلى ..... \\
\hline
\end{tabular}




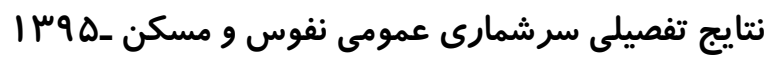

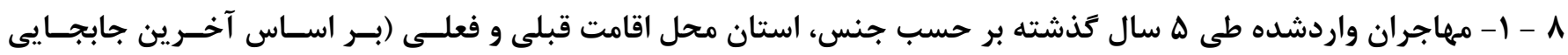
(نقاط روستايى)

انجامشده)(دنباله)

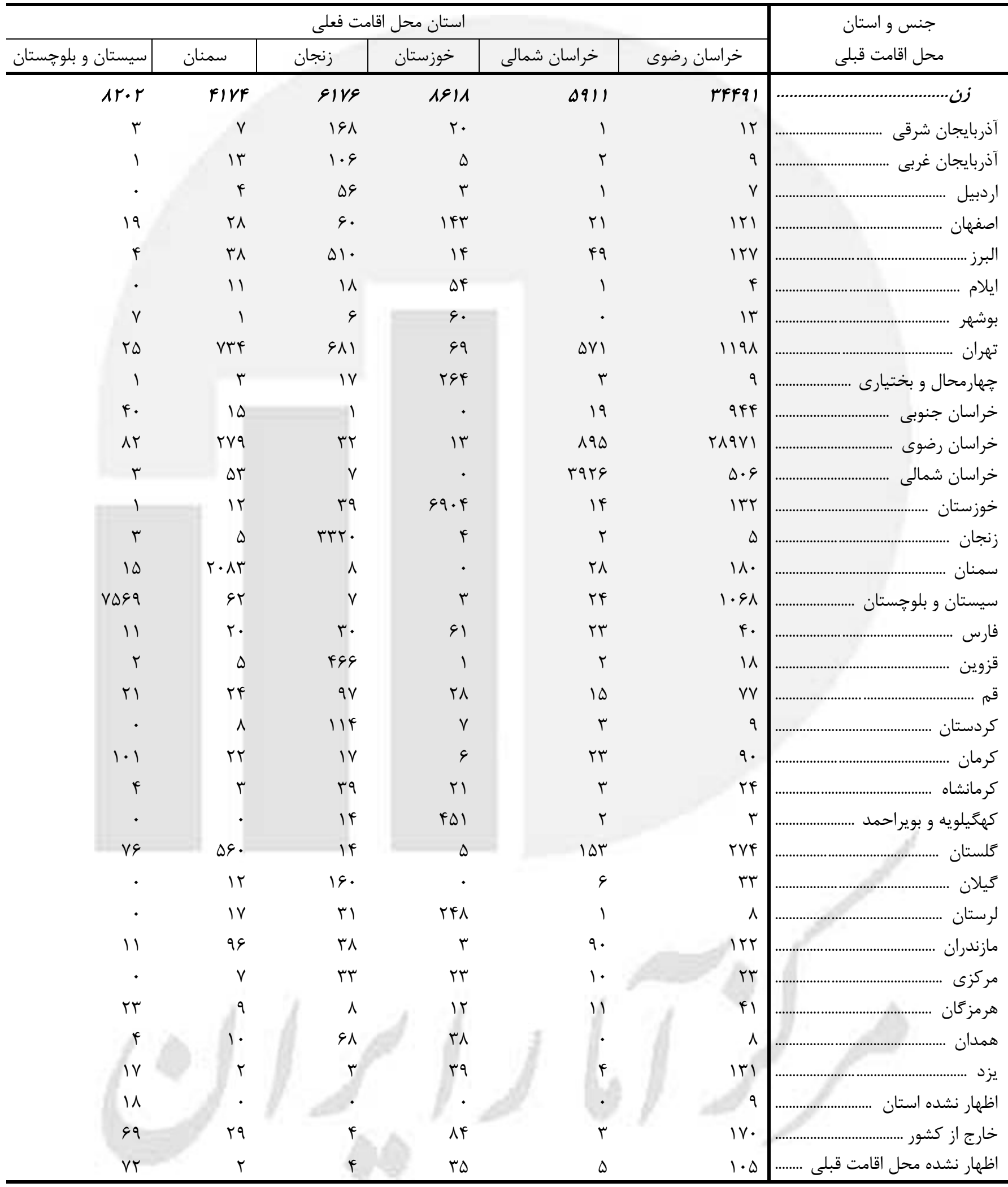


^ - ا- مهاجران واردشده طى ه سال كذشته بر حسب جنس، استان محل اقامت قبلى و فعلـى (بـر اســاس آخــرين جابجـايى (نقاط روستايى)

انجامشده)(دنباله)

\begin{tabular}{|c|c|c|c|c|c|}
\hline \multicolumn{5}{|c|}{ استان محل اقامت فعلى } & \multirow{2}{*}{ محل اقامت قو استان } \\
\hline 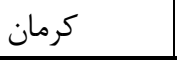 & كردستان & قم & قزوين & فارس & \\
\hline Irivr & 11190 & 1949 & rqar & 19999 & 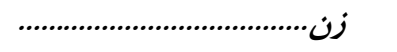 \\
\hline$\Delta$ & $\Delta 1$ & r & rq & 9 & 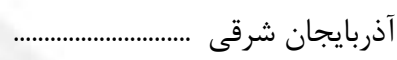 \\
\hline r & rq. & 1 & 99 & $1 \cdot$ & 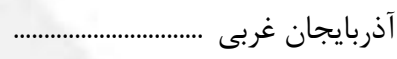 \\
\hline$\checkmark$ & it & $\cdot$ & 9 & v & 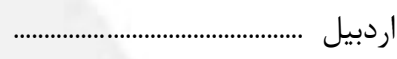 \\
\hline rی & it & fF & 19 & INT & اصفهان ............................................ \\
\hline 11 & 91 & if & rvq & $\wedge$ & 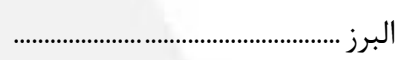 \\
\hline r & r & $\cdot$ & r & c & ايلام ................................................. \\
\hline r & r & r & r & $\Delta T_{I}$ & 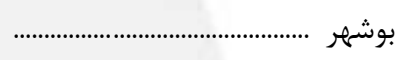 \\
\hline$\Delta F$ & $r v \cdot$ & $r \cdot 9$ & VVr & 4. & تهران .............................................. \\
\hline$\wedge$ & f & 1 & r & $r \wedge$ & جهارمحال و بختيارى ................. \\
\hline ra & . & 1 & . & 1 & 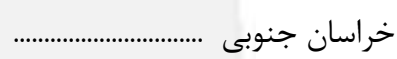 \\
\hline GT & r & rI & sV & r & 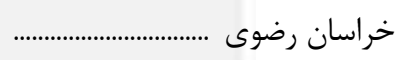 \\
\hline r & 1 & 1 & $\Delta$ & r & 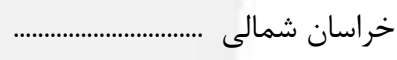 \\
\hline rq & pr & 11 & 9 & 199 & 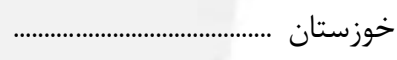 \\
\hline$\cdot$ & $\Delta T$ & $\Delta$ & irs & \& & 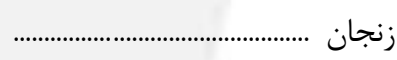 \\
\hline$v$ & 11 & . & $\wedge$ & $\Delta$ & 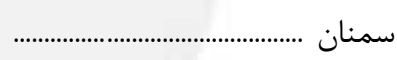 \\
\hline r. & 4 & 1 & iq & c. & 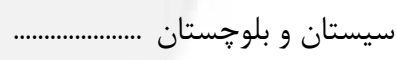 \\
\hline ITr & IV & $\Delta$ & f & IfF.q & فارس ...................................... \\
\hline f & זr & $\Delta$ & rqv & r & 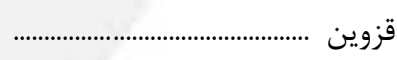 \\
\hline$\Delta \cdot$ & r & ITrV & fr & $\Delta \varphi$ & قم ................................................... \\
\hline r & 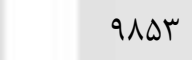 & r & Tr & 14 & كردستان ............................................. \\
\hline IIrgV & f & f & rl & 99 & كرمان ........................................... \\
\hline v & ודי & r & $\Delta \varphi$ & 19 & كرمانشاه ........................................... \\
\hline r & · & . & 1 & $r \Delta \Delta$ & كهَيلويه و بويراحمد .................. \\
\hline ri & 1 & r & iv & 4 & كلستان ................................... \\
\hline r & v & 1 & $q 4$ & 11 & گ \\
\hline$\wedge$ & r & $\Delta$ & rs & ir & 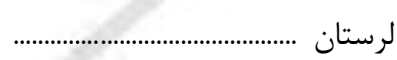 \\
\hline r & $\Delta$ & 1 & rQ & rl & مازندران ........... \\
\hline$\cdot$ & IV & VA & r^ & Ir & 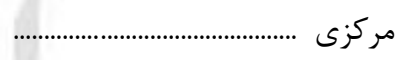 \\
\hline rqf & 4 & द & f & rAT & 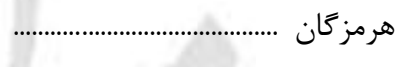 \\
\hline r & $1 \cdot 0$ & 9 & if & 14 & 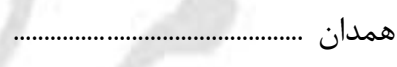 \\
\hline $\begin{array}{r}64 \\
r\end{array}$ & $T$ & . & r & $\frac{r}{r}$ & 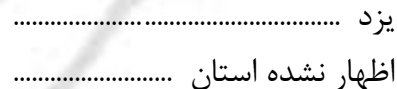 \\
\hline$r Y$ & 10 & ivr & rV & זrt & 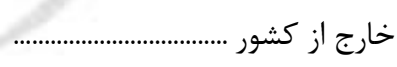 \\
\hline$\Lambda$. & r & r & 4 & 19 & اظهار نشده محل اقامت قبلى ...... \\
\hline
\end{tabular}


| نتايج تفصيلى سرشمارى عمومى نفوس و مسكن _هD

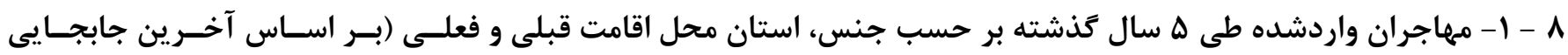
(نقاط روستايى)

انجام شده)(دنباله)

\begin{tabular}{|c|c|c|c|c|c|}
\hline \multicolumn{5}{|c|}{ استان محل اقامت فعلى } & \multirow{2}{*}{ محل اقامت ق قبلى } \\
\hline 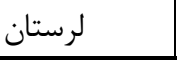 & 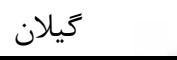 & كلستان & كهيَيلويه و بويراحمد & كرمانشاه & \\
\hline 9994 & $119 \cdot 9$ & larte & AEVF & $\Delta q \mid A$ & 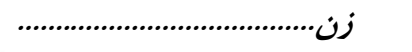 \\
\hline$\wedge$ & v & 11 & r & 19 & 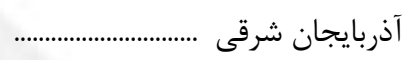 \\
\hline 1. & rr & v & $r$ & $\wedge$ & 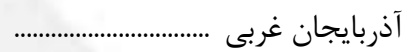 \\
\hline$\cdot$ & $\operatorname{reA}$ & r & r & $\wedge$ & اردبيل .............................................. \\
\hline TAl & IVT & rv & 101 & 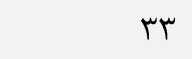 & |صفهان ................................. \\
\hline 90 & vri & q & $\Delta$ & v. & البرز .................................... \\
\hline lip & $\Delta$ & 1 & r & $\Delta r$ & ايلام ................................................ \\
\hline 10 & rv & 9 & 11. & 9 & 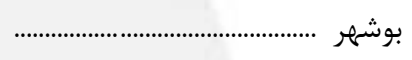 \\
\hline 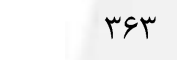 & TQFq & $\Delta 9 \mathrm{~V}$ & 11 & rit & 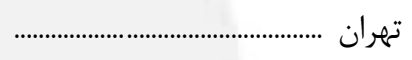 \\
\hline$\Delta \varphi$ & 1 & 1 & $s q$ & r & 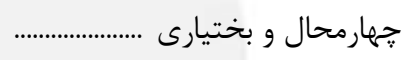 \\
\hline . & . & rی & r & 1 & خراسان جنوبى ........................... \\
\hline re & r & rQ9 & r & 10 & خراسان رضوى ............................ \\
\hline 1 & v & 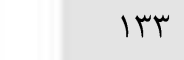 & 1 & · & 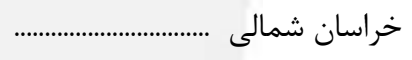 \\
\hline 995 & sf & 9 & Iq & $9 V$ & 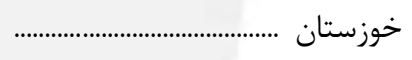 \\
\hline r & $1 \cdots$ & $\Delta$ & $\cdot$ & $\Delta$ & 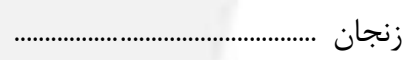 \\
\hline$\Delta$ & tr & $r \cdot 1$ & 1 & r & سمنان ................................................... \\
\hline$\wedge$ & TH & $9 r \wedge$ & 11 & 1 & 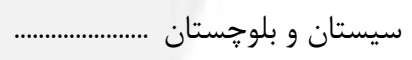 \\
\hline هI & $\Delta V$ & ז & $|4|$ & it & فارس ................................................... \\
\hline 9 & $\Delta r q$ & 19 & v & 19 & قزوين .................................. \\
\hline iv & $11 \mathrm{~V}$ & rq & $\wedge$ & 11 & 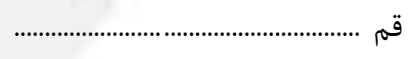 \\
\hline ra & rq & if & $r$ & TYl & 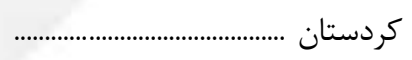 \\
\hline$\wedge$ & rی & $r \cdot$ & v & 11 & 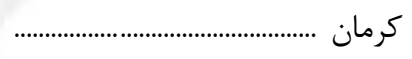 \\
\hline ווזr & ra & r & 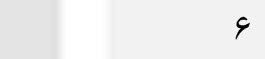 & F्ञाt & 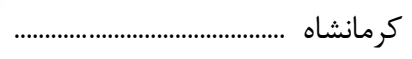 \\
\hline lif & r & · & VDGY & r & كهخيلويه و بويراحمد .................... \\
\hline & $4_{1}$ & Irra. & r & r & كلستان ............................ \\
\hline 1. & ITVG. & 11 & 1 & r & كيلان ............................................. \\
\hline fele & ir & r & $r$ & pr & 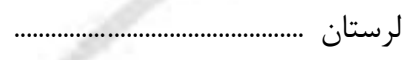 \\
\hline 14 & in & IVr & r & \& & مازندران ............................. \\
\hline 91 & IV. & 19 & $\Delta$ & rt & 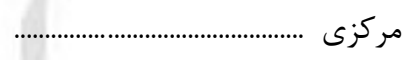 \\
\hline rᄉ & $11 \pi$ & \&) & r. & 10 & هرمزكان ............................................. \\
\hline$\checkmark \Delta$ & r & v & v & $s 4$ & همدان ................................................ \\
\hline lf & 19 & iv & ru & r & يزد .............................................. \\
\hline T & 19 & r & 4 & 19 & 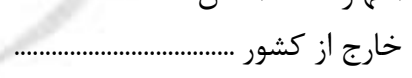 \\
\hline ir & 4 & 19 & $\checkmark$ & 1. & اظهار نشده محل اقامت قبلى ....... \\
\hline
\end{tabular}


^ - ا- مهاجران واردشده طى ه سال كذشته بر حسب جنس، استان محل اقامت قبلى و فعلـى (بـر اســاس آخــرين جابجـايى (نقاط روستايى)

انجامشده) (دنباله)

\begin{tabular}{|c|c|c|c|c|c|}
\hline \multicolumn{5}{|c|}{ استان محل اقامت فعلى } & \multirow{2}{*}{ محل اقامت قبلى واستان } \\
\hline 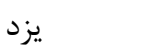 & 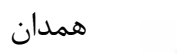 & هرمزكان & مركزى & 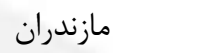 & \\
\hline crar & 9919 & $1.1 \mathrm{re}$ & $\Delta \& \wedge \Lambda$ & rFqA1 & 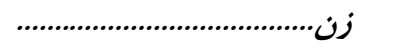 \\
\hline r & \& & $\mu_{1}$ & 10 & 90 & 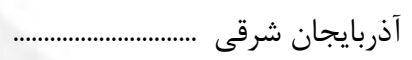 \\
\hline$\Delta$ & re & \& & $\wedge$ & \&V & 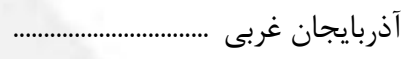 \\
\hline 1 & 1. & v & द & 191 & اردبيل .............................................. \\
\hline IDT & $V \mu$ & QI & ve & rVq & |صفهان ............................................ \\
\hline$|4|$ & $r \cdot r$ & 11 & $1 \cdot r$ & $4 q 1$ & 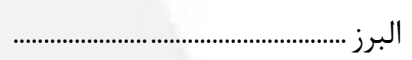 \\
\hline r & ia & $\Delta$ & ir & ra & ايلام .................................................. \\
\hline rt & re & $\Lambda F$ & 9 & 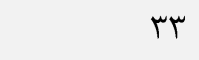 & 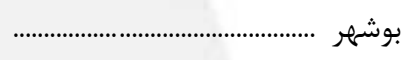 \\
\hline 149 & sAF & rv & $119 \mathrm{~V}$ & TVQQ & 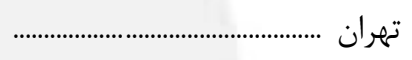 \\
\hline$r \cdot$ & ir & ع & 10 & 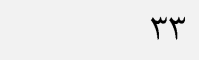 & جهارمحال و بختيارى .................. \\
\hline er & r & ir & $\Delta$ & $\Delta V$ & 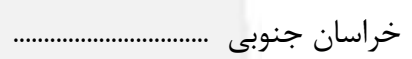 \\
\hline $1 . r$ & r. & $\Delta F$ & FV & VT. & خراسان رضوى ............................ \\
\hline r & $\Delta$ & it & 9 & 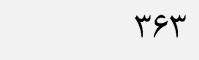 & 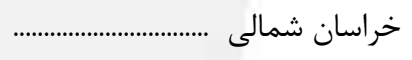 \\
\hline$\lambda F$ & Tr & re & vr & 101 & 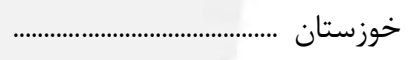 \\
\hline$\cdot$ & ra & \& & $\wedge$ & $\vee$. & 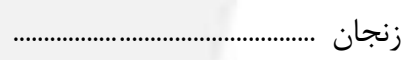 \\
\hline r & 10 & r & r & $r \cdot \varphi$ & سمنان ................................................. \\
\hline$r \cdot \Lambda$ & rt & rAY & 19 & TEY & 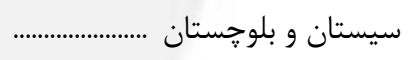 \\
\hline TrD & is & $\varepsilon \vee q$ & 11 & 111 & فارس ..................................................... \\
\hline r & 11 & r & 14 & 1.9 & قزوين .................................. \\
\hline$\Delta V$ & red & ir & rRI & 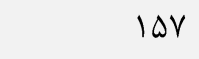 & 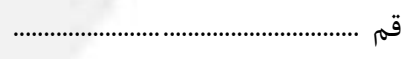 \\
\hline r & rta & $\wedge$ & ז & 110 & كردستان ........................................... \\
\hline Tar & 1. & 991 & rI & $\Delta \wedge$ & كرمان ............................................... \\
\hline ir & rی. & $r$. & \&A & 119 & 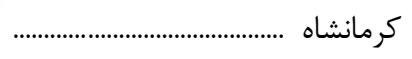 \\
\hline iv & 9 & tr & $\varepsilon$ & 19 & كهخيلويه و بويراحمد .................... \\
\hline r & ir & r) & r. & $111 \mathrm{~V}$ & 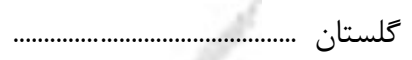 \\
\hline$\wedge$ & 19 & TY & ry & $\Delta V r$ & كيلان ............................................. \\
\hline 19 & IQF & rt & $11 \mathrm{~V}$ & $\wedge$. & 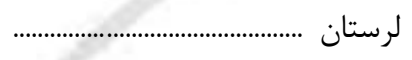 \\
\hline 9 & 19 & ir & 11 & IETYA & 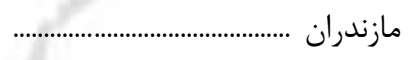 \\
\hline r & $|F|$ & 11 & 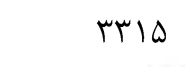 & Va & 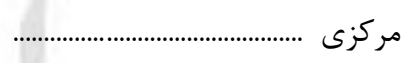 \\
\hline$\Delta \Delta$ & $r$. & VeIV & $1 \cdot$ & $|0|$ & 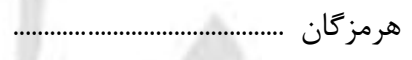 \\
\hline$\wedge$ & Fris & $1 \cdot$ & $1 \cdot 4$ & $1 \cdot 9$ & همدان ............................................... \\
\hline $\begin{array}{r}r \Delta q V \\
r\end{array}$ & $\begin{array}{l}\Delta \\
r\end{array}$ & $\begin{aligned} r \\
r\end{aligned}$ & 9 & $\begin{array}{r}r q \\
r\end{array}$ & 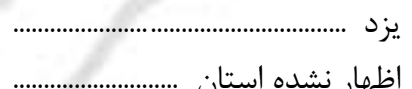 \\
\hline is & r & tri & $\wedge$ & fr & 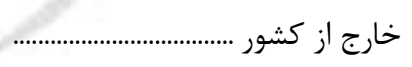 \\
\hline$\wedge$ & rv & 19 & v & pr & اظهار نشده محل اقامت قبلى ....... \\
\hline
\end{tabular}


| نتايج تفصيلى سرشمارى عمومى نفوس و مسكن _هD

9 - 1 - مهاجران وارد شده طى ه سال كذشته بر حسب جنس، سن و مدت اقامت (بر اساس آخرين جابجايى انجامشده) (كل)

\begin{tabular}{|c|c|c|c|c|c|c|c|c|}
\hline نشده & 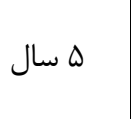 & 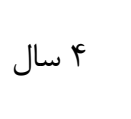 & 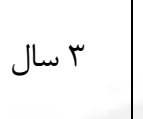 & 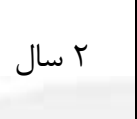 & ا & يكى سال & جمع & جنس و سن \\
\hline rFrry & rrarr. & $0.911 r$ & $r \Delta F \cdot q \varphi$ & 1rrasr & vrrad. & $1 \% 190 .$. & $F r . .911$ & 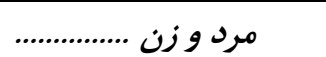 \\
\hline 1480 & & 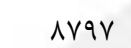 & TVAIQ & RAr.r & DYGTY & D.r. & TFITYI & 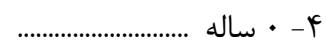 \\
\hline rysq & IATA. & 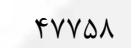 & GबVGT & $9 V \cdot V I$ & 0.991 & NFTVD & rrvevg & 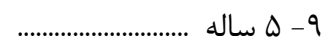 \\
\hline ris9 & l0949 & rQSVT & $\Delta \cdot r \cdot r$ & $\Delta F \cdot r q$ & FFaV. & VDFGV & TVATAV & f • • ساله .......................... \\
\hline rEDV & $|F V E|$ & r|बाr & $F q \mid F \Delta$ & GINFF & $\vee १ \vee \cdot \Delta$ & $\mid V K G D$. & fIrrad & 19 اله ساله........................ \\
\hline rqvr & trirk & $9.9 V \wedge$ & 1. VqFV & $1 r \cdot 19 r$ & IrtQNT & $19 \cdot$ rks & 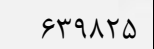 & 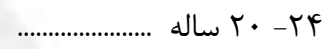 \\
\hline ruq & 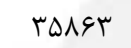 & VEDTr & $\| \& \wedge \Lambda$ & ITETRI & IIrr.F & IVETAT & GOTAT. & q \\
\hline 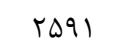 & rAVTF & NIQTV & $\| \Delta r \cdot \Lambda$ & ITYTVK & qrq४र & $\mid 48191$ & 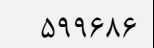 & 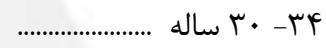 \\
\hline IVAS & rV\&99 & DVTrT & V9Y19 & va人kr & $91 \cdot 10$ & $9 \vee \Delta \wedge \Lambda$ & $F \cdot F r \Lambda$. & 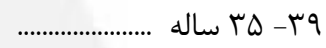 \\
\hline וrma & 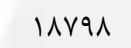 & rvi.c & $F q \Delta \backslash \Delta$ & F^s.l & rVroג & ఎq४⿻. & TAYTVR & 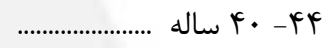 \\
\hline$\Lambda \cdot \Delta$ & Irরৎ9 & TASAT & 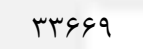 & rTSAF & TARTA & $\uparrow \cdot 1 \Lambda$. & IVTIYF & ...................... \\
\hline q4q & $१ \Delta १ \Delta$ & $1914 q$ & rIst人 & TIrTA & $1 \Delta V \nabla q$ & TATA. & $111 \cdot \wedge 1$ & 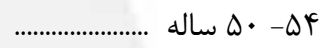 \\
\hline YAD & $V \cdot r y$ & 11948 & IFVAT & lfrrq & 1.499 & $\mid V \cdot \cdot c$ & VG.rt & هو $ه ا$ \\
\hline זrז & FFGT & VAFY & 9011 & q४q४ & $99 \cdot \Delta$ & $111 \Delta T$ & $k q f \cdot 1$ & 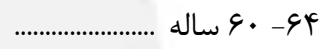 \\
\hline TFF & rबQ. & FFqD & DFTD & $\Delta H I I$ & 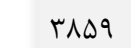 & Groq & rNINT & 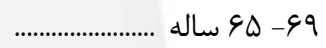 \\
\hline 195 & IDQr & rgVF & r199 & MITE & אשrr & rqvब & $|V \cdot \Delta|$ & ساله $V \cdot-V{ }^{c}$ \\
\hline trF & Trtr & rदा山 & $4 \wedge \notin q$ & $\Delta \cdot \wedge \Delta$ & rVGF & sVIf & reVVF & Vاله و بيشتر ................... VD \\
\hline IrIAD & $I r \cdot \Delta F A$ & ralar. & rVIsle & FIVTAI & rygrur & $99 \cdot 190$ & rrl.rar & 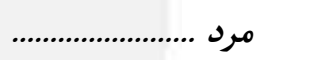 \\
\hline VVG & & $r \Delta \cdot r$ & IFrNK & TFETF & TRTIV & DrVA & ITFTq. & ץ- • ساله ........................ \\
\hline$\| \cdot \Delta$ & qTDT & TFDST & MFFVA & MFEFT & TGIFF & rront & IVrą9 & 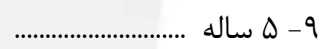 \\
\hline IIrk & $1|8|$ & $1 \wedge r \& 9$ & rQV৭६ & rVq.r & TYNTA & 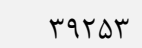 & IFTEQV & 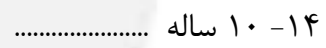 \\
\hline $1 F \cdot F$ & VQqF & IDGFT & rrq৭A & $r \cdot \Delta T$. & ETDSq & $|| r \mid$. & TrtqTY & 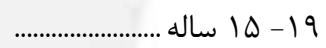 \\
\hline$|\Lambda r|$ & $1 \cdot \sqrt{ } 9$. & TFYFq & frqu. & $\Delta \Delta \cdot r)$ & GITTK & $1.9 .1 \%$ & tr.trta & F • • ساله ........................ \\
\hline $1 \Delta \Delta F$ & IEDTF & TTVAD & $\Delta \cdot \Delta r$ & $9 \cdot 199$ & DFfFi & $q \cdot 9 \cdot r$ & $r \cdot q \wedge r q$ & \\
\hline 1189 & 19999 & R.rtg & $\Delta \wedge 1 \cdot r$ & GTFET & FMNIT & RVTrV & $r \cdot \lambda i v \wedge$ & ץ \\
\hline MAs & Ifras & $r \cdot \Delta q q$ & FTGDF & кrqq. & mrFYA & $\Delta F \| 1$ & $r r \cdot I V q$ & q \\
\hline G. & $1.9 \ldots$ & $r \cdot r \wedge 9$ & TAING & rVAIV & TIFTh & MFFqD & IFTETV & ..................... fr \\
\hline r११ & $V v \cdot 1$ & IFFr & 1А१९ & $M T Y \cdot V$ & $|f \varepsilon| \wedge$ & triv. & qVDTD & ..................... rq ساله \\
\hline rme & DrGV & वाIV & $I T \cdot \Delta \cdot$ & 11999 & $q \cdot v r$ & $\mid f \Delta \Delta \varphi$ & GTSGD & • • \\
\hline rut & r१Q. & gFts & $\Lambda \cdot v r$ & 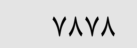 & $\Delta V r q$ & 9491 & $f \mid \Lambda \cdot \Delta$ & ه \\
\hline $1 \wedge F$ & rFGq & Fा11 & $\Delta \backslash \Delta \Delta$ & $\Delta \cdot F r$ & rVRr & $q \cdot 4 \Delta$ & reVVq & 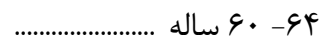 \\
\hline |r| & Irr. & trre & TVRV & $r \varphi_{\Lambda}$. & 19r & rier & IFrt. & 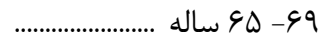 \\
\hline qv & 111 & IrAF & IGTA & IQF. & $11 \wedge \mathrm{V}$ & 1901 & $\Lambda \& \mid r$ & ساله $V \cdot-V{ }^{c}$ \\
\hline if. & ITIV & $114 q$ & rmas & $r F \cdot G$ & $|\vee 9|$ & rigr & וrवq & Vاله و بيشتر .................... VD \\
\hline I TAFT & IIfrgr & raArAT & rATFA. & rr. rAr & rFegIA & $\Delta \Delta \Delta \mathcal{E} \cdot \Delta$ & $r \cdot q \cdot q \cdot 1$ & תש....... \\
\hline $9 \wedge 9$ & & FrqD & Irfert & rravı & TAFT. & FqQIV & $\mid 19941$ & ץ • • ساله ......................... \\
\hline 1194 & $q \cdot r \wedge$ & (TM & TrTAD & TYFTG & TFAIV & $f \cdot v q r$ & |qसVII & 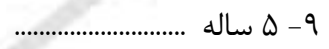 \\
\hline 1.41 & $\nabla \wedge \cdot \Delta$ & $I V r \cdot r$ & TFG.V & reIrV & TIVTT & rGTIF & IrFAr. & 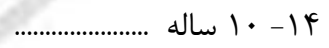 \\
\hline ITAK & VIFV & $|09 V|$ & TDIFV & MITTF & (4) & VFFE. & $19 \cdot 411$ & 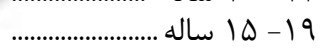 \\
\hline$r|Q|$ & IrqYA & TEMrq & $90 \cdot 1 \mathrm{~V}$ & VDITI & 9194. & NFrme & 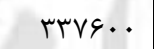 & ץ • • ساله ........................ \\
\hline MNF & $194 \pi 9$ & Frrrs & SFATV & $V M r \cdot r$ & $\Delta \vee \wedge \notin r$ & $\wedge \Delta \& \vee q$ & m4\&991 & 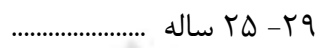 \\
\hline$|f| \Delta$ & $\backslash \wedge \vee \Delta \Delta$ & FIr. & $\Delta V Y \cdot F$ & Q991. & FFiQ9 & GNAGF & $r 910 \cdot \Lambda$ & 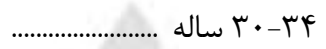 \\
\hline $9 .$. & $1 \% 9 \ldots$ & Тя८सq & rGDSD & rqlar & TVDSV & FreVt & $\mid$ AFT. I & 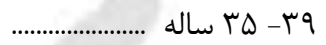 \\
\hline grv & 1191 & $1991 \mathrm{~V}$ & TIrtg & $r \cdot V \wedge F$ & 1Q9T. & TATSA & $1 \cdot \wedge \vee \Delta \cdot$ & 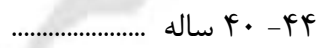 \\
\hline $4 \cdot 4$ & 9190 & IITFS & IFEVE & Ifrpt & $1 \cdot V r$. & $1 \mathrm{~V} \cdot 1$. & VFD९q & 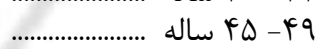 \\
\hline ML & FTTA & VDTK & $9 \Delta \wedge \Lambda$ & $q \operatorname{sqq}$ & $q V \cdot V$ & 1.994 & FAFTH & 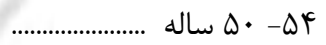 \\
\hline TFV & $r \cdot \Lambda f$ & $\Delta \& q$. & sVI. & gFal & Frr. & $V D I Q$ & MFTTY & هاله ........................... \\
\hline Ifq & 1994 & TH & Frgr & Fral & מזוץ & $\Delta l \cdot V$ & TrGTq & ...................... 94 ساله \\
\hline $11 \pi$ & ITT. & $4 / 1$ & 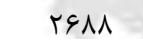 & 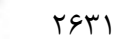 & 1949 & rIQV & 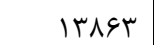 & 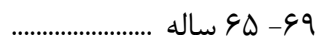 \\
\hline $9 \Delta$ & vrs & irq. & $|\Delta V|$ & $\mid \Delta \wedge \varepsilon$ & $\| F \Delta$ & $r \cdot I V$ & NFrq & ساله V................... -VY \\
\hline irf & $|r| s$ & IV^s & KFVI & r\&Vq & $19 V 4$ & TATr & $|r v \wedge|$ & ساله و بيشتر .................... VD \\
\hline
\end{tabular}


9 - 1 - مهاجران وارد شده طى ه سال كذشته بر حسب جنس، سن و مدت اقامت (بر اساس آخرين جابجايى انجامشده) (دنباله) (نقاط شهرى)

\begin{tabular}{|c|c|c|c|c|c|c|c|c|}
\hline الشهار & 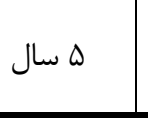 & 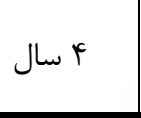 & r سال & 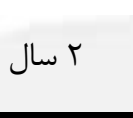 & ا 1 سال & كمتر از يك & جمع & جنس و سن \\
\hline r.reg & l119fref & rrafaq & sfle.1 & $r \cdot$ fira & ه9TाIr & $91 \cdot q r$. & rasfrra & مرد و زن \\
\hline $119 \pi$ & & $v r \cdot 1$ & trigF & rq४^я & Frrrs & Аrтq৭ & $1999 \cdot 1$ & ץ- • • ساله ............. \\
\hline $191 \mathrm{~V}$ & IFVY. & F.lFt & $\Delta \Delta q \cdot T$ & $\Delta \Delta \Delta G T$ & Fis99 & 99499 & TYQD.V & 9 ه ساله .......................... \\
\hline IVTq & $1 \% \wedge \wedge 9$ & $r \cdots v$. & FrIGA & GE.rt & raTIV & 9.19. & TYGTED & 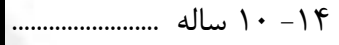 \\
\hline$r+r$ & llGTr & reqVV & $F \cdot r \Delta$. & $\Delta \cdot v \cdot$ & SFrAs & IrGFre & THINDS & 9 19 اله ساله ....................... \\
\hline re.r & I9Tat & DTH. I & $9 \mu .94$ & 11.919 & १८१४६ & IfFVIF & DTYTQA & |...................... \\
\hline$r \Lambda \cdot \Delta$ & rqfif & 9QDTH & $9 \wedge \uparrow 91$ & llkrt. & qTrVQ & ।FI^৭9 & DFAV.F & a..................... \\
\hline rI\&D & rTrQq & $v \cdot \wedge \Lambda 1$ & $99 \vee \cdot 9$ & $1 . k g k V$ & $V \Lambda \cdot k q$ & $I T r \cdot r V$ & $0.9 V F V$ & F \\
\hline lify & $r r q . q$ & rquar & gNTqF & $9 \Lambda \cdot V F^{k}$ & $\Delta|r| \mid$ & NIFFA & TEYVTS & 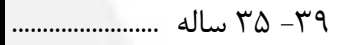 \\
\hline $1 \cdot r \Delta$ & IQTTS & Mlat. & frrqu & flllv & IIISV & Q..rq & rirqIV & |..................... \\
\hline 949 & 11.14 & $r r \cdot \wedge 9$ & 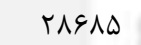 & TVG.V & $r 1.91$ & $r r \Delta \cdot r$ & IFFGM & |...................... \\
\hline DTV & VTIF & $|F T| F$ & 11199 & $I V V \Delta \Delta$ & $I r \cdot \Lambda T$ & $r 1 . .1$ & $9 T \cdot 19$ & |....................... \\
\hline rیI & $\Delta \cdot \psi \wedge$ & $9 \vee \wedge \wedge$ & IrIVF & $119 \wedge \mathrm{V}$ & $\Lambda \uparrow \Delta \Delta$ & $1 F \cdot \mu f$ & SIDSV & |...................... $ه \Delta$ - $\Delta 9$ \\
\hline 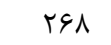 & MIf. & GTqF & VAlf & $v 9.4$ & DGTF & qYVG & hart & ץ \\
\hline$r \cdot \Lambda$ & $1 \wedge 1$. & rYr. & feit & FrMA & ris9 & DTFI & rTAYG & 99- 90 ساله ....................... \\
\hline 109 & $1 \cdot \Delta \Delta$ & $r \cdot r$ & TAKG & TQTr & $19 \cdot 1$ & & זוזוז & |........................ dساله - -VF \\
\hline rll & IVAT & $r \cdot \Delta r$ & $r \cdot \Delta r$ & rrei & $r \cdot v \Delta$ & DGrq & tr.tr & ساله و بيشتر ........................ \\
\hline qArr & qqTaq & rifqs. & rIDqAT & rFAqqT & $r \cdot r r \cdot f$ & $\Delta / f \cdot . r$ & $11 \cdot r \mu \cdot q$ & 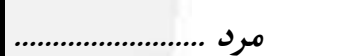 \\
\hline gri & & rYFa & 11998 & t.rtt & $T Y \cdot \Lambda \Lambda$ & FYFS9 & $1 .|r F|$ & ץ- • ساله ........................... \\
\hline $1 .+9$ & veVt & $r .9 \pi r$ & TMMGT & r $\wedge \Delta \Delta \Delta$ & rirs. & $r \Delta \wedge \Delta F$ & lervad & |............................. \\
\hline$q \cdot v$ & 9099 & IDFTA & tIfi. & rrrql & IVAG4 & $r \cdot \wedge V \Psi$ & IIQFVT & ץ |l •l ساله ................... \\
\hline$\| r \mid$ & $\Delta Q \Delta T$ & ITrVG & $19 v<9$ & TFETE & rrTaq l l & VFFIT & IVTD.G & 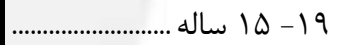 \\
\hline$|\Delta T|$ & $\Lambda \Delta Q V$ & rIIIr & rVFFY & \&q9.r & FV.qT & $v F i \cdot v$ & rTSVDA & ....................... \\
\hline IrFq & I & TAKMI & Frqug & DIrqV & FFMIF & 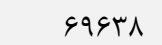 & $r \Delta I \cdot \Delta V$ & q \\
\hline qFr & $194 \wedge 1$ & $r \Delta \cdot r$. & $\Delta \cdots q f$ & DrqAG & f. pqp & GMTI. & TQQTFA & F \\
\hline$v \cdot \Lambda$ & $1 \% 109$ & rerat & rब9VV & $r v \cdot q$. & TrYYG & $r \notin \Delta .$. & INAIGF & q \\
\hline k91 & 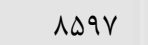 & IVG4G & TFIF| & rra. 4 & IVA99 & rADQq & IT.AYQ & |...................... \\
\hline$r \cdot v$ & Glfr & ITFAF & IGTr. & $1 \Delta F \cdot \varphi$ & $\|r\|$ & 19.19 & 11999 & |...................... \\
\hline r\&4 & pirq & VAAV & 1.199 & $1 . .1 r$ & $V F \wedge 1$ & 11945 & Dार१९ & |....................... \\
\hline 119 & rAIV & DrVq & $49 \cdot \mathrm{V}$ & $94 \cdot \Delta$ & FASA & veqv & $r r \Delta \Delta q$ & |...................... \\
\hline lQF & IVr. & r req & Find & $F \cdot 11$ & $r \cdot . \wedge$ & Fqur & rirar & |....................... \\
\hline $11 r$ & qे. & 1949 & rI9T & r|बג & 1099 & TQQT & $11 \% 9 \mathrm{~V}$ & 99-...................... \\
\hline ve & 019 & 1.9. & $1 r \cdot r$ & $|r|$. & quv & rar & GVQV & |....................... \\
\hline 1.9 & ATS & lart & 1990 & 1901 & 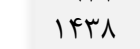 & rGYG & 1. FFF & Vاله و بيشتر .................. \\
\hline $1 . \arg$ & qriva & rr. kqq & rTAGTE & rabIVr & $r 191.9$ & reqsid & IVeifra & رن.. \\
\hline$\Delta V T$ & & rabs & 11191 & 19494 & $r .44 V$ & ५११ч. & १QT६V & ץ- • ש ساله ........................ \\
\hline q & VTFA & 190r. & $r v \cdot Y$. & $r \vee \cdots \Lambda$ & T.rIS & MTEFT & ITAVIT & - \\
\hline ATr & sT9. & IFEFT & $r \cdot V \Delta \Lambda$ & r|g4| & IVTAT & rarAV & $11 \cdot$ Vqr & 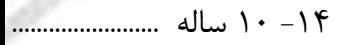 \\
\hline $1 \cdot \lambda r$ & $\Delta 9 \Lambda$. & $1 M F \cdot 1$ & $r \cdot v \cdot 1$ & TAFHF & TI. Tr & GT.TQ & 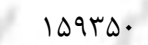 & 9 - 19 ساله ـ........................ \\
\hline INVT & 1.910 & $41 \cdot 19$ & $\Delta \Delta 919$ & GTYAV & DIMAF & $v \cdot 4 \cdot v$ & KNDQFT & |..................... \\
\hline $1 \Delta \Delta 9$ & 19110 & rVT.r & $\Delta \Delta \Delta \mu_{T}$ & grarr & ४^१९। & VTTQA & rQFGFV & q \\
\hline ITrT & IQVYA & $r \Delta \Delta+1$ & Fq910 & 01991 & $r \vee \Delta \Delta \Delta$ & DAMTV & $r \Delta \cdot \uparrow q q$ & r \\
\hline Vru & $1 \cdot v \Delta$. & $r r \cdot \Delta q$ & MISIV & $r \cdot q \wedge F$ & THFVQ & raq4ی & $|O V Q V|$ & q ז- هז ساله ....................... \\
\hline DTV & garı & Ifrge & INTAS & $|V a| \mid$ & Irrq1 - l & rIFAV & $94 \cdot 91$ & |...................... \\
\hline TFT & rAVI & $99 \cdot \Delta$ & ITFAD & $\mid r T \cdot 1$ & 1911 & IFFAV & GTaFT & ....................... \\
\hline rघl & MIAD & GMTV & vaqv & VVFY & $\Delta 9 \cdot 1$ & $q \cdot v q$ & F. & |...................... \\
\hline 190 & TITI & 80.9 & $\Delta \Delta \& V$ & DTAY & rAMV & grrv & $r \Lambda \cdots \Lambda$ & |...................... $ه \Delta$ - $ه 9$ \\
\hline $11 \mathrm{~F}$ & $|f|$. & rव५ & एद्व & $r \Delta \Lambda \Lambda$ & rब19 & Fref & MAGrq & |........................ \\
\hline १९ & Af. & IVAF & TMTI & TrT. & 19. & r\&M & 11 fFq & 99- 90 ساله ...................... \\
\hline ᄉ. & QHG & $111 \pi$ & ITMF & Irr & 9ท। & 1999 & $V \cdot \Delta \varphi$ & |....................... ساله V•-VF \\
\hline $1 \cdot r$ & 911 & 1049 & $r \cdot \Lambda V$ & $r+r$ & IG\%V & $r . . r$ & $11 \Delta V q$ & Vاله و بيشتر ..................... \\
\hline
\end{tabular}




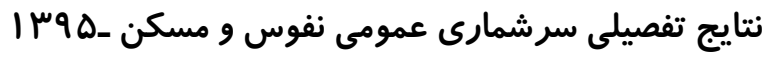

9 - 1 - مههاجران وارد شده طى ه سال كذشته بر حسب جنس، سن و مدت اقامت (بــر اســاس آخــرين جابجـــيى انجـامشـده) (نقاط روستايى)

(دنباله)

\begin{tabular}{|c|c|c|c|c|c|c|c|c|}
\hline أشهار & 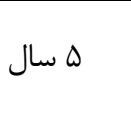 & 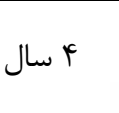 & 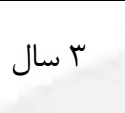 & 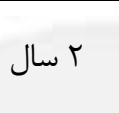 & ا 1 سال & سمتر از يك & جمع & جنس و سن \\
\hline Frel & $F \Delta q \cdot q$ & verar & IIFFA & I Impre & IrqArr & rrass. & vrstar & 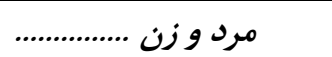 \\
\hline TVT & & 1499 & FATI & NFIS & $99 \cdot r$ & 199.4 & Ffe्str & ץ- • ساله .............................. \\
\hline FAT & ras. & $V \& \mid \Delta$ & $1 \cdot \wedge 91$ & $110 \cdot 1$ & $q r \& \Delta$ & IFAVq & $\Delta \Lambda ו V$. & 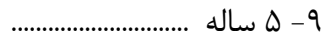 \\
\hline fr. & $r \cdot V V$ & $\Delta \varphi \cdot r$ & ATrd & $1 \cdots v$ & qты & $1 \Delta r \cdot V$ & $\Delta T \cdot T r$ & 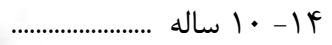 \\
\hline$F \Delta F$ & $\mathrm{~m} .9$ & Fqus & $199 \Delta$ & IIVVF & $10 M 19$ & TVRIT & 11499 & 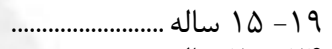 \\
\hline$\Delta 99$ & FYAS & AFV & IFAMF & $194 \mathrm{Fr}$ & $r F . . q$ & FASTT & IIVATV & r • • ساله ......................... \\
\hline Q9T & GFFq & 1.99. & 19419 & 19901 & $19 \cdot r 9$ & merse & $1 \cdot$ Vर19 & q....................... \\
\hline FTE & $\operatorname{s\notin g} \Delta$ & 1.948 & $1 \Delta \Delta 99$ & IVVTE & Ifqr & TFIOF & ८११४१ & 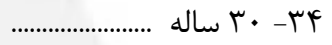 \\
\hline re. & FVAV & $\vee \wedge \wedge$. & 1.940 & $11 V 99$ & $9 \Lambda \cdot f$ & $|8| f$. & sisto & 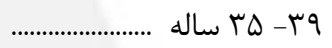 \\
\hline$r \cdot r$ & 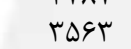 & 0199 & VII & VFAF & 9191 & qVTF & rqfe. & 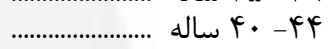 \\
\hline $10 \varphi$ & TADT & rब१ & FqAF & fqrV & FYFV & घqVV & TVFAS & . \\
\hline ITK & trAl & rqTa & THFT & raVr & r\&qV & FFFq & 11999 & 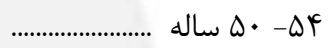 \\
\hline $1 \cdot r$ & 1919 & tira & rG. 9 & TEFT & r.IF & rqVT & IFFed & 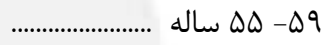 \\
\hline$\varepsilon_{\Delta}$ & מצמו & IrFq & $I V \cdot F$ & IVAM & $|r \wedge|$ & IAVG & ૧૯人૬ & 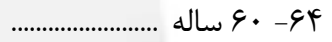 \\
\hline re & VA. & VVD & 1.14 & Tr4 & 4q & $1 \cdot 11$ & QTHV & ......................... 99 - \\
\hline rq & $4 q \Lambda$ & FVI & $\Delta G$ & ఎq & FTF & $9 \Delta r$ & אזrr & 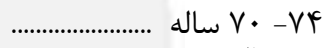 \\
\hline س & 99. & $\Delta \wedge r$ & AIV & NTF & 919 & $1 \cdot \wedge \Delta$ & FVDI & 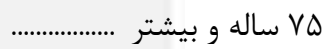 \\
\hline rrFA & rerag & rear. & $\Delta \Delta \& H F$ & 8ArI9 & $r r \cdot r \lambda$ & IFEAqr & $f \cdot v \cdot 11$ & 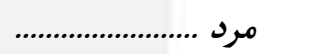 \\
\hline $1 \Delta \Delta$ & . & $V \Delta V$ & rTAV & kr.r & DIrq & $1 . r 19$ & $r r \cdot r q$ & 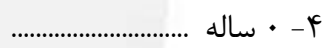 \\
\hline$r \Delta \varphi$ & IV^. & rqf. & $\Delta 919$ & $4 \cdot \Lambda V$ & frat & VVYA & $r \cdot|v|$ & 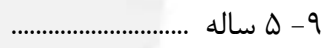 \\
\hline וג & IDGY & tqqu & FrAs & $\Delta Q \|$ & fqYF & ᄉrی. & tVQNa & 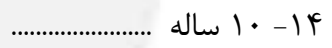 \\
\hline thr & IEFT & trag & FYFq & $\Delta \wedge \Lambda F$ & qY). & r\&VqV & D. Q & 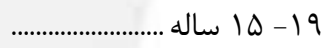 \\
\hline rq. & r T & rth & DFAS & NIrq & IFTr. & $r 19 \cdot 0$ & GQFV. & r • • ساله ....................... \\
\hline$r \cdot \Delta$ & TtTD & $F \Delta \Delta F$ & VITF & qFVT & $1.14 \mathrm{~V}$ & $r \cdot 990$ & $\Delta \Delta V V T$ & \\
\hline 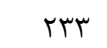 & TFAN & DrAS & $\Lambda \cdot 1$. & qFV & NK19 & $\|f\| V$ & ґ^१५. & r • • ساله ............................ \\
\hline IVA & rgrV & rr.. & ఎ१४ & $94 .$. & QVIT & 9911 & $r \Delta \cdot 1 \Delta$ & q \\
\hline $1 \cdot f$ & 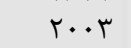 & tAFt & $F \cdot F \Delta$ & स्II & 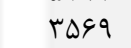 & DQTG & TrA. & 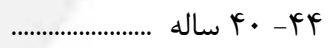 \\
\hline at & $\mid \Delta \Delta \Lambda$ & 1904 & tVAT & $r \wedge \cdot 1$ & $r \Delta \cdot \Lambda$ & FIDF & IDArq & ..................... rq $r q$ \\
\hline $9 \wedge$ & Irr人 & IFr. & $|\wedge \Delta|$ & $19 \Delta V$ & $|09|$ & tarkt & $1 \cdot \vee 99$ & 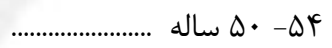 \\
\hline$\Delta T$ & (111 & $11 \Delta V$ & 1499 & IFVr & 1181 & IVqF & NFFG & 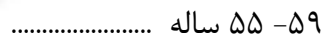 \\
\hline$r$. & Vrq & $V F \Delta$ & $9 \vee$. & I. TD & VAF & 1111 & 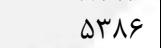 & 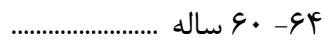 \\
\hline 19 & f.. & FFl & $\Delta F D$ & DIT & rav & $\Delta F q$ & Thtr & ........................ 99 - 99 \\
\hline (1) & ५१९ & rqp & met & חזי & $r \omega$ & טזr מש & $1 \wedge \Delta \Delta$ & ساله ..................... $V \cdot$ \\
\hline r & rqт & me & זrt & FFA & 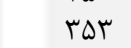 & $\Delta 99$ & rofq & ساله و بيشتر ................. VD \\
\hline$r \cdot I r$ & rigir & ryrar & $\Delta \& A \Delta F$ & $9 \Delta 1 \cdot 9$ & $\Delta \& A \cdot q$ & $1191 \mathrm{~V}$ & reqior & 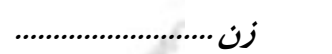 \\
\hline 118 & . & vrq & trme & fllf & eVrr & $9 \Delta \wedge \vee$ & rIDSF & 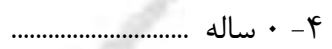 \\
\hline TrG & IVA. & revo & DTFD & DFYI & $F \Delta \cdot 1$ & $V|\Delta|$ & หУ৭१৭ & 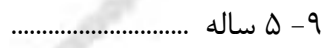 \\
\hline$r \cdot q$ & $|\Delta| \Delta$ & T\&GT & rAFq & k\&qG & frva & GarV & $T F \cdot T$ & 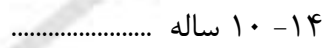 \\
\hline$|v|$ & IFEV & roV. & fefes & $\Delta \wedge q$. & 91.9 & $1 \cdot f \mid \theta$ & $1.9 \Lambda$ & 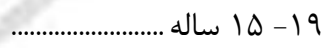 \\
\hline rVq & trat & DTF. & 9491 & MrkF & qVVe & ITRTV & $\Delta T \cdot \Delta V$ & 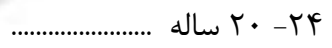 \\
\hline TAV & MTtY & gfrs & $9 r 90$ & $1 \cdot x \vee q$ & $\wedge 9 \cdot r$ & $|M F T|$ & $\Delta Y \cdot F Y$ & 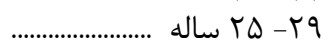 \\
\hline 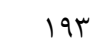 & rqVV & DHG. & $\vee \Delta \wedge 9$ & NTFq & $49 \cdot 4$ & $1 \cdots r V$ & $p_{1} \ldots q$ & ץ • • ساله . . \\
\hline IST & tia. & ron. & fqpi & 0199 & $k \cdot 9 r$ & gDTq & r૬६r. & q \\
\hline $1 \ldots$ & $1 \Delta \varepsilon$. & מדtל & $r \cdot v r$ & rivr & TETT & $r \Lambda \cdot \Lambda$ & 19909 & 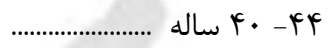 \\
\hline$q 4$ & Irgr & lef. & TTYI & rive & IVrq & TATR & $119 \Delta \mathrm{V}$ & ..................... rq $r q$ \\
\hline$\Delta F$ & $1 \cdot k r$ & $I T \cdot \Delta$ & 1091 & 1918 & $11 \cdot 9$ & 1910 & NTr. & 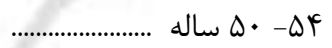 \\
\hline$\Delta T$ & NQH & $9 \wedge 1$ & $11 \mathrm{kr}$ & 1199 & NFr & $11 V \wedge$ & 9र19 & 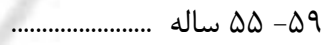 \\
\hline$r \Delta$ & $\Delta \Lambda F$ & q.F & Vru & VG & DIV & VAr & c... & 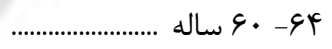 \\
\hline IV & rی. & ( ) & F\&V & iा & ( & 499 & tFIF & ........................ 99 - 99 \\
\hline 10 & 199 & IVV & tru & TET & IVF & rik & ח & ساله ....................... $V \cdot$ \\
\hline rt & ra1 & $r \Delta V$ & rAk & rVG & ( ) & 019 & $t t \cdot t$ & ساله و بيشتر ..................... VD \\
\hline
\end{tabular}


• 1 - - مهاجران واردشده از خارج كشور طى ه سال كذشته بر حسب جنس، سن و استان محل اقامت فعلى (بر اساس آخرين (كل)

\begin{tabular}{|c|c|c|c|c|c|c|c|c|c|c|c|}
\hline \multicolumn{11}{|c|}{ محل اقامت فعلى } & \multirow[b]{2}{*}{ جنس و سن } \\
\hline جراسان & |جهارمحال & تهران & بوشهر & ايلام & البرز & اصفهان & اردبيل & آذربايجان & آذربايجان & جمع & \\
\hline$r \lambda$ & ris & 0119. & $F q \cdot \Delta$ & $q \pi$ & 9119 & Arre & 111 & 15. & ו ו & $11 \cdot 149$ & مرد وزن...... \\
\hline 9 & r & MIV & tri & r & $F \Delta \Lambda$ & sts & v & r & rq & $V \cdot \wedge \varsigma$ & ץ- • ساله ................. \\
\hline 4 & r & $r \cdots \wedge$ & TET & r & $\Delta \wedge \Lambda$ & V\&q & 4 & Ve & rq & $9 \notin 81$ & 9- ه ساله .................. \\
\hline ir & 10 & гА१ & IVT & v & FTE & pqr & 9 & mf & tr & $99 \wedge \Delta$ & ץ|- •| ساله ....... \\
\hline r & r & $\Delta \wedge 9 \vee$ & qی & $\wedge$ & Vrr & $\wedge \Delta \wedge$ & 9 & TF & rᄉ & וrrqA & 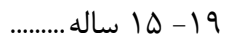 \\
\hline r & $\wedge$ & $9.1 r$ & ITMA & r & $11 \ldots$ & $19 V$. & 19 & 99 & $r v$ & 19Tr & ץ ץ- • ساله ....... \\
\hline 9 & rI & VGF. & VVq & $\Delta$ & VAV & מזו & rq & גזו & 91 & $19 V \cdot 1$ & qr- \\
\hline r & tr & $\Delta V \Delta \Delta$ & $r v$. & 19 & qr. & $\Lambda F \Delta$ & +1 & IVF & Irs & 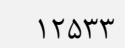 & ץ ץ- • ساله ....... \\
\hline ri & 19 & ferpe & rma & 1. & fat & GTr & tr & 91 & $1 \cdot V$ & qYqr & qז- ضץ ساله ....... \\
\hline$\wedge$ & IV & TETT & 11. & 1. & rq1 & rVF & ir & $\Delta F$ & (i) & $\Delta \varphi .4$ & 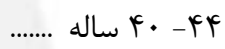 \\
\hline V & tr & I $19 V$ & 11 & 9 & $r \cdot 4$ & r\$q & 10 & rv & ب & rast & q q \\
\hline 1 & TF & Ired & QI & $\Delta$ & IV. & $1 \Delta \Delta$ & $\wedge$ & r & rq & TVYV & 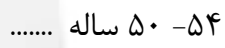 \\
\hline . & ir & 199 & $r \Delta$ & r & $1 \cdot V$ & 94 & f & 1. & 1. & $|1|$. & $\Delta$ ساله -...... \\
\hline . & 11 & $v \cdot 1$ & 19 & . & 99 & $\Lambda$ & r & 9 & IV & IrF. & ץ- •و ساله ........ \\
\hline 1 & v & FIT & 4 & r & r. & $\psi_{\wedge}$ & r & 1 & v & $\wedge \ldots$ & 9- 90 ساله ........ \\
\hline . & 1 & $r q \Delta$ & 1 & . & ry & $\Delta \cdot$ & r & 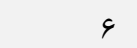 & $\Delta$ & $\Delta \Delta \Delta$ & ساله ........ \\
\hline . & r & (rug & r & . & TV & f. & r & f & $\Delta$ & $\Delta 91$ & VD ساله و بيشتر... \\
\hline $\mathrm{fr}$ & $1 \Delta A$ & rerir & rase & $p q$ & rasr & $\Delta r \cdot q$ & $1 \pi$. & prr & rvr & grreg & 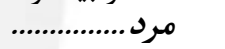 \\
\hline$r$ & 1 & $19 \ldots$ & 118 & 1 & TYF & rt. & r & rV & TA & TEFT & ץ- • ساله ................ \\
\hline i & 4 & $r \cdot \Lambda r$ & IrF & f & rit & fis & $\Delta$ & fr & ir & сqтя & 9- Q ساله .................... \\
\hline r & $\wedge$ & $|G T|$ & 111 & $\Delta$ & $r \cdot V$ & TGF & r & $r \cdot$ & r. & एक्ष & ץ|- •| ساله ........ \\
\hline r & $\wedge$ & rQDL & q1r & 1 & $\Delta T V$ & $\Delta V V$ & $\Delta$ & r & 11 & 9194 & 91 - ها ساله................ \\
\hline r & 9 & GQT. & IIDr & r & VrV & $1.9 \mathrm{~V}$ & r & $r \Delta$ & r. & מצוזו & ץ ץ- • ساله ....... \\
\hline$\Delta$ & 19 & DTAV & 999 & r & DTE & 941 & 19 & $v \Delta$ & FV & $|1<q|$ & qr - T ساله ....... \\
\hline 4 & 19 & rNTr & מצr & 11 & fif & $\Delta \Delta \Lambda$ & rt & 99 & r & NKFT & ץ ץ- • ساله ....... \\
\hline 4 & 9 & TAFI & $r .$. & $\wedge$ & r৭V & FYI & rו & 99 & $\Delta \Lambda$ & $9 \cdot 14$ & qז- ضז ساله ....... \\
\hline 4 & ir & 1997 & 9. & r & 199 & $r \& \Lambda$ & 9 & ry & r. & rVD. & 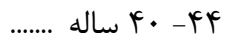 \\
\hline r & $r$. & ITIF & sq & 4 & ITF & $r \cdot r$ & $\wedge$ & r & rq & reqV & q \\
\hline 1 & TF & MAY & $f_{1}$ & r & 114 & 90 & 4 & $r$. & 19 & IVAT & \\
\hline . & 1. & $\Delta \wedge F$ & rt & r & v. & 91 & . & V & 9 & 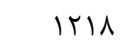 & \\
\hline . & 1 . & fil & 19 & . & Fa & $\Delta V$ & r & $\Delta$ & 11 & (Tr & ץ- •و ساله ........ \\
\hline 1 & 4 & trut & $\Delta$ & 1 & r & ri & r & . & 4 & kq9 & 9- 90 ساله ........ \\
\hline . & 1 & IV. & . & . & TF & rq & . & f & 1 & rrv & שاله ......... \\
\hline . & r & $1 \wedge \Delta$ & 1 & . & 10 & rt & 1 & f & f & MFT & VD VD و بيشتر . \\
\hline ra & $\Delta \Lambda$ & IVFVV & $v 19$ & FF & & $r \cdot r d$ & ev & rev & raq & $r \Lambda \Delta \cdot r$ & 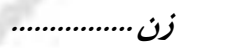 \\
\hline r & r & IOIV & $1 \cdot f$ & 1 & TMY & $r \cdot \varphi$ & r & rq & If & MFFY & ץ- • ساله ................. \\
\hline r & v & 1948 & $\mid r \Lambda$ & 9 & TVE & ror & 1 & r & IV & FATQ & 9- Q ساله ................. \\
\hline 9 & v & ITVT & 91 & r & $r 19$ & rrq & 4 & If & 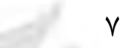 & r. 49 & ץ|- •| ساله ....... \\
\hline . & $\Delta$ & IrkF & $\checkmark \cdot$ & V & $r \cdot \Delta$ & $r \wedge l$ & f & 11 & IV & Tr. & 91 - ها ساله................. \\
\hline 1 & r & rfar & 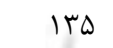 & r & זTr & G.r & 4 & ff & IV & $\Delta 9 \Delta$. & ץ • • שاله .......... \\
\hline 1 & r & Trat & N & r & rQ1 & $r \cdot r$ & 1 . & qr & FF & QTIV & qr- \\
\hline V & 11 & 19RT & FV & $\Delta$ & ris & TAV & 9 & $\vee \wedge$ & ه & 419. & ץ • • ساله ............ \\
\hline$\checkmark$ & $\cdot$ & سMטا & r山 & r & $19 V$ & YII & 9 & r & qq & $r t \cdot \Lambda$ & qז- ضץ ساله ....... \\
\hline r & $\Delta$ & 979 & $r$. & $\wedge$ & 90 & 1.9 & r & $r$. & 11 & $1 \wedge \Delta 4$ & 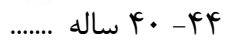 \\
\hline r & r & gar & IV & r & NT & $9 V$ & v & if & v & VIrV & q q \\
\hline$\cdot$ & & FAr & 1. & 1 & $\Delta \Lambda$ & c. & r & r & 1 . & $q Y \Delta$ & \\
\hline$\cdot$ & r & TIT & r & & rv & 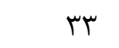 & f & $r$ & 1 & DQT & 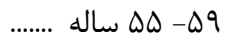 \\
\hline . & 1 & rq. & $r$ & . & TF & r & . & f & 4 & DIV & ץ. •و ساله .......... \\
\hline$\cdot$ & 1 & IVA & 1 & 1 & IV & IV & . & 1 & 1 & $r \cdot \psi$ & 9- 90 ساله ........ \\
\hline$\cdot$ & . & ITD & 1 & · & 1 . & YI & r & r & f & TIN & • • Vاله ........ \\
\hline . & 1 & 10 & 1 & . & Ir & 11 & 1 & . & 1 & rFq & VD Vاله و بيشتر.. \\
\hline
\end{tabular}


•ا - ا- مهاجران واردشده از خارج كشور طى ه سال كذشته بر حسب جنس، سن و استان محل اقامت فعلى (بر اساس آخرين (كل)

جابجايى انجامشده) (دنباله)

\begin{tabular}{|c|c|c|c|c|c|c|c|c|c|c|c|}
\hline \multicolumn{11}{|c|}{ محل اقامت فعلى } & \multirow[b]{2}{*}{ جنس و سن } \\
\hline كرمان & كردستان & 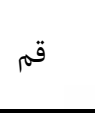 & قزوين & فارس & بلوجستان & سمنان & زنجان & خوزستان & خراسان & خراسان & \\
\hline$r \cdot q 1$ & 191 & sVrA & gri & $r \| r$ & $\overline{1 \Delta r}$ & rqf & rav & Ifref & 1.1 & VVq. & مرد وزن...... \\
\hline ג & $\Delta F$ & $\Delta / F$ & rV & FVr & rq & If & $\wedge$ & 99 & 9 & siv & 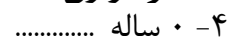 \\
\hline 111 & 99 & $\varphi \Delta \varphi$ & FV & 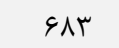 & 94 & rq & If & 19 & f & I. rی & - ه ساله ................. \\
\hline س & 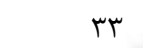 & FFA & 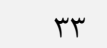 & Far & ه & rq & 9 & 1.9 & 4 & VQF & f|- • | ساله ............ \\
\hline rVG & TF & $\Delta \wedge \Delta$ & $\vee \wedge$ & $\wedge \notin \vee$ & ^r & r. & 11 & 190 & $\wedge$ & ब\&Y & 19- ها ساله .............. \\
\hline$\Delta F$. & $\uparrow \wedge$ & If\&F & IfF & $1 \cdot 11$ & $14 q$ & $V F$ & 9 & TAY & r & 119 & 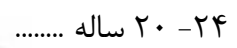 \\
\hline pqV & IVV & IraV & 11 & I.r. & 149 & $9 r$ & ry & rrq & $\wedge$ & $9 \wedge \cdot$ & qr- \\
\hline$F a$. & INF & VDT & vi & VHe & ז & $\Delta \Delta$ & $F \Delta$ & 199 & 1. & बr & 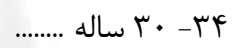 \\
\hline mif & 119 & $r \Delta \Lambda$ & fr & $\Delta \wedge \vee$ & NT & ro & $\Delta 1$ & IFT & 1. & $v \cdot v$ & qץ- هץ ساله ............ \\
\hline gre & VV & trut & ץ & $r \Delta$. & $\Delta 1$ & 11 & $p q$ & $\wedge \varsigma$ & 19 & FVr & 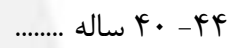 \\
\hline$\Lambda$ & fr & IFV & rV & TVF & 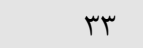 & 11 & ґ^ & سو & 11 & rT. & ......... \\
\hline$v \Delta$ & 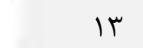 & qV & r & 194 & 19 & 11 & If & ra & r & $r \cdot \wedge$ & 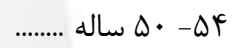 \\
\hline f. & v & \&Y & \& & IFD & rו & 4 & 9 & rV & $\Lambda$ & Irv & \\
\hline TF & 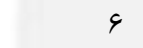 & (i) & $\varepsilon$ & $1 \ldots$ & $\checkmark$ & r & 1 & 11 & r & १७ & 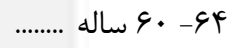 \\
\hline rQ & $\Delta$ & $r \Delta$ & r & $v^{k}$ & f & 1 & r & 19 & r & r^ & 99- 9 ساله ....... . \\
\hline r & 1 & 19 & q & זr & 1 & . & 1 & $\Delta$ & . & et & ساله ......... -VF \\
\hline 19 & r & rt & r & ऍ & $\Delta$ & r & r & $\Delta$ & · & rF & VD ساله و بيشتر .. \\
\hline ral & $\Delta r \Lambda$ & ryra & תrr & fras & str & $r \Delta$. & rla & $1 \cdot 1$ & $\Delta V$ & Figr & 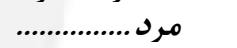 \\
\hline qr & rq & TAl & r & TMF & rV & $\wedge$ & V & $\Delta V$ & $\Delta$ & $r \cdot r$ & ץ- • ساله ................... \\
\hline $1 \cdot 0$ & ra & 部 & 19 & MFI & FV & 11 & $\Delta$ & $\wedge \varsigma$ & & $\Delta \Delta \Lambda$ & - ه ساله ............ \\
\hline $11 r$ & ir & $r \cdot q$ & Ir & TAT & TV & 1. & 4 & QV & 1 & rv^ & f|- • | ساله ............. \\
\hline$r \cdot \boldsymbol{q}$ & If & rVq & $r \Delta$ & 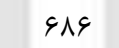 & $\Delta q$ & rt & r & IFT & r & ry. & 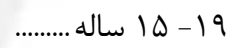 \\
\hline frv & ra & VG. & 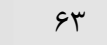 & ATD & 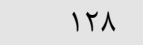 & $\Delta T$ & $\Delta$ & $|\wedge|$ & 1 & Fis & ץ · • • ساله ......... \\
\hline FTI & $1 \cdot \Delta$ & $1 \cdot 9$ & Qr & Ver & $1 \cdot 0$ & r^ & rV & IFV & \& & $\Delta r \Delta$ & qr- \\
\hline rVV & 119 & fEY & Fr & fre & 91 & r^ & r. & ITS & $\Delta$ & Far & Fr • • ساله ............. \\
\hline$r \Delta \Lambda$ & $\Lambda \cdot$ & rit & Tr & rVA & 91 & TF & ry & 99 & r & $r q \Delta$ & q" هץ ساله ........ \\
\hline س & $q f$ & $\mid F \wedge$ & 19 & TFV & (i) & 11 & fr & $\Delta \Lambda$ & 11 & TVT & 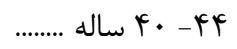 \\
\hline$\Delta 9$ & re & 9 . & 19 & $1 \wedge \Delta$ & r & rו & r山 & iv & v & 194 & 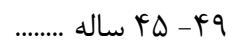 \\
\hline$\Delta T$ & $v$ & $\Delta \Delta$ & $\wedge$ & IFV & 19 & $\wedge$ & 1. & rI & 1 & $1 \cdot \Delta$ & F.......... \\
\hline r & $\Delta$ & rq & $\Delta$ & $11 \pi$ & 1 . & f & V & $r \cdot$ & $\wedge$ & $\wedge \Delta$ & \\
\hline 19 & f & 19 & $\Delta$ & א & r & 1 & 1 & 11 & r & qr & 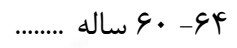 \\
\hline 11 & $\Delta$ & If & r & $\Delta \Delta$ & r & 1 & r & 11 & r & r & 99- 9 ساله ....... \\
\hline 11 & · & $\wedge$ & r & 19 & 1 & $\cdot$ & 1 & $\Delta$ & $\cdot$ & tr & ساله $V \cdot$ • -........ \\
\hline If & · & If & $\cdot$ & Tr & f & r & $\cdot$ & r & . & IV & VD ساله و بيشتر .. \\
\hline$r \cdot r$ & rre & $\mu \cdot r \cdot$ & rq1 & rurp & rr. & IFF & $1 \mathrm{r}$ & $\Delta \Delta F$ & FF & $r \Delta q v$ & 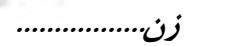 \\
\hline Va & ro & אחץ & if & 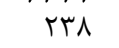 & it & 4 & 1 & rq & f & mif & 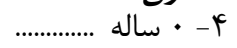 \\
\hline$\Lambda r$ & ry & MI & r^ & MET & Fa & ri & 9 & VV & f & $\psi_{\wedge}$. & 9- ه ساله ............... \\
\hline vi & $r \cdot$ & q & $r \cdot$ & rII & re & 19 & r & rq & $\Delta$ & rVG & f|- • | ساله .......... \\
\hline VT & $1 \cdot$ & $r \cdot \varphi$ & Fr & $|\Lambda|$ & tr & $\wedge$ & $\wedge$ & س & $\Delta$ & שזr & 19-1 هاله ........... \\
\hline $1 \cdot r$ & 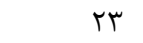 & $V \cdot r$ & 11 & 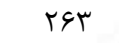 & rI & rt & r & vi & r & r.. & r • • الب ساله ........ \\
\hline Vq & VT & $\Delta F \wedge$ & rᄉ & TVV & TF & $r \Delta$ & V & NT & r & FFa & qr- \\
\hline Vr & $9 \wedge$ & rq. & rq & TAT & ra & IV & 10 & VI & $\Delta$ & rیr & ץ • • ساله .............. \\
\hline$\Delta \varphi$ & rq & $1 F \Delta$ & 19 & $r \cdot q$ & KI & 11 & iv & er & 4 & rir & qץ- هץ ساله ........ \\
\hline r & r & 19 & IV & $1 \cdot r$ & 1. & $\checkmark$ & V & rᄉ & $\Delta$ & $r \cdot I$ & 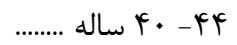 \\
\hline TF & $\varepsilon$ & $\Delta V$ & $\wedge$ & 19 & 1. & $\Delta$ & r & 19 & f & ITV & \\
\hline r & 4 & GT & $\Delta$ & is & r & r & f & if & 1 & $1 \cdot r$ & ......... \\
\hline 9 & r & r & 1 & r & r & r & r & v & . & $\Delta T$ & ه \\
\hline$\wedge$ & r & rt & 1 & rv & r & 1 & . & v & . & my & 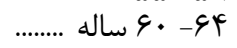 \\
\hline v & $\cdot$ & 11 & 1 & 19 & 1 & $\cdot$ & · & $\Delta$ & · & 10 & 99- 9 90 ساله ....... \\
\hline r & 1 & $\wedge$ & 1 & $\checkmark$ & · & $\cdot$ & - & • & · & 10 & ساله ........ V. \\
\hline r & r & $\wedge$ & r & 11 & 1 & $\cdot$ & r & r & $\cdot$ & IV & VD ساله و بيشتر ... \\
\hline
\end{tabular}


•ا - ا- مهاجران واردشده از خارج كشور طى ه سال تذشته بر حسب جنس، سن و استان محل اقامت فعلى (بر اساس آخرين (كل)

جابجايبى انجامشده) (دنباله)

\begin{tabular}{|c|c|c|c|c|c|c|c|c|c|c|}
\hline \multicolumn{10}{|c|}{ محل اقامت فعلى } & \multirow[b]{2}{*}{ جنس و سن } \\
\hline 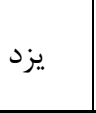 & همدان & هرمزكان & مركزى & مازندران & 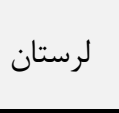 & كيلان & كلستان & كهيَيلويه و & كرمانشاه & \\
\hline $11 \cdot r$ & red & rase & $|r v|$ & val & 91 & 811 & $f \mid f$ & rvq & Frl & مرد و زن.......... \\
\hline $1 \cdot k$ & 11 & $I V \wedge$ & $1 \cdot 1$ & rᄉ & r & r. & 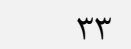 & 19 & r. & ץ- • ساله ................ \\
\hline 159 & it & ror & ITK & ry & 9 & r. & $F \Delta$ & V & is & 9- ه ساله .................. \\
\hline$\Lambda F$ & 19 & IV. & $\wedge \Delta$ & re & $\checkmark$ & $r$. & r & $\Delta$ & $r \Delta$ & f|- • | ساله ......... \\
\hline$|F|$ & 11 & rrq & 191 & iq & 1. & 19 & rI & r & 11 & 19 - 10 ساله ........... \\
\hline rیd & rᄉ & $\Delta F V$ & TFA & $\vee q$ & r & $9 \wedge$ & r. & $\Delta \varphi$ & TF & ץ • • שاله .......... \\
\hline$r \cdot r$ & $r v$ & FF. & $1 \wedge 9$ & 11. & If & NT & $\Delta 1$ & rq & $9 \Lambda$ & qr-.......... \\
\hline to & rq & rAV & ITV & Ifd & ir & 115 & 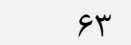 & rq & v9 & 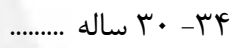 \\
\hline $\mid r \wedge$ & tr & rtq & $1 \cdot e^{c}$ & 19 & $\wedge$ & 110 & $\Delta \wedge$ & rᄉ & gf & qץ- טس ساله ........... \\
\hline$\wedge \Delta$ & ry & هוr & $\Delta 9$ & Gr & If & $\Delta F$ & r. & TF & Fr & 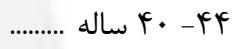 \\
\hline re & tr & 91 & $f \Delta$ & fr & 1. & fq & $r \cdot$ & 1. & rt & ......... \\
\hline ra & 4 & q. & $r \Delta$ & rᄉ & 1 & rq & 1. & 11 & V & 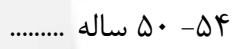 \\
\hline rT & $\wedge$ & Gr & $r \cdot$ & $r \Delta$ & $\Delta$ & re & $\wedge$ & f & f & -......... \\
\hline 11 & $\wedge$ & re & 11 & r & r & IV & $\varphi$ & r & 9 & 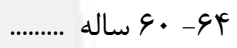 \\
\hline$\checkmark$ & r & rt & V & 19 & . & YI & $\Delta$ & f & r & 9- 9 9 ساله ......... \\
\hline 4 & r & 1. & $\wedge$ & 11 & . & 9 & r & r & f & ساله .......... سال $V \cdot V$ \\
\hline f & 1 & 10 & $\wedge$ & V & . & V & . & . & r & VD ساله و بيشتر ... \\
\hline rar & $|9|$ & $r \cdot r_{1}$ & $1 r \Lambda$ & $\Delta \cdot 1$ & $\Delta r$ & FrA & rir & rel & re. & 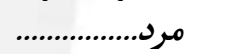 \\
\hline$\uparrow \wedge$ & v & 19 & $\Delta \varphi$ & tr & . & If & 10 & it & $r \cdot$ & ץ- • ساله .................. \\
\hline Ve & V & Trt & 94 & IV & r & 10 & $r \cdot$ & $r$ & tr & 9- ه ساله ................... \\
\hline pq & V & 99 & $\uparrow \wedge$ & 11 & f & 10 & r - (1) & r & 19 & f|- • 1 ساله ......... \\
\hline 19. & it & ror & IFT & rV & 4 & ir & 11 & r & 11 & 19 - ها ساله ............ \\
\hline MI & 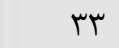 & fre & $I V \Delta$ & $\Delta V$ & r & $\Delta T$ & ir & $4 q$ & 1. & 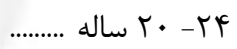 \\
\hline TQT & 19 & שוץ & ITG & $\checkmark \cdot$ & 9 & fq & tr & rq & rQ & q \\
\hline $11 \mathrm{~V}$ & 11 & מזr & $\Lambda$. & $9 \Delta$ & $\Delta$ & VT & $f$. & rq & fr & F • • ساله ........... \\
\hline שrו & $\wedge$ & $|1|$ & 99 & pq & r & 99 & rT & TF & (i) & qץ- טז ساله .......... \\
\hline $9 V$ & rr & $1 \cdot v$ & re & ५q & $\wedge$ & re & سו & $r \cdot$ & ו & 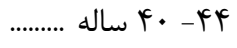 \\
\hline$r \Lambda$ & r & $9 \wedge$ & rV & rV & V & 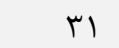 & IV & $\Lambda$ & $r \cdot$ & .......... \\
\hline 11 & f & $i \Delta$ & 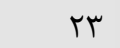 & rG & 1 & IV & f & 1. & r & ........... \\
\hline 19 & f & FV & ir & 11 & f & rt & $\Delta$ & r & $r$ & ه - \\
\hline$v$ & $\Delta$ & $r \wedge$ & $\Delta$ & 9 & r & 9 & $\Delta$ & r & $\Delta$ & 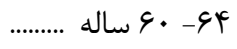 \\
\hline f & r & 19 & r & it & - & r (1) - (1) & r & f & r & 9. \\
\hline$\Delta$ & 1 & 9 & $\Delta$ & V & - & $\Delta$ & 1 & r & r & ......... ساله $V \cdot-V F$ \\
\hline r & . & 11 & $\Delta$ & $\Delta$ & . & 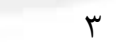 & . & - & 1 & VD ساله و بيشتر ... \\
\hline$F_{1}$ & $1 \cdot f$ & 111 & fqr & rq. & $F \Delta$ & re. & $r \cdot l$ & $\Delta \Lambda$ & ril & 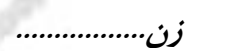 \\
\hline$\Delta \varphi$ & f & 19 & $F \Delta$ & 19 & r & 19 & 11 & v & $r$ r. & ץ-................... \\
\hline L & $\Delta$ & IT. & 99 & IV & q & 10 & $r \Delta$ & $\Delta$ & r) & - ه ساله .................. \\
\hline ra & it & $V f^{c}$ & rV & 11 & r & $\Delta$ & 19 & r & 9 & f|- • | ساله .......... \\
\hline$\Delta 1$ & 4 & $V V$ & $p q$ & 9 & f & $\checkmark$ & 1 . & $\wedge$ & V & 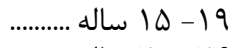 \\
\hline$\varepsilon F$ & $\Delta$ & 111 & $V \cdot$ & rt & 1 & 19 & 11 & v & if & 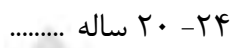 \\
\hline QI & 11 & ITV & $\varepsilon$. & $r$. & $\Delta$ & rq & rq & v & Fr & q......... \\
\hline rᄉ & 11 & gr & FV & $\Delta \cdot$ & $\checkmark$ & f. & 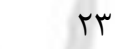 & 1 . & ع & 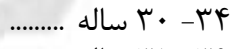 \\
\hline$r \omega$ & 19 & $\uparrow \wedge$ & r山 & r. & 4 & $p q$ & re & f & זr & qז- \\
\hline 11 & 11 & $r \Lambda$ & r & rr & 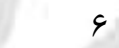 & 11 & IV & f & it & ......... \\
\hline 4 & 9 & r. & 11 & 10 & r & 10 & r & $r$ & it & ......... \\
\hline$\checkmark$ & r & 10 & ir & ir & - & 9 & $\varepsilon$ & 1 & f & ........... \\
\hline 4 & f & 10 & $\wedge$ & If & 1 & 1. & r & 1 & r & ه9 - \\
\hline f & r & f & سו & r & 1 & $\Lambda$ & 1 & . & f & 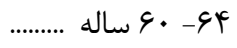 \\
\hline r & . & 9 & i & f & . & $\Lambda$ & r & . & 1 & 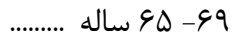 \\
\hline 1 & 1 & r & r & f & . & r & 1 & - & 1 & ساله .......... \\
\hline r & 1 & f & r & $r$ & $\cdot$ & i & $\cdot$ & $\cdot$ & $r$ & VD ساله و بيشتر .... \\
\hline
\end{tabular}


•ا - ا- مهاجران واردشده از خارج كشور طى ه سال كذشته بر حسب جنس، سن و استان محل اقامت فعلى (بر اساس آخرين (نقاط شهرى)

جابجايى انجامشده) (دنباله)

\begin{tabular}{|c|c|c|c|c|c|c|c|c|c|c|c|}
\hline \multicolumn{11}{|c|}{ محل اقامت فعلى } & \multirow[b]{2}{*}{ جنس و سن } \\
\hline خراسان & و بختيارى & تهران & بوشهر & ايلام & البرز البر & اصفهان & اردبيل & غآذربيى & شرقى آذربايجان & جمع ( جم & \\
\hline$V \Delta$ & IVr & $F \Delta F=\Delta$ & $r \Delta \cdot r$ & $v v$ & all. & VIA1 & $1 \Delta \Delta$ & $v r r$ & g.r & qfFID & مرد و زن....... \\
\hline 9 & $r$ & T\&IS & $1 \wedge \Delta$ & $r$ & rqA & $\Delta \wedge \vee$ & 9 & $\Delta V$ & rı & 9.90 & ץ- • ساله ................. \\
\hline q & ir & rrqf & TMt & 11 & fqf & ViN & $\Delta$ & 9. & rᄉ & $\Lambda \cdot \Lambda F$ & 9 -.............. \\
\hline 11 & If & TFqF & זسו & 4 & rav & FAT & 9 & r & TQ & DVQT & ץ||- •| ساله ....... \\
\hline r & 11 & DITT & $V \Psi V$ & 4 & $\Delta \varphi q$ & VIr & $\wedge$ & rt & TF & 1.1 .9 & 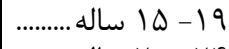 \\
\hline r & 4 & VAr & $9 \Delta V$ & f & 199 & | & rו & $\Delta V$ & rq & $10 \wedge 9 F$ & 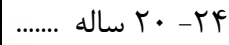 \\
\hline q & 19 & $91 \cdot 9$ & $\Delta \Lambda \mu$ & 1 & s49 & $1 \cdot 19$ & 11 & ITV & 19 & $|f| \Lambda$. & 9 \\
\hline זו & $r \Delta$ & बr११ & TVQ & rו & G & VMF & rv & 101 & IFF & $1.9 V T$ & F \\
\hline ir & 19 & K.YG & $19 f$ & $q$ & $4 \cdot 9$ & $\Delta F$. & 19 & 9. & $1 . r$ & NIrV & qז- هץ ساله ....... \\
\hline $\mathrm{v}$ & $1 \pi$ & Tet. & $\wedge F$ & 1. & $T Q 1$ & Trt & 11 & هI & rq & FqY^ & |....... \\
\hline $\mathrm{v}$ & 19 & $\mid V I I$ & 4. & \& & $|1|$ & TFI & rו & rt & r. & MYGF & q \\
\hline 1 & r & IKrV & $r \Delta$ & $\Delta$ & lfF & IrV & r & זr & ro & TMEI & ........ \\
\hline . & $\wedge$ & $\Delta+1$ & 11 & r & 90 & r & i & 1. & 1. & 1091 & 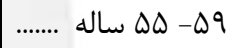 \\
\hline . & 9 & Gru & 10 & . & $\Delta V$ & 11 & r & 9 & 10 & 1189 & 4 \\
\hline 1 & $\Delta$ & rVA & $r$ & r & TQ & iq & r & . & v & vil & 99- 90 ساله ....... \\
\hline . & 1 & red & 1 & . & rq & is & r & 4 & $\Delta$ & $\forall M$ & ........ ساله \\
\hline - & r & TIT & 1 & . & זr & rq & r & r & $\Delta$ & DTr & ساله و بيشتر . VD \\
\hline $\mathrm{Fr}$ & $1 \pi$. & r9119 & raqr & Fr & riar & frro & $1 \ldots$ & frq & rat & q. & مرد ........................ \\
\hline r & 1 & G & 99 & 1 & 191 & $r \cdot 1$ & r & ra & TY & mlle & ץ- · שاله ................. \\
\hline f & $\Delta$ & $I V \Delta q$ & 110 & $r$ & tat & rMA & r & rq & 11 & FI9T & |............. . \\
\hline r & $\Lambda$ & Irvg & 19 & $\Delta$ & $|V|$ & r & r & 19 & 11 & $r \cdot \Delta q$ & ץ|- •| ساله ....... \\
\hline$r$ & v & rqvq & $9 \Lambda$. & 1 & $f \cdot f$ & FFA & r & ir & 9 & VTEV & 19-1 هاله س.......... \\
\hline$r$ & $\Delta$ & DVTG & NFr & $r$ & qIf & Vas & 9 & r & 19 & 1.991 & 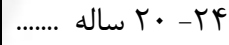 \\
\hline$\Delta$ & IV & FVI. & $0 \cdot 9$ & 1 & Trt & $V \cdot r$ & IT & vi & iq & qDT. & q \\
\hline 4 & If & requ & THF & 9 & ع & fQY & rq & 19 & vi & $v \cdot q r$ & F \\
\hline \& & 9 & TOAV & 195 & $\wedge$ & $T \Delta V$ & אسץ & 11 & 9) & $\Delta \Delta$ & $\Delta \backslash \Delta \Delta$ & 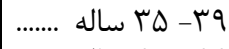 \\
\hline$\Delta$ & 1. & IDEV & $9 \Lambda$ & r & 199 & TIV & $\wedge$ & Tr & rی & rTIS & f...... \\
\hline f & $1 f$ & 11.9 & iq & r & 1.9 & IVe & $\wedge$ & ri & rq & rYYI & q \\
\hline 1 & $1 \pi$ & $1 \cdot 1$ & TV & f & 94 & vq & r & $r$. & 19 & $10 \cdot 0$ & 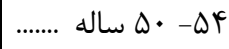 \\
\hline . & 9 & $\Delta F V$ & 10 & r & GT & $\Delta T$ & . & v & 9 & $1 \cdot \Delta V$ & 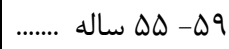 \\
\hline . & $\wedge$ & rVe & זו & . & rی & UT & r & $\Delta$ & 9 & VTr & 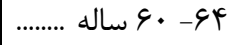 \\
\hline 1 & r & rIf & r & 1 & 11 & r. & r & . & 4 & kFF & 99- 9 ساله ....... \\
\hline . & 1 & $14 q$ & . & . & rI & tr & . & f & 1 & rM & 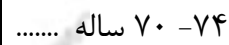 \\
\hline . & 1 & 191 & 1 & . & ir & r) & 1 & f & f & rq1 & VD Vاله و بيشتر . . \\
\hline rr & $\Delta r$ & $|\Delta Q| \bar{E}$ & $9 \cdot 9$ & ra & $19 \pi \mu$ & rAgr & $\Delta \Delta$ & ra1 & ra. & reIAT & زن............................ \\
\hline r & $r$ & $1 r q$. & 19 & 1 & $r .$. & rAS & r & tr & if & r901 & ץ- • שاله ............. \\
\hline$r$ & $\mathrm{v}$ & lera & $1 \cdot V$ & 9 & אזr & . & 1 & TY & IV & rल१厂 & -................ \\
\hline$\wedge$ & 9 & 1111 & iv & 1 & 119 & rID & \& & it & v & rqq4 & ץ ا- ·. ساله ....... \\
\hline . & f & WF & $\Delta V$ & $\Delta$ & 190 & T\&Q & f & 1. & 10 & TVGT & 19- هاله ساله........ \\
\hline 1 & 1 & rI.V & 114 & $r$ & TAT & $\Delta \varphi \Delta$ & i & ry & IV & pars & 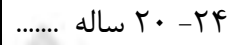 \\
\hline 1 & r & $r .99$ & $v^{k}$ & . & rIV & rیז & q & $\Delta \varphi$ & זr & F99. & 9 \\
\hline v & 11 & $11 \cdot 1$ & i) & c & r.. & rV. & $\wedge$ & 99 & TH & rAVq & ץ \\
\hline 4 & 1 & lerq & r & 1 & 149 & $r \cdot V$ & $\wedge$ & rq & FV & rqVT & q"ז- מז ساله ....... \\
\hline r & $r$ & NAT & 19 & $\wedge$ & NT & $1 \cdot 0$ & r & 19 & 11 & IVIT & |...... \\
\hline r & r & $9 \cdot 0$ & if & $\hat{r}$ & VD & 90 & $\Delta$ & 11 & f & $119 \pi$ & q \\
\hline . & 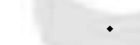 & pre & $\Lambda$ & 1 & $\Delta$. & $\Delta \Lambda$ & . & r & 9 & Nזq & ........ \\
\hline . & r & rqf & $r$ & . & זr & m & f & r & 1 & $\Delta F I$ & 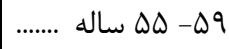 \\
\hline . & 1 & TET & r & $\cdot$ & 19 & ru & . & f & 4 & FQS & 4و- ·9 ساله ........ \\
\hline • & 1 & 194 & 1 & 1 & If & 19 & . & $\cdot$ & 1 & rVV & 9- ه ه ساله ....... \\
\hline . & . & 119 & 1 & . & $\Lambda$ & rI & $r$ & r & f & $r .$. & ساله ....... \\
\hline . & 1 & leF & . & 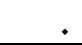 & 11 & 11 & 1 & 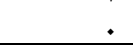 & 1 & ו וrץ & VD Vاله و بيشتر \\
\hline
\end{tabular}


•ا - ا- مهاجران واردشده از خارج كشور طى ه سال تذشته بر حسب جنس، سن و استان محل اقامت فعلى (بر اساس آخرين (نقاط شهرى)

جابجايبى انجامشده) (دنباله)

\begin{tabular}{|c|c|c|c|c|c|c|c|c|c|c|c|}
\hline \multicolumn{11}{|c|}{ محل اقامت فعلى } & \multirow[b]{2}{*}{ جنس و سن } \\
\hline كرمان & كردستان & قم & قزوين & فارس & بلوجستان & سمنان & زنجان & |خوزستان | & خراسان & خراسان & \\
\hline iqra & 119 & grf. & rr & $\Delta \Lambda \Delta \Lambda$ & $\Delta Q T$ & gre & 114 & Ira. & $9 \Delta$ & $V|r|$ & مرد و زن...... \\
\hline$\Delta f$ & 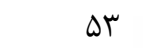 & 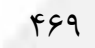 & r) & 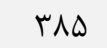 & TV & V & $\wedge$ & V. & $\wedge$ & $\Delta \wedge \vee$ & 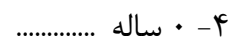 \\
\hline $1 \cdot r$ & $9 \wedge$ & $\Delta 9 \Delta$ & $r \Delta$ & $\Delta \Delta V$ & c. & tr & If & 149 & f & qVD & 9- ه ساله ............. \\
\hline 91 & r & f) & $r \wedge$ & ५१९ & r t & IV & 9 & 19 & 9 & VTd & f|- •| ساله ........ \\
\hline 194 & TF & DTV & $\Delta 9$ & 999 & Fa & 11 & 11 & 119 & $\wedge$ & ETF & 19 - ها ساله ............ \\
\hline$r \cdot r$ & f. & $\mid r \cdot r$ & ITS & سזر & 99 & id & f & 199 & f & V^I & 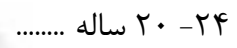 \\
\hline$|4|$ & $19 \mathrm{~V}$ & $\mid r q 1$ & gf & $\wedge \notin \vee$ & $\Lambda$ & 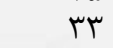 & $r \cdot$ & 194 & 4 & $q F V$ & qr....... \\
\hline TFT & $\operatorname{lVr}$ & VTF & gr & \&T. & $\varepsilon V$ & 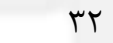 & re & $|V|$ & 9 & 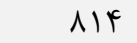 & ץ • •r ساله ......... \\
\hline 199 & 110 & גזس & щ^ & pq. & $\Delta$. & Tr & rt & $15 q$ & 1. & GAF & qr- טז ساله ....... \\
\hline $9 \Lambda$ & $V F$ & rIV & 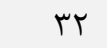 & rqu & 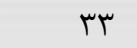 & 10 & 11 & $V V$ & If & $F \Delta \Lambda$ & \\
\hline$f$. & (i) & Tr & rG & פש Tr & זr & 11 & r & $\Delta V$ & 11 & r.r & \\
\hline pq & IT & $\Lambda V$ & $1 \cdot$ & 109 & it & 9 & 9 & r. & r & 199 & ......... \\
\hline rt & 9 & $\Delta F$ & 4 & ITF & v & r & V & T\& & $\wedge$ & سזו & \\
\hline If & 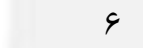 & m & \& & $\Lambda \vee$ & r & 1 & $\cdot$ & 19 & r & 94 & ع \\
\hline سו & $\Delta$ & rt & r & 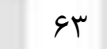 & r & 1 & r & 10 & r & rᄉ & 99- 90 ساله ........ \\
\hline$\wedge$ & 1 & it & r & 10 & 1 & - & 1 & $\Delta$ & • & FT & ساله ........ -VF \\
\hline$\wedge$ & r & 11 & r & ו & r & $r$ & r & f & · & r. & VD ساله و بيشتر ... \\
\hline 1199 & $\Delta 11$ & revr & rat & rasr & ral & $|r|$ & $1 \cdot 0$ & 11. & $\Delta F$ & $f . . F$ & 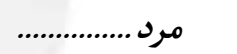 \\
\hline$r$. & rq & $r \Delta \Delta$ & 9 & 19. & 11 & f & V & r & $\Delta$ & rql & ץ- • ساله ................ \\
\hline$\Delta r$ & rF & $r \cdot \Lambda$ & If & TVT & TV & ir & $\Delta$ & 90 & $\cdot$ & TH & 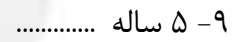 \\
\hline$\uparrow \wedge$ & $\pi$ & $1 \wedge \mathrm{V}$ & $1 \cdot$ & TIV & if & c & 4 & $\Delta F$ & 1 & HeV & f|- •| ساله .......... \\
\hline 119 & if & TFT & 11 & $\Delta f$. & 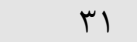 & \& & 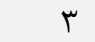 & 91 & r & (4t & 19 - 19 ساله ............... \\
\hline r d & 19 & RTM & QI & 911 & $\Lambda F$ & TF & 1 & IFF & 1 & $r \cdot r$ & r • • שاله .......... \\
\hline rID & $1 \cdots$ & VVr & rV & GTF & VT & $1 f$ & If & ITF & $\Delta$ & DTT & qr- \\
\hline 191 & 1.9 & FFI & ґ^ & एq। & id & 19 & tr & $1 \cdot 0$ & $\Delta$ & frv & 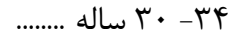 \\
\hline | & VV & $r \cdot r$ & rt & щ. & G & it & 10 & $\wedge \vee$ & f & rAt & qr- هـ ساله ........ \\
\hline$\Delta \Delta$ & GT & IrF & 10 & $r \cdot \Delta$ & TV & $\Lambda$ & 11 & $\Delta T$ & 9 & rG人 & 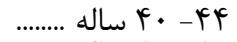 \\
\hline rq & ra & NT & 11 & $I \Delta V$ & 10 & V & $1 \cdot$ & ft & V & K & ........ $F \Delta-f q$ \\
\hline re & c & $4 q$ & 9 & 111 & 1 . & 9 & r & 19 & 1 & १७ & ......... \\
\hline 11 & f & me & $\Delta$ & 90 & 4 & 1 & $\Delta$ & 19 & $\Lambda$ & NT & هو - $\Delta$ ساله ....... \\
\hline$\wedge$ & f & 10 & $\Delta$ & $\Delta \varphi$ & r & 1 & $\cdot$ & $1 \cdot$ & r & 91 & 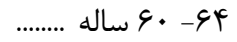 \\
\hline V & $\Delta$ & it & r & $f \Delta$ & 1 & 1 & r & 1 . & r & 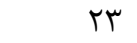 & 9 - 9 هاله........ \\
\hline$\Lambda$ & - & $\Delta$ & r & 11 & 1 & - & 1 & $\Delta$ & • & tr & ساله ......... -VF \\
\hline V & - & $1 \cdot$ & $\cdot$ & YI & $r$ & r & $\cdot$ & r & · & 19 & VD ساله و بيشتر ... \\
\hline fre & $r \cdot 1$ & rese & $r v i$ & 1990 & $|9|$ & 110 & $v \wedge$ & fr. & $F_{1}$ & retr & 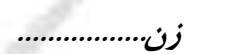 \\
\hline py & Tr & rIf & ir & 190 & 9 & r & 1 & TV & r & rqs & ץ- • ساله .................. \\
\hline$\Delta \cdot$ & ry & rAV & r) & $r \wedge \Delta$ & 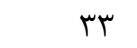 & 10 & 9 & GF & f & FQT & 9-............... \\
\hline r & 19 & THF & 11 & 11. & 11 & Ir & r & ra & $\Delta$ & $r \Delta \Lambda$ & f|- • | ساله ......... \\
\hline FV & 1 . & rAD & $\mid \varphi_{1}$ & $1 \Delta \varphi$ & if & $\Delta$ & $\wedge$ & (i) & $\Delta$ & $r \cdot r$ & 19 - 19 ساله ............. \\
\hline$q V$ & YI & qV9 & $\vee \Delta$ & Trt & 10 & YI & r & $\Delta \Delta$ & r & rVA & 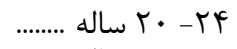 \\
\hline Fq & $\varepsilon V$ & $\Delta T \Delta$ & rV & TF & 19 & 19 & 4 & V. & 1 & Frd & qr-........ . \\
\hline$f \Delta$ & $q f$ & rAT & TG & rrq & tr & سו & If & 99 & f & rV & F . • ساله ......... \\
\hline r山 & ऍی & Ire & 19 & 11 & if & 1. & IV & fT & 4 & $r \cdot r$ & qז- هץ ساله ............ \\
\hline سו & IT & N & iv & T & 4 & V & V & ra & $\Delta$ & 19 & 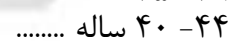 \\
\hline If & 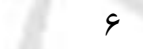 & $\Delta \cdot$ & $\wedge$ & vq & $\wedge$ & f & r & 10 & f & $M$. & ........ \\
\hline 10 & 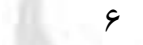 & rᄉ & r & (1) & r & r & r & 11 & 1 & 99 & F.......... \\
\hline c & r & $r \cdot$ & 1 & rq & 1 & r & r & V & • & DI & ه9 - \\
\hline 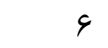 & r & 19 & 1 & r & 1 & . & . & $\varphi$ & - & 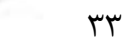 & 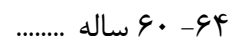 \\
\hline 4 & • & $1 \cdot$ & 1 & 11 & 1 & · & $\cdot$ & $\Delta$ & • & 10 & 9 - 9 9 ساله ........ \\
\hline$\cdot$ & 1 & V & 1 & i & • & $\cdot$ & $\cdot$ & • & - & 10 & 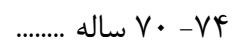 \\
\hline 1 & r & $\wedge$ & r & 1 . & 1 & . & r & 1 & . & If & VD ساله و بيشتر ... \\
\hline
\end{tabular}


• - ا- مهاجران واردشده از خارج كشور طى ه سال تذشته بر حسب جنس، سن واستان محل اقامت فعلى (بر اساس آخرين (نقاط شهرى)

جابجايى انجامشده) (دنباله)

\begin{tabular}{|c|c|c|c|c|c|c|c|c|c|c|}
\hline \multicolumn{10}{|c|}{ محل اقامت فعلى } & \multirow[b]{2}{*}{ جنس و سن } \\
\hline يزد & همدان & هرمزكان & مركزى & مازندران & 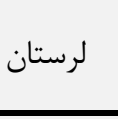 & كيلان & كلستان & كهيَيلويه و & كرمانشاه & \\
\hline 94. & re. & $I V \cdot r$ & $1 \cdot 14$ & sta & 9. & sra & raf & $19 \pi$ & Frt & مرد و زن...... \\
\hline$\Lambda V$ & 11 & ITV & ^. & r & t & rq & rq & IV & ץ & ץ-.................. \\
\hline 111 & IT & IAr & 1.1 & $r \cdot$ & $\wedge$ & $r \Lambda$ & kq & v & Fr & 9 - ه ساله ................. \\
\hline 99 & 19 & 11. & VI & $r$. & v & 19 & r. & $\Delta$ & TF & f|- •| ساله ....... \\
\hline $1 T \Delta$ & IV & IVT & 109 & ry & $\wedge$ & 19 & rl & 11 & 10 & 19 - ها ساله ......... \\
\hline 109 & rV & $r \cdot \Lambda$ & $1 \wedge \Delta$ & $\Delta \varphi$ & r & 4. & $r \Delta$ & Ft & 11 & 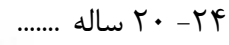 \\
\hline$\pi$. & rq & TAT & IrF & $\Lambda \Lambda$ & ir & $v \Delta$ & is & $r \Delta$ & 4. & q ז- \\
\hline 91 & rq & INT & $1 . r$ & ITr & ir & 1.9 & $\Delta V$ & rA & ve & 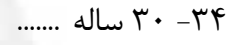 \\
\hline$\Delta \Lambda$ & rq & 1149 & $\Lambda \mathrm{V}$ & ve & $\Lambda$ & 11. & $\Delta \Delta$ & 19 & 91 & qז- טז ساله ....... \\
\hline$i \Delta$ & re & 11 & $\Delta$. & kq & IT & DI & rq & if & (i) & Fl....... \\
\hline 19 & r & $\Delta F$ & re & f. & 9 & r & 19 & f & $r \Lambda$ & q \\
\hline 10 & 4 & ro & $T V$ & r & 1 & r & 9 & r & $\Delta$ & f....... \\
\hline IV & $v$ & rq & 10 & r. & $\Delta$ & rᄉ & $\wedge$ & 1 & f & 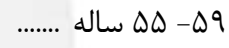 \\
\hline 9 & $\wedge$ & it & If & 11 & r & 19 & $\Delta$ & r & 9 & ץ \\
\hline v & r & ir & v & ir & . & ri & $\Delta$ & r & $r$ & 99- 9D ساله ....... \\
\hline f & r & a & $v$ & 9 & . & $\mathrm{v}$ & r & r & r & ساله ........ V. -VF \\
\hline r & 1 & c & $\Lambda$ & $\Delta$ & - & V & - & - & $r$ & VD ساله و بيشتر .. \\
\hline$\Delta V \Delta$ & 101 & $11 \Delta 9$ & sra & raq & FA & rav & 199 & $|f|$ & $r F$. & 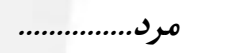 \\
\hline (i) & v & qV & is & 11 & - & ir & r & 11 & $r \cdot$ & ץ- • ساله ................ \\
\hline q & $v$ & $9 q$ & pq & 19 & r & If & $r$. & r & $r \Delta$ & -.............. \\
\hline rv & v & 90 & rq & 10 & f & if & it & r & 19 & ץ|- • •| ساله ....... \\
\hline$\Lambda$. & ir & IKF & 119 & TV & $\Delta$ & ir & 11 & 11 & 1. & 19 - ها ساله ......... \\
\hline $1 \cdot r$ & rt & TTV & אז' & rV & r & $i \wedge$ & 1. & rq & v & 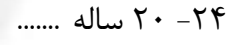 \\
\hline ve & 10 & $I V \Lambda$ & $\Lambda \Delta$ & $\Delta T$ & v & ri & $r$. & 19 & $r$. & q \\
\hline 90 & 11 & ITF & $9 \Delta$ & $\Lambda$ & $\Delta$ & v. & re & 11 & (i) & F \\
\hline ry & v & $1 \cdot \Delta$ & $\Delta \Delta$ & il & r & GT & r & 10 & rq & 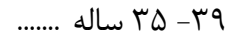 \\
\hline$r \Lambda$ & r & gr & rq & $r \Lambda$ & v & ra & ir & 1. & $r$. & f....... \\
\hline if & Ir & rV & 19 & $r \Delta$ & 9 & $r \wedge$ & 19 & r & iv & q \\
\hline 1. & r & 19 & iv & rT & 1 & 10 & f & f & $r$ & ........ \\
\hline 11 & r & 11 & $\Lambda$ & 1. & r & 11 & $\Delta$ & & $r$ & 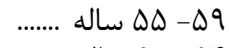 \\
\hline$\Delta$ & $\Delta$ & 11 & $\Delta$ & v & r & $\Lambda$ & f & r & $\Delta$ & 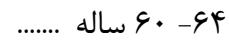 \\
\hline r & r & 1. & r & 1. & . & Ir & $r$ & r & r & 99 - 90 ساله ...... \\
\hline r & 1 & 1 & $\Delta$ & $\Delta$ & - & r & 1 & r & $r$ & ساله ........ V. -Vץ \\
\hline r & . & r & $\Delta$ & r & . & r & . & . & 1 & VD ساله و بيشتر .. \\
\hline r\&a & $1 . r$ & $\Delta F V$ & $r \cdot \Delta$ & req & kr & $r+1$ & 111 & $\Delta r$ & 195 & 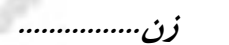 \\
\hline is & r & q. & ry & r & r & If & 19 & 4 & 11 & ץ- • ساله ................ \\
\hline is & $\Delta$ & 19 & $\Delta T$ & le & $\Delta$ & lf & re & $\Delta$ & 11 & - \\
\hline r & ir & $i d$ & rt & 10 & r & $\Delta$ & 11 & $r$ & $\Lambda$ & 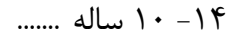 \\
\hline ia & $\Delta$ & is & pr & v & r & v & 1. & $\mathrm{v}$ & $\Delta$ & 19 - ها ساله ........ \\
\hline$\Delta V$ & $\Delta$ & 1) & $\Delta r$ & 19 & 1 & ir & 10 & 9 & 11 & 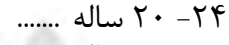 \\
\hline kq & 11 & $\Delta F$ & $4 q$ & re & $\Delta$ & זr & rq & 4 & f. & 9- - \\
\hline rq & 11 & is & rv & rq & v & rq & r & 1. & ro & 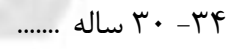 \\
\hline TF & 19 & re & rT & $r \omega$ & 9 & is & rq & r & tr & qז- טז ساله ....... \\
\hline IV & 11 & 19 & rl & rl & $\Delta$ & 19 & IV & r & 11 & 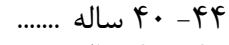 \\
\hline$\Delta$ & 9 & IV & IV & 10 & r & 10 & r & 1 & 11 & q \\
\hline$\Delta$ & r & 9 & 1. & 1. & . & V & $\Delta$ & . & r & ....... \\
\hline 4 & r & $\wedge$ & v & 1. & 1 & 1. & r & 1 & r & 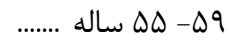 \\
\hline r & r & 1 & 9 & r & 1 & $\wedge$ & 1 & . & r & 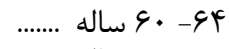 \\
\hline r & . & r & k & r & . & $\hat{\imath}$ & r & . & 1 & 9 9 90 ساله ....... \\
\hline 1 & 1 & r & r & r & . & f & 1 & . & 1 & ساله ....... V• - Vץ \\
\hline r & 1 & . & r & r & . & f & . & . & r & VD ساله و بيشتر .. \\
\hline
\end{tabular}


•ا - ا- مهاجران واردشده از خارج كشور طى ه سال كذشته بر حسب جنس، سن و استان محل اقامت فعلى (بر اساس آخرين (نقاط روستايى) (برس)

جابجاييى انجامشده) (دنباله)

\begin{tabular}{|c|c|c|c|c|c|c|c|c|c|c|c|}
\hline \multicolumn{11}{|c|}{ محل اقامت فعلى } & \multirow[b]{2}{*}{ جنس و سن } \\
\hline خراسان & و جهارمحال & تهران & بوشهر & ايلام & البرز & اصفهان & 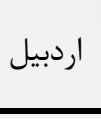 & آذربايجان & شرقايجان & جمع & \\
\hline$r$ & $\mathrm{Fr}$ & $\Delta V \wedge \Delta$ & $11 . r$ & 18 & $1 \ldots 9$ & $11 F$ & re & r & $r q$ & $\mid$ EFIF & مرد و زن....... \\
\hline · & - & $0 \cdot 1$ & rद & - & $\varphi$. & rq & 1 & 4 & 1 & $|\cdot r|$ & f-.................. \\
\hline . & 1 & qif & $f$. & r & $q 4$ & DI & 1 & 19 & 1 & ITVV & 9 ه ساله ................. \\
\hline 1 & 1 & ५११ & rq & 1 & 99 & (f) & . & r & r & qur & f|- · · ساله ......... \\
\hline$\cdot$ & r & VVD & TFE & r & 19r & $14 \Delta$ & 1 & r & f & rTAq & 19 - هاله ساله............ \\
\hline · & r & 1189 & اس וr & · & $r \cdot r$ & $r \cdot q$ & \& & it & 1 & 9 & 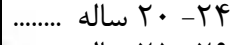 \\
\hline · & r & $\Lambda r$ & 199 & f & Irی & rrv & $\wedge$ & 11 & r & TAYA & qr - \\
\hline . & r & FQS & $9 \Delta$ & r & 94 & 111 & r & 19 & r & $|\Delta \varphi|$ & 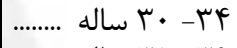 \\
\hline 1 & r & mFA & (F) & 1 & $\Delta \Lambda$ & $9 r$ & r & $\wedge$ & $\Delta$ & 1190 & qז- ט ساله ......... \\
\hline 1 & f & 194 & rG & - & f. & $\Delta T$ & 1 & r & r & GVA & ........ \\
\hline • & $\varepsilon$ & $1 \Delta \varepsilon$ & TI & r & rd & rA & r & $\Delta$ & $\varepsilon$ & $\Delta \cdots$ & q....... . \\
\hline - & 11 & IrA & 19 & - & re & 11 & $\Delta$ & · & 1 & r人⿻ & \\
\hline • & f & $\Delta \Delta$ & V & - & ir & 11 & - & - & · & rIT & \\
\hline$\cdot$ & r & 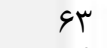 & r & - & ir & V & - & - & r & 191 & |......... . \\
\hline - & r & mp & r & - & $\Delta$ & r & - & 1 & - & 19 & 99- 9 90 ساله ......... \\
\hline • & - & r. & · & - & $\Delta$ & r & · & . & . & $9 V$ & 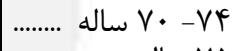 \\
\hline • & 1 & 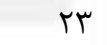 & 1 & - & f & 1 & - & - & . & 99 & VD ساله و بيشتر .... \\
\hline 1 & re & rarf & 919 & $r$ & 999 & $91 F$ & $r \cdot$ & $\mu f$ & $r$. & $1 r \cdot q r$ & 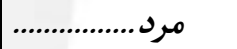 \\
\hline . & - & try & rI & - & rq & 19 & 1 & r & 1 & $\Delta T \Lambda$ & f- • ساله ............... \\
\hline$\cdot$ & 1 & שזr & 19 & r & $\Delta \cdot$ & rᄉ & 1 & $\wedge$ & 1 & VFF & 9 ه هاله ................ \\
\hline • & • & TFA & $r \Delta$ & - & re & rV & · & 1 & r & $\Delta \varphi$. & f|- · · ساله ......... \\
\hline$\cdot$ & 1 & $\Delta V F$ & سזr & - & r & $1 \% 9$ & 1 & 1 & r & lNFG & 19 - 19 ساله .............. \\
\hline - & 1 & vqf & щ. & - & 194 & TRI & i & r & 1 & $r \& \Delta \Delta$ & 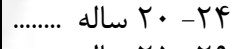 \\
\hline$\cdot$ & r & $\Delta V V$ & $1 \wedge V$ & 1 & 94 & rin & r & r & 1 & 1971 & q \\
\hline • & r & ( & 19 & r & $\vee \wedge$ & 94 & r & v & r & $1 T \Delta$. & 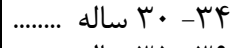 \\
\hline$\cdot$ & r & rof & ґ^ & - & f. & $\wedge \wedge$ & r & $\Delta$ & r & 949 & qז- ט ساله ........ \\
\hline 1 & r & Ir. & rt & - & $r{ }^{2}$ & DI & 1 & r & r & $\Delta \mu F$ & 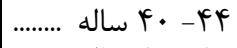 \\
\hline$\cdot$ & 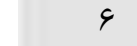 & $1 \cdot 1$ & 11 & $r$ & 11 & rq & & r & r & mVe & \\
\hline$\cdot$ & 11 & $\wedge 1$ & $1 f$ & - & 11 & 19 & 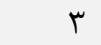 & · & . & trV & \\
\hline . & k & rv & V & - & $\wedge$ & 9 & - & . & . & 191 & \\
\hline - & r & ra & r & - & V & f & - & . & r & $1 \ldots$ & \\
\hline$\cdot$ & r & $r \cdot$ & r & • & r & 1 & - & . & - & GT & 99 -.......... \\
\hline$\cdot$ & · & rI & - & · & r & r & · & - & · & fq & ساله ........ \\
\hline • & 1 & IV & $\cdot$ & • & r & 1 & $\cdot$ & · & • & $\Delta 1$ & VD ساله و بيشتر .... \\
\hline$r$ & $\Delta$ & 1991 & $11 \pi$ & 9 & rוr & 195 & ir & $k q$ & 9 & Frel & 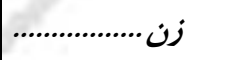 \\
\hline$\cdot$ & • & trd & 10 & - & re & $r \cdot$ & - & r & - & pqr & ץ • • ساله .................. \\
\hline$\cdot$ & • & rq1 & TI & · & fF & 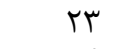 & · & $\wedge$ & • & س ( & 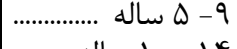 \\
\hline 1 & 1 & $1 \Delta F$ & If & 1 & 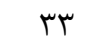 & If & · & r & . & rVt & f|- · · ساله ........ \\
\hline - & 1 & $r \cdot 1$ & r (1) & r & f. & 19 & • & 1 & r & FFT & 19 - 1ه ساله ............ \\
\hline$\cdot$ & 1 & r^d & Y) & · & is & ऍ^ & r & $1 \cdot$ & . & VTF & \\
\hline$\cdot$ & • & $r \Delta F$ & 9 & r & fF & 19 & f & V & 1 & $\Delta \Delta V$ & q \\
\hline$\cdot$ & & ITY & 4 & 1 & 19 & IV & 1 & 9 & · & आו & 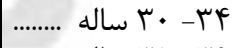 \\
\hline 1 & . & 94 & r & 1 & 11 & f & 1 & r & r & קדe & qr- \\
\hline$\cdot$ & $r$ & q & f & · & Ir & 1 & - & 1 & • & Iff & 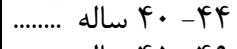 \\
\hline$\cdot$ & - & $\uparrow \wedge$ & 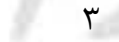 & 1 & V & r & r & r & r & ITF & \\
\hline$\cdot$ & - & FV & r & & $\Lambda$ & r & r & · & 1 & $1 \cdot 9$ & F • • \\
\hline - & - & 11 & - & • & f & r & · & - & - & 01 & \\
\hline$\cdot$ & • & rᄉ & 1 & • & $\Delta$ & r & • & · & - & 41 & \\
\hline$\cdot$ & • & If & • & $\cdot$ & r & 1 & $\cdot$ & 1 & - & TV & 99- 9 ساله .......... \\
\hline · & · & 9 & $\cdot$ & • & r & $\cdot$ & - & · & • & 11 & |....... ساله \\
\hline$\cdot$ & $\cdot$ & 9 & 1 & $\cdot$ & 1 & . & $\cdot$ & . & . & 11 & VD ساله و بيشتر .... \\
\hline
\end{tabular}


•ا - ا- مهاجران واردشده از خارج كشور طى ه سال كذشته بر حسب جنس، سن و استان محل اقامت فعلى (بر اساس آخرين

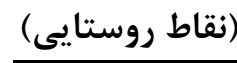

جابجايى انجامشده) (دنباله)

\begin{tabular}{|c|c|c|c|c|c|c|c|c|c|c|c|}
\hline \multicolumn{11}{|c|}{ محل اقامت فعلى } & \multirow[b]{2}{*}{ جنس و سن } \\
\hline كرمان & | كردستان & قم & قزوين & فارس & بلوجستان & سمنان & ز زنجان & خوزستان & خراسان & خراسان & \\
\hline leqr & Fr & Fre & 91 & $1 T \Delta \Delta$ & $r \cdot 1$ & 101 & 118 & raf & 8 & $r r q$ & مرد و زن........ \\
\hline$\Delta F$ & 1 & ia & 9 & $\Lambda \vee$ & ir & $\mathrm{v}$ & . & rq & 1 & r. & ץ- • ساله ................. \\
\hline$\Lambda \Delta$ & 1 & 4) & IT & ITS & r & it & . & me & . & q & |............... \\
\hline 94 & 1 & rV & $\Delta$ & 94 & rI & 9 & . & IV & . & rq & ץ|- •| ساله ........ \\
\hline זוץ & . & $\Delta \Lambda$ & 19 & $|V|$ & rی & 19 & . & $\Delta \varphi$ & . & rq & 19 - 19 ساله.................. \\
\hline ru & $\wedge$ & GT & 11 & $r \Delta \Delta$ & $\Delta \cdot$ & rq & $\Delta$ & $\Delta \Gamma$ & . & ra & ץ........ \\
\hline צ בץr & 1. & $\Delta q$ & IV & IQT & il & $r$. & If & ra & r & זr & q \\
\hline$r \cdot V$ & 11 & $r \Lambda$ & $v$ & 119 & re & זr & 9 & $r \Delta$ & 1 & tr & 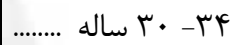 \\
\hline 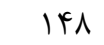 & r & $r \cdot$ & $\Delta$ & qV & r & 14 & 19 & 14 & . & זr & qז- هץ ساله ........ \\
\hline 91 & $r$ & IV & r & $\Delta T$ & 11 & r & ו & 9 & r & 10 & 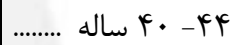 \\
\hline kr & 1 & 10 & 1 & rی & 1. & $\mathrm{v}$ & ra & 9 & . & IV & q \\
\hline rq & 1 & 1. & r & rF & $v$ & r & $\wedge$ & $\Delta$ & . & ir & ......... \\
\hline 11 & 1 & $\wedge$ & . & r) & 4 & r & r & 1 & . & f & 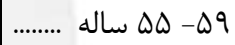 \\
\hline 1. & . & $\mathrm{v}$ & . & Ir & r & 1 & 1 & r & . & r & 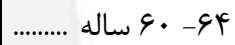 \\
\hline ir & . & $r$ & . & 11 & r & . & . & 1 & . & . & 9 90 ساله ......... \\
\hline$\Delta$ & . & r & 1 & $\Lambda$ & . & . & . & . & . & . & ......... ساله \\
\hline$\Lambda$ & - & r & . & v & r & · & · & 1 & • & f & ساله و بيشتر .... \\
\hline 1195 & $r r$ & rqg & $v_{1}$ & $9 \pi r$ & rer & 149 & 11. & $r .$. & $r$ & 109 & 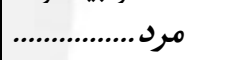 \\
\hline זr & . & rq & f & kF & 9 & r & . & 14 & . & ir & ץ- · ساله .................. \\
\hline$\Delta T$ & 1 & r. & $\Delta$ & 99 & $r$. & 4 & . & rl & . & ra & 9 ه ساله .............. \\
\hline$q 4$ & . & r & r & ra & س & 4 & . & 14 & . & 11 & ץ|- •|| ساله ........ \\
\hline 111 & . & rV & IV & 148 & ru & 19 & . & pq & . & 11 & 19 - 19 ساله................... \\
\hline$r \cdot r$ & 9 & rV & ir & rIf & Fy & rA & r & rV & . & $1 \pi$ & F........ \\
\hline$r \cdot 9$ & $\Delta$ & rq & 19 & 119 & זr & Ty & r & r & 1 & r & q \\
\hline 189 & $\mathrm{r}$ & rl & i & $\Lambda r$ & זr & 19 & $\Lambda$ & r. & . & 19 & 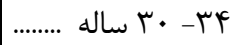 \\
\hline$I T V$ & $r$ & 11 & $r$ & $9 \Lambda$ & $r \Delta$ & ir & 19 & ir & . & r & qr- هץ ساله ........ \\
\hline$\Delta \Lambda$ & r & $1 f^{\mathrm{F}}$ & f & FT & lf & r & ז & 4 & r & r & F........ \\
\hline זץ & 1 & $\wedge$ & 1 & rA & $\wedge$ & 9 & ro & $\Delta$ & 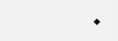 & $1 \cdot$ & q \\
\hline 11 & 1 & 9 & $r$ & rq & 4 & r & $v$ & r & . & $\Lambda$ & \\
\hline r & 1 & $\Delta$ & - & 11 & r & r & r & 1 & . & $r$ & ......... \\
\hline$\Lambda$ & . & f & . & $v$ & 1 & . & 1 & 1 & . & r & 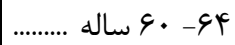 \\
\hline 11 & - & r & - & 1. & r & . & . & 1 & . & . & 99- 90 ساله ........ \\
\hline r & - & r & 1 & $\Delta$ & . & . & . & . & . & . & ......... ساله \\
\hline v & 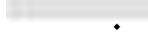 & f & 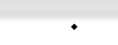 & 9 & r & . & . & . & . & 1 & VD ساله و بيشتر .... \\
\hline$r r_{1}$ & 10 & IVr & $r r$ & rer & 89 & rq & f & Af & $r$ & IV. & 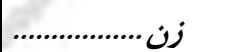 \\
\hline r & 1 & 19 & r & r & r & r & . & it & 1 & 11 & ץ- • ساله .............. \\
\hline זr & . & ऍ & $\mathrm{v}$ & $\Delta V$ & ir & 4 & . & 14 & . & rג & 9 ه ساله .............. \\
\hline rA & 1 & 10 & $r$ & ו & $\wedge$ & r & . & f & . & 11 & ץ|- •| ساله ........ \\
\hline TQ & - & rl & r & ra & 1. & r & . & ir & . & rI & 19- ها ساله .......... \\
\hline re & r & $r \Delta$ & 4 & i) & 4 & 1 & 1 & 19 & . & rT & ץ......... \\
\hline$r$. & $\Delta$ & r & 1 & rF & $\Lambda$ & 4 & 1 & IT & 1 & $r \cdot$ & qr- \\
\hline ru & f & v & r & זr & r & r & 1 & $\Delta$ & 1 & 9 & 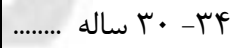 \\
\hline rI & 1 & 9 & r & rq & v & 1 & . & 1 & & 1. & qr- טr ساله ......... \\
\hline 1. & 1 & $r$ & . & 1. & r & . & . & $r$ & & & ........ \\
\hline 1. & - & v & & 1 . & r & 1 & . & & & $\mathrm{v}$ & q \\
\hline$\Lambda$ & & r & 1 & $a$ & 1 & - & 1 & r & & f & ........ \\
\hline$\Delta$ & 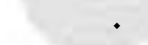 & $r$ & . & r & $r$ & . & . & & . & 1 & \\
\hline r & - & r & - & 9 & r & 1 & - & 1 & . & 1 & 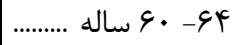 \\
\hline 1 & - & 1 & - & 1 & - & - & - & · & . & - & 9- ه هاله ........ \\
\hline r & - & 1 & - & r & - & - & - & . & . & - & 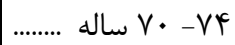 \\
\hline 1 & . & . & . & 1 & . & . & . & 1 & . & r & VD ساله و بيشتر .... \\
\hline
\end{tabular}


•ا - ا- مهاجران واردشده از خارج كشور طى ه سال كذشته بر حسب جنس، سن و استان محل اقامت فعلى (بر اساس آخرين (نقاط روستايى)

جابجايى انجامشده) (دنباله)

\begin{tabular}{|c|c|c|c|c|c|c|c|c|c|c|}
\hline \multicolumn{10}{|c|}{ محل اقامت فعلى } & \multirow[b]{2}{*}{ جنس و سن } \\
\hline يزد & همدان & هرمزكان & مركزى & مازندران & 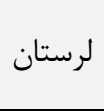 & ك تيلان & كلستان & كهيَيلويه و & كرمانشاه & \\
\hline $19 \pi$ & $\Delta$ & 1194 & rA1 & IfG & 1 & a. & $r$. & 19 & rq & مرد و زن......... \\
\hline IV & $\cdot$ & QI & rI & v & . & f & r & $r$ & $r$ & ץ- • • ساله ............... \\
\hline 11 & - & 99 & rI & r & 1 & r & 1 & . & $\Delta$ & |.................. \\
\hline 10 & - & 9. & if & 4 & . & 1 & $r$ & . & 1 & | أ- •| ساله .......... \\
\hline 119 & 1 & $1 \Delta V$ & r & ir & r & . & . & r & r & 9 1 19 ساله ............ \\
\hline TTE & 1 & rrq & 4 . & זr & . & $\wedge$ & $\Delta$ & If & 9 & 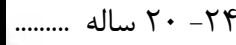 \\
\hline lN & 1 & $I V A$ & $\Delta T$ & tr & $r$ & v & $\Delta$ & 11 & $\wedge$ & 9 \\
\hline ITF & . & $1 \cdot 0$ & $r \Delta$ & זr & . & 4 & 9 & 11 & r & 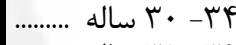 \\
\hline 9. & 1 & q. & IV & $1 \pi$ & . & $\Delta$ & r & 9 & r & q ץ- هـ ساله ........... \\
\hline r. & - & $\Delta F$ & 9 & 1r & r & r & 1 & 1. & r & |......... \\
\hline 10 & . & pi & 9 & r & 1 & r & 1 & 9 & f & q.......... \\
\hline 1. & - & ra & $\wedge$ & 4 & · & r & 1 & $\mathrm{v}$ & r & |........... \\
\hline$\Delta$ & 1 & re & $\Delta$ & $\Delta$ & . & f & . & r & . & |......... \\
\hline r & - & r. & r & r & · & 1 & 1 & . & . & 4 \\
\hline . & . & 9 & . & r & . & . & . & . & . & 99- 90 ساله .......... \\
\hline r & . & $\Delta$ & 1 & r & . & t & . & . & . & 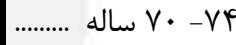 \\
\hline . & & 11 & . & r & . & . & . & . & . & VD Vاله و بيشتر ..... | \\
\hline 111 & r & 195 & r.. & $1 . r$ & $\Delta$ & r & IV & 1. & $r$. & مرد........................ \\
\hline v & - & r & 1. & r & . & r & r & 1 & . & ץ- • • ساله ................. \\
\hline ז & - & rı & IV & 1 & · & 1 & . & . & r & |.................. \\
\hline ir & . & r & 9 & r & . & 1 & 1 & . & . & 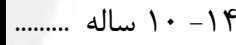 \\
\hline 11. & - & $M \Lambda$ & rq & 1. & 1 & . & . & ir & 1 & 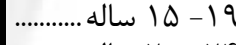 \\
\hline 519 & 1 & $r \cdot V$ & Fr & r. & . & r & r & ז & r & 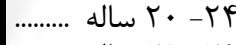 \\
\hline IVE & 1 & 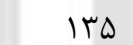 & $q_{1}$ & 11 & r & f & $r$ & 1 . & $\Delta$ & 9 \\
\hline ITr & - & 19 & 10 & it & - & r & 9 & 11 & r & 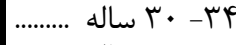 \\
\hline 19 & 1 & ve & if & $\Lambda$ & . & r & 1 & 9 & r & 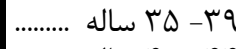 \\
\hline rq & . & id & v & 11 & 1 & 1 & 1 & 1 . & 1 & 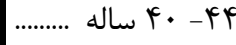 \\
\hline lif & . & r & $\Lambda$ & r & 1 & r & 1 & $\Delta$ & r & q q - \\
\hline$\Lambda$ & - & rq & q & r & · & r & . & 4 & 1 & |........... \\
\hline$\Delta$ & . & rq & f & 1 & . & f & . & r & . & 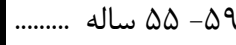 \\
\hline r & . & IV & . & r & . & 1 & 1 & . & . & 4 \\
\hline . & - & 9 & - & r & . & . & . & . & . & 99- 9 90 ساله ......... \\
\hline r & . & $\Delta$ & . & $r$ & . & r & . & . & . & 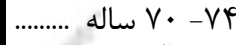 \\
\hline . & . & $\mathrm{v}$ & . & r & . & . & . & . & . & VD ساله و بيشتر ... \\
\hline$F \Delta$ & $r$ & $r v i$ & 11 & FF & $r$ & 19 & 14 & $q$ & 19 & 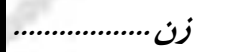 \\
\hline 1. & . & rq & 11 & r & . & r & $r$ & 1 & r & ץ- • ساله ............... \\
\hline$\Delta$ & . & r & if & r & 1 & 1 & 1 & . & r & |.................. \\
\hline r & - & rq & $\Delta$ & r & . & . & 1 & . & 1 & 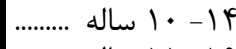 \\
\hline 9 & 1 & rq & 9 & r & 1 & . & . & 1 & r & 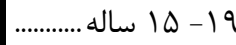 \\
\hline v & . & Tr & IV & r & . & r & r & 1 & r & 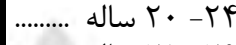 \\
\hline v & & r & 11 & c & - & $r$ & r & 1 & r & q........... \\
\hline r & - & 19 & 1. & 11 & . & r & . & & 1 & ץ \\
\hline 1 & - & if & r & $\Delta$ & . & 1 & r & & 1 & 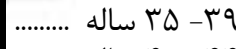 \\
\hline 1 & . & 9 & r & r & 1 & $r$ & . & & & |.......... \\
\hline 1 & & 1r & 1 & . & . & . & - & & 1 & q \\
\hline r & & 9 & $r$ & r & . & $r$ & 1 & 1 & 1 & |........... \\
\hline . & 1 & v & 1 & r & . & . & . & . & . & |........ . \\
\hline . & . & r & f & . & . & . & . & . & . & 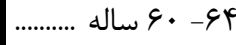 \\
\hline - & - & r & . & r & • & . & . & . & . & |............ \\
\hline$\cdot$ & - & $r$ & 1 & · & · & · & . & · & & |........ . \\
\hline . & & f & - & . & . & - & & - & & VD VDاله و بيشتر ..... \\
\hline
\end{tabular}


| نتايج تفصيلى سرشمارى عمومى نفوس و مسكن _MD

11 - ا- مهاجران وارد شده از خارج كشور طى ه سال كذشته بر حسب جنس، كشور محل اقامت قبلى و استان محل اقامت (كل) فعلى

\begin{tabular}{|c|c|c|c|c|c|c|c|c|c|c|c|}
\hline \multicolumn{11}{|c|}{ استان محل اقامت فعلى } & \multirow{2}{*}{ جنس و كشور محل } \\
\hline خراسان & و קهتهارمحال & ت تهران & بوشهر & ايلام & البرز & اصفهان & اردبيل & غآذربايجان & شرقيايجان & جمع & \\
\hline$r A$ & ris & D119. & $F \varepsilon \cdot \omega$ & $9 \pi$ & 8119 & Arre & $1 A V$ & Ar. & 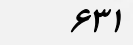 & $11 \cdot 1 r 9$ & مرد و زن............. \\
\hline rI & 11 & $r \Delta \wedge 99$ & Frea & . & FArs & $9.1 \mathrm{~V}$ & . & $\Delta$ & r & $V \cdot r \mid r$ & افغانستان ............................ \\
\hline r & . & 911 & 44 & . & ऍ & IV9 & . & r & . & TAFT & ياكستان ............................... \\
\hline f & rT & 1.90 & rv & $\Lambda$ & ז & 11. & f & $r$ & 11 & TQII & امارات متحده عربى ..... \\
\hline - & rl & १९. & r & is & $V r$ & r/9 & ra & ria & $\mu r$ & 9190 & عراق ........................... \\
\hline . & 11 & ra & r & r & Fe & 19. & r & v & 4 & 1999 & هند .............................. \\
\hline TY & r & $1 T \Delta V$ & $r \Delta$ & r & 19 & ו & $\wedge$ & 19 & r & שrV & 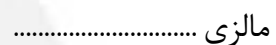 \\
\hline f & r & 1010 & 1 & 1 & ITT & IV. & $\wedge$ & TF & ו & TFYq & ايالات متحده آمر يكا.... \\
\hline 1 & $\wedge$ & $V \cdot r$ & 4 & r & 11 & 1.9 & 11 & TF & ra & $\mid f \cdot F$ & آلمان.......... \\
\hline rI & 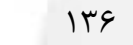 & $\Lambda \Delta \vee \Lambda$ & $\wedge$. & rq & VAT & $119 \mathrm{~V}$ & $1 \% 4$ & rq & $r \in V$ & IqVEV & 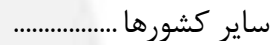 \\
\hline . & 1 & IVV & 11 & $r$ & 1 . & (i) & r & $v$ & f & rFv & اظهار نشده ............................... \\
\hline
\end{tabular}

\begin{tabular}{|c|c|c|c|c|c|c|c|c|c|c|c|}
\hline \multicolumn{11}{|c|}{ استان محل اقامت فعلى } & \multirow[b]{2}{*}{ جنس و كشور محل } \\
\hline كرمان & كردستان & قم & قزوين & 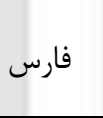 & سلوجستان و & سمنان & زنجان & خوزستان & خراسان & خراسان & \\
\hline$r .91$ & 191 & srva & 9ri & $r \| r$ & $1 \Delta r$ & rqq & rav & Iqre & 1.1 & VVq. & 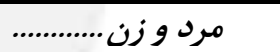 \\
\hline rQVG & . & INTS & TTV & $k F \cdot q$ & Far & rVA & 1 & VAT & r & rDSA & افغانستان ............................ \\
\hline rA & i & $11 M F$ & ז & iq & TVE & 9 & . & 19 & r & r & ياكستان .......................... \\
\hline 19 & r & $r \cdot r$ & $\wedge$ & $1.1 \mathrm{~V}$ & rV & r & 1 & Vr & r & IrF & أمارات متحده عربى...... \\
\hline 11 & $9 \Delta V$ & $99 \mathrm{~V}$ & rq & $\Delta \Delta$ & r & $\wedge$ & 9 & rq. & 9 & TIMS & عراق ............................. \\
\hline IV & $\Delta$ & FAT & द & $9 \pi$ & $\Delta$ & $\Delta$ & v & זr & . & ITA & هند ............................. \\
\hline$\Delta T$ & r & rq & if & 101 & r & 11 & IV & r. & $\Delta$ & $I Q V$ & 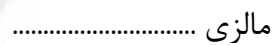 \\
\hline rq & 1 & $4 q$ & $\wedge$ & $1 \wedge \Delta$ & 1 & $\wedge$ & $\Delta$ & i) & r & $\wedge$. & ايالات متحده آمر يكا.... \\
\hline 9 & 19 & $\Delta V$ & 1. & $\Delta T$ & - & 1 & IT & $r$. & r & vq & 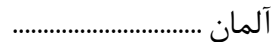 \\
\hline HYA & 199 & $r \mu \Delta q$ & r. 9 & $11 T \Delta$ & $4 \Lambda$ & 91 & TFD & raT & 90 & 111. & ساير كشورها ............... \\
\hline$q$ & 1 & 1. & . & 4 & $\wedge$ & $\cdot$ & . & 19 & 1 & 9 & الظهار نشده.................... \\
\hline
\end{tabular}

\begin{tabular}{|c|c|c|c|c|c|c|c|c|c|c|}
\hline \multicolumn{10}{|c|}{ استان محل اقامت فعلى } & \multirow{2}{*}{ جنس و كشور محل } \\
\hline يزد & همدان & هرمزَان & 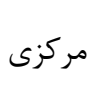 & مازندران & ل ل لرستان & ك ت كيلان & كلستان & كويراحمديه و & كرمانشاه & \\
\hline $11 \cdot r$ & $r \& \Delta$ & rA\&9 & $|r v|$ & V91 & 91 & 911 & fir & rrq & $F V_{1}$ & مرد وزن. \\
\hline IFVD & 1 & IVQ. & $1 \cdot \lambda r$ & 194 & 1 & rq & 119 & 119 & r & افغانستان ....................... \\
\hline 91 & $r$ & IQT & 11 & $\wedge$ & 1 . & $r$ & r & . & . & باكتان ................................. \\
\hline v & . & FAs & \& & fy & r & ry & IV & • & 19 & أمارات متحده عربى ...... \\
\hline TY & 4. & 4 & ו & re & 9 & 10 & r & 1 & rیS & عراق ............................ \\
\hline$\Delta F$ & r & וा & rT & rV & $\mathrm{v}$ & 11 & r & r & ir & هند ..................................... \\
\hline 19 & rI & r & IV & Vr & 1 & זי & $r \omega$ & if & re & 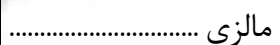 \\
\hline 1. & 9 & r & r & a. & r & i) & I & & 9 & ايالات متحده آمر يكا..... \\
\hline 1 & 19 & $\Delta$ & 11 & $\Delta T$ & 11 & Q) & 1 . & r & $q$ & 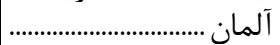 \\
\hline $1 \cdot 4$ & IFT & TAD & IVT & आl & $\Delta \varphi$ & Fat & $r \cdot 9$ & GY & 1.9 & ساير كشورها................. \\
\hline 11 & 1 & 1. & 1 & 4 & . & 1 & . & 1 & . & 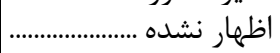 \\
\hline
\end{tabular}


11 - ا- مهاجران وارد شده از خارج كشور طى ه سال كذشته بر حسب جنس، كشور محل اقامت قبلى و استان محل اقامت (كل)

فعلى (دنباله)

\begin{tabular}{|c|c|c|c|c|c|c|c|c|c|c|c|}
\hline \multicolumn{11}{|c|}{ استان محل اقامت فعلى } & \multirow{2}{*}{ جنس و كشور محل } \\
\hline جراسان & و بخهتيارى & ت تهران & بوشهر & ايلام & البرز البر & اصفهان & اردبيل & غربى آذربايجان & $\begin{array}{l}\text { آذربايجان } \\
\text { شرقى } \\
\end{array}$ & جمع ( جم & \\
\hline $\mathrm{Fr}$ & 101 & $r r v i r$ & ra19 & Fq & raAr & $\Delta r \cdot q$ & ir. & fvr & $r v r$ & vrrug & 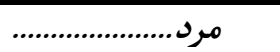 \\
\hline If & 1. & TQT. 9 & rVt. & . & MISF & ५ १८ & . & $r$ & 1 & $p q . r q$ & افغانستان ............................. \\
\hline 1 & . & rᄉl & $\Delta \Delta$ & . & ro & $1 \cdot r$ & . & 1 & . & $I \Lambda T \Lambda$ & 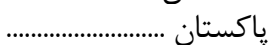 \\
\hline$r$ & r & $\Delta \Delta r$ & r & c & i) & $\Delta \varphi$ & r & r & $\mathrm{v}$ & $19 V \%$ & أمارات متحده عر \\
\hline - & $r \cdot$ & $\Delta \varphi$. & r & 19 & id & 110 & 19 & TFT & r & rety & عراق .......................... \\
\hline . & 4 & $r \cdot r$ & ir & r & rT & vi & r & $r$ & r & १४१ & هند ............. \\
\hline 1 . & r & GTa & 11 & 1 & f. & V V & 4 & If & TF & ITQF & مالزى ........ \\
\hline r & r & ২৭१ & 1 & . & $9 \Delta$ & $1 \cdot 0$ & r & If & 19 & אזrו & ايالات متحده آمر يكا..... \\
\hline . & $\Delta$ & r r & $\Delta$ & $r$ & r & $\Delta V$ & $\mathrm{v}$ & 19 & 19 & vav & آلمان.............................. \\
\hline ri & $1 \ldots$ & FAVE & is & 19 & frut & $v \cdot \wedge$ & VV & 199 & rVA & llFAs & 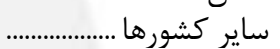 \\
\hline . & . & 110 & 9 & 1 & f & ו & $r$ & f & r & rII & اظهار نشده ........................................... \\
\hline
\end{tabular}

\begin{tabular}{|c|c|c|c|c|c|c|c|c|c|c|c|}
\hline \multicolumn{11}{|c|}{ استان محل اقامت فعلى } & \multirow{2}{*}{ جنس و كشور محل } \\
\hline كرمان & كردستان & قم & قزوين & فارس & سلوجستان و & سمنان & ز زنجان & خوزستان & خراسان & خراسان & \\
\hline rrql & $\Delta r \Lambda$ & rrrs & $\overline{r r r}$ & FVAq & str & $r \Delta$. & $r / a$ & $1 \cdot 1$. & $\Delta r$ & Fist & 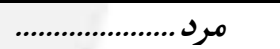 \\
\hline 1948 & . & $1.1 \mathrm{~V}$ & 191 & rIAr & TrG & 19. & . & $9 \cdot 1$ & 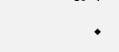 & $|11|$ & 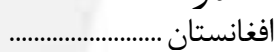 \\
\hline TF & r & 4.9 & 9 & r & r/9 & 4 & . & 11 & 4 & $1 T \Delta$ & 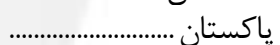 \\
\hline ir & r & INT & $r$ & $G \cdot V$ & rF & 9 & 1 & بq & 1 & $9 V$ & أمارات متحده عربى....... \\
\hline$\Lambda$ & 411 & TIT & IV & fF & r & r & 9 & | & r & 1198 & عراق ..................................... \\
\hline 9 & r & TYI & f & rv & f & 1 & $\Delta$ & $r$. & . & 91 & 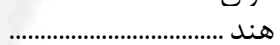 \\
\hline r & 1 & 11 & 9 & 95 & r & 4 & 1. & TV & r & V^ & 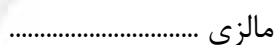 \\
\hline 10 & 1 & ra & v & 111 & 1 & f & r & rI & $r$ & (i) & ايالات متحده آمريكا..... \\
\hline$\Delta$ & if & ו & f & זr & . & 1 & 9 & 1. & r & kq & آلمان ......................................... \\
\hline r & $1 \cdot r$ & $1 \pi \cdot 1$ & $V \Delta$ & sts & rq & سץ & INT & rII & rv & 994 & ساير كشورها ................. \\
\hline v & . & $r$ & . & r & $\Delta$ & · & . & $\Delta$ & 1 & $\Delta$ & اظهار نشده................... \\
\hline
\end{tabular}

\begin{tabular}{|c|c|c|c|c|c|c|c|c|c|c|}
\hline \multicolumn{10}{|c|}{ استان محل اقامت فعلى } & \multirow{2}{*}{ جنس و كشور محل } \\
\hline يزد & همدان & هرمزكان & مركزى & مازندران & 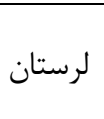 & كيلان & كلستان & كويريلويه و & كرمانشاه & \\
\hline 1rar & $|9|$ & $r \cdot r_{1}$ & AVA & $a \cdot 1$ & $\Delta r$ & FrA & ris & rri & $r \varepsilon$. & 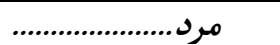 \\
\hline $119 \mathrm{~V}$ & 1 & $1 \mu \cdot \Delta$ & $9 \vee 9$ & $I Q V$ & 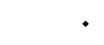 & 19 & a. & $1 \Delta \Delta$ & 1 & افغانستان ............................. \\
\hline$\Delta T$ & $r$ & q & 19 & 4 & \& & r & 1 & . & . & 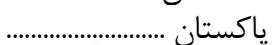 \\
\hline$\Delta$ & . & TDF & r & tr & r & r. & $\checkmark$ & · & ir & أمارات متحده عربى ...... \\
\hline IT & $r q$ & f & 19 & 19 & r & 14 & r & 1 & lev & عاق .................................... \\
\hline vr & f & Ird & iv & 10 & r & $\wedge$ & 11 & $\Lambda$ & v & هند ................................ \\
\hline IT & 1 . & rt & 1. & Fr & 1 & rV & Ir & 9 & 10 & 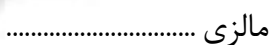 \\
\hline v & $\mathrm{v}$ & r & 1 & r & r & r & 11 & & k & ايالات متحده آمر يكا..... \\
\hline 1 & $\wedge$ & f & ir & rV & q & re & c & r & \& & آلمان.................................. \\
\hline$\Delta \Delta$ & q. & 111 & ITF & INT & rq & TA & $11 \%$ & pq & $9 \wedge$ & ساير كشورها ................. \\
\hline 9 & . & f & . & r & . & 1 & . & . & . & اظهار نشده .................... \\
\hline
\end{tabular}


| نتايج تفصيلى سرشمارى عمومى نفوس و مسكن _MD

11 - ا- مهاجران وارد شده از خارج كشور طى ه سال كذشته بر حسب جنس، كشور محل اقامت قبلى و استان محل اقامت (ك) فعلى (دنباله)

\begin{tabular}{|c|c|c|c|c|c|c|c|c|c|c|c|}
\hline \multicolumn{11}{|c|}{ استان محل اقامت فعلى } & \multirow[b]{2}{*}{ جنس و كشور محل } \\
\hline جراسان & و بختيارى & ت ت تهران & بوشهر & ايلام & البرز & اصفهان & اردبيل & غربى آذربايجان & شرقى & جمع ( جم & \\
\hline ra & $\Delta \Lambda$ & IVFVV & $V 19$ & FF & pres & $r \cdot r \Delta$ & sv & rev & raq & $r \Lambda \Delta \cdot r$ & 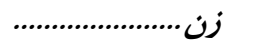 \\
\hline v & 1 & $1.9 \wedge \mathrm{V}$ & SYQ & $\cdot$ & ISVT & $r \cdot r \cdot$ & $\cdot$ & r & r & TINK & افغانستان ......................... \\
\hline$r$ & . & rTV & 9 & . & ז & $v^{k}$ & . & r & . & 1114 & ياكستان ............................... \\
\hline r & 9 & DFT & if & r & Ft & $\Delta F$ & 1 & - & 11 & lork & امارات متحده عربى ...... \\
\hline . & 1 & k.. & 1 & TV & rA & $1 \cdot 4$ & 9 & 195 & 11 & TVYA & عراق ............................ \\
\hline - & $\Delta$ & 19. & 1 & - & tr & 19 & - & r & f & VT. & هند ................................ \\
\hline If & r & GTT & 14 & 1 & $4 q$ & 91 & r & $\Delta$ & 19 & 1119 & مالزى ............................... \\
\hline 1 & - & VIS & - & 1 & $\Delta V$ & 90 & f & 1. & ir & $1.9 V$ & ايالات متحده آمر يكا..... \\
\hline 1 & r & 119 & 1 & - & rı & 49 & i & $\Delta$ & 9 & $4 \cdot V$ & آلمان ................................. \\
\hline$\wedge$ & re & $r V \cdot r$ & rt & $1 \cdot$ & $r \cdot q$ & ४^q & pq & 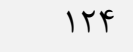 & 119 & ArEl & 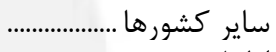 \\
\hline - & 1 & at & r & 1 & 4 & 1. & 1 & r & r & (re & 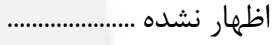 \\
\hline
\end{tabular}

\begin{tabular}{|c|c|c|c|c|c|c|c|c|c|c|c|}
\hline \multicolumn{11}{|c|}{ استان محل اقامت فعلى } & \multirow[b]{2}{*}{ جنس و كشور محل } \\
\hline كرمان & كردستان & قم & قزوين & فارس & بلوجستان & سمنان & زنجان & خ خوزستان & خراسان & خراسان & \\
\hline$v \cdot v$ & rer & $r \cdot r$. & ras & rrer & $r \mu$. & IfF & 15 & $\Delta \Delta F$ & Ff & raqr & زن....................................... \\
\hline$\Delta \wedge 9$ & . & 1.9 & $1 r q$ & IFTK & ITV & $\Lambda \Lambda$ & 1 & IVF & r & $19 \wedge \mathrm{V}$ & |فغانستان .................................... \\
\hline r & r & $\Delta T \Delta$ & $\mathrm{v}$ & 10 & $\Delta V$ & r & . & $\Delta$ & $\mathrm{v}$ & 114 & پِاكستان ................................ \\
\hline$v$ & . & rT & $\Delta$ & fl. & r & v & . & $r v$ & 1 & SV & امارات متح \\
\hline r & THE & $r \Delta \omega$ & ir & 11 & . & $\Delta$ & r & $1 \% 9$ & r & $9 \wedge 9$ & عراق ............................ \\
\hline$\wedge$ & r & T. & r & rq & 1 & r & $r$ & ז & - & QV & هند ................................. \\
\hline rI & 1 & 11 & $\Delta$ & 49 & . & $\Delta$ & $\mathrm{v}$ & r & r & vq & 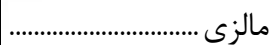 \\
\hline if & . & TF & 1 & $v^{k}$ & . & r & r & $r$. & 1 & rq & ايالات متحده آمريكا .... \\
\hline f & $\Delta$ & rq & 9 & 19 & . & . & r & 1. & 1 & $r \Delta$ & 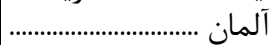 \\
\hline$\Delta \Delta$ & 99 & $1 \cdot \Delta \Lambda$ & |r| - & evq & rq & $r \Lambda$ & ז & IFT & $r \Lambda$ & 019 & 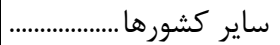 \\
\hline r & 1 & $\Lambda$ & . & f & r & ${ }^{\circ}$ & 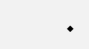 & 11 & $\cdot$ & r & 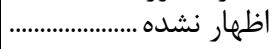 \\
\hline
\end{tabular}

\begin{tabular}{|c|c|c|c|c|c|c|c|c|c|c|}
\hline \multicolumn{10}{|c|}{ استان محل اقامت فعلى } & \multirow{2}{*}{ جنس و كشور محل } \\
\hline يزد & همدان & هرمزكان & مركزى & مازندران & ل ل لرستان & كيلان & كلستان & كهيكيلويه و & كرمانشا & \\
\hline (i). & $1 \cdot 4$ & 111 & kqu & rq. & $i \Delta$ & rq. & $r \cdot 1$ & $\Delta \Lambda$ & rII & 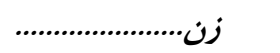 \\
\hline$r \cdot \Lambda$ & . & ifa & $f \cdot r$ & rv & 1 & ri & 49 & ו & r & |فغانستان ................................... \\
\hline 19 & . & r & r & r & f & . & 1 & 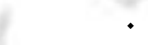 & 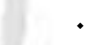 & باكستان .......................... \\
\hline r & & Tr & r & rT & - & If & 1 . & - & $\mathrm{v}$ & أمارات متحد \\
\hline ir & rI & r & 10 & 1. & r & 1 & - & - & 149 & عراق............................. \\
\hline 11 & 9 & 4 & $\Delta$ & ir & r & 1 . & 11 & $\Delta$ & $\Delta$ & هند ................................... \\
\hline v & 11 & 19 & $v$ & ו & . & 19 & r & $\wedge$ & 11 & مالزى .............................. \\
\hline r & r & - & r & 11 & 1 & 11 & r & - & $\Delta$ & ايالات متحده آمريكا ... \\
\hline . & $\Lambda$ & 1 & 4 & TQ & $\Delta$ & IV & r & . & r & 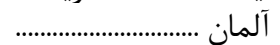 \\
\hline $\mathrm{kq}$ & $\Delta T$ & १४ & is & $1 \pi 9$ & TV & $|V|$ & 94 & r & r & 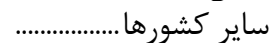 \\
\hline$r$ & 1 & 4 & 1 & r & . & • & . & 1 & & اظههار نشده ................... \\
\hline
\end{tabular}


II - ا- مهاجران وارد شده از خارج كشور طى ه سال كذشته بر حسب جنس، كشور محل اقامت قبلى و استان محل اقامت (نقاط شهرى)

فعلى (دنباله)

\begin{tabular}{|c|c|c|c|c|c|c|c|c|c|c|c|}
\hline \multicolumn{11}{|c|}{ استان محل اقامت فعلى } & \multirow{2}{*}{ جنس و كشور محل } \\
\hline خراسان & و جهتارمحال & تمهران & بوشهر & ايلام & البرز & اصفهان & اردبيل & غربـى آذبايجان & شرقى & جمع ( جم & \\
\hline$r \Delta$ & ivr & $F \Delta F \cdot \Delta$ & $r \Delta \cdot r$ & $r v$ & all. & VIA1 & $1 \Delta \Delta$ & vrr & q.r & qFela & 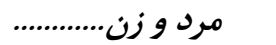 \\
\hline rI & v & $r \cdot r 99$ & 1ו גוזי & . & rql. & 99.1 & $\cdot$ & . & r & $\Delta 9191$ & افغانستان ..... \\
\hline r & - & FYA & Fr & - & r & IVD & . & r & . & TEFT & پاكستان ........................ \\
\hline k & rT & 1.94 & rI & $\wedge$ & 11 & 1.9 & . & r & 11 & ५৭१V & امارات متحده عربى ...... \\
\hline . & r. & $9 \Delta \Delta$ & r & 廿4 & 90 & ris & 10 & rV. & $r$. & 09.9 & عراق ............................... \\
\hline - & v & rAV & $\pi$ & r & س4 & 109 & r & $\mathrm{v}$ & 4 & IDSV & 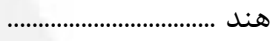 \\
\hline r) & r & $|r \Delta|$ & Ta & r & $\Lambda \Delta$ & Ire & $\mathrm{v}$ & 19 & r & & 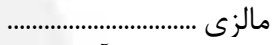 \\
\hline q & r & $101 \%$ & 1 & 1 & 119 & IV. & $\mathrm{v}$ & rF & $r_{\Delta}$ & KF. & ايالات متحده آمر يكا..... \\
\hline 1 & $\wedge$ & $\vee \cdot$. & 9 & 1 & $v^{r}$ & $1 \cdot 0$ & 1. & r & $r \Delta$ & ITV & آلمان ......... \\
\hline r) & $1 \cdot r$ & 1011 & $q f$ & TV & $V \cdot r$ & 1111 & 114 & 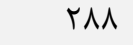 & $F \Delta$. & INQTF & 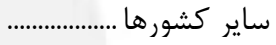 \\
\hline . & 1 & $14 \hat{A}$ & 1. & - & $\wedge$ & rA & - & f & r & r94 & اظهار نشده ...... \\
\hline
\end{tabular}

\begin{tabular}{|c|c|c|c|c|c|c|c|c|c|c|c|}
\hline \multicolumn{11}{|c|}{ استان محل اقامت فعلى } & \multirow{2}{*}{ جنس و كشور محل } \\
\hline كرمان & كردستان & قم & 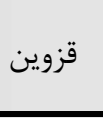 & 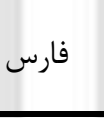 & سبستوجستان و & سمنان & زنجان & خوزستان & خراسان & خراسان & \\
\hline I fra & 119 & grup. & arr & $\Delta \wedge \Delta \Lambda$ & $\Delta \Delta r$ & gre & 1Ar & Ira. & $9 \Delta$ & VFrI & 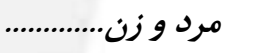 \\
\hline $11 \Delta F$ & . & $|f| \mid$ & TMF & rata & r.. & זrו & . & Drq & . & 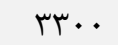 & افغانستان ................................... \\
\hline 11 & r & $111 \%$ & וr & זץ & 199 & 9 & - & r & r & THa & پاكستان ......................... \\
\hline 19 & r & T. F & $\wedge$ & V91 & rI & $\pi$ & 1 & VT & r & 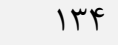 & امارات متح \\
\hline 1. & GTI & 994 & rq & $4 q$ & r & 9 & v & TYA & 4 & rIfF & 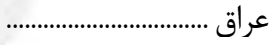 \\
\hline 10 & $\Delta$ & FET & 4 & 4) & $\Delta$ & $\Delta$ & v & זr & - & 114 & 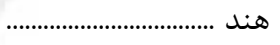 \\
\hline Q1 & r & rq & If & 109 & 1 & 11 & IV & r. & $\Delta$ & $I \Delta V$ & مالزى ................ \\
\hline TV & 1 & $4 q$ & $\wedge$ & $1 \Lambda$. & 1 & $\Lambda$ & $\Delta$ & (i) & $r$ & $\wedge$. & ايالات متحده آمر يكا..... \\
\hline 9 & 19 & $\Delta V$ & 1. & $\Delta$. & . & 1 & 11 & r. & r & vq & آلمان ..................................... \\
\hline r & 195 & rrol & $r \cdot 1$ & 991 & $1 q$ & Q1 & ITS & MEA & 81 & 1199 & ساير كشورها .................. \\
\hline$\Delta$ & 1 & 1. & . & $\Delta$ & $r$ & . & . & 19 & 1 & v & 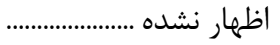 \\
\hline
\end{tabular}

\begin{tabular}{|c|c|c|c|c|c|c|c|c|c|c|}
\hline \multicolumn{10}{|c|}{ استان محل اقامت فعلى } & \multirow{2}{*}{ جنس و كشور محل } \\
\hline 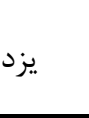 & همدان & هرمزان & مركزى & مازندران & ل ل لرستان & كيلان & علمتان & كهيريلويه و & كرمانشاه & \\
\hline 94. & rq. & $I V \cdot r$ & $1 \cdot 14$ & sFa & 9. & sru & raf & 194 & Frr & مرد و زن.............. \\
\hline Vil & 1 & $11 r 9$ & 110 & $11 \mathrm{~V}$ & 1 & TI & 91 & IrV & r & 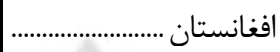 \\
\hline$\Delta$. & r & kq & 11 & $\Delta$ & 1. & 1 & r & . & . & ياكستان ................................. \\
\hline 4 & & FFq & 4 & ז' & r & ry & IV & & 19 & امارات متحده ع \\
\hline TF & $\Delta \varphi$ & 4 & r & $r \cdot$ & 1 & 11 & r & 1 & Y\$1 & عراق ............................... \\
\hline rI & $1 \pi$ & $\Lambda \Delta$ & Tr & ra & $\mathrm{v}$ & IV & r) & $1 \pi$ & 11 & هند .................................. \\
\hline 19 & rl & r & IV & $g q$ & 1 & et & $r \Delta$ & If & rq & مالزى .... \\
\hline 1. & 9 & r & r & is & r & rq & ir & · & 9 & ايالات متحده آمر يكا..... \\
\hline 1 & 19 & r & 11 & is & 11 & $4 q$ & 9 & r & $\wedge$ & آلمان .................................... \\
\hline १V & IFT & ITV & 19. & TVY & $\Delta F$ & FTE & 198 & rq & 94 & 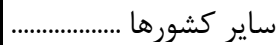 \\
\hline 1 & . & 9 & 1 & 9 & . & . & . & . & $\cdot$ & اظهار نشده..................... \\
\hline
\end{tabular}


| نتايج تفصيلى سرشمارى عمومى نفوس و مسكن _MD

11 - ا- مهاجران وارد شده از خارج كشور طى ه سال كذشته بر حسب جنس، كشور محل اقامت قبلى و استان محل اقامت (نقاط شهرى)

فعلى(دنباله)

\begin{tabular}{|c|c|c|c|c|c|c|c|c|c|c|c|}
\hline \multicolumn{11}{|c|}{ استان محل اقامت فعلى } & \multirow{2}{*}{ جنس و كشور محل } \\
\hline جراسان & و بختيارى & تمهران & بوشهر & ايلام & البرز البر & اصفهان & اردبيل & 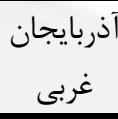 & شرقى & جمع & \\
\hline Fr & 15. & r9119 & raqr & rr & rIAr & frra & $1 \ldots$ & frq & rar & g.rmr & مرد .............................. \\
\hline if & v & TIQAT & TVYT & ${ }^{\circ}$ & rQIS & $r \cdot T V$ & . & - & 1 & एАЬ৭९ & افغانستان ........................ \\
\hline 1 & . & TVR & ry & . & 10 & $1 \cdot 1$ & . & 1 & . & IFEV & ياكستان ............................. \\
\hline$r$ & 14 & $\Delta Q T$ & 14 & k & r. & $\Delta F$ & - & r & $\mathrm{v}$ & 1994 & امارات متحده عربى ..... \\
\hline - & 19 & $\Delta \Delta \varphi$ & 1 & 19 & r. & 114 & rו & r/9 & rI & וזוז & عراق ............................. \\
\hline . & $\Delta$ & 191 & ir & r & rT & $v$. & $r$ & r & r & $\Lambda \Delta Q$ & 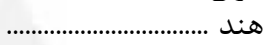 \\
\hline 9 & r & GKT & 11 & 1 & rV & VV & $\Delta$ & ir & re & ITHF & 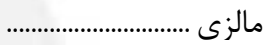 \\
\hline$r$ & r & V9v & 1 & - & $4 \varphi^{4}$ & $1 \cdot 0$ & e & if & 19 & & ايالات متحده آمريكا.... \\
\hline - & $\Delta$ & rᄉl & $\Delta$ & 1 & rV & $\Delta \varphi$ & 4 & IV & 19 & VVr & 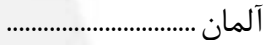 \\
\hline r & $9 V$ & FATE & rq & 11 & fif & $V \cdot r$ & v. & $19 \mathrm{~V}$ & rGY & $1 \cdot \Lambda V^{F}$ & 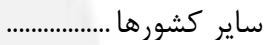 \\
\hline$\cdot$ & $\cdot$ & 94 & $\Lambda$ & $\cdot$ & $r$ & 19 & . & r & 1 & IQT & 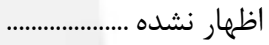 \\
\hline
\end{tabular}

\begin{tabular}{|c|c|c|c|c|c|c|c|c|c|c|c|}
\hline \multicolumn{11}{|c|}{ استان محل اقامت فعلى } & \multirow[b]{2}{*}{ جنس و كشور محل } \\
\hline كرمان ل & كردستان & قم & قزوين ق & 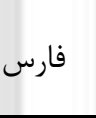 & | بلوجستان & سمنا & 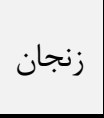 & خوزستان & خراسان & خراسان & \\
\hline 1199 & DII & revr & rar & rasr & rql & $|r|$ & 1.0 & 11. & $\Delta F$ & $f . . r$ & 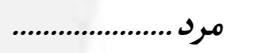 \\
\hline ATr & . & VG & $1 \pi q$ & TAIQ & t. & vi & . & FTD & . & IVQ. & 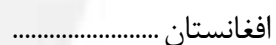 \\
\hline if & r & ब99 & 9 & rI & 1re & 9 & . & r & 9 & سזו & ياكستان ........................... \\
\hline 1. & r & IAT & r & Far & ir & 4 & 1 & ra & 1 & sV & أمارات متحده عربي ...... \\
\hline$\wedge$ & rq. & mIl & IV & c. & r & r & $\Delta$ & ITV & f & IIAT & 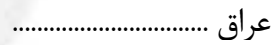 \\
\hline$\Lambda$ & r & rYI & r & ra & i & 1 & $\Delta$ & r. & - & 4. & هند ...................................... \\
\hline r. & 1 & 11 & 9 & 91 & 1 & 9 & 1. & TV & r & $\mathrm{v \Lambda}$ & 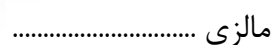 \\
\hline if & 1 & $r \omega$ & v & 1.9 & 1 & f & r & rI & r & i) & ايالات متحده آمريكا.... \\
\hline$\Delta$ & if & r & f & ו & . & 1 & $\wedge$ & 1. & $r$ & Fy & آلمان .......................................... \\
\hline TAF & १V & $\mu \ldots$ & $v^{r}$ & $\Delta \Delta V$ & rq & rr & ve & $r \cdot V$ & re & $9 \Delta \varphi$ & ساير كشورها ............................. \\
\hline i & . & r & $\cdot$ & 1 & r & . & . & $\Delta$ & 1 & $r$ & اظهار نشده...................... \\
\hline
\end{tabular}

\begin{tabular}{|c|c|c|c|c|c|c|c|c|c|c|}
\hline \multicolumn{10}{|c|}{ استان محل اقامت فعلى } & \multirow{2}{*}{ جنس و كشور محل } \\
\hline 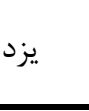 & همدان & هرمزكان & مركزى & مازندران & 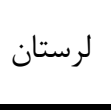 & كَيلان & كلستان & كهيخيلويه و & كرمانشاه & \\
\hline$\Delta V \Delta$ & 101 & llag & sva & 199 & FA & rar & 199 & $|F|$ & $\mu r$. & 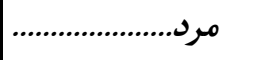 \\
\hline FeV & 1 & $\Lambda \cdot \Delta$ & 4^q & ז & - & 11 & F & 11. & 1 & |فغانستان ........ \\
\hline ry & r & FT & 18 & r & 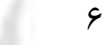 & 1 & 1 & 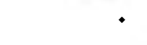 & 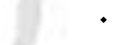 & ياكستان ........................... \\
\hline f & - & $|r|$ & r & rT & r & $r$. & v & - & IT & امارات متحده عربى...... \\
\hline IT & re & r & Ir & 14 & 1 & 11 & r & 1 & Ire & 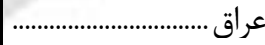 \\
\hline 1. & r & v9 & IV & 10 & r & v & 1. & $\wedge$ & 4 & 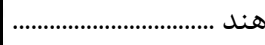 \\
\hline IT & 1 . & 19 & 1. & ru & 1 & rV & Ir & 4 & $\Delta$ & 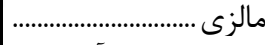 \\
\hline $\mathrm{v}$ & v & r & 1 & $r \Lambda$ & r & ri & 11 & 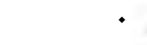 & r & يالات متحده آمريكا ... \\
\hline 1 & $\wedge$ & r & ir & Tr & 4 & r & $a$ & r & $\Delta$ & آلمان .................................. \\
\hline is & 9 . & Vq & $11 \mathrm{~V}$ & 19. & TV & rQV & $1 \cdot 4$ & 14 & $\Delta 9$ & ساير كشورها................. \\
\hline 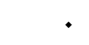 & $\cdot$ & r & . & r & . & . & $\cdot$ & . & • & |ظهار نشده .................... \\
\hline
\end{tabular}


II - ا- مهاجران وارد شده از خارج كشور طى ه سال كذشته بر حسب جنس، كشور محل اقامت قبلى و استان محل اقامت (نقاط شهرى)

فعلى (دنباله)

\begin{tabular}{|c|c|c|c|c|c|c|c|c|c|c|c|}
\hline \multicolumn{11}{|c|}{ استان محل اقامت فعلى } & \multirow{2}{*}{ جنس و كشور محل } \\
\hline جراسان & و بختيارى & ت ت تهران & بوشهر & ايلام & البرز & اصفهان & اردبيل & آذربايجان & شرقى & جمع ( جم & \\
\hline$r \mu$ & $\Delta r$ & $|\Delta \Delta| \&$ & 9.9 & ra & $194 \pi$ & rAgr & $\Delta \Delta$ & ras & ra. & reIAT & 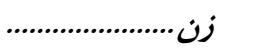 \\
\hline $\mathrm{v}$ & . & $M \Lambda \vee V$ & DFG & - & $1 r q 4$ & IAVF & - & $\cdot$ & r & IVG.T & افغانتان .......................... \\
\hline$r$ & . & IVD & 9 & . & $\Lambda$ & ve & . & r & . & १९८ & ياكستان ............................. \\
\hline r & 9 & $\Delta F_{1}$ & v & i & i) & $\Delta T$ & - & . & 11 & I ITKF & امارات متحده عربى ..... \\
\hline - & 1 & ५११ & 1 & r. & ro & $1 \cdot 4$ & r & $|Q|$ & 9 & 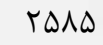 & عراق ............................. \\
\hline . & r & 119 & 1 & . & rI & 19 & . & i & r & VII & 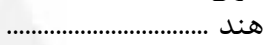 \\
\hline IT & r & 919 & If & 1 & is & 41 & r & i & 19 & $11 \cdot r$ & 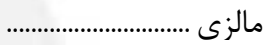 \\
\hline 1 & - & VIS & - & 1 & $\Delta \Delta$ & 90 & r & 1 . & 9 & $1 \cdot \wedge \Delta$ & ايالات متحده آمريكا.... \\
\hline 1 & r & 119 & 1 & - & re & $1 q$ & i & $\Delta$ & 9 & G.4 & 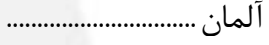 \\
\hline$\wedge$ & ra & ra八V & $T \Delta$ & 9 & r^9 & FAS & FF & $|r|$ & 1149 & $\Lambda \cdot \Delta \cdot$ & 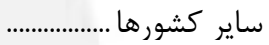 \\
\hline . & 1 & $\Delta F$ & r & • & 4 & 9 & - & 1 & 1 & 114 & 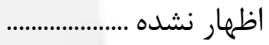 \\
\hline
\end{tabular}

\begin{tabular}{|c|c|c|c|c|c|c|c|c|c|c|c|}
\hline \multicolumn{11}{|c|}{ استان محل اقامت فعلى } & \multirow{2}{*}{ جنس و كشور محل } \\
\hline كرمان & كردستان & قم & قزوين & فارس & سلوجستان و & سمنار & زنجان & 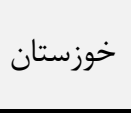 & خراسان & خراسان & \\
\hline pre & $r \cdot 1$ & ress & rri & 1990 & $|9|$ & 110 & $r \Lambda$ & fr. & Fi & rept & 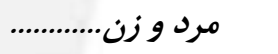 \\
\hline אשr & $\cdot$ & gFA & $1 \cdot 0$ & $1 \cdot r \cdot$ & 91 & 91 & - & $1 \cdot f$ & - & $1 \Delta \Delta$. & افغانستان ......................... \\
\hline r & r & $\Delta / F$ & V & ir & 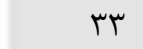 & r & · & - & V & 115 & 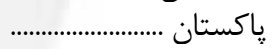 \\
\hline 9 & · & rt & $\Delta$ & rth & 9 & $\checkmark$ & · & rV & 1 & GV & امارات متحده عربى ..... \\
\hline r & (lו & $r \Delta \Delta$ & it & 9 & • & r & r & $|r|$ & r & 9ब5 & 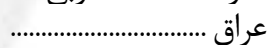 \\
\hline V & r & $r \cdot r$ & $r$ & rG & 1 & f & r & Ir & · & 99 & هند ................................. \\
\hline r) & 1 & 11 & $\Delta$ & $9 \Delta$ & . & $\Delta$ & V & سו & r & $\vee 9$ & 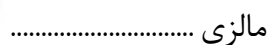 \\
\hline سו & - & rF & 1 & VI & · & r & r & $r \cdot$ & 1 & rq & ايالات متحده آمريكا.... \\
\hline f & $\Delta$ & rq & 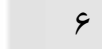 & 19 & · & · & r & $1 \cdot$ & 1 & ra & 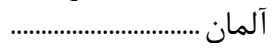 \\
\hline iq & 99 & $1 \cdot \Delta \Lambda$ & IrA & FFI & $r \cdot$ & r^ & 91 & $|f|$ & tr & سום & 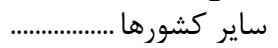 \\
\hline 1 & 1 & $\wedge$ & - & f & . & · & · & 11 & $\cdot$ & r & 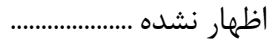 \\
\hline
\end{tabular}

\begin{tabular}{|c|c|c|c|c|c|c|c|c|c|c|}
\hline \multicolumn{10}{|c|}{ استان محل اقامت فعلى } & \multirow{2}{*}{ جنس و كشور محل } \\
\hline 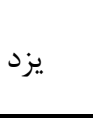 & همدان & هرمزكان & مركزى & مازندران & ل ل لرستان & كَيلان & كلستان & كهيريلويه و & كرمانشاه & \\
\hline red & $1 . r$ & $\Delta F V$ & $r \cdot \Delta$ & reg & fr & $r F 1$ & 111 & ar & 195 & زن............................... \\
\hline TEF & . & rmp & rTs & rF & 1 & 1. & $\Delta \Delta$ & tV & $r$ & افغانستان .................................. \\
\hline 19 & . & V & r & 1 & r & . & 1 & . & . & 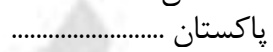 \\
\hline r & & ITA & r & r) & - & 14 & 1. & & $\checkmark$ & أمارات متحده عربى ..... \\
\hline ir & & r & 1 . & $\mathrm{v}$ & - & • & - & - & ITr & عراق .............................. \\
\hline 11 & 9 & 9 & $\Delta$ & 1. & r & 1. & 11 & $\Delta$ & $\Delta$ & 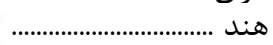 \\
\hline v & 11 & r & $\checkmark$ & rq & . & 10 & r & $\wedge$ & 11 & مالزى ..... \\
\hline r & r & . & r & IV & 1 & 11 & 1 & & $\Delta$ & ايالات متحده آمر يكا.... \\
\hline . & $\wedge$ & 1 & 9 & rF & $\Delta$ & IV & r & . & $r$ & آلمان ........................................ \\
\hline $4 q$ & $\Delta T$ & QI & re & 111 & Tr & $l \Delta V$ & q & it & ro & ساير كشورها ................ \\
\hline 1 & . & $\Delta$ & 1 & r & . & . & . & . & $\cdot$ & اظهار نشده .................. \\
\hline
\end{tabular}




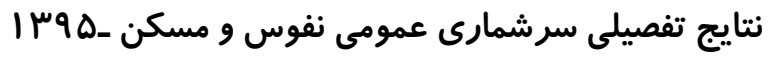

II - ا- مهاجران وارد شده از خارج كشور طى ه سال كذشته بر حسب جنس، كشور محل اقامت قبلى و استان محل اقامت

\begin{tabular}{|c|c|c|c|c|c|c|c|c|c|c|c|}
\hline \multicolumn{10}{|c|}{ (نقاط روستايى) } & \multicolumn{2}{|c|}{ فعلى (دنباله) } \\
\hline \multicolumn{11}{|c|}{ استان محل اقامت فعلى } & \multirow[b]{2}{*}{ جنس و كشور محل } \\
\hline جراسان & و جهارمحال & 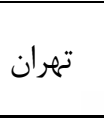 & 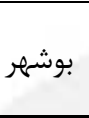 & ايلام & 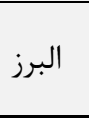 & اصفهان & 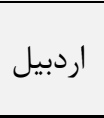 & غربى آذربايجان & شرقى & جمع (ج جم & \\
\hline$r$ & $\mathrm{Fr}$ & $\Delta r \wedge \Delta$ & $11 \cdot r$ & 19 & $1 \ldots 9$ & $11 \% 8$ & $r \mu$ & 15 & rq & $\mid$ EFIF & 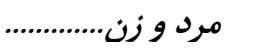 \\
\hline . & f & DFqV & $1 . F V$ & . & 948 & 11119 & . & $\Delta$ & . & $|f \cdot| f$ & افغانستان ......................... \\
\hline - & - & IV. & rI & - & 10 & 1 & - & - & - & $\Delta \cdots$ & ياكستان .......................... \\
\hline - & . & r & 18 & - & r & f & f & - & - & $\Delta / F$ & امارات متحده عربى ...... \\
\hline - & 1 & $\Delta$ & 1 & 1 . & $\wedge$ & 1 & 1. & 90 & f & $r \Delta Q$ & عراق .......................... \\
\hline . & r & $\Delta$ & - & 1 & 1 & 1 & - & - & - & ITr & 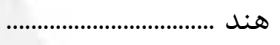 \\
\hline r & . & 9 & . & . & r & . & 1 & r & . & rv & مالزى ................ \\
\hline - & - & r & - & - & r & - & 1 & - & 4 & TV & ايالات متحده آمريكا..... \\
\hline . & . & r & - & 1 & $\Lambda$ & 1 & 1 & r & . & TV & آلمان ..................................... \\
\hline - & rF & $9 V$ & 19 & r & f. & 9 & ir & $\Delta$ & IV & Arr & 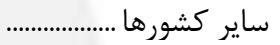 \\
\hline . & . & rq & 1 & r & r & 14 & r & r & r & 11 & 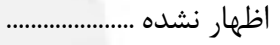 \\
\hline
\end{tabular}

\begin{tabular}{|c|c|c|c|c|c|c|c|c|c|c|c|}
\hline \multicolumn{11}{|c|}{ استان محل اقامت فعلى } & \multirow{2}{*}{ جنس و كشور محل } \\
\hline كرمان & كردستان & قم & قزوين ق & فارس & سبلوجتان و & سمنان & زنجان & خوزستان & خراسان & خراسان & \\
\hline leqr & $\mathrm{Fr}$ & Fra & 91 & $1 T \Delta \Delta$ & $\mu \cdot 1$ & 101 & $11 f^{6}$ & raf & 8 & $r r q$ & 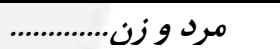 \\
\hline IFTY & 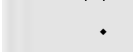 & fid & भ & AVI & lar & 148 & 1 & rar & r & reA & 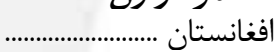 \\
\hline 1. & . & rI & . & Ir & $1 \cdot v$ & . & . & זו & . & r & 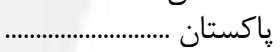 \\
\hline r & 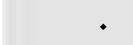 & . & . & TTE & 19 & . & . & 1 & . & . & أمارات متحده عربي ....... \\
\hline 1 & rq & 1 & - & 4 & . & r & r & ir & . & pr & عراق ................................... \\
\hline r & $\cdot$ & - & · & $r$ & . & . & . & . & . & r & هند ......................................... \\
\hline 1 & . & . & . & r & 1 & . & . & . & . & . & مالزى ................................ \\
\hline r & - & - & . & $\Delta$ & . & - & . & . & . & . & ايالات متحده آمر يكا...... \\
\hline - & - & - & - & r & - & 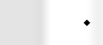 & 1 & - & - & 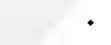 & 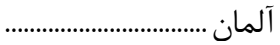 \\
\hline 11 & 4 & 1 & $\Delta$ & ITV & 19 & 1 . & 11. & $\Delta$ & r & 11 & ساير كشورها .................... \\
\hline r & . & . & . & 1 & $\Delta$ & - & . & . & . & r & 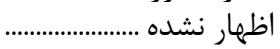 \\
\hline
\end{tabular}

\begin{tabular}{|c|c|c|c|c|c|c|c|c|c|c|}
\hline \multicolumn{10}{|c|}{ استان محل اقامت فعلى } & \multirow{2}{*}{ جنس و كشور محل } \\
\hline 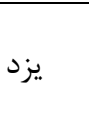 & همدان & هرمزكان & مركزى & مازندران & 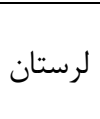 & كيلان & كلستان & كهيريلويه و & كرمانشاه & \\
\hline $19 \pi$ & $\Delta$ & $119 \pi$ & rAM & IfF & 1 & a & $r$. & 19 & $\mu q$ & 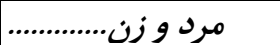 \\
\hline vat & - & 911 & rqA & VV & . & 1 & 11 & $4 q$ & - & 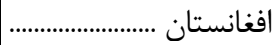 \\
\hline 11 & . & $1 \cdot r$ & . & r & . & 1 & . & . & . & ياكتان ............................... \\
\hline 1 & . & TrV & . & 1 & 1 & . & . & 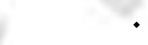 & . & أمارات متحده عربي ...... \\
\hline$\cdot$ & & & $\wedge$ & \& & $\Delta$ & $r$ & • & & ro & 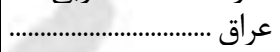 \\
\hline q & & is & & r & . & 1 & 1 & & 1 & هند ............................... \\
\hline . & & & & $\begin{array}{c}9 \\
\Delta\end{array}$ & & 1 & 1 & & & 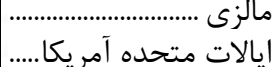 \\
\hline . & & 1 & & 1 & & $r$ & 1 & & 1 & آلّمان ........................................... \\
\hline V & - & 101 & ir & rq & r & r. & 9 & (4) & ir & ساير كشورها................. \\
\hline 1. & 1 & 1 & . & . & • & 1 & • & 1 & . & 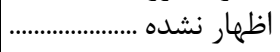 \\
\hline
\end{tabular}


11 - ا- مهاجران وارد شده از خارج كشور طى ه سال كذشته بر حسب جنس، كشور محل اقامت قبلى و استان محل اقامت

\begin{tabular}{|c|c|c|c|c|c|c|c|c|c|c|c|}
\hline \multicolumn{11}{|c|}{ (نقاط روستايى) } & \multirow{2}{*}{ فعلى (دنباله) } \\
\hline \multicolumn{11}{|c|}{ استان محل اقامت فعلى } & \\
\hline جنوبى & و جهارمحال & 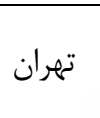 & بوشهر & 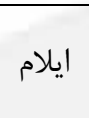 & البرز البر & اصفهان & 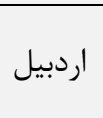 & غربـ آذربان & شرقى آذبايجان & جمع ( جم & جنس و كشور محل \\
\hline 1 & $r$ & rate & 919 & $\bar{v}$ & 998 & $914^{4}$ & $r$. & $\mu f$ & $r$. & $15 \cdot 94$ & 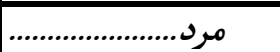 \\
\hline . & r & reTr & $9 \& \wedge$ & . & $9+\lambda$ & १६. & . & r & . & 1. 1. Tr & افغانستان ............................ \\
\hline . & . & $1 \cdot 1$ & rI & . & 1. & 1 & . & . & . & rیl & ياكستان ............................ \\
\hline . & - & 1 & $q$ & - & 1 & r & $r$ & - & . & ऍ. & أمارات متحده عربى ...... \\
\hline . & 1 & F & 1 & r & $\Delta$ & 1 & 4 & TF & r & 119 & عراق .......................... \\
\hline . & 1 & i & - & 1 & - & 1 & - & - & . & זr & 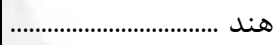 \\
\hline 1 & . & r & . & . & r & . & 1 & r & . & r. & 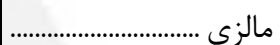 \\
\hline . & . & r & . & . & 1 & . & . & . & r & 10 & ايالات متحده آمريكا..... \\
\hline . & . & r & . & 1 & 4 & 1 & 1 & r & . & Ty & آلمان ............................................. \\
\hline . & זr & $\Delta T$ & $q$ & 1 & $r$. & 4 & v & r & If & GIT & 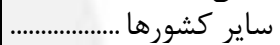 \\
\hline • & · & rI & 1 & 1 & r & it & r & 1 & 1 & $\Delta 9$ & 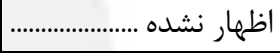 \\
\hline
\end{tabular}

\begin{tabular}{|c|c|c|c|c|c|c|c|c|c|c|c|}
\hline \multicolumn{11}{|c|}{ استان محل اقامت فعلى } & \multirow[b]{2}{*}{ جنس و كشور محل } \\
\hline كرمان & كردستان & قم & قزوين & 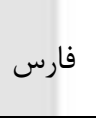 & بلوجتان و و & سمنان & زنجان & خوزستان & خراسان & خراسان & \\
\hline 1194 & $r r$ & T\&g & $v_{1}$ & $9 \pi r$ & rrr & 179 & 11. & $r \cdot$. & $\mu$ & 109 & 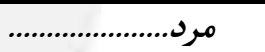 \\
\hline 1190 & 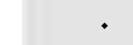 & $r \Delta F$ & 99 & 991 & ITF & 119 & . & ra & 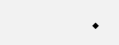 & וזו & افغانستان .................................... \\
\hline 1. & - & 1. & 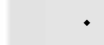 & 1 . & $\Lambda \Gamma$ & - & . & $\wedge$ & - & r & ياكستان ............................. \\
\hline$r$ & . & . & . & lfF & ir & . & . & 1 & . & . & أمارات متحده عربى ..... \\
\hline - & rI & 1 & - & r & - & . & 1 & f & - & 10 & عراق ............................... \\
\hline 1 & $\cdot$ & • & - & r & · & - & - & . & • & 1 & هند .................................. \\
\hline 1 & . & . & . & 1 & 1 & . & . & . & 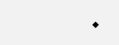 & . & مالزى ....................................... \\
\hline 1 & . & . & . & $r$ & . & . & . & . & . & . & ايالات متحده آمر يكا ... \\
\hline . & - & 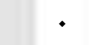 & . & $r$ & - & . & 1 & . & 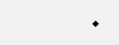 & - & آلمان ............................... \\
\hline 9 & 9 & 1 & r & 19 & 1. & 1 . & $1 \cdot 1$ & f & r & $\wedge$ & 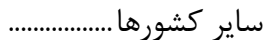 \\
\hline r & . & . & . & 1 & r & • & . & . & . & r & 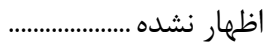 \\
\hline
\end{tabular}

\begin{tabular}{|c|c|c|c|c|c|c|c|c|c|c|}
\hline \multicolumn{10}{|c|}{ استان محل اقامت فعلى } & \multirow[b]{2}{*}{ جنس و كشور محل } \\
\hline 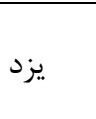 & همدان & هرمزحان & مركزى & مازندران & ل ل ل ل ل & كيلان & كلستان & كويريلويه و & كرمانشاه & \\
\hline 111 & $r$ & 195 & $r .$. & $1 . r$ & a & r & 11 & 1. & r. & مرد.............................. \\
\hline VT. & • & $\Delta \ldots$ & 19. & s4 & • & & 1 & $i \Delta$ & . & 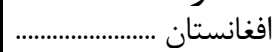 \\
\hline 11 & . & $9 \mathrm{~V}$ & - & r & . & & . & . & - & ياكستان ......................... \\
\hline 1 & . & سזו & . & . & 1 & & . & . & . & أمارات متحده عربي ..... \\
\hline . & r & & r & r & r & 4 & . & & 9 & 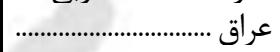 \\
\hline qK & & 48 & . & . & . & & 1 & & 1 & هند ............................... \\
\hline & & & & T & & & & & & 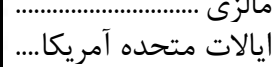 \\
\hline - & & 1 & & r & 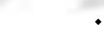 & & 1 & & & آلمان ................................. \\
\hline $\mathrm{V}$ & & $11 \%$ & $\mathrm{v}$ & r & r & 1 & 1 & ra & $q$ & ساير كشورها.................. \\
\hline 9 & • & . & . & . & • & & 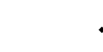 & . & . & 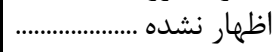 \\
\hline
\end{tabular}




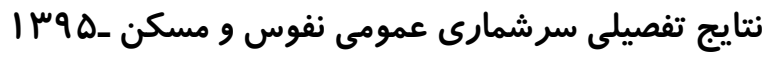

11 - ا- مهاجران وارد شده از خارج كشور طى ه سال كذشته بر حسب جنس، كشور محل اقامت قبلى و استان محل اقامت

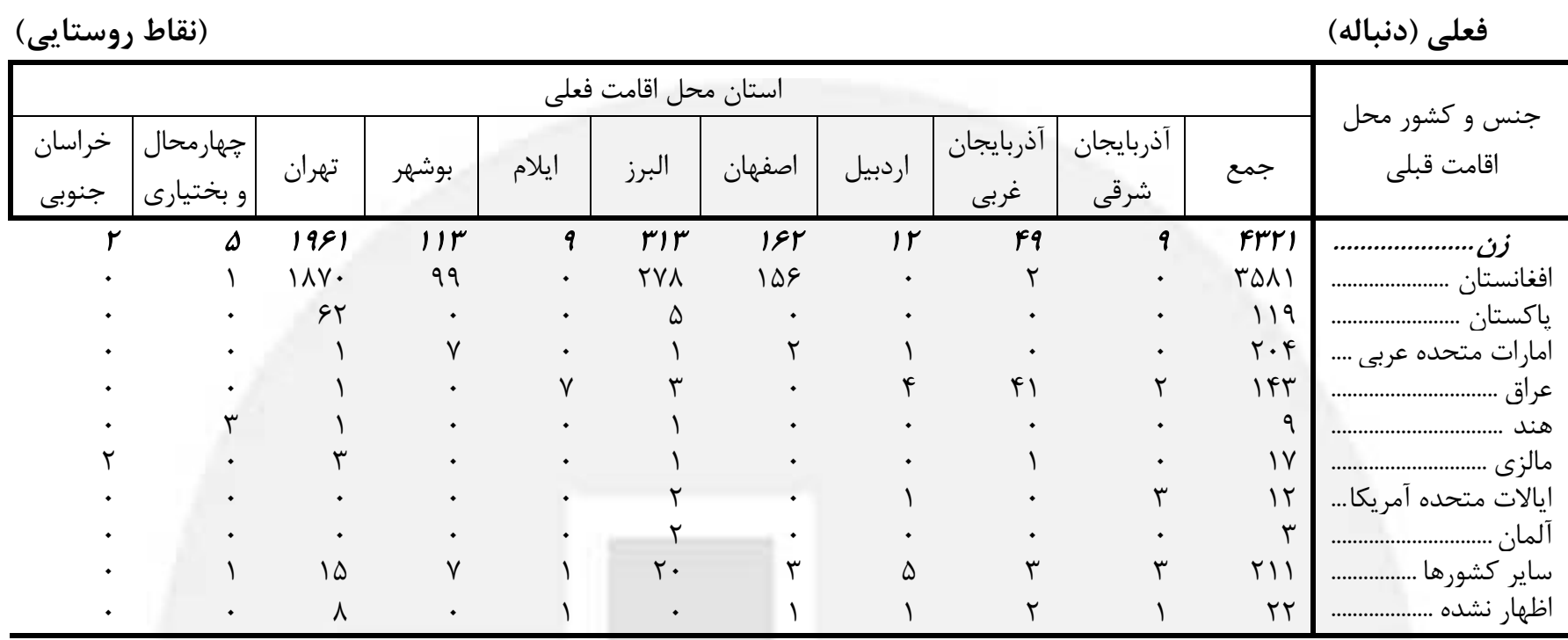

\begin{tabular}{|c|c|c|c|c|c|c|c|c|c|c|c|}
\hline \multirow[b]{2}{*}{ كرمان } & \multicolumn{10}{|c|}{ استان محل اقامت فعلى } & \multirow{2}{*}{ جنس و كشور محل } \\
\hline & كردستان & قم & قزوين & فارس & |بلوجستان & سمنان & ز زنجان & خوزستان & خراسان & خراسان & \\
\hline$r v 1$ & 10 & IVr & $\overline{r r}$ & $\overline{r \mu r}$ & 99 & $r q$ & $\bar{F}$ & $A^{f}$ & $\bar{r}$ & $\mathrm{IV}$. & 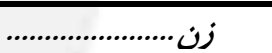 \\
\hline rQV & . & 191 & TF & $r \cdot r$ & rq & rV & 1 & $\checkmark \cdot$ & r & IrV & افغانستان ........................ \\
\hline . & - & 11 & . & r & TF & . & . & $\Delta$ & · & r & 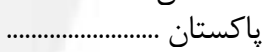 \\
\hline 1 & . & . & . & Ar & f & . & . & . & . & . & أمارات متحده عربي ..... \\
\hline 1 & 10 & - & . & r & . & r & 1 & $\wedge$ & . & tr & عراق ..................................... \\
\hline 1 & $\cdot$ & $\cdot$ & - & . & . & . & . & . & . & 1 & هند ...................................... \\
\hline . & . & . & . & 1 & . & . & . & . & . & . & مالزي ................................ \\
\hline 1 & - & . & - & r & . & . & - & . & . & . & ايالات متحده آمريكا.... \\
\hline . & - & - & - & . & - & - & - & - & . & - & 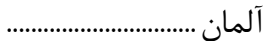 \\
\hline 9 & - & - & r & r人 & 9 & - & r & 1 & 1 & r & ساير كشورها ................ \\
\hline 1 & . & . & . & . & r & . & . & . & . & . & اظهار نشده ................. \\
\hline
\end{tabular}

\begin{tabular}{|c|c|c|c|c|c|c|c|c|c|c|}
\hline \multicolumn{10}{|c|}{ استان محل اقامت فعلى } & \multirow{2}{*}{ جنس و كشور محل } \\
\hline يزد & همدان & هرمزكان & مركزى & مازندران & ل ل ل ل ل & كَيلان & كلمتان & كهيريلويه و & كرمانشاه & \\
\hline$F a$ & 1 & $r r_{1}$ & 11 & FF & 1 & 1 & $1 \pi$ & 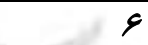 & & 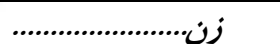 \\
\hline FF & . & 111 & vᄉ & r & 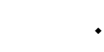 & r & 11 & f & . & 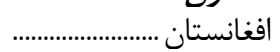 \\
\hline . & . & 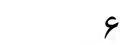 & . & 1 & . & . & & $\cdot$ & . & ياكتان ................................... \\
\hline . & . & 1.4 & . & 1 & . & & - & - & . & أمارات متحده عربى...... \\
\hline . & & · & $\Delta$ & r & r & tha & . & • & 19 & عراق .................................. \\
\hline & & r & & $\Delta$ & & & 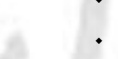 & & & 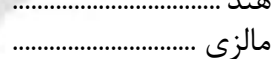 \\
\hline . & & & & & & & & & & آيالات متحده آمر يكا.... \\
\hline . & . & is & $\Delta$ & IV & . & ir & 1 & 1 & r & ساير كشورها ........................................... \\
\hline 1 & 1 & 1 & . & . & . & . & . & 1 & . & اظهار نشده................... \\
\hline
\end{tabular}


ז| - 1 - جمعيت 9 ساله و بيشتر بر حسب جنس، سن، وضع سكونت و وضع سواد

\begin{tabular}{|c|c|c|c|c|c|c|c|c|}
\hline \multicolumn{4}{|c|}{ ساكن در نقاط شهرى } & \multicolumn{4}{|c|}{ جمع } & \multirow[b]{2}{*}{ جنس و سن } \\
\hline اظهارنشده & بىسواد & با سواد & 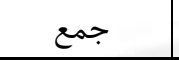 & اظهارنشده & بىسواد & با سواد & جمع & \\
\hline וץ.ru & Fisqfi. & $F \cdot r \cdot \Delta \cdot \Delta F$ & arr.vala & $F F \cdot V q$ & $\Lambda V q \Delta \Delta \Delta r$ & gregsve. & vid.erar & مرد و زن ............ \\
\hline 1199 & $101 \wedge 9$. & rFDQTH. & 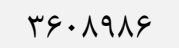 & TETF & $r f|\cdot| f$ & $\forall \wedge F \cdot V \& \Delta$ & $\Delta \cdot \Lambda F F \cdot r$ & 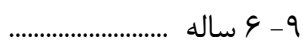 \\
\hline$v \cdot 9$ & IrT.q. & $\Lambda \cdot 999 \Lambda$ & १५१V९V & q४V & $\mid \wedge \Delta \varphi \cdot f$ & $114198 \mathrm{~V}$ & $\| r \cdot \Lambda \Delta \Delta \Lambda$ & 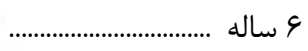 \\
\hline$r \Delta \Delta$ & IrNAT & $q \cdot q \wedge q_{1}$ & $q r F \cdot F \wedge$ & $\Delta T F$ & TFVT. & ITVTIF. & IrQYTAF & ساله .......................... \\
\hline אre & AVIT & $\wedge \vee \vee \wedge .$. & MA\&qFD & $\Delta 9 \wedge$ & 19919 & ITHFAVF & $1 T \Delta T \cdot \Lambda \Lambda$ & 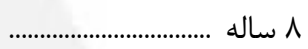 \\
\hline rदq & VTre & $\Lambda G \cdot G Y 1$ & NGATrG & $\Delta r \Delta$ & $\mid f \cdot v f$ & ITIIVVF & ITKGTVR & 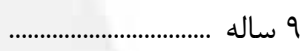 \\
\hline $10 \cdot 9$ & एद911 & F. IVATG & $F \cdot \Delta G T F T$ & TIDT & verqu & $\Delta G \| \wedge \mu F$ & $\Delta S \wedge \Lambda \mu \wedge F$ & 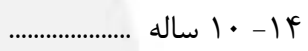 \\
\hline سקr & $V k \cdot r$ & 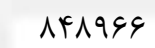 & NDGVFT & 019 & I $p q p q$ & IT. IFTD & $|r| \& \wedge 9$. & • • ساله ................... \\
\hline TIS & $991 \mathrm{~V}$ & $14 \cdots 99$ & NTGqTr & 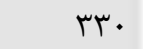 & Ir.tr & $\| F \wedge V I \Lambda$ & $11 \varepsilon r \cdot V \cdot$ & 11 ساله ....... \\
\hline rum & VY\&S & $V q \cdot r r$. & 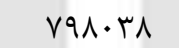 & $F \Delta \Delta$ & $14 q . q$ & $11 \cdot 1110$ & IIIVIVG & 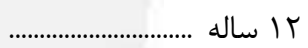 \\
\hline rG4 & $V \Delta \Delta T$ & VAFDTY & Vartu. & rqs & IDTVE & I. ANTTV & $11 \cdot$ ५999 & זן ساله ........... \\
\hline m19 & VAVr & VVrq৭१ & VATI91 & $F \Delta \Delta$ & IETFD & $1 \cdot V \mid \Delta F q$ & 1. NArFq & 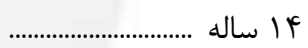 \\
\hline $1 \mathrm{MN}$ & $\Delta \Delta 91 \pi$ & ґАЯтАґУ & r & TERT & $\mid 191 \cdot 1$ & $\Delta M F \cdot r \Delta F$ & $\Delta F \Delta \wedge १ १ \vee$ & 19- ها ساله ............ \\
\hline r.99 & $9 \cdot 1 \vee 9$ & FFAVৎqI & 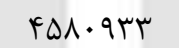 & fiv. & |Avq|r & gr...VqV & \&rqr人vq & 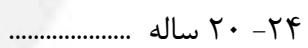 \\
\hline FrA. & $I f \cdot V \Delta V$ & $\Delta q \Delta \Delta \Delta \vee V$ & $91 \cdots 91 f^{f}$ & $\Delta \Delta V \cdot$ & $r q \cdot r \vee q$ & $\vee q \cdot \Delta \cdot \Lambda f$ & س & q r \\
\hline FUVY & 191491 & GFGIAFG & G9TVRIS & $\Delta \wedge \Delta \varphi$ & $r q \cdot V q I$ & NTAFTQG & 1૬..91r & ץ • • ساله ............. \\
\hline mViq & I9F^९V & $\Delta \backslash 9 \leftrightarrow \varphi \wedge \Delta$ & DHqTTVI & FAN & 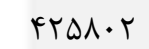 & 99.9911 & $V \cdot r V \Delta 9 \Lambda$ & q \\
\hline rᄉrq & rब৭९ाI & rqTAFrg & 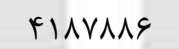 & r\&AT & $\Delta F \mid r \cdot F$ & FqVRrTl & $\Delta \Delta \backslash \wedge r \cdot V$ & ................... fF \\
\hline TFFT & $\mathrm{rV \Delta} \cdot \wedge 9$ & 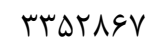 & r & migr & VIDGMT & fllfrqV & שזוTMNF & . . \\
\hline 1919 & $\mid F \backslash 991$ & roVVETS & & rFqs & $\Lambda \Delta \cdot 11 \mathrm{~V}$ & & rqrఎqV। & (............ \\
\hline $\mid f \wedge \Delta$ & $\Delta \wedge \Delta \wedge \vee q$ & 19GVFFA & rDQYAIT & $r \cdots q$ & $1 \cdot f r \mid 91$ & س r & سوه & ............. \\
\hline IITV & $\Delta \wedge I \vee \Delta \Delta$ & ITTVGGS & $191 \cdot \Delta F \wedge$ & $10 \cdots$ & $1 \cdot 1$ HAVF & $10 Y R 199$ & TAFTAVT & 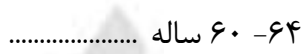 \\
\hline$V \& V$ & Fqтil. & $V \Delta Q 1 \cdot 1$ & 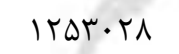 & | & $\wedge \uparrow q \cdot v \wedge$ & $\Lambda \varepsilon \mid r \Delta \Delta$ & IVIIfEF & 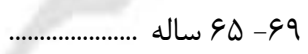 \\
\hline$\Delta V_{1}$ & $r \cdot V \Delta T G$ & $f f \mid f \cdot \Lambda$ & $\Lambda \ll q \Delta \cdot \Delta$ & Vqs & 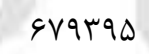 & pqupre & IIVVGTA & ساله .................. س • VY \\
\hline 994 & 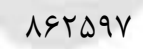 & $\uparrow \wedge q \cdot p$. & I IUYGK. & IFVF & IFTVFqD & DQMFG. & I91FFrq & VD ساله و بيشتر ...... \\
\hline
\end{tabular}




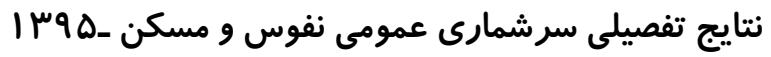

rا - 1 - جمعيت 9 ساله و بيشتر بر حسب جنس، سن، وضع سكونت و وضع سواد (دنباله)

\begin{tabular}{|c|c|c|c|c|c|c|c|c|}
\hline \multicolumn{4}{|c|}{ غير ساكن } & \multicolumn{4}{|c|}{ ساكن در نقاط روستايى } & \multirow[b]{2}{*}{ جنس و سن } \\
\hline نشده & بىسواد & با سواد & جمع & نشده & 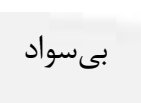 & با سواد & جمع & \\
\hline $1 \cdot r$ & 19vir & $r v r v f$ & fFisq & $1.9 \Delta \Delta$ & rq.9prl & Ifruprer & IATAFEAN & 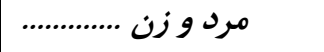 \\
\hline v & $\Delta \Gamma_{I}$ & $r q .9$ & rIfV & $V \Delta I$ & $\Lambda \Lambda \Delta Q Y$ & IrATaYs & IFVKTV. & 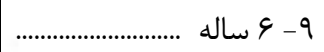 \\
\hline r & ऍ. & prq & var & ret & GKT.F & MIfar. & rVVq৭1 & ع ساله .................................. \\
\hline . & $\Delta F$ & V19 & $\Lambda \cdot r$ & 199 & $1 \cdot$ VAF & $r \varphi \mid \Delta \Lambda$. & TVTOH & Vاله ........... س \\
\hline r & V^ & $9 v$. & VQ. & 19r & VArG & $r \Delta G Y \cdot Y$ & requq & 1 ساله ............... \\
\hline 1 & $\Delta 9$ & $V F_{1}$ & $\Lambda \cdot 1$ & $1 \Delta \Delta$ & sVVq & TD. YIT & TAVHFG & 9 ساله ................ \\
\hline r & rar & reft & ५१९९ & gAt & rvird & $109 \cdot r 9 \Delta$ & IGTAIFT & fl|- • اله س....... \\
\hline . & V & $\Lambda \Delta V$ & qभ. & Ifr & VEVr & rDIG.r & rDQTIA & . 1 ساله .............. \\
\hline$\cdot$ & 90 & $V \vee \Delta$ & $\Delta f$. & 114 & grt. & rTVAFF & MFrqA & 11 ساله ........ \\
\hline$\cdot$ & $\Delta 9$ & vis & VVQ & r & Vrul & $r 1 \cdot \wedge \Delta q$ & 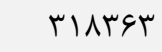 & ז اله ......... \\
\hline r & 99 & sV. & V\&i & IrA & $\vee \varepsilon \Delta \Delta$ & atra & 41.911 & זا ساله ............. \\
\hline r & $\wedge \varsigma$ & sTQ & VIr & Irt & ArAS & r৭९৭४ब & $r \cdot \Delta \mu F \Delta$ & flf ساله .......... \\
\hline 9 & 911 & ro19 & firq & VEa & $\Delta 9 \Delta V \nabla$ & IFFrAq1 & DD. FTt. & 9 1 19 ساله \\
\hline ir & $\wedge \vee$. & $f \cdot v q$ & $|q 99|$ & 1.95 & 99199 & $I V \cdot q \cdot T V$ & 11.9910 & 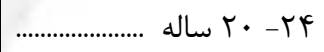 \\
\hline 9 & $1 \cdot 01$ & $r q .1$ & 4981 & $|r \wedge|$ & $|F \wedge \& V|$ & 19409.9 & $r \cdot 9 \Delta \wedge \Delta \Delta \Lambda$ & q \\
\hline v & $1 \cdot r 8$ & rVV. & $r \wedge \cdot r$ & IrVV & IVAFry & IVএ৭९৯. & 19९9११९ & ץ ץ- • ساله ........ \\
\hline 14 & Iraf & rFqT & rq.. & 110. & rTQDFI & $|f| \cdot V \Psi q$ & IGFIFTV & qז- טז ساله \\
\hline$\wedge$ & 1099 & 1911 & r190 & Ard & TA.ITF & 1. FGYGV & ITTVRTE & 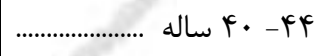 \\
\hline$\checkmark$ & IVT. & $15 \cdot 9$ & r. & ver & TMATr & $V G \cdot|r|$ & 1.99911 & q \\
\hline v & 1999 & vra & TFM & $\Delta V$. & rVAYG. & 19019V & NVTYTV & F \\
\hline r & IEAT & DrT & $r \cdot q$ & $\Delta r$. & FAFGT. & TrAFt & VqüVr & 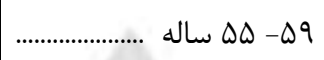 \\
\hline 4 & 1011 & TAT & IVAs & rQV & $4 r \cdot G \cdot 1$ & 1997V1 & qr.rrq & f \\
\hline r & 999 & 119 & $1 \cdot 1 V$ & TAT & rofqTq & AITH & FAVHFq & 99- 90 ساله \\
\hline 1 & GVD & q & 119 & TTF & TVIIqF & $\Delta \Delta ৭ \wedge \mu$ & TYVY.I & ساله ................... - س V \\
\hline 9 & $1 \cdot 4 \lambda$ & $\Delta \Delta$ & 11.9 & EVD & DGHAD. & gFrga & Gr人\&q. & V VD ساله و بيشتر ... \\
\hline
\end{tabular}


|r - 1 - جمعيت \& ساله و بيشتر بر حسب جنس، سن، وضع سكونت و وضع سواد (دنباله)

\begin{tabular}{|c|c|c|c|c|c|c|c|c|}
\hline \multicolumn{4}{|c|}{ ساكن در نقاط شهرى } & \multicolumn{4}{|c|}{ جمع } & \multirow[b]{2}{*}{ جنس و سن } \\
\hline اظهارنشده & 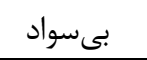 & با سواد & جمع & اظهارنشده & 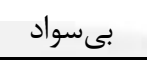 & با سواد & جمع & \\
\hline rirg. & $|r r r| \cdot r$ & ra. FrAFA & revalrt. & rarql & rTHEAIA & rrairalv & relevare & مرد ....... \\
\hline $9 \Delta \Lambda$ & $\vee \vee q \cdot \Lambda$ & IVV.rqq & $|\wedge F q| \varepsilon D$ & $|r| \cdot$ & ITHIFV & $r F \Lambda \cdot V Q V$ & $r G \cdot \Delta T I T$ & 9- 9 ساله ....... \\
\hline rqA & GYMA. & גוזיוא & FVGDGG & rqז & 9QTHI & DYFAGG & $9 V \cdot \Delta \wedge q$ & 9 ساله ........ \\
\hline 194 & $V \cdot 9 V$ & 499119 & prrevq & rV. & $\mid$ TRT & 901910 & 994119 & V ساله ....... \\
\hline$r \cdot r$ & FTDQ & $F \Delta \cdot T r \Lambda$ & FDFq91 & rM & $\wedge 1 \wedge \Delta$ & grrTVq & GFIVAT & ^ ساله ....... \\
\hline 194 & $r V \cdot r$ & 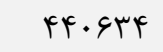 & FFEATq & rq. & vi.. & $94.99 V$ & $g r \Lambda \cdot \Delta V$ & 9 ساله ...... \\
\hline vq. & $M k \cdot F$ & $r \cdot \Delta \Delta ৭ 9 T$ & $r \cdot V \Delta \backslash \wedge \varepsilon$ & $111 \mathrm{~V}$ & TGFAT & TAVTATr & rqIIfrT & ז ا- •| ساله \\
\hline 119 & TEF & FTDQTF & ктqтяя & rat & $V F \cdot r$ & द|धศवा & $G K F \cdot \Delta \Lambda$ & •الـ ال...... \\
\hline 11. & rTVA & FI91VR & FTMTEI & IVV & greq & 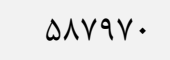 & $\Delta q F \Delta \wedge G$ & 11 ساله .... \\
\hline$|1|$ & rgAr & $F \cdot F \| Q$ & $r \cdot v q v q$ & rMa & Vrrq & DGFYIA & $\Delta V \backslash 9 \wedge \Delta$ & ז| ساله ...... \\
\hline IDF & rArq & $r \cdot \| 1 V r$ & $f \cdot \Delta \backslash \Delta \varphi$ & rif & very & $\Delta \Delta V I I I$ & DGFVGT & זا ساله ..... \\
\hline 109 & rqvi & rqDrqV & rqqFY & TTF & VAVD & DFVqRT & $\Delta \Delta G \cdot r T$ & fl| ساله ........ \\
\hline $11 V T$ & rqvqp & 19घ9481 & $r \ldots r m k$ & 1919 & DVQYA & TVRGITI & 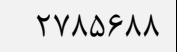 & 9 1 - ها ساله \\
\hline 1941 & p4q91 & TrIFTAS & TKGIT.D & TETV & $\Lambda \wedge \vee \vee \Delta$ & rIFDDS & rTrGqVD & ץ \\
\hline TGT. & 90197 & 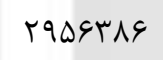 & T. TFT. & reqf & ITVTIT & F.Irvrq & FIFTEFA & q \\
\hline r111 & $V T \cdot D$ & TMETEET & 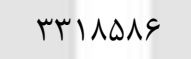 & $F \cdot r \Delta$ & $\mid \tau \cdot V \Delta \Delta$ & 4190991 & FTF.FFA & 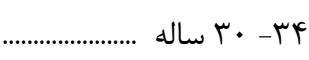 \\
\hline$r \Delta \Delta G$ & VEFTE & TEDITAT & TVTATrQ & rrv & IDQTVV & rFIrVFq & rDVTF.r & qז- هז ساله \\
\hline$r \cdot r^{\prime}$ & 19119 & T. FATIV & TITETYG & relr & IVANFr & TEMTETK & rᄉוrیq. & 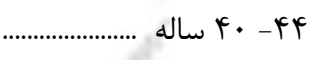 \\
\hline 1991 & $\| \Delta F \Delta \Lambda$ & $|V A F q F|$ & $19 \cdot r \cdot 9 V$ & THFV & TYFATq & TYYYGDI & TFAFFTY & q \\
\hline$|M F|$ & IFIOTE & $\mid r \cdot r \& 4 \Lambda$ & IDFEDTD & IVF. & TETGAF & $|V| \cdot \mid Q \cdot$ & k & (....... \\
\hline $1 \cdot r 4$ & MA.TET & $11.49 \Delta r$ & $|r \wedge \Delta Q T|$ & 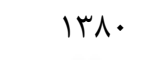 & rrNIV. & Irr.rAF & $198994 \mathrm{~F}$ & (.......... \\
\hline VAT & $1 \Lambda \cdot \Lambda \Lambda V$ & vVAvqI & $q 9 \cdot k r \cdot$ & 995 & 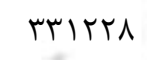 & QT. kसr & ITATGGT & 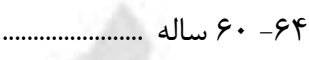 \\
\hline rAT & $10.1 \mathrm{kV}$ & FAFFYq & $q \cdot \Delta \cdot V \Lambda$ & gDT & TVGATV & DTIFTI & .191. & 9 9- ه \\
\hline זTr & $1 r \Delta s \cdot \Lambda$ & TVQTAT & FIOTAK & prt & r\&\&Grq & MTF.FI & $\Delta V I I I T$ & ساله .................... $V \cdot-V F$ \\
\hline kqr & 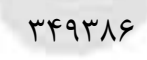 & DTYG. & GATD.q & $V \Delta \varphi$ & qrV... & rАV৭૬ & 1. TOVT. & V VD \\
\hline
\end{tabular}


זا - 1 - جمعيت \& ساله و بيشتر بر حسب جنس، سن، وضع سكونت و وضع سواد (دنباله)

\begin{tabular}{|c|c|c|c|c|c|c|c|c|}
\hline \multicolumn{4}{|c|}{ غير ساكن } & \multicolumn{4}{|c|}{ ساكن در نقاط روستايى } & \multirow{2}{*}{ جنس و سن } \\
\hline 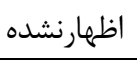 & 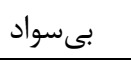 & 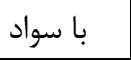 & جمع & 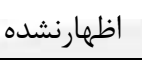 & 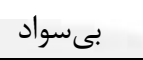 & 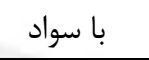 & جمع & \\
\hline$\Delta \Lambda$ & $V 9 \Delta 1$ & $19 \cdot 1 \gamma$ & $r F i \cdot r$ & $r \cdot q r$ & IFq\&FDA & rafaqur & qrard.r & 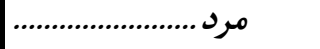 \\
\hline f & rqA & Irی. & I9DT & rFA & fFquI & $\vee \cdot q \cdot \vee \wedge$ & VDFTqV & |.......................... 9 -9 ساله \\
\hline r & $\mid \Delta \Lambda$ & ror & rוt & ITT & r & 191790 & $|949|$. & 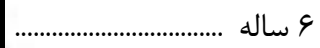 \\
\hline . & $i \Delta$ & rAf & frq & VV & $\Delta \Delta 19$ & $|\wedge \Delta F| T$ & $191 \cdots 1$ & Vاله ......................................... س V \\
\hline 1 & re & rpq & rAt & r & ऍ人१६ & INTV.r & 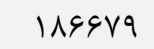 & 1 ساله .................. \\
\hline 1 & 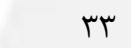 & rqf & FrA & 99 & Dه & ।V৭ৎ99 & $\mid \wedge \mu_{1}$ & 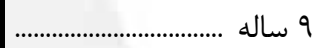 \\
\hline r & IVF & 1959 & $r_{1} \cdot r$ & rTd & $189 \cdot \Delta$ & $\Lambda 1 \Delta q \cdot \Delta$ & Arfird & f| \\
\hline • & r. & FQT & FAT & $\vee \Delta$ & ( & $\mid \Lambda \cdot \varphi \cdot \Delta$ & $|A F T|$. & • ساله ................................. \\
\hline . & re & $f \|$ & FFt & $9 V$ & q & | $९ \vee \& \wedge \&$ & $I V \cdot \Lambda \Lambda r$ & 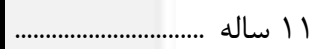 \\
\hline . & 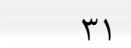 & rqr & מצF & $\Delta V$ & هוg & 109911 & 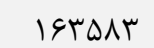 & 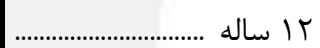 \\
\hline 1 & ry & rol & rیs & $\Delta 9$ & rovf & $1 \Delta \Delta \Delta \wedge V$ & IDQTr. & ساله س................. \\
\hline 1 & FV & rt. & reᄉ & $9 V$ & r^DV & DQTIS & IDSTF. & | | ساله ........................... \\
\hline f & מצr & 1991 & rtqם & FFT & tVATI & VDFVqD & $V \wedge r \cdot \Delta q$ & 19-1 19 ساله .............. \\
\hline$\Delta$ & fqf & trAl & rqd. & VII & שוسזץ & 9rAvas & QVTAT. & 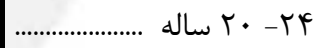 \\
\hline$\Delta$ & pqv & $r \mid 90$ & r\&\&V & ^९9 & S|DTI & $1 \cdot \Delta F \backslash \Lambda \Lambda$ & $1119 \Delta \vee \wedge$ & ..................... \\
\hline f & $F \Delta F$ & $\mid \Delta \Lambda$ & $r \cdot r \Lambda$ & $q \cdot r$ & \&人५৭६ & $9 \Delta \cdot 9 T \Delta$ & $1.191 \mathrm{TF}$ & F \\
\hline V & $\Delta 9 \varphi$ & IFr. & $r$ & 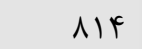 & $\Lambda \cdot r \wedge \Delta$ & $V 9.949$ & $\Lambda F T \cdot G \Delta$ & q \\
\hline f & grג & 990 & IETV & $\Delta 99$ & $94 \cdot 99$ & DNTTKT & GVQqIV & ... \\
\hline$\Delta$ & $\vee \backslash \wedge$ & MNF & $19 \cdot V$ & $\Delta F F$ & س & FFINTE & DQ & \\
\hline$\Delta$ & \&人९ & 011 & $15 \cdot 9$ & rqp & ITIFVT & $r \cdot \Delta q \& Y$ & FrVAr. & F \\
\hline r & VVQ & rNT & 1109 & MFT & $\mid \Delta V I \Delta H$ & TrQTKq & TATAFY & .......... \\
\hline r & VG. & $r \cdot \Delta$ & $99 \wedge$ & r & $|f q \Delta \Lambda|$ & IFIFFV & rवाтघD & 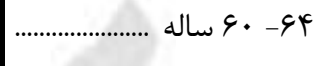 \\
\hline$r$ & س & 94 & GYA & 191 & $|r G| \Delta V$ & 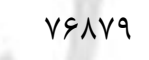 & $r \cdot r t \cdot r$ & 99-.................... \\
\hline 1 & $k \cdot 1$ & 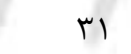 & אسץ & $1 \cdot 1$ & $11 \cdot 9 r$. & fresu & ।DQrq৭ & 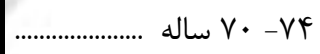 \\
\hline$\Delta$ & VII & $4 q$ & $\vee \varphi_{\Delta}$ & $r \Delta \Lambda$ & r^ৎq.r & DQTAF & MFYFFE & 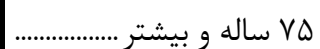 \\
\hline
\end{tabular}


rا - 1 - جمعيت \& ساله و بيشتر بر حسب جنس، سن، وضع سكونت و وضع سواد (دنباله)

\begin{tabular}{|c|c|c|c|c|c|c|c|c|}
\hline \multicolumn{4}{|c|}{ ساكن در نقاط شهرى } & \multicolumn{4}{|c|}{ 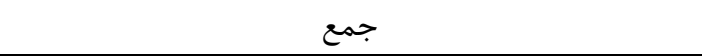 } & \multirow{2}{*}{ جنس } \\
\hline اظطهارنشده & بي سواد & با سواد & جمع & اظهارنشده & بـ بـواد & با سواد & 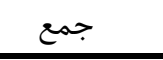 & \\
\hline$\| v a \mid$ & $r \mid f r r \cdot 1$ & rrtarres & refigrad & IDEAM & $\Delta \Delta \& q \cdot r \Delta$ & ravarafr & rarrabsg & 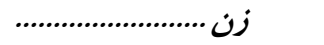 \\
\hline$q \cdot \wedge$ & VrqAT & $|9 \wedge<q 4|$ & |VD৭AT| & $|M| F$ & IIVA\&V & rma... & rFYqI/q & 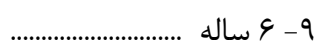 \\
\hline MFI & DQTI. & rq५८०. & FATT. 1 & FNA & $9 \cdot r V r$ & DFVIII & दтV१६q & 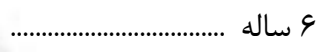 \\
\hline 194 & SVAD & FETVt & 40.999 & rar & $1 T \cdot 19$ & GT. TrD & GMTDGA & Vاله .............................. \\
\hline trq & FEAT & FTVAVT & FTtTAF & r. & I ו ו & $9 \cdot 1090$ & G1.rrs & 1 ساله .......... \\
\hline IVe & TUMF & P1991V & Frtagy & rea & q9Vt & $\Delta 91 \cdot V \mathrm{~V}$ & Q9ATIS & 9 ساله .............. \\
\hline VIS & $1 \wedge \Delta \cdot V$ & I9GIAYK & $1911 \cdot \Delta V$ & 1.ra & rVqla & $r Y Y \Lambda \cdot 11$ & rVYGQ9I & 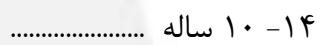 \\
\hline$M F$ & rVG. & FITERT & FIVTVE & TAT & VQFE & $\Delta \wedge \Delta \cdot r F$ & DQTAKT & • • ساله ............. \\
\hline 1.9 & 9 9 פשr & F.PTS & $r \cdot r g V I$ & IQT & gDA & $\Delta G \cdot V F \Lambda$ & DEVFAF & 11 ساله ....... \\
\hline$|0|$ & TVAr & 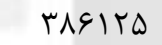 & $r q \cdots \Delta q$ & rIV & VQVV & DrVTqV & $\Delta F \Delta \backslash 91$ & 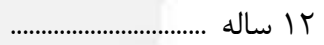 \\
\hline $11 \%$ & TVY & rArrFq & rAVIAF & IAT & VArq & QMITIS & DTQTrV & rا ساله ............ \\
\hline 194 & rq.r & rVAV.r & TATVEV & וזr & $\Lambda \mu v$. & DrMGIS & DTYTIV & 1F اله س.......... \\
\hline V19 & re119 & 19TrKE9 & $190 \cdot r \cdot r$ & זr & $\Delta \Lambda \backslash \varepsilon \mu$ & KQIFITK & TEVYr.9 & 19 19 اله اله ... \\
\hline$\| F \Delta$ & FOIVA & THRTH.D & rTIGVTA & TH & $991 \% \mathrm{~V}$ & $r \cdot \Delta \Delta Y Y Y$ & rIQQQ.F & F • • שاله ....... \\
\hline 199. & VDDG & r999191 & $r \cdot V G F \mid F$ & $r \cdot V \varphi$ & ISTTEV & rAGTrFD & $Y \cdot \Delta V \& \Lambda \Lambda$ & q \\
\hline lFDF & А१५१५ & 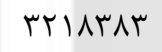 & . & |ATI & $r \ldots q$ & $r \cdot \Delta \Lambda G Y \Lambda$ & FYG. F9D & 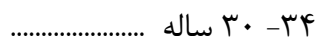 \\
\hline 1194 & $|r \cdot F F|$ & TAFTHTY & тяятатв & $10 \cdot 9$ & $T V \cdot \Delta T \Delta$ & MI94IG4 & $r F 90190$ & q" q- هז ساله ...... \\
\hline $1 q^{\prime}$ & IVTEQT & IAVVYI9 & $T \cdot \Delta \mid \Delta F$. & 1.99 & TETFEI & $r M F \cdot \Lambda \Lambda V$ & TY.FFIV & \\
\hline$V F \Delta$ & 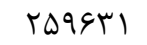 & IDGVQYG & INTNK·r & $q \& \mathrm{~V}$ & $k q 11 . r$ & IMM9949 & rrYAS99 & 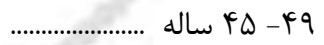 \\
\hline$\Delta \vee \wedge$ & H.r.kt & IIVTVAN & $|0 \cdot F V V|$ & VDS & DAGFrT & IrGKr.1 & & 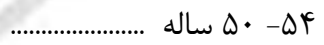 \\
\hline kiq & $F \cdot \Delta G r V$ & NGYV१D & $\mid$ TYMAN| & 949 & $V \cdot r \cdot r I$ & $9 \vee 9 . .9$ & 191.909 & L $\Delta$ - $-\Delta q$ \\
\hline rVa & $\uparrow \cdot \wedge \wedge \wedge$ & DFANVD & 90.1111 & $\Delta \cdot \Lambda$ & GNTEKS & $9 \cdot 9 V \Delta G$ & $\mid$ |r८९9|. & 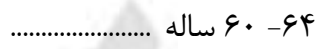 \\
\hline rea & Trtratr & $r \cdot F \& \Delta T$ & GYVqD. & rvq & DVTYKI & rरq৭सF & $q \cdot r \Delta \Delta F$ & 99- 9 9 ساله \\
\hline$r F \Lambda$ & rVI911 & $19 T \cdot \Delta 9$ & FTETT & rq4 & FTrVAS & IVrrqu & $9.901 \pi$ & ساله .................... \\
\hline$\Delta \cdot$ & DITII & $|\Delta G \psi|$. & $9 V \cdot|r|$ & ViN & $v q \cdot k q q$ & $19 \Delta F q V$ & $q \Delta \varphi \vee \cdot q$ & VD ساله و بيشتر \\
\hline
\end{tabular}


זا - 1 - جمعيت \& ساله و بيشتر بر حسب جنس، سن، وضع سكونت و وضع سواد (دنباله)

\begin{tabular}{|c|c|c|c|c|c|c|c|c|}
\hline \multicolumn{4}{|c|}{ غير ساكن } & \multicolumn{4}{|c|}{ ساكن در نقاط روستايى } & \multirow{2}{*}{ جنس و سن } \\
\hline 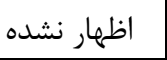 & 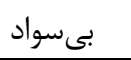 & با سواد & جمع & اظمهار نشده & 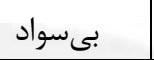 & 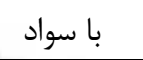 & جمع & \\
\hline$F \Delta$ & AVAF & Irar & $r \cdot .19$ & raqr & rfirgrr & gFADrr. & $19 \cdot r 110$ & 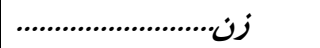 \\
\hline r & 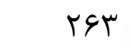 & Irrq & 1490 & $r \cdot r$ & FTETT & GVTAFA & VIVAVK & 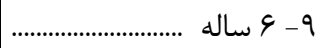 \\
\hline r & IDT & TrG & rی. & IFr & $r_{1} 11$ & DTHATM & INFTAM & 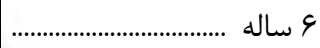 \\
\hline . & ५ & 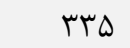 & rve & 94 & $\Delta r \& \Delta$ & $|V 9| 9 \Lambda$ & $1 \Lambda \mid \Delta T \Delta$ & ساله ......................................... V \\
\hline 1 & iq & ITI & rGی & $\wedge \cdot$ & rqur & IVrV.r & IVVRIF & 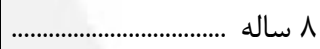 \\
\hline . & rq & MFV & سקr & 19 & mfif & IV.VFT & IVFTFE & 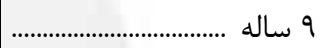 \\
\hline r & IVA & IVIV & $119 V$ & MV & 19rr. & VYFFe. & vqf..v & 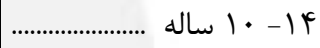 \\
\hline . & r & $\varphi \cdot \Delta$ & FFA & $9 \wedge$ & mer & 181198 & $I V \Delta \cdots \wedge$ & 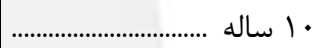 \\
\hline • & 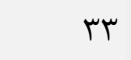 & rap & rqv & FV & dו & $19 \cdot 101$ & ISTFis & 11 ساله ....... \\
\hline . & rᄉ & met & rar & 99 & MVGS & $10 \cdot 94 \wedge$ & IDFVA. & זاله ........ \\
\hline 1 & ra & riq & $r \Delta \Delta$ & 99 & $r \cdot \lambda l$ & IFVDFA & 101991 & سا ساله .......... \\
\hline 1 & rq & $r \cdot \Delta$ & MFQ & $9 V$ & FET & IfFe. 9 & $|<q| \cdot \Delta$ & fl ساله ............. \\
\hline$\Delta$ & TAN & $|\Delta \Delta|$ & MAF & $r \cdot r$ & rIVAS & $9 \wedge 91 \cdot r$ & VTIISI & 19 اله ..................... \\
\hline V & $f \cdot q$ & 1091 & $r \cdot 11$ & rᄉl & $\Delta r \Delta \Delta r$ & VN·ru & NFFIGD & 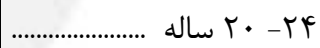 \\
\hline f & $\Delta \Delta F$ & Ifre & 1994 & fir & $\wedge \vee \backslash \Delta$. & $\wedge 91 \vee 1 \wedge$ & १マ१५^. & q........................ \\
\hline r & $\Delta V T$ & 119 & IVED & rVF & $|1 \cdot| f \mid$ & $\Lambda r q \cdot \Delta \Delta$ & $q \vee q \Delta \vee$. & 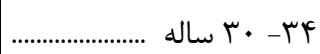 \\
\hline V & $\Lambda T \wedge$ & $1.9 r$ & $1 \wedge 98$ & وس" & 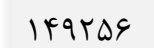 & spqrV. & Vqquя & q \\
\hline f & 941 & r & $\mid \Delta \varepsilon \wedge$ & gr & $\mid \Lambda \Lambda \cdot r \Lambda$ & $F \& \mu \cdot r \Delta$ & sDIr.q & 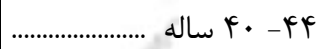 \\
\hline$r$ & $1 \cdots r$ & fro & Ifrq & $r \cdots$ & $r r \cdot q v$. & rIArqD & $\Delta ץ \wedge ৭ \& \Delta$ & q q \\
\hline r & $1 \cdot 1$ & TIV & IrTg & IVG & 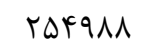 & سותו & fefrgy & ....................... \\
\hline$r$ & $q \cdot V$ & $|f|$ & $1 \cdot \Delta \cdot$ & $I V \wedge$ & rqVFV & $11 \pi \cdot v$ & FI. VTh & ماله ..................... $ه 9$ \\
\hline r & $v \Delta \Lambda$ & $\Delta V$ & $\wedge 11$ & 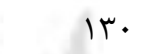 & $r \Lambda l \cdot r$. & DVATF & rr人qVF & 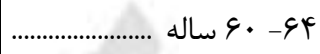 \\
\hline . & pre & r & FQq & 114 & rTAVVt & TDTDQ & rAFIFA & ...................... 99 - 99 \\
\hline & tre & ir & rᄉs & 119 & $19 \cdot \Delta q F$ & IIrTa & $I V T \cdot D$ & ساله .................. $V \cdot V^{f}$ \\
\hline 1 & עr & \& & mpF & TIV & rvequs & $9 \cdot 11$ & TAETFY & VQ ساله و بيشتر ........................ \\
\hline
\end{tabular}


سا - 1 - جمعيت 9 ساله و بيشتر بر حسب جنس، سن، وضع سواد و سطح سواد

\begin{tabular}{|c|c|c|c|c|c|}
\hline \multicolumn{4}{|c|}{ باسواد } & \multirow[b]{2}{*}{ جمع } & \multirow[b]{2}{*}{ جنس و سن } \\
\hline 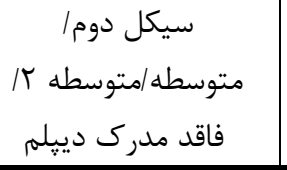 & | پايان راهنمايى/متوسطه إهنمايى، & | ابتدايى/ پايان ابتدايىى & جمع & & \\
\hline DarFar. & Ireira. & larigrer & ereqgye. & vid.erar & 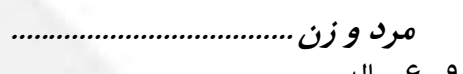 \\
\hline & & $F \Lambda \cdot T F \Delta Q$ & $\forall \wedge F \cdot V \& D$ & $\Delta \cdot \Lambda F F \cdot r$ & \\
\hline IFFYAF & rQIIFYV & TQוATrT & DQ INAFF & DGMAYAF & e \\
\hline 199011. & 9т9५91 & TMTMEF & $\Delta M F \cdot T \Delta F$ & DFब८१qV & 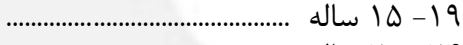 \\
\hline$\Delta \wedge 9999$ & NIrAFF & ६१९१९१ & $94 \cdot . v 9 V$ & GัMYAVq & 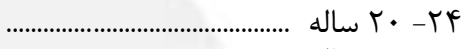 \\
\hline sqrave & ITAFIVT & AFrutk & $\vee q \cdot \Delta \cdot \wedge r$ & r & \\
\hline 9.9TrT & IFFATIQ & $114 q \Delta q F$ & NTAFYGQ & 19...91\% & \\
\hline $\mathrm{FV} \cdot \lambda \mathrm{kT}$ & ITFOATA & וrוrq.4 & $99.991 \mathrm{r}$ & $V \cdot r V \Delta Q \Lambda$ & q \\
\hline 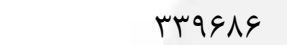 & $1 . \mid V \& 10$ & Irqkrt. & RQYHrTI & $\Delta \Delta \backslash \Lambda Y \cdot V$ & .................... \\
\hline rqT.91 & $\wedge$ ^৭৭৯১ & |rVTar| & Fllfrar & FATITI & 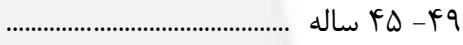 \\
\hline rIII91 & $\Delta V \cdot \Delta T \Delta$ & 1. MFTFD & $r \cdot v r r \Delta \Lambda$ & 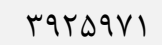 & ماله \\
\hline irkfq. & $r r \cdot \wedge 9 \Delta$ & MAFVES & $r$ r.qrqr & $r r \Delta \cdot \Delta q \mu$ & 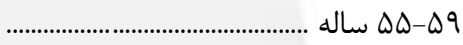 \\
\hline VVDGY & IMAFT. & GqVqVF & $10 T Y 199$ & TAFTAVT & 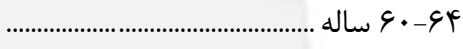 \\
\hline אוTM & 1.rVוג & FIGFYF & $\Lambda \& 1 r \Delta \Delta$ & IVIIIEY & 9 \\
\hline rergu & ఎ१९ाq & 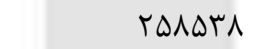 & FqVFFF & IIVVGTS & ساله $V \cdot-V^{\natural}$ \\
\hline$T F \cdot \Delta I$ & $91 \cdot V^{k}$ & rTqYяA & DQTKG. & 19ATETQ & ساله و بيشتر ........................................ \\
\hline MIAFYEA & efrrilad & $199|F F|$ & rrqirqir & relevate & مرد ............... \\
\hline & & TFEITRI & $Y F \lambda \cdot V \Delta V$ & $r G \cdot \Delta T I F$ & 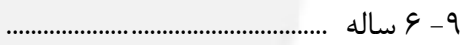 \\
\hline VIVQ9 & ITQY.QT & IFq. $1 F q$ & TAVYATY & rqIIFr & fe \\
\hline $1.091 \ldots$ & ivil.a & IFr.kT & TKYAITI & TYADSAM & 19 -19 اله .................... \\
\hline$r \Delta \Delta \varphi \cdot \Lambda$ & सrqार. & rTITVR & rIFDDG & rTrgava & 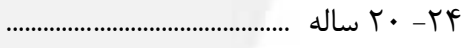 \\
\hline чqщqАर & VEFVTK & ५А११९9 & r.IrVrq & FIFHFYS & 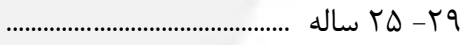 \\
\hline rqADFq & $\wedge 1 \cdot .91$ & DTMTES & 4) $9099 \Lambda$ & FMF.FYA & 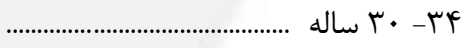 \\
\hline TMITTL & $V r \Lambda \cdot \Lambda F$ & $\Delta q \cdot V I r$ & rFIrVFq & rQVYF.r & 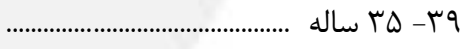 \\
\hline IQYFFA & $\Delta \wedge V \Delta 19$ & $91.10 T$ & TEMTFYT & rAlrAq. & שاله . \\
\hline IFVATD & FAITKI & GKrT.1 & TYTVGDI & TFAFETY & (.................... \\
\hline ITTVGA & rFINIF & YAVG. T & $|V| \cdot \mid Q \cdot$ & 19VQDVF & ساله $\Delta \cdot-\Delta F$ \\
\hline 11rघ9 & $190 \cdot V \Lambda$ & FEgF.t & Irr.rیF & 199994F & 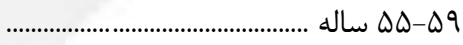 \\
\hline FNIזם & 119Kr. & $r \varphi \Delta \Delta \cdot r$ & GT. F\&T & ITATGGT & (4.......................... \\
\hline rEFI9 & gFVr & THAGTS & DTIFTI & $\wedge \cdot \wedge 91$. & 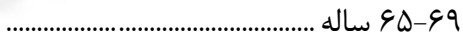 \\
\hline $19 \mathrm{MM}$ & 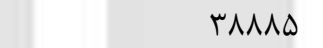 & IQ9T^ब & MYF.FI & QVIIIT & ساله $V \cdot-V^{f}$ \\
\hline $1 V \cdot 9 \Lambda$ & FTTQD & TKTATA & rAV৭\& & 1. TUVT. & ل ساله و بيشتر ....................... VD \\
\hline$r r \Delta \cdot r \Delta \Delta$ & FqYAIAD & 9TrFA91 & ravarafr & rarrasqg & 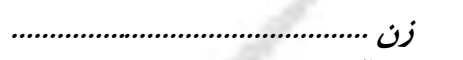 \\
\hline & & THFIIMA & rrs... & rFYqIAq & 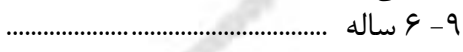 \\
\hline VTETA & ITIQYAD & IFTVD.G & $T V r \Lambda \cdot 11$ & rVYGQ9I & (f \\
\hline $9 \cdot 9 \cdot 1$. & $F \Delta D \mid q T$ & $19 \cdot r \cdot r$ & TEIFITr & rघVTr.q & 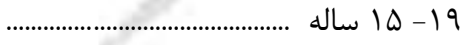 \\
\hline$r$ rI.91 & rVF\&g4 & TVQG.T & $r \cdot \Delta \Delta T M Y$ & $r \mid \Delta \Delta q \cdot \varphi$ & שاله . \\
\hline 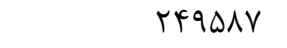 & $\Delta \cdot 94 \Delta$. & FAFTID & rAqTrYG & $r \cdot \Delta V \& \wedge \Lambda$ & 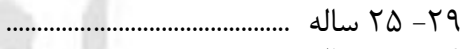 \\
\hline$r F \cdot 9 \wedge \mu$ & $\Delta 9 \Lambda \mid T \Lambda$ & GIVTYA & $r \cdot \Delta \wedge \& T \Lambda$ & FrG. 490 & 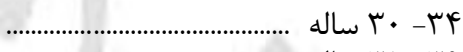 \\
\hline $119 a \cdot 1$ & D. VFFF & VTHIGT & rIqHIGF & $r F 90190$ & q \\
\hline IFTFYA & cr...q9 & VAfign & $r \mu F \cdot \Lambda \Lambda V$ & TV.FYIV & n................ \\
\hline llFAgK & rDAvGY & $V F \cdot 9 r$. & IMMGG4 & rrYAя99 & 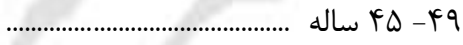 \\
\hline АМґq & rTAVII & DHGG & IrGTr. & $190.49 V$ & 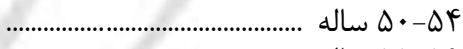 \\
\hline DTITF & ITAVAV & FHATFE & $9 \vee 9 . .9$ & 191.909 & ساله ............................................... \\
\hline rQFTY & $V r \cdot 9$. & T. TFV & $9.9 V \Delta G$ & 1 |Ү१९|. & 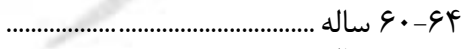 \\
\hline 14q1K & ґА१५. & IVVYQA & rтq৭भF & $q \cdot r \Delta \Delta F$ & 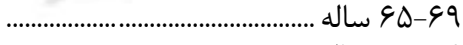 \\
\hline v91. & $r \cdot V \Delta F$ & 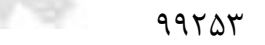 & IVrrqu & 9.901T & ساله . $V \cdot-V^{\digamma}$ \\
\hline $991 \mathrm{r}$ & $114 \vee 9$ & $1.9 \mathrm{kF}$. & 19DFqV & $909 V \cdot q$ & Vاله و بيشتر ....................................... \\
\hline
\end{tabular}


سا - 1 - جمعيت \& ساله و بيشتر بر حسب جنس، سن، وضع سواد و سطح سواد (دنباله)

\begin{tabular}{|c|c|c|c|c|c|}
\hline \multirow[b]{2}{*}{ 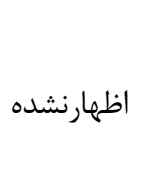 } & \multirow[b]{2}{*}{ 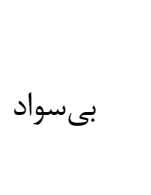 } & \multicolumn{3}{|c|}{ 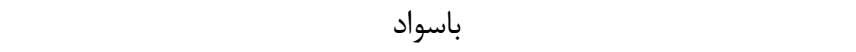 } & \multirow[b]{2}{*}{ جنس و سن } \\
\hline & & تحصيلى نامشخص و اظهاى تحصيلى، دوره & 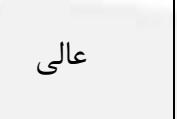 & ييش دانشخاهى و & \\
\hline$q f \cdot v q$ & 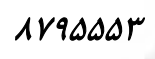 & $r \in V r \cdot r$ & |rgirgal & Ireqrare & 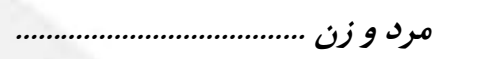 \\
\hline TGTF & $r F|\cdot| F$ & rیr. & . & & 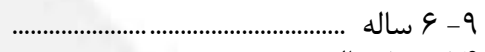 \\
\hline TIAT & veral & rVrqG & TFQ & & ץl \\
\hline TEKT & 1191.1 & ra१vя & GDVGTI & $|F Y \Lambda| \cdot \Delta$ & 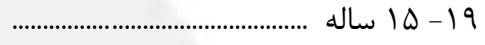 \\
\hline fiv. & IAVqIT & Trtre & TYAETHI & $\mid \vee q 4 \lambda \cdot \Lambda$ & 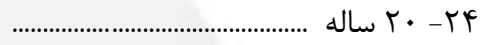 \\
\hline$\Delta \Delta V$. & $r q . \vee \vee q$ & IVTIV & rqAFi.. & TIGTEMG & \\
\hline$\Delta \wedge \Delta \varphi$ & rF.VAl & $1911 \mathrm{~F}$ & TDQVHFA & TFrt. 19 & . . \\
\hline FAMr & FTON.t & $\mid$ IET| & 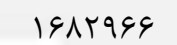 & $|\wedge \vee q \cdot \Delta|$ & q \\
\hline reAt & $\Delta F \mid r \cdot F$ & ITMTE & $1.99 \wedge \mathrm{VI}$ & $11 F T \Delta \cdot \Delta$ & 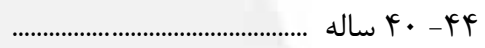 \\
\hline riqf & VIDGTY & 11.ra & $V \wedge \cdot r g F$ & AFYAqF & .......................................... \\
\hline TFQG & $\Lambda \Delta \cdot 11 \mathrm{~V}$ & 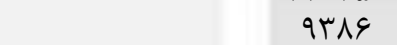 & $0.1 \% F q$ & VE\&\&9T & ساله \\
\hline$r \cdot . q$ & $1 . F Y \mid 91$ & 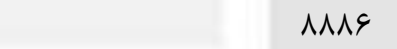 & TOTFIS & 9.499. & 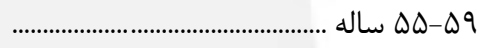 \\
\hline 10. & 1.1 rAVF & 1110 & YFOYYq & FFYAVq & 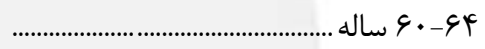 \\
\hline $1 . r 1$ & $\wedge \uparrow q \cdot v \wedge$ & $91 \mathrm{rA}$ & IrIQTA & IGTrTD & 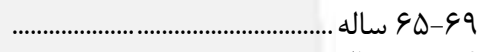 \\
\hline va9 & 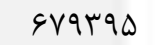 & Fイ९T & $v \cdot 1 \Delta \Delta$ & Vq941 & ساله ه $V \cdot-V{ }^{\natural}$ \\
\hline leVF & IFTVFqD & 1.1. & GTr.人 & GQVDQ & 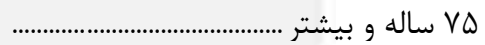 \\
\hline raral & rrTEDIA & Irarag & VIFFTAV & V. prepe. & 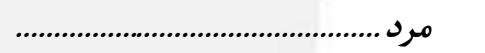 \\
\hline$|r|$. & ITHIFV & $194 \wedge 9$ & & & 9-9 ساله ..................... \\
\hline $111 \mathrm{~V}$ & rgYAr & 1८94. & 1149 & & fl \\
\hline 1919 & QVqYA & $|Q F| \Delta$ & rQ19९9 & 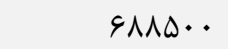 & 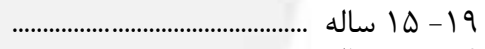 \\
\hline terv & AAVVQ & $119 V 9$ & ItT...8N & ᄉqVघDF & ...................... \\
\hline rkqf & ITRTIT & $q \uparrow a$. & $|F| \Delta \Delta \wedge F$ & $1.09 \wedge T \&$ & ماله ................................ \\
\hline$r \cdot r \Delta$ & $\mid F \cdot V \Delta \Delta$ & $9 \varphi \cdot V$ & 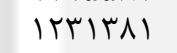 & $11 \mathrm{Vrgq4}$ & 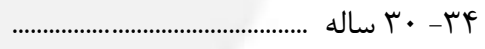 \\
\hline rrv & lQDTVV & AFVF & $\Lambda F M \Lambda \cdot r$ & GFEMFT & \\
\hline reוr & IVANFr & VIAF & GIGG4T & 9ाrs।9 & F \\
\hline TTEV & TYFATQ & GrFV & FqDFV & FEFVVI & ماله . rq \\
\hline IVF. & TEMGAF H H H H H & $\Delta r \Delta G$ & 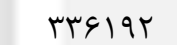 & FIEFIN & ساله ... \\
\hline 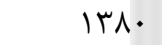 & rrilv. & $\Delta \cdots$ & YFYAGT & rQF\&VD & ......................... \\
\hline 994 & rTITKA & $\forall \lambda \cdot \Delta$ & IVFAFF & KI.ArV & † \\
\hline GDT & TVGATV & ५४१৭ & $9 \Lambda \cdot r \cdot$ & १११४१ & 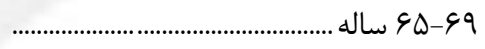 \\
\hline Trt & rFGGT & $r \cdot \varphi_{1}$ & $\Delta \& \& \wedge \Delta$ & DIVDV & 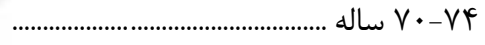 \\
\hline$V \Delta S$ & qur... & 9919 & DTDVD & $\operatorname{csr} \cdot \Lambda$ & 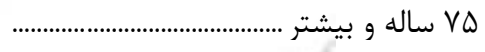 \\
\hline IS\&AM & $\Delta \Delta \varepsilon q \cdot r \Delta$ & 111918 & steqref & segarth & 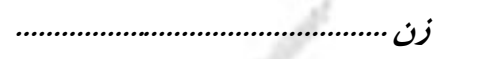 \\
\hline 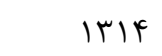 & IIVA\&V & IMAT. & - & 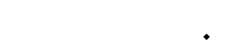 & 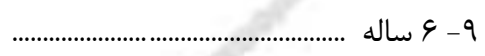 \\
\hline $1 \cdot r \Delta$ & rVq1Q & MFrs & $\Delta q$ & & 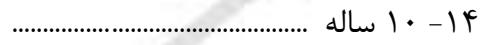 \\
\hline $1 \cdot r$ & $\Delta \wedge \backslash \varepsilon \mu$ & $|f<\varepsilon|$ & $r \cdot \Delta 9 \Delta T$ & $V r a 9 \cdot \Delta$ & 19 اله اله . \\
\hline THL & ११।rV & $1 . \Delta 4$. & IrG9IGK & $\Lambda q V \backslash \Delta F$ & ץ \\
\hline$r \cdot V q$ & IGTYGV & VVAV & $|\Delta \& \wedge \Delta| \&$ & $\| \cdot r \Lambda 1$. & ساله \\
\hline$|\Lambda \mu|$ & $r \ldots q$ & $V r \cdot V$ & IrGQ99V & 1Tळq५१ด & ץ • • \\
\hline $10 \cdot 9$ & $T V \cdot \Delta T \Delta$ & GIFV & NMFISF & $q \mu r v \cdot q$ & q \\
\hline 1.99 & MGTEGI & DIF. & $r \Delta \cdot r T q$ & DrMAIS & 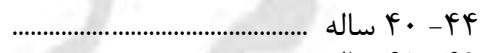 \\
\hline$q 4 \mathrm{~V}$ & (q11.r & 4911 & rAYAMA & 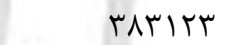 & a \\
\hline VAS & DAGKr & $\boldsymbol{F} \cdot r$. & $19 \Delta \mid \Delta V$ & $r \cdot r V F$ & 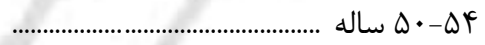 \\
\hline 949 & $V \cdot r \cdot r 1$ & rیMe & $1 \cdot F \Delta Q T$ & $r \Delta \cdot r / Q$ & ساله ............................................ \\
\hline$\Delta \cdot \Lambda$ & GNTEYS & . וזr & $\varphi \Delta F \cdot \Delta$ & $M T H \cdot \Delta T$ & 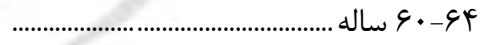 \\
\hline rvq & QVYTFI & roTq & $r r \Delta \cdot \Lambda$ & GTKYG & 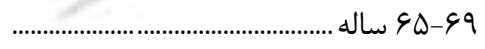 \\
\hline rat & FTTVDG & IATT & IDFV. & rAIAF & ساله ه $V \cdot-V{ }^{\natural}$ \\
\hline ViN & Vq. FqF & m111 & १९५ & $r \cdot \Delta \Delta I$ & 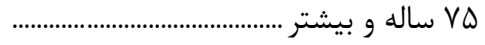 \\
\hline
\end{tabular}




\begin{tabular}{|c|c|c|c|c|c|}
\hline \multicolumn{4}{|c|}{ باسواد } & \multirow[b]{2}{*}{ جمع } & \multirow[b]{2}{*}{ جنس و سن } \\
\hline متوسطه/متوسطه ماقد مدرم/ & يايان راهنمايى/متوسطه اول راهنمايى/ & | & جمع & & \\
\hline FIAFrar & $11 r q \cdot r \Delta$ & $15 \cdot 9 \cdot 9 \cdot 9$ & $F \wedge r \cdot \Delta \cdot \Lambda F$ & arr.vala & مرد و زن ............ \\
\hline & & rFr. 190 & rFDQTH. & $r q \cdot 1919$ & 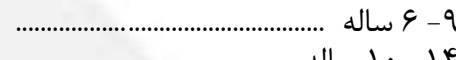 \\
\hline WrAFV & IAVVGYA & $r \cdot . / A V T$ & F.IVATE & F. DSTFY & f \\
\hline$|<q \mu| \cdot r$ & $\Delta \Delta r V \cdot \Delta$ & $1 r q \cdot 14$ & 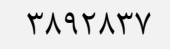 & $r 9 \Delta \cdot 94 \Lambda$ & 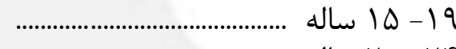 \\
\hline 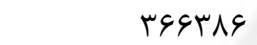 & FQADTE & 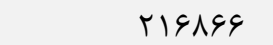 & FYAVGqI & $r \Delta \Lambda \cdot q \mu r$ & 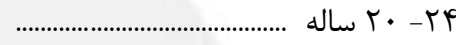 \\
\hline FrNIqR & VAVATI & fir..c & $\Delta 9 \Delta \Delta \Delta \vee V$ & $91 . .914$ & ساله . $r \Delta$ \\
\hline FEVTNI & QATKYA & GIVTDQ & s49IN4G & GQTVVIG & 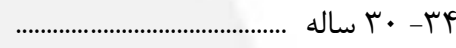 \\
\hline TETDNT & $\Lambda 9 . \Delta I V$ & VDTIET & 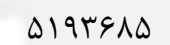 & DYQTYYI & q \\
\hline TVOANI & $V V V \cdot V \Delta$ & 19.rq. & rqTaFts & FIAVAイS & 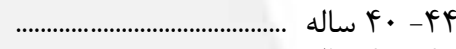 \\
\hline THFAVA & $9 \vee 9199$ & qrrrs. & rMar人gV & $r V r \cdot r q q$ & 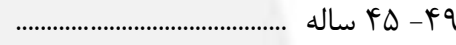 \\
\hline$|\wedge \Delta \cdot Y|$ & FYQDSI & VTFEIV & TAVVETS & $r \cdot \Delta 1 r \cdot \varphi$ & ساله $\Delta \cdot-\Delta \uparrow$ \\
\hline $1 T \cdot 9 V \Delta$ & TVAVAI & $9 \Delta V \cdot 19$ & I9GVFFA & TADFAIT & (1) $\Delta \Delta-\Delta 9$ \\
\hline$v 19 \cdot f$ & $199 \mathrm{rVV}$ & $\Delta T \cdot \cdot \Delta \Delta$ & ITKVGGG & $191 \cdot \Delta F \wedge$ & 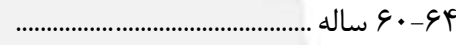 \\
\hline rА१५r & qYquF & - D - 9... & $V \Delta 91.1$ & $\mid r \Delta r \cdot r \Lambda$ & ............................................. $9 \Delta-99$ \\
\hline$r+99$ & $\Delta \Delta \Delta \mid{ }^{\prime}$ & TITAGT & Fflf. 1 & $\wedge+q \Delta \cdot \Delta$ & 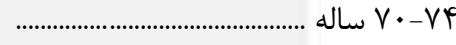 \\
\hline TTATY & DVYGT & TVDIFV & r^q. k. & ITUTGK. & 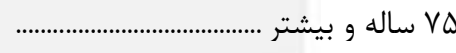 \\
\hline reigri & FAFGFqG & $\Delta 9 \Delta F q 9 \pi$ & ra. FrAFA & revairt. & مرد ............... \\
\hline & & IVQVGTY & $1 V V \cdot r q q$ & $|\wedge \uparrow q| \& \Delta$ & 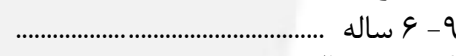 \\
\hline QSQT. & 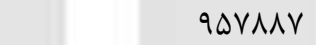 & 1. 1. & $r \cdot \Delta \Delta ৭ 9 r$ & $r \cdot V Q \mid \wedge Q$ & 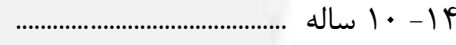 \\
\hline 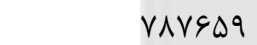 & TATVTF & 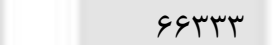 & 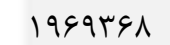 & r...rru & 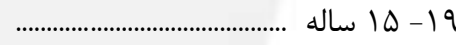 \\
\hline$T T \cdot T \Delta V$ & TFEMFI & 1.199. & TYIFYAS & TYQIT.D & (1) \\
\hline rQVDVq & ४९१५१९ & T.r.TAV & 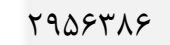 & T. TFY.. & ساله . $r \Delta$ \\
\hline 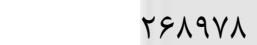 & 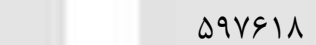 & 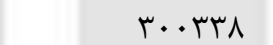 & TMFTEET & rTINQAS & 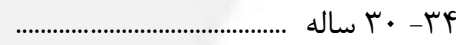 \\
\hline$r 1.94 \Delta$ & 019910 & TFAFAT & TEDITLT & TVYATra & ( \\
\hline IDTAKT & FTIDAF & TEVVAI & T.YATIV & MITERYG & (1) \\
\hline ITIGKG & rVY491 & $4 \cdot 9119$ & $\mid V \wedge F q\} \mid$ & $19 \cdot Y \cdot 9 V$ & .................................... \\
\hline 1. rर\&D & TVETEF & TrQTqF & $\mid F \cdot$ rG9 & IDFEDTL & (..................... \\
\hline$V \cdot g+1$ & IETIKT & $r \cdot \Lambda r k \varepsilon$ & $11.4 \& \Delta r$ & $\mid$ |YQQYT| & ساله هـ-....................................... \\
\hline Frato & 1.1199 & TQDATA & VVAvqI & Q9. सr. & 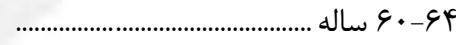 \\
\hline FFFIF & $\Delta V \Delta \Delta T$ & IV9991 & FDFFFq & $G \cdot \Delta \cdot V \Lambda$ & \$............................................. \\
\hline IQTHE & $r \Delta r \Delta F$ & ITrKa. & TVqTAT & FIOTAK & 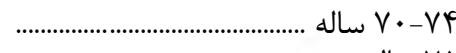 \\
\hline 10994 & $r q \cdot \vee \wedge$ & IVEF.T & 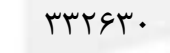 & GNTA. 9 & ل ساله و بيشتر ............... \\
\hline $114 r \cdot 18$ & ragrara & gIragir & rerarres & refierqa & 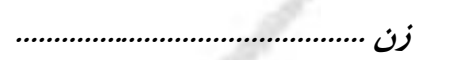 \\
\hline & & $\mid$ ISTSHI & $|\varepsilon \wedge F q 4|$ & IVQQATI & 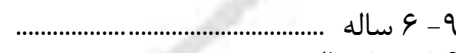 \\
\hline DVYIV & $919 \vee 41$ & qVTGY. & 1991NFF & $1911 \cdot \Delta V$ & f| \\
\hline$V \cdot \Delta F F F$ & $r V \cdot q \Lambda 1$ & VYGVG & 19RrKG9 & $190 \cdot r \cdot r$ & 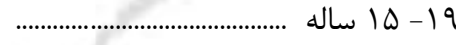 \\
\hline $14 q \cdot r q$ & KITIND & llFAVG & TYYMY.D & rMIQVYA & 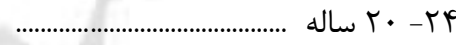 \\
\hline$|V \cdot 9| \mathrm{F}$ & TIATTK & TITVIq & r999191 & r.VGFIF & 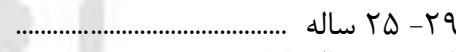 \\
\hline$I V A F \cdot r$ & rAFVr. & MI991V & rTINזAr & $r r \cdot q 1 r$. & ………........................ \\
\hline IDIEFV & $r V r q \cdot r$ & $r \cdot v \& v q$ & TAFTMTY & 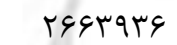 & q................... \\
\hline IrT. rq & MFDFqI & 1949. 9 & IAVRTI9 & $r \cdot \Delta / \Delta F$. & 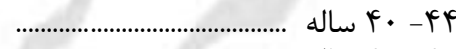 \\
\hline $1 . r 9 \Delta r$ & $r \cdot \Delta \Delta r \Delta$ & D1Eरq1 & IDSVGYG & INTAY.r & 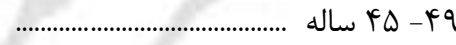 \\
\hline NIIVe & T. TrQY & L.q.r & $\| V R V \Delta \Lambda$ & $10 \cdot F V V \mid$ & ساله $\Delta \cdot-\Delta f$ \\
\hline$\Delta \cdot . r F$ & $11 \Delta G \mu q$ & MFAVF. & NGYYQD & $|r \& \wedge \Lambda \Lambda|$ & 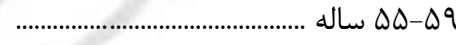 \\
\hline rATVQ & 9V911 & TAFIN. & DFAAVA & 90.111 & 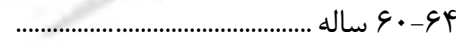 \\
\hline $1 F \Delta \cdot q$ & rVYAl & $1 \Delta 9 r \cdot r$ & $r \cdot \varphi \& \Delta T$ & \&YVqD. & 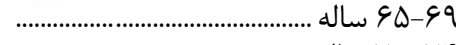 \\
\hline VVr. & $r \cdot 109$ & NaYAr & $19 T \cdot \Delta 9$ & FMETTE & 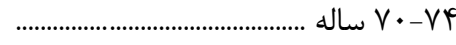 \\
\hline GNH & INTAD & $q \wedge \vee \vee \Delta$ & 10941. & $9 V \cdot|r|$ & ساله و بيشتر .................................. \\
\hline
\end{tabular}


را - 1 - جمعيت \& ساله و بيشتر بر حسب جنس، سن، وضع سواد و سطح سواد (دنباله)

\begin{tabular}{|c|c|c|c|c|c|}
\hline \multirow[b]{2}{*}{ 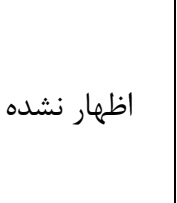 } & \multirow[b]{2}{*}{ 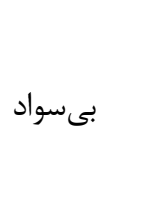 } & \multicolumn{3}{|c|}{ باسواد } & \multirow[b]{2}{*}{ جنس و سن } \\
\hline & & تحصيلى نامشخص و اظظهاى تحصيلى، دوره & 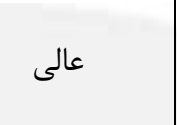 & 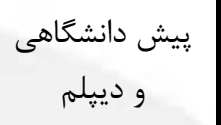 & \\
\hline 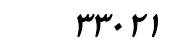 & FAqqFi. & $|v \& 91|$ & Irerilr & $11 F \Delta \cdot q V T$ & 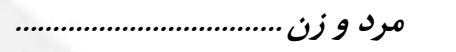 \\
\hline 1199 & $101 \wedge 9$. & $r \Delta \cdot 9 \Delta$ & . & & 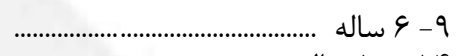 \\
\hline $10 \cdot 9$ & एव911 & TFT. D & IV & & 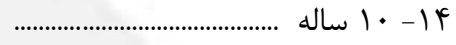 \\
\hline $1 M M \Lambda$ & $\Delta \Delta 91 \%$ & r|AYI & DVTATV & $111 r \varepsilon \Delta 9$ & 19 اله ................................ \\
\hline$r .49$ & $9 \cdot 1 \vee 9$ & 19949 & rMlGarA & ITITVDS & (1ل \\
\hline FTA. & $\mid F \cdot V \Delta V$ & $|r \cdot \Lambda|$ & T9.194D & $|V \cdot r V T|$ & 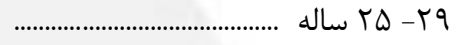 \\
\hline farr & $181 \% 91$ & $\mid$ TKA| & rrGArTq & t. TETAT & 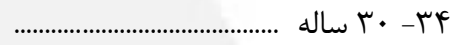 \\
\hline rVוq & I9FNGV & $1 \cdot V 91$ & $|\Delta 9| \cdot r 9$ & 191DSTV & 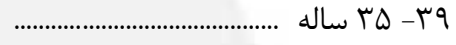 \\
\hline rیrq & rब१९ाI & $91 .$. & १৭९१८५ & $1 . .4 \cdot r \Lambda$ & ماله \\
\hline TEFT & $r V \Delta \cdot \wedge q$ & הזוl & $V k \cdot 119$ & VVGa人r & 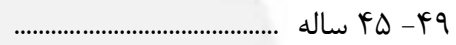 \\
\hline 1919 & FV।991 & VIqF & $\because \vee \wedge \Delta \Delta \Delta$ & $99 \Delta 9 \Delta \Lambda$ & (.................... \\
\hline IFAD & $\Delta \wedge \Delta \wedge \vee q$ & GAVG & MTEFQA & $\Delta Q V Q q T$ & ساله .................................... $ه$ س \\
\hline IITV & $\Delta \Lambda \backslash V \Delta \Delta$ & GTDF & THT. 11 & rTAT.Q & \\
\hline VEV & FquाA. & k99k & ITATAT & IDSTQA & 9 99 \\
\hline$\Delta V_{1}$ & F.VATG & $r \Lambda \cdot \Delta$ & $9 \wedge 909$ & $V V Q \cdot \varphi$ & 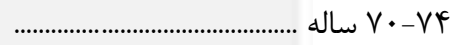 \\
\hline ११५ & 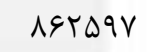 & VArF & $G \cdot 1 k t$ & $G D \cdot r V$ & ساله و بيشتر ......................................... \\
\hline rirr. & $|r r r| \cdot r$ & qfVrg & qurrabs & $\Delta V \Delta r r \cdot r$ & 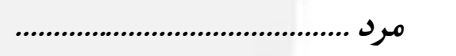 \\
\hline $9 \Delta \Lambda$ & $\vee \vee q \cdot \wedge$ & 1 1K990 & $\cdot$ & . & 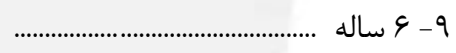 \\
\hline vq. & $\mid \Lambda F \cdot F$ & ITr.F & $1 \mathrm{r}$ & & 14 \\
\hline $11 \mathrm{Vr}$ & rqvqf & $11 \cdots 1$ & rq৭४९৯ & DTTIAT & 19 اله س............................... \\
\hline $194 \mid$ & FFq91 & Nret & 1 1 1 1 1 1 1 1 1 & GTrANF & ساله $r$ r \\
\hline rat. & QDI9F & $9 \pi \cdot \Lambda$ & $11994 \mathrm{FT}$ & NIGKAT & q \\
\hline आIו & $V T \cdot \Delta$ & $9 \wedge \Delta \Delta$ & $11 \cdot \Delta \Delta \Delta$ & QGFITF & 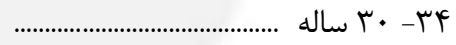 \\
\hline$r \Delta \Delta \varphi$ & VFFTE & बादा & VrVDr. & vargiv & qr \\
\hline$r \cdot 1 \cdot$ & 19119 & DTAT & DQVGQF & $\Delta T Y \cdot V F$ & n \\
\hline 1991 & $\| \Delta F \Delta \Lambda$ & $k V \cdot q$ & FEATET & FIrATr & 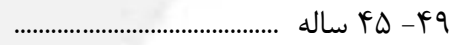 \\
\hline$|r F|$ & IFIDTE & F.rq & rIVTVQ & rYAAri & ......................................... \\
\hline 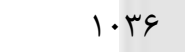 & IN. TFT & rvis & rтr人q1 & rYYqTV & ساله ............................................... $ه$ \\
\hline VAT & $\Lambda \Lambda \cdot \Lambda \Lambda V$ & TQTF & 19VQDQ & ।१९९Q४ & ......................................... \\
\hline FAT & $10.1 \mathrm{FV}$ & rQVQ & $9 \Delta \backslash \Delta \Delta$ & $9 \Delta \cdot \Delta \cdot$ & $9 \Delta-99$ ساله ........................................ \\
\hline 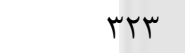 & $1 r \Delta s \cdot \Lambda$ & trme & DrTDF & सq८9 & ساله ............................................ \\
\hline pqr & rFqY^S & $\Delta 1 \cdot \Delta$ & 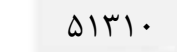 & fFYel & 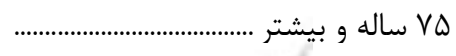 \\
\hline||$v a \mid$ & rIfrr.1 & Arrad & $\Delta q T \cdot 1 \Delta \Delta$ & D\&qr\&\&A & 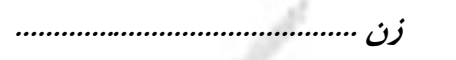 \\
\hline $9 \cdot 1$ & vrqur & ITF.. & - & $\cdot$ & 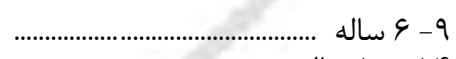 \\
\hline vis & $\Lambda \Lambda \Delta \cdot V$ & $|r| \cdot 1$ & ra & . & F \\
\hline VIS & r8119 & $1 \cdot \Lambda r$. & $r V r \cdot 9 q$ & $\Delta q . F \vee Q$ & 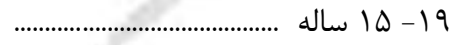 \\
\hline$\| F \Delta$ & FoIVA & ATAG & $\| 1 / \pi / \Delta V$ & GVAAVT & (1) \\
\hline 199. & $V D \Delta G K$ & $\Delta V V r$ & $\| F \cdot \Delta \Delta \mid F$ & MAGKFq & 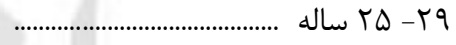 \\
\hline IFAF & А१९९ा & DrqG & ITERVVG & $1 \cdot v \cdot 101$ & 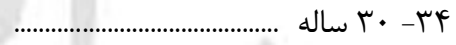 \\
\hline llar & $|r \cdot k \mu|$ & FQ91 & VAFYAS & $\Lambda T I \cdot T \cdot$ & q \\
\hline $1 q^{\prime}$ & IVTKGT & 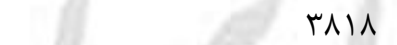 & FTaTM & FArQGF & 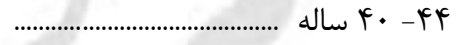 \\
\hline VFa & TQQGTI & $r q \cdot \Delta$ & rVGQQY & reTVEG & ساله . $4 Q$ \\
\hline$\Delta \vee \wedge$ & (r. & rIDQ & $191 \% 1$. & mIgNtr & ساله ................................... \\
\hline prq & $F \cdot \Delta \& \Psi V$ & mis. & 1. TASV & TFYGDS & ساله ......................................... $ه ا$ \\
\hline rva & $\uparrow \cdots \wedge \& \wedge$ & TVR. & GEAOT & ITITAT & (4 \\
\hline rघa & 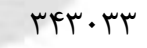 & $r 110$ & $r r \cdot q v$ & GITHA & $9 \Delta-99$ ساله ....................................... \\
\hline TFA & TVI9וA & 1099 & $1 \Delta r \cdot r$ & TVNIF & ساله .................................... \\
\hline$\Delta \cdots$ & DIrTII & TVYq & qDTK & $r \cdot r \wedge \varepsilon$ & 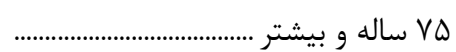 \\
\hline
\end{tabular}




\begin{tabular}{|c|c|c|c|c|c|}
\hline \multicolumn{4}{|c|}{ 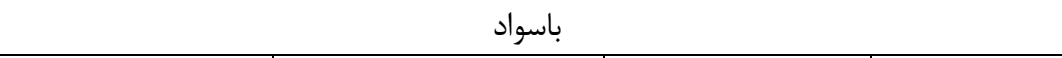 } & \multirow[b]{2}{*}{ 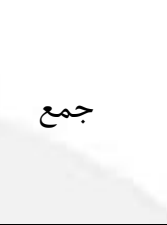 } & \multirow[b]{2}{*}{ جنس و سن } \\
\hline 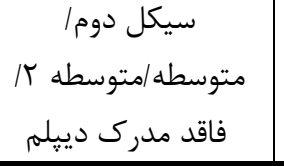 & 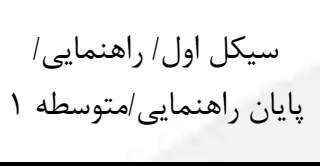 & | ابتدايى / هايان ابتدايى سواد آموزى & 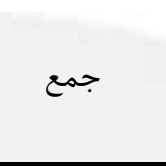 & & \\
\hline Irevagr & relsqug & 911.911 & IFrmer.r & IATAFEA1 & مرد و زن . \\
\hline - & - & 1 1тя৭६q. & IrArqrg & IFVTYV. & 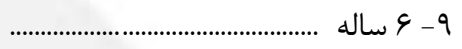 \\
\hline$r \cdot \Delta \cdot q$ & grrq. r & 91 rVq4 & $109 \cdot 14 \Delta$ & IETAIFT & 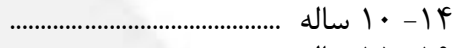 \\
\hline FVIT人q & 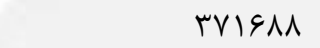 & $19 \mu \cdot r \mu$ & IfFr人q1 & ID. FTT. & 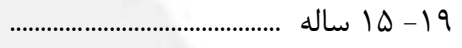 \\
\hline r) 9949 & rofDGq & rVAVGT & $I V \cdot q \cdot r V$ & 11.9910 & 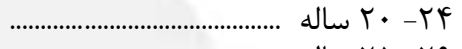 \\
\hline$r \cdot \Delta \cdot V q$ & 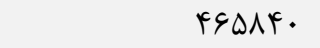 & Fr人qTT & 19409.9 & $r \cdot 9 \Delta \wedge \Delta \wedge$ & 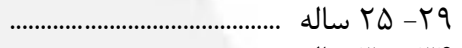 \\
\hline $19109 V$ & FEDTHF & $\Delta T_{1} \cdot 9 l$ & IV^৭ฯ^. & 19९949F & • • • ساله . . \\
\hline $1 \cdot 1 \cdot 99$ & raftre & $\Delta \Delta 9 \Delta \backslash V$ & $|f| \cdot V m G$ & IEFIFTV & q \\
\hline qrv.r & $r \boldsymbol{r} \cdot r \cdot r$ & טrrqAV & 1. F\&TEV & ITTVTtG & 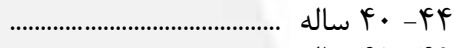 \\
\hline ryfe. & $\mid \varepsilon \cdot \Delta \mu_{1}$ & FFAVTF & $V G \cdot|r|$ & $1.998 \wedge \wedge$ & ساله $r d q$ \\
\hline$r G \cdot \Lambda t$ & qTAFt & rqqu凶d & $49019 \mathrm{~V}$ & AVTYTV & • \\
\hline irvq. & $F r \cdot r q$ & trRTIN & THFTt & VqTuVr & ساله $ه$ س $ه ا$ \\
\hline$\Delta 9 \Delta 1$ & r & IFVVGV & ।99rV। & q & 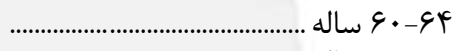 \\
\hline$r r \cdot r$ & AVVr & 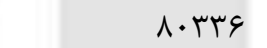 & I.rIT & FQVRFq & 9D-99 ساله . \\
\hline | & fItr & FD\& & $\Delta \Delta ৭ \wedge \mu$ & rtRe. I & ......................................... ساله $V \cdot-V k$ \\
\hline ITrT & $r V \cdot \Delta$ & $\Delta F \cdot \Lambda \cdot$ & GFrad & 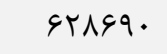 & 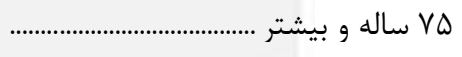 \\
\hline ArIarA & I 1114rm. & $r \cdot r \wedge q 1 f$ & rAFAqAr & qrara.r & مرد .......................... \\
\hline - & & R. TrG. & $V \cdot q \cdot V \wedge$ & VDFrqV & 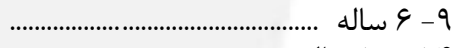 \\
\hline$|\Delta T| \mid$ & ( & FG. THQ & $\wedge 1 \Delta q \cdot \Delta$ & NFFIrd & | \\
\hline rqVqVA & 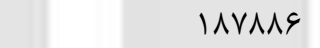 & Velfe & VDFVQD & $\vee \wedge r \cdot \Delta q$ & 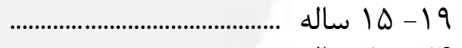 \\
\hline $1 r \Delta \cdot$. & |9rसG| & $11 \wedge V \cdot r$ & 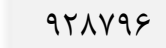 & QYTAT. & 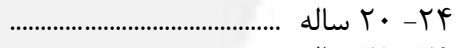 \\
\hline ITET·D & rVYAGK & $|\Lambda \Lambda| F F$ & $1 \cdot \Delta F \backslash \Lambda \Lambda$ & $1119 \Delta \mathrm{VA}$ & ج \\
\hline qqfrर & rNT. & 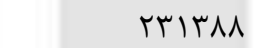 & $9 \Delta \cdot 9 r \Delta$ & $1.191 \mathrm{TF}$ & • • • ساله . . \\
\hline$V \cdot r \wedge q$ & trI.Nt & TFFe. 9 & VG. 949 & $A F T \cdot 9 D$ & q \\
\hline Frtal & $|\Delta \Delta V| \wedge$ & TFINDT & DATTtT & 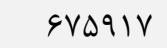 & 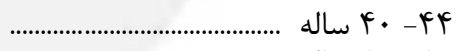 \\
\hline 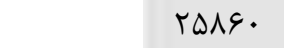 & 1.Vrgr & rrFq.. & FFINTE & מט & 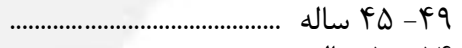 \\
\hline IANVD & GVFAN & $1919 \cdot r$ & $r \cdot \Delta q \& F$ & FrVAr. & • \\
\hline $1 \cdot v \cdot r$ & r & ITVATI & rtartq & TATAFF & .................... $\Delta \Delta-\Delta 9$ \\
\hline$F \Delta \cdot r$ & $10 \cdot 1 V$ & १৭४זЬ & IFIFFV & rqIT\&D & 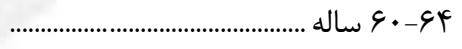 \\
\hline 1991 & VTIQ & $\Delta \wedge \wedge \varepsilon\rangle$ & 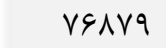 & $r \cdot r t \cdot r$ & $9 \Delta-99$ ساله \\
\hline $1 \cdot \Delta 1$ & rarq & $r \Delta \wedge \vee \wedge$ & fFeDA & 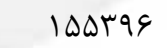 & ساله V•-VF \\
\hline $1 \cdot v r$ & מוtr & FETA & $\Delta D Y \Lambda F$ & MFTEFE & VD VD و بيشتر ........... \\
\hline DrgFeF & 1 prre.9 & $r \cdot 1 r r v f$ & sFAarT. & $19 \cdot r / 10$ & 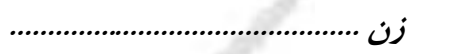 \\
\hline • & - & GQVFT. & GVMAYA & VIVAVr & 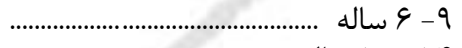 \\
\hline $10 Y 9 \Lambda$ & rq৭TFD & 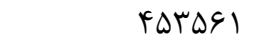 & VVFFE. & 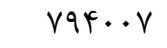 & 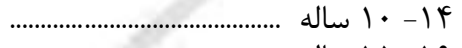 \\
\hline 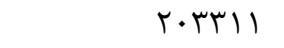 & $1 N r N \cdot r$ & $119 \wedge \Lambda \Lambda$ & $9 \wedge 91 \cdot r$ & VTIISI & 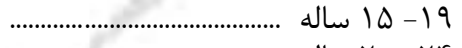 \\
\hline NFqrq & IETr. 1 & $19 \cdots 09$ & RN.tri & ArFIGD & 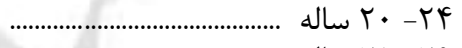 \\
\hline 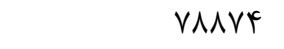 & $19.9 \mathrm{Vr}$ & $r F \cdot V V \wedge$ & $\wedge 91 \vee \backslash \wedge$ & १マ৭५^. & 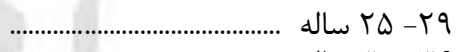 \\
\hline GTIVD & $|\wedge T| V \mid$ & rq৭\&VT & $\Delta \mu q \cdot \Delta \Delta$ & $q<q \Delta V$. & 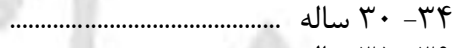 \\
\hline rVVVV & lmmq & rifq.人 & spqrV. & V११rद५ & q \\
\hline$t \cdot$ trd & NFFAD & rqIIrT & 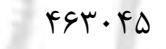 & $9 \Delta 1 T \cdot 9$ & 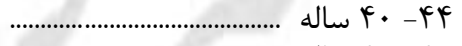 \\
\hline $11 \Delta \Lambda$ & $\Delta M I G \Lambda$ & TtMATK & TINT⿱Q & $\Delta \digamma \wedge 9 \hookrightarrow \Delta$ & 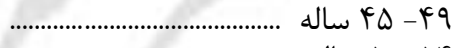 \\
\hline$V T \cdot q$ & TEMAF & ITVFAT & سוזr & fFergy & •-QF ساله . \\
\hline$r \cdot \wedge \varepsilon$ & 1.114 & 1949V & IIr.Vr & $F_{1} \cdot V T \Lambda$ & 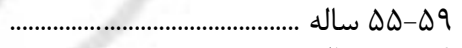 \\
\hline $11 \mathrm{FV}$ & $|f| \cdot 9$ & FATET & $\Delta V A Y F$ & 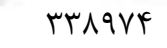 & 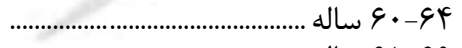 \\
\hline$f \cdot r$ & $I \Delta \Delta V$ & TIFVD & TDTDQ & TAFIFD & 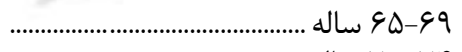 \\
\hline $11 \cdot$ & $\Delta q F$ & १४९। & IITHO & $I V T \cdot D$ & ساله ........................................... \\
\hline 149 & pqr & veqr & $9 \cdot 11$ & TAGTFF & 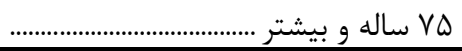 \\
\hline
\end{tabular}




\begin{tabular}{|c|c|c|c|c|c|}
\hline \multirow[b]{2}{*}{ اظهارنشده } & \multirow[b]{2}{*}{ بي بوسواد } & \multicolumn{2}{|c|}{ باسواد } & & \multirow[b]{2}{*}{ 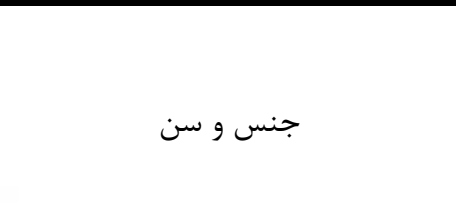 } \\
\hline & & تحصيلى نامشخص و اظهار نشاى تحصيلى دوره & 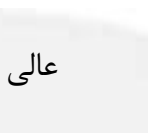 & و و و ديش دانشعاهى & \\
\hline $1.9 \Delta \Delta$ & $r q . q F \mu l$ & $V \cdot r e V$ & IrFATE & rerat.. & 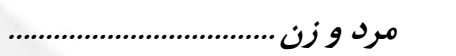 \\
\hline VDI & $\Lambda \Lambda \Delta q \mu$ & פ & . & & q-9 ساله . \\
\hline GFT & rVIra & $1 r \cdot \lambda f$ & vr & & 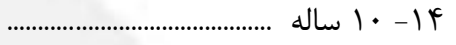 \\
\hline $\operatorname{VEa}$ & $\Delta 9 \Delta V V$ & $\lambda \cdot k f$ & $\Lambda \& 9 \Delta \Lambda$ & TIFAND & 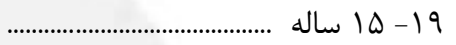 \\
\hline 1.94 & १९人ৎ૬ & $\Delta q \cdot 1$ & r99.99 & FAll.. & ( \\
\hline$|r \Lambda|$ & $|F \wedge \& V|$ & DITA & rNIG94 & FQQTVR & 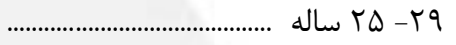 \\
\hline ITVV & IVNAry & $F \Delta \Delta \&$ & TTMATK & rq人४i. & 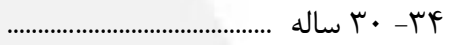 \\
\hline 110 & rTQDFI & rAfv & IrIAKq & $r q r \cdot \Lambda 1$ & \\
\hline Nro & $r A \cdot I T F$ & rTI9 & 9914r & 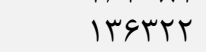 & ........................................ \\
\hline VEF & 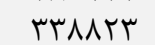 & rVIA & $r q \Delta \cdot r$ & VIr.a & (اله $r q$ \\
\hline$\Delta V \cdot$ & rVG4G. & r।19 & TTVED & 0.994 & 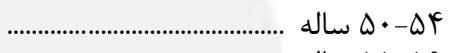 \\
\hline DT. & FAFET. & $r . . q$ & loqf. & TVMTE & ساله ....................................... $ه$ \\
\hline rev & $k r \cdot 9 \cdot 1$ & $1 \wedge \Delta \Lambda$ & NTTA & lagk4 & 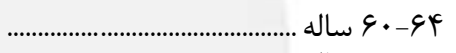 \\
\hline tAT & rofqrq & lark & rTV & $\Delta 9 Y 1$ & 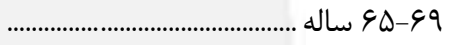 \\
\hline TME & rVIIqF & $1 . \Delta \Lambda$ & 1491 & TEMF & ساله V•-VF \\
\hline FVD & $\Delta G M \wedge \Delta$. & TrGG & 11490 & IVTV & 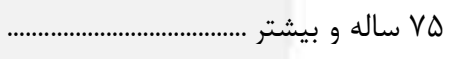 \\
\hline$r \cdot q r$ & $\mid F q \varepsilon F \Delta A$ & $f \cdot q 1 b$ & $11 \cdot 141$ & Irefref & مرد \\
\hline rFA & fqqui & 9111 & . & & 9-...................................... \\
\hline TTQ & $1 \vee q \cdot 0$ & GVQT & i & & ץ $\mid$ ساله \\
\hline fer & tYATI & $r \varphi \cdot 1$ & DTFIG & 190991 & 19 اله ................................. \\
\hline vil & שודזי & 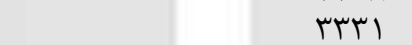 & r|GTal & TETIF. & ساله \\
\hline 199 & G|QT| & rirv & rIMAIV & tKt.tt & 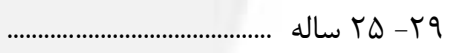 \\
\hline$q \cdot r$ & S人ras & triq & $I T \Delta V \cdot V$ & r.9r91 & \\
\hline $11 f$ & $\Lambda \cdot r \Lambda \Delta$ & $r+1$ & VII9V & $\mid D I F A \Lambda$ & \\
\hline$\Delta 99$ & $94 \cdot 99$ & 1191 & 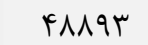 & $910 \cdot r$ & ماله \\
\hline DFF & 1.人rar & 1948 & rITIQ & $\Delta \cdot \Lambda \Delta T$ & 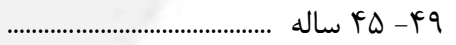 \\
\hline rqf & ITIFVT & IrIS & 1119. & TVATY & 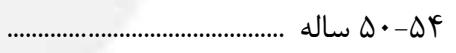 \\
\hline MET & $\mid \Delta V I \Delta T$ & ITAK & 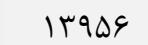 & ra९AT & ساله ........................................... \\
\hline r r & $|f q \Delta \wedge|$ & IrVq & VTVD & IrAkV & q \\
\hline 191 & $|r \&| \Delta V$ & $1 \cdot r$. & TAGT & rarr & 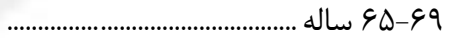 \\
\hline $1 \cdot 1$ & 11.94. & $\Lambda \cdot \Delta$ & . זrון & $r \cdot 90$ & 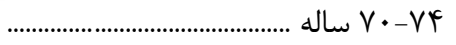 \\
\hline$r \Delta \Lambda$ & rی९q.r & IMAF & IrGF & lifer & 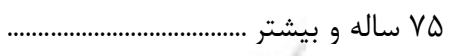 \\
\hline raqr & reIrgrr & ragrer & $\Delta r A v \cdot \Delta$ & qveare & زن ................. \\
\hline$r \cdot r$ & FTETr & $8+11$ & - & . & 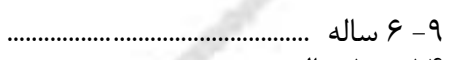 \\
\hline MIV & $19 r \mu$. & Grre & ry & & 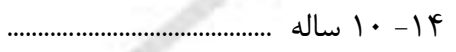 \\
\hline$r \cdot r$ & MIVDS & 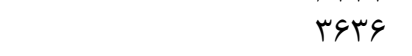 & TYQFT & IFAqTF & 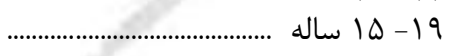 \\
\hline rیl & $\Delta T \Delta \Delta T$ & rTV. & $1 \Delta r \lambda \cdot \Delta$ & rivas. & 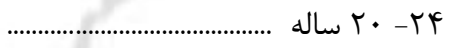 \\
\hline FIr & $\wedge \vee \backslash \Delta$. & 1991 & IGTAEV & rIETAI & \\
\hline rVF & $|1| 4 \mid$. & $11 \cdot 9$ & $1 . \mu 110$ & $1 \wedge 911 \%$ & ماله \\
\hline 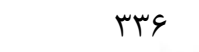 & IFqTDG & loks & $\Delta \cdot 9 \Delta T$ & 111094 & ......................................... \\
\hline צ & $M \Lambda \cdot r \Lambda$ & $\mid$ & $r \cdot q r$. & FYAT. & ماله \\
\hline r.. & $r r \cdot q V$. & $1 \cdot \lambda r$ & $\Lambda T \wedge$ & $r \cdot r \Delta T$ & 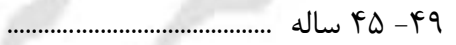 \\
\hline IVe & TQFqMA & AVr & rAVQ & IrFF. & صاله $\Delta \cdot-\Delta F$ \\
\hline IVA & rqverv & VTS & $191 \mathrm{~F}$ & VGaF & ساله ........................................... \\
\hline Ir. & rAI. T. & $\Delta \vee q$ & $9 \Delta \mu$ & rVqV & 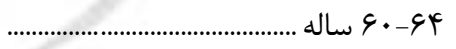 \\
\hline 114 & TrAVVT & fif & (4) & 991 & 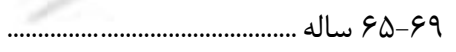 \\
\hline 119 & $19 \cdot \Delta 94$ & TAT & 191 & raq & 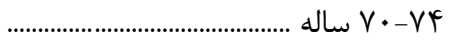 \\
\hline TIV & TVGqYG & rat & 1.1 & $r \varphi \Delta$ & 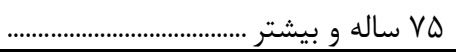 \\
\hline
\end{tabular}


| | | - جمعيت 9 ساله و بيشتر در حال تحصيل بر حسب جنس، سن و دوره تحصيلى

\begin{tabular}{|c|c|c|c|c|c|c|}
\hline \multicolumn{5}{|c|}{ محصلين داخل كشور } & \multirow[b]{2}{*}{ 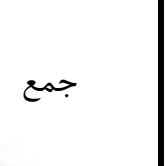 } & \multirow[b]{2}{*}{ جنس و سن } \\
\hline رِيش دانشخاهى & متوسطه r متوسه| & متوسطه | & سواد آموزى إيى & جمع & & \\
\hline llerarr & 1918rTf & $r \cdot$ lavar & VAFAFET & $\mid V \varepsilon a \cdots a$ & IVvrrase & 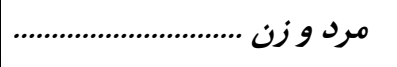 \\
\hline$\cdot$ & . & . & $1 \cdot 9 V \cdot V r$ & 1.VOYA. & 1. VEVFV & ع ساله ................... \\
\hline$\cdot$ & · & • & $|r| 9 \Delta \Delta \Lambda$ & ITTEDAD & ITYATOI| & Vاله ............ \\
\hline$\cdot$ & . & . & llরrqgr & $119.9 v r$ & $119 T V \Delta V$ & 1 ساله ........ \\
\hline$\cdot$ & · & · & $119 r \Delta \cdot r$ & $11994 \wedge 1$ & $11 V \cdot 199$ & 9 ساله ........ \\
\hline$\cdot$ & $\Delta r$ & IVAD & $\| v \wedge \cdots r$ & $11 \wedge \Delta 99 \Delta$ & llAvrq. & • إله ... \\
\hline$\cdot$ & $\Delta \varphi$ & ITNIT & $111 \cdot 1 \cdot 9$ & $11 r 9 \wedge 91$ & $\| r \mid \Delta S \Lambda$ & 11 الهاله ..... \\
\hline · & 1099 & $V r 9099$ & MTK.AV & $1 \cdot V \cdot r \& 1$ & 1.VIArF & كاله \\
\hline$\cdot$ & rgmF & $9 \cdot V \Delta 1$. & ITEVET & $1.4 \cdot 949$ & 1. FrFqG & זا ساله ........ \\
\hline$\cdot$ & $1 r \Delta \wedge \Delta q$ & $\Lambda \cdot r 990$ & $\Delta \Delta \wedge \Delta \wedge$ & $1 \cdots v$ & $1 \cdot .1 \Delta V V$ & 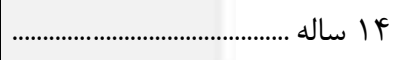 \\
\hline $9 .$. & $\Delta V T \Delta \Delta V$ & 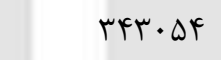 & TFVED & qч^rq. & $q<q \wedge 10$ & ها ساله ........ \\
\hline 1.949 & VAFAFA & qVYAF & IrqYA & MAFIIT & $\Lambda \Lambda \Delta \Delta \cdot \Delta$ & عاله ساله ..... \\
\hline F. FFES & TATI. & rANAT & १\&५ & $V Q \Lambda \Delta F \Delta$ & Vद..rq & IV ساله ........ \\
\hline TQT.TV & $V \cdot 944$ & $|r| K$. & rAIr & $\Delta \wedge<\& 91$ & 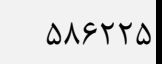 & 11 الهاله ..... \\
\hline IrqG५s & $r q 1 \Delta r$ & 9914 & एवा9 & $\Delta r \wedge \Delta \wedge V$ & $\Delta r \cdot \mid \Lambda \Lambda$ & 19 ساله ... \\
\hline ATIAV & loror & FVG. & $r \ldots$ & rqArql & $\Delta \cdots r \mu$ & • r ساله ..... \\
\hline Dr\&q. & $1 \cdot 1 \cdot 9$ & rqvi & rघ99 & FVVDQT & сүवr.人 & آT ساله ... \\
\hline$r \Delta \Lambda \cdot \varphi$ & הזו. & rदq1 & 194. & f. $q \Delta r q$ & f.人rद. & זr ساله ................ \\
\hline TFrAs & GNAT & retg & INTK & MYYADSV & rT\&GIT & זץ ساله ........ \\
\hline 18111 & $\Delta \Delta V \Lambda$ & rMAG & logt & rGTAVA & rGGTIV & ץ Tاله ......... \\
\hline IrTAG & 14.9 & TKt & $109 T$ & 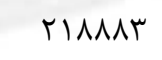 & TMIFTM & ST Tاله \\
\hline ११४. & Tark & $r \cdot q r$ & lor. & 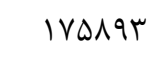 & IVAGT১ & צץ ساله ... \\
\hline$\Lambda \notin \varepsilon \Lambda$ & $r \cdot v q$ & IMAV & 1990 & $|F \wedge \Delta| T$ & IDIOTK & V TV ساله . \\
\hline VAr. & TETG & IVAr & $|\Delta T|$ & $|r \Delta q T|$ & IrAMGr & ^ז ساله ........ \\
\hline GYGT & Trto & $|V|$. & $10 \cdot 9$ & $\| r \Delta \cdot \Lambda$ & $\| \Delta \Delta F \Delta$ & qج ساله ..... \\
\hline 941 & זמזמא & $|\wedge 9|$ & 1949 & $1.91 \Delta T$ & $\| r \mid \wedge r$ & 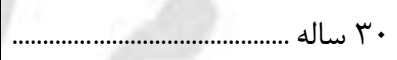 \\
\hline$\Lambda$ & rIrA & $1 \Lambda \cdot \Delta$ & 1091 & $1 \cdot T \cdot V F$ & $1 \cdot \Delta \cdot r$ & آب ساله .... \\
\hline GMTT & $r \mid \cdot r$ & INT. & IGTF & $99 \Delta G Y$ & $99 \% \vee \cdot$ & זr ساله ....... \\
\hline Q9М१ & 119. & $1 V \cdot \Lambda$ & IVAT & 1499 & $\Lambda V F \cdot$. & 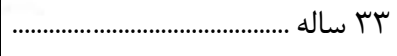 \\
\hline$\Delta \Delta १ \Delta$ & IVFF & $194 \lambda$ & IVqF & VAVAV & 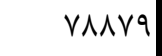 & \\
\hline$\Delta \omega \cdot r \Delta$ & $r \cdot V \mid q$ & TFYAM & $r \wedge \Delta \cdot \kappa^{c}$ & GMYOAT & EqarVA & هـ ساله و بيشتر ..... \\
\hline
\end{tabular}


| نتايج تفصيلى سرشمارى عمومى نفوس و مسكن _ه |

|f 1 - - جمعيت 9 ساله و بيشتر در حال تحصيل بر حسب جنس، سن و دوره تحصيلى (دنباله)

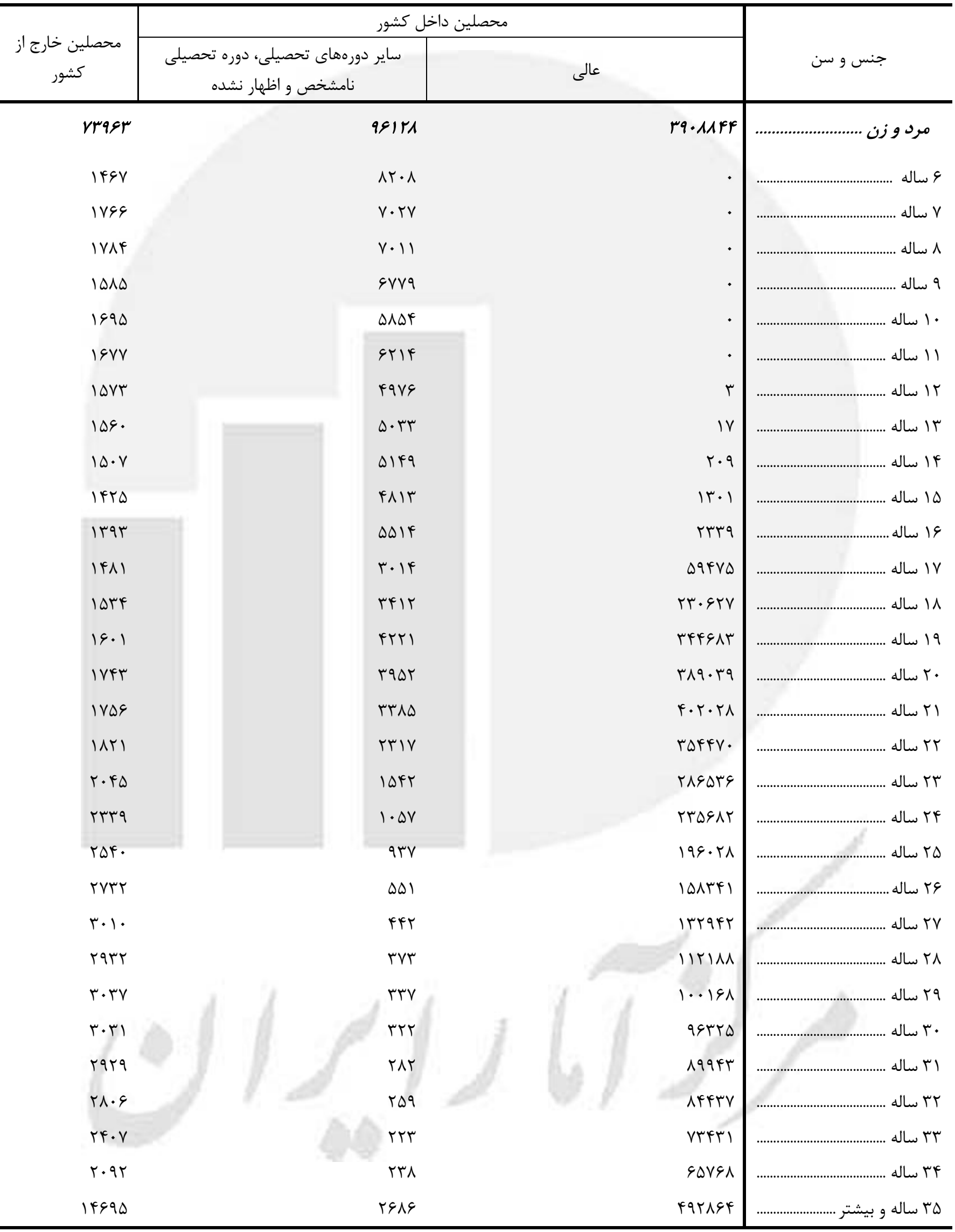


| If - - جمعيت 9 ساله و بيشتر در حال تحصيل بر حسب جنس، سن و دوره تحصيلى (دنباله)

\begin{tabular}{|c|c|c|c|c|c|c|}
\hline \multicolumn{5}{|c|}{ محصلين داخل كشور } & \multirow[b]{2}{*}{ 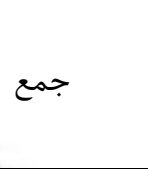 } & \multirow[b]{2}{*}{ جنس و سن } \\
\hline ي بيش دانشكاهى & | متوسطه/ متوسطه r| & راهنمايى/ متوسطه | & سواد آموزى ابتى / & 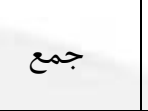 & & \\
\hline $9|1 \& \Delta|$ & $1 \cdot r v r \cdot a$ & |DAAVr| & ragkerl & qrroqra & 9rrraga & مرد................. \\
\hline . & . & . & DF\&VQG & $\Delta \Delta \cdot \wedge v{ }^{4}$ & $\Delta \Delta \backslash \& Y q$ & 9 ساله ............................................ \\
\hline - & - & - & GrFi.. & GTATOT & grqTrs & ……………........... \\
\hline . & . & . & 9.999. & 91.941 & दा1DTG & 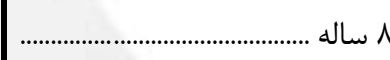 \\
\hline - & . & . & $\Delta q \Delta F \vee q$ & $\Delta ৭ \wedge १ 1 \wedge$ & 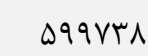 & 9 9 ساله ......... \\
\hline . & Ft & $94 \lambda$ & $\varphi \cdot \nvdash \wedge \wedge \Delta$ & 9.人Arr & 9.999. & 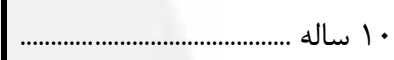 \\
\hline - & et & GMGT & $\Delta V \cdot T r \cdot$ & QVqVIS & $\Delta \Lambda \cdot \Delta \Delta I$ & 11 ساله ......... \\
\hline - & ᄉrv & rVVFA. & IVIVed & DQTGTD & DQTKET & זاله .......... \\
\hline - & $\backslash \wedge \vee \wedge$ & FEATIE & GVYTF & $\Delta F \cdot r q 1$ & $\Delta f \backslash 19 \Delta$ & זا ساله ........ \\
\hline - & GVGVV & $F T \cdot \Delta r q$ & $r \cdot \Delta \cdot r$ & DTIDTH & DTHTH & fl| ساله ......... \\
\hline Far & rq०१Vद & IADTD. & $\mid$ TET| & rqA人rq & $<990 \wedge \Delta$ & صا ساله ............... \\
\hline$\Delta \Delta 91$ & $r q 4 \cdot \wedge \Delta$ & DFET & VIF & 498190 & $1999 \Delta \wedge$ & ع| ساله .......... \\
\hline $191 F 48$ & IFTFEA & $1 V \cdot 9$. & $\Delta T \Lambda$. & 4.1919 & F. TVGD & IV ساله ........ \\
\hline IrVDVq & 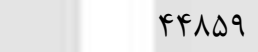 & vrif & TVYS & MIVVTE & 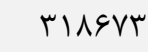 & 1) ساله ......... \\
\hline VTMET & $\mid \Lambda \Lambda \cdot \Lambda$ & FTYA & TIVV & TVAr.G & TVQTFV & 19 ساله ........... \\
\hline FreqA & १४^. & $r . . r$ & IVYr & TAKFT. & $r \Delta F Y \cdot Y$ & .......... \\
\hline rА१६4 & 9194 & TEFV & lofq & rrArAd & rrqfir & ا ب ساله ........ \\
\hline $197 \cdot q^{k}$ & $\Delta r V r$ & $r \Delta \cdot r$ & $111 \mathrm{D}$ & $r \cdot \Delta \Delta A T$ & T. GVYG & Y T ساله ........ \\
\hline $\mid f \cdot \Delta$. & fert & trug & $1 \cdot 19$ & 199794 & $I V \cdot G Y Y$ & זr ساله ......... \\
\hline $1 \cdot r \cdot r$ & rq. & 1990 & $9 \Delta \Delta$ & $14.4 \varepsilon$. & $|f| q 4$. & ץ Tاله .............................. \\
\hline V१९। & rqIf & IVte & gFT & $\mid 19941$ & $11 \wedge r \cdot \Delta$ & ه א ساله . \\
\hline DqT. & risa & |QTI & 9.9 & qщघाr & १QTVQ & ع ساله .............. \\
\hline$\Delta T \Delta F$ & 1948 & $14 \mid \Lambda$ & 901 & V৭८१४ & 11994 & V TV سله ... \\
\hline iqV & $19 \cdot r$ & ITFE & $\wedge \notin \Delta$ & $G \wedge \Delta F \mid$ & V. FAr & ^ץ ساله ....... \\
\hline raAv & אוצו & 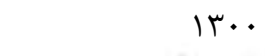 & זrו & Glorq & $q T \Delta \Delta T^{F}$ & q ساله ....... \\
\hline$G T \cdot \wedge$ & $\mid k \cdot 1$ & $x, r$ & १४६ & $9 \cdot 4 \cdot 9$ & grifle & 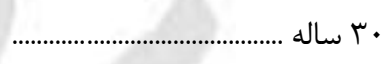 \\
\hline$r \cdot \Delta V$ & IrAF & IrSV & qVD & $\Delta V \cdot . q$ & $\Delta \wedge \wedge 99$ & 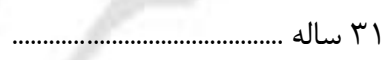 \\
\hline 41.1 & TKE & 1rar & $1 \cdot 11$ & Q DFrq & DSITE & זr ساله ........ \\
\hline rqه९ & $11 \Delta \Lambda$ & ITVF & $111 r$ & rAVqT & Q & ץץ ساله ........................................... \\
\hline rvrq & 1.91 & ITrV & 114. & FDITA & FEFV & 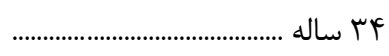 \\
\hline $4 \cdot 9 \Delta 9$ & $\mid x+19$ & $r \cdot T \cdot \varphi$ & TATED & FrArqu & सrq६D. & 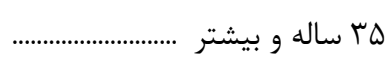 \\
\hline
\end{tabular}




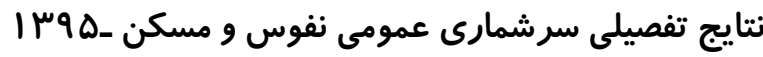

flf - 1 - جمعيت \& ساله و بيشتر در حال تحصيل بر حسب جنس، سن و دوره تحصيلى (دنباله)

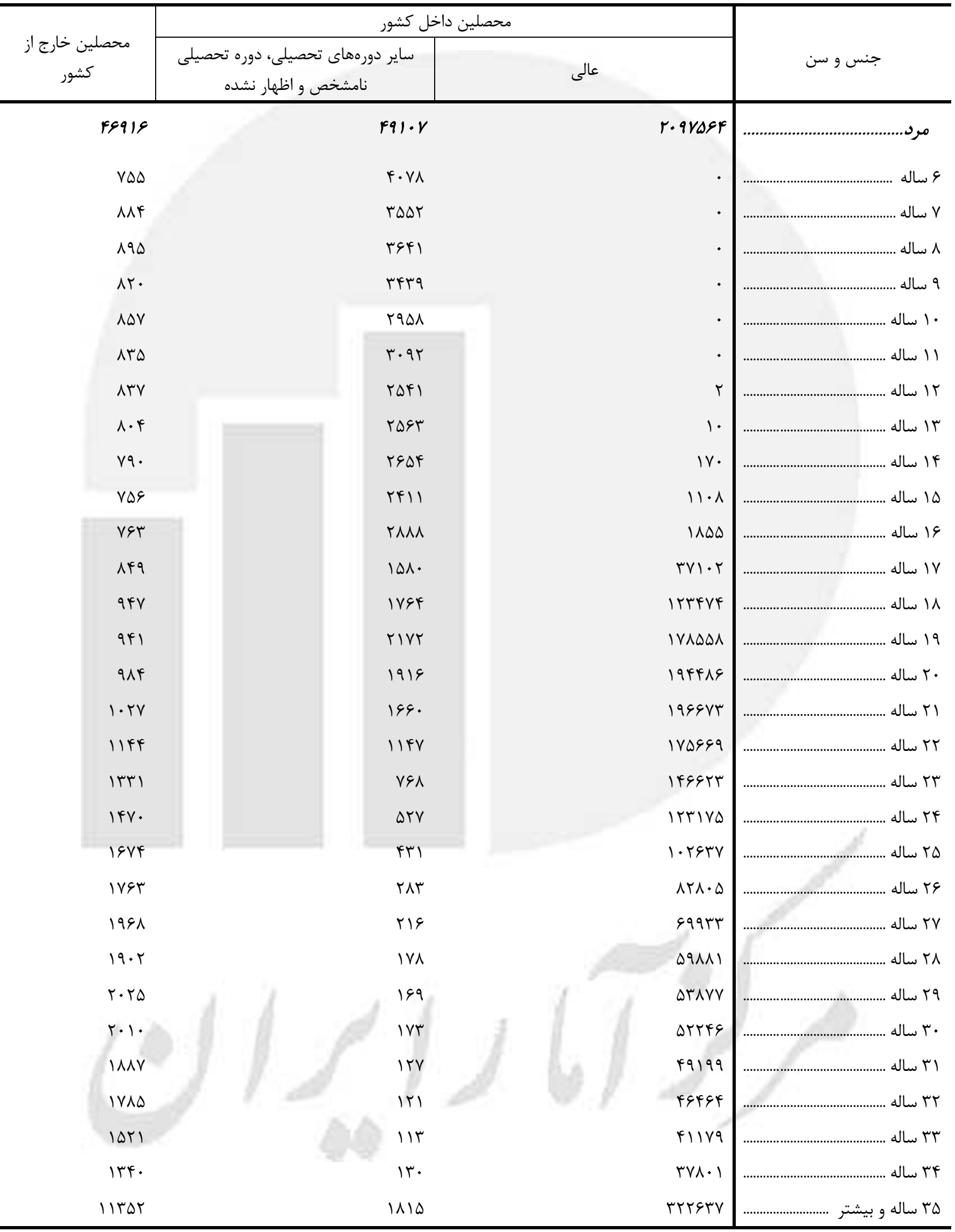


|f 1 - - جمعيت 9 ساله و بيشتر در حال تحصيل بر حسب جنس، سن و دوره تحصيلى (دنباله)

\begin{tabular}{|c|c|c|c|c|c|c|}
\hline \multicolumn{5}{|c|}{ محصلين داخل كشور } & \multirow[b]{2}{*}{ جمع } & \multirow[b]{2}{*}{ جنس و سن } \\
\hline پيش دانشخاهى & | متوسطه/ متوسطه r| & | راهنمايى / متوسطه | & سواد آموزى & جمع & & \\
\hline$\Delta F \Delta q T r$ & 141919 & lervegr & reararl & ArVF.re & $1 F \cdot 1 \cdot v r$ & زن .............................................. \\
\hline • & · & $\cdot$ & $\Delta T \cdot T V G$ & DTFY. G & $\Delta T \Delta \| 1 \Lambda$ & 9 ساله ........................................ \\
\hline - & - & • & $\Delta q F V \Delta \Lambda$ & DQ人Tr & 099110 & 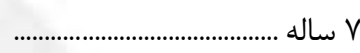 \\
\hline - & • & . & DVGqVT & $\Delta \Lambda \cdot M F T$ & $\Delta \Lambda|r T|$ & م ساله ........ \\
\hline . & - & . & $\Delta Q V \cdot T r$ & $\Delta V \cdot r G \mu$ & $\Delta V \| T \wedge$ & 9 ساله ..................... \\
\hline - & 1. & ᄉrv & $\Delta V T 119$ & DVGヘGY & $\Delta V \nabla V \cdot$. & • ا ساله ........ \\
\hline - & If & SYQ. & $\Delta F \cdot \Delta \wedge q$ & $\Delta \Delta \cdot I V \Delta$ & $\Delta \Delta I \cdot \mid V$ & 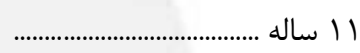 \\
\hline - & $V \Delta 9$ & raYII9 & IDTHT & DIVGTG & DIATVT & 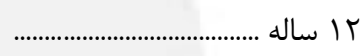 \\
\hline - & IVAS & frarqf & $\Delta V \cdot \mid \Lambda$ & $\Delta \cdot \Delta F \Delta$ & $0 \cdot 1 \mu \cdot 1$ & זן ساله ................ \\
\hline - & GAINT & rArFeg & 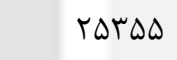 & FVADTV & FVATDF & f 1 ساله ......... \\
\hline prv & TYVDAI & $1 \Delta V \lambda \cdot Y$ & $111 \mathrm{kF}$ & frqD\&l & RA. TH. & ها ساله ........ \\
\hline$\Delta r \Delta \Lambda$ & TG. YAT & FTIDD & $\Delta \wedge \mu$ & fivalv & FINDFV & 19 19 ساله ........ \\
\hline$r \cdot 9 .$. & $11.9 \Delta 9$ & M & pret & rDGGrq & raVral & 1V ساله .......... IV \\
\hline IrDFDA & $r \Delta \Lambda \cdot r$ & FAYG & $r \cdot V G$ & rब9990 & $r \& V \Delta \Delta T$ & 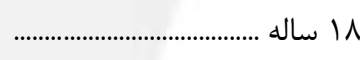 \\
\hline SVYAT & 1. TKE & TVRG & IVET & $r \Delta \cdot r \Lambda I$ & $r \Delta \cdot q \& 1$ & 19 ساله ................... \\
\hline ५१९८१ & $\Delta \Delta V T$ & IVOV & Tre & TFYAVI & TFDGT. & • . . ساله ........ \\
\hline TAVTS & rqIV & ITYK & $11 \%$. & rसqוबV & r & ال ساله ........ \\
\hline $191 .$. & rqu & 1194 & $V \Delta \Delta$ & $r \cdot . q \Delta V$ & $r \cdot 19 T r$ & r Tاله ................. \\
\hline (1. & TFID & $11 \ldots$ & VRG & IDQTVF & $10 \Delta 9 \wedge \Lambda$ & זr ساله .......... \\
\hline $99 \cdot 1$ & $19 V \pi$ & 191 & 9.9 & ITMEIA & ITFTAV & ץ Tاله ......................... \\
\hline DTTD & 1990 & $9 \wedge \Delta$ & $9 \Delta$. & 1. TRQT & $1 . r 111$ & 1 Tl Tاله . \\
\hline rq১. & Irrr & DTr & GTI & ATrA. & ArTEq & عץ ساله ....... \\
\hline rule & $11 \Delta T$ & $4 \& 9$ & veF & $9 \wedge 110$ & $99 \wedge \Delta V$ & TV ساله .. \\
\hline rVDQ & $1 \cdot r F$ & frq & 999 & $\Delta V r q$. & $\Delta \Lambda F T$. & א r ساله ......... \\
\hline FFVD & १दर & (i). & gVr & $0.9 \vee 9$ & 01991 & q ج ساله ................ \\
\hline FFVD & (1) & $F \Delta q$ & gQT & FAVES & FqY & • ب ساله ........... \\
\hline TrDI & $\Lambda \Delta F$ & Fra & GTr & $40 \cdot 90$ & 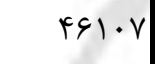 & اب ساله ................. \\
\hline TrYI & $\Lambda \Delta 9$ & FrA & 4.9 & FTTYD & FTYES & r ب ساله .... \\
\hline$r \cdot r t$ & VTr & fre & s4i & rgr. & $r v \cdot \Lambda v$ & זr ساله .......................... \\
\hline $1 \wedge \Delta \varphi$ & qQT & 411 & $\varepsilon \Delta F$ & mekq & MTF. I & r ساله .................................... \\
\hline 14.99 & grav & FOAT & 1.rrq & $r \cdot G r \wedge \Delta$ & $r \cdot 9 G r \wedge$ & هَ ساله و بيشتر ......... \\
\hline
\end{tabular}




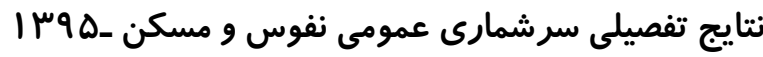

ff 1 - 1 - جمعيت \& ساله و بيشتر در حال تحصيل بر حسب جنس، سن و دوره تحصيلى (دنباله)

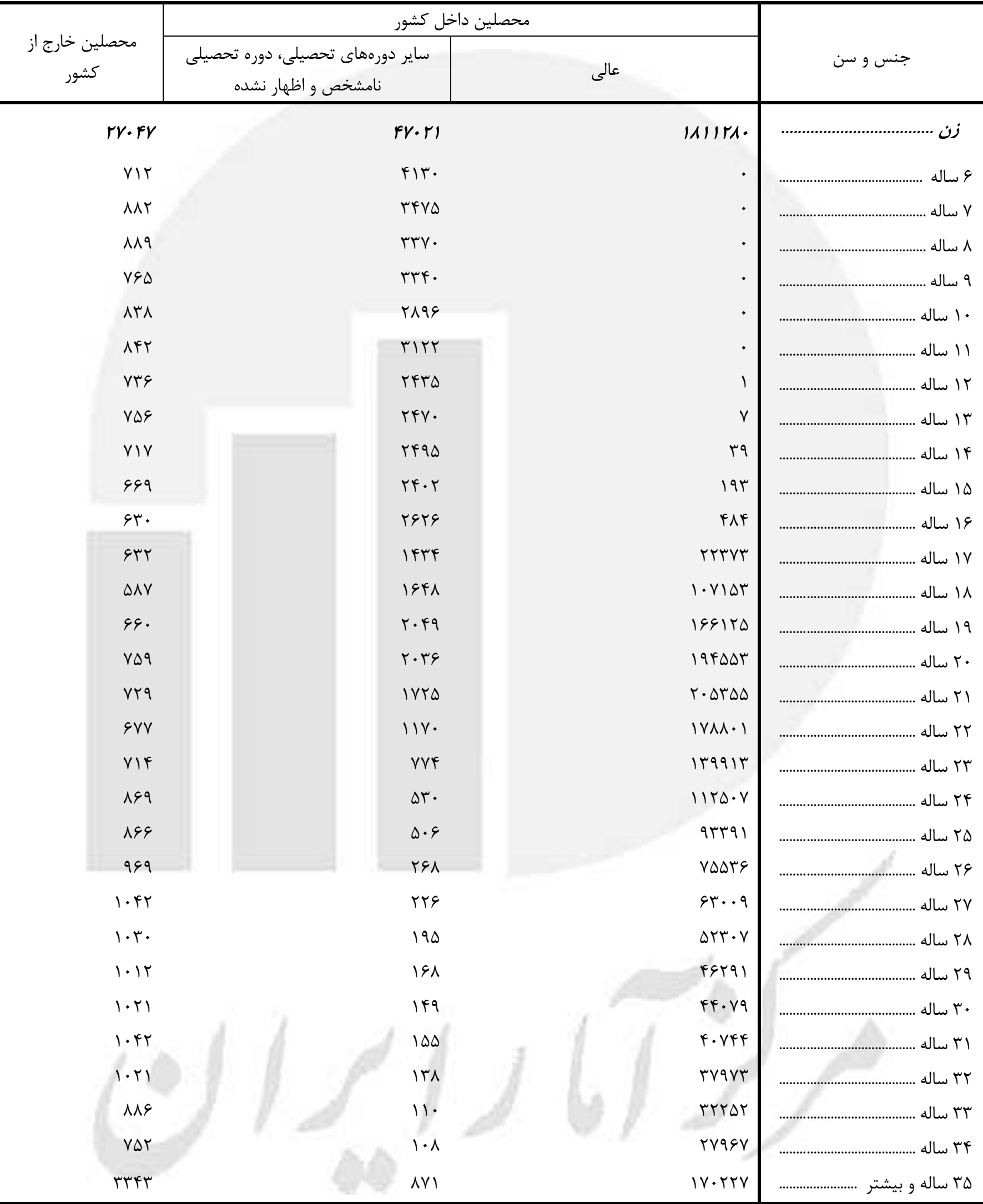




\begin{tabular}{|c|c|c|c|c|c|c|}
\hline \multicolumn{5}{|c|}{ محصلين داخل كشور } & \multirow[b]{2}{*}{ 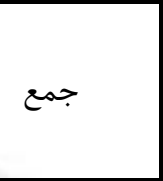 } & \multirow[b]{2}{*}{ جنس و سن } \\
\hline ريش دانشَاهى & | متوسطه/ متوسطه | | & | راهنمايى/ متوسطه 1 | & سواد آموزى ابتى & 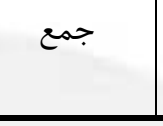 & & \\
\hline qAVera & $10 \cdot r \cdot 18$ & rerrerta & DrFAIAs & irsarrs. & $\mid$ merqqs| & 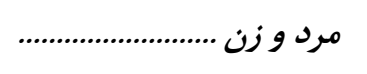 \\
\hline - & · & $\cdot$ & $V V \cdot \Delta r \Lambda$ & VVGYI. & VVVIOT & q ساله .............................................. \\
\hline - & . & · & AVDrDS & $M \Lambda \cdot I T$. & мАाাr. & ساله ............................. \\
\hline - & . & . & NF\&qla & NFqDTV & $\Lambda \Delta \cdot \Delta r V$ & 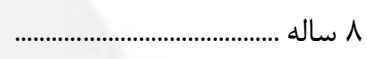 \\
\hline - & . & . & $\Lambda T \wedge \Lambda \wedge V$ & (1) & NTFTDS & 9 ساله ..................... \\
\hline . & $r \cdot$ & 1194 & NrGTVF & AFITt. & NFTIVA & 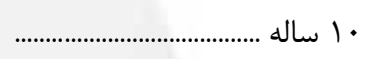 \\
\hline$\cdot$ & rq & $9 \Lambda \cdot \Delta$ & VqVQV. & N1IFar & NIYFFi| & 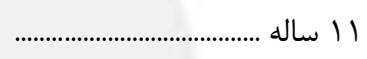 \\
\hline - & $11 \mathrm{~F}$. & $\Delta G T \cdot \cdot \Lambda$ & rIIIVe & VVVVT. & 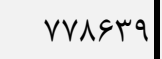 & 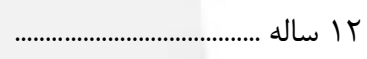 \\
\hline - & rVar & gNTrTr & VATrV & VGDQFV & 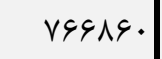 & سا ساله ............. \\
\hline - & $1 \cdot 111 \mathrm{~F}$ & D৭AVTV & rTSDQ & VFFI9G & VEDITE & 14 ساله ........ \\
\hline VTS & FGTAVT & TFTI. & $|f F f|$ & VTD\&qI & $V Y Q \Delta \Lambda \cdot$ & ها ساله ................... \\
\hline 199\% & G. rAFF & $G r \cdot \wedge r$ & $V \mid i$. & GMAFVD & ध৯৭४৯. & ع 19 ساله ............. \\
\hline rrqrrq & IMAVFT & 19191 & DQ & G. TYSD & G. rTqY & ساله .......................... IV \\
\hline TIFTtD & FVETY & GTYF & r\$9 & FVGVG. & erVAuv & 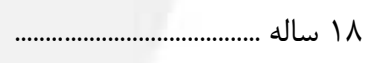 \\
\hline $11 r r \cdot \Delta$ & I 1बY & TAFT & rifq & FETT. & FATEST & 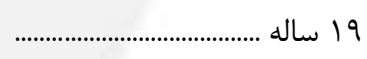 \\
\hline $90 \wedge 99$ & $99 \cdot 4$ & $T F \cdot G$ & IDHE & FTIV.V & Frr.91 & 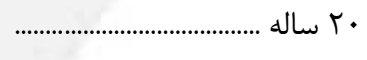 \\
\hline reg. 9 & $V \cdot V t$ & $r \cdot \Delta V$ & $|f|$. & $r \cdot \Delta V I T$ & $k \cdot v 1 \cdot \varphi$ & اله ساله ............................. \\
\hline TATY & DFrV & $r \cdots v$ & 949 & MFAT. 9 & rष9811 & ץ ساله ............................................ \\
\hline IN9YV & $49 \cdot 1$ & $19 \cdot r$ & AMV & TVAI.V & rVVVAN & 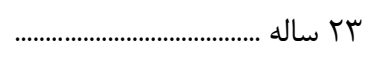 \\
\hline Irr.r & rATq & 191. & $v \cdot \wedge$ & TYGTAF & rTAKTI & 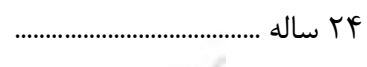 \\
\hline 1.rTV & TrAQ & Ira. & VAI & INADQT & $19 \cdot V T V$ & 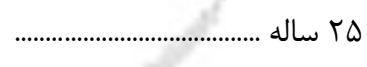 \\
\hline$V V \Delta S$ & rQVT & $11 \mathrm{Vr}$ & VAV & 10r.qr & $\mid \Delta \Delta F \cdot r$ & צr ساله ........ \\
\hline $9 \wedge \Delta 9$ & rrg. & lirt & 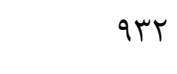 & $\mid r \cdot r \wedge \cdot$ & 1 IrTa19 & V TV \\
\hline$G \cdot r r$ & 1990 & $11 \cdot r$ & 119 & $111 \cdot \mathrm{KF}^{-}$ & $\| r \Delta \Delta \Lambda$ & 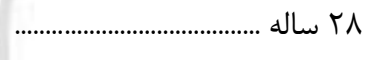 \\
\hline QMII & IVVA & $1 \cdot \Delta \Lambda$ & Art & $1 \cdots r \cdot 1$ & $1 . r q \mu r$ & 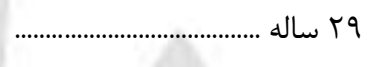 \\
\hline DGTV & $11 \cdot 9$ & $1 T \cdot 9$ & $q T \Delta$ & $91 \cdots 9$ & $1 . .9 \times 9$ & (r............... \\
\hline DrTV & $|v| \cdot$ & $1 r \cdot 1$ & $9 \Delta \mathrm{T}$ & १T०१९ & 90199 & 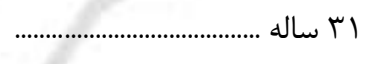 \\
\hline DFT & 1909 & ITFF & qry & 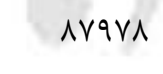 & $q \cdot r \cdot$. & 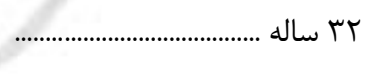 \\
\hline$\Delta / \Delta$. & $10 \cdot V$ & 1190 & $1 \cdot 19$ & VVGVY & VqVAr & 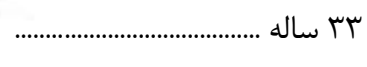 \\
\hline 4910 & letr & $11 r \pi$ & $\| \Delta v$ & $v \cdot 411$ & $V T I A V$ & 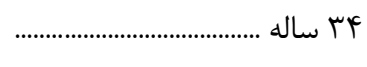 \\
\hline kqTar & $1 V 9.9$ & $19 \mu \Delta F$ & r\&DAD & $\Delta \wedge r q \wedge \Delta$ & $\Delta Q Y I M T$ & 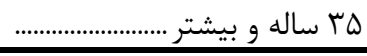 \\
\hline
\end{tabular}




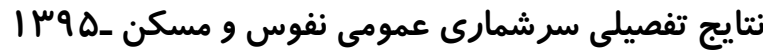

(نقاط شهرى)

If 1 - 1 - جمعيت 9 ساله و بيشتر در حال تحصيل بر حسب جنس، سن و دوره تحصيلى (دنباله)

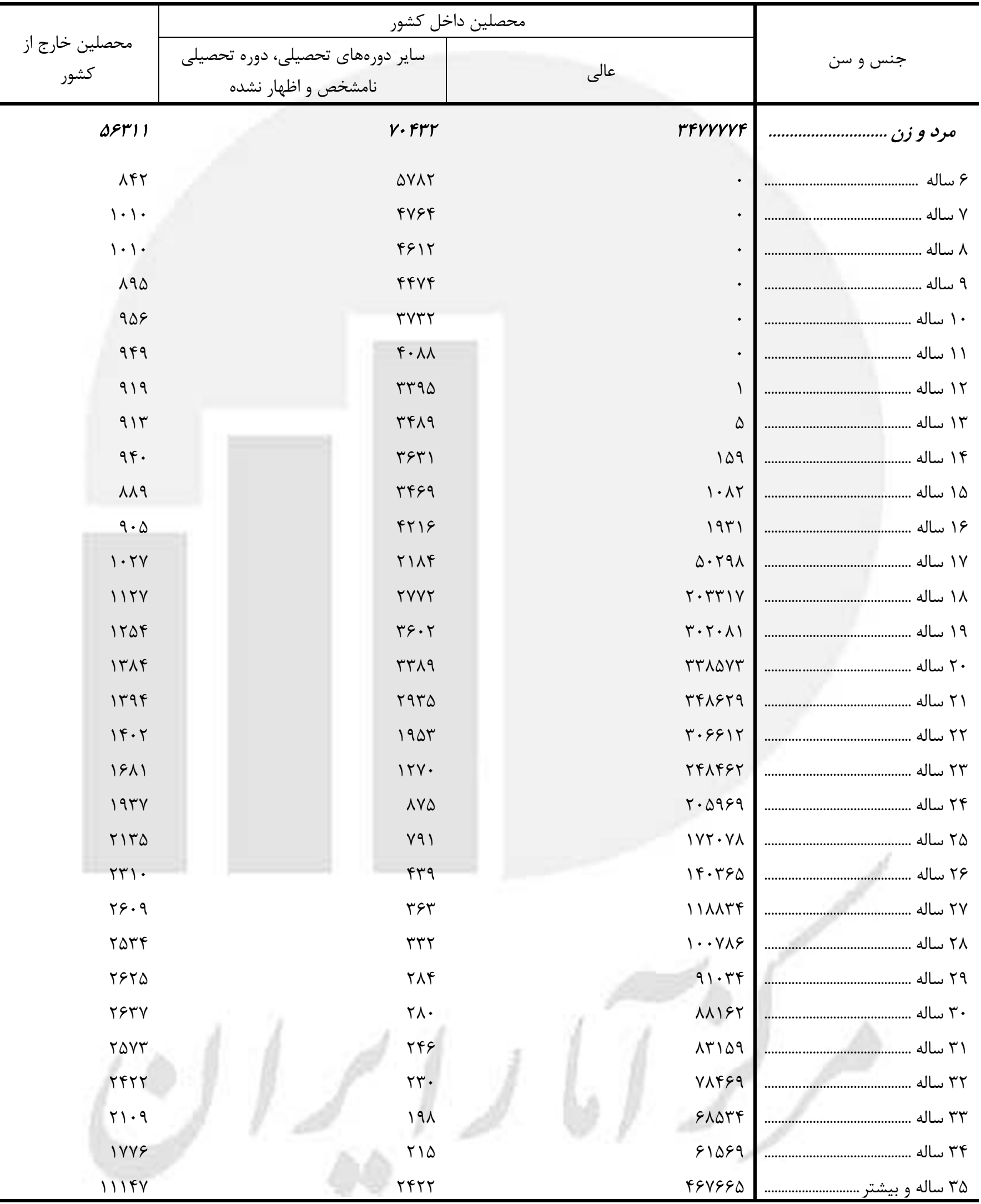




\begin{tabular}{|c|c|c|c|c|c|c|}
\hline \multicolumn{5}{|c|}{ محصلين داخل كشور } & \multirow[b]{2}{*}{ 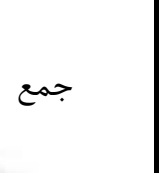 } & \multirow[b]{2}{*}{ جنس و سن } \\
\hline بيش دانشًاهى & | متوسطه/ متوسطه r| & | راهنمايى/ متوسطه | & سواد آموزى ابتى & جمع - اع & & \\
\hline rq9هAr & V^991A & llasrrr & rVDARIq & $r \cdot v r r a r$ & VI. varA & 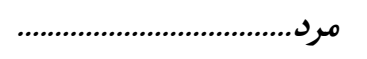 \\
\hline . & - & $\cdot$ & rqfars & rqVFAV & rqvar人 & ع ساله ............................................... \\
\hline \multirow[t]{2}{*}{. } & · & . & FratAV & $4 \Delta \cdot 9 \Delta q$ & $F \Delta \| \Delta T$ & Vاله ........................................ \\
\hline & . & • & RTIAV & FTDDGT & erg. Vr & 1 ساله .................. \\
\hline$\cdot$ & . & . & FTFTYD & FTEDAT & FTV.rF & 9 ساله ................. \\
\hline . & if & אrt & Frq191 & Fiti.. & FTrIAV & ل اله س.............................. \\
\hline • & r) & FMAS & $r \cdot \wedge 9 r \wedge$ & FIOAFV & FIGTRD & 11 ساله .............. \\
\hline \multirow{2}{*}{. } & $\Delta \wedge 1$ & rAFAvq & 11149. & rq४ৎ90 & ५११।६r & 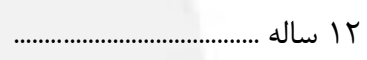 \\
\hline & $\mid r \cdot r$ & rFAMVT & $f \mid k \cdot \varphi$ & TqMFAT & гатяा। & ז1 ساله .......... \\
\hline . & DrVVA & $r \cdot \wedge v i r$ & $|\wedge| \Delta \Lambda$ & rATGK. & rNTITA & fle \\
\hline$r v \cdot$ & rrgit. & irrrta & vAra & TYEVTA & $r V \Delta T \cdot r$ & ها ساله .......... \\
\hline FATT & $r \cdot \Lambda F \Delta F$ & rrquу & $r \cdot q V$ & TAFVTA & $r \Delta \Delta 191$ & 19 ساله ................. \\
\hline IGTOIV & $1 \cdot r \wedge \Lambda$. & १५.. & $r \cdot 9 r$ & MIIQTE & $r|r| \cdot v$ & Vاله ............ \\
\hline $11 . .1 f$ & $r . .90$ & rVrr & 1010 & rorrAq & $r \Delta F \cdot V \cdot$ & 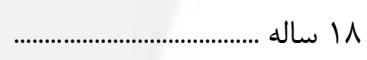 \\
\hline$\Delta \& V \cdot \Delta$ & $|r \cdot r|$ & $r|f|$ & $11 \mathrm{rV}$ & rT\&AVq & TRVDNI & 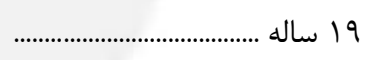 \\
\hline TrTGG & $9 \pi \cdot \varphi$ & lfqk & $\wedge \wedge \Delta$ & $r \cdot \Lambda \Lambda \mu r$ & $r \cdot 9 \Delta V \Delta$ & ........................ \\
\hline TTEDF & FFM & ITrV & Nrq & 199099 & $19 V r r \wedge$ & ال ساله .............. \\
\hline DQIFT & reVA & | וזr| & $\Delta \& \&$ & $199 \mathrm{rv}$. & $\mid V \cdot r \cdot \Lambda$ & 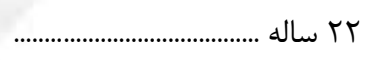 \\
\hline $1.9 \Delta F$ & rqDr & $|T \Delta|$ & $\Delta \cdot r$ & 1таяя. & $|f| \cdots r \mid$ & r ساله ..................................... \\
\hline$V V \Delta \Delta$ & TET. & 1.94 & FAt & IIVrAs & $\| \wedge \Delta \Delta F$ & .......................... \\
\hline G. FV & 1994 & $q 4$. & FFa & arrre & 99.99 & 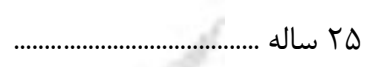 \\
\hline FAFV & IDFA & $\wedge \Delta \varphi$ & FrA & vaft. & $\wedge \cdot \wedge \vee q$ & 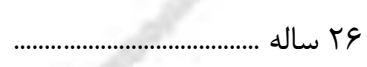 \\
\hline FiND & $1 r \wedge 9$ & $\wedge \Delta 9$ & $\Delta \cdot \Delta$ & GNFTE & $v \cdot .9 \Delta$ & 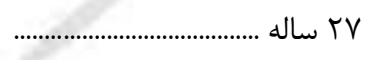 \\
\hline rVa. & $11 \wedge r$ & אrr & fat & DQTI. & $q \cdot \vee q \cdot$ & 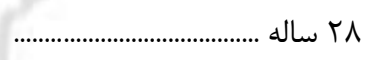 \\
\hline TMtr & $1 \cdots 9$ & val & FVe & DrNTq & $\Delta \Delta \Delta \backslash \Delta$ & qr ساله .............. \\
\hline rolf & 1.94 & $\wedge 91$ & Dre & $\Delta r \Delta \cdot \varphi$ & $\Delta \Delta । 9 T$ & 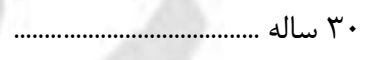 \\
\hline$r F \cdot 1$ & 1.11 & $9 \cdot 0$ & $\Delta \varphi 9$ & $\Delta 11 T \Delta$ & DTVTE & آ ساله .................. \\
\hline$r \Delta \cdot \Lambda$ & grt & 948 & $\Delta 99$ & kAq4i & $\Delta \cdot r \mid r$ & r ب ساله .................. \\
\hline rrad & $q \cdot r$ & $\wedge \wedge \Delta$ & 990 & FFINF & FAFAT & سז ساله .............................................. \\
\hline MTYI & $\wedge \vee q$ & 人ঙ & ver & $4 \cdot 999$ & $k T \cdot V r$ & 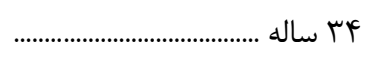 \\
\hline rgt.r & $I T \cdot \Delta V$ & $\mid \Delta \& \Lambda \Lambda$ & 19415 & rAqFrk & rqvянद & هץ ساله ........... \\
\hline
\end{tabular}




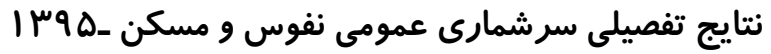

| If - ا جمعيت \& ساله و بيشتر در حال تحصيل بر حسب جنس، سن و دوره تحصيلى (دنباله)

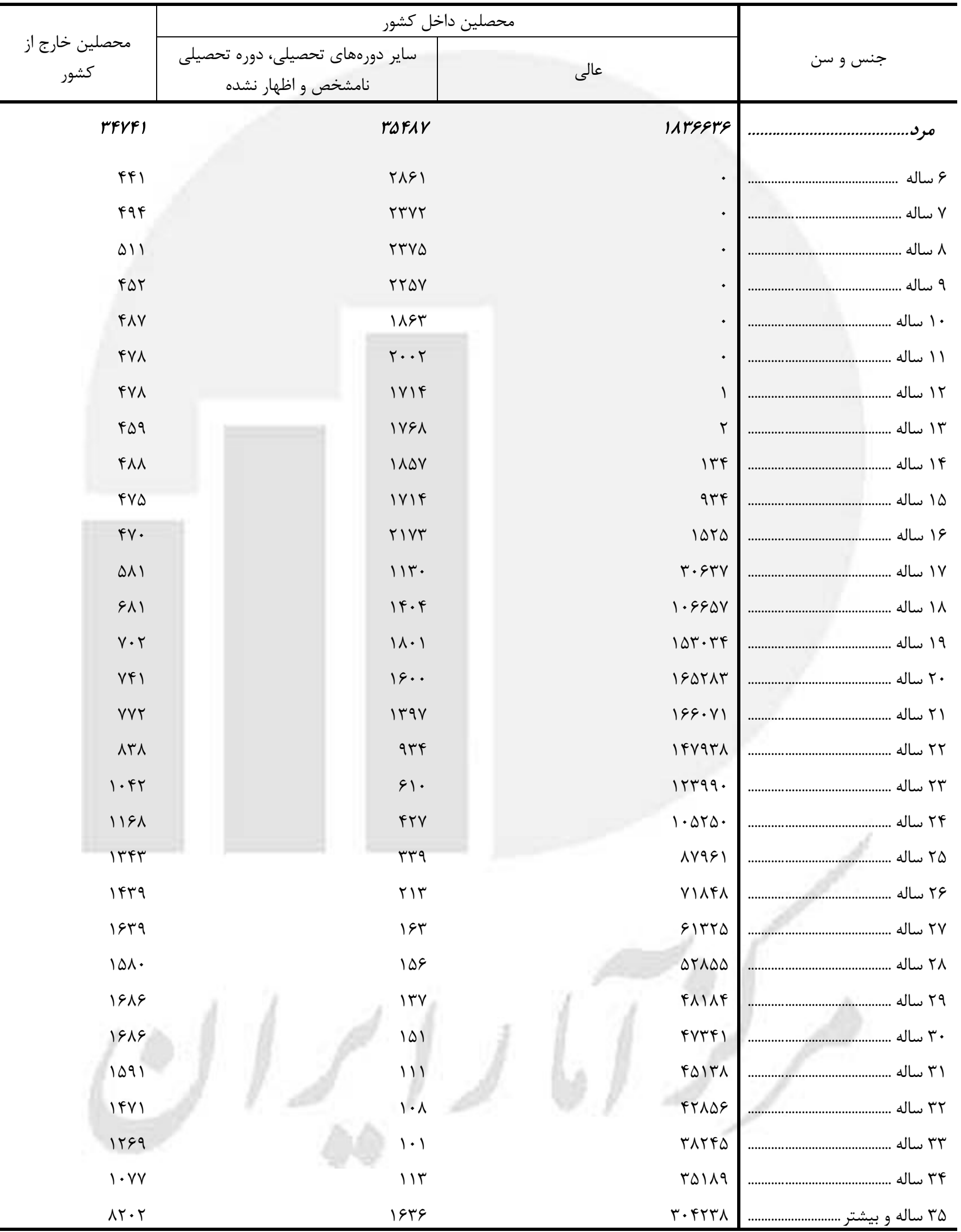




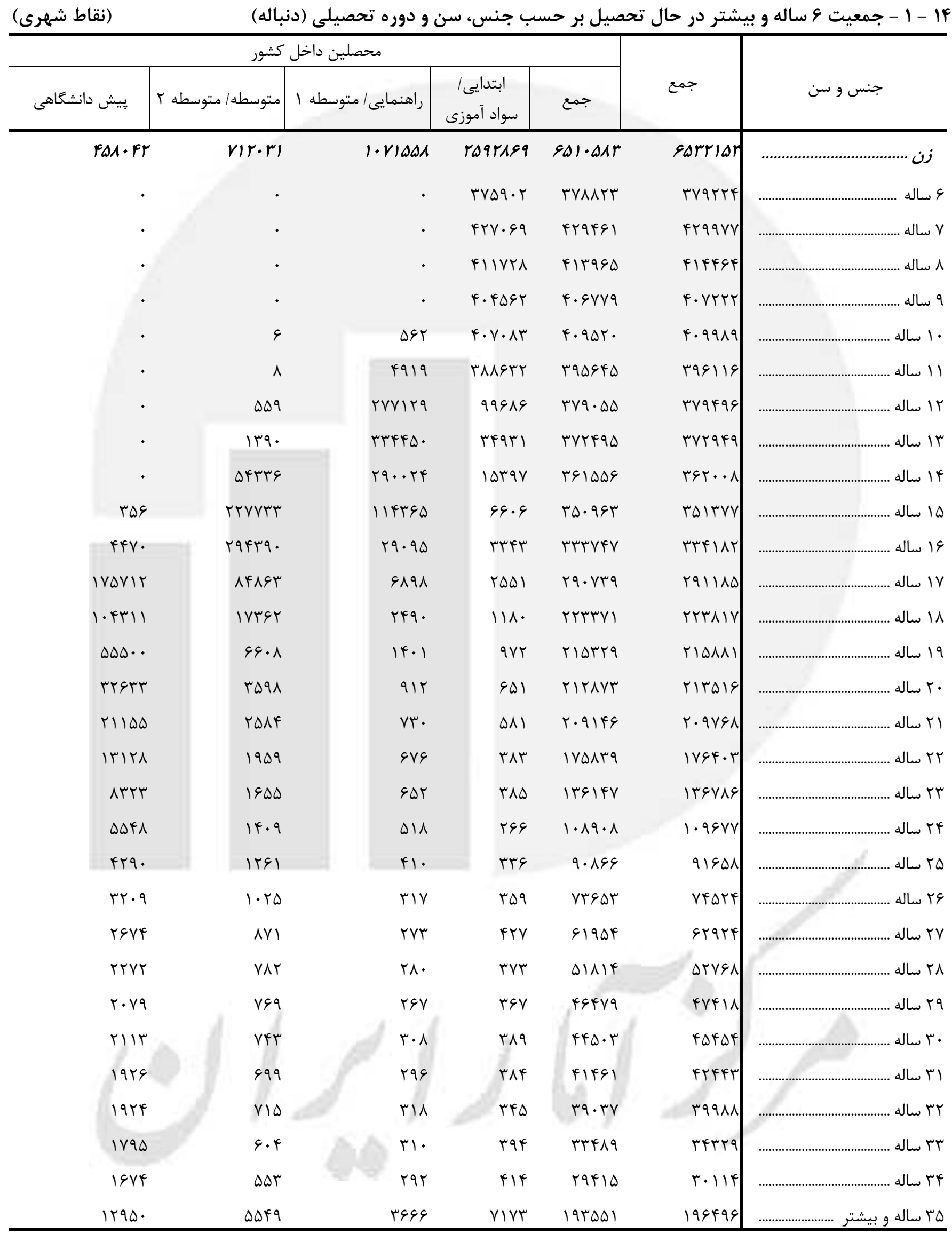




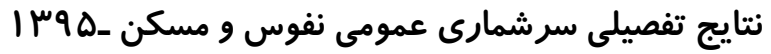

(نقاط شهرى) - (نقي)

If 1 - 1 - جمعيت 9 ساله و بيشتر در حال تحصيل بر حسب جنس، سن و دوره تحصيلى (دنباله)

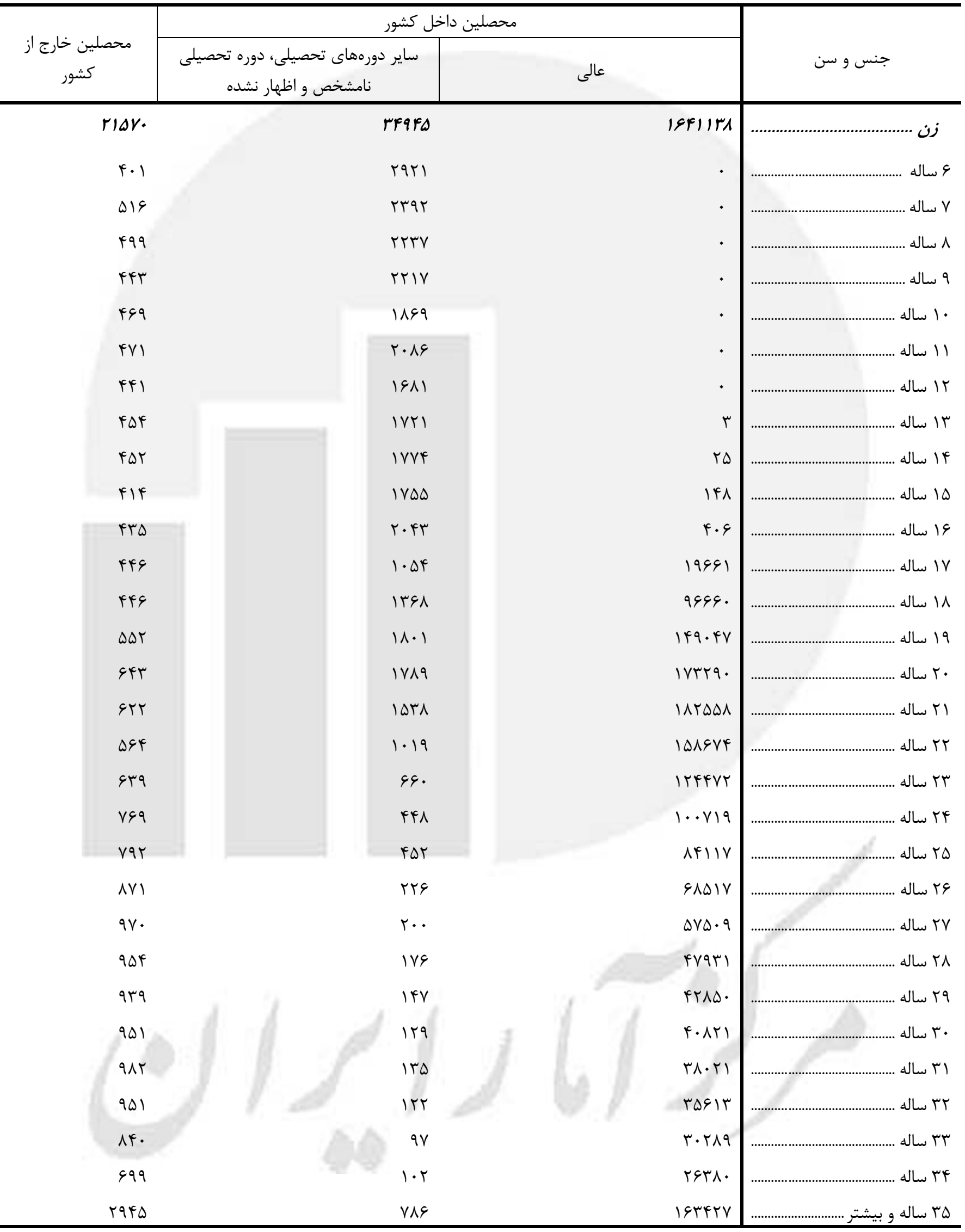




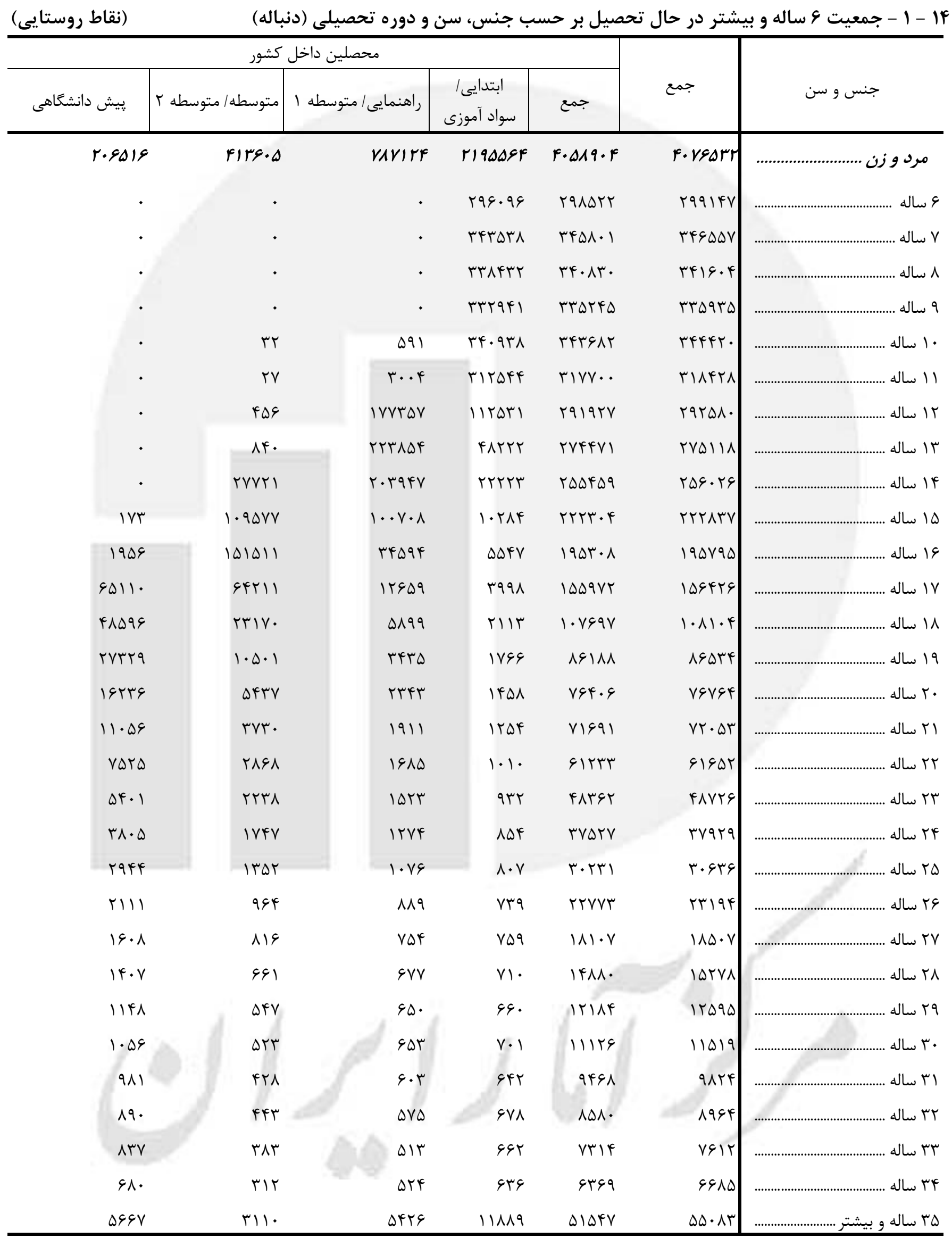




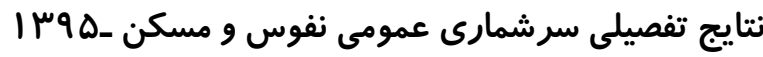

(نقاط روستايى)

If 1 - 1 - جمعيت 9 ساله و بيشتر در حال تحصيل بر حسب جنس، سن و دوره تحصيلى (دنباله)

كحصلين خارج از

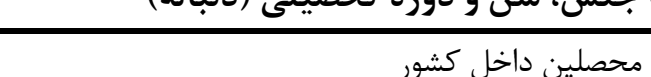

بيشتر دالى

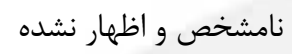

IVerA

\begin{tabular}{|c|c|}
\hline gro & TFTE \\
\hline$V \Delta Q$ & TKGK \\
\hline VVF & rrqA \\
\hline 99. & $r r \cdot r$ \\
\hline VTA & $r|r|$ \\
\hline VYA & TITo \\
\hline gar & $|\Delta \Lambda|$ \\
\hline GFV & IQFT \\
\hline$\Delta \& V$ & 1011 \\
\hline זrه & ITKE \\
\hline FAV & IrqV \\
\hline$F \Delta F$ & r. \\
\hline$r \cdot V$ & sq. \\
\hline rFe & 919 \\
\hline$r \Delta \Lambda$ & $\Delta G r$ \\
\hline raY & FYA \\
\hline 419 & TGG \\
\hline 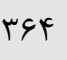 & TVT \\
\hline$r \cdot r$ & IAT \\
\hline$r \cdot \Delta$ & 148 \\
\hline Frl & $11 \pi$ \\
\hline$f .$. & vq \\
\hline rq1 & i) \\
\hline fil & Wr \\
\hline rq & FT \\
\hline$r \Delta \varphi$ & re \\
\hline rAץ & rq \\
\hline rqA & ro \\
\hline TIS & r \\
\hline
\end{tabular}

جنس و سن

$F r \cdot F \cdot q$

9

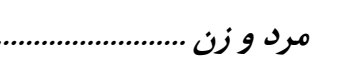

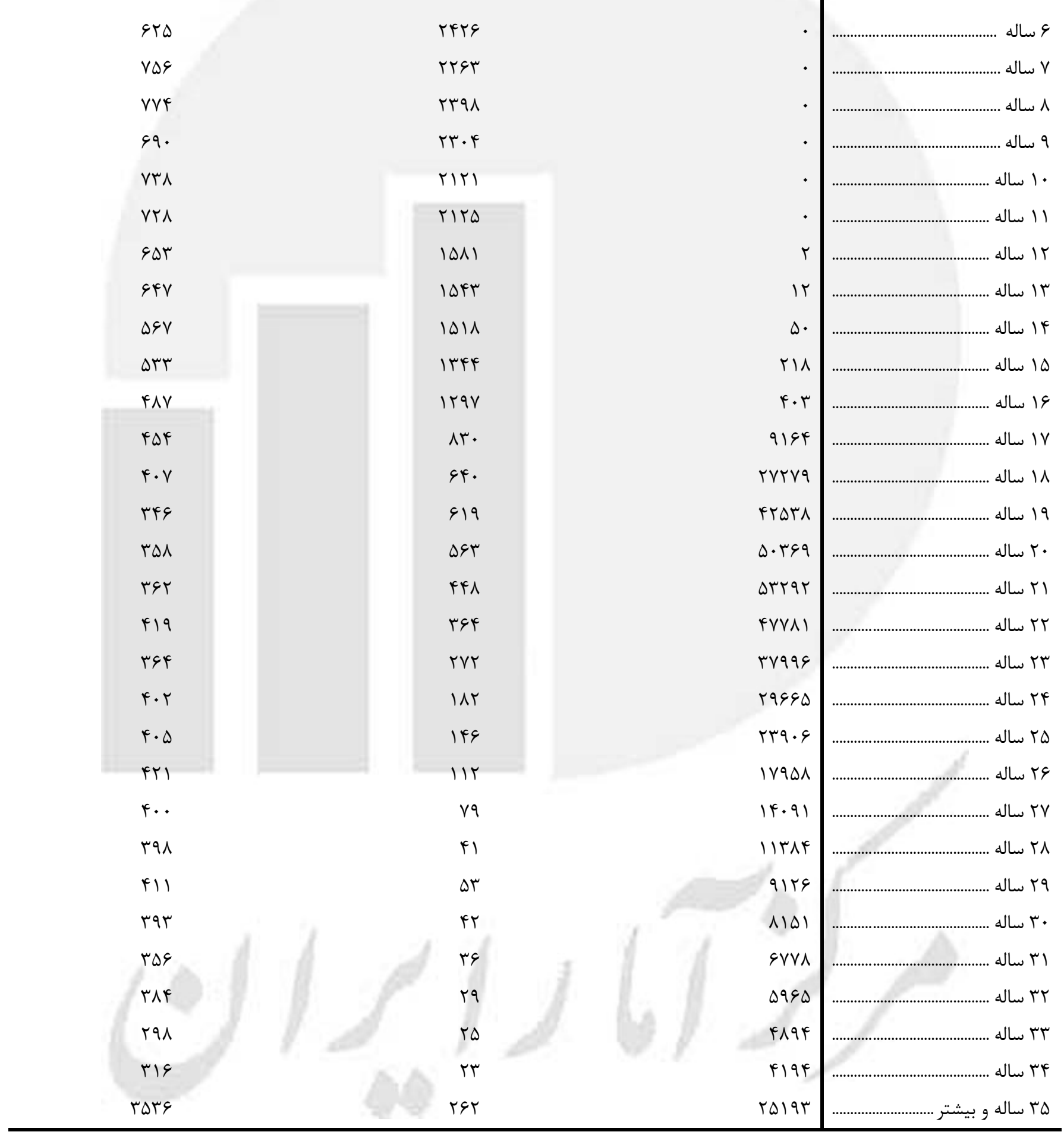




\begin{tabular}{|c|c|c|c|c|c|c|}
\hline \multicolumn{5}{|c|}{ محصلين داخل كشور } & \multirow[b]{2}{*}{ 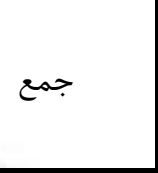 } & \multirow[b]{2}{*}{ جنس و سن } \\
\hline ي بيش دانشخاهى & | متوسطه/ متوسطه r| & | راهنمايی/ متوسطه | & سواد آموزى ابتدائ & جمع & & \\
\hline $111 \mathrm{~N} \cdot \mathrm{r}$ & rrgard & FrTIVF & 11rघV^9 & rIqAVV. & $r r 1.9 T 9$ & 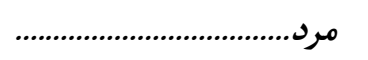 \\
\hline · & - & • & 10194 & $|\Delta T| Q$. & IOFKEF & 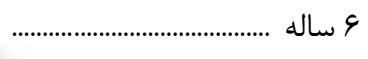 \\
\hline • & - & $\cdot$ & $|V \&| \Delta V$ & IVVTrV & IVVVTV & 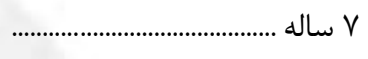 \\
\hline • & - & · & IVrFVq & IVEVES & IVDITq & 1 ساله ......................... \\
\hline - & · & · & $1 V \cdot \vee \wedge q$ & 18198. & IVTrMa & 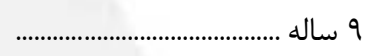 \\
\hline - & rA & MIs & IVATEA & $I V \& V \cdot V$ & $\mid V V \cdot V G$ & 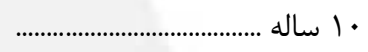 \\
\hline - & rl & IfVD & $19 \cdot 9 \cdot 1$ & lempq4 & $|\& Y \wedge \Delta|$ & 1) \\
\hline . & TAS & QTFQF & $4 \cdot \cdot \sqrt{4}$ & $|\Delta M G| F$ & ІQRqVY & 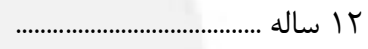 \\
\hline - & FYe & $11910 T$ & TEYI9 & IFGG4A & $\mid 49994$ & 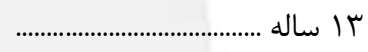 \\
\hline - & $\mid r \wedge \Lambda \Delta$ & IIIErV & IrTqV & IrAGQT & $\mid r \wedge q \Delta F$ & fle \\
\hline q & 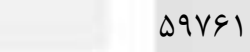 & $\Delta V r \Lambda F$ & $\Delta \vee \& \Delta$ & ITHAVT & ITFIOF & ها ساله .............. \\
\hline 1.91 & $\Lambda \Delta \Delta I V$ & $r \cdot \Delta \Lambda T$ & $r \cdot 9 \Lambda$ & MITVF & $\| \Delta \Delta Q V$ & ع| ساله .......... \\
\hline TFAGY & rAFVT & VVFr & TrID & 9.199 & $q \cdot r \varepsilon V$ & IV ساله ............. \\
\hline TVYAQ & IFVEV & rogq & $|r| \Lambda$ & sfinI & SFYEV & 1 | ساله .................. \\
\hline $1 \Delta \Delta \wedge \Delta$ & sVV. & rI. & 991 & DITI. & $\Delta \mid \Delta F \lambda$ & 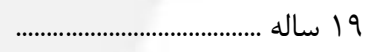 \\
\hline $9 T \cdot T$ & MEQT & $10 \cdot 1$ & $\Lambda F \wedge$ & pefeq & FEVII & • ץ ساله .............................. \\
\hline grqf & rraA & $1 \pi 11$ & VIV & fivi. & F।9९० & ا ז ساله ........... \\
\hline$Y \Delta \Delta q$ & $1 \wedge 91$ & 1199 & GKA & TGIOT & rar $\Delta \Lambda$ & r Tاله ............... \\
\hline rrq. & leva & $1 \cdot V V$ & $\Delta \Lambda T$ & rवTET & 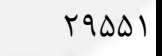 & 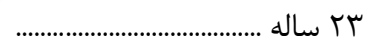 \\
\hline TFED & llAk & $9 \cdot 1$ & DIT & $r \mu \cdot r$ & שמוזיז & 1 Tاله ............. \\
\hline 1911 & 911 & $\Lambda \cdot 1$ & kq9 & 111499 & 19198 & ه ساله ......... \\
\hline$|r v|$ & 919 & gVF & FVA & $|f| \Delta \mid$ & IFFVF & צr ساله ............... \\
\hline 1.91 & $\Delta M F$ & $\Delta \Delta \Lambda$ & fro & $\| T \Delta \mid$ & $110 \vee 9$ & V TV \\
\hline qT. & 419 & $\Delta T \cdot$ & 419 & वा11 & १ & א^ ساله ......... \\
\hline$V D F$ & TQS & $\Delta \cdot V$ & $r \Delta \varphi$ & VदqI & $\Lambda \cdot r q$ & q ساله .......................... \\
\hline 494 & (גז & $\Delta \cdot r$ & fF. & $9 \wedge 9$. & VTIY & • r.................... \\
\hline & & & 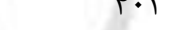 & 4) & & ....... o \\
\hline 4. & $r \Delta \Delta$ & rیq & fiv & 49.4 & 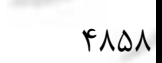 & זr ساله ....................................... \\
\hline 491 & rit & $r \cdot \Delta$ & एव६ & firv & qr.. & 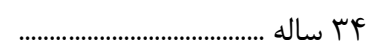 \\
\hline FAFq & TMG & FDII & MAMF & TAMTV & F1999 & هـ ساله و بيشتر ......... \\
\hline
\end{tabular}




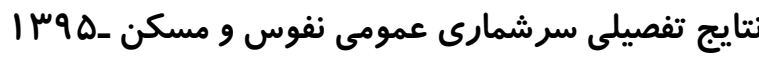

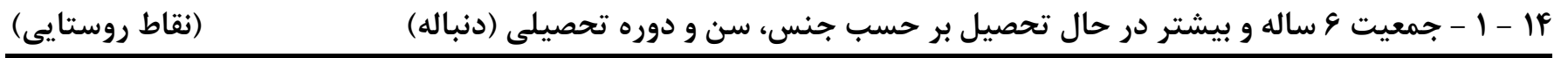

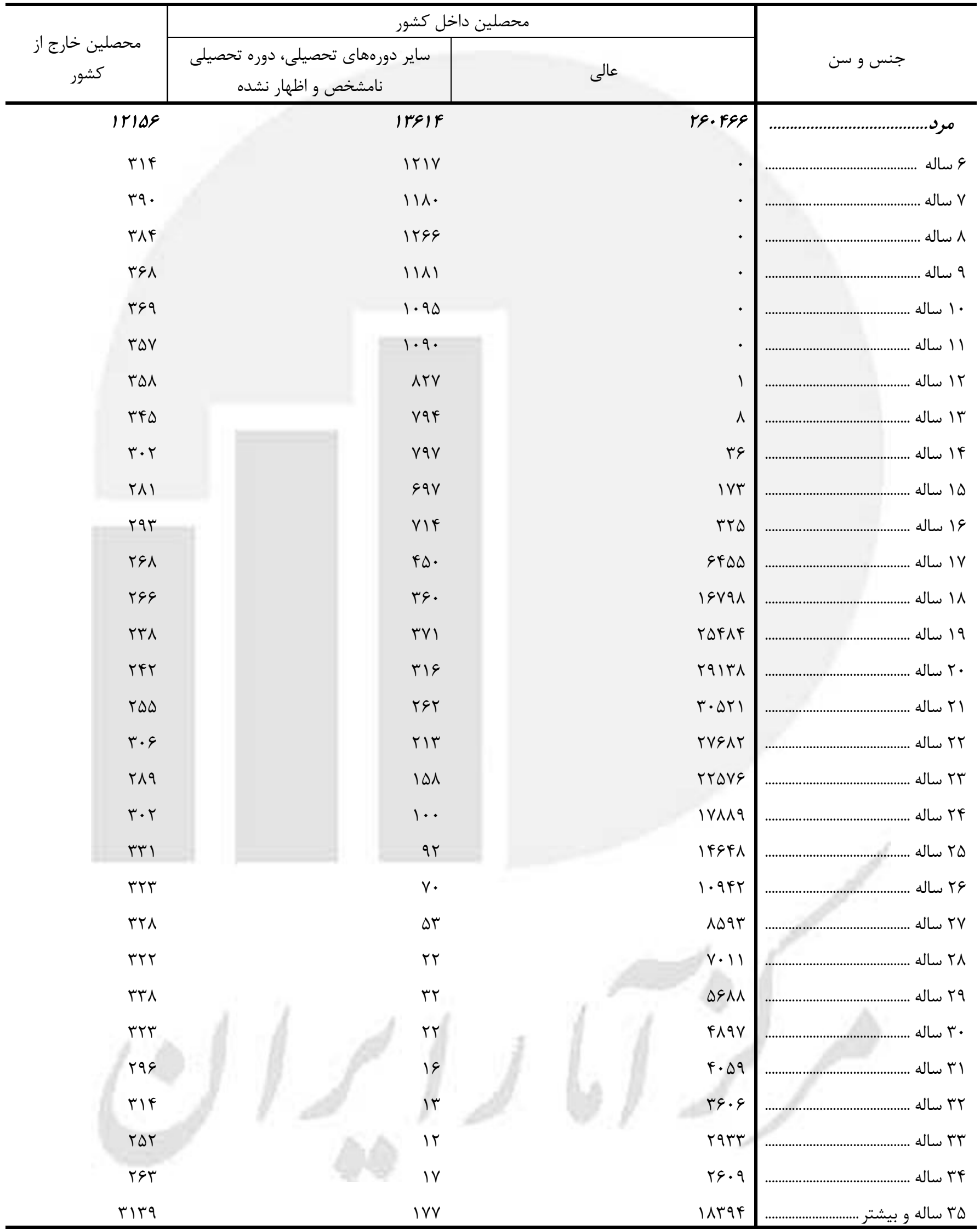




\begin{tabular}{|c|c|c|c|c|c|c|}
\hline \multicolumn{5}{|c|}{ محصلين داخل كشور } & \multirow[b]{2}{*}{ 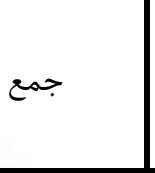 } & \multirow[b]{2}{*}{ جنس و سن } \\
\hline بيش دانشَاهى & | متوسطه/ متوسطه r & | راهنمايى / متوسطه | & سواد آموزى ابتدائ & 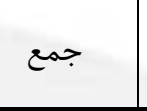 & & \\
\hline \multirow[t]{11}{*}{ AVrIf } & IV\&\&A. & rafqa. & 1. DAVYA & $119 \cdot 1 \pi F$ & $119 \Delta S \cdot 9$ & زن ز...... \\
\hline & · & · & IFFIGK & lFarVt & IFDSAT & q ساله ............................................. \\
\hline & · & - & $|9 V \mathrm{~N}|$ & $19 \lambda \& \& 4$ & $19 \Lambda \Lambda r \cdot$ & ساله ............... \\
\hline & · & · & IEYqDT & $199 \cdot 10$ & IGAYVD & 1 ساله .............. \\
\hline & $\cdot$ & $\cdot$ & IETIOT & IETTVD & 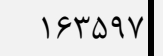 & 9 ساله ................ \\
\hline & r & rVQ & $19 \Delta 9 V$. & 1999VD & IEVTFY & • (1 ساله ........ \\
\hline & 9 & $10 r 9$ & 1019K9 & IDFT.G & lQFAVV & 11 ساله ................ \\
\hline & $r \cdot$. & $\Lambda \notin q \cdot r$ & $\Delta T F \Delta \Delta$ & 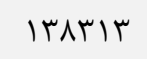 & $\mid r \wedge q \cdot \wedge$ & זاله \\
\hline & raq & $1 \cdot k v \cdot 1$ & $r t \cdot r$ & irVArt & $\mid$ ITITS| & זا ساله ........ \\
\hline & Ir人нs & 9rrl. & १९५८ & $119 \Lambda \cdot V$ & $11 V \cdot V r$ & fl اله ساله ....... \\
\hline & 19118 & FMTTF & FDI9 & 9人सा & 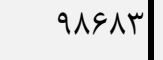 & ها لهاله ......... \\
\hline$\wedge \wedge \Lambda$ & $9099 F$ & $1 F \cdot 1 r$ & TFVq & $\Delta F \cdot r F$ & NFTRA & عاله ساله ......... \\
\hline T. TFV & TQVTA & $\mid 4919$ & IVAr & GOVVR & $9 \Delta 9 \Delta 9$ & IV ساله ......... \\
\hline$r \| \cdot V$ & NFrt & trte. & 190 & erole & freav & 1 | ساله ............... \\
\hline IIVFF & rVI & שחזו & V\&A & rFAVA & rसqA६ & 19 ساله ................ \\
\hline$V \cdot r F$ & $19 V r$ & Net & 91. & rIqrV & $r T \cdot \Delta r$ & • ץ ساله .............. \\
\hline FAGT & אזrו & ט१ & $\Delta r V$ & r११८। & $r \cdots \wedge \Lambda$ & ال ساله .............. \\
\hline r৭६4 & qvV & 019 & rVt & $r \Delta \cdot \Lambda I$ & TDI QF & ז ساله .............................. \\
\hline$r \cdot 11$ & VQq & fis & ra. & $191 \ldots$ & $191 \vee 0$ & ץץ ساله ........................... \\
\hline 1T4. & $\Delta G K$ & rVr & MFT & IFYq & $14 \Delta 99$ & 1............. \\
\hline r & gre & rVQ & rII & $11 \pi 90$ & $114 r q$ & ه ساله ......... \\
\hline$v F$. & TYA & rid & TQ1 & NGTY & $\Delta V T \cdot$ & 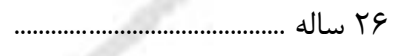 \\
\hline$\Delta F$. & tAL & 199 & MIF & GヘDS & $99 \times 1$ & V T Tاله ........ \\
\hline rAV & TFT & $1 \Delta V$ & rq1 & $\Delta \Delta \varphi q$ & $\Delta s \varphi \Delta$ & 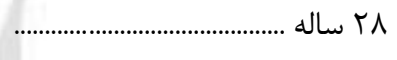 \\
\hline raf & 194 & Ifr & $r \cdot r$ & f\&qu & rQSG & 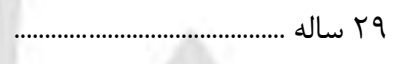 \\
\hline rat & $1 M 1$ & $|0|$ & r\&l & FTrS & $r \mu \cdot q$ & 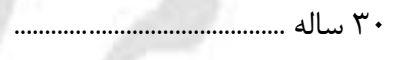 \\
\hline TTS & $1 \Delta \Delta$ & IFT & ruq & rद.. & req. & 1 آ ساله ............. \\
\hline rqV & lfF & 11. & Tq. & ખ\S & TTDS & זr ساله ........ \\
\hline trV & $1 r \Lambda$ & ITF & TYD & $r V \cdot \Lambda$ & TVAF & זr ساله ........................................... \\
\hline INT & $1 \cdots$ & 119 & TF. & Trtr & rTAD & ......................................... \\
\hline 1111 & $V \notin \Lambda$ & 910 & $r \cdot \Delta \Delta$ & ITVT. & $|r| 1 V$ & هـ ساله و بيشتر .. \\
\hline
\end{tabular}


| نتايج تفصيلى سرشمارى عمومى نفوس و مسكن _ه |

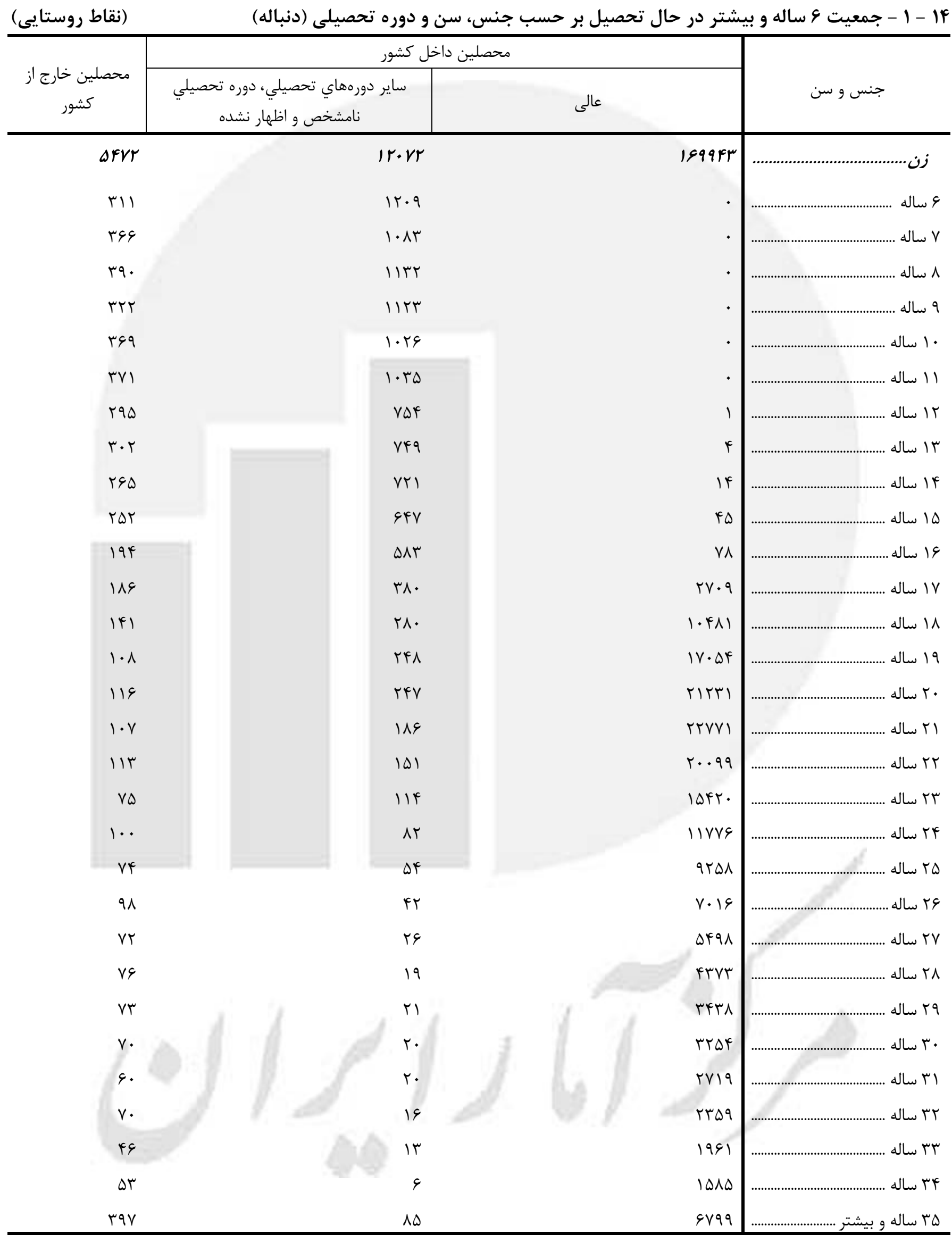



ها - 1 - باسوادان 9 ساله و بيشتر كه در حال حاضر تحصيل نمى كنند بر حسب جنس، سن و دوره تحصيلى

سيكل دوم/متوسطه/متوسطه //

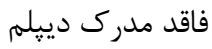

$$
\begin{aligned}
& \text { سيكل اول/ راهنمايى / پايان } \\
& \text { راهنمايى/متوسطه | }
\end{aligned}
$$

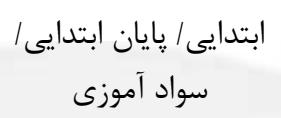

Arqq.FI

raqF\&AF

rqu

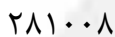

DrGTaV

GTYAQT

DQFAKF

FG.. Fi

rmI Trq

rogqra

r.人rl.

ITIAV

$V V \cdot \Delta T$

FIITS

TFI99

rrवाA

$r / r \lambda \cdot \Delta r$

$110 \mathrm{~A}$

IDVGGD

THTEY.

rA. IAF

rOAVYI

rVTrYr

I9IOVI

I FrV.

IT. EFV

A.rTd

FVVDV

TETAV

IETTD

I99VT

IFAFETV

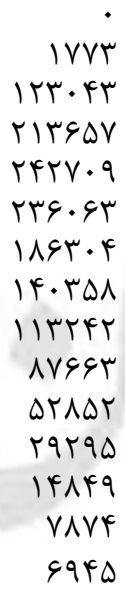

\section{. 1 | | |}

prq. r

FHESAN

VAGTDF

ITKGF. .

IFIVVGF

ITY. TV.

१९१YT

NTVYFF

D\&F१९q

TIA.

INVTAI

I. TI99

DqTqV

G. NTF

frg. rra

IV.Vq

r.. VFF

FI911V

VTII.V

NQTVIF

VISIOF

DVIVI9

FV. 91 .

mसGद्

$195 \mathrm{~g} 9$

\|QFII

gFrat

rAv.人

FTITV

MFANAIF

TENTK

rmate

reVISV

D. DTQY

$\Delta G F \cdot \Delta$.

$\Delta \cdot F 119$

FTVDI.

rDSNTF

TTVVTT

|TQTI|

viNF.

rNA.V

$r \cdot 9 \wedge 9$

I $199 \mathrm{~V}$
ITITAN

TVAGTA

FA. FDI

AYFI.

IITFQAF

ITAVT.

ITVIDFF

IrDQTDQ

I. FFINA

AVVADH

GQTaTr

FIFTEA

TQVT.D

rTVEVI

$\Delta \cdot \mid 1 F \cdot 1$

$\Lambda F \cdot V \Lambda$

FrqQA

111.9 .

FI. IVA

rVFG19

DITAFI

DGQGFY

DqRबQV

GINGTF

FVANTE

FFIIT.

TETATI

FMVI.

IOAFTV

TTIV.I

$\Delta \Delta D \cdot \Delta A V$

VarAr

VVr..

ISFDSD

YV. TVT

FFqFIN

GITIF

VIVAG.

VVAqFY

VTGGTI

DFFTET

FTEVTK

r.

IVRIET

94र\&A

$1 \cdot \Delta 9 \vee$.

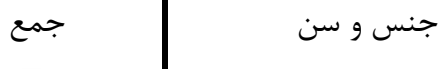

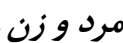

9-9 ساله .

ISDQAF

IV.Y..

ISIAFT

FI911..

$V \cdot \Delta \& \mid \& \psi$

VV.VFAK

GTQGIII

FVGTE. F

rQ人Td.V

r. IrFAr

rTVAqRD

IDIDQTq

१DG.. 9

FqF्D

$\Delta \Delta \cdot T \backslash \Lambda$

rmmreare

$\Lambda \Delta F \wedge V$

GTTID

VATETT

TII. TVV

rof...IT

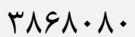

ए।NIFAI

YFAI.VA

rIT.r.r

ISGDG

Ir. grfF

Q1IV.r

DYVDFA

TKT.IT

rND\&G।

rIrADS.F

$\Lambda \cdot$ \&qV

1.9910

$\Lambda \& \Delta \Lambda \cdot 1$

r. NIFTr

rols|Q.

rNTqR.r

r.VFGG.

TYAIDTE

INQTH.Q

ITFVVGV

qघqसq।

G. rNHE

rTAFEF

IVTET

ISFGDV

|

19

q

Q

qr

q

ساله $F$

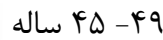

ساله $\Delta \cdot \Delta F$

هاله $\Delta$ س $\Delta$ - $\Delta 9$



$90-99$

ساله $V \cdot-V F$

VD ساله و بيشتر .... VD

مرد ...

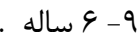

|

19

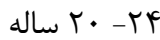

Q

qr

q

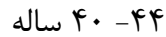

س $F \Delta-r q$

ساله

ساله $\Delta \Delta-\Delta 9$





ساله $V \cdot-V F$

ساله و بيشتر ل......................... سال ل

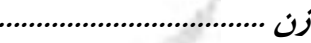

9-9 9

q

19 19

T

q

q

وץ- dץ س س ساله

ساله $F$. F

q

ساله

ساله $\Delta \omega-\Delta 9$

اله

9D-99

ساله $V \cdot-V F$

VD 


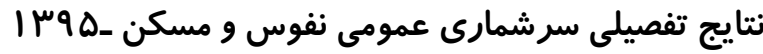

ها - ا - باسوادان 9 ساله و بيشتر كه در حال حاضر تحصيل نمى كنند بر حسب جنس، سن و دوره تحصيلى (دنباله) (كل)

\begin{tabular}{|c|c|c|c|}
\hline تحصيلى نامشخص دورهاى تحصيلى، دوره & عالى & دييلم/ يیش دانشخاهى & جنس و سن \\
\hline $11 v 99$. & 9\&rA1AR & $1 r F \Delta .91 \mathrm{~V}$ & مرد وزن .. \\
\hline Tatr & • & - & 9- 9 ساله . \\
\hline$r \cdot 9 \Delta$ & If & & f \\
\hline frql & IVTaY H H H & $q .494 q$ & 19 اله ـ............................ \\
\hline 人Ir. & $\Lambda .91 V \Lambda$ & lovirq. & 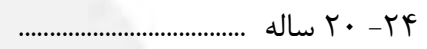 \\
\hline $1 T \cdot 90$ & TYEVFA. & TI. TYYA & q \\
\hline ITAGF & TIV. QTF & $r$ r/A & 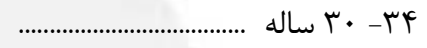 \\
\hline llrar & $\mid F$ FIfI & $1 A F+\cdot 90$ & q \\
\hline 91Tद & १५१८९ด & $\|r \cdot r\|$ & 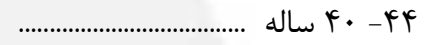 \\
\hline$q \cdot \wedge r$ & $v \cdots 109$ & לוזrוזה & 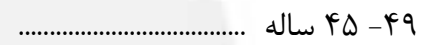 \\
\hline Nrqf & $F V \cdot F \Delta \Delta$ & VTNT.V & ........................................ \\
\hline س & FFIDAN & $9 . .1 T F$ & $\Delta$ ساله ه $\Delta \Delta-\Delta q$ \\
\hline VVru & rraVII & TEYAGY & ....................................... 94 \\
\hline س9וr & pr...kr & 19140. & 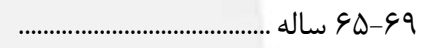 \\
\hline irfs & GqFY & $\vee १ \Delta \vee \wedge$ & wl............................... \\
\hline $999 \wedge$ & GIDTE & 994II & 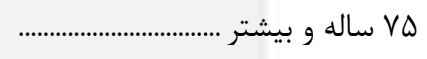 \\
\hline sKeda & $\Delta \cdot 0.0919$ & EMEVTET & 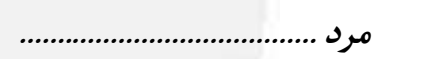 \\
\hline $14 \cdot q$ & . & & 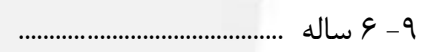 \\
\hline $1.1 \mathrm{~V}$ & r & & F \\
\hline TTET & $\Lambda \Lambda \Delta V$ & TRIVTE & 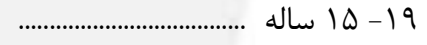 \\
\hline אוז & rVArre & VVAVTD & ………………....... \\
\hline Gr. 1 & I. IETVV & $1 \cdot T I F \Delta \Delta$ & ............................... \\
\hline GNFV & qq4रrद & $\|f\| v \mid$ & 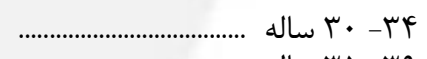 \\
\hline 9.94 & $99 \Delta 949$ & $91991 \mathrm{~V}$ & q \\
\hline DIVq & DYMF.D & $\Delta 999 \cdot V$ & .............................. \\
\hline FVAr & hrANTi & FATMEV & .............................. \\
\hline fefey & KIFDQD & $4.994 \wedge$ & ................................. \\
\hline rrrs & rTqqFi & $r \Delta \cdot 9 \Delta 1$ & 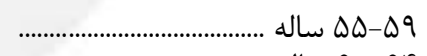 \\
\hline rqq. & |Vri.. & r.qfif & ..................................... \\
\hline מאז & १९৯১૬ & qq४V। & 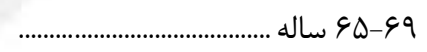 \\
\hline TAFT & $\Delta F \cdot \wedge q$ & $\Delta \backslash \Delta \backslash F$ & 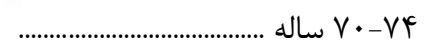 \\
\hline sMAV & $0191 \mathrm{~V}$ & $r \Delta q \wedge \varphi$ & ساله و بيشتر ..................................... \\
\hline$\Delta r \cdot r \Delta$ & rertage & \&l.reva & 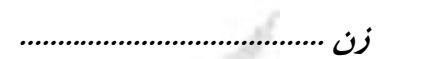 \\
\hline$|r| F$ & - & - & 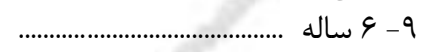 \\
\hline $1 \cdot \vee \wedge$ & 11 & & f \\
\hline TAYq & $\Lambda \Delta \cdot \Delta$ & 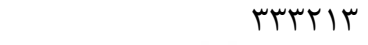 & 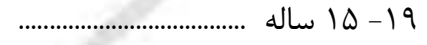 \\
\hline$r \wedge \cdot q$ & $R T \cdot \Lambda \Delta T$ & $\vee १ \Delta ९ 9 \Delta$ & 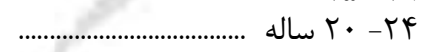 \\
\hline$\Delta \wedge G Y$ & $|r \mu| \cdot V \pi$ & 1. $11 \vee q 4$ & q \\
\hline $9.1 \mathrm{~V}$ & $11 V 9191$ & ITEFQTY & F \\
\hline ( THD. & VRAT.r & qRTIFA & q \\
\hline FAFV & F. 949 . & $\Delta T H G \cdot F$ & 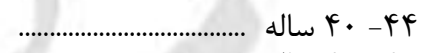 \\
\hline rr.. & 19וTr & rVq9. & (r).............................. \\
\hline r $\wedge$. & $10 \Delta 9 .$. & $\begin{array}{l}\text { TYNTAQ } \\
\text { TEQIVT }\end{array}$ & a.............................. \\
\hline $\begin{array}{ll}\text { rVAd } \\
r y e d\end{array}$ & $\begin{array}{l}1.194 V \\
g \notin 811\end{array}$ & $\begin{array}{l}\text { KFqIVT } \\
\text { ITKEA. }\end{array}$ & 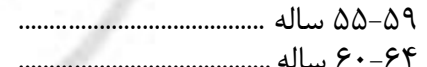 \\
\hline $\begin{array}{l}\text { KTFA } \\
\text { TFA. }\end{array}$ & $\begin{array}{l}\text { g49II } \\
\text { HUIAV }\end{array}$ & $\begin{array}{l}\text { TrTPQ } \\
\text { 919V9 }\end{array}$ & 9 $9 \Delta-9$ \\
\hline $1 \Lambda \cdot r$ & $|\Delta M F|$ & $r \Lambda \cdot G r$ & 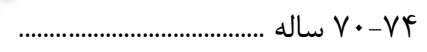 \\
\hline$r \cdot \wedge 1$ & q०น & T. FTS & 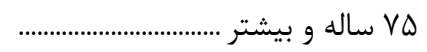 \\
\hline
\end{tabular}


ها - 1 - باسوادان 9 ساله و بيشتر كه در حال حاضر تحصيل نمىكنند بر حسب جنس، سن و دوره تحصيلى (دنباله) (نقاط شهرى) (دبال)

\begin{tabular}{|c|c|c|c|c|}
\hline 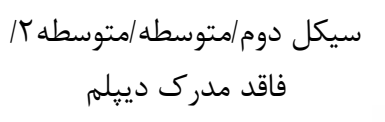 & 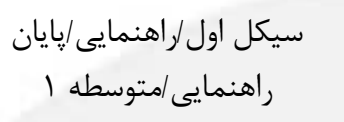 & ابتدايى/يايان ابتدايى/ سواد آموزى & 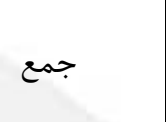 & جنس و سن \\
\hline rq99.99 & $\triangle 1 F \& \Delta \Delta q$ & sqravas & referiff & 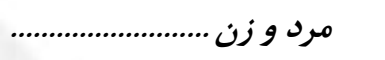 \\
\hline & . & $1 \cdot \Delta 9 \vee 9$ & $1 \cdot V \notin F 1$ & -9 عاله \\
\hline سחטا & $r \cdot r r q$ & Ffrme & $q V \Delta \cdot V$ & 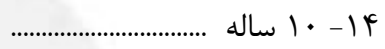 \\
\hline $1991 \mathrm{VV}$ & $r T \cdot 999$ & $1 \cdot \Delta \wedge r q$ & 9 qF9q1 & 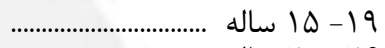 \\
\hline gagrm & FFY QDS & $r \cdot \Lambda \cdot q r$ & 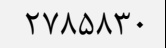 & 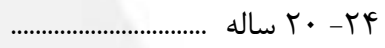 \\
\hline 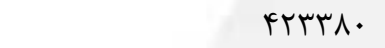 & $V V \cdot \cdots r$ & $F \cdot 1949$ & DTYFTD. & 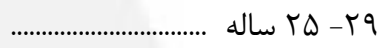 \\
\hline FTEATD & $99 \zeta \cdot \Delta \cdot$ & G. TrDA & $\Delta 9 \Lambda \cdot r q \Delta$ & 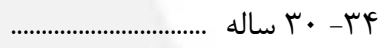 \\
\hline TLFT.. & $\Lambda V \Psi \cdot 1 \Delta$ & $V H G \mid \Delta F$ & $\nvdash \wedge \wedge \Delta r \Delta \wedge$ & q \\
\hline rצ9410 & VATATT & NFDQTI & rVfirms & 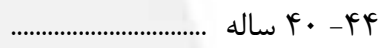 \\
\hline tr.trt & $4 V \cdot \Delta 1$ & $9119 \cdot 9$ & rTHVIIT & 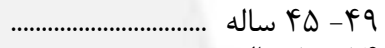 \\
\hline INTEIT & FVIETD & VTVVGD & TDTQGYI & • • \\
\hline $1190 \wedge \mathrm{V}$ & TVGDSq & 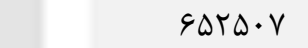 & I gFFGT. & 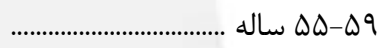 \\
\hline VIfET & 19人ץя & DIRTr & ITINTHF & ع \\
\hline r^vol & qFDTR & rmpfqf & VDFVGI & 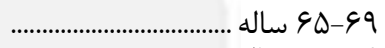 \\
\hline rTqA. & $\Delta \Delta \Psi_{1}$ & rllqve & сrqIrq & ساله $V \cdot-V V^{c}$ \\
\hline trRID & $\Delta V \backslash \Delta G$ & rVF. IS & Fへ૬DTV & 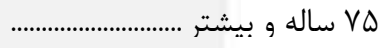 \\
\hline $10 \Delta \wedge \vee q 9$ & 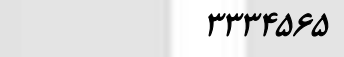 & rlal.l & $I V \gamma r \cdot \Delta \Delta \Delta$ & 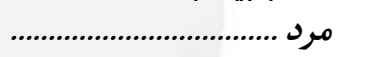 \\
\hline & & DFAFG & $\Delta \Delta V Y \wedge$ & 9-................................ \\
\hline \&r山 & AVtes & $|\wedge \vee| \varphi$ & rAVTr & 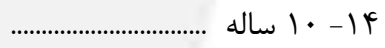 \\
\hline $9 \Delta 9 .$. & $1 \cdot F \Delta \mid \Delta$ & $\mid\langle\wedge \cdot r l$ & $F F \cdot G q F$ & 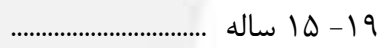 \\
\hline 191190 & rma. II & $q \Delta q 41$ & ITITIT & 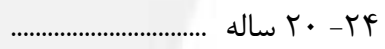 \\
\hline$r \Delta \vee 9 \Delta 1$ & FAFFET & 191104 & $r \Delta \varepsilon \mid \Delta \wedge \Lambda$ & q \\
\hline rबI^बD & $\Delta \Lambda \cdot I V V$ & 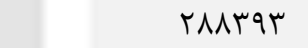 & TQGTFVq & 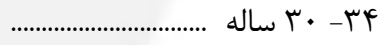 \\
\hline$r \cdot \Delta r q I$ & $0 \cdot 19 r \wedge$ & מוזוזr & TFATYRT & q \\
\hline I pqrqq & pr. rvq & raspVG & $1911 \vee 94$ & ساله \\
\hline $11149 \Lambda$ & एद9119 & rq1.r & $1 V \cdot 111 \cdot$ & 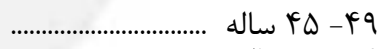 \\
\hline $1 \cdot r \| 11$ & $r V \cdot|\Delta|$ & rt. Fr. & 1499199 & 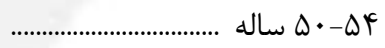 \\
\hline 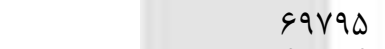 & IEITUT & r. $4 q 9 q$ & $1 \cdot \wedge V \vee r \Delta$ & ساله $\Delta ا$ هو \\
\hline krtef & $1 \cdot 9 \cdot 9$ & rятq9d & 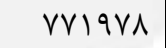 & 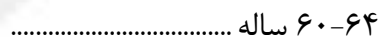 \\
\hline TFH. & $\Delta V Y \& I$ & $I V \wedge V \cdot r$ & $F \Delta \mid F \cdot q$ & 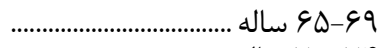 \\
\hline$I \Delta T \wedge \Delta$ & TUYII & |rtN|. & rVRVE & ساله . V•VF \\
\hline 10919 & ए人१९s & IVDGৎ. & $r \cdot \wedge g F$ & 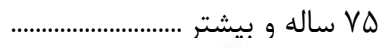 \\
\hline $11 \cdot v r r$. & $r \Delta \| 199 F$ & rarırıa & IesvraAr & 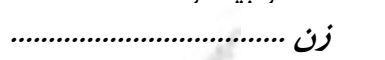 \\
\hline$\cdot$ & $\cdot$ & 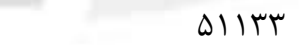 & $\Delta 1 \wedge 9$ & 9- q ساله . \\
\hline$\wedge 91$ & $119 \cdot r$ & rDG & rAVAF & f \\
\hline VraVV & 119111 & $\Delta \vee \vee q \Lambda$ & D.FTrV & 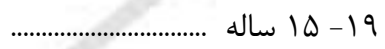 \\
\hline IMFF. I & $r \cdot V q r d$ & $\|T\| \Delta T$ & IFTTEIN & r \\
\hline 19DFTq & r|QS|| & $r l \cdot V k$ & T\&GT\&GT & \\
\hline IVFG9. & 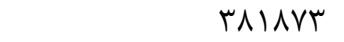 & आاس & 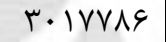 & 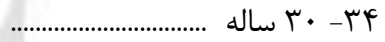 \\
\hline $14 \wedge 9 \cdot 9$ & TVITAV & $F \cdot r \cdot r l$ & TFTrQAD & q \\
\hline IT. THE & MFTFFT & $\uparrow \wedge q \cdot \Delta \Delta$ & INTKDS. & f \\
\hline 1. IVGF & r.rqur & $\Delta I T \Delta V$. & TMLQRT & 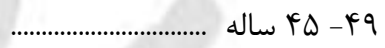 \\
\hline$\Lambda \cdot+q \Delta$ & T.I FVY & $F \cdot V r V \Delta$ & $11 \Delta q \& V \Delta$ & • • 0 ساله . \\
\hline pqvqr & IIDTIV & HFVD.人 & $\wedge \Delta ૬ \wedge ৭ \Delta$ & 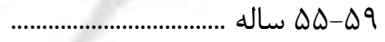 \\
\hline 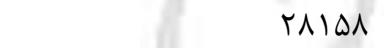 & GVVDV & rטTr.V & DFGTDG & 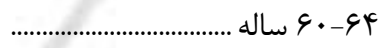 \\
\hline IFED. & TVYGT & $|\Delta \Delta \vee q|$ & $r \cdot r r \Delta \Delta$ & 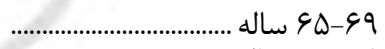 \\
\hline$\vee \vee 9 Q$ & $r . .9 q$ & 19199 & |9|r人s & ساله . V.-VF \\
\hline sVaq & $|A T|$. & qरros & l $\Delta \Delta \varepsilon V$ & 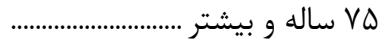 \\
\hline
\end{tabular}




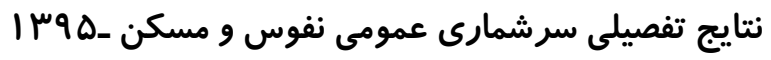

ها - 1 - باسوادان 9 ساله و بيشتر كه در حال حاضر تحصيل نمىكنند بر حسب جنس، سن و دوره تحصيلى (دنباله) (نقاط شهرى)

\begin{tabular}{|c|c|c|c|}
\hline تحصيلى نامشخص و واظهاى تحصيلى، دوره & عالى & دييلم/ ييش دانشكاهى & جنس و سن \\
\hline $1 v \cdot 11$ & Arrgafr & 1. rregq1 & 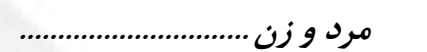 \\
\hline 1995 & . & & 9 -9 ساله .............................. \\
\hline ITAF & $\mathrm{v}$ & & ץ \\
\hline M & $|T K \Delta|$ & стrq.. & 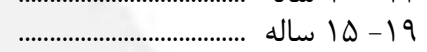 \\
\hline$\Delta T I F$ & $99.1 T \Lambda$ & llसG|kT & F \\
\hline$\Lambda \Delta \cdot r$ & $199 \mathrm{r} \Delta \Delta \Lambda$ & $19 \Delta 9 \Lambda \cdot \Lambda$ & .................................... \\
\hline $9 \Delta \Delta V$ & l9VMFTF & 1999F4a & 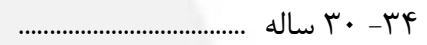 \\
\hline$\Lambda \Delta \Delta 1$ & IrTYTQD & $\mid \Delta \wedge \varphi \cdot k r$ & q \\
\hline VTVD & $\Lambda g \vee Q \cdot T$ & 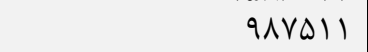 & 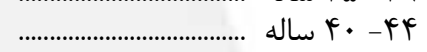 \\
\hline gqFe & $994 \cdot V q$ & VGFY.. & 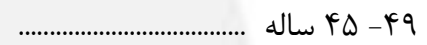 \\
\hline gFt & Fअ人१וr & GMNTEK & 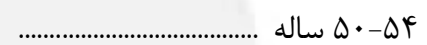 \\
\hline 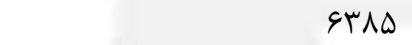 & TrGIIA & DGMFGY & .................................. $ه$ ه \\
\hline G..r & TYM\&\&D & rTgkTq & 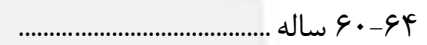 \\
\hline FASI & ITEATA & $1 \Delta \Delta \varphi \cdot V$ & \\
\hline rVTS & GVQGY & VVIVT & ساله \\
\hline VYFA & G.r.r & gqV.r & 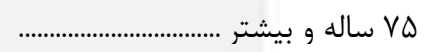 \\
\hline fr. 19 & Fqq|FAl & DTIVEAT & 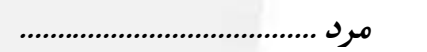 \\
\hline$q \cdot r$ & . & & 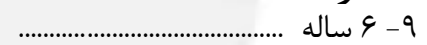 \\
\hline GTQ & 1 & & 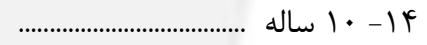 \\
\hline lifkF & DATT & INDTAT & 19 اله ساله......................... \\
\hline$T V \cdot \Delta$ & $r q . F \Delta r$ & $\Delta F \cdot T \cdot V$ & ( \\
\hline krqu & $\Lambda Q \Delta F \cdot Y$ & VAVATS & 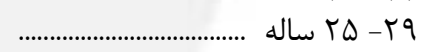 \\
\hline$\Delta 1 \cdot r$ & $\Lambda M \Lambda I \Lambda \Lambda$ & QTAVQF & 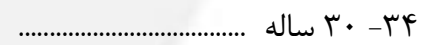 \\
\hline FDQT & $9 \Gamma \Delta \cdot \wedge 9$ & VVTAFT & q \\
\hline rquF & FN. rVQ & $\Delta \cdot \Lambda T \& r$ & (...………………...... \\
\hline rबם & $\forall 1 \cdot \Delta \ldots$ & f. frat & q.............................. \\
\hline MFTt & rQ૬૬AT & TVMTET & 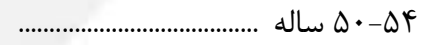 \\
\hline r. & rTGKqA & rTIAq. & ساله .................................. $ه$ \\
\hline פוז" & IEFqAr & $19 \Delta \vee \& \mid$ & ף \\
\hline trAT & $q 4 \cdot k T$ & q49IV & ….................................... $9 Q 9$ \\
\hline TIVT & DTVAN & FqFV & 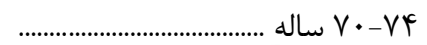 \\
\hline$\Delta \cdot F T$ & $\Delta \cdot V \Delta q$ & FFOHA & 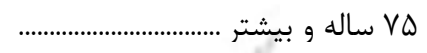 \\
\hline$f . . g r$ & FreafeI & $\Delta r / 9 \cdot 10$ & 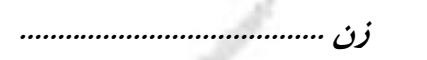 \\
\hline Vq. & - & - & 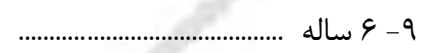 \\
\hline 909 & 9 & & 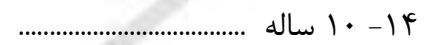 \\
\hline 1994 & GKrg & TFAGYA & 19 19 ساله ................................. \\
\hline$r \Delta \cdot q$ & ५५९९Vब & Q9०१५ & …1.......................... \\
\hline Frll & $1.911 \Delta F$ & 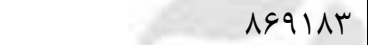 & q \\
\hline FEDQ & 1. NDTFS & $1 \cdot \Delta \vee 991$ & 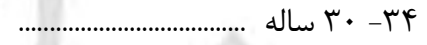 \\
\hline r৭४८ & $99 \pi r \cdot 9$ & $11 r \Delta \cdot 1$ & q \\
\hline MFEI & TAVITV & FVGTYA & 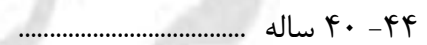 \\
\hline rTAl & roTaVq & $r \Delta 9 \Lambda \cdot \varphi$ & 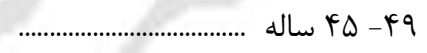 \\
\hline r... & |QTKTI & rikq.. & 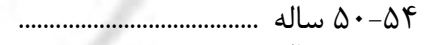 \\
\hline$r \cdot \Lambda \uparrow$ & ११४५. & YFIDVF & 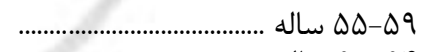 \\
\hline rqVF & GMGAT & $1 \% \cdot 9 V \Lambda$ & 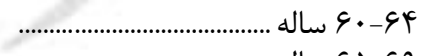 \\
\hline $\begin{array}{r}r \cdot v q \\
i \Delta \Delta k\end{array}$ & rTVAT & $\begin{array}{l}4.99 . \\
\text { rvcoc }\end{array}$ & 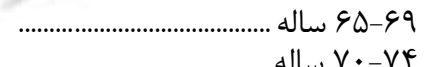 \\
\hline $\begin{array}{l}1 \Delta \Delta F \\
T V \cdot r\end{array}$ & $\begin{array}{l}\text { lQIVE } \\
\text { oxce }\end{array}$ & $\begin{array}{l}\text { tV999 } \\
\text { r.19C }\end{array}$ & 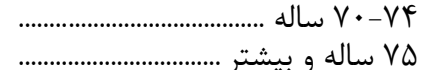 \\
\hline$T V \cdot r$ & qfyt & $r \cdot \mid G Y$ & Vاله و بيشتر ................................... \\
\hline
\end{tabular}


ها - 1 - باسوادان 9 ساله و بيشتر كه در حال حاضر تحصيل نمىكنند بر حسب جنس، سن و دوره تحصيلى (دنباله) (نقاط روستايى)

\begin{tabular}{|c|c|c|c|c|}
\hline سيكل دوم/متوسطه/متوسطه // فاقد مدرك دييلم & 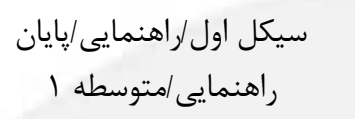 & ابتدايى/يايان ابتدايى/ سوادوزى & جمع & جنس و سن \\
\hline$q r r \cdot 1$. & $r r q 1 F \cdot \Delta$ & ravqlag & $1 \cdot$ larferf & مرد و زن ...................................................... \\
\hline . & - & $\Delta \vee \backslash \Lambda$. & $\Delta \Lambda \| \mu_{\Lambda}$ & - 9 ساله ............................ \\
\hline וrqD & rrYAq & Vबस्I & $1 \cdot r \cdot 91$ & 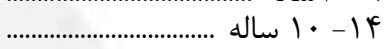 \\
\hline $1119 \Delta \mu$ & r|rkqi & $\mid \& \wedge \varsigma \wedge$. & SVITVE & 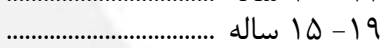 \\
\hline r. rgfq & TFTEVG & $r V I \cdot r r$ & IF. FFV & 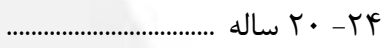 \\
\hline I994IV & FDDGTS & FY. VYG & INTAFVT & q ${ }^{\prime}$ \\
\hline $\mid \Delta \Lambda \cdot \Delta \Delta$ & $F \Delta \Delta \cdot \Lambda T$ & $\Delta Y I F G Y$ & IVTFFqV & 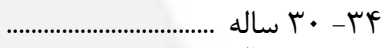 \\
\hline $1 \cdot \Delta \& F G$ & MFGGT M & DFqATI & ITG人TAF & q \\
\hline STYIT & س & $\Delta r \Delta \cdot F$ & 1.19941 & 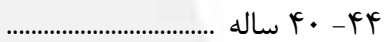 \\
\hline rघquV & IDVFTA & FFTAFT & VFFI. & 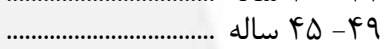 \\
\hline rQS9) & GTrAT & 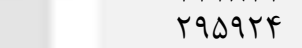 & $F \wedge V \cdot \wedge F$ & 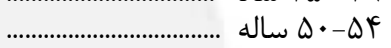 \\
\hline IraVa & fITV & $r T \Delta \cdot G$ & 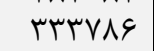 & ساله $\Delta \Delta-\Delta 9$ \\
\hline$\Delta \Delta \wedge \mu$ & 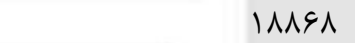 & IfGFT. & $19 V \cdot r d$ & 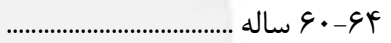 \\
\hline rmin & 1\&\&F & 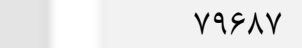 & سז11 • & 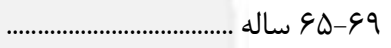 \\
\hline$|r| \Lambda$ & $r \cdot \Lambda F$ & ForqT & $\Delta \Delta \& \wedge I$ & 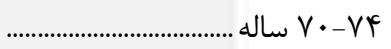 \\
\hline $14 \cdot 1$ & r49T & DrGIF & GTVYG & 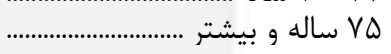 \\
\hline ararg. & IFrr. VF & $1189 \cdot v 9$ & DQDTrAr & 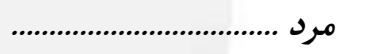 \\
\hline & & rqIrی & rqg4r & 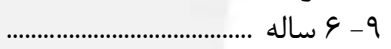 \\
\hline$\Delta r$. & $\Lambda \mu \cdot r$ & $r \Delta \cdot r$. & TFYFV & 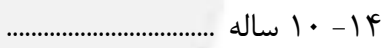 \\
\hline GKro. & $9 \Delta १ \Delta ९$ & $G r \Delta \cdot V$ & r. & 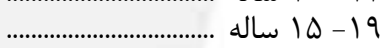 \\
\hline ITHOT. & |Arvis & $\| r \Delta G F$ & $V F \Delta \cdot \Lambda \varepsilon$ & 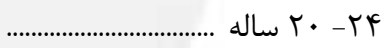 \\
\hline Itr.rG & rब9।9T & $|\wedge r| \cdot \Lambda$ & 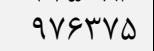 & ساله rQ $\mathrm{d}^{\mathrm{a}}$ \\
\hline १९VDV & TRITL & trTATK & $q \cdot r \cdot \Delta 1$ & 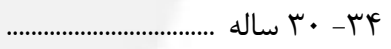 \\
\hline GATrL & rIfIFr & 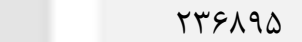 & VTVVGA & q \\
\hline FYIFF & IDIITO & TrDQVY & $\Delta S \mid r q F$ & 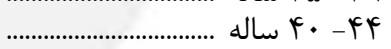 \\
\hline rol9. & $1 \cdot 1499$ & $r t \ldots q r$ & FrAIFq & ( \\
\hline$|\wedge \Delta \cdot|$ & מץ. & $|09| \cdot \Delta$ & rqq..q & 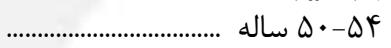 \\
\hline $1 \cdot 019$ & rIr.Q & 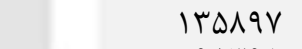 & ( & ساله $\Delta \Delta-\Delta 9$ \\
\hline FFFV & IFVAM & $9 \wedge r q \Delta$ & ITQDTT & 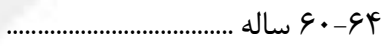 \\
\hline $19 \vee 9$ & $V|r|$ & ه人rv & $V q \cdot i v$ & ..................................... 99 \\
\hline $1 \cdot r q$ & rFqD & rog.. & FFTH & ساله $V \cdot-V Y$ \\
\hline $1 \cdot \Delta \mu$ & rivg & fq..r & DFVFA & ساله و بيشتر ................................... VD \\
\hline rfarq. & qVarr & $r \cdot I v \cdot r v$ & $F q \cdot a \cdot \Delta l$ & 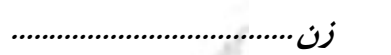 \\
\hline & & $r \Lambda \cdot f t$ & rAFqD & 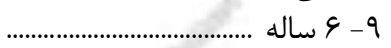 \\
\hline$\Lambda \vee \Delta$ & $|\Delta| \wedge \Delta$ & (DIrG| & GVAFF & fle \\
\hline fqp.r & IIVArd & $1.91 \mathrm{Vm}$ & $r q \cdot \Delta \cdot \cdot$ & 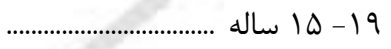 \\
\hline Vq। rq & । $\Delta \wedge 9 \varphi$. & IDVFe. & 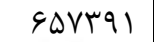 & 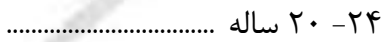 \\
\hline VVINI & سז41194 & 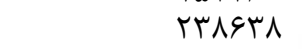 & $\Lambda \Delta Y \cdot q \Lambda$ & 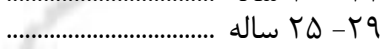 \\
\hline $91 r 91$ & 11190 & rqVघr. & NT. FFE & 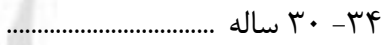 \\
\hline rVTII & ITrFA| & (rqu & $94 \cdot 919$ & q \\
\hline$r .94 \Lambda$ & $\wedge$ «q^ & rᄉq4\&9 & FDATFV & 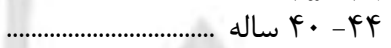 \\
\hline IIFEV & DYAFI & TTHVD. & 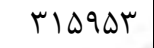 & .............................. \\
\hline Vis. & reTrq & $11 \% \wedge 19$ & $\backslash \wedge \Lambda \cdot V \Delta$ & (1) $\Delta$ ساله . \\
\hline$r \cdot \Delta \varphi$ & $1 \cdots V r$ & $191 \cdot 9$ & MTFDS & ساله $\Delta \Delta-\Delta q$ \\
\hline 1114 & $r \cdot \Lambda$. & $r \wedge \cdot r_{\Delta}$ & DVDYT & ....................................... \\
\hline ५१९ & IDFT & rITU. & $r \Delta \cdot \wedge \varepsilon$ & 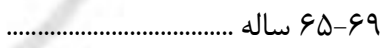 \\
\hline 189 & $\Delta \wedge 9$ & १९q४ & IITFT & ساله $V \cdot-V Y$ \\
\hline $\mid r \wedge$ & $\uparrow \wedge \Delta$ & V9II & ^৭マ^ & ساله و بيشتر .................................. VD \\
\hline
\end{tabular}




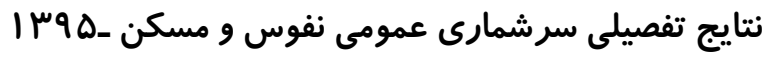

ها - 1 - باسوادان 9 ساله و بيشتر كه در حال حاضر تحصيل نمىكنند بر حسب جنس، سن و دوره تحصيلى (دنباله) (نقاط روستايى) (نقيلي)

\begin{tabular}{|c|c|c|c|}
\hline تحصيلى نامشخص دورهاى تحصيلى، دوره & & دييلم/ بيش دانشخاهى & جنس و سن \\
\hline$r \cdot \Delta \& V$ & $91 \cdot 1 \mathrm{rr}$ & $r \cdot I l r a r$ & 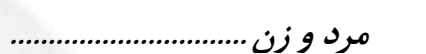 \\
\hline $9 \Delta \wedge$ & - & . & 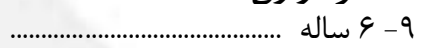 \\
\hline $1 \cdot 9$ & $\checkmark$ & - & 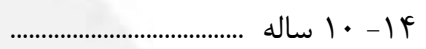 \\
\hline 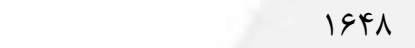 & 0.99 & $I V \cdot \Lambda \cdot \Delta$ & 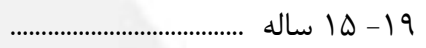 \\
\hline rqוr & IFNATK & מקqqu & ساله ............................... TH \\
\hline$r \Delta \Delta \Delta$ & $r \cdot r \Delta \cdot v$ & FFANTT & ساله \\
\hline 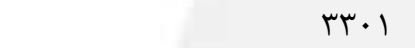 & 19Vmr & 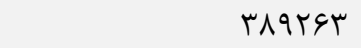 & 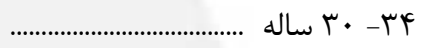 \\
\hline tNHF & $1.9 \mathrm{~V} \Delta \Lambda$ & rDS99T & 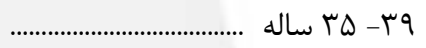 \\
\hline refq & Grr.V & ITTDQV & ساله . F · Pf \\
\hline (TוT & rG.r & $99 \cdot 11$ & ساله $F Q$ \\
\hline $1 \wedge \Delta 9$ & rIQ19 & FqAvr & ................................. \\
\hline$I V V A$ & IQYUT & rदט१^ & ساله . $ه ا$ هو \\
\hline سRו & 1.re & $1 \& 490$ & ......................................... \\
\hline ITUT & Trid & $\Delta \Lambda \mu V$ & 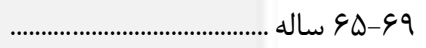 \\
\hline $1 \cdot 19$ & IfGT & $r F \cdot r$ & 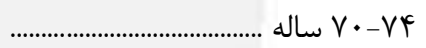 \\
\hline 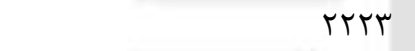 & ITt & $I V \cdot r$ & 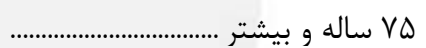 \\
\hline$|V \varepsilon| \mid$ & DFrVVF & 11 TrADQ & 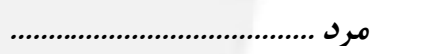 \\
\hline$\Delta \cdot \Delta$ & • & $\cdot$ & 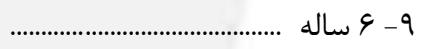 \\
\hline एव) & r & & • • اله ساله . \\
\hline$\Lambda 1 F$ & $r \cdot r \Delta$ & AGTrF & 19 اله س.......................... \\
\hline 1910 & AVVYG & rrFqFa & 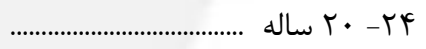 \\
\hline $19 \cdot 0$ & $1 V \cdot V \mid q$ & THEIV & ساله \\
\hline$|V F|$ & $1.9 \mathrm{fF}$. & t. TIFV & 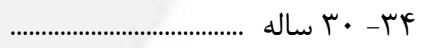 \\
\hline 11490 & $q \cdot \vee q$. & $|f \&| f \mid$ & 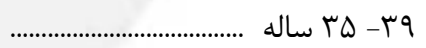 \\
\hline ITFF & FTqVD & NATrt & ساله . F. Pf \\
\hline $111 \mathrm{~V}$ & thrAt & 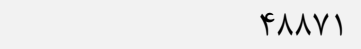 & ساله $F Q$ \\
\hline $1 \cdot 11$ & IVAFq & TEDT. & 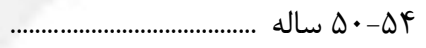 \\
\hline $1 \cdot V V$ & ITATV & $r q \cdots \Delta$ & ساله . $ه ا$ هو \\
\hline 119. & $V_{1} \cdot v$ & Irata & 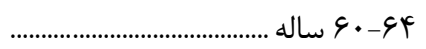 \\
\hline 901 & rᄉll & $F \wedge \uparrow \wedge$ & 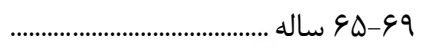 \\
\hline$V V \cdot$ & IraV & $r \cdot r V$ & ساله . V.-VY \\
\hline $\mid \wedge F \Delta$ & ITTV & IfFT & VD ساله و بيشتر .................... \\
\hline Irqus & rev. 99 & 11rvq1 & 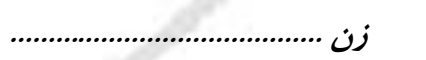 \\
\hline Far & - & - & 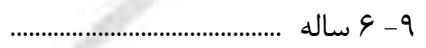 \\
\hline Fin & $\Delta$ & • & 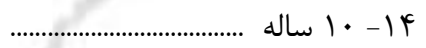 \\
\hline 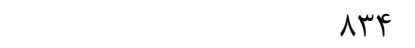 & $r \cdot V r$ & AFYAI & 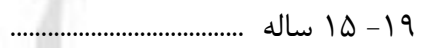 \\
\hline 1491 & 91.99 & $1994 F \wedge$ & (Tץ \\
\hline 190. & |rTVq1 & TITK.D & q \\
\hline $1 \Delta 9$. & $9 \cdot 19 r$ & $|A V| 19$ & 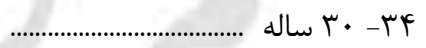 \\
\hline 11499 & 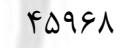 & $|1 \cdot \Delta \Delta|$ & q \\
\hline $1 T \cdot \Delta$ & זrm & FFTtD & ساله . F · P \\
\hline $1 \cdot 19$ & VVDS & $r \cdot \mid r \cdot$ & ساله $F Q$ \\
\hline$\Lambda F \wedge$ & T\&GV & ITHAT & 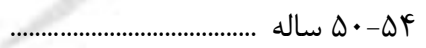 \\
\hline$v \cdot 1$ & 1970 & VDqT & 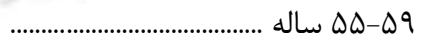 \\
\hline$\Delta V{ }^{\prime}$ & 949 & TVV. & 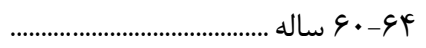 \\
\hline$r \cdot 1$ & $f \cdot r$ & 919 & 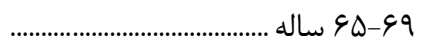 \\
\hline rpq & 190 & rGV & 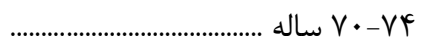 \\
\hline rVA & $9 \Delta$ & rQl & 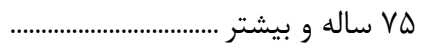 \\
\hline
\end{tabular}


19 - 19 - دانشجويان دانشخاهها و موسسات آموزش عالى داخل كشور برحسب جنس، سن و دورهى تحصيلى (كل)

\begin{tabular}{|c|c|c|c|c|c|}
\hline دكتراى تخصصى| & و دوكتراى حرفهاى ليسانس & 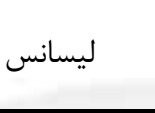 & فوقدييلم & 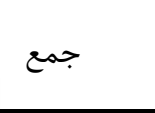 & جنس و سن \\
\hline$|r \Delta| \Delta$ & $\Lambda \cdot$ rara & TIfFrgF & Aravqd & $r q \cdot \wedge \Lambda f F$ & مرد و زن مرن \\
\hline 9 & $\Delta \varphi$ & TFE & $r \Delta \Delta \Lambda$ & r^ৎq & 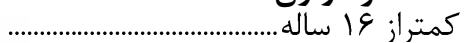 \\
\hline (I) & $11 \%$ & $r \Delta V \mu$ & $\Delta \Delta \vee \varepsilon \Lambda$ & $\Delta q F \vee \Delta$ & 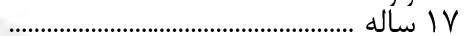 \\
\hline aाr & $F G \cdot F$ & I тrq9я & $1 \cdot|f| \Delta$ & r.GTV & 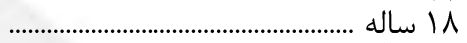 \\
\hline 1.11 & $1 \Delta \vee q$ & Yाlब99 & IrrFq. & MFFENT & 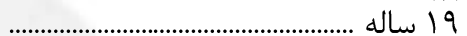 \\
\hline IFVA & $1.9 T r$ & T\&ヘT१D & $1 \cdot$ Neff & ५А१.५ & 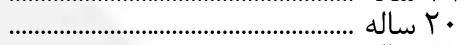 \\
\hline DQTE & $\mid$ TMEI & T.FTYG & Nזیזু & $Y \cdot r \cdot r \Lambda$ & اله \\
\hline lar. & $r V \cdot \Lambda r$ & $r \notin q .4 q$ & $\Delta 91 \cdot 9$ & rDFFV. & 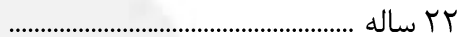 \\
\hline 1111 & $\Delta \cdot V \mu \cdot$ & 19.919 & Fr.VG & rAGDHG & r ساله ...1. \\
\hline$r / 90$ & $99.1 \mathrm{~V}$ & $|r T| 99$ & rrm. & rrDGAT & 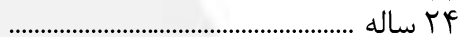 \\
\hline rIVD & $v \cdots 91$ & $99 \wedge \cdot 9$ & rQqYG & $199 \cdot Y \Lambda$ & ساله rb \\
\hline (r & घ५৭19 & $V \cdot \Delta V F^{c}$ & $r \cdot 191$ & $|\Delta \Lambda Y F|$ & 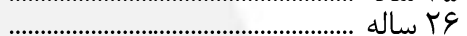 \\
\hline$\Delta q \cdot 1$ & DYADF & $\Delta G \vee \wedge \vee$ & $\mid V F \ldots$ & IrTgFt & ץاله \\
\hline 99r. & FFrr. & FaVYA & IFVG. & IITINA & \\
\hline 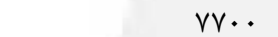 & ґ११ґ^ & एवा19 & $|m f| \mid$ & 1.191 & † \\
\hline$\Lambda 1 \cdot V$ & rᄉkqV & 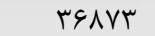 & ITAFA & QGTTD & 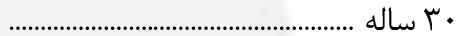 \\
\hline $118 \Lambda$ & $r G \cdot V V$ & MTFES & ITKAT & 19q4 & Iاله \\
\hline VVYF & rrtro & riv.. & IIVVA & NFFry & 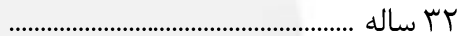 \\
\hline SVAT & rANFG & TVYAS & $1 \cdot \Delta r G$ & VHFTI & r \\
\hline$\Delta q \mu \Delta$ & rDQF. & rFFqq & qvqץ & 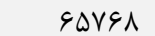 & 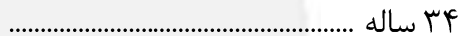 \\
\hline F१९८F & IAVQ9. & IN. TTE & VF१९s & FqY^GF & 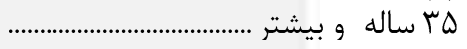 \\
\hline vaAse & frs. q. & $1 \cdot 991 \cdot 1$ & DTFFA. & $r \cdot q V \Delta q F$ & 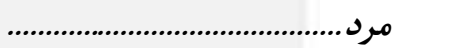 \\
\hline$\wedge$ & rv & If. & rq६. & mIFa & 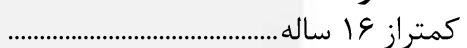 \\
\hline 11 & $\wedge \Delta$ & $r \cdot \varepsilon \cdot$ & reqke & rri.r & 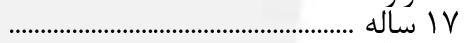 \\
\hline$r 90$ & rF^q & Q9TVV & gifir & ITMEVF & 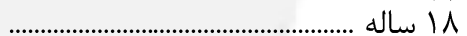 \\
\hline fVr & FTAV & १९७rr & $V F \cdot \varphi \Delta$ & $I \vee \wedge \Delta \Delta \Lambda$ & 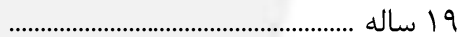 \\
\hline 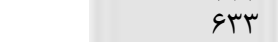 & 0.99 & IrTAFA & я४qrq & I9FFAG & ...………………………………..... \\
\hline Gब & DVAr & $\mid F \cdot F \cdot F$ & Fq人if & 1999VK & اله ساله \\
\hline 994 & $1 \pi 111$ & IrDAGT & r4..r & IVDSG9 & r Tاله \\
\hline NFG & rFFVE & qFFAl & T\&AT. & IFEAT & 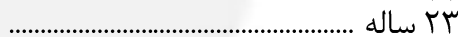 \\
\hline $11 \mathrm{~F}$ & rmFA. & 9V9.1 & $r \cdot q \Delta r$ & ITIVD & 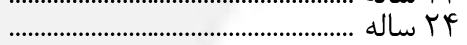 \\
\hline $18 \cdot 9$ & 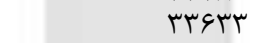 & $\Delta \cdot$ UGF & 19941 & I. TERV & 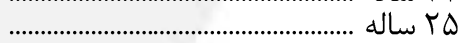 \\
\hline TETV & $r \cdot 109$ & ए६६9V & 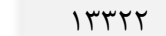 & $\Lambda r \Lambda \cdot \Delta$ & \\
\hline r & rDQ९ৎ & TQDTQ & 11499 & 999\% & 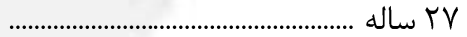 \\
\hline rیטK & rTrVA & rrql. & qVF. & $\Delta 9 \wedge \Lambda 1$ & 凡 \\
\hline FYqI & $r \cdot T \cdot r$ & $r \cdot r \Delta q$ & $q \cdot r \mu$ & DrAVV & rq \\
\hline fFFF & $191 \vee 9$ & 19ror & $\Lambda \Delta V$. & DTFFE & . \\
\hline 40.9 & $1 \wedge 90 \wedge$ & IVDID & ATr. & 19199 & ال ساله \\
\hline FrVE & IVATA & $19 \mathrm{VIT}$ & $\vee \wedge \Delta \cdot$ & FEFEF & 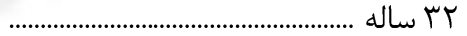 \\
\hline ५^१ץ & $1 \Delta \mu 9 \Delta$ & 14\&99 & VIqf & fllvq & 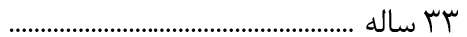 \\
\hline rGTh & $|F| 9 V$ & IrTgV & $9 V \cdot 9$ & $r \vee \wedge \cdot 1$ & Fl \\
\hline TVETF & $|r| F \mid$ & $11 \cdot r V F$ & DTATq & TrTETV & 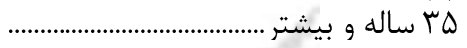 \\
\hline rerge & rVAFFA & 1. vatas & هוrוr & $|1| 1 r \lambda$. & 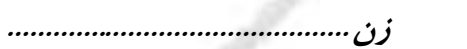 \\
\hline 1 & 19 & 1.9 & $\Delta 9 \wedge$ & VTF & 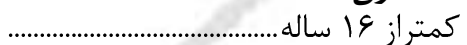 \\
\hline 1 . & rی & |DIr & $t \cdot N T t$ & TrMVT & أله /V \\
\hline riv & $r \| Q_{0}$ & gFVIq & $r \ldots r$ & $1 \cdot v i \Delta r$ & 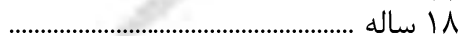 \\
\hline$\Delta F \Delta$ & frat & $111 \wedge 94$ & FqFro & $\mid 991 \mathrm{rD}$ & 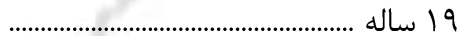 \\
\hline$\Lambda F \Delta$ & $\Delta \Delta \omega G$ & IFFAFY & erv. $\Delta$ & 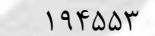 & 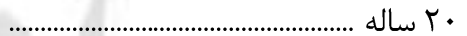 \\
\hline 人 & 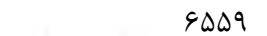 & IErqTr & $m F \cdot 11$ & $r \cdot \Delta r \Delta \Delta$ & اله ساله \\
\hline 人re & $|r q v|$ & $|f \cdot| \Lambda V$ & $r \mu \Lambda \cdot v$ & $\mid \vee \wedge \wedge \cdot 1$ & r \\
\hline $9 \Leftrightarrow \Delta$ & TETOF & 9gFr & IETDG & $14991 \%$ & 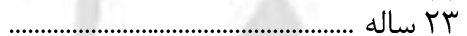 \\
\hline $1 \cdot \Delta \Delta$ & $r \Delta \Delta r V$ & GFDGA & IITFV & $\| r \Delta \cdot V$ & 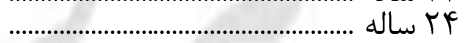 \\
\hline 1494 & TGYGD & FEFYS & $9 \cdot 10$ & qщтq। & 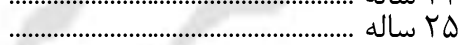 \\
\hline 1919 & TTATV & rт人VV & GNFG & VDDHG & 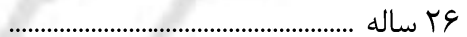 \\
\hline TQTA & TVYAN & TVRGT & Q9M & $9 r . .9$ & 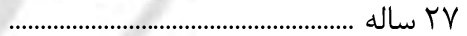 \\
\hline$r .9 \mathrm{~V}$ & TMTAT & 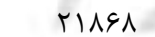 & $\Delta \cdot r \cdot$ & $\Delta r r \cdot V$ & 凡 \\
\hline$M F \cdot q$ & lavrF & IAVG. & Fr人 & स्रवा & Yqu \\
\hline 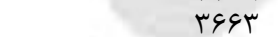 & $|\wedge 9| \wedge$ & IVAT. & FrVA & $F F \cdot V q$ & 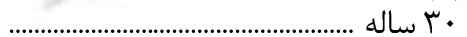 \\
\hline rद६ & 18119 & $|094|$ & $k \cdot r t$ & $F \cdot V F F$ & 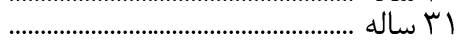 \\
\hline rTa. & $1 \Delta V \cdot V$ & 14911 & rव५ی & rVqVT & r ساله . \\
\hline r^ఎq & $|r F \Delta|$ & Iroq. & rMat & TrTAT & 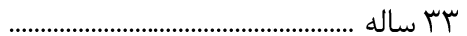 \\
\hline$r \mu \cdot r$ & lirvr & $114 \cdot 4$ & $r \cdot N \Delta$ & TVQSV & 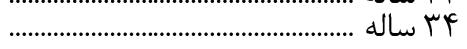 \\
\hline ITAK. & 9911. & $\vee \cdots \Delta \cdot$ & TIFEV & IV.TTV & 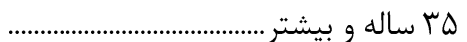 \\
\hline
\end{tabular}


| نتايج تفصيلى سرشمارى عمومى نفوس و مسكن _QD

19 - 1 - دانشجويان دانشعاهها و موسسات آموزش عالى داخل كشور بر حسب جنس، سن و دورهى تحصيلى (دنباله) (نقاط شهرى)

\begin{tabular}{|c|c|c|c|c|c|}
\hline دكتراى تخصصى/ & و فوق ليسانس & 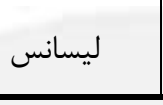 & فوقدييلم & جمع & جنس و سن \\
\hline$|r| 1 \cdot r$ & $r \Delta \Delta \Delta q F$ & $19 \ldots$ rAF & $r \cdot . v q \mu$ & revryre & 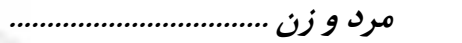 \\
\hline 9 & $\Delta \cdot$ & TIS & $r q \cdot r$ & mIVA & 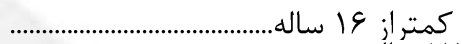 \\
\hline rI & 94 & rift & $p V \cdot r q$ & $\Delta \cdot r q \Lambda$ & IV ساله IV \\
\hline$\Delta \wedge r$ & frvq & IItrIN & 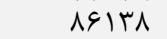 & 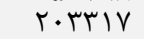 & 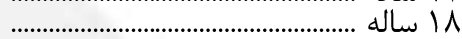 \\
\hline १४^ & NIF. & IN9૬4 & 1.rtr & $r \cdot r \cdot \Lambda l$ & 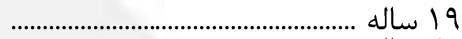 \\
\hline$|f| V$ & $1 \cdots r \Lambda$ & מדrtr & $\wedge \wedge q \cdot \Delta$ & 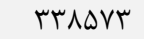 & 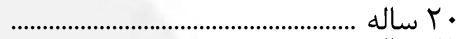 \\
\hline IFFV & $110 \wedge 9$ & T\&NIVT & GVFI & rFAGYq & 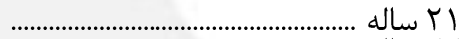 \\
\hline IfYK & rQH. & 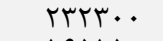 & 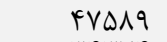 & r.991T & 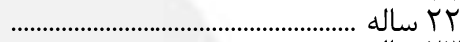 \\
\hline 1991 & FVTFV & 19010 & retge & TFAFGT & 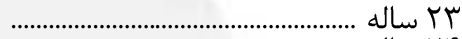 \\
\hline$r \cdot V l$ & gFINH & IITVKA & rఎ৭1V & $r \cdot \Delta 949$ & 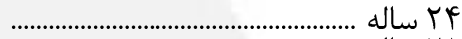 \\
\hline$r \cdot 10$ & SYAVA & $\Lambda r \cdot \Delta \varphi$ & rIIrq & IVT.VA & 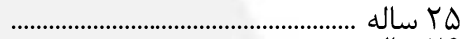 \\
\hline$F F \cdot \Delta$ & DATSV & q. १r人 & IधVDD & $\mid F \cdot r G D$ & 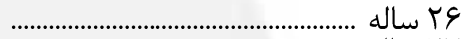 \\
\hline$\Delta \xi Y$. & 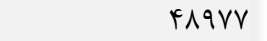 & fqrqV & IFAT. & IINAKF & 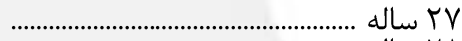 \\
\hline 9099 & FIF & f.. V. & ITG9. & 1 . V^९ & 人 \\
\hline VYNI & rV।99 & KFVI9 & IIVTa & $91 \cdot r y$ & q ${ }^{q}$ \\
\hline VVYT & rఎqrs & 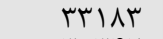 & $|I T V|$ & MAIGr & 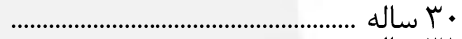 \\
\hline V911 & ruqt & r. ret & 1.944 & ATIQ9 & 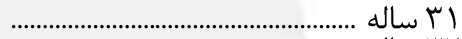 \\
\hline VFqu & r|f.l & r人१९F & $1 \cdot \Delta \wedge 1$ & VAf\&9 & 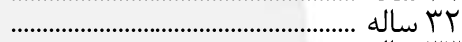 \\
\hline GDYq & TVYAL & $r \Delta \cdot r V$ & qDTF & GADHF & 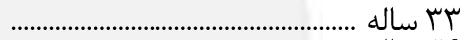 \\
\hline$\Delta \vee \Delta \varphi$ & rFIG & TrGID & MNAT & 91099 & 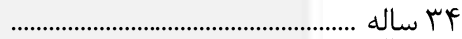 \\
\hline 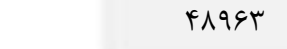 & $1 \wedge \cdot \vee \Delta \Delta$ & 199101 & 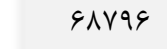 & FৎV९९Q & 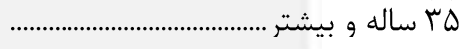 \\
\hline reir. & rq1rq1 & qradVA & Fru.qr & 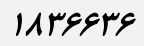 & 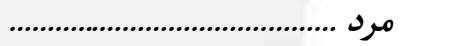 \\
\hline$\wedge$ & rl & MT & thrte & rఎ१९ & 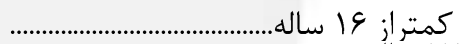 \\
\hline 11 & 99 & $I \vee \wedge \Lambda$ & rAVGq & r.qrV & 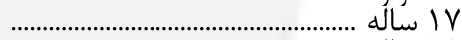 \\
\hline tre & rmi. & $\Delta T Q T$. & Mr (IוID & $1.99 \Delta V$ & 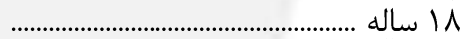 \\
\hline FFA & F. rq & $\Lambda \Lambda \cdot 1 \Delta$ & $\varphi \cdot \Delta f \Delta$ & $\mid \Delta T \cdot r F$ & 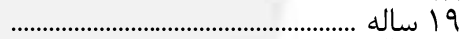 \\
\hline $9 \cdot 1$ & FVTr & $1 \cdot \vee 94 \Delta$ & $0199 F$ & I & • ${ }^{*}$ \\
\hline बrq & DHFF & Ir. 914 & rqा। & $199 \cdot V 1$ & 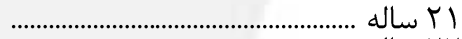 \\
\hline GTd & $|r \cdot \wedge|$ & $1 \cdot V Y F I$ & rVqAI & IFVqTA & Y ${ }^{\prime}$ \\
\hline VVV & THFEV & VaVVI & $r \cdot q \vee \Delta$ & Irrqq. & 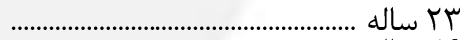 \\
\hline 1.90 & r.991 & $\Delta \varphi \wedge \vee r$ & |G9Y| & $1 \cdot \Delta T \Delta \cdot$ & 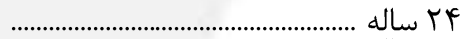 \\
\hline $19 \cdot r$ & $r \cdot 9 r \wedge$ & Fr. 19 & ITGFY & $\wedge \vee 94 ।$ & 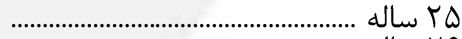 \\
\hline rYAl & $r V F \cdot V$ & r. 994 & 1.999 & VIAYA & 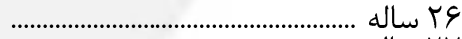 \\
\hline rtו & rTTAV & taITt & QVTD & GITrD & 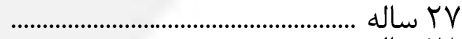 \\
\hline rGfq & r·rیr & $r \cdot \Delta 19$ & $\Lambda r \cdot v$ & $\Delta T \wedge \Delta \Delta$ & 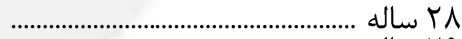 \\
\hline$r \cdot V \wedge$ & $1 \wedge \Delta \cdot 1$ & IVVTF & $\vee \wedge \vee ।$ & $F \wedge \mid \wedge F$ & 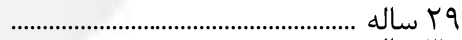 \\
\hline FTFY & 11499 & IVTVq & VAYI & FVMFI & 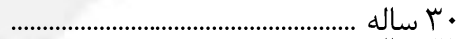 \\
\hline FTFF & $\mid V \& \Lambda \cdot$ & $I \Delta V \Delta F$ & VRG. & FDIrA & 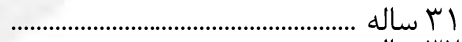 \\
\hline FTHD & IGFTA & $|\Delta| V \Delta$ & $\vee \cdot 11$ & FrへDG & 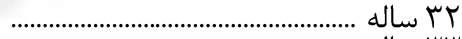 \\
\hline rVDq & IFUVF & ITFFT & 9499 & HATFD & 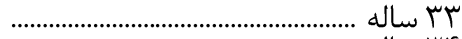 \\
\hline$r \omega \cdot r$ & $I M r \cdot r$ & Irter & $9 \cdot \vee q$ & r山\^9 & 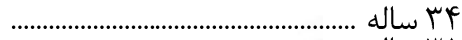 \\
\hline rGৎTV & $\| \& F \Delta$ & $1 \cdot r \Delta \vee q$ & FADAT & ( ) & 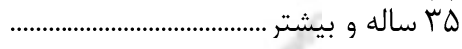 \\
\hline pFqm & $r \Delta \varphi \Lambda \cdot r$ & $9 v 1 r \cdot q$ & revgqg & IFFIINA & 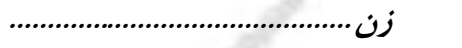 \\
\hline 1 & 19 & צr & $4 \& 9$ & $\Delta \wedge r$ & 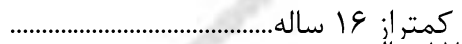 \\
\hline $1 \cdot$ & tr & IrDF & INTV. & 19991 & 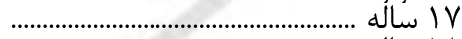 \\
\hline$r \cdot \Lambda$ & $r \cdot r q$ & ब9rq1 & $r \Delta \cdot 1 \Delta$ & 9994. & 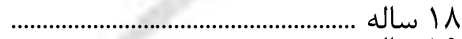 \\
\hline$\Delta r \cdot$ & $f \| f$ & $1 \cdot 19 Y \Lambda$ & FTVVD & $1 F q \cdot F V$ & 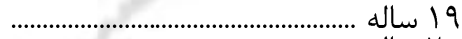 \\
\hline 119 & $\Delta \mu \cdot \Delta$ & $\| r \cdot r \Delta \Lambda$ & r9q11 & IVTrq. & • \\
\hline 111 & GTFD & $\mid F \vee 1 \wedge q$ & rᄉr.G & 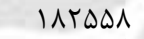 & 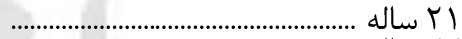 \\
\hline$\checkmark \wedge \Lambda$ & 1419 & $1 r \Delta \cdot \Delta q$ & $199 \cdot 1$ & IDAGVF & 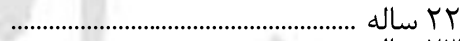 \\
\hline 914 & TFVA. & ADrvq & 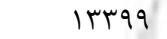 & ITFFVT & 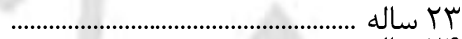 \\
\hline $1 \cdots 9$ & rmpqt & $\Delta \varphi \wedge \Delta \Delta$ & 9тя६ & $1 \cdots \times 19$ & 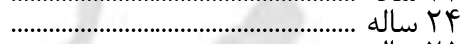 \\
\hline$|f| T$ & reta. & F. 99V & $V Y \wedge V$ & $\Delta F \| V$ & 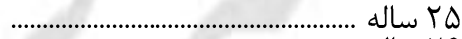 \\
\hline I9YF & r·^я. & rqqFY & $\Delta \vee \wedge 9$ & ધ^DIV & 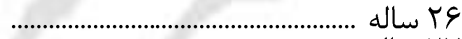 \\
\hline rFYq & TAVT. & TFTED & $\Delta \cdot 9 \Delta$ & $\Delta \vee \Delta \cdot 9$ & 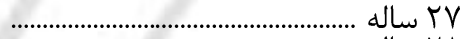 \\
\hline$r 90 \cdot$ & $r l \cdot V r$ & $19 \Delta \Delta F$ & Fror & FVqui & 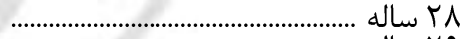 \\
\hline 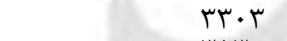 & 11991 & 19910 & rへGF & Fr^D. & 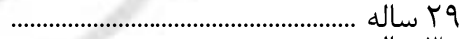 \\
\hline rar. & IVGTV & $1 \Delta 9 \cdot F$ & $r V \Delta \cdot$ & $F \cdot \Lambda T I$ & 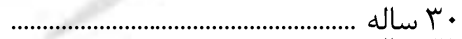 \\
\hline rDQV & ISTGY & $\mid f \Delta \wedge \Lambda$ & rG. F & $r \Lambda \cdot r l$ & 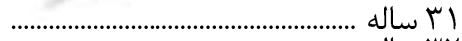 \\
\hline rTG人 & I fqя & $1 \% \wedge 19$ & 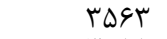 & rबGIr & 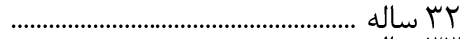 \\
\hline TVV. & ITAN. & $\| \Delta \Lambda F$ & $r \cdot \Delta \Delta$ & $r \cdot r \wedge q$ & 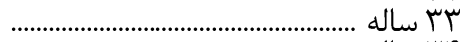 \\
\hline rTDT & $1.91 \mathrm{~F}$ & $1 \cdot f 11$ & $r \wedge \cdot r$ & rя广人. & 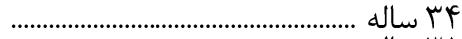 \\
\hline ITHE & $G F+\Delta$ & GQDVT & $r \cdot r \mid r$ & IETFYV & 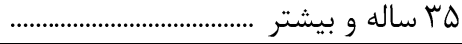 \\
\hline
\end{tabular}


18 - 1 - دانشجويان دانشعاهها و موسسات آموزش عالى داخل كشور بر حسب جنس، سن و دورهى تحصيلى (دنباله) (نقاط روستايى)

\begin{tabular}{|c|c|c|c|c|c|}
\hline دكتراى تخصصى| & و دوق ليسانس حرفهاي & 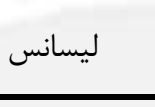 & فوقدييلم & جمع & جنس و سن \\
\hline$F \cdot F r$ & evarg & rerger & Iregre & $k \mu \cdot r \cdot q$ & 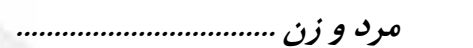 \\
\hline • & 4 & $r$. & spq & $\varepsilon \wedge \Delta$ & 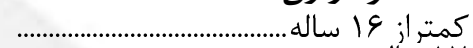 \\
\hline & IV & pr. & Ariv & 9194 & 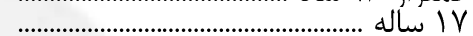 \\
\hline r. & rTQ & IIVVr & IDTAT & TVYVq & 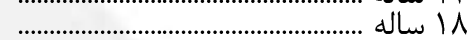 \\
\hline f. & krq & rIgrt & $r \cdot I r v$ & FTOTA & 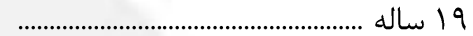 \\
\hline 9) & ט9 ז & $r . . r \wedge$ & $199 \wedge \mathrm{V}$ & $\Delta \cdot r G q$ & 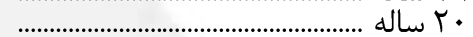 \\
\hline vq & VQT & $r \varepsilon l \cdot r$ & 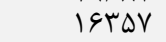 & DrTqR & ا \\
\hline $1 \cdot V$ & $|V \wedge|$ & $r r v \cdot V$ & ITIAG & FVYAI & 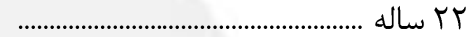 \\
\hline IT. & rFAl & TQVTV & 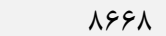 & एУ११९ & 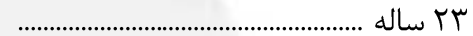 \\
\hline ITF & FArr & MAY. & GTAN & r१९sब & 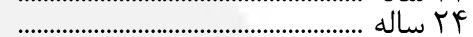 \\
\hline 19. & QTI & 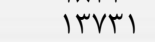 & pras & rrq. & ${ }$ \\
\hline$r \cdot \Lambda$ & FVIV & QGTD & $r \mu \cdot \Lambda$ & $\mid \vee q \Delta \Lambda$ & q \\
\hline rel & rAve & VFVq & TQVQ & $|f \cdot 9|$ & 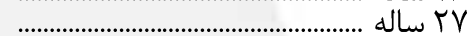 \\
\hline ri & TTVT & $\Delta 999$ & r.9r & lirkF & 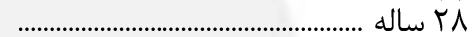 \\
\hline 199 & rVTq & Frqv & $19 \mathrm{VI}$ & 9179 & 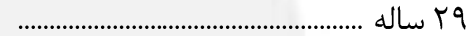 \\
\hline rTa & $r \Delta \Delta q$ & rEAt & $1 Q V \Delta$ & $\wedge|\Delta|$ & . \\
\hline$r \Delta V$ & tITt & ए.. & $I T \wedge \Lambda$ & GVVA & 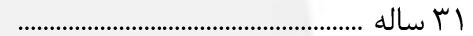 \\
\hline ו וT & INKF & $r V \cdot r$ & $119 \mathrm{~V}$ & $\Delta ৭ 9 \Delta$ & r \\
\hline TYF & Irar & TTQS & $1 \cdot r r$ & F^१ץ & 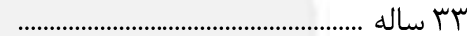 \\
\hline 189 & ITYF & $|\wedge \Lambda|$ & 91. & figf & 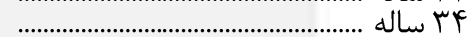 \\
\hline 991 & Gヘrd & 11191 & 9199 & TDIQT & 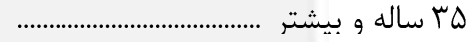 \\
\hline rrie & raras & $|r r|$. & qllar & rq. Fqg & 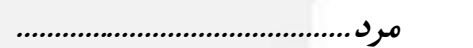 \\
\hline & 4 & IV & $\Delta T \cdot$ & $\Delta F r$ & كمتر از 9 الهاله..... \\
\hline . & 19 & rVI & 9191 & G广Da & 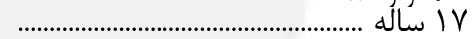 \\
\hline rI & 149 & GTAT & 1. TVG & 19V91 & 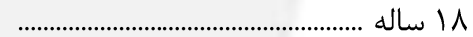 \\
\hline ra & rQl & $11 \mathrm{~V} \cdot 1$ & IrFar & TAFAF & 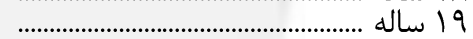 \\
\hline r & MFT & IDADH & $|r q 1|$ & rqIrی & • ساله . \\
\hline re & Fri & I QYAK & $1.99 \mathrm{~V}$ & $r \cdot \Delta r I$ & ا \\
\hline$\Delta 9$ & $1 \cdot r \cdot$ & $1 \wedge \Delta 9 \Delta$ & 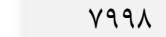 & tVANT & 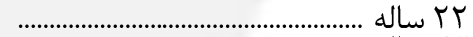 \\
\hline 99 & $r \cdots \Lambda$ & IFGAF & $\Delta \wedge 1 \Delta$ & TRAVE & 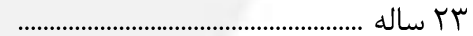 \\
\hline va & rVA & 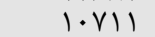 & Fild & $1 \vee \wedge \wedge q$ & 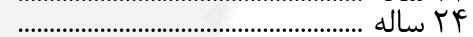 \\
\hline $1 \cdot V$ & $r \cdots \Delta$ & NTQQ & TTVV & IfEYA & 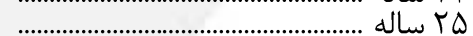 \\
\hline life & rVQ. & $\Delta 99 \Delta$ & rTDI & $1.9 \mathrm{Fr}$ & 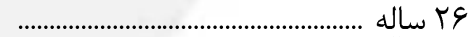 \\
\hline IET & $r r \cdot \Lambda$ & Fr人f & IVrq & $\Lambda \Delta q \pi$ & Vاله \\
\hline t. F & 1994 & 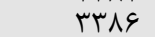 & IfTV & $v \cdot 11$ & 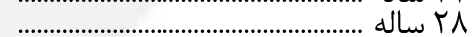 \\
\hline rוז & $i V \cdot r$ & TETT & 110 & $\Delta \& \wedge \Lambda$ & 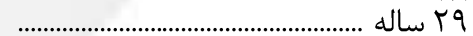 \\
\hline$r \cdot r$ & IQVA & $r \cdot 99$ & $1.4 \lambda$ & ץ^१ท & 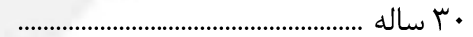 \\
\hline 195 & ITVE & $|V \varepsilon|$ & $\wedge$ ^. & $r \cdot \Delta q$ & 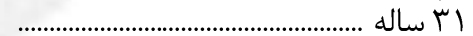 \\
\hline 149 & $1 \cdot 9$. & IQTS & NTr & rद. & 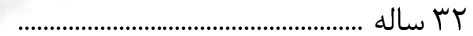 \\
\hline $1 \pi \Delta$ & ArI & ITAT & VTQ & זמצץ & 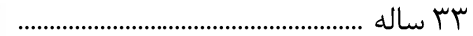 \\
\hline ITF & $\mathrm{V} 9 \mathrm{D}$ & $1 \cdot 9$. & sr. & rq. 9 & 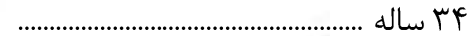 \\
\hline V9v & pq६. & Vब91 & rq49 & $1 \wedge r q 4$ & 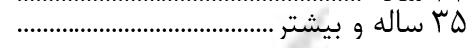 \\
\hline | וrm| & lasta & 1. EFar & rrart & leqqfr & 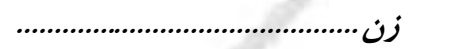 \\
\hline$\cdot$ & - & r & 149 & IFT & 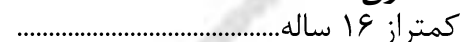 \\
\hline . & 1 & 109 & TQRq & $r v \cdot q$ & 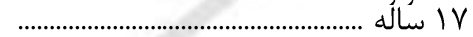 \\
\hline 9 & ve & DFT. & rqve & $1 \cdot+\wedge 1$ & / اله ساله \\
\hline 10 & IVA & $1 \cdot T Y 1$ & Gq4. & $I V \cdot \Delta F$ & 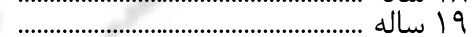 \\
\hline rq & ral & $|F| V \Delta$ & GVVG & ITIMI & 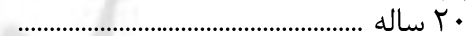 \\
\hline$i \Delta$ & rif & IEVTr & $\Delta 99$. & rTVRI & ا Yاله \\
\hline Fへ & VQI & IDIIT & 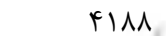 & $r \ldots 99$ & 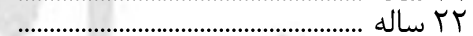 \\
\hline Q) & IFV & $11 \cdot k \pi$ & TNAT & IQFT. & 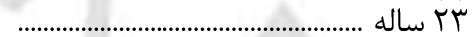 \\
\hline pq & $r \cdot r \Delta$ & $V V \cdot q$ & $19 V \pi$ & IIVVe & 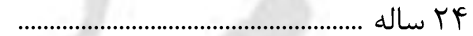 \\
\hline QT & rrif & DFVT & 1019 & $9 r \Delta \Lambda$ & 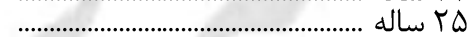 \\
\hline ar & $199 \mathrm{~V}$ & г г. & $1 \cdot \Delta V$ & $v \cdot 19$ & 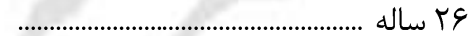 \\
\hline 99 & $109 \Lambda$ & r990 & NHe & $\Delta F q \Lambda$ & 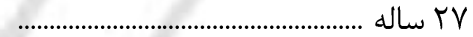 \\
\hline $11 \mathrm{~V}$ & ITVA & & 990 & Frvi & 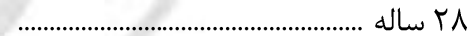 \\
\hline 1.9 & $1 \cdot r 4$ & IVVa & QTI & rFi & 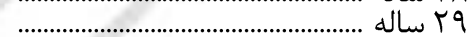 \\
\hline זr & 911 & 1914 & QTV & MTQF & 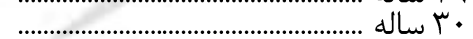 \\
\hline 90 & $\Lambda \Delta \varphi$ & IKF. & FrA & rVIQ & اس ساله ...…………………………………… \\
\hline Ar & VFF & $119 \Lambda$ & red & rraq & r \\
\hline 19 & $\Delta V I$ & $1 \ldots y$ & rav & 1991 & 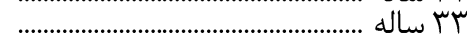 \\
\hline$\Delta \Delta$ & FQq & V91 & $r \wedge \cdot$ & $1 \Delta \wedge \Delta$ & 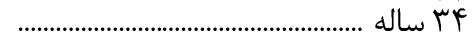 \\
\hline 194 & IAVQ & reV & Irar & 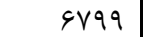 & 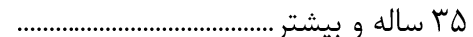 \\
\hline
\end{tabular}




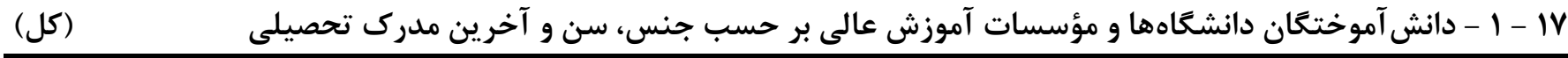

\begin{tabular}{|c|c|c|c|c|c|}
\hline دكتراى تخصصى| & و دوكتراى حرفهاى ليسانس & 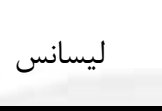 & 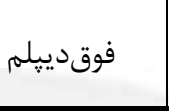 & جمع & 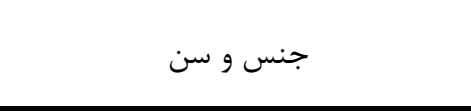 \\
\hline levagr & IrqIrat & DAT. TFT & rrraled & qqrasar & مرد و زن ..................... \\
\hline r & r & r & $1 \cdot v$ & ira & 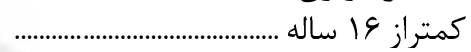 \\
\hline is & הו & rVAF & ITIV & IVYFI & ساله IV-19 \\
\hline feq & 11149 & DIFTIA & TATAFY & $\Lambda .91 V \Lambda$ & (1) \\
\hline$\Delta G \cdot r$ & rGGKYq & $10 \ldots r q q$ & $49 \Delta \cdot \Delta \cdot$ & TYGVFA. & q............... \\
\hline $194 \cdot 9$ & rFANAT & $1 \% 91 \cdot \wedge 9$ & $\Delta \cdot \varphi \operatorname{sir}$ & $r I V \cdot q u r$ & 1......................... \\
\hline rDG.. & TYTAQT & $\wedge 9 \Delta 911$ & rI9VVV & $|F F F| F \mid$ & q \\
\hline T.MYI & |QTQTI & $\Delta \Lambda \Lambda F \& V$ & I9NQTS & १९१८९ด & ( \\
\hline TFIGT & $|r| 999$ & fi...10 & IFFTAT & $V \cdot .109$ & qq \\
\hline INFqr & 9q49r & TFQVY. & $|r g V F|$ & $F V \cdot F \Delta \Delta$ & ................... \\
\hline 119.1 & Trimt & IOVAVR & IrFqAT & rFIOAN & (1)........................ $\Delta \Delta-\Delta q$ \\
\hline VTSD & rrDGQ & $1 \cdot 1 \cdot 10$ & 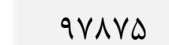 & rHEVII & ץ \\
\hline & $1 \Delta \Delta \Lambda$. & GFTTG & FFarr & זאק.. & 9 9 ساله \\
\hline rVVe & $1.11 r$ & rTVVr & rIVAn & GQFTV & ساله . $V \cdot-V{ }^{q}$ \\
\hline q..r & $111 \mathrm{rV}$ & r৭९९९ & lfVr. & GIDTG & 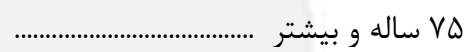 \\
\hline $1 \cdot \Delta \wedge \Delta$. & Vratev & rrarrra & Irefire & $\Delta \cdot 0 \Delta 919$ & 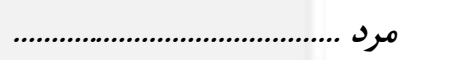 \\
\hline & r & 11 & $\Delta F$ & $9 V$ & 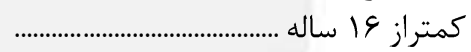 \\
\hline IV & irv & IMAT & GVQV & 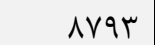 & ساله $1 \mathrm{~V}-19$ \\
\hline$r \cdot 1$ & $\Delta V \backslash \Delta$ & $r \mid r \cdot 9 \Lambda$ & IDQTFT & rVArrg & 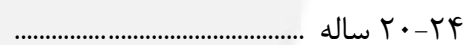 \\
\hline reQT & ITTY.F & G4r.qr & TSAFTV & 1.rGTVV & \\
\hline $1 \cdot 1 F \Delta$ & $19 \Delta V I F$ & $\Delta \Delta \cdot F \mid F$ & reVVGT & १९९४४६ & F \\
\hline IDSTS & $|r r q| \mid$ & rADVYS & IVI949 & $9909 \% 9$ & ..................... \\
\hline IFTFD & $1 \cdots 910$ & M. IV & $91 \cdot 99$ & $\Delta M K F \cdot \Delta$ & ................... \\
\hline IATVF & AVArt & TFTEFT & $q \cdots v r$ & FTMATI & ....................... \\
\hline $\mid f \Delta \wedge \Lambda$ & $0191 F$ & $10 \wedge \wedge 9 \mid$ & 1918т & $r \digamma F \Delta \Delta \Delta$ & ................ \\
\hline $9 \Delta)^{9}$ & rqT\&V & 111rघA & 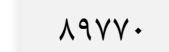 & rrqq४ו & ..................... $\Delta \Delta-\Delta q$ \\
\hline GTYG & 19091 & $\vee १ ৭ \cdot \wedge$ & GGKAD & $|V r| \ldots$ & .................... \\
\hline 4991 & ITrk & Fヘ९99 & $r \cdot r F q$ & १९৯८९ & .................... \\
\hline rmar & $\wedge \vee \wedge)$ & 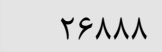 & 10.94 & $\Delta F \cdot \wedge \varepsilon$ & ساله ......................... \\
\hline$\Delta \Delta \wedge \Lambda$ & $1 \cdots+1$ & $r \Delta \cdots \Delta$ & $11 r \Delta r$ & $0191 \mathrm{~V}$ & 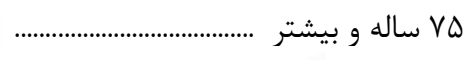 \\
\hline ferlit & DarIIV & r.rrg.t & $|\cdot| a \cdot r \mid$ & Ferrasf & 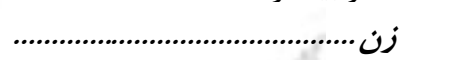 \\
\hline r & 1 & ir & $\Delta r$ & $8 \wedge$ & 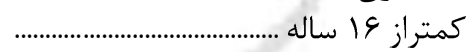 \\
\hline rq & $1 \cdot 1$ & $19 \cdot r$ & s419 & NFY & 1V-19 ساله ................... \\
\hline TqK & GITr & $r \cdot 1 r \Delta$. & ITMT.D & $F r \cdot \Lambda \Delta T$ & 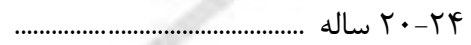 \\
\hline rqषq & $|F F| F D$ & NQVTAS & TRGGTT & سR & .......................... \\
\hline Nkqk & וATIrq & VEVGVD & rrदqr. & $11 \vee 9191$ & (................... \\
\hline 9994 & १९q४ץ & $\forall \wedge \cdot \mid \wedge \Delta$ & $|4 \lambda| 1 \mid$ & $V r \Lambda T \cdot r$ & q q- \\
\hline 9.99 & 01919 & rVArqI & $V \cdot r \Delta V$ & r.q44. & ….................................. \\
\hline$\Delta \wedge \Lambda \Lambda$ & rr人⿻V & 19VRVR & DFTI. & (l) & ..................................... $r q$ \\
\hline rq. & IVDVA & ^я^ґq & FVDVq & $1 \Delta \Delta q \ldots$ & .............. \\
\hline$r \cdot 90$ & 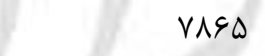 & $\varphi \& \Delta \cdot \Delta$ & FATIT & $1.19 \mathrm{kV}$ & ........... $\Delta \Delta-\Delta q$ \\
\hline $1 \cdots 9$ & $r \cdots \Delta$ & $r \Lambda l \cdot V$ & rifq. & 94811 & ......................................... \\
\hline gसr & $r \cdot V$ & $1 \Delta \Delta \&$ & lfGVt & 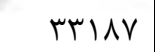 & 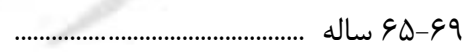 \\
\hline FTI & | (וזו| & 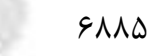 & $9 V \cdot r$ & $|\Delta M F|$ & ساله ....................................... \\
\hline Fid & $1 \cdot 19$ & <491 & ruv & $9 \Delta q_{9}$ & 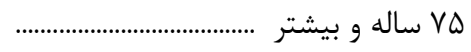 \\
\hline
\end{tabular}


IV - I - دانشآموختغان دانشعاهها و مؤسسات آموزش عالى بر حسب جنس، سن و آخرين مدرى تحصيلى (دنباله) (نقاط شهرى)

\begin{tabular}{|c|c|c|c|c|c|}
\hline دكتراى تخصصى| & و دوق ليسانس حرفهاي & ليسانس & فوقدييلم & جمع & جنس و سن \\
\hline$|f F r| 9$ & mrinir & ararras & $r I \cdot 1 \Delta r F$ & Arreger & 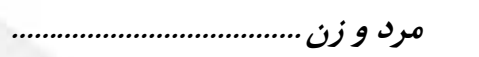 \\
\hline 1 & r & r. & st & $\Lambda \wedge$ & 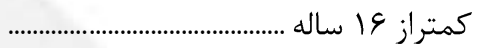 \\
\hline$r_{\Delta}$ & IET & rVFe & QTTV & ITIV. & ساله lV-19 \\
\hline rar & $1 \cdots 1$ & FTEFID & 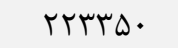 & $99 \cdot 114$ & 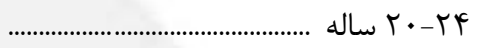 \\
\hline$\Delta / f$. & tFrgif & IrqTIOT & FrISDT & $19 \varepsilon r \Delta \Delta \Lambda$ & ( \\
\hline $1 \wedge \Delta 94$ & rt人III & $\| \vee V \Delta \cdot \Lambda \Lambda$ & $F \Delta|g Y|$ & I9VTFTF & Fץ \\
\hline rFqq. & rITAKT & $1 \cdots 9 \vee 1$ & $r \wedge \Lambda \Lambda \cdot I$ & Irtrtad & q \\
\hline 19949 & IFEYAT & $\Delta F q \cdot F \Delta$ & $1 \Delta r \cdot V q$ & $\Lambda \& V \Delta \cdot r$ & 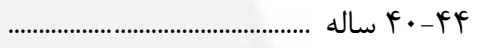 \\
\hline THVTt & 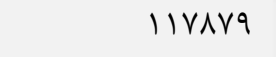 & r^^qศV & | ( & $4 q 4 \cdot V q$ & .............................. \\
\hline $1 \Lambda T \cdot G$ & GVVTV & rMTAVI & $|r \wedge| \cdot q$ & FF^९ाT & ساله . $\Delta \cdot-\Delta F$ \\
\hline llfF. & rGTIT & 101499 & ITVIG9 & TrgI11 & ................... $\Delta \Delta-\Delta 9$ \\
\hline VIrI & 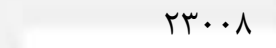 & $1 \cdot r \hat{r} \cdot r$ & QTVYF & rTAG9D & 19.-94 ساله ....... \\
\hline$\Delta T I T$ & IDTVA & GTVDS & crovq & ITGATD & 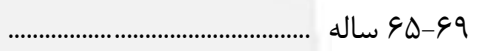 \\
\hline rघ94 & १q४. & rr.人k & TITFF & gVq\&F & 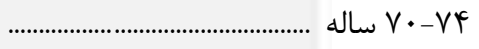 \\
\hline$\Delta \wedge \vee r$ & $1 \cdot \lambda \Lambda r$ & $r q \cdot q$. & Ifrav & $G \cdot r \cdot r$ & ساله و بيشتر VD \\
\hline $1 \cdot r \cdot F r$ & eqrral & rFvagri & $|1190| \&$ & FFqIFAI & 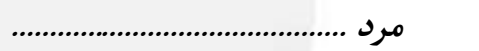 \\
\hline$\cdot$ & r & $\wedge$ & rq & rq & 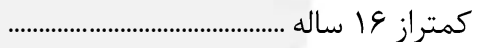 \\
\hline 10 & 94 & $1 \pi$ & frve & $\Delta \vee \wedge F$ & ساله IV-19 \\
\hline $14 q$ & fघIV & $19 \Delta T \cdot F$ & It. & $r q \cdot r \Delta r$ & ......................................... \\
\hline 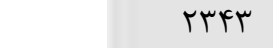 & $1 \cdot 11 \vee 9$ & $\Delta T T \cdot G T$ & TrTAT. & $\Lambda \notin \Delta F \cdot F$ & 胃 \\
\hline $1 \cdot r \Delta \cdot$ & $1 \Delta \mu \cdot q \cdot$ & 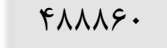 & 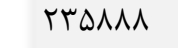 & $\wedge \wedge \Lambda \backslash \wedge \Lambda$ & \\
\hline IDTIT & $\|\varepsilon\| F D$ & TDITET & IDTFEV & $\varepsilon \Psi \Delta \cdot \wedge \varepsilon$ & q \\
\hline 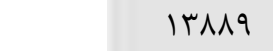 & 99194 & 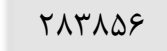 & NGFTV & $\varphi \wedge \cdot r v \Delta$ & (1...................................... \\
\hline $1 \vee 9 \ldots$ & AFGT. & TRETTE & $\wedge \mid \& \Delta F$ & $p_{1} \cdot \Delta \cdots$ & fQ-Fq \\
\hline אוץ" & $\Delta \cdot r \wedge F$ & IFq9TV & rrer & r৭\&४৯T & 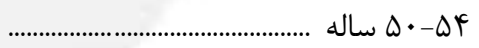 \\
\hline १५१९ & TAFFI & $1 \cdot \Delta \& Y T$ & 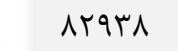 & rrgrqu & ساله $\Delta \Delta-\Delta 9$ \\
\hline $9|r|$ & $19 \cdot 9$. & RVI. r & \&rsq. & I\&49人ץ & 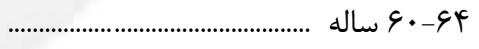 \\
\hline FarV & Irqq4 & prrqu & $r q \cdot \vee \wedge$ & $q F \cdot p r$ & \\
\hline rth. & AEYr & T\&YGG & 14819 & $\Delta r \vee \wedge \Lambda$ & ساله $V \cdot-V Y$ \\
\hline DFGT & 9111 & TFFAT & $11 \cdot r$ & $\Delta \cdot \vee \Delta q$ & 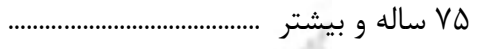 \\
\hline firve & DrqD\&r & rVYrgla & $9 r r \cdot .1$ & FYEAFEI & زن............................ \\
\hline 1 & 1 & it & ra & $4 q$ & 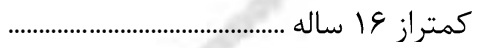 \\
\hline$r \cdot$ & $\checkmark \cdot$ & IfFG & $\uparrow \wedge \Delta \cdot$ & 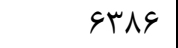 & ساله IV-19 \\
\hline$r \cdot r$ & 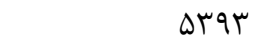 & TEITII & I. TA\&V & r\&१९VD & 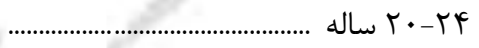 \\
\hline rVav & IrDFTA & $\vee(9) \cdot 9$. & 19人Nrt & $1 \cdot 9 \Lambda 1 \Delta F$ & TL-Yq ساله \\
\hline NTFF & $|V \Delta \cdot r|$ & GヘGTYA & rIDVDr & 1. NDTFE & 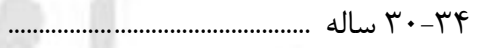 \\
\hline 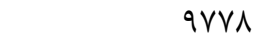 & 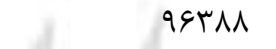 & fFqV.q & ( & 9qrr.q & q \\
\hline$q \cdot r v$ & $\Delta \cdot r \Delta q$ & rधQ1199 & gDGFT & rAVITV & 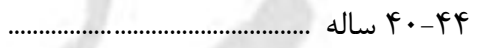 \\
\hline$\Delta \wedge T T$ & THLQ & |ETEY| & $\Delta \backslash \wedge V V$ & raravq & 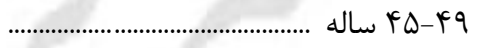 \\
\hline 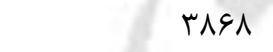 & IVTKR & NFqFF & FG.VG & |QTTKI & 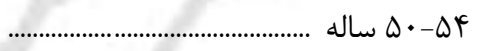 \\
\hline retr & VVVT & FASVV & FETTA & १९V५. & ساله $\Delta \Delta-\Delta 9$ \\
\hline $1 \cdots$ & rqpa & TrV.. & rler & GMGAT & | \\
\hline sta & trAK & 1هrgr & $\mid r \Delta \cdot 1$ & rtvir & 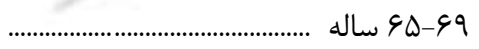 \\
\hline fis & 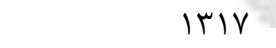 & $9 \wedge 11$ & G\&Td & |DIVe & ساله V.-VY \\
\hline $4 \|$ & $1 \cdot V r$ & $\varphi q \cdot V$ & rut & qFFF & 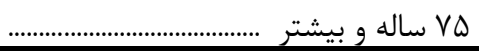 \\
\hline
\end{tabular}


نتايج تفصيلى سرشمارى عمومى نفوس و مسكن _هوس |

IV - I - دانشآموختغان دانشعاهها و مؤسسات آموزش عالى بر حسب جنس، سن و آخرين مدرى تحصيلى (دنباله) (نقاط روستايى)

\begin{tabular}{|c|c|c|c|c|c|}
\hline دكتراى تخصصى| & و دكتراى حرفهاى ليسانس & 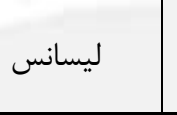 & فوقدييلم & جمع & جنس و سن \\
\hline rer. & sqarr & DEVAIT & $r r \cdot r \cdot 1$ & $91 \cdot 1 \mathrm{rr}$ & 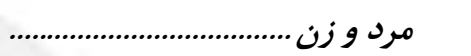 \\
\hline 1 & . & r & pr & iv & 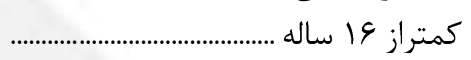 \\
\hline 11 & VQ & $1 \cdot r \Delta$ & rq५ & $\Delta \cdot \Delta q$ & ساله $1 \mathrm{~V}-19$ \\
\hline 111 & INKA & AVV৭\& & $\Delta q \cdot V V$ & IFAMTK & 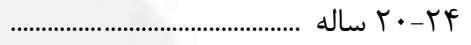 \\
\hline$F \Delta q$ & rTRIS & $r \cdot V \cdot 90$ & VTrGV & $r \cdot r \Delta \cdot V$ & ........................................ \\
\hline VIT & t.VRT & $1 r r q .9$ & Qrqvq & 19VMrT & F \\
\hline $4 \cdot V$ & I. MIF & $q 4 q \cdot \Delta$ & r.qur & $1.9 \mathrm{~V} \Delta \mathrm{\Lambda}$ & \\
\hline fir & G.VV & гячq. & IEFTA & s rr.V & 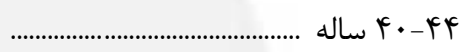 \\
\hline krq & 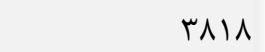 & rl. rq & $1 \cdot v r \Delta$ & $r q \cdot r \Lambda$ & ....................................... \\
\hline rA\& & IVAT & $1 \cdot \wedge \Delta$ & $\wedge 81 \wedge$ & r|Q|S & ..................................... \\
\hline 191 & 919 & GDSV & $\vee \wedge \cdot \Lambda$ & IQFAT & ساله ......................................... $ه \Delta-\Delta q$ \\
\hline ITF & $\Delta \Delta V$ & rri. & FIFD & $1 \cdot r q$ & 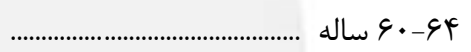 \\
\hline 99 & $r \cdot r$ & IfVY & IMFT & rTIQ & 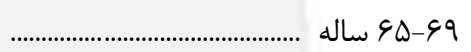 \\
\hline VA & ivr & 919 & QTr & IfET & ساله ........................................ \\
\hline ז. & TFY & $\Delta \vee \Delta$ & rVr & Trt & 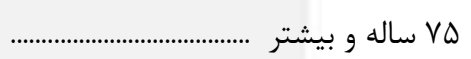 \\
\hline rrqa & Faqve & riven. & Irvrr. & $\Delta F r V Y F$ & 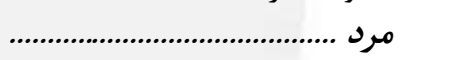 \\
\hline · & . & r & $r \Delta$ & rA & 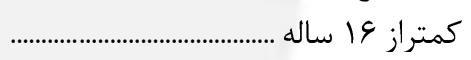 \\
\hline r & fF & $\Delta \vee q$ & trRE & ५११९ & 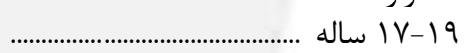 \\
\hline$\Delta r$ & $1.9 v$ & prrqd & rAvAr & AVRYG & ...................................... \\
\hline$r \cdot q$ & $14 \ldots q$ & $11 \cdot \wedge V F$ & FQDYF & $|V \cdot V| q$ & ......................................... $r \Delta-r q$ \\
\hline fqr & $|r g| \Lambda$ & 91498 & rוגזr & 1. GF. & \\
\hline Frt & 9V9l & MFFTE & $191 \times 1$ & $q \cdot \vee q$. & q............................................ \\
\hline rar & Frr. & 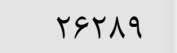 & 11914 & Frava & w...................... \\
\hline rvr & rri. & 19490 & $\Lambda F \cdot r$ & tATAT & $\ldots$ \\
\hline$r \Delta$. & IDTV & $\wedge 9 \Delta \Delta$ & vilv & ivAFq & . \\
\hline 149 & NTr & $\Delta V F$ & GATD & ITSTY & 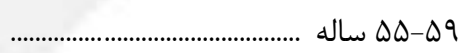 \\
\hline 110 & $\Delta \cdots$ & $r \Lambda \cdot r$ & r\&८9 & $v 1 \cdot v$ & 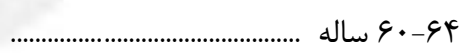 \\
\hline 91 & rVq & ITVK & 1199 & rیוI & \\
\hline Vr & 101 & GTY & pyF & Irav & 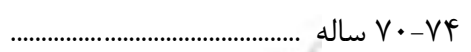 \\
\hline Ire & r. & $\Delta T_{1}$ & ra. & ITTV & VD ساله و بيشتر ........... \\
\hline Arr & rrafr & requrr & 94141 & $r q v .99$ & 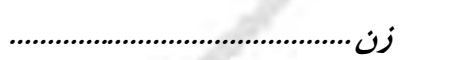 \\
\hline 1 & . & . & 11 & 19 & 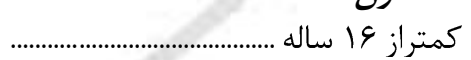 \\
\hline 9 & r & Fas & logk & $r \cdot 4$. & 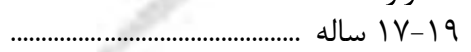 \\
\hline$\Delta 9$ & $V F_{1}$ & $f \ldots l$ & $r \cdot r q \Delta$ & 91.99 & (1).................. \\
\hline 10 & $\wedge \vee \cdot \vee$ & 99191 & TVRAT & $|r r v q|$ & ............... \\
\hline r19 & $1 \| F$ & glfir & rllke & $q \cdot \wedge 9 r$ & F \\
\hline $1 \wedge \Delta$ & $r \Delta \Delta r$ & $r \cdot 4 \& 9$ & ||$v 9 \mid$ & rब१९人 & q \\
\hline$\Delta 9$ & ITSV & $|r| \cdot \mid$ & rila & I ITrT & 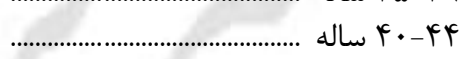 \\
\hline 94 & $9 \cdot 1$ & FVDI & 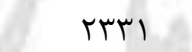 & $V V \Delta S$ & 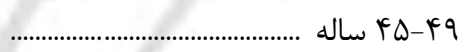 \\
\hline re & rra & 1190 & $10 \cdot 1$ & r८९V & 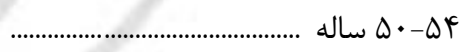 \\
\hline rt & q & ATV & q人ץ & $19 r \Delta$ & 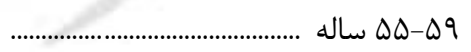 \\
\hline 9 & $\Delta V$ & $r \cdot v$ & Fas & १५१ & 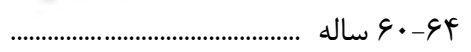 \\
\hline$\wedge$ & זr & $r \cdot$. & IVr & $f \cdot f$ & ........................................... \\
\hline$\Delta$ & if & GV & vq & 190 & ساله . $V \cdot-V{ }^{4}$ \\
\hline r & if & $\Delta F$ & rr & $9 \Delta$ & 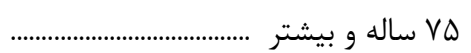 \\
\hline
\end{tabular}




\begin{tabular}{|c|c|c|c|c|}
\hline \multicolumn{3}{|c|}{ جمعيت فعال } & \multirow{2}{*}{ 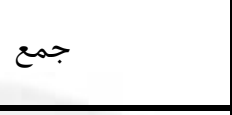 } & \multirow{2}{*}{ جنس و سن } \\
\hline بيكار & 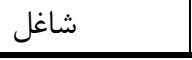 & جمع - اع & & \\
\hline rraArla & rrev. q11 & raqrqT.r & eqferla19 & 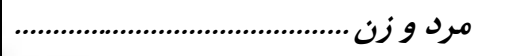 \\
\hline 9499 & ५११. 1 & $F \Delta \Delta q \vee$ & $\Delta G \Lambda \Lambda r \wedge F$ & f \\
\hline$|\Delta F \cdot \Delta|$ & DTrTG. & SVGTII & $\Delta F \Delta \wedge १ १ \vee$ & 19-19 ساله ................. \\
\hline VQFVAV & IrFV.qr & rI. IAr. & 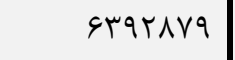 & r \\
\hline 1.99491 & $r r \cdot q 4 F 1$ & $k F \cdot \Delta \Lambda \cdot q$ & $\Lambda r \cdot \| r r$ & \\
\hline GTATEV & fiDVrqu & FVqDVF. & $\wedge \varepsilon \cdot .91 \%$ & ..................... \\
\hline$r 1 \cdot 9 \Delta V$ & r\$90109 & 4.99119 & $\vee \cdot r \vee \Delta q \Lambda$ & q \\
\hline ITDSFr & TAYETV. & r..9q1r & $\Delta \Delta I \wedge r \cdot V$ & 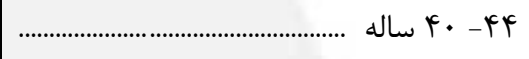 \\
\hline $9911 f$ & TFFVRTD & rolGAFq & 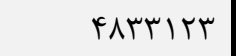 & ......... . \\
\hline Thet & IV.VRTY & IVFFYAD & rqYఎq४I & (............. \\
\hline$r r q \cdot q$ & ITSDFVA & $|r \Lambda \cdot r \Lambda|$ & 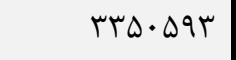 & 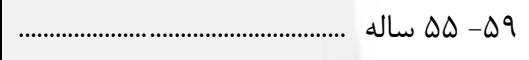 \\
\hline $\mid F F \Delta \Lambda$ & VTAFGq & VEqqYY & TAFTAVT & 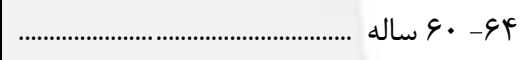 \\
\hline $\mid \Delta \& \wedge \Delta$ & $\Delta \Lambda \cdot r \cdot \cdot$ & $\Delta १ \Delta ৭ \wedge \Delta$ & FAVIDIA & ه ع ساله و بيشتر ........... \\
\hline rrrasur & $19411 \% 8$. & $r \mid \Delta 9 . . r r$ & rragreir & 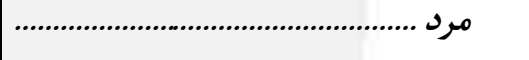 \\
\hline fare & reVV. & MIMFF & TQIIfrT & f \\
\hline $11 \cdot r \cdot r$ & $|F| 190$ & $\Delta \Delta / F 99$ & 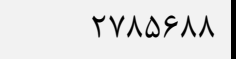 & 19-19 ساله .................. \\
\hline$\Delta \Delta \Lambda \cdot F q$ & 1199990 & IVTVYIF & rrreqva & (......... \\
\hline VATYqI & 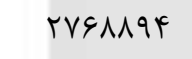 & TATRGAD & FIFTEFA & q \\
\hline flequr & reqDVqr & rq1·vr. & FTF. FFA & Fr \\
\hline$r \cdot \wedge \vee q \vee$ & r.१९५ १А & $r r \cdot \wedge 190$ & TUVYF.r & q \\
\hline 9q4V & TFEFTIA & 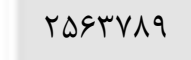 & rیIr人q. & 1...................... \\
\hline$\Delta \cdot \wedge \vee V$ & TITATVD & rIVqIar & TFAFETY & qq \\
\hline rq৭४ץ & $10 \cdot$ MFV & IOTMEAT & 19VDQVF & ............... \\
\hline$r \mid \Lambda .$. & IIIAVGV & $\| f \cdot \Delta \& V$ & $199994 \mathrm{rF}$ & ................ \\
\hline $114 \wedge 9$ & GMFATr & GFDQTT & ITATGGT & y \\
\hline $14 \Delta \cdot 9$ & $\varphi q \cdot \Delta \cdot r$ & eva. it & $T F \cdot \Delta V Y T$ & ه هاله و بيشتر ............... \\
\hline qvagkr & rraqarA & frequivi & rTASqTVV & 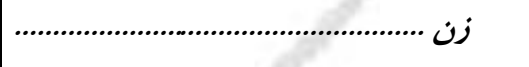 \\
\hline 1945 & 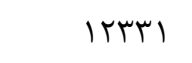 & IFTOK & rVVA991 & |f أ- •| ساله \\
\hline fryer & $11 \cdot 90$ & IFANFT & TEVHT. & 19- 19 اله \\
\hline $199 V \cdot 1$ & IVVrqu & TYFI. & $r \mid \Delta \Delta q \cdot F$ & F \\
\hline TFTOVY & $\Delta F \cdot \Delta F V$ & MATITF & $r \cdot \Delta V G \wedge \Lambda$ & qr \\
\hline TrMEI. & $9919 .$. & $\wedge \wedge \Delta \cdot 1 \cdot$ & FrG. FED & r \\
\hline $1 \cdot r \mid 9$. & $\Delta 9 \Delta \vee 91$ & 99マ9५। & rF40190 & 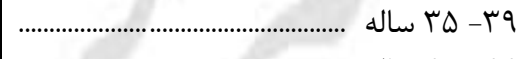 \\
\hline reIVT & $r \cdot 99 \Delta r$ & FFEITF & TV.FFIV & (....... \\
\hline IATrV & rlq49. & rrVदq & 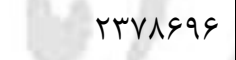 & q q q \\
\hline VFDQ & t.rNAr & $r \| 1 r \cdot r$ & $190 \cdot r 9 V$ & .................................................. \\
\hline rl. & $1 r q v \cdot 1$ & $1 \% 911 F$ & $191 \cdot 909$ & 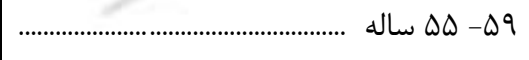 \\
\hline r৭99 & $1 \cdot 1 \cdot 49$ & $1 \cdot f \cdot \cdot \Delta$ & $|r \wedge 99|$. & . \\
\hline $11 V 9$ & $119 \vee 98$ & $1 T \cdot 9 V \pi$ & TFEOVVE & Q \\
\hline
\end{tabular}


11 - 1 - جمعيت +ا ساله و بيشتر بر حسب جنس، سن و وضع فعاليت (دنباله)

\begin{tabular}{|c|c|c|c|c|c|c|}
\hline \multirow{2}{*}{ اظهار نشده } & \multicolumn{5}{|c|}{ جمعيت غير فعال } & \multirow{2}{*}{ جنس و سن } \\
\hline & 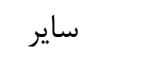 & داراى درامد & خانهدار & محصل & 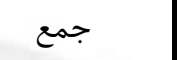 & \\
\hline reIVIf & revarte & reratrer & $r \cdot \Delta \& F q T$. & |rreisqI & f.rrl.vr & 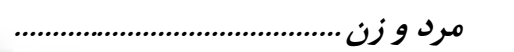 \\
\hline Fint & 14994 & 199 & VAFVG & DFIDGTG & $\Delta G K \Lambda G \cdot F$ & ץ \\
\hline VTrT & GETTOV & FATK & GTAFAI & $r \varepsilon \Lambda . . . r$ & FVVDTGF & 19- ها ساله. ........ \\
\hline TMEAT & VDTTET & $1 \cdot k r$. & 19.9949 & 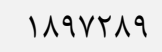 & FYGVG.V & ............... \\
\hline pq..q & rGMADF & INFAK & rV. qrg & 909919 & 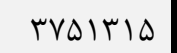 & q \\
\hline Drral & reVEVe & TVETE & r. ८9१५V & $r \cdot v \cdot \Delta r$ & TVDINAT & ץ \\
\hline 49110 & IqVATD & MFIlD & TG. FTrA & 149.99 & 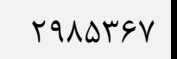 & q \\
\hline$r \cdot \wedge \Delta q$ & $r r \cdot \wedge V V$ & GTETV & rl.人rrd & VD९৭૬ & TEVVATD & 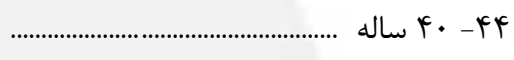 \\
\hline rITr. & $\mid$ TrTS| & TIOT.V & $1911 V r 9$ & FFAFV & $r T Q D \cdot r F$ & ........ \\
\hline ITFOA & FAVTA & $4 q \cdot q \cdot v$ & $|9 \cdot 9 \vee r|$ & $194 \cdot r$ & 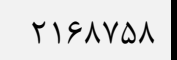 & 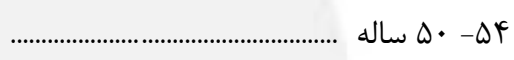 \\
\hline V^l. & 19871 & GATMFV & ITATYFT & $\Lambda \cdot \psi_{1}$ & T.GTF.T & 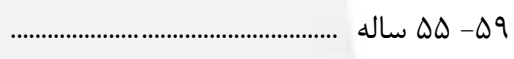 \\
\hline ferd & $\Lambda \cdots \Delta$ & $v(1.19$ & $1 . r \& r \cdot 9$ & $r \Lambda \cdot \Lambda$ & IVANTII & 4 4- .9 ساله ...... \\
\hline $9 \Delta \Delta$. & $9 \vee \vee । 90$ & IFEVTIV & MTRTET & $r t \cdot \Lambda$ & 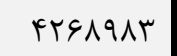 & هو ساله و بيشتر ... \\
\hline rrisar & rrqg.l. & ra1999. & IreqFer & sriaral & $11 \mathrm{VF} \cdot q \mathrm{rr}$ & مرد ............. \\
\hline e & VRrAV & $\forall \wedge$. & rY^A & 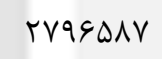 & rAVYAFr & f ا- •| ساله ... \\
\hline DrTq & rVTqFi & rIOV & NFAT & 19FETI. & TrYANQ. & 19- ه اله س............. \\
\hline$r \cdot r \cdot V$ & $01999 \mathrm{~V}$ & $V \Delta V I$ & 14191 & QDTFAM & 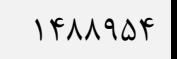 & F \\
\hline ५१८१८ & TrGNAD & $1 \pi G \cdot \Delta$ & $|\Delta F| r$ & TTQQGT & $\Delta \Lambda \cdot \wedge \varepsilon \Delta$ & qז- \\
\hline Fqurt & r. QqVF & IVVVr & $1 \Delta V \cdot 1$ & ITVTEV & $r \Lambda \cdot r 9 \Delta$ & 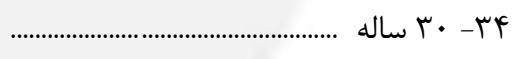 \\
\hline FTr.D & IIVTrV & $r \cdot \Lambda \Lambda 1$ & $1 r \Delta \Delta \Delta$ & $V \cdot \wedge r \cdot$ & $r$ rID. r & 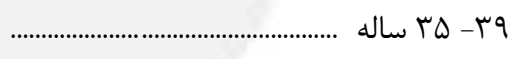 \\
\hline TAYGV & $|r| r||$ & $r q \cdot v f^{p}$ & 91.9 & FTrF. & TrIVTrF & 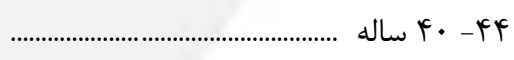 \\
\hline $19.9 V$ & $\Delta q \vee \cdot F$ & 19.919 & $\wedge\ulcorner\wedge q$ & TVI99 & rDGIVA & \\
\hline $1 \cdot V V_{1}$ & TrtT. & rर११९9 & VAFi & Tr.q & Frita. & 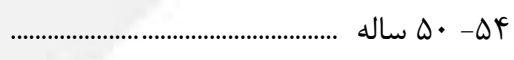 \\
\hline दॅq1 & VArs & $\Delta \cdot 1 T \& \Delta$ & Arqq & $\Delta F A I$ & DrTqVe & \\
\hline TrOV & rqq4 & $\Delta q .1 r q$ & $\wedge|\wedge|$ & $r \cdot v \cdot$ & G. rrAf & ץ \\
\hline rAvq & VDITTE & IIFGDG & rrrq. & $19 V F$ & 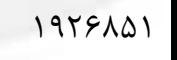 & ه9 ساله و بيشتر .. \\
\hline$r \cdot \Delta r$ & Iratrif & ATDAFV & r. errara & DQFFFI. & $r 1 \& q .1 F q$ & زن ....................... \\
\hline $194 \mathrm{~V}$ & gqurs & r人⿻ & V।৭1 & ral9. Fr & TVG.VGI & | |- •| ساله \\
\hline 1994 & 119419 & 1r49 & 819999 & IVTDSQT & TAFGFVE & 19- هاله 19 \\
\hline TIFA & THEDFA & rADQ & IDQFFYA & $9 \notin 4 \lambda \cdot 1$ & 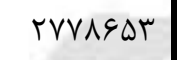 & 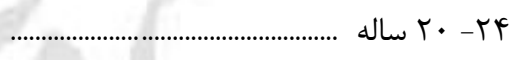 \\
\hline 4114 & 1 1r9999 & $\Delta \wedge \vee \wedge$ & rяqrq4q & 吾 & $r I V \cdot r \Delta \cdot$ & q \\
\hline r৭९৯ & irra.r & 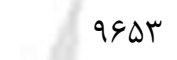 & T. DFTTS & $1991 \cdot 9$ & rrVIFAV & ( \\
\hline & $\Lambda \cdot \Delta \wedge \Lambda$ & IMTME & TQqIVVT & VArG9 & TVGKAGT & 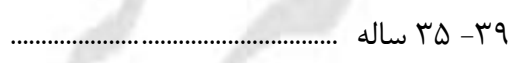 \\
\hline teqT & १९६९५ & 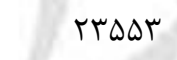 & T. १9TTG & קמrag & $r T \Delta \Delta \Lambda \cdot 1$ & ( \\
\hline 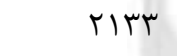 & $q r \Delta \Delta V$ & DFTTI & 19.rFF. & IVGYA & $r \cdot r \Lambda \Lambda ૬ \varphi$ & ........... \\
\hline $19 \wedge \mathrm{V}$ & $r \varepsilon \Delta \cdot \Lambda$ & 1.1811 & $19 \cdot \mid 11$ & $V r \cdot 9$ & IVrVF+1 & f \\
\hline 1419 & 11940 & $|0| \cdot 1 r$ & IrVrNFq & TAG. & IDTqFTE & 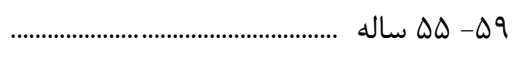 \\
\hline $1 \cdot V \wedge$ & $\Delta \cdot 11$ & $10 \cdot 90$ & I. TAITA & 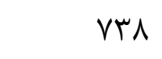 & WAYATV & 가. \\
\hline reVI & rTAAVI & TY. $Q \Delta Q T$ & $I V 9 \Delta \cdot V T$ & $\Delta r K$ & TMETITT & هو ساله و بيشتر ............... \\
\hline
\end{tabular}


11 - 1 - جمعيت +ا ساله و بيشتر بر حسب جنس، سن و وضع فعاليت (دنباله)

\begin{tabular}{|c|c|c|c|c|}
\hline \multicolumn{3}{|c|}{ جمعيت فعال } & \multirow[b]{2}{*}{ 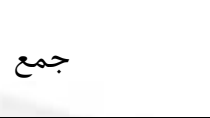 } & \multirow[b]{2}{*}{ جنس و سن } \\
\hline بيكار & 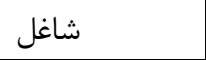 & 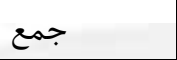 & & \\
\hline ratirar & IEAFFTAA & $19 \cdot 8 \Delta \Delta F$ & 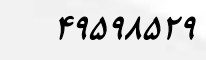 & 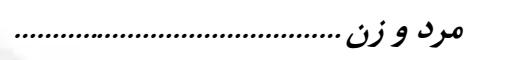 \\
\hline$r \Lambda \cdot \Delta$ & $194 \Delta 9$ & trIGY & F. DSTFY & f \\
\hline qusrq & 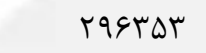 & ५А११८५ & $r 9 \Delta \cdot \varepsilon r \wedge$ & 19-19 ساله ............... \\
\hline DTDGYq & NATTVT & $1 r \wedge \wedge 9 \cdot 1$ & $r \Delta \Lambda \cdot q r r$ & 1 \\
\hline$\wedge 91919$ & 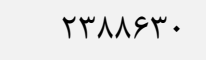 & rTD. 919 & $91 . .914$ & q \\
\hline DTVATI & riveritr & rяq४qrर & gerrVIS & 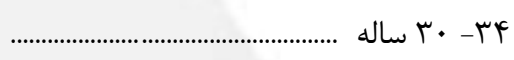 \\
\hline rqVVF. & $r \wedge|\Lambda| Q \mid$ & $r \cdot \wedge \Delta \wedge 91$ & DHQTTYI & q \\
\hline llirky & TIVI90I & TYNDTQD & 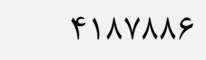 & 1................... \\
\hline DSVOT & 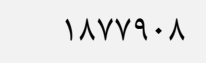 & 19 I FE9. & rVr. rqq & ............... \\
\hline$r \wedge \Lambda \cdot \Delta$ & $|r \Lambda \cdot| r \mid$ & $1 r \cdot \wedge 948$ & $r \cdot \Delta \mid r \cdot \varphi$ & 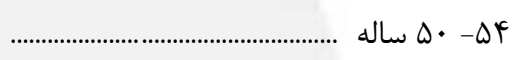 \\
\hline $199 \cdot 4$ & MADTGT & $9 \cdot 1 \wedge 99$ & TDQFAIT & ............ \\
\hline$\wedge ৭ ९ \Delta$ & feqvat & EVTVDq & $191 \cdot \Delta F A$ & 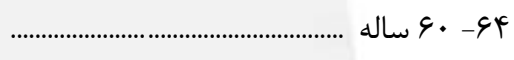 \\
\hline$V \Delta \cdot r$ & $r \mid \Lambda \cdot F r$ & TTQDFS & MFDQIET & 9 9 ساله و بيشتر ................. \\
\hline$|v| 1 \cdot q$. & Irqarf.a & $1 \Delta \& V \cdot \varepsilon q \Delta$ & 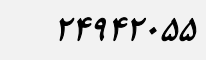 & 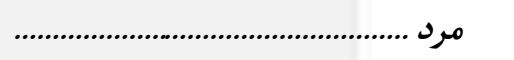 \\
\hline$r \cdot r \Delta$ & irvar & $1 \Delta \wedge \Delta \Lambda$ & $r \cdot V \Delta I \wedge S$ & f|- · ال ساله .... \\
\hline 99.94 & TATrYA & rINFFI & r...rrr & 19- 19 ساله .... \\
\hline relvqI & VTEVET & $11 \cdot \wedge \Delta H_{F}$ & TrEIT.Q & 1 \\
\hline DVFFAl & I9צ9IAT & $r \Delta F \cdot G q T$ & r. TFt. & q \\
\hline rस्वा1 & TGTVAVY & TaGFVAN & 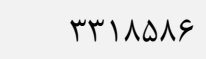 & (r \\
\hline $1110 \cdot \Delta$ & rrtQDII & TDII. 19 & TVYATrd & q \\
\hline$\wedge r 9 \wedge 1$ & INTATEV & IITITFA & TITETHE & ..................... \\
\hline FIFAT & $1919 \vee \Delta V$ & 1991Tr. & 19.r.9V & .............. \\
\hline rTAVT & WrGIFA & $\| r q \cdot r \mid$ & IDF\&DTD & ...................... \\
\hline Ir৭१९ & 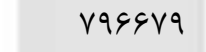 & 11.990 & $|r \wedge \Delta Q T|$ & 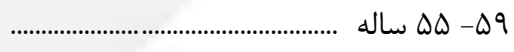 \\
\hline$V \cdot r q$ & f. GVAT & FIrAII & $99 \cdot 4 r$. & \\
\hline gqTr & rFATQA & TADTR. & IV. YAV. & ه عاله و بيشتر .................... \\
\hline $1 \cdot r / 9 r$ & raqlabr & $r r q a \cdot F_{a}$ & TFEDFFVF & 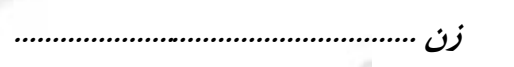 \\
\hline Vr. & $\Delta \Delta \vee \varepsilon$ & qr. & $1911 \cdot \Delta V$ & | | - • ساله \\
\hline TVDSG & frqvo & $V|\Delta F|$ & $190 \cdot r \cdot r$ & 19 1 ا ساله \\
\hline larkrk & Irearq & $r \Lambda \cdot r q V$ & rrIGVYA & 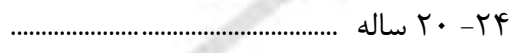 \\
\hline$r \wedge V \Delta \cdot \Delta$ & FTYFAA & $V \cdot 99 \Delta r$ & $r \cdot V G 4 \mid k$ & q \\
\hline 19.91. & DFTATE & Vrrites & rr.qाr. & 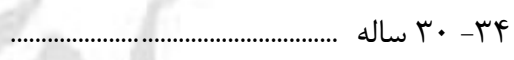 \\
\hline A\&Tro & FMAG. & DVFAVD & 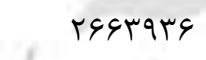 & qז- טז ساله \\
\hline r.rar & rrmeNe & rgF. FV & $r \cdot \Delta / \Delta F$. & 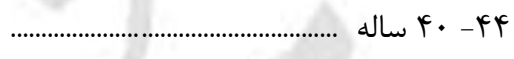 \\
\hline $10 T \wedge 9$ & $r \Delta \Lambda|\Delta|$ & TrMeF. & INTMr.t & ................... \\
\hline DQTT & lQTqVT & $1099 \cdot 0$ & $10 \cdot \operatorname{cr} \mid$ & (........... \\
\hline KEIM & $M \Lambda \Delta \Lambda T^{\prime}$ & $91 \% \cdot 1$ & $|r \& \Lambda \Lambda \Lambda|$ & 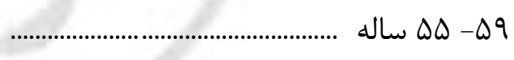 \\
\hline 1948 & $\Delta \Lambda \cdot 1 r$ & $\Delta 994 \wedge$ & 90.111 & ץ \\
\hline$\Delta V \cdot$ & sqVरs & V.rIs & IVATTqR & 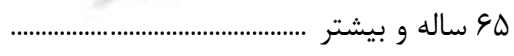 \\
\hline
\end{tabular}


11 - 1 - جمعيت +ا ساله و بيشتر بر حسب جنس، سن و وضع فعاليت (دنباله)

\begin{tabular}{|c|c|c|c|c|c|c|}
\hline \multirow{2}{*}{ اظطهار نشده } & \multicolumn{5}{|c|}{ جمعيت غير فعال } & \multirow{2}{*}{ جنس و سن } \\
\hline & ساير & داراى در آمد & خانهدار & محصل & جمع & \\
\hline IVITEF & TFEAAR. & ruivef. & $1 F q 1 \cdot v \cdot v$ & $9 D 9 F F I A$ & $r \cdot r q \mid$ red & مرد و زن \\
\hline TMAF & GrGDT & FT. & MIMFF & 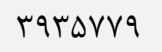 & $F \cdot \pi 1190$ & 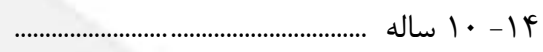 \\
\hline$\Delta T^{\prime} \cdot$ & rVFFqD & rofe & TEITTE & rq1V।91 & $r \Delta \Delta \Delta F \Delta \varphi$ & 19- ه اله .................. \\
\hline$|\Delta \Delta r|$ & fqIfir & 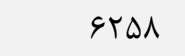 & $1 . G V M T 1$ & 19110.9 & mIVea. & 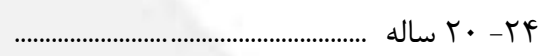 \\
\hline rqIrv & rEYSA. & $\mid r \Delta \Lambda \cdot$ & 1999.18 & $\Delta V F \& \mid F$ & 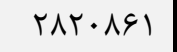 & qr - Tاله ............... \\
\hline$r r_{\lambda} \cdot q$ & rulva. & r. FIr & $r+\Delta .91$ & rrVrI. & rАq४qVr & 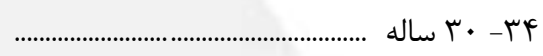 \\
\hline$r 99 \cdot V$ & 19тrVq & rबDIT & $190 . r 99$ & I TGKAg & TTVEFVT & 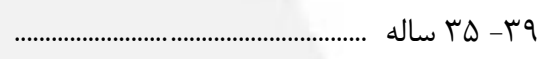 \\
\hline I9V9V & $r \cdot r s q$ & DTrDI & IDG.GTV & sq4VV & IANTAYF & 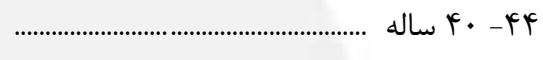 \\
\hline 1T & 1. बוrזם & $1911 \Delta V$ & IFrqvav & FIAFA & IVATITV & qq........ \\
\hline 1195 & Frifis & FFATY. & ITYFF.F & $11 \cdot 91$ & IVTFIAN & 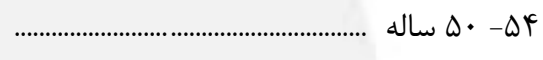 \\
\hline$\Delta \cdot G 4$ & IVrqv & $\Delta ৭ \Delta \cdot V V$ & $1 \cdot r \Lambda \cdot T_{1}$ & VTAV & IEFVAAT & 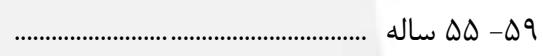 \\
\hline rव९ा & GrI9 & $G V \Delta \cdot V \Lambda$ & $v \Delta \cdots+$ & raT. & IFrrath & 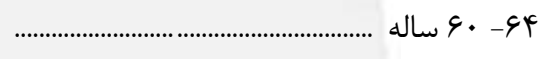 \\
\hline FrA. & $\Delta \Delta T \wedge \& \Delta$ & Ir人⿻qทq & IrArG.F & 1119 & TITATrY & ه9 ساله و بيش \\
\hline $10 \cdot r \Delta s$ & $18 \cdot 1 \mathrm{rad}$ & rasfq.r & 91Frer & FAD\&FI. & $91 r \mid r \cdot F$ & مرد .................. \\
\hline IDTA & rgr. & rMY & $|\wedge \&|$ & $r \cdot 19 r \cdot 1$ & $r \cdot \Delta \vee \wedge \cdot$. & ץ ا-- •| ساله . \\
\hline 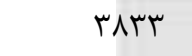 & 19KND9 & IATA & \&१९१ & $10 \cdot V F \cdot k$ & $19 \vee \wedge \cdot 9$. & 19- 10 ساله ... \\
\hline ITTDF & MFIEFT & FYqT & VATI & VADVGY & IIrqfiv & 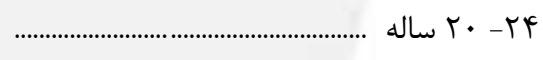 \\
\hline$r \& \mid \cdot 0$ & IETA.r & 1197 & $1 \cdot \operatorname{teA}$ & rVDQAF & FAVETT & q \\
\hline MIQSF & IVANIT & ITEVD & 11494 & $|r| M \Lambda \mid$ & TMIATF & F \\
\hline TVQY. & $1.1 F A T$ & $|\Delta 91|$ & $9 T \cdot \Delta$ & GMOTI & 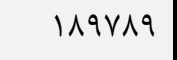 & q \\
\hline$M \cdot V \Delta$ & $1 r \cdot 0 \cdot 9$ & rißMq & GKYY & rN191 & $198 \cdot r 4$ & ........ \\
\hline$|r| \cdot r$ & DGTVR & IFIGNT & $\Delta \vee \& \Delta$ & $r \Delta \cdot 9 \Delta$ & TYAYVD & q q \\
\hline$v \cdots r$ & r.qAG & roTING & $\Delta \Delta \|$ & $111 r V$ & rq. & 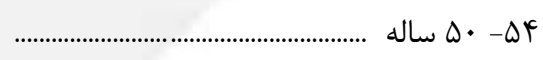 \\
\hline filfs & $V \cdot 1 T$ & FATrt & $\Delta \Lambda \cdot 1$ & fqve & fritr. & ............... \\
\hline rTAD & rrVV & DHFVII & DFTH & INAT & DFFEF & ץ \\
\hline TAS. & FI90rq & $1 \cdots V \cdot V \Delta$ & IV.rG & lfF. & $1 F F \Delta \cdot \Lambda \cdot$ & 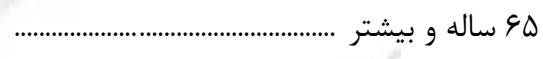 \\
\hline$r \cdot 911$ & $18.8 r r$ & rarrrr & IFA19TVF & rvrrdel & r|re. Fel & زن ........... \\
\hline Iros & TVMYA & 119 & rqYAr & 1919rVA & 19Vrr90 & ץ |- • • ساله \\
\hline IrEV & 11.948 & $\vee \backslash \Lambda$ & 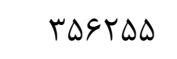 & If. qVAV & IAVVras & 19 - ها ساله \\
\hline TTVY & $|f q v V|$ & IV94 & $1 \cdot \Delta 91 \cdot \cdot$ & NTAVEV & $r \cdot r V \cdot \Lambda F$ & 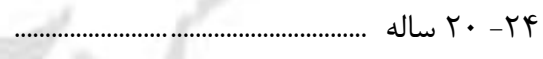 \\
\hline$r \cdot r t$ & $1.1 \Lambda F V$ & rrAr & $19 \Delta \wedge \Delta \Delta 99$ & rqА६r. & THETETG & q \\
\hline rAFD & $1 \cdot \Delta 9 \vee \wedge$ & VVrV & $r r \cdot r \Delta q \Delta$ & $1 \Delta \Delta \wedge T q$ & rQVTIYq & F \\
\hline rTrV & GIATV & $1 \cdot 9 \cdot 1$ & 1941.91 & VYヘ९D & $r \cdot \wedge 99 \wedge F$ & qז- טז ساله \\
\hline 1999 & 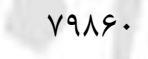 & $r \cdot r \& T$ & IDQFT.. & rirvq & $19 \wedge \Delta \Lambda \cdot 1$ & 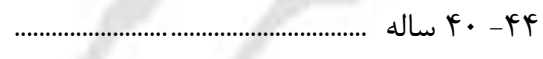 \\
\hline$|0|$. & $\Delta r \cdot q T$ & $\forall q \uparrow \wedge \Delta$ & IFrF.rT & IEVAr & IDQTROT & q \\
\hline 1111 & TrVT. & $9 \Delta \cdot \wedge F$ & IrIMAqr & 9971 & IMFTEVA & ..................... \\
\hline 911 & $1 \cdot r \wedge \Delta$ & IFIVFF & D.TYTY. & reitr & IIVGVG & 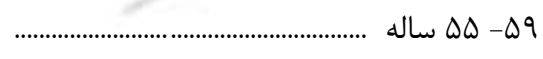 \\
\hline$v \cdot 4$ & rAFt & $\mid F \cdot r g V$ & VFFAVA & sVV & M194QF & 4 \\
\hline IVT. & 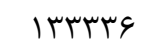 & rV৭q. F & ITGGDSA & kqq & $19 \Lambda \cdot r \Delta V$ & ه9 ساله و بيشتر ......... \\
\hline
\end{tabular}




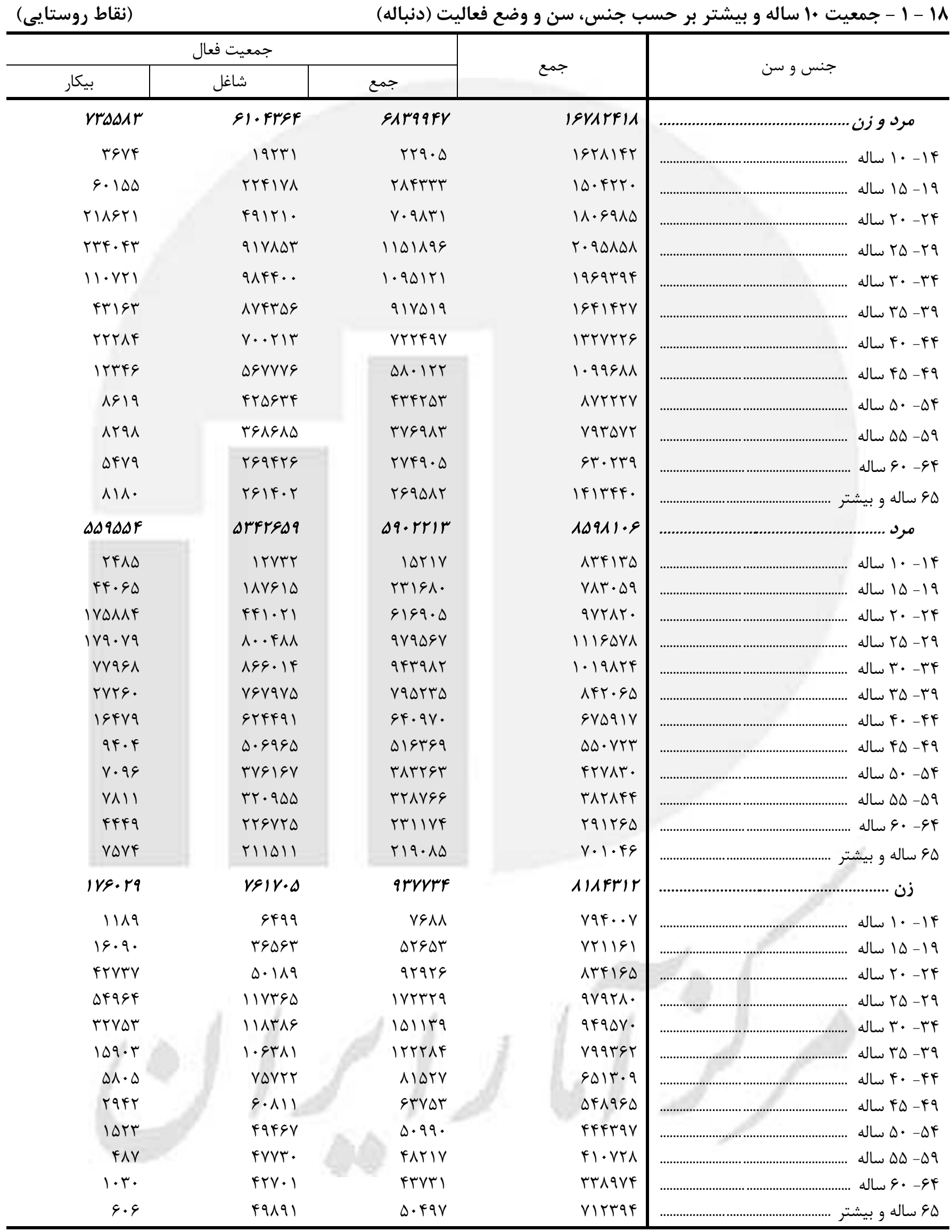


11 - 1 - جمعيت +ا ساله و بيشتر بر حسب جنس، سن و وضع فعاليت (دنباله)

\begin{tabular}{|c|c|c|c|c|c|c|}
\hline \multirow{2}{*}{ 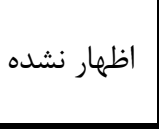 } & \multicolumn{5}{|c|}{ جمعيت غير فعال } & \multirow{2}{*}{ جنس و سن } \\
\hline & 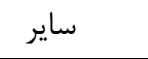 & داراى درآمد & خانهدار & محصل & 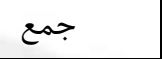 & \\
\hline$q \cdot r \cdot r$ & $|r \cdot V F| F$ & f.vrrr & $\Delta \Delta V F A \mid \Delta$ & regrvid & q1arreq & 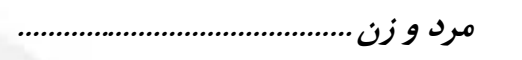 \\
\hline irat & (1) & fis & кrqus & IFVRTtG & $19 \cdot r q 4 \Delta$ & ץ \\
\hline $41 \cdot 9$ & $|\wedge \vee \Delta Q|$ & 1991 & rצ4944 & $V \Leftrightarrow \backslash \Delta \Delta \Delta$ & IrIVRVA & 19- ها ساله ........... \\
\hline Vq.r & TEIFTO & FIDS & $\Delta r \wedge F \cdot \Lambda$ & TADTAT & I. $19 r \Delta 1$ & ( \\
\hline $\mid \& \wedge \Delta \varphi$ & $99 \cdot \vee 9$ & $\Delta \wedge \vee \vee$ & VRqTGF & $\Lambda F \wedge \Lambda$ & 9491.9 & q \\
\hline $\mid \Lambda F \& \Lambda$ & GDGYK & $R \cdot r$ & VATAG. & rq4ו9 & $\Lambda \Delta \Delta \Lambda \cdot \Delta$ & (............. \\
\hline $1911 \mathrm{~V}$ & TFYqQ & $\vee \Delta \Lambda \Lambda$ & GATQTV & $I r V \cdot V$ & $V \cdot V V Y I$ & qז- ضr ساله ............ \\
\hline $11 \cdot V F$ & $r \cdot r \notin 9$ & $1 \cdot r \& 4$ & $\Delta F \& V \cdot r$ & 9r19 & $\Delta q r \varphi \Delta \Delta$ & ץ \\
\hline VG. T & $1 r q \cdot r$ & $T F \cdot r F$ & $F V I \cdot r V$ & ५१९९ & 011994 & q \\
\hline FTAF & $\Delta r 99$ & FrsID & $r \Lambda F \Delta \cdot r$ & $1 T \cdot r$ & frrtr. & 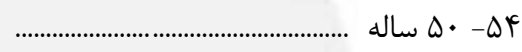 \\
\hline TVTr & rrg. & DYTFA & raral. & GDF & FITADT & ........ \\
\hline 1499 & IVAD & $9 \Delta 911$ & rADAIV & rVA & 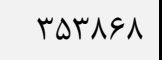 & 4 ب .9 ساله .... \\
\hline TTQF & Frr.rl & $11 \cdot 1 \pi 9$ & $\Delta r \Lambda \mid r \Lambda$ & 419 & $\| F \mid g \cdot F$ & ه9 ساله و بيش \\
\hline $11 r \cdot 9$ & VAD\&AV & rTFAgF & FAFIV & $1 F \Delta q .18$ & TEIFEAF & مرد ........... \\
\hline$v \cdot r$ & $r \cdot \varphi \cdot \Delta$ & TKG & 1919 & VVDVFF & NIATIF & f أ- • اله ساله . \\
\hline $14 \wedge 9$ & 1.19Tr & $|\pi|$ & rFqD & Frg|DI & $\Delta \& q \wedge q$. & 19- ها ساله ......... \\
\hline$V \cdot q v$ & IVEVGq & $r .99$ & F\&\&4 & 199449 & 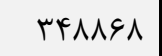 & 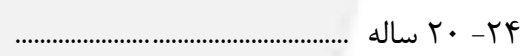 \\
\hline$|r V \wedge|$ & я४११। & Froh & FqQV & fq19q & ITrtr. & qr- \\
\hline IVTLY & Mrגוג & $\Delta \cdot \wedge 9$ & Frt. & $1 \Delta r \Delta \Delta$ & $\Delta \wedge \& \wedge q$ & 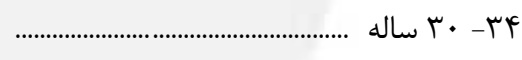 \\
\hline$|0| G 4$ & IDVGT & $\Delta T \Delta q$ & TMET & $V r \cdot r$ & ris94 & 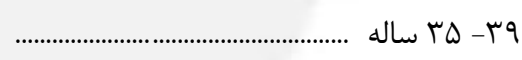 \\
\hline $1 \cdot r \wedge 1$ & $1.9 V \mathrm{~V}$ & VIVF & reVr & FIFT & TFG94 & 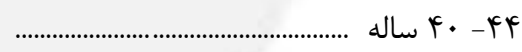 \\
\hline $991 \mathrm{~V}$ & TFIO & $194 .$. & rDIA & rITF & TVHSV & q \\
\hline$r V \Delta q$ & lQTE & ro991 & THTD & 999 & $\uparrow \cdot \Lambda \cdot \Lambda$ & • • • ساله .......... \\
\hline THEI & $\Delta T F$ & frqle & TDQT & $\Delta \cdot V$ & DIArV & 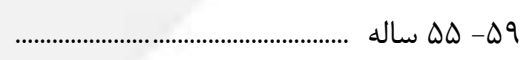 \\
\hline 1.99 & siv & $\Delta \Delta F \cdot q$ & TVAT & rIV & $\Delta \wedge 99 \Delta$ & ץ \\
\hline $1 r \cdot V$ & $r r \cdot V G$. & $|r q 4|$. & $1 \cdot r \Delta \cdot$ & TrF & $F \Lambda \cdot 9 \Delta F$ & له ساله و بيش \\
\hline 1994 & frivry & ArraA & sarquqA & $r r \cdot r r \cdot r$ & VrrraAa & زن .................. \\
\hline$\Delta \Lambda \Lambda$ & FIVTr & $r \cdot$. & FTrIS & V.IFAT & 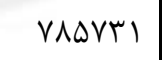 & | | - • اله \\
\hline gr. & V^ৎ૬^ & gqV & TEMISq & TTQF. & 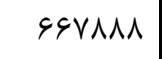 & 19 - ها ساله \\
\hline$\Lambda \Delta \varphi$ & 19994 & 1.9 & DrTYEF & IIAMAr & $V k \cdot r \wedge r$ & 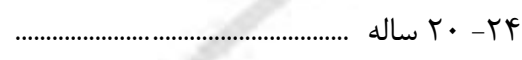 \\
\hline $1 \cdot V \Delta$ & $r \Delta \cdot \Lambda \Lambda$ & $14 \wedge 9$ & VKFT. V & reqqr & $\Lambda \cdot \Delta \wedge \vee \varphi$ & qr - \\
\hline 1110 & $m \mid \Lambda \cdot \varphi$ & 1919 & V\&qqT. & Irqs4 & VqVTाब & F F- • ساله \\
\hline $1 \cdot r \mu$ & IAVTr & rTtq & $\varepsilon \varphi q \Delta \wedge \wedge$ & $\Delta F \cdot F$ & $q \vee G \cdot \Delta \Delta$ & q ז- טז ساله \\
\hline Vqr & 19895 & $r \cdot q$. & $\Delta F F \cdot T$. & $r \cdot V V$ & 09८9८9 & 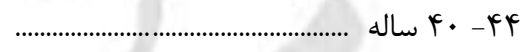 \\
\hline 910 & $1.4 \wedge 9$ & FVrF & $\leftrightarrow \varphi \wedge \Delta \cdot q$ & $\wedge \varepsilon \Delta$ & FAFDQV & q q - ه \\
\hline 190 & rVVr & GGTK & TATIVY & 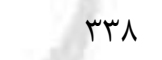 & एव५वार & ( \\
\hline pq9 & lafG & qurf & $r \Delta \cdot 911$ & IFV & $r G T \cdot 10$ & \\
\hline$r v \cdot$ & 1191 & $1 \cdot \Delta \vee q$ & rAT. $9 \Delta$ & 91 & rqYAVT & 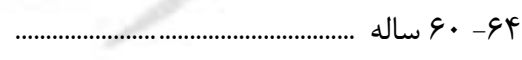 \\
\hline$q 4 \mathrm{~V}$ & 9YTEl & $r \cdot V T G$ & DTYAYA & $\wedge \Delta$ & $99 \cdot 90 \cdot$ & 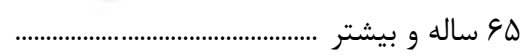 \\
\hline
\end{tabular}


19 - 1 - جمعيت +1 ساله و بيشتر بر حسب جنس، وضع فعاليت اقتصادى و سطح سواد

\begin{tabular}{|c|c|c|c|c|c|c|}
\hline \multicolumn{5}{|c|}{ با سواد } & \multirow[b]{2}{*}{ جمع } & \multirow[b]{2}{*}{ جنس و وضع فعاليت } \\
\hline ديبلم و يیش دانشى & ميكل دوم / متوسطه| & 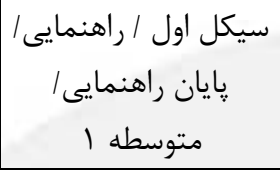 & ابتدايى/ سوادآموزى /ايان & جمع & & \\
\hline Ireqrarf & DATFAT. & | Irelrג. & IrFIrarr & 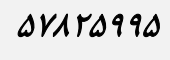 & gefrla19 & 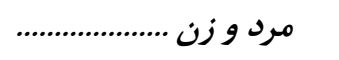 \\
\hline $9 . V \times 991$ & 19VKFET & frqgk. 1 & FFITIDI & THD. GGTT & 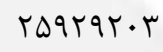 & فعال .............................. \\
\hline$\Delta T \cdot 9111$ & IGVGV.r & $F \cdot r F \cdot 1 Q$ & FllGKVF & $r \cdot r q \Delta \cdot v \cdot$ & rTSV.q11 & شاغل .................. \\
\hline 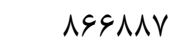 & rqDVFi & FeTrqT & rqQVVV & rII & TTOATID & بيكار ....................................... \\
\hline VQV911\% & TOFVYAD & sV人৭VIr & 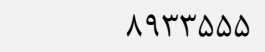 & mFl. IFrk & $r \cdot r r l \cdot V r$ & غير فعال .............................. \\
\hline FIFET & IFVar & VDTDQ & $9119 V$ & rIVqTa & TEIVIF & 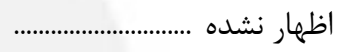 \\
\hline V. rerke. & rIAFTEA & serpiad & sar. IV. & r.perte. & rragreIr & 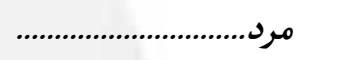 \\
\hline 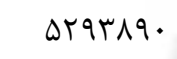 & IAT.IV. & FIQTIQT & $r q \uparrow q \cdots \Delta$ & 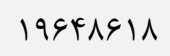 & $r \mid 09 \ldots r r$ & فعال .......................... \\
\hline feqTH. 9 & $109 \cdot \Lambda 1 V$ & rVAVTrt & rVII\&9. & IVFATKAI & 1941149. & شاغل .................... \\
\hline $9 \Delta \cdot \Delta \Lambda 1$ & rQqTQY & 4.4918 & THYTFS & TIGGT\&V & TrVADVT & بيكار ................................................ \\
\hline $1991 \mathrm{rFV}$ & $i r \Delta \cdot \cdot v \wedge$ & rIGArIF & TOIVTIN & $1 \cdot \Delta \vee q \cdots v$ & IIVF.9rr & غير فعال ................................. \\
\hline rq1.r & $1 f \cdot I V$ & VTVTA & srapr & r. Fard & rrI\&DV & 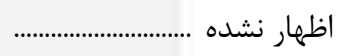 \\
\hline sqgarre & $r \mu \Delta \cdot r \Delta \Delta$ & FarAlas & sA1rv.r & rvrarara & rrabqrrr & 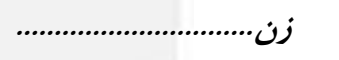 \\
\hline$\vee v q 1 \cdot 1$ & IDTTVT & T.FTDQ & FATIFG & $r \wedge \Delta \Lambda \cdot \mid r$ & krrqivi & فعال .......................................... \\
\hline$\Delta G Y \Lambda \cdot T$ & $11 \Delta \wedge \wedge \Delta$ & TFGVVA & F.FVIF & rqITVIq & 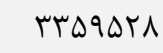 & شاغل ...................................... \\
\hline rIST.9 & 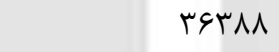 & $\Delta V F V$ & DNFTt & qFaTqD & qVqGस & 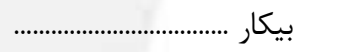 \\
\hline 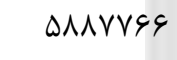 & rI9Vr.V & एवराएव9 & gFIGrTV & THATYFYV & rAFq. IFq & غير فعال ......................................... \\
\hline rrg. & VVQ & TQTI & FTY. & Irrqf & $r \cdots \Delta V$ & 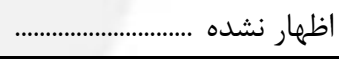 \\
\hline
\end{tabular}

\begin{tabular}{|c|c|c|c|c|}
\hline \multirow[b]{2}{*}{ اظهار نشده } & \multirow[b]{2}{*}{ بى سواد } & \multicolumn{2}{|c|}{ با سواد } & \multirow{2}{*}{ جنس و وضع فعاليت } \\
\hline & & تحصيلى نامشخص دورهاى تحصيلى، دوره & 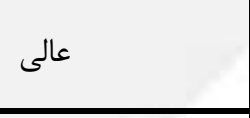 & \\
\hline FIFDA & 1DAFATG & $r \cdot 199 \mathrm{~V}$ & $\mid$ Mg|rsal & 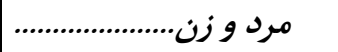 \\
\hline TTDS & TFT. TID & G. QFT & 949189. & فعال ......................................... \\
\hline $19 \cdot r$ & TTYK.19 & DQFVY & $\Delta r \cdot q \mu q \varepsilon$ & شاغل ................................... \\
\hline rat & 148499 & $\Delta F V$. & I1NQTqF & 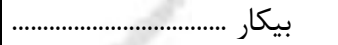 \\
\hline TIYI & GITVOIV & |fets & $V 1 \cdot v r 9 V$ & غير فعال ........ \\
\hline$r V \cdot \nabla \Lambda$ & $q V \cdot V$ & rGAF & $\| F \Delta G Y$ & 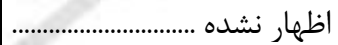 \\
\hline$r \gamma \cdot \Lambda 1$ & rl.rrr & $1109 \cdot r$ & VIFFYAY & 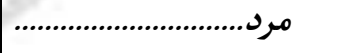 \\
\hline $191 \%$ & $19490 \cdot r$ & DIIVI & FTETTYQ & فعال .......................................... \\
\hline $19 \vee 0$ & IATYETK & FVIrq & TVRTI99 & شاغل ................................. \\
\hline TrV & 111.91 & F. FT & $81 \cdot . r$. & بيكار .......................................... \\
\hline FTS & 119149. & GYArT & TV^৭YIV & غير فعال .......................................... \\
\hline TFVFT & rrva & 1199 & $|r \wedge F|$ & 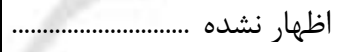 \\
\hline IfFYF & $\Delta F \Delta \| \& A$ & $94 \cdot 9 f$ & gFgqrgf & 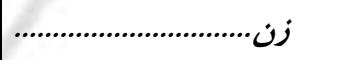 \\
\hline rfy & $r \lambda \cdot \lambda i r$ & $9 \vee V 1$ & r|fq4al & فعال ........................................... \\
\hline TYY & F\&SDAt & NHFr & IQVFI9V & شاغل ............................................. \\
\hline $11 \mathrm{~V}$ & TFETI & IFTA & $\Delta V D T G Y$ & بيكار ................................... \\
\hline 1990 & Fq৭9. Tr & NIDHA & 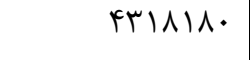 & غير فعال .................................. \\
\hline ITrt & FTM & IVAD & IVTK & 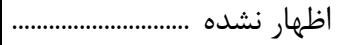 \\
\hline
\end{tabular}




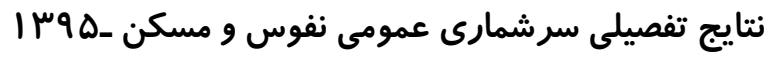

\begin{tabular}{|c|c|c|c|c|c|c|}
\hline \multicolumn{5}{|c|}{ با سواد } & \multirow[b]{2}{*}{ جمع } & \multirow[b]{2}{*}{ وضع فعاليت اقتصادى و } \\
\hline دييلم و يِيش & | متوسطه/متوسطه | | | & 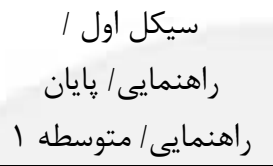 & 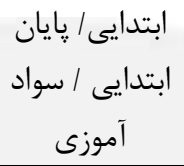 & 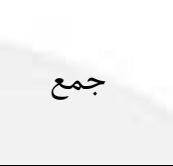 & & \\
\hline $11 \mathrm{Fa} \cdot 9 \mathrm{Vr}$ & FIAfrar & $11 r q \cdot r \Delta$ & $199 \cdot F F_{1}$ & FFAFqADF & Fqดq1arq & 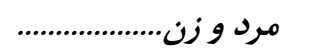 \\
\hline 499..9V & $|f| \Delta f \cdot f$ & $r \cdot \Lambda \cdot . q r$ & 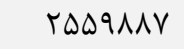 & $|v q| \cdot \wedge \mid f$ & $19.9 \Delta \Delta F$ & فعال .......................................... \\
\hline FTGV. TY & $1198 v 98$ & TVG.VTA & rr人ৎD. & $\mid \Delta F \& \Psi \Delta \cdot \Lambda$ & ISDFFTOA & شاغل ............ \\
\hline घqr.VD & rIVG.V & عسسوוץ & 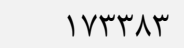 & TFFVT.G & TATITAT & بيكار ................. \\
\hline słgFAVG & rVD१QTr & $\Delta \cdot q r F I$ & $q \cdot \Delta \wedge \wedge 19$ & r\&V৭人ятr & $r \cdot r g \mid \& r \Delta$ & 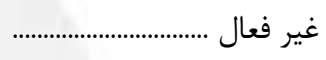 \\
\hline rब१९१ & $q F \Delta 1$ & fqя. & fIVTa & $\mid f \cdot f \cdot V$ & IVITFF & 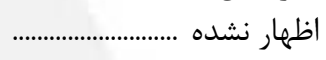 \\
\hline$\Delta V \Delta V r \cdot f$ & rrgirvi & FAFEFqG & flarraq & rrrryarq & $r f q F r \cdot \Delta \Delta$ & مرد........ \\
\hline$q r \cdot 9 \cdot 9 r$ & $|r \cdot V 9 r|$ & rANTrVq & rmtavtr & IFVTIDI9 & $109 V \cdot 49 \Delta$ & 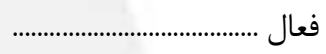 \\
\hline rVqmfGl & $1119 \cdot 90$ & rఎ৭१९৯. & r|NसEII & $1 r \cdot 9 r q . q$ & $I T q \Delta T F \cdot \Delta$ & 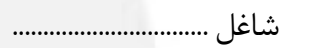 \\
\hline$\Delta \mid \Delta \&{ }_{1}$ & 191148 & rArצq9 & $|f \&| \& 4$ & $|\varepsilon \Delta \wedge \varepsilon|$. & $|\vee| \wedge \cdot q$. & 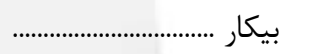 \\
\hline IFTrADr & $1 \cdot \hat{F} \& \Delta \Delta \Lambda$ & IEIETFA & $|\Lambda T \wedge \Delta \Lambda|$ & NFTDIVT & $q|r| r \cdot r$ & 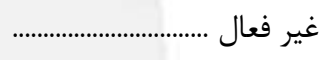 \\
\hline TFTdq & МА१५ & 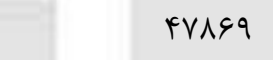 & $r q \cdots \Delta$ & $\| r \cdot \Lambda \Delta V$ & $1 \Delta \cdot r \Delta \varphi$ & 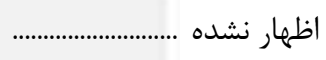 \\
\hline DqqrqqA & $11 r r \cdot 19$ & raqrarq & fFer.1r & $r l \Delta r r r \cdot \Delta$ & TFEDFFYF & 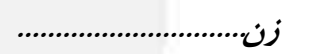 \\
\hline $9 \Delta 1 \cdots \Delta$ & 1. venr & I $9 \vee \& \wedge \Delta$ & $r+11 f$ & ए।१९९१८ & $r r q \Delta \cdot F \Delta$ & فعال ................................................. \\
\hline FVrDSI & NIV.r & $|9| \cdot 4 \lambda$ & $r \cdot r \wedge q 4$ & $r F \cdots \Delta 9 q$ & 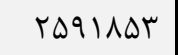 & 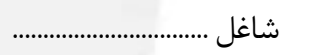 \\
\hline IVVFFF & 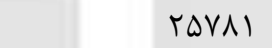 & reqTV & TVTTI & V^^ৎ৭૬ & $\Lambda \cdot r / 9 r$ & 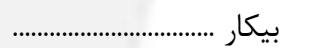 \\
\hline$\Delta \cdot F_{1} \cdot r r$ & IVIFqVF & r & אוtrTH & INHVHFE. & $r|r F \cdot F F|$ & 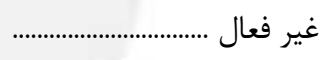 \\
\hline let. & $\Delta \Delta q$ & $|V \Delta|$ & Trr. & $9 \Delta \Delta$. & $r \cdot 9 \wedge \Lambda$ & 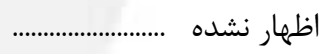 \\
\hline
\end{tabular}

\begin{tabular}{|c|c|c|c|c|}
\hline \multirow[b]{2}{*}{ 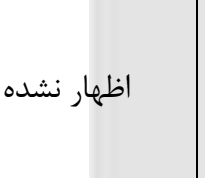 } & \multirow[b]{2}{*}{ بى سواد } & \multicolumn{2}{|l|}{ 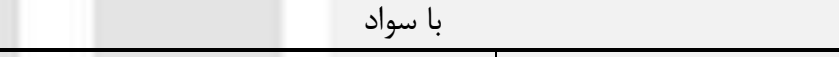 } & \multirow{2}{*}{ جنس و وضع فعاليت } \\
\hline & & ساير دورههاى تحصيلى، دوره تحصيلى & 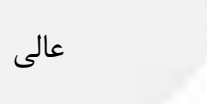 & \\
\hline rllab & FrIVAr. & 101919 & 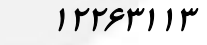 & 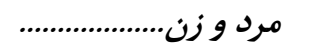 \\
\hline $11 \cdot 9$ & $110 Y q 1 V$ & FINTI & $\Delta \wedge \Delta T_{\Delta} F_{1}$ & 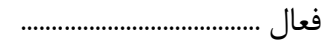 \\
\hline$I \Delta \Delta V$ & $1 \cdot \vee 9194$ & rAIGF & FNIrTqR & شاغل .......................................... \\
\hline TQT & VTVTF & rGDV & $1 \cdot r \cdot r F \Lambda$ & 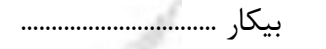 \\
\hline ISTE & rDSITVG & 1.VTEA & 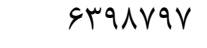 & 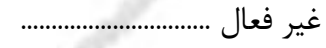 \\
\hline TVVI. & rttV & tATV & $1 \cdot V \vee \Delta$ & 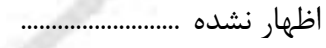 \\
\hline r.ritr & IEFFIgF & $1 r \cdot 91$ & srrugad & 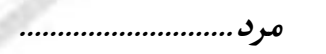 \\
\hline IDTY & qFVFDF & $r \Delta \cdot \wedge \varepsilon$ & TADVTGA & فعال .......................................... \\
\hline ITUT & $\Lambda \Lambda \Lambda I F F$ & THFA. & 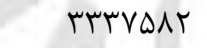 & شاغل .................................... \\
\hline IV. & 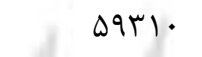 & TG.G & $0199 \wedge 9$ & 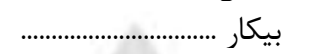 \\
\hline MIF & $99 \Delta V I V$ & $f \Delta \Delta \Delta \mid$ & TFEGTAT & 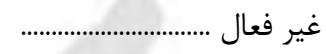 \\
\hline INFV & M & IFTF & $१ ५ \cdot \wedge$ & 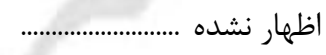 \\
\hline $1 \cdot 1 \mathrm{kr}$ & r.vrurg & $991 \Delta \Delta$ & $\Delta 94 \cdot 1 \Delta \Delta$ & 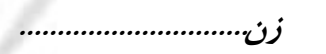 \\
\hline rAV & $r \cdot \Delta K \& r$ & GVTD & 19994VT & 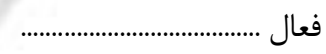 \\
\hline$r \cdot \Delta$ & $191 \cdot 19$ & $\Delta G \wedge F$ & $\mid$ IFVVII & شاغل ................................... \\
\hline Ar & $|f F| F$ & $1 \cdot \Delta 1$ & $\Delta T \cdot \Delta G Y$ & 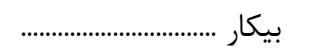 \\
\hline (TTK & 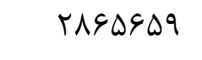 & GIVIV & dqupld & 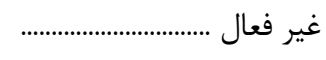 \\
\hline qrut & $r T \cdot r$ & $\mid f \cdot r$ & $I F \& V$ & 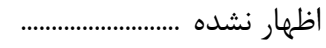 \\
\hline
\end{tabular}




\begin{tabular}{|c|c|c|c|c|c|c|}
\hline \multicolumn{5}{|c|}{ با سواد } & \multirow[b]{2}{*}{ جمع } & \multirow[b]{2}{*}{ جنس و وضع فعاليت } \\
\hline دييلم و يیش دانشاهى & 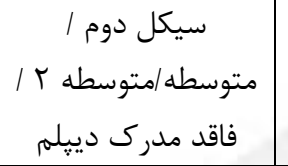 & 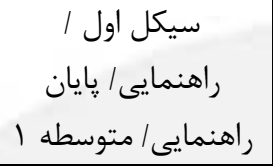 & ابتدايى/ سواد آموزى / آيان & جمع & & \\
\hline rrrar.. & irevagr & rrlequq & freirqu & IrqAIrvg & Ievarfia & 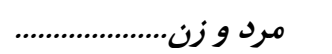 \\
\hline $111 \cdot v<q$ & $\Delta \Delta \Delta \wedge \Delta \vee$ & $|f| r \cdots \Delta$ & INFDFAD & $\Delta \Delta \wedge \backslash \Delta \cdot 1$ & G人rqqศV & فعال .......................................... \\
\hline $9 M V \backslash 11$ & $F \vee \vee \wedge \cdot r$ & $14 V \cdot 119$ & ivrruq. & Fq।人स।D & Gl. FrGF & 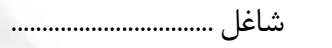 \\
\hline 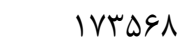 & $V \wedge \cdot \Delta r$ & IFTNIS & ITt.9D & ब9TING & 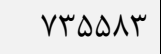 & 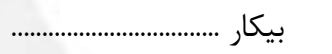 \\
\hline $1114 \cdot 91$ & 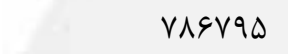 & IVVArIT & rAgqFT. & VTATFTF & १^DTTGQ & 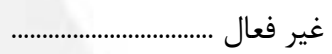 \\
\hline IDFG. & $\Delta T F$. & TDSTI & rदा T & VYFAI & $q \cdot r \cdot r$ & 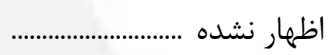 \\
\hline I TEFYGF & ArIara & 1114rm. & rrretaf & vIrqq. $F$ & $10911 \cdot 9$ & 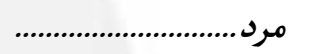 \\
\hline १人५q४⿻ & DाIrq. & $|r \cdot V T Y|$ & 19IFTM & Fq19IVT & QQP TrIT & 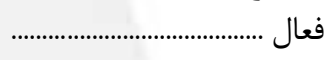 \\
\hline NFATI. & FF世人IN & $\| \wedge \Delta \mid \wedge V$ & פשrMT & FF. qrg. & DTFTGDQ & 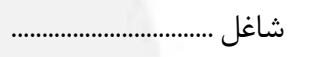 \\
\hline IrFVGG & GVEV & ITt.rt & $91 \cdots 1$ & $0.991 T$ & $\Delta \Delta 9 \Delta \Delta F$ & 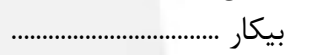 \\
\hline TEV. YG & $r \cdot \Delta \| r$ & DDIKGY & $9 \wedge V \cdot 91$ & $r \mid 0 \cdots 91$ & rGIFG人r & 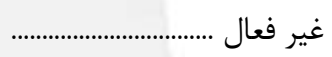 \\
\hline IFVET & DITF & TFAFV & TFqTD & VMGYI & $\Lambda 1 r \cdot 9$ & 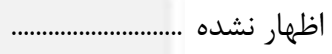 \\
\hline grfars & DrgFef & g. & FFIFqFF & DAIIfFr & AIAFTIT & 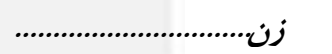 \\
\hline ITVVVT & FFDSV & 1. DVAF & rmוFr & घ९DTrq & qrVVrF & 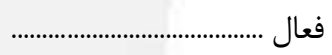 \\
\hline 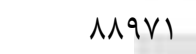 & r & $\Lambda \Delta \cdots r$ & $r \cdots \Delta r$ & $\Delta \cdot 9 \cdot \Delta \Delta$ & $V \& \mid V \cdot \Delta$ & 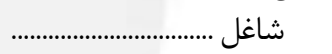 \\
\hline$r N \Lambda \cdot r$ & $1 \cdot \Delta \wedge 1$ & r.VAr & rl.qp & IDGTVF & IVG.rq & 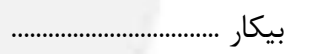 \\
\hline$\Lambda F G \cdot F \Delta$ & $F \wedge|\& \wedge|$ & $|T T V \cdot \Delta|$ & rINTrtq & سMTKRT & VTTVDAD & 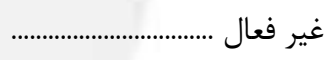 \\
\hline$\vee \backslash 1$ & ris & Vrf & $\mid f \& \wedge$ & بیl. & А११५ & 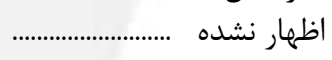 \\
\hline
\end{tabular}

\begin{tabular}{|c|c|c|c|c|}
\hline \multirow[b]{2}{*}{ اظهار نشده } & \multirow[b]{2}{*}{ بع سواد } & \multicolumn{2}{|c|}{ با سواد } & \multirow{2}{*}{ جنس و وضع فعاليت } \\
\hline & & تحصيلى نامشخص دورهاى تحصيلى، دوره & عالى & \\
\hline $1 \cdot r \cdot F$ & rar.1ra & $\Delta v \cdot 11$ & IFFATE & 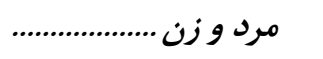 \\
\hline FYF & ITSN.tr & $19 \cdot 1 r$ & GMVTrT & فعال ..................................... \\
\hline צ & IINQVIT & IVTAF & FqYKSV & شاغل................................... \\
\hline$\Lambda \Lambda$ & VRT. & IV99 & IFYNDQ & بيكار ................................. \\
\hline FAt & rQDQYG & $r v \cdot v q$ & $V \cdot V V Y q$ & غير فعال ............................. \\
\hline $9 \% 91$ & rFAT & $\Lambda \Delta T$ & rVAD & 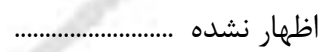 \\
\hline SVID & IFAIFAY & rrvar & (1.|r| & 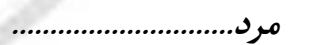 \\
\hline rVA & 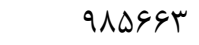 & $19 \cdot \Delta \Delta$ & FAFTaY & 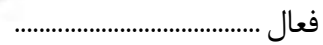 \\
\hline MIS & & 14849 & $r q 4 \cdot v q$ & شاغل................................. \\
\hline GT & $\Delta r \Delta \Lambda$. & IfTE & $q \cdot r \mid r$ & بيكار ........................................ \\
\hline 111 & FAFFAT & IVTVI & TKTH.V & غير فعال ........................... \\
\hline GTYG & ITFT & in & TaTr & 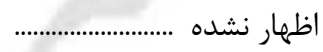 \\
\hline rfAq & rrgqral & FrrIf & $\Delta r A v \cdot \Delta$ & 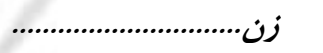 \\
\hline is & TVTHAQ & $r \cdot r \Lambda$ & $\mid \Delta r \cdot r \cdot$ & فعال ....................................... \\
\hline$r \cdot$ & TATGK. & $r \& \Delta \Delta$ & ૧人५^ی & 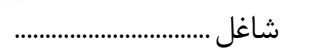 \\
\hline re & $19 \times r 9$ & rrr & DFEFT & بيكار .................................... \\
\hline rVI & $r \cdot q Y \wedge \wedge 1$ & $19 \Lambda \cdot \Delta$ & TADFTT & غير فعال ...................................... \\
\hline$r \cdot V r$ & rIII & rیI & TQR & اظهار نشده .......................... \\
\hline
\end{tabular}




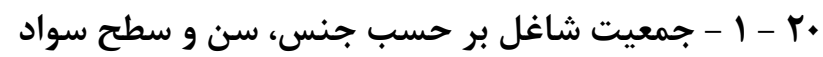

\begin{tabular}{|c|c|c|c|c|c|c|}
\hline \multicolumn{5}{|c|}{ با سواد } & \multirow[b]{2}{*}{ جمع } & \multirow[b]{2}{*}{ جنس و سن } \\
\hline و ييش دانشخاهى & 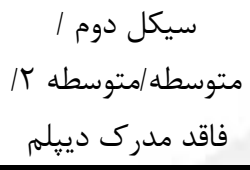 & 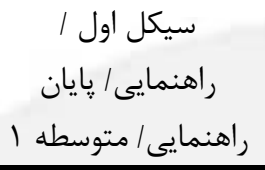 & ابتدايى/ سواد آموزى /ايان & جمع ( ) جمع & & \\
\hline$\Delta r \cdot 9111$ & IEVEV.r & $r \cdot r \mu \cdot 10$ & fllerve & $r \cdot r q \Delta \cdot r$. & rrev.911 & 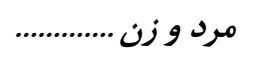 \\
\hline • & 91. & $1 \cdot \wedge \Delta T$ & rIfTG & rTSAL & rq1. & ץ | • • ساله ....................... \\
\hline$\Delta \Lambda \cdot V \vee \Lambda$ & TAIFQI & $4 \cdot 94 \cdot V$ & TFY. AD & IVATVAT & 1 1994TK & 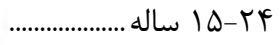 \\
\hline NV৭919 & $r \cdot 9 \cdot 94$ & 919940 & $r \Delta|f| f$ & 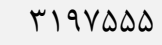 & $r r . q p \psi 1$ & q ${ }^{\prime}$ \\
\hline TYFAFIV & 1. MATFV & ५৭१९人१। & rD. IFFG & $|\Delta T \wedge||\Delta|$ & IVFATITK & • • ساله و بيشتر \\
\hline Fakpr.q & $|\Delta F \cdot 1| \mathrm{V}$ & rraverr & rvlleq. & IVFATraI & lqul|kq. & 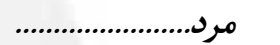 \\
\hline - & $\Delta \Lambda \Lambda$ & VTVI & $|f| \Delta \Delta$ & TYTAY & rqVV. & f | - • ساله .......... \\
\hline$\Delta \cdot r \Delta T Y$ & TQQYAF & TVQI.Y & r.人 r r r & $|\Delta H Q| G Y$ & $191 \cdot \lambda r$. & \\
\hline VAFTME & rAYSa. & 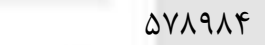 & $r \cdot q \cdot v r$ & $r \varphi \vee \Lambda \cdot V \Lambda$ & 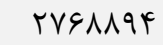 & q \\
\hline$r T \Delta Q \Delta F I$ & 1.19490 & TATOAVA & rivq499 & ITTFANTT & 149.4999 & 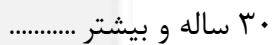 \\
\hline$\Delta G Y A \cdot r$ & $\| \Delta A \Lambda \Delta$ & rFEVYA & $F \cdot F V I F$ & rqIrriq & 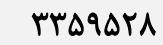 & زن............................ \\
\hline . & rTr & roג & VTVE & $11 \% 90$ & וTזו & ץ |- • اله ....................... \\
\hline VATFF & TrISV & $M F \Delta \cdot r$ & & rÆ\&911 & rQAFqR & ץ \\
\hline qDSAT & MlfFe & rVGNI & FTMEI & DI GFV & $\Delta F \cdot \Delta F V$ & qץ \\
\hline 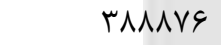 & VI9QT & $1 V 1 \cdot 1 r$ & rTIGFV & rITARTq & TQFAIDV & • r ساله و بيشتر .................. \\
\hline
\end{tabular}

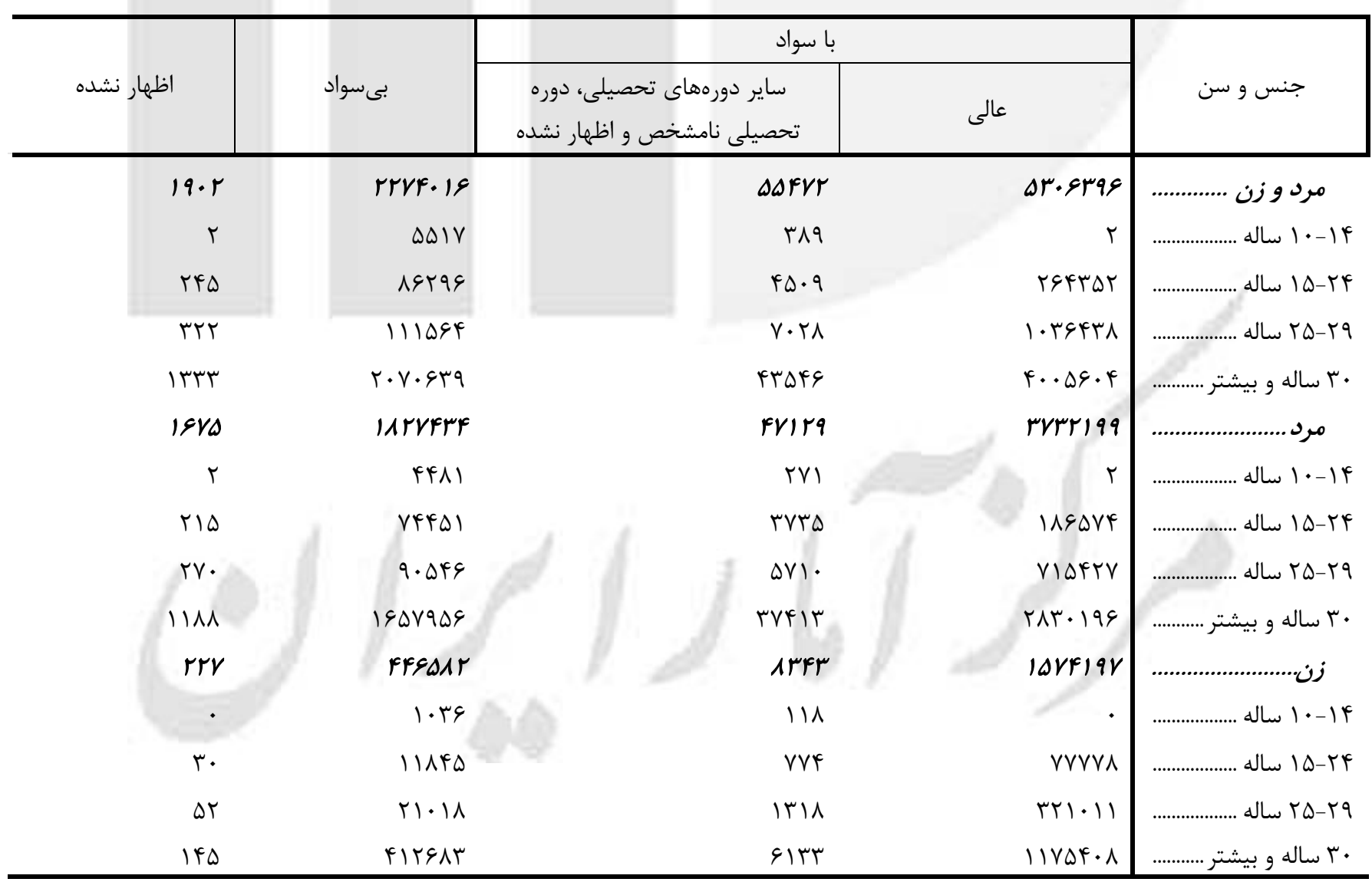



• † - 1 - جمعيت شاغل بر حسب جنس، سن و سطح سواد (دنباله)

\begin{tabular}{|c|c|c|c|c|c|c|}
\hline \multicolumn{5}{|c|}{ با سواد } & \multirow[b]{2}{*}{ جمع } & \multirow[b]{2}{*}{ جنس و سن } \\
\hline و پيش دانشگًاهى & 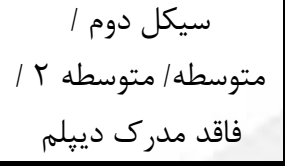 & 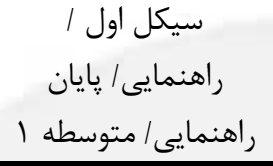 & ابتدايى / سواد آموزى هايتان & جمع & & \\
\hline Frgr.rr & $1198 \mathrm{rqr}$ & $r v \varepsilon \cdot r r s$ & rrasd.r & IDFqra.A & IEDFFTAA & 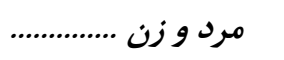 \\
\hline - & سזט & ఎqVT & $1 . .94$ & 19149 & $194 \Delta 9$ & 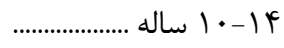 \\
\hline 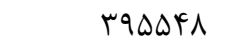 & $19 V 190$ & TYIOTI & |.GTTI & 11. & IIfqGTD & | \\
\hline GVVEVA & $r \cdot r \mid \Lambda I$ & rᄉוr.. & $\mid \vee \backslash \wedge 94$ & rmrtqle & 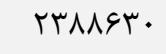 & q \\
\hline ए।9भ१९६ & ATVAMA & TIOT. TU & $r \cdot 9119 \mathrm{~V}$ & $\mid r \cdot \Delta F \cdot V$ & Irq1GGFF & 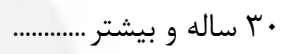 \\
\hline ryquegl & $1119 \cdot 90$ & rఎq99A. & Iוgrilr & $14 \cdot 8 r q . q$ & 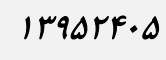 & 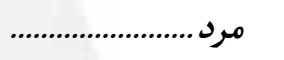 \\
\hline - & MFA & $r \cdot r \Lambda$ & $V \cdot r V$ & $119 \cdot 1$ & IrVAr & 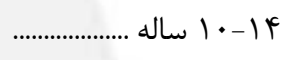 \\
\hline mrVge & IDFFFV & $r \cdot \Delta r \Delta r$ & १९TD\& & $q r q \uparrow \cdot 1$ & qVq|r। & ץ اله ساله ................ \\
\hline$q \cdot r k \cdot \Lambda$ & 1Аqщq & H & $\mid \Delta V G \Delta F$ & $19 T 1111$ & 199911T & q \\
\hline TADTYAV & $V V 19 \cdot V$ & $r \cdot r \wedge 91 r$ & I9TrGGF & $1 \cdot 19 \cdot V T \Delta$ & 1.99m & •r ساله و بيشتر ............ \\
\hline Frragl & $1 / r \cdot r$ & $|q| \cdot F A$ & $r \cdot r \wedge q r$ & $r F \cdot \Delta \Delta q q$ & $r \Delta q \mid \wedge \Delta r$ & 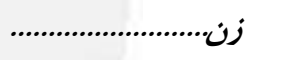 \\
\hline - & $1 \wedge \Delta$ & IgFF & $r \cdot \Delta \varphi$ & DYFA & $\Delta \Delta \vee \varepsilon$ & 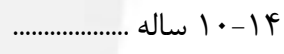 \\
\hline DVVAT & ITVEA & 19199 & 1.990 & 1яя9rd & $I V \cdot \Delta \cdot q$ & 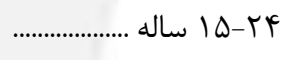 \\
\hline$V F \cdot V \cdot$ & ITVAN & 19114 & IFTrq & FITVTF & FTYFFA & q................... \\
\hline rfiv.q & $\Delta \Delta 9 \wedge 1$ & אוזו & IVDAM & MIFGAT & 199mז & 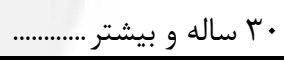 \\
\hline
\end{tabular}

\begin{tabular}{|c|c|c|c|c|}
\hline \multirow{2}{*}{ اظهار نشده } & \multirow[b]{2}{*}{ بى سواد } & \multicolumn{2}{|l|}{ با سواد } & \multirow[b]{2}{*}{ جنس و سن } \\
\hline & & ساير دورههاى تحصيلى، دوره تحصيلى & & \\
\hline$I \Delta \Delta V$ & 1.89194 & ralef & ralrgrar & 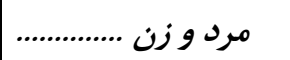 \\
\hline 1 & $r \Delta \cdot q$ & rFq & r & ץ | ا ساله ..................... \\
\hline IVr & Frils & reIV & & ץ-.................... \\
\hline 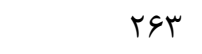 & DTFDI & FqT. & AqVDTF & q....................... \\
\hline $11 r$. & $91 \cdot 118$ & $r .99 \Lambda$ & س r & 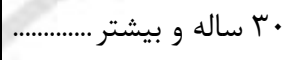 \\
\hline Irat & MAAIFF & rrFA. & rmraAt & 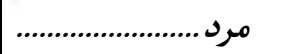 \\
\hline 1 & $r|\Lambda|$ & $1 \wedge 9$ & r & 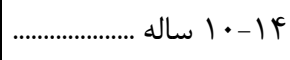 \\
\hline $14 \Delta$ & 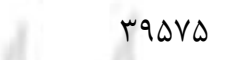 & $r t \cdot 1$ & IFrga & ال ساله ..................... \\
\hline rir & EFYAV & TVFa & $q \cdot \Delta \Delta q F$ & q....................... \\
\hline ११५ & $1 \cdot 19 \cdot 1$ & TETHA & $r \Delta \wedge \wedge \varepsilon \cdot V$ & 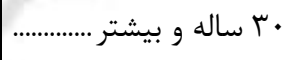 \\
\hline$r \cdot \Delta$ & $191 \cdot 199$ & $\Delta \& A F$ & $|F r \Delta V| \mid$ & 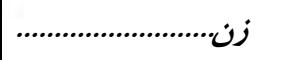 \\
\hline - & rth & r & - & 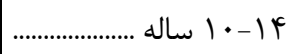 \\
\hline$r \wedge$ & $r \Delta f \mid$ & fis & GqVDD & ال ساله ..................... \\
\hline$\Delta \cdot$ & N\&q4 & $\Lambda \wedge \Delta$ & rq1qp. & q................... \\
\hline ITV & $|V \wedge \Delta| \&$ & grt. & $1114 \cdot 19$ & •r ساله و بيشتر ............. \\
\hline
\end{tabular}




\begin{tabular}{|c|c|c|c|c|c|c|}
\hline \multicolumn{5}{|c|}{ با سواد } & \multirow[b]{2}{*}{ جمع } & \multirow[b]{2}{*}{ جنس و سن } \\
\hline و ويش دانشخاهى & |متوسل دوم / متوسطه| & | سيكل اول / راهنمايى/ راهنمايى/ & ابتدايى/ سواد آموزى يايان & جمع & & \\
\hline \multirow[t]{2}{*}{$9 r r \mid 11$} & $f r r d \cdot f$ & $15 r \cdot 119$ & ivereq. & FqIArIa & gl. krefs & 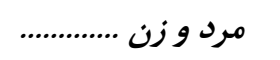 \\
\hline & rVf & FVrT & $11 \cdot \wedge \Delta$ & | & $\mid 9 T 41$ & 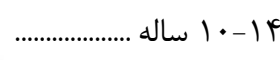 \\
\hline INEGTF & IIrAFV & IAVTAT & grequg & $q V r \cdot q$. & VIDrAN & ץ الץ-..................... \\
\hline$T \cdot T \cdot T r$ & $1 \cdot r V \cdot \varphi$ & rrFqgr & $I \vee \wedge \Delta \wedge \Delta$ & $\Lambda \varepsilon \cdot r V \Delta$ & 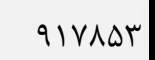 & q....................... \\
\hline$\Delta \Delta \cdot \Delta r$. & rQQAVV & NFrtit & |rq94ی| & TrGADI9 & FFDINGT & • r ساله و بيشتر ........... \\
\hline \multirow[t]{2}{*}{ AFArI. } & Ferald & $\| \wedge \Delta \mid A V$ & larrerry & FF. qre. & DTEYSAq & 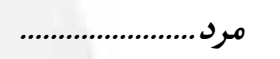 \\
\hline & rrv & MI91 & 9991 & $1 \cdot Y \wedge \Lambda$ & ITVKT & 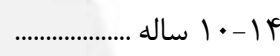 \\
\hline IEFTAV & 1. FATI & 199171 & $1118 \cdot v$ & DqfrTG & GYAGKG & 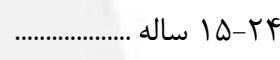 \\
\hline $\mid \Lambda \cdot \kappa \lambda$. & $q \Delta \cdot V \nabla$ & rivi99 & $10 \cdot V r \Lambda$ & $V \Delta \Delta I T \Delta$ & $\Lambda \cdots \psi \wedge \Lambda$ & q \\
\hline D. rekr & rergVr & VQDS\&q & IrorAqR & $r \cdot$ rquाl & $r q \cdot \cdot \wedge \cdot r$ & •r ساله و بيشتر........... \\
\hline 14981 & rrqus & $1 \Delta \cdot . r$ & $r \cdots \Delta r$ & $\Delta \cdot 9 \cdot \Delta \Delta$ & $v \varepsilon \mid v \cdot a$ & 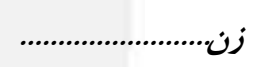 \\
\hline$\cdot$ & IrV & logt & $r \cdot \wedge v$ & $\Delta \Lambda A T$ & 9499 & † |- • اله ....................... \\
\hline r.rut & 9ाष & $|111|$ & TTETT & VAVQF & ASVAT & ץ الץ-...................... \\
\hline TIDFV & 19r9 & IVVGF & TVAFV & $1 \cdot \Delta r \Delta$. & llVres & 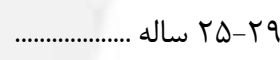 \\
\hline$r v \cdot \wedge v$ & $109 \cdot F$ & FVDGY & IFAFAV & $r \mid 9 r \cdot \Lambda$ & $\Delta \Delta 1 \cdot \wedge 9$ & •r ساله و بيشتر............ \\
\hline
\end{tabular}

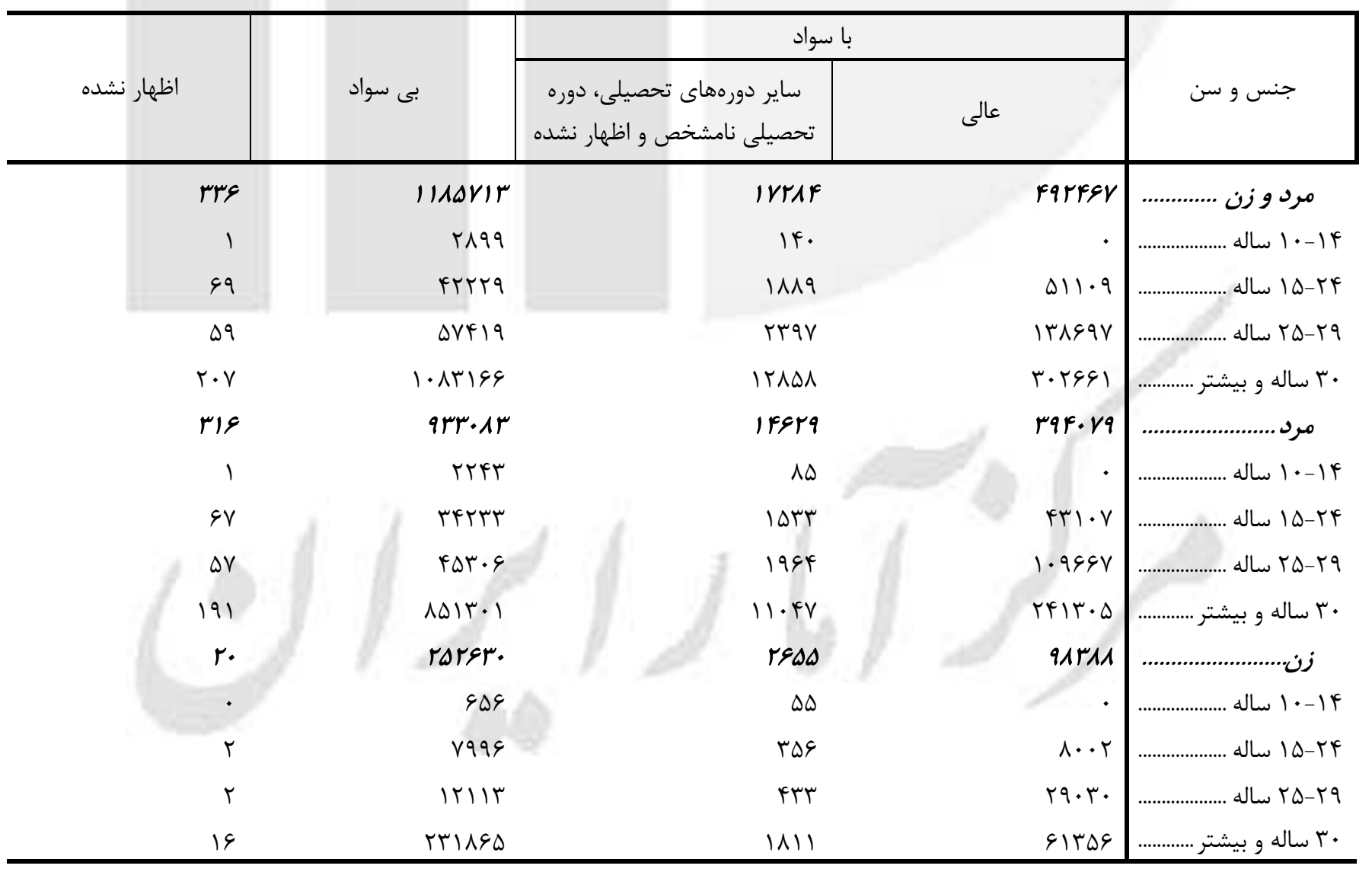




\begin{tabular}{|c|c|c|c|c|c|c|}
\hline \multicolumn{5}{|c|}{ با سواد } & \multirow[b]{2}{*}{ جمع } & \multirow[b]{2}{*}{ جنس و سن } \\
\hline و يِش دانشعاهى ديلم & ميكل دوم / متوسطه | مدرس / ماقد & 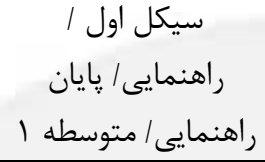 & ابتدايى/ سواد آموزى /ايان & جمع & & \\
\hline 1\&\&1AV & rqDVFI & ferrar & rqarrr & rll ragr & rranta & مرد و زن .............. \\
\hline - & $11 \mathrm{~V}$ & $\mid r \cdot r$ & $r \varphi \Delta \Lambda$ & DTTD & 9499 & 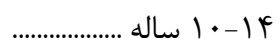 \\
\hline$r r \Delta \cdot \Delta l$ & 1198 & IFTFAV & GQATI & MAG. Kr & $q \cdot \wedge 1 \cdot 1$ & اله اله ...................... \\
\hline TEGTFE & $\Lambda \Delta \cdot \Delta V$ & Ir.kF. & घQV१V & $1 \cdot V T \backslash \wedge 9$ & 1. 9\&r\&A & 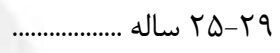 \\
\hline TNDQQT & $q \cdot v q \vee$ & $1 \Lambda V \cdot q \pi$ & $19 \cdot 0 \cdot 1$ & $\| F \lambda \mid \cdot \Delta$ & ITFEDFT & • r ساله و بيشتر ........... \\
\hline $8 \Delta \cdot \Delta \Lambda 1$ & raqTar & $f \cdot F q 19$ & rrVYFA & rIEAYEV & rrrAarr & 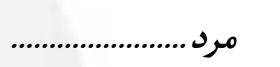 \\
\hline$\cdot$ & 9. & $1 \cdot 1 \mathrm{~F}$ & rfqu & एद्V & FaVF & 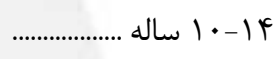 \\
\hline TAGTYG & $1 \cdot \Delta \Delta \wedge T$ & ITEMFI & DITVV & $9 \Delta \cdot \Lambda T K$ & GQATAT & 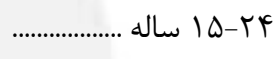 \\
\hline 19mrkq & $V \Delta V \Delta$. & $\| \varepsilon \Delta \Delta D$ & DrT. & VTDGFT & VDrVqI & 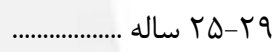 \\
\hline$r \cdot 1 . .9$ & VVqTI & larqf. & $\mid r \cdot r \varepsilon V$ & $\forall \vee \& 1 \cdot \Delta$ & $\Lambda \Delta \backslash \Lambda \Delta F$ & • r ساله و بيشتر .......... \\
\hline rIST.9 & TEYAM & DVFrV & DAFrt & १FAT QD & qYagFr & 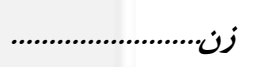 \\
\hline & Tr & r19 & 1190 & IOTA & I9T & 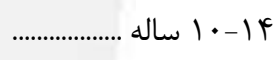 \\
\hline VANTA & $|F| A M$ & 19148 & IFDFF & THATYI & $r F \cdot r \Delta D$ & ץ \\
\hline 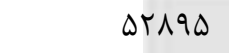 & $9 \% \cdot V$ & $1 r \wedge 19$ & $1 r \Delta \wedge 9$ & TMEDFG & TETAVV & ף ז- ז ساله ............................. \\
\hline$\wedge F \Delta \wedge \&$ & Ir^ৎ9 & TFITK & $r \cdot 1 r r$ & rVT... & एq4919 & •r ساله و بيشتر ............ \\
\hline
\end{tabular}

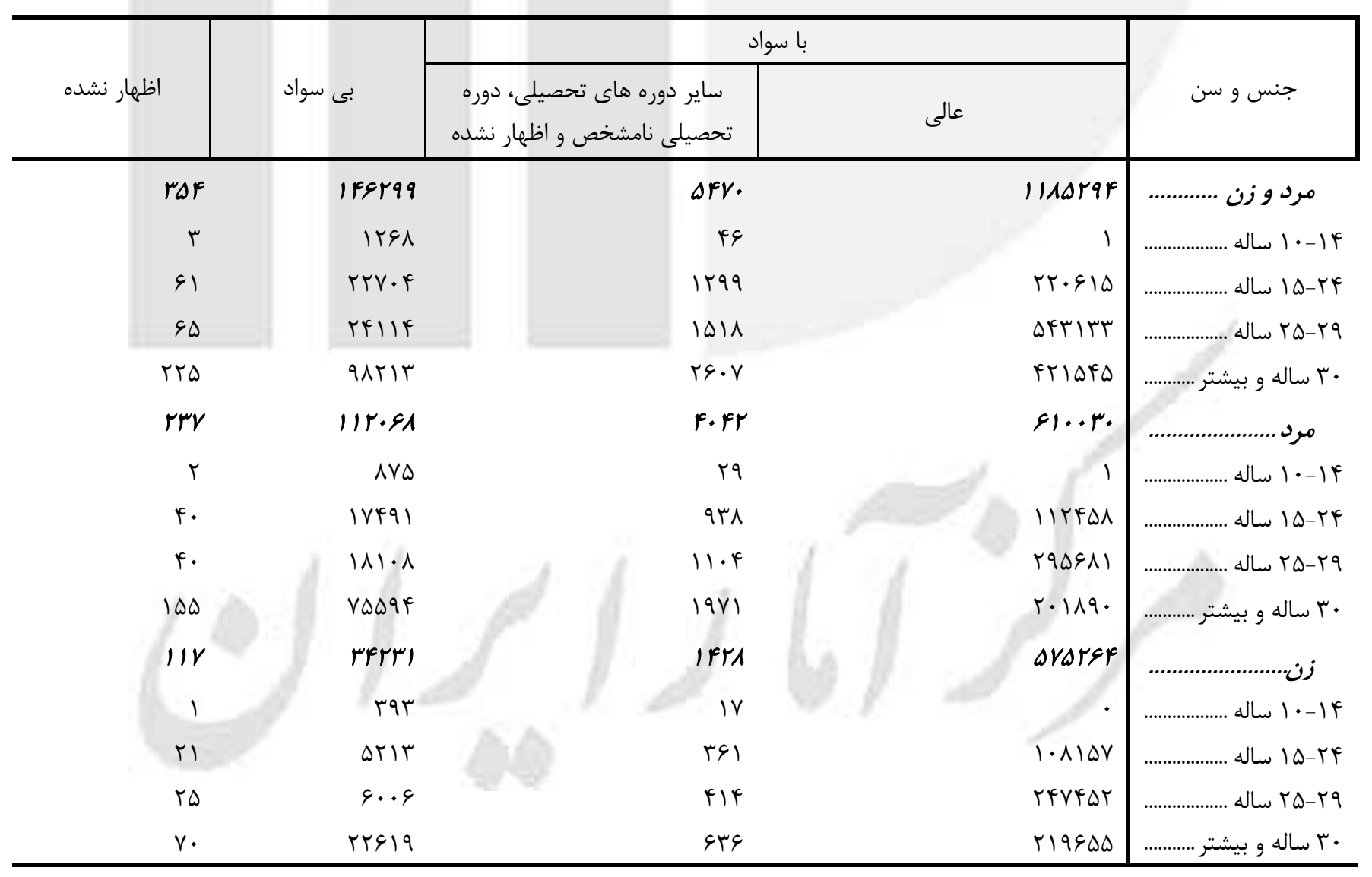


Iا - I - جمعيت بيكار بر حسب جنس، سن و سطح سواد (دنباله)

\begin{tabular}{|c|c|c|c|c|c|c|}
\hline \multicolumn{5}{|c|}{ با سواد } & \multirow[b]{2}{*}{ جمع } & \multirow[b]{2}{*}{ جنس و سن } \\
\hline دييلم و يِيش & ميكل دوم / متوسطه| & سيكل اول / راهنمايى راهنمايى/ & ابتدايى/ سواد آموزى /ايتى & جمع ( - جم & & \\
\hline \multirow[t]{2}{*}{ sqr.Va } & rive.r & عrare & ivrrar & FFFVT. & TaTITAT & مرد و زن ............. \\
\hline & 90 & VAr & $|r F|$ & rISV & $r \Lambda \cdot \Delta$ & ץ ا • ا ساله ................... \\
\hline TFDIAS & VА१Vr & NTEFF & TAQTA & $G T \cdot Y V D$ & GTarQ1 & | \\
\hline 198111 & glate & ASTD. & TMTY. & NFquیI & 181918 & q \\
\hline$r \Delta 1 \cdot V I$ & V9949 & 149999 & $11 . r 94$ & QVDTAT & 1. TVKTM & •r ساله و بيشتر ....................... \\
\hline \multirow[t]{2}{*}{ DID\&FI } & 191148 & rareq9 & IfEIeT & $\mid \& \Delta \wedge 91$. & 1211.9. & 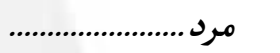 \\
\hline & qq & ४१V & १९४ & IGTF & $r \cdot V \Delta$ & f أ- •| ساله ......... \\
\hline INFETV & $V \cdots r V$ & VTDFG & $r r \Lambda \cdot G$ & FF. FAT & FFVADF & 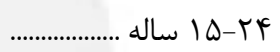 \\
\hline IDFTQG & $\Delta \Delta T \Delta Q$ & VVATV & rATA. & DGFFT & DVFYAI & qr- \\
\hline IVGDQA & 99411 & IrIVTq & 941.9 & $9 \Delta T \cdot 9 \Delta$ & 9949人. & •r ساله و بيشتر ......................... \\
\hline IVYFFF & raral & regry & rerrel & va1999 & $1 . r 194$ & 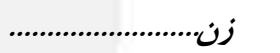 \\
\hline . & 19 & 149 & rVF & DFr & Vr. & ץ | • • ساله ................. \\
\hline$q \cdot \Delta F q$ & ८৭५ & $1 . .91$ & FVTr & IVq9זr & $|1| F \cdot F$ & ץ \\
\hline FTFYT & \& MA & NFr & pqp. & TAFqFT & $r \wedge \vee \Delta \cdot \Delta$ & 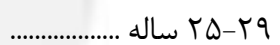 \\
\hline VEFV & $1 . \operatorname{ktg}$ & IVq. & $I V I \Lambda \Delta$ & TMTTMA & r & 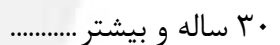 \\
\hline
\end{tabular}

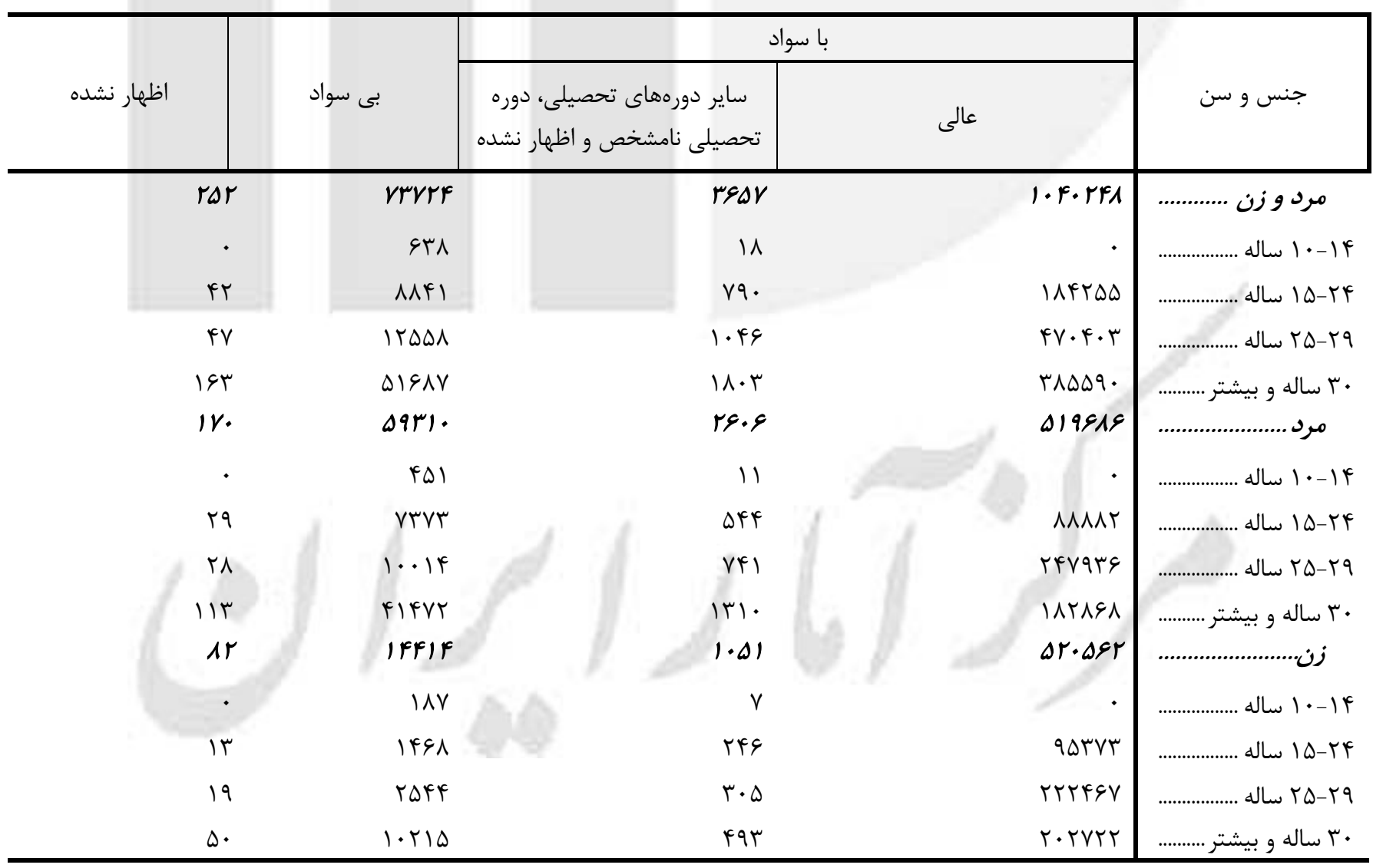




\begin{tabular}{|c|c|c|c|c|c|c|}
\hline \multicolumn{3}{|c|}{ 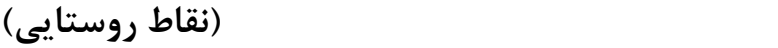 } & \multicolumn{4}{|c|}{ r - I - جمعيت بيكار بر حسب جنس، سن و سطح سواد (دنباله) } \\
\hline \multicolumn{5}{|c|}{ 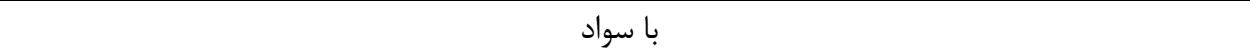 } & \multirow[b]{2}{*}{ جمع } & \multirow[b]{2}{*}{ 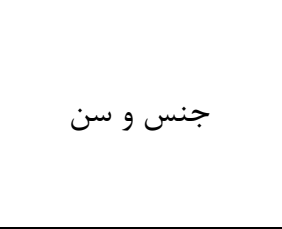 } \\
\hline 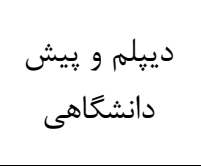 & 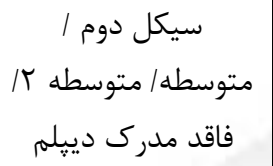 & 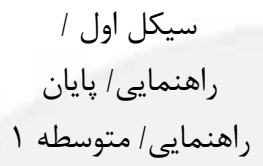 & ابتدايى / سواد آموزى / آيان & جمع & & \\
\hline IVTAGA & $V \wedge \cdot \Delta r$ & IFrAIS & Irt.9Q & \&9MIA\& & VTDAAr & مرد و زن ............ \\
\hline • & $\Delta T$ & 909 & • (ודץ & $r \cdot p q$ & reVt & 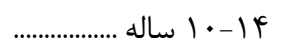 \\
\hline$\wedge ৭ \vee \cdot \vee$ & $F \cdot V F \Lambda$ & $9 \cdot 9 \Lambda \Lambda$ & rV. १९ & $r \varphi \Delta \cdot r V$ & rVAVVG & ................. \\
\hline Fqus. & מםوسזr & FFITY & rTATS & TTKDIT & THF. FT & و r \\
\hline TFQ. & Ir人⿻. & פשr" & $0.19 \mu$ & IVTDVA & r19.9. & •r ساله و بيشتر .......... \\
\hline Irfyge & grfyr & Irtere & $91 \ldots 1$ & 0.9914 & $\Delta \Delta q \Delta \Delta F$ & 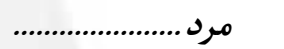 \\
\hline - & (i) & $F \wedge \varepsilon$ & $|\Delta T|$ & $r .99$ & rFAD & f| - | ساله ................... \\
\hline$V \mid<\& 9$ & $r \Delta \Delta \cdot r$ & $\Delta \mid \& V \Delta$ & TVMTT & $r .9919$ & r19q4q & ال ساله ............... \\
\hline rیq. & $r \cdot Y \wedge 1$ & 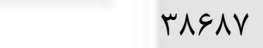 & rF^१V & $|V| \cdots$ & $189 \cdot 199$ & \\
\hline rfrqg & llfeV & आIA & TVYFI & Irrq4V & $|\Delta \Lambda \cdot F|$ & 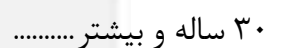 \\
\hline$r \Lambda \Lambda \cdot r$ & $1 \cdot \Delta 11$ & r.var & rl. qf & lagrVF & lvg.rq & 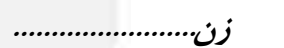 \\
\hline - & 11 & r & マ^९ & qAr & 1119 & 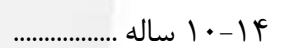 \\
\hline INTrA & DTFD & $q \cdot 11$ & qVDF & $\Delta \Delta|\mu|$ & DANYV & اله اله ................. \\
\hline $1.4 \Delta 9$ & rवाt & DFFV & VEYq & $010 \cdot 9$ & $\Delta F Q Q F$ & ................. \\
\hline $1 \cdot 1 \cdot 0$ & TFIT & $914 q$ & Irart & 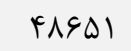 & $91.4 q$ & •r ساله و بيشتر .......... \\
\hline
\end{tabular}

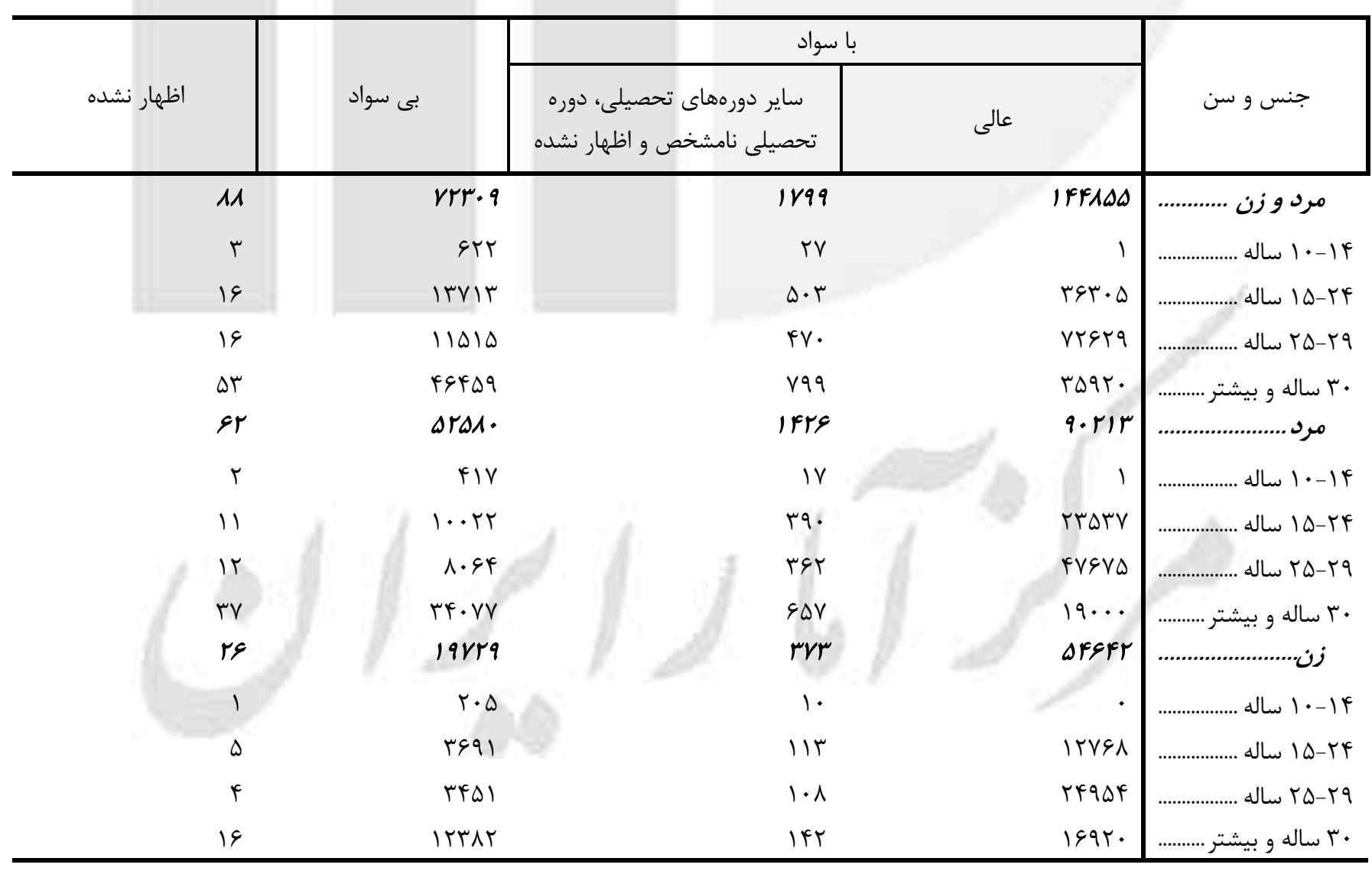


r T - 1 - جمعيت +ا ساله و بيشتر بر حسب سن، جنس و وضع زناشويى

\begin{tabular}{|c|c|c|c|c|c|c|c|c|c|}
\hline \multirow{4}{*}{ ا نشده } & \multicolumn{7}{|c|}{ 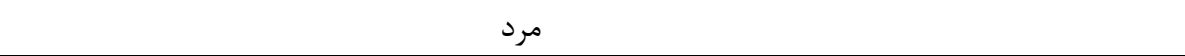 } & \multirow{4}{*}{ جمع } & \multirow{4}{*}{ سن } \\
\hline & \multirow{3}{*}{ هركز ازدواج } & \multicolumn{5}{|c|}{ حداقل يكبار ازدواج كرده } & \multirow[b]{3}{*}{ 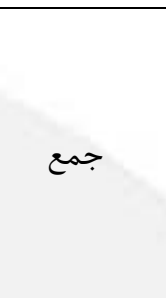 } & & \\
\hline & & \multirow[b]{2}{*}{ | اظهده } & \multicolumn{2}{|c|}{ بى همسر } & \multirow[b]{2}{*}{ داراى همسر } & \multirow[b]{2}{*}{ جمع } & & & \\
\hline & & & بلاق بليل & فودمت & & & & & \\
\hline $19 \Delta \& 9$ & llabrarr & Arr & rq9.1f & $r r q \cdot r l$ & riraqreq & rla11r.g & rragrgir & gefrla19 & 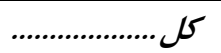 \\
\hline rTVT & TAVTAMQ & $\wedge \Lambda$ & $|r|$. & rیr & MFYA. & rदrधा & rq1Ifrr & 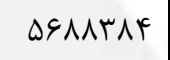 & ץ |- • اساله............. \\
\hline rtrae & TVIV.GF & $11 V$ & $19 \vee \wedge$ & DIT & gratr & Gबro. & 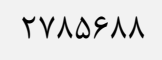 & 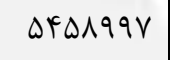 & 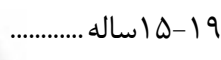 \\
\hline rqด. & rDQGTTS & 110 & ITETV & $11 \% \Delta$ & grrq.r & दrVVqq & & 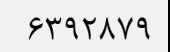 & ץ \\
\hline$r \Delta \wedge \Delta$ & 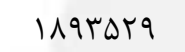 & $\vee \cdot$ & FVV.r & rVGD & rlagvqF & TREVTMI & FIfTfFA & سזוIי•ה & q \\
\hline IOAT & MATrTK & 91 & $v q \cdot 41$ & FFTE & TrVTle & TFDDGTY & FTF. FFA & 19..91 & ץ \\
\hline 1119 & TrI.99 & 99 & $V \Delta \cdot \Delta \cdot$ & ८१९. & Mाबq.Vब & $r T \Delta \cdot \mid \wedge \Delta$ & rQVTF.r & $\vee \cdot r \vee \Delta q \Lambda$ & 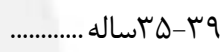 \\
\hline 819 & ITATFE & $\Delta \Lambda$ & DFTT. & vef. & TETET.V & T\&NM. rQ & r人Ir人q. & $\Delta \Delta \backslash \wedge r \cdot V$ & ............... \\
\hline$\Delta 91$ & gQVTr & $\Delta r$ & frqu. & 1.911 & TrmrYV. & rrAvIry & TFAFFYY & FArTITH & .............. \\
\hline$\forall \Delta \Delta$ & $r \Delta V \Delta V$ & fr & ५৭৭१८ & $\mid F \lambda \cdot F$ & INqFAYq & 19тqтя & I $9 V \Delta \Delta V F$ & rqTळqVI & 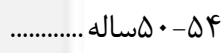 \\
\hline 419 & $r \cdot \Delta \Delta \Lambda$ & rی & TRIDF & TIFIV & $19 \cdot \Delta r \Delta \Lambda$ & 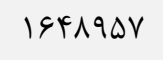 & $199994 \mathrm{~F}$ & 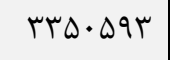 & 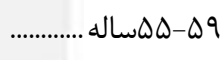 \\
\hline אחז & 1.ArT & سץ & וrqvr & TAYAN & $\| 9971 F$ & $|r F| Q \cdot \Lambda$ & IrATGGT & TAFTAVR & 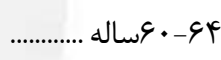 \\
\hline 1599 & $|F \& \wedge|$ & $\wedge \varphi$ & $11 \ldots+f$ & rmilh. & rIf. Fqu & rr人१Vदץ & TY. DVFT & FAVIDIA & ه9 ساله و بيشتر ... \\
\hline Irras & $1 \Delta r \cdot 1 \& \Delta$ & fir & ruprefe & rererg & laAfrefeq & IsrqA1FF & rFqFr. Da & 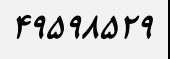 & نقاط شهرى ..... \\
\hline 191. & $r \cdot \Delta \cdot \Lambda r r$ & r. & VVq & TFV & rISVV & TrVFT & $r \cdot V \Delta \backslash \wedge S$ & $F \cdot \Delta G Y F T$ & 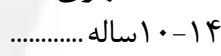 \\
\hline $19 V V^{k}$ & 199.911 & $\Delta T$ & | & MIS & rदाQ. & rVVEq & r...rrr & r৭০. & 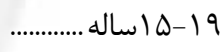 \\
\hline THTT & ING9.rD & $\Delta \varphi$ & 1991 & gFf & rATDSG & Г৭५१४४ & TTEIT.D & r F & 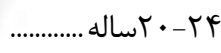 \\
\hline 1998 & IfFqIFr & rq & rqv.. & 1901 & |DrFEN. & $1 Q V Y \cdot G$. & r. TFT.. & $41 . .914$ & q \\
\hline ITTD & VIVIre & rq & GDIAV & rArq & TATYIGT & TE..TTV & 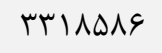 & gervile & 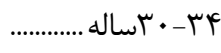 \\
\hline Ave & $r \& \mid F \cdot V$ & $r v$ & $q_{T M} \Delta \cdot q$ & $r q \cdot v$ & rrq৯ఎ৭१ & TYGG. DT & TVTATrQ & DrqTrVI & q \\
\hline $4 \wedge$. & I.TIAY & rq & सq. rq & $|q 99|$ & 191480. & $r \cdot r r s \vee q$ & TITETKE & FIAVANG & F.............. \\
\hline Fr & $\Delta \Delta \Delta \Lambda$. & rq & rVFFe & VATY & $1 \Lambda \cdot 1 \cdot V \cdot$ & $1144 \cdot V q$ & $19 \cdot r \cdot 9 V$ & rv.r & .............. \\
\hline rov & r.rq. & rq & TEATT & $1.9 .$. & IFVArV. & $|\Delta| \Delta \Lambda \mid \Lambda$ & 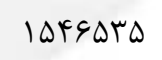 & $r \cdot \Delta 1 r \cdot \varphi$ & 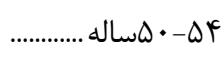 \\
\hline זוז & $|V m| \mid$ & iv & 19994 & $1 \Delta \Delta \Delta F^{F}$ & IrrT.g4 & IrGATqV & $|r \wedge \Delta q \pi|$ & TDQFAIT & \\
\hline TFS & $\wedge 9 \Delta \vee$ & 19 & ITFTr & T.VRG & $911 \cdot 4$. & QDITYA & १९. सr. & $191 \cdot \Delta F \wedge$ & 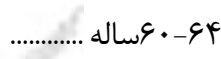 \\
\hline $9 \cdot 1$ & 11.18 & $\Delta T$ & IDTFA & IQTKR & |DTTKTI & 199.940 & $I V \cdot r \wedge V \cdot$ & rFDDI\&K & ه9 ساله و بيشتر ... \\
\hline fify & $r \cdot \mid V \varepsilon \cdot q$ & ras & sartr & $1 \cdot 8 \cdot 1 f$ & $\Delta F \cdot F V I A$ & adVerar & $10911 \cdot 8$ & Istarfia & نقاط روستا ييى. \\
\hline 49. & 119995 & $i \Delta$ & DTq & Ira & ITVVF & IrFAr & NTFITA & IETAIFT & 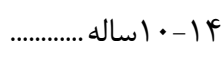 \\
\hline 999 & VQrqGI & $\varepsilon$. & vis & 190 & $r V F=1$ & $r \wedge r \cdot r$ & VAr·DQ & ID.FTT. & 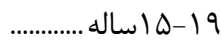 \\
\hline VT. & $V R V A \cdot r$ & $\Delta \Delta$ & rqqi & 499 & rтQ人.r & FEFTQA & QVTAT. & 11.9910 & ץ · • اساله ................... \\
\hline$\Delta \Lambda \cdot$ & FFT人qV & rv & 1.911 & $11 \cdot 1$ & $99.9 V 0$ & sVrl. 1 & $\| 119 \Delta \mathrm{VA}$ & $r \cdot 9 \Delta \wedge \Delta \wedge$ & qr \\
\hline rar & IEDFVT & rq & ITATF & IOSV & $\Lambda \Gamma \wedge \Delta \Lambda$. & $\Lambda \Delta F \ldots$ & $1.191 \mathrm{TF}$ & 1989494 & ץ • • "ساله .................. \\
\hline atra & ఎ१५q। & r. & llkVk & $r \cdot \Delta F$ & V\&AMMII & VATETq & NFT. GD & IEFIFTV & 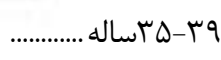 \\
\hline Ire & rrquq & rq & $\Delta r$. . & TFQI & GFTIQF & GATAFE & GVDqIV & ITTVTYG & F............... \\
\hline 111 & $11 \cdot 19$ & rr & $\Delta F \cdot \Lambda$ & आl. & $\Delta r \cdot q V F$ & $\Delta T 9 \Delta 19$ & $\Delta \Delta \cdot V T r$ & $1.998 \wedge \Lambda$ & q \\
\hline 94 & $\Delta r \Delta \varphi$ & 11 & ryll & rıv^ & $\forall i a \cdot V Q$ & FTtMAT & FrVAr. & NVTTYY & 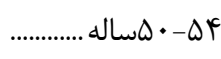 \\
\hline q & TMTI & 11 & FFDQ & $\Delta \Lambda \mu F$ & TVITte & 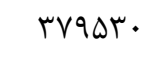 & rATAFF & VqTaVr & \\
\hline$\Lambda F$ & $\mid N F \Lambda$ & If & 1019 & VDIT & $r \Lambda \cdot r q$. & rАqसr & rqIr\&D & $q r \cdot r r q$ & 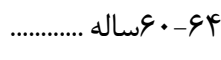 \\
\hline 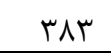 & rGFi & س & TYHF & VVGV. & $919 \Delta \wedge \Delta$ & sqV.rr & $v \cdot 1.49$ & IFIMEF. & له ساله و بيشتر. . \\
\hline
\end{tabular}


r T - 1 - جمعيت •ا ساله و بيشتر بر حسب سن، جنس و وضع زناشويى (دنباله)

\begin{tabular}{|c|c|c|c|c|c|c|c|c|}
\hline \multirow{4}{*}{ نشده } & & \multicolumn{6}{|c|}{ زن - ت } & \multirow{4}{*}{ سن } \\
\hline & \multirow{3}{*}{ هركز ازدواج } & \multirow[b]{3}{*}{ اظهار نشده } & \multicolumn{4}{|c|}{ حداقل يكبار ازدواج كرده } & \multirow{3}{*}{ 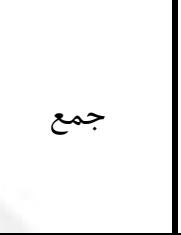 } & \\
\hline & & & \multicolumn{2}{|c|}{ بى همسر } & \multirow[b]{2}{*}{ داراى همسر } & \multirow[b]{2}{*}{ جمع } & & \\
\hline & & & بلادليل & بهمدليل فوت & & & & \\
\hline verr & $1 \Delta 9 \& \vee \wedge 9$ & $r \cdot q f$ & virgar & rrasq1r & rllf.arr & reTaATaG & rrAsqrVV & 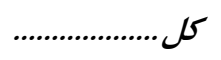 \\
\hline $1 . F \Delta$ & TVMAFEA & $r \cdot r$ & $\Delta 91$ & rte & TEFTT & TVFYA & rVVदqal & 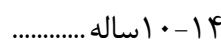 \\
\hline १४६ & $r \cdot q \wedge \wedge 9 \Delta$ & TEV & $1.91 \mathrm{~F}$ & 1194 & $\Delta S|F| r$ & DVFESA & TEVRr.q & 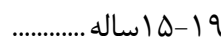 \\
\hline IATE & $|r v \cdot V \wedge|$ & $T \cdot \Delta$ & FIrAV & FAGY & |VrGATI & IVArTAV & $r(\Delta \Delta q \cdot \tau$ & ץ \\
\hline v91 & 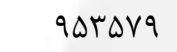 & 190 & AVDTV & IFrVt & T..ITTF & גוسץ.וץ & $\varphi \cdot \Delta V \& \wedge \Lambda$ & qr \\
\hline f. 9 & $G F \Delta \Delta \Delta T$ & $r \mid \Lambda$ & $1 r q \Lambda \Lambda F$ & rIfed & rFarqF. & $r \varepsilon \mid r \Delta \cdot V$ & FTG. FED & F \\
\hline$r \Delta \omega$ & Tempet & rt. & $|r \cdot V| F \mid$ & DFqVG & rqT $\Delta \Delta \Delta q$ & ए।. Ifqद & TFEDI9D & وس-هاساله .................. \\
\hline IFT & IATEMA & 191 & qIfir & $\wedge \Delta V \Delta V$ & THFTEV & TDT.人TV & tr.fFIV & 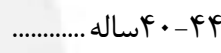 \\
\hline 149 & $1 . F \wedge 99$ & 19. & VVAIV & IFFEG & $r \cdot 9101 T$ & TTVKGAI & 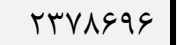 & .............. \\
\hline 19. & $\Delta Q \Delta V T$ & rir & $\Delta \vee G \cdot 1$ & INGTTQ & IEFGGTE & 119.990 & $190 . r 97$ & 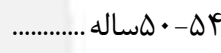 \\
\hline rl. & raTV. & $1 M \Lambda$ & $\mid F_{1} \cdot r_{\Delta}$ & rQ१४QT & ITFETR & IEFDIVq & 191.909 & .............. \\
\hline 195 & $195 \wedge 9$ & ru & rFqAK & risQ9. & 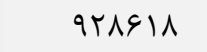 & IrV. FTq & $\mid r \wedge 991$. & 1............... • • • \\
\hline $1 \cdot v \cdot$ & rrG\&D & VQV & rquqr & Ir.qrदץ & $11 \cdot \mid \Delta T A$ & TFFI. FI & TFEDVVE & ه \& ساله و بيشتر ... \\
\hline$\Delta \& r r$ & eraAvif & $r \cdot 99$ & $81 \cdot 1 F q$ & IVA. ERF & $|\Delta V 91 \Delta \Delta|$ & IAIErIrr & TFEDFFYF & نقاط شهرى ..... \\
\hline Vrr & $19 G T Y \cdot 1$ & $|r|$ & req & IFT & $|90|$ & IVITY & $1911 \cdot \Delta V$ & | أ- •اساله............. \\
\hline$V \notin q$ & 19.91149 & IrF & gVVq & gar & rrTAFI & $M F \cdot F \cdot G$ & $190 \cdot r \cdot r$ & 19-ه اساله .................. \\
\hline $19 \mathrm{VV}$ & $1 \cdot 19 \cdot 4 q$ & $|r|$ & $r \cdot \Delta 9 r$ & rq1Q & $1191 \mathrm{HEF}$ & Irtr..r & rTIQVTA & 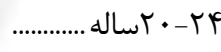 \\
\hline 991 & VATT.. & ITT & $V \cdot 991$ & QFTI & TTET.IT & THTTDQT & $r \cdot v g F \mid f$ & 9r-............... \\
\hline r19 & fqva. 1 & $|f|$ & $1111 \cdot 4$ & Trmes & reVV.rq & rAIITI. & • שוף. & ץז- • اساله ............. \\
\hline $1 M 1$ & TEMTK & 149 & $1 . \Delta 9 \wedge 9$ & एव५६६ & rTDQTHF & $r F \ldots r T \Delta$ & 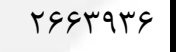 & 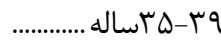 \\
\hline 9. & IFVVG & IrF & $\Lambda \cdot r \Delta \Lambda$ & GTr.V & $|\vee \wedge| \cdot \wedge \Delta$ & I9THGAF & $r \cdot \Delta \mid \Delta r \cdot$ & 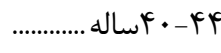 \\
\hline $1 \cdot 0$ & VVAVG & If. & 99.1 . & $1 \ldots q v$ & IDAIFTF & $|V \Delta \cdot G T|$ & IATATET & ............ \\
\hline 119 & FVTrd & 190 & $\Delta I V \cdot \Lambda$ & $|f| 1.1$ & ITEFFFE & IFUVFT. & $10 \cdot F \vee V 1$ & 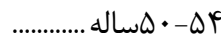 \\
\hline $1 \mp \lambda$ & 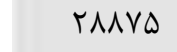 & ITF & 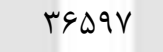 & IAFTYV & $1 \cdots \wedge 9 \cdots$ & $\mid r r q \wedge \Delta \wedge$ & $|r \& \wedge \Lambda \Lambda|$ & 9 \\
\hline lre & 10999 & 199 & $r t \cdot N I$ & THT. FQ & sVAV.1 & १५т११९ & $90 \cdot 111$ & 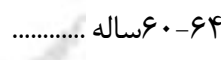 \\
\hline VTF & INAFT & $\Delta 99$ & rFqAV & qFoIVD & Vब1990 & IVTTVTE & IVATRqT & ه9 ساله و بيشتر ... \\
\hline larq & $\mathrm{rl} \cdot 19 \mathrm{rr}$ & qFV & 1.1119 & eqVell & $\Delta r r \cdot \varepsilon \Delta F$ & $9 \cdot 1 \cdot 1 r l$ & Alakrit & نقاط روستا يیى.. \\
\hline$r \cdot q$ & VVrrq. & $\wedge \cdot$ & req & $\Delta f$ & 19190 & $r \cdot r \cdot \Lambda$ & vq $\ldots$. v & ץ |- • اساله ............ \\
\hline Trt & FMATIS & 11. & rArF & $\Delta F_{1}$ & TTATHY & THTVtT & $V T \| 191$ & 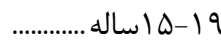 \\
\hline $1 \Delta \Delta$ & rArG. & 99 & 1.VAr & lqfe & DrVG . & $\Delta \Delta \cdot \kappa \cdot \varphi$ & NTFISD & 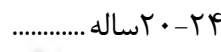 \\
\hline $1 \% 8$ & $19971 \%$ & vr & 19019 & kquq & VAVqIT & VYGFFT & १४१५А. & q \\
\hline$\wedge 1$ & IFVGgr & VQ & $\mid \Lambda \cdot \Delta \Lambda$ & 9111 & VVFAVD & A.IATS & $q \uparrow q \Delta V$. & 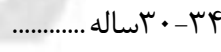 \\
\hline 91 & १९४१४ & ve & س & IODAT & $99111 T$ & $9990 \cdot r$ & У११५द् & qז-ه \\
\hline 49 & $\Delta \Delta \Delta r F$ & $\Delta V$ & $111 \mathrm{FF}$ & rTDIV & $\Delta 91.11$ & $\triangle Q \Delta V T q$ & $901 \% \cdot 9$ & 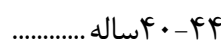 \\
\hline r. & TVTrq & $\Delta \cdot$ & $\wedge \Delta \wedge 9$ & TrYGI & eVAVAs & $\Delta T \backslash G \wedge G$ & 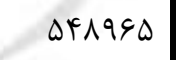 & ............. \\
\hline r & $1 r r \cdot q$ & $i \wedge$ & $\Delta \wedge \wedge 9$ & $40 \cdot 19$ & $\lceil\wedge 1 \cdot 19$ & ETT. ED & fefergy & 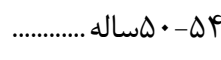 \\
\hline$\Delta \Lambda$ & grve & Q & FETT & GATFV & $r r F \Delta V A$ & F. FTQG & $F 1 \cdot V r \Lambda$ & هو \\
\hline sq & rTAF & 99 & rᄉ9V & 人rr人q & TFATVI & THDGYG & rr人qVe & 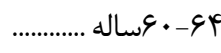 \\
\hline MFT & $4 \lambda .9$ & $1 M \Lambda$ & FY.Y & remrV. & rrAMAT & V.VTFY & VIrrge & هو ساله و بيشتر ... \\
\hline
\end{tabular}


r r - 1 - جمعيت +1 ساله و بيشتر بر حسب جنس، سن، وضع سواد و وضع زناشويى

\begin{tabular}{|c|c|c|c|c|c|c|}
\hline \multirow[b]{3}{*}{ اظهار نشده } & \multicolumn{5}{|c|}{ 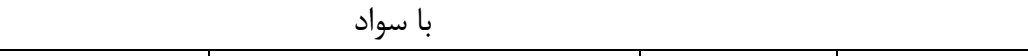 } & \multirow{3}{*}{ جنس و سن } \\
\hline & \multirow{2}{*}{ ازدواج نكرده } & \multicolumn{2}{|c|}{ بي همسر } & \multirow[b]{2}{*}{ داراى همسر } & \multirow[b]{2}{*}{ 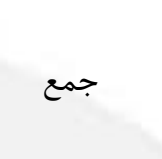 } & \\
\hline & & بلاقليل & بهدليل فوت & & & \\
\hline $118 \cdot r$ & 19DFqfFr & $1 \cdot 19 \cdot 19$ & 1. rrary & merid. If & araraq9a & مرد و زن ........ \\
\hline 1094 & $\Delta \Delta r q \Delta \varsigma \Delta$ & INFD & $\Delta \cdot r$ & GNHTV & $\Delta 9 \| \Lambda \mu F$ & 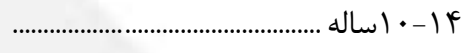 \\
\hline $10 \Delta 9$ & FVTV१QV & ITYAV & $|f \wedge|$ & Q৭९१V & $\Delta T Y \cdot T \Delta F$ & 19-Q اساله ............... \\
\hline rqYI & 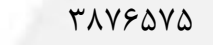 & DTGGY & $\Delta r \Delta \Lambda$ & TYGTYYQ & $9 T \cdot . V 9 V$ & 1.............. \\
\hline 1999 & tVDATHF & iriVRt & 10190 & kqqVqF4 & $v q \cdot \Delta \cdot \lambda f$ & q \\
\hline 915 & $\mid F \Delta r \cdot \wedge q$ & 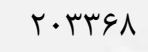 & r।Q9द & gDGDHTI & NTAFTQG & F \\
\hline 40 . & GTQQYG & IAV৭9T & $\Delta \cdot F V$ & $\Delta V F I \Lambda F \wedge$ & $99.991 \%$ & 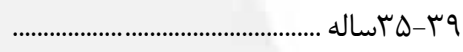 \\
\hline reV & reVA.1 & ITETIT & $V \cdot \wedge r I$ & FFq1Ir. & FqVTrTl & ................ \\
\hline raf & $|f| V \cdot r$ & $1 \cdot$ A & १^९५ळ & rVQD.rI & Fllftar & ( \\
\hline TFT & $\vee \Delta \Delta \wedge \Lambda$ & $V \Delta \Delta \wedge r$ & $1111 \ldots$ & rA.rIFe & $r \cdot V r r \Delta \Lambda$ & ........... \\
\hline TFV & FIGAF & DITH. & ITVATV & $r \cdot V \Delta \varphi q \Delta$ & $r r \cdot q r q \mu$ & .................. \\
\hline $1 \wedge \Delta$ & $r \cdot 994$ & $r 9 \Delta \cdot r$ & IrVIre & |rrq4iג & 10TVI99 & 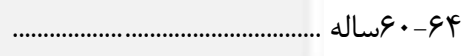 \\
\hline $9 \wedge \Delta$ & T.rIF & rVqA. & rG.rVA & $10 . r \wedge 9 T$ & 191KTFQ & هو ساله و بيشتر .......... \\
\hline$V \Delta \cdot F^{f}$ & $11 r \Delta \& 99 \mathrm{~V}$ & rrrraq & Ifrarr & IAFFaqTV & r.ferrig. & 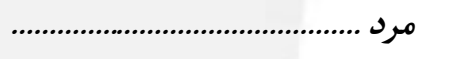 \\
\hline 1199 & rArrrq. & 1r\&9 & TFA & (5TrTr & TAVTATr & 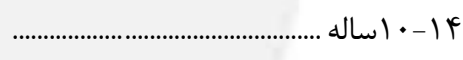 \\
\hline 111. & resprq. & INAT & $4 \& 1$ & $\Delta \wedge r \wedge \Lambda$ & TVYGITI & 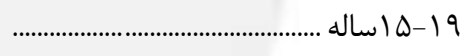 \\
\hline loVV & TQYYqTY & IrIVE & 919 & 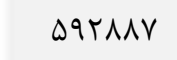 & MIFADGK & ץ \\
\hline IFDS & $1 \wedge F r \Delta \Delta D$ & FETID & TMVt & $r 119 \cdot r \mid$ & F. ITVrq & q \\
\hline qrq & $\Lambda F \vee \Delta \wedge \Delta$ & $\vee \& \wedge \Delta$. & rı.. & rTGGVqF & Fl90991 & 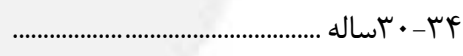 \\
\hline rar & rqvalr & VTrrq & FAND & $r \cdot r \wedge \mid F q$ & MFIFVFq & q \\
\hline rrq & $11111 \mathrm{~V}$ & $\Delta \mid \Delta \cdot 1$ & 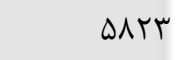 & TFETVGY & TETTETE & F \\
\hline $19 \mathrm{~V}$ & $\Delta 999$. & ґ৭৭५ळ & $111 \mathrm{~F}$ & TITYVYA & TYYYGDI & q \\
\hline$|F|$ & rqIVA & $r V F \cdot r$ & $1 \cdot \Delta \varphi \Delta$ & IEFYAGF & $|V| \cdot 10$. & F \\
\hline 1.9 & $I \Delta N \mid T$ & $19 \Delta V r$ & $\mid f \cdot a$ & $\mid r \Lambda \cdot \Lambda \Lambda \Delta$ & Irr.rAF & \\
\hline$\wedge \varepsilon$ & VETT & $11 \wedge \mathrm{V}$. & $\mid g F \Delta \Lambda$ & MArrqV & qT. FFT & 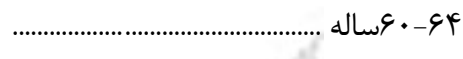 \\
\hline ו ו ו & $v q \cdot 1$ & ITEAV & $1 \cdot 1 \cdot 9$ & llfrk.. & IFFMFTD & ه9 ساله و بيشتر .. \\
\hline$f \cdot q 1$ & ATqTFTE & sFarA. & AVqqaf & $I V \Delta V T \cdot V r$ & rvrquara & زن .................................... \\
\hline rq1 & TV. TTVD & $\Delta V \&$ & 101 & MFG. F & $r V r \Lambda \cdot 11$ & ץ |- • اساله ..................... \\
\hline fis & T.GTDGV & $1 \cdot r \cdot a$ & $1 \cdot r \cdot$ & 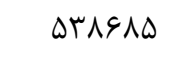 & TEIFITK & 19-19 اساله ....................... \\
\hline IMFF & $\mid$ |rMAYI & $r \cdot r \wedge \Lambda$ & prag & $19 V \cdot r 94$ & $r \cdot \Delta \Delta T H F$ & ץ \\
\hline DIT & $91) 9 \vee 9$ & $\Lambda \Delta F \Delta V$ & ITVqT & 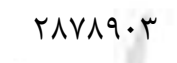 & rAQTTFQ & ............ \\
\hline trr & $q \cdot \Delta \Delta \cdot{ }^{4}$ & $|r \varepsilon \Delta| \Lambda$ & TVYQS & 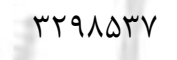 & $r \cdot \Delta \Lambda \& Y \Lambda$ & F \\
\hline$i \wedge V$ & $r$ ru.rt & $1109 \Delta T$ & $r \Delta \Delta q T$ & $r V \cdot r 999$ & riqmig4 & 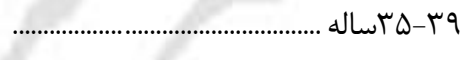 \\
\hline 111 & IDGSAF & NFVII & $90 \cdots 1$ & T. MERGG & $M T Y \cdot \Lambda \Lambda V$ & F \\
\hline ITV & $\Lambda \Delta \cdot 1 f$ & $8 \wedge \vee \cdot \wedge$ & $9 \cdot \Delta 11$ & IEFTYAS & IMAGG4S & (.............. \\
\hline $1 \cdot 1$ & reql. & $\forall \wedge 1 \wedge$. & $1 \cdot A r r \Delta$ & $119 \cdot r \wedge r$ & IrGTr. 1 & 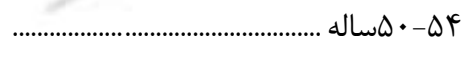 \\
\hline $1 \mathrm{r} \Lambda$ & TANVT & rISDV & ITHOHT & VqFAl. & $9 \vee 9 . .9$ & .......................... \\
\hline 99 & Irrmy & IVATE & $1 \pi \cdot 991$ & $\{\Delta \Delta \cdot r l$ & $9 \cdot 9 \vee \Delta G$ & 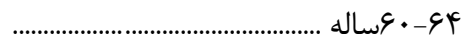 \\
\hline raF & ITFIT & IDTqT & TN. TVR & rq. 49 r & GSMNTF & ه9 ساله و بيشتر ......................... \\
\hline
\end{tabular}




\begin{tabular}{|c|c|c|c|c|c|c|}
\hline \multirow[b]{3}{*}{ اظهار نشده } & \multicolumn{5}{|c|}{ 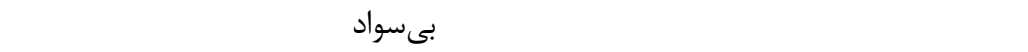 } & \multirow{3}{*}{ جنس و سن } \\
\hline & \multirow{2}{*}{ ازدواج نكرده } & \multicolumn{2}{|c|}{ بـ همسر } & \multirow[b]{2}{*}{ داراى همسر } & \multirow[b]{2}{*}{ 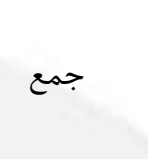 } & \\
\hline & & طلاقليل & بهدليل فوت & & & \\
\hline re & g.|ar| & arare & 1999911 & g|DAFAI & 1DAFARq & 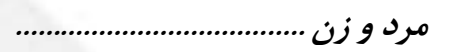 \\
\hline 199 & VID9V & ع & $1 \cdot 0$ & TFEF & verqu & | | - • اساله ........... \\
\hline IVT & $\Lambda \vee \Delta \vee \Delta$ & $r \cdot r$ & TTS & TVATE & 1191.1 & 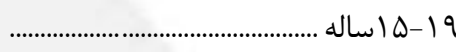 \\
\hline$M A$ & ヘ৭૬५V & IrFA & 949 & $991 \cdot 4$ & IAVqIT & F \\
\hline אזו & $\Lambda \Lambda \cdot r q$ & TFYA & 1999 & 199919 & $r q . r v q$ & 9r- \\
\hline IrA & $V D \cdot r T$ & $\Delta \Delta \|$ & FrAT & 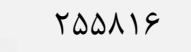 & TF.VEI & 1 • • \\
\hline 111 & $\Delta \wedge r \mid G$ & VVG. & $1 . F V T$ & rFqTFT & FrOA.r & q \\
\hline १V & $r \cdot v i r$ & 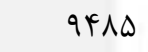 & TtMTE & 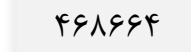 & $\Delta F I T \cdot Y$ & ......... \\
\hline 1.9 & ห৭४१९ & lIAMF & Ferıv & GTVEAS & VIDGTT & .................. \\
\hline IrA & 19994 & $119 v 9$ & NTtr & VrellV & $\Lambda \Delta \cdot 11 \mathrm{~V}$ & ................. \\
\hline Trt & $|F| r \mid$ & 11948 & IFTET & $\Lambda V T \Delta V$. & $1 \cdot \operatorname{tr} \mid 91$ & ............. \\
\hline 191 & q1rर & qFFs & $r \cdot V 99 V$ & VAVArt & $1 \cdot 1$ HAVF & 1......................... \\
\hline$\Lambda \cdot \Delta$ & ।V११९ & $194 \cdot V$ & $11 V 9914$ & IVTVAFT & 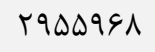 & 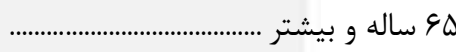 \\
\hline $1 \cdot F A$ & ravear & ralve & $|1| \ldots F$ & roqAFqI & rl.rrvi & 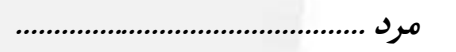 \\
\hline 119 & raDrd & (i) & rv & $V Q I$ & rGYAr & † ا- • اساله .......................... \\
\hline 119 & DrrGq & 99 & $\Delta 1$ & $\Delta r \cdot r$ & QV৭rی & 19-ها اساله ................ \\
\hline (re & $\Delta V D F q$ & Faq & IQF & $r \cdot q V V$ & $\wedge \wedge \vee \vee \Delta$ & ץ · • ז ساله .......................... \\
\hline 99 & 19190 & $|r v|$ & rq. & Vels. & ITVTIT & q......................... \\
\hline $1 \Delta$ & $r \Delta \cdot r \cdot$ & TIVTr & GTF & $1 \cdot r \wedge \Delta T$ & $\mid f \cdot V \Delta \Delta$ & 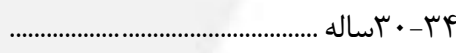 \\
\hline 91 & rTAKA & rघ91 & 1.99 & $I T \Lambda \Delta \Lambda \Lambda$ & IDQTVV & 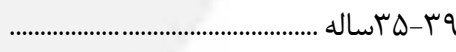 \\
\hline is & IrqVD & $r \Lambda \cdot F$ & 1911 & $19 \cdot r \cdot V$ & IVANFr & 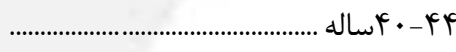 \\
\hline 4. & $99 \Delta 9$ & rq19 & $r \Delta \Delta q$ & $r \cdot \wedge १ ९ \Delta$ & TrFATq & $\ldots$ \\
\hline kr & GQFI & TDGA & THTK & $r \Delta \cdot r q 9$ & TERGAY & .............. \\
\hline r. & eVr. & TQVE & $V F \cdot q$ & TMTETT & rr⿲IV. & . \\
\hline rq & rive & rI. & IIAr & mIf.qI & TMITKA & 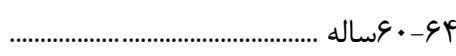 \\
\hline$r \cdot V$ & GVET & TIT & 101.19 & १९४।Vब & $119 \cdot f V V$ & 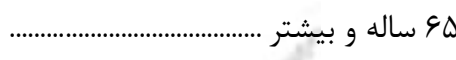 \\
\hline IrAD & $r \cdot r d \gamma q$ & evrr. & IDIAFVF & 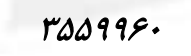 & $\Delta F \Delta \| G A$ & 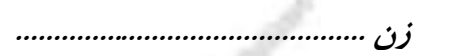 \\
\hline$\Delta \cdot$ & rG.GT & Tt & $9 \Lambda$ & IVIT & rVq1Q & † ا • • اساله ............................ \\
\hline Dr & $r \Delta T \cdot \varphi$ & $r \cdot V$ & IVF & TTOTH & $\Delta \Lambda \| \& T$ & 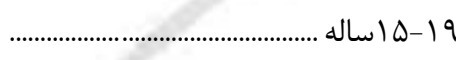 \\
\hline$\forall \wedge$ & rT.VA & $1 \wedge 9$ & 490 & GDSTV & १৭1\% & ץ \\
\hline rv & rAMFI & $r \cdot \Delta V$ & lQVG & $I T \cdot V \Delta S$ & IETYEV & q \\
\hline er & $r \cdots r$ & 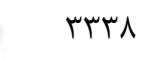 & rघQ9 & 10TQGr & $r \cdots q$ & 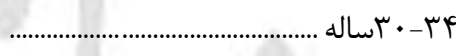 \\
\hline$\Delta \cdot$ & rorvi & 0.99 & $q \pi V r$ & $r T \cdot 9 \Delta \Delta$ & $T V \cdot \Delta T \Delta$ & 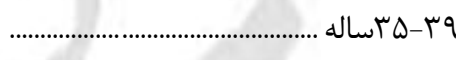 \\
\hline 01 & TEVTr & 9911 & $r \cdot V r \Delta$ & $r \cdot \Lambda T \Delta V$ & raTFGI & 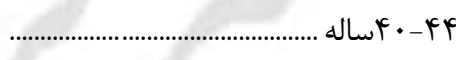 \\
\hline is & 1914. & $1 \wedge 91$ & FrATA & $\{|\wedge<q|$ & $1911 \cdot r$ & .............. \\
\hline$\wedge \Delta$ & TIMI & $94 \cdot 1$ & VV৭९9 & 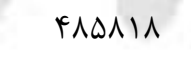 & DAGKr & 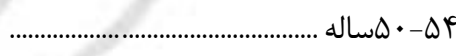 \\
\hline qT & १५१। & qसG & 1 IrG.rA & $\Delta F q \mid F \wedge$ & $V \cdot r \cdot r I$ & ساله $\Delta \Delta \Delta-\Delta 9$ \\
\hline Trt & $\Delta q \Delta F$ & VFFa & $19 \Delta \wedge V^{4}$ & FVMrel & GNTEYG & ץ \\
\hline$\Delta 9 \Lambda$ & 11rre & $1 f \cdot 9 f$ & $1 \cdot r \wedge \wedge 9 \Delta$ & $V 4.99 \Lambda$ & $|V q \Delta \& q|$ & له عاله و بيشتر ........ \\
\hline
\end{tabular}




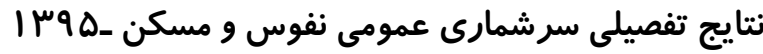

\begin{tabular}{|c|c|c|c|c|c|c|}
\hline \multicolumn{7}{|c|}{ سrr - 1 - جمعيت •ا ساله و بيشتر بر حسب جنس، سن، وضع سواد و وضع زناشويى (دنباله) } \\
\hline \multicolumn{6}{|c|}{ 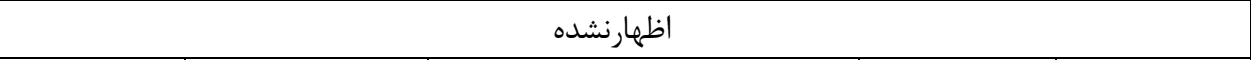 } & \multirow{3}{*}{ 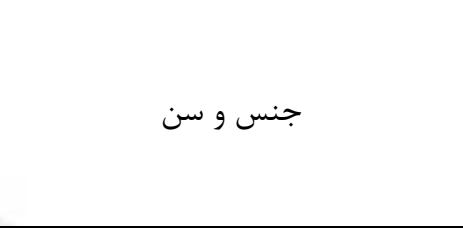 } \\
\hline \multirow[b]{2}{*}{ اظهار نشده } & \multirow{2}{*}{ ازدواج نكرده } & \multicolumn{2}{|c|}{ بى همسر } & \multirow[b]{2}{*}{ داراى همسر } & \multirow[b]{2}{*}{ جمع } & \\
\hline & & بلاقليل & بهدليل فوت & & & \\
\hline IrVar & revr & reI & rer & rerty & FIFAD & 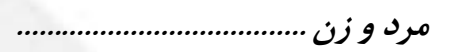 \\
\hline lNFa & 190 & · & 1 & 111 & rIAT & (اله \\
\hline 19148 & rqv & r & - & $r \Delta V$ & TEKT & 9-19 اساله ............................. \\
\hline$r \cdot \cdot 1$ & $\Lambda \cdot \Delta$ & ir & r & Ira. & fiv. & Fاله \\
\hline lQTrq & $\wedge ґ \wedge$ & rq & 4 & rIOA & $\Delta \Delta \mathrm{Q}$ & qra-................... \\
\hline ITTV & gVF & iq & it & r^৭V & $\Delta \wedge \Delta \varphi$ & 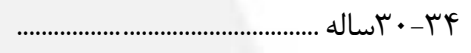 \\
\hline$q \cdot r$ & ґی) & rq & IV & TAFF & FMN & 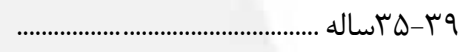 \\
\hline$\Delta 99$ & $|V|$ & ro & $r \cdot$ & r^q. & rघAT & 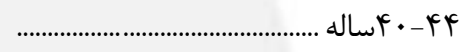 \\
\hline$\Delta \Delta T$ & $9 \Delta$ & r. & r & rFqD & rIqF & 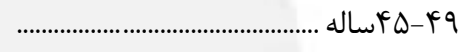 \\
\hline$\Delta \cdot r$ & iv & r^ & tr & $1 \wedge 95$ & TFqQ & (Dاله ........... \\
\hline 494 & rr & ir & il & 1499 & $r \cdot \cdot q$ & (1) \\
\hline fer & ir & V & $\Delta \Delta$ & $9 \wedge \mathrm{r}$ & $10 \cdots$ & ( \\
\hline IVTT & r & 1. & TQI & ITND & $r r \cdot 1$ & 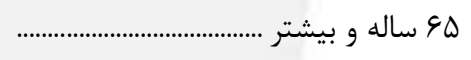 \\
\hline $14 r 9$ & rIAs & 1.9 & $1 \cdot f$ & $|f \lambda F|$ & $r v \cdot 11$ & 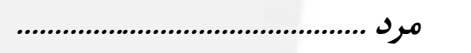 \\
\hline 1.49 & q4 & $\cdot$ & 1 & 9 & $111 \mathrm{~V}$ & 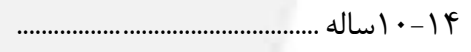 \\
\hline ITET & $r \cdot \Delta$ & • & $\cdot$ & $\Delta r$ & 1919 & 19-1 اساله ......... \\
\hline ITAT & Ver & r & r & $\Delta r \wedge$ & reTr & ץ \\
\hline $11 \cdot r$ & VVq & 19 & r & 1094 & reqF & a qra-ra............ \\
\hline 919 & srq & 11 & r & TFAV & $r \cdot r \Delta$ & 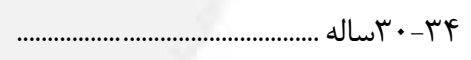 \\
\hline 994 & TYA & $r \cdot$ & 9 & rug & rrvv & q \\
\hline$r \cdot r$ & lar & 10 & 9 & $r \cdot r q$ & reוr & ........................ \\
\hline rAv & $\wedge r$ & 9 & $\wedge$ & IVG. & THEV & ........................................... d \\
\hline ris & rı & 10 & 9 & 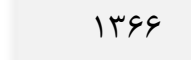 & IVF. & ........................ \\
\hline ras & 19 & $\checkmark$ & $\wedge$ & 1.01 & irی. & 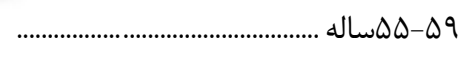 \\
\hline FFF & it & r & v & VTS & 995 & 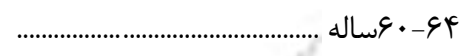 \\
\hline AFV & iv & r & $\Delta \Delta$ & $91 \mathrm{~V}$ & $M k$. & ه هاله و بيشتر ........ \\
\hline (9q1r & FAF & irt & raq & AFAS & IFrVF & زن ................................ \\
\hline V99 & $|r|$ & $\cdot$ & $\cdot$ & $1 \cdot 0$ & $1 . r \Delta$ & 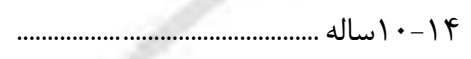 \\
\hline VTF & 94 & r & $\cdot$ & $t \cdot \Delta$ & $1 \cdot r \pi$ & 19-1 ا ساله .............. \\
\hline$q 4 q$ & gr & 1. & . & 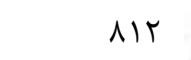 & lorr & (Tاله \\
\hline (t) & $\Delta 9$ & ir & r & $109 \Delta$ & $r \cdot v q$ & q و \\
\hline$r \cdot \Lambda$ & is & r^ & 1. & lfF. & $|\wedge r|$ & 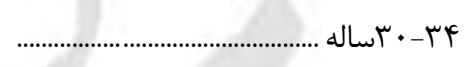 \\
\hline rra & 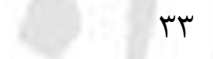 & 19 & 11 & $I r \cdot \Delta$ & $10 \cdot 9$ & q \\
\hline 194 & IV & $r \cdot$ & If & $\Lambda \Delta F$ & 1.99 & 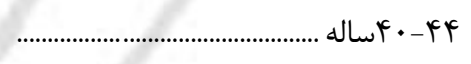 \\
\hline 199 & it & 11 & r & Vra & $q \uparrow V$ & ......................... \\
\hline IAV & 9 & ir & rl & DrG & $V \Delta S$ & 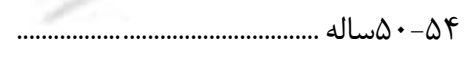 \\
\hline 191 & $\checkmark$ & 4 & זr & fid & sтq & 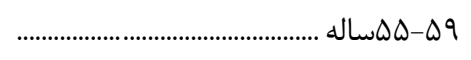 \\
\hline 199 & 1 & r & is & $r \Delta S$ & $\Delta \cdot \Lambda$ & ץ \\
\hline$\Lambda \vee \Delta$ & 19 & 4 & 199 & 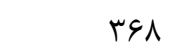 & $|f \&|$ & 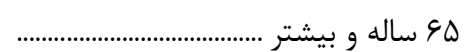 \\
\hline
\end{tabular}




\begin{tabular}{|c|c|c|c|c|c|c|}
\hline \multicolumn{2}{|l|}{ 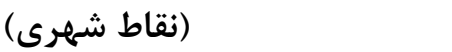 } & \multicolumn{5}{|c|}{ rr - 1 - جمعيت +1 ساله و بيشتر بر حسب جنس، سن، وضع سواد و وضع زناشويى (دنباله) } \\
\hline \multicolumn{6}{|c|}{ با سواد } & \multirow{3}{*}{ 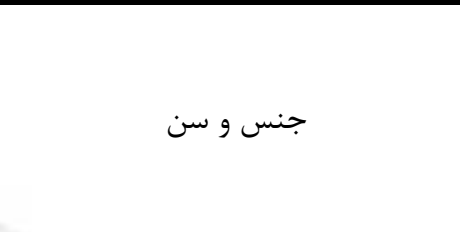 } \\
\hline \multirow[b]{2}{*}{ 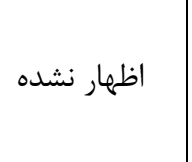 } & \multirow{2}{*}{ ازدواج نكرده } & \multicolumn{2}{|c|}{ بى همسر } & \multirow[b]{2}{*}{ داراى همسر } & \multirow[b]{2}{*}{ جمع } & \\
\hline & & بلاق & بهدليل فوت & & & \\
\hline arat & $\mid F V \cdot 9991$ & AMFila & $9 \cdot \Delta \varepsilon$. & rarfarge & FFAFqADF & 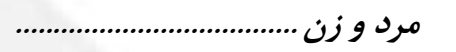 \\
\hline $114 \lambda$ & 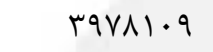 & $11 \cdot 0$ & rut & rvir. & F. IVArg & 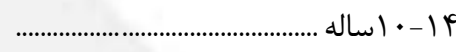 \\
\hline 1111 & raTsVa. & $\checkmark \wedge \Delta V$ & AVT & TDST. D & 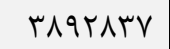 & 9 | 19 اساله .......................... \\
\hline TQT. & $r q \cdot V r q \Lambda$ & 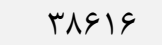 & rTh. & IQT०৭१V & FYAVG9I & 1................ \\
\hline lark & rlQ999F & 1. DAGY & 1. TFT & $r G \Lambda \cdot \Lambda F q$ & $\Delta q \Delta \Delta \Delta V V$ & qז-מ ساله ......................... \\
\hline VT. & $\|V \Delta\| \Delta F$ & $\mid V F \cdot . q$ & grmז & $\Delta \cdot \Lambda \wedge \& T V$ & GFGINAG & ץ · •rاساله ........................ \\
\hline DIT & $49 \Delta 91$. & $\mid 9 \times 941$ & rAVIS & fүqтqтя & DI $949 \wedge \Delta$ & q \\
\hline TVT & $r .9499$ & $1 T \cdot 99 T$ & $\Delta 919 \pi$ & TOHANFT & TqTDFTG & 1................. \\
\hline TrQ & IIVIAT & 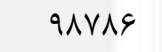 & 11991 & T. DFVET & THATAEV & a................ \\
\hline$r \cdot \Lambda$ & GGFTt & $V \cdot v q$ & 1. & rmptil & rAVVFTs & 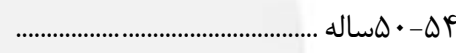 \\
\hline$r \cdot \varphi$ & $r \vee q \Delta \Delta$ & $r \wedge 1 \cdot r$ & $\mid \pi r \cdot \Delta \Delta$ & IVDAIT. & I9EVFFA & .............. \\
\hline$|f|$ & $19 \Delta \Delta F$ & rVq.q & $|r \Delta| \cdot \mid$ & ||$\Delta F q \& \mid$ & IrTVGGS & 1............... \\
\hline$\Delta F r$ & $191 V 8$ & reVIT & TrFIVV & $1 r \cdot \wedge q 4$. & $19 \wedge 9 \Delta \& 9$ & ه 9 ساله و بيشتر .. \\
\hline arar & Arefr.f & rivras & ITrADF & |fFeVII. & rrervarq & 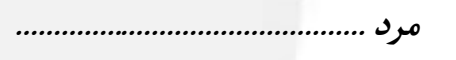 \\
\hline$\wedge \vee 1$ & T.rTVYF & VAT & rtq & $r \mid r \cdot \Delta$ & $r \cdot \Delta \Delta ৭ 9 r$ & 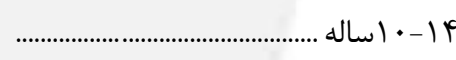 \\
\hline$\vee \wedge \Delta$ & I ITrDSV & 1119 & ५৭१ & Trork & 19६948人 & 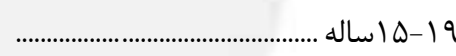 \\
\hline$I T \Delta \Delta$ & $1 \wedge r \Delta \Delta q$. & NFEs & $\Delta \vee q$ & rgAFIV & TTIFTAG & Y \\
\hline 1111 & $|F T| \Delta V \mid$ & $r \Delta q \cdot r$ & lkq & Ifqgrth & 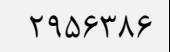 & qr \\
\hline$\Delta I T$ & $99 \Delta V q F$ & $q 49 \Delta q$ & 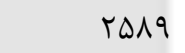 & $r F \Lambda \cdot G \cdot q$ & TTFTEGT & 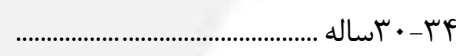 \\
\hline rVV & TFVATD & G19VD & $r \Delta \cdot r$ & rrmvavt & rEDITLT & 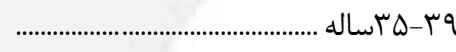 \\
\hline IAr & $q r \Delta \wedge \Lambda$ & FFF. 9 & FrAT & $19 \cdot \Delta V \Delta \Delta \Delta$ & T. YATIV & ץ - • • \\
\hline 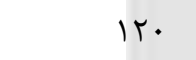 & farks & rofqV & 9499 & 19qrVVq & IVAFqFi & a......................... \\
\hline 119 & TEIFF & TFAGA & ^EQT & ITFMNAD & $\mid f \cdot$ ragh & 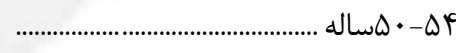 \\
\hline$\wedge \varepsilon$ & IFrut & IVqF. & 11999 & $1.9 \cdot \Delta 9 F$ & $11.49 \Delta R$ & 9 \\
\hline$\Delta \Delta$ & 999. & $11 \cdots r$ & $|4| r q$ & $V \notin \notin 91 D$ & VYAVqI & 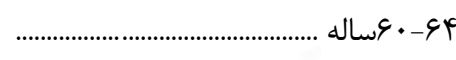 \\
\hline rFq & VTrI & $111 F A$ & $9 \wedge 1 .$. & १УА५. & 1.994T1 & 9 ساله و بيشتر ........ \\
\hline rFAq & srearar & DSEATV & $r r \mu_{1} . q$ & IrAYASAS & rlarrr.a & زن ............. \\
\hline TVV & I IFATND & TFT & $1 \cdot 0$ & IDVTD & 19911/rF & † | • اساله ......................... \\
\hline TrA & IDQTTYT & $99 \vee \Lambda$ & $\Delta V r$ & TMTGSV & 19rrtsq & 19-ه اساله ................ \\
\hline ITVD & $1 \cdot V I \& \vee \wedge$ & $r \cdot|V|$ & $r V \cdot I$ & $119 \vee \Delta \Lambda$. & THYTH.D & ץ \\
\hline Far & VTAFT & 99909 & $\wedge \vee \Delta$. & TINFE. & र999191 & qז-د ساله ............... \\
\hline$r \cdot \Lambda$ & fVqug. & $11 \cdots+v$ & $r \cdot V F \cdot$ & $r G \cdot \Lambda \cdot r \Lambda$ & TMTAKT & ................. \\
\hline Iro & $r F \Lambda \cdot \Lambda \Delta$ & 1. rq49 & TATIT & 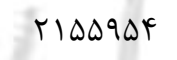 & TQFTHT & 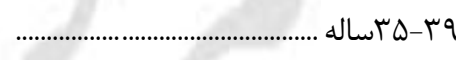 \\
\hline 19 & $\| \Delta \wedge \vee \wedge$ & VATAT & 01911 & $1 \& \mu r \cdot 11$ & IAVVYIQ & f \\
\hline $1 \cdot 0$ & $q \vee q \cdot V$ & GTr人q & VDGGY & IrG.9G & logVqTg & q \\
\hline 19 & $r \cdot r \wedge \Lambda$ & $F \Delta T \cdot \Lambda$ & quetr & 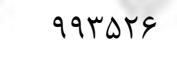 & $\| V r V \Delta \Lambda$ & 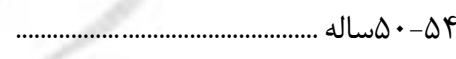 \\
\hline $1 T$ & TrGTI & $r \cdot 19 r$ & $111 r \Delta 9$ & sqVQTS & 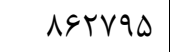 & 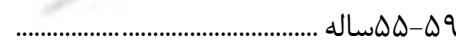 \\
\hline$\wedge \varphi$ & IrDGY & $199 \cdot V$ & $11 \cdot 9 V r$ & F.人rks & DFMAVD & ب. \\
\hline rq4 & 11940 & $\mid F \wedge \varepsilon D$ & reDrVV & $r r \cdot q r V$ & GTrII1 & له ساله و بيشتر ................. \\
\hline
\end{tabular}




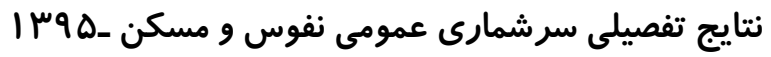

(نقاط شهرى)

r T - 1 - جمعيت •ا ساله و بيشتر بر حسب جنس، سن، وضع سواد و وضع زناشويى (دنباله)

\begin{tabular}{|c|c|c|c|c|c|c|}
\hline \multicolumn{6}{|c|}{ بىسواد } & \multirow{3}{*}{ جنس و سن } \\
\hline \multirow[b]{2}{*}{ اظهار نشده } & \multirow{2}{*}{ ازدواج نكرده } & \multicolumn{2}{|c|}{ بي همسر } & \multirow[b]{2}{*}{ داراى همسر } & \multirow[b]{2}{*}{ جمع } & \\
\hline & & بلاق & بهدليل فوت & & & \\
\hline ITFT & r.virq & $\Delta 9 \Delta \cdot 1$ & 1. vrres & rrvpreq & rvivar. & 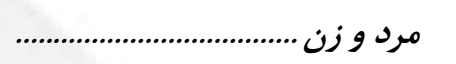 \\
\hline vi & raVAv & r & $\Delta \Delta$ & १४Q & एद्वा & 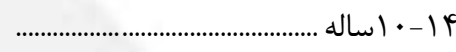 \\
\hline GV & FrqDQ & IOT & 99 & ITEKT & $\Delta \Delta q \mid r$ & 19-1 اساله . \\
\hline vr & FFI qR & G9T & TVV & FFqRT & $9.1 \vee 9$ & •r. \\
\hline 4. & freqf & 1119 & ATV & qrrq. & $\mid f \cdot V \Delta V$ & q \\
\hline$\Delta \varphi$ & ґА৭८ґ & rQDI & MKT & llvk49 & $191 \% 91$ & (...................... \\
\hline$\Delta F$ & 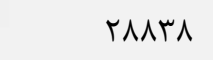 & FTFT & FAFS & IQVIAV & I9FA૬V & q \\
\hline rᄉ & $r \cdot r \Delta \Lambda$ & $\Delta \& 1$. & 1.909 & THESTE & rQ৭9१ו & 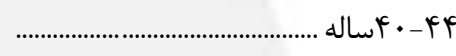 \\
\hline$\Delta \cdot$ & 1094. & VEQT & rڤG.. & $r T \Delta \Lambda \Delta \Delta$ & $r V \Delta \cdot \wedge q$ & ................... \\
\hline$\vee \wedge$ & $111 r \Delta$ & 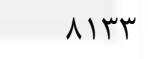 & FA૬ヘT & f.rqqu & FV|99। & ............. . . \\
\hline 99 & (TוK & 1148 & ^९999 & FATVDD & $\Delta \wedge \Delta \wedge \vee q$ & ............. \\
\hline 94 & DTAV & 49.1 & IrAGKY & $|F| \cdot|q|$ & $\Delta \wedge I V \Delta \Delta$ & 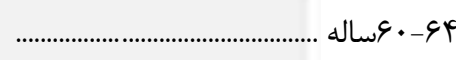 \\
\hline 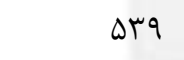 & 1.990 & $\mid r \Delta \|$ & VEFITE & qufreq & IVGrr.r. & 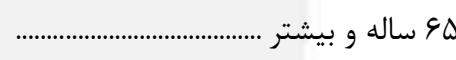 \\
\hline a11 & iefirt & losVr & 99997 & Ireraq. & Ieffigf & 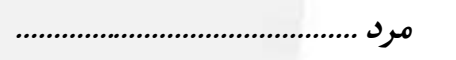 \\
\hline er & $1 \Lambda \cdot \Delta \Lambda$ & 19 & 11 & r\&q & $\mid N F \cdot F$ & 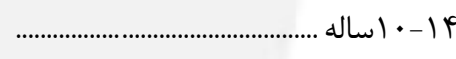 \\
\hline $4 q$ & rVI.. & Qr & IV & rQVe & rqvqp & 9 1 اساله ................................ \\
\hline$\Delta F$ & rq१९V & TFE & q & $\mid F V G \Lambda$ & frqq1 & Y \\
\hline iv & r\&q\& & VAv & lQS & TVYFI & 90194 & q...................... \\
\hline kr & $r \cdot \wedge V F^{q}$ & $|\pi| 9$ & $r \Delta q$ & pqsir & $V T \cdot \Delta$ & ........................ \\
\hline r & IrGTE & 1011 & r91 & $\Delta \Lambda \Lambda \Delta r$ & VEFTE & 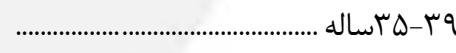 \\
\hline rl & AFAr & $191 \mathrm{~V}$ & GVD & VATYM & 19119 & 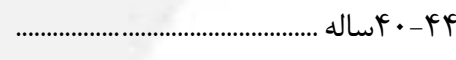 \\
\hline r & G५99 & 1941 & אזrו & 1. ब9Ar & IIDFDA & 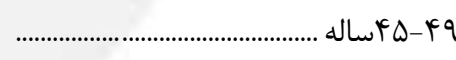 \\
\hline r & $f \backslash \wedge \Delta$ & $|q 4|$ & TTED & Tht & IFIDTE & 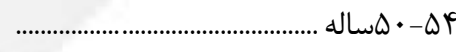 \\
\hline r. & r৭९9 & IVID & rAFA & IVIध9T & MA.TET & $\ldots$ \\
\hline 19 & 1909 & ler. & $99 .$. & $I V \cdot \Lambda \Lambda \Delta$ & $1 \Lambda \cdot \wedge \Lambda V$ & 1.................... \\
\hline Trt & rVVe & rrqf & NFFAD & DFTHAF & GMQIFI & له ساله و بيشتر .................. \\
\hline vrr & $1 \mathrm{kr} . . \mathrm{g}$ & requa & grerper & $191 r \pi \mid s$ & $r \cdot v r r r g$ & 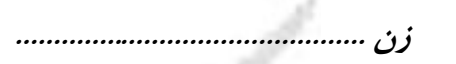 \\
\hline$r \wedge$ & IVVrq & $v$ & rV & $V \cdot q$ & $1 \Lambda \Delta \cdot V$ & 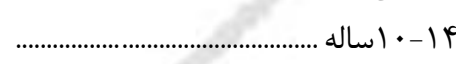 \\
\hline 11 & $1 \Delta \wedge \Delta Q$ & $1 \cdots$ & vq & 1.949 & r9119 & 19 \\
\hline 11 & IFres & Fis & rIf & $r \cdot r \cdot r$ & FUIVA & 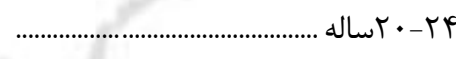 \\
\hline ir & $|V V M|$ & $1 \cdot r q$ & sVI & 09119 & $V \Delta \Delta G T$ & q........... \\
\hline Ir & $111 \cdot 9$ & IVTD & $1 \Delta \wedge \mu$ & GVADH & ᄉ9५ & ץ \\
\hline r & $\mid \Delta T I T$ & TVTF & fifN & QATrF & $|r \cdot F F|$ & q qra- \\
\hline iv & $\| \wedge \vee \Delta$ & 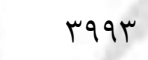 & $1 \cdot r \wedge F$ & IFVRT & IVTEqT & 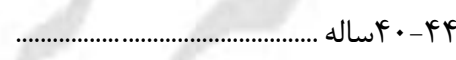 \\
\hline 11 & 9991 & $\Delta V I r$ & TEREV & rIQAvr & TQQЯTा & ......................................... \\
\hline$\Delta \Delta$ & q94. & grar & faptr & $r V \cdot \Delta 11$ & rrekt & (سلماله \\
\hline is & DTFV & gसr & $\Lambda T \wedge \Delta I$ & r11.9r & $r \cdot \Delta q r V$ & 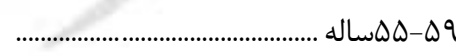 \\
\hline ve & 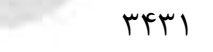 & DIVI & ITt.rF & $r V \cdot I \Delta G$ & $\uparrow \cdot \bullet \wedge \uparrow \wedge$ & 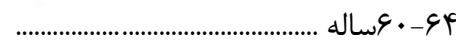 \\
\hline$r \cdot v$ & 9119 & $1.11 \mathrm{~V}$ & sV৭\&४q & Fाl11. & IITAIET & له ساله و بيشتر ................. \\
\hline
\end{tabular}




\begin{tabular}{|c|c|c|c|c|c|c|}
\hline \multicolumn{2}{|l|}{ 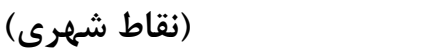 } & \multicolumn{5}{|c|}{ rr - 1 - جمعيت +1 ساله و بيشتر بر حسب جنس، سن، وضع سواد و وضع زناشويى (دنباله) } \\
\hline \multicolumn{6}{|c|}{ 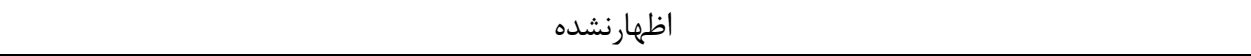 } & \multirow{3}{*}{ 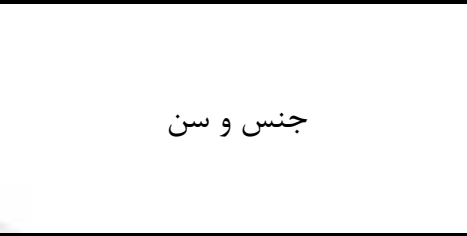 } \\
\hline \multirow[b]{2}{*}{ 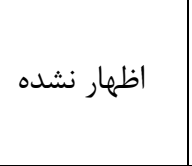 } & \multirow{2}{*}{ ازدواج نكرده } & \multicolumn{2}{|c|}{ بى همسر } & \multirow[b]{2}{*}{ 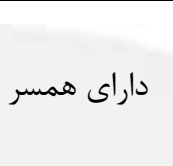 } & \multirow[b]{2}{*}{ جمع } & \\
\hline & & بلاق & بهدليل فوت & & & \\
\hline $1 \ldots 9$ & rraq & irr & rat & IVAra & rllab & مرد و زن .................. \\
\hline IrAs & Ir人 & • & $\cdot$ & AT & $10 \cdot 9$ & (اله \\
\hline IFrq & rif & 1 & $\cdot$ & lfF & $\ \wedge \Lambda \wedge$ & 19-19 ا ساله ...................... \\
\hline $1 F \wedge \Delta$ & 9ाr & $\Delta$ & r & १९। & $r .99$ & F \\
\hline 1110 & $9 \Delta \Delta$ & $r \cdot$ & r & TFMA & FrA. & 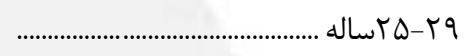 \\
\hline १५^ & 491 & ry & f & $r \cdot 9 \Lambda$ & FaVT & F \\
\hline $9 V F^{F}$ & tAT & rT & 11 & TVT. & PYI9 & 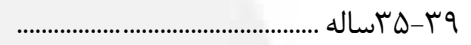 \\
\hline Frt & 149 & $r \Delta$ & 19 & TrES & rArq & 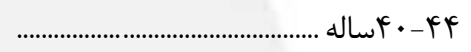 \\
\hline pry & vr & 19 & r & ।८৭V & TEAT & ......................... \\
\hline rVA & ऍی & rI & $r \cdot$ & lfar & 1919 & ............ \\
\hline ra. & 11 & 11 & rV & 1.19 & $1 \mp \wedge \Delta$ & $\ldots$ \\
\hline rrg & it & f & is & vrq & $11 \pi v$ & 1........................... \\
\hline 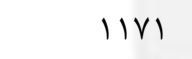 & 19 & $\wedge$ & $r \cdot 1$ & 914 & rII & 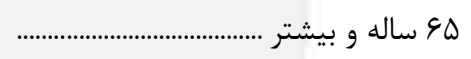 \\
\hline spep & rere & $1 r$ & $r a$ & l1req & r.rir & 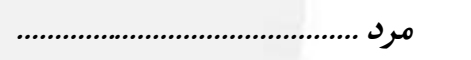 \\
\hline Vre & DI & . & · & r & vq. & 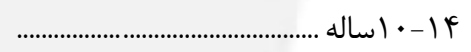 \\
\hline 19т & TFF & . & . & re & $11 \mathrm{Vr}$ & 9 19 ا ساله ............ \\
\hline १४. & $\Delta \& \Lambda$ & • & r & ґی) & 1941 & .................... \\
\hline จ१^ & 9.9 & $1 \cdot$ & r & $\mid r \cdot 1$ & rat. & ..................... \\
\hline 999 & 494 & it & 1 & 194. & $\mathrm{~m} 11$ & ( \\
\hline$\Delta \cdot \Delta$ & TQS & 19 & $\Delta$ & IVVF & $r \Delta \Delta \varphi$ & q q \\
\hline$r \cdot \Delta$ & 119 & r & r & IOVT & $r \cdot 1 \cdot$ & ........................ \\
\hline rit & 90 & $\wedge$ & $\Delta$ & $1 r \cdot 1$ & 1991 & ........... \\
\hline KYI & r & ז & r & $1 \cdot \Delta r$ & $|r|$ & 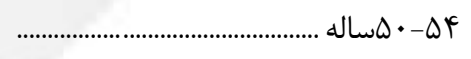 \\
\hline rme & 11 & $\checkmark$ & $v$ & vVV & 1.48 & ............. \\
\hline 194 & 11 & 1 & $v$ & $\Delta F$. & VQT & .................. \\
\hline$\Delta \vee q$ & 1. & r & et & q94 & $1 \% 91$ & 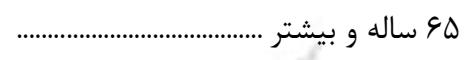 \\
\hline rafa & ral & qf & $r v e$ & sarq & $1 \cdot 1 \mathrm{Fr}$ & 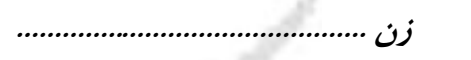 \\
\hline$\Delta \Delta \cdot$ & $\wedge \vee$ & · & $\cdot$ & v9 & vis & ץ \\
\hline QTV & v. & 1 & $\cdot$ & $1 \cdot 1$ & Vis & 19 اساله ............................ \\
\hline$\Delta / \Delta$ & $F \Delta$ & $\Delta$ & $\cdot$ & $\Delta \Lambda \cdot$ & $114 \Delta$ & ץ • \\
\hline riv & is & $1 \cdot$ & $\cdot$ & ITAV & 199. & 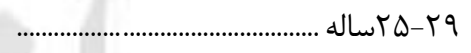 \\
\hline rq & rT & tr & r & 1101 & lFat & 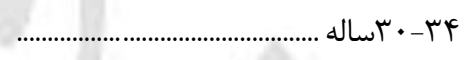 \\
\hline 199 & re & 19 & 4 & $9 \uparrow 9$ & 1194 & q q-a \\
\hline 111 & ז & it & it & gVF & 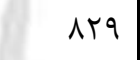 & ................ \\
\hline ITT & $\wedge$ & $\wedge$ & 11 & $\Delta \wedge 9$ & $v \notin \Delta$ & ......... . . \\
\hline irv & v & $\wedge$ & iv & $4 \cdot q$ & $\Delta \vee \wedge$ & 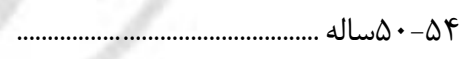 \\
\hline 119 & v & f & r. & $r \cdot r$ & pqq & 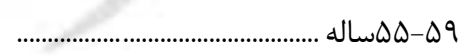 \\
\hline 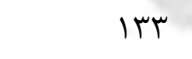 & 1 & r & rq & 199 & rVQ & ץ • • \\
\hline$\Delta 9 T$ & 9 & $\Delta$ & 109 & rFA & $1 \cdot 1 \pi$ & 9 ساله و بيشتر .......... \\
\hline
\end{tabular}


نتايج تفصيلى سرشمارى عمومى نفوس و مسكن _هوس |

\begin{tabular}{|c|c|c|c|c|c|c|}
\hline \multirow[b]{3}{*}{ اظهار نشده } & \multicolumn{5}{|c|}{ 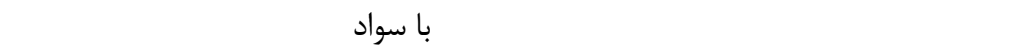 } & \multirow{3}{*}{ جنس و سن } \\
\hline & \multirow{2}{*}{ ازدواج نكرده } & \multicolumn{2}{|c|}{ بى همسر } & \multirow[b]{2}{*}{ داراى همسر } & \multirow[b]{2}{*}{ جمع } & \\
\hline & & طلاقليل & بلهدليل فوت & & & \\
\hline rra. & FArggrt & Irfedr & irgior & VAGITEA & IrqaIrve & 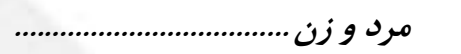 \\
\hline qrq & $\mid \Delta \Delta \vee \wedge G F$ & $\vee r \wedge$ & 191 & MIDS & $1 \Delta q \cdot r \xi \Delta$ & ץ \\
\hline fre & $119 \vee 9 \vee 1$ & fFi. & $q \cdot V$ & $r F \cdot r \Delta \varphi$ & IFFr人q1 & 9-19 اساله ......... \\
\hline r^. & 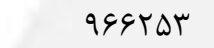 & $\mid r \cdot r \Lambda$ & $r \cdot V r$ & VTGTAT & $I V \cdot q \cdot r V$ & 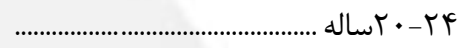 \\
\hline rta & DQqFYF & $r \Delta \wedge \wedge F$ & $p q \mid f$ & ITIOHDq & $194 \Delta 9 \cdot 9$ & q \\
\hline IN & trVire & rqur) & $\Lambda T \Delta \cdot$ & IFVFV. & ।V^৭ৎ^• & (r • • \\
\hline 149 & $1 \% q 9 \cdot r$ & r... r & ||$V \mid$ & IrFDq\&q & $|f| \cdot V$ rg & q ץ-טساله ........ \\
\hline vf & $\Delta \wedge r \cdot I$ & $\mid \Delta F \wedge \Delta$ & $|f Q| f$ & 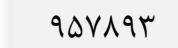 & 1. f\&YGV & 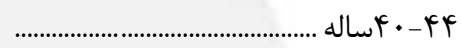 \\
\hline q & TFa. I & 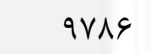 & 1994. & $V \cdot 9141$ & $V G \cdot|r|$ & (1) \\
\hline سץ & 91 Tr & $\Delta F E F$ & IDFVT & $r \varepsilon \Delta \cdot 9 r$ & Fq019V & 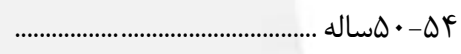 \\
\hline rq & mVII & $r \cdot 9 \Lambda$ & IfFer & rIVII & THATt & \\
\hline pr & $\mid f \cdot r$ & $1 \Delta \vee q$ & $\mid r \cdots \wedge$ & INFTMN & 1997V1 & 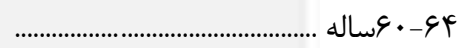 \\
\hline 149 & $11 \pi$. & $I T \Delta \Delta$ & TEIVG & 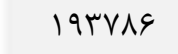 & THTYAS & 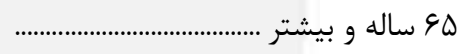 \\
\hline$|q V|$ & TANFDQF & $\Delta \Delta q q F$ & raras & fivrreq & virqq.f & 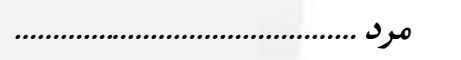 \\
\hline rt. & $\Lambda \cdot r \& V R$ & $\Delta \cdot r$ & 110 & Irrqr & $\wedge 1 \Delta q \cdot \Delta$ & 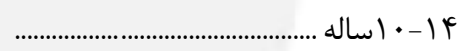 \\
\hline r19 & VY^११९ & $V \cdot r$ & 191 & rfsqs & VDFV१D & 19-19 اساله .......... \\
\hline M la & $V \cdot r T \Delta$ & TVTV & $r \cdot 1$ & tTRITI & 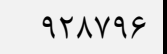 & Fץ - • اساله ........ \\
\hline r६q & $F r \cdot G V q$ & 1.rar & $\wedge \vee \wedge$ & Gr।qV. & $1 \cdot \Delta F \backslash \wedge \Lambda$ & q \\
\hline r & $|D| T \& \Lambda$ & ITASV & $1 T \cdot 9$ & $\vee \wedge \Delta|\&|$ & $9 \Delta \cdot 9 r \Delta$ & ץ \\
\hline NT & $\Delta \cdot \mid \Delta \Lambda$ & I.r. & Irat & $999 \cdot \Delta F$ & $V 9.999$ & q \\
\hline is & $I V F \Delta D$ & $V \cdot r \Delta$ & IDTF & $\Delta \Delta V I \& T$ & DATTYT & 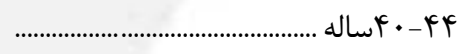 \\
\hline pq & $V k \cdot r$ & FrVA & $1 \vee 99$ & FTAT. T & FFINTE & \\
\hline rI & $r \cdot 10$ & tFqu & $19 \ldots$ & 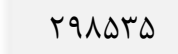 & $r \cdot \Delta 994$ & •- $\cdot \Delta f$ \\
\hline tr & IfGF & $19 \cdot 9$ & rtqk & r।99я & rTAKFq & 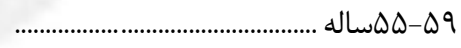 \\
\hline rq & sTd & NQT & trte & $|r V 9| 1$ & IFIFFV & ع \\
\hline$\wedge 1$ & qqu & ATV & $11 r \wedge 9$ & $\mid 9 r q 91$ & IVGATI & هاله و سيشتر .............. \\
\hline $9 \cdot 9$ & IqFr.VA & virsa & $1 \cdot|19|$ & rqsiarg & $\Delta A / I F V r$ & زن .................. \\
\hline 119 & $V \Delta \Delta 191$ & trit & س & MAR & VYFis. & 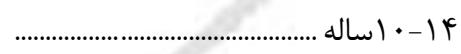 \\
\hline 110 & $\varphi q q \cdot \Delta \Delta$ & rVTV & fFE & rIQVG. & 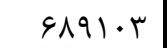 & 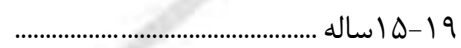 \\
\hline 90 & rGG. rA & |.rII & 1990 & $\Delta \cdot r \mid G r$ & $V \Lambda \cdot r M_{1}$ & F \\
\hline$\Delta \varphi$ & $I V \wedge V{ }^{E} \Delta$ & IDFqT & f.re & яqтr^q & 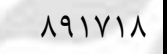 & q \\
\hline c. & $\mid r \Delta \wedge \varepsilon \wedge$ & lefor & $V \cdot r f$ & घ人৭\&૫৭ & $\wedge r q \cdot \Delta \Delta$ & F \\
\hline pr & VqVid & Irsq4 & $1.4 \% 9$ & $\Delta r \& q 1 \Delta$ & sqqrV. & 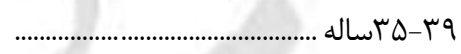 \\
\hline$r \Lambda$ & $F \cdot V F q$ & $\Lambda F \Delta$. & $1 \pi \cdot q \cdot$ & $f \cdots r^{\mu l}$ & $\forall \notin r \cdot r \Delta$ & 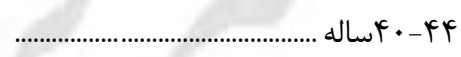 \\
\hline 19 & $18 \cdot 91$ & $\Delta F \cdot \Lambda$ & $|F| F \mid$ & rA. qrq & rIAT9D & ......... \\
\hline ir & 9119 & ravi & Irovr & $199 \Delta \Delta \Lambda$ & 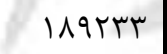 & 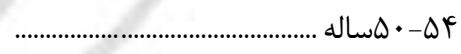 \\
\hline IV & THFV & Ifqr & $|r| 99$ & $q \vee \backslash 4 \wedge$ & Mr & .......... \\
\hline Ir & $V \& 9$ & VTV & $9 \hookrightarrow \wedge \Lambda$ & FGaTV & DVATF & ع. \\
\hline$\Delta \wedge$ & reV & FrA & IFAAV & rqATd & 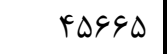 & 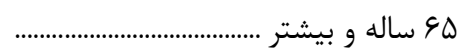 \\
\hline
\end{tabular}




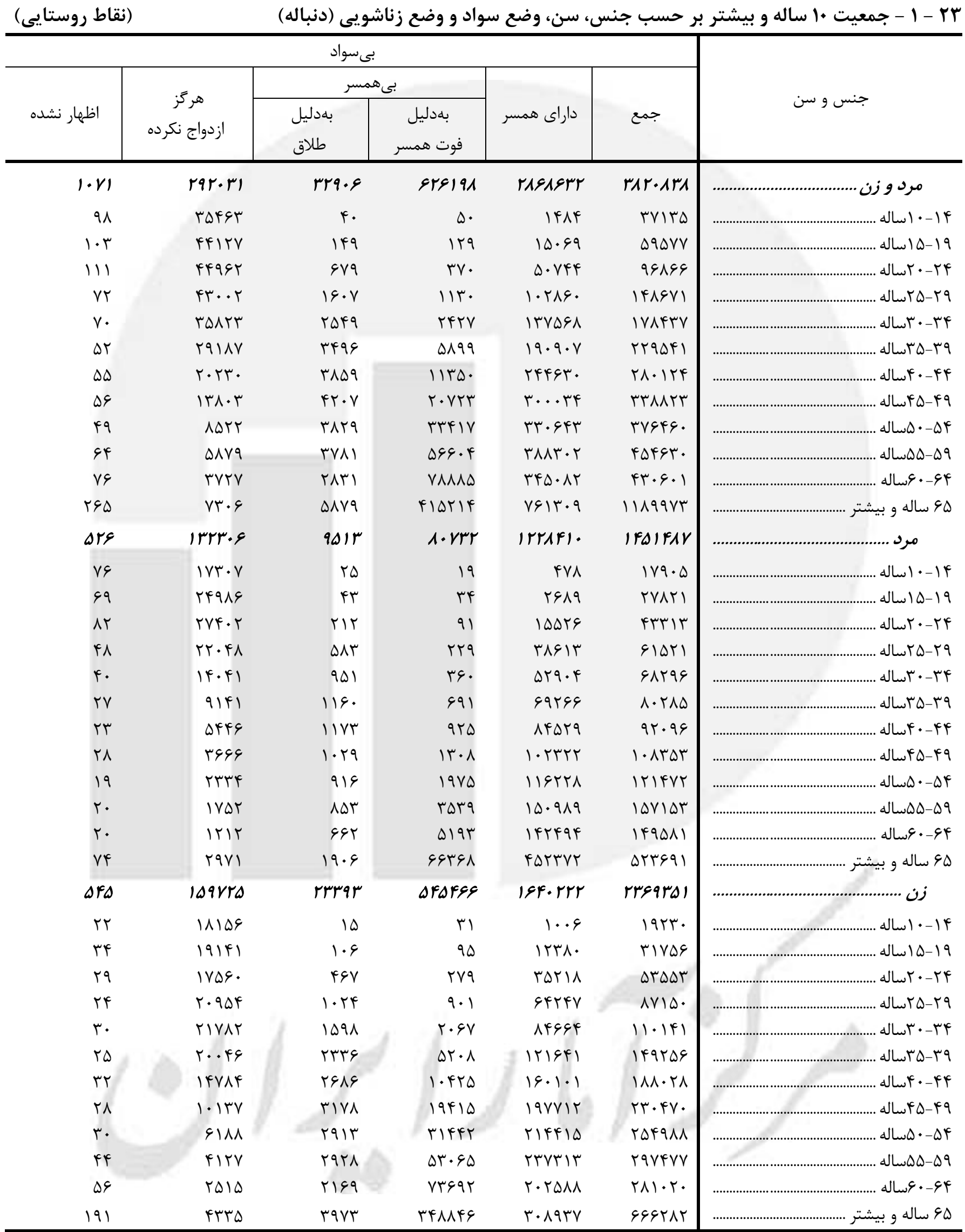


| نقايج تفصيلى سرشمارى عمومى نفوس و مسكن _ه |

\begin{tabular}{|c|c|c|c|c|c|c|}
\hline \multicolumn{6}{|c|}{ 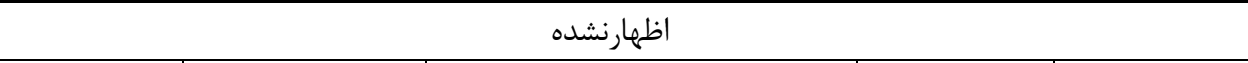 } & \multirow{3}{*}{ جنس و سن } \\
\hline \multirow[b]{2}{*}{ اظهار نشده } & \multirow{2}{*}{ ازدواج نكرده } & \multicolumn{2}{|c|}{ بي همسر } & \multirow[b]{2}{*}{ داراى همسر } & \multirow[b]{2}{*}{ 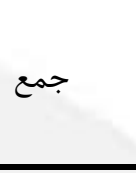 } & \\
\hline & & بلاقليل & بهدليل فوت & & & \\
\hline r\&s. & Ara & ef & 11. & DFVA & $1 \cdot r \cdot F$ & 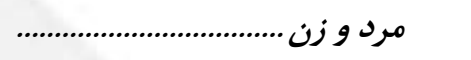 \\
\hline$\Delta \Delta V$ & $\Delta \Delta$ & . & 1 & rq & GKT & 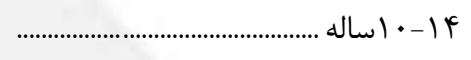 \\
\hline$\Delta \Delta T$ & V9 & 1 & $\cdot$ & $11 \pi$ & $v \notin \Delta$ & 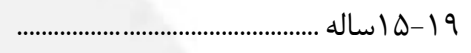 \\
\hline$\Delta \cdot \Lambda$ & 191 & $\checkmark$ & $\cdot$ & ऍА૬ & 1.95 & .......................... \\
\hline 4iA & lیr & 9 & r & 991 & $|r \wedge|$ & 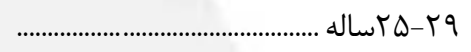 \\
\hline rAr & IVE & it & $\wedge$ & v१v & irvV & 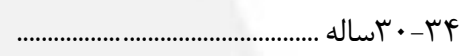 \\
\hline rTI & 99 & V & 4 & AIV & $110 \cdot$ & q \\
\hline irv & ET & 1 . & f & gRt & $\Delta \mathrm{N}_{\Delta}$ & 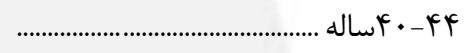 \\
\hline 119 & rI & r & $\wedge$ & $\Delta 90$ & veF & (1) $r \Delta-r q$ \\
\hline 119 & 9 & $\checkmark$ & v & FrA & $\Delta v \cdot$ & ............... \\
\hline $11 r$ & $\Delta$ & r & If & rAV & $\Delta r \cdot$ & 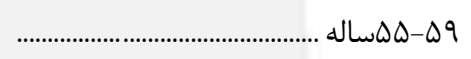 \\
\hline 114 & 1 & r & 9 & TYI & rev & ع \\
\hline DFT & if & r & $\Delta \cdot$ & rVt & 911 & 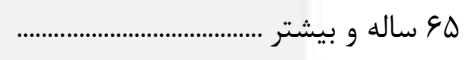 \\
\hline rrra & VFq & re & re & rava & svia & مرد ...................... \\
\hline$r \cdot q$ & 15 & • & 1 & $r$ & rTQ & 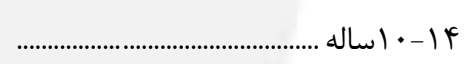 \\
\hline rqA & $\Delta 9$ & · & $\cdot$ & 19 & eqt & 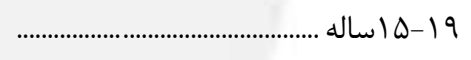 \\
\hline rVı & IVD & r & · & 109 & vil & . \\
\hline$r \cdot$. & IV. & 4 & 1 & rat & 199 & ................ \\
\hline riN & 194 & 4 & 1 & $\Delta 10$ & $9 \cdot r$ & 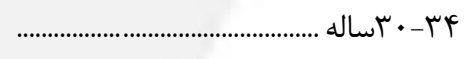 \\
\hline 109 & ar & i & 1 & $\Delta \varphi_{1}$ & $11 F$ & 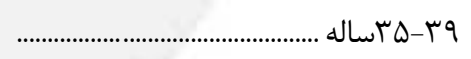 \\
\hline$q 4$ & rᄉ & r & r & far & $\Delta 99$ & (....................... \\
\hline vr & IV & 1 & r & fa. & DFF & q \\
\hline v. & $\checkmark$ & r & r & Mit & rqf & (ساله d - d - d \\
\hline Gr & $\Delta$ & · & 1 & TVF & TKT & ........................ \\
\hline $4 q$ & 1 & r & $\cdot$ & $1 \wedge \Delta$ & ruv & 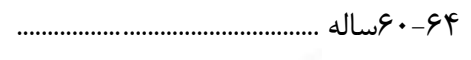 \\
\hline rql & v & 1 & r & TAT & $\Delta M Y$ & 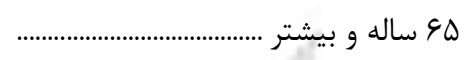 \\
\hline ITET & 149 & ra & 1F & 1199 & rFA9 & 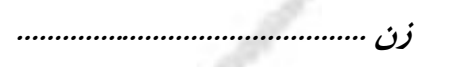 \\
\hline TYA & r & . & . & rq & riv & 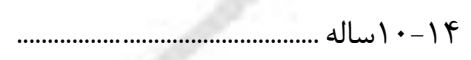 \\
\hline$M A$ & r. & 1 & $\cdot$ & १V & $r \cdot r$ & 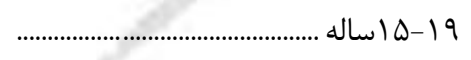 \\
\hline $1 r$. & 19 & $\Delta$ & · & rr. & rNl & F \\
\hline 111 & ז & r & r & TVE & fir & q q \\
\hline 99 & ir & q & v & tAr & rVF & F \\
\hline 90 & $\checkmark$ & r & $\Delta$ & ros & 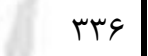 & q \\
\hline er & r & $\wedge$ & r & 189 & 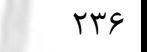 & F.................... \\
\hline er & r & r & $\Delta$ & IfD & $r \cdot \cdot$ & ......................... \\
\hline $4 q$ & r & $\Delta$ & r & 119 & IVe & 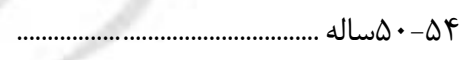 \\
\hline$\Delta \cdot$ & $\cdot$ & r & 1r & 114 & $i v \wedge$ & (1) ه هاله $\Delta$ ه \\
\hline 94 & . & 1 & 9 & $\Delta \varphi$ & $1 r \cdot$ & ع \\
\hline tAT & $\checkmark$ & 1 & rr & 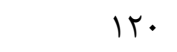 & eqv & 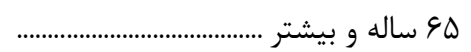 \\
\hline
\end{tabular}




\begin{tabular}{|c|c|c|c|c|c|}
\hline \multicolumn{4}{|c|}{ باسواد } & \multirow[b]{2}{*}{ جمع } & \multirow[b]{2}{*}{ جنس و سن } \\
\hline | متوسطه /متوسطل دوم | مديك & 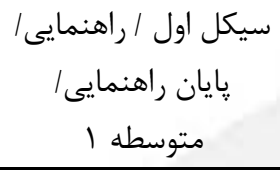 & ابتدايى / إيان آتدايى آموزى & جمع & & \\
\hline rsAFeqr & FrglFAF & rAFv. al & 19QFqFFr & $r \cdot$ IDFETE & $\cdots$ \\
\hline$|f| \mid \wedge \Delta$ & TFVVVAI & 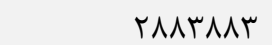 & $\Delta \Delta r q \Delta \& \Delta$ & $\Delta Q 11 \mathrm{raV}$ & 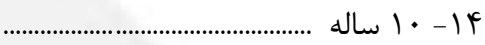 \\
\hline |ATTVVI & VQTIMq & 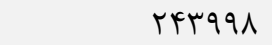 & FVTYQDV & FAlQ9Tq & 19 - 19 ساله ....................... \\
\hline TrATIF & TEYQI9 & $1991 \mathrm{VA}$ & rAVGDVA & r৭९े... & . \\
\hline$r \cdot 1 \cdot V 1$ & $r \cdot V \Delta I$. & IVTVR. & TVQATHE & $r \Lambda \& V I \cdot \Lambda$ & \\
\hline $99 \Delta \mu^{4}$ & $1 \wedge V \cdot 91$ & |TIMLI & $14 \Delta r \cdot 19$ & IDTAVAS & \\
\hline NIAY. & $|V| \ll \& 9$ & rIQTII & $1194 . . r$ & IrAFFT & 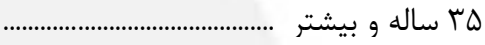 \\
\hline 181Frs. & rarr.qr & 1914TAF & $11 \mathrm{r \Delta s992}$ & I labrarr & 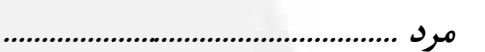 \\
\hline$v \cdot 191$ & ITVVGQ9 & $\mid f \gamma \cdots 1$ & TAYYTq. & TAVYAMQ & ץ \\
\hline 1. एव९५. & 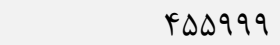 & ITTVQD & reg4rq. & TVIV.GY & 19 19 \\
\hline$T V F \cdot I \Lambda$ & rqAFVG & IrFG. F & TATVqUF & TAQGTYG & • \\
\hline $19 \wedge 910$ & TQFYTI & 1.9901 & INFTDQD & 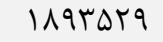 & q \\
\hline VVrFq & $|f| \Delta \Delta \Delta$ & $9 \vee 119$ & $\Lambda F \vee \Delta \wedge \Delta$ & MArTrF & . \\
\hline DFTAV & $1 \cdot k \cdot V k$ & VRr.. & DTGYFT & 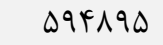 & 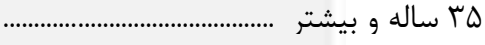 \\
\hline $9999 \% \mathrm{r}$ & ivrarar & IASAVqV & Argrets & 1ه9\&V19 & 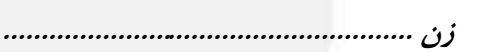 \\
\hline$V \cdot r q 4$ & $\mid r \cdots \Delta \Delta$ & IFIHAVQ & TY. TYYD & rVYAFE & ץ \\
\hline VQTाFI & rqvif. & $111 r \cdot r$ & $r \cdot G T \Delta Q V$ & $r \cdot q \wedge \wedge 90$ & 19 19 \\
\hline DFTQG & 49.4T & GDTVF & 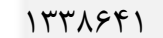 & $|r v \cdot v \wedge|$ & 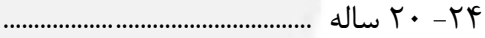 \\
\hline MTFDS & QTMIV & GTVYT & $9149 \vee 9$ & $q \Delta r \Delta \vee q$ & 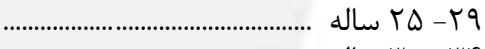 \\
\hline TrIAV & FQDFT & GFIGT & $q \cdot \Delta \Delta \cdot F^{2}$ & GYOQDT & 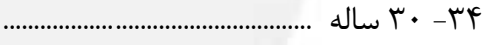 \\
\hline TVDGK & $9 \vee r 90$ & $|F| 0 \mid 1$ & G9VVG. & VAqQFF & لـ ساله و بيشتر ................ \\
\hline
\end{tabular}

\begin{tabular}{|c|c|c|c|c|c|}
\hline \multirow[b]{2}{*}{ اظهارنشده } & \multirow[b]{2}{*}{ 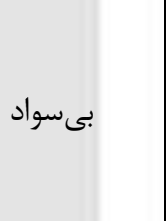 } & \multicolumn{3}{|c|}{ 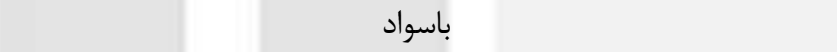 } & \multirow[b]{2}{*}{ جنس و سن } \\
\hline & & ساير دور ههاى تحصيلى، دوره & عالى & دانشخاهى ديش & \\
\hline rever & $\varepsilon \cdot|\Delta r|$ & $949 \Delta 9$ & DIDAFqV & $r a \cdot r v r q$ & 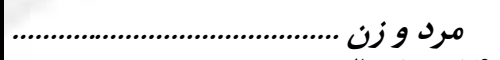 \\
\hline 190 & VIQqV & $r \varepsilon \Delta \cdot \Lambda$ & rM & & 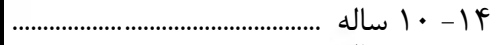 \\
\hline rqv & $\Lambda \vee \Delta \vee \Delta$ & rVqVV & GYTITK & ITFVqFq & | 19 اله ال.................................... \\
\hline$\Lambda \cdot \Delta$ & М৭૬TV & IGTVA & 1909490 & $1 \cdot \mid 1 \cdot T_{1}$ & 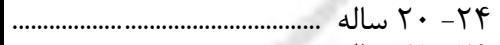 \\
\hline 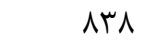 & $M \Lambda \cdot r \varphi$ & G.Y. & $\|F \& \wedge \Lambda\|$ & $4 \cdot r \cdot 1 \Lambda$ & |....................................... \\
\hline gVF & $V \Delta \cdot r \mu$ & $r \cdot v{ }^{k}$ & G9DQRG & rrgqq4 & |..1. \\
\hline Vबr & 1 1 ৭९V & ५१९९ & FIDTr. & $r \cdot V \backslash \wedge F$ & 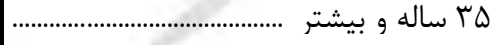 \\
\hline rist & ravear & a.rqr & rrrrash & rerrel. & $\ldots$ \\
\hline at & rabra & $|\wedge \Delta|$ & $1 \wedge \Delta$ & & ץ \\
\hline$r \cdot \Delta$ & DrMGq & $10 \cdot 1 \mathrm{~V}$ & rFG419 & GVFAT. & 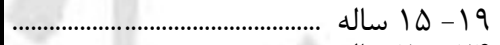 \\
\hline ver & DVQFq & aVrr & $1.99 r \cdot \Delta$ & $V Y I \lambda \cdot 9$ & 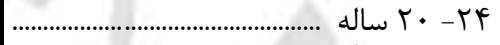 \\
\hline VVq & 49190 & rqqF & $\Lambda \Delta \ldots F F$ & $F \Delta \& V \cdot 1$ & |................................... \\
\hline grq & $r \Delta \cdot r$. & IVVT & rMGAVF & TYTAKS & 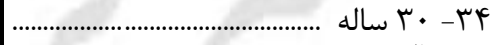 \\
\hline 991 & gVq人र & IFTV & $|f| .9 \mid$ & IDIVKF & 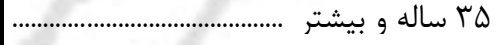 \\
\hline FAF & r. rava & FrafF & rraks.q & IrVRITE & 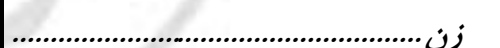 \\
\hline $\mid$ & rद. द & ।V৭9^ & QT & & ץ \\
\hline 94 & $r \Delta T \cdot \varphi$ & Irq9. & $r V \Delta V \cdot r$ & DYMFIQ & 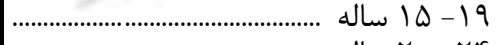 \\
\hline Gr & $r T \cdot V \Lambda$ & $99 \Delta 9$ & NQVIG. & rAqTIT & (... \\
\hline$\Delta 9$ & rAMFi & $r \cdot V q$ & s|AvVI & IFATAV & |......................................... \\
\hline Fa & $r \ldots r$ & $1 \mu \cdot r$ & 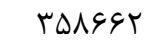 & IITGYA & | \\
\hline 90 & $|r| 8 \wedge 9$ & IQVT & TYETAQ & IDQFE. & هr ساله و بيشتر ........................................ \\
\hline
\end{tabular}


| نتايج تفصيلى سرشمارى عمومى نفوس و مسكن _ه |

(نقاط شهرى)

PF 1 - TF جمعيت +ا ساله و بيشتر هر كز ازدواج نكرده بر حسب جنس، سن و سطح سواد (دنباله)

\begin{tabular}{|c|c|c|c|c|c|}
\hline \multicolumn{4}{|c|}{ 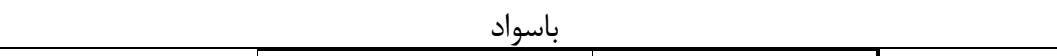 } & \multirow[b]{2}{*}{ جمع } & \multirow[b]{2}{*}{ جنس و سن } \\
\hline 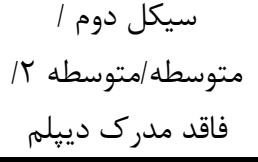 & سيايان راهنمايى / متوسطه / راهنمايى/ & ابتدايى / سواد آموزى / يايان & جمع & & \\
\hline$r \cdot 1 \cdot v e r$ & $r 9 v 1 \cdot 9 r$ & rerarra & $\mid f r \cdot q \& 81$ & $10.19 \Delta V 9$ & مرد و زن ............... \\
\hline $11 r \cdot 1$ & $\backslash \wedge \Delta \wedge \Lambda \Lambda \Lambda$ & 191FrTES & rqv^l.q & $F \cdot I F \cdot r F$ & f \\
\hline$|f| \cdot \Delta q \mu$ & F9Y999 & $1 \cdot r \Delta \& 9$ & rorgVq. & $r \Delta \gamma \cdot . q$. & 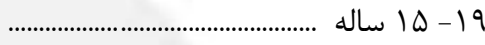 \\
\hline$r \cdot \Delta T \Delta V$ & $r \cdot r \Lambda \cdot r$ & NFqTV & rq.VT\&A & $r q \Delta T \cdot V F$ & r \\
\hline $\mid F \cdot r \mu d$ & $1909 \vee 9$ & ATIAF & rlo9994 & Th. TMET & 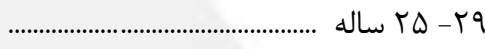 \\
\hline VDVAq & $15 \cdot .19$ & 99491 & $\| V \Delta \mid \Delta F$ & ITIFETS & 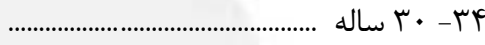 \\
\hline g9VAI & $|r V F| \mid$ & 119410 & QQDTYG & 1. g9trm & 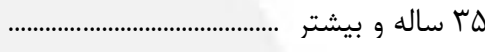 \\
\hline Irrrara & IVFAFEq & Iravare & Argfr.f & $1 \Delta r \cdot 1 \& \Delta$ & 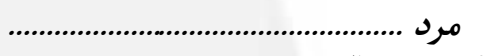 \\
\hline$\Delta \Delta \wedge \vee q$ & $q 4 \wedge F \cdot V$ & 1.19411 & t. TtRTh & $r \cdot \Delta \cdot \Lambda r r$ & 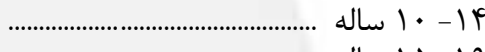 \\
\hline VYVFID & $T V \Delta \cdot V T$ & $9 \mid \Lambda \cdot V$ & I QTHDSV & 199.911 & \\
\hline IVTrMq & $I V \cdot r \wedge \Delta$ & GT QDF & $1 \wedge r \Delta \Delta q$. & $1 \wedge 99 \cdot r \Delta$ & 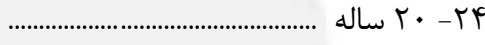 \\
\hline 119991 & ISVDIA & G.TVT & $|F T| Q Y \mid$ & IFFqIFr & \\
\hline $9.91 \mathrm{~V}$ & $1 .+4191$ & Fret & $99 \Delta V q 4$ & VIVITF & r \\
\hline$\uparrow q \cdot \Delta \Lambda$ & $\Lambda r \cdot \mid \Lambda$ & DrGqF & $f \notin \Delta \cdot \Delta \Lambda$ & r^\&ヘ19 & 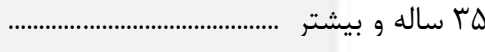 \\
\hline VVVTrF & ITrqgTF & lletgr & erFarar & EFAAVIF & 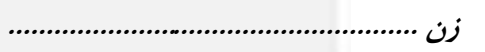 \\
\hline$\Delta G \mid Y q$ & $91 \cdot 4 \wedge 1$ & १९५৭४৯ & I IFDHAD & 1994T.1 & ץ \\
\hline grmiVA & IAVGrT & fIVAT & 1D9TTTR & 19.91189 & 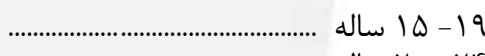 \\
\hline Tr.11 & TTDIA & rI9Vr & $1 \cdot V \mid \varepsilon \vee \wedge$ & $1 \cdot 19 \cdot 49$ & 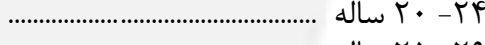 \\
\hline t.rYA & rAFQA & rig1t & VTQFTH & VATr.. & 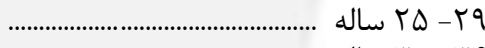 \\
\hline $14 \hat{r} \cdot r$ & $r \Delta \wedge \Delta I$ & rT৭\&V & pVqug. & \&qVa.1 & 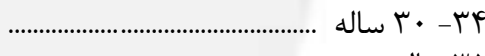 \\
\hline r.VTr & ferqu & घ99TI & $\Delta T \cdot T \Lambda \Lambda$ & DV৭\&।f & 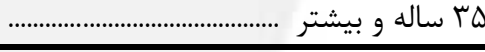 \\
\hline
\end{tabular}

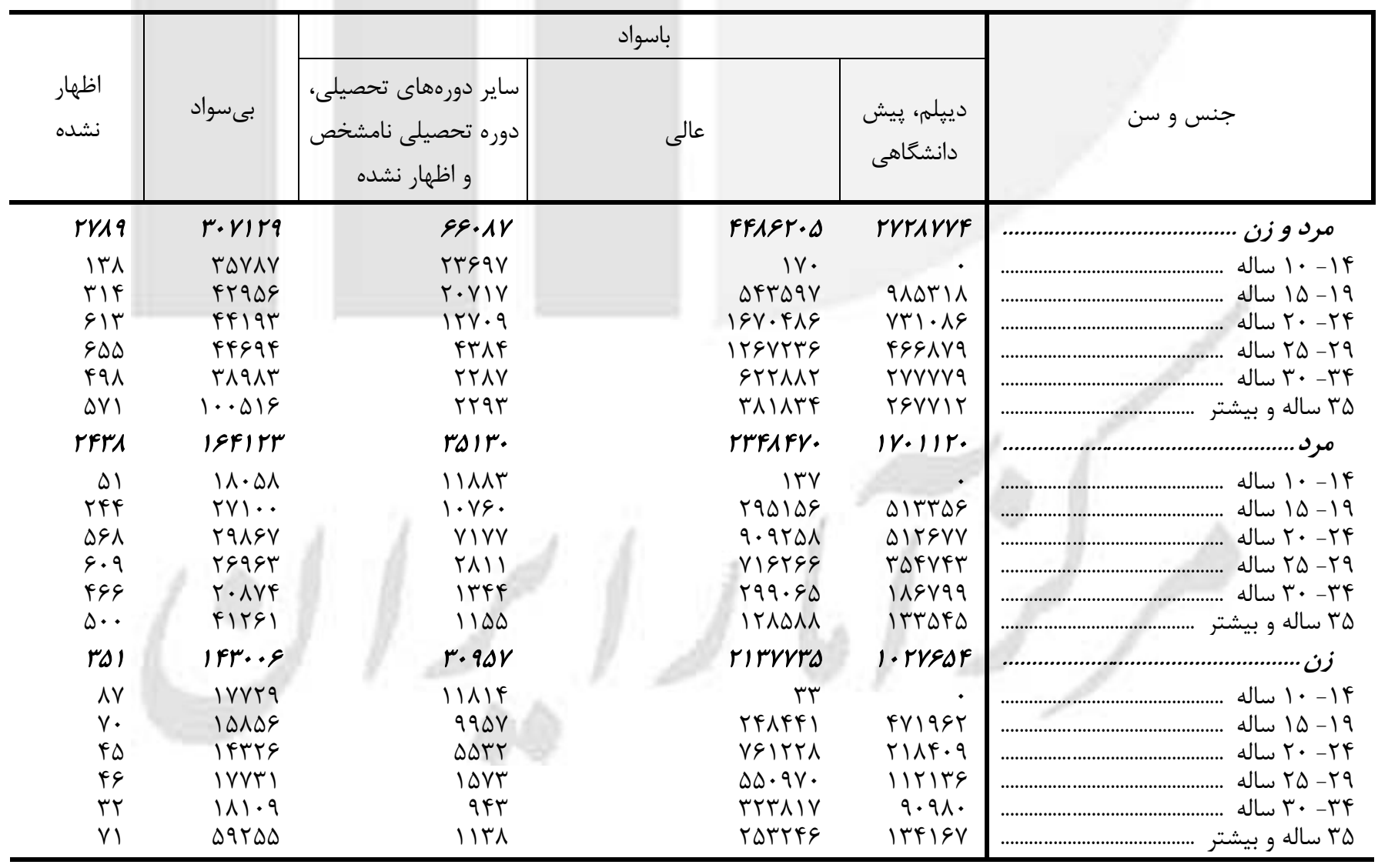




\begin{tabular}{|c|c|c|c|c|c|}
\hline \multicolumn{4}{|c|}{ 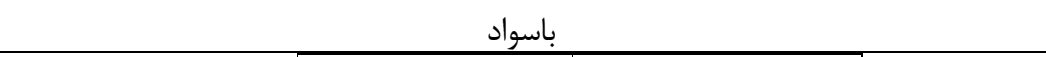 } & \multirow[b]{2}{*}{ جمع } & \multirow[b]{2}{*}{ 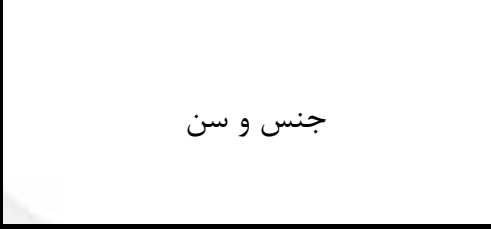 } \\
\hline متوسط دوم / متوسطه / مدر / ماقد & 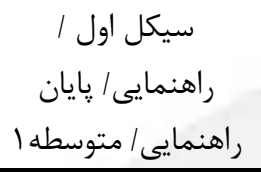 & ابتدايى / سواد آموزى / آيان & جمع & & \\
\hline evrerd & $151 \cdot r 99$ & $|F \cdot| A F \Delta$ & rargerr & DII9DrA & مرد و زن .... \\
\hline$r q 1<q$ & glvark & $\wedge 9 \vee 910$ & $1 \Delta \Delta \vee \wedge \varepsilon F$ & IDQTHAT & 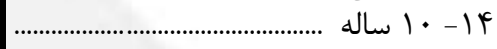 \\
\hline FTIFqV & r人94וI & Irqfir & $119 \vee 9 \vee 1$ & ITFTIVV & 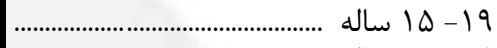 \\
\hline ItTVDA & 191110 & $\|f\| r G$ & 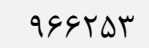 & $1.11 \mathrm{f} \cdot 9$ & 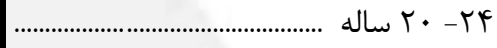 \\
\hline$q \cdot \Delta \Lambda F$ & 111119 & $q \cdots \Delta r$ & DQQFTF & GFYG. 9 & q \\
\hline rm\&GA & $\Delta \varphi \wedge \wedge \varepsilon$ & GFVT. & tVRITE & פחוזוr & 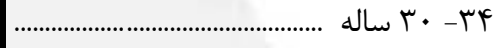 \\
\hline IfqVq & qrq.. & $909 \cdot 9$ & rtVqNe & mIG人tq & 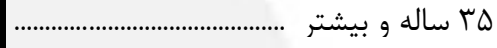 \\
\hline Fa. rTa & VAIVIF & sArVtes & RAAFADF & $r \cdot \mid v g \cdot q$ & 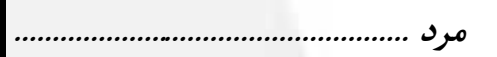 \\
\hline Ifqq4 & rTAVDI & FATTAV & $\Lambda \cdot r \& V \mu$ & 11999r & | \\
\hline TEIVGV & M. pFr & $V \cdot r \Delta \mu$ & 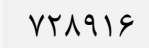 & VDrqGI & 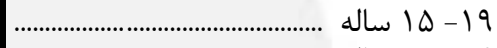 \\
\hline $1 \cdots \Delta \Delta \Delta$ & ITVA.1 & $V|| f \mid$ & V.rTt & $V T V \Lambda \cdot r$ & 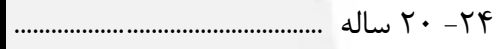 \\
\hline FADTV & 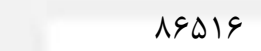 & qqurr & FT. \&Vq & FFTAQV & q \\
\hline $19 \mu \cdot 1$ & TVTFV & MFtr & $|\Delta| T \& \Lambda$ & IEDFVT & 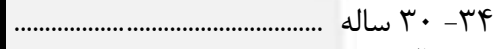 \\
\hline NIEF & $r \cdot 9 \Delta \varphi$ & $r \cdot \wedge \vee q$ & $\Lambda \cdot$ vqr & I. VANT & 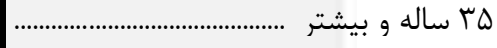 \\
\hline retrie. & Fq1૬1ब & $V 1 F .99$ & $19 F T \cdot V A$ & $r 1.19 r r$ & 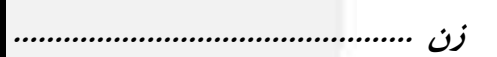 \\
\hline$|f| \Delta \Delta$ & r人9IVV & FF $\Delta \varphi \Delta \Lambda$ & $V \Delta \Delta 191$ & VVrrq. & 1f \\
\hline l८৭Vr. & $1 \cdot \wedge \wedge 9 \wedge$ & ฯ^৭९. & $\uparrow \& q \cdot \Delta \Delta$ & FANTIS & 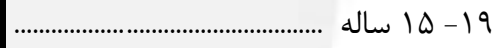 \\
\hline trter & 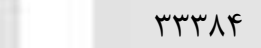 & frqqه & TGG. rA & rATG. r & 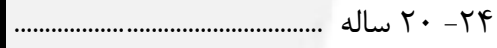 \\
\hline$I T \cdot F V$ & TFEVT & F. $q \vee q$ & IVAVFA & 199V1r & . \\
\hline Vrg. & 19849 & $f_{1} \cdot V V$ & $\mid r \Delta \wedge \& \wedge$ & IFVGG & 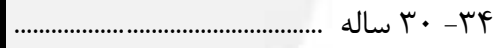 \\
\hline $9 \wedge 10$ & rTqRF & VFVY. & $\mid F \vee 191$ & r. qrFV & 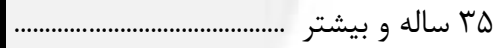 \\
\hline
\end{tabular}

\begin{tabular}{|c|c|c|c|c|c|c|}
\hline \multirow[b]{2}{*}{ الظهار } & \multirow[b]{2}{*}{ 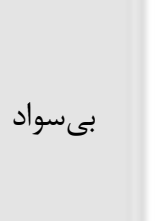 } & \multicolumn{4}{|c|}{ باسواد } & \multirow[b]{2}{*}{ جنس و سن } \\
\hline & & | دوره تحصيلى نامشخص و و هاى تحصيلى، & عالى & & دانشآهى بيش & \\
\hline AVA & rar.rl & resta & & $s v 1 \cdot F l$ & rVrave & مرد و زن ................. \\
\hline$\Delta \Delta$ & TAFGT & $\mid r \lambda \cdot r$ & & 91 & & 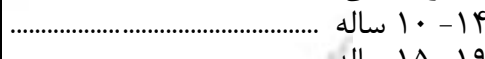 \\
\hline vq & FFITV & VTFq & & $V \wedge F \cdot r$ & rqT.qV & 19 19 \\
\hline 191 & FFqG & rGQ4 & & $r A Q F \cdot F$ & rVq1. & ( \\
\hline lar & re..r & $|9 \mu|$ & & $r \cdot 11 \wedge \Delta$ & IrFVAr & 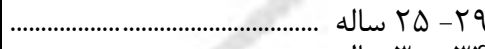 \\
\hline IV\& & rQAYr & V^s & & VTATS & $\Delta \Lambda \Delta F$ & זr \\
\hline 191 & MMQDF & $v \cdot r$ & & MrFFY & rquys & 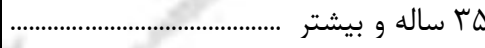 \\
\hline ves & $1 \pi \mu r \cdot s$ & IDTFF & & FrFatr & $\Delta r \Delta \cdot . r$ & 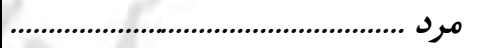 \\
\hline it & $I V Y \cdot V$ & GGTr & & is & & 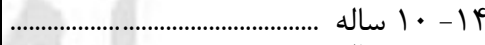 \\
\hline$\Delta q$ & rFq19 & Frol & & $011 \vee 9$ & $19 \cdot 1 \mathrm{Kr}$ & 19 1 19 ساله ................... \\
\hline IVD & TVF. & TAYT & & IA9G4D & $r \cdot \wedge \Delta \omega$ & ץ \\
\hline IV. & rY.YA & $111 \% 9$ & & IrTYG & $1.194 T$ & Q \\
\hline سوا & $\mid f \cdot+i$ & GTV & & TVYTA & $r \Delta q 1 \Delta$ & 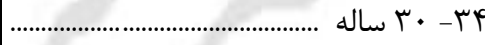 \\
\hline $19 \mathrm{~V}$ & TEQTT & rVI & & ITFEI & $M \cdot N T$ & 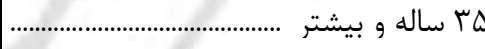 \\
\hline 149 & laqVTa & 11094 & & rFEDIA & rFAAVT & 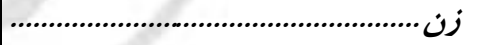 \\
\hline Fr & $|\wedge| \Delta \varphi$ & $9|1|$ & & r. & & 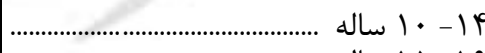 \\
\hline$r$. & $|9| 4 \mid$ & r१११ & & TYYTA & $1.1 K V F$ & 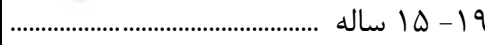 \\
\hline 19 & IVAG. & $\| r \mid$ & & $9 \Delta \vee 99$ & $V \cdot \Delta \Delta q$ & . \\
\hline r & $r \cdot 9 \Delta F$ & $\Delta \cdot r$ & & GVGq4 & | lal & q \\
\hline ir & TIVAT & $r \Delta q$ & & $r F \Lambda \cdot \Lambda$ & TMETD & 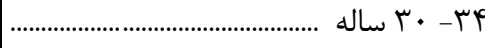 \\
\hline rF & GTITK & זמצ & & r...r & TIT\&G & 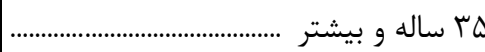 \\
\hline
\end{tabular}


| نتايج تفصيلى سرشمارى عمومى نفوس و مسكن _ه |

•

\begin{tabular}{|c|c|c|c|c|c|}
\hline \multicolumn{4}{|c|}{ 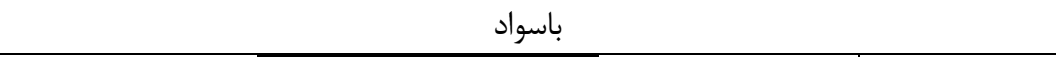 } & \multirow[b]{2}{*}{ 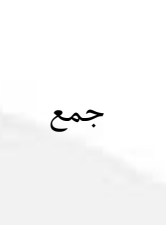 } & \multirow[b]{2}{*}{ 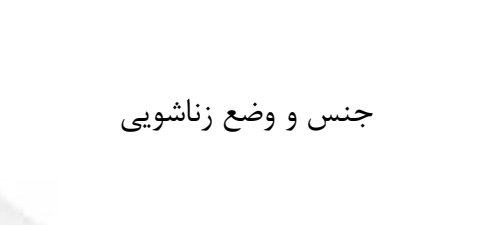 } \\
\hline | متوسطه /متوسطه دوم / & يايان راهنمايى / متوسطه / راهنمايى | & |ابتدايى/ سوادآموزى / يايان & جمع & & \\
\hline DATFAT. & I Irelr. & IreIrarr & बraraqqa & geferla19 & 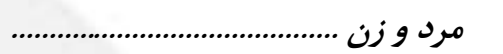 \\
\hline r\&৭\&V९^ & QVFrqดq & ANVmr.r & HGTIN.IF & prrqqvar & 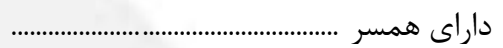 \\
\hline$\Delta V I F \Delta$ & IETEVG & $\Delta Y \backslash 991$ & 1. rVAVV & tRTA. IN & 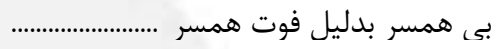 \\
\hline $9 \Delta \mid \uparrow \wedge$ & 191.94 & 199109 & $1 \cdot 19 \cdot 19$ & 1111199 & 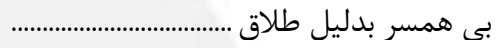 \\
\hline r\&AF\&9V & FTGIFAG & $r \wedge F V \cdot \Delta l$ & I9DFqFTr & r. IDFATG & 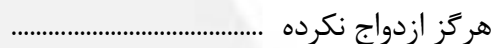 \\
\hline VAT & $11 \% 90$ & rtre & $119 \cdot r$ & TVGAV & 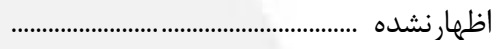 \\
\hline MIAFTED & sprulab & sar. Ir. & r.prete. & rugrgir & 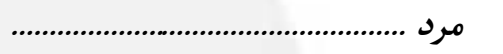 \\
\hline $\mid f 49 \wedge 99$ & rVarrad & FFIITKA & INGFDqTV & 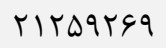 & 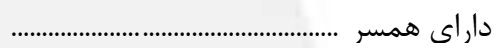 \\
\hline$\wedge 9 \Delta ।$ & THTHT & GヘVAT & IFVGT & rrq.ru & 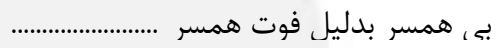 \\
\hline $\mathrm{Fr} \cdot 9 \mathrm{~V}$ & NDHGF & $q \cdot r \cdot r$ & rVYVqq & ५q. ^ץ & 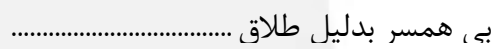 \\
\hline IGAFVG. & rQTr.qR & 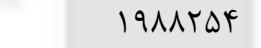 & IIrब९99V & IIDUVAKV & 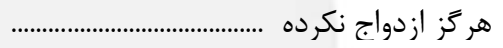 \\
\hline$\Delta \wedge \Lambda$ & $1 \cdot+1$ & $10 \cdot k$ & $V \Delta \cdot r$ & $|\vee r q|$ & 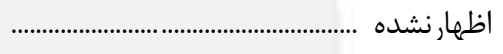 \\
\hline$r r \Delta \cdot r \Delta \omega$ & Fqral1a & sA1rr.r & rrrquara & rrsaqrVr & 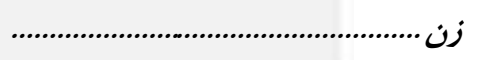 \\
\hline IrFq人६q & r१Q।ध.r & FFET.VF & $I V Q V T \cdot V V$ & $r \| I \cdot \Delta r r$ & 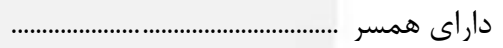 \\
\hline FA19F & $\mid F \| H F$ & FATR.q & $\wedge \vee १ १ \Delta \digamma$ & 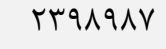 & 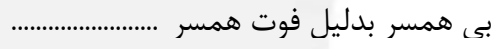 \\
\hline$\Delta T \cdot \Lambda I$ & $1 \cdot \Delta V \cdot \cdots$ & $1 \cdot \wedge V \Delta V$ & SFDTA. & VITVAT & 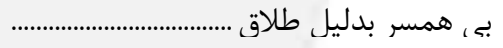 \\
\hline १९११५ & IVTqRqR & । $\Delta \wedge \vee १ \vee$ & NTATFYG & $\wedge \Delta ৭ \& \vee \wedge ৭$ & 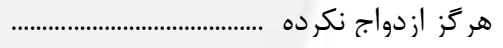 \\
\hline$I V F$ & rof & 19६ & $p \cdot 91$ & 1.499 & اظعارنشده ............ \\
\hline
\end{tabular}

\begin{tabular}{|c|c|c|c|c|c|}
\hline \multirow[b]{2}{*}{ 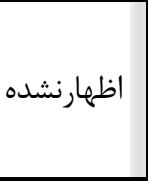 } & \multirow[b]{2}{*}{ 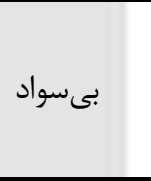 } & \multicolumn{3}{|c|}{ باسواد } & \multirow[b]{2}{*}{ جنس و وضع زناشويى } \\
\hline & & تحصيلى نامشخص دورهاى تحصيلى، دوره & عالى & دييلم، هِيش & \\
\hline fIfDA & 1DQFARq & $r \cdot 199 \mathrm{~V}$ & $\mid$ |rg|real & Irgqravf & 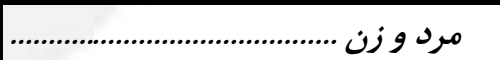 \\
\hline עrtr & 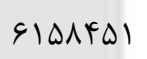 & 1.rrs. & $N I \cdot V I \cdot r$ & १९৭४১.५ & 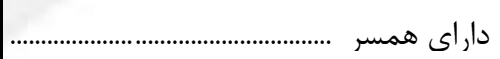 \\
\hline FqK & $19999 \vee \wedge$ & $\Lambda \cdot \vee \Delta$ & 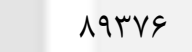 & IAVAIF & 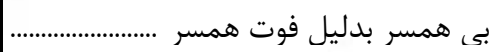 \\
\hline 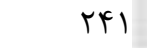 & GTDFG & $r \Delta \ldots$ & rQFqTI & r. GTAV & بـ ،مسر بدليل طلاق ......... \\
\hline reVt & G.|QT| & $9 ५ 9 \Delta 4$ & $\Delta \backslash \Delta \wedge F q \vee$ & $r \Delta \cdot r v r q$ & 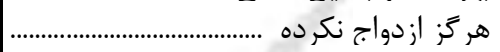 \\
\hline ITVAT & 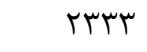 & $r \cdot \Lambda 9$ & $r \vee \Delta \Delta$ & Irmt & 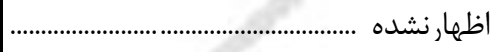 \\
\hline$r v \cdot 11$ & $r 1 \cdot r r v i$ & $1109 \cdot r$ & VIfFFAV & V. TFTH. & 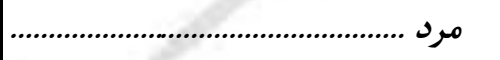 \\
\hline$|F \wedge F|$ & $r \Delta q \wedge<q 1$ & GITr. & FreVq.V & FGGGTTA & 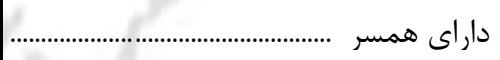 \\
\hline $1 \cdot 4$ & $|\wedge| \cdots k$ & IVre & 19109 & raTAI & بـ ، همسر بدليل فوت همسر \\
\hline $1 \cdot 9$ & rDIVG & $1 \cdots \infty$ & $\Lambda \cdot \Delta G \psi$ & 1.r世qע & بs همسر بدليل طلاق ........ \\
\hline MMA & rqVGar & D.rar & TrVrAMA & TYTVGI. & هر كز ازدواج نكرده .................... \\
\hline M & 1.41 & 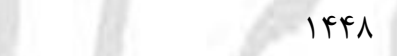 & $r \cdot 99$ & $\Lambda \Delta F$ & 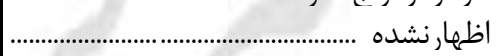 \\
\hline lerrf & $\Delta F \Delta I I \& A$ & $q r \cdot q f$ & grequgf & sqgartur & 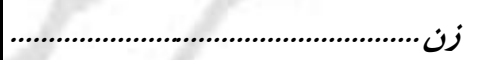 \\
\hline 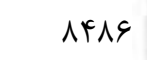 & rЬЬ११९. & FT.G. & rᄉrq190 & $D \cdot T V T V \Delta$ & 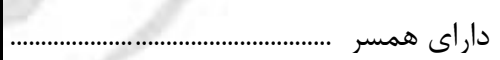 \\
\hline$r \Delta q$ & $|\Delta| \Lambda \& V F$ & grrv & $9901 V$ & $181 \Delta \& 4$ & 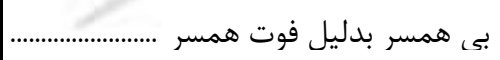 \\
\hline Trt & sVrv. & 1490 & IVFTUV & r. r^q. & 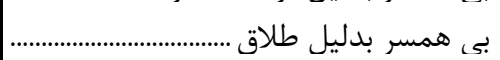 \\
\hline FAF & $r \cdot r \wedge \vee q$ & FTAGF & rrAFG. & ITVVITS & 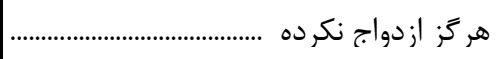 \\
\hline eqाr & ITND & gru & 1919 & rی. & 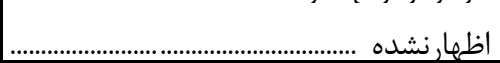 \\
\hline
\end{tabular}


VD - I - جمعيت • ا ساله و بيشتر بر حسب جنس، وضع زناشويى و سطح سواد (دنباله)

\begin{tabular}{|c|c|c|c|c|c|}
\hline \multicolumn{4}{|c|}{ باسواد } & \multirow[b]{2}{*}{ جمع } & \multirow[b]{2}{*}{ جنس و وضع زناشويى } \\
\hline 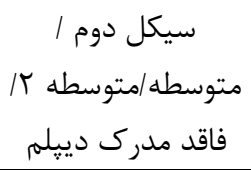 & 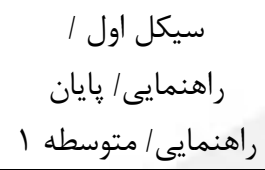 & سايان ابتدايى / آمواد آموزى & جمع & & \\
\hline FIAFrar & A1ra.ra & $1 \& 9 \cdot F+1$ & FFAFqADF & 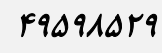 & 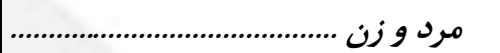 \\
\hline$r \cdot r q \Delta 91$ & $\psi \wedge \Delta \Delta \cdot \xi \psi$ & 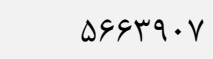 & TAMFAVGS & misk.9.. & 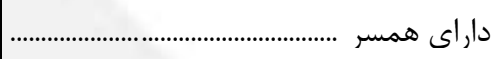 \\
\hline$\Delta T \cdot T G$ & IFDQFF & Frt.rA & $q \cdots \Delta \varphi$. & 19VrTar & 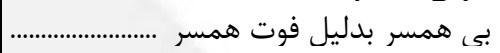 \\
\hline NIFFV & lD\&K\&9 & ITHKN & MAFeid & qFFTqR & 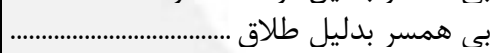 \\
\hline$r \cdot l \cdot V \varepsilon r$ & r৭४৯.१५ & rerqurq & $|f V \cdot q 49|$ & $10 \cdot 190 \vee 9$ & 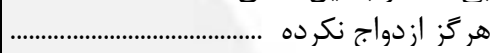 \\
\hline$\Delta \Delta \cdot$ & १४ब & Ifre & QTQT & $r \cdot \Delta \cdot r$ & اظهارنشده ............................... \\
\hline rreirri & FAFEYqG & flarraq & rrrrvafq & rFqFr.DD & 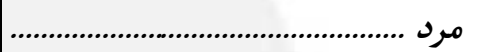 \\
\hline $1 \cdot \lambda r r \cdot V$ & tRI.trt & $r N \cdot T_{Q P I}$ & IFESVII. & DQAFTHFq & داراى همسر \\
\hline VAYT & |রबTा & QTYIT & ITrDQF & TYKATG & 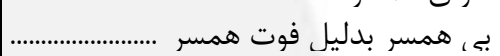 \\
\hline refGG & $9 \Lambda 4 \cdot 9$ & $F F \cdot 19$ & rIVVA & THEFA & 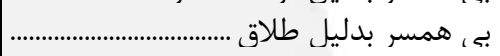 \\
\hline ITrTarq & IVFAFE9 & IrqVQVG & ArGqT. F & $\Lambda \Delta r \cdot \Lambda \varepsilon \Delta$ & 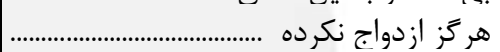 \\
\hline fis & VID & 94 . & QVqu & ITVGN & 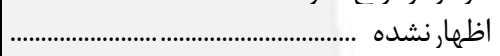 \\
\hline $114 r+18$ & raqrarq & FFer.1T & rlarrrea & TFEDEFVF & زن........................... \\
\hline १QSYAF & rIFVRVT & rASIrGS & I $\wedge \vee \wedge \varphi \Delta \varphi$ & $|\Delta \vee q \wedge \Delta \Delta|$ & 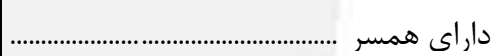 \\
\hline perqu & 149914 & rV৭ATa & $V \vee \wedge . .4$ & IVD. GKF & 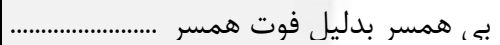 \\
\hline F×911 & Av৭9. & v919F & DGGATV & $91 \cdot 149$ & 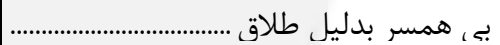 \\
\hline VVVTYY & ITrGGTF & IIFTIGK & GTFATDV & GFMNIF & هركز ازدواج نكر ده ...................................... \\
\hline IrF & rq. & $\Delta M F$ & $r F \Delta Q$ & VVYG & 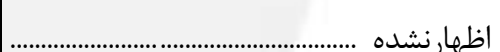 \\
\hline
\end{tabular}

\begin{tabular}{|c|c|c|c|c|c|}
\hline \multirow[b]{2}{*}{ 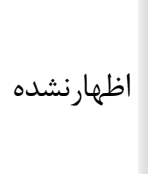 } & \multirow[b]{2}{*}{ 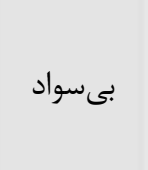 } & \multicolumn{3}{|c|}{ باسواد } & \multirow[b]{2}{*}{ جنس و وضع زناشويى } \\
\hline & & تحصيلى نامشخص دوره واظى تحصيلى، دوره & 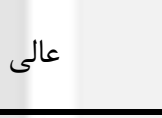 & دانشخاهى، & \\
\hline rllod & frivar. & 101918 & irterilr & $11 F a \cdot 9 \mathrm{Vr}$ & 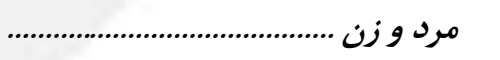 \\
\hline IVArA & TTVRT.G & VATIQ & VFFGGG4 & ATETHFA & 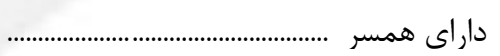 \\
\hline TaT & $1 \cdot$ VYTKI & $499 \mathrm{~V}$ & NDQMT & IVATIK & بي همسر بدليل فوت همس \\
\hline IVV & $\Delta 90 \cdot 1$ & rI. & TF.VQT & $r \Lambda \cdot 9 r)$ & بى همسر بدليل طلاق ...... \\
\hline rVAq & $r \cdot V I r q$ & $94 \cdot 1 \mathrm{~V}$ & FYAST.Q D & TVYAYVE & هر كز ازدواج نكرده ......... \\
\hline $1 \ldots 9$ & ITET & 1110 & rolı & 94. & اظهارنشده .......................... \\
\hline r.rir & $\mid$ GFFIGF & $1 \Gamma \cdot 91$ & srreradi & $\Delta V \Delta V r \cdot F$ & 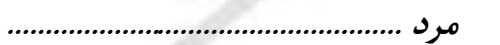 \\
\hline $11 r<9$ & 1щяґq9. & $r r \Delta \Delta \Lambda$ & 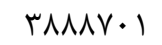 & rqH人Vז। & داراي همسر \\
\hline VA & $9999 \mathrm{~V}$ & ITAV & $\backslash \wedge \vee \Delta \Delta$ & $T F \cdot T \Delta$ & بى همسر بدليل فوت همسر \\
\hline$\Lambda \mu$ & $1 \Delta \Delta V Y$ & $\Lambda \mu$. & $V Q \mid 9 \Lambda$ & GYATS & بـ، همسر بدليل طلاق ....... \\
\hline TFM & IEFITK & rQIT. & THFAFY. & $I V \cdot 11 Y \cdot$ & هر زز ازدواج نكر ده .................... \\
\hline gret & $\Delta 11$ & ITDS & INGY & G.r & 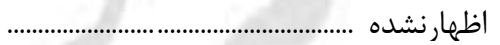 \\
\hline $1 \cdot 1 \mathrm{Fr}^{\mathrm{T}}$ & r.vrrus & 99100 & $\Delta 9 T \cdot 1 \Delta \Delta$ & DFqT\&\&A & 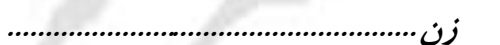 \\
\hline qDVq & 1919 & 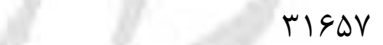 & $r \Delta \Delta \vee Q Q Y$ & Frrmglf & 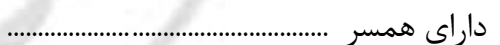 \\
\hline TVY & QVTMYF & $\Delta F I$. & GVIVA & IDFTAV & بى همسر بدليل فوت همس \\
\hline 94 & Frars & ITVK & IGDSTD & $1 \wedge \vee \vee 9 \Delta$ & 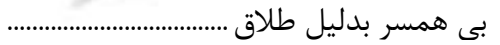 \\
\hline ral & $14 r \cdot .4$ & $r \cdot 9 \Delta V$ & ritrVta & 1. TVGDF & 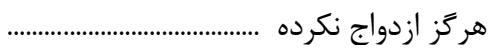 \\
\hline rafa & VTr & $\Delta \Delta q$ & $19 \Delta F$ & ऑ॥ & اظهارنشده ..................... \\
\hline
\end{tabular}




\begin{tabular}{|c|c|c|c|c|c|}
\hline \multicolumn{2}{|l|}{ 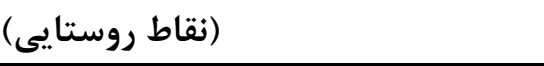 } & \multicolumn{4}{|c|}{ ID - I - جمعيت +1 ساله و بيشتر بر حسب جنس، وضع زناشويى و سطح سواد (دنباله) } \\
\hline \multicolumn{4}{|c|}{ 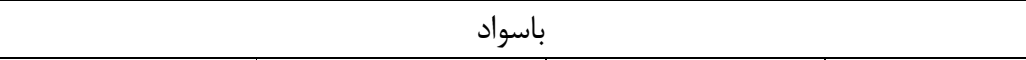 } & \multirow[b]{2}{*}{ جمع اع } & \multirow[b]{2}{*}{ جنس و وضع زناشويى } \\
\hline | متوسطه /متوسطله د د ماقد مدرك دييله & 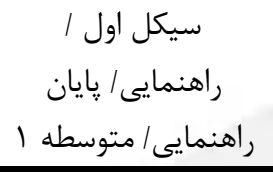 & ابتدايى/ ابتدايى / هايان آموزى & 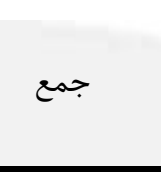 & & \\
\hline Irevgqr & requgra & FVFI rqA & Irqdirrg & |qvarfiA & 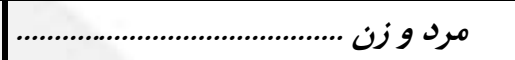 \\
\hline gDgrqr & INArGD. & מז.r.r & VA૬IT\&D & 1.VHATVT & 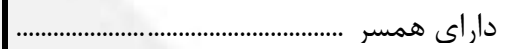 \\
\hline$\Delta \cdot \wedge \varepsilon$ & IV^99 & 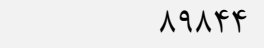 & ITVIIV & VDTFTA & 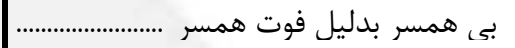 \\
\hline ITEVT & rFDVA & FAVTr & $I M r \cdot \lambda r$ & $19 V \cdot \Delta T$ & 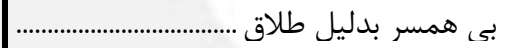 \\
\hline GVTERD & $1 \% \wedge \cdot r q 9$ & $|F \cdot| \Lambda F \Delta$ & FATGGTK & $\Delta 119 \Delta \mathrm{H}$ & 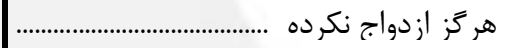 \\
\hline$r \cdot v$ & FIr & $\Lambda \Delta r$ & tru. & $V \cdot r$ & 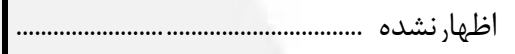 \\
\hline ArIDTA & 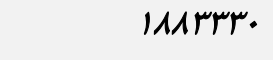 & rrreraf & virqq.f & $1 \Delta 911 \cdot 9$ & 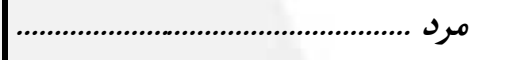 \\
\hline rGMIGF & $1 \cdot \wedge \cdot V \uparrow \wedge$ & $19 \cdot \Delta r \Delta \Delta$ & FIVTVTq & $\Delta F \cdot F V \backslash \Lambda$ & 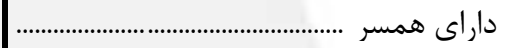 \\
\hline Irar & 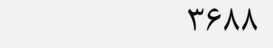 & $19 \Delta 11$ & TATAS & $\left.1 \cdot 9 \cdot 1\right|^{f}$ & 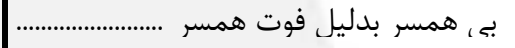 \\
\hline GDVq & $19 \wedge \Delta 9$ & 19194 & $\Delta \Delta \varphi q \uparrow$ & ( ) & 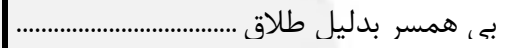 \\
\hline RQPTHA & VAIVIF & 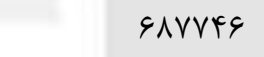 & $r \wedge \Lambda F \Delta \Delta F$ & $r \cdot \mid V q \cdot \varphi$ & 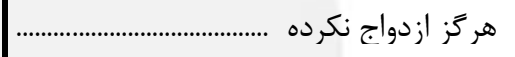 \\
\hline $19 \Lambda$ & mt & $\Delta F$ & $19 V 1$ & FATd & 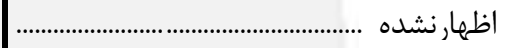 \\
\hline Drefer & 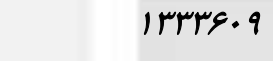 & rFIFqFF & $\Delta A I I F V T$ & AIAfrit & 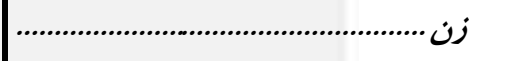 \\
\hline TarrTA & $\Lambda \cdot r q \cdot r$ & । $৭ \vee \& 9 \Lambda$ & TENADHG & $\Delta M r \cdot \varphi \Delta F$ & 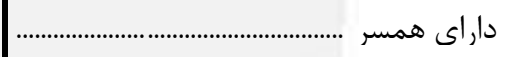 \\
\hline rvqf & $|F T| \mid$ & VTrte & $1 \cdot|\wedge 9|$ & SFVFII & 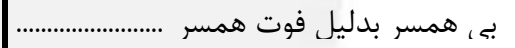 \\
\hline$V \cdot 9 r$ & $18 V 19$ & TQDFI & 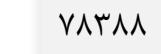 & $1 \cdot 1119$ & 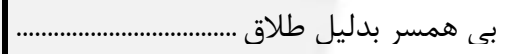 \\
\hline TrTMI. & 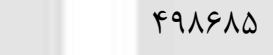 & $V \mid F \cdot 99$ & $19 F T \cdot V A$ & $r 1 \cdot 19 r r$ & 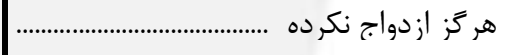 \\
\hline rq & 94 & r). & $9 \cdot 9$ & rFqG & 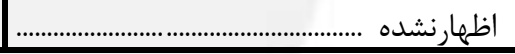 \\
\hline
\end{tabular}

\begin{tabular}{|c|c|c|c|c|c|}
\hline \multirow[b]{2}{*}{ 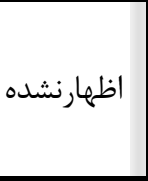 } & \multirow[b]{2}{*}{ 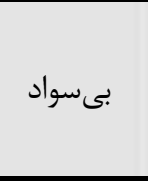 } & \multicolumn{3}{|c|}{ باسواد } & \multirow[b]{2}{*}{ جنس و وضع زناشويى } \\
\hline & & تحصيلى نامشخص ور إظى تحصيلى، دوره & 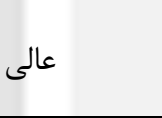 & دييلم، يِيش دانشخاهى & \\
\hline $1 \cdot r \cdot r$ & rar.ara & $\Delta r \cdot 11$ & IrFAATE & rerar.. & 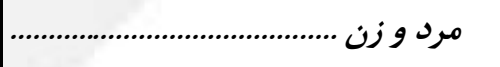 \\
\hline DFVD & 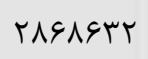 & thItrt & s9..r. & IFr..rk & 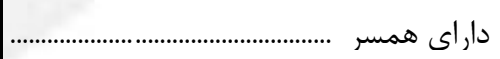 \\
\hline 11. & Gर9191 & IrVV & remp & qfVr & 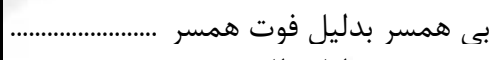 \\
\hline gr & rrq. & r9d & $14 \cdot 91$ & $r \Delta \varphi \cdot \varphi$ & بى همسر بدليل طلاق ........ \\
\hline$\Lambda \vee \Delta$ & rat.rI & 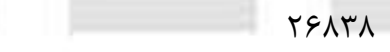 & $9 \times 1 \cdot+1$ & VVrAVF & 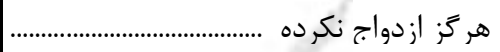 \\
\hline rq1. & $1 \cdot \sqrt{1}$ & rघ9 & 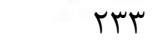 & $r \cdot \Delta$ & 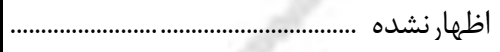 \\
\hline eria & IfDIFAV & rergr & $11 \cdot|r|$ & Irefret & 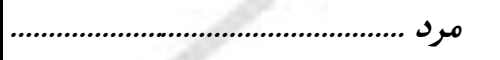 \\
\hline ravq & ITTAKI. & IVVF. & rV^৭rV & VYSVAD & 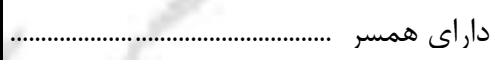 \\
\hline rq & $\Lambda \cdot V M r$ & FQI & $11 \ldots$ & $T r \cdot V$ & بى همسر بدليل فوت همس \\
\hline rq & $901 \%$ & IVT & DrGA & $1 \cdot \Delta T F$ & بى همسر بدليل طلاق ..... \\
\hline Vis & 1 Irr.9 & IDTFE & FTFATK & $\Delta T \Delta \cdot \cdot r$ & هركز ازدواج نكرده .................. \\
\hline 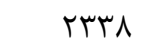 & DrG & 19 & $r \cdot r$ & THS & 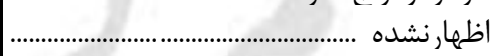 \\
\hline rFAq & rrgaral & rerif & $\Delta r \wedge r \cdot \Delta$ & qVFarg & 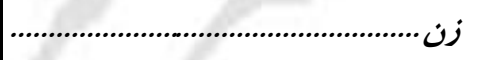 \\
\hline 1199 & IST. TrT & 1. rar & $r \wedge 1 \cdot 9 r$ & V.rTAT & داراى همسر ........................ \\
\hline$\wedge f$ & DFDFEG & 948 & trme & VTV. & بى همسر بدليل فوت هم \\
\hline rᄉ & rrтq4 & rTr & $\Lambda \vee r$. & $10 \cdot \lambda r$ & 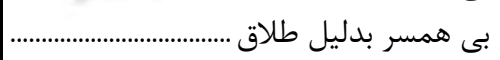 \\
\hline $1 r 9$ & IDQVTD & $1109 F$ & rFGDIA & TFANVT & 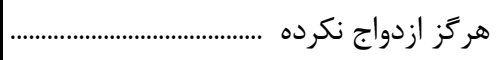 \\
\hline ITET & $\Delta F \Delta$ & vq & $r$. & $\Delta 9$ & 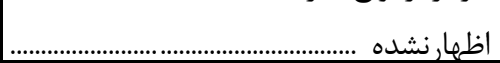 \\
\hline
\end{tabular}




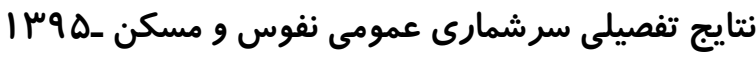

צr - 1 - جمعيت +1 ساله و بيشتر بر حسب جنس، وضع زناشويى و وضع فعاليت

\begin{tabular}{|c|c|c|c|c|}
\hline \multicolumn{3}{|c|}{ جمعيت فعال } & \multirow{2}{*}{ 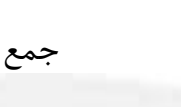 } & \multirow{2}{*}{ جنس و وضع زناشويى ل } \\
\hline بيكار & شاغل & 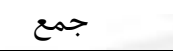 & & \\
\hline rraAria & rrgv. q11 & roqrqT.r & eqferla19 & , n \\
\hline rrvadrr & $19411 \mathrm{~kg}$. & $r / \Delta 9 . . r r$ & rragrgir & 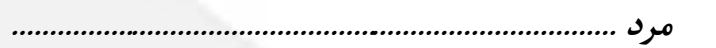 \\
\hline VFqVDr & $19 \cdot r \wedge \Lambda \wedge V$ & 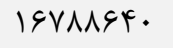 & rITDQYGQ & 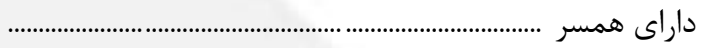 \\
\hline mFV & $1 \cdot 91 \cdot 4$ & IITUVD & rтq.ri & بىهمسر بهدليل فوت هم \\
\hline grolv & $r F V \cdot G \Lambda$ & $r_{1} \cdot \Delta \wedge \Delta$ & 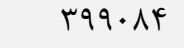 & 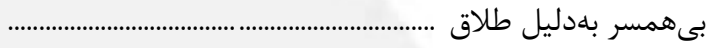 \\
\hline $\mid$ |FITH & $r q \mid r \cdot \Delta \cdot$ & FTVOHAI & IIDDVArV & 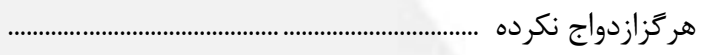 \\
\hline$\Delta \cdot \cdot$ & tral & rADI & $|V r q|$ & 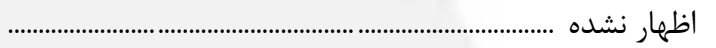 \\
\hline qvagpr & rraqQTA & frugivi & rrabqrry & 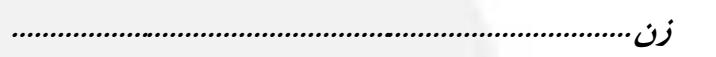 \\
\hline TIV.r & TINTYFF & $r \Delta \cdot r q F V$ & $r \| K \cdot \Delta r T$ & 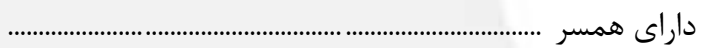 \\
\hline ध^१५ & THFTIK & TFII.G & 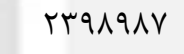 & بى همسر بهدليل فوت هم \\
\hline DTqFF & $|\wedge F \vee \wedge|$ & rTVVTD & VITVAT & 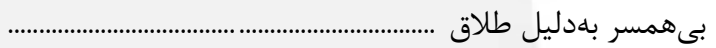 \\
\hline 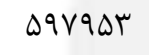 & $V \Delta \Lambda \cdot r \Delta$ & 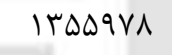 & 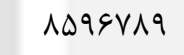 & 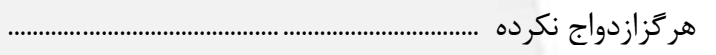 \\
\hline $10 \cdot$ & red & fid & $1 \cdot r 99$ & 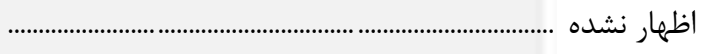 \\
\hline raritar & IEAFFTAA & $19 \cdot q \Delta \Delta F$ & 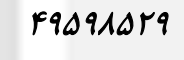 & 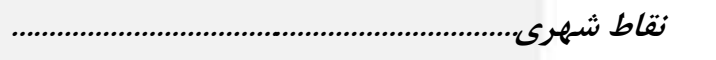 \\
\hline$|v| 1 \cdot q \cdot$ & $I r q \Delta T F \cdot \Delta$ & $1 \Delta \& V \cdot F q \Delta$ & rFqFT. DQ & مرد .................... \\
\hline$\Delta \Delta r q 1 q$ & METFYIF & ITIVRITH & DONFTHFq & 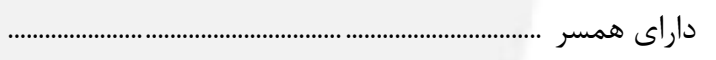 \\
\hline TINF & $99 \wedge \Delta 1$ & $99 \cdot r \Delta$ & TrTETQ & بىهمسر بهدليل فوت هم \\
\hline$\Delta F \wedge F q$ & $r \cdot r q \cdot \varphi$ & $r \Delta \vee V \Delta \Delta$ & ( & بىهمر بهدليل طلاق ...... \\
\hline $11 \cdot \vee \vee \wedge 9$ & $r \cdot \Delta q V \vee q$ & 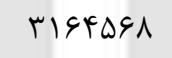 & $\wedge \Delta \mu \cdot \wedge \varsigma \Delta$ & 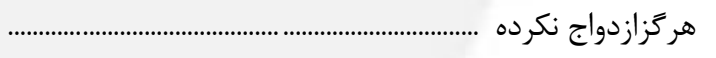 \\
\hline req & $19 \Delta \Delta$ & $r \cdot r$ & ITVGN & 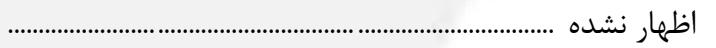 \\
\hline $1 \cdot r / 9 r$ & raqIADr & $r \mu q \Delta \cdot F \Delta$ & FFEDFFYF & زن ............................. \\
\hline rVTqYD & 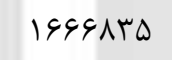 & 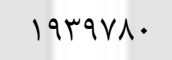 & $|\Delta \vee 9 \wedge \Delta \Delta|$ & 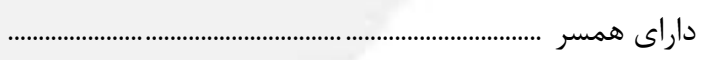 \\
\hline$\Delta 19$. & $\mid 01 \cdot 1 \mathrm{~V}$ & IDSIVV & IVD. GYF & بى همسر بهدليل فوت هم \\
\hline FVD.. & 19909 & rIf.q. & $91 \cdot \wedge f q$ & 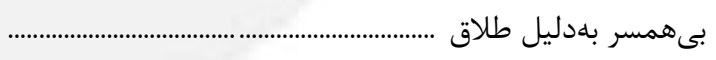 \\
\hline FVVFA & $G \cdot V T \cdot \cdot$ & $1 \cdot \wedge F \& \wedge \Lambda$ & SYANVIF & 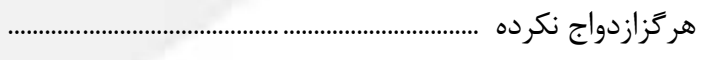 \\
\hline 99 & YII & ו. & VVre & 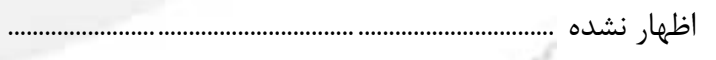 \\
\hline vrabAr & gl. pref & g1rqqFy & ievarfin & 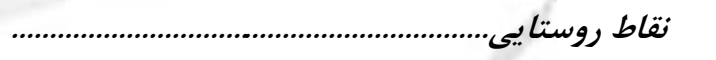 \\
\hline$\Delta \Delta q \Delta \Delta F$ & DrFYFDq & Dq.rrir & $10911 \cdot 9$ & 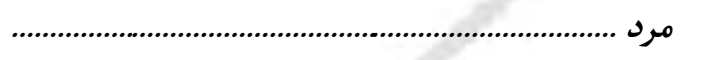 \\
\hline 199VVr & $F F \cdot r v \cdot q$ & $\forall q \ldots+\wedge 1$ & $\Delta F \cdot F V \backslash \Lambda$ & 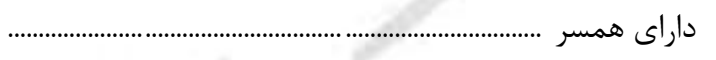 \\
\hline ITAF & $k t \cdot i r$ & prtap & $1 \cdot 9 \cdot 14$ & بى همسر بهدليل فوت هم \\
\hline$\wedge \notin \Delta ।$ & FrAtr & DYFVA & GATrT & 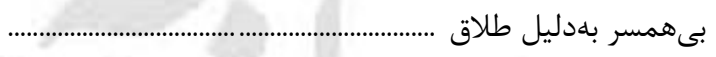 \\
\hline$r \Delta r V \cdot I$ & NDTFYT & $M \cdot \Delta I T F$ & $r \cdot \mid V q \cdot 9$ & 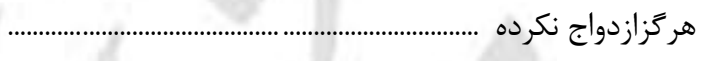 \\
\hline If4 & \&ヘV & 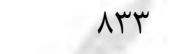 & rord & 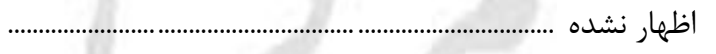 \\
\hline $1 V q \cdot r q$ & $V q I V \cdot \Delta$ & qrvpre & Alakrir & زن.......... \\
\hline FAVTG & DIISTI & $\Delta \varphi \cdot T F V$ & ( & 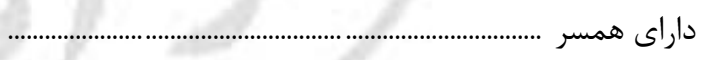 \\
\hline$|V T|$ & ATArd & NFDGG & SFVFII & 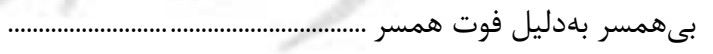 \\
\hline DFF. & $111 \% 9$ & rrusq & $1 \cdot 1119$ & 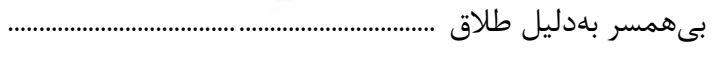 \\
\hline $\mid r \cdot \lambda r$ & $1 F q \cdot V r$ & r\&q।QV & $r 1 \cdot 194 r$ & 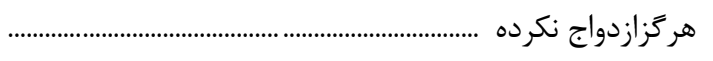 \\
\hline$\uparrow \wedge$ & FV & $9 \Delta$ & rFqG & اظهار نشده ..... \\
\hline
\end{tabular}




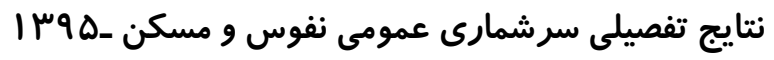

צץ - 1 - جمعيت +1 ساله و بيشتر بر حسب جنس، وضع زناشويى و وضع فعاليت (دنباله)

\begin{tabular}{|c|c|c|c|c|c|c|}
\hline \multirow[b]{2}{*}{ 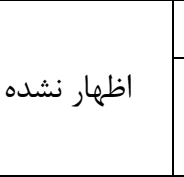 } & \multicolumn{5}{|c|}{ جمعيت غير فعال } & \multirow[b]{2}{*}{ 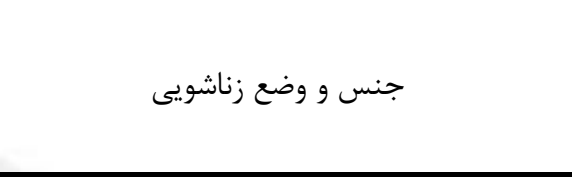 } \\
\hline & ساير & داراى درامد & خانهدار & محصل & جمع & \\
\hline reIVIf & revarte & rrrarrr & $r \cdot \Delta \&$ Sqr. & $|r r g| \& q 1$ & $r \cdot r r l \cdot v r$ & 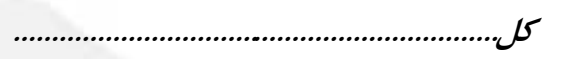 \\
\hline rrisar & rrqg.l. & rı19я9. & irgater & sriaral & $11 \mathrm{VF} \cdot \mathrm{grr}$ & مرد ............... \\
\hline IFITVA & $\mid 1 \pi \mu \cdot 91$ & TVIVTMA & VG4ab & f.l krv & Frrqual & 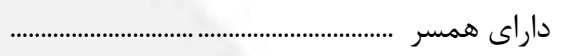 \\
\hline far & NQTGV & $11 \cdot \lambda \cdot \Delta$ & ।А५৭६ & 1 1т94 & rIDQGY & 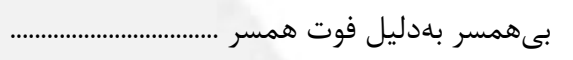 \\
\hline TERT & Frt. & rETAN & ferl & 11891 & $\wedge \Delta \wedge \varsigma \vee$ & 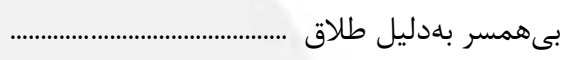 \\
\hline VDFYA & IITYVE. & rFqGV & rVDAT & 09.1999 & $v 1 \cdot v \cdots \wedge$ & 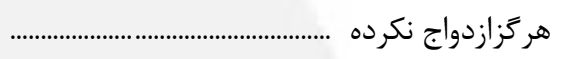 \\
\hline $111 \cdot V$ & 9IT & IFT & rA & 1901 & TVRT & 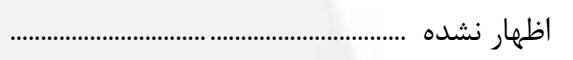 \\
\hline$r \cdot \Delta \Delta r$ & IrATrif & ATSAFV & r.errare & $\Delta q F F F I$. & $r A F q .1 F q$ & 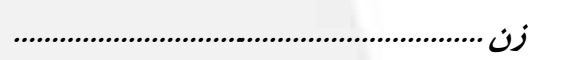 \\
\hline IVrVV & FIGATV & TrVTIT & IVTV·rAr & G. FFV & 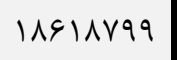 & داراى همسر ......................... \\
\hline IrQ9 & 199909 & FIDQAT & IDSVAND & 9194 & TIDSOAD & بى همسر بهدليل فوت هم \\
\hline $1 \ldots k$ & frite & FAqIT & 音 & fISVV & $F V F \cdot \Delta r$ & بىهمسر بهدليل طلاق .. \\
\hline 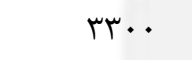 & $9 \Delta T \cdot 9$. & $\varphi \& \Delta \Delta q$ & 1 IFqr. & $\Delta Y \wedge 9 \Delta \wedge \varsigma$ & VTRVDII & 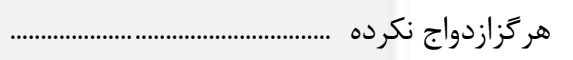 \\
\hline 991. & rra & INT & $1 \cdot \wedge \varepsilon$ & $10 \cdot 1$ & $r r \cdot 1$ & 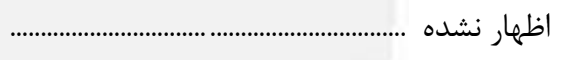 \\
\hline IVITEF & TFEAMA. & rriver. & $1 F q 1 \cdot v \cdot v$ & $9 \Delta 9 F F 11$ & $r \cdot r \varepsilon \mid g f d$ & نقاط شهرى................ \\
\hline $1 a \cdot r \Delta \varepsilon$ & $18 \cdot 1 \mathrm{raA}$ & ragfq.r & 9) frer & FAD\&gl. & qIrIT.F & مرد ......... \\
\hline $91 r \cdot f$ & $V \varepsilon \Delta \Delta V$. & TYIQDG. & $\Delta T \cdot Y I$ & rMgVal & rQVrqाr & 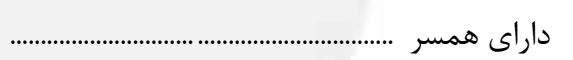 \\
\hline TrF & FVDIF & qTaTV & $M 11 \mu F$ & 1.90 & lQTrV. & بىهمسر بهدليل فوت همسر ......... \\
\hline lerv & rG. rr & TFFts & rFA. & $1 \cdots 94$ & $V F \cdot \Delta r$ & 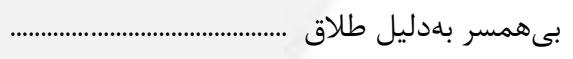 \\
\hline FADFT & VANVIT & TVTEV & TFVAD & $r \Delta \cdot v \cdot l$ & DTIVVDF & 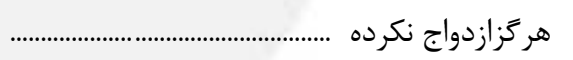 \\
\hline$\Lambda \Delta F \Lambda$ & 419 & 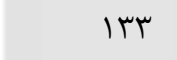 & Ir & 1901 & rte & 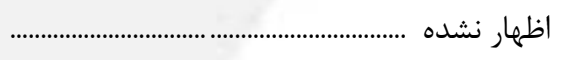 \\
\hline$r \cdot 911$ & $19.84 t$ & varrrr & IFAAqTVF & rvrrd.1 & rITF. FFI & زن.................................... \\
\hline ITEVT & rQDQTT & $r 1 \cdot r \cdot q$ & IrVIq9AT & $\Delta T \cdot Y \wedge \Delta$ & IrNFET & 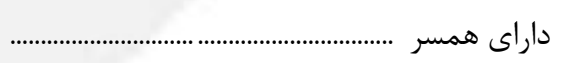 \\
\hline$\Lambda \cdot \Delta$ & 1. TAYT & raviar & IIrAIVA & $\Delta F \wedge q$ & IDQYGFT & 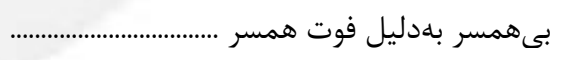 \\
\hline$\Delta \wedge r$ & rNTat & frres & $r V Y \cdot \cdot \Delta$ & rVTar & ragiv & 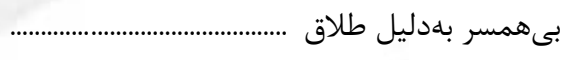 \\
\hline trat & FTHETV & fivru & VGTrG. & fIVTIIN & $\Delta F \cdot I V A T$ & 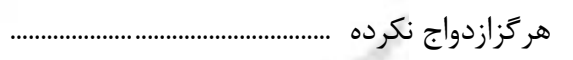 \\
\hline rAFs & rq1 & 199 & veq & Iret & $r \Delta \Lambda \cdot$ & 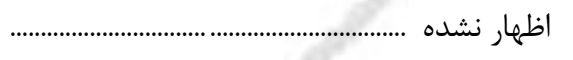 \\
\hline$q \cdot r \cdot r$ & $\| r \cdot V F \mid F$ & f.vrre & $\Delta \Delta Y F A I D$ & regrid & qAarreq & نقاط روستا يیى......... \\
\hline $11 r \cdot 9$ & VADSAV & MTFDFF & FafIV & $1 F \Delta q \cdot 18$ & TEIFEAF & 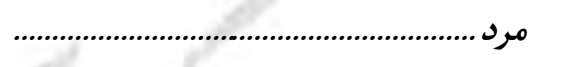 \\
\hline $4 q 94 \wedge$ & rqVQV. & rqvevV & TFF. r & grerq & VQFTAq & 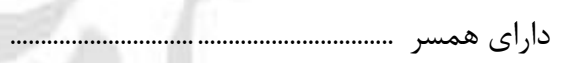 \\
\hline $18 \mathrm{~V}$ & trVEt & $I V T \Delta \cdot$ & VKG. & ras & GTOL. & بى همسر بهدليل فوت هم \\
\hline 990 & VITV & $|94|$ & 99. & IV.r & llve. & بىهمسر بهدليل طلاق .......... \\
\hline 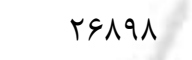 & $r V r \cdot 91$ & V\&AV & ITVEq & IrqT.AV & $I V \wedge \Delta \Delta \wedge F^{\prime}$ & هركزازدواج نكرده ....................... \\
\hline$r+1$ & $1 \wedge V$ & & 10 & rq. & $0 \cdot 1$ & 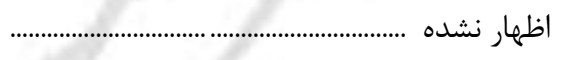 \\
\hline 1994 & eriver & Arval & DorquqA & $1 r \cdot r r \cdot r$ & VrrraAa & 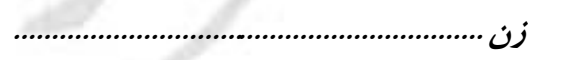 \\
\hline DrAF & $|r \cdot 9 r|$ & 19911 & FAFTIDT & ᄉrq৭। & FVGD.rr & 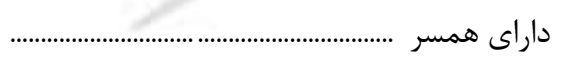 \\
\hline $4 q$. & $\varepsilon q \cdot Y l$ & $\Delta \Lambda F \cdot r$ & crqTळq & $9 V r$ & $\Delta G Y T \Delta \Delta$ & بىهمسر بهدليل فوت همسر .............................. \\
\hline Frt & $\Lambda \vee V r$ & Toft & GTIAV & FrTd & VVATA & 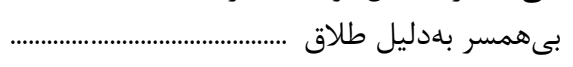 \\
\hline $1 \cdot 11$ & rTYANA & rNit & FAFFED & $11148 \cdot r$ & IATIVAT & هر گزازدواج نكرده ............................................. \\
\hline IVAS & ITV & ir & rme & $|4|$ & 910 & 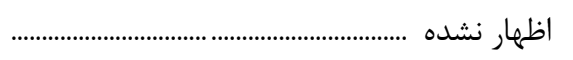 \\
\hline
\end{tabular}


VV - 1 - زنان •ا ساله و بيشتر بر حسب سن، وضع زنساشويى، تعداد فرزندان زنده بـهـدنيا آورده و در حسال حاضر زنده زنان حداقل يكبار ازدواج كرده

\begin{tabular}{|c|c|c|c|c|c|}
\hline \multirow[b]{2}{*}{ زت تعداد كل فرزندان } & \multicolumn{3}{|c|}{ زنان حداقل يك بار ازدواج كرده } & \multirow[b]{2}{*}{ ز زنان · •ا ساله } & \multirow[b]{2}{*}{ 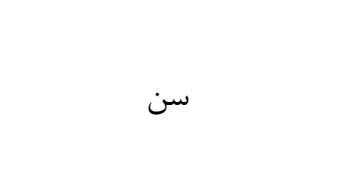 } \\
\hline & حرزندان زنده به زبه دنيا آورده يا در & حرز حال حاضر زنده زنده را اظيهار كرده آ درد در & جمع & & \\
\hline $9 \Delta 9 \Delta \cdot 1 \mu 1$ & frfa. & rfr.vq.q & rFTaDTaF & rrabqrry & 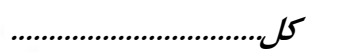 \\
\hline$\Delta V F \Lambda$ & $r \cdot 9$ & rvirq & TVFYA & rVYGQ৭। & fe \\
\hline IVESA. & $9 \uparrow \wedge$ & DVTAF. & DVFESA & TEVTr.q & |a-19 اله ........................... \\
\hline$|r q T| \Delta$. & riva & $I V A \cdot I I T$ & IVArTAV & $r \mid \Delta \Delta q \cdot F$ & (Tاله ............... \\
\hline$r \Delta V \vee q \Delta F$ & $\Delta \varphi \Delta \Delta$ & r. ૧V९६ & 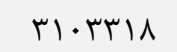 & $r \cdot \Delta \vee \& \wedge \Lambda$ & qra-............................. \\
\hline$\Delta V q \Delta \& q \Lambda$ & 9099 & $r q \cdot v q \cdot \Lambda$ & $r q \mid r \Delta \cdot V$ & FrG. FED & \\
\hline GYFVADG & q.. & $r . q \Delta F q T$ & m. IFqG & MYADI9D & q q \\
\hline GTETAVT & qv. & rDISITE & $r \Delta T \cdot \Lambda T V$ & tr.fFIV & wly \\
\hline $91.919 \vee$ & 4१९. & rr\&q4qI & TYYrGNI & rrVএৎ৭९ & ㄴ......................... \\
\hline gq91FqT & TFtr & INAVTrT & 119.990 & $190 \cdot r 9 V$ & (ساله .......... \\
\hline VETIVAS & riM & 1841991 & IEFDIVq & $191 \cdot 909$ & ............... \\
\hline $99999 \cdot 1$ & trYe & ITEVV.r & IrV.rtq & $\mid$ |r८११|. & (q \\
\hline IfFF\&q9. & GDFT & TFTEFAN & $|F| F|\cdot| q \mid$ & TFEDVVG & 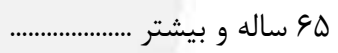 \\
\hline FerdAAIA & rrall & 1A1rarir & IAIETIrr & TFEDEFVF & نقاط شهرى ............... \\
\hline MI\&A & $r \cdot 9$ & $1991 \%$ & IVITK & $1911 \cdot \Delta V$ & 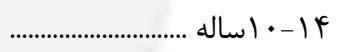 \\
\hline$q \mu \Delta q \uparrow$ & 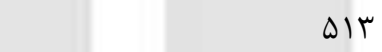 & гт৭८१ & MF. F.G & $190 \cdot r \cdot r$ & 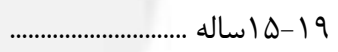 \\
\hline$\Lambda \cdot 1 r \cdot 9$ & $r \cdot . \varphi$ & Irrq999 & Irrt..r & TrוgVrA & 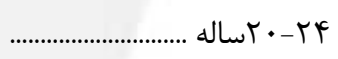 \\
\hline TFDIFFA & гятq & rTINGIF & TrTTDQT & r.vGFIf & q \\
\hline fr...pr & fref & $r \Lambda \cdot \subseteq \Delta ૬ \varphi$ & r人וrা. & • & ץ ·r................................. \\
\hline FEVTHIT & FT. & Trqsरा9 & TF..FTS & ТяЯт৭४⿻ & 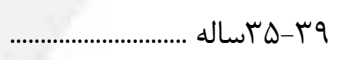 \\
\hline FATVES. & TTMA & 19r.rव९ & I9THGAF & $r \cdot \Delta \mid \Delta F$. & .......................... \\
\hline Fq1901V & rव९ा & IVFVGG. & $|V \Delta \cdot G T|$ & INTAY.r & ........................... \\
\hline $0 . r r \wedge \& 9$ & TFFV & IFAFqVT & IFDVFT. & $10 \cdot F V V \mid$ & ........................... \\
\hline$\Delta T r \cdot 99 q$ & riso & ITrVGar & $\mid r r q \wedge \Delta \Lambda$ & $|r \& \Lambda \Lambda \Lambda|$ & ..................................... \\
\hline rQNT.rr & $1 \wedge \Delta 9$ & qMTITV & १५т११९ & 90.111 & 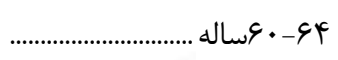 \\
\hline $914 \pi 190$ & fere & IVTAYAT & IVTTVTS & IVATTqT & 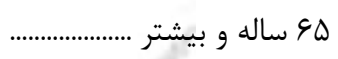 \\
\hline lqAFVqq1 & lfr.. & 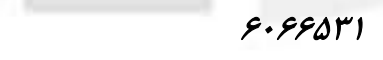 & $8 \cdot 1 \cdot 1+1$ & AlAFTIT & نقاط روستا ييى............. \\
\hline$r \Delta V I$ & 99 & $r \cdot r \cdot q$ & $r \cdot r \cdot \Lambda$ & vq4..v & 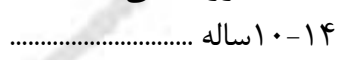 \\
\hline $1 \cdot 91$. & $r \cdot \Lambda$ & trutik & TMTVtr & $V T \| 191$ & 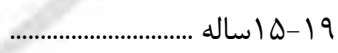 \\
\hline rq... & 1114 & DFqYA. & $\Delta \Delta \cdot F \cdot \varphi$ & ArFIGD & \\
\hline llTrtar & $19 \wedge \Delta$ & VVVVDV & VYGFET & 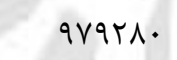 & q \\
\hline$|\Delta q T F| D$ & TMT & А....r & A.INTS & $q \uparrow q \Delta V$. & ץ · •r \\
\hline$I V V \cdot A T V$ & IVGT & gqvVt. & $9990 \cdot r$ & V৭१५द & 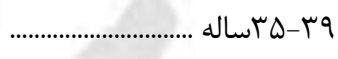 \\
\hline$|1 \cdots| \varepsilon 1$ & IrrV & DqFTLT & DQQVTq & $9 \Delta 1 r \cdot 9$ & 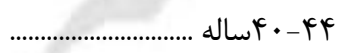 \\
\hline IMAFEFV & 1191 & $\Delta T \cdot F q \Delta$ & $\Delta T I G \wedge G$ & $\Delta F \wedge \neg \& \Delta$ & q \\
\hline $19 Y \wedge 019$ & $q 4 q$ & prl.99 & FHT. FD & fefrqu & $\ldots$ \\
\hline 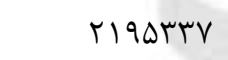 & १४४ & f.r.r.q & F. Fras & FI. VTA & ............................. \\
\hline$r \cdot \Lambda \cdot r \wedge \varphi$ & $\Lambda F \Delta$ & rmFVAl & rTDGTS & rr人qV4 & 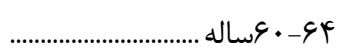 \\
\hline FAQVATK & $r \cdot q V$ & $V \cdot 0190$ & V.VYYYT & VITrqY & هو ساله و بيشتر . \\
\hline
\end{tabular}




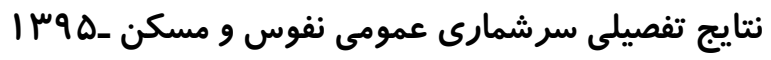

VV - 1 - زنان •ا ساله و بيشتر بر حسب سن، وضع زنــاشويى، تعداد فرزندان زنده بــه دنيا آورده و در حسـال حاضر زنــده زنــان حداقل يكبار ازدواج كرده (دنباله)

\begin{tabular}{|c|c|c|c|}
\hline وضع زناشويى اظهار نشده & 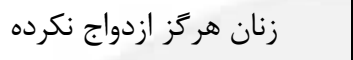 & تعداد فرزندان درحال حاضر زنده & 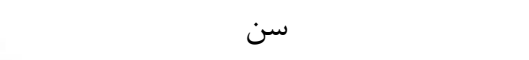 \\
\hline verr & $1 \Delta 99 \vee 19$ & ETFYFADD & 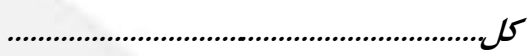 \\
\hline $1 . k \Delta$ & TVKAFEA & $\Delta \& \Lambda$. & fle \\
\hline १४६ & $r \cdot 9 \wedge \wedge \varepsilon \Delta$ & $1 V \pi 119$ & 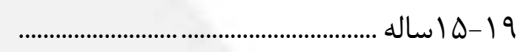 \\
\hline INkG & $|r v \cdot v \wedge|$ & $I T \Lambda \cdot r \Lambda T$ & (ساله \\
\hline v91 & 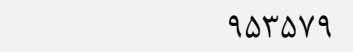 & TQFTIIT & .................... \\
\hline f. 9 & $G Y \Delta \Delta \Delta \Delta T$ & $\Delta V T \Delta q q Y$ & 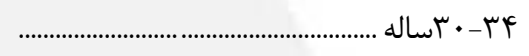 \\
\hline$r \Delta \Delta$ & TEMFEF & grFrulq & q \\
\hline IFt & IATEMA & GI QFYFF & ......... \\
\hline 149 & $1.4 \wedge 9 \varphi$ & 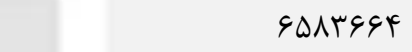 & 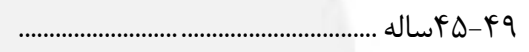 \\
\hline 19. & $\Delta q \Delta V r$ & $999 \cdot 9 \cdot 0$ & (ساله \\
\hline rl. & raTr. & V.. GKFT & .......... . . . \\
\hline 194 & $19 r \wedge 9$ & ब1994.V & ...................... \\
\hline $1 \cdot v \cdot$ & rme9d & ITVIIAMV & 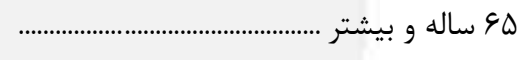 \\
\hline$\Delta \mathscr{Q r r}$ & sFAMVIF & rrqq.rar & نقاط شهرى............ \\
\hline VHe & $199 \pi \mathrm{T} \cdot 1$ & आ11 & 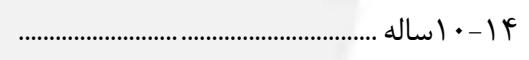 \\
\hline$V \notin q$ & 19.91199 & १५५ १४ & 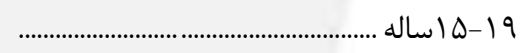 \\
\hline $19 \mathrm{VV}$ & $1 \cdot 19 \cdot 4 q$ & Vqrqur & F \\
\hline 991 & VQTT.. & TETVYGI & ................... \\
\hline r19 & Fqva.1 & $4 \mid 0.901$ & F \\
\hline $1 M 1$ & TEMTrT & Fจ৭१९।९ & q \\
\hline q. & IrVVG9 & FFrg.rF & (1) \\
\hline $1 \cdot 0$ & VVDVe & FVGre. & 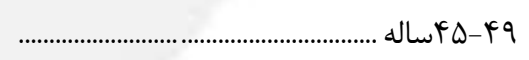 \\
\hline 119 & FVrTa & rArti. & 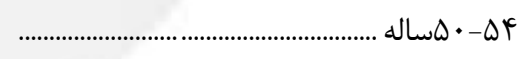 \\
\hline $\mid F \wedge$ & TAMVD & FAFFFAG & $\ldots$ \\
\hline 1re & 10999 & FTVTYTE & q \\
\hline VYF & INAKr & ヘ९DHKGY & 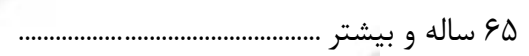 \\
\hline $10 F q$ & rl. $194 r$ & IAFrrase & 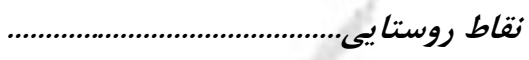 \\
\hline$r \cdot 9$ & vVrrq. & $r \Delta \Delta T$ & (س) اله \\
\hline rtr & FMATIS & $\Lambda \cdot r<q$ & a 19 اساله \\
\hline $10 \Delta$ & rArg.r & FADGTA & (.................. \\
\hline 1re & 199715 & 111 rvq1 & q $q$ ra \\
\hline 11 & lfVGq & IAVTIGY & ץ \\
\hline 41 & १९४१४ & । ४rवя८৭ & q q \\
\hline is & $\Delta \Delta \Delta r Y$ & IVATTAD & ................... \\
\hline & rVTra & $1 M \mid F F \wedge 9$ & ................... a \\
\hline er & $1 r r \cdot q$ & IATrIFF & (w) \\
\hline$\Delta \wedge$ & grvf & $r \cdot \Delta 9909$ & . \\
\hline q4 & rTAF & 1919109 & 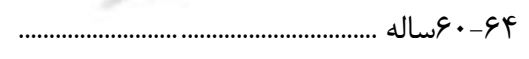 \\
\hline ret & $4 \wedge \cdot 9$ & $\varphi \cdot \Delta r \cdot G$. & 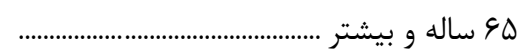 \\
\hline
\end{tabular}




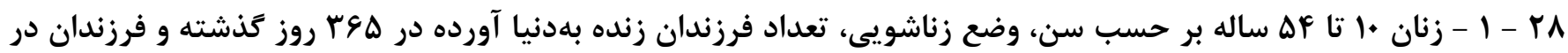

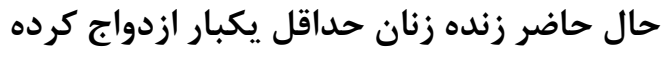

\begin{tabular}{|c|c|c|c|c|c|}
\hline \multirow[b]{2}{*}{ تعداد كل فرزندان زنده } & \multicolumn{3}{|c|}{ زنان حداقل يك بار ازدواج كرده } & \multirow[b]{2}{*}{ 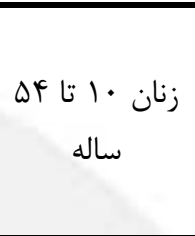 } & \multirow[b]{2}{*}{ 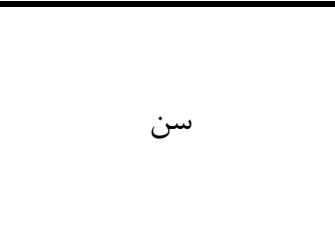 } \\
\hline & 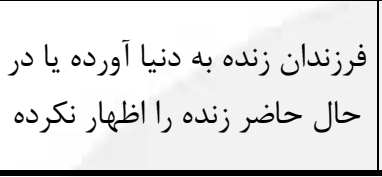 & 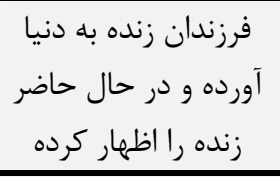 & 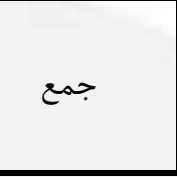 & & \\
\hline $\mid F F \lambda \cdot F q$ & rrqgv & IAAEAVE. & $111991 \mathrm{~V} \cdot \mathrm{V}$ & rVFTr.re & 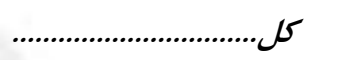 \\
\hline$\Lambda \wedge \vee$ & $r \cdot v$ & rV|f| & TVFFA & rVV९9৭I & 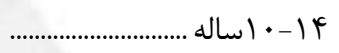 \\
\hline घ9人ঙ. & $9 \cdot 9$ & $\Delta V Y \Delta \Delta q$ & 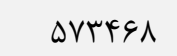 & TEVRT.q & 19-1 ا ساله ............. \\
\hline 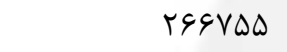 & $\mu \cdot \mathrm{V}$ & $|\vee \wedge \cdot| \Lambda \cdot$ & IVATYAV & $r \mid \Delta \Delta q \cdot F$ & F \\
\hline$F r \cdot v \varepsilon D$ & $\Delta r \cdot \varphi$ & $r \cdot 9 \Lambda \cdot 1 r$ & & $r \cdot \Delta V \& \wedge \Lambda$ & q $q$ q- \\
\hline$k \cdot|\Delta| V$ & GTצA & rq. & 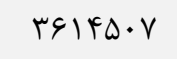 & FTG. KGD & 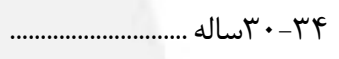 \\
\hline 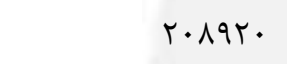 & $\Delta \Delta \wedge \Delta$ & $r .90911$ & r. 1499 & MFEDI9D & 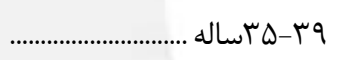 \\
\hline$\Delta q \mu I f$ & FTIt & TQIGQTA & $T \Delta T \cdot \wedge r V$ & TV.FFIV & (ft \\
\hline $11 \cdot 19$ & rAGF & rTS9NIV & TTRYGNI & rrVAя9я & (q q \\
\hline$\Delta \cdot k T$ & r & IAMVTDS & 119.990 & 19०.r१У & (هاله \\
\hline 1.rrgar & ruive & Ifrerrey & IFTDSDFF & r. sADIAT & نقاط شهرى. \\
\hline (1). & $r \cdot r$ & 19910 & IVITK & $1911 \cdot \Delta V$ & 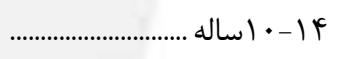 \\
\hline$r v \cdot r \Delta$ & FAD & l & $M F \cdot F \cdot G$ & $190 \cdot r \cdot r$ & 19-19 ا ساله ............ \\
\hline IVDI99 & $19 \Delta \Delta$ & 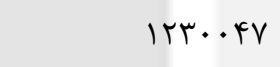 & ITrt..r & TrIGVTA & 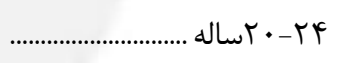 \\
\hline TITATa & rri. & THMAKT & THTTDQT & r.vafif & q \\
\hline$r \cdot \Delta \vee \Lambda$. & F\&qq & $r \Lambda \cdot 9 \Lambda 1 I$ & rNIIrা. & . & fr \\
\hline IDQGTD & ए৭९८ & rragFor & TF..FTD & 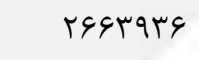 & 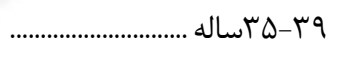 \\
\hline гqтал & $r \cdot 91$ & $19 T \cdot \Delta \Lambda 9$ & I9rrgAF & $r \cdot \Delta I \Delta Y$. & 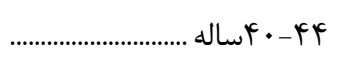 \\
\hline VEr & rNiQ & $\mid V F V \lambda \cdot \varphi$ & $|V \Delta \cdot G T|$ & INTAK·r & q q \\
\hline TATr & retq & $|F \Delta F q \Lambda|$ & IFAVFT. & $10 \cdot F V V \mid$ & 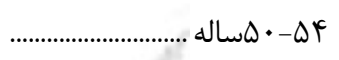 \\
\hline f. qre. & qavr & rerre.qD & remregs & surrele & نقاط روستا ييى............. \\
\hline erv & 99 & $r \cdot r \cdot q$ & $r \cdot r \cdot \Lambda$ & $\vee q 4 . . v$ & f أ-• اساله ... \\
\hline rqvזם & fir & 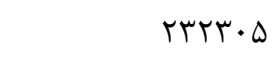 & TMTVtr & $V T \| 191$ & 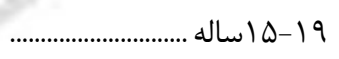 \\
\hline $914 \cdot 1$ & $111 \pi$ & DFqRqT & $\Delta \Delta \cdot \varphi \cdot \varphi$ & NTFISD & F \\
\hline||$V \cdot r \mid$ & 1099 & VVVAVT & BgGeft & १४१५^. & qז-ט זساله .... \\
\hline $9 \Delta \Delta \wedge$. & IVF. & $1 \cdots \wedge 9$ & $\Lambda \cdot 1 \Lambda T s$ & $q \uparrow q \Delta V$. & 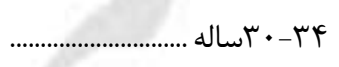 \\
\hline$\Delta r \mid 9 \Delta$ & $1 \Delta \wedge \Lambda$ & 997910 & $9990 \cdot r$ & V৭qrदर & 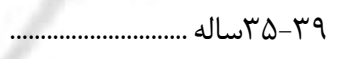 \\
\hline IGAVG & 1119 & $\Delta q Y \Delta \Delta$. & $\Delta q \Delta V Y q$ & $9011 \% \cdot 9$ & F \\
\hline$r \Delta \wedge \Delta$ & D.tr & $\Delta T \cdot G G Y$ & $\Delta r \mid 9 \wedge 9$ & $\Delta F \wedge १ \& \Delta$ & ........................... a \\
\hline$|\Delta|$. & $\Lambda F \Delta$ & Frit.. & FrT. FD & fefrqy & 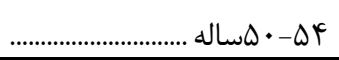 \\
\hline
\end{tabular}




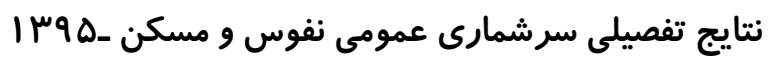

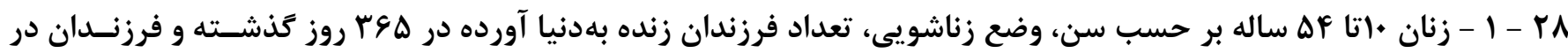
حال حاضر زنده زنان حداقل يكبار ازدواج كرده (دنباله ونساله

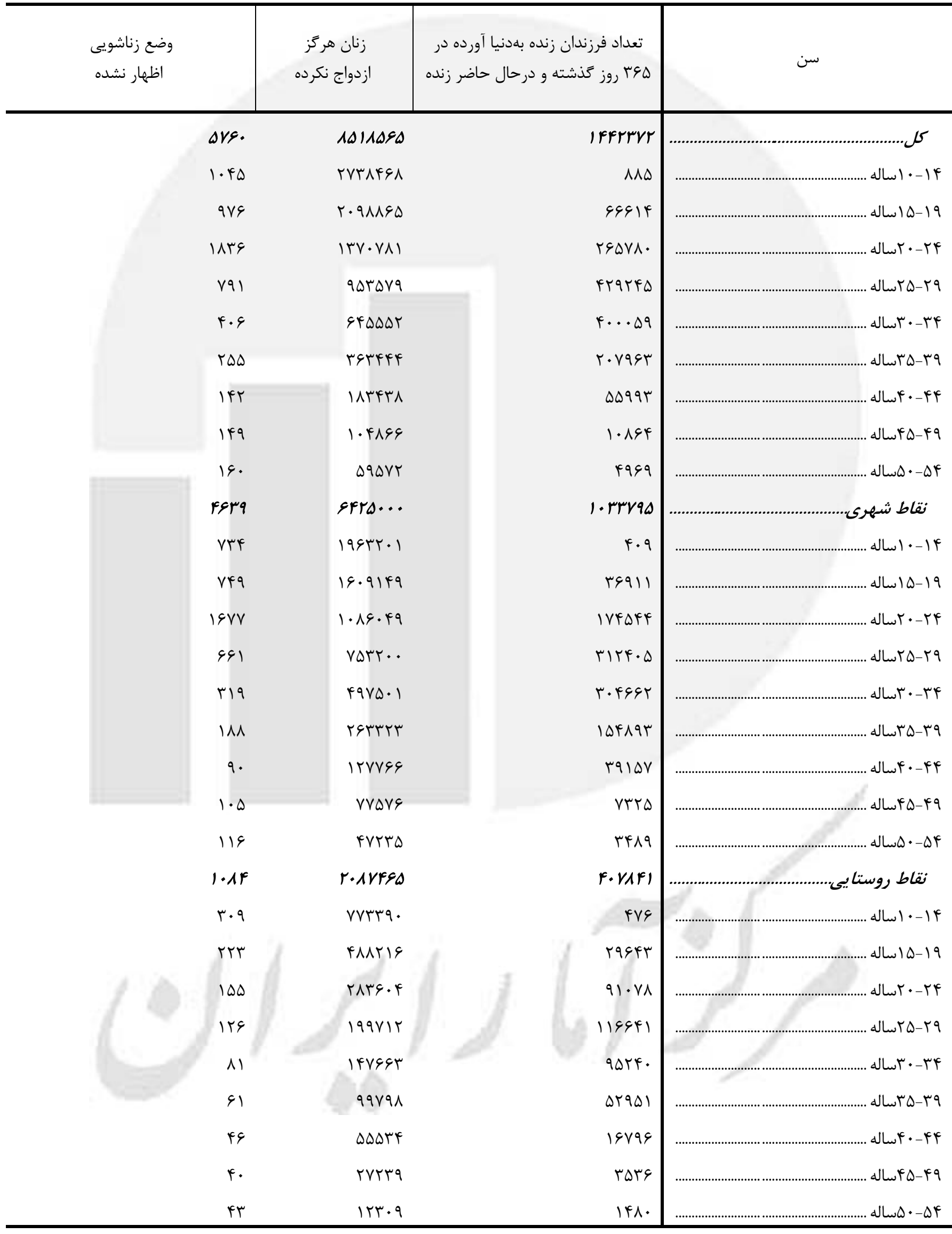




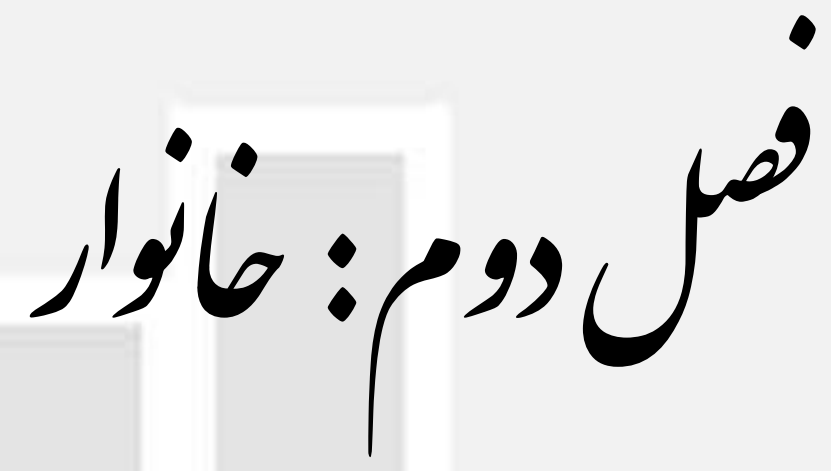




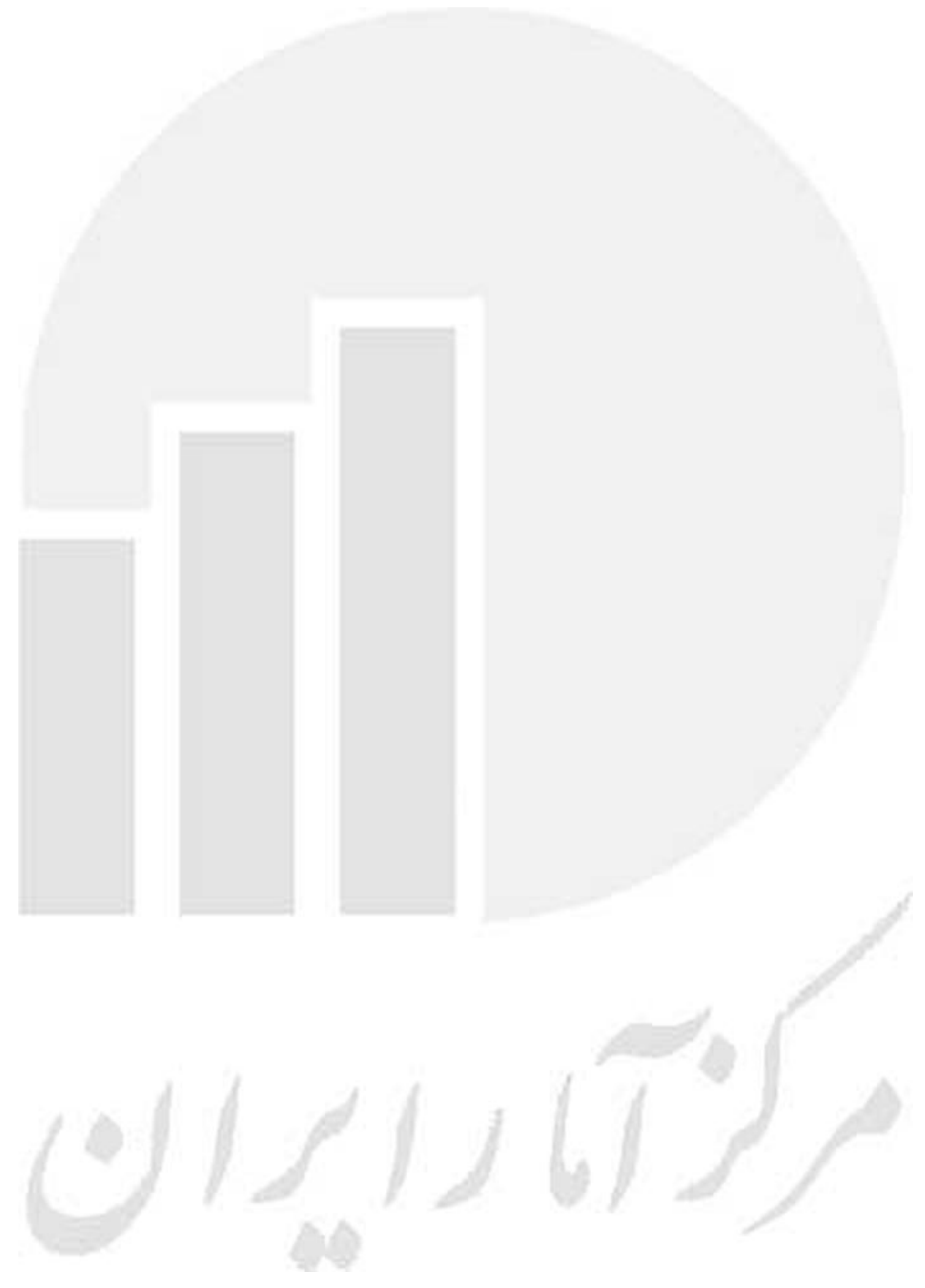



ا _ r ـ جمعيت در خانوارهاى معمولى برحسب جنس، سن و تعداد افراد در خانوار

\begin{tabular}{|c|c|c|c|c|c|c|}
\hline 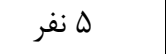 & 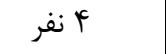 & 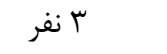 & ك ا نفر & ا نفر & جمع - اع & جنس و سن \\
\hline$|r r| a \cdot q$. & regarevt & $r \cdot \Delta 9919$. & $99 V \Delta q \Delta F$ & r. Feril & VAVYef.r & 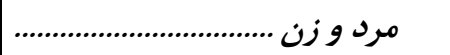 \\
\hline $114 \varepsilon 9 \cdot \Delta$ & TAFFFAI & TFTHEDS & DSFTH & . & $V \cdot \lambda F \mid F \wedge$ & ץ- • • ساله .............. \\
\hline ITrVTAF & rq৭q४⿻ & IrmqVA & Niriv & - & $q Y \cdot r \cdot V I$ & - \\
\hline IFTrAVt & TFETF.G & VETIKI & $1 \cdot 4109$ & $r V \cdot V$ & DGMGGTY & 1 \\
\hline$|r| q \mid \Delta \Delta$ & $19 \cdot 4 V \cdot \varphi$ & АDTrA. & rVr人le & TIDTE & $\Delta r \cdot q \Lambda F$. & 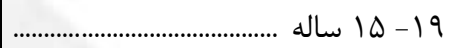 \\
\hline $1 \cdot 1 \cdot 9 \mathrm{~V}$ & IGAFTVD & $109 \wedge \vee \wedge$ & DاسM & vrfir & q. FVVGq & 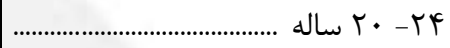 \\
\hline$\wedge \wedge \varsigma \Delta \Delta \vee$ & $r \cdot \wedge D F F G$ & TVATATF & IDDVTTY & IrQTq. & N.FTAVV & \\
\hline$q r \cdot V r q$ & 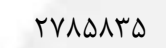 & TQDFAMA & $119 \vee T \Delta 1$ & IrGATV & NFqFTII & 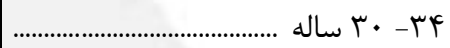 \\
\hline $1 \cdot V F \mid 9 \Lambda$ & $r \Lambda F \cdot \Lambda \cdot 1$ & INDGFTA & $\Delta \wedge 119$ & $11 \varepsilon r \cdot r$ & $999 \cdot 1 \mathrm{kr}$ & q \\
\hline 1. rGTUF & Tr. TFrt & 1191149 & rیl. & $9 \nvdash \wedge \wedge \wedge$ & $\Delta \& \& \wedge 91 \Delta$ & 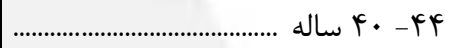 \\
\hline$\wedge r \Delta \wedge \vee \Delta$ & $|\wedge| \& q \cdot 1$ & $111 \cdot 1 \cdot 9$ & 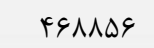 & $1 \cdot+\Delta 1 D$ & 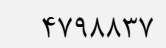 & ................................... \\
\hline 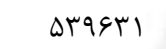 & $11 \wedge 94 \cdot 9$ & IITrADD & $Q \Delta D \cdot F V$ & $1194 \mathrm{r}$. & rq. & 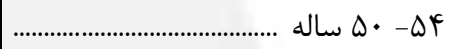 \\
\hline refqFA & VVETEq & $q 9 \cdot<q$. & NTrVeV & $|F q| \varepsilon V$ & 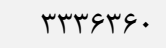 & 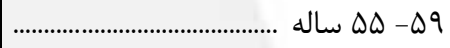 \\
\hline THT.MG & FGDVGF & $V \cdot 9 \wedge k r$ & 111991 & $|V V F| Q$ & TOMFTA. & 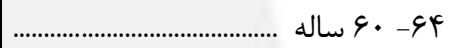 \\
\hline$M \cdot T V \cdot$ & TFAFFT & FTrVqV & $94 \cdot 999$ & 19Frve & $1 V \cdot 99 \cdot \Delta$ & 1...................... \\
\hline g9qur & $\mid r \wedge 9 \Delta \Delta$ & TFTOTF & $\forall \wedge \Delta \varphi \Delta l$ & t. tRIT & $11 V \times 419$ & ساله V V \\
\hline $11 \cdot r 9 \Delta$ & 191119 & raYAr) & VANTAq & DTVVrA & I9VTFED & 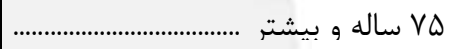 \\
\hline grg.rar & IrAFrFaD & 1. referd & $F r \cdot F F \cdot r$ & g1FVqF & rqgqrarr & 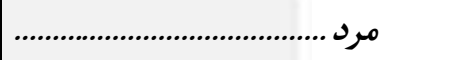 \\
\hline$\Delta q|F \Delta|$ & IFGDFFA & IYFFEVI & rAqFV & . & rGYQDI9. & f \\
\hline GVDGG. & ।QDVI9V & 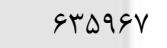 & fIrgt & · & TrNI. & q \\
\hline$V \mid q 1 \cdot r$ & $\mid r q 19 r$. & rql.rर & FAr.q & IrVt & TANTEKI & 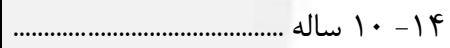 \\
\hline SYAVAS & I. TYTOA & FIDTrV & VVGDV & IrVAV & $r q|\Delta \Delta q|$ & 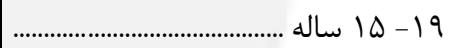 \\
\hline$G \cdot \Delta r \Delta \Lambda$ & 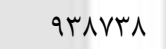 & gDTIT. & MFTFqA & $\Delta r \wedge \Delta \Lambda$ & r.IIVTr & 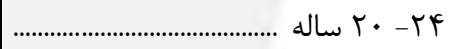 \\
\hline FVGVGr & $q F F \cdot r \wedge$ & ITrITIQ & $\wedge \Delta \Delta ৭ १ \Delta$ & ^৭ґ^৭ & $f \cdot 19191$ & q \\
\hline$r \vee v 9 \Delta \wedge$ & $1 T 11914$ & lerqfra & VTDSVA & MATVV & FTFqTAI & 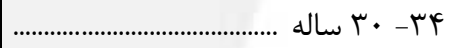 \\
\hline$F \& \| \Delta F$ & $\mid f \cdot \wedge \wedge 9 \Delta$ & $1 \cdot$ DVqFT & 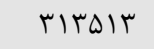 & $9 \Lambda \cdot 94$ & Ta. FTrd & q \\
\hline DTTTVT & $\mid$ ITSVRT & $\Delta q \cdot 4 q 1$ & $I \Delta V \cdot T F$ & 49q1. & rVGqqFF & q \\
\hline r\&AV.l & $1 \cdot$ IAfT. & DTITIT & $|\Delta F V| \Lambda$ & FATV. & TFTFET. & (fD - $r q$ \\
\hline rוrvi & $9 \wedge \Lambda \cdot \wedge f$ & Drrvqr & rrqศqq & rq४^s & $19 \Delta V \vee 9 F$ & •- \\
\hline$r 1.910$ & FFqfFT & $\Delta \cdot \mid f \cdot r$ & rTaFsa & rVGYq & 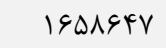 & 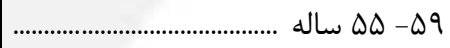 \\
\hline IrNIVV & $r V \cdot r \wedge D$ & rVDqqF & roffFe & rrifv & |TFGGT & 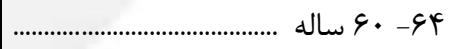 \\
\hline 99719 & IFYAMA & $r r \cdot V \Lambda \cdot$ & rAD૬rV & $r \Lambda \cdot Y \Lambda$ & $\Lambda \cdot \Delta 9 \wedge \vee$ & 9 \\
\hline 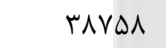 & Nrs4q & $\mid \digamma \wedge \wedge \Delta$ & TFFTMD & rबqur & DSqTKT & ساله V. $V \cdot{ }^{c}$ \\
\hline ( ) & $1 \cdot 1 \vee 94$ & $r \cdot|f| \Lambda$ & 0.9019 & IITAVD & $1 \cdot r r \cdot 1 r$ & 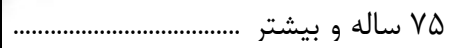 \\
\hline$\Delta q \Delta F q V A$ & Irada. IV & $1.1 \mathrm{rrin}$ & arriabr & 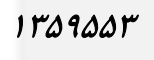 & rqIIras. & 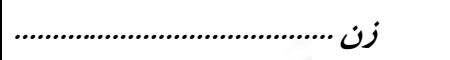 \\
\hline$\Delta \Delta \Delta F \Delta F$ & $1 r V q . r q$ & 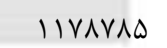 & tritir & . & 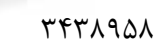 & 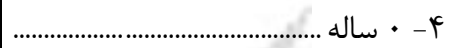 \\
\hline 99109F & IFATYGS & $091 \cdot 11$ & ५৭१८৯ & . & $|r| r \mid \cdots q$ & - \\
\hline VITrV. & $11 \vee \cdot \vee \wedge c$ & $r \Delta l \cdot q r$ & $\Delta \Delta १ \Delta$ & 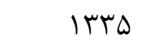 & TVDF..I & l • اله ساله \\
\hline$\Delta V \cdot r \& q$ & AVTFYA & $k r y \cdot q r$ & rq४109 & vrrq & TDQFTFq & 19 اله س.................................. \\
\hline$r q \Delta \wedge r q$ & VFDGTV & 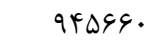 & sr. $11 V$ & $r \cdot \Delta \Delta r$ & r.r. & • • اله \\
\hline f. qvqץ & $\|f\| f \|$ & $|f \varepsilon| r \cdot \Delta$ & V. ITTV & rq..। & F. rmVIS & q \\
\hline DFTVAI & IQVRADH & ITTOFAT & FVIOVR & $\uparrow \wedge \Delta \Delta \cdot$ & FTEFAG. & 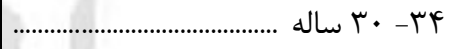 \\
\hline $9|r \cdot| k$ & $\mid 1419.9$ & 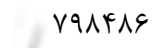 & rEVGV & FAYF. & MFDGG. & q \\
\hline$\Delta I F \cdot \Delta r$ & $1 \cdot 9 \Delta V \cdot 1$ & $q . \cdot q 4 \wedge$ & rтrq৭q & frquı & 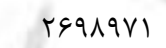 & 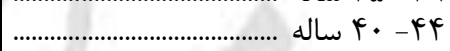 \\
\hline reVIVE & VQGYAI & 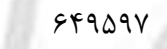 & MIFIrA & DQTFD & THETIV & 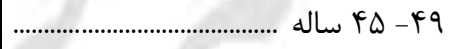 \\
\hline TrGFAT & D. ITtK & $\Delta \wedge 9 \cdot 4 r$ & FTIDFA & 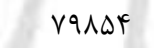 & I GFGNTV & • \\
\hline אrrfDו & TTGATV & $\vdash \wedge १ \cdot \wedge \varsigma$ & FqATAT & 111011 & IgVVRIT & 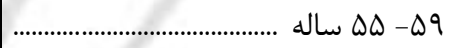 \\
\hline$q \leftrightarrow \wedge \Delta q$ & $19 \Delta F V q$ & rmrkqq & FAVTAY & IFFTEN & ITAVGFq & 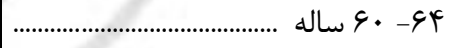 \\
\hline$\Delta 1 \cdot \Delta f$ & $1 \cdots \Delta \Delta \Delta$ & $19 r \cdot 18$ & TDQTHT & IG9TYA & $9 \cdots 911$ & 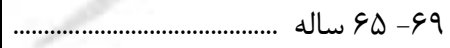 \\
\hline TAIVS & FqK. & qrदVर & TFIFIS & IVDVA. & G. DTVG & ساله V. $V \cdot{ }^{c}$ \\
\hline DGQTT & 9.99 & qufir & TVAVF. & FIDIEK & $9 \Delta \backslash F \Delta T$ & VD ساله و بيشتر ............... \\
\hline
\end{tabular}


I ـ ـ ـ جمعيت در خانوارهاى معمولى برحسب جنس، سن و تعداد افراد در خانوار (دنباله)

\begin{tabular}{|c|c|c|c|c|c|}
\hline و و بيشتر & 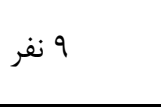 & 1 نفر & 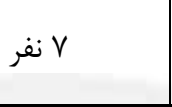 & 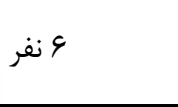 & جنس و سن \\
\hline rertir & ryvief & sqATEF & iererta & FrFFAAF & 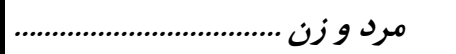 \\
\hline TETQF & TVATI & DqMTK & ITFFT. & rGDTFT & | • • ساله . \\
\hline rVDAD & Trt. & VRDIS & $|991 \%|$ & FFVETG & | \\
\hline$r \cdots \wedge 9$ & rATrt & ᄉ९VTr & t.VEVT & DrGArq & 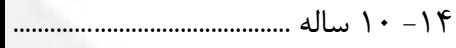 \\
\hline 音 & rvrvq & 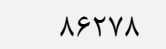 & $191 F \mid F$ & $F \wedge \Delta F \Delta$. & 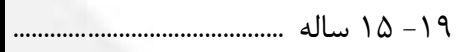 \\
\hline rQIGK & $r \cdot r v t$ & VTG.r & $|V F| \Delta q$ & FTFFqT & 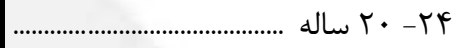 \\
\hline MATr & trtru & $\Delta \wedge r \cdot r$ & $\mid F \notin \varepsilon \Lambda$. & ५ & q \\
\hline ITVTV & $1 \wedge \cdots 1$ & $|q \Delta \wedge \&|$ & IIDGFT & $r \cdot \Delta F F$. & ץ • • ساله . \\
\hline$|r| G F$ & IEGTr & fiver & $1 \cdot \vee 918$ & mirfqg & q \\
\hline $1 \ldots 9 r$ & $\mid f \cdot . r$ & refGs & $q \Lambda \cdot r \Delta$ & H. FFV & | \\
\hline$\Lambda T \cdot r$ & IISV9 & r.rar & AFrr. & rDQFT. & | \\
\hline 9.91 & ArVV & TrG.q & $G Y \Lambda \cdot F$ & $1 \Lambda K V \cdot 1$ & |.1...................................... \\
\hline pqir & $R \cdot r$ & $19 \cdot 4 V$ & DIGAF & |rqाוr & |................................................... \\
\hline$r \Delta \cdot q$ & FAV. & ITIF & $r<q . q$ & 91.99 & 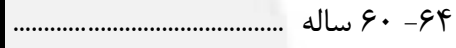 \\
\hline$r \cdot 1 \cdot$ & $r \Lambda \cdot \varphi$ & Vrri & 19119 & $\Delta \cdot 9 \vee V$ & |........................................ 90 - \\
\hline$|r T|$ & laTr & Fiᄉ. & IIrT. & $r q \Delta \wedge \Delta$ & 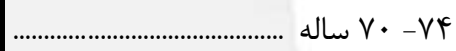 \\
\hline trag & rqlf & $\checkmark V \Delta \Delta$ & rIGTa & 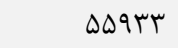 & ساله و بيشتر ......................................... \\
\hline IIrrefe & Irateg & m lrmar & Ar.prr & $r r \cdot r r \cdot r$ & 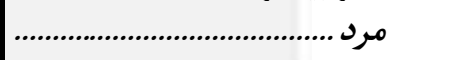 \\
\hline irfar & $|f| \mid \wedge$ & $r \cdot r)$ & qqr.r & INVFAT & 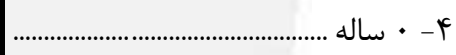 \\
\hline IrAvq & $109 \cdot 9$ & 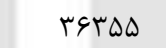 & NrFI9 & TrITIV & |..................................................... \\
\hline$|f q V|$ & INDVr & frife & १९९৯। & rDFq19 & 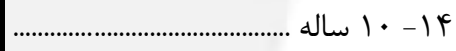 \\
\hline IQDr. & $19 r \vee 9$ & $q r v \cdot \varphi$ & $1 . \cdots 1 r r$ & rFqIrq & 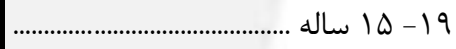 \\
\hline Irgrv & $199 \mathrm{~V} 9$ & $F \cdot \Delta V \Delta$ & 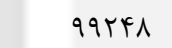 & $r F q 110$ & 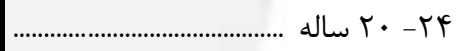 \\
\hline $91 \cdot r$ & IrFqQ & MTITH & vAvrs & $1994 \cdot 9$ & |..................................... \\
\hline GMFT & $V \vee \Delta \varphi$ & 19114 & $\Delta \cdot r \varepsilon \wedge$ & ITIVET & 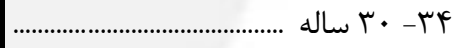 \\
\hline frre & 9|rা & lQVqF & fivat & ITETYF & q \\
\hline fife & $41 \cdot 1$ & $10 \wedge \wedge 9$ & crq. $\Delta$ & $|f T| \varepsilon \mid$ & | \\
\hline$p \cdot 91$ & $\Delta \wedge 9$. & $|\Delta r \wedge|$ & Frq11 & $114 \cdot 19$ & | \\
\hline rTDS & FFDS & $\mid r \cdot g r$ & 酒 & 1.9811 & 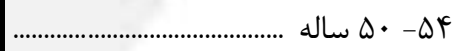 \\
\hline trAt & rqז人 & $1 \cdot \Delta 10$ & 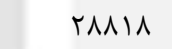 & $V \wedge \cdot 19$ & 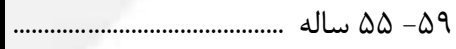 \\
\hline$r \cdot \wedge \Delta$ & tAtr & Vql. & $r \cdot r q$ & $\Delta T \cdot T \varphi$ & | \\
\hline$I r \cdot \Lambda$ & 194. & prra & $\| \Delta \Delta F$ & 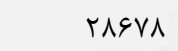 & و \\
\hline$v \Delta \cdot$ & I. & rql. & GQVq & $1990 \mathrm{~V}$ & | ساله $V \cdot-V{ }^{4}$ \\
\hline ITKG & 1010 & h.tr & $1 \cdot v \cdot 1$ & rब911 & ساله و بيشتر ...................................... \\
\hline 1.9989 & Iraste & mFrall & Alarqu & $r \mid r \cdot I V r$ & 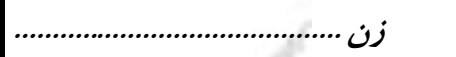 \\
\hline ITVGT & $M K \cdot r$ & $r q \cdot r r$ & 90111 & I $\vee \vee \wedge q$. & ץ- • ساله ..1.1. \\
\hline $1 \pi v \cdot \varphi$ & 19490 & rV|s| & $\Lambda \Delta V \cdot r$ & TRETIQ & | \\
\hline 10111 & 19991 & 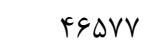 & $1 \cdot \vee \vee 91$ & rVIqT. & 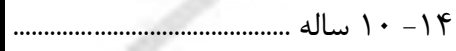 \\
\hline $\mid 4 \lambda \cdot \varphi$ & $1 \wedge \Delta \cdots$ & FTOVT & qNTqr & THETrI & 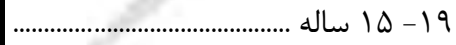 \\
\hline 11DTE & 1 14999 & rtr. & $v \notin q 11$ & IVDrVA & Y • • ساله . \\
\hline MArq & l. ver & r\&9VV & qQq4D & IEIFr & q \\
\hline VYヘD & 1. TFA & $r G \cdot r \Lambda$ & gDrVF & $\mid V r q 91$ & 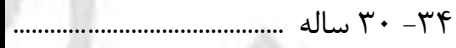 \\
\hline VFYA & $1 \cdot \Delta \cdot 1$ & rDqrq & sqird & IAVTVY & q \\
\hline DSFG & $\vee \wedge 9 \Delta$ & $r \cdot \Delta V V$ & $\Delta F I T$. & $|9| \pi \mid \Delta$ & | \\
\hline (4) & $\Delta \vee \wedge \varphi$ & IFqVT & FIrIt & $|r| F \cdot 1$ & | \\
\hline$r \Lambda \cdot \Delta$ & TATI & $1 \cdot \Delta F G$ & rqfer & $\Lambda r \cdot \Lambda r$ & 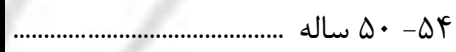 \\
\hline rir. & $r \cdot 9 \Delta$ & NDIT & TYASG & 91.94 & 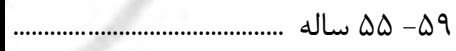 \\
\hline IFTE & $r \cdot r \wedge$ & $\Delta \Delta r{ }^{\prime}$ & IFAVV & rq.. & | \\
\hline h.t & 1199 & 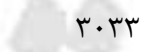 & אזrt & rtrqa & |.............................................. \\
\hline ivi & glf & $1 \Delta V \cdot$ & 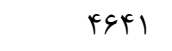 & ITGKA & ساله $V \cdot-V{ }^{4}$ \\
\hline $1 \cdot r \cdot$ & 1149 & זry & $1.9 T F$ & r...rt & Vاله و بيشتر ............. سال \\
\hline
\end{tabular}


ا - Y - جمعيت در خانوارهاى معمولى برحسب جنس، سن و تعداد افراد در خانوار (دنباله)

\begin{tabular}{|c|c|c|c|c|c|c|}
\hline 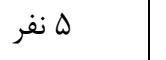 & 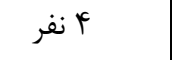 & 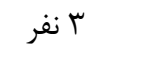 & 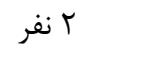 & 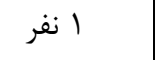 & 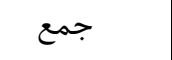 & جنس و سن \\
\hline $1 \Delta q \cdot \cdot v \Delta$ & r. fqrqur & $19 \cdot \Delta F T F F$ & VFAITFE & $|F q \Delta| r \Delta$ & DArIfrar & 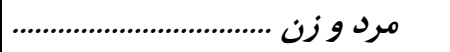 \\
\hline VRVYAq & $r \cdot \Delta \wedge q \wedge \varepsilon$ & IAFrqDS & rGGKT & · & $499 \Delta 919$ & 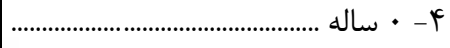 \\
\hline 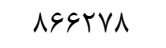 & trmeqge & q1รqrq & grmeq & . & ForqAir & ح \\
\hline $9 \& \wedge \forall \& 1$ & 191 fre. & $\Delta \wedge \varsigma \Delta \Delta$ & VVGGA & IFT. & F. rrast & l \\
\hline AVMrTI & IDIAVKF & grVArI & rस৭६тl & $|r \wedge| \Delta$ & rVDq।\&V & 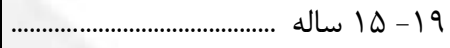 \\
\hline VTrmV & $|r V| \cdot \Delta \mid$ & $\mid 1 K r \ldots 1$ & gq|fF| & $0 \cdot\{19$ & $F r \cdot r \& \Delta \cdot$ & 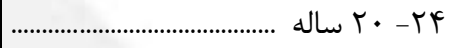 \\
\hline 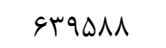 & IDIDSFV & $r \cdot q q \cdot r V$ & |rmag. & $9 \mu \wedge \wedge \wedge$ & $\Delta q \wedge \vee \wedge \Delta F$ & q \\
\hline $94 \cdot 910$ & t. NFFIt & $r F \cdot q V T \Delta$ & 1.rqfa & 1.9110 & $q \Delta \Delta q \cdot V F$ & • • שاله . \\
\hline VTAN9T & tTIAAVF & $|\Delta F q| \cdot r$ & FV.VTr & qTFVF & DTFATTE & q \\
\hline VMrTgY & 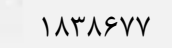 & $१ \Delta \wedge \vee \wedge \wedge$ & TANTrQ & $V M G \cdot r$ & Fiه人।qV & 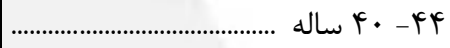 \\
\hline GTrq. I & $|F A T \cdot| F$ & qrFVAD & TFVFqD & $111 \Delta \Delta$ & $r v \cdot q \wedge r \Delta$ & 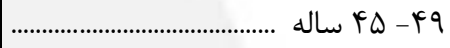 \\
\hline FIrG.V & $q$ qrq4q & 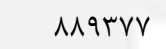 & FArOAI & qrVA. & r.rNtre & • \\
\hline$r V \Delta G \cdot \Lambda$ & बr.rIT & $V \vee \& G \cdot \Delta$ & GIrrqd & $\| r \Delta \Delta \mid$ & $r \Delta F G \cdot \Lambda I$ & 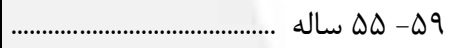 \\
\hline 1994or & TGFYqD & $\Delta \Delta I T T$. & DQTTEY & Ir.rVG & $19 \cdot \Delta 1 \Delta \Delta$ & • • \\
\hline Avrrv & 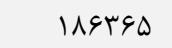 & MtIF.l & Fด৭१Yr & $|r q \Delta 9|$ & IrFqqVq & 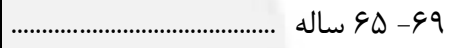 \\
\hline FYYAD & $99 \cdot 4 \wedge$ & $111 \Delta V$ & TFATIF & IFAVTE & AFVMAN & ساله V. $V V^{c}$ \\
\hline VQHEV & $11 r \cdot v f$ & t. RTtr & $\Delta T F I \Delta q$ & TDQTFD & IrFDQFq & 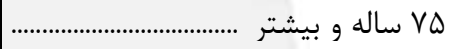 \\
\hline perpreg & $1.098 r 99$ & $11 \mu \cdot \Delta \cdot 1$ & ralevVr & D. rrar & $r q r \lambda \cdot r q q$ & 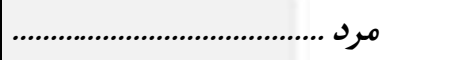 \\
\hline$r \wedge \cdot \Delta \wedge \vee$ & $1 \cdot \Delta 91 \Delta \Delta$ & qłrvqr & $|\Lambda \Lambda| F$ & . & 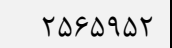 & 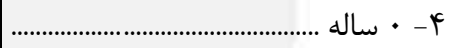 \\
\hline Fr人IGF & lloVqVr & $\Delta \cdot \Delta l \cdot r$ & MIFAD & . & THTGDGT & q \\
\hline FAFqGT & $999 \cdot \vee r$ & $r .9919$ & rVAIT & $v \Delta \cdot$ & $r \cdot \Delta \vee \wedge l \cdot$ & l \\
\hline FATSDS & $1 \cdot 9181$ & TIDQTA & $\Delta F \varepsilon \Delta F$ & $\wedge \vee \Delta \Lambda$ & IAVAFFA & 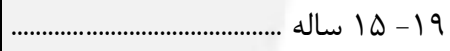 \\
\hline FTEFTA & $V \cdot 9190$ & Forvqq & rTHANA & roqvr & $r \cdot q$ FVDq & 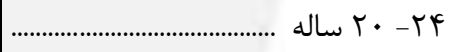 \\
\hline roIr.. & घqтाT. & $q \Delta \varphi \mid r q$ & 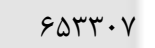 & $G \Delta \vee \Delta \Delta$ & rqFINHF & q \\
\hline TETTVD & AVADFT & $14 \cdot 1119$ & $\varphi \cdot \Delta \varphi 9 V$ & 99511 & 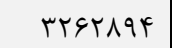 & ץ • • ساله . \\
\hline r..rtr & 1. VEFT. & $\wedge \wedge \wedge \Delta \varsigma \wedge$ & roqIVq & $\Delta \mu G \cdot r$ & r\&AVAVF & q \\
\hline एद। V१Q & 914994 & FA૬.r & $|r| 9 \wedge 9$ & rMAGT & 111.914 & 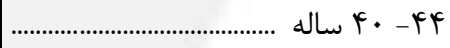 \\
\hline$r r q \cdot \Delta V$ & ᄉrVArV & FTE. V & IIFTa. & raFq. & IMAFVDS & Wa $r q$ \\
\hline TFY. DG & DVTVA & FrfTFq & IGGTVD & rll. & IDrG..r & • \\
\hline $19 \cdot 1 \Delta \Delta$ & rGarvq & rqYFVD & TFDIFV & 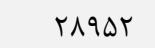 & ITVGTrt & 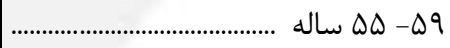 \\
\hline $9 \vee \vee 1$. & rIGDAr & $r a 1 \cdots t$ & rघ19T1 & rFqDQ & $9 \Delta 99 \cdot V$ & 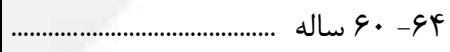 \\
\hline DITV & IITVIN & |Vqur| & $r \cdot V \Delta F_{1}$ & T. TFY & G.rIVD & 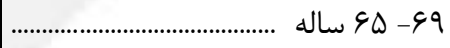 \\
\hline 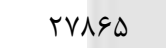 & GTrTV & |IFFF| & IVFFA| & IAVTS & $f\|f\| F$ & ساله V. $V V^{c}$ \\
\hline rFqDI & G9ITr & $|1 \% 9| \wedge 9$ & $r F \cdot F \Delta D$ & 99199 & SV9ATs & 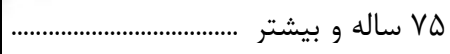 \\
\hline $91991 \cdot q$ & $919 \Delta 9 V \pi$ & varryig & rqgFaVf & qqrafr & rq. rermer & 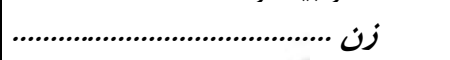 \\
\hline$r \Delta \varphi V \cdot r$ & $999 \wedge \mu 1$ & $q \ldots 1 q \mu$ & IVArq & . & TFYq\&GY & 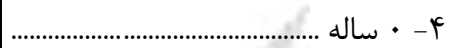 \\
\hline FrAIIF & $1 \cdot V V \cdot Y_{1}$ & FVa人rv & $r \cdot \wedge \& \uparrow$ & . & TtITtOI & q \\
\hline FArFqq & Q1DTGV & rVqqur & $\varphi \cdot \Delta \varphi$ & $9 V$. & $199 \Delta 1 \Delta T$ & f • اله ساله \\
\hline 419990 & $V \cdot 9 \Delta \& r$ & MTrTq & I $149 \& V$ & $r \cdot \Delta V$ & $141 \cdot v 19$ & 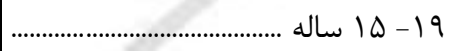 \\
\hline rqяqr & $\Delta S Y \wedge \Delta S$ & $9994 \cdot r$ & reVQDL & IFFFY & $r r \cdot 9 \wedge 91$ & 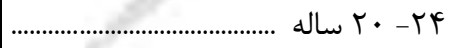 \\
\hline 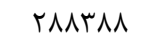 & NTTATV & $\|$ IFrq11 & DArTqF & 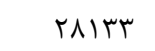 & $r \cdot r q \cdot r \cdot$ & q $r_{\Delta}$ ساله . \\
\hline 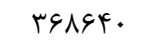 & $I T \cdot \Delta \wedge \gamma$ & $11 \cdot 1918$ & rqvrvq & r৭q.r & rт৭\&।1. & 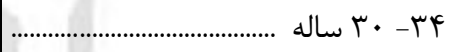 \\
\hline 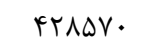 & MFFFAF & $9 \varphi \cdot \Delta r \Delta$ & TIIDFF & 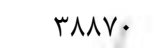 & TEDVTLT & q \\
\hline rVIFEV & $\Lambda \Delta \Delta 9 \wedge 1$ & FVTVGa & 19ятrq & TFYFI & $r \cdot r \vee \Delta \Lambda r$ & Lاله \\
\hline trrafF & GFYIVY & $\Delta 1 \cdot V \vee \wedge$ & TMtrfa & FAS9D & $1 \wedge r \Delta \cdot V q$ & 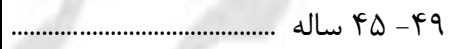 \\
\hline$|V| \Delta \Delta \mid$ & $r \cdot r|q|$ & $r \notin \Delta \cdot r \Lambda$ & MIGT.9 & 919V4 & DD. THKT & ....................................... \\
\hline IIFVDr & rDFqur & rvqוr. & rGAIFA & $\wedge r \Delta q 9$ & 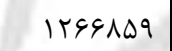 & 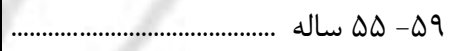 \\
\hline 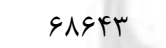 & IFVqIT & rorris & 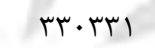 & $1 \cdot \Delta F I V$ & $q \uparrow \wedge \Delta F \wedge$ & • • \\
\hline rq..p & VHGFV & IFY.r. & TATHAT & 119418 & $\operatorname{srs\Lambda } \cdot r$ & 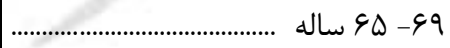 \\
\hline 1994. & TrATI & G91rt & IV·人 r & IrV... & FrmtVe & ساله V. $V V^{c}$ \\
\hline$f \cdot\{19$ & Frgar & $q \Lambda \cdot r V$ & $194 V \cdot F$ & rAqrFq & GQDVTr & 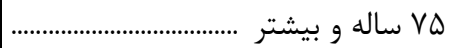 \\
\hline
\end{tabular}




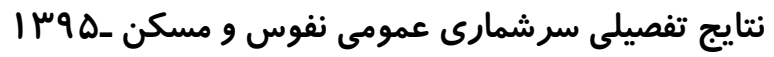

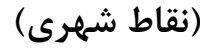

ا ـ Y ـ جمعيت در خانوارهاى معمولى برحسب جنس، سن و تعداد افراد در خانوار (دنباله)

\begin{tabular}{|c|c|c|c|c|c|}
\hline و • • انفر & 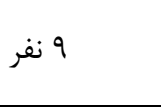 & 1 نفر & 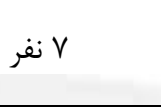 & 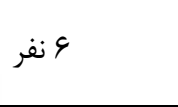 & جنس و سن \\
\hline$\|F\| F$. & Ifryer & raIADG & q1 rarr & revara. & 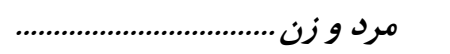 \\
\hline 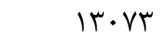 & $\mid r \& \Delta \Lambda$ & $r V \Delta \Lambda$ & GDFVF & 1999०९ & ץ- • ساله . \\
\hline ITtrt & $1 F \wedge \Delta q$ & TFtTt & Nrrsq & TFEOVI & - \\
\hline IFATE & IVqTa & FT. 19 & I.tFIN & 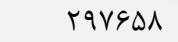 & f f • • ساله . \\
\hline$|\Delta| r \mid$ & INTFT & FYFq9 & $1 \cdot \Delta \cdot c$ & rQDATr & 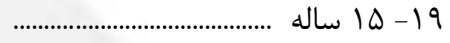 \\
\hline IMFTA & IETTE & ए११८५ & $1 \cdot 191$ & $r V \Delta \cdot 9 \Delta$ & 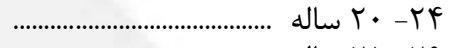 \\
\hline $1 \cdot \sqrt{ } \& \Lambda$ & $1 r q \cdot V$ & rदाबQ & qr人rv & TFAFIS & 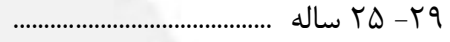 \\
\hline $1 \cdot 19$ & $1 \cdot 911$ & TAGFY & VRVAT & $r \cdots \Delta \& r$ & 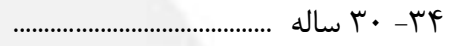 \\
\hline gred & 191T & THFAV & G. TVR & IAVIFr & q \\
\hline $4 \wedge 99$ & $999 \vee$ & $11 \cdot V V$ & DI9T. & IArgFq & 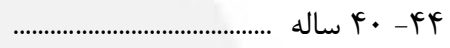 \\
\hline$f \cdot 1 f$ & $\Delta \wedge r q$ & $10 \Lambda 1 \Lambda$ & FVVGS & $19 \Lambda \cdot 4 \wedge$ & ساله . $q d Q$ \\
\hline זוזr & fETd & 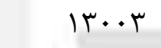 & ravif & IraTaV & 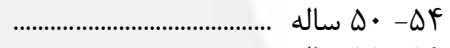 \\
\hline 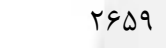 & $f \cdot v q$ & $1149 \mathrm{~V}$ & 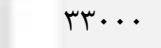 & १\&FVD & 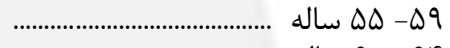 \\
\hline$r \cdot r \Delta$ & rq^६ & Ar৭९ & TMIFF & 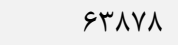 & 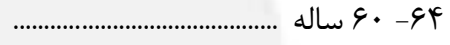 \\
\hline $11 \cdot 4$ & IVte & ferq & 14991 & rFAVQ & 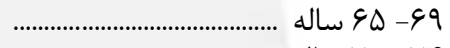 \\
\hline $9 \vee 9$ & $1 \cdot r$ & role & $v \cdot q \cdot$ & $199 \Delta \Delta$ & ساله V. \\
\hline $1 \cdot V \Delta$ & 1994 & Fr人f & $|r \cdot \varphi|$ & letr & 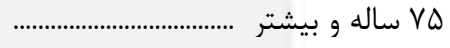 \\
\hline$\Delta V \varepsilon \cdot r$ & $r l \cdot r r$ & IVFEA & FAFFII & iraraqr & 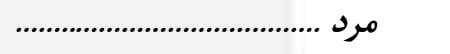 \\
\hline 999. & $\operatorname{si\Delta \Delta }$ & $\mid r \cdot \Delta r$ & r世я人9 & I. TVIV & f - • ساله ............................. \\
\hline gqu & VATF & 1994r & $F \cdot V Y \Lambda$ & $\mid r T \cdot \wedge \varphi$ & 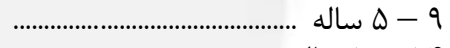 \\
\hline VIVA & $\wedge \vee \wedge \vee$ & $r \cdot t \cdot r$ & $4 q \ldots 1$ & IFrGTq & f \\
\hline VDAT & $91 \%$. & $r|| V \mid$ & $\Delta 10 \cdot r$ & $\mid F V \mu \cdot \Delta$ & 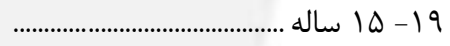 \\
\hline VIFA & А૬тq & rISIQ & $\Delta \Delta \wedge \varepsilon \Delta$ & IDGY.. & 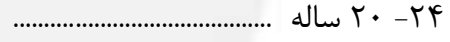 \\
\hline$\Delta V F$. & VQAT & l9FV & $\Delta 11 \Delta \Delta$ & Irлtr. & \\
\hline$r q \cdot \wedge$ & fqar & $\pi \cdot r \cdot$ & - l & $q \cdot k \vee \wedge$ & • • • ساله . \\
\hline rova & ritit & ^९9. & 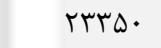 & VTVAT & q \\
\hline$r|8|$ & rq४^ & VYFA & TYFAF & $\wedge r \Delta \Lambda 1$ & 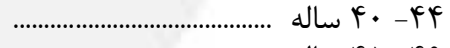 \\
\hline $194 \mathrm{~F}$ & r^९ด & VEVT & rT\&DQ & Avqre & 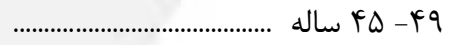 \\
\hline 1994 & rrvi & 9909 & $r \cdot .10$ & 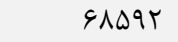 & 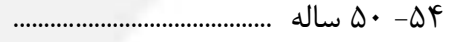 \\
\hline lfYF & rIgF & GITr & IVqFA & Drvif & صاله \\
\hline ITYF & $19 V \wedge$ & r\&AV & 14194 & r\&\&4l & 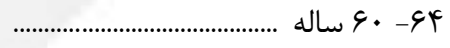 \\
\hline धヘV & $1 \cdots r$ & tRTt & $V \Delta V \Delta$ & 1994 & 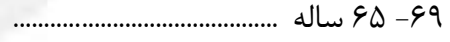 \\
\hline Frt & st. & $|\Delta \Lambda|$ & 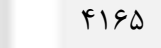 & $11 \Delta \Delta 9$ & ساله V. \\
\hline$\Delta V F$ & $\wedge \vee \vee$ & trat & GTVD & $19 \cdot 94$ & 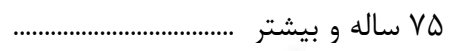 \\
\hline DFarA & VIVf. & $|V V| \& 1$ & FaAIIE & irrriar & 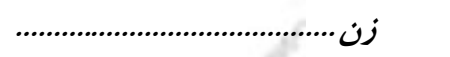 \\
\hline gr人r & gr.r & Irarq & MIVAd & qVTrq & ץ- • ساله . \\
\hline $9 \Delta 94$ & VFTD & IVrq. & FISTI & ITFFAD & 9 \\
\hline VTDA & 91 & TIMAF & DHFIV & $1 \Delta F \cdot r q$ & 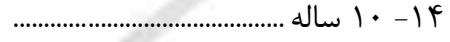 \\
\hline VDFA & TrTT & TITTA & $\Delta r \Delta \Delta \Lambda$ & $|F \wedge \Delta| \Lambda$ & 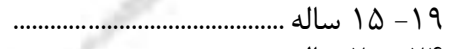 \\
\hline sru. & VQ99 & INHFV & $\operatorname{Fa\Lambda } \mid \Delta$ & $\| \wedge \wedge \varepsilon \Delta$ & F • שاله . \\
\hline$\Delta \cdot Y \Lambda$ & GTTD & $199 \mathrm{V9}$ & FTEAT & $11 \ldots+4$ & q \\
\hline 4111 & $4 \cdot 19$ & $1 \Delta G \cdot F$ & $c \cdot \Delta l$ & $11 \cdots \wedge \varepsilon$ & • • • ساله . . \\
\hline rvv. & $\Delta F q 9$ & IrVav & 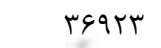 & 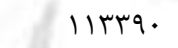 & q \\
\hline TVRA & f. 19 & 1. rTq & rqfre & $1 \cdots 9 \Lambda$ & 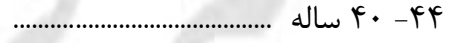 \\
\hline$r \cdot 9 V$ & rqFF & 1149 & $T F \| 11$ & $\Lambda \cdot 1 \cdot r$ & 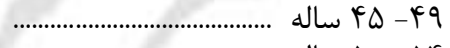 \\
\hline lQF. & trgt & GMFF & 11999 & $\triangle 9 \vee G \Delta$ & • \\
\hline ITra & $1 \wedge \wedge \Delta$ & 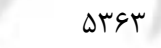 & $1 \Delta \cdot \Delta T$ & FTVGI & 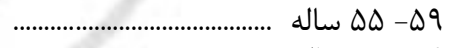 \\
\hline$\Lambda T_{1}$ & $1 r \cdot 1$ & re. 9 & $99 \Delta \mathrm{T}$ & TVTrV & 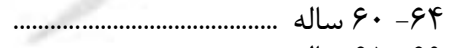 \\
\hline Fiv & Vef & $1 \wedge 97$ & DFTK & Ifqfr & 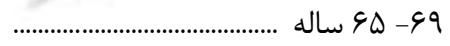 \\
\hline TFV & rat & qro & rQTD & ^ঙ৭q & 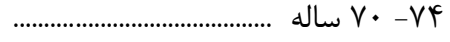 \\
\hline$\Delta \cdot 1$ & $\vee \wedge \vee$ & $r \cdot \wedge V$ & 9999 & T. TtY & 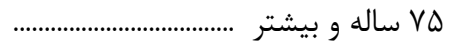 \\
\hline
\end{tabular}




\begin{tabular}{|c|c|c|c|c|c|c|}
\hline 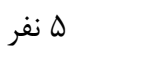 & 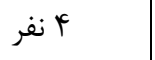 & 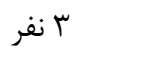 & 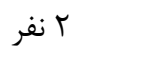 & ا ت ا نفر & 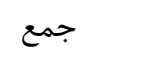 & جنس و سن \\
\hline rVIsDVD & slarr.f & rarergl & TFAADTA & DFrarr & r. rIrarr & 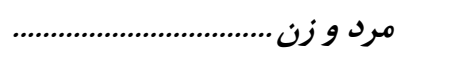 \\
\hline$f \cdot \wedge q f$. & VAFr.. & $\Delta \vee \wedge \Delta \& \mid$ & $199 \Delta \Delta$ & . & $r \cdot \Lambda F V \& \Lambda$ & 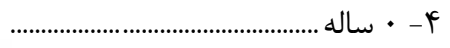 \\
\hline fध99^V & VGTYFT & TFADTV & $\mid \wedge \wedge \Delta \Lambda$ & - & INDArGG & 9 \\
\hline fqrrv. & $\Delta F V \cdot q \varphi$ & $|\Delta \Delta T| \&$ & rяா r & Irts & $19.99 \vee 1$ & 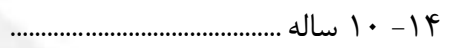 \\
\hline refqrA & rیDIIr & rIrqघA & 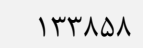 & $\Lambda \Delta V \mu$ & IFFGDTF & 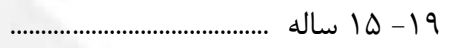 \\
\hline TVGATT & FIrTqI & FVAVTD & tRITII & TYGNI & $|V r \Lambda| \Delta \Lambda$ & 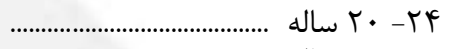 \\
\hline TFETrq & 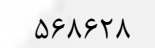 & GATrqV & $r 199 \cdot \Delta$ & आI1ब & $r \cdot \Delta \cdot r q T$ & \\
\hline rА१५\& & V.erg & DFFTDA & 19भVG9 & TYMFS & 19тוrmF & 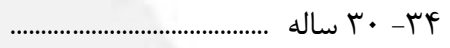 \\
\hline MFfGFi & GT.AVD & $r .9491$ & 1.9914 & thit & $1911 \mathrm{VIV}$ & q \\
\hline$r \cdot r \Delta \cdot$ & 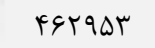 & rink & $94 \pi 19$ & $r \cdot 9 \vee V$ & 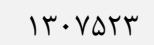 & 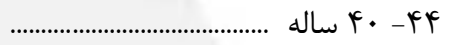 \\
\hline משTKR & MTIM & TFAFAT & $|r \cdot 9 r|$ & rT. rt & $1 \cdot \wedge \Delta 9 ९ 9$ & wla $F q$ \\
\hline ITDGFF & rirkrq & 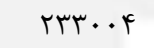 & $19 \Lambda \cdot 4 \cdot$ & rदTqV & 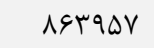 & 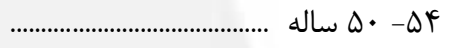 \\
\hline $19 \cdot 11$ & $1 \Delta \Delta F \& V$ & TITHOF & Tt. TG & rGMA & $\vee \wedge \Lambda \cdot \vee \cdot$ & 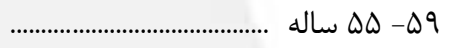 \\
\hline$\Delta \Delta F \wedge V$ & |...9ा & $|\Delta \Lambda \cdot \Lambda|$ & 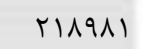 & 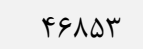 & grvmrq & 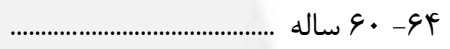 \\
\hline rTVq. & $\Delta \wedge \wedge \wedge \Delta$ & $1.11 \mathrm{rV}$ & IN.VTG & $\Delta r \& 9 \Lambda$ & $r \Delta \Delta \wedge r q$ & 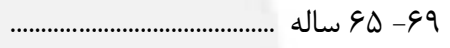 \\
\hline 19490 & $r T \Lambda \cdot V$ & $q \cdot V V \Delta$ & $|f \cdot| \cdot 1$ & $\Delta G \wedge V$ & TTEDIT & ساله $V \cdot-V F$ \\
\hline rFAls & 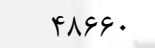 & $\Lambda V F \cdot V$ & rATVRq & ISATVE & GT\&A.V & 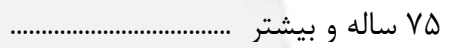 \\
\hline $19 r r g .8$ & rerastr & retrets & IIAFAFT & $11 r \cdot r \cdot$ & $1 \cdot r \Delta \& 19 \Delta$ & 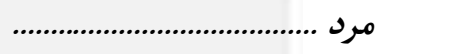 \\
\hline$r l \cdot 4 q \Delta$ & $F \cdot \Delta \varphi q \varphi$ & $r . . \mu \cdot r$ & $1 \cdots 9 \Delta$ & . & $1 \cdot$ VYYA. & 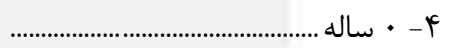 \\
\hline rrदqधя & 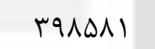 & $\| r \cdot \Delta \Lambda v$ & 9148 & . & QDTFY. & - \\
\hline ( ) & $r q r \cdot \mid r$ & AFTrI & $1 \cdot \Delta r \Lambda$ & $\Delta \wedge 9$ & NTrVI9 & 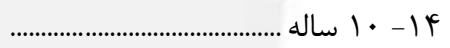 \\
\hline 1949Ts & TYTOVA & ११९११ & rTAVe & (9)11 & VHFAFA & 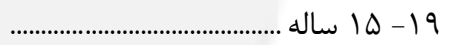 \\
\hline IVAr·^ & arוqu & 199VDr & IIATEY & 1990r & $9 / f \cdot 1 f$ & 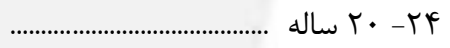 \\
\hline ITATID & $r \Delta \cdot r \wedge r$ & refFIV & t.tTRK & $r M Y \cdot \Lambda$ & $1 \cdot v \notin \& 4$. & q \\
\hline IIDFr. & lutratr & rtVAIf & $119 V \cdot V$ & IAvqr & $91 F+19$ & 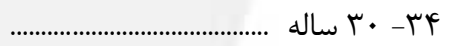 \\
\hline$|9 \cdot \Delta r|$ & ( & $199 \cdot r$. & $\Delta r \cdot \wedge r$ & $|f| r$. & $\Lambda \mid F r \Delta \Lambda$ & q \\
\hline $19.19 \mathrm{~V}$ & q & 1. FYFI & MFADV & $1 \cdot \vee 91$ & 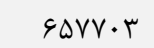 & . \\
\hline 119rदr & $M \cdot r r$. & 1.8949 & $f \cdot r q 1$ & $9 \Delta r \Delta$ & QrरTQV & 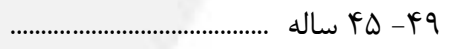 \\
\hline$V \cdot q r r$ & $\| \omega \cdot \psi \wedge$ & $1.9 r F$. & grapl & $\Lambda 1 \Lambda F$ & $R T \cdot \Delta \Lambda T$ & 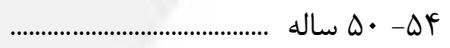 \\
\hline 49910 & ᄉrیl. & $1 \cdot r \varepsilon \wedge \Delta$ & $9 \cdot 1 r q$ & NDHG & rVAT\&G & 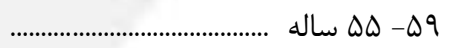 \\
\hline$r \cdot r \Delta T$ & $\Delta r \Delta 19$ & VVVal & 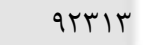 & $\Lambda \cdot G 4$ & $r \wedge q \cdot \Delta \varphi$ & 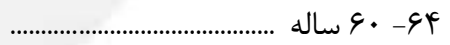 \\
\hline IVマ^. & $r r^{\prime} \cdot \Delta \cdot$ & $\Delta|r \Delta|$ & vVqu. & VVrI & t. tINF & ........................................ $9 \Delta$ - \\
\hline $1 \cdot \wedge \Delta F$ & $r \cdot r \Delta T$ & rदr. $\Delta$ & я৭яएV & 11rs & IDFVqG & 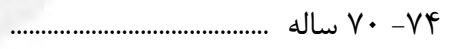 \\
\hline IArrq & rTQDQ & sr.V. & $|\& \Lambda \Lambda| F$ & FTAFE & MFIFTY & 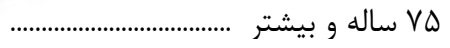 \\
\hline Iraragq & rqfalrV & $r r \cdot q \cdot r \Delta$ & $1 r \cdot r q 19$ & reasIV & $1 \cdot \Delta \Delta Q 9 r A$ & 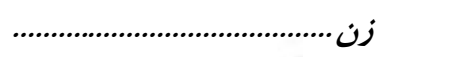 \\
\hline I9AFFD & rVAGтK & $r \vee \wedge \mid \Delta \Lambda$ & $9 \Delta १$. & . & $1 \cdots \vee \vee \wedge \Lambda$ & 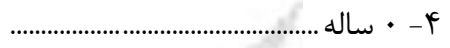 \\
\hline IIr & ref491 & $11 \vee 9 \Delta \cdot$ & $q \cdot r r$ & • & $q \cdot \Delta \wedge r \varepsilon$ & - \\
\hline rTqVGV & $r \Delta \Delta \cdot \wedge r$ & $V \cdot 99 \Delta$ & $1 \Delta \wedge \Delta \Delta$ & gFV & 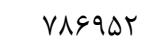 & 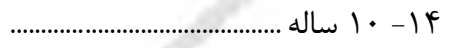 \\
\hline DD. MFT & IGTATA & IIfreq & $11 \cdot 91 r$ & røDa & \Isরs & 19 اله ساله . 19 \\
\hline $9 \wedge 9 \mid{ }^{4}$ & $\mid \Lambda \cdot r \Delta \varphi$ & TVQQVT & IDTqFq & $G \cdot r \wedge$ & NTFIFF & 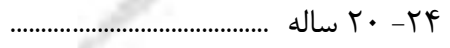 \\
\hline$\|r\| \| F$ & TINTES & rIVAN. & IIVGFT & VVVA & $q \vee \Delta V \cdot r$ & \\
\hline IVRArt & $r q V \Delta \cdot r$ & TIgFfF & $V F \cdot \Delta q$ & 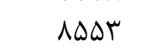 & $9 \& V \cdot 10$ & 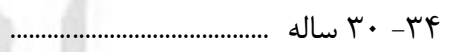 \\
\hline$|\wedge f| \mid$ & rイ९qTA & |rVATI & $\Delta \Delta \wedge 99$ & qTAT & 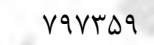 & q \\
\hline IFTr.r & r.991Y & ITVDqV & $\Delta V \& \& Y$ & 1.189 & grqAT. & 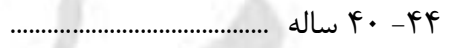 \\
\hline$q r \cdot v 1$ & 101991 & IrNAFr & $\Lambda \cdot 9 \Lambda$. & $1 r \Delta \cdot v$ & $\Delta F V V \cdot q$ & 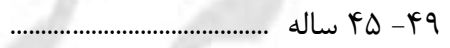 \\
\hline DFVII & 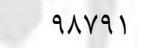 & ITrVGF & $1 \cdot 0 \cdot 99$ & $1111 \%$ & permpte & 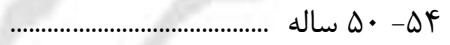 \\
\hline rq494 & VI\&OV & 1.9999 & Irq19V & TVADT & $p \cdot 91 \cdot r$ & 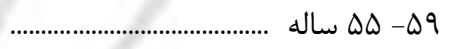 \\
\hline TAITA & FVFIT & $\Lambda \cdot r r$. & IrG94A & 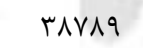 & m & G. -9Y ساله . \\
\hline $10 \cdot 1 \cdot$ & 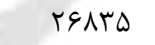 & fq1ve & I. rVAS & धৎ9९V & ror $\Leftrightarrow \Delta \Delta$ & 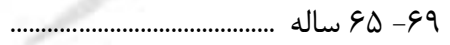 \\
\hline$\Lambda \Delta F\rangle$ & ITFDD & TFFV. & $V \cdot F V I$ & FAVrr & IVIVIS & ساله . $V \cdot V F$ \\
\hline ISFAV & $|9| \cdot \Delta$ & raTrV & $1 F 910$ & IrQVr. & 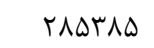 & 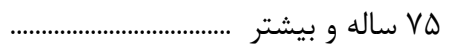 \\
\hline
\end{tabular}




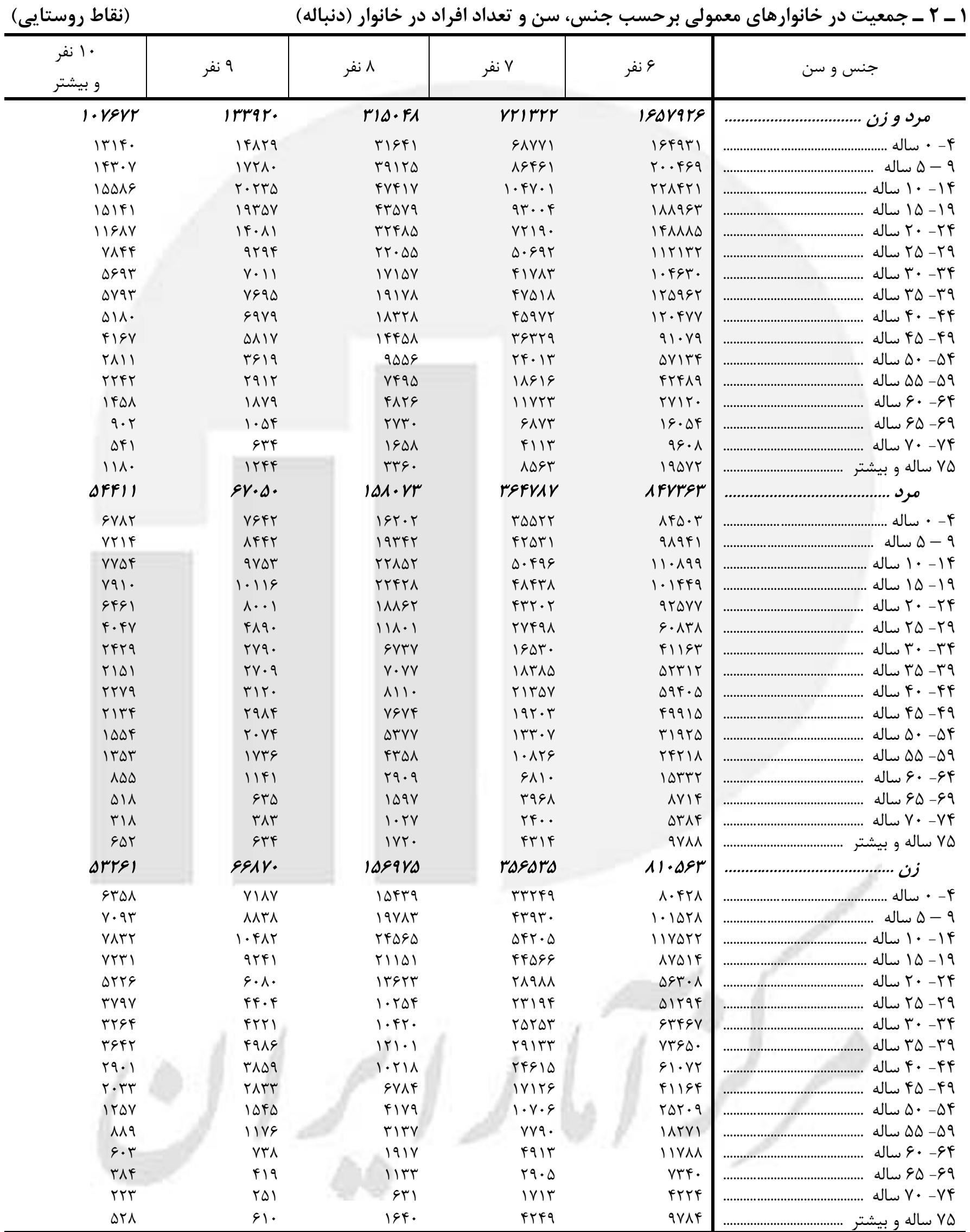




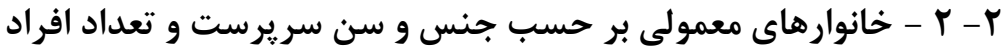

\begin{tabular}{|c|c|c|c|c|c|c|}
\hline 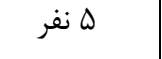 & 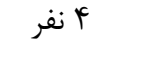 & كانفر & ك انفر & ا ل ا لفر & 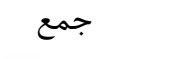 & جنس و سن سريرست \\
\hline regralt & gevrlld & g19яgr. & casvarv & roferiv & reirapq. & مرد و زن .................... \\
\hline v. & $r \cdot 9$ & vil & $r \cdot \wedge r$ & $r V \cdot V$ & $\Delta \Lambda T F$ & 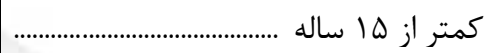 \\
\hline QTV & IArk & 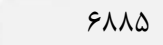 & $|A V| F$ & rIDTS & FqATr & 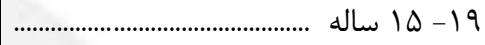 \\
\hline$\Delta \Delta V Y$ & r. GMr & IFAFTA & rqq.rq & VMFIT & $\Delta T I T \Delta V$ & F...................................... \\
\hline$|\varepsilon| \wedge \varepsilon$ & rVVGaq & $\Lambda r \Delta G \cdot \varphi$ & $V \wedge \cdot \Delta T_{q}$ & irarq. & 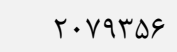 & q \\
\hline 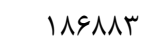 & $94 \cdot 199$ & $|F T \cdot| r q$ & $\vee \cdot \wedge \wedge ৭ 4$ & ITSATV & 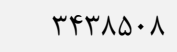 & ץ \\
\hline$F \cdot F|9|$ & ITHETGK & $1.1 V \times 99$ & гт৭१९. & $11 \varepsilon r \cdot F$ & rmfquts & q \\
\hline D. $99 T^{F}$ & ITH...qT & GleVkr & r.. rar & $9 \uparrow \wedge \wedge \wedge$ & TAFYTKA & (Fy \\
\hline eV. ers & 1. THTAV & $\Delta \Lambda \cdot r \cdot r$ & tivrar & $1 . F \Delta 1 Q$ & rq. q4Vq & ....................... $4 q$ \\
\hline MT.FAI & VI.VAY & DAGFTT & r. ५৭५४ & $1194 \mathrm{~F}$. & $r \cdot r \cdot r)$ & $\ldots$ \\
\hline$r+\cdot V r$ & $q \vee \Delta \Delta \wedge q$ & $\Delta G \cdot \Delta T F$ & Fr人৭99 & $|\& 9| \& V$ & IAGTEYG & 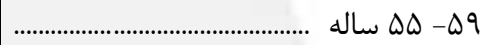 \\
\hline IrVrrga & rqศт.. & pr.piq & FAIFIT & IVVFID & lQVY\&Vq & |............ \\
\hline$V \Delta \cdot \Delta V$ & $191 \mathrm{rVT}$ & rRIIrV & 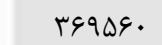 & lafrvg & $11 r \mid \cdot 11$ & 19- 99 ساله .................. \\
\hline$r \cdot \wedge r q$ & $q \cdot \vee \wedge q$ & IVT.G. & r. FAFV & t. trIt & טrqIIr & (............................................ \\
\hline FDFYG & I.r.IV & rTI994 & DQFITE & DrVVrA & IDTrrA. & VD ساله و بيشتر ............................ \\
\hline$r r 1.9 \Delta r$ & gratara & eruegrar & $\kappa \mid \Delta F+1 \Delta$ & GAFVEF & rl.evrry & مرد ..................... \\
\hline is & 149 & rAv & $1 r \cdot v$ & IrVT & 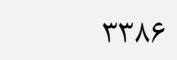 & كمتر از ها ساله ......... \\
\hline$r \Delta \Lambda$ & 1911 & $4 \cdot v 1$ & IQAGT & IrVAV & $r \Lambda \cdot v \varepsilon$ & 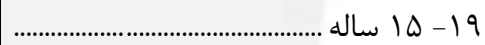 \\
\hline DTGG & rqYaq & 14.94 . & TAIDT. & $\Delta T \wedge \Delta \Lambda$ & FAr.q1 & (................. \\
\hline ferar & rVTqqF & $\Lambda T \cdot \Lambda V r$ & $V × \wedge 991$ & ८৭५८৭ & $199 \cdot r \Delta F$ & q \\
\hline INT.kt & ११८१४५ & 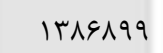 & 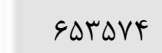 & MATVV & rtAFITA & ץ....................................... \\
\hline rqVTat & IrIFT.A & १९५. १७ & TVATFV & 91.94 & MIQTYIV & q \\
\hline$\Delta . \cdot g q V$ & $I r \cdot r \cdot r V$ & DQTHYA & $|r \Delta \Delta r|$ & (१११. & rबसrIA9 & 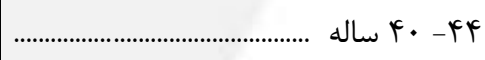 \\
\hline FAqTAK & $1 . . r|q|$ & 0.9999 & Iтqт人⿻ & raTr. & rTUTYAS & \\
\hline$r \cdot \wedge v \Delta$. & $91 \cdots 11$ & DTrQqY & $r r \cdot r_{1}$ & rałıs & 1991199 & (............ \\
\hline r.VVGY & FFFAFF & FqDTrs & rTQDIF & rygkq & |GसGTY & ............... \\
\hline IrGTG9 & TSVDSI & rVYDSI & $r \Delta I \cdot \varepsilon \Delta$ & rrify & שTrGT & 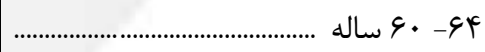 \\
\hline GVGAD & IFTIAK & TrAVES & rATEAV & $r \Lambda \cdot r \Lambda$ & 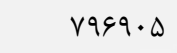 & 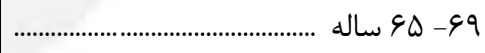 \\
\hline rVINe & NITrs & IFVF.D & TFTAFA & requT & $\Delta \varepsilon 19 \cdot q$ & ساله .............. \\
\hline FTYA. & $q r F \cdot 1$ & $19 \Delta \& r$. & $\Delta \cdot \Delta \& \& \psi$ & llTava & $9 \Lambda \cdot 1 r \pi$ & VD Vاله و بيشتر ........ \\
\hline $1 T \cdot \Delta q$ & rr.lAT & $\Delta r \cdot r r v$ & Arratar & $1 r \Delta q \Delta \Delta r$ & $r \cdot q \mid v a r$ & 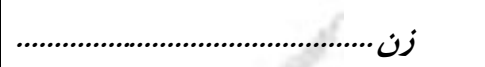 \\
\hline ra & 4. & try & vrV & Drs & 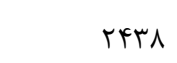 & كمتر از ها ساله .... \\
\hline vq & TrV & $11 F$ & TNAT & vVrq & $\|V \Delta\|$ & 19 1 1 ساله .............. \\
\hline$r \cdot \varphi$ & $11 V r$ & $r+40$ & $1 T \Delta 19$ & $r \cdot \Delta \Delta F$ & एवाद् & F \\
\hline IFrq & $q V \cdot \Delta$ & $|q V T|$ & ridru & $r_{4} . .1$ & 191.5 & q \\
\hline rati & 11199 & TrTr. & DQTTY & $\uparrow \wedge \Delta \Delta$. & lDFrA. & Fץ \\
\hline 99.9 & $r \cdot \mid \Delta F$ & DIrG9 & skgkT & FATF. & 190911 & 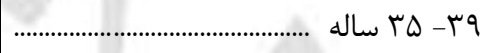 \\
\hline qrVV & $r V \cdot r Q$ & sKF. & q4qTा & requs & rIf.rq & ( \\
\hline $11.9 r$ & M1199 & $V \cdot r \cdot G$ & V४৭१९ & DQTFQ & 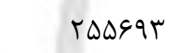 & q \\
\hline $11 V \cdot 1$ & $r \cdot 911$ & gektA & 1994ם & 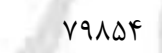 & rAIAVT & (DF \\
\hline Irr.q & $r \cdot v e \Delta$ & SQTMA & $99 \uparrow \Delta \Delta$ & 111011 & TTETVD & 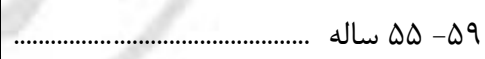 \\
\hline 1111. & rqvтq & $\Delta \vee \wedge \Delta \Lambda$ & $1 . . r F v$ & IFETEN & TFQDFS & ץ \\
\hline VrVY & $11 \cdot 9$. & krmal & $\Lambda \Delta q \cdot r$ & IGQTrA & TrFIIT & 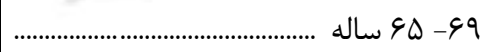 \\
\hline ratr & $9 \Delta \& \mathrm{~T}$ & $r \ll \& \Delta \Delta$ & 91999 & IVQVA. & TVVD.r & ساله $V \cdot-V{ }^{4}$ \\
\hline ५१९९ & 19.9 & TATGT & MMGGT & FIDIGT & DFrTDV & ساله و بيشتر ........................ \\
\hline
\end{tabular}


r - Y - خانوارهاى معمولى بر حسب جنس و سن سريرست و تعداد افراد (دنباله)

\begin{tabular}{|c|c|c|c|c|c|}
\hline و و بيشتر & 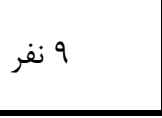 & 1 نفر & 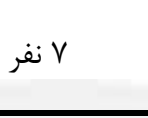 & 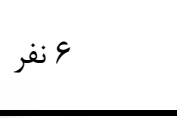 & جنس و سن سريرست \\
\hline$r \cdot \Delta \Delta A$ & $r \cdot v a q$ & 1rarr & rerved & vrralf & 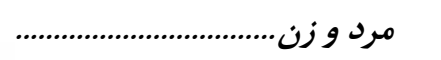 \\
\hline r & 1 & r & 1. & $r v$ & 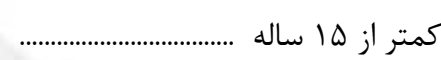 \\
\hline 9 & 11 & re & VA & 19 & 19 19 ساله ................................. \\
\hline$\Lambda V$ & $9 \Lambda$ & lar & rTS & 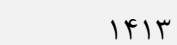 & 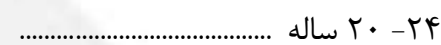 \\
\hline rur & rAs & ו ו & rषा1 & ११४६ & Q \\
\hline $9 \wedge 1$ & 118. & rqq. & $1 \cdot 199$ & rqтqя & 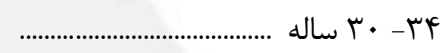 \\
\hline 1948 & g & $q 4 \cdot F$ & TrYIV & 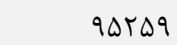 & q \\
\hline MTEF & DIQV & $1 \% q .$. & rqve. & Ira.vı & 누눈 \\
\hline ratr & $\Delta \& V_{1}$ & ifqv. & FrifA & $|r v \||$ & ..................................... \\
\hline 41.9 & FFAV & $|r| 99$ & 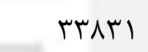 & $1 \cdot r \Delta \cdot r$ & (a................................. \\
\hline TrFq & ५११९ & $1 \cdot \vee 99$ & rqA५ & $1 \cdot 90$. & ساله ................................. $ه ا$ \\
\hline r.q. & TMM & vAv. & $r \cdot \Lambda \Lambda 9$ & DFATV & 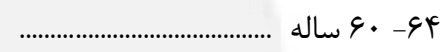 \\
\hline 1194 & $|q v|$ & FFrl & 119rv & r. rqu & 9......................................... 90 \\
\hline$v \cdot 4$ & 919 & TATS & squV & $|v| 9 \mid$ & 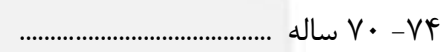 \\
\hline$\wedge \notin \vee$ & $1 \cdot v \Delta$ & TQY) & v९9u & 19049 & ساله و بيشتر .................................... \\
\hline 1994 & rarab & VqV\&A & rerrag & \&qF\&DF & 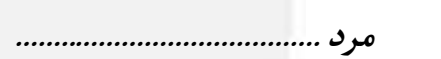 \\
\hline 1 & 0 & r & v & 19 & 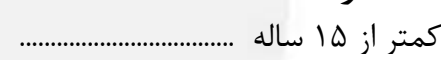 \\
\hline $\mathrm{v}$ & $\wedge$ & ra & 91 & 199 & 19 19 \\
\hline$v^{k}$ & qr & iva & rq१ & גוז & ساله $r$ r \\
\hline TrQ & rV. & vq. & rFA & १९१९ & q \\
\hline q4. & $1.9 \mathrm{~V}$ & rrq4 & I.rTV & $r \Lambda . . r$ & 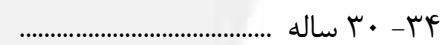 \\
\hline Mar & riQ9 & 19\%ब & reIr. & QYGAT & q \\
\hline TIוT & (9१1 & ITF.r & rAFAl & IrIVTa & 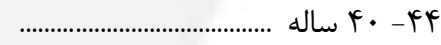 \\
\hline rolf & DFV & IFFAq & $r \cdot \Lambda \cdot 1$ & 9 & 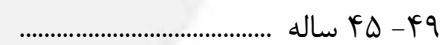 \\
\hline rqА & FrM & lladr & MTFF. & QAFV & ساله . $ه \cdot-\Delta f$ \\
\hline TEMT & rV^q & 1. TFS & TAIAF & VबDID & ه $ه$ ساله $\Delta$ - \\
\hline 197. & rrl. & $v e \cdot 1$ & 1949. & $0 \cdot \vee \wedge 9$ & ץ. \\
\hline$\| r \mid$ & IQDT & firf & $11.9 \mathrm{~V}$ & TVRIT & 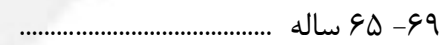 \\
\hline 999 & qur & $T F \cdot \Delta$ & $41 .$. & $109 \cdot 9$ & ساله V. \\
\hline 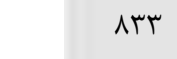 & $1 \cdot r \mu$ & TAKS & vrru & INATS & 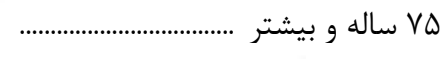 \\
\hline $9 r v$ & $|F|$ & rved & 1. Feg & rale. & 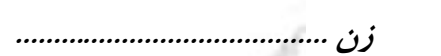 \\
\hline 1 & 1 & 1 & r & 11 & 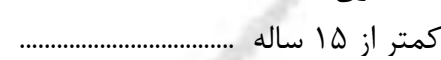 \\
\hline r & r & 1 & 1 . & re & 19 اله ساله ................................... \\
\hline זו & $\Delta$ & 9 & tr & 90 & (1) \\
\hline 11 & 19 & (i) & 10 . & 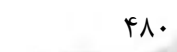 & ساله $r \Delta$ - \\
\hline is & vr & 194 & DFT & $\mid$ |ावा & …………………………... \\
\hline q & IVV & Faq & $1.9 \mathrm{~V}$ & raV & q \\
\hline$|r|$ & IVE & 491 & $1 T \Delta q$ & rrma & 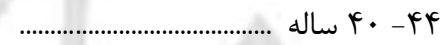 \\
\hline rזו & 199 & Q11 & IrFV & rV৭D & 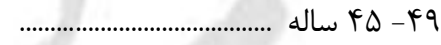 \\
\hline IrA & 199 & 019 & $|r q|$ & r.rq & 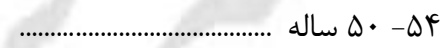 \\
\hline $11 \mathrm{~V}$ & $r \cdot V$ & $\Delta \Delta F$ & laqV & Frto & ساله .............................. $\Delta ا$ \\
\hline ir. & $|V|$ & rqq & IFTE & $r \cdot r \wedge$ & 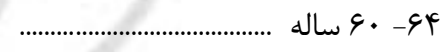 \\
\hline vr & 119 & TAV & $\wedge v$. & rqA. & 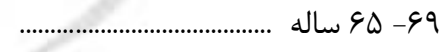 \\
\hline r. & $\Delta F$ & $1 r$. & rAv & ITAT & ساله ..................................... \\
\hline re & il & 90 & rq. & $1 \ldots k$ & ساله و بيشتر ............................... \\
\hline
\end{tabular}


r-r - خ - خانوارهاى معمولى بر حسب جنس و سن سريرست و تعداد افراد (دنباله)

\begin{tabular}{|c|c|c|c|c|c|c|}
\hline 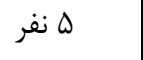 & 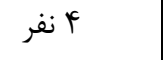 & 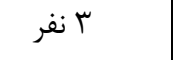 & 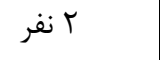 & 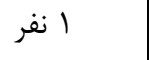 & 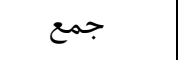 & جنس و سن سريرست \\
\hline$|V| \Lambda \cdot 1 \Delta$ & Direter & $\Delta r \Delta I f \cdot \Lambda$ & $r V F+q V \mu$ & IFqAITA & $1 \Lambda \cdot v \Delta V A V$ & 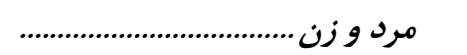 \\
\hline TF & $\vee \wedge$ & rیI & $1 \cdot r k$ & lif. & r^৯. & 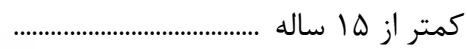 \\
\hline 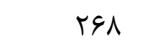 & 991 & 竞 & 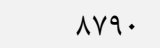 & $|r \Lambda| \Delta$ & 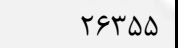 & 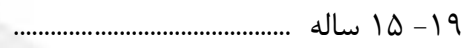 \\
\hline r৭०V & $|\Delta \wedge| r$ & NTADT & IEFVAr & $\Delta \cdot f \mid \varepsilon$ & rIN.人t & 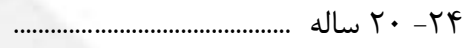 \\
\hline$r F \cdot .1$ & $19 \pi \mathrm{rVq}$ & $\Delta V \Delta \cdot Y \Lambda$ & DQMTKG & 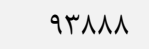 & IFAVTGY & (اله \\
\hline $1 \cdot 9 \cdot 5 \Lambda$ & ячq9.1 & DTrtr. & $\Delta q \mid F \Delta T$ & 1.9110 & 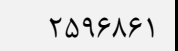 & 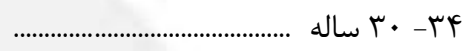 \\
\hline TDIEAT & $1 \cdots \vee \vee \wedge \vee$ & NDIMFF & TAITV. & QTFVF & TDDTHTT & q \\
\hline rrquk. & $q V F \cdot r F$ & $\Delta \cdot r q 4$. & $1 \Delta V \cdot q r$ & $V M G \cdot r$ & 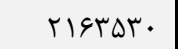 & 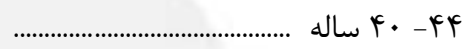 \\
\hline rFAN.r & AFVrGl & FATDII & $19 r 90$. & $\wedge 11 \Delta \Delta$ & $r \cdot r \Delta \cdot \Lambda r$ & 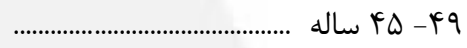 \\
\hline TF\&MAq & $\Delta \wedge 9 \Delta ९\rangle$ & FENVTK & rtVqIV & qrV^. & IVTGGVY & • • \\
\hline ISVVDS & 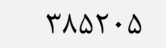 & FFTADT & TINTTD & $\| T \Delta \Delta \mid$ & IDITIKD & 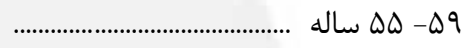 \\
\hline $1 \cdot+\Delta \cdot 1$ & rmEVAN & rK. rV. & Mrgati & Ir.rvg & $\mid r \cdot v \cdot v$ & 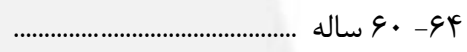 \\
\hline$\Delta \Delta \vee 9 Q$ & $|r \Delta \cdot \wedge|$ & $r 1 \cdot r q \Lambda$ & rVIr.r & $|r q \Delta \varphi|$ & 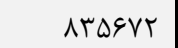 & ................. \\
\hline rqDrq & s^s.F & מאזמאו & TrI.rG & IFAVTS & ૬ાґর૬. & ساله ........................... \\
\hline rqqFT & $v \cdots q$. & IDDGYV & Y.r^AT & rDqTFD & $1 \cdot r \wedge \cdot 99$ & 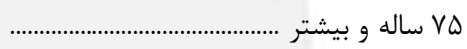 \\
\hline $1 q q \cdot q \cdot v$ & $p q q .+r q$ & FqFFrA1 & $r \cdot \Lambda v \notin q 1$ & D.rrar & lQVVrfqF & 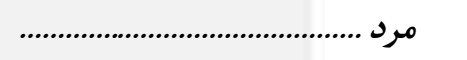 \\
\hline ir & 91 & 199 & 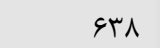 & $v \Delta \cdot$ & 1990 & 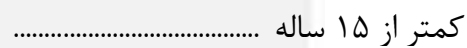 \\
\hline tra & $\wedge 9$. & rqQ & VFFA & $\wedge \vee \Delta \Lambda$ & T. FTY & 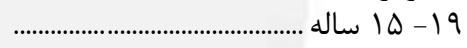 \\
\hline$r \wedge \cdot 1$ & IOTVK & N.rNi & $1 \Delta V \cdot \wedge F$ & roqVर & rqTV.r & 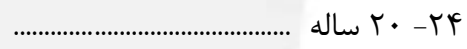 \\
\hline r r & $|9| 1 \mid 49$ & $\Delta S \Delta \Delta \wedge F$ & $\Delta V \cdots V r$ & $\varepsilon \Delta V \Delta \Delta$ & Iratrat & q \\
\hline I. rqवV & GTrVFA & 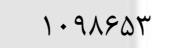 & $\Delta F G \cdot \mid \Lambda$ & 99rाI & TFVGDA. & • • • ساله ...1. \\
\hline TFVYTF & ११४\८. & AIITFA & TrVFI9 & $\Delta r G \cdot F$ & หrqq४^я & q \\
\hline rqтqтq & $9 \Delta F Y \wedge \Delta$ & FATVRT & $1 \cdot r \cdot \Delta r$ & rMAgr & 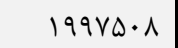 & ساله . f p ff \\
\hline MFITIV & АтrヘG. & $F \cdot \Delta \Delta 9 \varphi$ & $1 \cdot 1 \cdot \Delta F$ & rafq. & $|\Lambda T Y A|$ & 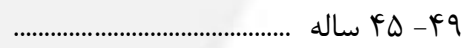 \\
\hline rr人rgh & $\Delta \& \Delta \wedge \uparrow \&$ & FIFANK & $\mid \Delta \Lambda \cdot \Delta \Lambda$ & $m 11 \cdot r$ & $10 \cdot$ FVYG & 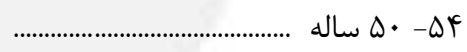 \\
\hline $1 \Delta \wedge \Delta \Delta \varphi$ & r & rarirs & rrqqя. & 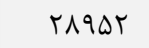 & $\mid r \varepsilon \cdot \Delta \cdot r$ & 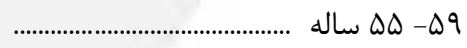 \\
\hline Q⿻५. r & וזמאוז & $r 9 \Delta \cdot \wedge r$ & $r \Delta q \cdot \Delta V$ & rFq०Q & QFDFGT & . 94 \\
\hline D. T\& T & IIIrgV & IVVGVT & $r \cdot \Delta \wedge \& V$ & T. TFF & $\Delta 94.9 F$ & q \\
\hline rqVYq & 91109 & IIIKFV & IVrFe.. & IAVTS & $f \cdot \wedge r q \mu$ & ساله V............................... \\
\hline TVDVT & grrqu & Ird.rg & rrVTuV & 99199 & $901 r 90$ & 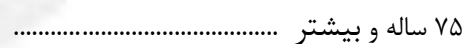 \\
\hline$\Delta V \mid \cdot \Lambda$ & prefer & $r \cdot v \cdot r \cdot$ & sarrit & qqTAFr & 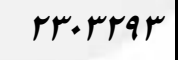 & 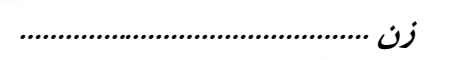 \\
\hline it & iv & $\Lambda \Delta$ & ५१६ & $q V$. & $11 \wedge \Delta$ & 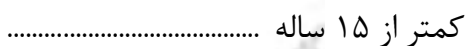 \\
\hline re & $1 \cdot 1$ & rVD & ITFD & $r \cdot \Delta V$ & $\Delta 9 \mu 1$ & 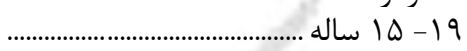 \\
\hline lهs & $\Delta F$. & rYsq & V९99 & lffyt & TSHA. & 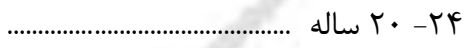 \\
\hline 99V & 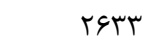 & grfy & trthe & 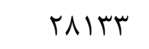 & GYOTI & 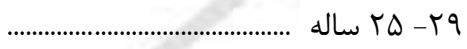 \\
\hline$r \cdot 91$ & VIDr & TFDVV & FaFra & ५१९.r & $|r \cdot r \wedge|$ & • • r ساله ...1. \\
\hline$r q \Delta \wedge$ & $\mid r \Lambda \cdot v$ & $4 \ldots 99$ & $\Delta r \wedge \Delta I$ & 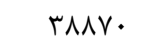 & IDTAKr & q \\
\hline$\Delta q \cdot 1$ & $19 \Delta 49$ & $49 q \cdot 1$ & $\Delta \mu \cdot l \cdot$ & revel & $199 \cdot r 4$ & ساله r f \\
\hline$\vee \Delta \wedge \Delta$ & rra.l & $\Delta 9910$ & दY人99 & $f \Delta \& 9 \Delta$ & r..rVr & 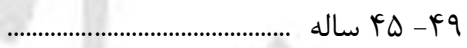 \\
\hline ADTI & rmpla & $\Delta r \Lambda F$. & 99109 & SISVS & TKI9DI & • \\
\hline $94 .$. & trait & DIVIV & VATAD & $\wedge r \Delta q 9$ & TDIETR & 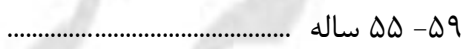 \\
\hline 1rq1 & $r \cdot r \Delta V$ & FDIMA & $V V \Delta \Lambda F$ & $1 \cdot \Delta F I V$ & TSIDFF & 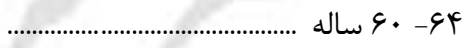 \\
\hline س & irvif & MTGTS & gDFTV & 119418 & rrqQVA & q \\
\hline rVA. & VFFA & $191 V 9$ & FVGKG & IrV... & $r \cdot \Delta F \& V$ & ساله $V \cdot-V F$ \\
\hline rrv. & GVEV & $r \cdot 9 \cdot 1$ & $99 \Delta \cdot \Delta$ & rیqrFq & rAsV.r & 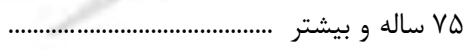 \\
\hline
\end{tabular}


| نتايج تفصيلى سرشمارى عمومى نفوس و مسكن _ه |

r-r-r - خانوار هاى معمولى بر حسب جنس و سن سريرست و تعداد افراد (دنباله)

\begin{tabular}{|c|c|c|c|c|c|}
\hline و و بيشتر & 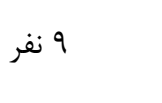 & 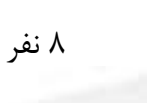 & 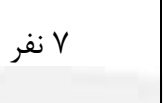 & 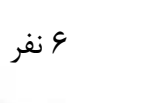 & جنس و سن سريرست \\
\hline 1. Far & la19r & erast & $|r+\mu|$ & Fegerd & مرد و زن ............. \\
\hline 1 & 1 & 1 & r & $\wedge$ & 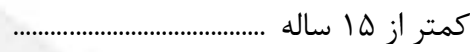 \\
\hline r & 9 & 19 & is & aT & 19 اله .................................. \\
\hline ev & r. & $1 . r$ & TFQ & $\Delta T V$ & ساله \\
\hline IQT & $|V|$ & fVe & ITVF & $\Delta \cdot k q$ & q \\
\hline एव & $\Delta \wedge r$ & IVGT & $\Delta \cdot r \Lambda$ & $194 \Delta \Delta$ & 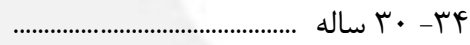 \\
\hline $91 \mathrm{~V}$ & IFDS & k. १1 & ITKAT & YAMIA & 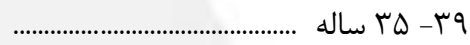 \\
\hline lats & 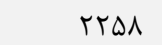 & GTा & 19.91 & VGTVG & ............... \\
\hline IVYG & TMIQ & VHFD & rTASI & $\Lambda 99 \Delta V$ & 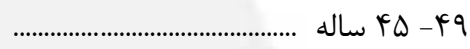 \\
\hline $19 Q F$ & rugr & sVif & T.TYA & sqvat & 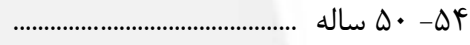 \\
\hline lff. & TrTY & GMFV & ING9F & $\Delta \Delta \Lambda I V$ & 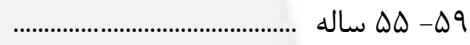 \\
\hline ITF. & IVTS & FAM & IrAFA & rAVIQ & . \\
\hline $9 \wedge \Delta$ & 1.r. & $r \Lambda \cdot \Delta$ & v१.. & TITKY & 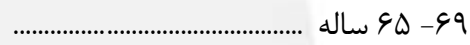 \\
\hline fi. & 919 & lQFF & fiar & 11119 & ساله \\
\hline rAF & GYF & $19 \vee 1$ & FAVT & $|r| \cdot \Delta$ & 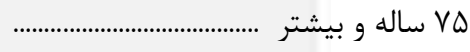 \\
\hline $99 \%$. & 14999 & FIFFT & ITread & erviar & 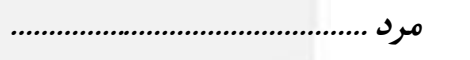 \\
\hline - & - & 1 & r & $\Delta$ & 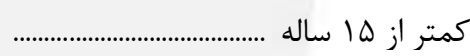 \\
\hline r & r & 10 & rq & $\Delta F$ & 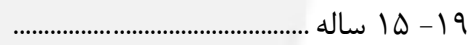 \\
\hline Fi & rq & १७ & ו & $v \wedge$. & 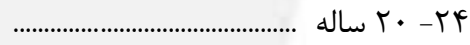 \\
\hline lis & 194 & Fa. & $1 \% \cdot$. & FATK & 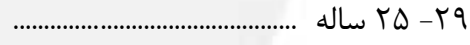 \\
\hline rq1 & DFA & 199. & FVV & IAGT & 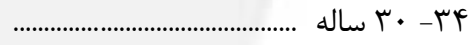 \\
\hline AVT & ITr & rAG & llVkr & Fres. & qז- هץ ساله ....................... \\
\hline IreV & rivi & $\Delta q \vee$. & $|\Lambda F| V$ & VEDIT & 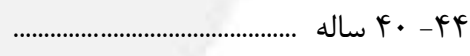 \\
\hline$|94|$ & rब१९ & $V \cdot \Delta T$ & Tr.9Q & NFTH & ..................... $4 q$ \\
\hline$|\Delta V|$ & TrGT & grVF & 19Mkt & 99919 & 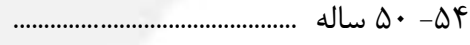 \\
\hline Tra & r.११ & $\Delta 9 \Delta V$ & IVAIT & DrQqF & (................. $\Delta \Delta-\Delta 9$ \\
\hline $11 \Delta V$ & $191 \%$ & FAFE & IrVqF & TAVTr & ب \\
\hline $94 \mathrm{~N}$ & qFF & r४৭१ & VTFV & 19TAT & ......................... $9 \mathrm{a}-99$ \\
\hline r r r & $\Delta \wedge F$ & IFEV & r $\Lambda \Delta \Lambda$ & $1 . \lambda F$ & ساله . $r \cdot V^{k}$ \\
\hline ral & DqF & 1814 & retar & lITrF & 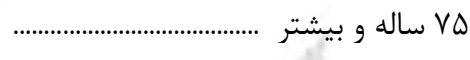 \\
\hline$\Delta V r$ & $1 \& V$ & rup. & sqve & lakf & 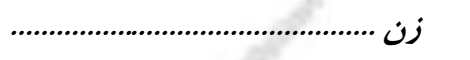 \\
\hline 1 & 1 & · & . & r & كمتر از ها ساله ................... \\
\hline · & r & 1 & 9 & $\wedge$ & 19 1 19 ساله ................... \\
\hline$\Delta$ & 1 & $\Delta$ & if & iv & 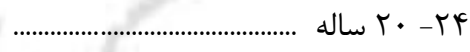 \\
\hline 4 & $\wedge$ & rq & ve & TrQ & ( \\
\hline ru & rı & $1 . r$ & rघ1 & VTT & ( \\
\hline Fa & $\vee \wedge$ & TTV & $\Delta F$. & $1 \pi \Delta \Lambda$ & q \\
\hline 49 & $\wedge \vee$ & rFT & 901 & INAr & . \\
\hline $1 \Delta$ & 119 & rqז & var & TFTD & (q q \\
\hline$\wedge r$ & Ire & $r \mu$. & $q \pi \Delta$ & rAFA & ....... \\
\hline VV & Ire & rq. & IIAT & Trtr & 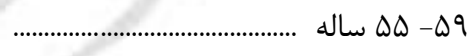 \\
\hline$\Lambda \mu$ & Irr & ref & $1 \cdot \Delta F$ & ५१९९ & ..................................... \\
\hline FV & ve & $r \cdot 4$ & gar & 1999 & 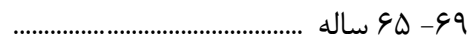 \\
\hline tr & $r \Delta$ & qv & $r 9 \Delta$ & qrr & 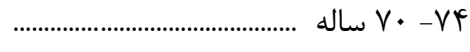 \\
\hline 19 & $r \cdot$ & 99 & r19 & VAl & 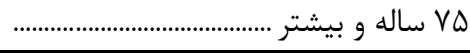 \\
\hline
\end{tabular}




\begin{tabular}{|c|c|c|c|c|c|c|}
\hline 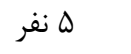 & 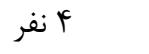 & 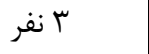 & r ا كنر & 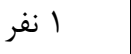 & جمع - اع & جنس و سن سريرست \\
\hline Verrida & lafeqre & $1015 \cdot 9 \mathrm{~V}$ & I TFFFEF & DFrarr & $q \cdot r \lambda \cdot q \Delta$ & 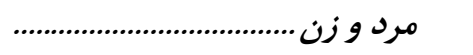 \\
\hline is & $1 \% 9$ & err & $1 \cdot 1 f^{f}$ & Irts & rAVA & 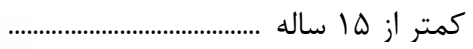 \\
\hline r\&q & 1Fs & rarA & $9 \wedge \& 5$ & $\Lambda \Delta V r$ & TMTE. & 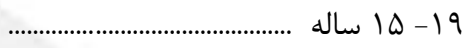 \\
\hline TG. Y & $|F \vee \wedge|$ & GTYID & $99 . .9$ & treNI & T. KY. & 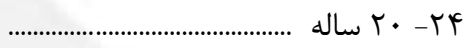 \\
\hline THIFE & $11 r V \cdot r$ & rG.IVF & 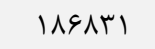 & आIی9 & $G Y \cdot V F V$ & qr \\
\hline $1 \cdot 999$ & 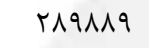 & r৭\&D.r & livifq & TRMED & ^५११人६ & 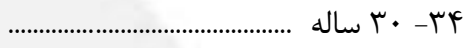 \\
\hline IDTYIT & rTDANG & $19 \Delta 99 F$ & DAfFq & tritit & $\vee 9 \Delta \cdot r \Lambda$ & q \\
\hline $1091 \cdot 1$ & rDDGৎT & $11 \cdot \wedge r v$ & frr.. & T. qVV & $9 \wedge 19 \vee$. & 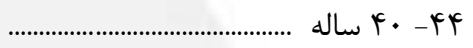 \\
\hline ITITAS & $|\wedge \Delta \& \Delta|$ & $11 V F \cdot 9$ & DTTY. & tr. kt & DATEFD & ساله \\
\hline VHrag & $\mid r \cdot q \pi \Delta$ & IT. F\& & 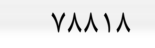 & rबT৭V & FVFq1 & • $\Delta$ ساله . \\
\hline$\Delta T I \Delta \Lambda$ & $9 \cdot 111$ & $119 \mathrm{rvq}$ & $11 \cdot 0 \cdot 1$ & 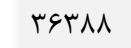 & 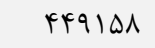 & \\
\hline TTVDS & Q9T1G & ^৭194 & $\| F \Delta \mid F$ & 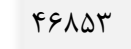 & rvirry & 19............... \\
\hline 19194 & $r 4.9 \wedge$ & 9.991 & $9 \Lambda \cdot \Delta \varphi$ & $\Delta F \& 9 \Lambda$ & rAFG. & (1) 99 - 99 \\
\hline||$r \varepsilon \mid$ & rTIII & 41019 & ArदG & $\Delta G \wedge \vee r$ & TYEVT. & 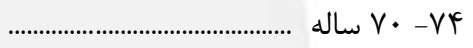 \\
\hline IDFQ. & riیrq & 99199 & 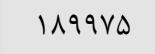 & IEATVE & fNkrqu & 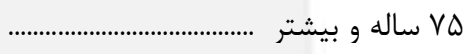 \\
\hline vilfre & $1 F q \cdot 1 \cdot r$ & Iraq1If & 1. gfirt & $11 r \cdot r \cdot$ & DrAIEFF & 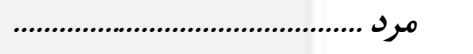 \\
\hline 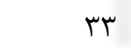 & $\wedge \vee$ & r^s & s4q & $\Delta \wedge 9$ & leqr & 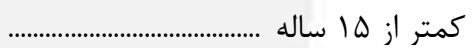 \\
\hline rTG & VTI & $r \cdot q \mu$ & Arri & $\mid 9911$ & $\mid V \in G \Lambda$ & 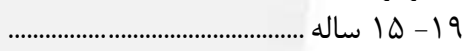 \\
\hline TFAL & $|f| Q$. & G.FTT & gFtir & $199 \Delta \mathrm{r}$ & IMAVK. & r • \\
\hline rIfIT & IIIgrV & $r \Delta F q \cdot r$ & $\mid \vee \wedge \varepsilon \cdot V$ & $r m t \cdot \Lambda$ & DQGTTI & rQ - rq \\
\hline VA9YT & $r \wedge \Delta \wedge \Delta F$ & 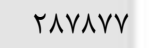 & $1 \cdot V Y 99$ & luvar & $\Lambda \cdot \varepsilon \cdot \Delta r$ & 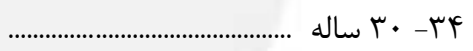 \\
\hline IFqTSV & rI9هDI & $1 \Delta F \Delta \Delta \Delta$ & $F V v \cdot V$ & $|f| r$. & VDTFTY & qץ- ه ساله ................... \\
\hline lDGFrD & TFNINF & १人५^৭ & Mाris & $1 \cdot \vee 91$ & GTFIYA & ساله . fr \\
\hline$\| \vee \wedge \wedge \Delta$ & IVVqV^ & $1 \cdot f \mid f G$ & rNIGr & $9 \Delta \pi \Delta$ & $\Delta Y V E \cdot V$ & .......... \\
\hline$v \cdot 19 v$ & 1114991 & 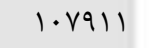 & GIVAT & $\wedge \backslash \wedge F$ & FIDTD. & • \\
\hline $4 q .94$ & Art. & $1 \cdot r \wedge \Delta q$ & ヘ९५^৭ & NDHE & TVEVTI & ساله .............................. $ه 9$ \\
\hline r१९४। & $\Delta r \cdot r q$ & VVTAK & $911 \cdot 1$ & $\Lambda \cdot G 4$ & r^९DIT & .................. 94 \\
\hline IVrG. & ris9V & 0.911 & VVArL & VVrI & $r \cdot 19$. & \\
\hline $1 \cdot 4 \cdot$. & $r \cdots l$ & $r G \cdot \Delta \Delta$ & 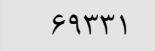 & 11rs & IQTVAV & 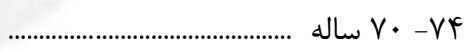 \\
\hline IFAKG & $r \cdots r$ & G. FFE & $\mid \& \vee \wedge \Delta \Lambda$ & FTOFE & rtVqut & 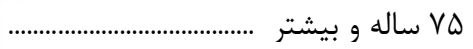 \\
\hline rFAVq & DEATF & $11 r q 14$ & $|1 \cdot| F \mid$ & reasir & VAFFAI & 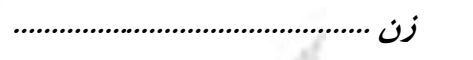 \\
\hline ir & gr & irv & red & gqV & $|r| 9$ & 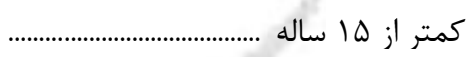 \\
\hline fr & Ira & erd & $|4 q|$ & 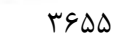 & DVVT & 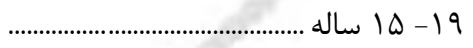 \\
\hline If4 & qM & 1994 & frav & $G \cdot r \Lambda$ & ITSVT & 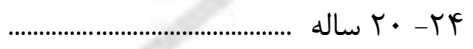 \\
\hline VII & $r \cdot q \Delta$ & $\Delta r V \cdot$ & NTrF & VVVA & TFETE & q \\
\hline IVVV & $r \cdot r \Delta$ & NGTG & $9 \wedge \Delta \mathrm{r}$ & $\Lambda \Delta \Delta r$ & 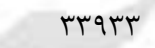 & Fץ \\
\hline rqfe & grta & 11119 & I.VET & qTAT & FrD१G & q \\
\hline 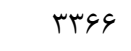 & VEVA & ITFEA & $11 M A F$ & 1.189 & FrAft & 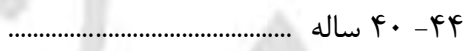 \\
\hline meVI & VAVT & IrTgr & $1 \Delta \cdot \Delta \Lambda$ & $1 r \omega \cdot V$ & $\Delta \Delta T H \Lambda$ & \\
\hline risq & gqfe & ITSDT & IV.re & 11114 & Q9Yr। & • \\
\hline$r \cdot 9 \Delta$ & 9911 & ITST. & rIIIr & TVADT & Vefer & 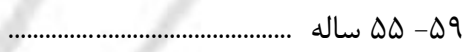 \\
\hline$r \Lambda \cdot \Delta$ & GTEV & Iref. & $r T V \cdot G$ & 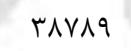 & NFArF & 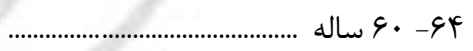 \\
\hline INTK & ervi & qVer & T. ETI & $4 \& 9 \& V$ & NFFi. & 99- \\
\hline$\wedge \notin 1$ & 1I. & $\Delta F G F$ & IFrTd & FAVTr & VIqfr & ساله $V \cdot-V F$ \\
\hline GTF & IArV & $\Delta V \Delta r$ & rTIIV & ITQVY. & $|\Delta \& \&| \mid$ & 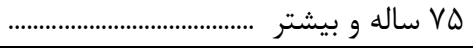 \\
\hline
\end{tabular}


| نتايج تفصيلى سرشمارى عمومى نفوس و مسكن _ه |

\begin{tabular}{|c|c|c|c|c|c|}
\hline و و بيشتر & 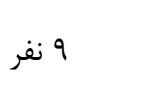 & م نفر & 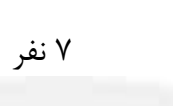 & 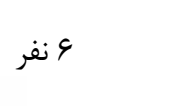 & جنس و سن سريرست \\
\hline $1 \cdots r \Lambda$ & IFAN. & rqral & $1 \cdot r \cdot f q$ & rygrel & 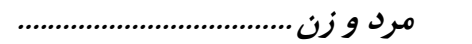 \\
\hline 1 & . & r & $\wedge$ & 19 & 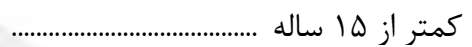 \\
\hline$\Delta$ & $\Delta$ & $r \cdot$ & rt & $1 \cdots$ & 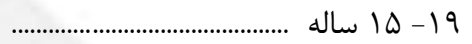 \\
\hline f. & rᄉ & AT & IVA & $\Delta \wedge \uparrow$ & 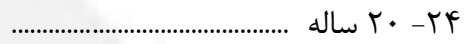 \\
\hline$\Lambda \Delta$ & 110 & ruf & (rrq & qqIV & q \\
\hline rیD & $\Delta \wedge \varphi$ & IVTY & $\Delta \wedge \mid \vee$ & 19991 & 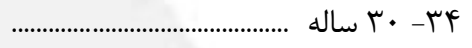 \\
\hline $1 \cdot 19$ & $1 \wedge \vee \Delta$ & $\Delta r q T$ & Ir人qr & fGrq1 & qץ- \\
\hline $11 \cdot r$ & r^१! & V९৯१ & $r \cdot \varphi \cdot \Lambda$ & $\Delta \wedge \Delta T_{1}$ & 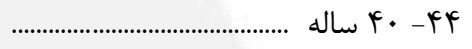 \\
\hline IfFE & $r \cdot \Lambda \cdot$ & DFTA & 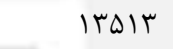 & rtgla & (D) \\
\hline$\mu \cdot \Delta$ & $I V \Delta \cdot$ & fFrq & 11.94 & $r \Delta \cdot r \Delta$ & 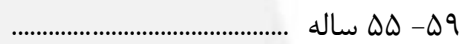 \\
\hline NFF & $11 \mathrm{Fr}$ & r৭९V & $v \cdot 11$ & $|q \cdot| f \mid$ & 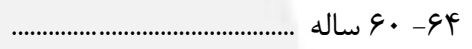 \\
\hline$\Delta \cdot V$ & gFV & $19 \cdot V$ & $f \cdot r q$ & $q 1 \% \wedge$ & (9D - 99 \\
\hline rq⿻ & rqV & $9 \wedge 9$ & rtr. & DTYA & ( ساله ............... \\
\hline fAr & FFA & ITF. & $r \cdot \wedge \Delta$ & Vrq1 & 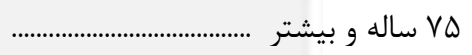 \\
\hline $99 v \pi$ & $1 F r \cdot 1$ & rvqaq & qqraF & reggra & مرد مر........ \\
\hline 1 & - & 1 & $\Delta$ & 11 & 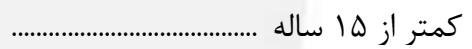 \\
\hline$r$ & r & $r \cdot$ & rA & Af & 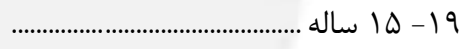 \\
\hline re & tr & V^ & 190 & DrG & 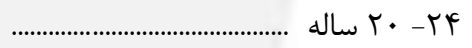 \\
\hline$\Lambda$. & $1 \cdot v$ & 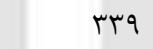 & 1194 & feqr & 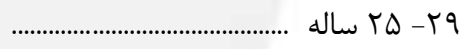 \\
\hline IVAT & $r \wedge \cdot r$ & $V F \cdot r$ & $r \cdot \cdots l$ & $\Delta V \cdot F V$ & 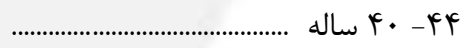 \\
\hline 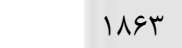 & r^ৎฺ & VRr & IA\&VK & 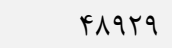 & 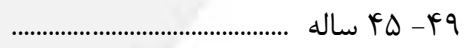 \\
\hline$|f \cdot|$ & $r \cdot 10$ & $\Delta T \Delta T$ & $\mid r \cdot \Delta \Lambda$ & rIF & 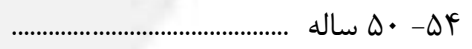 \\
\hline ITSD & IENT & FrgD & $1 \cdot 9 r \Lambda$ & rmatr & 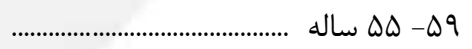 \\
\hline$\Lambda \cdot \vee$ & 1.94 & tAkt & gqY. & $10 \cdot r$ & 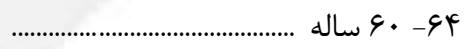 \\
\hline 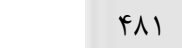 & $\varphi \cdot \Delta$ & IDTG & $r \wedge \cdot q$ & NFTA & 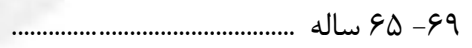 \\
\hline rNT & rFA & $9 \Delta \varphi$ & trth & $\Delta \cdot r q$ & 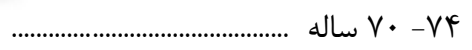 \\
\hline 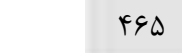 & fry & $|r| \mid$ & $r \cdot \mid f$ & VIV & 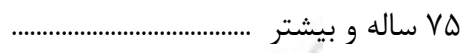 \\
\hline rad & $\Delta r r$ & Ifrer & rygr & 9999 & 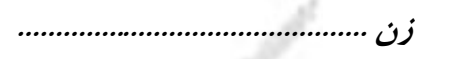 \\
\hline . & - & 1 & 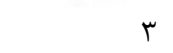 & $\wedge$ & كمتر از ها ساله \\
\hline r & 1 & - & r & 19 & 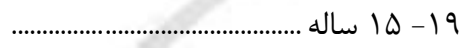 \\
\hline$\wedge$ & f & f & 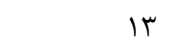 & $\varphi \wedge$ & 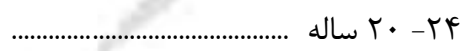 \\
\hline$\Delta$ & $\wedge$ & 10 & VG & rof & جr \\
\hline 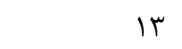 & $r \Delta$ & 94 & rNi & ६४৯ & ץ ץ- •r ساله ... \\
\hline 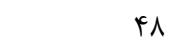 & 99 & rte & $\Delta \Delta \varphi$ & IrIV & 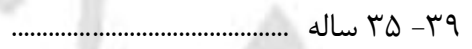 \\
\hline$\Delta r$ & $\wedge 9$ & $r \Delta \Delta$ & $\varepsilon \cdot V$ & IFAF & 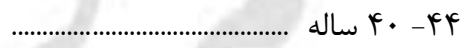 \\
\hline$\uparrow \wedge$ & 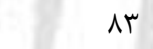 & ris & $\Delta \Delta r$ & ITEV & FQ \\
\hline$\varphi \Delta$ & 90 & IVG & $r \Delta \Delta$ & IIVG & 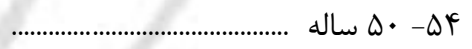 \\
\hline f. & $9 \wedge$ & 194 & fqY & $|1| 1$ & 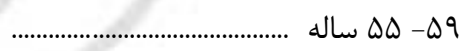 \\
\hline rv & iへ & ITF & rvi & $1 \cdot r v$ & 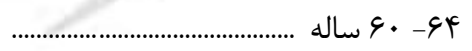 \\
\hline re & fr & $\wedge 1$ & tiV & 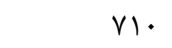 & 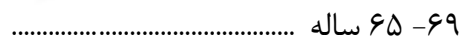 \\
\hline 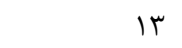 & 19 & 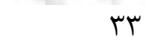 & 94 & rva & سالd V. -VF \\
\hline 11 & 11 & rq & vi & TrI & 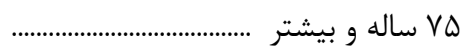 \\
\hline
\end{tabular}




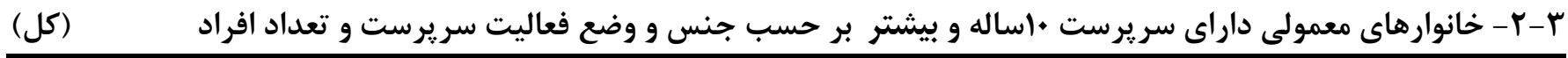

\begin{tabular}{|c|c|c|c|c|c|c|}
\hline ه لفر & بأنفر & ك لفر & ك ب نفر & ا نفر & جمع & فعاليت سريرست وضع \\
\hline reqr...r & sqvr.qr & sAgsfas & rqurrt. & r. feril & rFIrAarl & مرد م \\
\hline 19rvors & Dr.VATr & $r q \Delta r \cdots \wedge$ & TVrAVVA & q.F... & 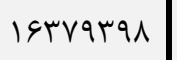 & عل \\
\hline$\Delta \Lambda \Lambda \cdot V$ & $11 \cdot 111$ & $r r \cdot 1 T S$ & IVFq9T & $\Delta T I V \Delta$ & VTIATY & كار .............. \\
\hline rosq. & NFIFT & $q \vee q \cdot \Delta$ & $1 \cdot T r T \Lambda$ & DFDFV & rVTqAT & $\omega$ \\
\hline G994N & IVIrav & $r 9 v \cdot 10$ & DFIDTF & VAVGT० & $19 \wedge r r \cdot V$ & دار \\
\hline$r \wedge \Delta \cdot \Delta \Delta$ & Qq.r.F & ММ৭६४ & $9 \wedge \Delta \cdot \Delta$. & revivi & | & داراى درامد بد \\
\hline$\Lambda \Lambda \cdot \Delta r$ & THGHFT & TrFFAT & $p+1 \cdot v q$ & IAYAND & | | | | & 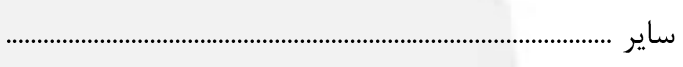 \\
\hline ITYF & rq9V & זוسץ & mesq & $991 \%$ & 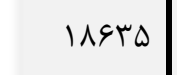 & هبار ن \\
\hline rrd. qra & sfarqur & gregl19 & flargre & SAFVEF & rl.svr.. & 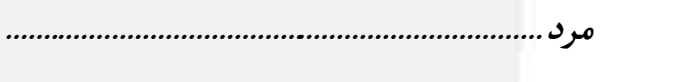 \\
\hline 19TGYDF & DTVGYqI & $Y \wedge V \cdot r \Delta Q$ & $r q \cdot Y|Q|$ & FrTaGI & IQ9TाIrT & 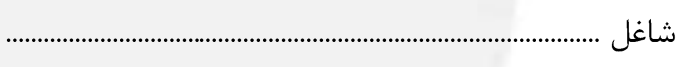 \\
\hline DATQT & IVArrq & THEGET & 19191. & roqIV & GArIVV & كار ............... \\
\hline TARVT & $\wedge r q \Delta 9$ & QTrFI & 918ץर & & | & \\
\hline VEAV & 11.99 & refqI & TFATS & 11914 & $9 \cdot 9 \cdot 1$ & خانهدار ................. \\
\hline rVब919 & 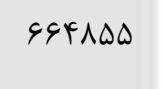 & ArrqT. & 191.49 & १९९৭४ & TAFIV.V & داراى درامد بدر \\
\hline$\Lambda \Delta F \cdot r$ & rT৭६बA & $r \cdot \wedge 9 \Delta T$ & F.VFIV & Arrig & IIVIard & \\
\hline 1101 & rیrq & rqAF & rی৭1 & Frte & Ifrvq & اظهار نشده . \\
\hline$\Delta r \cdot \Delta r$ & $r r \cdot I v e$ & $\Delta r \cdot r \varepsilon V$ & Arrafer & $1 r \Delta q \Delta \Delta r$ & | וr|q. & \\
\hline 11111 & TIDTI & Nrveq & ITKGTV & $|\Lambda| \cdot 4$. & FrATED & \\
\hline$\Delta \Delta F$ & 1949 & grAF & $I T \cdot N T$ & $1 \varepsilon r \Delta \Lambda$ & rAgYe & كار ......................... \\
\hline MIN & $11 \wedge r$ & rqgY & 1.99. & $T Y Y \cdot \Lambda$ & rqfif & 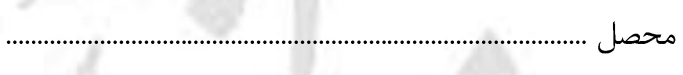 \\
\hline$\Delta 9 \mid 01$ & | |דrמט| & TFTATY & 019119 & VAG. 14 & $|199| 4 \cdot 4$ & \\
\hline NIre & TOMYQ & gqVIV & $|r F \cdot r|$ & $r \Delta \cdot r v \Lambda$ & EVArAs & \\
\hline TEQ1 & GQVD & $1 \Delta \Lambda \ldots$ & rMGS & $1 . .999$ & $|q| f \Delta Q$ & \\
\hline 99 & 101 & rrq & $\Delta V_{1}$ & T\&AV & rNDS & اظهار نشده ........ \\
\hline
\end{tabular}


| نتايج تفصيلى سرشمارى عمومى نفوس و مسكن _ه |

r-Y- خانوارهاى معمولى داراى سريرست +ا ساله و بيشتر بر حسب جنس و وضع فعاليت سريرست و تعداد افراد (دنباله) (كل)

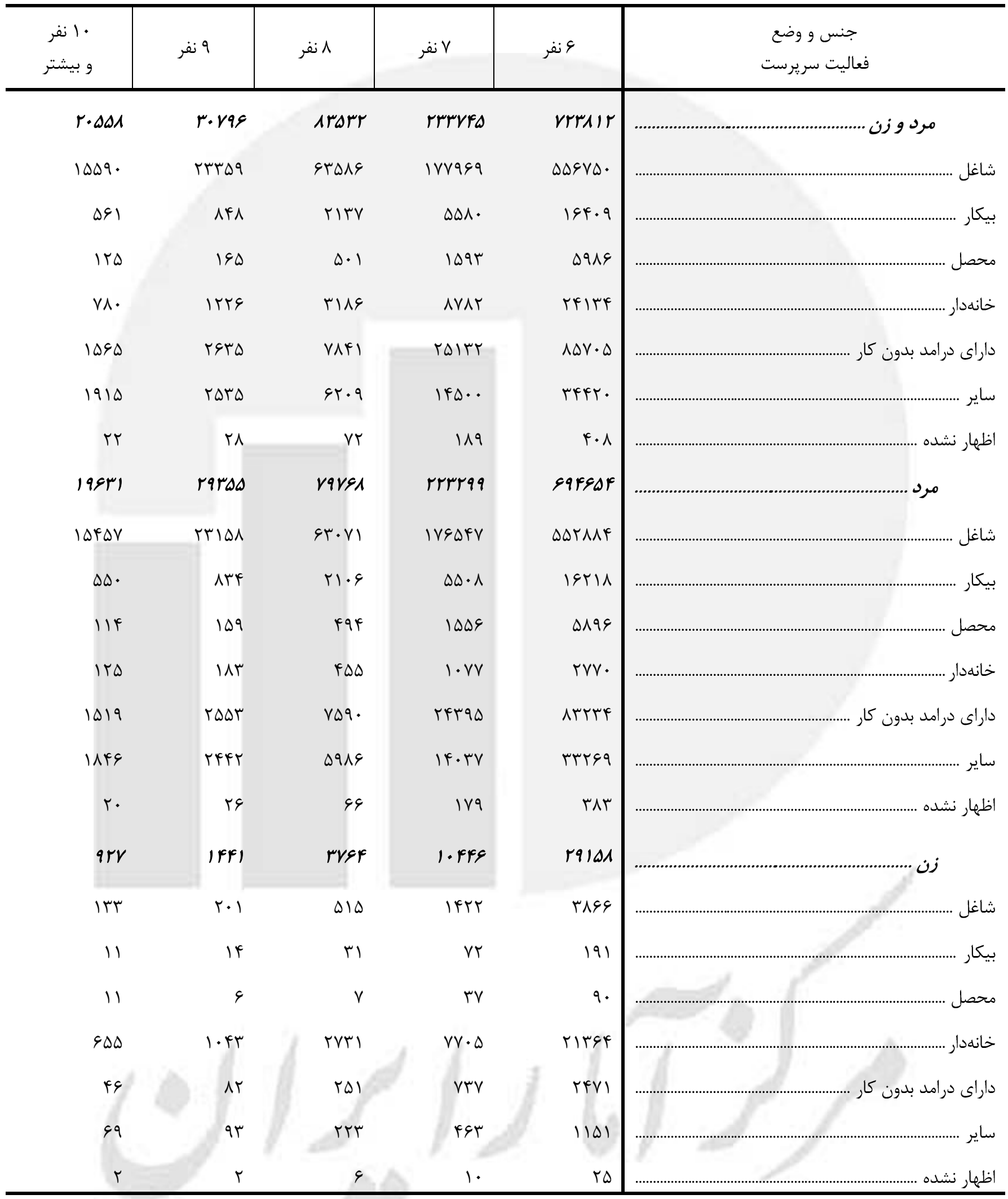


r-r- خانوارهاى معمولى داراى سريرست +1 ساله و بيشتر برحسب جنس و وضع فعاليت سريرست و تعداد افراد (دنباله) (نقاط شهرى)

\begin{tabular}{|c|c|c|c|c|c|c|}
\hline 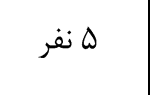 & | ل أفر & 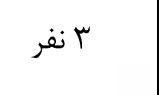 & 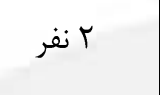 & ا نفر & جمع & فعاليت سريرست و وضع \\
\hline$|v| 1 \cdot 1 r$ & DIrreref & DraIrfF & rVf.rir & $|F q \Delta| r \Delta$ & 11.vara. & $\ldots \ldots \ldots \ldots \ldots \ldots \ldots$ \\
\hline ITQTATF & rqvтqu & rVVDGYI & $19 \wedge \varsigma \vee \cdot \vee$ & FF. TrG & II qTrAVD & شاغل .................. \\
\hline FIrqA & ITETFE & $|V F| \wedge 9$ & ITHE & fiDIS & $\Delta F \cdot F \wedge \varepsilon$ & 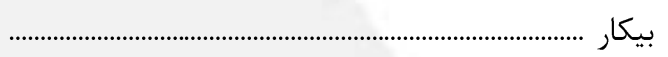 \\
\hline TIATI & VFrog & 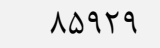 & 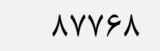 & 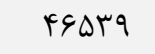 & TrTG人9 & تصل ....... \\
\hline FDDHV & ITFTE. & TVVAIq & $f \cdot 910$. & $\Delta \Delta \varepsilon \mid T$. & IFTFDq9 & انهدار ............... \\
\hline$r \Delta \Delta \wedge F T$ & \&тq人ทr & ᄉ.rvq1 & $\Lambda \Delta \Delta F \vee q$ & rqDFrq & TQFDFVI & داراى درامد بدون ك \\
\hline$\Delta ৭ \wedge \Delta \vee$ & INTTAE & ומשr & 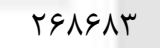 & $11 \cdot f \Delta F$ & $\Lambda \wedge \varepsilon \cdot \nvdash \wedge$ & 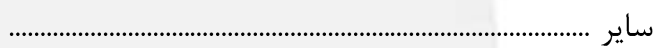 \\
\hline سז1 & riva & TFVF & $r \Delta \cdot 1$ & FATI & ITIAT & اظهار نشده. \\
\hline $199 \cdot 9 \cdot 9$ & pqq..r. & FqFerffa & $r \cdot 1 \gamma r r r$ & D.rrar & larrrtar & مرد ........ \\
\hline ITADAFT & rqDIVFA & rV. qVFA & $11 \vee 9194$ & $r \cdot \Delta f 19$ & $\| \Delta q \Delta \cdot \Delta F$ & شاغل .......... \\
\hline 4.979 & MFVT & $19 \wedge \vee \ldots$ & $|r| \Delta \cdot \varphi$ & TVDFF & $\Delta \cdot V \uparrow \Delta \cdot$ & بيكار .................. \\
\hline TIQVD & VMris & AIVqs & $\vee \wedge \cdot \wedge V$ & TEAFT & TAVATV & صل ....... \\
\hline FEIT & ITETD & IVVGT & ISFDV & GAT. & $G \cdot V T \Delta$ & خانهدار ........... \\
\hline TYAVDA & 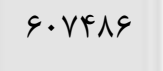 & VFTVGD & VFFfqR & $\Lambda \cdot V \wedge F$ & TOTVTAV & داراى درامد بدون " \\
\hline$\Delta \wedge F \cdot q$ & $|\vee \wedge \cdot|$. & tr. rIF & TFDFTA & $r \wedge \Lambda \cdot r$ & VArTDq & اير .................. \\
\hline VAF & $r \cdot v r$ & THET & $r) \cdot \Lambda$ & $r \cdot v l$ & 1.901 & اظهار نشده .... \\
\hline$\Delta V I \cdot r$ & letrif & $F \cdot 9999$ & sar.rq & qqrafr & $r \mu \cdot r \cdot q r$ & زن ...... \\
\hline 9995 & rTI9I & ८४८१९ & I.VDIr & $|r| \Lambda \cdot V$ & rrVArI & اغل ............. \\
\hline rVT & 1011 & $\Delta F \wedge q$ & 11011 & IrqVT & צr. & كار ................. \\
\hline THE & $1 \cdots 1$ & سוץ & $99 \wedge 1$ & 19998 & MFAGT & محصل ...................... \\
\hline$F \cdot 9 r \Delta$ & IIVTa & $r q \cdot \Delta \varphi$ & ए人१६१ए & DFqT.. & ITVRAVF & 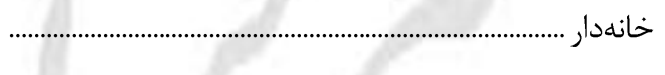 \\
\hline$V \cdot \Lambda \Delta$ & TrTAV & G..TG & 11.919 & rITSED & $F|\Lambda| \wedge F$ & راى درامد بدون ' \\
\hline$|F| \wedge$ & FTVE & $111 \wedge \mathrm{V}$ & THTDQ & 91901 & $1 \cdot r \vee \wedge 9$ & 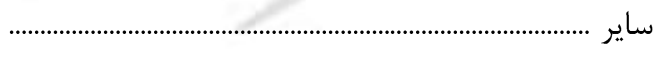 \\
\hline rq & $1 \cdot 9$ & rit & ra & IVG. & TLI & اظهار نشده ........ \\
\hline
\end{tabular}




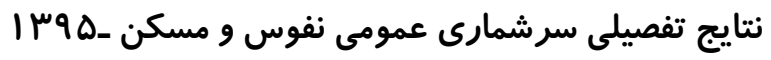

r-r- خانوارهاى معمولى داراى سريرست •1 ساله و بيشتر برحسب جنس و وضع فعاليت سريرست و تعداد افراد (دنباله) (نقاط شهرى)

\begin{tabular}{|c|c|c|c|c|c|}
\hline و و بيشتر & 9 نفر & ᄉ نفر & V Vفر & 9 نفر & فعاليت سريرست و وضع \\
\hline $1 . \mathrm{Fqr}$ & $1 \Delta A \& H$ & frast & $|r \cdot r q|$ & FFEgTF & 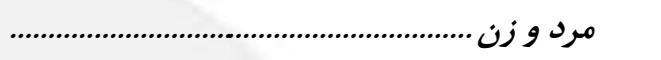 \\
\hline VQVF & $11 \pi 1$. & $\Pi \| \Delta \Lambda$ & $9 r \cdot r q$ & rTIFET & شاغل ................. \\
\hline 190 & red & $q 4 V$ & rVq. & $991 \wedge$ & بيكار ............... \\
\hline vi & $1 \cdot 0$ & rTA & $11 K \pi$ & reqq & محصل ........ \\
\hline pqF & VYF & $19 \vee \Delta$ & $\Delta \Delta F \Delta$ & $1 \Delta \wedge \vee \Delta$ & خانهدار.......... \\
\hline 1119 & $r \cdot \Lambda r$ & grVA & 51.19 & VArVt & ...………………...... \\
\hline १९ा & IrV. & r|q1 & VVGF & $r \cdot 11$. & ساير .... \\
\hline v & 9 & $r \Delta$ & 94 & Trt & اظهار نشده \\
\hline 995. & 18999 & FIEFT & I TrEsa & FrVIAT & ي رد...... \\
\hline$V \Delta \cdot G$ & $11 T \cdot 1$ & $r \cdot \wedge \wedge q$ & q1KrV & rI9rVq & شاغل ........... \\
\hline 195 & $r \Delta \Lambda$ & $9 \Gamma \wedge$ & TVQV & $91 \cdot 9$ & بيكار .............. \\
\hline $9 V$ & 1.1 & TrT & 1.99 & FDQT & محصل ...... \\
\hline $9 T$ & 91 & Tr & $\Delta \Delta q$ & $10 \cdot r$ & خانهدار ............ \\
\hline 1149 & r.l. & 9199 & $T \cdot Y \cdot r$ & VTrVI & داراى درامد بد \\
\hline 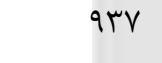 & |TMI & $r \cdot V r$ & VQFY & 19011 & ساير ................... \\
\hline v & r & rt & 9. & rT. & $\ldots$ \\
\hline$\Delta V r$ & $1 \& V$ & rre. & sqve & IgFFI & ...... \\
\hline 91 & 1.9 & TVT & マ^৭ & rIAF & \\
\hline$r$ & $\checkmark$ & 19 & זr & $11 \mathrm{r}$ & بار .................. \\
\hline f & f & & TV & $\Delta \varphi$ & \\
\hline & Vr & $r$. & GIV & $r 1 \cdot \varphi$ & دارا \\
\hline$r \Delta$ & rq & 19 & Tr. & 099 & ساير ........... \\
\hline · & $r$ & $r$ & r & ir & 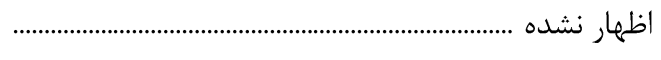 \\
\hline
\end{tabular}


r-r- خانوارهاى معمولى داراى سريرست +1 ساله و بيشتر برحسب جنس و وضع فعاليت سريرست و تعداد افراد (دنباله) (نقاط روستايى)

\begin{tabular}{|c|c|c|c|c|c|c|}
\hline ل ل لفر & ل أنفر & 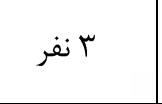 & ك ا نفر & ا نفر & جمع & فعاليت سريرست وضع \\
\hline$V \in \mu r \cdot V$ & $|\Delta F \& q|$. & 1011992 & Ireras & DFrATr & $q \cdot r r \Delta q F$ & مرد , \\
\hline GFTINI & פזוזוזו & $\| V \Delta V \Delta \Delta$ & V\&qV\&l & ISIDTD & FETrAtr & اغل ...... \\
\hline$I V \Delta \cdot r$ & pramt & $\Delta \Delta Q T F$ & Fiq4a & $1 \cdot \Delta V F$ & 101194 & بيكار .............. \\
\hline rAsV & 9YAI & 11909 & IFATq & VArI & $\Delta \cdots \Delta 1$ & مصل. \\
\hline$r I \cdot \Delta V$ & F\&QGT & $19 \cdot 4 \varepsilon$ & Irdוt & TYIT.r & 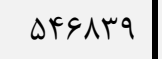 & خانهدار ........ \\
\hline rq19V & $9 \cdot r 9 \Delta$ & $\wedge \Delta \vee ৭ ৭$ & IYQDYF & DIEVT & rVFY.r & 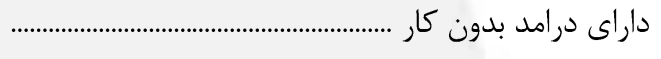 \\
\hline$r(1) \cdot \varphi$ & 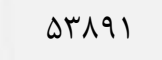 & qrV.. & $I V T \cdot \Delta \Delta$ & $v r \cdot \Delta \Delta$ & $r \notin \varepsilon \cdot \Delta T$ & ساير ........... \\
\hline$r 90$ & $\wedge / F$ & NTF & १९ा & $191 \mathrm{~V}$ & QHTH & اظهار نشده . \\
\hline viafer & $1 F q \ldots q r$ & $1 r q 9 \cdot \Delta r$ & 1. grala & IAr.r. & arAIraq & مرد ......... \\
\hline 849.19 & IrTIGGT & $11 \Delta \Lambda \cdot r q$ & VYTAGY & $11 r v .$. & FrTFTDQ & كاغل ......... \\
\hline IVTrT & freqf & $\Delta F q T$. & F. rरQ & $\wedge r .$. & $\mid V \Delta G \cdot T$ & بيكار ........... \\
\hline rvqD & $99 \cdot V$ & IIfr & ITOHY & DITV & $F \Delta Q F F$ & محصل ....... \\
\hline 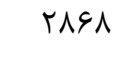 & DFrF & GVTD & $\Lambda 19 \Lambda$ & 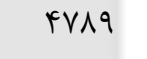 & $r \cdot \mid k r$ & خانهدار ر.............................. \\
\hline TNIFA & DVTMF & V9111 & llskq & $\mid \Delta \wedge \& Y$ & MIFTrA & داراى درامد بد \\
\hline$r 99.9$ & $\Delta / \Delta \ldots$ & $M \Lambda \cdot 9 V$ & $|9| 91 \mid$ & rसाTा & rAvQrA & 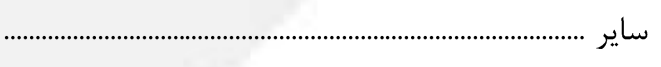 \\
\hline rqA & VET & VIA & VAV & $11 \cdot 1$ & $r \cdot \Delta r$ & اظهار نشده . \\
\hline rFArA & DFAIV & IIrgFe & IVq9VF & redAIV & vastra & \\
\hline fist & QTVर & IVYIS & r\&人9V & FANTA & $1.909 \mathrm{~V}$ & - \\
\hline INT & Fru & 994 & $10 \Delta 9$ & TrVF & ब०११ & بيكار ............................ \\
\hline Vr & IVF & DTG & १९४ & raAk & $r \Delta \cdot v$ & صل ........ \\
\hline 11119 & FIOTA & Arr. & IrgqFF & TMGAIF & D1999V & خانهدار ر............. \\
\hline 1.49 & rव९ा & $94 \wedge 1$ & $M \cdot t r$ & $r \Delta \Lambda 1$. & $\varepsilon \cdot \cdot v V$ & \\
\hline 1198 & rrql & $r q . r$ & $1 \cdot r V F$ & rAqTF & $\Delta \wedge \Delta \backslash \Delta$ & ". \\
\hline TV & $\Delta r$ & 119 & IVe & $1 \wedge \varsigma$ & $|r \wedge|$ & اظههار \\
\hline
\end{tabular}


| نقايج تفصيلى سرشمارى عمومى نفوس و مسكن _ه |

r-r- خانوارهاى معمولى داراى سريرست +1 ساله و بيشتر بر حسب جنس و وضع فعاليت سريرست و تعداد افراد (دنباله) (نقاط روستايى)

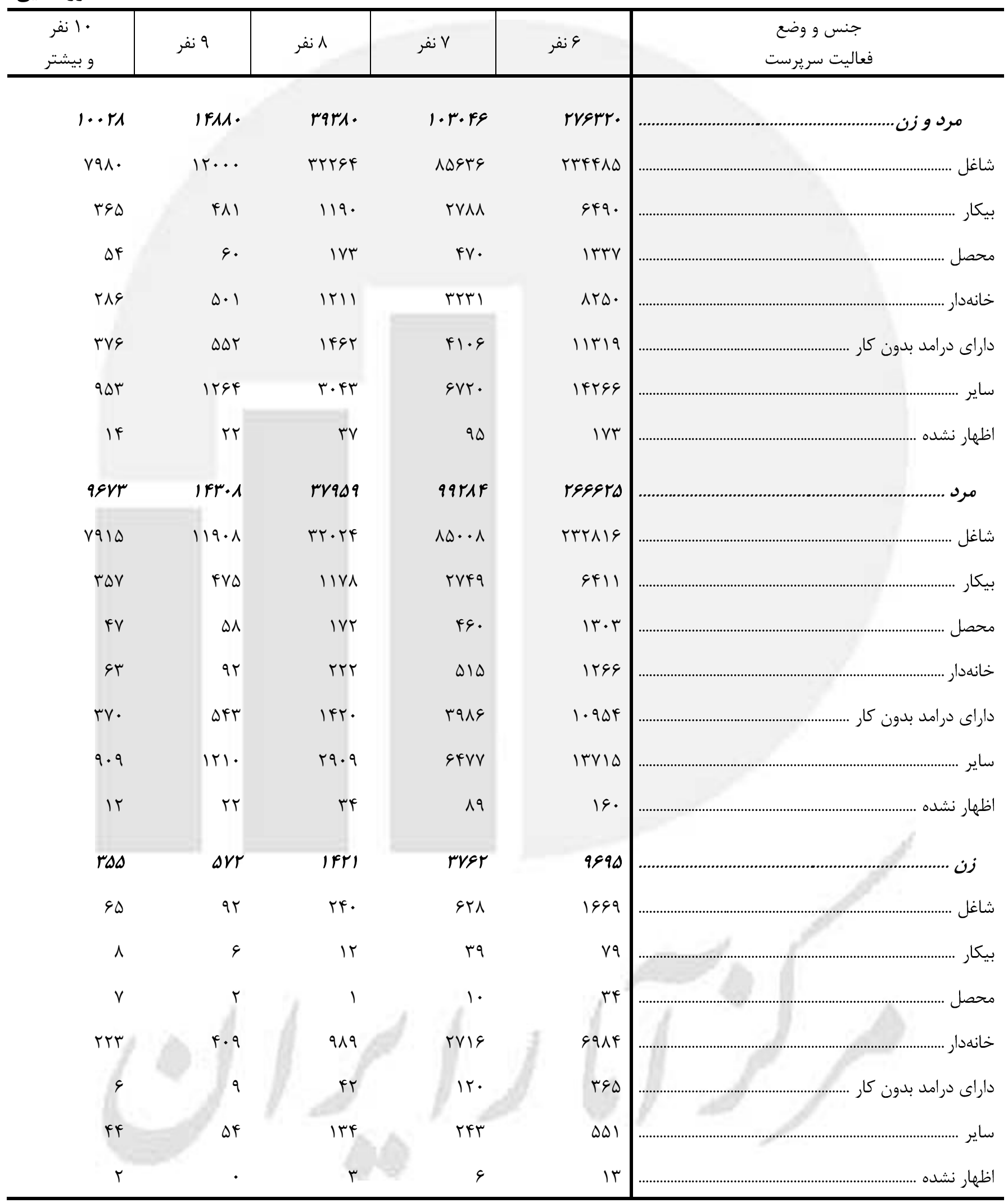


F-F-F - خانوارهاى معمولى بر حسب جنس سريرست، تعداد افراد خانوار، تعداد افراد شاغل و بيكار

\begin{tabular}{|c|c|c|c|c|c|c|}
\hline \multicolumn{5}{|c|}{ 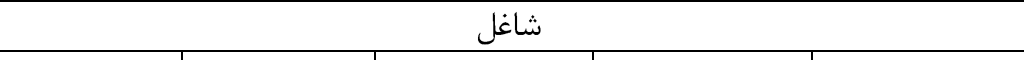 } & \multirow[b]{2}{*}{ جمع } & \multirow{2}{*}{ و تعداد افراد در خانوار } \\
\hline ل أ نفر و بيشتر & كا نفر & ك انفر & ا انفر & 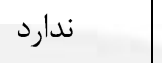 & & \\
\hline 1.1194 & ertras & $r \cdot$ raqra & IFFqD\&qq & $\varepsilon \cdot r \cdot V k r$ & reirquq. & 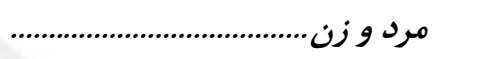 \\
\hline · & $\cdot$ & - & $9 \cdot f \cdot \cdot 1$ & IFFTMIS & r.YATIV & 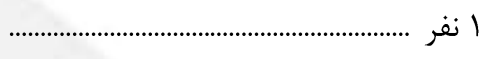 \\
\hline · & . & 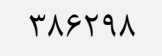 & r\&YqI\&D & I9DTDIF & 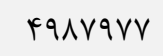 & r نفر ................ \\
\hline . & $F_{1} \cdot k v$ & $9.91 \Delta F$ & rogspir & Ira... & 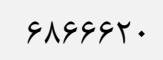 & ب نفر .................. \\
\hline Irrgy & IFEDVF & $1.91 \cdot 19$ & 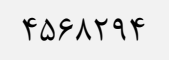 & $\Lambda \wedge r \wedge \cdot \vee$ & G9VTा11 & ץ نفر ........... \\
\hline$r \cdot \wedge v \varepsilon$ & $\mid r \& 4 \cdot 1$ & $\Leftrightarrow \& V V \Delta q$ & IDFVFTS & $r q . q 4$. & TYGT.IT & ه نفر ................ \\
\hline 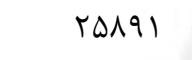 & $9|9 r|$ & IGTV.V & rq৭६V & VANTt & VTrAIF & ع نفر ............. \\
\hline $1 \Delta \Delta V \Delta$ & tQVIT & $\Delta \Lambda \cdot r)$ & $11.94 \mathrm{~F}$ & trVAF & trutra & نفر ............ ن V \\
\hline$\Lambda \cdot \Delta V$ & $11 r 91$ & rIIOV & rafis & $V \varphi \cdot \Delta$ & 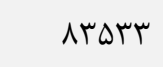 & ^ نفر ............... \\
\hline rQ^ब & $k V \cdot r$ & VAre & $11 \Delta V V^{k}$ & r\&9V & r.vqQ & 9 نفر ................ \\
\hline 4119 & r 491 & $p q \cdot v$ & GTAD & IDQT & $r \cdot \Delta \Delta \Lambda$ & • ا نفر و بيث \\
\hline ו & rגVrqi & $r 91.191$ & $1 r \gamma \cdot r r q \Delta$ & ravritr & rl.srrrr & 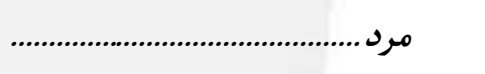 \\
\hline · & & & FrYqG। & rят人.r & GNGVGF & ا نفر ............ \\
\hline . & & $r \Delta g V \cdot 1$ & THFY.AV & IFAFTGV & $F \mid \Delta F \cdot \wedge \Delta$ & r بنفر ........... \\
\hline . & rTVtr & $\Lambda r V F=1$ & krvqugr & $1.9 \Delta r \cdot r$ & GTKGTqR & ب نفر .................. \\
\hline 11941 & ITTANT & $|\cdot r \cdot \Delta r|$ & rqq. 4 IV & VqVTVF & sFATqTa & ץ نفر ............. \\
\hline$r \Lambda \cdot r \Delta$ & IIAFES & $f \Delta \cdot V V$. & $1 \Delta T \cdot 1 \Delta F$ & TETOFA & $r r \Lambda \cdot 9 \Delta r$ & ه نفر ................. \\
\hline rrq10 & DNDTr & $|\Delta \& 4 A|$ & rAVTrFe & घArदI & GQFGQF & عنفر .......... \\
\hline IFATE & TATVR & $\Delta \Delta V \vee \Delta$ & $1 \cdot \sqrt{9} 19$ & $r \cdots q$ & Trrtq9 & نفر V V V V \\
\hline$\vee \Delta \wedge \Delta$ & $1 \cdot V F F$ & $r \cdot r \cdot q$ & mFraf & SVYG & V৭४९^ & ^ نفر .............. \\
\hline rVGe & FraV & vall & llrur & rrAs & 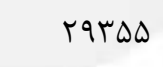 & 9 نفر ................. \\
\hline$r q \cdot \Delta$ & $r \Delta \cdot q$ & priq & $91 . r$ & 1 1т99 & 19841 & • ا نفر و بيث \\
\hline$A T \cdot r$ & rFAqa & 181VT. & varr.r & $r \cdot \Delta V$ rer & $r \cdot g i v a r$ & زن ز... \\
\hline · & $\cdot$ & - & $|\Lambda| \cdot r \cdot$ & IIVADIT & $1 r \Delta q \Delta \Delta T$ & ا نفر .......... \\
\hline · & · & rq०१४ & $r \cdot q \cdot v \wedge$ & rqATIV & 人rrیq & r.......... \\
\hline · & VTr. & VIVAT & $1 \wedge 9 \Delta \Delta$. & $r \Delta F V \cdot F$ & $\Delta T \cdot T T V$ & ب نفر ................. \\
\hline אזץk & Irव95 & $F \cdot \Delta F \Lambda$ & VVGVV & NGQHT & $r r \cdot \mid \Lambda r$ & ب نفر .......... \\
\hline rAYI & $\vee \wedge \Delta \Delta$ & 19919 & TVTAT & TV. QT & $\Lambda r \cdot \Delta q$ & ه نفر ................ \\
\hline 19v9 & rrqג & GTKG & 9.99 & 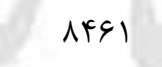 & rq19. & ونفر ................................ \\
\hline 1.49 & IrF. & TRAS & $r \cdot r q$ & TVVD & 1. tye & Vفر ............... \\
\hline eVr & $\Delta \Delta F$ & $\Lambda F \wedge$ & D.rr & $\Lambda \Delta 9$ & rVGa & ^ نفر ................................................ \\
\hline TrI & TFV & $r T \Delta$ & rrv & mII & $|f F|$ & 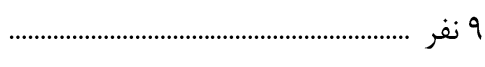 \\
\hline rII & 119 & $1 \wedge \Lambda$ & Iیr & 109 & $9 T V$ & •ا نفر و بيشتر ................ \\
\hline
\end{tabular}




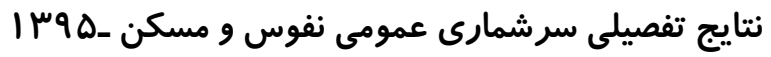

F-F-F- خانوارهاى معمولى بر حسب جنس سريرست، تعداد افراد خانوار، تعداد افراد شاغل و بيكار (دنباله)

\begin{tabular}{|c|c|c|c|c|c|}
\hline \multicolumn{5}{|c|}{ بيكار } & \multirow{2}{*}{ و و تعداد افراد در خانوار } \\
\hline | أ نفر و بيشتر & ب انفر & ك ا كفر & ا ل انفر & 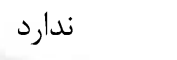 & \\
\hline $1997 \Delta$ & sentr & req111 & reritar & riffFagr & 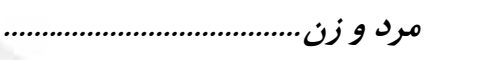 \\
\hline - & . & $\cdot$ & DTIVD & ISqFIFT & | نفر ............................................... \\
\hline - & - & $194 \wedge 9$ & rтqqяץ & FEYADFF & ץ بنفر .............. \\
\hline$\cdot$ & $9 \Delta \wedge$ & DTITV & VITrTe & $91 \cdots+91$ & ץ نفر .............. \\
\hline rer & $\Lambda \vee V r$ & 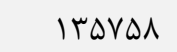 & $991 r 99$ & $\Delta \wedge \& \nu \cdot \Delta \Delta$ & | أنفر .......... \\
\hline$r \cdot V \wedge$ & $T Y \Delta Q$. & $q \Delta \Delta F q$ & T.MFYF & T. MEFII & ه نفر .................. \\
\hline$\Delta \wedge F \varphi$ & IVTTY & FIATD & 1.4190 & DQFVTI & و نفر ................ \\
\hline FATT & VQT. & $|\Delta \Delta| \&$ & rq..l & $1 \vee \cdot \cdot \wedge q$ & V نفر ........... \\
\hline TrVT & r৭९० & $\Delta \wedge F F$ & $1 r \cdot \mid f$ & DqurV & ^ نفر .................. \\
\hline $1 . r \Lambda$ & $1 \cdot \lambda r$ & $r r \cdot q$ & FVV. & ris9V & q نفر .............. \\
\hline$v \Delta \Delta$ & $V E V$ & $|f q|$ & rTAG & $14 F \cdot q$ & •ا نفر و بيشن \\
\hline$I f \cdot r F$ & $\Delta \Delta A T F$ & ria.gr & 19D.1rg & |Arrreq| & 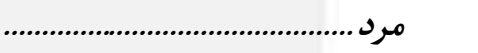 \\
\hline - & . & . & rबqIV & $9 \Delta \cdot \Lambda F V$ & | نفر ........... \\
\hline . & . & $|\Lambda \cdot v|$ & rrgrag & 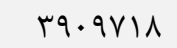 & r نفر ................ \\
\hline . & $\Delta 9 \Lambda$ & TEVAT & GTצGT. & DЯqYTQR & ب نفر ........... \\
\hline $1 \wedge \Delta$ & 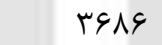 & 119491 & $94 \cdot 499$ & $\Delta V \cdot q r \cdot V$ & ץ نفر ........... \\
\hline qזם & TFT.V & $\Lambda \mu r \cdot I$ & rAvqFa & 19V949D & ه نفر .................... \\
\hline rqvi & $1 \Delta V \Delta Q$ & rqाוr & qАV१५ & $\Delta r G \cdot r r$ & ونفر ................. \\
\hline FITr & $999 \mathrm{~V}$ & lFoqr & $r|r| \cdot r$ & $|q T \Delta| F$ & V نفر ............... \\
\hline TIVE & TVVG & DFVF & ITHV & 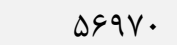 & ^ نفر ............... \\
\hline 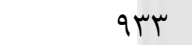 & $1 . r r$ & $r \cdot \Delta q$ & FAT. & $r \cdot \wedge r I$ & q نفر ................ \\
\hline$v \cdot 1$ & VIT & $14 \cdot 9$ & $r \cdot v \varepsilon$ & שמrri & . انفر و بيشتر .......................... \\
\hline rabl & 1.991 & $\Delta F V \Delta F$ & rAllke & $r r 119 . r$ & زر \\
\hline - & . & . & $19 \mathrm{T \Delta \Lambda}$ & ITKMTQD & انفر .............. \\
\hline · & - & $14 \mid 1$ & 11 rek & VIMAYs & r نفر .............. \\
\hline - & rद. & $r \Delta r \Delta \Delta$ & 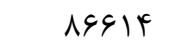 & $4 \cdot \vee 991$ & بـ............ \\
\hline v^ & $\Delta \cdot \wedge \vee$ & lefqV & $r \cdot V V r$ & IOVVFA & ץ نفر .......... \\
\hline $11 k T$ & THET & VYFA & IDFVq & DFqFG & ه نفر ................... \\
\hline$\wedge \vee \Delta$ & $|f r|$ & trit & $\Delta F \cdot r$ & 11991 & و نفر ............... \\
\hline 499 & $\Delta \Delta r$ & QTr & 1199 & gQVT & Vفر ........... \\
\hline 198 & 119 & rV. & GFT & TrEV & م نفر .............. \\
\hline$\Delta F$ & ra & Nr & $1 \Lambda$. & $\Delta \vee G$ & •انفر و بيشتر .............. \\
\hline
\end{tabular}


F-F-F- خانوار هاى معمولى بر حسب جنس سريرست، تعداد افراد خانوار، تعداد افراد شاغل و بيكار (دنباله)

\begin{tabular}{|c|c|c|c|c|c|c|}
\hline \multicolumn{5}{|c|}{ شاغل } & \multirow{2}{*}{ جمع } & \multirow{2}{*}{ و جنداد سريرست خرانوار } \\
\hline F نفر و بيشتر & ك ل كفر & ك انفر & ا لفر & 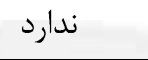 & & \\
\hline DAAAr & rVYeAs & rrargra & 1.v19rar & rrraq9l & $11 \cdot$ rarar & 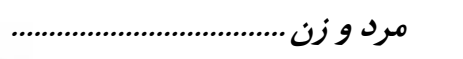 \\
\hline . & . & . & FF. TrG & $1 \cdot \Delta F \wedge 9 q$ & $|F q \Delta| r \Delta$ & ا نفر ....................................... \\
\hline . & . & $r \cdot 19 \Lambda$. & $19194 \cdot 1$ & $10194 \wedge \Delta$ & $r V F \cdot G V T$ & r نفر ................ \\
\hline . & TQVIT & $9991 V 1$ & $r \Delta I \Lambda I \Delta \Lambda$ & $11 \cdot \wedge r \varepsilon$. & $\Delta r \Delta I F \cdot \Lambda$ & ب نفر ................ \\
\hline$V \Delta \Lambda 1$ & 1.1001 & NIrAF| & TFAVGQD & VETAVA & DITHTET & أنفر ........... \\
\hline IAVF. & 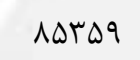 & rT. १९F & $1 \cdot \Delta 9 \Delta \Delta \&$ & גוזrm & $1 V 1 \Lambda \cdot 10$ & ه نفر ................ \\
\hline $10 Y 9 \Delta$ & rAVra & 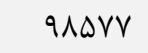 & rr人IIr & $\Delta \Delta q \cdot \Delta$ & FEGGTD & ونفر ................ \\
\hline $111 \Delta$ & $\mid \Delta F \& \Lambda$ & r $1 \wedge \Delta q$ & D৭\&Yq & $14 \Delta q$. & $|r \cdot r \varepsilon|$ & Vفر .............. \\
\hline FTAT & GTGT & $111 \wedge \mathrm{V}$ & |V^१| & ятq. & FrqAT & ^ نفر ................. \\
\hline$r \| l F$ & $r 9.9$ & f..r & $\Delta V / 9$ & 1419 & IDی & 9 نفر .................. \\
\hline$r \cdot \Lambda \varepsilon$ & 199. & reIV & ५१९९ & $\wedge \cdot$. & 1.495 & •ا نفر و بيشتر \\
\hline arraq & ralver & rlarla. & $1 \cdot 1 \cdot k V \cdot q$ & $r r \cdot q \Delta r q$ & larVrfaf & مرد ......... \\
\hline . & · & & $r \cdot \lambda<19$ & 19т人я૬ & D. TRAT & | نفر ................... \\
\hline . & $\cdot$ & TУ৭९१९ & $|\varepsilon V T \Delta Q|$ & IITAT.1 & $r \cdot \wedge v<\& 1$ & r نفر ............ \\
\hline · & $r \cdot r_{I} \cdot$ & GFIFTI & rrs9.91 & q1TFVq & FqFersh & ب نفر .............. \\
\hline 9911 & $q \cdot v \varepsilon v$ & VArTFG & ५т৭११•^ & GNITKF & rqq..rq & أنفر ............ \\
\hline IEVT. & V9019 & $r \cdot \wedge k t r$ & $1 \cdot r \cdot r \Delta \Lambda$ & ris99. & $199 \cdot 9 \cdot V$ & ه نفر ................ \\
\hline $1 r q \cdot \Delta$ & TETTR & qFIVT & rrIqVI & $\Delta \cdot \Lambda I r$ & FTVINT & ع نفر .............. \\
\hline $11 \cdot 1$ & IFATA & $r \cdot r r q$ & $\Delta V \& \wedge F$ & $1 r \cdot r q$ & $\mid K M G \wedge D$ & Vفر ........... ن V \\
\hline Takt & ४११९ & 1.910 & IVTrq & rqQ. & FIEFT & ^ نفر ............... \\
\hline 1911 & TFAT & rVvq & $\Delta \Delta 1$. & ITEV & 14999 & 9 نفر ............... \\
\hline 1900 & 11490 & reqr & r^११ & VIe & ११५. & • ا نفر و بيشتر ....... \\
\hline$\Delta \Delta \Lambda F$ & raq19 & $I r \cdot v F \Delta$ & gIFAAr & larerer & rr.rrar & زن ........... \\
\hline • & · & . & $|r| \Lambda \cdot V$ & $\wedge \notin 1 \cdot r \Delta$ & qQYAFr & ا نفر ........................ \\
\hline · & · & r1911 & TESVEV & rNFAN & GATTIT & r بنفر ............... \\
\hline · & $\Delta T \cdot T$ & $\Delta V Y F V$ & $1 \notin q . q$. & $194 \wedge 11$ & $r \cdot v \cdot r$. & r نفر ............... \\
\hline $9 .$. & $1 \cdot V \wedge F$ & TIDQT & $\Delta \wedge \Delta \wedge \vee$ & G|ro| & IGTTIF & أنفر ................... \\
\hline$r \cdot r \cdot$ & DANT & $|r \Delta V|$ & 19498 & IVTrA & $\Delta V I \cdot \Lambda$ & ه نفر ................... \\
\hline $1 \% q$. & TYIT & $F F \cdot D$ & GIFT & $\Delta \cdot 9 r$ & IgFET & ع نفر ............... \\
\hline$v \cdot v$ & qr. & $1 \Delta r$. & 1940 & logk & 99V9 & Vفر لن \\
\hline 1TE & $1 \Delta V$ & זr & $r \cdot q$ & IQT & $\Lambda \notin V$ & q نفر ............. \\
\hline$|r|$ & ira & ITF & $1 \cdot 1$ & $\Lambda F$ & $\Delta V T$ & • ا نفر و بيشتر \\
\hline
\end{tabular}


| نتايج تفصيلى سرشمارى عمومى نفوس و مسكن _ه |

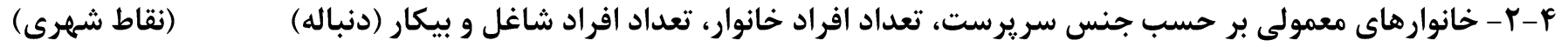

\begin{tabular}{|c|c|c|c|c|c|}
\hline \multicolumn{5}{|c|}{ بيكار } & \multirow{2}{*}{ و وتعداد افراد در خانوار } \\
\hline 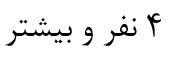 & 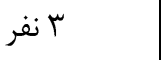 & r انفر & ا ل انفر & 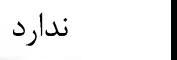 & \\
\hline irt.. & rqqvV & refq9a & IVfirer & IDqAVAA. & 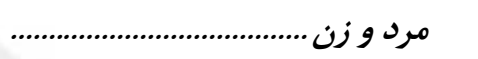 \\
\hline - & • & · & fiole & IFATG. 9 & 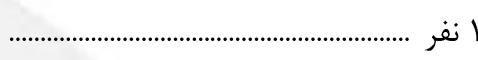 \\
\hline - & $\cdot$ & 19тrq & rYTANI & TFDINDT & r نفر ........................ \\
\hline - & gar & 41199 & $\Delta 9 \Lambda \cdot r \mu$ & FVFIDDr & ب نفر ................... \\
\hline 19. & $49 \cdot \mathrm{V}$ & 1. vav. & Drצ9491 & FYNINID & ب نفر ................ \\
\hline$|F \wedge|$ & rITVq & VTDG & TTYQST & וrqтүr. & مه نفر .............. \\
\hline Fris & ITVET & rq9.r & $\vee \cdot \wedge q$. & rTAVFT & و نفر .................... \\
\hline rTDF & DTQV & 1.rrF & r) $9 \Delta 9$ & 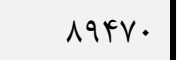 & لانفر ................... \\
\hline $19 \Delta 9$ & 1999 & rsq1 & $V k \cdot q$ & rqra. & 1نفر ................... \\
\hline 990 & $v \cdot$. & $\mid$ & 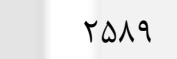 & $1 \cdot \Delta \Delta \wedge$ & 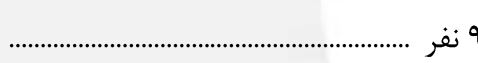 \\
\hline fre & py. & NFr & IVYF & 8999 & 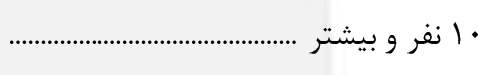 \\
\hline 991. & $f_{1} \cdots 1$ & $F F I \cdot \Delta \Delta$ & $101191 F$ & Irasıs.V & 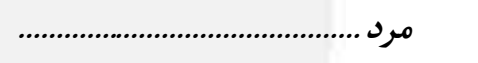 \\
\hline - & $\cdot$ & & TVQFF & prevrq & ا نفر ................. \\
\hline - & $\cdot$ & $10 \cdot \Delta \Delta$ & IVATAT & TAqTITF & ك نفر ................. \\
\hline - & rq9 & $r \cdot Y \Delta V$ & F৭८५AV & FFtrTVQ & Y نفر .................. \\
\hline $1 \% 9$ & TAFq & qFVIV & Fqfio. & FrgAFAF & 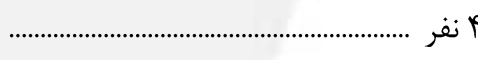 \\
\hline $4 \cdot 4$ & IAVTV & GVqFT & rIG.VG & IrQVDFA & a نفر ............................... \\
\hline rear & 11019 & rVAF. & 49949 & (IVIre & ونفر .............................. \\
\hline r१९. & FAFQ & q૬广द & $r \cdot \Delta q \Delta$ & АЬ૬ॅq & لانفر ............................ \\
\hline IDIT & INAT & एтая & 991. & rvq.. & 1 نفر ........................... \\
\hline GTI & QDT & $|r|$ & FFIS & $1 \ldots 94$ & ه نفر ............................. \\
\hline Fil & Fir & var & 1911 & 9994 & 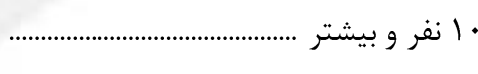 \\
\hline rrq. & 1989 & prapr & regaid & $r \cdot 119 \mathrm{rr}$ & زن .......... \\
\hline - & $\cdot$ & $\cdot$ & irqve & 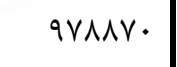 & | نفر ................ \\
\hline - & . & llNF & qrrqq & $\Delta \Delta \wedge \vee r q$ & r بفر ............... \\
\hline - & rAk & t.rit & VIVES & rIFTVA & r نفر ................ \\
\hline 91 & $r \cdot \Delta \Lambda$ & I Trat & rTDII & | & ب نفر .............. \\
\hline$\Delta V \mathrm{~V}$ & TAFT & DGT. & IIANV & TEIAT & ه نفر .................. \\
\hline 999 & $110 \mathrm{~T}$ & r. 94 & rapF & $119 \cdot v$ & צ' نفر .................... \\
\hline rar & fir & qVA & $|r 4|$ & | INT & لانفر ....................... \\
\hline IFT & I14 & TVT & riq & $1 \pi \Delta \cdot$ & 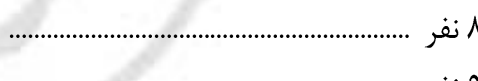 \\
\hline $\begin{array}{l}V^{k} \\
r \Delta\end{array}$ & $\begin{array}{l}q V \\
T V\end{array}$ & $\begin{array}{l}111 \\
011\end{array}$ & $\begin{array}{l}1 \mathrm{Vr} \\
119\end{array}$ & 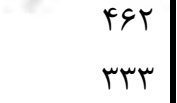 & 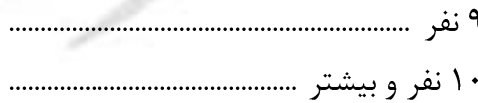 \\
\hline
\end{tabular}




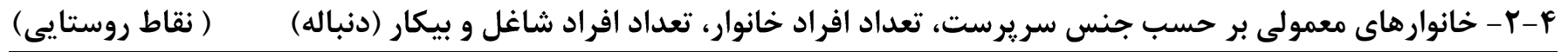

\begin{tabular}{|c|c|c|c|c|c|c|}
\hline \multicolumn{5}{|c|}{ شاغل } & \multirow{2}{*}{ 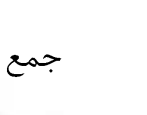 } & \multirow{2}{*}{ و تعداد افراد در خانوار خانوار } \\
\hline | ل انفر و بيشتر & ب انفر & ك انفر & ا لفر & 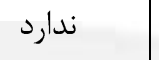 & & \\
\hline Fr. IT & IFrfar & VqIVaq & rVEATVF & 1 IrqTa91 & $9 \cdot r \lambda \cdot 9 \Delta$ & 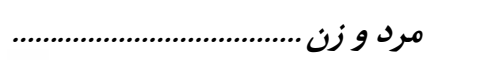 \\
\hline - & . & · & $191 \Delta T \Delta$ & rAgrit & DFVArV & ا نفر ................... \\
\hline - & - & NTrrF & VTATAQ & FTtryi & ITFFTEF & r نفر ................ \\
\hline . & IFqFV & $r .9 .91$ & 1. YEVTD & TFITAV & $|\Delta| T \cdot q V$ & ب بفر ................ \\
\hline DFTF & fFeqr & TY\&DI9 & 11.9109 & IFIIIT & IOFGQTE & ب ن \\
\hline $119 \cdot r$ & $F \cdot V H F$ & $\mid$ |fErV| & rAv. १1 & $\Delta V T \cdot q$ & VATID & ه نفر .............. \\
\hline $1 \cdot k r$. & $r r \cdot \wedge r$ & grqur & 1QV१९६ & $r \cdot q .$. & TVGMTI & 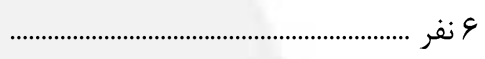 \\
\hline s948 & $11 r \cdot 4$ & rघ. १९ & 0.911 & $\wedge \backslash \Lambda F$ & $1 \cdot r \cdot 4 \varphi$ & V نفر ............ \\
\hline rVFe & $\Delta \cdot \cdot \varepsilon$ & ११९१ & IVFVD & MtQ & 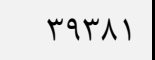 & 1 نفر ........... \\
\hline INAT & $r \cdot \wedge \Delta$ & rAr. & 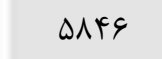 & ITVV & $\mid F \wedge \Lambda$ & 9 نفر ............. \\
\hline$r \cdot 11$ & 1999 & TYAY & rTA. & VQI & $1 \cdots r \Lambda$ & • ا نفر و بيشتر ....... \\
\hline rapa. & IrfFAr. & $V \Delta F=1 \Delta$ & roqIrA. & verrerg & DTAIEFF & مرد ................... \\
\hline · & · & & $11 r v$. & gqrT. & $M N \cdot T \cdot$ & ا نفر ........... \\
\hline · & · & VETDG & 9991.1 & rIAVGG & 1.GFIrT & r نفر ............ \\
\hline . & Ir995 & 190119 & 1...qта. & 101909 & 1 1тq१וf & ب نفر .......... \\
\hline Fqur & $F \mid Q \cdot V$ & TrVDQT & $1 \cdot 9 \cdot 1 \cdot 1$ & llQ9Vर & $\mid k q \cdot 1 \cdot r$ & ץ نفر ........... \\
\hline $111 \cdot r$ & rAvrq & $1 F 199 V$ & FVqITF & FVDIF & VINFte & ه نفر ............... \\
\hline 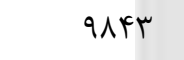 & $r T \cdot 91$ & GrI.D & $1 \Delta \Delta \cdot F \Delta$ & IVATY & rGGGTD & ع عنر ................. \\
\hline $9 r \cdot 1$ & $1 \cdot \sqrt{1} 99$ & TOTVF & FqATr & sqve & 99YरF & Vفر .......... \\
\hline$r \Delta \wedge \Delta$ & FNIN & १९६४ & $I V \cdot 9 V$ & rVqG & rVq०q & 1 نفر ................. \\
\hline$I V \Delta A$ & 1990 & rriq & $\Delta V \backslash \Lambda$ & 1111 & $\mid F r \cdot \Lambda$ & q نفر ................. \\
\hline 1941 & IqTo & TrtT & Tr.D & $8 \vee 9$ & १९Vर & • ا نفر و بيشتر \\
\hline rAST & A1AT & rVVFF & IVY99F & $\Delta r \cdot r \varepsilon q$ & VASFAI & زن ....... \\
\hline$\cdot$ & · & · & FAMTD & MIS99T & rGDAIV & ا نفر ............... \\
\hline · & · & $v \notin v \wedge$ & $\Delta 91 \Delta \wedge$ & $\| r \Delta \cdot \Delta$ & $|\lambda \cdot| f \mid$ & r بنفر ............. \\
\hline - & 1900 & IrqDT & rVTra & $\Delta 9 \vee \cdot 1$ & 11ז9人 & ب بنر ......... \\
\hline 011 & MIND & ^৭TV & $19 \cdot \Delta 1$ & $r \Delta \mid \Delta \cdot$ & DSATF & ץ نفر .......... \\
\hline$\wedge \cdot 1$ & $r \cdots \Delta$ & 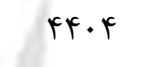 & vave & 9990 & TFAVq & ه نفر .......... \\
\hline$\Delta V V$ & $9 \wedge \Delta$ & $111 \mathrm{~V}$ & rqD। & PMG & १९९९ & 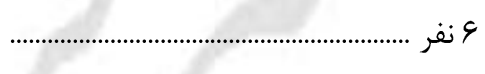 \\
\hline $\begin{array}{l}191 \\
\mid 91\end{array}$ & $\Lambda \Lambda$ & $\begin{array}{l}\text { VTD } \\
\text { rVG }\end{array}$ & $\begin{array}{l}1 \cdot v q \\
r v \wedge\end{array}$ & $\begin{array}{l}|Y| . \\
419\end{array}$ & $\begin{array}{l}\text { TVGT } \\
\text { IFTY }\end{array}$ & م نفر \\
\hline$q 4$ & 9. & 1.1 & IrA & 109 & $\Delta V Y$ & 9نفر .................................. \\
\hline$\Lambda$. & $q 4$ & $\varepsilon f$ & $V \Delta$ & VT & $r \Delta \Delta$ & • ا نفر و بيشتر ... \\
\hline
\end{tabular}




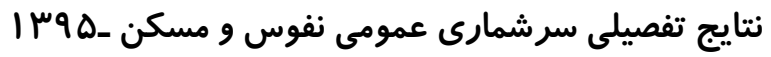

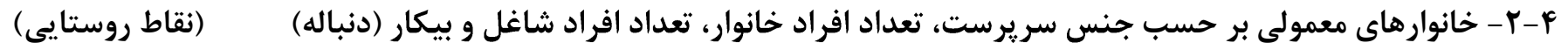

\begin{tabular}{|c|c|c|c|c|c|}
\hline \multicolumn{5}{|c|}{ بيكار } & \multirow{2}{*}{ و تعداد افراد در خانوار خانوار } \\
\hline ץ نفر و بيشتر & ك لفر & ك نفر & ا نفر & ن ندارد & \\
\hline frar & $1 V \cdot 98$ & $1 F 911$ & FAgrre & DFFTrat & مرد و زن ....... \\
\hline · & · & & $1 \cdot \Delta V F$ & DTVTET & ا نفر ......... \\
\hline · & · & TTFD & GVYAq & llVrVr. & r نفف ............ \\
\hline · & $r \cdot \Delta$ & 1.941 & $1 F \Delta \cdot \Delta q$ & $1 r \Delta \Delta \vee \wedge \Delta$ & " بنفر ........ \\
\hline Vr & r|91 & TVVYF & $\mid$ IFYAD & IrATa.V & F نفر .............. \\
\hline$\Delta q F$ & GTAF & रІव९q & VATET & 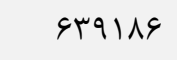 & ه نفر ....... \\
\hline 1499 & feve & $11 \mathrm{ANV}$ & משrqg & TTATHT & $\ldots$ \\
\hline $1 \pi 90$ & rTQq & 0191 & $1 F \cdot \mid r$ & N. MFT & V نفر ........ \\
\hline VIr & १९. & TIEA & $\Delta \Delta \Lambda F^{F}$ & ५११८६ & 1 نفر ....... \\
\hline q & rVA & $\wedge \wedge \Delta$ & rIVF & $111 \cdot r$ & 9نفر ........ \\
\hline TVV & $r \cdot r$ & gFt & 1011 & VYAS & . انفر و بين. \\
\hline Fl.r & Ifrgr & vrara & FrVAAr & rVaIraA & مرد .. \\
\hline$\cdot$ & · & & $\wedge r .$. & IVTVK. & ا نفر ........... \\
\hline · & $\cdot$ & $r \cdot 1 r$ & 1999q & $|\cdot| f|f|$ & ץ نفر ......... \\
\hline . & rrq & GMIF & $|r \cdot r| F$ & ITETTOV & r نفر ........ \\
\hline$\Delta \varphi$ & 11148 & refar & $1 \% 8191$ & ITKAYT. & F نفر ......... \\
\hline r. & $\Delta \Delta \Delta F$ & $r \cdot r / Q$ & VIVDV & $G T \cdot Y \Lambda$. & ه نفر ........ \\
\hline $1 \pi 11$ & $\varphi \mid \Delta \Lambda$ & IIrrA & TIVDI & rINIE. & ع نفر .......... \\
\hline 119. & $r \| 1 \Lambda$ & FqYF & IrFVE & $V \vee G .4$ & V نفر ........ \\
\hline 991 & $91 \mathrm{~V}$ & $r \cdot v \cdot$ & DYVI & r^qץ. & 1 نفر ...... \\
\hline$r \cdot q$ & red & NFs & $r \cdot 9 r$ & 1.991 & 9نفر ........ \\
\hline r\&A & $r 90$ & 9וr & IFAF & $V \cdot k r$ & •ا نفر و ب. \\
\hline$\varepsilon \Delta \Delta$ & reref & 1.v9r & DIEFA & $9 q 1 \cdot \mu r$ & \\
\hline · & $\cdot$ & · & TrVF & TGTAFr & انفر ....... \\
\hline · & $\cdot$ & TrT & $r \cdot r r$. & $109 \Delta \wedge 9$ & r نفر .... \\
\hline · & ve & FETY & IFAFD & QMFYA & ب نفر .... \\
\hline IV & $1 \cdot r \Delta$ & MTET & NTAT & FFYAV & F نفر ..... \\
\hline raf & $\vee \cdot$. & IETF & $r \Delta \wedge \Delta$ & $11 \mathrm{~V} \cdot 9$ & ه نفر .... \\
\hline IVA & M & 949 & IFVA & $V \cdot V r$ & في .... \\
\hline $\begin{array}{l}1 \cdot \Delta \\
\Delta T\end{array}$ & $\begin{array}{l}|q| \\
k r\end{array}$ & $\begin{array}{l}\text { TEF } \\
91\end{array}$ & $\begin{array}{l}\text { Drs } \\
r \mid r\end{array}$ & $\begin{array}{l}\text { TVYG } \\
1.19\end{array}$ & ل حنف .. \\
\hline$r$. & r & rq & vV & fir & q نف .............. \\
\hline 9 & $\wedge$ & rI & st & TEY & •ا نفر و بيشتر ....... \\
\hline
\end{tabular}


ه- - - خانوارهاى معمولى بر حسب جنس سريرست خانوار و تعداد افراد، تعداد افراد با سواد و بىسواد

\begin{tabular}{|c|c|c|c|c|c|c|}
\hline \multicolumn{5}{|c|}{ باسواد } & \multirow[b]{2}{*}{ جمع } & \multirow{2}{*}{ و جنداد افراد در خانوار خانوار } \\
\hline و و بيشتر & 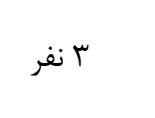 & ك انفر & ا ل انفر & 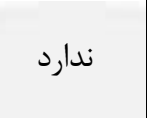 & & \\
\hline arrrquF & $\Delta 9 \Delta \Delta 991$ & ravrr.r & retr. re & IrAg9ir & relrqua. & 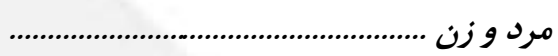 \\
\hline$\cdot$ & • & & $1.9 \wedge T 95$ & GFYAGT & T. FATIV & | نفر ............................. \\
\hline$\cdot$ & · & TFEVIIN & $\Lambda \Delta \Lambda I \Delta T$ & $V .$. s4s & Fq人VqrV & r نفر ............ \\
\hline$\cdot$ & $r \cdot \mid \Delta \gamma \nabla \cdot$ & TTOITA. & DITSGD & NDTUI & 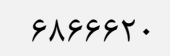 & r نفر ............. \\
\hline$r \cdot \Delta F T \cdot q$ & rmergtr & $11 r r \cdot q$. & llafq. & $r \varepsilon 1 \Delta \Delta$ & G9VTIII & ץ نفر ............... \\
\hline IVADFGF & fquAfr & ITEKAT & $r q \Lambda \cdot r$ & $I r \cdot r v$ & TrgT. Ir & ه نفر .............. \\
\hline $9 \cdot 190$. & VDVAV & TET. 9 & 1.90 & DVTr & VTrNIF & צنفر .............. \\
\hline$r \cdot \Delta r G$. & 19G4T & 91rs & reVA & rAMT & trmVES & Vفر ........... \\
\hline VYAN. & GT.r & IA\& & I. Tr & $I \Delta F \Delta$ & Trar & 1 نفر ................... \\
\hline trYFi & $M \cdot r$ & GrA & fVF & VFr & r.v१९ & 9 نفر ................. \\
\hline $1 \wedge r \wedge$. & 9ar & 481 & 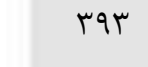 & 991 & $r \cdot \Delta \Delta \Lambda$ & •ا نفر و بيشتر ..... \\
\hline aAVaral & $\Delta \Delta \& Y q Y A$ & $\gamma r \cdot r \wedge \gamma$. & 1981199 & gFEFAT & $r 1 . s v r r r$ & مرد ......... \\
\hline & · & & 019194 & IgFIVE & GヘGVGF & ا نفر ................ \\
\hline$\cdot$ & . & 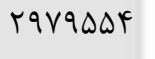 & DTRQVD & $90 \cdot 1 \cdot 9$ & $F \mid \Delta F \cdot \wedge \Delta$ & r نفر ........ \\
\hline$\cdot$ & TVIIFAN & $r \cdot 9 \cdot 1 \mathrm{Vr}$ & FVGAIF & VATIS & GMFGTQY & 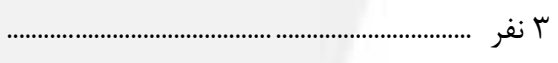 \\
\hline TQDVTrI & 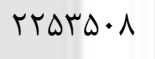 & $1.91 \% 9$. & $1 \cdot 9 q \cdot \Delta$ & ( & GFarqTa & ץ نفر ............. \\
\hline IVTMEF. & FAFAFS & IrI9AF & TATIS & 11994 & $r \mu \wedge \cdot 9 \Delta r$ & 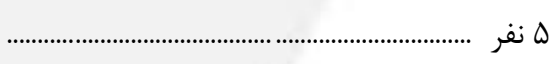 \\
\hline QATrII & VHIAF & roIVq & $\vee \Delta \Lambda$. & DrqT & $9 q 49 \Delta F$ & 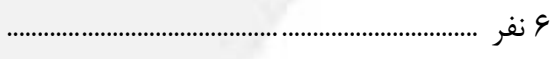 \\
\hline 1991.9 & $19 \cdot 19$ & QAVT & TATF & TEQT & rrrTqq & V نفر ....................... \\
\hline visrq & $f \cdot p q$ & IVVE & $9 \Delta r$ & $\mid$ |Fr| & 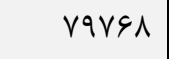 & ^ نفر ..................... \\
\hline refFE & $11 \Delta r$ & $4 \cdot r$ & fFF & $V \cdot r$ & $r q T \Delta \Delta$ & q نفر ................... \\
\hline $\mid V \Delta \Lambda$. & GTr & FrA & rद६ & gri & $\mid 9841$ & 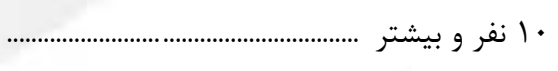 \\
\hline $191 \mathrm{rrr}$ & rq1. a. & gsarrt & $9 \Delta \Lambda 1 \& V$ & Afritg & $r \cdot q \mid v a r$ & زن . زن \\
\hline · & · & . & $\Delta \vee 91 .$. & 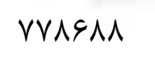 & $1 r \Delta 9 \Delta \Delta T$ & ا نفر ............. \\
\hline$\cdot$ & $\cdot$ & FeVAGF & rrodV^ & $\Delta \cdot \Delta r V$ & | & r نفر ........... \\
\hline$\cdot$ & TAFTVK & $191 \cdot V V$ & $r \Delta \wedge \Delta I$ & $q \cdot r \Delta$ & $\Delta T \cdot T r V$ & ץ بنفر ....... \\
\hline $99 \wedge 1 \wedge$ & $q \cdot r r q$ & rrی.. & $4 \cdot \wedge \Delta$ & rquo & $r T \cdot I \Lambda T$ & F نفر ....... \\
\hline$G T \cdot T F$ & Ir99V & kis & $1 F \wedge$ & 1.94 & $\Lambda r \cdot \Delta q$ & ه نفر ......... \\
\hline TFETI & $r \Delta V Y$ & $1 \cdot r \cdot$ & $Y \wedge \Delta$ & frq & rq19. & 4 نفر ........ \\
\hline $\begin{array}{l}\text { qTaf } \\
\text { rel }\end{array}$ & DFT & TET & $1 Q T^{2}$ & TH & 1.448 & 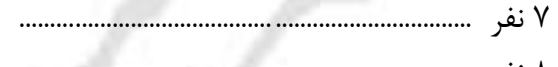 \\
\hline $1 \% 90$ & $\Delta T$ & ra & $\begin{array}{l}49 \\
r .\end{array}$ & rit & $\begin{array}{l}\text { TVYa } \\
\mid \text { IfFi }\end{array}$ & 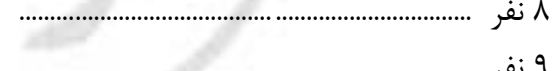 \\
\hline$\wedge .$. & $r \cdot$ & r & rV & iv & qrV & 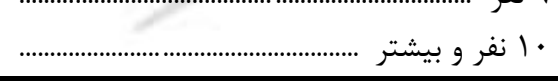 \\
\hline
\end{tabular}

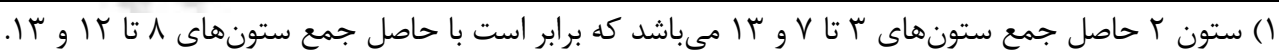




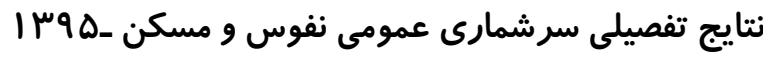

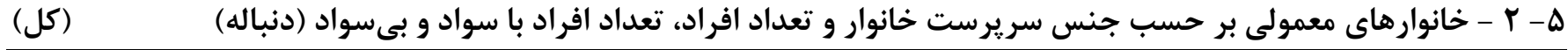

\begin{tabular}{|c|c|c|c|c|c|c|}
\hline \multirow{2}{*}{ نشده } & \multicolumn{5}{|c|}{ بي ل سواد } & \multirow{2}{*}{ و وتعداد افراد در خانوار خانوار } \\
\hline & 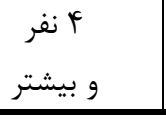 & كا لفر & ك ا نفر & ا لفر & 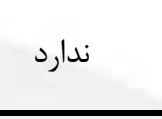 & \\
\hline $1 \cdot \varepsilon \Delta r$ & svrla & $19 r \Delta \Lambda$. & $198 D A F T$ & rAqQ9V. & IVqqVFT. & مرد و زن . \\
\hline$\Delta 1 \& T$ & - & $\cdot$ & - & GFTAGT & 1. QRTQT & ا نفر ............. \\
\hline$r \cdot \varphi \cdot$ & $\cdot$ & $\cdot$ & s944ा1 & Vq人qfF & rFqTGGT & r نفر .......... \\
\hline IDAF & $\cdot$ & $\Delta Y \wedge S V$ & ferqui & vrll11 & $\Delta Q M G \cdot \Lambda V$ & r بنر ........... \\
\hline ITr & $1 T \Delta \Delta q$ & $r \Delta \cdot \Delta r$ & $r \varphi \Delta \Delta \Delta V$ & $V \cdot \wedge r \wedge$. & $\Delta Q F \cdot F+1$ & F نفر .............. \\
\hline Frr & IFETA & TATKT & ктя१ч. & lון & IVTEQVQ & ه نفر ................... \\
\hline $1 \cdot 1$ & $1 r q 10$ & $r \varphi \Delta \Delta V$ & Irצ9YV & INTצQ9 & rVrG.人 & צ نفر ...................... \\
\hline$\Delta \varphi$ & $1 \cdot \Delta V F$ & $1 \Delta \Delta V q$ & DVIIT & gfief & ^८१९. & V نفر .............. \\
\hline$r$. & 9qvV & VArা & LIVTr & Thth & THTIF & ^ نفر ..................... \\
\hline$\varepsilon$ & $4 \cdot 19$ & rorr & 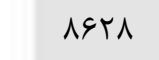 & V४৭9 & $v \cdot 1$. & q نفر .................. \\
\hline r & FATG & rAIr & DTKT & FrqG & raAv & •ا نفر و بيشتر ......... \\
\hline $1 \Delta 19$ & SIrFA & IVATAa & IAVIrTs & raler.a & Iefretar & مرد .................. \\
\hline rman & & & & IgFive & 019195 & ا نفر ...... \\
\hline INFV & $\cdot$ & & gFVVVT & $\Delta \cdot \Delta \cdot F \Lambda$ & r৭१९९ा1 & r بنفر ........ \\
\hline lyqr & • & 19.94 & FTMFAF & DSDI १V & $\Delta T_{1} \cdot . r q$ & r بنفر .......... \\
\hline 1191 & 1.91. & FIVET & TATMT. & GFYVGT & DFTYT. Q & ץ \\
\hline$r \cdot \Delta$ & $\| r \cdot v \wedge$ & TGTFV & TMTEY. & r१९८।ा & IV. IV9Y & ه نفر ...................... \\
\hline 99 & ITAKT & TQFY. & I THETV & $199 . \mathrm{rV}$ & rGMArA & צ نفر ...................... \\
\hline$\Delta \Delta$ & 991. & $1 Q \cdot r \Lambda$ & $\Delta \Delta \varphi \cdot V$ & QQDTY & ArISV & Vفر ............... \\
\hline$r$. & 9099 & VDVV & TYAFT & $r .9 V V$ & rTHQD & ^ نفر ................. \\
\hline 4 & rیו^ & MFI9 & ^ґ^৭ & $v \cdot 1$. & SVIT & 9 نفر ................ \\
\hline r & FFIT & TVYA & $\Delta \cdot \Delta F$ & rqvя & refy & •انفر و بيشتر ................ \\
\hline rirt & $9.9 v$ & Iferad & qfeis & Irrakga & IDFaIVT & 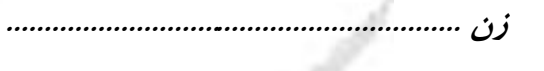 \\
\hline IVED & · & · & · & 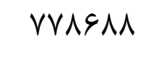 & $\Delta \vee 91 .$. & ا نفر ... \\
\hline rIT & • & · & pearq & К१५८१९ & FqTYFF & r نفر ...... \\
\hline 9T & . & sVVr & TIFAV & 190914 & rTG. 91 & ب نفر ....... \\
\hline 49 & 1949 & זוזי & IrTry & ATDIV & IINIK & F نفر .... \\
\hline 11 & 109 & $r \cdot 90$ & VII. & rGYAq & rFYAV & ه لفر ....... \\
\hline r & 1.95 & $11 r V$ & $r \Delta .$. & 14999 & qvV. & ع نفر ....... \\
\hline 1 & $\begin{array}{l}994 \\
r 11\end{array}$ & $\begin{array}{l}\Delta F I \\
T \Delta F\end{array}$ & 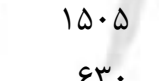 & kqFT & rVqY & ل نفر .............. \\
\hline . & 191 & 111 & rrq & $\Delta \wedge 9$ & rqv & 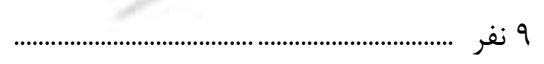 \\
\hline$\cdot$ & ret & VQ & 199 & rr. & If. & 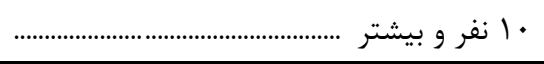 \\
\hline
\end{tabular}


ه- ا - خانوارهاى معمولى بر حسب جنس سريرست خانوار و تعداد افراد، تعداد افراد با سواد و بـسواد (دنباله) (نقاط شهرى)

\begin{tabular}{|c|c|c|c|c|c|c|}
\hline \multicolumn{5}{|c|}{ باسواد } & \multirow[b]{2}{*}{ 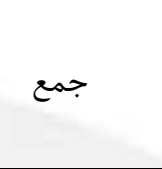 } & \multirow{2}{*}{ و وتعداد افراد در خانوار خانوار } \\
\hline و بيشتر & ب انفر & 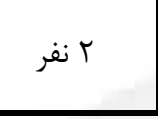 & ا انفر & 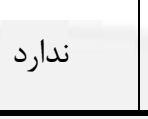 & & \\
\hline fFqaraf & $r q v \cdot r \mu r$ & g.qufar & lartere & $971 \cdot 11$ & $11 \cdot \operatorname{rarar}$ & 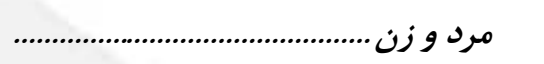 \\
\hline$\cdot$ & & & QTDGTY & $\Delta \varphi \Delta G G Y$ & $|F q \Delta| r \Delta$ & | انفر ................ \\
\hline . & & TAYATAK & DGrAF. & rÆ\&\q. & $M V F \cdot g V r$ & r نفر ............. \\
\hline$\cdot$ & $r \Delta \Lambda \cdot G r r$ & rFAT\&9. & TVYIT. & MYSDS & $\Delta r \Delta \mid F \cdot \Lambda$ & ب بفر ........... \\
\hline$r \Delta \Lambda \cdots \mid{ }^{\prime} \Delta$ & $|V \Delta I \Lambda| \Lambda$ & VTrGVT & $\Delta T \Delta V F$ & IFr. & DITHTET & f نفر ............ \\
\hline ITrNT.G & гqт... & $\varepsilon \wedge \Delta \wedge \vee$ & ITVAr & $0.9 r$ & $1 V 1 \Lambda \cdot 10$ & ه نفر ................. \\
\hline rqutar & rorAl & 11190 & reqf & TRAF & Frasta & ع نفر ............... \\
\hline$\| \Lambda \Delta Q A$ & GVGA & TETT & Irru & $114 \lambda$ & $|r \cdot r \varepsilon|$ & ل نفر ....... \\
\hline$r \cdot r \wedge F$ & IVte & Net & pqv & $4 .$. & requr & 1 نفر ........ \\
\hline $144 q 9$ & $\Delta F \Delta$ & r. & rrq & rVq & IDA૬T & 9 نفر ................ \\
\hline gref & וזr & ral & $r \cdot \Delta$ & rQq & $1.4 q r$ & 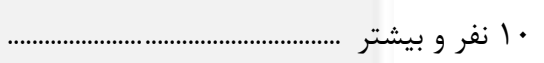 \\
\hline prrargr & FrFAIFV & $\Delta \Delta F q q T I$ & 1.98997 & $|q||q|$ & larrrfar & 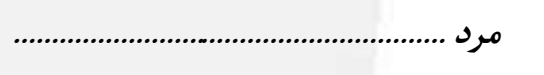 \\
\hline & & & FIFETE & NGTVI & D. TKAT & ا نفر ...... \\
\hline$\cdot$ & & TFTYQDI & rTAVTr & TMTTVE & $r \cdot A v+41$ & ז بنفر ......... \\
\hline$\cdot$ & rmrqIQ. & Trtlle. & TAINTE & $r 1 \cdot \Delta 9$ & faffrom & ب بنر .......... \\
\hline TYqQ|Q1 & $19 q \cdot r \Delta \Delta$ & $v \cdot 99 \cdot \Delta$ & pqs4 & $I r \cdot 4 \Delta$ & ४q৭..rq & ץ نفر .......... \\
\hline$|r q| \wedge r A$ & TNDSTD & द्र१९ & $|r| \ldots$ & 1499 & $199 \cdot 9 \cdot V$ & ه نفر ................... \\
\hline rVYITI & rmqAт & $1 \cdot V I f$ & TYAI & $r \cdot \Delta V$ & FTVINT & ع نفر ................... \\
\hline$\| F F \Delta \mid$ & GQTE & TFVA & 1109 & I. Fr & ITrGND & Vفر ............... \\
\hline$r|\Delta| Q \mid$ & 1911 & $\Lambda \cdot 1$ & fos & $\Delta F$. & FIGAT & 1 نفر ................. \\
\hline Irv.r & LIT & ras & rit & r\&q & 14999 & 9 نفر .................. \\
\hline ^९५^ & riv & rrq & 191 & 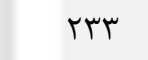 & ११५. & •ا لـفر و بيث \\
\hline |D९q9| & $r r r \cdot 18$ & afAarl & verery & $\Delta \cdot 9 \Delta \Delta V$ & rr.rrqu & \\
\hline . & . & $\cdot$ & DITT.A & pүarqu & Q9TAFT & ا نفر .. \\
\hline - & · & F & rTAIIN & TFEIF & GATMIT & ك نفر . \\
\hline . & rDIFqF & IYIDQ. & r.rIS & rबqV & $r \cdot V \cdot r$. & r نفر .... \\
\hline NrNGF & GIfG & IrVGV & rqTA & 1191 & $\mid$ GTIT & F نفر ...... \\
\hline 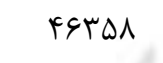 & VEVD & rI9T & qヘr & 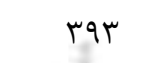 & $\Delta V I \cdot \Lambda$ & 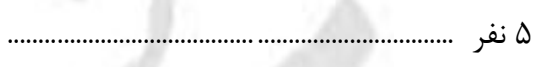 \\
\hline IVTr| & 1599 & YN1 & זTr & 198 & IgFFT & ع نفر .......... \\
\hline $91 \cdot r$ & TFY & lfF & vq & 1.9 & gqVG & Vفر ............ \\
\hline TIrT & 90 & i) & il & 9. & TrY. & ^ نفر ................................. \\
\hline V94 & rt & IT & iv & $1 \cdot$ & $\wedge \notin \vee$ & 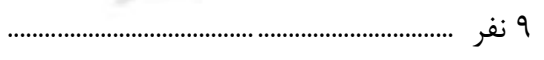 \\
\hline $0 \cdot 9$ & If & ir & $1 f$ & r\& & $\Delta V T$ & 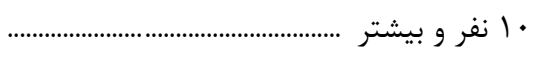 \\
\hline
\end{tabular}


| نتايج تفصيلى سرشمارى عمومى نفوس و مسكن _MD

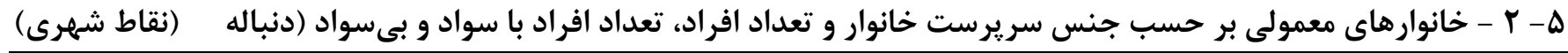

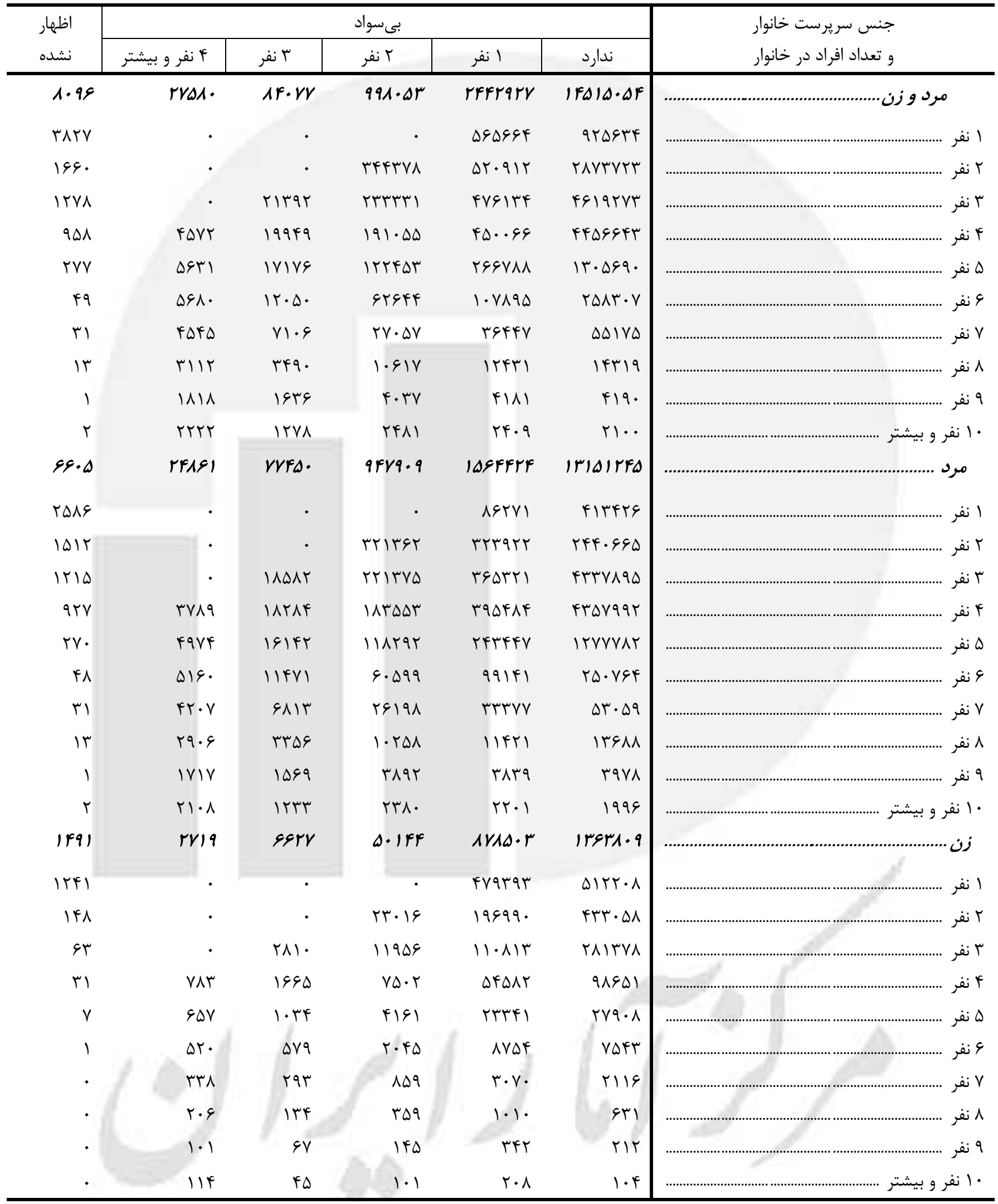


ه- r - خانوارهاى معمولى بر حسب جنس سريرست خانوار و تعداد افراد، تعداد افراد با سواد و بىسواد (دنباله) (نقاط روستايى)

\begin{tabular}{|c|c|c|c|c|c|c|}
\hline \multicolumn{5}{|c|}{ باسواد } & \multirow[b]{2}{*}{ جمع } & \multirow{2}{*}{ و تعداد افراد در خانوار } \\
\hline و و بيشتر & ك انفر & ك انفر & 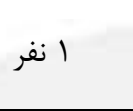 & 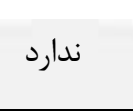 & & \\
\hline$|r v e \Delta q|$ & IrArgad & 11999948 & $29 .|r|$ & Alaras & $q \cdot r \lambda \cdot q \Delta$ & 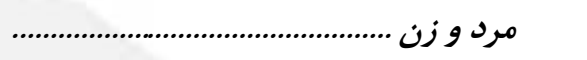 \\
\hline · & · & · & $|V \cdot V \Delta|$ & $r \vee \Delta \Lambda 1$. & DFVATV & | نفر |............................. \\
\hline - & $\cdot$ & DQVVAT & rqTFAT & TATEMI & ITFETEF & r نفر .............. \\
\hline · & FTEATD & VAVr.r & rTQDЯt & $\Delta \cdot r q r$ & $101 \% \cdot 9 V$ & ب بنر ............. \\
\hline PVRGVT & DqाrT. & 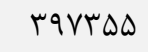 & GTDFV & TIVET & IDFGQTE & ץ نفر ............. \\
\hline FFeqVe & r.fiff. & GVDSV & 199.5 & $\checkmark \wedge \wedge \Delta$ & VATID & ه نفر ............ \\
\hline$r \mid r \cdot \Lambda r$ & $F \cdot r \cdot V$ & $\mid f q 1 \mathrm{~V}$ & Farl & TRt & TVGTYI & ونفر ........... \\
\hline 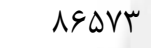 & ११५ & TFAT & IFTV & $18 \cdot 9$ & $1 \cdot r \cdot k 4$ & V نفر ........ \\
\hline refy & TFET & 1.14 & 019 & QTV & rq५یl & 1 نفر ....... \\
\hline $1 \pi r \cdot 1$ & GQF & rla & TK TK & $F \Delta D$ & IFAM. & q نفر .... \\
\hline $19 \cdot 1$ & rr. & $r \cdot q$ & IAV & $r \cdot r$ & $1 \cdots r \Lambda$ & •ا نفر و بي \\
\hline ITrafir & I HIFAFA & IVA. FAT & 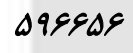 & Farrra & DTAIEFF & 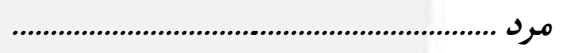 \\
\hline & & & 1.TIR & $\mathrm{r} \cdot \mathrm{ir}$ & IAT.T. & ا انفر .. \\
\hline - & - & $\Delta \Delta \cdot 9 \vee q$ & 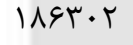 & rT\&A.人 & $1.94 I K r$ & ب نفر ... \\
\hline - & 4.1919 & VYYQDI & TYF.19 & FFANT & 1499114 & ب نفر ...... \\
\hline 49.994 & DGYFTE & TAVTYA & $\Delta q q^{F}$ & $1991 \mathrm{~V}$ & $1 F q \cdot 1 \cdot r$ & F \\
\hline Frl.rv & 191944 & qQT.. & $|q| \cdot \kappa^{k}$ & VTTD & VINFre & ه نفر ...... \\
\hline$r \cdot \Delta 9 Q 9$ & $r q \cdot r \Delta$ & Ifrsq & FrAl & r & rGGGTD & ع نفر .......... \\
\hline ATFTA & qQT. & GG & ITUT & $1 \Delta \Delta F$ & १৭Y人र & V نفر ........... \\
\hline TMGGF & TrQF & $99 \wedge$ & fqT & $\Lambda V^{F}$ & rV৭১৭ & ^ نفر .......... \\
\hline$|r V|$. & GMF & $r \cdot r$ & r. & Fre & $\mid F r \cdot \Lambda$ & q نفر ............... \\
\hline$\wedge 9 \mid f$ & $r \cdot r$ & 191 & IVF & rAT & १९Vर & •ا نفر و بيث \\
\hline filva & SA1IT & llakgF & laresd & rrrq.1 & VASFAI & زن . \\
\hline . & $\cdot$ & $\cdot$ & GQDTH & rqАVqr & 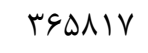 & ا نفر \\
\hline$\cdot$ & $\cdot$ & $F V I \cdot r$ & $1 \cdot V 10$. & TQATr & $|\Lambda \cdot| f \mid$ & ك بنفر \\
\hline$\cdot$ & rTVIq & QqTQT & IDFVT & $\Delta F_{1}$. & $11 r q 14$ & r بنفر ... \\
\hline $1 \pi \cdot 1 \cdot$ & rMAqF & $1 \cdots v$ & retr & $I V \Delta \Delta$ & $\Delta G \wedge F F$ & F انفر ..... \\
\hline $10 q \mu q$ & $\Delta \Delta \cdot F$ & THEV & V9A & 99. & rFAVq & ه نفر ... \\
\hline VrAG & ITVT & $\Delta F \Lambda$ & ra. & q ז & १९१९ & ع نفر .......... \\
\hline MIFA & ५१९ & $11 \mathrm{~V}$ & VD & ITS & TVGT & V نفر .......... \\
\hline$I r \cdot V$ & 19 & is & TV & $\Delta r$ & IFTY & ^ نفر ........ \\
\hline 491 & $r \cdot$ & ir & rו & rq & $\Delta V Y$ & 9 نفر ............... \\
\hline rqf & 19 & 11 & r & TI & $r \Delta \Delta$ & • ا نفر و بيثة \\
\hline
\end{tabular}


| نتايج تفصيلى سرشمارى عمومى نفوس و مسكن _MD

ه- r - خانوارهاى معمولى بر حسب جنس سريرست خانوار و تعداد افراد، تعداد افراد با سواد و بىسواد (دنباله) (نقاط روستايى)

\begin{tabular}{|c|c|c|c|c|c|c|}
\hline \multirow[b]{2}{*}{ الظهار نشده } & \multicolumn{5}{|c|}{ 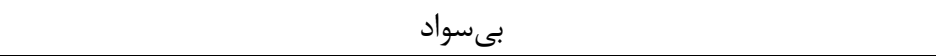 } & \multirow{2}{*}{ و وتعداد افراد در خانوار } \\
\hline & و و بيشتر & ك انفر & ك ا كنر & ا ل انفر & 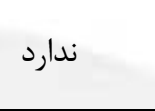 & \\
\hline rfqu & rargl & $1 \cdot v r r q$ & q๕rq18 & IFFAYAD & rFverql & 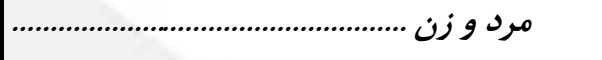 \\
\hline ITVE & · & $\cdot$ & & $r V \Delta \Lambda 1$. & $|V \cdot V \Delta|$ & ا نفر ............... \\
\hline rqu & · & $\cdot$ & TYANDF & TYVTFq & GIVVAr & ץ نفر .............. \\
\hline$r \cdot \Delta$ & . & MITH & rl.Vrq & TAFTET & 1. IDGTr & ץ نفر ................ \\
\hline rVq & VAMF & reqle & IVreVV & TDVFAT & $1 \cdot \lambda r V I$. & ץ \\
\hline $1 \& \Delta$ & $\wedge 9 .$. & $r) . . q$ & 1199.4 & $19 \Delta \Lambda \Lambda F$ & kr. kVF & ه لفر .......... \\
\hline$\Delta T$ & $\Lambda 1 r \wedge$ & $|F+|$ & я५१९६ & $V \notin \Delta \Lambda \Lambda$ & 110148 & ع نفر ................ \\
\hline TQ & $\Delta 9 \Delta 9$ & Nerq & rqq4Q & trati & $r \cdot v \notin V$ & V نفر ............ \\
\hline v & rAr. & Frif & $1 r \Delta \cdot 1$ & $91 \Delta \&$ & MANr & ^ نفر ................ \\
\hline$\Delta$ & TIVT & 1190 & ravı & mFIl & rAIA & 9 نفر ..................... \\
\hline 1 & rrqv & lorq & TVRr & IMAT & IFAs & • • نفر و بيشتر .... \\
\hline$|A v|$ & rఎqя. & $1 . .11$ & 9199.1 & qFArAs & reravis & مرد ....... \\
\hline VVD & · & $\cdot$ & & $V V \cdot I V$ & 1. FTrA & | نفر ............ \\
\hline rut & · & $\cdot$ & TTQF.D & 11.911 & $\Delta \Delta V V G G$ & ץ نفر .......... \\
\hline TVG & . & rVTqF & r.ITro & 199TVY & $q \vee \cdot \cdot r v$ & ץ نفر ........... \\
\hline rat & GVTr & rutry & $19 V 90 \mathrm{~V}$ & TrAG.V & 1. GKTGK & ץ نفر .......... \\
\hline 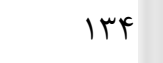 & $\wedge \cdots \vee$ & 19901 & llrvvr & lorgGF & Frre.. & ه نفر ................. \\
\hline DI & VAVT & IrরGr & $\varepsilon r \Delta \Delta$. & GQGVV & $11 r 914$ & צنفر ................. \\
\hline TY & $\triangle G \Psi \Delta$ & $\wedge|\wedge|$ & rqr.r & $r \varepsilon \cdot V I$ & $r \cdot . v i$ & Vفر .......... \\
\hline v & raty & flap & ITrT. & 9TRG & $\wedge \varepsilon \Delta \Delta$ & ^ نفر ..................... \\
\hline a & $r \cdot V \Lambda$ & IAFF & FFAF & migt & TVMT & 9 نفر .............. \\
\hline 1 & TrAA & 1999 & T990 & IVV. & $\mid f \Delta$ & • ا نفر و \\
\hline ser & rill & verq & perida & 1999199 & $r . . q v a$ & زن... \\
\hline 0.1 & · & $\cdot$ & $\cdot$ & rqAvqr & GQDTr & | انفر ..................... \\
\hline$q 4$ & $\cdot$ & $\cdot$ & TrFFq & १९्षा & ०999V & Y نفر ........ \\
\hline rq & $\cdot$ & rqup & $q q q 4$ & $\Delta F q Y$. & fF $\Delta \wedge \varphi$ & ץ نفر ......... \\
\hline 10 & 1101 & IgTr & $\Delta V r$. & $r \wedge \wedge \Delta \Delta$ & lapte & F نفر ........... \\
\hline 11 & 194 & $1 . \Delta 1$ & rir. & Irar. & GAVF & ه نفر ........ \\
\hline 1 & $\Delta 99$ & $\Delta F A$ & Ifts & (9)11 & TMTY & צ نفر .... \\
\hline $\begin{array}{l}1 \\
.\end{array}$ & $\begin{array}{l}\text { TYK } \\
\text { IVT }\end{array}$ & $\begin{array}{l}\text { rFA } \\
\text { Ir. }\end{array}$ & $\begin{array}{l}\text { GFr } \\
\text { rVI }\end{array}$ & $\begin{array}{l}\text { IAV. } \\
\text { Gr. }\end{array}$ & $\begin{array}{l}\text { GVG } \\
\text { TYA }\end{array}$ & ^ 1 نفر ......................... \\
\hline · & $9 \Delta$ & DI & $9 F$ & TEV & $1 \Delta$ & 9 نفر .................. \\
\hline$\cdot$ & 1.9 & $r$. & $9 \Lambda$ & $11 r$ & re & •ا نفر و بيشتر .................... \\
\hline
\end{tabular}


| نتايج تفصيلى سرشمارى عمومى نفوس و مسكن _MQ צ- - - خانوارهاى معمولى و تروهى بر حسب تعداد افراد و تعداد افراد در حال تحصيل به تفكيك جنس

\begin{tabular}{|c|c|c|c|c|c|c|}
\hline \multicolumn{5}{|c|}{ مرد } & \multirow[b]{2}{*}{ جمع ( جم } & \multirow[b]{2}{*}{ تعداد افراد در خانوار } \\
\hline بيشتر & 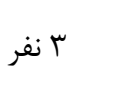 & ك انفر & 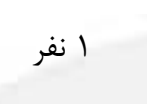 & ندارد & & \\
\hline $199 \mathrm{VV}$ & IVIrag & Irrrrad & ararl. I & |EAETFA| & TFIADITH & 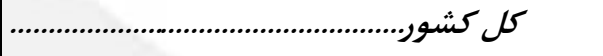 \\
\hline · & • & · & FVFAV & ।999५IV & $r \cdot r \& V V F$ & | نفر .................. \\
\hline · & & $9 \cdot 94$ & rrur.. & 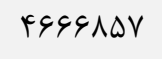 & $\Delta \cdot \wedge r \Delta I$ & Y ب........... \\
\hline · & IVTS & VEADT & IFVTVVF & 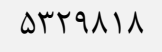 & 9111199 & 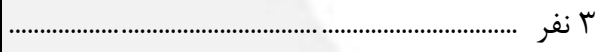 \\
\hline s49 & TVTAV & QDDIAT & $r \Delta V T \cdot F V$ & TFTVFAT & G9ArGIF & F \\
\hline tatr & VTITF & FTATMA & q४тr१q & $1 \cdot r F I \Delta D$ & rFEVAMA & 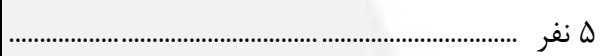 \\
\hline$\Delta \Delta \Delta F$ & rイ\&VV & ITVQVF & rq. rq. & rArATI & VTDQYG & ع نفر ......... \\
\hline plt & IVDqF & $F V \Delta \cdot V$ & vargf & $\wedge \varepsilon \cdot V F^{\epsilon}$ & THEVAI & V نفر ..... \\
\hline rqIr & NIFt & IVNIT & rqVqF & TAFI9 & $\Lambda F \cdot \Lambda$. & ^ نفر ..... \\
\hline IVIT & $r \Delta \cdot \Lambda$ & $9 \Lambda \Delta 9$ & 910. & 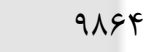 & r.. 9 . & q نفر ..... \\
\hline 1919 & TVMT & 4819 & DGYG & 9994 & riQq. & إنف \\
\hline Irrta & $|r \cdot 1 F|$ & 1.rkfre. & fergarre & IraIIIr & IAIIVVFT & ساكن در نقاط ث \\
\hline - & & & $f \cdot \Delta / \Delta$ & $|f \Delta \Delta \cdot f|$ & $1 \uparrow q \Delta \Delta \Delta Q 9$ & ا نفر .............. \\
\hline - & & $\Delta \Delta T q$ & TAQVII & $r \mu q \Delta \Delta \Delta \Lambda$ & rVDSATA & Y نفر ........ \\
\hline - & $19 \cdot V$ & GGTAT & $1 r \cdot \Lambda k q$. & F.人\&Tr & DTGYGIT & r بنفر ....... \\
\hline $9 \cdot \Delta$ & TFIMA & $\Delta T \Delta \cdot 9 \pi$ & $r \cdot T \cdot V \backslash Q$ & $r \Delta \Delta \cdot T V Y$ & QIT·AVT & F انفر ..... \\
\hline TFAF & $\Delta \Delta|9|$ & r.peqf & $9 \Delta \Lambda \cdot V 9$ & $v \cdot 11 \mathrm{VI}$ & IVTITAS & ه نفر ................. \\
\hline rVAr & TrAAV & . . . & $1090 \cdot 1$ & $|V V D|$. & fEVqA & צنفر ................ \\
\hline TYVG & 91.9 & $r \Delta \cdot V F$ & fflqf & $\Delta \cdot r q 1$ & $|r| \cdot 11$ & V نفر ........ \\
\hline ITVE & rqpq & м^r. & IfIVT & $19 \ldots$ & FFTKA & 1 نفر ......... \\
\hline จ१८ & IEVT & rraג & FADF & DrG. & 19.49 & 9 نفر ................. \\
\hline 948 & $|r V|$ & rrg. & r৭9V & ravV & $\| 1|f|$ & •انفر و بيشتر ................. \\
\hline rVrA & $\Delta \cdot 11$. & retrat & $|r||r d|$ & erralve & s.dirat & ساكن \\
\hline$\cdot$ & · & $\cdot$ & GVFT & $\Delta F \| T$. & DFVAGK & ا نفر \\
\hline$\cdot$ & · & $\Delta \Delta V$ & pqfat & 1191rVT & ITFATVT & r نفر \\
\hline$\cdot$ & 110 & $1 \cdot \Delta r q$ & rGMATI & $\mid r F \cdot q \Delta V$ & IDIDFET & ץ نفر ....... \\
\hline (i) & $r \cdot 9 F$ & 119119 & $\Delta Q \mid Q F F$ & AVATYF & IDFqVqY & F نفر ...... \\
\hline 149 & $1991 \mathrm{~V}$ & $I T \cdot \Delta A T$ & rAFVDA & THTITV & VEFAD. & ه نفر ..... \\
\hline IVGV & IFVES & $\Delta F I F$. & $1 \cdots \Delta \mid \Delta$ & $1 \cdot \Delta q \cdot r$ & $r V V \cdot V$. & ع نفر .... \\
\hline$T \cdot T V$ & 1499 & rrmva & rFqVI & $r \Delta \Delta \Delta \varphi$ & $1 \cdot r F \cdot r$ & V نفر ... \\
\hline IDTr & fIVA & ^१९. & Ir $\Delta V V$ & ITHA & 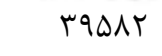 & ᄉ نفر .... \\
\hline 914 & INTr & rFqG & FTrA & fevq & 14991 & q نفر .................. \\
\hline $91 \mathrm{r}$ & 1909 & rra. & TGT. & ऍ... & 1.411 & • ا نفر و بيشتر \\
\hline
\end{tabular}

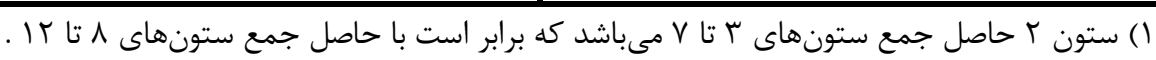


| نقايج تفصيلى سرشمارى عمومى نفوس و مسكن _ه |

צ- r - خانوارهاى معمولى و كروهى بر حسب تعداد افراد و تعداد افراد در حال تحصيل به تفكيك جنس (دنباله)

\begin{tabular}{|c|c|c|c|c|c|}
\hline \multicolumn{5}{|c|}{ زن } & \multirow{2}{*}{ تعداد افراد در خانوار } \\
\hline F أ نفر و بيشتر & ك انفر & r نفر & ا نفر & ندارد & \\
\hline Iefer & IfIIVF & Ilasta. & DFIETVF & $I V F A D \cdot I r$ & 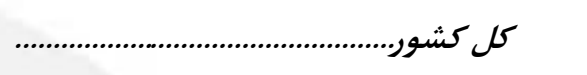 \\
\hline . & · & . & $r \cdot r \cdot r$ & $r \cdot 19 \Delta V$. & $\ldots$ \\
\hline$\cdot$ & & $V I \Delta \Delta$ & rᄉ199. & 191914द & ץ نفر ............................... \\
\hline$\cdot$ & IfIV & G.VIT & $|r \Delta S| r V$ & $\Delta \Delta ૬ ५ q \cdot r$ & r نفر ............... \\
\hline$r \cdot \Lambda$ & $\mid F \wedge \& V$ & FADITF & TFrThIT & 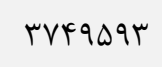 & ץ \\
\hline Trt & $\Delta r \Delta \Lambda \Lambda$ & rAVGIf & qFanIT & 1. vaff. & ه نفر ............. \\
\hline ( & ५११.V & IFIYFq & TATIVI & $r \wedge 9 . q r$ & צ نفر ........ \\
\hline RTt. & IAVAD & 49199 & VDAFq & $\wedge \wedge 9.1$ & Vفر .......... \\
\hline ५१११ & V^৭९ & $1 V \cdot 91$ & $r \Delta G \cdot \Lambda$ & $r \cdot \Delta I V$ & ^ نفر ......... \\
\hline $1 \Delta \wedge \Delta$ & TrGF & GTET & $q \cdot \wedge r$ & $1 \cdot 199$ & 9 نفر ............. \\
\hline IfFq & TrQ. & 4is. & $\Delta V r V$ & V৭q4 & 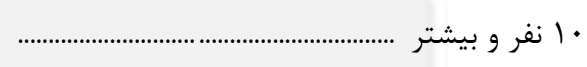 \\
\hline 1.915 & 1. regt & $119 \cdot 94$ & prradra & I TAADqRT & ساكن درنقاط \\
\hline . & - & . & r\&AMG & 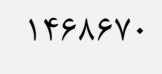 & ا نفر .............. \\
\hline . & $\cdot$ & G9AV & rTATYI & TFYIVA. & r نفر ............... \\
\hline · & ( & DrNI. & $1 \cdot \Delta \Delta \& \& \Delta$ & FroIN19 & ب نفر ................. \\
\hline TAV & $1 r \Delta \Delta q$ & $F 1.9 V F$ & I ITFAVG & TYVIFYV & ب انفر .......... \\
\hline IFEV & preq. & $r \Lambda \Lambda \cdot \Delta V$ & $99 \Delta \cdot \Delta V$ & VTrL.a & ه نفر ............. \\
\hline rTAT & $r \& 9.1$ & ^९911 & IDFAIA & IVrrag & ع نفر ............. \\
\hline rVq1 & $11 \cdot 19$ & $r \varepsilon \cdot \wedge r$ & flars & $191 \wedge 9$ & V نفر ............... V \\
\hline 1999 & flar & 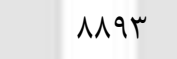 & אשחמו & |बrा| & ^ نفر .............................. \\
\hline$\Delta<q$ & lsk. & MIEV & FVr & DGAT & 9 نفر ....................... \\
\hline VAV & $11 r V$ & TITA & r^৭1 & FT. F & 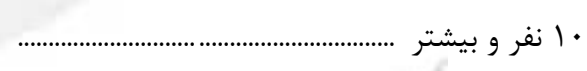 \\
\hline$\Delta F q \varepsilon$ & rVAaf & regeft & IIADEAF & FADSITE & ...................... \\
\hline$\cdot$ & . & · & Trgk & DFFG.. & ا نفر ........ \\
\hline · & $\cdot$ & $\forall \notin \Delta$ & DHFVE & llafFHF & r نفر ............. \\
\hline$\cdot$ & v9 & GAVG & $r \cdot .|9|$ & Ir.人rTs & با نفر ......... \\
\hline rl & $1 r \cdot \Delta$ & veraf & 491109 & qVQ१QT & ب انفر ... \\
\hline IAF & $1 \cdots 11$ & १९५११ & $r \Lambda \cdot r \& \Delta$ & TAFqTT & لمه نفر ..... \\
\hline $1 \cdot 1 r$ & ITINV & $010 \cdot 9$ & $97 \cdot 91$ & 110194 & ع نفر ..... \\
\hline lQTK & VVQF & $r \cdot V \& \Lambda$ & THATt & rqDTे & Vفر ............................ \\
\hline $1 \% q$. & ५५९9 & 11rq & שזrאו & |FTT| & ^ نفر ................ \\
\hline VHF & $194 \pi$ & rIII & FreV & DIAF & q نفر ...................... \\
\hline G9T & $11 r$. & $r \cdot r$. & TATt & rVAV & • ا نفر و بيشتر .... \\
\hline
\end{tabular}


خانوارهاى معمولى ساكن و گ - - -V

\begin{tabular}{|c|c|c|c|c|c|c|}
\hline اظهار نشده & ساير & 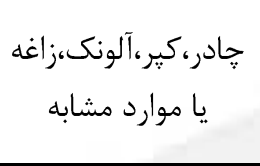 & 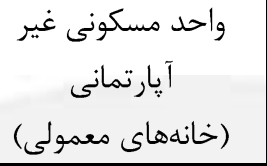 & وآحد مسكونى & جمع & تعداد افراد در خانوار \\
\hline$\Delta \& V V$ & farqir & $\mu v \mid F$ & IfarITr. & $q \cdot F \wedge q \Delta 1$ & rFIsqDTA & 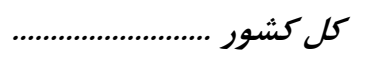 \\
\hline$r \Delta \Lambda$ & AFrt. & $r \mid \Delta \wedge \Delta$ & ITUKGV & 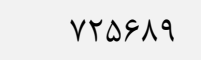 & r.prefiq & ا نفر ............................. \\
\hline$r \cdots \Lambda$ & 1.9099 & $r \cdot r r$ & rAVIFDD & $r \cdot \Delta \mid \Delta \Lambda$ & $\Delta \cdots \Delta r I I$ & r نفر ................ \\
\hline IFAT & $1 \cdot 9$ FFA & IAGTE & $r \Lambda \cdot \Delta r \Lambda \cdot$ & TQFTrFA & $\varepsilon \wedge \vee \wedge \cdot \Delta f$ & r نفر ............... \\
\hline$V V \cdot$ & 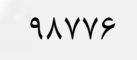 & IETFA & rqq६. pr & 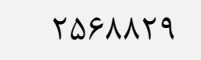 & 991.990 & F نفر .............. \\
\hline एq) & FVVET & $1 \cdot \Lambda r V$ & IVGI9Tr & qFar.F & rFGGT.G & ه نفر ............... \\
\hline 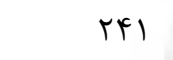 & $r \cdot r \cdot i$ & GFYA & $\Delta V \Delta \Delta V F$ & ITTOIF & $V T \Delta \cdot \Delta \Lambda$ & ع نفر ................ \\
\hline$|f|$ & 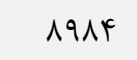 & rDTV & 1949or & $4 R I_{1} \cdot \Lambda$ & שTFIT & V نفر ............... \\
\hline 4. & rAFd & $19 \cdot 4$ & $v \cdot v 11$ & vrq. & ᄉrqı. & 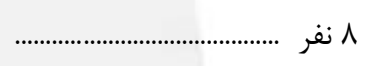 \\
\hline r & $1 V \cdot 1$ & $A F 1$ & T\&I\&V & TrAD & rl.rv & q نفر ................. \\
\hline מוr & (rזו & qqp & $1 \vee 9 \wedge 9$ & IFTE & TIDQT & •ا نفر و بيشتر .......... \\
\hline FFIA & $r \cdot F \wedge \Delta q$ & $r \cdot \Delta r A$ & $911 V \Delta F F$ & Ar..rar & IAIIVVFF & ساكن در نقاط شهر \\
\hline ra. & $r \cdot \varphi \Delta V$ & $G \cdot r \wedge$ & VFINFA & $V \cdot 99 V R$ & $1 \mid \angle 9 \Delta \Delta \Delta q$ & ا نفر ................... \\
\hline $19 \ldots$ & FTrGA & rYAN & IVVVDGG & 194.919 & 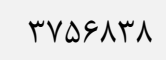 & r نفر ................... \\
\hline 1199 & 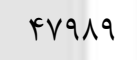 & gratr & TFVYFqT & TATTFTE & DTGTGIT & r نفر ............... \\
\hline$\Delta \Lambda 1$ & FFATQ & rTEN & TEITATI & rF\&qqVF & سVR & ץ نفر ........................... \\
\hline rیT & $\mid 1 \cdot 91$ & $r \cdot 9 q$ & $1 \cdot \Lambda \Lambda T \cdot \Delta$ & GITV.A & IVTITDS & ه نفر ................... \\
\hline lgt & 9199 & $1 \cdot 1 \cdot$ & 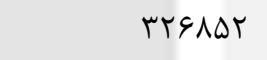 & IITVKG & FFVqA & ع نفر ................. \\
\hline 94 & TFII & س & $1 \cdot r v \cdot c$ & TFYAN & $|r| \cdot|1|$ & Vفر ............................ \\
\hline ऍ^ & 941 & rq1 & $r \varepsilon \Delta \Delta \Delta$ & spqs & FFrth & 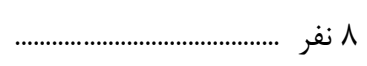 \\
\hline Tr & Far & ITS & Irfsq & $199 V$ & $19 \cdot 49$ & 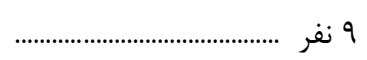 \\
\hline 119 & $r \Delta F$ & Irt & ( & $1 r \cdot 9$ & $\||| f \mid$ & 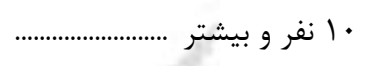 \\
\hline iraq & $r r \Lambda \cdot \Delta r$ & $1 \cdot \operatorname{lvg}$ & arervis & MFADFA & q.alvar & ساكن در نقاط روستا \\
\hline$\wedge$ & (F) & $1 \Delta \Delta \Delta V$ & 499919 & $19 \cdot 19$ & DFVAGT & ا نفر ................ \\
\hline$\varphi \cdot \wedge$ & grrq1 & ledrs & $1.94 \wedge 19$ & VFTET & ITEATRT & 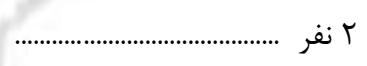 \\
\hline tAr & $914 \Delta q$ & $10 \cdot 9$ & IrTVVAN & $11 \cdot 1 T r$ & IDIDFFY & 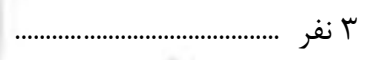 \\
\hline 119 & DFTFV & $1 r q 1$. & $\mid$ ITNLTI & $q \wedge \wedge \Delta \Delta$ & lofqVqr & ץ \\
\hline $1 \cdot 1$ & rq९्। & $\wedge \vee \& \wedge$ & SVTVTV & rtब৭я & VFFAD. & 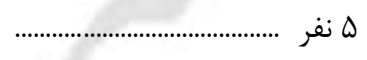 \\
\hline VV & |flita & DrFA & TFAVTK & $\wedge \vee \wedge \wedge$ & $r V v \cdot v \cdot$ & ع نفر ................. \\
\hline$\uparrow \wedge$ & gQVr & $r \cdot \mid f$ & $q \cdot q \not V$ & rAT. & $1 \cdot r F \cdot r$ & 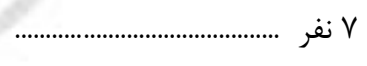 \\
\hline$r$ & $r q \cdot r$ & $19 \cdot 9$ & MFIDS & 194 & rqQАr & 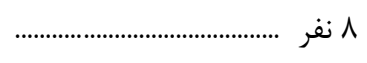 \\
\hline 19 & ITFN & 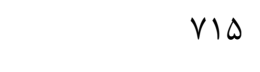 & Irצq1 & M & 14991 & 9 نفر م \\
\hline $9 V$ & AVG & DGT & $\wedge \& \Delta 9$ & TIV & 1.411 & 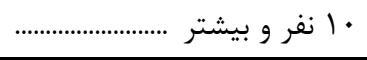 \\
\hline
\end{tabular}




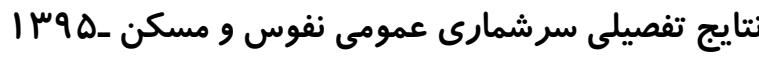

1 - - خانوارهاى معمولى و كروهى ساكن در واحد مسكونى معمولى بر حسب تعداد افراد و نحوه تصرف واحد مسكونى

\begin{tabular}{|c|c|c|c|c|c|}
\hline اظههار نشده & ساير & رهن/ استيجارى & ملكى عرصه و اعيان & 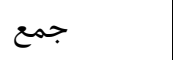 & تعداد افراد در خانوار \\
\hline$F F \cdot V \lambda$ & r. TAQFT & $r r \Delta \cdot r \Delta r$ & IFTAqAFA & $r r \Delta A \cdot r r l$ & 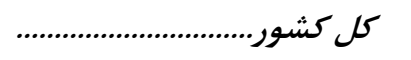 \\
\hline$\Lambda \vee \Delta \Delta$ & TAGGT & $\Delta F \Delta \Delta \backslash \Lambda$ & 1119481 & 19Yr।DS & 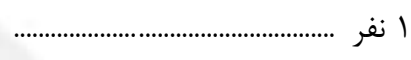 \\
\hline$\| r \Delta \Lambda$ & ETqVVD & $19 \cdot V I \wedge r$ & 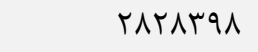 & FAVGGIT & ץ نفر ................. \\
\hline $1 \cdot V r q$ & 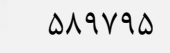 & rrgt.rV & rV^১৭૬V & GVFADTA & 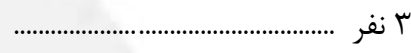 \\
\hline Nrrq & $\Delta \cdot 9 \Delta 91$ & $|9 r| r 4 \mid$ & FIr $\Delta \Delta \Lambda$ r & GDSYAVI & ץ نفر ................. \\
\hline Tht & $1949 \Delta 9$ & $\Delta V \& \mid \& 4$ & IEAFIVD & TF.VTHE & ه نفر ................. \\
\hline $1 \cdot r \cdot$ & FFIFT & $|\Delta \Delta \Delta 9|$ & FqVrTF & $991 \cdot 11$ & 9 نفر ................ \\
\hline er. & IrqTV & $\Delta \cdot F T V$ & ID९9\&V & rTIVEI & 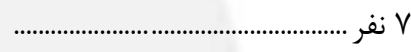 \\
\hline INT & $\Delta 1 \cdot V$ & $19 \cdot 1$ & $\Delta r \Lambda \cdot r$ & $\vee \wedge 1 \cdot 1$ & 1 نفر ............... \\
\hline 99 & $191 \%$ & VTFD & 19179 & TAFAT & 9 نفر .............. \\
\hline 91 & $1 F \cdot F$ & $\Delta \vee 1$. & ITYF. & 19410 & • ا نفر و بيشن \\
\hline$r \cdot r a l$ & laraseg & sasarAT & IVATETA & IrAArarr & ساكن در نقاط شهرى.......... \\
\hline gDAr & $r \cdots V V r$ & fqाrर. & VEqV^D & $|F F \wedge \Delta T|$ & | \\
\hline v^r. & rTIGTF & IFATYVG & 19rDFFq & rV.NFAT & r نفر .............. \\
\hline VTIS & kq.AF. & rlfrrm & reqferq & $\Delta r \cdot 991 \wedge$ & ب نفر .............. \\
\hline$\Delta G M F$ & f...qr & IVATTAI & rarroll & $\Delta \cdot \wedge r F q \Delta$ & † أنفر .......... \\
\hline 1994 & IIVDVq & DIDTQV & $1 \cdot 99 \cdot V F$ & $|V \cdot .9| r$ & له نفر ............. \\
\hline$\Delta \Delta G$ & TVFT. & ITaraA & TVVTMY & $F Y \cdot \Delta V \Lambda$ & 9 نفر .................. \\
\hline rrI & VrI. & FYAV. & VVD१T & IrVq94 & V نفر ............. V \\
\hline$\wedge \vee$ & TYAV & $10 \wedge \wedge 9$ & TYSIA & $F r \cdot \Delta l$ & ^ نفر ....................... \\
\hline rt & $\Lambda \mu \Delta$ & $9 \cdot 11$ & $\wedge F \wedge \Lambda$ & IDFFG & 9 نفر .................. \\
\hline rq & GTG & refF & DTF. & $1 \cdot \Delta r q$ & •ا نفر و بيشتر ........................................ \\
\hline Iratr & FAq.VE & sAkqVI & $F \Delta \cdot V F T$. & DEqTraF & ساكن \\
\hline TIVT & $90 \wedge+q$ & $\Delta F I Y N$ & rGG4VG & 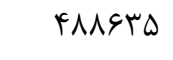 & ا نفر .... \\
\hline TFYA & $1 \cdot V \wedge \Delta 1$ & lorq.r & $q . r q 4 q$ & $\| \varepsilon \wedge|r|$ & ب بفر .... \\
\hline reir & $1 r \wedge 9 \Delta \Delta$ & rIfR.t & $1.91 \Delta \mu_{\Lambda}$ & $\mid$ |Fイ⿻|. & ب نفر ........... \\
\hline r990 & 1.90 .9 & 19111. & $\mid r \cdot T \cdot 90$ & IFATrVE & ץ نفر ............................. \\
\hline ITVD & $r \varepsilon \cdot 1$. & $9 \cdot \wedge 9 V$ & Q9१1.1 & V.GKTr & 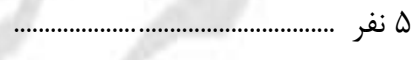 \\
\hline$r \cdot q$ & 991V & $V \Delta S V$ & Vqure & qTVGV & V نفر ......... \\
\hline 90 & r\&Q. & 4119 & rq1人я & $r \Delta \cdot \Delta \cdot$ & 1 نفر ................. \\
\hline ry & $1 \cdot V V$ & ITSF & 1.941 & $15 \cdot 19$ & $\ldots \ldots \ldots \ldots \ldots \ldots \ldots \ldots \ldots$ \\
\hline rT & VVA & 1.99 & $\vee \cdots$ & ANVG & •ا نفر و بيشتر ............... \\
\hline
\end{tabular}




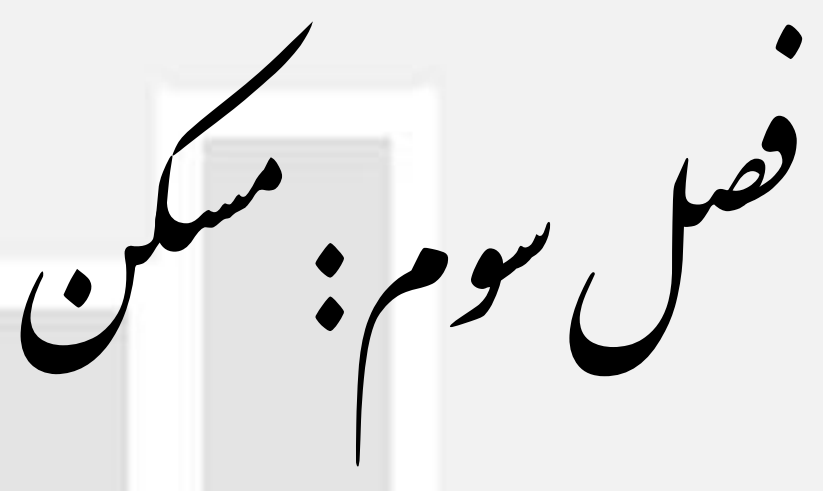




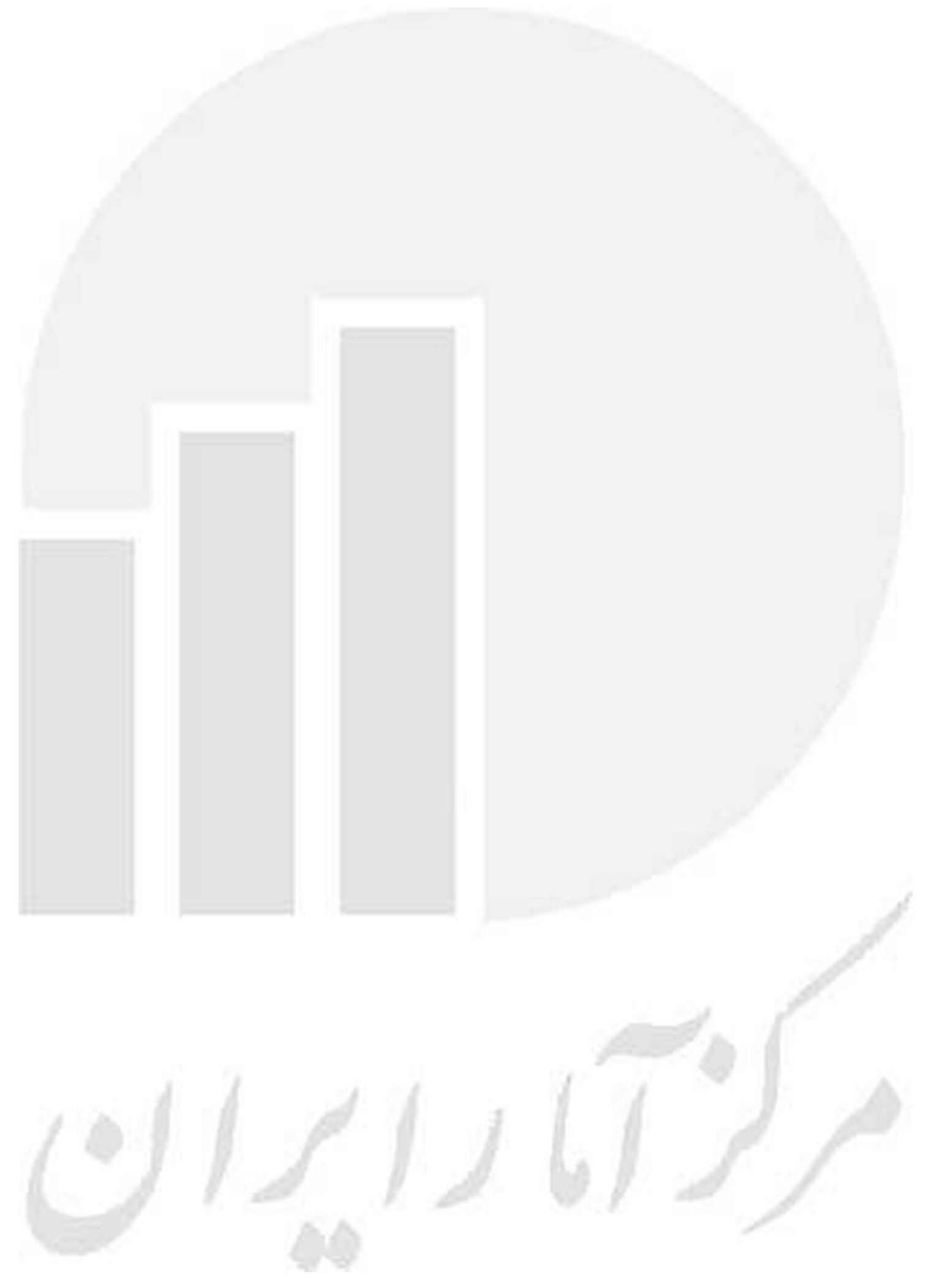




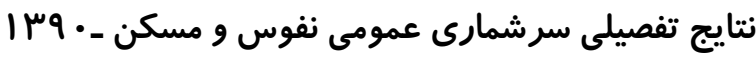

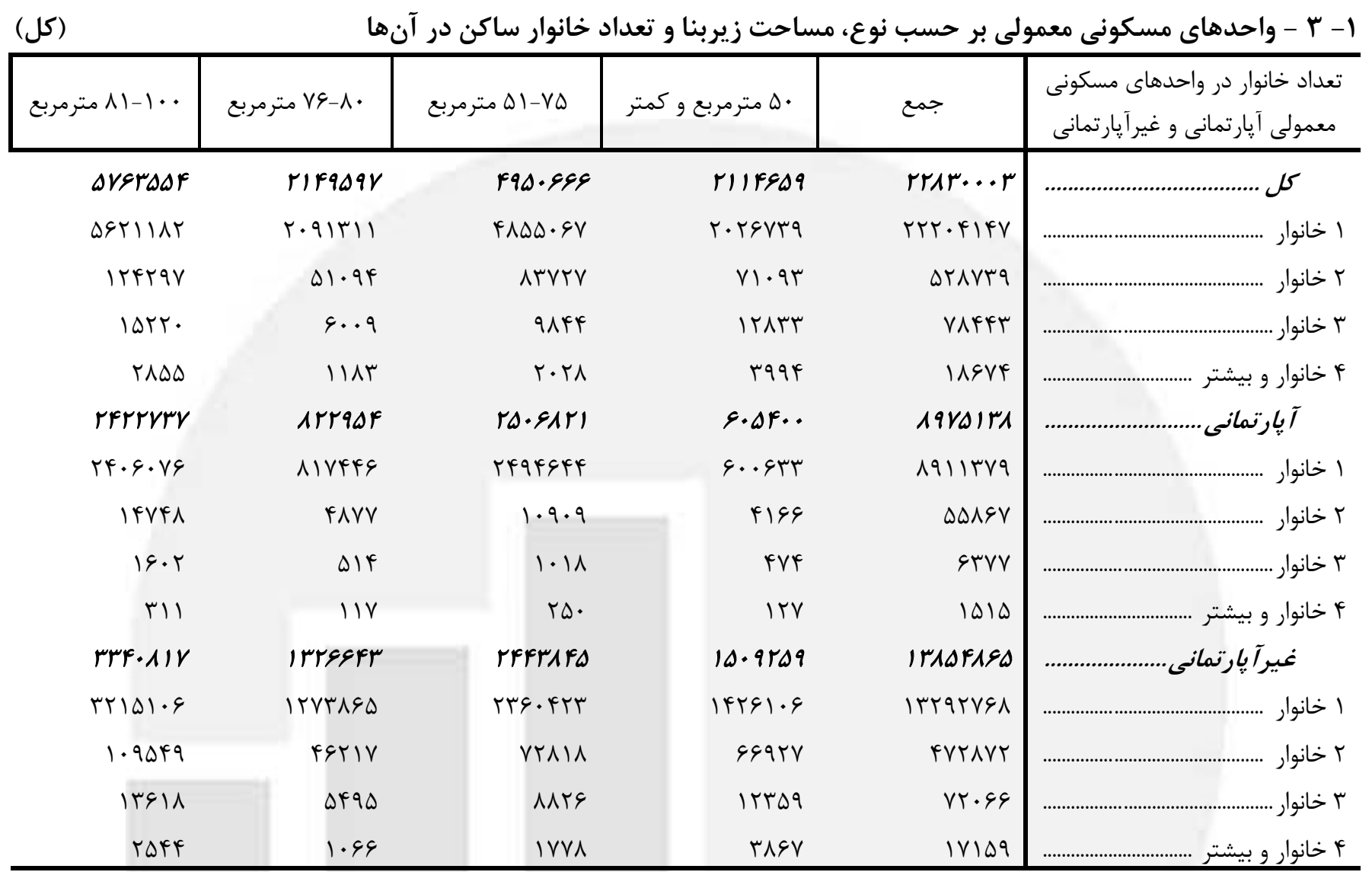

\begin{tabular}{|c|c|c|c|c|c|c|}
\hline اظهار نشده & بيشتر & ( & (5ترمربع & 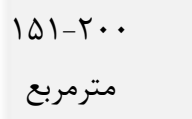 & مترمربع & تعدمولى خآوار دمر واحدهاى مسكونى و غيار آيارتمانى \\
\hline $99 \Delta \& V$ & rraqg & IEFA11 & sfladr & IDAAFa. & arrerver & كل .... \\
\hline$q V \cdot q 4$ & $r T \Delta \cdot V$ & $109.9 V$ & 9119Vर & |QTYVTI & DlGqFV & ا خانوار .......... \\
\hline $1 M \Lambda \Lambda$ & TrV & rqDI & IVTMT & FFEAT & $|r \cdot V| V$ & r خانوار ........ \\
\hline rFD & ve & אזrו & 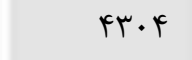 & 19८4 & 19910 & ب خانوار ....... \\
\hline rr. & re & $q \cdot V$ & lefF & trat & ra६a & F خ خانوار و بي \\
\hline firg. & $\Delta r .$. & reIry & irarrr & $F F \cdot . \Delta F$ & $1911 \pi \cdot 1$ & آپإرتم \\
\hline $4.9 \vee q$ & DrGG & $r r v \cdot \varphi$ & ITHFAN & freqqe & IQGFIFV & ا خانوار . \\
\hline rtq & rq & TAV & Ifof & fre. & $|4 q| \mid$ & r خانوار ........ \\
\hline rv & $\Delta$ & 19 & TAS & sтs & IVFe & ب خ خانوار .. \\
\hline ra & r & is & $v^{e}$ & 199 & rqv & F ب خانوار \\
\hline DArqV & rVAqG & $|f \cdot v \varepsilon|$ & $\Delta 1891$. & llfarqf & referart & غيرآيا \\
\hline$\Delta \varphi \cdot \wedge \Delta$ & TVYFI & $\mid$ |rorq| & FQDFAF & $1.9 V V r V$ & 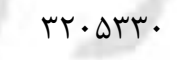 & ا خانوار ............... \\
\hline 1909 & rol & rGG4 & larrı & $r \cdot r \cdot r$ & $11 \Delta \Lambda \cdot 9$ & r خانوار ..... \\
\hline$r \cdot \Lambda$ & n & $11 \mathrm{kF}$ & $F \cdot \varphi \wedge$ & ArrA & IVAc9 & 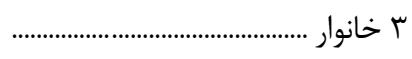 \\
\hline TFD & س & $\Delta G T$ & irv. & TITS & rDSA & f خ خانوار و بيشت \\
\hline
\end{tabular}




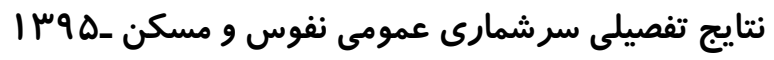

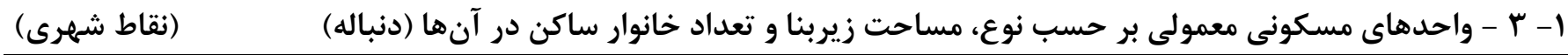

\begin{tabular}{|c|c|c|c|c|c|}
\hline 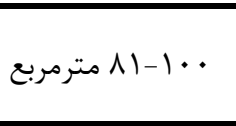 & 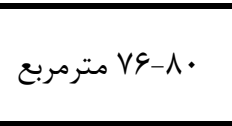 & 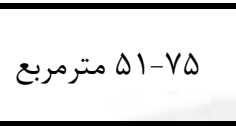 & 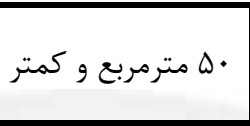 & جمع - اع & تعداد خانوار در واحدهاى مسكونى آيار تمانى و غير يارتمانى \\
\hline fressiql & IfAFrta & rafesq9 & IfIarAq & IVFaT.qg & 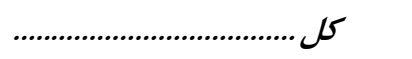 \\
\hline FTEIVTE & $|F \Delta \Delta| V T$ & TVQTAF. & ITVTYTV & $I V \cdot \Lambda \cdot \Delta r q$ & 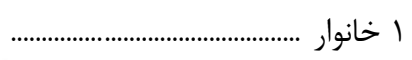 \\
\hline 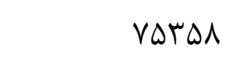 & rब८१९ & $\$ 4910$ & rद५वr & rt. & r خانوار ............ \\
\hline 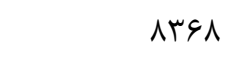 & revq & FEFT & DGTq & FTrVI & ب خانوار .............. \\
\hline ler. & FAV & $q \cdot r$ & lqT. & $91 T \Delta$ & 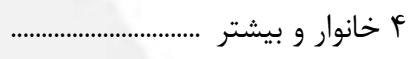 \\
\hline reriagr & rafiat & retigir & Drarker & 1єraA1. & آ بارتمانه \\
\hline rr.VTrV & $\vee \vee 9 \Delta \cdot \varphi$ & TFI. qVA & DVDI. T & 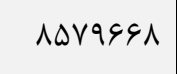 & 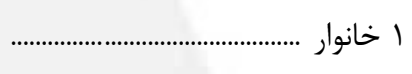 \\
\hline$\| r \cdot 9 V$ & fivi & $9 \wedge \mathrm{k}$. & rqva & $\uparrow १ ९ \Delta$. & r خانوار .... \\
\hline 9 & $r \cdot r$ & $\wedge 9 \wedge$ & rVA & Dral & 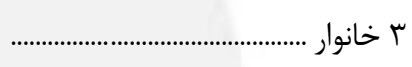 \\
\hline TDI & $1 . r$ & tre & $\wedge \kappa^{k}$ & $|r| 1$ & 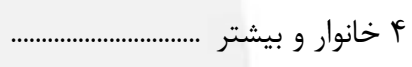 \\
\hline r. reqqr & $r \cdots \Delta r$ & Ierryar & Argate & 1419119 & 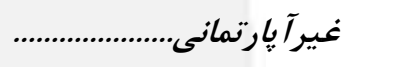 \\
\hline $190 F \& 91$ & GVDGQV & ITNIDGY & Vavira & $\wedge \Delta \cdots \wedge \vee 1$ & | خانوار ............................. \\
\hline grral & TIVTS & reVVD & Trgle & $r V \cdot F \wedge l$ & ץ خانوار .................................................... \\
\hline$V \cdot r q$ & rTVE & rVVF & DTAl & rяqr. & ب خانوار .................... \\
\hline 11189 & rAD & GVG & lofs & $v 9 / f$ & † خانوار و بيشتر ..... \\
\hline
\end{tabular}

\begin{tabular}{|c|c|c|c|c|c|c|}
\hline اظهار نشده & | • له مترمربع و & 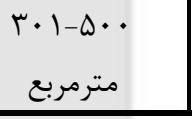 & 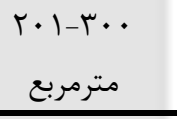 & 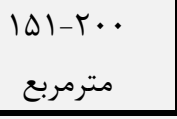 & 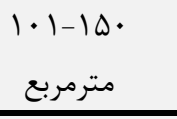 & معمولى آيار تمانى و غيرآيار دارتمانى مسكونى \\
\hline $1 Y \varepsilon \cdot \Delta$ & $19 \Delta F \mid$ & I TeFeV & DFrasa & Irerias & FFFIAIE & كل. \\
\hline N.NTK & 1941. & ITYFAF & $\Delta r \cdot \wedge \Delta q$ & IT. TFYG & FIFTRAT & ا خانوار ..... \\
\hline 1419 & IVT & к१чq & IrFV. & rrvrq & NATHK & ץ خانوار ................... \\
\hline זrז & rᄉ & V\&A & TVFA & $\Delta v \cdot q$ & $\| F \Delta V$ & 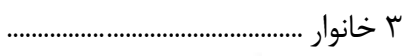 \\
\hline Trו & rI & $r \cdot 9$ & $\checkmark \wedge \Lambda$ & ITAF & TIFF & ץ خانوار و بيشتر \\
\hline raspd & freg & $r r d \cdot 1$ & IrITAF & FrADET & $1911 \Delta A F$ & آيارتمان \\
\hline$r q q \cdot \Delta$ & frrv & TEFET & 119998 & FTF..r & 11998091 & ا خانوار ... \\
\hline$r \cdot 1$ & TF & rq. & $|r| F$ & rAv. & ITTME & r خانوار ......... \\
\hline ra & r & vr & rII & $\Delta \Delta \varphi$ & 1499 & r خانوار ....... \\
\hline li & r & re & GT & שזו & $r$ & F خ خانوار \\
\hline erqg. & erva & 1. reda & ergaAl & $91 r \Delta 98$ & rrr. Tru & غيرآ \\
\hline fifin & I FDVT & $1 \cdots \cdot r$ & flllar & AVNETK & TYESETI & ا خانوار \\
\hline IrIs & $1 F 1$ & reVq & IrIDS & rA^ৎq & $V r \cdot . q$ & r خانوار \\
\hline$r \cdot \Lambda$ & ro & 999 & TATV & DIDT & 9991 & 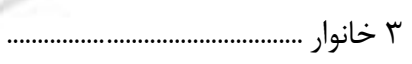 \\
\hline 119 & 19 & rVr & VTS & 1101 & $|\lambda F|$ & F خ خانوار و بيث \\
\hline
\end{tabular}


نتايج تفصيلى سرشمارى عمومى نفوس و مسكن _ه 1 |

\begin{tabular}{|c|c|c|c|c|c|}
\hline • · 1-1 مترمربع & • مG-1 مترمربع & Dت D -VD مربع & • له مترمربع و كمتر & جمع & تعداد خانوار در واحدهاى مسكونى \\
\hline |FI\&ger & squrgr & $11 \cdot \Delta 99 V$ & sq11r. & arrvqry & 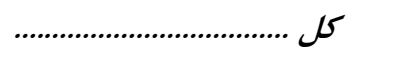 \\
\hline ITDqFEV & ATGIrA & 1. GTOTV & $G \Delta F \Delta \cdot T$ & DITHG. & ا خانوار ........ \\
\hline p^q४q & rDI91 & rVIIT & rFA.. & $r \cdot \wedge \varepsilon \cdot \Lambda$ & r خانوار ........ \\
\hline 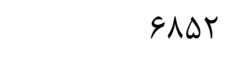 & ( & $\Delta T \cdot T$ & $V T \cdot Y$ & reIVT & r خانوار .......... \\
\hline IFTD & घ9८ & $11 \pi 9$ & rrgt & $q \Delta F q$ & $\ldots$ \\
\hline $1 \cdot .1 \mathrm{Fr}$ & rarrr & $1 \& q \cdot q$ & relar & rrqras & ........................ \\
\hline १人८५q & rVqf. & NrGGG & rQDH & IVII & ا خانوار ... \\
\hline 1911 & $v \cdot q$ & 1.99 & FAV & GTIV & r خانوار .... \\
\hline T\&K & 111 & 10 & 99 & $1 \cdot r q$ & r خانوار .. \\
\hline c. & 10 & rF & r & $r \cdot r$ & 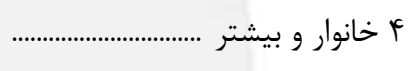 \\
\hline ITIDAT. & gredq. & $|\cdot r| \cdot \Delta A$ & evroir & a. rugva & ى \\
\hline $\mid r q \cdot G \cdot 1$ & $\Delta 91191$ & 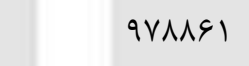 & 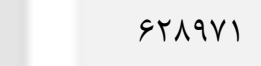 & FV৭।^qV & ا خانوار .. \\
\hline Frral & rFFat & $r G \cdot r$ & שואז & $r \cdot r r q l$ & r خانوار .... \\
\hline $9 \Delta \wedge q$ & rriq & $\Delta \cdot \Delta r$ & $v 1 \cdot \Lambda$ & rolke & r بانوار . \\
\hline Ires & $9 \wedge 1$ & $11 \cdot r$ & וTוT & GTFD & F خانوار و بيشت \\
\hline
\end{tabular}

\begin{tabular}{|c|c|c|c|c|c|c|}
\hline اظهار نشده & \begin{tabular}{|l|} 
\\
\end{tabular} & 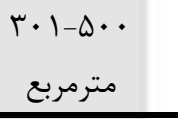 & 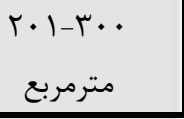 & 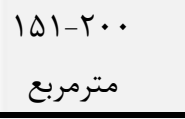 & 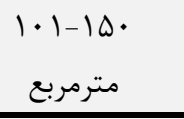 & تعداد خانوار در واحدهاى مسكونى \\
\hline leqgr & Irrab & rafel & $q f \cdot 1 r$ & regrar & $1 \cdot 11901$ & كل ........ \\
\hline |ETYI & ITI9V & rGq4 & MNII & ( & 1. r\&YqD & 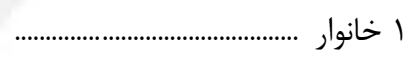 \\
\hline fVT & $1 \cdot \Delta$ & $1 \cdot 15$ & rVGr & IIVTF & FUFAF & r خانوار .......... \\
\hline 115 & ऍ^ & $\uparrow \notin \Delta$ & $1 \Delta \Delta \varphi$ & rtad & $\wedge \backslash \Delta \wedge$ & ץ خانوار ........................ \\
\hline ird & 10 & $r \cdot l$ & $\varphi \Delta \varphi$ & $1 \cdots 1$ & $|\Lambda T|$ & 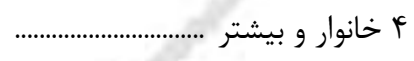 \\
\hline Iera & $\Delta r F$ & 1419 & rq11 & $\| f q F$ & sq9iv & آ إِ تمانح \\
\hline lQVF & $\Delta r q$ & ITEF & rvql & 1.991 & 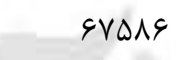 & ا خانوار .................. \\
\hline rA & r & TV & If. & rq. & $19 \wedge \mathrm{V}$ & r خانوار ...... \\
\hline it & r & IV & $f \Delta$ & $\wedge$. & $r \Delta \cdot$ & 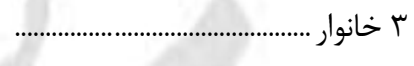 \\
\hline 11 & 1 & 11 & IT & 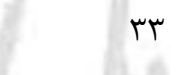 & 94 & 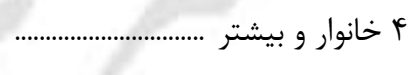 \\
\hline larrr & |rATI & $r v i \cdot r$ & 9.999 & rrevas & $1 . \mid$ rrel & غير آ يا \\
\hline IFGSV & 1 IrG9 & rarvq & NFTt & rIqTIF & $9 \Delta \wedge 9 \cdot 9$ & 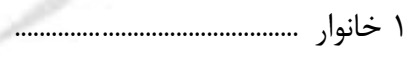 \\
\hline fFF & $1 \cdot r$ & $9 \wedge \Delta$ & TET & 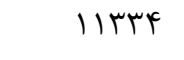 & fryar & 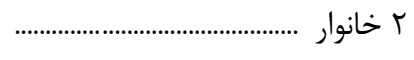 \\
\hline $1 \cdots$ & re & FFA & 1011 & miva & $\vee q \cdot \wedge$ & 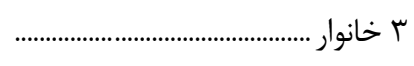 \\
\hline ITS & If & rq. & gfy & q४ & IVTV & f خانوار و بيشتر . \\
\hline
\end{tabular}




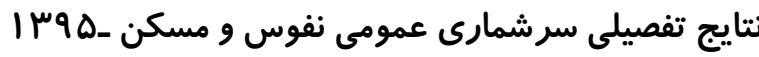
wr.

r- r - واحدهاى مسكونى معمولى بر حسب نوع، مساحت زيربنا، نوع اسكلت و مصالح عمده بهكار رفته در بنا

\begin{tabular}{|c|c|c|c|c|c|c|c|}
\hline \multicolumn{4}{|c|}{ ساير } & \multirow[b]{2}{*}{ بتن آرمه } & \multirow[b]{2}{*}{ فلزى } & \multirow[b]{2}{*}{ جمع } & \multirow{2}{*}{ مسكونى معمولى زير آيارتمانى و } \\
\hline با هر نوع سقف سمانى & سنح و جوب يا & سنَ و آهر و آهن يا & جمع & & & & \\
\hline$\|11<\varepsilon\| 1$ & $q r . . r s$ & $\Delta \Lambda \Delta \cdot 1 V q$ & $9 v \cdot r d 1 d$ & 8. Ierre & V. FrrAs & rrar...r & 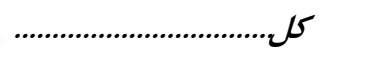 \\
\hline IVITYA & $1099 V$. & 91. Far & $\mid r F \cdot r .$. & TEDIRT & G. DVqF & rIIF909 & •ه مترمربع و كمتر ................ \\
\hline TMFYAQ & r.VTrG & $1 \cdot V V Y V V$ & $1 \wedge \Delta 19 T \wedge$ & $\mid$ IYVGq1 & INFGAT. & 190.949 & 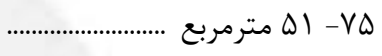 \\
\hline $1 r 9 \Delta \Lambda$. & $I T \cdot r F D$ & $\Delta G \cdot V \cdot r$ & १Мイ५९D & DFrTDV & $9|\Delta F| 9$ & rIrqه9V & . • مترمربع .......... \\
\hline TVQITI & TMIATI & IFITr.. & THTYATV & IGVADVV & IVEGTHE & $\Delta V G Y \Delta \Delta F$ & 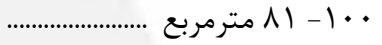 \\
\hline TIFAFT & $14811 \pi$ & IFETRYG & rI\&QSVD & |EFVAFI & 1Q.FATD & QTMTYVF & 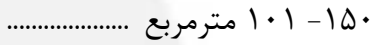 \\
\hline DQTYI & $r q .4 a$ & FAFATq & $\checkmark 119 \cdot 1$ & FTYGND & FATATA & $I \Delta \Lambda \Lambda F \Delta$. & 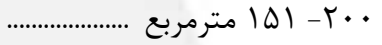 \\
\hline TYAF. & IEVTV & IQVYNT & $r q \Lambda \cdot r$. & 101994 & $1919 \wedge \Delta$ & GFI9DT & 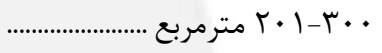 \\
\hline$\Lambda I r \Delta$ & GTYA & $r \Delta \cdot . \varphi$ & V৭\&人f & rQQYT & FqITr & IEFAMA & • • • •- • مترمربع . \\
\hline TFIF & IVVT & GヘEK & $19 \cdot V F$ & VEIT & $91 \mathrm{VV}$ & 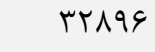 & 1 • له مترمربع و بيش \\
\hline $10 \cdot V$ & $9 \times 1$ & ITTIV & IAFTE & $1 \Delta V \Delta$. & rI9\&4 & १९८९V & اظهارنشده .................. \\
\hline DVrAs & rarAq & 1ra198 & $1 . \Delta I V V V$ & rAvA.rq & $r \cdot r \Delta q 1 F$ & 19VaIrA & آ إر رتمانى....... \\
\hline 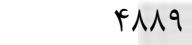 & $F \cdot \Delta \Delta$ & $\Lambda \Delta \cdot F^{q}$ & I.V.r. & DUREVT & MEFTE. & $q \cdot \Delta F \cdot$. & • له مترمربع و كمتر \\
\hline IFITE & $G T \cdot D$ & $r T \cdot \wedge \theta$ & TYKAN & $9 \wedge \mid \vee \wedge I$ & $\mid r \Delta \cdot r \cdot \Lambda$ & $r \Delta \cdot G \Lambda T I$ & \\
\hline $94 \cdot 4$ & TVQV & NF्ञाT & 1.9110 & $r \Delta \Lambda \cdot 1 r$ & 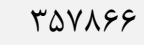 & ATR QDF & 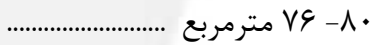 \\
\hline $1 Q F \cdot \Lambda$ & 91V9 & $r \cdot q r V r$ & $r \varphi \Delta \cdot \wedge r$ & $11 \pi 1.9$. & 1. TQAGK & TETTVTY & 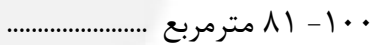 \\
\hline IIVTe & FTIF & IVETYK & $r \mid 9 . .1$ & Q९q४AF & vapqus & $1911 \% \cdot 1$ & • لها- | • 1 متر \\
\hline TATE & $1 \cdot k t$ & FHTED & $\Delta F \ldots$ & TEFEFT & INIras & $p q \cdot \Delta \phi$ & • · ·- |ه| مترمربع \\
\hline $9 \Delta \mu$ & FTY & IFAND & IAQTF & QFDQT & Q1V.9 & ITSTVT & 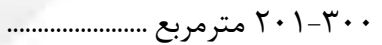 \\
\hline r\&q & VT & raM & $F \cdot V V$ & ח & 1.VKT & TFITY & 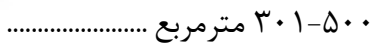 \\
\hline$\wedge$. & $\Delta 9$ & 491 & $\Lambda \Delta V$ & TMFY & rlar & $\Delta \Gamma . \cdot$ & ا له مترمربع و بيشتر \\
\hline r $9 \Delta$ & IVV & rNAT & F995 & ITFOV & $19 \mathrm{VV}$. & Firv. & اظهارنشده ..... \\
\hline 1. DVrrr & $q \cdot F V \in q$ & a. $11919 \pi$ & $\Lambda \& \Delta I \cdot r \Lambda$ & rirar.d & $r \cdot \cdot v r \cdot r$ & IrADFASA & غيرآ إِ رتمانى.. \\
\hline 19янта & $1 \Delta \Delta \& \mid \Delta$ & $\Delta T \Delta F \cdot \Lambda$ & DTrrA. & 1114. & TGIQTK & $10 \cdot 9 T \Delta 9$ & 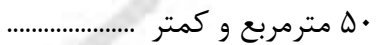 \\
\hline$T r \cdot 194$ & $r \cdot|| r \mid$ & NDVTqT & IQVVqT. & $r \varphi \Delta 91$. & DQGYIT & TFEYAFD & - اله مترمربع ... \\
\hline Irrqve & IIVAFA & FVG.91 & $\Lambda \Lambda I F \Delta$. & INAKFY & TQVDQT & IrTGGKT & 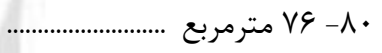 \\
\hline rQqVIT & TYAGFY & IT.TQYA & T.GVVFF & DFVFAV & $V T \cdot r V I$ & $r \mu F \cdot \Lambda I V$ & 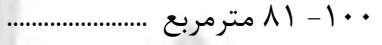 \\
\hline$T \cdot r \Lambda \cdot V$ & $|f| 199$ & ITSAFIS & q४q६VF & SVArDV & $v \cdot 9199$ & THFTAVT & • ا - - 1 • مترمربع \\
\hline DTFFE & $r \wedge \ldots 1$ & FFIOVF & $9 \Delta V 9 \cdot 1$ & TIATFT & TVIIVT & llfArqF & 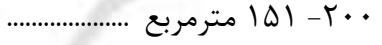 \\
\hline TIOAV & $19 \% \cdot 0$ & IATFQV & rVq. १९ & $9 Y 11 T$ & 1r99v9 & 01991. & $-\mu$. \\
\hline$\vee \wedge \Delta \varphi$ & 9111 & GT. IN & $V \Delta G \cdot V$ & TEQTा & rAFi & $|f \cdot V q|$ & • • • • • م مترمربع ..... \\
\hline trme & IVIT & $9 \pi 9 \Delta$ & IDTIV & 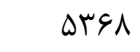 & 9914 & rVDQG & 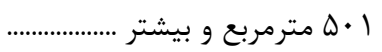 \\
\hline $111 \%$ & var & $q \mu q 4$ & ITFFY & שTq & DI9F & $\Delta \Lambda T Q V$ & اظهارنشده ...... \\
\hline
\end{tabular}


r- r - واحدهاى مسكونى معمولى بر حسب نوع، مساحت زيربنا، نوع اسكلت و مصالح عمده بهكار رفته در بنا (دنباله) (كل)

\begin{tabular}{|c|c|c|c|c|c|c|}
\hline \multirow{2}{*}{ نوع اسكلت و } & \multicolumn{5}{|c|}{ 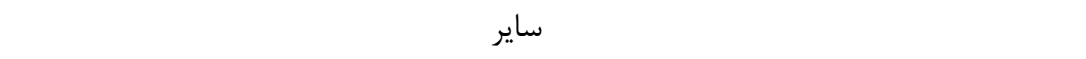 } & \multirow{2}{*}{ معمولى آيار تمانى و غير واحدآ يارتمانى مسكنى } \\
\hline & 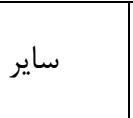 & خشت و كل & خشت و جوب & تمام جوب & تمام آجر يا سنَ و & \\
\hline svesq & RAF. qF & relarr & $r \lambda \cdot 81 r$ & rVDar & skrf. F & 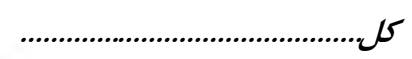 \\
\hline TEMT & rqurg & $1 \cdot \wedge \Delta \Gamma^{\circ}$ & qFArr & MArT & $\Delta V r \mu \Delta$ & 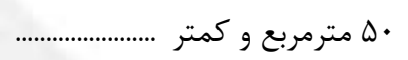 \\
\hline FATV & $\Delta \cdot V T r$ & $\Delta F I \cdot V$ & MMAqF & $1 \cdot r \cdot r$ & $99 . .9$ & 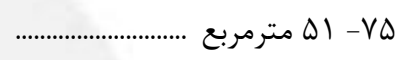 \\
\hline$r \Delta \Delta \varphi$ & TATAT & FrADF & fFAlq & five & $\Delta १ \Delta \cdot \Delta$ & 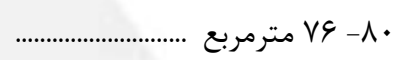 \\
\hline D919 & $V T \cdot V \Delta$ & q৭4.. & VVMr. & Vris & $19 \cdot \kappa \Delta \Delta$ & 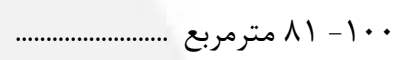 \\
\hline DFTR & gVGGY & 81910 & frqq1 & 4199 & IVTarf & 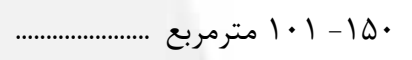 \\
\hline $19 r 9$ & rmIFD & rtran & 19109 & $I V \cdot \Lambda$ & Dیr人r & 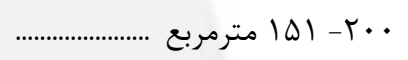 \\
\hline$\Delta \wedge r$ & $1 \cdot$ vq & $1 \Delta \varphi \Delta F$ & $\Lambda \cdot r \Lambda$ & vir & TEIAT & 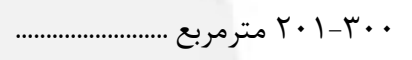 \\
\hline $\mid \& \lambda$ & Thes & qтя. & rFA. & ५৭९ & gVrr & 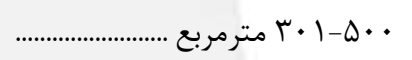 \\
\hline r & $1 \cdot \Delta$ & $1 \Delta \wedge \Delta$ & $1 . \mathrm{eV}$ & $1 \cdot 0$ & Irro & 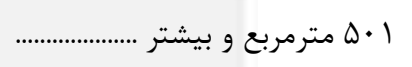 \\
\hline freig & k94 & $\wedge / f$ & rAd & fy & $1 \cdot r \cdot$ & 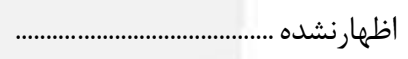 \\
\hline$q r F A$ & Dq9T. & NAFV & sAar & irre & $\Delta r r \Delta \Delta$ & 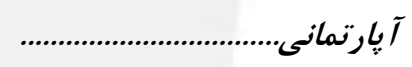 \\
\hline FFV & $\Delta \cdots$ & 1914 & IVVq & 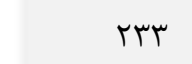 & $r \cdot r \Lambda$ & 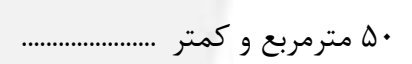 \\
\hline VTF & IVrVA & 1094 & 1914 & rav & ITEAT & 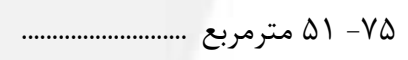 \\
\hline rq. & 9190 & $V F \Delta$ & vil & ifa & $\Delta \cdot r \Delta$ & 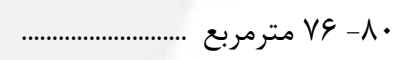 \\
\hline$v \cdot 1$ & 19949 & IVVV & $|r 4|$ & rVr & IrVGF & 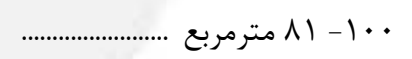 \\
\hline$\vee \wedge$. & $1 \cdot \Delta \Lambda$ & 1 1r94 & $\Lambda F \Delta$ & ir. & ITAIV & 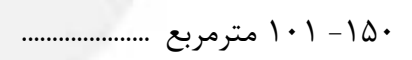 \\
\hline$r \Delta \Lambda$ & rFvq & $\Delta \Delta \Lambda$ & r99 & $\Delta 9$ & rev. & . · - اله| مترمربع ............... \\
\hline$\wedge \vee$ & 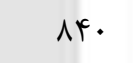 & ra1 & $1 \pi q$ & 11 & Irvq & 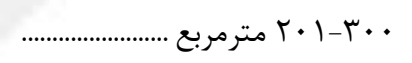 \\
\hline ra & $r \cdot r$ & 111 & $\Delta \varphi$ & if & rq & 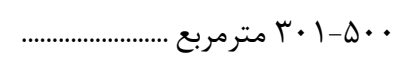 \\
\hline$\Delta$ & $11 \%$ & 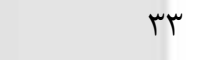 & rQ & r & Ve & 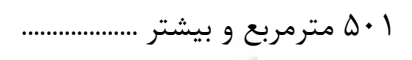 \\
\hline $9 \cdot \Delta 1$ & rif & VV & re & 11 & ו ו & 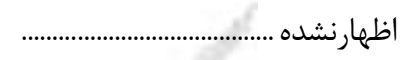 \\
\hline DArIA & ThEIFF & rar.r. & rrrarl & reriq & $\Delta 19 q \times q$ & 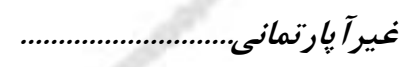 \\
\hline 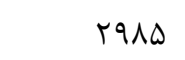 & TFFtg & $1.9 \Delta F \lambda$ & $q r \cdot \Delta f$ & $\wedge \Delta ৭$. & QHTqV & • له مترمربع و كمتر ..... \\
\hline$r \Lambda \cdot r$ & rmtga & NTDIF & AVYAI & 9149 & 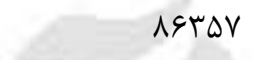 & \\
\hline TrQG & $1911 \mathrm{~V}$ & Frl. 9 & $|f| r \mid \cdot \Lambda$ & $r \cdot r$ & DFEV. & 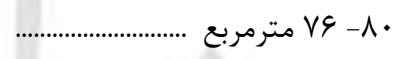 \\
\hline$\Delta T / Q$ & $\Delta \Delta \mid{ }_{T}$ & gFert & VQ9Vด & V. Ft & $\mid 49991$ & 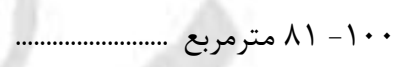 \\
\hline rgkt & $\Delta V \cdot \wedge f$ & $V \cdot \Delta F q$ & Ffiar & $p \cdot p q$ & $19 \cdot V I V$ & 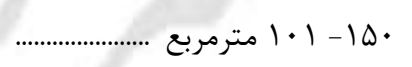 \\
\hline$|r v|$ & $r \cdot 999$ & тוג.. & $19 \Delta 9$. & 1949 & $\Delta F q \mid r$ & 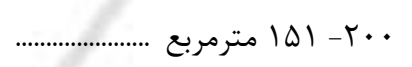 \\
\hline pq4 & $99 \Delta F$ & 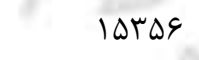 & $\vee \wedge १ 9$ & 990 & $r F A \cdot r$ & 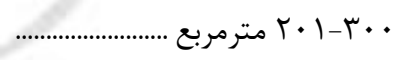 \\
\hline 111 & mTre & GTET & METE & rAT & ste. & 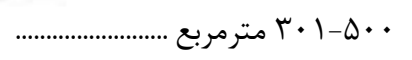 \\
\hline rᄉ & qu & $1 \Delta \Delta T$ & $1 \cdot T r$ & $1 \cdot r$ & 1194 & 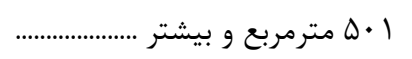 \\
\hline 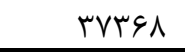 & TAT & $V r V$ & ral & 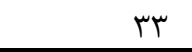 & V99 & 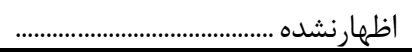 \\
\hline
\end{tabular}


r- r - واحدهاى مسكونى معمولى بر حسب نوع، مساحت زيربنا، نوع اسكلت و مصالح عمده بهكار رفته در بنا (دنباله) (نقاط شهرى)

\begin{tabular}{|c|c|c|c|c|c|c|c|}
\hline \multicolumn{4}{|c|}{ ساير } & \multirow[b]{2}{*}{ بتن آرمه } & \multirow[b]{2}{*}{ فلزى } & \multirow[b]{2}{*}{ جمع } & \multirow{2}{*}{ معمولى آيارتمانى و غير واحدآيارتمانى مسكونى } \\
\hline 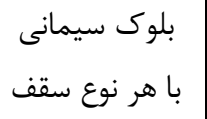 & سنَ و و جوب يا & سنَ و آجر و آهن يا & جمع & & & & \\
\hline 0.991. & ra.|r| & FrIATAD & G.VFFAD & $0 \cdot 11 \cdot 1 r$ & grfla11 & IVFAT.GQ & 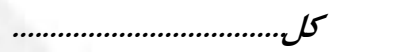 \\
\hline GSVGT & GFIDF & FASFIq & GAKrTF & 1999^४ & $\Delta r \cdot 4 q \Delta$ & $|f| \Delta \vee \wedge q$ & 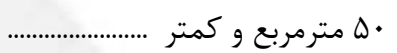 \\
\hline 1. TrGG & $\Lambda \cdot \wedge \notin 9$ & $11 r \Delta q \Delta$ & سوופسו & $1 \cdot \Lambda V \cdot r F$ & ISINGVG & rAfFsq & 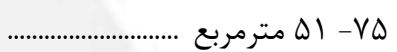 \\
\hline$\Delta T V \wedge \Delta$ & $F \cdot \mid \Delta V$ & $r V I \cdot r v$ & Q DTIFe & reqvar & 019110 & IFAFrtu & 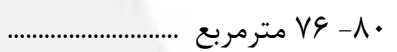 \\
\hline ITFDDS & 9149. & QNTEFV & ।r१११५ & $\mid F \cdot$ FET & IQr人rA. & Frre八91 & 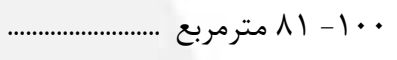 \\
\hline $1.9 \Delta V F^{F}$ & $\varepsilon \Lambda \cdot r \Lambda$ & 1.VATVD & $|F \& V G| \mid$ & If.rrgr & 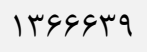 & ETFINIS & • ها - 1 • ا مترمربع .. \\
\hline rraq1 & TI911 & $f \cdot .|9|$ & $\Delta F \Delta \cdot \Lambda$. & rVGGYA & FIq.r. & ITETIDA & 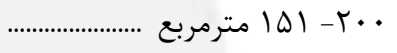 \\
\hline IrVAF & $9 \Delta \varphi$. & 19人ץ.r & 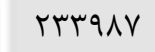 & 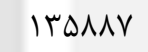 & IVVESG & $\Delta F \vee \wedge \varepsilon D$ & 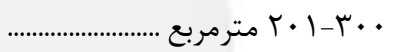 \\
\hline rYAl & TVAI & TATFT & DTVT. & $r \cdot 190$ & FrFal & ITEKEV & 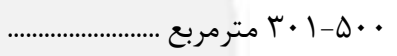 \\
\hline 949 & DFF & 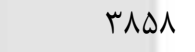 & $v \cdot 4 q$ & DEV. & 9994 & $|9 \Delta F|$ & 1 • 1 مترمربع و بيشتر \\
\hline 1119 & $4 .$. & IIVFA & lQFV. & IQIFV & $r I \cdot \Delta T$ & $1 r q \cdot \Delta$ & اظهارنشده ..................... \\
\hline FAAT. & isvir & varaqs & qeveqr & rVFAF.. & ralfrla & 1єrass. & آ إ رتمانى ......... \\
\hline 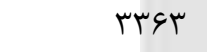 & $r V \cdot q$ & $\Lambda \cdot \Delta \Delta r$ & 9६†૬। & $1 \notin 910$. & Trme.t & DVGFET & • له مترمربع و كمتر .............. \\
\hline $11 \wedge \Delta \Delta$ & FEA. & $r 1 \cdots v q$ & TAGTAT & QDFT QD & $|r| \cdot \Delta \varphi q$ & TFYI9IT & \\
\hline$\Delta \cdot 9 \Delta$ & IGTT & $V q \cdot \Delta r$ & १९VTठ & rerAls & 1h & VAFIAT & 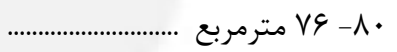 \\
\hline ITKTK & r人GT & 199490 & TETYFA & $1 \cdot \wedge \& r \Delta V$ & १৭५४रब & TrTIAqF & 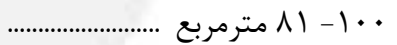 \\
\hline 9490 & rA11 & IsqV91 & 199911 & quFFAT & VVGGA. & $191101 F$ & • ها - 1 • ا مترمربع . \\
\hline FFT & veF & FITIF & $\Delta \cdot r V I$ & 199991 & IVVqDT & FTADGT & · · ·- |D| مترمربع . \\
\hline У१^ & rAV & $14 \cdot 4$. & IVTGF & (MITA & $0.99 \mathrm{~V}$ & ITITAF & 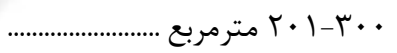 \\
\hline INT & $9 V$ & tris & Mef. & $\wedge १ \Delta \vee$ & I.rVV & $r T \Lambda \cdot \Lambda$ & 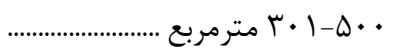 \\
\hline is & r. & r & $9 \cdot 9$ & $r \cdot 94$ & $r \cdot 91$ & FVदG & 1 ل ا مترمربع و بيشتر . \\
\hline rTF & | & $r q \wedge \Delta$ & FETV & IrTFq & $|9 \Delta F|$ & ras广b & 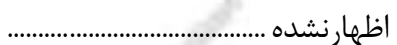 \\
\hline Ferra. & remelA & raTarAq & Dl. $9 v 9 \pi$ & ITEFFAT & rerviga & 1419119 & غيرآ بإرتمانى.... \\
\hline qтrqq & GIFYA & rVDAGG & $\Delta \wedge V \cdot G r$ & $Q \cdot \wedge r v$ & $198 \cdot 94$ & ArGQFG & • • مترمربع و كمتر \\
\hline $9|f| \mid$ & Vefie & G. TO19 & 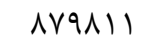 & ITTVYq & $f \cdot \wedge 11$. & IFTYVAV & V -VD \\
\hline 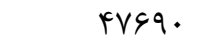 & KNDTD & rq1914 & FसqसाI & $109 \cdot 9$ & IVGFqV & $\vee \cdots \Delta r$ & 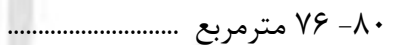 \\
\hline 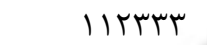 & $\wedge \vee \Delta Q \Lambda$ & $V \Lambda 9 \cdot \Lambda T$ & 11DV\&q. & MINTEF & $\Delta F \Delta V \Delta D$ & T. YFqqV & . . 1- 1 مترمربع ... \\
\hline $1 \cdots v 9$ & SOTIV & $91 \cdot \Delta V V$ & Ir\&VqY. & $\forall \& \wedge \wedge \vee q$ & $\Delta \wedge 99 \Delta 9$ & THTH & 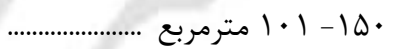 \\
\hline$M \| \Delta F$ & rITrV & 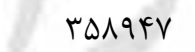 & qqqq.q & IVGGrV & $\langle F I .9 \Lambda$ & $91 r \Delta 99$ & 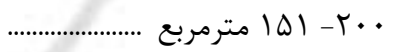 \\
\hline 1 1 919 & QTV & IDFTET & TIG9T & ATVEq & IrEVG9 & FrgDAI & 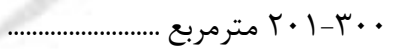 \\
\hline rчq9 & TVIF & TrATS & fark. & $r \mid r \cdot \Lambda$ & 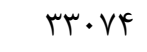 & $1 . r \varepsilon \Delta 9$ & 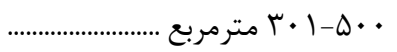 \\
\hline 911 & $\Delta T F$ & TYAD & Geter & rTV & Far & IFrVD & له مترمربع و بيشتر .................... \\
\hline$\Delta T_{1}$ & 199 & $1.9 \pi$ & 1. 1. (1) & $1 \wedge 91$ & $F \Delta \| 11$ & Frag. & 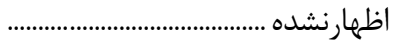 \\
\hline
\end{tabular}


r- r - واحدهاى مسكونى معمولى بر حسب نوع، مساحت زيربنا، نوع اسكلت و مصالح عمده بهكار رفته در بنا (دنباله)

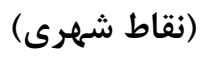

\begin{tabular}{|c|c|c|c|c|c|c|}
\hline \multirow{2}{*}{ نوع اسكلت و } & \multicolumn{5}{|c|}{ 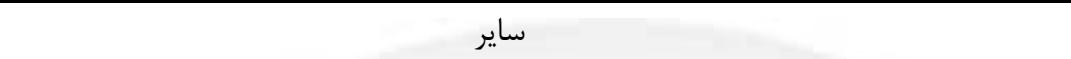 } & \multirow{2}{*}{ معمولى آيارتمانى و غيراح واحداى إرتمانى مسكونى } \\
\hline & 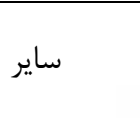 & خشت و زل & خشت و خوب & تمام جوب & سنَ & \\
\hline rval. & 11. Frg & $I V \Delta \cdot 11$ & $1 \ldots 10$ & 19211 & rql.1f & 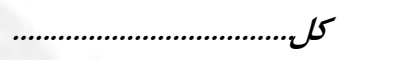 \\
\hline 1914 & $1919 V$ & T\&IDG & $|9 T r|$ & FrAV & $r \cdot I r \Lambda$ & 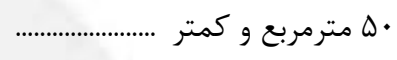 \\
\hline rArs & एт৭९q & TYDGQ & 1999. & F\&\& & DGTVD & ............................ DI -VD \\
\hline liAt & $\mid$ EFE & $\mid$ |rTq| & qrVI & $r \cdots$ & rq1G4 & 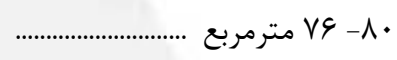 \\
\hline$r q \Delta \Delta$ & FDITV & $r \cdot l \Delta r$ & $r|\Lambda| \Lambda$ & rquF & $q \cdot m \times l$ & 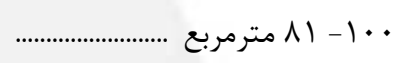 \\
\hline FT. Y & Fr人l. & rVIIN & 1949. & $r \Lambda \cdot 9$ & $\| F+1$. & 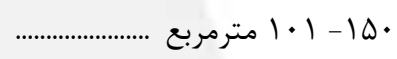 \\
\hline Ifr. & $18 \cdot 19$ & IMATF & vevi & lrq4 & FFATq & 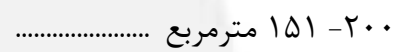 \\
\hline$\Delta T \Delta$ & $\Lambda \cdot 9 \Lambda$ & 9014 & rAvı & YAV & $r \cdot r 9 \Delta$ & 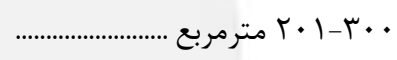 \\
\hline$|r|$ & l9rV & 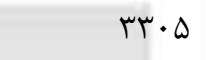 & IFEA & lat & fEAT & 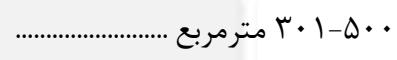 \\
\hline rA & 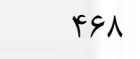 & DQT & rq9 & fr & $\Delta \wedge r$ & 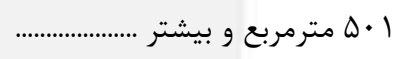 \\
\hline r.q५५ & rq. & $\Delta \varphi q$ & 197 & 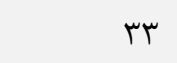 & $\vee \wedge \Lambda$ & 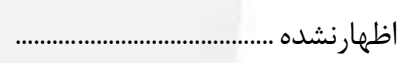 \\
\hline 1req & DETrF & Fras & rVqr & $1 \mathrm{kr}$ & ryagr & 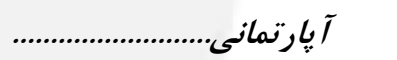 \\
\hline kr. & retr & 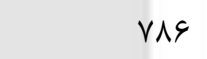 & $\Delta q \Lambda$ & irq & req. & 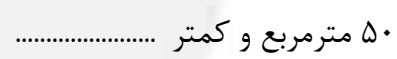 \\
\hline 999 & 19994 & vil & s4i & TFA & IIEFV & 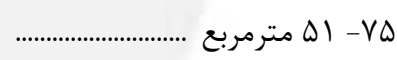 \\
\hline ter & $\Delta \Lambda / F$ & reV & TAT & 90 & FETV & •^ • مترمربع ............... \\
\hline $99 \mathrm{~V}$ & $1 \Delta \wedge \vee \wedge$ & $94 \wedge$ & $\Delta V T$ & $r \cdot 9$ & $\mid r \cdot 91$ & 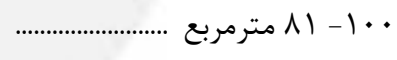 \\
\hline$v e$. & q४४१ & ^r. & 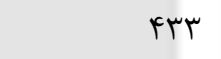 & 90 & llft. & 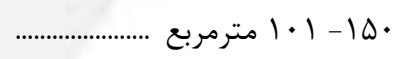 \\
\hline TFA & rtat & 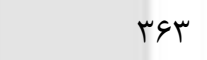 & $|0|$ & \&A & TITr & 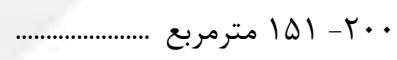 \\
\hline$\Lambda \Delta$ & VRG & r & GT & 11 & ITTV & 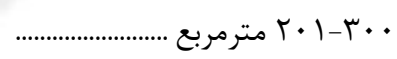 \\
\hline me & IFA & $4 \Lambda$ & rQ & 9 & rו & 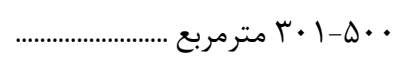 \\
\hline$\Delta$ & $\wedge 1$ & 11 & ir & · & 9) & 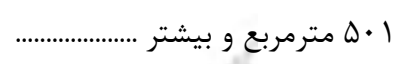 \\
\hline DTIA & $t \cdot r$ & $\Delta 9$ & rl & $\wedge$ & $r \cdot V$ & 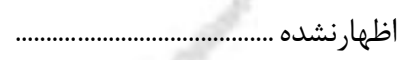 \\
\hline malfl & ITFT.r & $r v \cdot r \cdot r$ & qrrar & 11181 & rerifi & غيرآ إرتمانى....... \\
\hline $1 \Delta \Delta T^{\prime}$ & $11 \Delta G \varphi$ & rarV. & IAGTr & 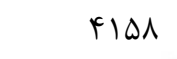 & rGG H & • له مترمربع و كمتر \\
\hline rITV & $19 r \cdot \Delta$ & rrvqu & 19419 & FEIN & FFETA & 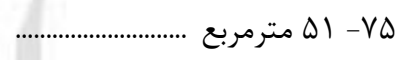 \\
\hline Irrq & AGTV & IrqTF & 9.19 & $19 \cdot 0$ & TFVTr & 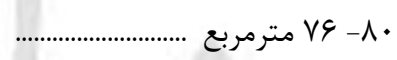 \\
\hline TYMA & rartq & rqт.r & TITES & rVYA & VArQ. & 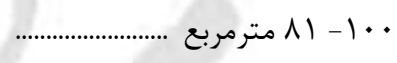 \\
\hline regt & $M F \cdot r$ & rarAN & $19 \cdot \Delta V$ & rill & 1. rqv. & • لها - ا. ا مترمربع . \\
\hline IINT & IFVTV & $\mid\langle|\varepsilon|$ & VAT. & IFFE & fifiv & • . . - اه| مترمربع ... \\
\hline pq. & VRrT & qrरq & rی19 & eVe & 19191 & 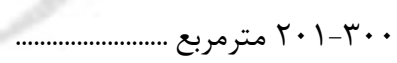 \\
\hline $9 \vee$ & IVar & rtry & Trt & $1 \Delta \Lambda$ & Frt & 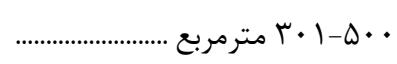 \\
\hline r & rAV & $\Delta \wedge 1$ & rAk & er & $\Delta T_{I}$ & 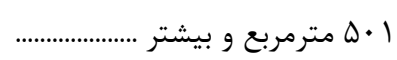 \\
\hline$r \Delta V \backslash \Lambda$ & $1 M$ & هI. & IVS & rQ & $\Delta \wedge 1$ & 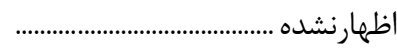 \\
\hline
\end{tabular}


r- r - واحدهاى مسكونى معمولى بر حسب نوع، مساحت زيربنا، نوع اسكلت و مصالح عمده بهكار رفته در بنا (دنباله)

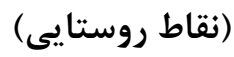

\begin{tabular}{|c|c|c|c|c|c|c|c|}
\hline \multicolumn{4}{|c|}{ ساير } & \multirow[b]{2}{*}{ بتن آرمه } & \multirow[b]{2}{*}{ فلزى } & \multirow[b]{2}{*}{ جمع } & \multirow[b]{2}{*}{ مسمولى زيربنا واحدهاى مسكونى } \\
\hline بلو با هر نوع سقف & سنَ آجر و جوب يا & سنجر و آهن يا & جمع & & & & \\
\hline$\varepsilon \cdot a \cdot \cdot 1$ & $\Delta F q q \cdot V$ & IDTraqF & rerarr. & 9 9R|al & $1 \cdot 1 r \ldots$ & arrvarr & كل...... \\
\hline $1 \cdot$ ffG & $9 \Delta \Delta 19$ & س & $\Delta \Delta ९ q \vee \mathcal{G}$ & GDIFG & VQY৭Q & 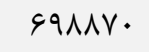 & •ل مترمربع و كمتر .............. \\
\hline rr|r| & ITEFG. & TETVAT & $V \backslash \Delta V G \Delta$ & $19.99 \mathrm{~V}$ & THVAFF & $11 \cdot \Delta 99 V$ & ال مترمربع ..... -VD مت \\
\hline V९V৭D & $\Lambda \cdot 1 \wedge \Lambda$ & 1 $1949 V$ & $F \Delta \Delta 119$ & $\| r \Delta s \Delta$ & $q \Delta \varepsilon \cdot f$ & GGDTGK & 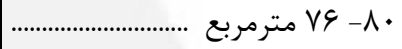 \\
\hline $1 \Delta \cdot \Delta 9 \Delta$ & $|F \cdot r q|$ & FTQVAT & 9rт人9т & rVTqDq & $r \cdot V \wedge \Delta r$ & |f|घ94 & • • - 1 1 مترمربع ....... \\
\hline 1.4999 & $\vee \wedge \cdot \wedge \Delta$ & TEVTGY & $991 \cdot 94$ & TFFFV & $1 \% \wedge 199$ & $1 \cdot 11901$ & • ها - ا • ا مترمربع ...... \\
\hline TI\&A. & $I V \cdot q 4$ & ᄉF\&VA & IG9DTA & $F \varphi \cdot \Delta V$ & 1 & TFETQT & • · ץ- اله| مترمربع ...... \\
\hline AVDS & VIEV & $r q \cdot v q$ & GY.rT & IOVVV & $|F T| 9$ & $q r \cdot \Lambda V$ & • . ·- • • مترمربع .. \\
\hline FEFF & MFEV & qVGY & rqq\&F & $\Delta \vee \Delta q$ & $\Delta \varepsilon \wedge I$ & TAFTI & • • • - | • م مترمربع . \\
\hline $\mid V F \wedge$ & ItrA & $r \cdots \Delta$ & $q \cdot r \Delta$ & TIFT & riیr & Irrad & | • ه مترمربع و بيشتر . \\
\hline MGT & rVI & 1499 & rqs4 & $9 \cdot r$ & $91 \%$ & 19994 & 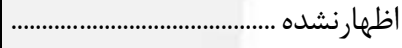 \\
\hline$\| F E D$ & ADVE & $F \Delta q .$. & $1 F \cdot 1 \Delta$ & ireferg & IrIVEA & rraral & 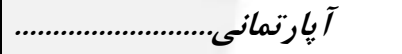 \\
\hline IDTG & ITHE & FFql & $1 \cdot V \Delta q$ & FATR & $1 \cdot \wedge \Delta \Lambda$ & T\&IQV & • له مترمربع و كمتر .... \\
\hline rtr. & $I V \Delta \Delta$ & $1 \cdots 9$ & 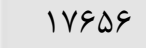 & TVYAS & rqVFr & $14 q \cdot q$ & 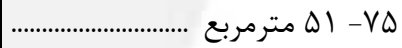 \\
\hline $10 \cdot 9$ & 1190 & $\Delta \Delta \varphi$. & $1 \cdots 1$ & $|F| Y V$ & IFDFA & rAVVT & 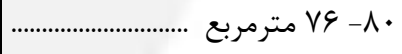 \\
\hline ri^d & & $1 r q \cdot V$ & rTAKA & FFVTR & גוtr & $1 \cdot \cdots \wedge r$ & • • |- 1 مترمربع ..... \\
\hline TYYI & $\mid r \cdot r$ & $9 \Delta T \Delta$ & lQTr. & $r \Delta \cdot \cdots l$ & INTDS & 994IV & • ها - ا • ا مترمربع ...... \\
\hline r^৭ & r.. & $r \cdot \Delta l$ & rerq & 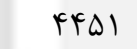 & 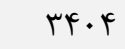 & llfqf & 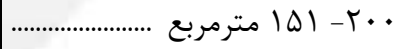 \\
\hline $1 \Delta \Delta$ & 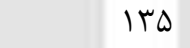 & $\Lambda r \Delta$ & $10 G$. & $\| f \mid F$ & $1 \cdot 1 r$ & 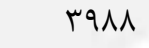 & • • ·- • • مترمربع .. \\
\hline$\wedge \vee$ & $V \cdot$ & TVT & str & (reg & rFD & 1119 & 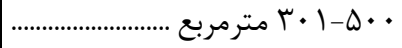 \\
\hline re & rq & $9 \Delta$ & $r \Delta l$ & $10 \cdot$ & س & $\Delta M F$ & 1 • له مترمربع و بيشتر . \\
\hline VI & iq & 191 & $r \Delta \Delta$ & $r \cdot \Lambda$ & rtq & IETD & 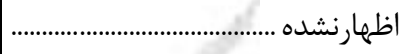 \\
\hline DqRAFT & DFIFr & IfAsqqF & MAFFFFA & rquVrr & svadra & D. rasva & غيرآ پإرتمانى. \\
\hline $1 \cdot r q 4$. & qfiv. & IFqDFT & DFETIV & G.Grr & EFfFI & GVTVIT & • له مترمربع و كمتر . \\
\hline ITAVAT & $I T F V \cdot \Delta$ & TATVVE & $9911 \cdot 9$ & |r|M| & $|1 N| \cdot r$ & $1 \cdot r 1 \cdot \Delta \Lambda$ & 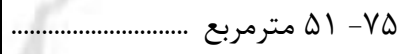 \\
\hline VDTAS & Vq.r & $|\wedge F| \cdot V$ & $F F \Delta \cdot r q$ & $9944 \wedge$ & $\Lambda 1 \cdot \Delta \varphi$ & 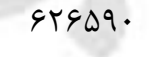 & 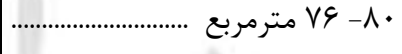 \\
\hline IFVMA. & $\mid r \Lambda \cdot F f$ & fIsplfs & $q 1 \cdot \Delta t r$ & TrGTrT & $|V F G| G$ & ITIONT. & 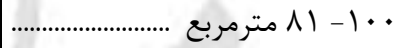 \\
\hline I. TVYA & VG91T & rov^rq & GNIVFF & $r \cdot q r V \wedge$ & 11994. & $1 \cdot|r M F|$ & • ل ا - | • ا مترمربع \\
\hline r|rq| & IEVGF & ATETV & 195人99 & $f 19.9$ & $r \cdot 1 \cdot r$ & rmFVqA & 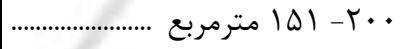 \\
\hline$\Lambda \varepsilon \cdot 1$ & V.rt & TATDF & ETFVT & IFrat & Irtev & $9 \ldots 99$ & 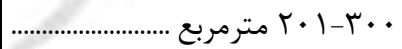 \\
\hline$r \Delta \Delta V$ & rrqV & qfqr & TETTV & DFTH & ( & rVI.r & 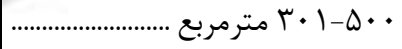 \\
\hline IVIS & 1119 & rq1. & AVVF & 1995 & $r \cdot \Delta \cdot$ & $|T \wedge T|$ & 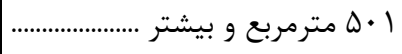 \\
\hline rql & rTd & $1 r \cdot 1$ & re. 9 & rqه & 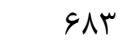 & ( & 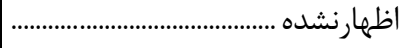 \\
\hline
\end{tabular}


r- r - واحدهاى مسكونى معمولى بر حسب نوع، مساحت زيربنا، نوع اسكلت و مصالح عمده بهكار رفته در بنا (دنباله) (نقاط روستايى)

\begin{tabular}{|c|c|c|c|c|c|c|}
\hline \multirow{2}{*}{ نوع اسكلت و مصالح } & \multicolumn{5}{|c|}{ 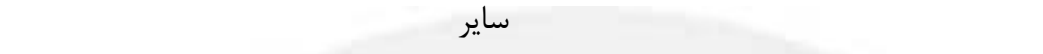 } & \multirow{2}{*}{ مساحت زيربنا واحدهاى مسكونى } \\
\hline & 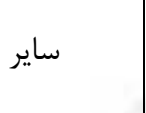 & خشت و كل & خشت و جوب & 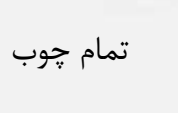 & سنح و آجر آجر & \\
\hline$r \cdot l \Delta \varepsilon$ & 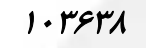 & rasFiq & $r \Lambda \cdot \Delta r r$ & IVAFI & ratrT. & 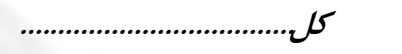 \\
\hline IfFq & ITtr & ATrVF & VASIT & FATS & $r V T \cdot V$ & 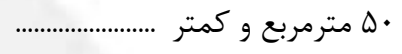 \\
\hline 1991 & IVVDF & $\Delta 9 \Delta \Gamma \wedge$ & GヘqrF & $\Delta \Delta F$ & FTVMF & 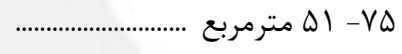 \\
\hline $1 \cdot V F$ & $1 \cdot \lambda \mid 1$ & 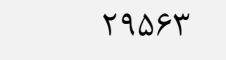 & 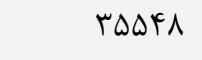 & rIVe & $r \cdot r F_{1}$ & • مترمربع ........................ \\
\hline 1991 & rqqY^ & DGTYA & $\Delta \Delta \Delta T Y$ & 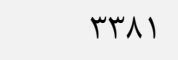 & $v \cdot 11 f$ & 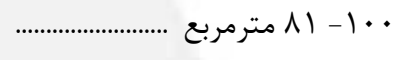 \\
\hline 1719 & rTADF & rFVqV & $r \wedge \Delta \cdot \Lambda$ & 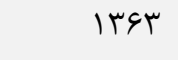 & $\Delta q I Y F$ & • •ا - | • ا مترمربع ................. \\
\hline 199 & GITs & Irork & $91 \wedge 1$ & fif & IrNFF & 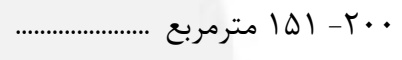 \\
\hline$\Delta \wedge$ & TVTS & GIfT & $f \mid Q$ & Trg & $\Delta \vee \wedge \vee$ & 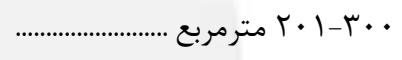 \\
\hline IV & 1499 & $r \cdot \Delta \Delta$ & (tht & ITr & trRi & 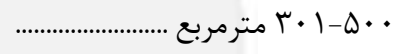 \\
\hline$\Delta$ & $\Delta \wedge t$ & ११५ & VQI & st & $9 \Delta \varphi$ & 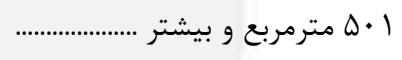 \\
\hline ITFAT & Ve & TFD & 111 & 11 & TFT & 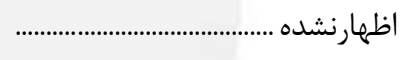 \\
\hline $9 \vee 9$ & meqg & FIgl & $F \cdot 1 \Delta$ & rq. & $\Delta A I r$ & آيإرتمانى.................... \\
\hline IV & rGV & 1199 & 1111 & $1 \cdot f$ & $\Delta F \wedge$ & 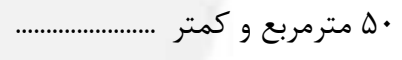 \\
\hline ra & vif & NTt & QYर & 115 & $1 \cdots \Delta$ & 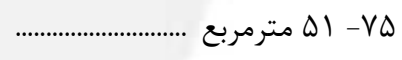 \\
\hline iV & ral & rVA & $p \Delta q$ & $\Delta \cdot$ & $9 \cdot 1$ & ................. مترمربع V9 . . \\
\hline ry & $1 \cdot V 1$ & 1rq & $\vee \wedge 9$ & $9 V$ & $19 V$ & 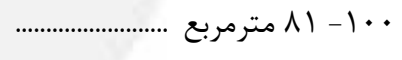 \\
\hline f. & $1 \cdot 1$ & 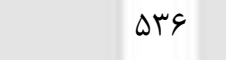 & fir & $r \Delta$ & ITVR & 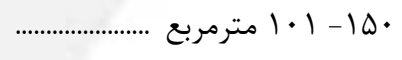 \\
\hline $1 \cdot$ & $11 \mathrm{~V}$ & 190 & $\mid F \wedge$ & 11 & ris & 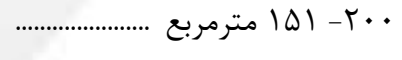 \\
\hline$r$ & $1 \cdot r$ & 110 & $9 V$ & V & lor & 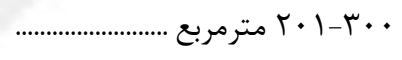 \\
\hline 1 & $\Delta V$ & $\Delta \cdot$ & r & $\wedge$ & gr & 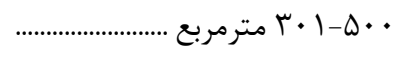 \\
\hline - & ret & tr & 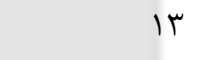 & $r$ & 10 & 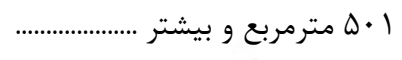 \\
\hline 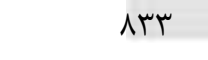 & it & 11 & 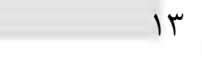 & r & re & 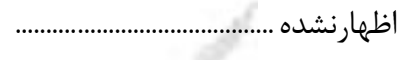 \\
\hline $191 \mathrm{rr}$ & 999fr & rarrita & TYGFFA & $|V F \Delta|$ & $r F \& D \cdot A$ & غيرآ يا رتمانى...... \\
\hline IFTt & $\mid r \wedge 9 \Delta$ & $\wedge I I \vee \wedge$ & VEFTI & FFTt & rø909 & 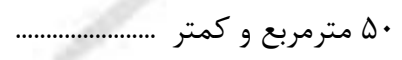 \\
\hline 1999 & $I V \cdot r \cdot$ & $\Delta \wedge \vee \backslash \varepsilon$ & sVagr & DFTA & fIVTq & 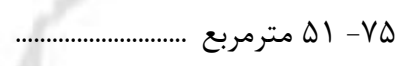 \\
\hline $1 \cdot \Delta V$ & $1.4 q$. & rq1^ब & $r \Delta \cdot \wedge 9$ & TITE & rqVr & 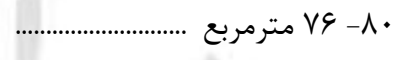 \\
\hline $197 V$ & 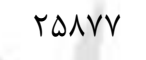 & $\Delta \Delta F 19$ & DFVTr & ( & GAFYI & 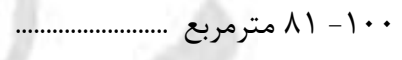 \\
\hline 1189 & r r & MFTEl & $r \wedge \cdot 99$ & 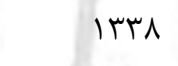 & DVVFV & 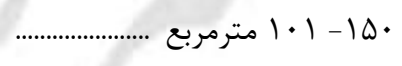 \\
\hline 119 & ఎ१५q & 9 פ פשrו & $q \cdot r \cdot$ & $r \cdot r$ & Irkqs & 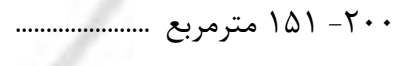 \\
\hline$\Delta \varphi$ & tGTt & $q \cdot r V$ & $r \cdot \wedge r$ & $r 19$ & $\Delta G T \Delta$ & 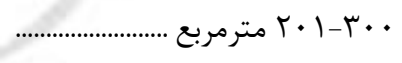 \\
\hline 19 & IFFT & $r \cdot \omega$ & $41 \cdot 1$ & ITF & $r+q$ & 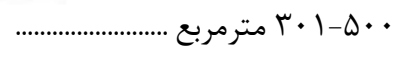 \\
\hline$\Delta$ & $\Delta \Delta \cdot$ & $9 \vee 1$ & 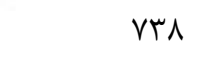 & $\Delta 9$ & $g(1$ & 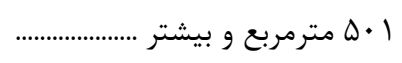 \\
\hline 1190. & gr & TTV & $I V \Delta$ & $\wedge$ & tin & اظهارنشده ...................................... \\
\hline
\end{tabular}

